$\frac{12}{2.20}-96 \mathrm{~g}$ S(i)

\title{
Evaluation of Radioactive Scrap Metal Recycling
}

Environmental Assessment Division Argonne National Laboratory

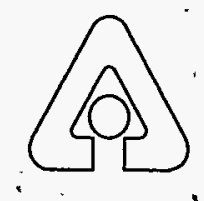

Operated by The University of Chicago, under Contract W-37-109-Eng-38, for the

United States Department of Energy 


\section{Argonne National Laboratory}

Argonne National Laboratory, with facilities in the states of Illinois and Idaho, is owned by the United States Government, and operated by the University of Chicago under the provisions of a contract with the Dejpartment of Energy.' This technical memo is a product of Argonne's Environmental Assessment Division (EAD). -For information on the division's scientific and engineering activities, contact:

Director, Environmental Assessment Division

Argonne National Laboratary

Argonne, Illinois 60439-4815

Telephone (708) 252-3107

Presented in this technical memo, are preliminary results of ongoing work or work that is more limited in scope and depth than that described in formal reports issued by the EAD.

Publishing support services were provided by Argonne's Information and Publishing Division (for more information, see IPD's home page; http://www.ipd.an!.gov/).

\section{Disclaimer}

This report was prepared as an account of work sponsored by an agency of the United States Government. Neither the United States, Government nor any agency thereof, nor any of their employees, makes any warranty, express or implied, or assumes any legal liability or responsibility for the accuracy, completeness, or usefulness of any information, apparatus, product; or process disclosed, or represents that its use would not infringe privately owned rights. Reference herein to any specific commercial product, process, or service by trade name, trademark, manufacturer, or otherwise, does not necessarily constitute or imply its endorsement, recommendation, or favoring by the United States Government or any agency thereof. The views and opinions of authors expressed herein do not. necessarily state or reflect thiose of the United States Government or any agency thereof.

Reproduced directly from the best available copy.

Available to DOE and DOE contractors from the Office of Scientific and Technical information, P.O. Box 62, Oak'Ridge, TN 37831; prices availáble from (423) $576-8401$.

Available to the public from the National Technical' information Service, U.S. Department of Commerce, 5285 Port Royal Road, Springfiéld, VA 22161. 


\section{Evaluation of Radioactive Scrap Metal Recycling}

by L.A. Nieves, ${ }^{\star}$ S.Y. Chen, E.J. Kohout, ${ }^{\star}$ B. Nabelssi, R.W. Tilbrook, ${ }^{\star}$ and S.E. Wilson ${ }^{\star}$

Environmental Assessment Division,

Argonne National Laboratory, 9700 South Cass Avenue, Argonne, Illinois 60439

December 1995

Work sponsored by United States Department of Energy, Office of Environmental Restoration

* Nieves, Kohout, and Wilson are affiliated with Argonne's Decision and Information Sciences Division and Tilbrook with its Reactor Engineering Division.

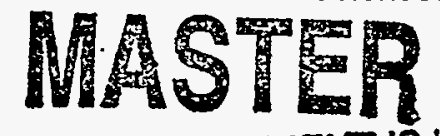




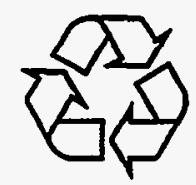

This report is printed on recycled paper.

ii 


\section{CONTENTS}

ACKNOWLEDGMENTS $\ldots \ldots \ldots \ldots \ldots \ldots \ldots \ldots \ldots \ldots \ldots \ldots \ldots \ldots$

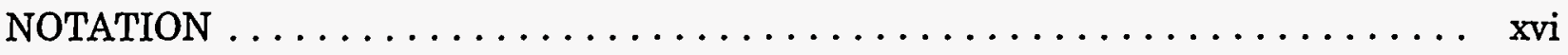

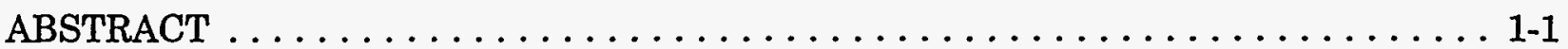

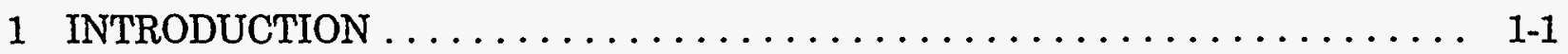

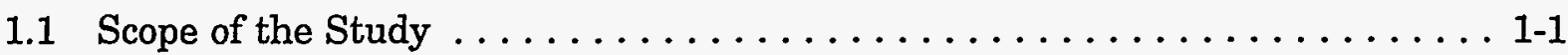

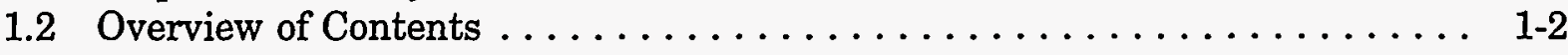

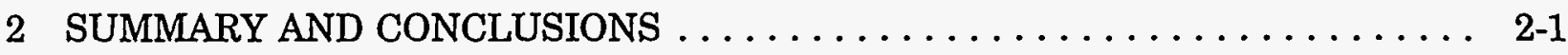

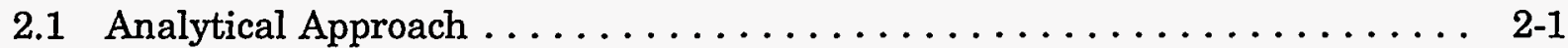

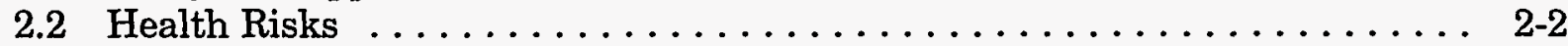

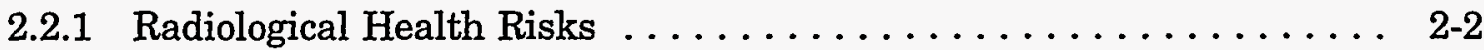

2.2 .2 Nonradiological Health Risks $\ldots \ldots \ldots \ldots \ldots \ldots \ldots \ldots \ldots \ldots .2-5$

2.2.3 Relative Magnitude of Health Risks $\ldots \ldots \ldots \ldots \ldots \ldots \ldots \ldots$ 2-7

2.3 Environmental Impacts $\ldots \ldots \ldots \ldots \ldots \ldots \ldots \ldots \ldots \ldots \ldots \ldots . \ldots \ldots \ldots . \ldots \ldots$

2.3.1 Impacts on Land Resources $\ldots \ldots \ldots \ldots \ldots \ldots \ldots \ldots \ldots \ldots .2-8$

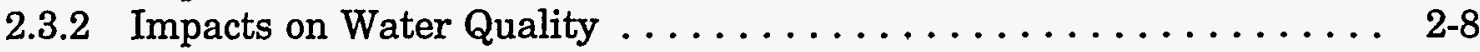

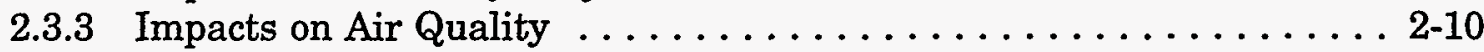

2.3.4 Impacts on Energy Resources $\ldots \ldots \ldots \ldots \ldots \ldots \ldots \ldots \ldots .2-10$

2.3.5 Relative Magnitude of Environmental Impacts ........... 2-10

2.4 Socioeconomic Issues and Impacts $\ldots \ldots \ldots \ldots \ldots \ldots \ldots \ldots \ldots \ldots \ldots \ldots \ldots \ldots \ldots \ldots .11$

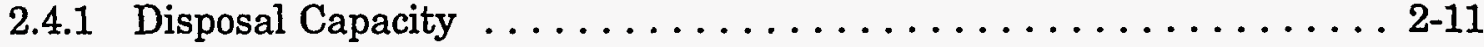

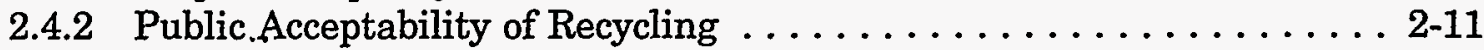

2.4.3 Metal Market Impacts . . . . . . . . . . . . . . . . . . . 2-12

2.4.4 Impact Distribution $\ldots \ldots \ldots \ldots \ldots \ldots \ldots \ldots \ldots \ldots \ldots \ldots \ldots \ldots \ldots \ldots \ldots, 12$

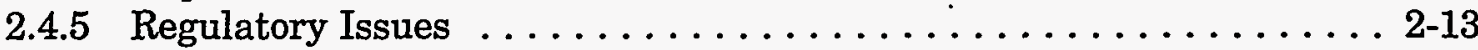

2.4.6 Relative Magnitude of Socioeconomic Impacts ............ 2-13

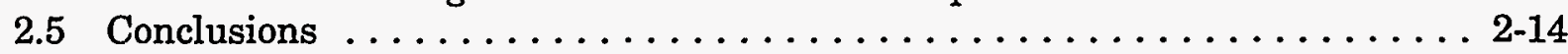

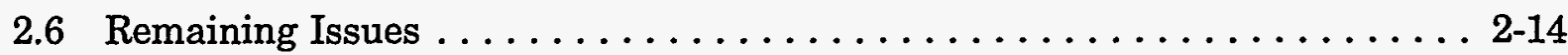

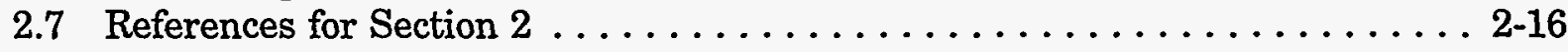

3 RADIOACTIVE SCRAP METAL INVENTORY $\ldots \ldots \ldots \ldots \ldots \ldots \ldots \ldots$.

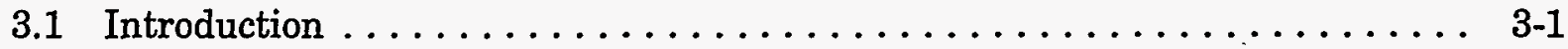

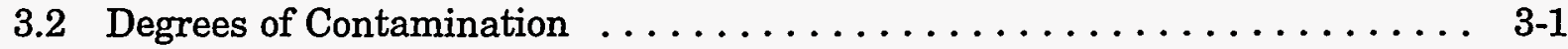

3.3 Basic Assumptions . . . . . . . . . . . . . . . . . . . . . .

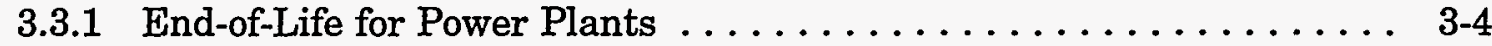

3.3.2 Radioactive Decay . . . . . . . . . . . .

3.3.3 Categorization of Metals $\ldots \ldots \ldots \ldots \ldots \ldots \ldots \ldots \ldots \ldots \ldots$ 3-6

3.3.4 Miscellaneous Assumptions . . . . . . . . . . . . . .

3.4 Sources of Radioactive Scrap Metal $\ldots \ldots \ldots \ldots \ldots \ldots \ldots \ldots \ldots$ 3-7

3.4.1 World Nuclear Power Plants $\ldots \ldots \ldots \ldots \ldots \ldots \ldots \ldots . . \ldots .7$ 


\section{CONTENTS (Cont.)}

3.4.2 Nuclear Fuel Cycle Facilities . . . . . . . . . . . . . . . 3-8

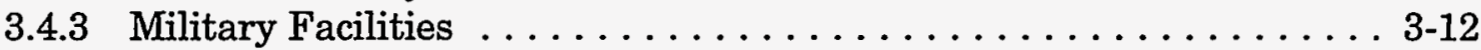

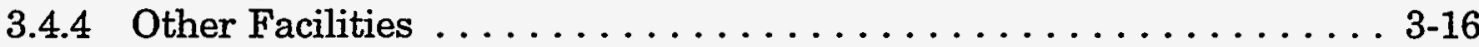

3.4.5 Operations and Maintenance ................... 3-18

3.4 .6 Extraction Equipment $\ldots \ldots \ldots \ldots \ldots \ldots \ldots \ldots \ldots \ldots \ldots \ldots \ldots \ldots$

3.5 Estimates of Total Scrap Metal Inventory . . . . . . . . . . . . . 3-19

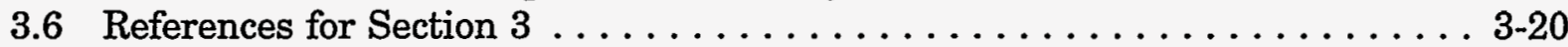

4 INTERNATIONAL SCRAP METAL MARKET $\ldots \ldots \ldots \ldots \ldots \ldots \ldots \ldots$. 4

4.1 Scrap Metal Terminology and Processes $\ldots \ldots \ldots \ldots \ldots \ldots \ldots \ldots$ 4-1

4.1.1 Scrap Metal Terminology . . . . . . . . . . . . . . . . . . 4 4-1

4.1.2 Scrap Collection and Processing $\ldots \ldots \ldots \ldots \ldots \ldots \ldots \ldots .4 .6 \ldots$

4.1.3 Scrap Smelting and Refining Processes .............. 4-6

4.2 International Scrap Metal Trade $\ldots \ldots \ldots \ldots \ldots \ldots \ldots \ldots \ldots \ldots . \ldots \ldots$

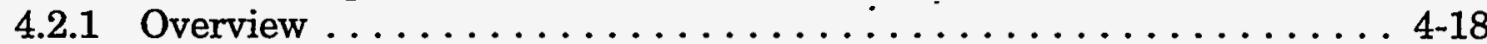

4.2.2 Scrap Metal Supply and Demand $\ldots \ldots \ldots \ldots \ldots \ldots \ldots \ldots \ldots$ 4-18

4.2.3 Metal Trade Profiles $\ldots \ldots \ldots \ldots \ldots \ldots \ldots \ldots \ldots \ldots \ldots \ldots .4 .21$

4.2.4 Recent Trends in Scrap Prices . . . . . . . . . . . . . . 4-26

4.3 Current Industry Practice for Processing Contaminated Scrap . . . . . . . . 4-31

4.3.1 Sources of Radioactive Material in Scrap Metal . . . . . . . . . . . 4-33

4.3.2 Radiation Detection Systems . . . . . . . . . . . . . . 4-35

4.3.3 Current Practice ........................ 4-37

4.4 Market Impact of Recycling Radioactive Scrap Metal . . . . . . . . . . 4-37

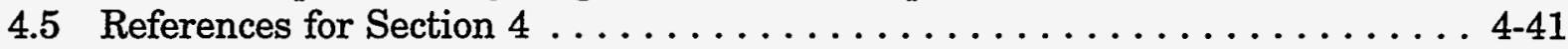

5 IMPACTS OF RADIOACTIVE SCRAP METAL RECYCLING . . . . . . . . . 5 5-1

5.1 Overview of the Recycle Process $\ldots \ldots \ldots \ldots \ldots \ldots \ldots \ldots \ldots \ldots$ 5-1

5.2 Radiological Health Effects $\ldots \ldots \ldots \ldots \ldots \ldots \ldots \ldots \ldots \ldots \ldots . \ldots \ldots$

5.2 .1 Assessment Methodology $\ldots \ldots \ldots \ldots \ldots \ldots \ldots \ldots \ldots \ldots \ldots$ 5-5

5.2 .2 Dose Estimates . . . . . . . . . . . . . . . . . . . . 5-7

5.2.3 Derived Release Levels . . . . . . . . . . . . . . . . . . . 5-17

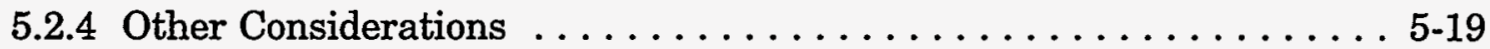

5.2.5 Summary of Radiological Health Impact Analysis . . . . . . . . 5-21

5.3 Nonradiological Health Effects $\ldots \ldots \ldots \ldots \ldots \ldots \ldots \ldots \ldots \ldots .21$

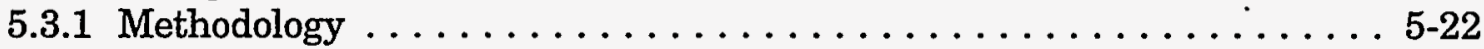

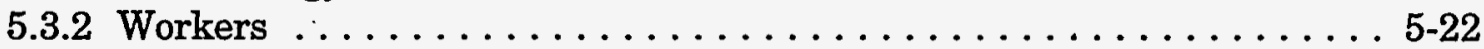

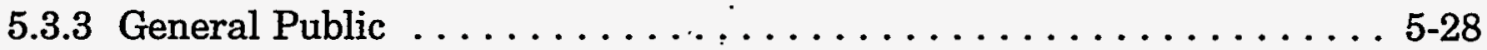

5.3.4 Summary of Nonradiological Health Impact Analysis . . . . . . . . 5-37

5.4 Environmental Impacts $\ldots \ldots \ldots \ldots \ldots \ldots \ldots \ldots \ldots \ldots \ldots \ldots .37$

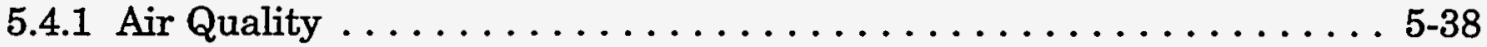

5.4 .2 Land Use/Disturbance $\ldots \ldots \ldots \ldots \ldots \ldots \ldots \ldots \ldots \ldots \ldots .38$

5.4.3 Water Quality/Resources $\ldots \ldots \ldots \ldots \ldots \ldots \ldots \ldots \ldots \ldots . \ldots \ldots$

5.4 .4 Energy Requirements ................... $5-38$

5.4.5 Industrial Technology Impacts $\ldots \ldots \ldots \ldots \ldots \ldots \ldots \ldots \ldots . . \ldots \ldots$ 


\section{CONTENTS (Cont.)}

5.5 References for Section $5 \ldots \ldots \ldots \ldots \ldots \ldots \ldots \ldots \ldots \ldots \ldots \ldots$

6 IMPACTS OF RADIOACTIVE SCRAP METAL DISPOSAL

AND REPLACEMENT . . . . . . . . . . . . . . . . . . . . 6-1

6.1 Disposal of Radioactive Scrap Metal as Low-Level Waste . . . . . . . . . . . 6-1

6.1.1 Disposal Process ....................... 6-1

6.1.2 Health Risks of Disposal ...................... 6-2

6.1.3 Land Use and Disposal Site Capacity ............... 6-2

6.2 Replacement of Radioactive Scrap Metal . . . . . . . . . . . . . . 6-6

6.2 .1 Metal Mining and Refining Processes ............... 6-6

6.2.2 Health Risks of Metal Mining and Refining ................ 6-9

6.2.3 Environmental Impacts of Metal Mining and Refining . . . . . . . . 6-12

6.2.4 Coal Mining and Coke Production Processes . . . . . . . . . . . . . 6-22

6.2.5 Health Risks of Coal Mining and Coke Production .......... 6-25

6.2.6 Environmental Impacts of Coal Mining and Coke Production . . . . 6-29

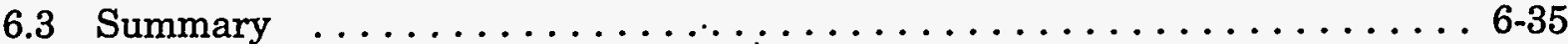

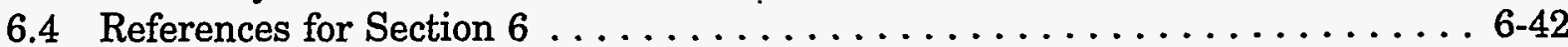

7 SOCIAL AND POLITICAL CONTEXT OF RADIOACTIVE SCRAP

METAL RECYCLING $\ldots \ldots \ldots \ldots \ldots \ldots \ldots \ldots \ldots \ldots \ldots \ldots \ldots \ldots \ldots$

7.1 Regulatory Principles Related to Radioactivity in

Consumer Products . . . . . . . . . . . . . . . . . . . . . . 7-1

7.1.1 Regulatory Framework Affecting the Exemption Process . . . . . . . 7-2

7.1.2 Dose Limitation Principles Underlying the

Exemption Process ..................... 7-3

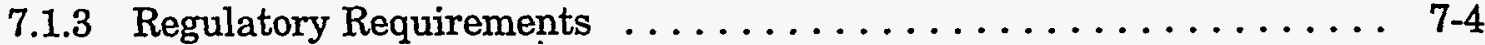

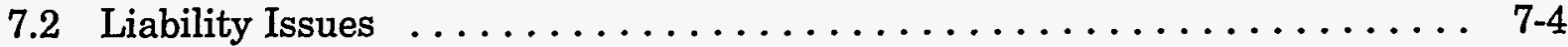

7.2.1 Strict Liability in Tort - U.S.A. Law $\ldots \ldots \ldots \ldots \ldots \ldots \ldots \ldots$

7.2 .2 Products Liability in Other Countries ............... 7-7

7.3 Assessment of Recycling Acceptability to the Public . . . . . . . . . . . . 7-9

7.3.1 Cultural Context of Risk Perception and Risk Acceptability . . . . . . 7-9

7.3.2 Cross-Cultural Comparison of Attitudes

toward Radioactivity .................... 7-11

7.3.3 Implications for Acceptability of RSM Recycling . . . . . . . . 7-14

7.4 Recycling Acceptability to Stakeholder Organizations . . . . . . . . . . . 7-16

7.4.1 Identification of Stakeholder Organizations . . . . . . . . . 7-16

7.4.2 Survey of Positions of Stakeholder Organizations . . . . . . . 7-17

7.4.3 Major Concerns of Stakeholder Organizations ............ 7-19

7.4.4 Evaluation of Trade-Offs by Stakeholder Organizations . . . . . . . . 7-20

7.5 Factors Affecting Social and Political Impacts of Radioactive

Scrap Metal Recycling . . . . . . . . . . . . . . . . . . . . 7-21

7.5.1 Benefit and Risk Perceptions by Stakeholder Organizations

and the Public 


\section{CONTENTS (Cont.)}

7.5.2 Detectability of Radiation in Scrap Inputs and

Finished Products . . . . . . . . . . . . . . . . . . . . . 7-22

7.5.3 Public Confidence in Institutional Controls . . . . . . . . . . . . . 7-22

7.5.4 Nonuniformity of Release Standards among Countries . . . . . . . 7-23

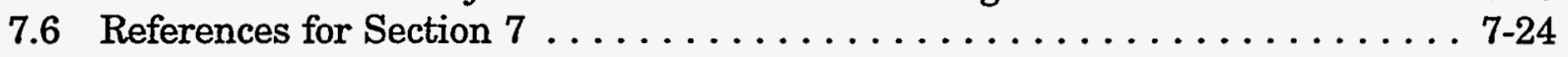

APPENDIX A: Methodology and Summary Tables for Power Reactor

Reference Plant Data Sets . . . . . . . . . . . . . . A A-1

APPENDIX B: Annual Increments in Potential Scrap Metal Inventory

from Nuclear Power Plants . . . . . . . . . . . . . . B-1

APPENDIX C: Radiological Risk Assessment Methodology and

Sensitivity Analysis . . . . . . . . . . . . . . . . . C-1

APPENDIX D: Baseline Dose Estimates for Worker and Public Scenarios . . . . . . . D-1

APPENDIX E: Environmental Risk Context and Profiles of Toxic

Substances and Associated Health Effects .............. E-1

APPENDIX F: Questionnaire on Recycling and List of Respondents . . . . . . . F-1

\section{TABLES}

2.1 Health Risk Estimates for Radioactive Scrap Metal

Management Alternatives $\ldots \ldots \ldots \ldots \ldots \ldots \ldots \ldots \ldots \ldots \ldots \ldots \ldots \ldots$

2.2 Environmental Impacts of Activities Associated with Radioactive

Scrap Metal Management Alternatives $\ldots \ldots \ldots \ldots \ldots \ldots \ldots \ldots \ldots$. $2-9$

2.3 Comparison of Impacts from the Radioactive Scrap Metal

Management Alternatives . . . . . . . . . . . . . . . . . .

3.1 Activity Categories of Scrap Metal $\ldots \ldots \ldots \ldots \ldots \ldots \ldots \ldots \ldots \ldots$

3.2 Example of Effects of Decay Period on Quantities of Scrap in Each Activity Category $\ldots \ldots \ldots \ldots \ldots \ldots \ldots \ldots \ldots \ldots \ldots \ldots$

3.3 Reference Plant Metals Data . . . . . . . . . . . . . . . . . 3-9

3.4 Total Estimated Power Plant Scrap Metal Mass by Activity Category, 50 Years after Plant Start-Up, by Metal Type and by Region . . . . . . . . . . . . . . . . . . . . . . 


\section{TABLES (Cont.)}

3.5 World Enrichment Plants . . . . . . . . . . . . . . . . . . . 3-13

3.6 U.S.A. Uranium Enrichment Plant Metal Scrap ... . . . . . . . . 3-14

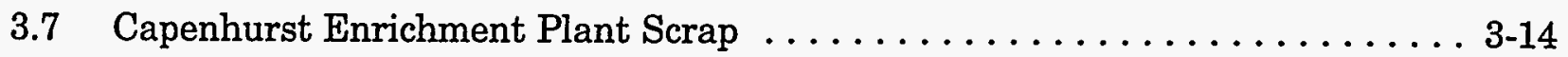

3.8 Military Facilities That Are Sources of Radioactive Scrap Metal . . . . . . 3-15

3.9 List of U.S.A. Production Reactors . . . . . . . . . . . . . . . 3-15

3.10 Summary of Radioactive Scrap Metal Inventory Estimates from Various Sources by Metal Type $\ldots \ldots \ldots \ldots \ldots \ldots \ldots \ldots \ldots . . \ldots \ldots$

4.1 Size Ranges of Basic Oxygen Process and Electric Arc Furnace

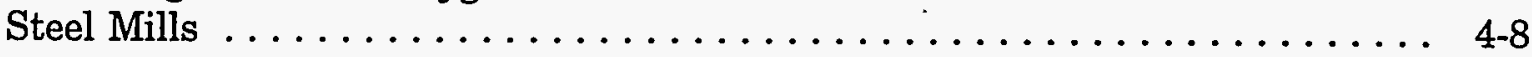

4.2 Domestic U.S.A. Consumption of Old and New Aluminum Scrap, 1989-1990

4.3 Principal Uses of Blast-Furnace Slag $\ldots \ldots \ldots \ldots \ldots \ldots \ldots \ldots \ldots \ldots$ 4-17

4.4 Domestic U.S.A. End Uses of Commodity Metals . . . . . . . . . 4-20

4.5 International Scrap Iron and Steel Trade . . . . . . . . .

4.6 International Scrap Aluminum Trade $\ldots \ldots \ldots \ldots \ldots \ldots \ldots \ldots \ldots \ldots .23$

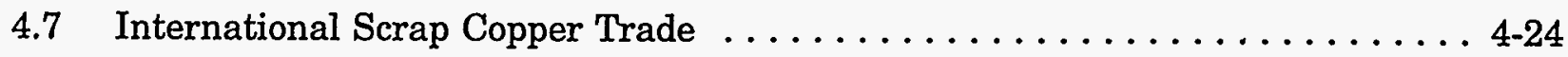

4.8 International Scrap Lead Trade $\ldots \ldots \ldots \ldots \ldots \ldots \ldots \ldots \ldots \ldots \ldots .4 .25$

4.9 International Scrap Nickel Trade $\ldots \ldots \ldots \ldots \ldots \ldots \ldots \ldots \ldots \ldots \ldots \ldots \ldots$

4.10 International Scrap Zinc Trade $\ldots \ldots \ldots \ldots \ldots \ldots \ldots \ldots \ldots \ldots \ldots .4 .27$

4.11 Projected Average Annual Releases of Suspect and SurfaceContaminated - Removable Categories of Radioactive Scrap Metal from Power Plants Worldwide, 2010-2043

4.12 Projected Average Annual Radioactive Scrap Metal Flows for the Period 2010-2043 as Percentages of 1989 International Scrap Metal Imports 


\section{TABLES (Cont.)}

4.13 Projected Average Annual Radioactive Scrap Metal Flows for the Period 2010-2043 as Percentages of 1989 International Commodity Metal Consumption . . . . . . . . . . . . . . . . 4-39

4.14 Comparison of Projected Annual Average Quantity of RSM Iron and Steel Available, 2010-2043, with Scrap Iron and Steel Consumption Volatility, $1985-1989 \ldots \ldots \ldots \ldots \ldots \ldots \ldots \ldots \ldots \ldots$. . . . . . . . . . . . . . . .

5.1 Tier Structure, End-Use Options, and Scope of Analysis for Radioactive Scrap Metal Recycle Alternatives

5.2 Summary of Constraining Individual Worker Doses and Derived Activity Levels for Unrestricted Recycle Worker Scenarios with 10,000 and 50,000 throughput $\ldots \ldots \ldots \ldots \ldots \ldots \ldots \ldots \ldots \ldots \ldots \ldots \ldots \ldots$

5.3 Worker Population Doses for Unrestricted Recycle Based on Annual Smelter Throughputs of $10,000 \mathrm{t}$ and $50,000 \mathrm{t}$ of Radioactive Scrap Metal

5.4 Constraining Individual Public Doses and Derived Activity Levels under Scenarios for Reusing Radioactive Scrap Metal Objects

5.5 Constraining Individual Public Doses and Derived Activity Levels under Scenarios for Unrestricted Recycling of Radioactive Scrap Metal . . . . 5-13

5.6 Summary of Public Doses Associated with Gaseous Radioactive Emissions from a Steel Smelting Plant

5.7 Estimated Public Individual Doses for Unrestricted Disposal at a Landfill

5.8 Derived Radioactive Scrap Metal Release Levels for Unrestricted

Recycle and Prescribed Initial Use, Showing the

Constraining Scenarios

5.9 Occupational Standards and Guidelines for Chemical Contaminants . . . . 5-25

5.10 Intakes and Risks Associated with the Inhalation Pathway for Smelter Emissions

5.11 Intakes and Risks Associated with the Produce Ingestion

Pathway for Smelter Emissions

6.1 Top 10 Countries' Annual Iron Ore and Crude Steel Production, 1980 and 1990 


\section{TABLES (Cont.)}

6.2 Top 10 Countries' Annual Production of Copper,.Aluminum, Lead,

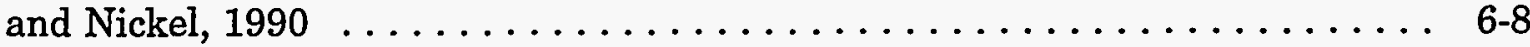

6.3 Emissions of Trace Metals to the Atmosphere and Water from Metal Production Operations . .......................... 6-14

6.4 Components as a Percentage of Total Mass of Particulate Emissions from Basic Oxygen Noncombusted Gas Systems .

6.5 Radionuclides in Particulate Emissions from Reference Copper and Alumina Plants . . . . . . . . . . . . . . . . . . . . . 6 6 -16

6.6 Activity of Naturally Occurring Radionuclides in Alumina Plant Process Samples ............................. 6-19

6.7 Activity of Naturally Occurring Radionuclides in Metal Slags . . . . . . . 6 6-19

6.8 Consumption/Production Statistics for U.S.A. Coal and Coke, 1970,1980 , and $1990 \ldots \ldots \ldots \ldots \ldots \ldots \ldots \ldots \ldots \ldots \ldots \ldots \ldots \ldots \ldots \ldots \ldots \ldots \ldots .24$

6.9 Quantifiable Resource Requirements, Discharges, and Impacts from Coal Mining, Coal Preparation, Coal Storage, and Coal Transport per Ton of Steel Produced

6.10 Types and Quantities of Environmental Impacts, Effects, and Risks from the Coking of Coal and Related Processing . . . . . . . . . . . . 6-28

6.11 Identification of Environmental Impacts, Effects, and Risks from Coal Mining, Coal Preparation, Coal Storage, and Coal Transportation . . . . . . 6-30

6.12 Quantifiable Discharges and Impacts of Iron Ore/Steel Production per Ton of Steel Produced

6.13 Quantifiable Discharges and Impacts of Copper Production per Ton of Copper Produced

6.14 Quantifiable Discharges and Impacts of Aluminum Production per Ton of Aluminum Produced

7.1 Comparative Risk Ratings and Rankings for Norwegian, American, Hungarian, French, and Hong Kongese Populations . . . . . . . . . 7-12

7.2 Stakeholder Organizations Surveyed Regarding Radioactive Scrap

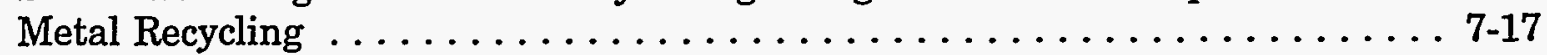




\section{TABLES (Cont.)}

B.1 Annual Increments in Scrap-Metal Inventory from Nuclear Power Plants for the U.S.A.

B.2 Annual Increments in Scrap-Metal Inventory from Nuclear Power Plants for North America.

B.3 Annual Increments in Scrap-Metal Inventory from Nuclear Power

Plants for Europe

B.4 Annual Increments in Scrap-Metal Inventory from Nuclear Power

Plants for the Former Soviet Union

B.5 Annual Increments in Scrap-Metal Inventory from Nuclear Power

Plant for Asia.

B.6 Annual Increments in Scrap-Metal Inventory from Nuclear Power Plants for the Remainder of the World

B.7 Worldwide Summations of the Annual Increments in Scrap-Metal Inventory from the Nuclear Power Plants

C.1 Inhalation and Ingestion Dose Conversion Factors $\ldots \ldots \ldots \ldots \ldots \ldots$

C.2 Exposure Parameters Used to Model Worker Scenarios . . . . . . . . . . . C-13

C.3 Exposure Parameters Used to Model Surface Reuse, Consumer Products, Specified Initial Use, and Controlled Recycle Scenarios . . . . . . . C-17

C.4 Partitioning Factors $\ldots \ldots \ldots \ldots \ldots \ldots \ldots \ldots \ldots \ldots \ldots \ldots \ldots \ldots \ldots \ldots$

C.5 Assumptions Used in CAP88 Calculations . . . . . . . . . . . . . C-21

C.6 Key Parameters in Dose Estimation for Radioactive Scrap Metal Reuse or Recycling . . . . . . . . . . . . . . . . . .

C.7 Steel Mill Technology and Capacity Relative to Potential 50,000-t Annual Radioactive Scrap Metal Throughput in North America . . . . . . . . . C-28

C.8 Steel Melt Partitioning Factors of Representative Radionuclides . . . . . . . C-29

C.9 Assumptions Used in Probabilistic Analysis of Dose Estimates

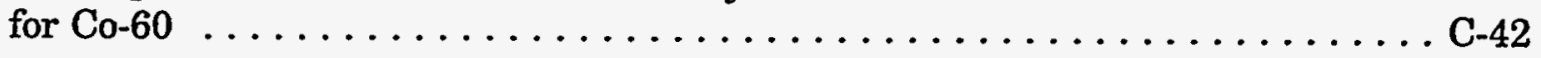

D.1 Baseline Worker Doses for a 2,000-h Scrap Delivery Loader . . . . . . . . . . . D-4

D.2 Baseline Worker Doses for a 2,000-h Scrap Delivery Truck Driver . . . . . . . D-5 


\section{TABLES (Cont.)}

D.3 Baseline Worker Doses for a 2,000-h Scrap Cutter $\ldots \ldots \ldots \ldots \ldots \ldots$ D-6

D.4 Baseline Worker Doses for a 2,000-h Scrap Processor . . . . . . . . . . D-7

D.5 Baseline Worker Doses for a 2,000-h Smelting Worker ........... D-8

D.6 Baseline Worker Doses for a 2,000-h Smelting Loader . . . . . . . . . . . D-9

D.7 Baseline Worker Doses for a 2,000-h Smelting Operator $\ldots \ldots \ldots \ldots$ D-10

D.8 Baseline Worker Doses for a 2,000-h Baghouse Processor . . . . . . . . . . D-11

D.9 Baseline Worker Doses for a 2,000-h Industrial Products Caster $1 \ldots \ldots \ldots$ D-12

D.10 Baseline Worker Doses for a 2,000-h Industrial Products Caster 2 . . . . . . D-13

D.11 Baseline Worker Doses for a 2,000-h Industrial Products Slag Worker ............................... D.

D.12 Baseline Worker Doses for a 2,000-h Industrial Products Loader . . . . . . . D-15

D.13 Baseline Worker Doses for a 2,000-h Industrial Products

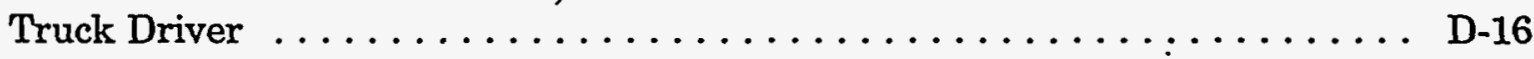

D.14 Baseline Worker Doses for a 2,000-h Initial Fabrication

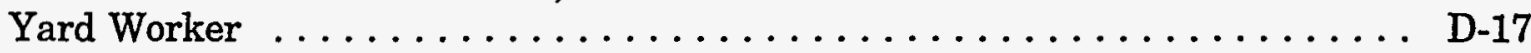

D.15 Baseline Worker Doses for a 2,000-h Initial Fabrication Sheet Worker ............................ D

D.16 Baseline Worker Doses for a 2,000-h Initial Fabrication Coil Worker ............................... D-19

D.17 Baseline Worker Doses for a 2,000-h Final Fabrication Sheet Worker . . . . . . . . . . . . . . . . . . . . . . . .

D.18 Baseline Worker Doses for a 2,000-h Final Fabrication Coil Worker . . . . . . . . . . . . . . . .

D.19 Baseline Worker Doses for a 2,000-h Distribution Loader . . . . . . . . . . D-22

D.20 Baseline Worker Doses for a 2,000-h Distribution Truck Driver . . . . . . . D-23

D.21 Baseline Worker Doses for a 2,000-h Distribution Sheet Worker ........ D-24 
TABLES (Cont.)

D.22 Baseline Worker Doses for a 2,000-h Distribution

Warehouse Worker ............................ D-25

D.23 Baseline Public Doses for Tool Reuse $\ldots \ldots \ldots \ldots \ldots \ldots \ldots \ldots \ldots$ D-26

D.24 Baseline Public Doses for Building Occupancy Scenario $\ldots \ldots \ldots \ldots$ D-27

D.25 Baseline Public Doses for a 100-t Batch - Parking Lot Scenario

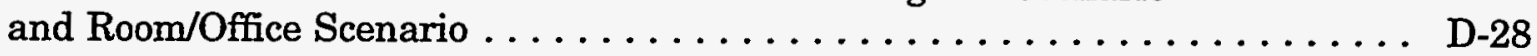

D.26 Baseline Public Doses for a 100-t Batch - Appliance Scenario and Automobile Scenario ....................... D-29

D.27 Baseline Public Doses for a 100-t Batch - Office Furniture Scenario and Home Furniture Scenario $\ldots \ldots \ldots \ldots \ldots \ldots \ldots \ldots$ D-30

D.28 Baseline Public Doses for a 100-t Batch — Frying Pan Scenario ....... D-31

D.29 Baseline Public Doses for a 100-t Batch — Highway

Pavement Scenario ............................ D-32

D.30 Baseline Public Doses for a 100-t Batch - Public Building

Scenario and Bridge Scenario . . . . . . . . . . . . . . . . .

D.31 Public Doses for Stack Emission Scenario $\ldots \ldots \ldots \ldots \ldots \ldots \ldots \ldots$ D-34

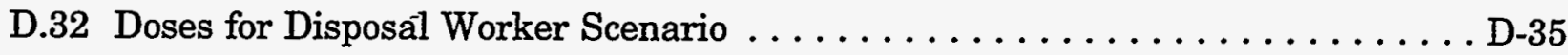

D.33 Doses for Disposal Resident Scenario . . . . . . . . . . . . . D-36

E.1 Occupational Exposure of Nonnuclear Workers $\ldots \ldots \ldots \ldots \ldots \ldots \ldots$ E-4

E.2 Population Exposure from Consumer Products in the U.S.A. $\ldots \ldots \ldots \ldots$ E-6

E.3 Naturally Occurring Radioactive Concentrations in the Environment . . . . . E E-7

E.4 Sources of Population Exposure to Environmental Radiation $\ldots \ldots \ldots \ldots$ E-8

E.5 Fatality Risks Associated with Common Activities in the U.S.A. . . . . . . . E-10

E.6 Baseline Mortality Risk Levels and Costs Associated with Selected U.S.A. Regulations . . . . . . . . . . . . . . . . . . . . E-11 


\section{FIGURES}

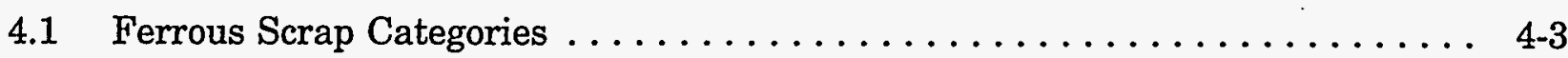

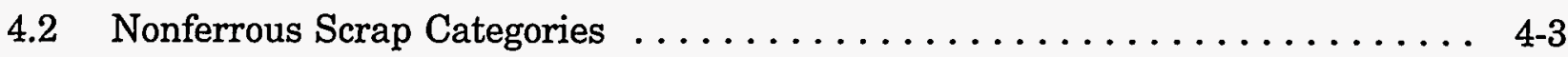

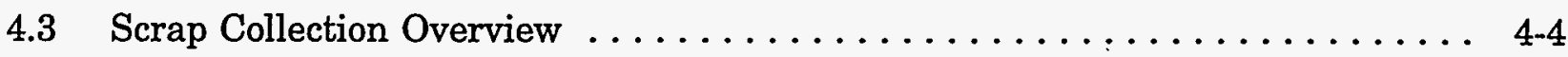

4.4 Iron Scrap Flow Diagram $\ldots \ldots \ldots \ldots \ldots \ldots \ldots \ldots \ldots \ldots \ldots \ldots \ldots \ldots$

4.5 Aluminum Scrap Flow Diagram $\ldots \ldots \ldots \ldots \ldots \ldots \ldots \ldots \ldots \ldots \ldots \ldots \ldots$

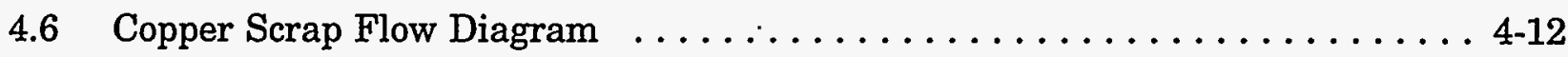

4.7 Nickel Scrap Flow Diagram $\ldots \ldots \ldots \ldots \ldots \ldots \ldots \ldots \ldots \ldots \ldots \ldots \ldots \ldots \ldots$

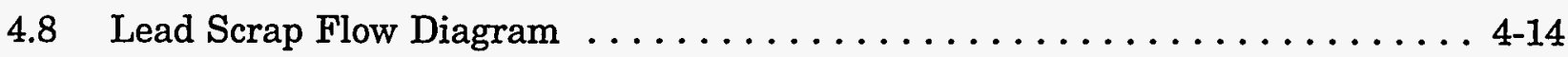

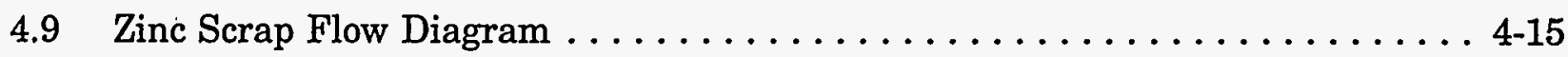

4.101989 International Scrap Trade $\ldots \ldots \ldots \ldots \ldots \ldots \ldots \ldots \ldots \ldots \ldots . \ldots \ldots .22$

4.11 U.S.A. Scrap Iron and Steel Prices $\ldots \ldots \ldots \ldots \ldots \ldots \ldots \ldots \ldots \ldots \ldots \ldots \ldots \ldots \ldots .28$

4.12 U.S.A. Scrap Stainless Steel Prices $\ldots \ldots \ldots \ldots \ldots \ldots \ldots \ldots \ldots \ldots \ldots . . \ldots \ldots$

4.13 U.S.A. Scrap Aluminum Prices $\ldots \ldots \ldots \ldots \ldots \ldots \ldots \ldots \ldots \ldots \ldots \ldots \ldots \ldots$

4.14 U.S.A. Scrap No. 2 Copper Prices $\ldots \ldots \ldots \ldots \ldots \ldots \ldots \ldots \ldots \ldots \ldots$ 4-30

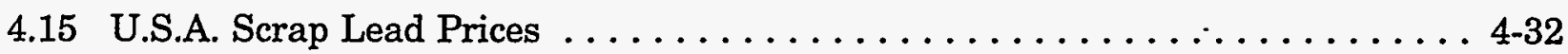

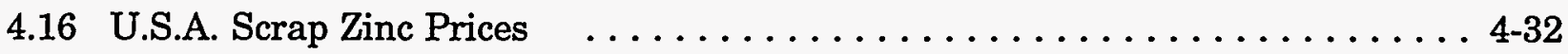

4.17 Number of Discoveries of Radioactive Materials in Recycled

Metal Worldwide ........................... 4 44

4.18 Relative Frequency of Radioactive Material Types Found in Recycled Metal . ............................ 4 44

4.19 International Scrap Iron and Steel Consumption, 1985-1989 . . . . . . 4-40

5.1 Process for Assessment and Release of Radioactive Scrap Metal . . . . . . . 5 5-3

5.2 Variation in Total Dose Rate over Time for a Radon Parent Nuclide . . . . 5-20

B.1 Annual Increments in Scrap-Metal Inventory from Nuclear Power

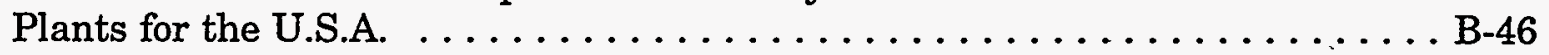




\section{FIGURES (Cont.)}

B.2 Annual Increments in Scrap-Metal Inventory from Nuclear Power

Plants for North America

B.3 Annual Increments in Scrap-Metal Inventory from Nuclear Power

Plants for Europe

B.4 Annual Increments in Scrap-Metal Inventory from Nuclear Power

Plants for the Former Soviet Union

B.5 Annual Increments in Scrap-Metal Inventory from Nuclear Power

Plants for Asia

B.6 Annual Increments in Scrap-Metal Inventory from Nuclear Power

Plants for the Remainder of the World

B.7 Worldwide Summations of the Annual Increments in Scrap-Metal

Inventory from Nuclear Power Plants . . . . . . . . . . . . . . B-64

C.1 Computational Process for Volumetric Release Levels . . . . . . . . . . . C-25

C.2 Computational Process for Surface Release Levels . . . . . . . . . . . . . C-26

C.3 - Parameter Relationships to Worker Dose Estimates for the Slag

Worker Scenario

C:4 Relative Contribution of Dose Pathways for Tier A-1 Reuse

Scenarios under Modified-Conservative Case Assumptions

C.5 Effects on Dose Estimates of Incorporating Dilution and

Partitioning Information under the Tier B-1 Taxi Driver Scenario

C.6 Dose Estimate Variation for Tier B-1 under Parameter Assumptions

for Each Case . . . . . . . . . . . . . . . . . . . . . . .

C.7 Dose Estimate Variation for Tier A-1 under Parameter Assumptions

for Each Case . . . . . . . . . . . . . . . . . . . . . . C-39

C.8 Parameter Range and Shape of Distribution in Probabilistic Analysis . . . . . C-40

C.9 Probabilistic Parameters in Worker Dose Calculation for Co-60 by Using

Simulated Data . . . . . . . . . . . . . . . . . . C-41

C.10 Cumulative Probability for Co-60 Small Object Caster Dose . . . . . . . . . . . C-42 


\section{ACKNOWLEDGMENTS}

The research discussed in this report was conducted in support of the U.S. Department of Energy's (DOE's) participation in the Organization for Economic Cooperation and Development, Nuclear Energy Agency, Co-operative Programme on Decommissioning, Task Group on Recycling and Reuse. As representatives participating in this group, W.E. Murphie and M.J. Lilly, III, of DOE's Office of Environmental Restoration, have provided both research direction and review. The authors also benefitted from insights and comments provided by other members of the task group, including S. Menon, A.-C. Sandin, and I. Lund (Sweden); L. Teunckens (Belgium); A.-M. Chapuis and M. Jeanjacques (France); S. Thierfeldt (Germany); A.B. Howden (England); and K. Fujiki and H. Nakamura (Japan). Interagency coordination and discussion were offered by R.A. Meck of the U.S. Nuclear Regulatory Commission, Environmental Policy Section; E. Durman and J. MacKinney of the U.S. Environmental Protection Agency, Office of Radiation and Indoor Air; and A. Wallo of DOE's Office of Environmental Safety and Health. A. Deckert of Brenk Systemplanung (Germany) also provided technical comments.

S.Y. Chen served as project manager and L.A. Nieves as principal investigator. L.J. Habegger provided project management initially. Responsibilities for various substantive areas of the research were shared as follows: Potential Scrap Inventory - R.W. Tilbrook, lead, with T.A. Brunner, C.E. Dickerman, R.G. Palm, and G.S. Stanford; Scrap Metal Markets - E.K. Kohout, lead, with R. Fabbrini and C.L. Willens; Radiological Health Risk Assessment - S.Y. Chen, lead, with D.J. LePoire, B. Nabelssi, and L.A. Nieves; Nonradiological Health Risk Assessment- H.M. Hartmann, M.M. MacDonell, C.B. Szpunar, and S.E. Wilson; Environmental Impact Assessment - S.E. Wilson, lead, with D.L. Blunt, M.J. Davis, L.A. Nieves, and C.B. Szpunar; Socioeconomic Impact Assessment-L.A. Nieves, lead, with C.J. Burke, D. Gualtieri, and E.K. Hocking. E. Faillace provided numerous reviews of material related to radiological risks. Editorial assistance was provided by J. DePue, M. Moniger, D. Robinson, and D. Wyman. Administrative support was ably provided by B.J. Pruitte-Deal. 


\section{NOTATION}

The following is a list of the acronyms, abbreviations, and units of measure used in this document.

\section{ACRONYMS, INITIALISMS, AND ABBREVIATIONS}

ACGIH

AGR

ALARA

ANL

ATSDR

BOF

BRC

BWR

CAAA

CANDU

CEC

DCF

DHHS

DOE

DRI

EAF

EC

GCR

HTGR

HWR

IAEA

ICRP

LGR

LLW

LMFBR

LMGMR

LMR

LWR

NCRP

NEA

NIOSH
American Conference of Governmental Industrial Hygienists advanced gas-cooled reactor as low as reasonably achievable Argonne National Laboratory Agency for Toxic Substances and Disease Registry

basic oxygen furnace below regulatory concern boiling-water reactor

Clean Air Act Amendments

Canadian deuterium-uranium (reactor)

Commission of the European Communities

dose conversion factor

U.S. Department of Health and Human Services

U.S. Department of Energy

direct reduced iron

electric arc furnace

European Economic Community

gas-cooled reactor

high-temperature, gas-cooled reactor

heavy=water reactor

International Atomic Energy Agency

International Commission on Radiation Protection

light-water-cooled, graphite-moderated reactor

low-level (radioactive) waste

liquid-metal, fast breeder reactor

liquid-metal, graphite moderated reactor

liquid-metal reactor

light-water reactor

National Council on Radiation Protection and Measurements Nucelar Energy Agency

National Institute for Occupational Safety and Health 
NOAEL

NORM

NSPS

OECD

ORNL

OSHA

PAH

PCB

PCI

PEL

PHWR

POM

PWR

RBMK

REL

RSM

SEG

SIC

SWU

TLL

TWA

U.S.A.

USEPA

USNRC

VVER

ZGS no observed adverse effect level

naturally occurring radioactive materials

New Source Performance Standards

Organization for Economic Cooperation and Development

Oak Ridge National Laboratory

Occupational Safety and Health Administration

polynuclear aromatic hydrocarbon

polychlorinated biphenyl

pulverized coal injection

permissible exposure level

pressurized heavy-water reactor

polycyclic organic matter

pressurized-water reactor

type of former Soviet Union reactor

recommended exposure limit

radioactive scrap metal

Scientific Ecology Group

Standard Industrial Classification

separative work unit

threshold limit value

time-weighted average

United States of America

U.S. Environmental Protection Agency

U.S. Nuclear Regulatory Commission

type of former Soviet Union reactor

Zero Gradient Synchrotron

\section{UNITS OF MEASURE}

$\begin{array}{ll}\mathrm{Bq} & \text { becquerel(s) } \\ \mathrm{cm} & \text { centimeter(s) } \\ \mathrm{cm}^{2} & \text { square centimeter(s) } \\ \mathrm{cm}^{3} & \text { cubic centimeter(s) } \\ \mathrm{dB} & \text { decibels } \\ \mathrm{g} & \text { gram(s) } \\ \mathrm{GeV} & \text { giga electron volt(s) } \\ \mathrm{Gy} & \text { gray(s) } \\ \mathrm{h} & \text { hour(s) } \\ \mathrm{kg} & \text { kilogram(s) } \\ \mathrm{km} & \text { kilometer(s) } \\ \mathrm{L} & \text { liter(s) }\end{array}$




$\begin{array}{ll}\mathrm{m}^{2} & \text { square meter(s) } \\ \mathrm{m}^{3} & \text { cubic meter(s) } \\ \mathrm{mm} & \text { millimeter(s) } \\ \mathrm{MWe} & \text { megawatt(s)-electric } \\ \mathrm{ppm} & \text { parts per million } \\ \mathrm{Sv} & \text { sievert(s) } \\ \mathrm{t} & \text { metric ton }(\mathrm{s})(1,000 \mathrm{~kg}) \\ \mathrm{yr} & \text { year(s) }\end{array}$




\title{
EVALUATION OF RADIOACTIVE SCRAP METAL RECYCLING
}

by

L.A. Nieves, S.Y. Chen, E.J. Kohout, B. Nabelssi, R.W. Tilbrook, and S.E. Wilson

\begin{abstract}
This report evaluates the human health risks and environmental and sociopolitical impacts of options for recycling radioactive scrap metal (RSM) or disposing of and replacing it. Argonne National Laboratory (ANL) is assisting the U.S. Department of Energy (DOE), Office of Environmental Restoration and Waste Management, Oak Ridge Programs Division, in assessing the implications of RSM management alternatives. This study is intended to support the DOE contribution to a study of metal recycling being conducted by the Task Group on Recycling and Reuse of the Organization for Economic Cooperation and Development. The focus is on evaluating the justification for the practice of recycling RSM, and the case of iron and steel scrap is used as an example in assessing the impacts. To conduct the evaluation, a considerable set of data was compiled and developed. Much of this information is included in this document to provide a source book of information.
\end{abstract}

\section{INTRODUCTION}

\subsection{SCOPE OF THE STUDY}

Almost all of the previous literature related to RSM recycling has emphasized the radiological risks to human health that result from reusing RSM. To evaluate the justification for recycling as a practice, this study considers a much broader range of the detriments associated with the two RSM management alternatives: (1) recycling and (2) disposing of and replacing metal stocks. The scope of this study includes a quantitative assessment of both the radiological and nonradiological impacts on human health. Information on other risks from environmental and anthropogenic sources is provided as contextual background for considering RSM management alternatives. This study also considers radiological and nonradiological impacts on the environment that result from operational activities and process emissions. Major types of social and economic impacts are identified and evaluated in qualitative terms. The study does not develop estimates of the comparative costs of recycling versus disposal, which could also be considered when the justification for recycling is being evaluated. 


\subsection{OVERVIEW OF CONTENTS}

The approach used in this evaluation is to develop a broad characterization of recycling process scenarios to determine the scope of impacts that must be considered. Impacts are presented first for recycling (Section 5) and then for the alternative of disposal and replacement (Section 6). The concept of alternative levels of regulatory control for RSM release for recycling, or "tiers," is incorporated into the analysis. The analytical framework employed to evaluate recycle alternatives is briefly described in Section 1.2. Section 2 summarizes the study findings, covering impacts both from RSM recycling process options and from the alternative of RSM disposal and metal replacement.

Partial worldwide RSM inventory estimates are presented in Section 3 . While the spectrum of potential RSM sources is identified, comprehensive estimates of metal masses are only developed for nuclear power plants. Information for RSM from power plants is presented in the most detail because of the nature of the available data. Weapons facilities are likely to be significant sources of RSM, but quantities are very difficult to ascertain lacking specific data. The quantity of RSM available from weapons facilities and other sources is assumed to be at least equal to that available from nuclear power plants. This inventory indicates the quantities of metals by type (and the associated categories of contamination characteristics) that could be available for recycling. It also provides estimates of the possible timing of scrap flows.

Section 4 describes the international market context in which recycled RSM would have to be accepted and traded if it were released for unrestricted use. It provides information on metal production and market structure as background to considering potential impacts of RSM recycling. This evaluation covers international scrap flows in response to supply and demand factors and the near-term price and trade situation. Recent experiences relative to radioactive contamination of scrap and the industry response in the U.S.A. are also discussed.

Impacts of RSM recycling options are addressed in Section 5, which uses iron and steel scrap as an example because this segment makes up the largest portion of available scrap. As a basis for impact evaluation, a tiered release concept and associated exposure scenarios are defined. The discussion includes radiological impacts to metal workers and to the public, radiological impacts to industrial technologies identified as possibly being sensitive, and nonradiological impacts to workers from decontamination and smelting activities required for RSM recycling. Release levels for RSM are derived on the basis of worker and public exposure estimates for the release tiers. Although the focus is on health, environmental impacts of RSM recycling processes are also evaluated.

Section 6 summarizes the impacts of the alternative of not recycling the RSM, again focusing on iron and steel. This discussion addresses appropriate disposal of the contaminated metals and production of replacement metal supplies. For replacement of discarded RSM, the impacts on air, land, water, and energy resources, as well as on worker and public health, are presented for mining and refining. The impacts of producing coking coal for use in production of steel are also addressed. 
Socioeconomic and political impacts of recycling are discussed in Section 7. A brief review is included of some crucial issues that must be addressed to facilitate recycling of RSM. An overview of the regulatory principles and processes for exempting RSM-containing products from regulatory control is presented first, followed by a discussion of the legal issues involving products liability that must be considered before RSM recycling is undertaken by commercial firms. Information on cross-cultural similarities and differences in perceptions of nuclear-related risks is presented, and results of an effort to ascertain the likely positions of key organizations in the recycling policy arena are reported. Finally, key factors and issues that are likely to affect public acceptance of RSM recycling are summarized. 


$$
1-4
$$




\section{SUMMARY AND CONCLUSIONS}

Current and potential sources of radioactive scrap metal (RSM) include nuclear power plants, nuclear fuel cycle facilities, weapons production facilities, research and development reactors, high-energy accelerators, industrial sterilizer plants, industrial radiography equipment, medical facilities and equipment, and petroleum and phosphate rock extraction equipment. Millions of metric tons $(t)$ of scrap iron and steel, stainless steel, and copper - as well as lesser quantities of aluminum, nickel, lead, and zirconium - are likely to become available in the future as these facilities are withdrawn from service.

The major alternatives for managing RSM are to either (1) develop a regulatory process for decontamination and recycling that will safeguard human health or (2) dispose of the RSM and replace the metal stocks. To date, relatively small quantities of RSM from various facilities have been recycled for public use, but thousands of tons have been recycled within the nuclear industry (Menon and Teunckens 1994; Hertzler et al. 1993). The magnitude of the potentially available supply, as well as the very low level of radioactivity in a major portion of it, warrant consideration of a broad range of end uses for this material.

This study evaluates recycling as a management alternative for radioactive steel scrap within the context of the system of radiological protection recommended by the International Commission on Radiological Protection (ICRP) (1991). Impacts of recycling are compared to those associated with disposing of and replacing the metal. The clear conclusions are that recycling is justified as a practice, that protection can be optimized through implementation of a tiered system of release criteria, and that individual dose can be controlled to acceptable levels.

\subsection{ANALYTICAL APPROACH}

Strategies for managing RSM must be evaluated within the context of principles for regulation of practices that result in radiation exposure of the public. The ICRP (1991) has recommended a system of radiological protection based on three general principles. The first is that before any practice involving increased radiation exposure is instituted, it must be justified as providing greater good than harm. To evaluate whether a practice does more good than harm the ICRP recommends that all detriments of the practice be considered, not just the radiological detriment. Second, radiation protection, including the cost of regulatory control, should be optimized. This involves keeping individual and population doses as low as reasonable achievable, given economic and social factors. It also involves equity considerations regarding the distribution of risk. Third, individual risks must be controlled at a sufficiently low level so as not to warrant regulatory concern.

Given these guidelines, this study evaluates the health risks, environmental impacts, and socioeconomic issues associated with the RSM management alternatives. Both radiological and nonradiological risks to human health are assessed, but the treatment of 
radiological risks is more detailed because of the need to explore issues related to potential development of international standards for recycling. The assessment of health risks focuses on the public, including industrial workers. Mlustrative examples are presented for iron and steel scrap because it constitutes a major portion of the potential RSM volume. The parameter, dose, and activity level values that are specific to steel in this report would need further investigation before the findings could be applied to the recycling of nonferrous metals. Environmental impacts are discussed in terms of the nature and relative magnitude of effects on environmental quality and resources. Socioeconomic issues related to recycling RSM are identified, and their implications for implementation of recycling are discussed.

For RSM recycling, a tiered system of release criteria for a wide range of end uses is evaluated because this approach has the advantage of matching RSM supply with demand while controlling public health risks at a very low level. Controlling health risks is accomplished by tailoring release levels to both the radiological characteristics of the scrap and its potential end uses. The tiered release concept includes options of unrestricted release of surface-contaminated metal in its existing form (e.g., machinery) for reuse or disposal, unrestricted recycle of ingots cast from RSM after melting in a controlled facility, prescribed initial use of RSM products, and controlled recycle in the nuclear industry.

The alternative to releasing RSM is to dispose of it in a low-level waste (LLW) disposal facility. This process requires cutting and packaging RSM for transportation and disposal and could also involve decontamination to reduce worker exposures and melting to reduce volume. Disposal would result in withdrawal of the RSM from world stocks of metal, major portions of which are normally recycled. At the margin, metal stocks are increased or replaced by metal newly produced from ore. Therefore, metal replacement activities are considered as contributing to the detriment associated with RSM disposal. These activities include mining of ore, ore enrichment or refining, metal smelting, casting and fabrication, and production of the energy required for these activities.

\subsection{HEALTH RISKS}

\subsubsection{Radiological Health Risks}

Radiological risks from either RSM recycling/reuse or disposal and replacement are very low. Estimates of radiological risks associated with 50,000 $\mathrm{t}$ of RSM under either alternative are summarized in Table 2.1. For illustrative purposes, the release levels for the tiers are derived on the basis of limiting the public dose to $10 \mu \mathrm{Sv} / \mathrm{yr}$ (International Atomic Energy Agency [IAEA] 1988). On this basis, lifetime cancer fatality risks to individual members of the public, including industrial workers, from recycling 50,000 t of RSM would be less than $10^{-6}$. For the RSM disposal alternative, radiological risks from exposure of the public as a result of RSM disposal are assumed not to exceed regulatory limits of $10^{-5}$. Overall, the level of individual risk to the public is likely to be slightly lower for recycling than for disposal due to the greater stringency of the dose constraints. Individual risks to nuclear workers are subject to a regulatory limit of $10^{-3}$ for either recycling or disposal. For 
TABLE 2.1 Health Risk Estimates for Radioactive Scrap Metal (Steel) Management Alternatives

\begin{tabular}{|c|c|c|c|c|}
\hline \multirow[b]{2}{*}{ Activity } & \multirow[b]{2}{*}{ Group Affected } & \multirow[b]{2}{*}{ Risk Type } & \multicolumn{2}{|c|}{$\begin{array}{l}\text { Health Risk Estimate from } \\
\text { One Year of Activity }\end{array}$} \\
\hline & & & Recycle/Reuse & Disposal/Replacement \\
\hline \multirow[t]{2}{*}{ RSM transportation ${ }^{b}$} & Public & $\begin{array}{l}\text { Accident/fatalities } \\
\text { Radiation/cancer }\end{array}$ & $\begin{array}{l}5 \times 10^{-3} \text { (collective) } \\
\text { Negligible }\end{array}$ & $\begin{array}{l}5 \times 10^{-3} \text { (collective) } \\
\text { Negligible }\end{array}$ \\
\hline & Truck drivers & Radiation/cancer & $1 \times 10^{-5}$ & $1 \times 10^{-5}$ \\
\hline \multirow[t]{2}{*}{ RSM disposal (LLW) } & Nuclear workers & Radiation/cancer & $10^{-3}$ (regulatory limit $\left.{ }^{c}\right)$ & $10^{-3}$ (regulatory limit ${ }^{c}$ ) \\
\hline & Public & Radiation/cancer & $\begin{array}{l}5 \times 10^{-5} \text { (regulatory } \\
\text { limit }{ }^{\mathrm{c}} \text { ) }\end{array}$ & $\begin{array}{l}5 \times 10^{-5} \text { (regulatory } \\
\text { limit }^{c} \text { ) }\end{array}$ \\
\hline $\begin{array}{l}\text { RSM decontamination } \\
\text { and preparation }\end{array}$ & Nuclear workers & $\begin{array}{l}\text { Radiation/cancer } \\
\text { Chemical/cancer }\end{array}$ & $\begin{array}{l}10^{-3}\left(\text { regulatory limit }^{c}\right) \\
10^{-3}(\text { regulatory limit })\end{array}$ & NA \\
\hline \multirow[t]{2}{*}{ Controlled smelting } & Nuclear workers & $\begin{array}{l}\text { Radiation/cancer } \\
\text { Chemical/cancer } \\
\text { Accident/fatalities }\end{array}$ & $\begin{array}{l}10^{-3} \text { (regulatory limit }^{c} \text { ) } \\
10^{-3} \text { (regulatory limit } \\
\text { Unquantified } \\
\text { Ud }\end{array}$ & NA \\
\hline & Public & $\begin{array}{l}\text { Radiation/cancer } \\
\text { Chemical/cancer }\end{array}$ & $\begin{array}{l}\text { Unquantified } \\
\text { Unquantified }\end{array}$ & NA \\
\hline \multirow[t]{2}{*}{ Ingot transportation ${ }^{b}$} & Truck drivers & Radiation/cancer & $1 \times 10^{-5}$ & NA \\
\hline & Public & $\begin{array}{l}\text { Accident/fatalities } \\
\text { Radiation/cancer }\end{array}$ & $\begin{array}{l}5 \times 10^{-3} \text { (collective) } \\
\text { Negligible }\end{array}$ & NA \\
\hline \multirow[t]{2}{*}{ Commercial smelting } & Smelter workers & $\begin{array}{l}\text { Radiation/cancer } \\
\text { Chemical/cancer } \\
\text { Accident/fatalities } \\
\text { and injuries }\end{array}$ & $\begin{array}{l}\left.10^{-7} \text { to } 10^{-6} \text { (note } \mathrm{c}\right) \\
\left.10^{-3} \text { (regulatory limit }{ }^{\mathrm{c}}\right) \\
8 \times 10^{0}\end{array}$ & $\begin{array}{l}\text { Unquantified } \\
\left.10^{-3} \text { (regulatory limit }{ }^{c}\right) \\
8 \times 10^{0}\end{array}$ \\
\hline & Public & $\begin{array}{l}\text { Radiation/cancer } \\
\text { Chemical/cancer }\end{array}$ & $\begin{array}{l}3 \times 10^{-8} \text { (note c) } \\
2 \times 10^{-4}\end{array}$ & $\begin{array}{l}\text { Unquantified } \\
2 \times 10^{-4}\end{array}$ \\
\hline Steel end use & Public & Radiation/cancer & $10^{-7}-10^{-6}$ (note c) & NA \\
\hline \multirow[t]{2}{*}{$\begin{array}{l}\text { Iron ore mining and } \\
\text { enrichment }\end{array}$} & Miners & $\begin{array}{l}\text { Radiation/cancer } \\
\text { Chemical/cancer } \\
\text { Accident/fatalities }\end{array}$ & NA & $\begin{array}{l}5 \times 10^{-5} \text { to } 3 \times 10^{-3} \\
\left.10^{-3} \text { (regulatory limit }\right) \\
1 \times 10^{-2}\end{array}$ \\
\hline & Public & Chemical/cancer & NA & Unquantified \\
\hline Ore transportation & Public & Accident/fatalities & NA & $\begin{array}{l}1 \times 10^{-3} \text { to } 4 \times 10^{-2} \\
\left(\text { collective }^{\mathrm{e}}\right)\end{array}$ \\
\hline \multirow{3}{*}{$\begin{array}{l}\text { Coking coal } \\
\text { production }\end{array}$} & Miners & Accident/fatalities & $\mathrm{NA}$ & $2 \times 10^{-3}$ to $3 \times 10^{-2}$ \\
\hline & Oven workers & Chemical/cancer & NA & $1 \times 10^{-2}$ to $6 \times 10^{0}$ \\
\hline & Public & Chemical/cancer & NA & $1 \times 10^{-3}$ to $7 \times 10^{-2}$ \\
\hline Coke transportation & Public & Accident/fatalities & & $\begin{array}{l}1 \times 10^{-3} \text { to } 4 \times 10^{-2} \\
\text { (collective }{ }^{\mathrm{e}} \text { ) }\end{array}$ \\
\hline
\end{tabular}




\section{TABLE 2.1 (Cont.)}

\begin{tabular}{|c|c|c|c|c|}
\hline \multirow[b]{2}{*}{ Activity } & \multirow[b]{2}{*}{ Group Affected } & \multirow[b]{2}{*}{ Risk Type } & \multicolumn{2}{|c|}{$\begin{array}{l}\text { Health Risk Estimate from } \\
\text { One Year of Activity }\end{array}$} \\
\hline & & & Recycle/Reuse & Disposal/Replacement \\
\hline \multirow[t]{2}{*}{$\begin{array}{l}\text { Pig iron production } \\
\text { (blast furnace) }\end{array}$} & Workers & $\begin{array}{l}\text { Radiation/cancer } \\
\text { Chemical/cancer }\end{array}$ & NA & $\begin{array}{l}\text { Unquantified } \\
10^{-3} \text { (regulatory limit') }\end{array}$ \\
\hline & Public & $\begin{array}{l}\text { Radiation/cancer } \\
\text { Chemical/cancer }\end{array}$ & NA & $\begin{array}{l}\text { Unquantified } \\
2 \times 10^{-4}\end{array}$ \\
\hline \multicolumn{5}{|c|}{$\begin{array}{l}\text { A Assumes } 50,000 \text { t of RSM or replacement steel. All risks are reported for the most exposed individual unless } \\
\text { designated as collective. NA = not applicable. }\end{array}$} \\
\hline \multicolumn{5}{|c|}{ b Assumes $100 \mathrm{~km}$ per round trip and $20 \mathrm{t}$ per shipment. } \\
\hline \multicolumn{5}{|c|}{$\begin{array}{l}\text { Maximum individual lifetime risk of cancer fatality resulting from one year of exposure at the maximum permissible } \\
\text { concentration. }\end{array}$} \\
\hline \multicolumn{5}{|c|}{ d Accident rates are likely to be substantially lower than in commercial facilities. } \\
\hline \multicolumn{5}{|c|}{ e Rail transport has the lowest rate and truck transport the highest. } \\
\hline
\end{tabular}

replacement of disposed RSM, the upper range of risks to metal miners from natural occurring radioactivity, mainly radon (United Nations 1993), is about the same magnitude as the regulatory limits for nuclear workers.

On the basis of the radiological health impact analysis, several conclusions have been reached. Implementation of a tiered-release concept in such standards would provide flexibility in the release of radioactive scrap metals without sacrificing public protection. Release standards should be based on reasonable assumptions regarding key parameters. For example, radionuclide partitioning factor ranges for steel melting under various conditions are fairly well documented for a number of important nuclides. Also, a minimum level of likely RSM dilution in commercial smelters can be established based on current practices. In addition to the nuclide partitioning factors and metal dilution factor, several other sensitive parameters have been identified. These parameters include dust loading for smelter worker scenarios and the particulate surface emission rate for reuse scenarios; the corrosion rate of frying pans for the ingestion pathway scenario; and the radon emanation factor for radon parents in unrestricted reuse scenarios. These sensitive parameters deserve further investigation.

Different categories of release levels should be established for like groupings of radionuclides. Levels for such a radionuclide group should not be driven by a single nuclide or a few nuclides, such as Co-60. Rather, a separate (and more restricted) release level can be assigned for Co-60. Although the constraining individual doses are generally those for commercial smelter workers, an RSM throughput of 50,000 t results in collective doses for the public that may cause concern (particularly for Co-60) with regard to the criterion of 1 person-Sv for an annual practice. 
The nuclide category of radon parents was analyzed for the unrestricted reuse option with the results indicating that the activity levels must be quite low to meet the dose constraint of $10 \mu \mathrm{Sv} / \mathrm{yr}$. Determining appropriate release levels is complicated by the fact that radon buildup from decay product ingrowth results in a maximum dose several years following release.

\subsubsection{Nonradiological Health Risks}

Both the recycle and the disposal and replacement alternatives involve health risks from worker and public exposures to chemicals that are carcinogenic or toxic, as well as from workplace and transportation accidents. Of these two major types of risks, the fatality risks to the public and workers from accidents are higher and much more immediate than the risks from chemical (or radiation) exposure. Health risks for individuals from chemical exposures and accidents are summarized in Table 2.1.

\subsubsection{Accidents}

Accident risks from transportation and smelting operations apply to both RSM recycling and replacement. On the basis of accident fatality rates for combination trucks on interstate highways in the U.S.A. (Saricks and Kvitek 1991), about $1 \times 10^{-2}$ fatalities would be expected for recycling 50,000 t (assuming two 100-km transport segments). Disposal would require shipment of RSM to the LLW disposal site, with a risk of $5 \times 10^{-3}$ fatalities for $100 \mathrm{~km}$ transport of 50,000 t. In addition, both iron ore and coking coal would require transportation to the steel foundry. For 50,000 t, this would require two segments of bulk transport with a combined risk of $3 \times 10^{-3}$ to $9 \times 10^{-2}$ fatalities on the basis of data for coal (U.S. Department of Energy [DOE] 1988). The total risk estimate for disposal/replacement transportation is $7 \times 10^{-3}$ to $9 \times 10^{-2}$.

Replacement of RSM would involve accident risks for workers involved in metal and coal mining activities. On the basis of the 1990 fatality rate for iron miners in the U.S.A. (U.S. Department of Labor 1991), to replace 50,000 t of RSM, about $10^{-2}$ worker fatalities would be expected. For coal mining, replacing 50,000 t of RSM would incur additional fatality risks for coal miners of $2 \times 10^{-3}$ to $3 \times 10^{-2}$ (based on DOE 1988).

The annual rate of fatalities and major injuries from blast furnace operation (U.S. Department of Labor 1989) is equivalent to 7 fatalities or disabling injuries from pig iron production to replace 50,000 $\mathrm{t}$ of RSM. The fatality and serious injury rate for iron and steel foundries is also relatively high (U.S. Department of Labor 1989), resulting in an additional risk of 8 fatalities or disabling injuries for production of 50,000 $t$ of replacement steel or RSM melting at a commercial smelter. This results in a total risk from steel production processes of about 15 serious injuries or fatalities. Steel replacement also involves accident risks in coking coal production, but these accidents are not quantified in this study. 


\subsubsection{Chemical Exposures}

Chemical exposures for workers and the public from smelting operations are likely to be similar for the RSM recycling and RSM replacement alternatives. However, replacement would also result in worker and public exposure to chemicals from metal ore and coal mining, coking coal production, and pig iron production. Although impacts to workers and the public are not quantified for releases of toxic chemicals to air, water, and soil during mining and releases from tailings piles and mine wastes, the released substances are associated with cancer and a variety of other serious illnesses.

As part of the decontamination and recycle process, RSM may be melted in a controlled melt facility. As a result of radiological exposure controls, chemical exposures of radiation workers and the public from these activities are likely to be very low. After release for unrestricted recycling, RSM could be remelted in a commercial smelter, resulting in chemical exposures to commercial metal workers and to the downwind population. The resulting health impacts would be similar to those that occur from routine commercial recycling of scrap in metal production. For the RSM replacement alternative, similar types of chemical exposures would occur from both pig iron production (blast furnace) and steel smelting (basic oxygen process) required for finished steel.

RSM replacement also requires the production of coke from coal for producing iron in blast furnaces as an input to steel production. Emissions from coking ovens have been implicated in both cancers and chronic respiratory ailments. For replacement of 50,000 $\mathrm{t}$ of RSM, the cancer fatality risk is $1 \times 10^{-2}$ to $6 \times 10^{0}$ for workers, depending on emission controls; and $1 \times 10^{-3}$ to $7 \times 10^{-2}$ for the public (based on Dong et al. 1988).

The assumptions used to calculate intake of air emissions from smelting are conservative overestimates for the general population. Of the contaminants of concern, five (arsenic, cadmium, chromium VI, lead, and nickel) are classified as known or probable human carcinogens via inhalation. The carcinogenic risk of lead cannot be calculated at this time due to lack of necessary data. The calculated inhalation carcinogenic risks associated with the upper estimate of steel production emissions range from $7 \times 10^{-7}$ for cadmium to $2 \times 10^{-4}$ for chromium, with a sum risk of $2 \times 10^{-4}$.

Although air emissions are the main source of public exposure from smelting, workers may also be exposed to dust in the workplace atmosphere and from slag handling. The key contaminants in blast furnace slag are arsenic and mercury, and those in steel slag are arsenic, fluoride, and molybdenum. The key contaminants for dust/sludge solids from air pollution control devices in steel furnaces are cadmium, mercury, molybdenum, and selenium; contaminants associated with blast furnaces are arsenic, chromium, fluoride, and selenium.

Smelting residuals could also have impacts on the public, depending on waste disposal practices. The likelihood of adverse impacts to groundwater from these contaminants is low where certain mitigating conditions exist. The likelihood of adverse impacts to surface water from slag is also generally low because of the small fraction of erodible-sized solids $(\leq 0.1 \mathrm{~mm})$, and the likelihood can be further reduced by runon/runoff controls. For 
dust/sludge solids, the particle size ( $<0.02$ to $2 \mathrm{~mm}$ ) results in susceptibility to air transport (U.S. Environmental Protection Agency [USEPA] 1990). Thus, impacts could result from uncontrolled placement of this waste (e.g., depending on a facility's proximity to a drinking water source).

For human exposures to airborne particulates, the key contaminants for slag are arsenic, chromium, manganese, and nickel; those for dust/sludge are arsenic, cadmium, and chromium. In general, the large size of slag fragments (most are $>100 \mu \mathrm{m}$ in diameter) limits the potential for downwind exposures (USEPA 1990). Thus, public exposures to slag particles are less likely than are exposures to dust/sludge particles. The location of receptors relative to a facility is the primary factor in determining the potential significance of exposures.

\subsubsection{Relative Magnitude of Health Risks}

Potential health risks to workers and the general public are associated with both the recycle/reuse and the disposal and replacement management alternatives for RSM. These alternatives involve health risks from exposures to radiation and toxic elements, as well as from industrial and transportation accidents. For both alternatives, the risks to workers from workplace accidents and to the public from transportation accidents are greater in magnitude than the risks from radioactive materials or chemicals.

Regulatory constraints on radiation exposure of workers and the general public would hold risks to very low levels under either alternative. Releasing RSM that met the derived activity levels for the modified-conservative unrestricted reuse or recycle, or prescribed initial use cases would result in a lifetime cancer fatality risk level for an individual of the general public of $10^{-7}$ to $10^{-6}$ from annual exposure (based on Safety Series No. 89 [IAEA 1988]). Risks to commercial metal workers would be of a similar magnitude and could potentially be reduced further by use of protective measures. The total collective risk level would be $10^{-2}$ to $10^{-1}$ cancer fatalities from an annual recycling practice. For the replacement alternative, some miners could be exposed to naturally occurring radioactivity that could approach the level of the regulatory limit for nuclear workers. Such exposures would be more likely for nonferrous metals, such as copper, than for iron mining.

The nonradiological health risks would be greater overall than the radiological risks for either alternative. The highest health risk levels would be those for fatalities or disabling injuries from workplace accidents. For the recycling alternative, these risks would apply to decontamination activities, including controlled melting, and to commercial smelting. The risks would be at least twice as high for the disposal and replacement option because it would involve iron mining, coal mining, coke production, and blast furnace operation for pig iron production in addition to steel smelting. Transportation accident fatality risks would be on the order of $10^{-3}$ for each $100 \mathrm{~km}$ that the RSM or replacement materials were shipped. Transportation requirements and, therefore, risks would likely be higher for disposal/replacement than for recycling. Chemical risks to commercial metal workers and the public from melting RSM would be similar in nature to, but less than, those generated by smelting metal from ore. 
For the portion of RSM that comprises the relatively large quantity of suspect, but probably nonradioactive scrap, both the radiological and nonradiological risks to the public and metal workers would be lower for recycling than for replacement because most of the radionuclides and contaminants that naturally occur in ore would have been removed in the original smelting of the RSM. Overall, the recycle option involves controlled risks borne by radiation workers and small increases in risks to commercial metal workers and the public. The disposal and replacement option, on the other hand, involves controlled risks to radiation workers and substantial increases in relatively uncontrolled risks to miners and the public. Health risks for the disposal/replacement alternative would be at least twice the level of risks for the RSM recycling alternative.

\subsection{ENVIRONMENTAL IMPACTS}

Impacts to air, land, water, and energy resources from RSM recycle or disposal and replacement are difficult to quantify; a qualitative discussion is presented below. The major types of environmental effects likely to be associated with each alternative are summarized in Table 2.2.

\subsubsection{Impacts on Land Resources}

Recycling RSM would produce relatively minor impacts to land use. Less than $10 \%$ of the inputs to controlled melting of RSM would require disposal as LLW. The disposal and replacement option, in contrast, is likely to substantially impact land use because of the requirements for RSM disposal area, replacement iron ore mining, and coal mining for coke production. Lands that are disturbed or contaminated by toxic metals in this process are generally not reclaimed, even in countries with applicable environmental legislation (Johnson and Paone 1982). In addition, huge piles of mining wastes and ore tailings may be left exposed, from which toxic chemicals would continue to be leached. Quantities of mining wastes are commonly 100 or more times the quantity of ore extracted.

\subsubsection{Impacts on Water Quality}

To the extent that aggressive decontamination efforts would be employed, RSM recycling could result in some effluent releases to nearby surface water bodies. These effluents would be treated to meet local standards for release and would have negligible impacts on water quality. Metal replacement activities, however, are likely to cause adverse impacts to both plants and animals from acidification and sedimentation of surface waters. Leaching of toxic and radioactive chemicals to both surface water and groundwater is also a problem, especially in the case of nonferrous metals. The acidity of mine drainage water promotes leaching of heavy metals from soils, transferring them to streams and rivers where they may be concentrated in some parts of the food chain. These problems tend to persist long after mine operations have ceased. 
TABLE 2.2 Environmental Impacts of Activities Associated with Radioactive Scrap Metal (Steel) Management Alternatives

\begin{tabular}{|c|c|c|}
\hline \multirow{2}{*}{$\begin{array}{l}\text { Resource } \\
\text { Affected }\end{array}$} & \multicolumn{2}{|c|}{ Impacts from RSM (Steel) Management Alternatives } \\
\hline & Recycle/Reuse & Dispose and Replace \\
\hline Land use & $\begin{array}{l}\text { Some LLW involved, but } \\
\text { no new sites required }\end{array}$ & $\begin{array}{l}\text { Substantial expansion of LLW } \\
\text { disposal site capacity required } \\
\text { Increased land use for mining } \\
\text { Increased land disruption and } \\
\text { damage from mining wastes } \\
\text { Accumulation of heavy metals in } \\
\text { soils as a result of mining and } \\
\text { refining }\end{array}$ \\
\hline Water quality & $\begin{array}{l}\text { Controlled release of } \\
\text { decontamination } \\
\text { effluents }\end{array}$ & $\begin{array}{l}\text { Acidification of surface water } \\
\text { flowing from mining sites } \\
\text { Increased leaching of heavy metals } \\
\text { from soils and mining wastes } \\
\text { into surface and groundwater } \\
\text { Leaching of radioactive elements } \\
\text { from mining wastes into surface } \\
\text { water and groundwater } \\
\text { Increased sedimentation of streams } \\
\text { and rivers } \\
\text { Release of heavy metals from } \\
\text { smelting into surface water }\end{array}$ \\
\hline Air quality & $\begin{array}{l}\text { Emissions of } \mathrm{SO}_{2} \text { from } \\
\text { smelting }\end{array}$ & $\begin{array}{l}\text { Greater emissions of } \mathrm{SO}_{2} \text { from } \\
\text { smelting }\end{array}$ \\
\hline & $\begin{array}{l}\text { Emissions of toxic } \\
\text { chemicals and } \\
\text { radioactive materials } \\
\text { from smelting }\end{array}$ & $\begin{array}{l}\text { Emissions of toxic chemicals from } \\
\text { mining operations, waste piles, } \\
\text { smelting, and coke production } \\
\text { Emissions of naturally occurring } \\
\text { radioactive materials from mining } \\
\text { and smelting }\end{array}$ \\
\hline $\begin{array}{l}\text { Mineral } \\
\text { resources }\end{array}$ & $\begin{array}{l}\text { LLW disposal may be } \\
\text { needed for some slag } \\
\text { (instead of being usable) }\end{array}$ & $\begin{array}{l}\text { Substantial metal ore quantities } \\
\text { required } \\
\text { Substantial coal quantities required } \\
\text { for coke inputs to iron production }\end{array}$ \\
\hline $\begin{array}{l}\text { Energy } \\
\text { resources }\end{array}$ & $\begin{array}{l}\text { Some energy use for } \\
\text { smelting scrap }\end{array}$ & $\begin{array}{l}\text { Much higher energy use in refining } \\
\text { ores and in producing coke }\end{array}$ \\
\hline
\end{tabular}




\subsubsection{Impacts on Air Quality}

Recycling of RSM involves three major types of activities that could generate emissions that would degrade air quality: decontamination, melting in a controlled smelter, and remelting at a commercial mill. The presence of radioactivity and hazardous chemicals requires efficient emission-control technology for exhaust air in decontamination and melting activities, so emissions from these activities are likely to be negligible. Controls would likely be less stringent on emissions from commercial steel mills where the RSM would be remelted and some air quality impacts could occur. However, emissions from recycling are less than those from primary metal smelting because many impurities have previously been removed and less energy is generally required for recycling. For the disposal and replacement option, substantial impacts to air quality would result from metal replacement activities. Most air emissions generated in metal production come from the ore enrichment and refining processes, and, in the case of steel, from coke production.

\subsubsection{Impacts on Energy Resources}

The energy requirement for steel replacement is likely to be two to three times greater than that for the RSM recycling alternative. In metal production generally, most of the required energy inputs are applied in the refining stage. The relative energy savings from using copper or aluminum scrap are even greater than for steel scrap. Although some decontamination techniques such as electropolishing are relatively energy intensive, energy use is still likely to be less for recycling RSM than for replacement.

\subsubsection{Relative Magnitude of Environmental Impacts}

Major differences exist in the environmental impacts associated with the recycling and disposal alternatives. In general, recycling RSM would have less of an environmental impact and would require a smaller commitment of natural resources. The disposal and replacement alternative would require substantial land area for RSM disposal, and metal replacement processes would result in major disruption of land for mining and in contamination of land and water with toxic elements. Radionuclides and heavy metals would be released to air and water during refining processes, and much greater energy resources would be required than is the case for recycling scrap metal. For steel, the impacts would be substantially larger for replacement than for recycling in virtually all categories.

Producing $1 \mathrm{t}$ of steel from raw materials requires more than $2 \mathrm{t}$ of iron ore and $0.5 \mathrm{t}$ of coke, and mining the ore and coal produces numerous tons of wastes. Substantial land areas are disturbed or contaminated by toxic metals in this process, and these areas are usually not reclaimed. Both toxic and radioactive elements are released to surface waters, and rivers can be damaged by sedimentation as a result of mining and refining processes for metal replacement. Water quality impacts from RSM recycling, in contrast, are likely to be kept to minimal levels by regulatory controls and good operating practices. 
Only in the air emissions category would impacts of recycling approach those of disposal and replacement. The nature of emissions from smelting would be similar in both cases, but quantities of hazardous emissions from melting scrap are likely to be smaller because many impurities would have previously been removed. In addition, recycling of scrap steel would require two to three times less energy, thus reducing secondary impacts from fuel combustion. For all the processes required, air quality impacts would likely to be somewhat higher from metal replacement than from recycling.

\subsection{SOCIOECONOMIC ISSUES AND IMPACTS}

Several issues are relevant to the choice between the RSM management alternatives of recycle/reuse and disposal/replacement. Such issues include LLW disposal site availability, public acceptance of recycling, potential impacts of either alternative on metal markets, effect of radioactivity in the metal supply on sensitive industrial uses of metal, international equity issues, and need for an international regulatory standard for RSM recycling.

\subsubsection{Disposal Capacity}

Disposal of the potential international RSM inventory as LLW would require disposal capacity of approximately $5 \times 10^{6} \mathrm{~m}^{3}$ (assuming uncompacted metal with $30 \%$ void space). This contrasts with current commercial LLW disposal rates for all types of materials of $3 \times 10^{5} \mathrm{~m}^{3} / \mathrm{yr}$ in the U.S.A. (Oak Ridge National Laboratory 1992). Although new LLW disposal facilities are anticipated to become available, disposal cost in the U.S.A. are likely to continue to increase, and access to disposal sites is likely to be limited on the basis of the geographic location of the waste generator. In a number of European countries, LLW disposal facilities currently are available or under construction, but in general new facilities will be required to accommodate wastes generated during nuclear facility decommissioning (Nuclear Energy Agency 1991). There are major political constraints on availability of disposal capacity because siting and operation of LLW disposal facilities is a significant issue in several countries.

\subsubsection{Public Acceptability of Recycling}

The public may see the choice between recycling or disposing of RSM as an issue of having a metal supply that is clean versus having one that is radioactive, although the issue is not actually that clear-cut. Iron and steel, for instance, generally contain small amounts of naturally occurring radioactive materials that originate with the ore deposits or with the coal used in coke production. Measured background activities of uranium and thorium in steel are on the order of 10-5 to 10-4 Bq/g (Knoll 1979). In addition to naturally occurring activity, there are several other sources of radioactivity in iron and steel. For example, traces of Co-60 from measuring devices used in smelting are commonly found in steel, and reports are increasingly frequent of the discovery of metal that has been accidentally contaminated 
by the inclusion of sealed radiation sources with melted scrap or for which the activity source is unknown.

Radioactive materials are currently used by the public virtually throughout the world, with varying degrees of public recognition of the associated risks. Radioactivity is incorporated intentionally, for its beneficial properties, in a variety of medical and household products and in personal items. It also occurs naturally in some products and is an unintended by-product of beneficial functions of others. Public perceptions of risk related to use of these products are influenced by product benefits, product familiarity, and the extent to which radioactive aspects of the product are publicized. RSM recycling differs from virtually all existing situations in which radioactivity is incorporated in consumer products because it does not provide a direct benefit. Instead, the main benefit of recycling RSM is the avoidance of environmental and health impacts from replacing the metal if it is not recycled.

\subsubsection{Metal Market Impacts}

On an annual basis, the estimated total worldwide RSM inventory could produce recycling flows of $5 \times 10^{5} \mathrm{t} / \mathrm{yr}$ of iron and steel, $1 \times 10^{5} \mathrm{t} / \mathrm{yr}$ of copper, and $4 \times 10^{4} \mathrm{t} / \mathrm{yr}$ of stainless steel over the period from 2010 to 2043 . Increasing scrap metal supply by recycling RSM is expected to create downward pressure on scrap prices. The magnitude of the effect will depend on the relative size of the RSM flow and on the demand situation. Comparison of the potential annual RSM flow with measures of metal demand in regional markets indicates that RSM is likely to constitute a very small portion of scrap imports or of annual variation in scrap consumption in these markets. As a result, price impacts are expected to be small. The one exception is copper because the RSM quantities are sufficient to depress prices somewhat in some regional markets.

\subsubsection{Impact Distribution}

The distribution of impacts from the RSM management alternatives depends on the locations of RSM processing and disposal facilities and the locations of mining and metal production activities. In general, the inventory of RSM is greatest in relatively industrialized countries, and RSM is likely to be processed for recycling or to be disposed of in its region of origin. Risks from these activities are expected to be controlled, and no major risk shifting among regions is involved. Nor is risk shifting likely from product trade, even though metal product and scrap metal trade flows tend to be from more to less industrialized countries. If RSM was released only when it presented negligible public risk, these net trade flows would not represent a risk shifting of any significance. Establishment of an international standard for radioactivity in metals would provide a safeguard against transfer of risk among countries.

The major potential for impact shifting arises in the case of RSM disposal and replacement. Much of the world's ore production and refining occurs in less developed 
countries and in countries that do not have strong systems for environmental and health protection. The distribution of raw material production among countries and the substantial health and environmental impacts of metal production create the potential for significant impacts in less developed countries if the option of RSM disposal and replacement is implemented.

\subsubsection{Regulatory Issues}

Recycling RSM is currently impeded by the lack of an accepted international standard for unrestricted release of this material. Some European countries have developed release standards, but contaminated metals are generally evaluated and released on a project-specific basis. The U.S.A. currently has a surface contamination standard for material release, Regulatory Guide 1.86 (U.S. Nuclear Regulatory Commission [USNRC] 1974) but none for volumetric activity. Development of worldwide RSM recycling will require further effort to determine appropriate activity levels to ensure protection of public health under possible conditions of exposure. A single set of international standards is needed to guide the unrestricted release of RSM because the international trade in scrap metals and metal products is so extensive. Differing national release standards will have adverse international trade ramifications.

\subsubsection{Relative Magnitude of Socioeconomic Impacts}

The availability and cost of LLW disposal site capacity is one of the most critical socioeconomic issues related to the RSM alternatives. If the RSM were disposed of as LLW, it would require greater LLW disposal site capacity than is currently available or planned, with all of the attendant problems of site development. In contrast, recycling of RSM would require much less LLW disposal site capacity to accommodate the residuals from decontami- . nation procedures.

Metal market impacts from either alternative are likely to be minimal because RSM would represent only a small proportion of total metal production and metal scrap. However, some price effects could occur in regional markets for some metals.

RSM recycling and disposal activities are likely to take place in the countries in which the RSM sources are located. Metal replacement activities, especially mining, will occur in the locations where metal deposits are actively mined. Many of these mines are in less developed countries, which also tend to have less stringent health and environmental regulations and enforcement than the industrialized countries. As a result, RSM disposal and replacement has the potential for shifting the risks of RSM management to countries other than those generating significant quantities of RSM.

The issue of possible impacts on sensitive technologies from radioactivity in the metal supply has been found to have minimal impacts. This issue has to be, and has been, 
dealt with regardless of whether RSM is recycled because many types of finished metal contain low levels of radioactivity.

Public acceptability of the concept of recycling materials with traces of radioactivity may be problematic because of the stigma associated with the nuclear industry in most industrialized countries. At the same time, RSM recycling has been carried out successfully in small quantities in a number of countries, and products containing low levels of added or naturally occurring radioactivity are widely used. The risks and impacts of metal replacement activities receive relatively less attention than radiological risks in most countries, even though they are substantially greater and more immediate. Acceptability of RSM recycling may depend on dissemination of information regarding the trade-offs and development of an international standard for material release as well as the regulatory infrastructure needed to implement that standard.

\subsection{CONCLUSIONS}

This study assessed and compared the impacts of RSM recycling to those of disposal and replacement within the context of the system of radiological protection. The findings indicate that recycling is justified as a practice. This is based on the finding that the health and environmental detriments associated with recycling are less than those of not recycling. Second, radiological protection for the practice of recycling can be optimized through implementing a tiered system of release criteria for materials suitable for unrestricted recycling, and use of other low-level contaminated materials within controlled environments. Third, such a system can be implemented while controlling individual and population doses to levels recommended by international agencies.

The health and environmental impacts and the socioeconomic issues associated with the two RSM management alternatives are compared in Table 2.3. Overall, recycling of RSM is likely to result in fewer impacts than disposing of and replacing it. The health and environmental impacts of recycling are clearly lower, in that health risks of recycling are almost half those for disposal/replacement and environmental impacts are orders of magnitude lower. The comparison of socioeconomic impacts is less clear. RSM disposal will be very costly and will adversely impact availability of low-level waste disposal capacity for materials that are impractical or infeasible to recycle. On the other hand, some public opposition to RSM recycling is likely, regardless of how low the risks may be. The extent of public acceptance of recycling is likely to be affected by the quality of the regulatory process and the provision of information regarding comparative risks of the RSM management alternatives.

\subsection{REMAINING ISSUES}

Several. issues that merit attention were outside of the study scope or have not been fully addressed. One of these is the issue of nuclear worker exposure from activities required for recycling, to the extent that these are above and beyond requirements for disposal. 


\section{TABLE 2.3 Comparison of Impacts from the Radioactive Scrap Metal Management Alternatives}

\begin{tabular}{|c|c|c|}
\hline \multirow[b]{2}{*}{ Impact Categories } & \multicolumn{2}{|c|}{ Impacts from RSM (Steel) Management Alternatives } \\
\hline & - Recycle/Reuse & Dispose and Replace \\
\hline \multicolumn{3}{|l|}{ Human Health Effect Risk ${ }^{a}$} \\
\hline Radiological risk & $\begin{array}{l}10^{-7} \text { to } 10^{-6} \text { fatal cancer risk } \\
\text { to metal workers and public; } \\
10^{-2} \text { to } 10^{-1} \text { population risk } \\
\text { per year of practice }\end{array}$ & $\begin{array}{l}\text { Potential elevated cancer risk } \\
\text { to miners }\end{array}$ \\
\hline $\begin{array}{l}\text { Nonradiological risks } \\
\text { Accidents (work place) }\end{array}$ & $\begin{array}{l}\text { About } 7 \text { fatalities or serious } \\
\text { injuries to workers }\end{array}$ & $\begin{array}{l}\text { About } 15 \text { fatalities or serious } \\
\text { injuries to workers }\end{array}$ \\
\hline Accidents (transportation) & $\begin{array}{l}10^{-2} \text { collective fatality risk to } \\
\text { workers and public }\end{array}$ & $\begin{array}{l}10^{-2} \text { collective fatality risk to } \\
\text { workers and public }\end{array}$ \\
\hline $\begin{array}{l}\text { Chemical exposure from } \\
\text { smelting }\end{array}$ & $\begin{array}{l}10^{-3} \text { fatal cancer risk to } \\
\text { workers; } 10^{-4} \text { to public }\end{array}$ & $\begin{array}{l}10^{-3} \text { fatal cancer risk to } \\
\text { workers; } 10^{-4} \text { to public }\end{array}$ \\
\hline $\begin{array}{l}\text { Chemical exposure from coke } \\
\text { production }\end{array}$ & None & $\begin{array}{l}1 \text { fatal cancer risk to workers; } \\
10^{-2} \text { to public }\end{array}$ \\
\hline \multicolumn{3}{|c|}{ Environmental Quality and Resource Use } \\
\hline Land disturbance & Minimal & Substantial \\
\hline Water quality degradation & Minimal & Substantial \\
\hline Air quality degradation & Moderate & Moderate \\
\hline Mineral resource requirement & Minimal & Substantial \\
\hline Energy requirement & Moderate & Substantial \\
\hline \multicolumn{3}{|l|}{ Socioeconomic Issues } \\
\hline LLW site capacity & Minimal & Substantial \\
\hline Public acceptability & $\begin{array}{l}\text { Varies among countries; some } \\
\text { opposition likely }\end{array}$ & $\begin{array}{l}\text { Generally accepted except for } \\
\text { local concerns }\end{array}$ \\
\hline Metal market impacts & Minimal & Minimal \\
\hline Risk distribution & $\begin{array}{l}\text { Risk largely borne in country } \\
\text { generating RSM }\end{array}$ & $\begin{array}{l}\text { Risk largely shifted to less } \\
\text { developed countries }\end{array}$ \\
\hline Industrial applications & Minimal & None \\
\hline
\end{tabular}

a Risk estimates represent maximum individual lifetime risk associated with a 50,000-t throughput. 
Relevant activities include metal surveying, sorting, decontamination, and controlled melting. Individual dose from these activities would be constrained by regulation; it is the population dose that could differ substantially for nuclear workers between the two alternatives. These differences have not be addressed in the literature to date.

A second issue involves the survey requirements for certification for release of metals that are not first melted. Both worker dose and survey cost may limit the feasibility of certifying objects for release for reuse. This study did not address issues of implementation; these remain for further evaluation.

Developing appropriate activity levels for unrestricted release of low-level contaminated materials requires an assessment of both the probabilities associated with various degrees of public exposure and the uncertainties regarding data and models for exposure parameters. This study includes extensive sensitivity analysis (discussed in Appendix C) to identify key parameters of the exposure models and it employs more realistic values for these parameters than most previous studies. There is still, however, considerable uncertainty regarding factors such as RSM dilution, melt partitioning, and surface contaminant transfer rates. Standard practice is to employ conservative assumptions in situations of uncertainty. In the case of RSM, the resulting high degree of public protection from exposure would be achieved with a disproportionately high resource commitment. Thus, further research, including collection of operational data, is recommended to reduce uncertainty regarding key exposure parameters.

The major open issue pertaining to recycling is that of public acceptability. There is evidence of public acceptance of many technologies that result in low levels of public exposure to ionizing radiation, but there is also evidence of a public hypersensitivity to issues and exposures related to the nuclear industry. An informal survey found a willingness on the part of industry and broad-focus environmental organizations to consider all aspects of the RSM management alternatives, so long as health and safety issues were not compromised. Public acceptance of RSM recycling will require documentation of public, including worker, safety; public education regarding the trade-offs between radiological detriment and other types of health and environmental detriments, involvement of a broad range of contaminated scrap generators, and a trustworthy system for certifying RSM contamination levels at the point of release.

\subsection{REFERENCES FOR SECTION 2}

DOE - see U.S. Department of Energy.

Dong, M.H., et al., 1988, American Journal of Epidemiology 128:860-873. [As cited in British Carbonisation Research Association Quarterly 39:31-65.]

Hertzler, T., et al., 1993, Recycle of DOE Radiologically Contaminated Metal - A Scoping Study, Draft, Science Application International Corp., Idaho Falls, Idaho.

IAEA - see International Atomic Energy Agency. 
International Atomic Energy Agency, 1988, Principles for the Exemption of Radiation Sources and Practices from Regulatory Control, IAEA Safety Series No. 89, Vienna, Austria.

International Commission on Radiological Protection, 1991, 1990 Recommendations of the International Commission on Radiological Protection, ICRP Publication 60, Pergamon Press, Oxford, United Kingdom.

Johnson, W., and J. Paone, 1982, Land Utilization and Reclamation in the Mining Industry, 1930-80, Information Circular 8862, U.S. Department of the Interior, Bureau of Mines, Washington, D.C.

Knoll, G.F., 1979, Radiation Detection and Measurement, John Wiley and Sons, New York, N.Y.

Menon, S., and L. Teunckens, 1994, "Application of Exemption Concepts: Overview of Practices in Some Countries," presented at Waste Management '94, Tucson, Ariz., February 27 - March 3.

Nuclear Energy Agency, 1991, Decommissioning of Nuclear Facilities: An Analysis of the Variability of Decommissioning Cost Estimates, Organization for Economic Cooperation and Development, Paris, France.

Oak Ridge National Laboratory, 1992, Integrated Data Base for 1992: U.S. Spent Fuel and Radioactive Waste Inventories, Projections, and Characteristics, DOE/RW-0006, Rev. 8, prepared for U.S. Department of Energy, Office of Environmental Restoration and Waste Management, Oct.

Saricks, C., and T. Kvitek, 1991, "Trends in State-Level Freight Accident Rates: An Extension of Risk Factor Development for RADTRAN," presented at 71st Annual Transportation Research Board Meeting, Washington, D.C.

United Nations, 1993, Sources, Effects, and Risks of Ionizing Radiation, United Nations Scientific Committee on the Effects of Atomic Radiation, New York, N.Y.

U.S. Department of Energy, 1988, Energy Technologies and the Environment: Environmental Information Handbook, DOE/EH-0077, Washington, D.C., Oct.

U.S. Department of Labor, 1989, Occupational Injuries and Illnesses in the United States by Industry, 1987, Bureau of Labor Statistics Bulletin 2328, Washington, D.C.

U.S. Department of Labor, 1991, Injury Experience in Metallic Mineral Mining, 1990, Information Report 1201, Mine Safety and Health Administration, Denver, Colo.

U.S. Environmental Protection Agency, 1990, Report to Congress on Special Wastes from Mineral Processing, EPA/530-SW-90-070C, Office of Solid Waste and Emergency Response, Washington, D.C.

USEPA - see U.S. Environmental Protection Agency. 
USNRC - see U.S. Nuclear Regulatory Commission.

U.S. Nuclear Regulatory Commission, 1974, Termination of Operating License for Nuclear Reactors, Regulatory Guide 1.86, Washington, D.C. 


\section{RADIOACTIVE SCRAP METAL INVENTORY}

\subsection{INTRODUCTION}

This section presents estimates of the quantities of radioactive scrap metal (RSM) that could potentially be recycled from the major sources of RSM: the nuclear power industry, the weapons industry, and the petroleum and phosphorous extraction industries. More information is available for nuclear power plants than for the other two sources, and so the estimates rely heavily on nuclear power plant data. The discussion includes estimates of metal mass and information on metal type, nature of the radioactivity, and the timing and regional location of the potential material flows. Appendix A provides details on the method used to estimate the masses of RSM from nuclear power plants.

Section 3.2 identifies and defines the categories of degrees of radioactive contamination used in this report and discusses the suitability of each category for recycling. Section 3.3 examines the basic assumptions underlying the estimates of metal mass, and Section 3.4 identifies and briefly discusses the significant sources of RSM. The estimates of RSM from the nuclear power industry were developed from a detailed database on power reactors (Appendix A). The estimates of metal mass from the oil and phosphorous extraction industries were derived from a published report on those industries. Defense industry information was very hard to obtain, so that portion of the estimate was taken to be a factor of the estimate for the nuclear power industry.

\subsection{DEGREES OF CONTAMINATION}

Radioactive scrap can be classified by the anticipated level of radioactivity (activity level), which depends on facility design, operating history, maintenance, decay time, and decommissioning strategy. For this inventory, the metal scrap has been divided into the four general categories defined in Table 3.1: (1) suspect radioactive, (2) surface-contaminated removable, (3) surface-contaminated - fixed, and (4) activated.

Because necessary data are largely not available, allocation of metal masses to these categories is based on component function in source plant operations rather than on activity levels. For a specific plant, the amounts of metals in the various activity-level classifications depend on such factors as facility design, operating history, and length of time since shutdown. Examples of assignment of components to the four general activity categories are as follows:

- Suspect Radioactive

- Pressurized-water reactor (PWR) feedwater lines;

- PWR steam lines and turbines; 
TABLE 3.1 Activity Categories of Scrap Metal

\begin{tabular}{|c|c|}
\hline Category & Description \\
\hline Suspect Radioactive & $\begin{array}{l}\text { This category consists of components with no significant } \\
\text { surface contamination or activation. These components } \\
\text { generally come from systems that are not associated with } \\
\text { the reactor fuel or primary coolant systems. Examples } \\
\text { include the cooling water system and the electrical } \\
\text { generating and transmission systems. In some cases, } \\
\text { health physics surveys will be required to confirm whether } \\
\text { a specific component or system from a specific facility is } \\
\text { nonradioactive. In most of the cases in which } \\
\text { contamination is found, surface decontamination should be } \\
\text { sufficient to produce a nonradioactive product. }\end{array}$ \\
\hline $\begin{array}{l}\text { Surface-Contaminated - } \\
\text { Removable }\end{array}$ & $\begin{array}{l}\text { This category consists of components that may have } \\
\text { significant levels of surface contamination that can be } \\
\text { removed to a level permitting unrestricted use. Extensive } \\
\text { decontamination may be required for some components. } \\
\text { These metals come from buildings and systems that are, or } \\
\text { could be, exposed to primary coolant or fuel during normal } \\
\text { operations or during any leaks or spills. The resulting } \\
\text { surface contamination is due to fission or activation } \\
\text { products in the coolant or released gases. Such items } \\
\text { include the reactor building crane and containment } \\
\text { building liner. This group includes system components } \\
\text { with tritium impregnation caused by hydrogen diffusion. }\end{array}$ \\
\hline $\begin{array}{l}\text { Surface-Contaminated - } \\
\text { Fixed }\end{array}$ & $\begin{array}{l}\text { This category consists of components with significant } \\
\text { levels of surface contamination that penetrates or is bound } \\
\text { to the metal. There may also be some metal activation. } \\
\text { Decontamination sufficient to permit unrestricted use is } \\
\text { unlikely. }\end{array}$ \\
\hline Activated & $\begin{array}{l}\text { This category consists of components with significant } \\
\text { levels of activation. These materials may also have high } \\
\text { levels of surface contamination. Decontamination may be } \\
\text { performed to reduce worker radiation exposure, but } \\
\text { decontamination alone is not expected to be sufficient to } \\
\text { produce material free of significant activity. }\end{array}$ \\
\hline
\end{tabular}


- Reactor building reinforcing bars (rebar) (>95\% in this category);

- Cooling towers, mechanical systems, and piping;

- Water-cleaning systems;

- Diesel generator systems;

- Switchyard equipment, transformers, electrical busses, batteries, etc.;

- Control and instrumentation cables (>95\% in this category); and

- Building metal in turbine and other auxiliary buildings.

- Surface-Contaminated - Removable

- Reactor containment-building crane;

- Reactor containment-building liner;

- Reactor building structural steel;

- Crane for fuel handling;

- Fuel-handling machine;

- Fuel storage pool liner and equipment;

- PWR primary loop lines, outside reactor cavity;

- PWR primary pumps and valves;

- Boiling-water reactor (BWR) steam lines and turbines; and

- PWR steam generators and accumulators (parts).

- Surface-Contaminated - Fixed ${ }^{1}$

- Liquid radwaste systems (some components);

- Fuel reprocessing system components; and

- PWR steam generators and accumulators (parts).

- Activated $^{2}$

- Reactor pressure vessel;

- Reactor pressure vessel cover and internals;

- Control rod drive lines;

- Boron poison lines and similar components within reactor cavity;

- Instrumentation and control cables (small fraction of total); and

- Reactor building structural steel proximate to reactor pressure vessel (small fraction of total).

Most of the activated radioactive components identified above are in areas of the plant not conveniently accessible for early decontamination and processing. By the time these items are ready for disposal, activities in most of the lower-activity metal will have decayed to a level appropriate for reclassification as clean or cleanable scrap.

1 For the case of nuclear power plants, this category includes only a small fraction of the contaminated scrap.

2 Decontamination may be performed to reduce worker radiation exposure, but decontamination alone is not expected to be sufficient to produce material free of significant activity. 


\subsection{BASIC ASSUMPTIONS}

\subsubsection{End-of-Life for Power Plants}

Nuclear power plants have useful lives of approximately 40 years. When the useful lives of existing plants expire, large quantities of RSM will become available for recycling as plants are dismantled. A number of assumptions can be made concerning the extent to which nuclear facilities are dismantled. For example, a phased approach can be used in which only limited removal of material occurs before the appropriate portions of a site are secured for a scheduled number of years in order to allow radioactivity to decay before dismantlement is resumed. On the other hand, a site can be decontaminated and reclaimed as rapidly as regulations allow, to the point at which the site, including all remaining structures, is released for unrestricted use. At the extreme end is the "greenfield" case, in which all hardware, radioactivity, and structures have been removed, and the site is returned to landscape.

The U.S. Nuclear Regulatory Commission (USNRC 1988) has defined three classifications for decommissioning of nuclear facilities:

- DECON: ". . .equipment, structures and portions of a facility and site containing radioactive contaminants are removed or decontaminated to a level that permits the property to be released for unrestricted use shortly after cessation of operations."

- SAFSTOR: ". . the nuclear facility is placed and maintained in such condition that the nuclear facility can be safely stored and subsequently decontaminated (deferred decontamination) to levels that permit release for unrestricted use."

- ENTOMB: ". . radioactive contaminants are encased in a structurally long-lived material, such as concrete. The entombment structure is appropriately maintained, and continued surveillance is carried out until the radioactivity decays to a level permitting unrestricted release." As noted on p. 170 of the 1991 Integrated Data Base report (Oak Ridge National Laboratory [ORNL] 1991), this alternative would be allowable for facilities contaminated with relatively short-lived nuclides that would decay to levels permitting unrestricted use within a period on the order of 100 years.

Essentially, SAFSTOR and ENTOMB are options for deferring the eventual implementation of the requirements of $\mathrm{DECON}$.

For the purposes of this report, the assumption is made that the site is decontaminated and reclaimed to the point at which it is released for unrestricted use in "greenfield" condition. At that point, all radioactive scrap will have been removed. 


\subsubsection{Radioactive Decay}

Because of the process of radioactive decay, the quantity of radioactivity decreases with time after plant shutdown. Decommissioning and demolition of a plant may be deliberately delayed or conducted in time-separated stages in order to decrease the total dose to workers. Because of licensing requirements that radioactive systems be maintained in a safe condition, a plant cannot be decommissioned until several years after shutdown. For example, the primary coolant circuit and all of its supporting systems must be maintained in their active conditions while fuel is still in the core, and the fuel storage pool must be supported until it is defueled. The decontamination and decommissioning plan must be approved by the relevant authorities, and all appropriate licenses and permits must be obtained or modified. Consequently, the time between shutdown and the date of scrap availability is very unlikely to be less than 10 years. For the reference plants, metal masses in the activity-level categories are estimated for a time about 5 to 10 years after plant shutdown. For practical purposes, the largest decrease in radioactivity inventory is associated with the short-lived isotopes and occurs between shutdown and the earliest time that major demolition work can begin.

Subsequent decreases in the radioactive inventory over time are also significant. For example, a delay in operations on activated steel for about 100 years would result in a decrease by a factor of about $10^{6}$ in the inventory of the five-year half-life Co-60 activation product. Such a delay could be an important means of reducing worker dose. Many utility planners have proposed postponing the start of major dismantling of activated power reactor facilities until 40 to 50 years after shutdown, and some are considering delay periods as long as 100 years.

The results of different decay times after shutdown (assuming a 1-Bq/g limit for the suspect radioactive category) are illustrated in Table 3.2 for light-water reactors (LWRs) in the U.S.A. Metals with fixed surface contamination are included in the "activated" category. In this case, the active stainless steel category does not change. Because the copper contains a small percentage of silver, the active copper mass does not change, either. After 50 years' delay, the masses of activated iron and mild steel, activated aluminum, and decontaminatable ${ }^{3}$ metals of all categories with activity greater than $1 \mathrm{~Bq} / \mathrm{g}$ are about $50 \%$ of the masses after 10 years. After 100 years' delay, the activated mass is about $40 \%$ of the 10 -year mass, based on the advanced gas-cooled reactor (AGR) calculations. The decontaminatable mass after 100 years' delay is estimated to have dropped to $25 \%$ of that at 10 years. Table 3.2 lists the total iron and mild steel masses for U.S.A. power reactors assumed to be shut down in 2014 (the peak year) for three decay times: 50 years (the year 2024), 100 years (2074), and 150 years (2124) after start-up.

3 Corresponds to surface-contaminated — removable category. 
TABLE 3.2 Example of Effects of Decay Period on Quantities of Scrap in Each Activity Category ${ }^{\mathrm{a}}$

\begin{tabular}{|c|c|c|c|c|c|c|}
\hline \multirow[b]{2}{*}{ Year } & \multicolumn{2}{|c|}{ Suspect Radioactive } & \multicolumn{2}{|c|}{ Decontaminatable } & \multicolumn{2}{|c|}{ Activated $^{\mathrm{b}}$} \\
\hline & tons & $\%$ & tons & $\%$ & tons & $\%$ \\
\hline 2024 & 80,000 & 41 & 77,000 & 40 & 36,000 & 19 \\
\hline 2074 & 136,000 & 71 & 38,000 & 20 & 18,000 & 9 \\
\hline 2124 & 159,000 & 82 & 19,000 & 10 & 15,000 & 8 \\
\hline
\end{tabular}

a Quantities of iron and mild steel projected for U.S.A. LWRs assumed to be shut down in the year 2014, for three different decay periods. The scrap is categorized as suspect radioactive if its activity level is likely to be $1 \mathrm{~Bq} / \mathrm{g}$ or less.

b Includes metals with fixed surface contamination.

\subsubsection{Categorization of Metals}

For present purposes, it is necessary to employ broad classifications of scrap alloys, rather than to provide detailed data for the many alloys used in the industry. The metal classifications used are aluminum, copper, iron and steel, stainless steel, lead, nickel, and zirconium. The iron and steel category excludes metals that contain nickel. In general, iron or steel scrap containing nickel is classed as stainless steel (even if the nickel content is well below that of standard stainless steel alloys) because it is generally more feasible to upgrade the scrap by adding nickel (and other alloying elements) than it is to produce carbon/mild steel by removing the nickel. An example of this "stainless steel" classification applies to the typical U.S.A. water-reactor pressure vessel, which consists of thick-walled carbon steel clad with a stainless steel overlay for corrosion resistance. Although the reactor pressure vessel can be cut into sections for handling, it is not deemed feasible to separate the stainless steel from the base carbon steel. Other nickel alloys, such as Inconel, also are classed as stainless steel. Special nickel scrap, such as nickel diffusion barriers used in gaseous diffusion enrichment plants, also is classified as stainless steel.

\subsubsection{Miscellaneous Assumptions}

Some components of a nuclear power station have significant value as spare parts or as inputs to refurbishment of another plant. An active market already exists for nucleargrade spare parts. As existing reactors are decommissioned, some used parts with acceptable life remaining may be much more valuable if salvaged as components for reuse in other nuclear plants than if recycled as scrap metal. It is uncertain how much of any particular power plant will become available for unrestricted release and how much will be reused in the nuclear industry. For these estimates, all decommissioned metal was assumed to be recycled as scrap. 
Nuclear components and systems that are decommissioned contain materials other than metals - for example, insulation in electrical equipment, protective coatings on surfaces, and thermal insulation. In some cases these materials can be readily removed, but in other cases they cannot be removed and will remain adhered to the scrap. Such materials are not included here in any mass or volume estimates. Suspect radioactive reinforcing bar (rebar) in concrete is not included in the scrap estimates because the rebar is difficult and expensive to recycle from concrete structures and it constitutes a relatively small percentage of the total structure volume.

The estimates provided are based on typical plant operations, including duty-cycle events of reasonably high probability. The estimates do not reflect unusual increases in contaminated material types and masses that would be associated with accidents such as at Three Mile Island or Chernobyl.

\subsection{SOURCES OF RADIOACTIVE SCRAP METAL}

\subsubsection{World Nuclear Power Plants}

For this report, quantities of potential scrap metal have been estimated for the world listing of nuclear power plants (American Nuclear Society 1992; Nuclear Engineering International 1991, 1993). These estimates have been calculated with spreadsheet techniques and application of algorithms to estimate quantities of metal from each source on the basis of plant size and reactor type. Only plants listed as under construction or completed are included. Reactors of less than $100 \mathrm{MWe}$ are excluded. Appendix A documents the methods used to obtain the inventory parameters applied in various countries, presents the input data employed in the application of the methodology, and concludes with summary output tables and illustrations.

Most of the metal scrap resulting from dismantlement of nuclear power plants is not radioactive. The nonradioactive scrap includes metal that normally has not been exposed to radioactivity during reactor operations (e.g., in a PWR turbine hall). However, just by being on a nuclear power station site, all metal may be exposed to activity from a blowdown, from off-gassing, or even from neutrons passing through the biological shielding. Therefore, all metal on the site will be required to be treated as suspect and surveyed before being moved off the site. Examples of nonradioactive scrap are plant cranes (except the reactor containment building crane), structural steel, secondary containment steel, emergency diesel generators, control-room hardware, and most of the facility wiring. Large quantities of other reactor-plant metal also can be nonradioactive. Lead is used primarily for instrumentation shielding and protection of maintenance workers. It will, in general, not be used in locations where activation is likely, and any surface contamination will be readily removable.

The country with the largest installed nuclear generating capacity is the U.S.A. The list includes 118 U.S.A. power plants (including 8 no longer in operation): 80 PWRs (Babcock \& Wilcox, Combustion Engineering, and Westinghouse) and 38 BWRs (General Electric). Worldwide, PWR and BWR plants predominate, with significant numbers of pressurized 
heavy-water reactors (PWHRs) (primarily of the Canadian deuterium-uranium [CANDU] type), gas-cooled reactors (GCRs), and advanced gas-cooled reactors (AGRs). The former Soviet Union versions of PWRs are designated as VVER, and the former Soviet Union also has a version of the light-water-cooled, graphite-moderated reactor, designated as RBMK (Chernobyl-type). Table 3.3 summarizes RSM data for the reference plants, which are described in Section A.2 of Appendix A.

In Appendix B, Tables B.1 through B.7 present the estimated amounts of nuclear power plant scrap metal potentially available annually by geographic region. Part $A$ of each table presents the base case in which scrap metal from each plant is assumed to become available 50 years after start-up. This timing reflects a 40 -year plant lifetime plus 10 years for achieving cold shutdown, draining and securing systems, and regulatory permitting. To illustrate the effects of radioactive decay, estimates of metal quantity were calculated for two additional time scenarios: 100 years after start-up (Part B of the tables), and 150 years after start-up (Part $\mathrm{C}$ of the tables). A noticeable shift from the high-activity categories (activated, surface-contaminated - fixed, and surface-contaminated - removable) toward the lowest activity category (suspect radioactive) occurs with each 50-year increase in delay. Clearly, an approach of SAFSTOR (Section 3.3.1) significantly reduces the potential worker exposures and required disposal resources, space, and costs. This approach is outlined in Broad (1986) for PHWRs and is clearly being considered for the AGRs because of the long-term decay activities presented in Regan et al. (1984).

Because nuclear power plants are likely to be dismantled over a number of years, the tables and figures in Appendix B present the inventory estimates as a flow of metal over time. To provide perspective on the total metal inventory, Table 3.4 provides estimates of total metal masses for major regions of the world and also worldwide totals. These estimates indicate the mass of each metal type that would be available in each contamination category from all reactors if each reactor was dismantled 50 years after its start-up date. The values shown as totals for regions and the world represent the available stock of metal, independent of time and contamination considerations. Thus, about $8.7 \times 10^{6} t$ of iron and steel scrap will be available from nuclear power plants worldwide, with major portions of that total originating in North America and Europe. Copper scrap mass is less than a third of that for iron and steel, and the quantities of the other metal types are much smaller.

\subsubsection{Nuclear Fuel Cycle Facilities}

The nuclear fuel cycle includes processing of the fuel outside the reactor. Such activities involve mining and milling, enrichment, fabrication, reprocessing, and refabrication facilities. No activation of metal components occurs in the fuel cycle facilities. RSM from the mining and milling segment will be contaminated by naturally occurring radioactive material. In general, most of the fuel cycle RSM will have surfaces that can be readily decontaminated. Two possible exceptions are fuel reprocessing components in which the chemicals have penetrated significantly into the surfaces and uranium enrichment components that have been contaminated by enrichment feedstock containing irradiated uranium. Fuel 
TABLE 3.3 Reference Plant Metals Data

\begin{tabular}{|c|c|c|c|c|c|c|c|c|c|c|}
\hline \multirow{2}{*}{ Parameter } & \multicolumn{10}{|c|}{ Reference Reactors ${ }^{\mathrm{n}}$} \\
\hline & AGR & BWR & Magnox I & Magnox II & Magnox III & PHWR & PWR & RBMK & $\begin{array}{l}\text { VVER } \\
440\end{array}$ & $\begin{array}{l}\text { VVER } \\
1000\end{array}$ \\
\hline Reactor Size (MWe, net) & $N A^{b}$ & 1,000 & $<201$ & $>201$ & NA & 881 & 1,000 & NA & 440 & 1,000 \\
\hline \multicolumn{11}{|l|}{ Quantity of Metal ( $t$ ) } \\
\hline \multicolumn{11}{|l|}{ Aluminum } \\
\hline Suspect radioactive & 80 & 80 & 0 & 0 & 80 & 80 & 80 & 80 & 46 & 80 \\
\hline $\begin{array}{l}\text { Surface-contaminated - } \\
\text { removable }\end{array}$ & 15 & 15 & 0 & 0 & 15 & 15 & 15 & 15 & 9 & 15 \\
\hline $\begin{array}{l}\text { Surface-contaminated - } \\
\text { fixed }\end{array}$ & 0 & 0 & 0 & 0 & 0 & 0 & 0 & 0 & 0 & 0 \\
\hline Activated & 5 & 5 & 0 & 0 & 5 & 5 & 5 & 5 & 3 & 5 \\
\hline \multicolumn{11}{|l|}{ Copper } \\
\hline Suspect radioactive & 3,900 & 4,900 & 1,900 & 2,400 & 3,900 & 4,900 & 4,900 & 4,900 & 2,840 & 4,900 \\
\hline $\begin{array}{l}\text { Surface-contaminated - } \\
\text { removable }\end{array}$ & 80 & 80 & 50 & 50 & 80 & 80 & 80 & 80 & 46 & 80 \\
\hline $\begin{array}{l}\text { Surface-contaminated - } \\
\text { fixed }\end{array}$ & 0 & 0 & 0 & 0 & 0 & 0 & 0 & 0 & 0 & 0 \\
\hline Activated & 20 & 20 & 50 & 50 & 20 & 20 & 20 & 20 & 12 & 20 \\
\hline \multicolumn{11}{|l|}{ Lead } \\
\hline Suspect radioactive & 20 & 20 & 0 & 0 & 20 & 20 & 20 & 0 & 20 & 20 \\
\hline $\begin{array}{l}\text { Surface-contaminated - } \\
\text { removable }\end{array}$ & 0 & 0 & 0 & 0 & 0 & 0 & 0 & 0 & 0 & 0 \\
\hline $\begin{array}{l}\text { Surface-contaminated - } \\
\text { fixed }\end{array}$ & 0 & 0 & 0 & 0 & 0 & 0 & 0 & 0 & 0 & 0 \\
\hline Activated & 0 & 0 & 0 & 0 & 0 & 0 & 0 & 0 & 0 & 0 \\
\hline
\end{tabular}




\section{TABLE 3.3 (Cont.)}

\begin{tabular}{|c|c|c|c|c|c|c|c|c|c|c|}
\hline \multirow[b]{2}{*}{ Parameter } & \multicolumn{10}{|c|}{ Reference Reactors ${ }^{\mathrm{a}}$} \\
\hline & AGR & BWR & Magnox I & Magnox II & Magnox III & PHWR & PWR & RBMK & $\begin{array}{l}\text { VVER } \\
440\end{array}$ & $\begin{array}{l}\text { VVER } \\
1000\end{array}$ \\
\hline \multicolumn{11}{|l|}{ Steel and Iron } \\
\hline Suspect radioactive & 12,770 & 5,000 & 3,800 & 4,690 & 12,770 & 8,000 & 8,290 & 19,248 & 12,030 & 19,248 \\
\hline $\begin{array}{l}\text { Surface-contaminated - } \\
\text { removable }\end{array}$ & 5,630 & 6,700 & 4,950 & 6,225 & 5,630 & 6,000 & 6,700 & 7,156 & 4,669 & 7,156 \\
\hline $\begin{array}{l}\text { Surface-contaminated - } \\
\text { fixed }\end{array}$ & 0 & 0 & 0 & 0 & .0 & 0 & 0 & 69 & 46 & 69 \\
\hline Activated & 2,100 & 3,500 & 1,000 & 1,000 & 2,100 & 2,940 & 2,940 & 581 & 363 & 581 \\
\hline \multicolumn{11}{|l|}{ Stainless Steel } \\
\hline Suspect radioactive & 60 & 0 & 100 & 100 & 60 & 290 & 0 & 0 & 0 & 0 \\
\hline $\begin{array}{l}\text { Surface-contaminated - } \\
\text { removable }\end{array}$ & 900 & 600 & 0 & 0 & 900 & 2,000 & 900 & 2,600 & 1,599 & 2,600 \\
\hline $\begin{array}{l}\text { Surface-contaminated - } \\
\text { fixed }\end{array}$ & 0 & 0 & 0 & 0 & 0 & 200 & 300 & 0 & 0 & 0 \\
\hline Activated & 165 & 670 & 0 & 0 & 165 & 2,100 & 670 & 406 & 254 & 406 \\
\hline \multicolumn{11}{|l|}{ Zirconium } \\
\hline & & & 0 & 0 & 0 & 0 & 0 & 0 & 0 & 0 \\
\hline Suspect radioactive & 0 & 0 & & & & & & & & \\
\hline $\begin{array}{l}\text { Surface-contaminated - } \\
\text { removable }\end{array}$ & 0 & 0 & 0 & 0 & 0 & 0 & 0 & 0 & 0 & 0 \\
\hline $\begin{array}{l}\text { Surface-contaminated - } \\
\text { fixed }\end{array}$ & 0 & 0 & 0 & 0 & 0 & 0 & 0 & 0 & 0 & 0 \\
\hline Activated & 0 & 0 & 0 & 0 & 0 & 25 & 0 & 100 & 0 & 0 \\
\hline
\end{tabular}

a See Section A.2, Appendix A, for discussion of reference plant types.

b NA = not applicable. 
TABLE 3.4 Total Estimated Power Plant Scrap Metal Mass by Activity Category, 50 Years after Plant Start-Up, by Metal Type and by Region

\begin{tabular}{|c|c|c|c|c|c|c|}
\hline \multirow[b]{2}{*}{ Region/Activity } & \multicolumn{6}{|c|}{ Mass $(1,000 \mathrm{t})$ by Metal Type } \\
\hline & Aluminum & Copper & Lead & $\begin{array}{c}\text { Iron and } \\
\text { Steel }\end{array}$ & $\begin{array}{c}\text { Stainless } \\
\text { Steel }\end{array}$ & Zirconium \\
\hline \multicolumn{7}{|l|}{ North America } \\
\hline Suspect radioactive & 11 & 669 & 3 & 1,025 & 6 & 0 \\
\hline $\begin{array}{l}\text { Surface-contaminated - } \\
\text { removable }\end{array}$ & 2 & 11 & 0 & 902 & 136 & 0 \\
\hline $\begin{array}{l}\text { Surface-contaminated - } \\
\text { fixed }\end{array}$ & 0 & 0 & 0 & $-^{a}$ & 28 & 0 \\
\hline Activated & 1 & 3 & $\mathbf{0}$ & 419 & 119 & 1 \\
\hline Total $^{\mathrm{b}}$ & 14 & 683 & 3 & 2,347 & 288 & 1 \\
\hline \multicolumn{7}{|l|}{ Europe } \\
\hline Suspect radioactive & 12 & 771 & 4 & 1,693 & 4 & 0 \\
\hline $\begin{array}{l}\text { Surface-contaminated - } \\
\text { removable }\end{array}$ & 2 & 13 & 0 & 1,128 & 183 & 0 \\
\hline $\begin{array}{l}\text { Surface-contaminated - } \\
\text { fixed }\end{array}$ & 0 & 0 & 0 & 2 & 25 & 0 \\
\hline Activated & 1 & 4 & $\mathbf{0}$ & 406 & 92 & - \\
\hline Total $^{b}$ & 15 & 788 & 4 & 3,229 & 304 & - \\
\hline \multicolumn{7}{|l|}{ Former Soviet Union } \\
\hline Suspect radioactive & 5 & 324 & 1 & 1,285 & 0 & 0 \\
\hline $\begin{array}{l}\text { Surface-contaminated - } \\
\text { removable }\end{array}$ & 1 & 5 & 0 & 480 & 173 & 0 \\
\hline $\begin{array}{l}\text { Surface-contaminated - } \\
\text { fixed }\end{array}$ & 0 & 0 & 0 & 5 & 0 & 0 \\
\hline Activated & - & 1 & 0 & 39 & 27 & 2 \\
\hline Total $^{b}$ & 7 & 331 & 1 & 1,809 & 200 & 2 \\
\hline \multicolumn{7}{|l|}{ Asia } \\
\hline Suspect radioactive & 5 & 335 & 2 & 478 & 2 & 0 \\
\hline $\begin{array}{l}\text { Surface-contaminated - } \\
\text { removable }\end{array}$ & 1 & 5 & 0 & 456 & 61 & 0 \\
\hline $\begin{array}{l}\text { Surface-contaminated - } \\
\text { fixed }\end{array}$ & 0 & 0 & 0 & $\mathbf{0}$ & 12 & 0 \\
\hline Activated & - & 1 & 0 & 216 & 55 & - \\
\hline Total $^{b}$ & 6 & 341 & 2 & 1,150 & 130 & - \\
\hline \multicolumn{7}{|l|}{ Rest of World } \\
\hline Suspect radioactive & 1 & 40 & - & 82 & 1 & $\mathbf{0}$ \\
\hline $\begin{array}{l}\text { Surface-contaminated - } \\
\text { removable }\end{array}$ & - & 1 & 0 & 55 & 12 & 0 \\
\hline $\begin{array}{l}\text { Surface-contaminated - } \\
\text { fixed }\end{array}$ & 0 & 0 & 0 & - & 2 & 0 \\
\hline Activated & - & - & 0 & 22 & 8 & - \\
\hline Total $^{b}$ & 1 & 41 & - & 159 & 23 & - \\
\hline \multicolumn{7}{|l|}{ World Total ${ }^{b}$} \\
\hline Suspect radioactive & 34 & 2,139 & 10 & 4,563 & 13 & 0 \\
\hline $\begin{array}{l}\text { Surface-contaminated - } \\
\text { removable }\end{array}$ & 6 & 35 & 0 & 3,021 & 565 & 0 \\
\hline $\begin{array}{l}\text { Surface-contaminated - } \\
\text { fixed }\end{array}$ & 0 & 0 & 0 & 7 & 67 & 0 \\
\hline Activated & 2 & 9 & 0 & 1,102 & 301 & 3 \\
\hline Total $^{\mathbf{b}}$ & 43 & 2,183 & 10 & 8,693 & 946 & 3 \\
\hline
\end{tabular}


reprocessing metal mass includes scrap from the decommissioning of the West Valley, New York, reprocessing facility as well as from reprocessing facilities outside the U.S.A.

The facilities used in the enrichment segment of the fuel cycle are large. In fact, the largest building in the U.S.A. is the K-25 facility at Oak Ridge, Tennessee, which has about 120 acres of floor space (DeLozer 1992). The U.S.A. uses gaseous diffusion enrichment; both gaseous diffusion and centrifuge plants are used in other countries.

Table 3.5 lists world enrichment facilities, including their capacities in thousands of separative work units per year (kSWU/yr) (Nuclear Engineering International 1992). The U.S.A. has three gaseous diffusion facilities: Paducah (11,300 kSWU/yr), Portsmouth (7,900 kSWU/yr), and Oak Ridge (7,700 kSWU/yr). DeLozer (1992) reports that the.K-25 site at Oak Ridge contains 9,000 t of nickel and that decommissioning of this plant will generate over $180,000 \mathrm{t}$ of scrap steel. The metal quantities from this site alone are roughly equivalent to the cumulative total of the $75 \mathrm{t}$ of nickel and 1,500 $\mathrm{t}$ of scrap steel per U.S.A. power plant. The three U.S. enrichment facilities combined had scrap piles estimated at over $92,000 \mathrm{t}$ of carbon steel and 6,000 $\mathrm{t}$ of aluminum in 1994 (DOE 1995).

Hertzler et al. (1993) provide information for a number of facilities, including the three U.S.A. gaseous diffusion enrichment plants. Although the authors use some alloy categories that do not correspond to those in this report, their values for the enrichment facilities are summarized in Table 3.6. These facilities are somewhat unique in having a relatively large mass of nickel.

Baxter and Bradbury (1992) describe the nearly completed decommissioning of the 650-kSWU/yr Capenhurst diffusion plant. The Capenhurst data provide a good indication of the large potential for decontamination of this type of scrap, because waste site capacity limitations provided strong incentive for recycling rather than burial. In fact, Baxter and Bradbury (1992) report that more than $99 \%$ of the total structure and contents of Capenhurst will be recycled as clean material. The Capenhurst data, for $650 \mathrm{kSWU} / \mathrm{yr}$, are given in Table 3.7. By completion of the Capenhurst dismantling, approximately 40,000 t of carbon steel, $11,000 \mathrm{t}$ of aluminum, and 3,500 $\mathrm{t}$ of electrical motors were cleared for release (Clements 1994).

\subsubsection{Military Facilities}

Military sources of RSM include naval propulsion reactors, production reactors, nuclear weapons production facilities, and related fuel cycles facilities (Table 3.8). Worldwide, about 600 propulsion reactors were on commissioned naval vessels in 1990 (Nucleonics Week 1993c). This figure exceeds the worldwide total of nuclear power plants. Enrichment facilities originally constructed and operated for military purposes have been extensively refurbished and redirected to civilian nuclear power programs. For consistent presentation, all enrichment facilities have been combined under civilian fuel cycle enrichment facilities. 
TABLE 3.5 World Enrichment Plants

\begin{tabular}{|c|c|c|c|c|}
\hline Country & Plant & $\begin{array}{c}\text { Capacity } \\
\text { (kSWU/yr) }\end{array}$ & Process & Status \\
\hline Argentina & $\begin{array}{l}\text { Pilcaniyeu-1 } \\
\text { Pilcaniyeu-2 }\end{array}$ & $\begin{array}{r}20 \\
100\end{array}$ & $\begin{array}{l}\text { Diffusion } \\
\text { Diffusion }\end{array}$ & $\begin{array}{l}\text { Operable } \\
\text { Construction }\end{array}$ \\
\hline Brazil & Resende & 10 & Jet nozzle & Construction \\
\hline China & Lanchow & 200 & Diffusion & Operable \\
\hline France & Tricastin & 10,800 & Diffusion & Operable \\
\hline Germany & $\begin{array}{l}\text { Gronau } \\
\text { KffK }\end{array}$ & $\begin{array}{r}400 \\
50\end{array}$ & $\begin{array}{l}\text { Centrifuge } \\
\text { Jet nozzle }\end{array}$ & $\begin{array}{l}\text { Operable } \\
\text { Operable }\end{array}$ \\
\hline Japan & $\begin{array}{l}\text { Hyuga } \\
\text { Ningyo-Toge (pilot) } \\
\text { Ningyo-Toge (demo) } \\
\text { Rokkasho-Mura } 1 \\
\text { Rokkasho-Mura } 2\end{array}$ & $\begin{array}{r}2 \\
200 \\
50 \\
150 \\
1,350\end{array}$ & $\begin{array}{l}\text { Chemical } \\
\text { Centrifuge } \\
\text { Centrifuge } \\
\text { Centrifuge } \\
\text { Centrifuge }\end{array}$ & $\begin{array}{l}\text { Operable } \\
\text { Operable } \\
\text { Operable } \\
\text { Construction } \\
\text { Planned }\end{array}$ \\
\hline Netherlands & Almelo & 1,200 & Centrifuge & Operable \\
\hline Pakistan & Kahuta & 5 & Centrifuge & Operable \\
\hline South Africa & Valindaba & 300 & Helicon & Operable \\
\hline United Kingdom & $\begin{array}{l}\text { Capenhurst Urenco } \\
\text { Capenhurst BNFL }\end{array}$ & $\begin{array}{l}850 \\
650\end{array}$ & $\begin{array}{l}\text { Centrifuge } \\
\text { Diffusion }\end{array}$ & $\begin{array}{l}\text { Operable } \\
\text { Shut down }\end{array}$ \\
\hline U.S.A. & $\begin{array}{l}\text { Paducah } \\
\text { Portsmouth } \\
\text { Oak Ridge }\end{array}$ & $\begin{array}{r}11,300 \\
7,900 \\
7,700\end{array}$ & $\begin{array}{l}\text { Diffusion } \\
\text { Diffusion } \\
\text { Diffusion }\end{array}$ & $\begin{array}{l}\text { Operable } \\
\text { Operable } \\
\text { Shut down }\end{array}$ \\
\hline $\begin{array}{l}\text { Former Soviet } \\
\text { Union }\end{array}$ & Siberia & 10,000 & Diffusion & Operable \\
\hline
\end{tabular}

Current plans for disposition of U.S.A. nuclear-powered submarines call for disposal of radioactive metal (about 1,000 $t$ per reactor) as low-level radioactive waste (LLW). By the end of 1990, 37 U.S.A. nuclear submarines had been retired from active service, and 14 of the reactor compartments had been disposed of as LLW at a government burial site, leaving 23 more reactor compartments in storage awaiting disposition. About 100 additional U.S.A. nuclear-powered submarines are expected to be decommissioned over the next 20-30 years (ORNL 1991). Present policy in the U.S.A. is for the fuel to be removed at Bremerton, followed by removal of surface contamination deposits by acid etching. After installation of additional bulkhead facings or canning plates, the isolated reactor compartment is barged to the Hanford area for land burial. Former Soviet Union practice has been to dispose of 
submarines at sea or by beaching. The estimated numbers of naval propulsion reactors as of 1990 , broken down by country, are as follows: 400 Russian, "upwards of 160" U.S.A., 21 United Kingdom, 10 French, and 6 Chinese (Nucleonics Week 1993c). If the value of $1,000 \mathrm{t}$ of metal per reactor is appropriate for the worldwide inventory, there would be a potential for about $600,000 t$ of activated stainless steel scrap from decommissioning of naval propulsion reactors. Accelerated decommissioning of naval reactors could have significant impact on burial facilities for a limited number of years.

All of the U.S.A. weapons production
TABLE 3.6 U.S.A. Uranium Enrichment Plant Metal Scrap

\begin{tabular}{lc}
\hline \multicolumn{1}{c}{ Metal Type } & $\begin{array}{c}\text { Metal } \\
\text { Mass (t) }\end{array}$ \\
\hline & \\
Aluminum $^{\mathrm{a}}$ & 27,000 \\
Copper & 7,000 \\
Steel/iron $^{\text {Stainless steel }}{ }^{\mathrm{b}}$ & 192,000 \\
Nickel & 12,000 \\
\hline
\end{tabular}

a Includes $\mathrm{Al} / \mathrm{Cu}$ alloy.

b Includes nickel-plated steel.

Source: Hertzler et al. (1993). reactors fall into two types: heavy-water reactors (HWRs), all at Savannah River; and light-water-cooled, graphite-moderated reactors (LGRs), all at Hanford. United Kingdom production reactors are of the GCR type. The former Soviet Union built a different type of LGR production reactor, the ancestor of Chernobyl-type RBMK reactors. Table 3.9 lists the U.S.A. production reactors: five HWRs, and eight LGRs (DOE 1980). One additional Hanford LGR, the $N$ Reactor, was equipped with power generation equipment and is listed as a shut down power reactor in the American Nuclear Society's 1992 World List of Nuclear Power Plants. Because of the unique reactor designs and the absence of power generation equipment, scrap metal from production reactors is not included in the inventory, except reactors equipped to generate at least $100 \mathrm{MWe}$. For inventory completeness, the $N$ Reactor is assigned the scrap values of the reference RBMK plant, although the detailed designs are, in fact, quite different.

TABLE 3.7 Capenhurst Enrichment Plant Scrap

\begin{tabular}{lcccc}
\hline & \multicolumn{4}{c}{ Metal Masses (t) } \\
\cline { 2 - 5 } Material & Steel & Aluminum & Other & Total \\
\hline Suspect radioactive & $\mathrm{NA}^{\mathrm{a}}$ & $\mathrm{NA}$ & $\mathrm{NA}$ & 114,000 \\
$\begin{array}{l}\text { Surface-contaminated } \\
\text { removable }\end{array}$ & 9,200 & 3,000 & 1,300 & 13,500 \\
$\begin{array}{l}\text { Activated and surface- } \\
\text { contaminated - fixed }\end{array}$ & NA & NA & NA & 1,000 \\
\hline
\end{tabular}

a Data detail not available. 
TABLE 3.8 Military Facilities That Are Sources of Radioactive Scrap Metal

Naval propulsion reactors, primarily submarine

Production reactors $^{\mathrm{a}}$

Military enrichment facilities ${ }^{b}$

Nuclear weapons production

Military fuel fabrication - propulsion reactors

Military fuel fabrication - production reactors

Reprocessing facilities for military programs

a See Table 3.9.

b Included in list of enrichment plants in Section 3.4.2 (Table 3.5).

TABLE 3.9 List of U.S.A. Production Reactors

\begin{tabular}{llcc}
\hline \multicolumn{1}{c}{ Reactor } & Type & & Year \\
Shut & Start-Up & $\begin{array}{c}\text { Sown } \\
\text { Down }\end{array}$ \\
\hline Savannah River Site & & & \\
C Reactor & HWR & 1955 & b \\
K Reactor & HWR & 1954 & b \\
L Reactor & HWR & 1954 & 1968 \\
P Reactor & HWR & .1954 & b \\
R Reactor & HWR & 1953 & 1964 \\
& & & \\
Hanford Site & & & \\
B Reactor & LGR & 1944 & 1968 \\
C Reactor & LGR & 1952 & 1969 \\
D Reactor & LGR & 1944 & 1967 \\
DR Reactor & LGR & 1950 & 1964 \\
F Reactor & LGR & 1945 & 1965 \\
H Reactor & LGR & 1949 & 1965 \\
KE Reactor & LGR & 1955 & 1971 \\
KW Reactor & LGR & 1955 & 1970 \\
\hline
\end{tabular}

a $\mathrm{HWR}=$ heavy-water reactor; LGR = light-watercooled, graphite-moderated reactor.

b Future status uncertain; not currently operating. 


\subsubsection{Other Facilities}

The category of "other facilities" covers a wide span of items, including small research and development and training reactors, large research reactors, developmental power reactors, small university accelerators, world-class high-energy accelerators, industrial sterilizer plants, industrial radiography equipment, and various medical facilities. Consistent identification of all such facilities across all categories and across different national jurisdictions is beyond the scope of this study.

A 1980 report by the U.S. Department of Energy (DOE 1980) lists 162 test, research, and university reactors (including medical), and 12 additional reactors of this type from military programs in the U.S.A. Although this total of 174 reactors exceeds the number of U.S.A. power reactors, the scrap metal mass potentially available from this reactor category is not a significant fraction of that from power plants.

RSM from accelerators is primarily activated, rather than surface-contaminated. Levels of contamination can vary greatly with design, accelerator beam currents, and accelerator energy. Numerous alloys are used in accelerators, including high-purity magnet iron, multicomponent superconducting magnet coils, exotic vacuum-chamber alloys, and others. Decommissioned research accelerators traditionally have served as a source of recycled material for newer research facilities, thus making it difficult to estimate overall types and quantities of radioactive scrap from accelerators. For example, the magnets from the 10-GeV Zero Gradient Synchrotron (ZGS) accelerator at Argonne National Laboratory in the U.S.A. were transferred to the Fermilab Tevatron for use as shielding. Much of the ZGS civil engineering structure was used for the Argonne National Laboratory Intense Pulsed Neutron Source facility (Martin 1993). Although older accelerators have been important sources of material for new accelerator facilities and projects, they do not represent a large total quantity of RSM compared with the overall quantities available from other kinds of facilities.

Research and development reactors are divided into two groups for this study: (1) test, research, and university reactors used as sources of radiation for basic and applied research, and (2) reactor development reactors. There are many different test, research, and university reactor designs and a wide array of power levels, ranging from many "zero power" facilities up to a few high-powered test reactors of $100 \mathrm{MWe}$ or more.

Typical research power levels are orders of magnitude less than those of power reactors, and most operate at atmospheric pressure. Thus, levels of activation and contamination per unit volume of scrap typically are much lower for these reactors than for power reactors, and the quantities of metal per reactor typically are much lower than those from power reactors. Excluding reactors that have been dismantled (such as the Argonne National Laboratory CP-3), transient reactors that have very little structure and that operate at negligible average power (such as the Sandia Pulsed Reactor II), and very-low-power reactors (such as the Georgia Tech Research Reactor), 105 research and development facilities exist in the U.S.A. (DOE 1980). These reactors have a wide range of design characteristics, power levels, relative levels of radioactivity, and metal quantities. Four of these 105 reactors 
have power level ratings of $100 \mathrm{MWe}$ or more, and they more properly belong with the developmental reactors, leaving 101 reactors in this general category.

The oldest existing research reactor is the Argonne National Laboratory CP-5 facility, which is now being decontaminated and decommissioned for unrestricted site use. Recyclable radioactive activated/contaminated metal scrap from CP-5 is to be provided to the Scientific Ecology Group Inc. (SEG) Smelter Facility in Oak Ridge, Tennessee, as authorized by the U.S. Department of Energy. The types of materials and the quantities of each that are recyclable are as follows (Ditch 1992):
$>90 \%$ stainless steel
About $20 t$
$>90 \%$ carbon steel
About $20 t$
$55 \%$ copper, $44 \%$ carbon steel
About $1 \mathrm{t}$ each
(electric motors)

Argonne National Laboratory performs presorting by commodity before shipment, and Scientific Ecology Group does additional sorting, as feasible, upon receipt. Motors are to be disassembled at the smelter facility, and it is expected that nonmetallic materials (e.g., insulation) will be burned off during smelting. The intent is to obtain products that are sufficiently pure to be stockpiled by the U.S. Department of Energy for use within its programs. Aluminum recycling is not included in the CP-5 program scope because at this time there is not sufficient demand for the aluminum. Although aluminum is present in CP-5, it is not present in large amounts in many research reactors. Multiplying the CP-5 data by 101 yields a rough order of magnitude estimate of the amount of RSM potentially available from research reactors in the U.S.A. The resulting estimates $(2,000 \mathrm{t}$ of stainless steel, 2,100 $\mathrm{t}$ of carbon steel, and $100 \mathrm{t}$ of copper) are very small compared with the magnitudes of scrap metal available from the U.S.A. power reactors.

Reactor development reactors tend to share the characteristics of the full-sized machines of the same types. Many, of course, represent end points in development and have few or no full-sized counterparts. The American Nuclear Society's 1992 World List of Nuclear Power Plants lists 16 U.S.A. developmental plants as no longer in service. One of these (the Shippingport PWR) has been dismantled, leaving a site capable of unrestricted use. The remaining 15 are categorized as follows: $6 \mathrm{BWR} ; 4 \mathrm{PWR} ; 2$ high-temperature, gas-cooled reactors (HTGRs); 1 liquid-metal, fast breeder reactor (LMFBR); 1 LGR; and 1 liquid-metal, graphite-moderated reactor (LMGMR). Adding the four test reactors excluded from the research list yields a total of only 19 U.S.A. development reactors, small in number and small in power compared with the large U.S.A. power reactor inventory. Developmental reactors are excluded from the scrap metal estimates if they have electrical output ratings of less than $100 \mathrm{MWe}$. Although the liquid-metal reactor (LMR) has been developed for demonstration and precommercial operation in several countries, relatively few have electrical output of at least 100 MWe. All of the larger LMRs are one-of-a-kind plants with highly uncertain operating lifetimes controlled more by external financial exigencies and governmental policy than by technical matters. For these reasons, particularly the unknown end-of-life, LMRs are excluded from the scrap metal estimates. 


\subsubsection{Operations and Maintenance}

Long before the end of a reactor's life, metal scrap will be generated during operating and maintenance activities involving major repairs. Scrap of this type will range from valves to steam generators, and may even include such items as reactor vessel heads (Nucleonics Week 1993b). The quantities of such materials depend upon such factors as reactor class, vendor, architect/engineer, age, and the operator.

In addition to the reactors themselves, operation and maintenance and repair streams must also be considered. Components in these streams range from small items up to steam generators. Reliability histories could be used to estimate such items as valve replacements, new instruments, and other components, and these estimates could then be factored into predicted schedules. However, most of these items are trivial in size compared with the total metals inventory. Steam generator replacements, however, can be significant. On the basis of the replacement mass for a North Anna-1 steam generator (Nucleonics Week 1993a), a nominal steam generator replacement would generate about $800 \mathrm{t}$ of contaminated steel of various alloys. Currently, U.S.A. practice is to treat the removed steam generators as radioactive waste. These replacement operations appear to be a significant source of RSM. Because of uncertainties in schedule and in identification of reactors requiring steam generator replacement, these replaced generators are not included in the scrap metal estimates.

\subsubsection{Extraction Equipment}

Beyond the nuclear industry, significant quantities of RSM are also associated with other areas of endeavor. The source of this RSM is equipment contaminated by naturally occurring radioactive materials. Typically, the radioactive material is brought to the surface with the required product and is left on the equipment as a scale, in the equipment as a sludge, or in the spoil from purification processes. The main sectors with such problems are the petroleum industry and phosphate mining.

Dehmel et al. (1992) state that there were more than 852,000 oil and gas wells in the U.S.A. in 1991 and that for a typical 10-well production facility there was about $35,000 \mathrm{ft}^{3}$ total disposal volume of components and $2,300 \mathrm{ft}^{3}$ of sludge and scale contaminated with naturally occurring radioactive material. Not all wells are contaminated, ranging from a "few" in some states up to $90 \%$ in other states. The main radiological contributors in oil pipe scale and sludge are Ra-226 and -228, with some uranium and thorium. In gas wells, radioactivity is associated with the radon daughters $\mathrm{Pb}-210$ and $\mathrm{Rn}-210$. Specific scale activity ranges from 3.7 to $15,000 \mathrm{~Bq} / \mathrm{g}$. The measured exposures range from 0.05 to $4 \mathrm{mR} / \mathrm{h}$ $\left(5 \times 10^{-7}\right.$ to $\left.4 \times 10^{-5} \mathrm{~Gy} / \mathrm{h}\right)$ for outside equipment up to $15 \mathrm{mR} / \mathrm{h}\left(1.5 \times 10^{-4} \mathrm{~Gy} / \mathrm{h}\right)$ inside. Although the doses are low and the scale and sludge can be removed, the large number of wells worldwide implies that the mass of scrap involved may be substantial. Dehmel et al. (1992) estimate that about $3 \times 10^{6} \mathrm{t}$ of metal scrap is produced annually. 


\subsection{ESTIMATES OF TOTAL SCRAP METAL INVENTORY}

Estimation of potential quantities of RSM potentially available worldwide is hindered both by a lack of published data and by the uncertainties associated with weapons facilities. It is likely that three categories of facilities - nuclear power, fuel cycle, and weapons production - are the largest potential sources of contaminated scrap metal, although the quantity of naturally contaminated petroleum extraction equipment and piping may also be substantial. Table 3.10 summarizes the inventory categories for which published estimates of scrap metal masses are available. The estimate for petroleum extraction equipment, however, is an annual flow of scrap, while the rest of the figures are for the total stock of contaminated, or suspect, metals.

More than $9 \times 10^{6} t$ of carbon steel will be available from nuclear power plant and uranium enrichment plant dismantlement, with major portions of that amount originating in North America and Europe. The mass of copper scrap is about $2 \times 10^{6} \mathrm{t}$, and that of stainless steel about $1 \times 10^{6} \mathrm{t}$. The quantities of other metal types are much smaller. The distribution of metal masses among the contamination categories varies by metal type, but the amount of potential scrap metal that is activated or has fixed contamination ranges from a very small portion for aluminum and copper to almost half of the total quantity for stainless steel (see Appendix B). The inclusion of scrap from weapons facilities (along with

TABLE 3.10 Summary of Radioactive Scrap Metal Inventory Estimates from Various Sources by Metal Type

Mass (1,000 t) by Metal Type

\begin{tabular}{lcccccc}
\cline { 3 - 7 } \multicolumn{1}{c}{ Source } & Aluminum & Copper & Lead & $\begin{array}{c}\text { Iron and } \\
\text { Steel }\end{array}$ & $\begin{array}{c}\text { Stainless } \\
\text { Steel }\end{array}$ & Nickel \\
\hline U.S.A. & & & & & & \\
Power plants & 14 & 683 & 3 & 2,347 & 288 & NA $^{\mathrm{a}}$ \\
Military & NA & NA & NA & NA & 160 & NA \\
R \& D reactors & NA & - b & NA & 2 & 2 & NA \\
Extraction equipment & NA & NA & NA & $3,000^{\mathrm{c}}$ & NA & \\
Enrichment plants & 27 & 7 & NA & 192 & 12 & 58 \\
World (includes U.S.A.) & & & & & & \\
Power plants & 43 & 2,183 & 10 & 8,693 & 946 & NA \\
Military & NA & NA & NA & NA & 600 & NA \\
\hline
\end{tabular}

a $\mathrm{NA}=$ No data available.

b Less than 1,000 t.

c Unspecified metal (includes piping, tanks, and equipment), annually available quantity according to Dehmel et al. (1992). 
that from other sources) would probably more than double these estimates, so the total inventory of potential metal scrap is on the order of $3 \times 10^{7} \mathrm{t}$. On an annual basis, this inventory could produce recycling flows of $5 \times 10^{5} \mathrm{t} / \mathrm{yr}$ of iron and steel, $1 \times 10^{5} \mathrm{t} / \mathrm{yr}$ of copper, and $4 \times 10^{4} \mathrm{t} / \mathrm{yr}$ of stainless steel over a 50 year period.

\subsection{REFERENCES FOR SECTION 3}

American Nuclear Society, 1992, "World List of Nuclear Power Plants," Nuclear News 35(10), Aug.

Baxter, S., and P. Bradbury, 1992, "Decommissioning of the Gaseous Diffusion Plant at BNFL Capenhurst," presented at Department of Energy Technology Development Workshop, Charleston, S.C., March 26.

Broad, L.G., 1986, "First CANDU-PHW Reactor to Be Decommissioned and Placed in SWS State," in Proc. of the First Regional Conference, American Nuclear Society, Pittsburgh, Penn., Sept., p. 247.

Clements, D.W., 1994, "Release of Various Materials (Aluminum, Steel, Copper, Bronze) from the Enrichment Installation of Capenhurst," in Proceedings of the Technical Seminar on Melting and Recycling of Metallic Waste Materials from Decommissioning of Nuclear Installations, held in Oct. 1993, EUR 15691 EN, European Commission, Brussels, Belgium.

Dehmel, J.-C., et al., 1992, Scrap Metal Recycling of NORM Contaminated Petroleum Equipment, prepared by S. Cohen \& Associates, McLean, Va., T.P. McNulty and Associates, Evergreen, Colo., and Hazen Research Inc., Golden, Colo., for Petroleum Environmental Research Forum, Ponca City, Okla., Sept.

DeLozer, M.F.P., 1992, "Decommissioning of Nuclear Facilities by the United States Department of Energy Oak Ridge Field Office," in Decommissioning Policies for Nuclear Facilities, Proc. of an International Seminar, Organization of Economic Cooperation and Development, Paris, France, p. 45.

Ditch, R., 1992, personal communications from Ditch (Argonne National Laboratory, Argonne, III.) to C.T. Dickerman (Argonne National Laboratory, Argonne, Ill.), Dec.

DOE - see U.S. Department of Energy.

Hertzler, T., et al., 1993, Recycle of DOE Radiologically Contaminated Metal, Science Applications International Corp., Idaho Falls, Idaho, Feb.

Martin, R., 1993, personal communication from Martin (Argonne National Laboratory, Argonne, Ml.) to T.H. Braid (Argonne National Laboratory, Argonne, Ml.), Jan. 4.

Nuclear Engineering International, 1991, World Nuclear Industry Handbook 1991, Surry, England. 
Nuclear Engineering International, 1992, World Nuclear Industry Handbook 1992, Surry, England.

Nuclear Engineering International, 1993, World Nuclear Industry Handbook 1993, Surry, England.

Nucleonics Week, 1993a, "Steam Generator Replacements Are on Schedule at North Anna," Jan. 28 , p. 8.

Nucleonics Week, 1993b, "EDF to Order Six New Vessel Heads and May Buy up to 36 Replacements," Feb. 4, p. 3.

Nucleonics Week, 1993c, "Old Submarine Reactors Are Not Just a Russian Problem," April 15, p. 6.

Oak Ridge National Laboratory, 1991, Integrated Data Base for 1991: U.S. Spent Fuel and Radioactive Waste Inventories, Projections, and Characteristics, DOE/RW-0006 (Rev. 7), prepared for U.S. Department of Energy, Washington, D.C., 1991.

ORNL - see Oak Ridge National Laboratory.

Regan, J.D., et al., 1984, Design Features Facilitating the Decommissioning of Advanced GasCooled Reactors, " Commission of the European Communities, Luxembourg.

U.S. Department of Energy, 1980, Nuclear Reactors Built, Being Built, or Planned, DOE/TIC8200-R42 (with annual addenda), Washington, D.C.

U.S. Department of Energy, 1995, U.S. Department of Energy Scrap Metal Inventory Report for the Office of Technology Development, Office of Environmental Management, Hazardous Waste Remedial Action Program, Oak Ridge Operations Office, Oak Ridge, Tenn.

USNRC - see U.S. Nuclear Regulatory Commission.

U.S. Nuclear Regulatory Commission, 1988, "General Requirements for Decommissioning Nuclear Facilities," Federal Register 53(123): 24018-24056, Washington, D.C., June 27. 


\section{INTERNATIONAL SCRAP METAL MARKET}

Scrap metal recycling provides a significant portion of supply for all types of metal. For instance, according to the Institute for Scrap Recycling Industries (1990), scrap processors in the U.S.A. annually handle approximately:

- $54.5 \times 10^{6} \mathrm{t}$ of scrap iron and steel,

- $6 \times 10^{6} \mathrm{t}$ of scrap stainless steel,

- $2.7 \times 10^{6} \mathrm{t}$ of scrap aluminum,

- $1.6 \times 10^{6} \mathrm{t}$ of scrap copper,

- $0.9 \times 10^{6} \mathrm{t}$ of scrap lead, and

- $0.2 \times 10^{6} \mathrm{t}$ of scrap zinc.

This section characterizes the international metal recycling industry for iron and steel scrap, stainless steel, aluminum, copper, lead, nickel, and zinc and assesses the market impact that a radioactive scrap metal (RSM) recycling program might have.

Section 4.1 describes the "product" (scrap metal) and introduces commonly used terminology and processes employed by the metal recycling industry. Although most of the information presented pertains to U.S.A. domestic markets and processes, it should also be relevant for any industrialized country (the primary sources and users of scrap metals). Information regarding markets and technology used in other countries is presented where available. Section 4.2 describes the forces that shape the international market and influence market viability. International scrap metal trade data are presented to identify those countries that are major exporters or importers of scrap metal. Section 4.3 discusses current industry practices for handling contaminated scrap, including procedures for dealing with contaminants ranging from chemicals and processing oils commonly found in scrap to radioactivity and hazardous chemicals. Section 4.4 summarizes the potential for market impacts from recycling nuclear industry scrap.

\subsection{SCRAP METAL TERMINOLOGY AND PROCESSES}

\subsubsection{Scrap Metal Terminology}

Metals are usually divided into two categories: ferrous (which includes all iron-based metals such as cast iron and steel) and nonferrous (which includes all other metals). For this report, "nonferrous scrap" refers only to aluminum, copper, lead, nickel, stainless steel, and zinc. 
Nonferrous metal refiners are classified as either primary or secondary. Primary smelters refine metal from ores, and secondary producers refine metal from scrap. These definitions are somewhat flexible, however, since some primary nonferrous smelters use scrap as input. By contrast, the steelmaking industry makes no distinction between primary and secondary production because scrap iron is generally recycled at the same plants that produce iron from ore. In recent years, however, minimills have evolved around electric arc furnaces using $100 \%$ scrap as inputs, and these plants can be viewed as "secondary" ferrous metal plants.

All scrap metal can be broadly classified into three generic types: "home," "industrial," and "obsolete," depending on its source or origin. Home scrap is produced in mills and foundries as a direct result of metal refining, casting, and milling operations and usually does not leave the plant where it originates. Home scrap is sometimes referred to as "runaround" or "revert" scrap. Industrial scrap (sometimes called "prompt" or "new" scrap) is produced by industrial sources during metal machining processes. Obsolete scrap comes from broken, worn-out, discarded objects, or objects that have otherwise outlived their usefulness.

Ferrous scrap is broadly classified into home and purchased scrap, depending on whether the scrap was generated at the mill or obtained from scrap dealers, respectively (Figure 4.1). Home scrap now accounts for about one fourth of total ferrous scrap consumption. In recent years, this fraction has fallen significantly because of improved technologies, such as continuous casting, and more efficient milling operations. Purchased scrap includes both industrial and obsolete scrap. Industrial scrap averages about one-third of total ferrous scrap consumption. The auto industry is the largest single source of industrial scrap. Obsolete scrap, almost half of the total, constitutes the remaining ferrous scrap consumption.

Although the volume of nonferrous scrap is not as large as that of ferrous scrap, it is more valuable. In 1991, the value of recycled nonferrous metals exceeded $\$ 7.5 \times 10^{9}$ in the U.S.A. (Jolly et al. 1993, p. 1), compared with $\$ 5.38 \times 10^{9}$ for ferrous scrap.

Nonferrous scrap is classified as either old scrap or new scrap (Figure 4.2), depending on whether the scrap is in the form of an end product. New scrap includes residues from metal fabrication and machining and from refining processes. New scrap is further classified as either runaround (home) or new purchased (industrial) scrap. As with ferrous scrap, runaround scrap is new scrap that has never left the plant that produced it. Purchased scrap is new scrap that is purchased by secondary refiners, much like ferrous industrial scrap. Old scrap, all of which is purchased, is discarded, used, worn out, or technologically obsolete objects. 

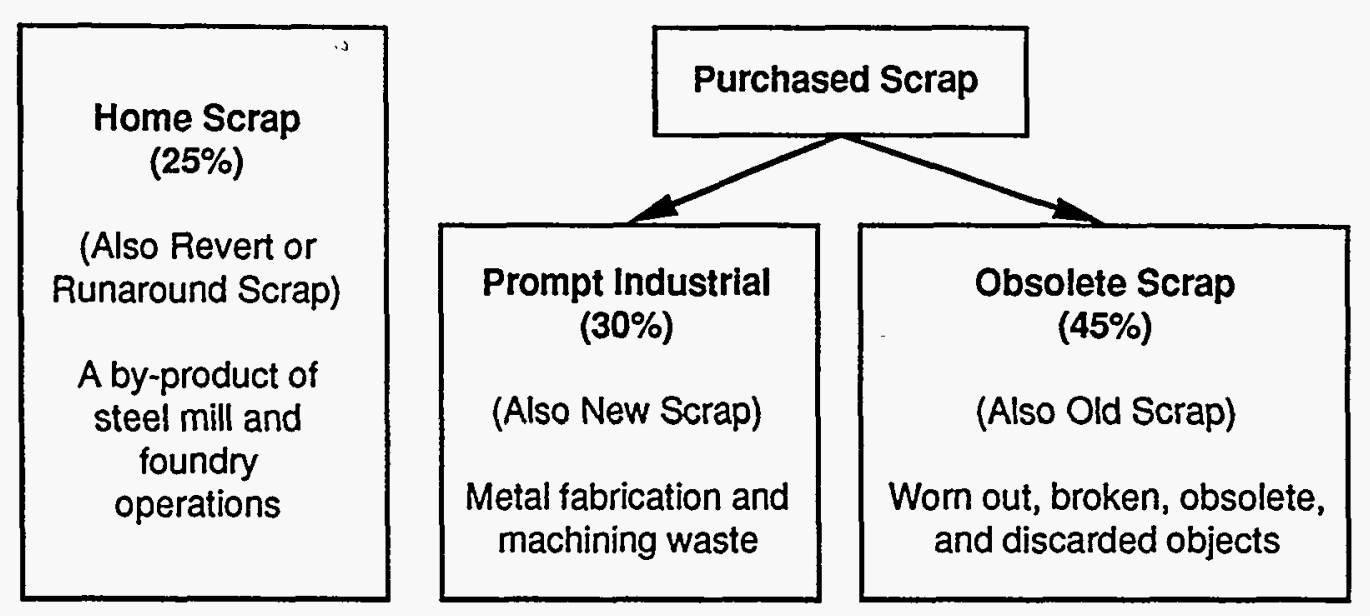

FIGURE 4.1 Ferrous Scrap Categories
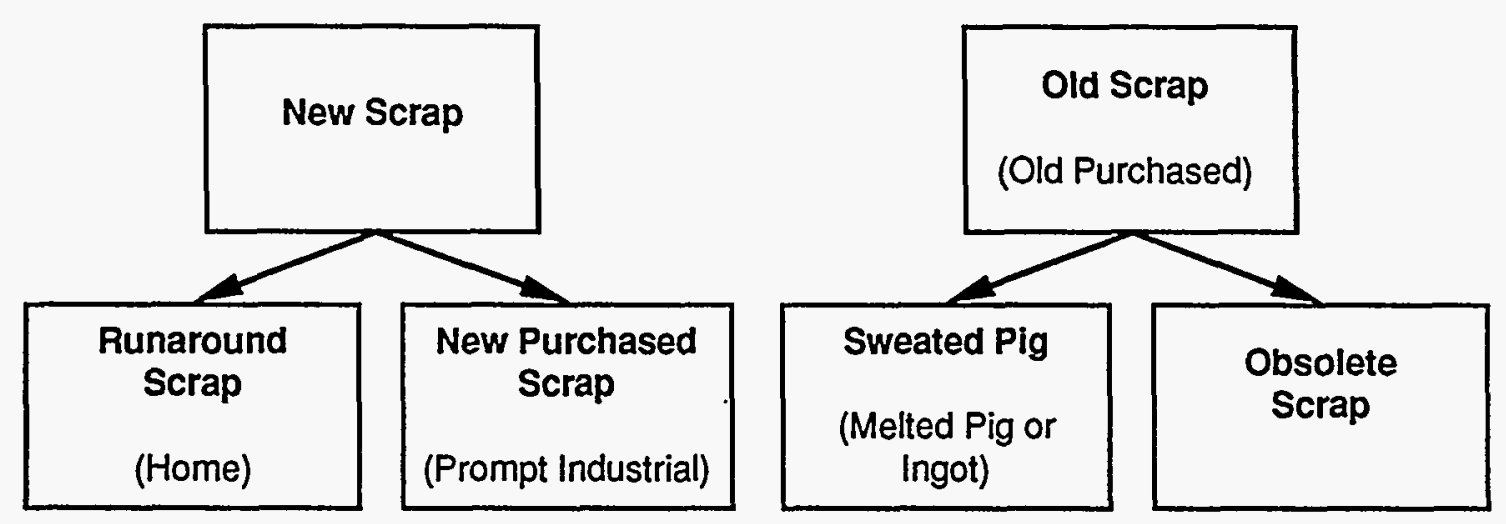

FIGURE 4.2 Nonferrous Scrap Categories

\subsubsection{Scrap Collection and Processing}

This section discusses purchased (industrial and obsolete) scrap collection and processing. Home scrap will not be discussed since it rarely leaves the foundry and is not handled by scrap processors.

\subsubsection{Industry Participants}

In the 1991-1992 reporting period, the U.S.A. secondary nonferrous metals industry (Standard Industrial Classification [SIC] 3341) had 88 companies reporting sales of $\$ 4.129 \times 10^{9}$ and 15,300 employees. The scrap and waste materials industry (SIC 5093) included 281 companies with $\$ 9.780 \times 10^{9}$ in sales and 25,700 employees (Towell 1992).

Figure 4.3 presents an overview of the scrap collection process. In this process, there are four functional roles for scrap market participants: collector, processor, broker/dealer, and consumer. These roles are described below. 


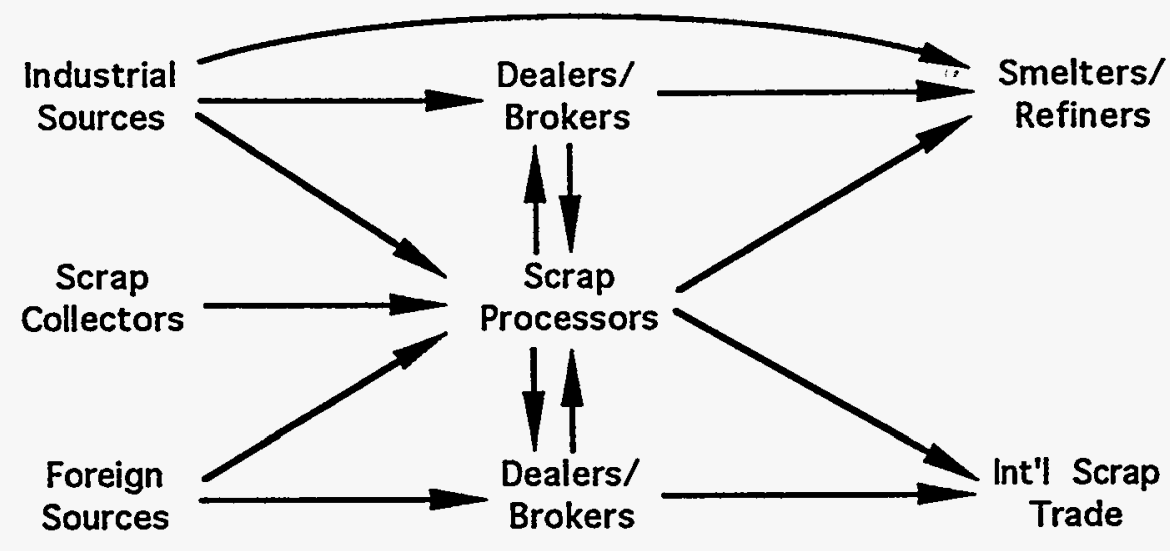

Raw Scrap

Processed Scrap

\section{FIGURE 4.3 Scrap Collection Overview}

\section{Collectors}

Collection is the first step in the scrap recycling process, and collectors gather scrap from its various sources and make it available for processing. Obsolete scrap comes from a variety of sources: government facilities, utility companies, auto dismantlers, railroads, shipyards, airlines, building dismantlers, junk collectors, and private citizens.

\section{Processors}

Scrap processors play a pivotal role by sorting, categorizing, and preparing scrap so it can be efficiently used by the scrap consumer. They employ a large variety of equipment (such as shears, balers, shredders, crushers, and cutting torches) and may incur significant capital costs for this equipment. The shredder has had an enormous impact on the scrap metal industry. An automobile shredder can reduce an automobile to fist-size pieces of scrap in less than one minute. The iron and steel fraction is magnetically separated from the other materials to produce high-quality scrap. Shredders, depending on their size, can process from 25,000 to 250,000 cars per year. Thus, shredders have made a large quantity of high-quality scrap metal available for recycling.

\section{Brokers/Dealers}

In the scrap metals industry, brokers buy and sell scrap but do not take physical possession of it. Dealers differ from brokers in that they do take possession of the scrap. Processors and buyers usually deal directly, but sometimes a scrap broker or dealer will serve as an intermediary. Brokers and dealers survive by having knowledge of the market superior to either the processor or the buyer. Because the scrap market is a collection of regional markets, local supply and demand imbalances can exist. Brokers gather information about 
remote markets and serve to facilitate trade by purchasing scrap where it is in excess supply and selling it where it is in demand.

Brokers and dealers also facilitate international trade by assuming some of the risks that can be involved. The international market is riskier because the lead time on orders can be from 90 to 120 days, compared with 30 days domestically (Institute of Scrap Iron and Steel 1984). The long lead time exposes the broker to adverse movements in scrap prices, as well as in foreign exchange rates. Brokers and dealers may also facilitate trade by providing financing for deals.

\section{Consumers}

Scrap consumers include secondary refiners, mills, and foundries. Mills and foundries demand scrap because it is cheaper to remelt scrap than to produce metal from ores.

\subsubsection{Scrap Grades}

Raw scrap is "graded" in order to assess the quantity and type of "tramp" or residual elements present in the scrap. Hundreds of grades exist for ferrous and nonferrous scrap metals. Tramp elements are materials or items that are difficult to remove during the smelting and refining processes, usually because of their chemical and metallurgical similarity with the metal of interest. Tramp elements also have a negative impact on the suitability of the metal for its intended use. For example, copper is considered to be a tramp element in ferrous scrap because it makes the metal difficult to work cold; therefore, the price of ferrous scrap decreases with increased copper content. However, steel used for structural and bar shapes, for example, can tolerate a greater fraction of copper content.

Of the three types of scrap (home, industrial, and obsolete), obsolete scrap is the most difficult to grade because the least is known about it. Knowledge of the scrap's prior use can give important clues about the quality of the metal and about possible alloying elements or contaminants. For example, products made from rolled steel tend to be higher quality because the steel must have fewer residuals to be able to tolerate the cold-rolling process. In contrast, cast products can tolerate a higher level of tramp elements, so they are generally assumed to be of a lower-quality steel.

Raw industrial scrap is generally easier to grade than obsolete scrap because the seller can document the quality of the metal. Industrial lubricants and process residues may contaminate the scrap, but in most cases these contaminants are burned off when the scrap is refined. 


\subsubsection{Scrap Smelting and Refining Processes}

The secondary smelting and refining phase of scrap metal recycling is not part of the scrap metal industry per se, but since the scrap industry is so closely linked to secondary refining, a brief discussion of the major processes is warranted.

\subsubsection{Scrap Iron and Steel Recycling}

Recycled ferrous scrap supplied $61 \%$ of U.S.A. raw iron and steel requirements in 1990 , up from 51\% in 1970 (Brown 1992). In 1991, domestic consumers used $40.7 \times 10^{6} \mathrm{t}$ of ferrous scrap, with a value of $\$ 4.15 \times 10^{9}$ (Brown 1993 , p. 1). In addition, $9.3 \times 10^{6} t$ of ferrous scrap with a value of $\$ 1.23 \times 10^{9}$ was exported.

Figure 4.4 illustrates the flow of iron from production through recycling. Most ferrous scrap is recycled in one of three ways - it may be charged to the blast furnace along with iron ore; it may be added directly to steelmaking furnaces; or it may be remelted at foundries. Because most ferrous scrap is recycled as steel, the steelmaking process is described in greater detail below.

In the past, steelmaking was highly integrated, which meant that one firm owned or controlled every step of the process, from mining the ore to milling the finished product. Integrated mills typically employed blast furnaces to produce molten refined iron, called pig iron, from the iron ore. Blast furnaces operate by blowing hot gas on raw ore, coke, limestone, and scrap. Chemical reactions cause the iron ore to be reduced to molten iron. ${ }^{1}$ The more volatile impurities evaporate and are blown off in the flue gas, while the less volatile impurities are drawn off in the slag formed from the limestone. The molten pig iron is then transferred to the steelmaking furnaces, which may be one of three types: basic oxygen furnace (BOF), electric arc furnace (EAF), and open-hearth furnace. Alloying elements are added to the iron in the steelmaking furnace, and the chemical composition of the mixture is adjusted to produce steel. The molten steel is transferred to either a continuous-casting machine or to ingot molds (Brown 1992). Continuous cast steel production represented $67 \%$ of total U.S.A. domestic raw steel production in 1990. In either case, the steel solidifies and is then milled into the primary shapes: blooms, billets, and slabs. Virtually all steel products are manufactured from these primary mill shapes.

Electric arc furnaces recently have become an important source of steel as steelmaking technology has evolved. Mills with EAFs usually have a smaller steelmaking capacity than integrated steel plants, but they may have larger scrap throughput.

1 Recent technical innovations include the direct reduction process, which produces direct reduced iron (DRI) by chemically treating iron ore without melting it. At present this technology is not economically feasible in most parts of the world, and only a small fraction of iron is treated this way. DRI is expected play a more prominent role in the future. 


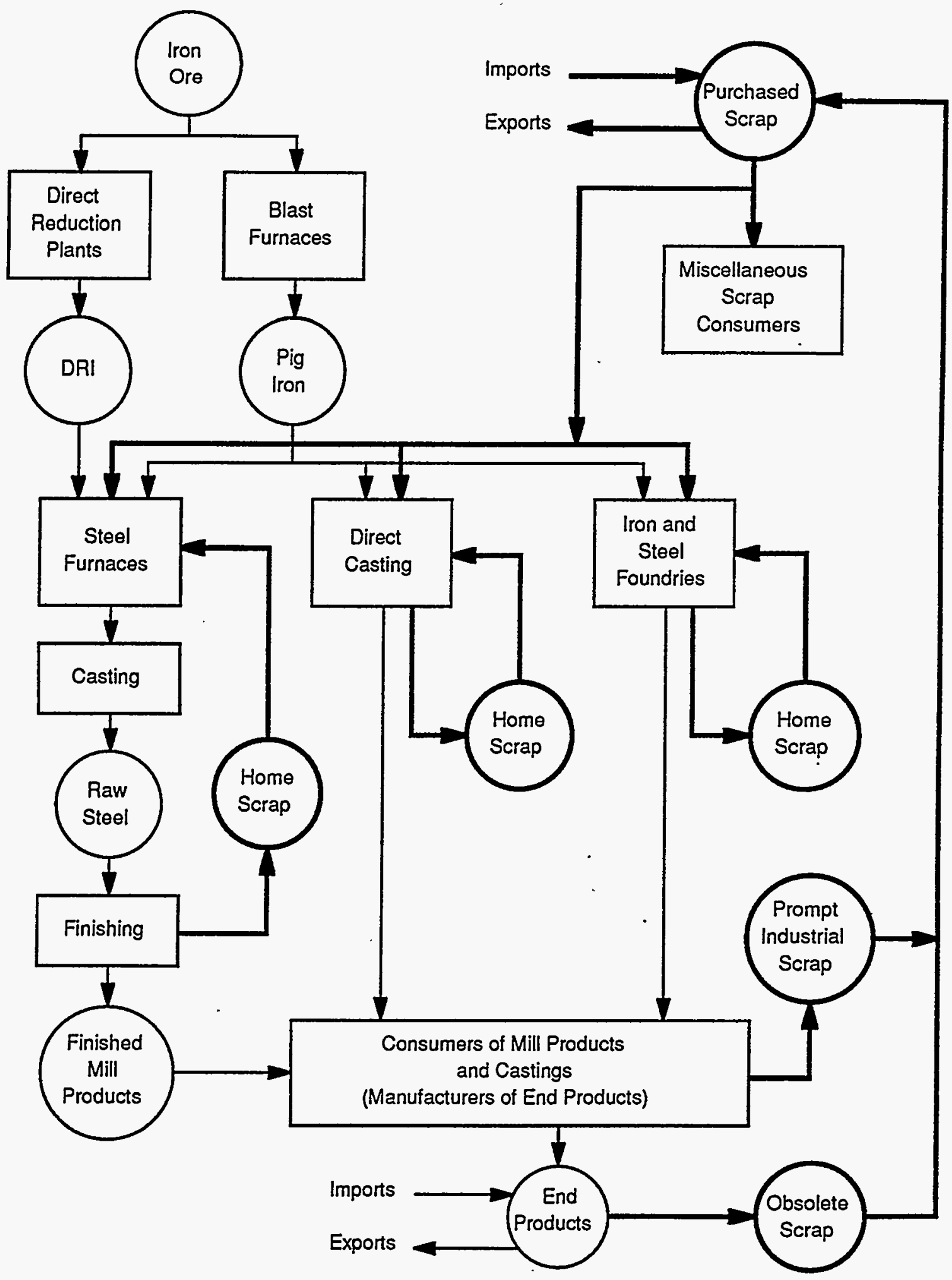

FIGURE 4.4 Iron Scrap Flow Diagram (Source: Based on U.S. Bureau of Mines 1985) 
They do not require the blast furnace step of the steelmaking process. Electric arc furnaces use nearly $100 \%$ scrap iron and steel for the furnace charge. Basic oxygen furnace processes typically use approximately 30\% scrap, but a significant portion of this scrap is runaround (home) scrap. Open-hearth furnaces use about $50 \%$ scrap, but this fraction can vary widely. As indicated in Table 4.1, although BOF plants generally have larger production capacities than EAF systems, scrap throughput is greater in the EAF systems. In 1990, the shares of U.S.A. domestic steel produced in EAF, BOF, and open-hearth furnaces were $37 \%$, $59 \%$, and 4\%, respectively (Brown 1992). A study by the U.S. Bureau of Mines (Brown 1992) found that the steelmaking industry's reliance on purchased (new plus old) scrap had increased sharply over the past 20 years. Total ferrous scrap consumed by U.S.A. steel mills was composed of $16 \%$ new (prompt industrial) scrap and $24 \%$ old (obsolete) scrap in 1970, compared with $29 \%$ new scrap and $44 \%$ old scrap in 1990 (Brown 1992).

Mills with electric arc furnaces have an economic advantage over integrated steel mills employing the basic oxygen process because the former are more energy efficient, emit less pollution, and consume scrap, which is relatively plentiful in industrially developed countries. As the number and production capacity of electric arc furnaces increases, scrap iron and steel will increase in value as input to these mills.

\subsubsection{Secondary Nonferrous Metal Refining}

Nonferrous metals are usually refined at secondary refiners (though some scrap is sent to primary refiners) and are typically handled in smaller quantities than ferrous metals. This section discusses typical secondary nonferrous refining processes and notes process differences among metals (aluminum, copper, lead, nickel, zinc).

TABLE 4.1 Size Ranges of Basic Oxygen Process and Electric Arc Furnace Steel Mills ${ }^{a}$

\begin{tabular}{lccc}
\hline \multirow{2}{*}{ Parameter } & BOF & \multicolumn{2}{c}{ Electric Arc Furnaces } \\
\cline { 3 - 4 } & & Large & Minimill \\
\hline Mill capacity $\left(10^{6}\right.$ t/yx $)$ & $0.9-2.4-4.5$ & $0.4-0.8-2.7$ & $0.05-0.39-2.7$ \\
Furnace size $(\mathrm{t})$ & $86-195-327$ & $73-136-363$ & $9-54-136$ \\
Scrap throughput $\left(10^{6}\right.$ t/yr $)$ & $0.27-0.73-1.36$ & $0.4-0.8-2.7$ & $0.05-0.39-2.7$ \\
\hline
\end{tabular}

a Data presented are low, typical, and high values.

Source: Dehmel et al. (1992, Table B-1). 


\section{Aluminum}

Aluminum recovery from scrap has increased tenfold since 1950 in the U.S.A., and recovery from old scrap has grown even more rapidly over the same time (Jolly et al. 1993). This increase in recycling in the U.S.A. is indicative of the international trend toward increased scrap recovery. In 1991, an estimated $2.5 \times 10^{6} \mathrm{t}$ of metal was recovered from purchased scrap in the U.S.A., of which about $60 \%$ was old scrap. The quantity of old scrap recovered equalled almost $30 \%$ of the total domestic aluminum metal demand for 1991 . The percentage is similar in other Western countries. One major factor in this trend has been increased recycling of used beverage containers. Figure 4.5 illustrates the flow of aluminum scrap through the recycling process.

Table 4.2 presents scrap consumption data by industry segment from 1989 to 1991 . Primary (integrated) producers are the largest consumers of scrap aluminum, but much of it comes form their industrial customers. Thus, the scrap used by primary producers tends to be more segregated than that used by the secondary smelters. Independent secondary producers play a crucial role in the aluminum recycling process. Their sole function is to convert aluminum scrap into a marketable product, almost exclusively alloys for the diecasting industry.

\section{Copper}

World copper production in 1990 totaled $9.4 \times 10^{6} \mathrm{t}$ (Jolly and Edelstein 1992). Copper scrap annually accounts for about $19 \%$ of world copper production. Figure 4.6 shows the flow of scrap copper through the recycling process. In recent years, about $40 \%$ of refined copper produced in Western Europe and about 22\% of refined copper produced in the U.S.A. was derived from copper scrap. (Jolly et al. 1993).

Copper has an excellent potential for recovery because few of its uses are dissipative in nature. Only about $0.5 \%$ of total copper consumption may be unretrievable due to use in applications such as chemicals. Scrap recovery is very price and cost sensitive; more obsolete scrap appears as the price of primary copper increases. Secondary copper costs only about half as much to produce as primary copper. Production of copper from scrap requires less than half the energy required for production from ore (Jolly et al. 1993).

Copper scrap also follows the scrap designations of old and new scrap. While new scrap can generally be remelted, most old scrap must be reprocessed either by smelting and refining or by more complex processes, such as leaching and electrowinning, to form a pure copper product (Jolly et al. 1993). In the U.S.A., new scrap recovery accounts for about 57\% of scrap recovery, while old scrap accounts for the remaining $43 \%$ (Jolly et al. 1993). 


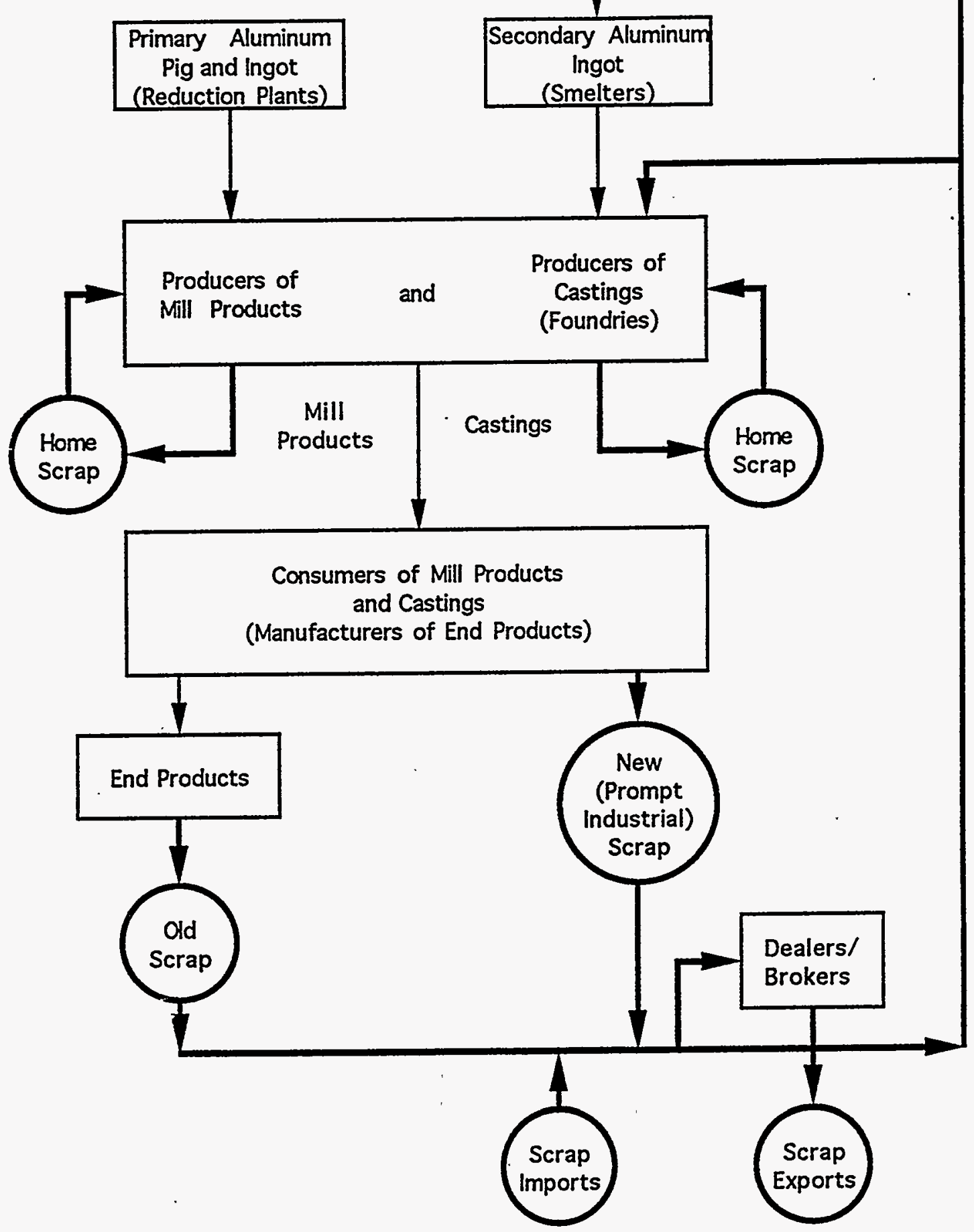

FIGURE 4.5 Aluminum Scrap Flow Diagram (Source: Based on U.S. Bureau of Mines 1985) 
TABLE 4.2 Domestic U.S.A. Consumption of Old and New Aluminum Scrap, 1989-1990

\begin{tabular}{lrrr}
\hline & \multicolumn{3}{c}{ Consumption $\left(10^{3} t\right)$} \\
\cline { 2 - 4 } \multicolumn{1}{c}{ Industry Segment } & 1989 & 1990 & 1991 \\
\hline Secondary smelters & 805.0 & 982.0 & $1,080.1$ \\
Primary producers & $1,027.5$ & $1,212.4$ & $1,260.8$ \\
Fabricators & 222.5 & 238.3 & 237.2 \\
Foundries & .83 .0 & 71.6 & 77.7 \\
Chemical producers & 36.0 & 57.0 & 31.0 \\
Total industry & $2,174.0$ & $2,561.4$ & $2,686.7$ \\
\hline
\end{tabular}

Sources: Jolly et al. (1993); Plunkert and Sehnke (1992).

\section{Nickel}

Nickel is recovered from four main types of scrap: ferrous-base, nickel-base, copperbase, and aluminum-base scrap. Ferrous-base nickel scrap is from stainless steel and constitutes by far the majority of nickel scrap. The stainless steel industry accounts for about $45 \%$ of nickel demand in the U.S.A. and more than $60 \%$ of world demand. In 1991, the U.S.A. recovered and consumed 32,520 tons of nickel from these four scrap categories, representing about $21 \%$ of total apparent nickel consumption for the year (Kuck 1993). Generally, stainless steel scrap is recycled to make stainless steel, nickel-bearing alloy scrap is recycled to make nickel-bearing alloys, and nickel-base superalloy scrap is recycled to make superalloys (Sibley 1985). Figure 4.7 illustrates the flow of nickel scrap through the recycling process.

\section{Lead}

In 1990, world secondary lead production is estimated at about $2,727.7 \mathrm{t}$, compared with primary production of $3,214 \mathrm{t}$. Therefore, $46 \%$ of world lead production was from secondary sources (Woodbury 1992). In the U.S.A., 70\% of lead consumption was from scrap lead (Garino 1993). Battery production is by far the largest consumer of lead - about $80 \%$ of U.S.A. demand and $60 \%$ of world demand. Batteries also supply nearly $90 \%$ of lead scrap in the U.S.A. When lead scrap is collected, it must be smelted and refined at secondary plants in order to meet customer specifications. The smelting process typically generates a highly purified product containing more than $99 \%$ lead (Woodbury 1992). The lead scrap recycling process is illustrated in Figure 4.8 . 


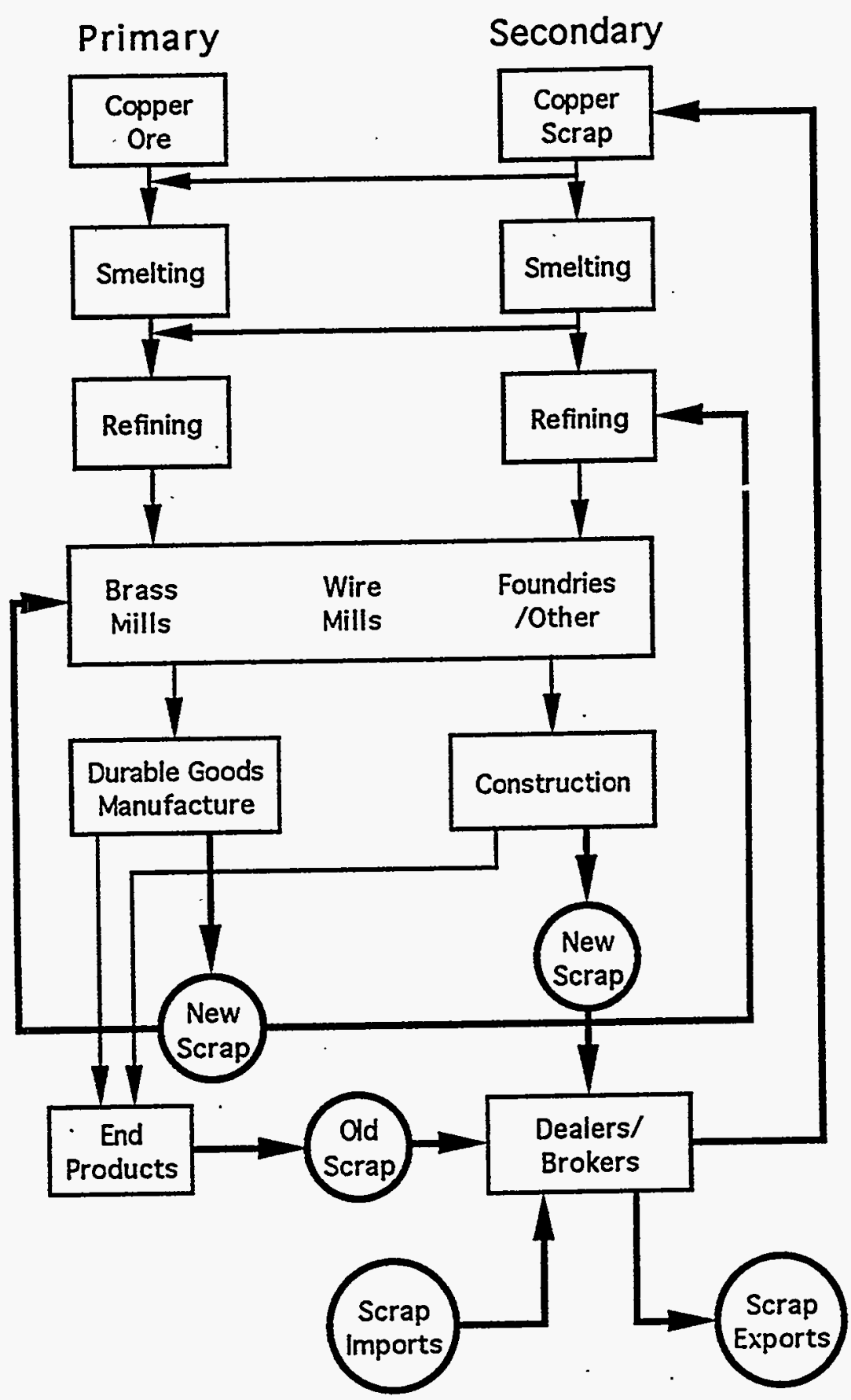

FIGURE 4.6 Copper Scrap Flow Diagram (excluding home scrap) (Source: Based on U.S. Bureau of Mines 1985) 


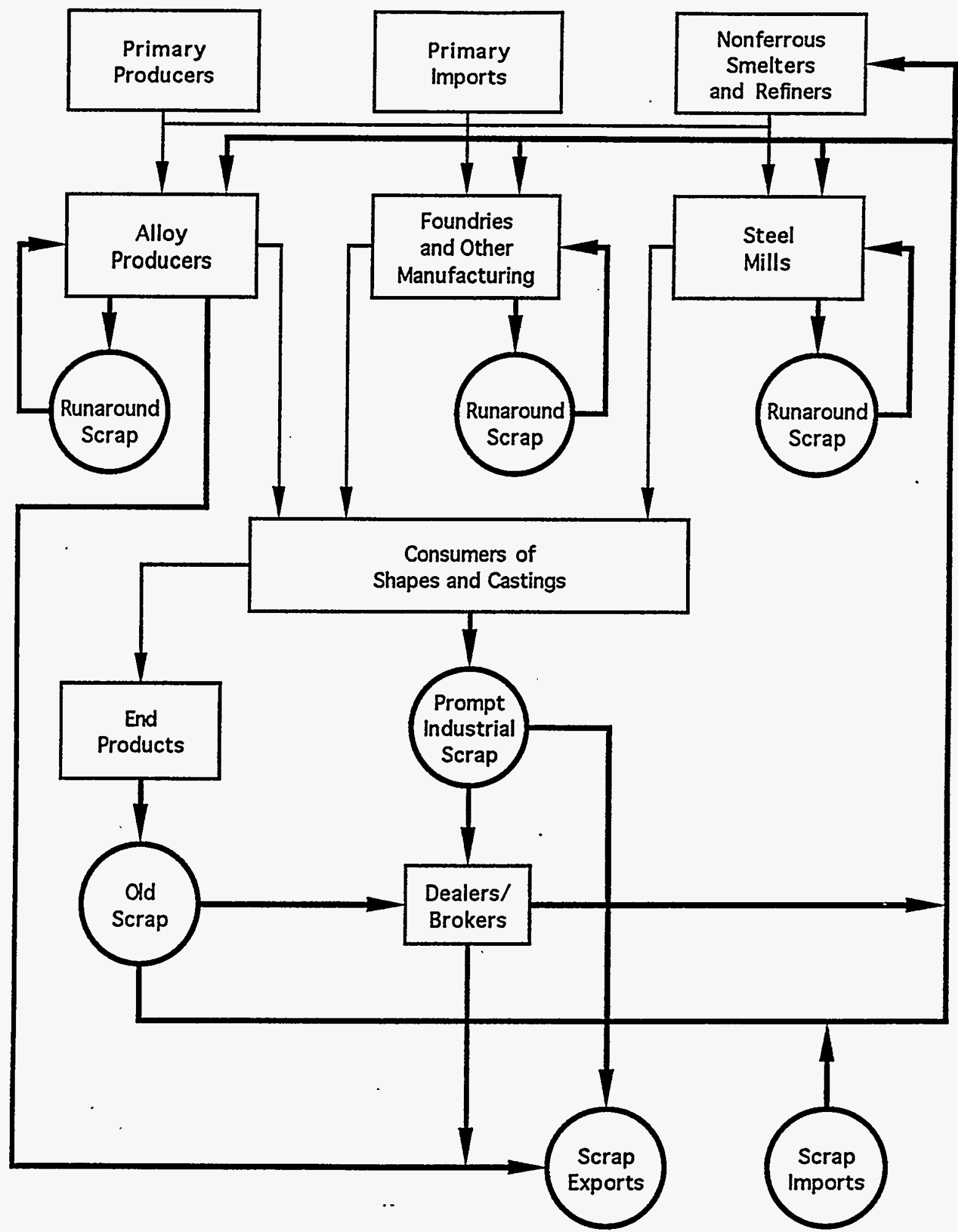

FIGURE 4.7 Nickel Scrap Flow Diagram (Source: Based on U.S. Bureau of Mines 1985) 


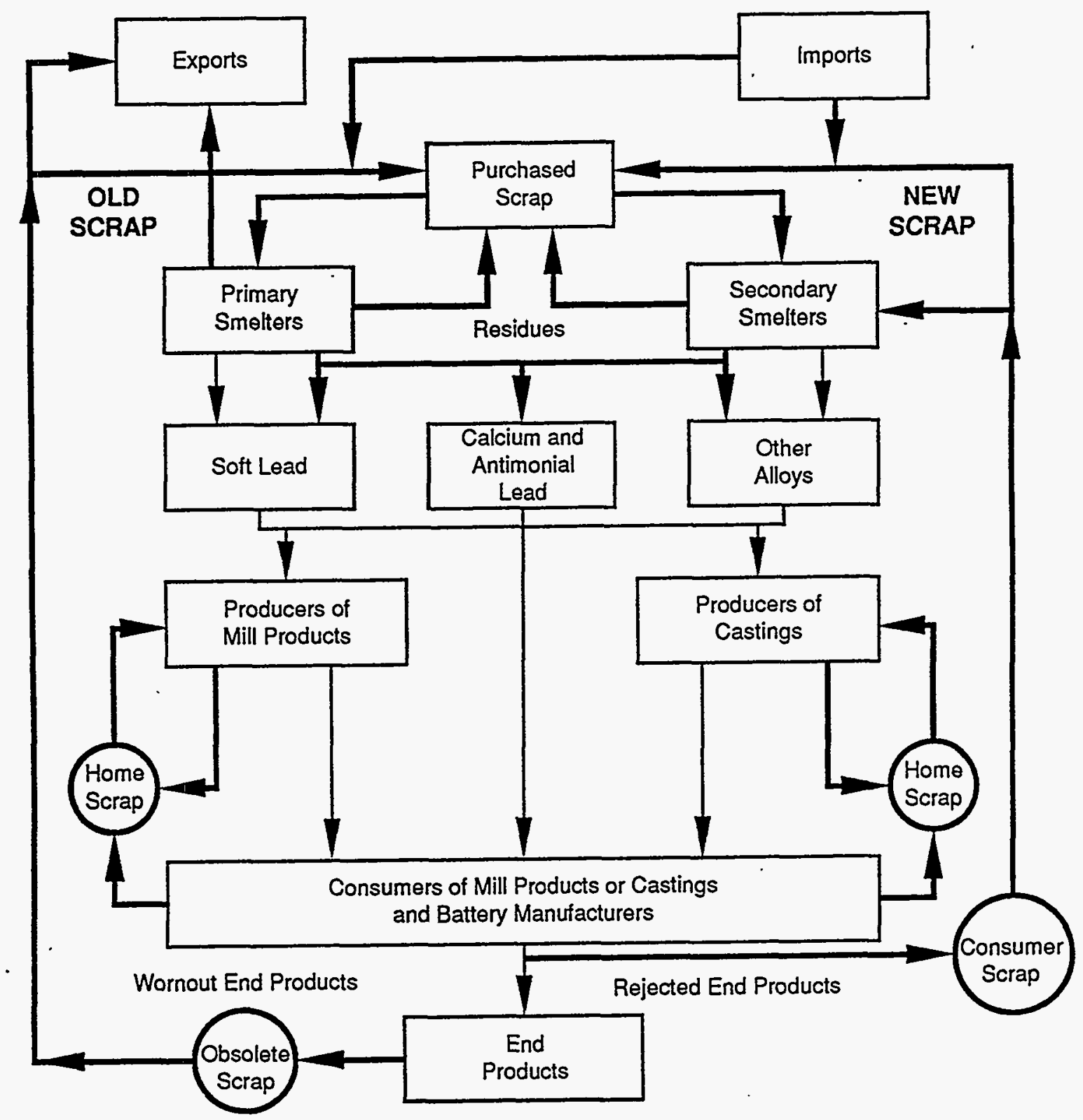

FIGURE 4.8 Lead Scrap Flow Diagram (Source: Based on U.S. Bureau of Mines 1985)

\section{Zine}

World zinc production exceeded $7 \times 10^{6} \mathrm{t}$ in 1991, while world zinc consumption was slightly less (Jolly 1992a). In 1991, scrap zinc accounted for $24 \%$ of zinc production in the U.S.A. (Garino 1993). The outlook for worldwide secondary zinc production is expected to remain strong as policies related to environmental and health protection continue to be implemented (Jolly 1992a).

In 1991, an estimated 450,000 t of zinc was recovered for recycle in the U.S.A. (Jolly 1992b). Figure 4.9 illustrates the zinc scrap recycling process. Zinc is recovered primarily 


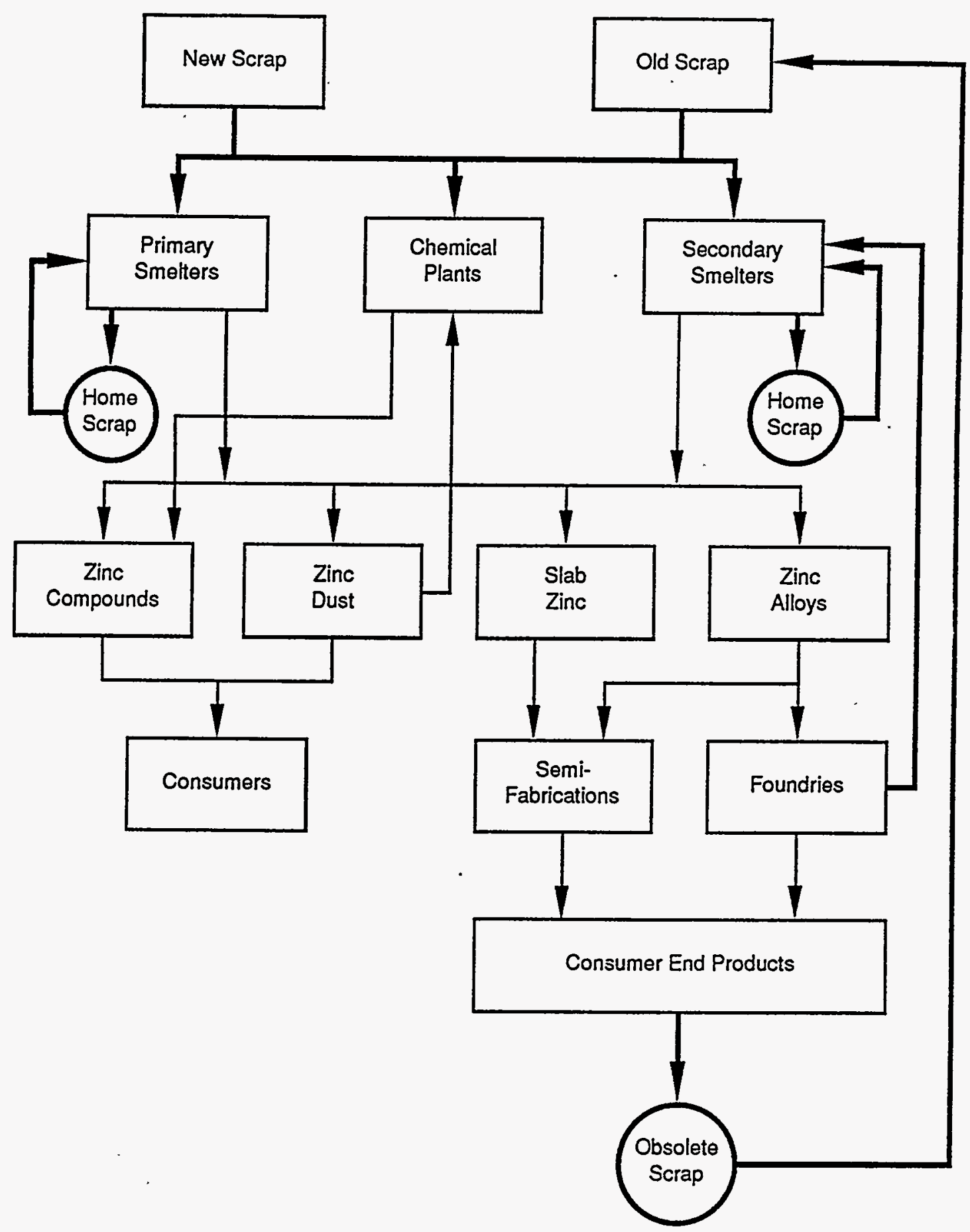

FIGURE 4.9 Zinc Scrap Flow Diagram (Source: Based on U.S. Bureau of Mines 1985) 
from zinc-base and copper-base scrap, with small amounts originating from aluminum-base and magnesium-base scrap. Scrap is recycled in a secondary smelter, where it is separated into its zinc constituent and residue materials. Because zinc is so often combined with other metals, scrap recycled in secondary smelters cannot be sufficiently refined to produce a highpurity metal. Lead, iron, cadmium, aluminum, and tin are the principal metals contributing to the impurity of secondary zinc (Cotterill 1992). Another problem in zinc recycling is that the many dissipative uses of zinc (such as in galvanizing, paints, and rubber, for example) have restricted recovery of zinc from old scrap (Jolly 1985).

\subsubsection{Ferrous/Nonferrous Slag}

Slag is a by-product of metal refining that has a number of uses. Slag plays an important role in the smelting and refining process because it removes and separates impurities associated with the metals. In addition, slag forms a cover on the molten metal, protecting it from oxidation and contamination by impurities. After the production process, slag may be discarded or used in a variety of applications. The U.S. Bureau of Mines' Dictionary of Mining, Mineral, and Related Terms (Thrush et al. 1968) defines slag as: a substance formed in any one of several ways by chemical action and fusion at furnace operating temperatures:

- In smelting operations, through the combination of flux, such as limestone, with the waste portion of the ore;

- In the refining for metals, by substances such as lime added for the purpose of effecting or aiding the refining; or

- By chemical reaction between refractories and fluxing agents such as coal ash, or between two different types of refractories.

In 1991 , about $25 \times 10^{6} \mathrm{t}$ of iron and steel slag, valued at $\$ 130 \times 10^{6}$, was sold or used in the U.S.A. (Solomon 1992). About $69 \%$ of the total was iron slag, and the remainder was steel slag. Most of the slag was used in the construction industry. Road base consumed about 50\% of the slag; asphaltic concrete aggregate, 14\%; concrete aggregate, 11\%; fill, 13\%; and other, $12 \%$ (Table 4.3). In Germany, the primary uses are as fill material, 24\%; and as ground covering, 19\% (CEC 1995).

Copper slag has a number of uses, such as railroad ballast, aggregate for road beds, soil conditioners, slag wool, light-weight concrete cement-making, and (recently) mineral wool. Copper production yields approximately $4 \mathrm{t}$ of slag per $1 \mathrm{t}$ of copper. Slag from other metal smelting processes is usually landfilled.

\subsection{INTERNATIONAL SCRAP METAL TRADE}

This section discusses some of the broader economic factors that shape international trade in scrap metals. The discussion begins with a brief overview of some of the factors and 
TABLE 4.3 Principal Uses of Blast-Furnace Slag

\begin{tabular}{|c|c|c|c|}
\hline Type & & Principal Uses & \\
\hline $\begin{array}{l}\text { Air cooled, } \\
\text { crushed and } \\
\text { screened slag }\end{array}$ & $\begin{array}{l}\text { Ballast, railroad } \\
\text { Concrete, portland cement } \\
\text { Concrete units: } \\
\text { masonry hollow } \\
\text { Binder course, } \\
\text { sheet asphalt pavement } \\
\text { Bituminous concrete base } \\
\text { or surface course } \\
\text { Bituminous macadam base } \\
\text { or surface course } \\
\text { Bituminous surface treatment }\end{array}$ & $\begin{array}{l}\text { Cushion course for brick } \\
\text { or block pavement } \\
\text { Sand for sheet asphalt } \\
\text { or bituminous concrete } \\
\text { Waterbound base } \\
\text { or wearing course } \\
\text { Sewage trickle-filter media } \\
\text { Roofing granules, bituminous } \\
\text { built-up roofing, } \\
\text { Mineral wool } \\
\text { Subbases and special } \\
\text { subgrade insulations }\end{array}$ & $\begin{array}{l}\text { Traffic bound roads, } \\
\text { berms, shoulders } \\
\text { Stabilized roads and bases } \\
\text { Porous backfill } \\
\text { and underdrains } \\
\text { Lightweight aggregate } \\
\text { expanded slag } \\
\text { Embankments, roadwalk fills, } \\
\text { bank slag } \\
\text { Glass sand, ceramic ware }\end{array}$ \\
\hline Granulated slag & $\begin{array}{l}\text { Portland cement } \\
\text { Slag cements } \\
\text { Soil corrective } \\
\quad \text { agricultural slag }\end{array}$ & $\begin{array}{l}\text { Roadway insulation courses } \\
\text { Special subgrade } \\
\text { and subbases } \\
\text { Ceramic ware glass sand }\end{array}$ & $\begin{array}{l}\text { Roadway fills } \\
\text { and embankments } \\
\text { Concrete units } \\
\text { Building blocks }\end{array}$ \\
\hline Expanded slag & $\begin{array}{l}\text { Concrete masonry units } \\
\text { Structural concrete } \\
\text { Fireproofing } \\
\text { Floor tile }\end{array}$ & $\begin{array}{l}\text { Precast products } \\
\text { Floor joints and slabs } \\
\text { Building blocks } \\
\text { Brick }\end{array}$ & $\begin{array}{l}\text { Acoustical tile } \\
\text { Curtain walls: } \\
\text { Back up insulation } \\
\text { Fire resistive }\end{array}$ \\
\hline
\end{tabular}

Source: McGannon (1971). 
trends that shape the scrap metal market. Then, factors affecting the supply and demand for scrap metal are discussed. Trade flows between geographic regions (Europe, North America, Asia, and others) are then examined. The section closes with analysis of recent trends in scrap metal prices.

\subsubsection{Overview}

In 1990, the international scrap metal trade totaled between $\$ 11.0$ and $12.8 \times 10^{9}$ (U.S.A. dollars) (United Nations 1992). ${ }^{2}$ Ferrous scrap accounted for $44 \%$ of the total value of scrap traded and nonferrous accounted for $56 \%$. International scrap trade occurs primarily between industrialized countries, but developing countries with emerging metal refining and fabricating capability may have significant trade (import) volumes. Recent analysis of iron and steel scrap trade data reveals a trend for scrap to flow from north to south - from industrialized to developing countries - as developing countries build up their domestic steel industries. Although international scrap trade usually involves processed scrap, it can include raw scrap. Processed scrap metals are freely traded commodities much like grains, precious metals, oil, or currencies. Unlike other commodities, however, no centralized trading place exists for scrap metal. ${ }^{3}$ Rather, scrap is bought and sold via telephone or face-to-face negotiations between dealer/processors, brokers, and mill/foundry operators.

When scrap dealers negotiate prices, published prices are used as a benchmark or starting point. International scrap prices also depend on several other factors, such as local demand, logistics (transportation costs, timing, etc.), quality (grade), exchange rates, and trade barriers (if applicable). For example, the high transportation cost associated with scrap tends to segment markets geographically. In the U.S.A., prices are quoted for Pittsburgh, Philadelphia, Chicago, Cleveland, St. Louis, Birmingham, and other cities, and these prices tend to reflect regional (local) supply and demand relationships.

\subsubsection{Scrap Metal Supply and Demand}

Home scrap has in the past been a significant source of scrap. Newer, more efficient technologies have reduced the quantity of home scrap generated and have reduced its importance. To offset the reduced supply of home scrap, steel fabricators are using more purchased scrap. During periods of weak domestic and international demand, most purchased scrap will be industrial scrap. Industrial scrap quantity is determined by the quality and level of manufacturing production. As manufacturing activity increases, so does the quantity of industrial scrap that is generated.

2 The range of values reflects different import and export totals, which should be equal to each other. This discrepancy is caused in part by different data collection practices for the various countries.

3 Refined metals are traded in centralized markets, such as the New York Commodities Exchange or the London Metals Exchange. 
In contrast, obsolete scrap is a "swing" product. Demand for obsolete scrap depends on the difference between total market demand for scrap and the quantity of industrial scrap available. In weak markets, industrial scrap may meet all of the demand for scrap, with the demand for obsolete scrap falling to nothing. In high demand periods, the demand for obsolete scrap increases as the supply of industrial scrap is consumed (Institute of Scrap Iron and Steel 1984). Thus, business fluctuations in the metals industry are greatly magnified for those handling obsolete scrap.

Given the present competitiveness of the world markets, the stability of scrap supply to manufacturers and refiners is critical. Business conditions today dictate that suppliers be able to consistently deliver quality product in a timely fashion on short notice. Thus, suppliers must anticipate business trade and maintain an adequate inventory at all times. In addition, scrap processors must pay adequate prices to the suppliers (collectors, metal fabricators, etc.) to support these sources during periods of weak demand. Thus, purchasing decisions of scrap buyers (traders) must factor in both short-term and long-term demand considerations.

To help ensure a continuous supply of scrap, many processors use forward contracts. A forward contract is an agreement for delivery of a specified quantity of scrap of a specified type at a specified time in the future (typical contract lengths are one, three, and six months) for a price agreed on today. Forward pricing is based upon expected future prices. Forward contracts have become prevalent with manufacturers/processors (such as Alcoa) and brokers/traders from whom manufacturers/processors purchase scrap. This practice helps ensure scrap supply into the future.

A common saying in the scrap metal industry is: "Scrap is bought, not sold." This reflects the fact that demand for scrap is almost wholly derived from the demand for the refined metal smelted from the scrap. Two other factors that influence the demand for scrap are the price of metal smelted from ore and the purity of the scrap. As the price of smelting metal from ore increases, the value of scrap goes up because it is relatively cheaper to refine from scrap. Similarly, if the scrap is relatively pure (i.e., free of tramp elements) then the scrap has greater value because it requires little or no refining.

The primary use of ferrous scrap continues to be in steel-making activities. Estimated world scrap consumption in 1989 was $388.5 \times 10^{6} \mathrm{t}$. The largest scrap consumer was Eastern Europe with $119 \times 10^{6} \mathrm{t}$ (or $31 \%$ ), followed by Western Europe with $82 \times 10^{6} \mathrm{t}$. The U.S.A. consumed $66 \times 10^{6} \mathrm{t}$. More than about $50 \%$ of all steel manufactured in the U.S.A. is made of scrap (Institute of Scrap Recycling Industries 1990). End uses of the commodity metals in the U.S.A. are listed in Table 4.4.

As environmental concerns become more prevalent worldwide, the recovery and use of scrap are likely to experience strong growth through the 21st century. Between 1983 and 1990, ferrous scrap recovery and use in the U.S.A. grew around 2\% annually, while Japan experienced a growth rate of $3 \%$ a year. As electric furnace use increases worldwide, so too will scrap consumption. 
TABLE 4.4 Domestic U.S.A. End Uses of Commodity Metals

\begin{tabular}{|c|c|c|}
\hline Commodity & Use & $\begin{array}{c}\text { Percent } \\
\text { Consumption }\end{array}$ \\
\hline \multirow[t]{6}{*}{ Aluminum } & Packaging & 33 \\
\hline & Transportation & 20 \\
\hline & Building & 19 \\
\hline & Electrical & 9 \\
\hline & Consumer & 8 \\
\hline & Other uses & 11 \\
\hline \multirow[t]{4}{*}{ Copper } & Building/construction & 40 \\
\hline & Electrical & 26 \\
\hline & Industrial machinery and equipment & 14 \\
\hline & Consumer and general products & 9 \\
\hline \multirow[t]{5}{*}{ Iron and Steel } & Warehouses and steel service centers & 21 \\
\hline & Transportation & 11 \\
\hline & Construction & 11 \\
\hline & Cans and containers & 6 \\
\hline & Other uses & 51 \\
\hline \multirow[t]{2}{*}{ Lead } & Transportation (batteries) & 75 \\
\hline & Other uses & 25 \\
\hline \multirow[t]{9}{*}{ Nickel } & Transportation & 26 \\
\hline & Chemicals & 12 \\
\hline & Electrical equipment & 8 \\
\hline & Construction & 8 \\
\hline & Fabricated metals & 7 \\
\hline & Machinery & 6 \\
\hline & Household appliances & 6 \\
\hline & Petroleum & 5 \\
\hline & Other uses & 22 \\
\hline \multirow[t]{5}{*}{ Zinc } & Construction materials & 46 \\
\hline & Transportation & 20 \\
\hline & Machinery & 11 \\
\hline & Electrical & 11 \\
\hline & Other uses & 12 \\
\hline
\end{tabular}

Source: U.S. Department of the Interior (1992). 


\subsubsection{Metal Trade Profiles}

Each of the scrap metals discussed in this study is traded internationally, and these global trading patterns are discussed here. Figure 4.10 shows the levels of 1989 international scrap shipments for the metals of interest. Iron and steel scrap has the greatest international trade volume $\left(42 \times 10^{6} \mathrm{t}\right)$ and nickel scrap has the least $\left(0.03 \times 10^{6} \mathrm{t}\right)$.

The data presented in this section represent transboundary shipments, not the domestic consumption for each country. Domestic consumption data would be more relevant because scrap metal markets are primarily regional. High transportation costs discourage transboundary shipments. Therefore, the data presented here will tend to underestimate global scrap metal activity. However, domestic consumption data were not readily available except for U.S.A. markets and for iron and steel scrap. One generalization can be made: larger market volumes facilitate trade. Thus, it should be easier to sell iron and steel scrap than, say, lead or zinc scrap. ${ }^{4}$

Furthermore, the data should be interpreted cautiously since there is evidence of data error in the fact that the world total exports do not equal total imports. This discrepancy may be attributed in part to unreported or inconsistent data from individual scrap dealers and brokers and metal manufacturing industries (Kauffmann 1993). As a consequence, world trade volumes are presented as an average of import and export totals, although regional and country data are presented as reported. Market shares are approximated to the nearest $5 \%$ increment.

\subsubsection{Iron and Steel Scrap}

As presented in Table 4.5, world iron and steel scrap trade increased significantly between 1985 and 1989. In 1989, the largest scrap exporting regions were North America (50\%) and Europe (almost 50\%). The remaining regions contributed relatively insignificant export volumes. By a wide margin, the U.S.A. was the largest single exporter (50\%), followed by the former West Germany (10\%) and France (10\%). Europe was the largest importer of scrap, accounting for 50\% of world imports; followed by Asia at (45\%); and North America at 5\%. The largest single country importers were Italy (15\%), Spain (10\%), Turkey (10\%), and South Korea (10\%). Japan, a major user of iron and steel for automobiles, imported little because most of their scrap needs are met internally.

\subsubsection{Aluminum Scrap}

Table 4.6 presents the international scrap aluminum trade volume by region. Between 1985 and 1989, world trade increased more than 50\%. In 1989, Europe was the largest exporting region at around $50 \%$ of world exports. North America followed with about

4 Nickel is a special case since it is used so commonly as an alloying element. 


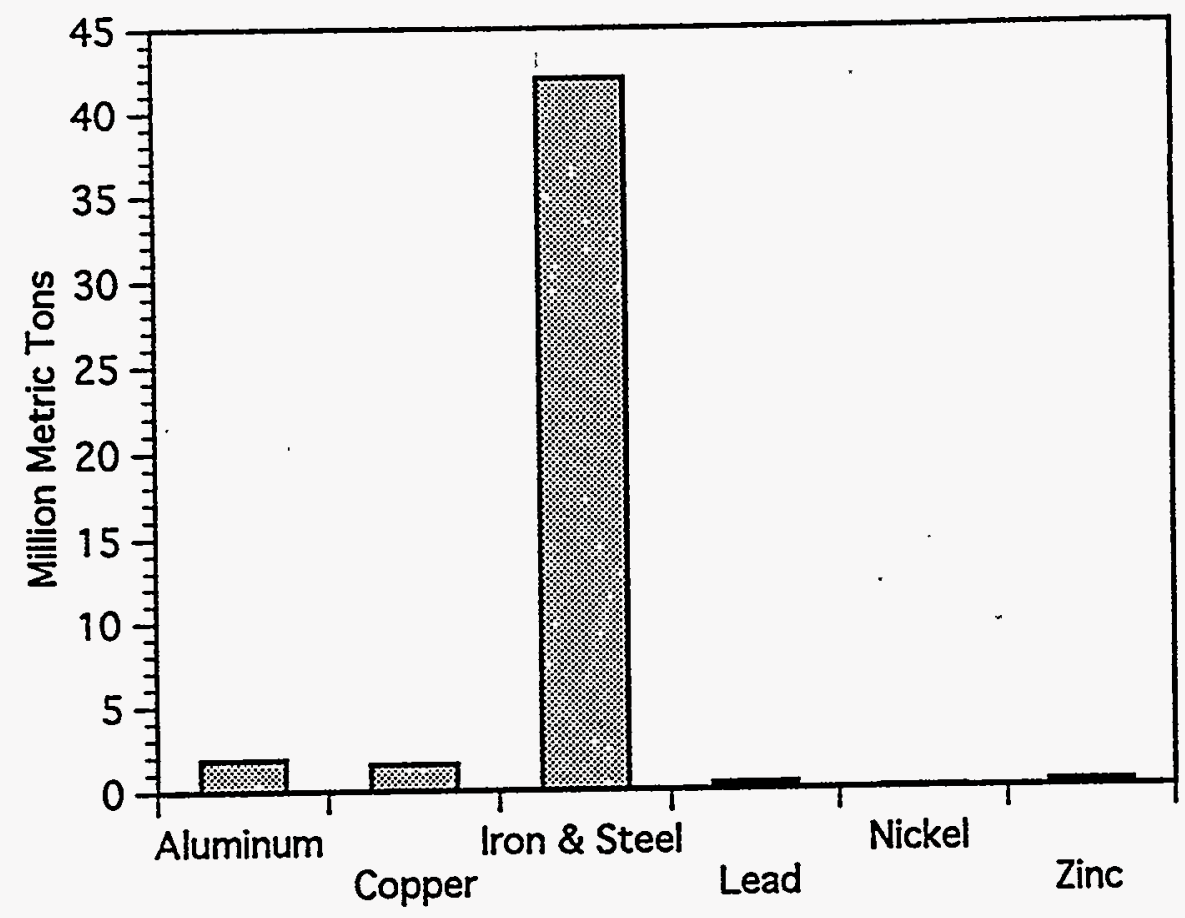

FIGURE 4.10 1989 International Scrap Trade

TABLE 4.5 International Scrap Iron and Steel Trade (in $10^{3} t$ )

\begin{tabular}{|c|c|c|c|c|}
\hline \multirow{2}{*}{$\begin{array}{l}\text { Continent and } \\
\text { Country Group }\end{array}$} & \multicolumn{2}{|c|}{ Exports } & \multicolumn{2}{|c|}{ Imports } \\
\hline & 1985 & 1989 & 1985 & 1989 \\
\hline North America & 9,985 & 22,082 & 1,429 & 2,476 \\
\hline Latin America & 85 & 0 & 1,672 & 259 \\
\hline \multicolumn{5}{|l|}{ Europe } \\
\hline European Community & 15,041 & 16,799 & 16,733 & 16,489 \\
\hline $\begin{array}{l}\text { European Free Trade } \\
\text { Association }\end{array}$ & 179 & 329 & 1,488 & 960 \\
\hline $\begin{array}{l}\text { Council for Mutual Economic } \\
\text { Assistance }\end{array}$ & 3,625 & 3,529 & 1,011 & 1,070 \\
\hline Other & 185 & 239 & 729 & 646 \\
\hline Total Europe & 19,030 & 20,896 & 19,960 & 19,166 \\
\hline Africa & 325 & 78 & 16 & 3 \\
\hline Asia & 1,482 & 1,730 & 10,423 & 16,615 \\
\hline Oceania & 489 & 987 & 4 & 2 \\
\hline World Total & 31,395 & 45,773 & 33,505 & 38,521 \\
\hline
\end{tabular}

Source: British Geological Survey (1991). 
TABLE 4.6 International Scrap Aluminum Trade (in $10^{3} \mathrm{t}$ )

\begin{tabular}{|c|c|c|c|c|}
\hline \multirow{2}{*}{$\begin{array}{l}\text { Continent and } \\
\text { Country Group }\end{array}$} & \multicolumn{2}{|c|}{ Exports } & \multicolumn{2}{|c|}{ Imports } \\
\hline & 1985 & 1989 & 1985 & 1989 \\
\hline North America & 491 & 740 & 181 & 265 \\
\hline Latin America & 5 & 2 & 1 & 3 \\
\hline \multicolumn{5}{|l|}{ Europe } \\
\hline European Community & 438 & 708 & 558 & 912 \\
\hline $\begin{array}{l}\text { European Free Trade } \\
\text { Association }\end{array}$ & 71 & 140 & 90 & 133 \\
\hline $\begin{array}{l}\text { Council for Mutual Economic } \\
\text { Assistance }\end{array}$ & 41 & 53 & 0 & 0 \\
\hline Other & $-{ }^{a}$ & 1 & 0 & 0 \\
\hline Total Europe & 550 & 903 & 648 & 1,045 \\
\hline Africa & 9 & 2 & 1 & - \\
\hline Asia & 71 & 126 & 392 & 557 \\
\hline Oceania & 21 & 8 & 3 & 0 \\
\hline World Total & 1,147 & 1,782 & 1,225 & 1,870 \\
\hline
\end{tabular}

$40 \%$ of world exports. The U.S.A. exported $30 \%$ of the world trade and was the largest single country exporter, followed by the former West Germany and Canada (at 10\% each). Europe was the largest importing region with $50 \%$ of world imports, followed by Asia at $30 \%$. The largest single country importers in 1989 were Japan at 20\%, the former West Germany at $15 \%$, and the U.S.A. at $10 \%$.

\subsubsection{Copper Scrap}

Table 4.7 indicates that smaller volume increases occurred in the international copper scrap trade than in aluminum trade. Copper trade volume over the 1985-1989 period increased approximately 35\% worldwide. In 1989, Europe accounted for $40 \%$ of world exports followed by North America at 30\%. The largest exporter was the U.S.A., accounting for 25\% of world exports, followed by France at 15\%. Europe led all importers with $60 \%$, and Asia was next at $20 \%$. The largest single importers were the former West Germany with $20 \%$ of world imports and Belgium at $10 \%$. 
TABLE 4.7 International Scrap Copper Trade (in $10^{3} t$ )

\begin{tabular}{|c|c|c|c|c|}
\hline \multirow{2}{*}{$\begin{array}{l}\text { Continent and } \\
\text { Country Group }\end{array}$} & \multicolumn{2}{|c|}{ Exports } & \multicolumn{2}{|c|}{ Imports } \\
\hline & 1985 & 1989 & 1985 & 1989 \\
\hline North America & 345 & 437 & 140 & 208 \\
\hline Latin America & 4 & 2 & 99 & 49 \\
\hline \multicolumn{5}{|l|}{ Europe } \\
\hline European Community & 457 & 713 & 689 & 950 \\
\hline $\begin{array}{l}\text { European Free Trade } \\
\text { Association }\end{array}$ & 44 & 68 & 72 & 51 \\
\hline $\begin{array}{l}\text { Council for Mutual Economic } \\
\text { Assistance }\end{array}$ & 40 & 29 & 33 & 32 \\
\hline Other & 2 & 2 & 1 & 1 \\
\hline Total Europe & 544 & 812 & 794 & $\begin{array}{r}1,03 \\
3\end{array}$ \\
\hline Africa & 23 & 13 & 1 & 2 \\
\hline Asia & 128 & 196 & 192 & 367 \\
\hline Oceania & 2 & 3 & 1 & 0 \\
\hline World Total & $\begin{array}{r}1,04 \\
9\end{array}$ & 1,462 & 1,228 & $\begin{array}{r}1,65 \\
9\end{array}$ \\
\hline
\end{tabular}

Source: British Geological Survey (1991).

\subsubsection{Lead Scrap}

Table 4.8 indicates the relatively small volume of international trade in scrap lead. Exports increased more than 15\% over the 1985-1989 period. The largest exporting regions were Europe (55\%) and North America (25\%). The largest exporting countries were the U.S.A. (20\%) and the United Kingdom (10\%). The largest importing regions were Asia and Europe at about $45 \%$ of imports each. The largest importing countries were Taiwan (20\%), Korea (10\%), France (10\%), and the former West Germany (10\%). Unlike most scrap metals, which have experienced growth over the last 20 years, lead production over the 1970-1990 period remained relatively constant. This condition may, in part, be attributed to two primary factors: (1) legislation calling for the reduction or elimination of some end uses of lead (and therefore of scrap) and (2) the continued reductions in lead use per battery and in ammunition (Woodbury 1992). Evidence indicates that the reduced demand for lead scrap experienced in the U.S.A. is likely to occur in the international markets as well. 
TABLE 4.8 International Scrap Lead Trade (in $10^{3} \mathrm{t}$ )

\begin{tabular}{|c|c|c|c|c|}
\hline \multirow{2}{*}{$\begin{array}{l}\text { Continent and } \\
\text { Country Group } \\
\end{array}$} & \multicolumn{2}{|c|}{ Exports } & \multicolumn{2}{|c|}{ Imports } \\
\hline & 1985 & 1989 & 1985 & 1989 \\
\hline North America & 71 & 68 & 46 & 38 \\
\hline Latin America & 2 & 0 & 1 & 0 \\
\hline \multicolumn{5}{|l|}{ Europe } \\
\hline European Community & 107 & 115 & 128 & 131 \\
\hline $\begin{array}{l}\text { European Free Trade } \\
\text { Association }\end{array}$ & 18 & 41 & 27 & 20 \\
\hline $\begin{array}{l}\text { Council for Mutual Economic } \\
\text { Assistance }\end{array}$ & 3 & 1 & 8 & 11 \\
\hline Other & 0 & 0 & 1 & 3 \\
\hline Total Europe & 128 & 157 & 163 & 166 \\
\hline Africa & 2 & 1 & 17 & 2 \\
\hline Asia & 17 & 55 & 108 & 167 \\
\hline Oceania & 19 & 0 & 0 & 0 \\
\hline World Total & 239 & 281 & 336 & 372 \\
\hline
\end{tabular}

Source: British Geological Survey (1991).

\subsubsection{Nickel Scrap}

Table 4.9 indicates trends in world nickel trade, which has increased over the 1985-1989 period. Europe with 50\% of world exports and North America with $40 \%$ were the largest exporting regions. The largest country exporters were the U.S.A. at $30 \%$, the former West Germany at $15 \%$, and Canada at $15 \%$. With $60 \%$ of word imports, Europe was the world's largest importing region by a significant margin. North America followed with 35\%. Canada was the largest importing country at $20 \%$; the former West Germany was second at $20 \%$; and Sweden was third at $15 \%$.

Because of nickel's widespread uses in industrial and consumer product applications, such as stainless steels, production (and the consumption of scrap) has increased significantly. Over the period 1950-1990, production increased about 600\%, an annual growth rate of about $4.6 \%$. 
TABLE 4.9 International Scrap Nickel Trade (in $\left.10^{3} t\right)$

\begin{tabular}{|c|c|c|c|c|}
\hline \multirow{2}{*}{$\begin{array}{l}\text { Continent and } \\
\text { Country Group }\end{array}$} & \multicolumn{2}{|c|}{ Exports } & \multicolumn{2}{|c|}{ Imports } \\
\hline & 1985 & 1989 & 1985 & 1989 \\
\hline North America & 19 & 23 & 5 & 24 \\
\hline Latin America & 0 & . 0 & 0 & 0 \\
\hline Europe & & & & \\
\hline European Community & 24 & 26 & 16 & 26 \\
\hline $\begin{array}{l}\text { European Free Trade } \\
\text { Association }\end{array}$ & 3 & 1 & 9 & 17 \\
\hline $\begin{array}{l}\text { Council for Mutual Economic } \\
\text { Assistance }\end{array}$ & 0 & 0 & 0 & 0 \\
\hline Other & $-{ }^{a}$ & 0 & 0 & 0 \\
\hline Total Europe & 27 & 27 & 25 & 43 \\
\hline Africa & - & 1 & 0 & 0 \\
\hline Asia & 3 & 4 & 5 & 4 \\
\hline World Total & 50 & 54 & 35 & 71 \\
\hline
\end{tabular}

a - denotes less than $10^{3} \mathrm{t}$.

Source: British Geological Survey (1991).

\subsubsection{Zinc Scrap}

As indicated in Table 4.10, zinc trade increased between 1985 and 1989. Major exporting regions were Europe at 55\% of world exports and North America at 35\%. The largest exporting counties were the U.S.A. (35\%), followed by the United Kingdom (10\%), the Netherlands (10\%), and the former West Germany (10\%). The major importing region in 1989 was Asia with $65 \%$ of world imports, followed by Europe at $35 \%$. The largest importing countries were Taiwan (60\%), the former West Germany (10\%), and Belgium (5\%). The remaining imports went primarily to other European countries.

\subsubsection{Recent Trends in Serap Prices}

This section examines price trends of scrap metals from 1987 through early 1993. Monthly average price data for each scrap metal are graphed from bid quote data published 
TABLE 4.10 International Scrap Zinc Trade (in $10^{3} t$ )

\begin{tabular}{|c|c|c|c|c|}
\hline \multirow{2}{*}{$\begin{array}{l}\text { Continent and } \\
\text { Country Group } \\
\end{array}$} & \multicolumn{2}{|c|}{ Exports } & \multicolumn{2}{|c|}{ Imports } \\
\hline & 1985 & 1989 & 1985 & 1989 \\
\hline North America & 57 & 109 & 3 & 11 \\
\hline Latin America & 0 & 0 & 0 & 0 \\
\hline \multicolumn{5}{|l|}{ Europe } \\
\hline European Community & 77 & 151 & 62 & 89 \\
\hline $\begin{array}{l}\text { European Free Trade } \\
\text { Association }\end{array}$ & 6 & 15 & $--^{a}$ & 1 \\
\hline $\begin{array}{l}\text { Council for Mutual Economic } \\
\text { Assistance }\end{array}$ & 4 & 2 & 0 & 0 \\
\hline Other & 0 & 0 & 0 & 0 \\
\hline Total Europe & 7 & 168 & 62 & 90 \\
\hline Africa & 0 & 0 & - & - \\
\hline Asia & 12 & 16 & 36 & 172 \\
\hline Oceania & 1 & 1 & 0 & 0 \\
\hline World Total & 157 & 295 & 101 & 273 \\
\hline
\end{tabular}

in Metal Statistics 1993 and in the June 1993 daily issues of American Metal Market. ${ }^{5}$ These time series share a few features: (1) many of the scrap prices peaked in the late 1980 s and then again in the early 1990s before trending downward through the remainder of the period; (2) the prices are volatile; and (3) the grades maintain their relative price relationships within metal type. The time series graphs are discussed below in more retail.

\subsubsection{Iron and Steel}

Figure 4.11 presents prices for three grades of scrap iron and steel. The grades presented - No. 1 heavy melting, No. 2 heavy melting, and plate and structural - are most likely to be comparable to RSM characteristics. Several features of this figure are notable: prices display no consistent trend; they are fairly volatile; the spread between grades varies

5 The bid quote is used (rather than the ask quote) because in the scrap metal market the buyer sets the price, not the seller. 


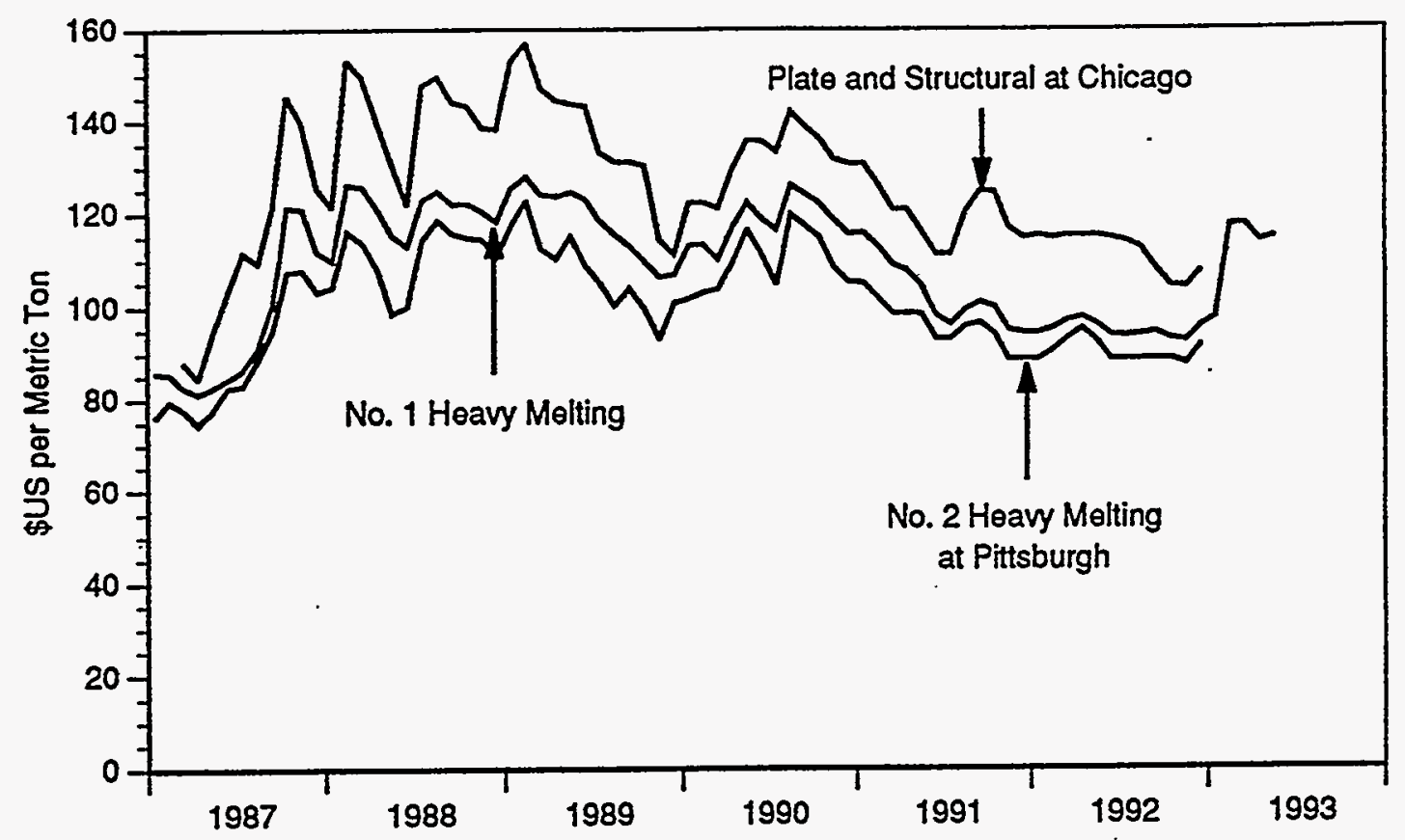

FIGURE 4.11 U.S.A. Scrap Iron and Steel Prices (Sources: 1987-1992 prices from American Metal Market Co. 1993a; 1993 prices based on June 1993 issues of American Metal Markets [American Metal Market Co. 1993b])

overtime, which indicates that the markets differ somewhat for different grades of scrap; and the three grades maintain their relative price relationships (i.e., plate and structural always has the highest price and No. 2 heavy melting has the lowest price). Prices increased early in the time period, peaking in February 1989 before declining unsteadily through 1992. Within one year, prices declined an average of more than $20 \%$, but scrap prices were relatively more volatile in the earlier part of the period.

\subsubsection{Stainless Steel}

Figure 4.12 presents the stainless steel scrap time series. Stainless scrap prices peaked dramatically in early 1989, increasing from $\$ 529.40$ per ton in February 1987 to $\$ 1,839.18$ per ton in March 1989. This change represented an increase of $247 \%$ over the 25 -month period. Less than one year later, however, prices had fallen to $\$ 786.41$, a decrease of more than 57\% from the peak. Prices rebounded through 1990, but a downward trend has occurred since mid-1990. As of December 1992, scrap stainless steel prices were about $\$ 702.72$ per ton. 


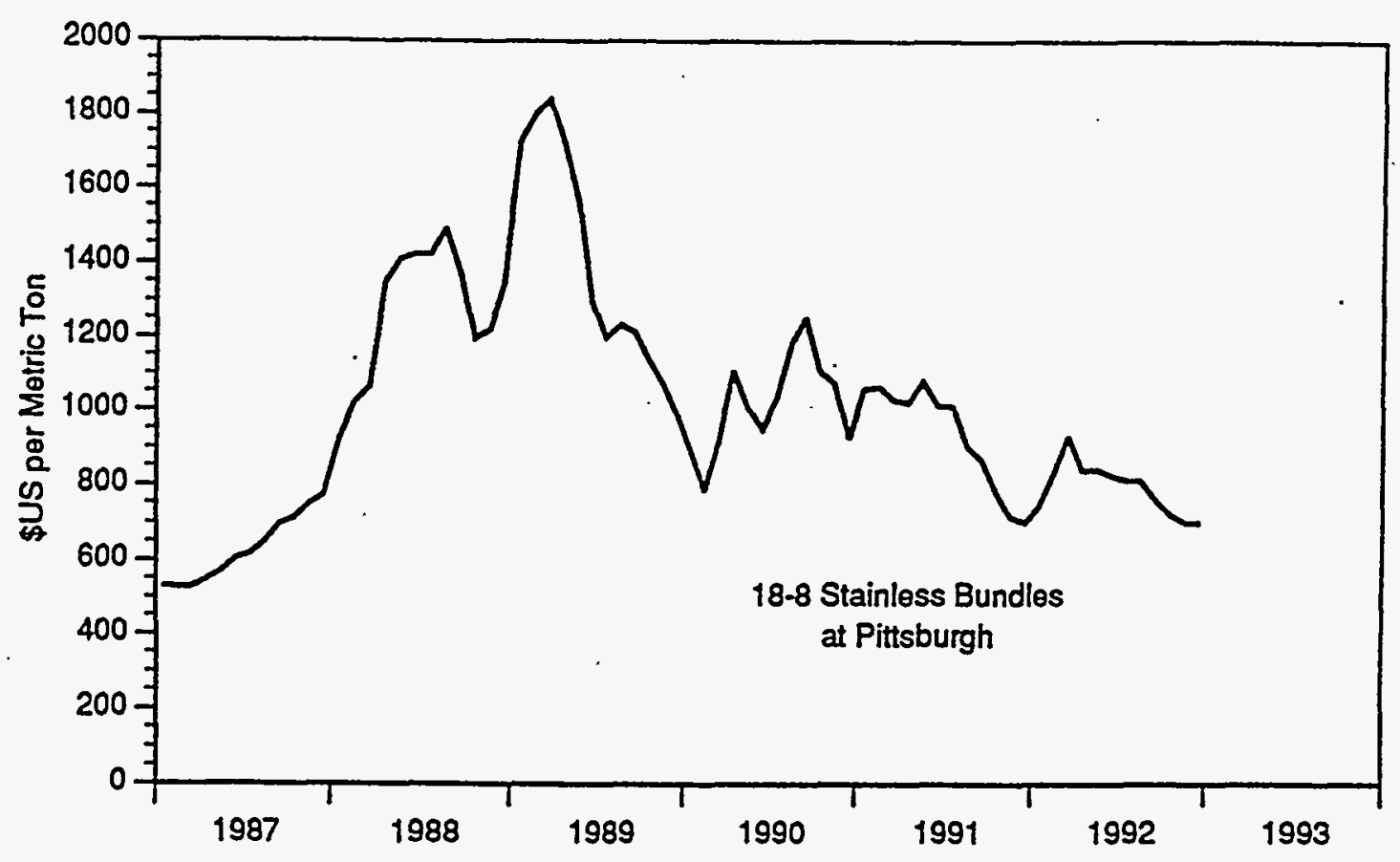

FIGURE 4.12 U.S.A. Scrap Stainless Steel Prices (Source: Based on prices from American Metal Market Co. 1993a)

\subsubsection{Aluminum}

Figure 4.13 presents the price time series for old sheet and cast aluminum scrap. Aluminum scrap prices peaked in mid-1988, almost a year earlier than ferrous scrap, at $\$ 1,497.60$ and $\$ 1,226.65$ per ton for retail and wholesale, ${ }^{6}$ respectively. Like ferrous scrap, aluminum scrap prices dropped through early 1990 before rebounding in mid-1990. Prices then fell unsteadily through mid-and late 1991, bottoming at $\$ 747.37$ per ton in June 1991 for retail old sheet and cast and $\$ 396.38$ per ton in December 1991 for wholesale old sheet and cast scrap. From mid-1988 to early 1990, scrap aluminum prices fell an average of $44 \%$ from their highs, and from April 1988 to December 1991, wholesale scrap prices fell to less than one third of the 1988 high.

\subsubsection{Copper}

Copper scrap prices displayed less volatility than prices for the metals discussed above, but the time series followed the same trends (Figure 4.14). Prices peaked in April 1989 at $\$ 2,445.58$ per ton for retail and $\$ 2,115.33$ per ton for wholesale No. 2 copper 6 Retail prices are those paid by smelters and other scrap consumers. Wholesale prices are the prices
paid by dealers who then resell the scrap to consumers. 


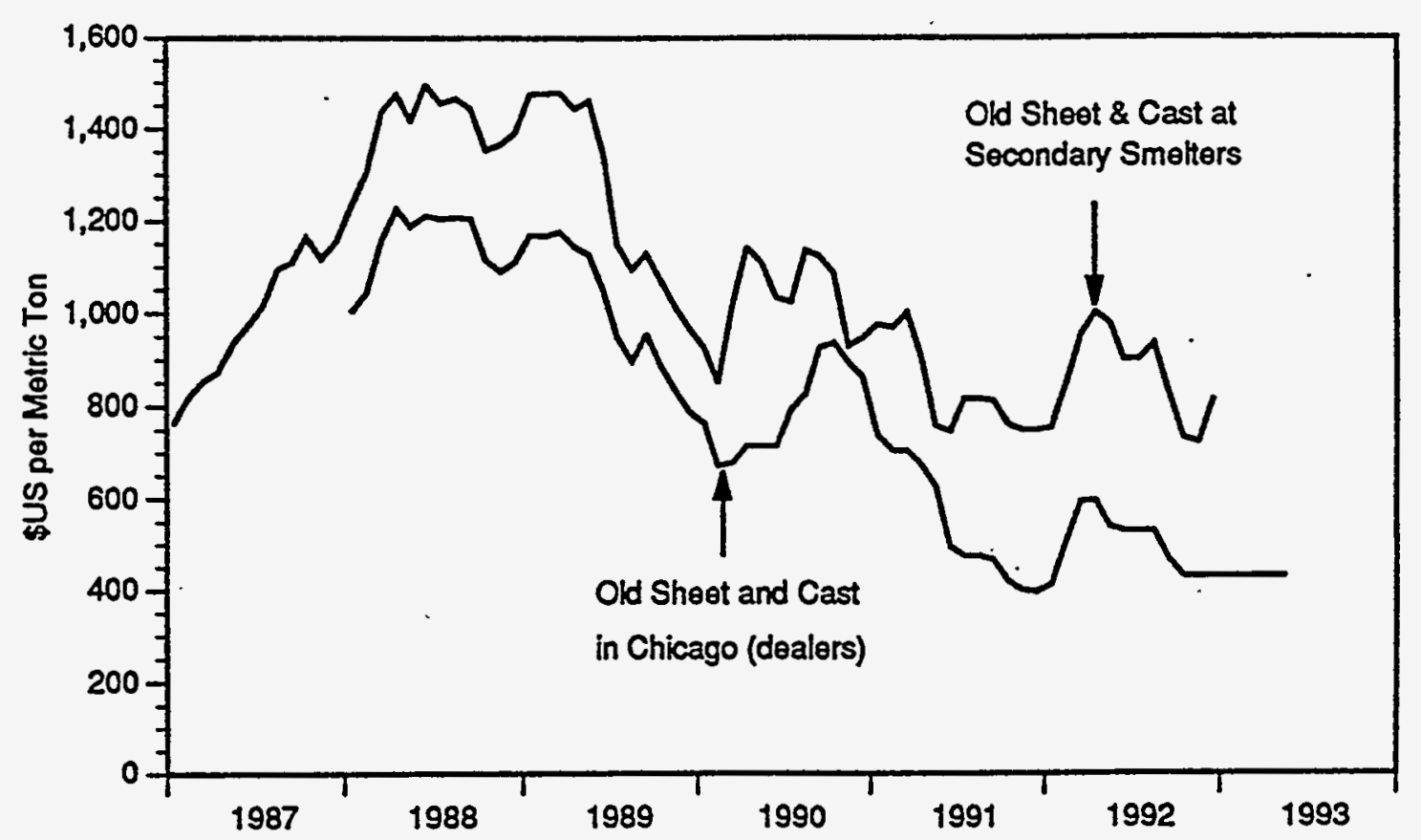

FIGURE 4.13 U.S.A. Scrap Aluminum Prices (Source: 1987-1992 prices from American Metal Market Co. 1993a, 1993 prices based on June 1993 issues of American Metal Markets [American Metal Markets Co. 1993b])

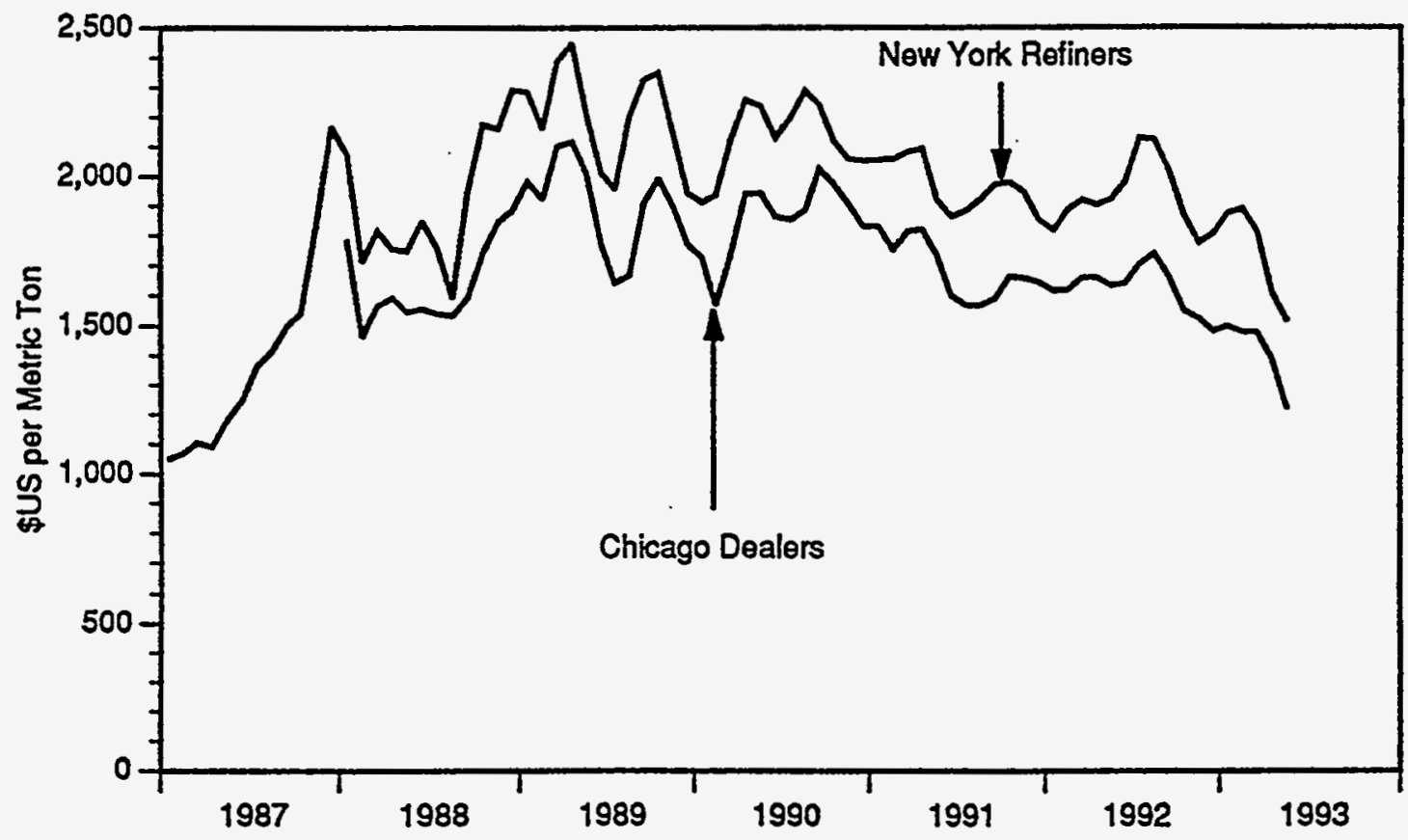

FIGURE 4.14 U.S.A. Scrap No. 2 Copper Prices (Sources: 1987-1992 prices from American Metal Market Co. 1993a; 1993 prices based on June 1993 issues of American Metal Markets [American Metal Market Co. 1993b]) 
scrap. Less than 12 months later, prices had fallen to $\$ 1,990.52$ and $\$ 1,565.25$ per ton, respectively, for an average decline of 22\%. Prices recovered through 1990 and then declined over the remainder of the period. Prices rallied somewhat in mid-1992, but did not reach 1990 prices. Since that period, however, prices have fallen almost $30 \%$.

\subsubsection{Lead}

As shown in Figure 4.15, lead prices did not follow the same pattern as other metals, but instead displayed a large degree of variability with an overall downward trend. Midwest heavy soft lead prices peaked in late 1988 at $\$ 429.90$ per ton and again in mid-1990 at $\$ 440.92$ per ton, but then fell to $\$ 242.51$ in mid-1991. The price then remained relatively constant through the end of the period.

\subsubsection{Nickel}

Nickel scrap prices are not as widely quoted as those for the other metals, but a scrap price trend may be inferred from the price history for the refined metal. Prices for refined nickel (99.9\% pure) reached a high the week of September 10, 1990, at $\$ 11,927$ per ton. Prices have since fallen, reaching a new low of $\$ 4,586$ per ton on August 18, 1993. The downward price trend has been caused by excess supply in the market. Traders cite selling by countries in the former Soviet Union as the primary source of new metal in the market. Nickel scrap trades at a discount to the refined metal price, and the discount may range from $5 \%$ to $75 \%$, with higher-grade, higher-quality scrap selling at a lesser discount. As of August 20,1993 , these discounts indicated a scrap nickel price range of $\$ 1,200$ to $\$ 4,460$ per ton (Kolb 1993).

\subsubsection{Zinc}

Prices for old zinc scrap peaked at $\$ 559.31$ per ton in early 1989 and then again at $\$ 584.22$ per ton in late 1990 and early 1991 (Figure 4.16). Prices fell more than 20\% in two months to $\$ 462.97$ in mid-1991 and have remained constant since then. The trend of steady prices is caused by the same market forces that affect the scrap lead industry. A reduction in the number of secondary zinc smelters has reduced competition within the industry, allowing scrap buyers to lock in prices on long-term contracts.

\subsection{CURRENT INDUSTRY PRACTICE FOR PROCESSING CONTAMINATED SCRAP}

Scrap yards, mills, and foundries must cope with a variety of contaminants in the metals they recycle. For example, lubricating oils and fluids and process acids may be left on the scrap. In most cases, process acids are neutralized before the processor handles the 


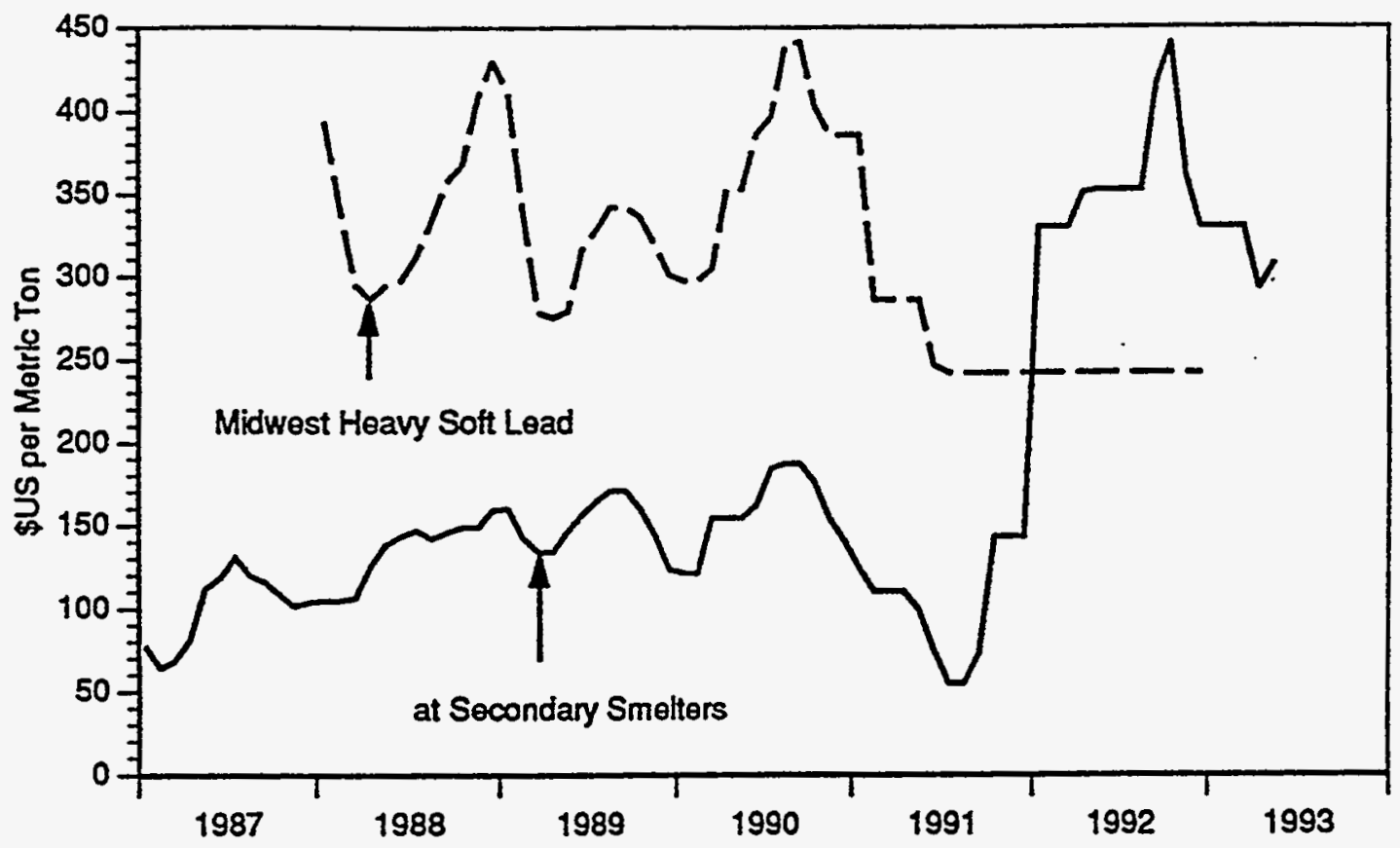

FIGURE 4.15 U.S.A. Scrap Lead Prices (Sources: 1987-1992 prices from American Metal Market Co. 1993a; 1993 prices based on June 1993 issues of American Metal Markets [American Metal Market Co. 1993b])

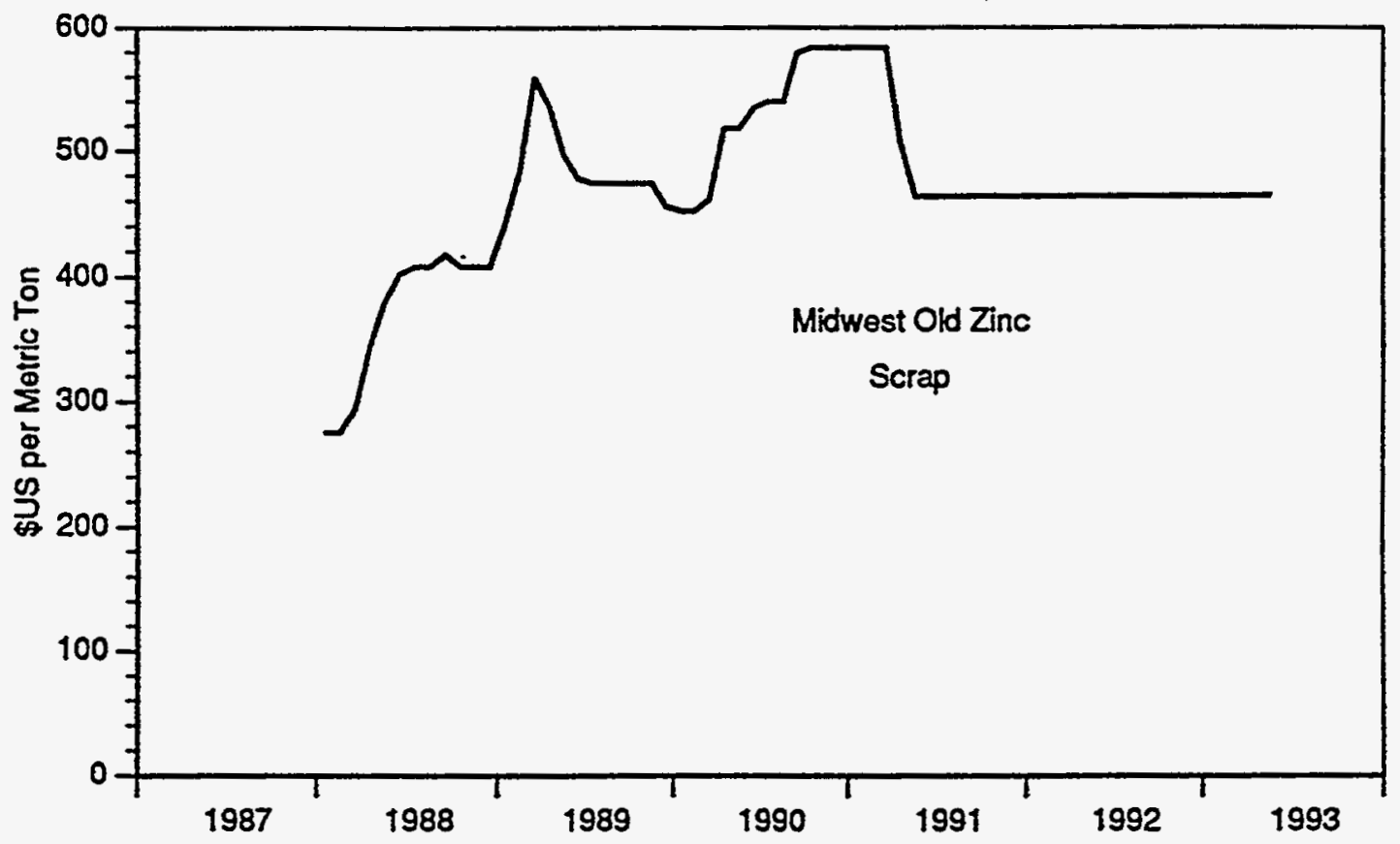

FIGURE 4.16 U.S.A. Scrap Zinc Prices (Sources: 1987-1992 prices from American Metal Market Co. 1993a; 1993 prices based on June 1993 issues of American Metal Markets [American Metal Market Co. 1993b]) 
scrap. Lubricating oils and fluids can be more of a problem to the scrap processor, because they can wash off or leach from scrap storage piles to contaminate the soil. Scrap contaminated with a significant quantity of these fluids is less desirable to scrap buyers, so it is downgraded in quality and price. When the scrap is melted, some elements in the oils may remain in the molten metal mixture, but usually only in insignificant quantities. These residues usually have minimal impact on the refined metal.

For hazardous chemicals, such as polychlorinated biphenyls (PCBs), the preferred solution is to avoid purchasing and processing contaminated scrap. This solution is accomplished by monitoring the scrap coming into the yard, by knowing the source of the scrap, and by rejecting any scrap that has even the potential to be contaminated. If the metal is obsolete scrap, the scrap processor must rely largely on the reputation of the scrap collector, because it is relatively easy to hide or mask substandard or contaminated materials in a large shipment. Competition in the industry is sufficient to quickly drive processors and dealers with poor reputations to bankruptcy. The remainder of this section discusses how the recycling industry deals with radioactivity in scrap.

\subsubsection{Sources of Radioactive Material in Scrap Metal}

Radioactive contamination of scrap metal is not a new phenomenon. The first wellpublicized incident in the U.S.A of smelting scrap containing radioactive materials occurred in 1983 at the Auburn Steel Company mill in New York (Lubenau and Yusko 1990). A major international incident occurred in 1984 in which Co-60 pellets from a medical teletherapy device were melted at a foundry in Mexico. The contaminated metal was used to make cast iron table legs and concrete reinforcing bars, some of which were then exported to the U.S.A. Other incidents have been reported around the world, but currently no comprehensive data exist for the extent of radioactive contamination in metal.

Figure 4.17 graphs the number of incidents worldwide since 1983 (tracked by Lubenau and Yusko 1995) in which radioactive materials were found in scrap or in the by-products after smelting (slag or flue dust). This information is from an informal database begun in the late 1980s. The upward trend is probably exaggerated because data is sparse for earlier years. In addition, the increase in incidents later in the period is probably caused by a greater number of detection systems installed at scrap yards and metal mills and foundries. As incomplete as the information is, however, it demonstrates that a problem with radioactive scrap metal exists. The database lists 315 incidents, 35 of which involved smelting. Figure 4.18 illustrates the relative frequency with which each type of radioactive material was found. Naturally occurring radioactive materials (including radium, uranium, and thorium) account for more than half of the incidents, and the radioactive material type is unknown in $26 \%$ of the incidents. 


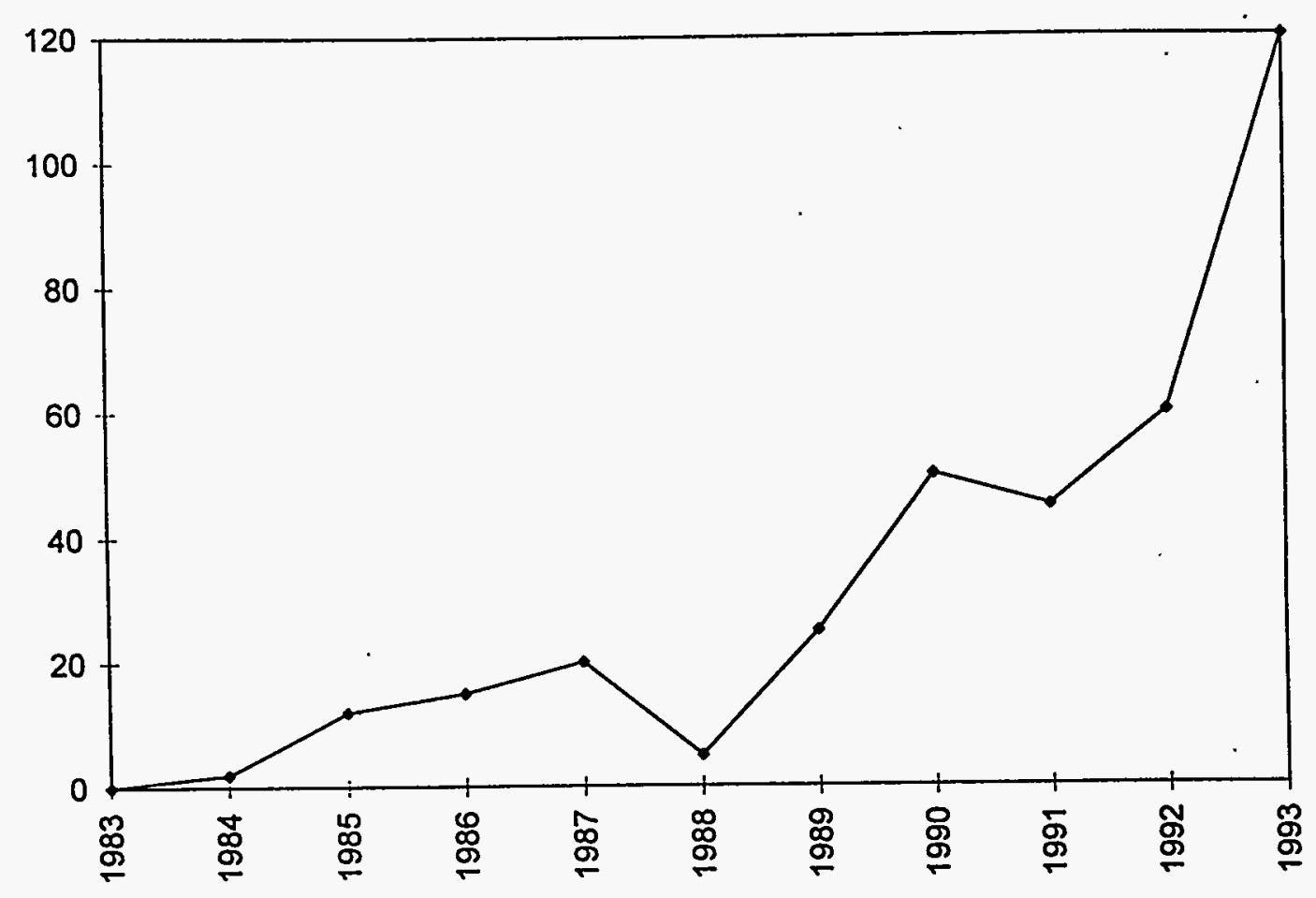

FIGURE 4.17 Number of Discoveries of Radioactive Materials in Recycled Metal Worldwide (Source: Lubenau and Yusko 1995)

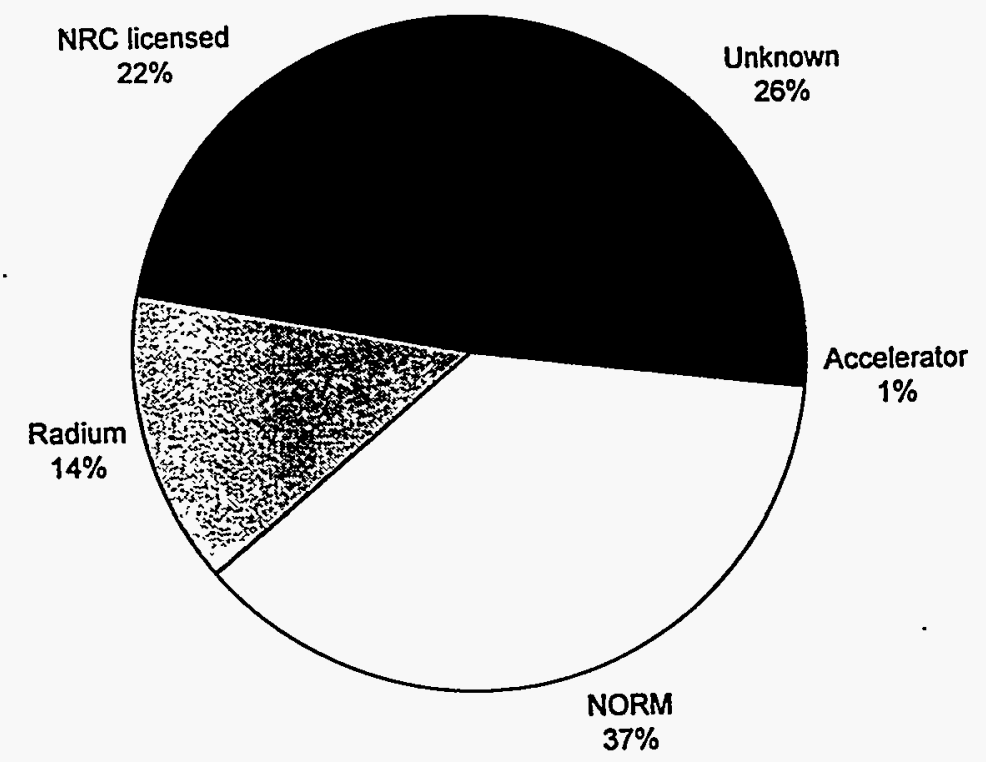

FIGURE 4.18 Relative Frequency of Radioactive Material Types Found in Recycled Metal (NORM = naturally occurring radioactive material [unspecified nuclides]) (Source: Lubenau and Yusko 1995) 
To prevent contamination of storage yards and process equipment, current industry practice is to be very vigilant and to reject any shipments that have even the slightest possibility of containing radioactive scrap. However, radioactive materials still continue to slip through.

The Institute of Scrap Recycling Industries (1993) places radioactivity in scrap in three categories: inherently radioactive scrap, scrap bearing sealed radioactive material, and scrap contaminated with radioactive material. Materials in the first category usually have been exposed to intense radiation fields, such as those found in particle accelerators or nuclear reactors. Nuclear facilities are highly regulated and staffed with knowledgeable personnel, however, so it is unlikely that radioactive materials from these sources will inadvertently contaminate the scrap metal supply. Co-60 is a radioactive material that is frequently used to indicate deterioration of refractory brick in furnaces. Sometimes sufficient quantities of this material can melt and leach into a batch of metal to contaminate it. These occurrences are rare, and when they happen, the degree of contamination is usually minor. In other instances, radioactive materials are alloyed with other metals to improve performance characteristics. For example, magnesium-thorium alloys are commonly used in aircraft engines.

Inclusion of sealed radioactive sources with scrap has occurred fairly frequently. Common sources include medical therapy or industrial radiography devices, plated sources, level gauges, and other measuring devices. Sealed sources are usually found in construction and demolition debris, especially from industrial facilities. Gamma-emitting nuclides, such as Cs-137, Co-60, and Am-241 are most common, both in sheer numbers and in quantity of radioactive material (La Mastra 1989). These sources are also reasonably easy to detect with widely available technology. Large activity sources (in excess of $3.7 \times 10^{12} \mathrm{~Bq}$ ), usually contained in medical therapy or industrial radiography devices, pose potentially severe consequences if melted. It is estimated that there are probably fewer than 20,000 such devices in use nationwide in the U.S.A. (LaMastra 1989).

Scrap contaminated with radioactive material (the last category) occurs frequently in the mineral extraction industries. As a consequence of mineral extraction processes, scale can form inside piping and equipment. This scale may contain abnormally high concentrations of naturally occurring radioactive material (NORM), usually Ra-226. The NORM content in pipe scale from oil and gas drilling can vary from undetectable to up to $1,500 \mathrm{~Bq} / \mathrm{g}$ (USEPA 1993). Other reports indicate that scale can exceed 3,700 Bq/g, a level of radioactivity that is about 100,000 times typical soil levels and that approaches levels found in uranium mines (Raloff 1991).

\subsubsection{Radiation Detection Systems}

In recent years, detection technology has improved significantly while costs have fallen, so some scrap yards have able to install fairly sophisticated radiation detection systems. The number of installed systems and the percentage of scrap metal being screened is not known, but both of these figures are probably rising. Some mills now insist as part of 
the terms of purchase contracts that their scrap feedstocks be monitored for radioactivity. This stipulation make sense in light of recent cleanup costs at facilities inadvertently contaminated. Decontamination costs have averaged around $\$ 1 \times 10^{6}$ (U.S. dollars), and at one facility the cost of decontamination reached almost $\$ 4 \times 10^{6}$.

Many types of radiation detection equipment are available, but essentially three types have been found practical for monitoring scrap metal: ionization meters, event counters, and scintillation detectors (Yusko 1991). Ionization meters measure photons and beta particles (and some energetic alpha particles). The system becomes sensitive to ambient temperature and pressure changes. Ionization meters can provide a measure of the exposure or exposure rate from the source. Event detectors are the most commonly available meters, such as Geiger-Mueller tubes. These detectors also measure photons and particles, but the photons and particles must have higher energy to penetrate the sensitive volume of the detection chamber. Event counters provide a count or a count rate, but not the actual exposure (or dose) as is provided by ionization meters. Scintillation detectors absorb energy and convert it to an electric signal. These detectors can be very sensitive, but like ionization meters, are sensitive to environmental effects. When coupled with microprocessors, these detectors can be used to determine which radionuclide is present, although this degree of sophistication is unnecessary for monitoring scrap.

Detectors can be hand held or stationary. Hand-held detectors tend to be less sensitive, but they can be placed closer to the scrap to facilitate detection. Other advantages are that hand-held detectors can be taken to all parts of the yard, and they are usually less costly than stationary monitors. Stationary detectors tend to be much more sensitive and much more expensive than hand-held units. By strategically placing detectors near gates, however, nearly all scrap and waste entering and leaving a yard can be monitored.

Several factors influence the effectiveness of detection systems. Larger sources or those with more energetic radiation are easier to detect. However, the radiation may be shielded, either intentionally (as a sealed source) or inadvertently by scrap. Higher energy radiation is more difficult to shield, but even moderately high energy radiation can be shielded by several feet of steel scrap. Thick, dense material can more effectively shield a radiation source than thin and loosely packed material. Thus, a radioactive source is more likely to be missed in a shipment of steel plate than in aluminum scrap. Furthermore, increasing the distance from the source decreases the probability that it will be detected. To be effective, detectors should be placed as close to the scrap to be monitored as is practical. The effectiveness of detection systems may be enhanced by shielding the detector. In a field test, an unshielded $2 \times 2$ inch sodium iodide crystal detector had a background reading of around 1,500 counts per minute (cpm). With the alarm point set at two times background level, a minimal scrap covering would effectively prevent detection of a shielded source (La Mastra 1989). When the detector was shielded, the background count dropped to $70 \mathrm{cpm}$, and a typical gauge could be detected under about $0.3 \mathrm{~m}$ of steel scrap.

Another way to increase detection success is to check both incoming and outgoing scrap and waste products. A source that enters the processing yard undetected may be 
exposed during processing by shifting the material and/or breaching a sealed source housing. These sources can be detected when the scrap leaves the yard. In addition, a significant number of detections at mills have occurred when monitors detected radiation in smelting wastes (slags and flue dust) as the waste was leaving the plant.

\subsubsection{Current Practice}

As noted above, an increasing number of scrap processing yards are being equipped with radiation detection systems, but it is not known how many yards have these systems or what percentage of scrap is monitored. One obstacle to adding more detection systems is the cost. The scrap business is extremely competitive, and many processors do not feel the additional cost is justified. Mills are generally seen as having greater financial resources to invest in monitors (and the consequences of contamination are more severe for mills). Some mills, however, now stipulate that their scrap feedstocks be monitored for radioactivity as a condition for taking delivery of the scrap.

The responses of processing yards and mills vary when radioactive scrap is detected. Some mills simply reject the entire shipment outright. Others shunt the suspect railcars or trucks aside to a speciall holding area and call in experts to assess the degree of radioactivity. Most sources that are identified are disposed of at low-level radioactive waste sites.

\subsection{MARKET IMPACT OF RECYCLING RADIOACTIVE SCRAP METAL}

As a consequence of dismantling nuclear facilities, large quantities of metal will become available for recycle. One concern is that the quantities of metal coming into the market will depress prices. For most of the metals reviewed in this study, however, impacts are expected to be minimal because the metal quantities are small relative to the size of the market. This section provides some measures of possible impacts and some perspective on the scrap market today.

Table 4.11 presents the projected average annual international RSM releases from nuclear power plants over the period 2010 to 2043. These estimates are added to the quantities of RSM from enrichment facilities. The resulting sum is doubled to account for RSM from weapons plants and other sources as well, producing the annual scrap flow estimates that follow. (See Section 3 for details of the basis for these estimates.) Iron and steel scrap together, at $5 \times 10^{5} \mathrm{t} / \mathrm{yr}$, dominates the other metals and will provide by far the greatest quantity of scrap. Copper is second, at $1 \times 10^{5} \mathrm{t} / \mathrm{yr}$, and stainless steel is third, at $4 \times 10^{4} \mathrm{t} / \mathrm{yr}$.

Increasing the supply of scrap by recycling RSM is expected to create downward pressure on scrap prices, assuming the quantity of scrap metal demanded remains constant. But demand rarely remains constant, and the global economy has shown increasing volatility in recent years. In addition, other market forces can overwhelm this downward price pressure, either positively or negatively, especially if the quantity of new scrap metal coming on the market is a small fraction of the existing market flows. For example, increased 
TABLE 4.11 Projected Average Annual Releases of Suspect and Surface-Contaminated - Removable Categories of Radioactive Scrap Metal from Power Plants Worldwide, 2010-2043

\begin{tabular}{|c|c|c|c|c|c|}
\hline \multirow[b]{2}{*}{ Region } & \multicolumn{5}{|c|}{ Releases ( $t$ ) } \\
\hline & Aluminum & Copper & Lead & $\begin{array}{l}\text { Iron and } \\
\text { Steel }\end{array}$ & $\begin{array}{l}\text { Stainless } \\
\text { Steel }\end{array}$ \\
\hline North America & 400 & 20,600 & 100 & 58,400 & 300 \\
\hline Europe & 400 & 23,800 & 100 & 5,900 & 700 \\
\hline Former Soviet Union & 200 & 10,000 & $-^{\mathrm{a}}$ & 53,500 & 5,200 \\
\hline Asia & 200 & 10,300 & - & 8,300 & 1,900 \\
\hline Rest of World & - & 1,200 & - & 4,100 & 400 \\
\hline Total $^{b}$ & 1,200 & 65,900 & 300 & 29,800 & 17,500 \\
\hline
\end{tabular}

demand due to an improving global economy or increased secondary refining capacity could provide much greater upward price pressure. A worsening global economic climate would probably affect scrap prices more than would a small increase in supply. Another point to consider is that even if the increase in scrap supply leads to lower scrap metal prices, this situation will likely have a beneficial effect for scrap metal consumers.

Three measures were used to assess the potential impacts of recycling RSM. The first measure was to evaluate the ratio of the average quantity of RSM available from power plant decommissioning annually to the 1989 international scrap metal imports. This measure compares the quantity of metal the region was required to import with the potential RSM supply from power plants, because, to some extent, imports will be competing with this new source of metal. If the potential RSM is a small fraction of imports, then minimal impacts can be expected. On the other hand, the measure may be misleading for producing/exporting regions. These ratios, presented in Table 4.12, were computed for aluminum, copper, lead, and iron and steel for five regions of the world. The largest proportion of RSM to imports is for copper, averaging $4 \%$ for the world, but making up over $30 \%$ of the former Soviet Union copper imports. Such a large percentage for the former Soviet Union reflects a relatively small (2.5\%) import volume compared with total domestic consumption (vs. $7.4 \%$ for North America or $24.9 \%$ for Europe). The proportions for other metals, however, amount to much less than $1 \%$ and, therefore, minimal impacts are expected from RSM supply.

One problem with the measure used above, as already explained, is that it may be skewed for exporting regions (leading to small imports and large ratios). A second measure developed was the ratio of the average quantity of RSM expected to be recycled each year to 
TABLE 4.12 Projected Average Annual Radioactive Scrap Metal Flows for the Period 2010-2043 as Percentages of 1989 International Scrap Metal Imports

\begin{tabular}{lcccc}
\hline \multicolumn{1}{c}{ Region } & $\begin{array}{c}\text { Aluminum } \\
(\%)\end{array}$ & $\begin{array}{c}\text { Copper } \\
(\%)\end{array}$ & $\begin{array}{c}\text { Lead } \\
(\%)\end{array}$ & $\begin{array}{c}\text { Iron and Steel } \\
(\%)\end{array}$ \\
\hline North America & 0.14 & 9.62 & 0.26 & 2.29 \\
Europe & 0.04 & 2.33 & 0.07 & 0.46 \\
Former Soviet Union & $\bar{a}^{\mathrm{a}}$ & 30.59 & 0.28 & 4.63 \\
Asia & 0.03 & 2.08 & 0.03 & 0.14 \\
Rest of World & 0.76 & 2.33 & 0.43 & 1.45 \\
& & & & \\
Total & 0.06 & 3.73 & 0.08 & 0.56 \\
\hline
\end{tabular}

a No imports reported for 1989.

the quantity of commodity metal consumption in 1989. Ideally, the best data to use for the denominator would be the quantity of secondary metal consumed, but this value was available only for iron and steel scrap. Ratios for the other metals include primary metal consumption in the denominator, and thus may underestimate the impacts of RSM recycling. These ratios are presented in Table 4.13 and display the same overall pattern as in Table 4.12, except that the measures are an order of magnitude smaller. Thus, the copper ratio is less than 1\%, and the other ratios are negligible. Furthermore, each region has similar measures, and none varies much from the average. From this measure, one might conclude that because the projected quantity of recycled RSM is small relative to current metal consumption, the impacts from recycling RSM are likely to be insignificant.

A third measure compares the quantity of projected RSM to be recycled to the annual volatility of scrap consumption. Annual scrap consumption data were available only for iron and steel. Figure 4.19 illustrates the scrap iron and steel consumption for the five-year

TABLE 4.13 Projected Average Annual Radioactive Scrap Metal Flows for the Period 2010-2043 as Percentages of 1989 International Commodity Metal Consumption

\begin{tabular}{|c|c|c|c|c|}
\hline Region & $\underset{(\%)}{\text { Aluminum }}$ & $\begin{array}{c}\text { Copper } \\
(\%)\end{array}$ & $\begin{array}{l}\text { Lead } \\
(\%)\end{array}$ & $\begin{array}{c}\text { Iron and Steel } \\
(\%)\end{array}$ \\
\hline North America & 0.01 & 0.78 & 0.01 & 0.08 \\
\hline Europe & 0.01 & 0.63 & 0.01 & 0.08 \\
\hline Former Soviet Union & 0.01 & 0.85 & 0.00 & 0.05 \\
\hline Asia & 0.00 & 0.25 & 0.00 & 0.03 \\
\hline Rest of World & 0.00 & 0.23 & 0.00 & 0.02 \\
\hline Total & 0.01 & 0.56 & 0.00 & 0.06 \\
\hline
\end{tabular}


period from 1985 to 1989 . A simple estimate of volatility was computed as the average absolute value of the year-to-year change in iron and steel scrap consumption over the period. The ratios computed from this quantity are shown in Table 4.14. This measure indicates that the quantity of iron and steel scrap available to be recycled each year averages a little more than $2 \%$ of the year-to-year volatility from 1985 to 1989 . Thus, this measure also suggests that the market impact of recycling iron and steel will be minimal.

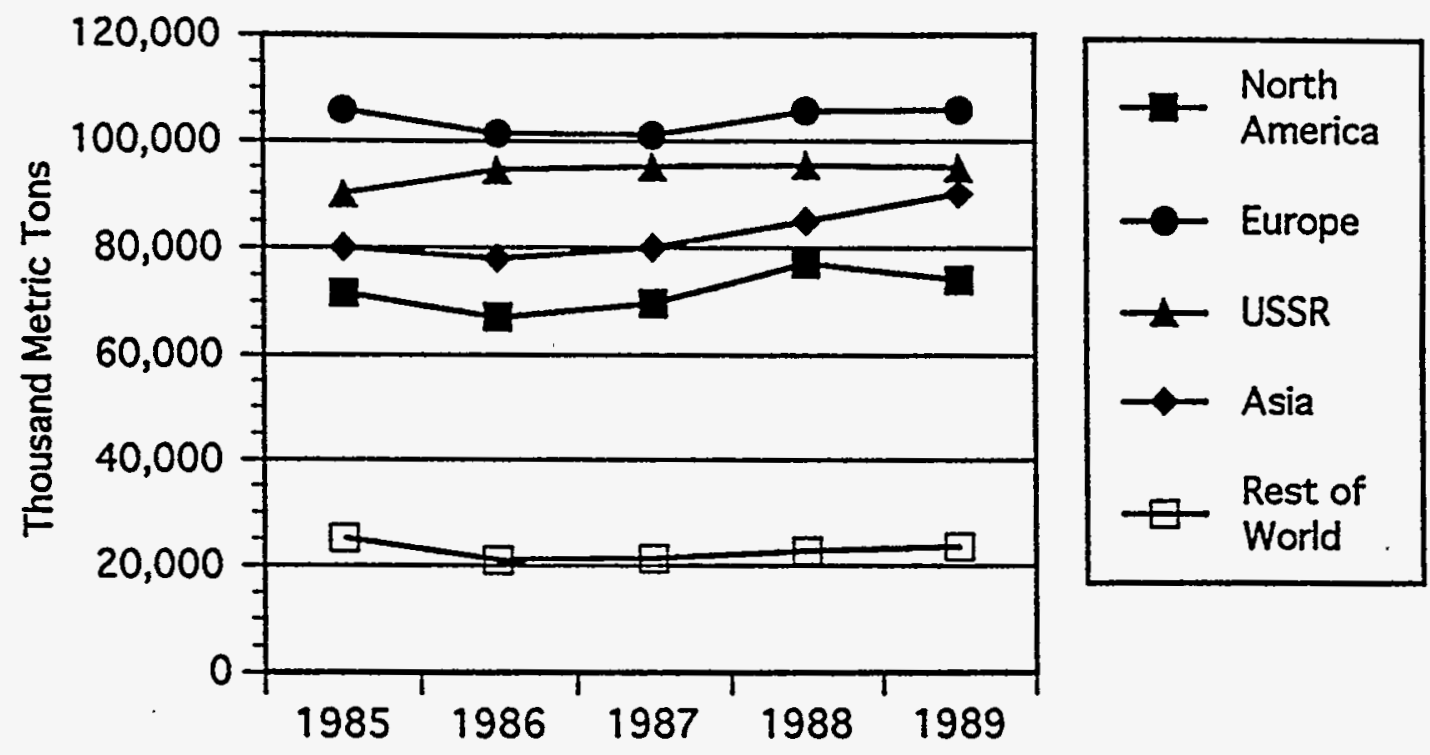

FIGURE 4.19 International Scrap Iron and Steel Consumption, 1985-1989 (Source: United Nations 1991)

TABLE 4.14 Comparison of Projected Annual Average Quantity of Radioactive Scrap Metal Iron and Steel Available, 2010-2043, with Scrap Iron and Steel Consumption Volatility, 1985-1989

\begin{tabular}{llc}
\hline \multicolumn{1}{c}{ Region } & $\begin{array}{c}\text { Volatility } \\
\left(10^{3} \mathrm{t}\right)\end{array}$ & $\begin{array}{c}\text { Ratio }^{\mathrm{b}} \\
(\%)\end{array}$ \\
\hline North America & 4,447 & 1.27 \\
Europe & 2,383 & 3.48 \\
Former Soviet Union & 1,425 & 3.48 \\
Asia & 3,500 & 0.69 \\
Rest of World & 1,651 & 0.23 \\
Total & & \\
\hline
\end{tabular}

a The average absolute value of year-to-year changes in consumption over the time period.

b Ratio of average annual quantity of RSM iron and steel available over the period 2010-2043 to 1985-1989 volatility. 
In conclusion, several measures were developed to assess the market impact of recycling the projected quantities of RSM. Copper may experience some downward price pressure. This situation would cause some difficulty for the scrap processors specializing in copper, but it should benefit downstream consumers. Other metal markets will probably not experience measurable impacts.

\subsection{REFERENCES FOR SECTION 4}

American Metal Market Co., 1993a, Metal Statistics 1993, New York, N.Y.

American Metal Market Co., 1993b, American Metal Market, New York, N.Y., June.

British Geological Survey, 1991, World Mineral Statistics 1985-1989, Keyworth, Nottingham.

Brown, R.E., 1992, Iron and Steel Scrap: Annual Report 1990, U.S. Department of the Interior, Bureau of Mines, Washington, D.C., April.

Brown, R.E., 1993, Iron and Steel Scrap: Annual Report 1991, U.S. Department of the Interior, Bureau of Mines, Washington, D.C., March.

Commission of the European Communities, 1995, Recommended Radiological Protection Criteria for the Recycling of Metals from the Dismantling of Nuclear Installations, EURO 295 (De/BS), Luxembourg.

Cotterill, C.H., 1992, "Zinc Metallurgy," in McGraw-Hill Encyclopedia of Science and Technology, 7th Ed., McGraw-Hill, New York, N.Y.

Dehmel, J.-C., et al., 1992, Scrap Metal Recycling of NORM Contaminated Petroleum Equipment, prepared by S. Cohen \& Associates, McLean, Va., T.P. McNulty and Associates, Evergreen, Colo., and Hazen Research Inc., Golden, Colo., for Petroleum Environmental Research Forum, Ponca City, Okla., Sept.

Garino, R.J., 1993, "1992 Commodity Wrap-Up," Scrap Processing and Recycling 50:3, May/June.

Institute of Scrap Iron and Steel Inc., 1984, Metallic Scrap: The Manufactured Resource, Washington, D.C.

Institute of Scrap Recycling Industries Inc., 1990, Recycling Scrap Iron and Steel, Washington, D.C.

Institute of Scrap Recycling Industries Inc., 1993, Radioactivity in the Scrap Recycling Process: Recommended Practice and Procedure, Washington D.C.

Jolly, J.H., 1985, "Zinc," in Mineral Facts and Problems, U.S. Department of the Interior, Bureau of Mines, Washington, D.C. 
Jolly, J.H., 1992a, Zinc: Annual Report 1991, U.S. Department of the Interior, Bureau of Mines, Washingtón, D.C., December.

Jolly, J.H., 1992b, "Zinc," Mineral Commodity Summaries 1992, U.S. Department of the Interior, Bureau of Mines, Washington, D.C.

Jolly, J.L.W., and D.L. Edelstein, 1992, Copper: Annual Report 1990, U.S. Department of the Interior, Bureau of Mines, Washington, D.C., April.

Jolly, J.L.W., et al., 1993, Recycling - Nonferrous Metals: 1991, U.S. Department of the Interior, Bureau of Mines, Washington, D.C., May.

Kauffmann, T., 1993, personal communication from Kauffmann (Colorado School of Mines, Golden, Colo.) to S. Wilson (Argonne National Laboratory, Argonne, Ill.), Feb. 25.

Kolb, M., 1993, personal communication from Kolb (David J. Joseph Co.) to E. Kohout (Argonne National Laboratory, Argonnè, Ill.), Aug، 20.

Kuck, P.H., 1993, Nickel: Annual Report 1991, U.S. Department of the Interior, Bureau of Mines, Washington, D.C., April.

LaMastra, A., 1989, Radioàctive Máterial in Steel Scrap: Its Occurrence, Consequences and Detection, Health Physics Associates, Inc.

Lubenau, J.O., and J.G. Yusko, 1990, "Radioactivity in Metal Scrap: Working Together to Solve a Problem," presented at the 35th Annual Meeting of the Health Physics Society, June 28.

Lubenau, J.O., and J.G. Yusko, 1995, "Radioactive Materials in Recycled Metals," Health Physics, 68(4), April.

McGannon, H.E., 1971, The Making, Shaping and Treating of Steel, 9th Ed., United States Steel, Pittsburgh, Penn.

Plunkert, P.A., and E.D. Sehnke, 1992, Aluminum, Bauxite, and Alumina: 1990 Annual Report, U.S. Department of the Interior, Bureau of Mines, Washington, D.C., March.

Raloff, J., 1991, "NORM: The New Hot Wastes," Science News 140(17), Oct. 26.

Sibley, S.F., 1985, "Nickel," in Mineral Facts and Problems, 1985, U.S. Department of the Interior, Büreau of Mines, Washington, D.C., May.

Solomon, C.C., 1992, "Iron and Steel Slag," in Mineral Commödity Summaries 1991, U.S. Department of the Interior, Bureau of Minès, Washington, D.C.

Thrush, P.W., et al.; 1968, A Dictionary of Mining, Mineral, and Related Terms, U.S. Department of the Interior, Bureau of Mines, Washington, D.C. 
Towell, J.E. (ed.), 1992, Ward's Business Directory of U.S. Private and Public Companies, Vol. 5, Gale Research Inc., Detroit, Mich.

United Nations, 1991, Iron and Steel Scrap: Its Significance and Influence on Further Developments in the Iron and Steel Industries, Economic Commission for Europe, New York, N.Y.

United Nations, 1992, 1990 International Trade Statistics Yearbook, Vol. 2, Department of Economic and Social Development, Statistical Office, New York, N.Y.

U.S. Bureau of Mines, 1985, Mineral Facts and Problems, 1985 Edition, Bulletin 675, Bureau of Mines, Washington, D.C.

U.S. Department of the Interior, 1992, Mineral Commodity Summaries 1992, Bureau of Mines, Washington, D.C.

U.S. Environmental Protection Agency, 1993, Diffuse NORM Wastes; Waste Characterization and Preliminary Risk Assessment, RAE-9232/1-2, Vol. I, Office of Radiation and Indoor Air, Washington, D.C., May.

Woodbury, W.D., 1992, Lead: 1990 Annual Report, U.S. Department of the Interior, Bureau of Mines, Washington, D.C., April.

Yusko, J.G., 1991, "Radioactivity in the Recycling Process," presentation to the Processing and Equipment Committee, Institute of Scrap Recycling Industries, Washington, D.C., Oct. 16. 
4-44 


\section{IMPACTS OF RADIOACTIVE SCRAP METAL RECYCLING}

This section presents an evaluation of potential health and environmental impacts of radioactive scrap metal (RSM) recycling. Section 5.1 provides an overview of the tiered release concept and of the major process activities involved in RSM recycling. The main types of health risks and environmental impacts that are likely to be associated with each process activity are discussed, and iron and steel are used as an example. Radiological risks to human health are assessed in Section 5.2, and nonradiological risks are assessed in Section 5.3. The discussion of radiological risks is more detailed because of the need to explore issues related to potential development of international standards for recycling. Section 5.4 discusses environmental impacts in terms of the nature and relative magnitude of effects on environmental quality and resources. The study scope did not include cost estimates for recycling.

\subsection{OVERVIEW OF THE RECYCLE PROCESS}

To date, relatively small quantities of RSM from various facilities have been recycled for public use, whereas thousands of tons have been recycled within the nuclear industry (Menon and Teunckens 1994; Hertzler et al. 1993). The magnitude of the potentially available supply and the very low level of radioactivity in a major portion of it (see discussion in Section 3) warrant consideration of a broad range of end uses for this material. To that end, a tiered system of release criteria for a wide range of product end uses is evaluated.

A tiered -release approach has the advantage of matching RSM supply with product demand while controlling public health risks and environmental impacts to meet international guidelines. Health risks are controlled by tailoring release levels to both the radiological characteristics of the scrap and its potential end uses. Figure 5.1 provides an overview of the conceptual process evaluated for RSM recycling. Four major types of material release are considered: unrestricted reuse of items in their original form, unrestricted recycle of melt-decontaminated metal into new products, prescribed initial use of metal products produced in a controlled environment, and controlled recycling within the nuclear industry. The tier definitions are summarized in Table 5.1, which also indicates the scope of the health risk assessment conducted for each tier.

Unrestricted reuse (Tier A) is evaluated for equipment or metal components or surfaces of buildings (e.g., office furniture, tools, or structural steel). The contamination may be either surface or volumetric and the metal is assumed to be surface decontaminated prior to certification for release. It is recognized that certification of volumetrically contaminated objects may present practical difficulties, however this assessment focusses on exposure risks, not limitations in activity detection capabilities. Health risks are evaluated for decontamination prior to release, transportation, public use, and disposal in a landfill. Scenarios assuming that large masses of metal released for reuse might be either recycled in a commercial smelter or disposed of in a municipal landfill were evaluated to assure that such an eventuality would not pose an unacceptable risk. In actuality, recycling or disposal of metal released for unrestricted reuse is likely to occur in circumstances that produce 
TABLE 5.1 Tier Structure, End-Use Options, and Scope of Analysis for Radioactive Scrap Metal Recycle Alternatives

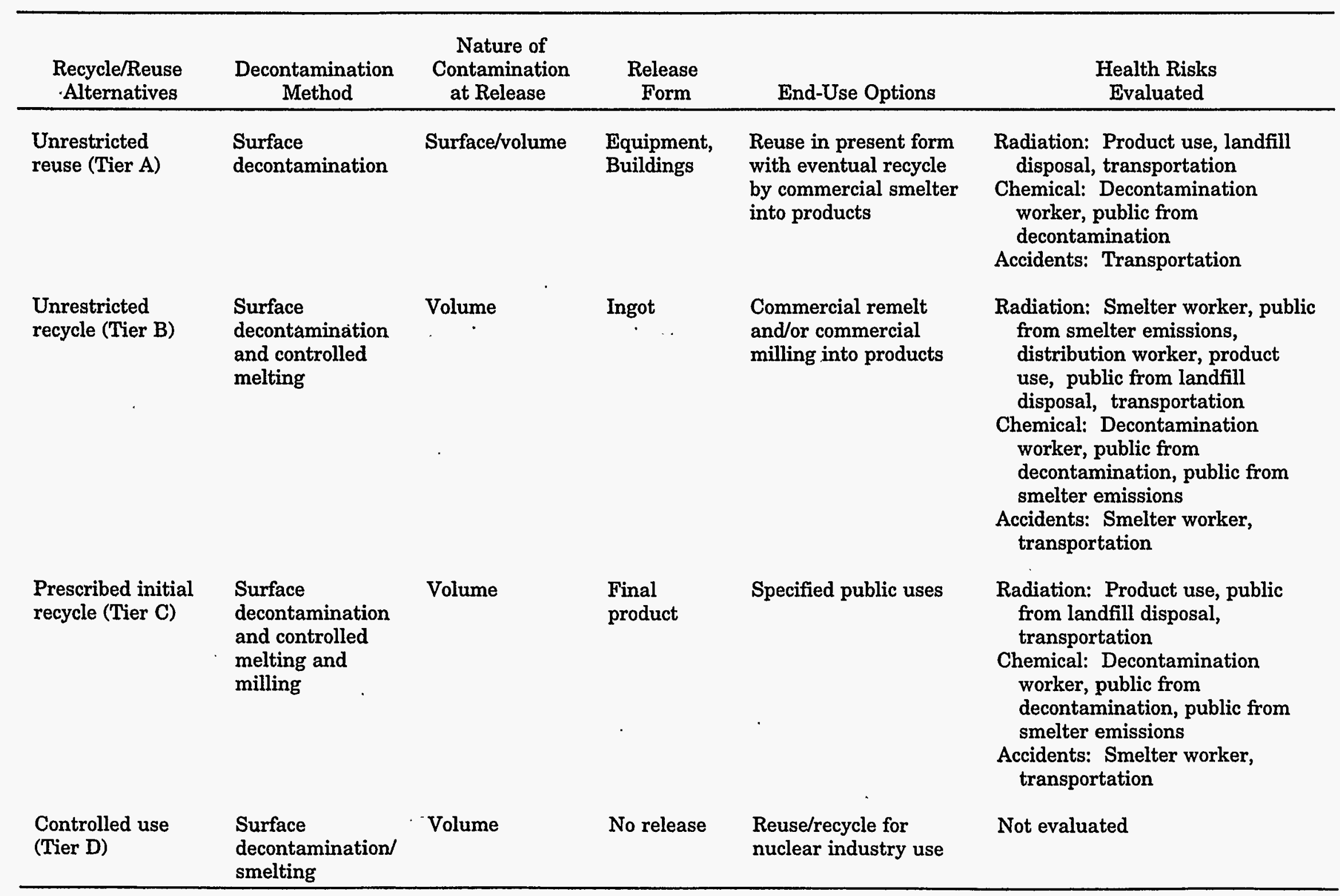




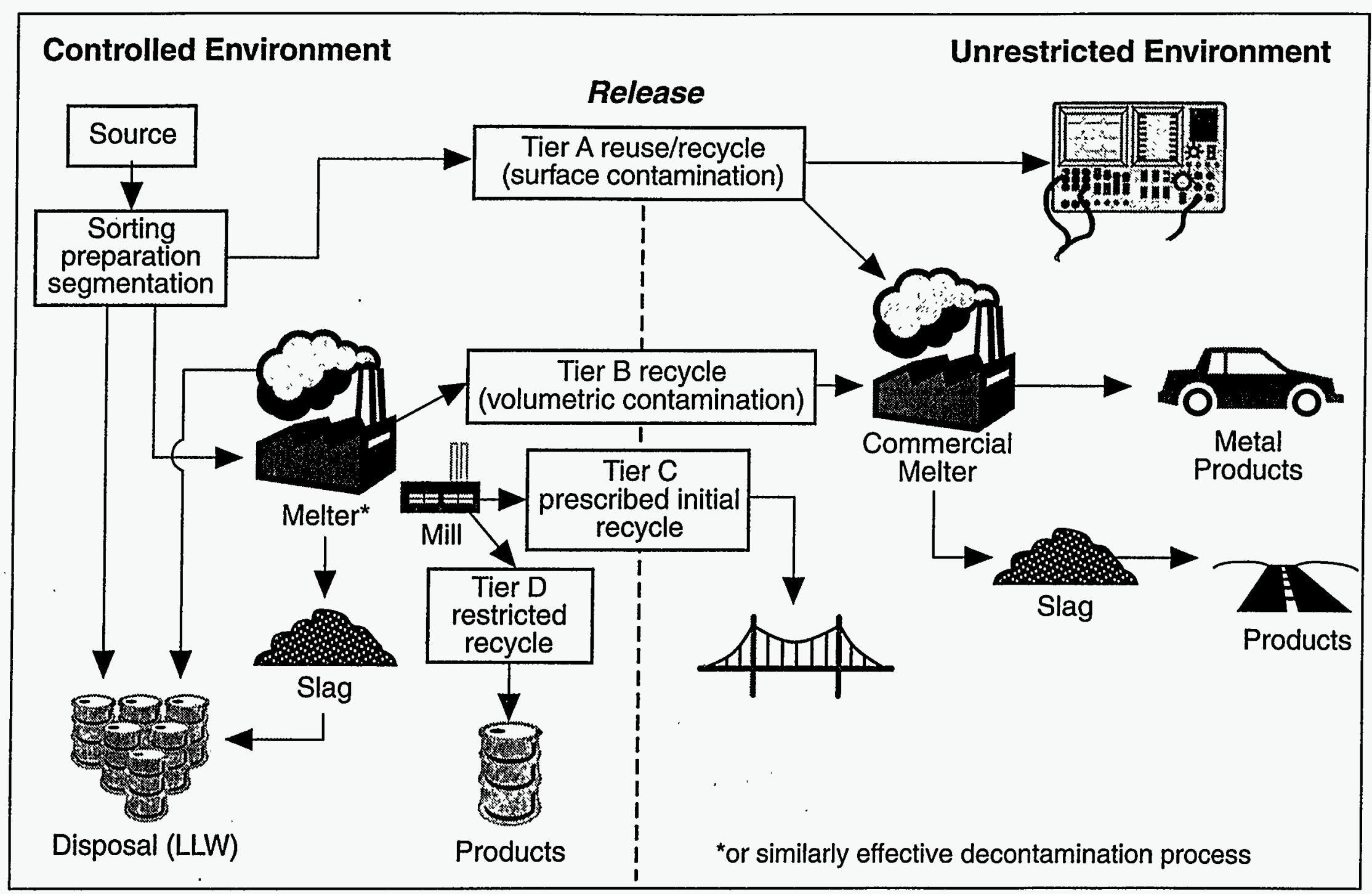

FIGURE 5.1 Process for Assessment and Release of Radioactive Scrap Metal 
extreme dilution of the activity. The unrestricted recycle process (Tier B) pertains to scrap with fixed-surface or volumetric activity that would be decontaminated and then melted in a controlled (licensed) facility. Melting in a controlled facility prior to release serves as a decontamination measure for some radionuclides and also has a very important function in facilitating measurement of the activity in the metal. Ingots would then be released for recycling. The primary expectation is that these would be remelted at a commercial smelter where they are likely to be diluted with other scrap, but the possibility that they might be milled without dilution is also evaluated. Health risks for Tier B recycling are evaluated for decontamination of the metal prior to and in the controlled melt, ingot processing in a commercial smelter, smelter emissions, product distribution, transportation, and landfill disposal. Radiation exposure scenarios are evaluated for a wide range of metal products in unrestricted uses. Slag from the commercial melting is assumed to be used in paving highways or parking lots.

Tier $\mathrm{C}$ release requires restricted distribution of finished metal products from a controlled melting and milling facility to prescribed initial uses that involve minimal public exposure. In the future, when the metal is again recycled (30 years assumed), it would be treated as common scrap. The main advantage of Tier $\mathrm{C}$ is the ability to recycle metals that are contaminated with relatively short-lived radionuclides while controlling health risks. For Tier C, external exposure is the only pathway potentially affecting health risk for the public. Omitting the commercial smelting and milling operations, the evaluation covered the same aspects as for unrestricted recycle (Tier B). Similarly to the unrestricted reuse case, any eventual recycling or disposal is likely to result in great dilution of any activity remaining in the metal.

Usable metal with activity that it is infeasible or impractical to reduce to Tier $\mathrm{C}$ levels would be recycled for use in environments with radiation controls (Tier D). The controlled use alternative is not discussed in this report. Related issues are addressed in programs such as the U.S. Department of Energy's Recycle 2000 initiative (Warren 1995). If even controlled recycling were judged technically or economically infeasible, scrap is assumed to be disposed of as low-level waste (LLW).

\subsection{RADIOLOGICAL HEALTH EFFECTS}

For the RSM recycling, radiological health risks were estimated for product end-use scenarios, as well as for emissions from commercial smelting of RSM, for product transportation, and for unrestricted landfill disposal of discarded RSM products. Detailed assessments of potential health risks were conducted for commercial metal workers and the general public. Radiological risks to health from activities of radiation workers prior to RSM release - such as metal sorting, decontamination, and packaging - were not evaluated in detail because these activities would take place in an environment where exposures would occur under regulatory limits. Such exposures might be required for either recycling or disposal of RSM. Disposal of RSM residuals at a LLW site would also be carried out by 
radiation workers, and exposures would be controlled by existing regulatory requirements. The risk estimates for disposal of RSM as LLW are based on regulatory limits and previous studies.

\subsubsection{Assessment Methodology}

Potential radiological impacts from the RSM alternatives were assessed in terms of the total effective dose equivalent (10 CFR 20 [USNRC 1990]), which is the sum of the effective dose equivalent from external exposures and the committed effective dose equivalent from internal exposures. Health impacts, expressed in terms of cancer fatalities, were obtained by multiplying the total effective dose equivalent by the health effects conversion factor of $5 \times 10^{-2}$ fatal cancers per sievert (Sv) (International Commission on Radiological Protection [ICRP] 1991). Total cancer incidence is two to three times the cancer fatality rate.

Radiological risks from metal recycle/reuse have been analyzed by various U.S. and international organizations (O'Donnell et al. 1978; U.S. Nuclear Regulatory Commission [USNRC] 1980; Commission of the European Communities [CEC] 1988, 1995; International Atomic Energy Agency [IAEA] 1992; S. Cohen \& Associates, Inc. 1995). This independent analysis was conducted to:

- Develop and evaluate an expanded set of scenarios - including smelting emissions, landfill disposal, and transportation — that is appropriate for the tiered release concept proposed in this study,

- Expand the nuclide categories considered to include volatile elements and radon parents (which may have been previously regulated, e.g., radium),

- Incorporate recently developed methodology and available information, and

- Emphasize a realistic approach to development of release standards.

The objective of this study is to (1) calculate baseline doses for the recycling alternatives and options by using conservative parameters; (2) perform a sensitivity analysis for key parameters to determine uncertainty levels and the degree to which they have been handled conservatively; and (3) advance the concepts of previous studies by identifying potentially appropriate release limit ranges on the basis of additional information regarding important parameters and using dose criteria that, in themselves, are protective of human health. Findings of the sensitivity analysis are discussed in Appendix C.

\subsubsection{Technical Approach}

Radiological impacts have been analyzed with the RESRAD-BUILD methodology developed at Argonne National Laboratory (Yu et al. 1994; methodology described in 
Appendix C). The framework of exposure scenarios and assumptions was taken from the IAEA Safety Series No. 111 (IAEA 1992). The IAEA methodology is similar to the USNRC approach documented in NUREG/CR-5512 (USNRC 1992) but with more detailed analytical features. This approach is designed to serve as a "screening model," whereas the RESRADBUILD assesses exposures in more detailed environmental settings. Inclusion of features such as room size and ventilation rate allow RESRAD-BUILD to investigate effects of parameters that are unavailable in previous studies, such as impacts from radon gases and the progeny radionuclides.

Three pathways were analyzed: inhalation of particulates and radon progeny, ingestion, and external gamma irradiation. Exposure estimates for the inhalation and ingestion pathways were calculated with the default parameters suggested by NUREG/CR-5512 and IAEA Safety Series No. 111. The internal dose conversion factors are based on ICRP Publication 30 (ICRP 1979), and the external dose conversion factors are derived from U.S. Environmental Protection Agency (USEPA) Federal Guidance Report No. 12 (USEPA 1993c). Impacts to the public from any radioactive emissions during the commercial melting process were also assessed. This analysis employed the CAP-88 code (USEPA 1992), assuming a generic urban environmental setting. For unrestricted disposal, health risks of RSM at a public landfill were assessed with the RESRAD code (Yu et al. 1993a).

Radionuclides can be categorized on the basis of several different considerations, such as the type and energy of radiation emitted (i.e., alpha, beta, or gamma) or the significant pathway (e.g., inhalation, ingestion, or external exposure). In general, doses are dominated by the inhalation pathway for alpha emitters, the ingestion pathway for beta emitters, and the external exposure pathway for gamma emitters. Gamma emitters are typically products of neutron activation associated with nuclear power plant operation; beta emitters are mostly fission products typically associated with spent nuclear fuel reprocessing; and alpha emitters are generally associated with nuclear fuel processing and enrichment operations. In addition, other nuclides - such as radon parent nuclides, tritium, and volatile elements (e.g., iodine) - exhibit environmental behavior that presents special problems regarding health impacts to humans, and these nuclides are included in this analysis of metal recycling risks.

On the basis of these considerations, five preliminary categories of nuclides were identified as providing an effective basis for defining release levels. These categories include alpha emitters, beta emitters, gamma emitters, volatile nuclides, and radon parents. Nuclides with constraining doses were selected for presentation from a broad preliminary assessment. These nuclides include Ac-227, Am-241, Pu-239, and U-238 for alpha emitters; Sr-90 and Tc-99 for beta emitters; Co-60, Cs-137, and Zn-65 for gamma emitters; H-3 and I-129 for volatile nuclides; and Ra-224, Ra-226, Th-230, and Th-232 for radon parents. The latter two categories of nuclides were analyzed only for reuse of surface contaminated objects under the product end use and unrestricted disposal scenarios. Exposure pathways for commercial smelter workers or public end-use scenarios have not been identified for either volatile nuclides or radon under the RSM recycle options because volatile nuclides would be 
removed in the controlled melt and because the radon parents are incorporated in slag or metal where the radon is immobilized.

\subsubsection{Derivation of Release Levels}

In view of the international perspective of this analysis, a dose criteria of $10 \mu \mathrm{Sv} / \mathrm{yr}$ per practice to an average member of the "critical group," as recommended by the IAEA (1988), was used for illustrative purposes. The "critical group" is defined as a group of individuals who are "representative of individuals receiving the highest levels of dose from a particular practice, and is defined so that it is reasonably homogeneous with respect to factors that affect the dose received" (IAEA 1988). Collective dose commitments to the general public over the useful life of the metal products are compared to the IAEArecommended level of 1 person-Sv/yr of a practice. Although the term "practice" has not been clearly defined, one suggested interpretation is the site producing materials for recycle or reuse (IAEA 1992). For this analysis, a "practice" is interpreted as a single commercial smelter/mill that accepts $50,000 \mathrm{t} / \mathrm{yr}$ of RSM ingots and produces consumer products. Details of the derivation of release levels in accordance with these principles are described in Appendix C.

\subsubsection{Dose Estimates}

Dose estimates were calculated for each of the major population groups and exposure situations that were identified. Doses are presented for commercial smelter workers, the public exposed to items released for reuse or products made with recycled RSM, the public exposed to smelter emissions, workers and the public exposed during RSM transportation, and the public exposed through RSM disposal in a municipal landfill or smelting residuals disposed in a LLW repository.

Individual dose estimates were calculated for each recycling tier and associated scenarios. Two basic parameters that play a key role in all RSM recycle (Tier B and C) scenarios for both worker and public doses are the RSM dilution rate and radionuclide partitioning factors (see Appendix $\mathrm{C}$ for a detailed discussion). In some previous studies, the baseline dose estimates have not specifically accounted for dilution of the RSM with uncontaminated metal or partitioning of the activity among ingots, slag and offgas/dust as a result of the melt process (e.g., O'Donnell et al. 1978; CEC 1988; IAEA 1992). Incorporating realistic values for these parameters substantially reduces conservatism in dose estimates. A parameter sensitivity analysis and definition of analytical cases is presented in Appendix C. The modified-conservative case, which is shown in the following tables, incorporates the two most sensitive parameters. The RSM dilution factor is assumed to be 1:10, and nuclide partitioning factors from the literature are applied. The sensitivity of individual dose estimates to various parameters is discussed in Appendix C.

Population dose is estimated by summing all committed doses over the duration of product life for exposed population groups, based on the distribution of metal in end products. 
Because the population dose accounts for the total exposure resulting from a year of RSM recycling operations, it is highly dependent on the annual throughput. The relation of throughput to unrestricted reuse applications is highly uncertain, so population dose was not calculated for Tier A. Population doses based on an RSM throughput of 50,000 t/yr have been estimated for both Tiers $\mathrm{B}$ and $\mathrm{C}$, with appropriate nuclide partitioning factors applied. The dilution factor was not considered because the total amount of activity available for population exposure is unaffected by dilution (i.e., dilution does not alter the amount of activity released). For workers, committed doses from all work steps associated with an unrestricted recycle practice are summed; for the general public, committed doses from all RSM end uses under either unrestricted recycle or prescribed initial use are considered separately.

\subsubsection{Doses to Industrial Workers from Recycling}

In each of the unrestricted recycle activities, commercial metal workers would receive exposures from the RSM. Worker scenarios for each step in the recycle process, which are presented in detail in Appendix C, are adapted from Safety Series No. 111 (IAEA 1992). Pathways for workers include inhalation, ingestion, and external exposures from metal preparation, smelting, and processing activities. Annual baseline doses for workers were estimated on the basis of 2,000 hours of exposure and were scaled for throughput levels of 10,000 and 50,000 $t$ of RSM. Doses from metal processing under the unrestricted reuse and prescribed-first-use scenarios and for controlled recycle are limited to nuclear facility workers. For these potential end uses of RSM, plant practices and controls on radiological exposure would limit doses to levels consistent with regulatory requirements, so dose estimates were not developed.

Table 5.2 lists constraining individual worker doses and derived activity levels for release of ingots to a commercial smelter and to a commercial mill. The derived activity levels, which are discussed further in Section 5.2.3, are for the metal at the point of release from the originating facility, decontamination facility, or controlled melter/mill. The ranges of levels for representative nuclides show the effect of throughput assumptions of 10,000 and $50,000 \mathrm{t}$ annually and potential effects of protective measures, such as respiratory protection or remote handling, for workers. For release to a smelter the constraining doses are for the slag worker and small object caster scenarios. The sheet and coil worker scenarios are constraining for release to a mill, which only involves rolling and fabrication of the metal.

Worker population doses for unrestricted recycle are presented in Table 5.3. In the dose calculations, the number of full-time workers was scaled for a 50,000 t/yr throughput. Dose estimates for remelting the ingots are dominated by doses to slag workers and small object casters, which constitute about $70 \%$ of the dose for alpha emitters. For gamma emitters, external doses to coil workers and warehouse workers are significant (more than $50 \%$ of total dose). The analysis of population dose for remelting of ingots bounds the case for of direct milling and fabrication of the metal without dilution. In the direct milling case, inhalation dose would be almost entirely avoided and exposure of workers in melt and slag operations would be avoided. 
TABLE 5.2 Summary of Constraining Individual Worker Doses and Derived Activity Levels for Unrestricted Recycle Worker Scenarios with 10,000 and 50,000 t Throughput

\begin{tabular}{|c|c|c|c|c|}
\hline \multirow[b]{2}{*}{$\begin{array}{c}\text { Representative } \\
\text { Nuclide }\end{array}$} & \multirow{2}{*}{$\begin{array}{l}\text { Constraining } \\
\text { Scenario } \\
\text { Individual } \\
\text { Dose }^{\mathrm{a}} \\
(\mu \mathrm{Sv} / \mathrm{yr}) \\
\end{array}$} & \multicolumn{3}{|c|}{ Derived Activity Level (Bq/g) } \\
\hline & & $10,000 t^{b}$ & $50,000 t^{c}$ & $\begin{array}{c}50,000 \mathrm{t} \text { with } \\
\text { Protection }^{\mathrm{d}}\end{array}$ \\
\hline \multicolumn{5}{|c|}{ Unrestricted release of ingots to commercial melting (Tier $B)^{e}$} \\
\hline Ac-227 & $4.9 \times 10^{1}$ & $1.0 \times 10^{0}$ & $2.1 \times 10^{-1}$ & $2.1 \times 10^{1}$ \\
\hline Am-241 & $2.1 \times 10^{0}$ & $2.4 \times 10^{1}$ & $4.7 \times 10^{0}$ & $4.7 \times 10^{2}$ \\
\hline $\mathrm{Pu}-239$ & $1.5 \times 10^{0}$ & $3.4 \times 10^{1}$ & $6.9 \times 10^{0}$ & $6.9 \times 10^{2}$ \\
\hline $\mathrm{U}-238$ & $2.2 \times 10^{0}$ & $2.3 \times 10^{1}$ & $4.5 \times 10^{0}$ & $4.5 \times 10^{2}$ \\
\hline Sr-90 & $4.4 \times 10^{-1}$ & $1.1 \times 10^{2}$ & $2.3 \times 10^{1}$ & $2.3 \times 10^{3}$ \\
\hline Tc-99 & $1.1 \times 10^{-2}$ & $4.8 \times 10^{3}$ & $9.5 \times 10^{2}$ & $9.5 \times 10^{4}$ \\
\hline $\mathrm{Co}-60$ & $1.5 \times 10^{1}$ & $3.4 \times 10^{0}$ & $6.9 \times 10^{-1}$ & f \\
\hline Cs-137 & $4.5 \times 10^{1}$ & $1.1 \times 10^{0}$ & $2.2 \times 10^{-1}$ & $-f$ \\
\hline $\mathrm{Zn}-65$ & $3.4 \times 10^{-1}$ & $1.5 \times 10^{2}$ & $2.9 \times 10^{1}$ & f \\
\hline \multicolumn{5}{|c|}{ Unrestricted release of ingots to commercial milling (Tier $B)^{g}$} \\
\hline Ac-227 & $8.1 \times 10^{0}$ & $6.2 \times 10^{0}$ & $1.2 \times 10^{0}$ & $-f$ \\
\hline Am-241 & $5.3 \times 10^{-1}$ & $9.4 \times 10^{1}$ & $1.9 \times 10^{1}$ & f \\
\hline $\mathrm{Pu}-239$ & $1.3 \times 10^{-3}$ & $3.8 \times 10^{4}$ & $7.5 \times 10^{3}$ & $-f$ \\
\hline U-238 & $5.5 \times 10^{-1}$ & $9.1 \times 10^{1}$ & $1.8 \times 10^{1}$ & $-f$ \\
\hline Sr-90 & $9.4 \times 10^{-2}$ & $5.3 \times 10^{2}$ & $1.1 \times 10^{2}$ & $-f$ \\
\hline Tc-99 & $7.0 \times 10^{-4}$ & $7.2 \times 10^{4}$ & $1.4 \times 10^{4}$ & $-f$ \\
\hline Co-60 & $6.0 \times 10^{1}$ & $8.4 \times 10^{-1}$ & $1.7 \times 10^{-1}$ & f \\
\hline Cs-137 & $1.3 \times 10^{1}$ & $3.8 \times 10^{0}$ & $2.2 \times 10^{-1}$ & $-f$ \\
\hline $\mathrm{Zn}-65$ & $9.0 \times 10^{0}$ & $5.5 \times 10^{0}$ & $1.1 \times 10^{0}$ & $-f$ \\
\hline
\end{tabular}

${ }^{2}$ Doses are based on an RSM activity concentration of $1 \mathrm{~Bq} / \mathrm{g}$ at the point of release. For the commercial melting case, a dilution rate of 1:10 and nuclide partitioning factors are applied.

b Activity that results in an annual dose of less than $10 \mu \mathrm{Sv}$ with 10,000 t RSM throughput annually.

c Activity that results in an annual dose of less than $10 \mu \mathrm{Sv}$ with 50,000 t RSM throughput annually.

d Respiratory protection factor of 0.01 applied to dose.

e All values are based on the slag worker scenario, except those for Co-60, which are for the small object caster scenario.

f Using remote control, all pathways could be controlled to the prescribed level.

g Values are based on the coil and sheet worker scenarios. 
TABLE 5.3 Worker Population Doses for Unrestricted Recycle Based on Annual Smelter Throughputs of $10,000 \mathrm{t}$ and $50,000 \mathrm{t}$ of Radioactive Scrap Metal

\begin{tabular}{|c|c|c|}
\hline \multirow[b]{2}{*}{$\begin{array}{l}\text { Representative } \\
\text { Nuclide }\end{array}$} & \multicolumn{2}{|c|}{$\begin{array}{l}\text { Population Dose } \\
\text { (person-Sv/yr) }^{\mathrm{a}}\end{array}$} \\
\hline & $\begin{array}{c}10,000 t \\
\text { Radioactive } \\
\text { Scrap Metal }\end{array}$ & $\begin{array}{c}50,000 \mathrm{t} \\
\text { Radioactive } \\
\text { Scrap Metal }\end{array}$ \\
\hline Ac-227 & $1.2 \times 10^{-3}$ & $6.1 \times 10^{-3}$ \\
\hline Am-241 & $6.1 \times 10^{-5}$ & $3.1 \times 10^{-4}$ \\
\hline $\mathrm{Pu}-239$ & $5.6 \times 10^{-5}$ & $2.8 \times 10^{-4}$ \\
\hline $\mathrm{U}-238$ & $4.3 \times 10^{-5}$ & $2.1 \times 10^{-4}$ \\
\hline Sr-90 & $1.1 \times 10^{-5}$ & $5.4 \times 10^{-5}$ \\
\hline Tc-99 & $4.4 \times 10^{-7}$ & $2.2 \times 10^{-6}$ \\
\hline Co-60 & $5.1 \times 10^{-3}$ & $2.5 \times 10^{-2}$ \\
\hline Cs-137 & $6.9 \times 10^{-4}$ & $3.5 \times 10^{-3}$ \\
\hline $\mathrm{Zn}-65$ & $7.1 \times 10^{-5}$ & $3.5 \times 10^{-4}$ \\
\hline
\end{tabular}

a Doses are based on a RSM activity concentration of $1 \mathrm{~Bq} / \mathrm{g}$ and nuclide partitioning factors. The throughput is assumed to be undiluted.

\subsubsection{Doses to the Public from Reuse/Recycling}

Public Reuse - Tier A. Two scenarios were analyzed for unrestricted release of surfacecontaminated objects for reuse. A standard, conservative building occupancy scenario (USNRC 1992) was analyzed for reuse of a building or as a bounding case for large equipment. Uniform contamination of the four walls of a $5 \times 5 \times 3 \mathrm{~m}$ room was assumed. A less conservative scenario was also developed for surface contamination of an area of $1 \mathrm{~m}^{2}$, which was assumed to generically characterize small tools or equipment. (See Appendix C for scenario detail.) Doses from surface contamination could occur through inhalation (including radon and its progeny), ingestion and external pathways.

The modified-conservative case results shown in Table 5.4 assumed that the surface has been decontaminated to the extent that only $1 \%$ of the activity present can become airborne. Parent nuclides with decay chains that emit radon and its decay progeny are included in the evaluation. Nuclides having significant radon doses include Ra-224, Ra-226, Th-230 and Th-232. 
TABLE 5.4 Constraining Individual Public Doses and Derived Activity Levels under Scenarios for Reusing Radioactive Scrap Metal Objects

\begin{tabular}{|c|c|c|c|c|c|c|c|}
\hline \multirow[b]{3}{*}{$\begin{array}{l}\text { Nuclide } \\
\text { Category }\end{array}$} & \multirow[b]{3}{*}{$\begin{array}{c}\text { Representative } \\
\text { Nuclide }\end{array}$} & \multicolumn{4}{|c|}{ Surface-Contaminated Objects } & \multirow{2}{*}{\multicolumn{2}{|c|}{$\begin{array}{c}\begin{array}{c}\text { Volumetrically } \\
\text { Contaminated Objects }\end{array} \\
\text { Tools and Equipment }\end{array}$}} \\
\hline & & \multicolumn{2}{|c|}{ Tools and Equipment ${ }^{a}$} & \multicolumn{2}{|c|}{ Building Occupancy } & & \\
\hline & & $\begin{array}{c}\text { Individual } \\
\text { Dose } \\
(\mu \mathrm{Sv} / \mathrm{yr})\end{array}$ & $\begin{array}{c}\text { Derived } \\
\text { Activity } \\
\text { Level }^{\mathrm{d}} \\
\left(\mathrm{Bq} / \mathrm{cm}^{2}\right)\end{array}$ & $\begin{array}{c}\text { Individual } \\
\text { Dose }^{c} \\
(\mu \mathrm{Sv} / \mathrm{yr})\end{array}$ & $\begin{array}{l}\text { Derived } \\
\text { Activity } \\
\text { Level }^{\mathrm{d}} \\
\left(\mathrm{Bq} / \mathrm{cm}^{2}\right)\end{array}$ & $\begin{array}{c}\text { Individual } \\
\text { Dose }^{\mathrm{e}} \\
(\mu \mathrm{Sv} / \mathrm{yr})\end{array}$ & $\begin{array}{c}\text { Derived } \\
\text { Activity } \\
\text { Level }^{\mathrm{d}} \\
\left(\mathrm{Bq} / \mathrm{cm}^{2}\right)\end{array}$ \\
\hline Alpha & $\begin{array}{c}\text { Ac-227 } \\
\text { Am-241 } \\
\text { Pu-239 } \\
\text { U-238 }\end{array}$ & $\begin{array}{l}8.5 \times 10^{0} \\
9.1 \times 10^{-1} \\
6.9 \times 10^{-1} \\
2.7 \times 10^{-1}\end{array}$ & $\begin{array}{l}1.2 \times 10^{0} \\
1.1 \times 10^{1} \\
1.5 \times 10^{1} \\
3.7 \times 10^{1}\end{array}$ & $\begin{array}{l}4.0 \times 10^{2} \\
4.2 \times 10^{1} \\
4.0 \times 10^{1} \\
7.7 \times 10^{0}\end{array}$ & $\begin{array}{l}2.5 \times 10^{-2} \\
2.4 \times 10^{-1} \\
2.5 \times 10^{-1} \\
1.3 \times 10^{0}\end{array}$ & $\begin{array}{l}9.1 \times 10^{0} \\
2.2 \times 10^{-1} \\
1.5 \times 10^{-3} \\
6.2 \times 10^{-1}\end{array}$ & $\begin{array}{l}1.1 \times 10^{0} \\
4.6 \times 10^{1} \\
6.9 \times 10^{3} \\
1.6 \times 10^{1}\end{array}$ \\
\hline Beta & $\begin{array}{l}\text { Sr-90 } \\
\text { Tc-99 }\end{array}$ & $\begin{array}{l}3.7 \times 10^{-2} \\
5.9 \times 10^{-4}\end{array}$ & $\begin{array}{l}2.7 \times 10^{2} \\
1.7 \times 10^{4}\end{array}$ & $\begin{array}{l}9.1 \times 10^{-1} \\
9.9 \times 10^{-3}\end{array}$ & $\begin{array}{l}1.1 \times 10^{1} \\
1.0 \times 10^{3}\end{array}$ & $\begin{array}{l}1.1 \times 10^{-1} \\
6.2 \times 10^{-4}\end{array}$ & $\begin{array}{l}9.4 \times 10^{1} \\
1.6 \times 10^{4}\end{array}$ \\
\hline Gamma & $\begin{array}{c}\mathrm{Co}-60 \\
\mathrm{Cs}-137 \\
\mathrm{Zn}-65\end{array}$ & $\begin{array}{l}9.3 \times 10^{0} \\
2.3 \times 10^{0} \\
1.5 \times 10^{0}\end{array}$ & $\begin{array}{l}1.1 \times 10^{0} \\
4.4 \times 10^{0} \\
6.8 \times 10^{0}\end{array}$ & $\begin{array}{l}3.4 \times 10^{1} \\
8.6 \times 10^{0} \\
5.3 \times 10^{0}\end{array}$ & $\begin{array}{l}3.0 \times 10^{-1} \\
1.2 \times 10^{0} \\
1.9 \times 10^{0}\end{array}$ & $\begin{array}{l}6.7 \times 10^{1} \\
1.5 \times 10^{1} \\
1.0 \times 10^{1}\end{array}$ & $\begin{array}{l}1.5 \times 10^{-1} \\
6.7 \times 10^{-1} \\
9.8 \times 10^{-1}\end{array}$ \\
\hline $\begin{array}{l}\text { Volatile } \\
\text { nuclides }\end{array}$ & $\begin{array}{c}\mathrm{H}-3 \\
\mathrm{I}-129\end{array}$ & $\begin{array}{l}6.3 \times 10^{-4} \\
1.7 \times 10^{0}\end{array}$ & $\begin{array}{l}1.6 \times 10^{4} \\
5.9 \times 10^{0}\end{array}$ & $\begin{array}{l}3.8 \times 10^{-2} \\
1.0 \times 10^{2}\end{array}$ & $\begin{array}{l}2.6 \times 10^{2} \\
1.0 \times 10^{-1}\end{array}$ & 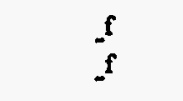 & $f$ \\
\hline Radong & $\begin{array}{l}\text { Ra-224 } \\
\text { Ra-226 } \\
\text { Th-232 }\end{array}$ & $\begin{array}{l}6.8 \times 10^{0} \\
2.7 \times 10^{1} \\
6.2 \times 10^{2}\end{array}$ & $\begin{array}{l}1.5 \times 10^{0} \\
3.7 \times 10^{-1} \\
1.6 \times 10^{-2}\end{array}$ & $\begin{array}{l}4.1 \times 10^{2} \\
1.6 \times 10^{3} \\
3.7 \times 10^{4}\end{array}$ & $\begin{array}{l}2.4 \times 10^{-2} \\
6.3 \times 10^{-3} \\
2.7 \times 10^{-4}\end{array}$ & $\begin{array}{l}f \\
f \\
f\end{array}$ & $\begin{array}{l}f \\
f f\end{array}$ \\
\hline
\end{tabular}

A Area of surface contamination is $1 \mathrm{~m}^{2}$ for generic assessment of tools and equipment.

b For volumetric contamination, the ingot caster scenario is used for generic assessment of tools and equipment.

c Doses are based on a radionuclide activity concentration of $1 \mathrm{~Bq} / \mathrm{cm}^{2}$ (after decontamination) and a surface transfer factor of 0.01 .

d Activity concentration that results in an individual dose of $10 \mu \mathrm{Sv} / \mathrm{yr}$.

e Doses are based on a radionuclide activity concentration of $1 \mathrm{~Bq} / \mathrm{g}$.

f Not analyzed.

g Ra-224 and Ra-226 are parent nuclides of Rn-220 and Rn-222, respectively; Th-232 decays to Ra-224. 
For unrestricted reuse of volume-contaminated tools, only external exposure is included in the dose calculation because all contamination is assumed to be immobile. The ingot caster scenario geometry based on Safety Series 111-P-1.1 (IAEA 1992) was used assuming no dilution or partitioning of nuclides. Table 5.4 presents individual doses and derived release levels for reuse of surface-contaminated tools and building areas, and for volumetrically contaminated tools.

Recycle to Consumer Products - Unrestricted Recycle or Prescribed Initial Use. Doses from the use of consumer products primarily result from external exposures to gamma radiation. However, for some nuclides, ingestion is the primary pathway under the frying pan scenario. The basic scenarios and assumptions follow Safety Series No. 111-P-1.1 (IAEA 1992). Products evaluated under unrestricted recycle scenarios include: automobile, frying pan, refrigerator, workplace walls, desk, and bed springs. Nuclide partitioning and dilution is assumed for commercial remelting of ingots. The commercial milling scenarios assume fabrication without remelting. The evaluation of commercial smelting also considers the use of slag in highway pavement. Modified-conservative-case doses for unrestricted recycle and prescribed first use are shown in Table 5.5. For products from unrestricted release to a smelter or a mill, the maximum individual doses are associated with the taxi driver scenario (external) and the frying pan scenario (ingestion).

External exposure is the only identifiable pathway to the public for the prescribedinitial-use scenarios. These scenarios were developed to represent the use of structural steel and reinforcing bars in bridges and public buildings. The constraining scenario for Tier $\mathrm{C}$ is the public building scenario.

Public population doses from product end-use scenarios (Tiers B and C) are also presented in Table 5.5. RSM throughput of 50,000 $\mathrm{t}$ was assumed to be distributed among end-use categories as follows: building materials $38 \%$, automobiles $30 \%$, frying pans $8 \%$, home furniture $8 \%$, office furniture $8 \%$ and appliances $8 \%$ (based on U.S. Bureau of Mines [1985]). From the metal mass of each end-use product and the RSM throughput, the number of products potentially distributed annually is estimated as a basis for calculating total public exposure. Population doses for unrestricted recycle (Tier B) are dominated by the building occupancy (20 to $40 \%$ ) and frying pan (10 to $30 \%$ ) scenarios. For prescribed initial uses, Tier C, the constraining population dose is from use of rebar in a public building. In both tiers, Co-60 population doses substantially exceed 1 person-Sv.

\subsubsection{Doses to the Public from Smelter Emissions}

Dose estimates for radioactive emissions during commercial smelting of recycled ingots are presented in Table $\mathbf{5 . 6}$ for the maximally exposed individual. The committed dose to the public was estimated on the basis of a 50,000-t/yr RSM throughput containing $1 \mathrm{~Bq} / \mathrm{g}$ of each nuclide. Doses are predominantly from the inhalation pathway; exposures to residual activity after the first year and from other pathways are negligible. Partitioning factors 
TABLE 5.5 Constraining Individual Public Doses and Derived Activity Levels under Scenarios for Unrestricted Recycling of Radioactive Scrap Metal

\begin{tabular}{|c|c|c|c|}
\hline $\begin{array}{c}\text { Representative } \\
\text { Nuclide }\end{array}$ & $\begin{array}{c}\text { Individual Dose }{ }^{a} \\
(\mu \mathrm{Sv} / \mathrm{yr})\end{array}$ & $\begin{array}{c}\text { Derived Activity } \\
\text { Level }^{\mathrm{b}}(\mathrm{Bq} / \mathrm{g})\end{array}$ & $\begin{array}{c}\text { Population Dose } \\
\text { (person-Sv) }\end{array}$ \\
\hline \multicolumn{4}{|c|}{ Consumer products from ingot recycle in a commercial smelter ${ }^{\mathrm{d}}$} \\
\hline Ac-227 & $2.4 \times 10^{-1}$ & $4.1 \times 10^{1}$ & $4.5 \times 10^{0}$ \\
\hline Am-241 & $5.8 \times 10^{-2}$ & $1.7 \times 10^{2}$ & $1.2 \times 10^{0}$ \\
\hline Pu-239 & $7.1 \times 10^{-3}$ & $1.4 \times 10^{3}$ & $5.9 \times 10^{-1}$ \\
\hline U-238 & $2.3 \times 10^{-2}$ & $4.4 \times 10^{2}$ & $3.0 \times 10^{-1}$ \\
\hline Sr-90 & $1.2 \times 10^{-3}$ & $8.6 \times 10^{3}$ & $3.4 \times 10^{-2}$ \\
\hline Tc-99 & $6.2 \times 10^{-5}$ & $1.6 \times 10^{5}$ & $9.5 \times 10^{-4}$ \\
\hline Co-60 & $8.3 \times 10^{0}$ & $1.2 \times 10^{0}$ & $6.2 \times 10^{1}$ \\
\hline Cs-137 & $2.2 \times 10^{-3}$ & $4.6 \times 10^{3}$ & $2.5 \times 10^{-2}$ \\
\hline $\mathrm{Zn}-65$ & $1.4 \times 10^{-2}$ & $7.2 \times 10^{2}$ & $2.7 \times 10^{-2}$ \\
\hline \multicolumn{4}{|c|}{ Pavement using slag from ingot recycle in a commercial smelter ${ }^{e}$} \\
\hline Ac-227 & $3.3 \times 10^{-3}$ & $3.0 \times 10^{3}$ & $1.5 \times 10^{-1}$ \\
\hline Am-241 & $7.9 \times 10^{-5}$ & $1.3 \times 10^{5}$ & $4.0 \times 10^{-3}$ \\
\hline Pu-239 & $5.2 \times 10^{-7}$ & $1.9 \times 10^{7}$ & $2.6 \times 10^{-5}$ \\
\hline $\mathrm{U}-238$ & $2.3 \times 10^{-4}$ & $4.4 \times 10^{4}$ & $1.2 \times 10^{-2}$ \\
\hline $\mathrm{Sr}-90$ & $3.5 \times 10^{-5}$ & $2.9 \times 10^{5}$ & $1.6 \times 10^{-3}$ \\
\hline Tc-99 & $2.3 \times 10^{-8}$ & $4.4 \times 10^{8}$ & $1.2 \times 10^{-6}$ \\
\hline Co-60 & $2.3 \times 10^{-4}$ & $4.4 \times 10^{4}$ & $6.9 \times 10^{-3}$ \\
\hline Cs-137 & $5.5 \times 10^{-3}$ & $1.8 \times 10^{3}$ & $2.5 \times 10^{-1}$ \\
\hline $\mathrm{Zn}-65$ & $3.7 \times 10^{-5}$ & $2.7 \times 10^{5}$ & $2.9 \times 10^{-4}$ \\
\hline \multicolumn{4}{|c|}{ Consumer products from ingot recycle in a commercial mill ${ }^{\mathrm{d}}$} \\
\hline Ac-227 & $2.4 \times 10^{1}$ & $4.1 \times 10^{-1}$ & $2.7 \times 10^{1}$ \\
\hline Am-241 & $5.8 \times 10^{0}$ & $1.7 \times 10^{0}$ & $7.2 \times 10^{0}$ \\
\hline Pu-239 & $7.1 \times 10^{-1}$ & $1.4 \times 10^{1}$ & $1.2 \times 10^{1}$ \\
\hline $\mathrm{U}-238$ & $2.3 \times 10^{0}$ & $4.4 \times 10^{0}$ & $2.9 \times 10^{0}$ \\
\hline Sr-90 & $1.2 \times 10^{-1}$ & $8.6 \times 10^{1}$ & $1.3 \times 10^{-1}$ \\
\hline Tc-99 & $6.2 \times 10^{-3}$ & $1.6 \times 10^{3}$ & $7.8 \times 10^{-3}$ \\
\hline Co-60 & $8.3 \times 10^{1}$ & $1.2 \times 10^{-1}$ & $6.2 \times 10^{1}$ \\
\hline Cs-137 & $2.2 \times 10^{1}$ & $4.6 \times 10^{-1}$ & $2.5 \times 10^{1}$ \\
\hline $\mathrm{Zn}-65$ & $1.4 \times 10^{1}$ & $7.2 \times 10^{-1}$ & $2.7 \times 10^{0}$ \\
\hline \multicolumn{4}{|c|}{ Prescribed initial use after controlled melt and milling ${ }^{f}$} \\
\hline Sr-90 & $3.4 \times 10^{-2}$ & $3.0 \times 10^{2}$ & $3.0 \times 10^{-1}$ \\
\hline Co-60 & $1.9 \times 10^{1}$ & $5.2 \times 10^{-1}$ & $6.3 \times 10^{1}$ \\
\hline Cs-137 & $3.2 \times 10^{0}$ & $3.1 \times 10^{0}$ & $2.9 \times 10^{1}$ \\
\hline $\mathrm{Zn}-65$ & $2.9 \times 10^{0}$ & $3.4 \times 10^{0}$ & $1.9 \times 10^{0}$ \\
\hline
\end{tabular}

Footnotes appear on next page. 
a Doses are based on an RSM activity concentration of $1 \mathrm{~Bq} / \mathrm{g}$ in the ingots and in prescribed-initial-use products. Modified-conservative case assumptions are applied to release to a commercial smelter, a dilution rate of 1:10, and nuclide partitioning factors.

b Activity concentration that results in an exposure of $10 \mu \mathrm{Sv} / \mathrm{yr}$.

c Doses are based on 50,000 $\mathrm{t}$ of RSM. Cumulative population dose over long-term use is included in the doses shown here.

d With one exception, the constraining scenario is the taxi driver; the frying pan scenario is constraining for $\mathrm{Pu}-239$.

e The exposures shown are for slag, but the derived levels are for RSM release from the controlled melter.

$f$ Because of its long half-life $\left(2 \times 10^{5}\right.$ years $), T c-99$ is not considered for Tier $\mathrm{C}$ release.

appropriate for offgas/dust were used in the calculation. The efficiency of the baghouse filtration system was assumed to be $99.95 \%$ (actual efficiencies could be higher), except for tritium releases to which filtration does not apply. The CAP88-PC code (USEPA 1992) was used with the scenario assumptions given in Appendix C. Doses from emissions from processing RSM in a commercial smelter are lower than doses from other scenarios and, therefore, do not constrain release levels.

Population doses from smelter emissions are presented in Table 5.6 for a $50,000 \mathrm{t}$ RSM ingot throughput with a $1 \mathrm{~Bq} / \mathrm{g}$ concentration of each nuclide. The doses were estimated with the CAP88-PC code and the same parameters used for the individual dose calculation. Doses from air emissions are generally orders of magnitude lower than those from worker exposures or public exposures from product end-use scenarios.

\subsubsection{Doses to Workers and the Public from RSM Transportation}

Radiological risks from transporting RSM would occur regardless of whether the metal were shipped for disposal or for decontamination and recycling. Doses would mainly result from gamma radiation exposure during routine shipment of strong gamma emitters such as Co-60. Alpha and beta radiation would be contained by the packaging in which the metal was transported. Current U.S. regulations (USNRC 1993b) specify dose limits equivalent to $100 \mu \mathrm{Sv} / \mathrm{h}$ at $1 \mathrm{~m}$ from the package surface and $20 \mu \mathrm{Sv} / \mathrm{h}$ at the crew compartment. RSM shipments with activity levels consistent with public (including smelter and mill workers) exposure scenario dose constraints would usually result in an external radiation field much lower than the regulatory limits for transportation. Detailed evaluation indicated that external dose for a typical RSM shipment is about two orders of magnitude less than U.S. regulatory limits (Chen et al. 1995). 
TABLE 5.6 Summary of Public Doses Associated with Gaseous Radioactive Emissions from a Steel Smelting Plant ${ }^{\text {a }}$

\begin{tabular}{lccc}
\hline $\begin{array}{c}\text { Nuclide } \\
\text { Category }\end{array}$ & $\begin{array}{c}\text { Represen- } \\
\text { tative } \\
\text { Nuclide }\end{array}$ & $\begin{array}{c}\text { Dose to Maximally } \\
\text { Exposed Individual } \\
\text { (pSv/yr) }\end{array}$ & $\begin{array}{c}\text { Population Dose } \\
\text { (person-Sv/yr) }\end{array}$ \\
\hline \multirow{2}{*}{ Alpha } & Ac-227 & $3.5 \times 10^{-3}$ & $4.8 \times 10^{-4}$ \\
& Am-241 & $3.0 \times 10^{-3}$ & $4.2 \times 10^{-4}$ \\
& Pu-239 & $2.0 \times 10^{-3}$ & $2.6 \times 10^{-4}$ \\
& U-238 & $6.7 \times 10^{-4}$ & $9.2 \times 10^{-5}$ \\
Beta & & & \\
& Sr-90 & $6.2 \times 10^{-4}$ & $1.6 \times 10^{-5}$ \\
Gamma & Tc-99 & $1.1 \times 10^{-3}$ & $3.4 \times 10^{-5}$ \\
& & & \\
& Co-60 & $2.8 \times 10^{-4}$ & $8.2 \times 10^{-6}$ \\
Volatile nuclides & Zn-65 & $5.4 \times 10^{-2}$ & $5.0 \times 10^{-5}$ \\
& & $3.1 \times 10^{-3}$ & $8.3 \times 10^{-5}$ \\
& H-3 & $3.8 \times 10^{-7}$ & $4.6 \times 10^{-8}$ \\
Radon & I-129 & $5.9 \times 10^{-2}$ & $1.0 \times 10^{-3}$ \\
& & & $2.8 \times 10^{-4}$ \\
& Ra-224 & $1.9 \times 10^{-3}$ & $1.9 \times 10^{-4}$ \\
& Ra-226 & $1.3 \times 10^{-3}$ & $8.3 \times 10^{-5}$ \\
\hline
\end{tabular}

a Based on $50,000 \mathrm{t} / \mathrm{yr}$ RSM throughput with $1 \mathrm{~Bq} / \mathrm{g}$ of each nuclide. Calculations were performed with the CAP88-PC code (USEPA 1992) assuming an off-gas filtration efficiency of $99.95 \%$ for particulates and the partitioning factors given in Appendix C, Table C.4.

b Maximally exposed individuals are located 100 to $700 \mathrm{~m}$ from the stack, depending on the radionuclide.

c Population includes public within an $80-\mathrm{km}$ radius of the plant.

The risks of accident-free transport at the regulatory dose limits were calculated with the RADTRAN code using the default values (e.g., speed) for rural, suburban, and urban locations (Neuhauser and Kanipe 1993). Risks for routine operations include those affecting the population (residents) along the route, passengers sharing the road, the population at vehicle stops, and vehicle crew members. Shipping 50,000 t of RSM for a distance of $100 \mathrm{~km}$ in $20 \mathrm{t}$-shipments would result in a maximum individual dose of $2 \times 10^{2} \mu \mathrm{Sv} / \mathrm{yr}$ (lifetime cancer fatality risks of $1 \times 10^{-5}$ ) for the crew. This assumed 2,000 hours per year of driving time per crew member. Health risks are calculated using the health risk conversion factors from ICRP-60 (ICRP 1991). For the crew and general public, the collective dose from transporting $50,000 \mathrm{t}$ a distance of $100 \mathrm{~km}$ is $2 \times 10^{-2}$ person-Sv, with estimated cancer fatality risks of $8 \times 10^{-4}$. The recycling alternative is assumed to involve two transportation 
activities: scrap from the originating site to the controlled melter and decontaminated metal in ingot form to a commercial melter or mill.

\subsubsection{Doses from Disposal Alternatives}

Two disposal alternatives were evaluated, disposal at an unrestricted landfill of RSM released for unrestricted reuse or recycle and disposal of residuals from RSM smelting at a dedicated LLW site. Only individual doses were estimated; population doses were not calculated because the uncertainties associated with site-specific parameters - such as leaching of wastes into groundwater, groundwater transport, distance to and size of the nearest aquifer, and type and extent of public use of the aquifer - preclude meaningful estimates.

The unrestricted disposal scenario assumed a pile of RSM $0.5 \mathrm{~m}$ thick and $11,400 \mathrm{~m}^{2}$ in area (corresponding to a 50,000-t mass) buried in a public landfill. This pile was assumed to be mixed with another $0.5 \mathrm{~m}$ of soil ( $1 \mathrm{~m}$ total thickness) and the mixture covered with a $0.5 \mathrm{~m}$ thickness of clean soil. The concentration of metal assumed in the scenario is very conservative for reusable RSM since the objects are likely to be disposed of in many landfills over an extended time period. There is additional conservatism in this scenario with regard to products of unrestricted recycle, since all of the activity would be volumetric. Half of the metal mass is assumed to comprise pieces with surface contamination (at $1 \mathrm{~Bq} / \mathrm{cm}^{2}$ ) with an average thickness of $10 \mathrm{~cm}$ and half pieces with volumetric contamination (at $1 \mathrm{~Bq} / \mathrm{g}$ ). The release mechanism in soil would be through metal corrosion, followed by leaching of contaminants to the groundwater. Complete removal of nuclides to soil was assumed to take place within one year after disposal for surface contamination and 100 years for volumetric contamination. The landfill was assumed to have restricted access for 30 years following disposal and to be released for public use thereafter, at which time a member of the public would reside at the landfill site and utilize well water from the site as the only drinking water source. Individual doses calculated with the RESRAD code ( $\mathrm{Yu}$ et al. 1993 ${ }^{\mathrm{b}}$ ) are presented in Table 5.7. For surface contamination, doses for most nuclides are less than $10 \mu \mathrm{Sv} / \mathrm{yr}$. For volumetric contamination, doses are generally on the order of $10 \mu \mathrm{Sv} / \mathrm{yr}$. The relatively high doses of some nuclides, such as Ra-226 or I-129, indicate that they require activity levels less than $1 \mathrm{~Bq} / \mathrm{g}$ to reduce doses to $10 \mu \mathrm{Sv} / \mathrm{yr}$.

Doses from disposal of RSM residuals from smelting at a LLW site were not specifically calculated. However, any type of LLW must meet existing disposal regulations (such as 10 CFR 61 [USNRC 1993a]). Health risks from RSM residuals disposal are likely to be lower than those estimated for LLW in general because nuclides would be bound in slag and dusts are likely to be solidified prior to disposal. EG\&G Idaho, Inc. (1987) indicates that doses from a LLW disposal facility to the maximally exposed individual, an intruder, range from 35 to $200 \mu \mathrm{Sv} / \mathrm{yr}$. Individual public doses must not exceed the regulatory limit of $1 \mathrm{mSv} / \mathrm{yr}$ (ICRP 1991; 10 CFR 20 [USNRC 1990]). 
TABLE 5.7 Estimated Public Individual Doses for Unrestricted Disposal ${ }^{\mathrm{a}}$ at a Landfill

\begin{tabular}{|c|c|c|c|c|c|}
\hline \multirow[b]{2}{*}{$\begin{array}{l}\text { Nuclide } \\
\text { Category }\end{array}$} & \multirow[b]{2}{*}{$\begin{array}{c}\text { Repre- } \\
\text { sentative } \\
\text { Nuclide }\end{array}$} & \multicolumn{2}{|c|}{ Individual Dose $^{b}$} & \multicolumn{2}{|c|}{ Derived Activity Level $^{\mathfrak{c}}$} \\
\hline & & $\begin{array}{c}\text { Surface } \\
\text { Contamination } \\
(\mu \mathrm{Sv} / \mathrm{yr})\end{array}$ & $\begin{array}{c}\text { Volume } \\
\text { Contamination } \\
(\mu \mathrm{Sv} / \mathrm{yr})\end{array}$ & $\begin{array}{c}\text { Surface } \\
\text { Contamination } \\
\left(\mathrm{Bq} / \mathrm{cm}^{2}\right)\end{array}$ & $\begin{array}{c}\text { Volume } \\
\text { Contamination } \\
(\mathrm{Bq} / \mathrm{g})\end{array}$ \\
\hline Alpha & $\begin{array}{l}\text { Ac-227 } \\
\text { Am-241 } \\
\text { Pu-239 } \\
\text { U-238 }\end{array}$ & $\begin{array}{l}1.4 \times 10^{0} \\
4.4 \times 10^{-1} \\
5.0 \times 10^{-1} \\
6.9 \times 10^{-2}\end{array}$ & $\begin{array}{l}4.0 \times 10^{1} \\
1.2 \times 10^{1} \\
1.3 \times 10^{1} \\
1.8 \times 10^{0}\end{array}$ & $\begin{array}{l}7.1 \times 10^{0} \\
2.3 \times 10^{1} \\
2.0 \times 10^{1} \\
1.4 \times 10^{2}\end{array}$ & $\begin{array}{l}2.5 \times 10^{-1} \\
8.3 \times 10^{-1} \\
7.7 \times 10^{-1} \\
5.6 \times 10^{0}\end{array}$ \\
\hline Beta & $\begin{array}{l}\text { Sr-90 } \\
\text { Tc-99 }\end{array}$ & $\begin{array}{l}2.6 \times 10^{0} \\
0.0\end{array}$ & $\begin{array}{l}7.0 \times 10^{1} \\
1.3 \times 10^{1}\end{array}$ & $\underset{-\mathrm{d}}{3.9} \times 10^{0}$ & $\begin{array}{l}1.4 \times 10^{-1} \\
7.7 \times 10^{-1}\end{array}$ \\
\hline Gamma & $\begin{array}{l}\text { Co-60 } \\
\text { Cs-137 } \\
\text { Zn-65 }\end{array}$ & $\begin{array}{l}1.3 \times 10^{-2} \\
2.5 \times 10^{-1} \\
0.0\end{array}$ & $\begin{array}{l}3.3 \times 10^{1} \\
3.0 \times 10^{0} \\
0.0\end{array}$ & $\begin{array}{c}7.7 \times 10^{2} \\
4.0 \times 10^{1} \\
. \mathrm{d}\end{array}$ & $\begin{array}{l}3.0 \times 10^{-1} \\
3.3 \times 10^{0} \\
-d\end{array}$ \\
\hline $\begin{array}{l}\text { Volatile } \\
\text { nuclides }\end{array}$ & $\begin{array}{l}\text { H-3 } \\
\text { I-129 }\end{array}$ & $\begin{array}{l}0.0 \\
0.0\end{array}$ & $\begin{array}{l}1.5 \times 10^{0} \\
3.8 \times 10^{3}\end{array}$ & $-d$ & $\begin{array}{l}6.7 \times 10^{0} \\
2.6 \times 10^{-3}\end{array}$ \\
\hline Radon & $\begin{array}{l}\text { Ra-226 } \\
\text { Th-232 }\end{array}$ & $\begin{array}{l}4.5 \times 10^{2} \\
6.3 \times 10^{0}\end{array}$ & $\begin{array}{l}1.3 \times 10^{4} \\
1.7 \times 10^{2}\end{array}$ & $\begin{array}{l}2.2 \times 10^{-2} \\
1.6 \times 10^{0}\end{array}$ & $\begin{array}{l}7.7 \times 10^{-4} \\
5.9 \times 10^{-2}\end{array}$ \\
\hline
\end{tabular}

a Doses are based on RESRAD calculation assuming 50,000 $\mathrm{t}$ RSM disposal in a single mass at one landfill. A residential scenario is assumed at the landfill after 30 years of restricted access following the disposal.

b Based on an assumed surface concentration of $1 \mathrm{~Bq} / \mathrm{cm}^{2}$ and an assumed volume concentration of $1 \mathrm{~Bq} / \mathrm{g}$ at the time of disposal.

c Based on an annual dose of $10 \mu \mathrm{Sv} / \mathrm{yr}$.

d Surface contaminant does not show long-term effects because of a high rate of leaching, transport, and accompanying dilution.

\subsubsection{Derived Release Levels}

Activity levels based on a $10 \mu \mathrm{Sv} / \mathrm{yr}$ dose limit have been derived from the individual dose estimates discussed in Section 5.2.2. For surface contaminated objects released for reuse, the derived activity levels shown in Table 5.4 are generally consistent with existing standards (e.g., Regulatory Guide 1.86 [USNRC 1974]) and with the derived levels in Safety Series No. 111-P-1.1 (IAEA 1992), except that radon emissions were not previously accounted for. Consideration of radon emission results in relatively large dose estimates for nuclides with radon in their decay chains. However, these estimates have large uncertainty ranges because of the uncertainty regarding the radon emanation rate from surface contamination. Dose buildup from decay product ingrowth is a concern for these nuclides and has been considered in deriving Tier A release levels. If radon gas and its progeny were included in deriving levels based on $10 \mu \mathrm{Sv} / \mathrm{yr}$, radionuclides such as Ra-226 would have such low release levels that it would be difficult, if not impossible, to measure compliance. For alpha emitters, 
the controlling parameter appears to be the contaminant emission rate (i.e., surface resuspension factor). For beta emitters, the ingestion rate is dominant. Empirical data for these key factors are limited, particularly pertaining to surfaces treated by current decontamination techniques. Continued research efforts, especially in experimental areas, are needed to improve upon the existing information.

Derived activity levels for constraining scenarios for unrestricted recycle of volumetrically contaminated ingots and prescribed initial uses are summarized in Table 5.8. The derived levels are based on a 50,000-t/yr RSM throughput and, for recycle in a commercial smelter, incorporate nuclide partitioning factors and an RSM dilution factor of 1:10. Release levels for ingot recycle in a mill and for prescribed initial use were derived from a RSM activity concentration without dilution after release and are constrained by public exposure to products. Slag product exposure scenarios were analyzed for the commercial smelter recycle case but were not constraining.

For recycle in a smelter, release levels for all nuclides are constrained by commercial smelter worker exposures. This is also true if the RSM throughput of a commercial smelter is 10,000 trather than $50,000 \mathrm{t}$. The only case in which public dose is nearly as constraining as worker dose is the Co-60, taxi driver scenario. Release levels for direct commercial milling of ingots from the controlled melter are constrained by public, rather than worker, exposures. Except for $\mathrm{Pu}-239$, which is higher than for recycling by remelting, the release levels for direct milling of ingots are of the same order of magnitude as for melting. This indicates that levels derived for recycling in a commercial smelter would be sufficiently protective, even if ingots that were released for remelt were directly milled.

TABLE 5.8 Derived Radioactive Scrap Metal Release Levels for Unrestricted Recycle and Prescribed Initial Use, Showing the Constraining Scenarios ${ }^{a}$

\begin{tabular}{|c|c|c|c|c|c|c|}
\hline \multirow[b]{2}{*}{$\begin{array}{l}\text { Repre- } \\
\text { sentative } \\
\text { Nuclide }\end{array}$} & \multicolumn{2}{|c|}{$\begin{array}{l}\text { Unrestricted Recycle in } \\
\text { Commercial Melt }\end{array}$} & \multicolumn{2}{|c|}{$\begin{array}{l}\text { Unrestricted Recycle in } \\
\text { Commercial Milling }\end{array}$} & \multicolumn{2}{|c|}{ Prescribed Initial Use } \\
\hline & $\begin{array}{c}\text { Derived } \\
\text { Levels (Bq/g } \\
\text { radioactive } \\
\text { scrap metal) }\end{array}$ & $\begin{array}{l}\text { Con- } \\
\text { straining } \\
\text { Scenario }\end{array}$ & $\begin{array}{c}\text { Derived } \\
\text { Levels (Bq/g } \\
\text { radioactive } \\
\text { scrap metal) }\end{array}$ & $\begin{array}{c}\text { Con- } \\
\text { straining } \\
\text { Scenario }\end{array}$ & $\begin{array}{c}\text { Derived } \\
\text { Levels (Bq/g } \\
\text { radioactive } \\
\text { scrap metal) }\end{array}$ & $\begin{array}{c}\text { Constraining } \\
\text { Scenario }\end{array}$ \\
\hline $\begin{array}{l}\text { Ac-227 } \\
\text { Am-241 } \\
\text { Pu-239 } \\
\text { U-238 } \\
\text { Sr-90 } \\
\text { Tc-99 } \\
\text { Co-60 } \\
\text { Cs-137 } \\
\text { Zn-65 }\end{array}$ & $\begin{array}{l}2 \times 10^{-1} \\
5 \times 10^{0} \\
7 \times 10^{0} \\
5 \times 10^{0} \\
2 \times 10^{1} \\
1 \times 10^{3} \\
7 \times 10^{-1} \\
2 \times 10^{-1} \\
3 \times 10^{1}\end{array}$ & $\begin{array}{l}\text { Slag worker } \\
\text { Slag worker } \\
\text { Slag worker } \\
\text { Slag worker } \\
\text { Slag worker } \\
\text { Slag worker } \\
\text { Caster } \\
\text { Slag worker } \\
\text { Slag worker }\end{array}$ & $\begin{array}{l}4 \times 10^{-1} \\
2 \times 10^{0} \\
1 \times 10^{1} \\
4 \times 10^{0} \\
9 \times 10^{1} \\
2 \times 10^{3} \\
1 \times 10^{-1} \\
5 \times 10^{-1} \\
7 \times 10^{-1}\end{array}$ & $\begin{array}{l}\text { Taxi driver } \\
\text { Taxi driver } \\
\text { Frying pan } \\
\text { Taxi driver } \\
\text { Taxi driver } \\
\text { Taxi driver } \\
\text { Taxi driver } \\
\text { Taxi driver } \\
\text { Taxi driver }\end{array}$ & $\begin{array}{c}\frac{b}{b} \\
-b \\
-b \\
-b \\
3 \times 10^{2} \\
=b \\
5 \times 10^{-1} \\
3 \times 10^{0} \\
3 \times 10^{a}\end{array}$ & $\begin{array}{c}- \\
- \\
- \\
\text { Public - building } \\
\text { - } \\
\text { Public - building } \\
\text { Public - building } \\
\text { Public - building }\end{array}$ \\
\hline
\end{tabular}

a Levels are constrained by $10 \mu \mathrm{Sv} / \mathrm{yr}$ and are based on $50,000 \mathrm{t}$ throughput.

b Tier $\mathrm{C}$ is not applicable to nuclides with long half-lives, e.g., Tc-99 is not considered for Tier $\mathrm{C}$ because its half-life is $2 \times 10^{5}$ years. 
Derived levels for prescribed initial uses are one order of magnitude less restrictive than those for unrestricted recycle by melting for Sr-90 and Cs-137 because of greater exposure distance and shorter exposure duration under the Tier $\mathrm{C}$ scenarios. Overall, however, the prescribed-initial-use applications do not provide much advantage in terms of avoiding public exposure. The advantage of Tier $\mathrm{C}$ is in avoiding commercial worker doses. Investigation of other Tier $\mathrm{C}$ applications is warranted where public access would be restricted (thereby substantially reducing population dose), such as in ships or military uses. The derived level for Co-60 is about the same for both Tiers B and C because there is less uncertainty regarding parameter values for external exposure than for other pathways and Co-60 remains almost entirely in metal after melting.

\subsubsection{Other Considerations}

Individual dose estimates were calculated for the first year following the release of RSM. Because radionuclides generally decay over time, doses are usually higher in the first year than in subsequent years. However, in some situations, higher doses would develop over time, rendering the first-year dose less constraining. These situations include the effect of years of RSM recycling, which would result in an increasing proportion of RSM in metal stocks over time, and the increase in nuclide concentration in surface contaminated objects resulting from decay product ingrowth (particularly for radon and its progeny). In addition, potential radioactivity reconcentration due to eventual disposal of obsolete RSM products must also be considered.

\subsubsection{Proliferation of Radioactive Scrap Metal in the Metal Supply}

Continued recycling of RSM will very gradually increase the percentage of RSM in the common metal scrap returned to smelters, which will effectively decrease the dilution rate for RSM over time. The resulting buildup of radioactivity in a typical consumer product for a recycling practice is estimated to be about $25 \%$ over 40 years (IAEA 1992). Considering the level of uncertainty in estimated doses and the very low doses associated with undiluted RSM, this increase is quite insignificant.

\subsubsection{Decay Product Ingrowth}

The doses calculated in this study have included the dose contributions from decay product nuclides with half-lives of less than one year. For most radionuclides, this is sufficient to account for potential dose buildup from decay product ingrowth.

For some nuclides, however, the potential buildup by ingrowth continues beyond the first year. This issue applies specifically to the reuse scenario of Tier A for surfaces contaminated by radon emitters. For example, Ra-228 (a nuclide in the thorium series with a half-life of 5.8 years) decays to Th-228 (half-life of 1.9 years), which in turn emits Rn-220 in the subsequent decays. Variation over time in the total dose from the Ra-228 and Th-228 
decay chains is shown in Figure 5.2; the dose peaks at about $1.8 \times 10^{4} \mu \mathrm{Sv} / \mathrm{yr}$ in less than five years. In contrast, the first-year dose for the room occupancy scenario with surface contamination is only about $2 \times 10^{3} \mu \mathrm{Sv} / \mathrm{yr}$, a factor of 10 less than the peak value. Of course, not all the radon parent nuclides have such a large buildup, but because of the potential dose increase over time, the dose should be estimated with a time frame specified for identifying the maximum doses, rather than just the first-year dose. In this study, doses are presented for the maximum year. For surface-contaminated objects a 30-year period of building occupancy and 10 years of tool use are considered.

\subsubsection{Reconcentration of Radioactivity at Disposal Sites}

Obsolete scrap will eventually be discarded to landfills where RSM activity could be reconcentrated. Reconcentration due to disposal should not be a serious concern for these tiers, however, since the dilution of obsolete RSM products in landfills is likely to be orders of magnitude greater than that assumed in the RSM landfill scenario. In addition, the period of metal end use before disposal will allow reduction of some activity levels by decay. Therefore, reconcentration of activity is unlikely to reach levels that merit concern.

When doses and derived levels for volumetrically contaminated recycle products under the landfill scenario assuming disposal of 50,000 t of RSM (shown in Table 5.7) are compared with those for reusable, surface-contaminated objects (Table 5.4), the levels for reuse of surface-contaminated objects are either lower or comparable and would therefore be protective even if the objects were disposed of, except for Sr-90. For volumetricallycontaminated object reuse, all of the release levels for alpha and beta emitters are substantially less constraining than levels for the landfill scenario. Release levels for volumetrically-contaminated ingots under Tiers B or C (Table 5.5), however, are generally less constraining than those derived for the landfill scenario. Derived activity levels for

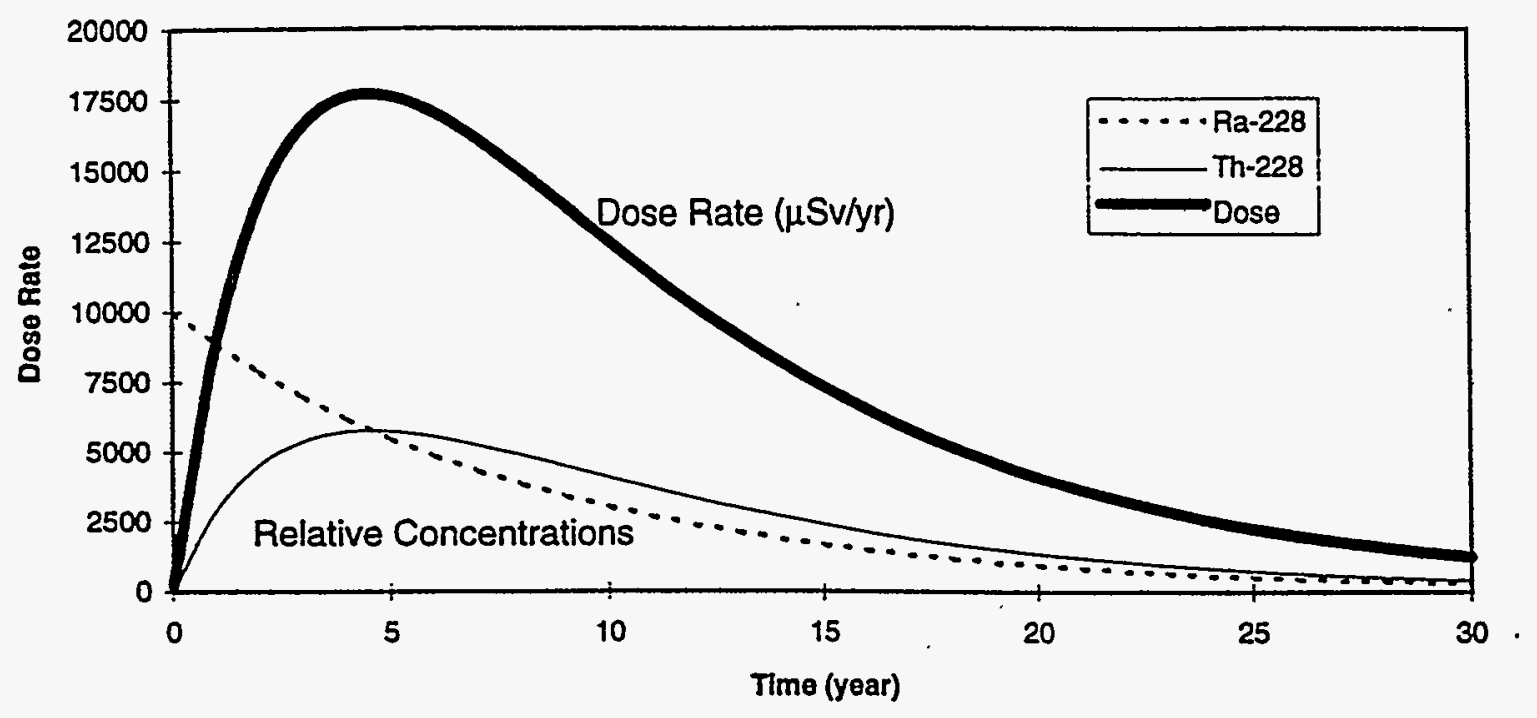

FIGURE 5.2 Variation in Total Dose Rate over Time for a Radon Parent Nuclide 
Tier B are generally at least two orders of magnitude higher than those for the landfill scenario. Thus, the derived release levels for volumetrically-contaminated metal to be reused or recycled are not found to be protective if 50,000 $t$ were disposed of under the very conservative assumptions of this analysis. Such an event is extremely unlikely.

\subsubsection{Uncertainty Analysis}

A simulated probabilistic analysis (discussed in Appendix C) was conducted to evaluate the advantages of this approach for standard development. It provides a means of explicitly accounting for the variability and uncertainty in key parameter values. However, currently available data for some of the key parameters affecting dose estimates for metal recycling activities are inadequate for the purposes of probabilistic analysis. Further characterization of these parameters will be required to obtain the advantages this approach offers for avoiding costly conservatism.

\subsubsection{Summary of Radiological Health Impact Analysis}

Radiological risks from either RSM recycling or reuse are quite low. Release levels for the proposed tiers were derived on the basis of limiting the public dose to $10 \mu \mathrm{Sv} / \mathrm{yr}$, so cancer fatality risks to individual members of the public, including industrial workers, from unrestricted recycling operations would be less than $10^{-6}$. Radiological risks to nuclear workers and of the public as a result of RSM disposal were assumed not to exceed regulatory limits of $10^{-3}$ for workers and $10^{-5}$ for the public. Radiation exposure of truck drivers during RSM transportation would result in individual risks of less than $10^{-5}$ and public exposure would be negligible.

\subsection{NONRADIOLOGICAL HEALTH EFFECTS}

This section describes potential nonradiological impacts associated with recycling RSM. Impacts may arise from decontamination activities, including metal melting in a controlled facility, that are above and beyond what would occur if the RSM were being disposed of. The impacts may also result from work place or transportation accidents and from emissions from commercial smelters after release of the decontamination RSM. These impacts include health effects to workers (Section 5.3.2) and the general public (Section 5.3.3).

Of the recycling process activities discussed in Section 5.1, only decontamination activities would be an incremental source of nonradiological health risks from using RSM instead of uncontaminated scrap. These operations are likely to be conducted in an enclosed facility, for which worker exposures would be the primary concern. The chemical exposure and accident risks associated with commercial smelting of RSM would be similar to those from using uncontaminated scrap. This section addresses the nonradiological risks associated with decontamination, smelting, and metal transportation activities. 


\subsubsection{Methodology}

The nonradiological health impacts that could result from human exposures associated with recycling RSM include both carcinogenic and noncarcinogenic effects. The methodology used to estimate these effects is as follows. The risk of developing cancer can be calculated by multiplying a person's estimated intake by a standard slope or potency factor. The potential for a noncarcinogenic effect can be indicated by a "hazard index," which represents the sum of the hazard quotients determined for individual contaminants. These hazard quotients are calculated by dividing the dose or intake estimated for a person by the standard reference dose for that contaminant that is generally considered safe or acceptable by the scientific community. The toxicity values applied in this assessment to estimate health effects that could result from chemical intakes were developed by the U.S. Environmental Protection Agency.

The following general equation is used to estimate contaminant intakes:

$$
\mathrm{I}=(\mathrm{C} \times \mathrm{CR} \times \mathrm{EF} \times \mathrm{ED}) /(\mathrm{BW} \times \mathrm{AT})
$$

where

$$
\begin{aligned}
I= & \text { intake of the chemical (mg/kg-day), } \\
\mathrm{C}= & \begin{aligned}
\text { concentration of the chemical in an environmental medium } \\
\text { (e.g., air or water) }\left(\mathrm{mg} / \mathrm{m}^{3} \text { in air or } \mathrm{mg} / \mathrm{L}\right. \text { in water), }
\end{aligned} \\
\mathrm{CR}= & \begin{aligned}
\text { contact rate of the exposed individual with the medium (e.g., } \\
\mathrm{m}^{3} / \text { day or air or } \mathrm{L} / \text { day of water), }
\end{aligned} \\
\mathrm{EF} \mathrm{=} & \text { exposure frequency (days/year), } \\
\mathrm{ED} \mathrm{=} & \text { exposure duration (years), } \\
\mathrm{BW}= & \text { body weight (kg), and } \\
\mathrm{AT}= & \text { averaging time (days). }
\end{aligned}
$$

Appropriate values for these parameters are determined by the specific exposure scenario, pathway, and receptor.

\subsubsection{Workers}

\subsubsection{Decontamination Chemical Exposures}

Inhalation of airborne contaminants within the decontamination facility is the primary pathway of concern for workers. To assess the health effects to workers from 
chemical exposures during decontamination activities, the following factors are considered: (1) the type of metal being decontaminated, (2) the type of activities, chemicals used, and emissions produced inside the facility; and (3) the type of clothing worn and protective equipment used. Nonradiological health effects are evaluated for the following contaminants: cadmium, chromium, copper, lead, manganese, nickel, uranium, and zinc. Other contaminants are not included because no adverse health effects are expected from related exposures or because standard toxicity values are not available to quantify potential effects even though the chemical is indicated as a carcinogen and/or toxic agent (e.g., lead). The potential health impacts associated with aluminum, iron, and lead inhalation are not quantified because standard toxicity values are not available. The toxicity associated with oral exposure to aluminum and iron is relatively low, and hence their contribution to total health impacts is expected to be low. Although aluminum and iron are somewhat more toxic via the inhalation route, their expected toxicities relative to the other metals for which health impacts can be quantified are relatively low. Lead is both highly toxic and a potential carcinogen, but no standard toxicity values to support quantitative analysis are currently available for this metal.

For this analysis, nonfixed surface contamination is assumed to have been removed from the RSM (e.g., by vacuuming or wiping) at the originating facility before the equipment or structure was dismantled. This assumption is based on the application of good engineering practices to control exposures during the scrap metal collection stage. Thus, the decontamination activities evaluated are those designed to address fixed contamination that can be removed from the surfaces of RSM by methods such as aggressive mechanical removal, electropolishing, chemical dissolution, and metal melting. General process information in the following discussion is summarized from Manion and LaGuardia (1980), Nuclear Energy Agency (1981), International Atomic Energy Agency (1985, 1986, 1987a), Loiselle (1993), and Masaidis (1993). The decontamination processes are first evaluated to assess chemical releases from which to estimate contaminant intakes and health effects. An evaluation of process hazards follows these risk calculations.

Mechanical removal can involve stripping or peeling (e.g., following a latex application), hydrolysing using a high-pressure water wash, or solid abrasive methods such as scraping, wire brushing, spalling, and blasting with sand, glass beads, or dry ice. The solid abrasive methods are most common, and these processes generate airborne emissions in addition to solid residuals. The hydrolysing process generates an aqueous waste, whereas peeling generates solid residuals. It is assumed that workers are not in direct contact with the aqueous waste stream or the solids; thus, the chemical exposure of primary concern for workers during decontamination operations is to airborne contaminants.

Electropolishing is a less common, but effective, decontamination method that uses phosphoric acid as the electrolyte to separate contaminants from the metal. The liquid waste generated by this process is neutralized, and contaminant solids are then removed by conventional processes such as gravity settling or filtration before discharging the effluent. No airborne emissions would be associated with the liquid waste or wet solids, and no 
adverse health effects would be expected from phosphates derived from the initial reagent following effluent release.

Chemical dissolution processes are commonly used to decontaminate scrap metal, and the following liquids can be used alone or in combination: organic solvents, alkaline permanganate and alkaline citrate, citric acid and detergents (soap), nitric acid and sodium fluoride, sulfuric acid and hydrogen peroxide, sulfamic acid, hydrochloric acid, and phosphoric acid. Sequestrants such as ethylenediamine tetraacetic acid can also be used to maintain metals in solution during the decontamination step. Although organic solvents are typically used to remove surface organic contamination such as oil and grease, these solvents are generally not part of the primary RSM decontamination process. These solvents are not used as frequently as the other liquids, and relatively small volumes are involved. Therefore, they are not considered further in this assessment.

The chemical dissolution processes generate liquid wastes that typically are neutralized and then are filtered or settled to remove solids in a process similar to that for electropolishing wastes. The key chemicals associated with the reagent solutions, relative to potential health effects from incidental ingestion, are fluoride, nitrate, and manganese. In addition, certain metals are of concern for dermal exposures. Sulfates and phosphates do not pose a human health threat, nor do citrates or soap. Since humans are not expected to be in extended contact with the liquid wastes, neither incidental ingestion nor dermal exposures are evaluated in this assessment.

The solid wastes generated by decontamination processes are often thermally treated (e.g., in an incinerator or melter) or immobilized (e.g, in a cement, bitumen, polymer, or glass matrix). Liquid wastes are typically treated by standard wastewater treatment processes such as flocculation, precipitation, filtration, ion exchange, and evaporation. Thermal treatment can result in airborne emissions, but nonvolatile chemicals would not be expected to be released from the liquid waste or wet solids. Thus, the airborne pathway is the primary concern for nonradiological exposures associated with thermal treatment.

Workers are assumed to use protective clothing and equipment as needed to limit contact with chemicals within the decontamination facility. For example, cotton coveralls or similar clothing would be worn routinely, and plastic or rubber clothing would be worn when handling acids; these measures would limit dermal contact. Respiratory protective equipment would be worn during any activities resulting in high indoor contaminant levels, and at least face masks would be worn to cover the nose and mouth when appropriate (e.g., when contaminant levels exceed work place standards).

To quantify potential health effects, it is assumed that worker protection standards would be met to limit occupational exposures to indoor particulates. Limiting concentrations for airborne contaminants are taken from the standards and guidelines presented in Table 5.9. The permissible exposure limits identified by the U.S. Occupational Safety and Health Administration (OSHA) for cadmium, trivalent chromium, copper, manganese, nickel, 


\begin{tabular}{|c|c|c|c|c|}
\hline \multirow[b]{2}{*}{ Contaminant } & \multicolumn{3}{|c|}{$\begin{array}{l}\text { Occupational Standard/ } \\
\text { Guideline }^{\mathrm{a}}\left(\mathrm{mg} / \mathrm{m}^{3}\right)\end{array}$} & \multirow[b]{2}{*}{ Comments } \\
\hline & $\begin{array}{l}\text { OSHA } \\
\text { PEL }^{\mathbf{b}}\end{array}$ & $\begin{array}{l}\text { ACGIH } \\
\text { TLV }^{\mathrm{c}}\end{array}$ & $\begin{array}{l}\text { NIOSH } \\
\text { REL }^{d}\end{array}$ & \\
\hline Cadmium & 0.005 & 0.05 & $-{ }^{e}$ & $\begin{array}{l}\text { PEL: All cadmium compounds, including dust and fumes. } \\
\text { TLV: Cadmium dusts and salts, as cadmium. }\end{array}$ \\
\hline Chromium III & 0.5 & 0.5 & 0.5 & Chromium III compounds, as chromium. \\
\hline Chromium VI & NA & 0.05 & $0.001^{\mathrm{e}}$ & $\begin{array}{l}\text { TLV: Water-soluble and certain water-insoluble chromium VI compounds, as } \\
\text { chromium. REL: For carcinogenic compounds; for noncarcinogenic compounds, } \\
\text { the REL is } 0.025 \mathrm{mg} / \mathrm{m}^{3} \text {, with a } 15 \text {-minute ceiling of } 0.05 \mathrm{mg} / \mathrm{m}^{3} \text {. }\end{array}$ \\
\hline Copper & 1 & 1 & 1 & $\begin{array}{l}\text { Dusts and mists, as copper. PEL and REL for copper fume is } 0.1 \mathrm{mg} / \mathrm{m}^{3} \text {; } \\
\text { TLV for copper fume is } 0.2 \mathrm{mg} / \mathrm{m}^{3} \text {. }\end{array}$ \\
\hline Lead $^{\mathrm{f}}$ & 0.05 & 0.15 & $<0.1$ & PEL: Inorganic compounds, as lead. TLV: Inorganic dust and fumes, as lead. \\
\hline Manganese & 1 & 5 & 5 & $\begin{array}{l}\text { PEL and REL: Fume, as manganese. TLV: Dust and compounds; TLV for } \\
\text { fume is } 1 \mathrm{mg} / \mathrm{m}^{3} \text {. }\end{array}$ \\
\hline Nickel & 0.1 & 0.1 & $0.015^{\mathrm{e}}$ & $\begin{array}{l}\text { PEL: Soluble compounds, as nickel; PEL for metallic nickel and insoluble } \\
\text { compounds is } 1 \mathrm{mg} / \mathrm{m}^{3} \text {, as nickel. } \\
\text { TLV: Soluble compounds as nickel; TLV for insoluble compounds is } 1 \mathrm{mg} / \mathrm{m}^{3} \text {. }\end{array}$ \\
\hline Uranium & 0.05 & 0.2 & 0.05 & $\begin{array}{l}\text { PEL and REL: Soluble compounds, as uranium; PEL and REL for insoluble } \\
\text { compounds is } 0.2 \mathrm{mg} / \mathrm{m}^{3} \text {, as uranium. TLV: Soluble and insoluble compounds, } \\
\text { as uranium. }\end{array}$ \\
\hline Zinc & 5 & 10 & 5 & $\begin{array}{l}\text { REL and PEL: Zinc oxide fume; } 15 \text {-minute ceiling is } 10 \mathrm{mg} / \mathrm{m}^{3} \text {. } \\
\text { TLV: Zinc oxide dust; TLV for fume is } 5 \mathrm{mg} / \mathrm{m}^{3} \text {. }\end{array}$ \\
\hline
\end{tabular}


a Each comment applies to the PEL, TLV, or REL (defined below), as specified; where no specific designation is noted, the comment applies to all three standards/guidelines; NA means no data are available.

b Permissible exposure limit (PEL) of the Occupational Safety and Health Administration (OSHA) (29 Code of Federal Regulations Part 1910); PELs are 8-hour time-weighted average (TWA) concentrations.

c Threshold limit value (TLV) of the American Conference of Governmental Industrial Hygienists (ACGIH 1990); TLVs are 8-hour TWA concentrations.

d Recommended exposure limit (REL) of National Institute for Occupational Safety and Health (NIOSH 1990). Unless otherwise noted, RELs are 10-hour TWA concentrations.

e Carcinogen; reduce exposure to lowest feasible level.

f Lead limits are presented for information purposes; standard USEPA toxicity values are not currently available for quantifying related health effects. 
uranium (insoluble compounds), and zinc were used. An OSHA value is not available for hexavalent chromium, so the threshold limit value of the American Conference of Governmental Industrial Hygienists (ACGIH 1990) was used.

Chemical intakes of airborne contaminants by a decontamination worker are estimated with Equation 5.1. The worker is assumed to be exposed $8 \mathrm{~h} /$ day, 5 days/week, for 50 weeks over 1 year. This unit duration is used so results can be readily scaled to estimate health effects for other time periods. The worker's inhalation rate is assumed to be $1.2 \mathrm{~m}^{3} / \mathrm{h}$; the body weight is assumed to be $70 \mathrm{~kg}$, which is the standard value for an adult (USEPA 1991). The average daily intake over 1 year is used to estimate noncarcinogenic effects, whereas the estimated annual intake is averaged over a lifetime of 70 years (25,550 days) to estimate cancer risks. These averaging times are different because the reference doses reflect "acceptable daily intakes" for noncarcinogens, whereas the slope factors applied to estimate cancer risks are based on an exposure period of 70 years.

With these conservative assumptions, a worker's lifetime risk of developing cancer from exposures to chemicals over one year of decontamination activities is estimated to be about $1 \times 10^{-3}$. To put this result in perspective, about $3 \times 10^{-1}$ Americans is expected to develop cancer from all causes (American Cancer Society 1992). Thus, the lifetime risk estimated for a decontamination worker is a small fraction $(0.3 \%)$ of the background cancer rate in the U.S.A. If the worker were exposed over 40 years, the incremental lifetime risk from this workplace exposure would increase to about $10 \%$ of the background rate.

The estimated hazard index for the worker exceeds 1, indicating that adverse noncarcinogenic effects could occur if this person were continually exposed to all of the airborne contaminants evaluated in this assessment with each at their individual concentration limits. (Hexavalent chromium is the primary contributor to health impacts.) This risk estimation approach is conservative, but the result is not inconsistent with data for occupational illnesses. For example, an annual occupational illness rate of about $3 \times 10^{-3}$ has been reported for workers in primary metal industries in the U.S.A. (U.S. Department of Labor 1986).

It is important to note that for these analyses, it was assumed that all metals were present at the maximum permissible concentrations for the entire exposure period and that no inhalation protection measures were taken. It is very unlikely that both assumptions would hold over the full exposure assessment period, especially for 40 years. In regulatory practice, the "allowable" concentrations are adjusted proportionately downward for those chemicals with similar (additive) toxicologic endpoints. When the concentrations of metals exceed their limits, protective measures would be taken to reduce exposures. Therefore, actual health effects for workers are expected to be well below the conservative estimates presented in this assessment. 


\subsubsection{Decontamination Accidents}

Workers could also be injured in accidents during decontamination operations. Process hazards associated with the various decontamination methods include water jet misfires during hydrolysing and skin or eye burns from spills or splashes of acid reagents during electropolishing or chemical dissolution processes. In addition, workers could experience common industrial accidents such as falling, being struck or caught by equipment or other objects, being electrocuted, or being burned by a fire or explosion.

The potential for worker injuries and fatalities from accidents can be derived from data for metal industries in the U.S.A. These data indicate that a facility employing 100 workers could expect 13 accidents with injuries per year, and the annual incidence rate of fatalities for the manufacturing industry is about $4 \times 10^{-3}$. Of this total, about $20 \%$ are attributed to being hit by machinery or other objects, $12 \%$ to industrial vehicle or equipment accidents, $10 \%$ to fire and explosions, $9 \%$ to electrocutions, and $8 \%$ to falls (U.S. Department of Labor 1986).

\subsubsection{Smelting Accidents}

For blast furnace and steel mill workers combined, the annual rate of fatalities and major injuries was $6 \times 10^{-2}$ workers (U.S. Department of Labor 1989), which is equivalent to $4 \times 10^{-4} / \mathrm{t}$ of steel and 7 fatalities or disabling injuries from blast furnace operation for throughput of 50,000 t. The fatality and serious injury rate for iron and steel foundries based on U.S. Department of Labor (1989) statistics is also relatively high, 7.5 for production of $50,000 \mathrm{t}$ of steel.

In conclusion, the likelihood that a worker would incur adverse health effects from exposures to chemical contaminants during RSM operations is expected to be similar to the likelihood of adverse affects associated with similar industrial operations that do not involve radioactive scrap. The potential for accidents and injuries (including from transportation) is expected to be lower in the RSM recycle activities that occur under radiation controls than if the worker were employed in a comparable job requiring similar skills because of the additional precautions taken when managing radioactive materials.

\subsubsection{General Public}

Health effects of decontamination chemical and smelting emissions exposures from recycling processes are discussed, as well as effects of transportation emissions and accidents. In regard to the finished metal products, the chemical composition of an item manufactured from recycled RSM would be essentially the same as that of a similar item manufactured from uncontaminated scrap. Hence, no incremental chemical exposures or health effects would be associated with the use of such a product. 


\subsubsection{Decontamination Chemical Exposures}

Emissions of airborne contaminants from a decontamination facility could also be a source of potential exposure to the general public. However, these emissions would have to be controlled to very low levels in order to meet licensing requirements. A representative analysis of this pathway is not conducted here because it requires defining the following process, control system, and location characteristics: the types and concentrations of contaminants produced, the pollution control systems used, facility stack heights, surrounding terrain, and local and regional meteorology. Although public exposures via the air pathway have not been quantified, health risks should be negligible because highly effective pollution control systems would be used to limit releases from an RSM decontamination facility.

The decontamination activities would result in some secondary wastes that would require disposal, including residuals collected from liquid wastes. However, the quantity of solids generated by decontaminating the RSM would be much smaller than the quantity of solid material that would be directly disposed of if the RSM were not recycled. The primary issue would be the increased concentration of radionuclides in the solids. Because the health impacts of direct disposal of RSM are anticipated to be insignificant (see Section 6.1), the impact of disposing of the relatively minor volume of secondary waste from decontamination activities is also expected to be negligible.

Liquid effluents could also be released from RSM decontamination facilities, depending on the process used, but these releases are assumed to meet the discharge requirements of the locale/country where each facility is situated. Although these releases could be a source of exposure to individuals downstream who use the receiving body of water for drinking and cooking, it is assumed that health protection would be a primary basis for the discharge levels to which the releases would be controlled. Therefore, human exposures to residual contaminants in the receiving water are expected to be negligible.

\subsubsection{Chemical Exposures from Smelting}

During the decontamination process, RSM may be melted in a controlled melt facility. As a result of radiological exposure controls, chemical exposures of radiation workers and the public from these activities are likely to be very low. After release for unrestricted recycling, RSM could be remelted in a commercial smelter, resulting in chemical exposures to commercial metal workers and to the downwind population. The resulting health impacts would be similar to those that occur from routine commercial recycling of scrap in metal production.

\section{Air Emissions from Smelting}

The approach taken to assess chemical exposure of the general public from smelting is based on chemical emissions data from steel production (Nriagu and Pacyna 1988). The analysis assumed that $50,000 \mathrm{t}$ of steel would be produced annually to replace disposed RSM. 
Emissions from this throughput are reported for the 11 metals that are the "chemical contaminants of concern" for this assessment, which are listed in Table 5.10.

To maintain consistency with the radiological analysis, output from the CAP- 88 code (USEPA 1992) for radionuclide emissions was used as the basis for estimating chemical concentrations at relevant receptor locations. This approach is valid because all the chemicals of concern are metals with transport mechanisms similar to those of the radionuclides. A radionuclide with a very long half-life (i.e., $\mathrm{Pu}$-239) was used to model transport of the metal particles. The receptor evaluated represents an individual at the high end of the range of possible exposures.

Exposure pathways considered were particulate inhalation and ingestion of produce. grown in contaminated soil. Meat and milk pathways were not included in the analysis because, for the chemical contaminants of concern, intake via these pathways was much less than via inhalation and produce ingestion. For the produce ingestion pathway, chemicalspecific plant uptake factors were obtained from Baes et al. (1984) in accordance with USEPA guidance (USEPA 1989a).

Standard USEPA methods (USEPA 1989a), namely, USEPA slope factors and reference doses, were used to assess carcinogenic risk and risk of systemic effects, respectively. A detailed explanation and discussion of this quantitative risk assessment methodology, including definition of terms, can be found in relevant USEPA documents and databases (USEPA 1989a, 1993a,b). The criteria used to evaluate significant risk in this assessment follow USEPA guidelines for Superfund and RCRA sites (USEPA 1990a,b). Summed carcinogenic risks falling in the range of $10^{-6}$ to $10^{-4}$ are considered acceptable. For systemic effects, a hazard index of less than one is considered acceptable (hazard index is the sum of intake divided by the reference dose value for each chemical of concern).

The assumptions used to calculate intake - including an inhalation rate of $22 \mathrm{~m}^{3} / \mathrm{d}$ by a 70-kg adult; an exposure duration of $24 \mathrm{~h} / \mathrm{d}, 365$ days/yr, for 70 years; and all ingested produce homegrown - are conservative overestimates for the general population. Additionally, although some reduction in particulate exposure while indoors is known to occur (Alzona et al. 1979), this reduction in exposure is not included in the intake calculations. Of the contaminants of concern, five (arsenic, cadmium, chromium VI, lead, and nickel) are classified as known or probable human carcinogens via inhalation. Because a slope factor for lead is not available, the carcinogenic risk cannot be calculated at this time. The calculated inhalation carcinogenic risks associated with the upper estimate of steel production emissions range from $7 \times 10^{-7}$ for cadmium to $1.5 \times 10^{-4}$ for chromium, with a sum risk of $1.7 \times 10^{-4}$. Details of the estimates are shown in Table 5.10.

The majority of chromium dust released from steel production is in the form of noncarcinogenic chromium III; also, of the total U.S.A. chromium emissions from all sources, $32 \%$ is in the form of chromium VI (Agency for Toxic Substances and Disease Registry 1989). Therefore, $32 \%$ of the emissions were assumed to be chromium VI in calculating risk, although this is probably an overestimate of the chromium VI releases from steel and iron manufacturing. 
TABLE 5.10 Intakes and Risks Associated with the Inhalation Pathway for Smelter Emissions ${ }^{a}$

\begin{tabular}{|c|c|c|c|c|c|c|c|}
\hline $\begin{array}{l}\text { Chemical } \\
\text { Contaminant } \\
\text { of Concern }\end{array}$ & $\begin{array}{c}\text { Emission } \\
\text { Rate } \\
(\mathrm{kg} / \mathrm{yr})\end{array}$ & $\begin{array}{c}\text { Maximum } \\
\text { Air } \\
\text { Concentra- } \\
\text { tion } \\
\left(\mathrm{mg} / \mathrm{m}^{3}\right)\end{array}$ & $\begin{array}{c}\text { Maximum } \\
\text { Intake }^{b} \\
(\mathrm{mg} / \mathrm{kg} / \mathrm{d})\end{array}$ & $\begin{array}{c}\text { Chronic } \\
\text { Inhalation } \\
\text { Slope } \\
\text { Factor } \\
\text { (mg/kg/d) } \\
\text { (m }\end{array}$ & $\begin{array}{c}\text { Chronic } \\
\text { Inhalation } \\
\text { Reference } \\
\text { Dose }^{c} \\
\text { (mg/kg/d) }\end{array}$ & $\begin{array}{c}\text { Lifetime } \\
\text { Carcinogenic } \\
\text { Risk Range }^{\mathrm{d}}\end{array}$ & $\begin{array}{l}\text { Hazard } \\
\text { Quotient } \\
\text { Range }^{\text {d }}\end{array}$ \\
\hline Antimony & $0.25-5.0$ & $8.9 \times 10^{-8}$ & $2.8 \times 10^{-8}$ & ND & $\mathrm{ND}$ & - & - \\
\hline Arsenic & $25-175$ & $3.1 \times 10^{-6}$ & $9.8 \times 10^{-7}$ & 15 & ND & $\begin{array}{l}2.1 \times 10^{-6} \text { to } \\
1.5 \times 10^{-5}\end{array}$ & - \\
\hline Cadmium & $2.0-20$ & $3.6 \times 10^{-7}$ & $1.1 \times 10^{-7}$ & 6.3 & ND & $\begin{array}{l}7.0 \times 10^{-8} \text { to } \\
7.0 \times 10^{-7}\end{array}$ & - \\
\hline Chromium $^{\mathrm{e}}$ & $\begin{array}{l}200 \\
2,000\end{array}$ & $3.6 \times 10^{-5}$ & $3.6 \times 10^{-6}$ & 42 & ND & $\begin{array}{l}1.5 \times 10^{-5} \text { to } \\
1.5 \times 10^{-4}\end{array}$ & - \\
\hline Copper & $10-200$ & $3.6 \times 10^{-6}$ & $1.1 \times 10^{-6}$ & ND & $\mathrm{ND}$ & - & - \\
\hline Lead & $75-1000$ & $1.8 \times 10^{-5}$ & NA & ND & ND & - & - \\
\hline Manganese & $75-2,000$ & $3.6 \times 10^{.5}$ & $1.1 \times 10^{-5}$ & ND & 0.00011 & - & $\begin{array}{l}0.0037 \text { to } \\
0.10\end{array}$ \\
\hline Nickel & $2.5-500$ & $8.9 \times 10^{-6}$ & $2.8 \times 10^{-6}$ & 0.84 & ND & $\begin{array}{l}1.2 \times 10^{-8} \text { to } \\
2.3 \times 10^{-6}\end{array}$ & - \\
\hline Selenium & $0.05-0.15$ & $2.7 \times 10^{-9}$ & $8.4 \times 10^{-10}$ & ND & $\mathrm{ND}$ & - & - \\
\hline Vanadium & $5.0-100$ & $1.8 \times 10^{-6}$ & $5.6 \times 10^{-7}$ & ND & ND & - & - \\
\hline Zinc & $\begin{array}{l}500 \\
2,250\end{array}$ & $4.0 \times 10^{-5}$ & $1.3 \times 10^{-5}$ & ND & ND & - & - \\
\hline Total & NA & NA & NA & NA & NA & $\begin{array}{l}1.7 \times 10^{-5} \text { to } \\
1.7 \times 10^{-4}\end{array}$ & $\begin{array}{l}0.0037 \text { to } \\
0.10\end{array}$ \\
\hline
\end{tabular}

a Emission rate obtained from Nriagu and Pacyna (1988) and assumed annual production rate of 50,000 t. Air concentrations calculated by using CAP-88 (USEPA 1992). Emission rate range and range of carcinogenic risk and hazard quotients reported; air concentrations and intake levels given only for upper end of range. NA = not applicable; ND = not available; $-=$ cannot be calculated.

b Intake calculated assuming $22-\mathrm{m}^{3} /$ day inhalation rate, $70-\mathrm{kg}$ body weight for 70 -year exposure; can be obtained by multiplying air concentration by factor of 0.314 .

c Slope factor and reference dose values obtained from USEPA $(1993 a, b)$.

d Carcinogenic risk calculated as intake multiplied by slope factor; hazard quotient calculated as intake divided by reference dose (USEPA 1989a).

e Chromium emissions assumed to be composed of $32 \%$ chromium VI (carcinogenic); therefore, intake value is multiplied by a factor of 0.32 . 
The individual risk from lead exposure cannot be calculated at this time, but the risk level is relatively low. The calculated air concentration (i.e., $0.018 \mu \mathrm{g} / \mathrm{m}^{3}$ ) is about 100 times lower than the $1.5 \mathrm{\mu g} / \mathrm{m}^{3}$ 90-day average mandated as the National Ambient Air Quality Standard under the Clean Air Act (40 CFR 50.12).

Only manganese currently has an inhalation reference dose available from the USEPA (1993b). For manganese, the hazard quotient (intake divided by reference dose) is approximately 0.1 , which indicates that the exposure would be about 10 times less than the level of concern for systemic toxicity.

Inhalation reference dose data are unavailable for the other chemical contaminants of concern. However, because the predicted daily intakes from inhalation are generally so low, it is unlikely that systemic toxicity estimates would be significant. This statement is based on currently available inhalation reference doses, which generally range from $10^{-5}$ to almost $1 \mathrm{mg} / \mathrm{kg}$ per day (USEPA 1993a,b).

For the produce ingestion pathway, only arsenic and lead (of the contaminants of concern shown in Table 5.11) are considered potentially carcinogenic when ingested by humans. Risk from arsenic via this pathway is within the range considered acceptable, ranging from $8.3 \times 10^{-7}$ to $5.8 \times 10^{-6}$. No slope factor or reference dose values are available for lead; however, the predicted soil concentration of $0.42 \mathrm{mg} / \mathrm{kg}$ is much less than the $500 \mathrm{mg} / \mathrm{kg}$ cleanup level for Superfund sites (USEPA 1989b).

Except for lead, oral reference doses are available for all the chemical contaminants of concern. Calculation of hazard quotients indicated that systemic toxicity was not of concern for the produce ingestion pathway (i.e., all hazard quotients were far less than one).

\section{Smelting Residuals}

Recycling RSM involves melting materials in foundries or steel mills that release residues to the environment. Some of the chemicals comprising these residues have been found to be injurious to human health, especially those from nonferrous metal processing. In steel making, the concentration of toxic chemicals in residues is generally very low, so that human health risks are negligible.

The USEPA recently evaluated wastes associated with iron and steel furnaces to determine whether they should be regulated as hazardous (USEPA 1990c). For this evaluation, possible carcinogenic risks and noncarcinogenic health effects for the maximally exposed individual were estimated from chronic exposures to contaminants released to groundwater, surface water, and air.

The basic oxygen furnace melts some combination of pig iron, scrap, and/or directreduced iron and is used in about $60 \%$ of steelmaking facilities. The electric arc furnace is used in most of the remainder of the facilities, and scrap is the predominant feed material. 
TABLE 5.11 Intakes and Risks Associated with the Produce Ingestion Pathway for Smelter Emissions ${ }^{a}$

\begin{tabular}{|c|c|c|c|c|c|c|c|c|c|}
\hline $\begin{array}{c}\text { Chemical } \\
\text { Contami- } \\
\text { nant of } \\
\text { Concern }\end{array}$ & $\begin{array}{c}\text { Emission } \\
\text { Rate } \\
\text { (kg/yr) }\end{array}$ & $\begin{array}{l}\text { Plant } \\
\text { Uptake } \\
\text { Factor }\end{array}$ & $\begin{array}{c}\text { Maximum } \\
\text { Soil } \\
\text { Concentra- } \\
\text { tion } \\
\text { (mg/kg) }\end{array}$ & $\begin{array}{c}\text { Maximum } \\
\text { Plant } \\
\text { Concentra- } \\
\text { tion }{ }^{b} \\
(\mathrm{mg} / \mathrm{kg})\end{array}$ & $\begin{array}{c}\text { Maximum } \\
\text { Intake }^{\mathrm{c}} \\
(\mathrm{mg} / \mathrm{kg} / \mathrm{d})\end{array}$ & $\begin{array}{l}\text { Chronic } \\
\text { Oral Slope } \\
\text { Factor } \\
(\mathrm{mg} / \mathrm{kg} / \mathrm{d})^{-1}\end{array}$ & $\begin{array}{c}\text { Chronic } \\
\text { Oral } \\
\text { Reference } \\
\text { Dose }^{\mathrm{d}} \\
(\mathrm{mg} / \mathrm{kg} / \mathrm{d})\end{array}$ & $\begin{array}{c}\text { Lifetime } \\
\text { Carcino- } \\
\text { genic Risk } \\
\text { Range }^{\mathrm{e}}\end{array}$ & $\begin{array}{c}\text { Hazard } \\
\text { Quotient } \\
\text { Range }^{\mathrm{e}}\end{array}$ \\
\hline Antimony & $0.25-5.0$ & 0.03 & $2.1 \times 10^{-4}$ & $6.3 \times 10^{-6}$ & $4.8 \times 10^{-8}$ & ND & 0.0004 & - & $\begin{array}{l}0.000006 \text { to } \\
0.00012\end{array}$ \\
\hline Arsenic & 25-175 & 0.006 & $7.3 \times 10^{-3}$ & $4.4 \times 10^{-5}$ & $3.3 \times 10^{-7}$ & 1.75 & 0.0003 & $\begin{array}{l}8.3 \times 10^{-8} \text { to } \\
5.8 \times 10^{-7}\end{array}$ & $\begin{array}{l}0.00016 \text { to } \\
0.0011\end{array}$ \\
\hline Cadmium & $2.0-20$ & 0.15 & $8.3 \times 10^{-4}$ & $1.3 \times 10^{-4}$ & $9.9 \times 10^{-7}$ & ND & 0.001 & - & $\begin{array}{l}0.000099 \text { to } \\
0.00099\end{array}$ \\
\hline Chromium $^{\mathrm{f}}$ & $\begin{array}{l}200 \\
2,000\end{array}$ & 0.0045 & $8.3 \times 10^{-2}$ & $3.8 \times 10^{-4}$ & $9.1 \times 10^{-7}$ & ND & 0.005 & - & $\begin{array}{l}0.000018 \text { to } \\
0.00018\end{array}$ \\
\hline Copper & $10-200$ & 0.25 & $8.3 \times 10^{-3}$ & $2.1 \times 10^{-3}$ & $1.6 \times 10^{-5}$ & ND & 0.037 & - & $\begin{array}{l}0.000022 \text { to } \\
0.00043\end{array}$ \\
\hline Lead & $75-1000$ & NA & $4.2 \times 10^{-2}$ & NA & NA & ND & & - & - \\
\hline Manganese & $75-2,000$ & 0.05 & $8.3 \times 10^{-2}$ & $4.2 \times 10^{-3}$ & $3.2 \times 10^{-6}$ & ND & 0.1 & - & $\begin{array}{l}0.000011 \text { to } \\
0.00032\end{array}$ \\
\hline Nickel & $2.5-500$ & 0.06 & $2.1 \times 10^{-2}$ & $1.3 \times 10^{-3}$ & $9.9 \times 10^{-6}$ & ND & 0.02 & - & $\begin{array}{l}0.0000024 \\
\text { to } 0.00049\end{array}$ \\
\hline Selenium & $0.05-0.15$ & 0.025 & $6.3 \times 10^{-6}$ & $1.6 \times 10^{-7}$ & $1.2 \times 10^{-9}$ & ND & 0.005 & - & $\begin{array}{l}8.1 \times 10^{-8} \text { to } \\
2.4 \times 10^{-7}\end{array}$ \\
\hline Vanadium & $5.0-100$ & 0.003 & $4.2 \times 10^{-3}$ & $1.3 \times 10^{-5}$ & $9.9 \times 10^{-8}$ & ND & 0.007 & - & $\begin{array}{l}0.0000007 \\
\text { to } 0.000014\end{array}$ \\
\hline Zinc & $\begin{array}{l}500- \\
2,250\end{array}$ & 0.9 & $9.4 \times 10^{-2}$ & $8.4 \times 10^{-2}$ & $6.4 \times 10^{-4}$ & ND & 0.3 & - & $\begin{array}{l}0.00047 \text { to } \\
0.0021\end{array}$ \\
\hline Total & NA & NA & NA & NA & NA & NA & NA & $\begin{array}{l}8.3 \times 10^{-7} \text { to } \\
5.8 \times 10^{-6}\end{array}$ & $\begin{array}{l}0.0009 \text { to } \\
0.0063\end{array}$ \\
\hline
\end{tabular}

Footnotes appear on next page. 


\section{TABLE 5.11 (Cont.)}

a Emission rate obtained from Nriagu and Pacyna (1988) and assumed annual production rate of 50,000 t. Soil concentrations calculated by using CAP-88 and assuming 15-cm mixing depth and soil density of $1.6 \mathrm{~g} / \mathrm{cm}^{3}$. Emission rate range and range of carcinogenic risk and hazard quotients reported; air concentrations and intake levels given only for upper end of range. NA $=$ not applicable; ND $=$ not available; $-=$ cannot be calculated.

b Plant uptake factors obtained from Baes et al. (1984); plant concentration equals soil concentration multipled by uptake factor.

c Intake calculated assuming ingestion rate of $0.53 \mathrm{~kg} / \mathrm{day}$ and body weight of $70 \mathrm{~kg}$.

d Slope factor and reference dose values obtained from USEPA (1993a,b).

e Carcinogenic risk calculated as intake multiplied by slope factor; hazard quotient calculated as intake divided by reference dose (USEPA 1989a).

$f$ Chromium emissions assumed to be composed of $32 \%$ chromium VI (carcinogenic); therefore, intake value is multiplied by a factor of 0.32 . 
In the basic oxygen process, pure oxygen is injected into molten metal to oxidize carbon, silicon, and other reactive metals. Wastes from these processes include slag and furnace gases, which are passed through air pollution control devices (dry collectors or wet scrubbers) to generate dust and/or sludge. The slag may contain oxides of silicon, aluminum, calcium, magnesium, and trace elements and fused oxides (including those of iron and manganese) combined with calcium silicates and ferrites. Dust/sludge (and uncaptured emissions) can contain metals such as arsenic, lead, nickel, and selenium in addition to organic compounds such as benzene and formaldehyde. Health effects associated with individual constituents of the residuals are described in Appendix E.

To assess potential health and environmental impacts associated with these wastes, the USEPA evaluated the intrinsic hazard of chemicals in the wastes and applied screening criteria to identify key contaminants. The intrinsic hazards were evaluated by testing the slags and the air pollution control dusts/sludges for corrosivity, reactivity, ignitability, and toxicity. Results indicated that the slags were not hazardous, and in fact these slags are commonly crushed for use as aggregate. For the dusts/sludges, the concentration of selenium in a small number of individual samples exceeded the regulatory level for toxicity (which is more appropriately assessed on the basis of multiple samples). For iron blast furnaces, the concentration of lead also exceeded the toxicity limit in a small number of individual samples.

The release and transport of key contaminants associated with steelmaking wastes were then evaluated, considering their persistence and mobility as well as potential volatilization (e.g., of organic contaminants) and leaching. To assess exposures, conservative assumptions were used to estimate intakes from routine inhalation of airborne contaminants, incidental ingestion of soil containing deposited contaminants (accounting for rates of soil ingestion by children), and ingestion of contaminated water. For example, it was assumed that (1) the airborne concentration of respirable particles (including windblown contaminants) equals $50 \mathrm{\mu g} / \mathrm{m}^{3}$ (the limit for particulate matter per the national ambient air quality standard), and the contaminant concentration in those particles equals its concentration in the given waste; (2) two liters of contaminated water is ingested per day; and (3) an individual is exposed for 70 years. Conservative assumptions were also applied to estimate risks; for example, chromium was assumed to be present as the toxic (hexavalent) form. A cancer incidence risk level of $1 \times 10^{-5}$ was the screening criterion.

For human exposures to airborne particulates, the key contaminants for slag are arsenic, chromium, manganese, and nickel; those for dust/sludge are arsenic, cadmium, and chromium. In general, the large size of slag fragments (most are $>100 \mu \mathrm{m}$ in diameter) limits the potential for downwind exposures. Only particles $<100 \mu \mathrm{m}$ are reasonably transportable; only those less than $30 \mu \mathrm{m}$ can be transported considerable distances; and only those $<10 \mu \mathrm{m}$ are respirable. Thus, exposures to slag particles are less likely than exposures to dust/sludge particles. The location of receptors relative to a facility is the primary factor in determining the potential significance of exposures.

For slag, airborne arsenic, chromium, and nickel were identified as potential contributors to a cancer risk above $1 \times 10^{-5}$, and inhalation of airborne manganese could 
result in noncancer health effects. Potential noncancer health effects from incidental soil ingestion were identified for arsenic, chromium, and thallium, and arsenic ingestion could account for a cancer risk above $1 \times 10^{-5}$. However, given that much of the slag would exceed respirable size, that the hexavalent form typically accounts for only about $30 \%$ of total chromium, and that receptors were assumed to be closer than is typical for such facilities, these risk values are considerable overestimates. If slag leachate were released to a drinking: water supply and diluted less than tenfold, long-term ingestion could result in noncancer health effects from antimony, arsenic, lead, and barium; arsenic could also account for a risk above $1 \times 10^{-5}$. These risk values are considered overestimates of potential impacts because of the conservative assumptions used and the likelihood of greater dilutions.

For the dust/sludge solids from furnace air pollution control devices, antimony, arsenic, lead, and thallium are indicated as potential contributors to noncarcinogenic health effects from incidental ingestion; arsenic could also account for a cancer risk above $1 \times 10^{-5}$. An inhalation risk above this level is indicated for arsenic, cadmium, and chromium. (The screening-level results for these solids are based on conservative assumptions regarding the respirable fraction and contaminant composition, as previously described for the slag components.) If leachate from these solids were diluted less than tenfold by a receiving water body, long-term ingestion could result in noncancer health effects from antimony, arsenic, cadmium, fluoride, lead, manganese, selenium, thallium, and zinc; arsenic could also account for a risk above $1 \times 10^{-5}$. As described above for the slags, these values are considered overestimates of potential impacts, and they can also be mitigated by site conditions.

The key contaminants in regard to water supply impacts for slag are arsenic, mercury, fluoride, and molybdenum. The key contaminants for dust/sludge solids from air pollution control devices are arsenic, chromium, fluoride, cadmium, mercury, molybdenum, and selenium. The likelihood of adverse impacts to groundwater from these contaminants is low where certain mitigating conditions exist. These conditions include the presence of clayey soils, a relatively low net groundwater recharge $(8-15 \mathrm{~cm} / \mathrm{yr})$, the presence of confining layers, and relatively deep $(15-23 \mathrm{~m})$, and large aquifers (with large dilution volumes). For the smaller dust/sludge solids, the contaminants are somewhat more available for leaching, and the potential for release, transport, and exposure via ranged from low to fairly high.

The likelihood of adverse impacts to surface water from slag is generally low because of the small fraction of erodible-size solids $(\leq 0.1 \mathrm{~mm})$ and can be further reduced by runon/runoff controls. The potential for significant exposure to contaminants released from slag solids via the surface water pathway was found to be moderate at most. For dust/sludge solids, the smaller particle size $(<0.02-2 \mathrm{~mm})$ translates to greater susceptibility to overland transport. Thus, potential impacts could result from uncontrolled placement of this waste (e.g., depending on a facility's proximity to a drinking water source).

From the risk assessment, available data identified no cases of danger to human health or the environment from iron blast furnaces or steel furnaces.' In addition, relatively few samples of air pollution control dust/sludge solids from these furnaces exhibited toxicity, and those few were generally at levels just above the regulatory limit. Although exposures 
can occur via ingestion and inhalation, facility engineering controls and population distance combine to limit the potential for adverse impacts.

\subsubsection{Transportation Accidents}

The recycle alternative would probably require transportation of RSM from the source facility to the site of the decontamination facility and controlled smelter. Disposal of $\mathrm{RSM}$ residuals would also require shipment by truck or rail to the LLW disposal site. All transport is assumed to occur by truck. The RSM ingot would then be transported to a commercial smelter and from there would enter normal manufacturing and distribution channels. Risks associated with vehicle operation (independent of cargo type) include traffic accident fatalities and potential cancer fatalities from vehicle exhaust emissions.

On the basis of accident fatality rates for combination trucks on interstate highways in the U.S.A. (Saricks and Kvitek 1991), a total of $5 \times 10^{-3}$ fatalities would be expected for recycling 50,000 $\mathrm{t}$ (assuming two 100-km transport segments). This is based on an estimated $2 \times 10^{-8}$ fatalities per shipment-km for accidents.

\subsubsection{Summary of Nonradiological Health Impact Analysis}

RSM recycle operations potentially present cancer fatality risks to workers and to the public from chemical exposures. Individual risks to both nuclear and industrial workers are likely to be less than the regulatory limit of $10^{-3}$. Risks to the most exposed member of the public are estimated to be on the order of $10^{-4}$. Fatality risks from accidents are substantially higher. Collective public risks from vehicle accidents in transporting RSM to a controlled melter and ingots to a commercial melter are estimated to be on the order of $10^{-2}$. The risk of industrial accidents resulting in fatalities or serious injuries from the controlled and commercial melting processes combined is somewhat greater than eight incidents per 50,000 $\mathrm{t}$ of RSM.

\subsection{ENVIRONMENTAL IMPACTS}

Potential impacts to environmental resources that might be associated with recycling RSM include those to air quality, water quality, energy, and biota that might be affected by resource requirements, emissions, or waste generated by those operations. Environmental impacts from RSM recycle are difficult to quantify so a qualitative discussion is presented in Sections 5.4.1 through 5.4.5. No significant incremental environmental impacts are expected to result from the addition of RSM to the recycling industry. Resource savings from recycling metal of all types are considerable, particularly with regard to energy. Additional benefits from using steel scrap include reductions of $90 \%$ in raw material consumption (mainly coal) (Lund 1993). Section 5.4.6 discusses the potential for impacts on sensitive industrial technologies. 


\subsubsection{Air Quality}

Recycling RSM involves three major activities that could generate emissions that would degrade air quality: decontamination, melting in a controlled smelter, and scrap remelting at a commercial mill. The presence of radioactivity and hazardous chemicals is likely to require efficient emission-control technology for exhaust air in decontamination and melting activities, so emissions from these activities are likely to have negligible impacts. Controls would likely be less stringent on emissions from commercial steel mills where the scrap would be remelted, and some air quality impacts are likely. However, in general; emissions from recycling are less than those from primary metal smelting because many impurities have previously been removed and less energy is generally required. A total reduction of $86 \%$ in air emissions for recycling has been estimated by Lund (1993).

\subsubsection{Land Use/Disturbance}

Impacts to land use from recycling RSM would be relatively minor. The main requirements are land for the development of facilities for decontamination and melting of RSM. About $10 \%$ of the inputs to controlled smelting would require disposal as LLW in the form of slag. Compared to steel production from ore and other raw materials, scrap recycling produces 97\% less mining waste (Lund 1993).

\subsubsection{Water Quality/Resources}

Impacts to water and associated biota could potentially occur in the specific location of a processing facility for RSM. However, releases are assumed to be controlled to acceptable standards of the locale/country of the facility. Nitrates and phosphates associated with the initial decontamination reagents are not expected to increase the eutrophication of the receiving water, nor are the naturally occurring metals and other elements in the effluent expected to incrementally affect the receiving water, because precipitates would be separated from the effluent stream before discharge, and the flow ratio would further reduce incremental contaminant concentrations upon mixing. Thus, the release of decontamination effluents to the receiving stream is not expected to adversely impact related environmental resources. Over all the processes involved, other than decontamination, scrap recycling has been found to require $40 \%$ less water and to produce $76 \%$ less water pollution than producing steel from raw materials (Lund 1993).

\subsubsection{Energy Requirements}

Production of one ton of steel entirely from scrap metal requires approximately 10.5 GJ of energy (Steiner 1993). In metal production generally, most of the required energy inputs are applied in the refining stage, which can be avoided by using scrap. The energy savings from producing just one ton of steel from scrap rather than ore can meet the electricity needs of one U.S.A. household for one year. The relative energy savings from 
using copper or aluminum scrap are even greater than for steel scrap. Copper production from scrap requires about half of the energy that primary production requires (Jolly et al. 1993). Manufacturing new aluminum cans from used ones requires $95 \%$ less energy than producing the cans from raw materials. Although some decontamination techniques such as electropolishing are relatively energy intensive, energy use for recycling RSM is still likely to be less than for replacement. These statements also generally apply to the commitment of energy in decontamination operations, except in the case of metal melting. The energy requirements for melting are high, and additional costs are associated with operation and maintenance for this facility compared with the other, common decontamination methods.

\subsubsection{Industrial Technology Impacts}

In a pilot study on the effects of radioactivity on scientific and technical equipment, the Japanese Atomic Energy Research Institute found that large-scale integrated circuits, high-sensitivity photographic film, and low-background radiation counters had the most potential for being deleteriously affected by residual radioactivity in metals (Kato et al. 1989). The possible impacts have been evaluated in more detail by S. Cohen \& Associates, Inc. (1995). They concluded that there is a potential for impacts and that technology sensitivity to radiation may increase in the future, but lacked sufficient information to identify specific levels of activity in metals that might cause such impacts. Indeed, radiationsensitive industries are coping with much higher radiation levels from ambient sources than would be introduced by RSM recycling

The computer industry could possibly be affected due to the effects of radiation on large-scale integrated circuits. The most important effect of radioactivity on such circuits is "soft error." Soft error is the temporary disruption of data caused by the movement of alpha particles through the circuit's memory array. The soft error rate is proportional to alpha flux and it increases as the integration density of large integrated circuits increases (Kato et al. 1989). As industry moves toward circuits with higher integration density, attention must be paid to the potential effects of residual radioactivity. The potential for soft error production due to naturally occurring uranium and thorium has been recognized for some time, so the industry seeks high-purity materials for inclusion in the circuits. The silicon chips are then encased in ceramic (which also may contain uranium or thorium impurities) or plastic material, which provides shielding from externally produced alpha and beta radiation. Modelling of alpha particle flux effects shows that a $1 \mathrm{~Bq} / \mathrm{g}$ concentration in metals used in chip construction would meet industry standards (Yamamoto and Kato 1995).

High-sensitivity photographic film, such as that used for industrial or medical X-rays, is particularly reactive to the presence of radiation. The effect of this radiation exposure is to create "fog" which interferes with the clarity of the picture. Because of normal background radiation, fog intensifies linearly with film storage duration (Kato et al. 1989). Thus, the effectiveness of high-sensitivity medical and industrial film is reduced as it is exposed to more sources of radiation - residual or background. 
Much of the world's steel supply has been contaminated as a result of the use of Co-60 in blast furnaces to assess furnace material deterioration and also the fallout from weapons testing. The resulting level of radioactivity in steel is estimated to be $10^{-5}$ to $10^{-4} \mathrm{~Bq} / \mathrm{g}$ (Knoll 1979) which presents negligible risks to human health. However, this level of contamination does affect the minimum detection level of low-level, background radiation counters. As a result, only uncontaminated steel is used as the shield material for wholebody counters, which have low detection limits (Kato et al. 1989). Current practice in the U.S.A. is to use steel produced from low-activity raw materials for this purpose. Since this is already the practice, recycling RSM would not affect low-level radiation counters.

Deleterious effects of residual radioactivity and the costs involved in eliminating or controlling those effects should be considered when regulators determine acceptable levels of residual radioactivity in recycled materials. However, the need to minimize effects of residual radioactivity is not a new problem but one that sensitive industries have developed strategies to cope with. In addition, the radiation levels from recycled RSM are likely to be low relative to radiation from ambient and other manmade sources.

\subsection{REFERENCES FOR SECTION 5}

ACGIH - see American Conference of Governmental Industrial Hygienists.

Agency for Toxic Substances and Disease Registry, 1989, Toxicological Profile for Chromium, ATSDR/TP-88/10, prepared by Syracuse Research Corporation for Agency for Toxic Substances and Disease Registry, U.S. Public Health Service in collaboration with: U.S. Environmental Protection Agency, July.

Alzona, J. et al., 1979, "Indoor-Outdoor Relationships for Airborne Particulate Matter of Outdoor Origin," Atmospheric Environment 13:55-60.

American Cancer Society, 1992, Cancer Facts \& Figures - 1992, Atlanta, Ga.

American Conference of Governmental Industrial Hygienists, 1990, 1990-1991 Threshold Limit Values for Chemical Substances and Physical Agents and Biological Exposure Indices, Cincinnati, Ohio.

Baes, C.F., et al., 1984, A Review and Analysis of Parameters for Assessing Transport of Environmentally Released Radionuclides through Agriculture, ORNL-5786, prepared by Oak Ridge National Laboratory, Oak Ridge, Tenn., for U.S. Department of Energy, Oak Ridge Operations, Oak Ridge, Tenn.

CEC - see Commission of the European Communities.

Chapuis, A.M., et al., undated, Exemption Limits for the Recycling of Materials from the Dismantling of Nuclear Installations, Commissariat á L'Energie Atomique, Fontenay-auxRosès, Frańce. 
Chen, S.Y., et al., 1995, "Assessment of Risks and Costs Associated with Transportation of DOE Radioactively Contaminated Carbon Steel," presented to the U.S. Department of Energy, Office of Environmental Management, Recycle 2000 Workshop, Salt Lake City, Utah, Sept. 26-27, 1995.

Commission of the European Communities, 1988, Radiation Protection Criteria for the Recycling of Materials from the Dismantling of Nuclear Materials, Radiation Protection No. 43, Luxembourg.

Commission of the European Communities, 1995, Recommended Radiological Protection Criteria for the Recycling of Metals from the Dismantling of Nuclear Installations , EUR0295 (De/BS), Draft Proposal, Luxembourg, Feb.

EG\&G Idaho, Inc., 1987, Conceptual Design Report Alternative Concepts for Low-Level Radioactive Waste Disposal, DOE/LLW-60T, National Low-Level Radioactive Waste Management Program, Idaho Falls, Idaho.

Healy, J.W., 1971, Surface Contamination: Decision Level, LA-4558-MS, Los Alamos National Laboratory, Los Alamos, N.M.

Hertzler, T., et al., 1993, Recycle of DOE Radiologically Contaminated Metal - A Scoping Study, Draft, Science Application International Corp., Idaho Falls, Idaho.

IAEA - see International Atomic Energy Agency.

ICRP - see International Commission on Radiological Protection.

International Atomic Energy Agency, 1985, Decontamination of Nuclear Facilities to Permit Operation, Inspection, Maintenance, Modification, or Plant Decommissioning, Technical Reports Series No. 249, STI/DOC/10/249, Vienna, Austria.

International Atomic Energy Agency, 1986, Methodology and Technology of Decommissioning Nuclear Facilities, Technical Report Series No. 267, Vienna, Austria.

International Atomic Energy Agency, 1987a, Packaging and Transportation of Radioactive Materials (PATRAM '86), Proceedings of a Symposium held in Davos, Switzerland, June 1620, STI/PUB/718, Vienna, Austria.

International Atomic Energy Agency, 1987b, Exemption of Radiation Sources and Practices from Regulatory Control, IAEA-TECDOC-401, Interim Report, Vienna, Austria.

International Atomic Energy Agency, 1988, Principles for the Exemption of Radiation Sources and Practices from Regulatory Control, IAEA Safety Series No. 89, Vienna, Austria.

International Atomic Energy Agency, 1992, Application of Exemption Principles to the Recycle and Reuse of Materials from Nuclear Facilities, IAEA Safety Series No. 111, Vienna, Austria. 
International Commission on Radiological Protection, 1979, Limits for Intakes of Radionuclides by Workers, ICRP Publication 30, Part 1 (and subsequent parts and supplements), Vol. 2, Nos. 3-4 through Vol. 8, No. 4, Pergamon Press, Oxford, United Kingdom.

International Commission on Radiological Protection, 1991, 1990 Recommendations of the International Commission on Radiological Protection, ICRP Publication 60, Pergamon Press, Oxford, United Kingdom.

Johnson, A., 1993, "Estimated Isotope Partitioning," transmittal from Johnson (Scientific Ecology Group, Oak Ridge, Tenn.) to S.Y. Chen (Argonne National Laboratory, Argonne, Ill.).

Jolly, J.L.W., et al., 1993, Recycling - Nonferrous Metals: 1991 Annual Report, U.S. Department of the Interior, Bureau of Mines, Washington, D.C., May.

Kato, S., et al., 1989, "Effects of Residual Radioactivity in Recycled Materials on Scientific and Industrial Equipments," in Residual Radioactivity and Recycling Criteria, Workshop Proceedings, St. Michaels, Md., Sept.

Knoll, G.F., 1979, Radiation Detection and Measurement, John Wiley and Sons, New York, N.Y.

Loiselle, V., 1993, personal communication from Loiselle (Quadrex Recycle Center, Oak Ridge, Tenn.) to S. Wilson (Argonne National Laboratory, Argonne, Ml.), June.

Lund, H., 1993, The McGraw-Hill Recycling Handbook, McGraw-Hill, Inc., New York, N.Y.

Manion, W.J., and T.S. LaGuardia, 1980, Decommissioning Handbook, DOE/EV/10128-1, prepared by Nuclear Energy Services, Inc., Danbury, Conn., for U.S. Department of Energy, Office of Nuclear Waste Management, Washington, D.C.

Masaidis, J., 1993, personal communication from J. Masaidis (U.S. Steel, Pittsburgh, Pa.) to S. Wilson (Argonne National Laboratory, Argonne, Ill.), June.

Menon, S., and L. Teunckens, 1994, "Application of Exemption Concepts: Overview of Practices in Some Countries," presented at Waste Management '94, Tucson, Ariz., Feb. 27March 3.

National Institute for Occupational Safety and Health, 1990, NIOSH Pocket Guide to Chemical Hazards, DHHS (NIOSH) Publication No. 90-117, U.S. Department of Health and Human Services, Public Health Service, Washington, D.C., June.

Neuhauser, K.S., and F.L. Kanipe, 1993, RADTRAN 4, Volume II: Technical Manual, SAND89-2370, Sandia National Laboratory, Albuquerque, N.M.

NIOSH - see National Institute for Occupational Safety and Health. 
Nriagu, J.O., and J.M. Pacyna, 1988, "Quantitative Assessment of Worldwide Contamination of Air, Water, and Soils by Trace Metals," Nature 333:134-139.

Nuclear Energy Agency, 1981, Decontamination Methods as Related to Decommissioning of Nuclear Facilities, Report by an NEA Group of Experts, Organization for Economic Cooperation and Development, Paris, France, March.

O'Donnell, F.R., et al., 1978, Potential Radiation Dose to Man from Recycle of Materials Reclaimed from a Decommissioned Nuclear Power Plant, NUREG/CR-0134, ORNL/NUREG/TM-215, prepared by Oak Ridge National Laboratory, Oak Ridge, Tenn., for the U.S. Nuclear Regulatory Commission, Washington, D.C.

Oztunali, O.I., et al., 1981, Data Base for Radioactive Waste Management: Impacts Analyses Methodology Report, NUREG/CR-1759, Vol. 3, U.S. Nuclear Regulatory Commission, Washington, D.C.

Saricks, C., and T. Kvitek, 1994, Longitudinal Review of State-Level Accident Statistics for Carriers of Interstate Freight, ANL/ESD/TM-68, Argonne National Laboratory, Argonne, IIl.

S. Cohen \& Associates, Inc., 1995, Analysis of the Potential Recycling of Department of Energy Radioactive Scrap Metal, prepared for U.S. Environmental Protection Agency, Office of Radiation and Indoor Air, McLean, Va.

Steiner, B.A., 1993, personal communication from Steiner (Vice President for Environment and Energy, American Iron and Steel Institute, Washington, D.C.) to S.E. Wilson (Argonne National Laboratory, Argonne, Ill.), Feb. 23.

U.S. Bureau of Mines, 1985, Mineral Facts and Problems, 1985 Edition, Bulletin 675, Washington, D.C.

U.S. Department of Labor, 1986, Occupational Injuries and Illnesses in the United States by Industry, 1986, Bulletin 2259, Bureau of Labor Statistics, Washington, D.C., May.

U.S. Department of Labor, 1989, Occupational Injuries and Illnesses in the United States by Industry, 1987, Bureau of Labor Statistics Bulletin 2328, Washington, D.C.

U.S. Environmental Protection Agency, 1989a, Risk Assessment Guidance for Superfund, Volume I: Human Health Evaluation Manual (Part A, Interim Final), EPA/540/1-89/001, prepared by Office of Emergency and Remedial Response, Washington, D.C., Dec.

U.S. Environmental Protection Agency, 1989b, Interim Guidance on Establishing Soil Lead Cleanup Levels at Superfund Sites, OSWER 9355.4-02, Office of Solid Waste and Emergency Response, Washington, D.C., Sept. 7.

U.S. Environmental Protection Agency, 1990a, "Corrective Action for Solid Waste Management Units (SWMUs) at Hazardous Waste Management Facilities," proposed rule, Title 40, Parts 264, 265, 270, and 271, Federal Register 55:30798, July 27. 
U.S. Environmental Protection Agency, 1990b, "National Oil and Hazardous Substances Pollution Contingency Plan; Final Rule (400 CFR Part 300)," Federal Register 55(35):61546176, Feb. 21.

U.S. Environmental Protection Agency, 1990c, Report to Congress on Special Wastes from Mineral Processing, EPA/530-SW-90-070C, Office of Solid Waste and Emergency Response, Washington, D.C.

U.S. Environmental Protection Agency, 1991, Human Health Evaluation Manual, Supplemental; Guidance: "Standard Default Exposure Factors, "memorandum from T. Fields, Jr. (Acting Director, Office of Emergency and Remedial Response) and B. Diamond (Office of Waste Programs Enforcement) to Director, Various Divisions, Regions I through IX, OSWER Directive 9285.6-03, Office of Solid Waste and Emergency Response, Washington, D.C., March 25.

U.S. Environmental Protection Agency, 1992, User's Guide for CAP88-PC, Version 1.0, 402-B-92-001, Office of Radiation Programs, Washington, D.C.

U.S. Environmental Protection Agency, 1993a, Health Effects Assessment Summary Tables, Annual Update, OERR 9200.6-303 (93-1), Office of Research and Development, Office of Emergency and Remedial Response, Washington, D.C., March.

U.S. Environmental Protection Agency, 1993b, "Integrated Risk Information System (IRIS)," Office of Research and Development, database, Oct.

U.S. Environmental Protection Agency 1993c, External Exposure to Radionuclides in Air, Water, and Soil, Federal Guidance Report No. 12, EPA 402-R-93-081, Washington, D.C.

USEPA - see U.S. Environmental Protection Agency.

USNRC - see U.S. Nuclear Regulatory Commission.

U.S. Nuclear Regulatory Commission, 1974, Termination of Operating License for Nuclear Reactors, Regulatory Guide 1.86, Washington, D.C.

U.S. Nuclear Regulatory Commission, 1980, Draft Environmental Statement Concerning Proposed Rulemaking Exemption from Licensing Requirements for Smelted Alloys Containing Residual Technetium and Low-Enriched Uranium, Office of Standards Development, Washington, D.C.

U.S. Nuclear Regulatory Commission, 1990, "Standards for Protection against Radiation," 10 CFR Part 20, Washington, D.C.

U.S. Nuclear Regulatory Commission, 1992, Residual Radioactive Contamination from Decommissioning: Volume 1, Technical Basis for Translating Contamination Levels to Annual Total Effective Dose Equivalent, NUREG/CR-5512, Washington, D.C. 
U.S. Nuclear Regulatory Commission, 1993a, "License Requirements for Land Disposal of Radioactive Waste," 10 CFR Part 61, Revised, Washington, D.C.

U.S. Nuclear Regulatory Commission, 1993b, "Packaging of Radioactive Material for Transport and Transportation of Radioactive Material under Certain Conditions," 10 CFR Part 71, Revised, Washington, D.C.

Warren, S., 1995, "Recycle 2000: the Process and Progress," presented at Beneficial Reuse '95, University of Tennessee, Knoxville, Tenn., July 31-Aug. 3.

Yamamoto, H., and S. Kato, 1995, "Effects on Radiation Sensitive Instruments from Recycling of Contaminated Metal," Proceedings of the Second Workshop on Residual Radioactivity and Recycling Criteria, U.S. Environmental Protection Agency and Japan Atomic energy Research Institute, Nov. 9-11, Tokai, Japan.

Yu, C., et al., 1993a, Data Collection Handbook to Support Modeling the Impacts of Radioactive Material in Soil, ANLJEAIS-8, Argonne National Laboratory, Argonne, Ill., April.

Yu, C., et al., 1993b, Manual for Implementing Residual Radioactive Material Guidelines Using RESRAD, Version 5, Working Draft for Comment, ANL/EAD/LD-2, Argonne National Laboratory, Argonne, ח1., Sept.

Yu, C., et al., 1994, RESRAD-BUILD: A Computer Model for Analyzing the Radiological Doses Resulting from the Remediation and Occupancy of Buildings Contaminated with Radioactive Material, ANL/EAD/LD-3, Argonne National. Laboratory, Argonne, 11 . 


\section{IMPACTS OF RADIOACTIVE SCRAP METAL DISPOSAL AND REPLACEMENT}

The alternative to recycling radioactive scrap metal (RSM) is to dispose of it - on the site of origin or in a designated low-level radioactive waste (LLW) disposal facility. Disposal would remove the RSM from the world stock of metals, major portions of which are normally recycled. Choosing not to use the RSM in production of new products would entail replacing this discarded metal with newly produced supplies. The mining and refining operations involved in producing the replacement stock would result in substantial impacts to human health and to air, land, and water resources. Section 6.1 discusses the health risks and issues associated with RSM disposal as LLW, including the costs and uncertainties regarding disposal-site capacity. Section 6.2 describes the impacts of the mining and refining associated with producing replacement metals. Section 6.3 examines the impacts of the production and consumption of coking coal in steel-making. Finally, Section 6.4 summarizes the various health and environmental impacts of not recycling RSM.

\subsection{DISPOSAL OF RADIOACTIVE SCRAP METAL AS LOW-LEVEL WASTE}

In this analysis, it is assumed that if RSM were not recycled, it would be transported to and disposed of in a licensed LLW disposal site. These activities would employ practices designed to limit worker and public radiation and chemical exposures to regulatory levels.

\subsubsection{Disposal Process}

Procedures for handling of RSM for collection and classification before disposal would likely be similar to those required before recycle or reuse. Therefore, impacts associated with these preliminary procedures would likely be similar for either the disposal or the recycle options for RSM and thus are not considered here. Some decontamination might also be required to prepare and package RSM for transportation to a LLW disposal site. This effort is likely to be less intensive for the disposal option than for recycling but would also be carried out by nuclear workers. It is assumed that worker exposures to radiation or chemicals would not exceed regulatory limits.

Disposal of RSM would involve the potential for three general types of health and environmental impacts. First are the health risks associated with the transport of the scrap to the disposal site. Second, health or environmental impacts could result from any release of contaminants from a disposal site. Finally, disposal requires the dedication of the disposal site for an indefinite period. Since disposal of RSM might involve the use of existing, licensed disposal facilities, issues associated with the use of such facilities for the disposal of RSM are also considered. 


\subsubsection{Health Risks of Disposal}

\subsubsection{Workers}

Radiation doses to transportation workers would be similar to those discussed for recycle in Section 5.2.2.4. Shipping 50,000 t of RSM for a distance of $100 \mathrm{~km}$ in 20-t shipments would result in a maximum individual dose to the crew of $2 \times 10^{2} \mu \mathrm{Sv} / \mathrm{yr}$ (lifetime cancer fatality risks of $1 \times 10^{-5}$ ).

Doses to workers involved in waste disposal activities would be limited by worker protection requirements. Therefore, individual maximum doses and risks to workers would be limited to an incremental lifetime cancer fatality risk of $10^{-3}$ per year of work. Collective worker doses at LLW disposal facilities would be small because of the small worker population exposed to radioactive materials at such facilities.

\subsubsection{Public}

Public risks from radiation exposure during RSM transportation for disposal would be similar to those discussed in Section 5.2.2.4. For the public, the collective dose is $2 \times 10^{-2}$ person-Sv for transporting 50,000 t of RSM a distance of $100 \mathrm{~km}$. Associated cancer fatality risks are $8 \times 10^{-4}$. Doses from disposal of 50,000 $t$ of RSM at a LLW site are not specifically evaluated. However, since the LLW must meet the existing regulations for disposal (such as 10 CFR 61 [USNRC 1993]), health impacts from RSM disposal are likely to be similar to those for LLW disposal in general. Individual public doses must not exceed a regulatory limit of $1 \mathrm{mSv} / \mathrm{yr}$ (ICRP-60 [ICRP 1991], 10 CFR 20 [USNRC 1990]), which corresponds to a fatal cancer risk of $5 \times 10^{-5}$. ALARA procedures in disposal site design and LLW management are likely to render actual risks substantially lower. In the absence of an off-site release of contamination, a well tapped into the disposal site, or an intruder entering the disposal area, there would be no radiological impacts to the general public from the operation of a LLW disposal facility. The likelihood of such a release or intrusion is expected to be small. Furthermore, even if such an event did occur, the individual doses that might be received would likely be small, particularly if the LLW waste was disposed of below ground. Likely doses to the maximally exposed individual, an intruder, have been estimated to range from 35 to $200 \mu \mathrm{Sv} / \mathrm{yr}$ (EG\&G 1987).

National traffic fatality statistics have been used to estimate transportation accident fatalities, as discussed in Section 5.3.3.3. For disposal of 50,000 $t$ of RSM, transportation accident fatality risks are approximately $5 \times 10^{-3}$ per $100 \mathrm{~km}$.

\subsubsection{Land Use and Disposal Site Capacity}

Most RSM generated in the U.S.A. will be Class A, B, or C LLW and therefore considered suitable for near-surface disposal (see 10 CFR 61.55 for definitions of Class A, B, and $\mathrm{C}$ wastes). Although projections are uncertain, very little waste of any type is produced 
in the greater-than-Class $\mathrm{C}$ category, which in general is not acceptable for near-surface disposal (Oak Ridge National Laboratory [ORNL] 1992). Only about $550 \mathrm{~m}^{3}$ of the more than $1.6 \times 10^{6} \mathrm{~m}^{3}$ of LLW that could be produced by decommissioning of commercial reactors in the U.S.A. during the period 1992-2030 will be greater-than-Class C LLW (ORNL 1992).

Not all countries intend to place most LLW in near-surface disposal sites as is done in the U.S.A. For example, Germany, Switzerland, and the United Kingdom either have decided to use, or are considering the use of, geologic disposal for all LLW. Other countries in Europe (e.g., France and Spain) use or plan to use near-surface disposal only for LLW that has no significant quantities of isotopes with half-lives greater than 30 years. European countries are generally considering deep geologic disposal for all other LLW (Zaccai 1990).

\subsubsection{Radioactive Scrap Metal Volumes Relative to Low-Level Waste Disposal Capacity}

A partial inventory of RSM from various potential sources is provided in Section 3. RSM is not the only type of waste material produced by such sources. In general, other construction materials (such as concrete) will contribute much larger volumes of LLW. In addition, for environmental restoration activities (which will be necessary at many facilities associated with weapons production), contaminated soil will generally provide even larger volumes of materials that will require disposal. For example, at the Fernald Site in the U.S.A., which was formerly used to produce high-purity uranium, scrap metal (including scrap metal currently in storage) will contribute less than $2 \%$ of the total volume of wastes that will be associated with remedial activities (U.S. Department of Energy [DOE] 1993; ORNL 1992). At the Weldon Spring site, which also produced high-purity uranium metal, the contribution of metal will be about 6\% of the total volume (MK-Ferguson Co. 1991). Metal will constitute about $10 \%$ of the total volume of the wastes associated with the decommissioning of the Oak Ridge Gaseous Diffusion Plant (Ebasco 1991; ORNL 1992). Concrete is expected to dominate the volume of waste materials generated by the decommissioning of nuclear power plants. Depending on how RSM disposal is managed as a part of a much larger overall disposal problem, the potential for impacts of RSM disposal could vary substantially.

The disposal volume of RSM generated by dismantling of power reactors is sensitive to the period of time between nuclear power plant shutdown and dismantling, as is illustrated by the projections presented in Section 3.3.2. Because of radioactive decay, delays in dismantlement of 50 to 100 years after decommissioning would result in major reductions in the quantity of radioactive scrap metal. Therefore, decisions concerning the schedule for dismantling will have a major impact on the volume of radioactive scrap that might require disposal. This issue is important for both on-site and off-site disposal. For off-site disposal, the volume will also determine transportation costs, which can be significant for cases in which wastes must be transported long distances.

All commercial LLW disposal sites in the U.S.A. combined were projected to receive about $33,000 \mathrm{~m}^{3}$ of LLW in 1993 (ORNL 1992). The annual disposal volume for commercial 
LLW in the U.S.A. has decreased substantially during the last decade because of increased disposal costs, waste compaction, and source reduction. The annual volume of LLW requiring disposal in the U.S.A. is projected to continue to decrease and to reach about $21,000 \mathrm{~m}^{3}$ in the year 2024 (ORNL 1992).

Table 3.4 (Section 3) provides estimates of the quantities of scrap iron and mild steel expected from U.S.A. power reactors 50 years after start-up. In the peak year of this scrap flow (2024), about 36,300 $\mathrm{t}$ of activated material, about 76,800 $\mathrm{t}$ of material with removable surface contamination, and about $79,700 \mathrm{t}$ of nonradioactive material would be produced. These quantities correspond to volumes of roughly $6,500,14,000$, and $14,500 \mathrm{~m}^{3}$, respectively, assuming metal with about $30 \%$ void space and a metal density of $8 \mathrm{t} / \mathrm{m}^{3}$. The volume of activated material alone would be equivalent to about $30 \%$ of the expected annual volume of commercial LLW in the U.S.A. in the year 2024; the volume of activated material plus material with surface contamination would be equivalent to about $100 \%$ of the expected annual LLW volume in the year 2024; and the volume of all the metal scrap would be equivalent to about $160 \%$ of expected annual LLW volume.

\subsubsection{Low-Level Waste Disposal Charges}

Only two commercial LLW sites are currently accepting new wastes in the U.S.A. - Barnwell, in South Carolina, and Richland, in the State of Washington. The unit cost of disposal for LLW is high and is increasing rapidly. For the Barnwell site, the basic disposal charge, ${ }^{1}$ as of January 1,1993 , is $\$ 2,083 / \mathrm{m}^{3}$ (about $\$ 330 / \mathrm{t}$ for steel, assuming $30 \%$ void space), plus a $2.4 \%$ county tax (Chem-Nuclear Systems 1993). Various surcharges, including one for activity, also apply. The basic disposal charge has increased from $\$ 466 / \mathrm{m}^{3}$ (about \$75/t for steel) in 1983 (in 1983 U.S. dollars), an average annual rate of increase of about $16 \%$. Average annual inflation in the U.S.A. over the same period was about $4 \%$. Some reduction in disposal charges may be possible for large-volume customers; however, basic costs will still remain high. In addition to the basic charge, a surtax of $\$ 1,200 / \mathrm{m}^{3}$ (about $\$ 190 / t$ for steel) also applies to wastes originating from states outside South Carolina, but inside the Southeast Compact. ${ }^{2}$ For states outside the Southeast Compact, a surtax of $\$ 7,766 / \mathrm{m}^{3}$ (about $\$ 1,240 / \mathrm{t}$ for steel) applies. Barnwell is scheduled to close for generators outside the Southeast Compact in July 1994. It will close in January 1996 for generators in the Southeast Compact.

The Washington site is already closed to most outside wastes. The basic disposal cost for that site (1993 U.S. dollars) is about $\$ 1,730 / \mathrm{m}^{3}$ (about $\$ 277 / \mathrm{t}$ for steel) (U.S. Ecology 1993). The actual disposal cost for the Washington site depends on the radiation rate at the surface of the waste container. Various surcharges also apply, including a surcharge for activity. Although new LLW disposal facilities are anticipated to become available, it is

1 All monetary values are given in U.S.A. dollars (\$) unless otherwise noted.

2 The Southeast Compact is a group of eight southern U.S.A. states that joined to manage their low-level radioactive waste, pursuant to the Low-Level Radioactive Waste Policy Act of 1980, which authorizes approved state compacts to exclude waste from out-of-compact states. 
expected that disposal costs in the U.S.A. will continue to increase and that access to LLW disposal sites will continue to be limited on the basis of the geographic location of the waste generator. Basic disposal costs at new facilities are expected to exceed $\$ 10,600 / \mathrm{m}^{3}$ (about $\$ 1,700 /$ for steel) (Gardner 1993).

Another facility in the U.S.A. - the Envirocare site in Utah - accepts low-activity wastes that do not require management at LLW sites but that still pose potential environmental concerns. A preliminary cost of about $\$ 200 / \mathrm{m}^{3}$ (which corresponds to about $\$ 32 / t$ for steel) was estimated in 1992 for disposal at Envirocare of about $500,000 \mathrm{~m}^{3}$ of waste from the Weldon Spring site (DOE 1992b). For smaller volumes (but above $1,400 \mathrm{~m}^{3} / \mathrm{yr}$ ), costs for the facility have historically been in the range of about $\$ 900-1,600 / \mathrm{m}^{3}$ (about $\$ 140-260 /$ for steel) (Gardner 1993).

In Europe, actual or anticipated costs for LLW disposal vary considerably but typically are a function primarily of site capacity and depth of disposal (Zaccai 1990). Costs for deep disposal are about two to three times those for shallow disposal for sites with similar capacities. Facilities for disposal of LLW currently are available or are under construction in a number of European countries, but, in general, new facilities will be required to accommodate wastes generated during the decommissioning of nuclear facilities (Nuclear Energy Agency 1991).

Anticipated costs (1992) for disposal in Belgium are BF 205,000/m (about BF 33,000/t for steel) for LLW with no significant quantities of isotopes with half-lives greater than 30 years and $\mathrm{BF} 325,000 / \mathrm{m}^{3}$ (about BF $52,000 / t$ for steel) for geologic disposal of other waste (Teunckens 1993). For France, the costs for off-site shallow land disposal for $\mathrm{LLW}$ were estimated in 1989 to be FF $5,000 / \mathrm{m}^{3}$ (about FF $800 / \mathrm{t}$ for steel) for a decommissioning project (Nuclear Energy Agency 1991). Estimated costs for the disposal of decommissioning wastes (which may not all be LLW) in several European countries are as follows (in 1990 U.S.A. dollars $/ \mathrm{m}^{3}$ ): Finland, $\$ 1,400-\$ 1,600$; Spain, \$2,000; Switzerland, $\$ 1,000$ (Nuclear Energy Agency 1991). (For steel with about 30\% void space, these costs correspond to a cost per ton of about $\$ 220-\$ 260, \$ 320$, and $\$ 160$, respectively.) In Canada, similar disposal costs for LLW were estimated to be (in 1990 U.S.A. dollars) $\$ 600-\$ 4,000 / \mathrm{m}^{3}$. (about $\$ 100-640 / t$ for steel) (Nuclear Energy Agency 1991). In the United Kingdom, current (1993/1994) provisional costs for LLW disposal at the Drigg site are $£ 632 / \mathrm{m}^{3}$ (about $£ 100 / t$ for steel) for surface disposal in engineered concrete vaults (Cross 1993). Because of a reduction in projected disposal volumes, the provisional cost for 1994/1995 (in 1993 money values) is $£ 1,043 / \mathrm{m}^{3}$ (about $£ 170 / t$ for steel). Charges for level of activity are also applied to wastes disposed of at Drigg. The United Kingdom has decided to abandon near-surface disposal of LLW at future sites.

Politically, LLW disposal is a significant issue in the U.S.A. in other countries. Public concern has resulted in a situation in which only two commercial sites in the U.S.A. are currently accepting LLW. One of these sites is scheduled to close soon, and restrictions or cost penalties apply to LLW on the basis of the geographic origin of the waste. Political decisions are likely to govern available LLW capacity and access in the U.S.A. during the 
period of interest for this study. However, other countries, in particular France and Sweden, have been successful in siting LLW disposal facilities (McCabe 1993).

Because RSM will typically contribute only a small fraction of the volume of wastes that will be generated by many of the facilities that are sources of RSM, the disposal of such scrap metal will generally result in long-term land use impacts or costs that are only incremental and likely negligible for those cases in which the various types of wastes are placed together in the same disposal facility. This situation would be particularly true in the case of a new facility dedicated to the disposal of wastes from a specific site. However, if RSM is segregated before disposal, managed separately, and shipped for disposal to an off-site facility, as might be the case for wastes generated by dismantling of commercial nuclear power plants, then the disposal of the scrap metal could place potentially significant demands on limited LLW disposal capacity. The significance of those demands would depend on the period of time allowed between facility shutdown and dismantlement. Unit costs for off-site disposal will be high, and, at least in the U.S.A., availability of and access to LLW disposal sites will be determined politically.

\subsection{REPLACEMENT OF RADIOACTIVE SCRAP. METAL}

RSM replacement requires both metal ore mining and refining and coke production from coal for manufacture of steel. Health and environonmental impacts of these activities are described below, and effects are estimated for replacing $50,000 \mathrm{t}$ of steel.

\subsubsection{Metal Mining and Refining Processes}

If $\mathrm{RSM}$ is not recycled, the discarded metal would be replaced through mining and processing ore. Because mining and refining often occur at the same location and with overlapping impacts, the impacts of mining and primary processing are discussed together. Steel production uses a significant amount of scrap in primary smelting - approximately 25-30\% of the charge in a basic oxygen furnace. The impact estimates for steel production presented below are adjusted for scrap use, indicating the impacts attributable to the virgin ore input per ton of steel produced.

The discussion presented here is limited to direct impacts of processing metals from ores. Impacts from the production and use of the fuel necessary to refine the ores or from the production and use of fluxes that must be added in the smelting processes are excluded. However, the impacts associated with coke production and consumption in steel-making are considered in Section 6.3.

\subsubsection{Mining}

The international distribution of the impacts of replacing RSM depends on the distribution of mining and refining operations. Annual production data for the 10 major producing countries are presented in Table 6.1 for iron and crude steel, and in Table 6.2 for 
TABLE 6.1 Top 10 Countries' Annual Iron Ore and Crude Steel Production, 1980 and $1990^{\mathrm{a}, \mathrm{b}, \mathrm{c}}$

\begin{tabular}{|c|c|c|c|c|}
\hline \multirow[b]{3}{*}{ Country } & \multicolumn{4}{|c|}{ Production $^{d}\left(10^{6} t\right)$} \\
\hline & \multicolumn{2}{|c|}{ Iron } & \multicolumn{2}{|c|}{ Steel } \\
\hline & 1980 & 1990 & 1980 & 1990 \\
\hline Australia & 95.5 & 110.0 & & \\
\hline Brazil & 114.7 & 150.0 & 15.3 & 20.6 \\
\hline Canada & 48.8 & 36.4 & & \\
\hline China & 68.1 & 118.0 & 37.1 & 66.0 \\
\hline Former Soviet Union & 244.7 & 236.0 & 147.9 & 154.0 \\
\hline France & & & 23.2 & 19.0 \\
\hline Germany $^{e}$ & & & 51.1 & 44.0 \\
\hline Italy & & & 26.5 & 25.4 \\
\hline India & 41.9 & 52.0 & & \\
\hline Japan & & & 111.4 & 110.3 \\
\hline Korea, Republic & & & 8.6 & 23.1 \\
\hline South Africa & 26.3 & 30.3 & & \\
\hline Sweden & 27.2 & 19.9 & & \\
\hline United Kingdom & & & 11.3 & 17.9 \\
\hline U.S.A. & 70.7 & 59.0 & 101.5 & 89.7 \\
\hline Venezuela & 16.1 & 20.4 & & \\
\hline Total - 10 Countries & 721.7 & 754.0 & 744.5 & 832.1 \\
\hline Total - World & 902.4 & 890.9 & 860.6 & 864.4 \\
\hline
\end{tabular}

a Iron ore production is expressed in gross weight of ore mined (marketable product). Iron ore production refers to iron ore, iron ore concentrates, and iron ore agglomerates (sinter and pellets).

b Crude steel production is defined as the total of usable ingots, continuously cast semifinished products, and liquid steel for castings. The United Nations' definition of crude steel is the equivalent of the term "raw steel" as used by the U.S.A. Raw steel is composed of about $30 \%$ scrap, with pig iron made from virgin ore accounting for the rest.

c Totals may not add exactly because of rounding.

d A blank indicates that a particular country in not one of the 10 leading producers of that commodity.

e Data are for both Federal Republic of Germany and German Democratic Republic.

Source: World Resources Institute (1992). 
TABLE 6.2 Top 10 Countries' Annual Production of Copper, Aluminum, Lead, and Nickel, 1990

\begin{tabular}{|c|c|c|c|c|c|c|c|}
\hline \multicolumn{2}{|c|}{ Copper ${ }^{b}$} & \multicolumn{2}{|c|}{ Aluminum $^{\mathrm{c}}$} & \multicolumn{2}{|l|}{ Lead $^{\text {d }}$} & \multicolumn{2}{|l|}{ Nickel $^{\circ}$} \\
\hline Country & $\begin{array}{l}\text { Production } \\
\left(10^{3} t\right)\end{array}$ & Country & $\begin{array}{l}\text { Production } \\
\left(10^{3} t\right)\end{array}$ & Country & $\begin{array}{l}\text { Production } \\
\left(10^{3} \mathrm{t}\right)\end{array}$ & Country & $\begin{array}{l}\text { Production } \\
\quad\left(10^{3} \mathrm{t}\right)\end{array}$ \\
\hline Chile & 1,603 & Australia & 40,697 & Australia & 563 & Former Soviet Union & 259 \\
\hline U.S.A. & 1587 & Guinea & 16,500 & U.S.A. & 495 & Canada & 202 \\
\hline Canada & 780 & Jamaica & 10,921 & Former Soviet Union & 450 & New Caledonia & 88 \\
\hline Former Soviet Union & 600 & Brazil & 8,760 & China & 315 & Australia & 70 \\
\hline Zambia & 445 & India & 5,000 & Canada & 236 & Indonesia & 58 \\
\hline Poland & 380 & Former Soviet Union & 4,200 & Peru & 189 & Cuba & 41 \\
\hline China. & 375 & China & 4,000 & Mexico & 180 & South Africa & 36 \\
\hline Zaire & 370 & Suriname & 3,267 & Korea, DPR & 120 & Dominican Republic & 33 \\
\hline Peru & 334 & Former Yugoslavia & 2,952 & Sweden & 90 & Botswana & 25 \\
\hline Australia & 316 & Greece & 2,700 & Former Yugoslavia & 73 & China & 25 \\
\hline Total - 10 Countries & 6,790 & & 98,987 & & 2,711 & & 837 \\
\hline Total - World & 8,814 & & 109,118 & & 3,367 & & 937 \\
\hline
\end{tabular}

a Totals may not add exactly because of rounding.

b The annual production data represent the metal content of the ore mined for copper.

c Aluminum (bauxite) is expressed in gross weight of ore mined (marketable product).

d The annual production data represent the metal content of the ore mined for lead.

- The annual production data represent the metal content of the ore mined for nickel.

Source: World Resources Institute (1992). 
copper, aluminum, lead, and nickel. These countries would be most likely to experience a majority of the impacts of RSM replacement.

In the mining of ores, the choice between surface or subsurface mining techniques for a particular site depends on such factors as the size, structure, and accessibility of the ore deposit. That choice makes a significant difference in the impacts of the mining operation. In the U.S.A., surface mining of minerals produced 11 times as much waste per ton of ore as underground mining did in 1988 and 8 times as much as waste in 1993 (Young 1992b). However, although subsurface mining generates less waste, it is more dangerous and expensive than surface mining.

\subsubsection{Refining/Smelting}

Most of the pig iron produced from a blast furnace is refined into steel; small amounts are made into other forms of iron, such as cast iron (DOE 1992a). Technological advances in blast furnace operations during the 1970-1990 period decreased the amount of coke required to produce a ton of pig iron by about 20\%, from $0.6 \mathrm{t}$ in 1970 to $0.5 \mathrm{t}$ in 1990 . The smaller amounts of coke consumed in U.S.A. steelmaking during the 1970-1990 period also reflect the greater use of the electric arc furnace (EAF), although to a lesser extent than the technological advances experienced in blast-furnace operations. Nevertheless, the share of total raw steel output from EAFs more than doubled from 15\% in 1970 to an average of $37 \%$ since 1986, as more scrap iron and steel was recycled into steelmaking. The EAF produces steel from a charge composed of $99 \%$ scrap and $1 \%$ iron pellets. Currently, the EAF has become more productive and versatile because technological improvements are reducing the time required to produce steel (American Iron and Steel Institute undated; DOE 1992a).

Coal consumption by the iron and steel industry can be expected to move towards the use of lower-quality coking coal in blends with high-quality coking coal, as well as the introduction and implementation of new technologies such as pulverized coal injection (PCI). This technique allows direct injection of limited amounts of coal into the blast furnace, in conjunction with coke and sintered iron ore. Direct injection of coal is more economical because $1 \mathrm{t}$ of pulverized coal, when injected, can replace $1.4 \mathrm{t}$ of coking coal; and noncoking coals can be used in injection (International Energy Agency 1992).

\subsubsection{Health Risks of Metal Mining and Refining}

Human health effects are associated with both mining and refining of metals. These effects include worker injuries, worker illnesses, and public illnesses due to exposure to toxic elements. Because of the nature of the available data, the health effects of mining and ore concentrating activities and of refining activities are presented separately. 


\subsubsection{Workers}

\section{Radiation Exposures}

Underground miners face the hazards of exposure to toxic gases and radon, as well as to low levels of other radionuclides, depending on the geology of the mine site. Copper and bauxite ores, for example, often occur in strata containing above-average concentrations of uranium, thorium, and their decay products. While radiation exposure poses less of a threat to aboveground miners, both underground miners and workers involved in ore-enhancing procedures can have significant exposures to radiation if proper safety and ventilation measures are not employed (U.S. Environmental Protection Agency [USEPA] 1978).

Radon concentrations of $280 \mathrm{~Bq} / \mathrm{m}^{3}$ were measured in the air in an underground iron mine in the U.S.A. in 1978 and in a similar mine in the Federal Republic of Germany in 1984. Studies of underground copper mines have found radon levels such as $160 \mathrm{~Bq} / \mathrm{m}^{3}$ in the U.S.A. in $1978,1,200 \mathrm{~Bq} / \mathrm{m}^{3}$ in India in 1987 , and a range of $9,000-20,000 \mathrm{~Bq} / \mathrm{m}^{3}$ in China from 1975 through 1978. Occupational exposures attributable to radiation in nonuranium mines have decreased with time because monitoring has led to a reduction of high-exposure situations. On the basis of these findings, the United Nations (1993) estimates annual radiation exposure of nonuranium miners at 0.1 to $200 \mathrm{mSv}$. The associated lifetime cancer fatality risk for miners due to these exposures is in the range of $5 \times 10^{-5}$ to $1 \times 10^{-2}$. The ower end of the range may be more representative of current conditions especially in more developed countries. The resulting collective dose to miners from replacing $50,000 \mathrm{t}$ of RSM is estimated to be about $4 \times 10^{-3}$ person-Sv/yr, assuming an average dose of $10 \mathrm{mSv} / \mathrm{yr}$.

\section{Mining Accidents}

Mining is a high-risk occupation. In 1990, the annual worker fatality rate in iron mining in the U.S.A. was $3 \times 10^{-4}$ and the occupational injury rate was $2.8 \times 10^{-2}$ (U.S. Department of Labor 1991). An "occupational injury" is defined as an injury for which medical treatment is administered, or which results in death or loss of consciousness, restriction of work or motion, inability to perform all job duties on any day after an injury, lost workdays, temporary assignment to other duties, transfer to another job, or termination of employment. In 1990, copper miners in the U.S.A. suffered 5 fatal and 260 occupational injuries. Refined copper production in that year totaled 1,566,876 t; thus, $3.1 \times 10^{-6}$ fatalities and $1.7 \times 10^{-4}$ injuries occurred per ton of primary copper produced $(260 \div 1,566,876)$. Also in 1990, iron ore miners had 6 fatalities and 345 occupational injuries (U.S. Department of Labor 1991) in mining the ore to produce 35,695,000 $t$ of steel (Kuck 1993). Adjusting for scrap content, the fatality rate was $2 \times 10^{-7}$ and the injury rate among miners was $1.3 \times 10^{-5}$ per ton of steel produced $(345 \div[35,695,000 \times 0.75])$. Since the U.S.A. no longer mines metalgrade bauxite ore, similar statistics were not available for aluminum production.

The severity of the injuries is indicated by the average number of lost workdays per injury. In 1990, an average of 88 workdays was lost for each mining injury (all types of 
mining combined). The copper mining average was 159 lost workdays and the iron ore mining average was 56 days, representing an average of 0.075 workday lost per ton of copper and 0.002 per ton of steel during mining operations (U.S. Department of Labor 1991).

Additional areas of particular health and safety concern in mines are excessive noise and inadequate ventilation of underground mines. Excessive noise from use of explosives at mines and use of heavy machinery at mines and refineries can cause hearing impairment. Poor ventilation can result in explosions and fires and can increase the risk of respiratory illnesses or suffocation.

\section{Refining Accidents}

According to the U.S. Department of Labor (1989), the annual rate of work-related fatalities and serious injuries in blast furnaces and steel mills in 1987 in the U.S.A. was $5.7 \times 10^{-2}$, compared with the entire private-sector average of $3.8 \times 10^{-2}$. The number of lost workdays for blast furnace and steel mill workers in 1987 was 155.6 per 100 workers, more than twice the private sector average of 69.9 per 100 people. On a production-unit basis, these numbers represent $1.4 \times 10^{-4}$ fatalities or injuries and $4 \times 10^{-3}$ lost workdays from refining activities for each ton of steel produced. Replacing 50,000 t of RSM would thus incur a risk of 7 worker fatalities or serious injuries.

The 1987 rate of work-related fatalities and serious injuries in of refining and smelting primary nonferrous metals in the U.S.A. was $7.7 \times 10^{-2}$. The values for specific metals included $6.9 \times 10^{-2}$ for primary copper, $0.9 \times 10^{-2}$ for primary aluminum, and $1.1 \times 10^{-1}$ for primary lead. These rates are among the highest for all occupations, representing $3.7 \times 10^{-4}$ fatalities and injuries for each ton of copper and $5.7 \times 10^{-4}$ for each ton of aluminum. The number of lost workdays per 100 full-time primary nonferrous workers in 1987 was 148.8 . The number of lost workdays per 100 workers in primary copper, primary aluminum, and primary lead were, respectively, 186.4, 156.7, and 296.8 - again, among the highest for all occupations. These rates represent 0.011 lost workdays per ton of aluminum produced and 0.010 lost workdays per ton of copper (U.S. Department of Labor 1989).

\subsubsection{Public}

\section{Chemical Exposures from Mining}

The health effects to the general public from mining stem primarily from trace elements from acid drainage or from dust blown from overburden and tailings piles. The most common exposure pathways to the general public are ingestion of contaminants from drinking water sources or the food chain and inhalation of suspended particulates. The range of possible effects of trace metal intake includes sterility, hypertension, birth defects, stunted growth, damage to the central nervous system, anemia and other hematological abnormalities, neurological damage, bone damage, urinary and hepatic disorders, cancer, and 
death (Brookins 1990). A listing of typical contaminants and associated health effects is provided in Appendix E.

\section{Mine Accidents}

Another hazard to the public is the danger of falling into an abandoned mine. The western U.S.A. alone has about 500,000 abandoned mines, and little funding is currently available to properly seal them. The number of deaths and injuries created by this hazard is not large, but it will continue to be a problem (Schneider 1993).

\section{Transportation Accidents}

Bulk transport of ore by train or barge would result in accident fatality risks for the public. Assuming replacement of 50,000 $\mathrm{t}$ of $\mathrm{RSM}$ and a 100-km transport distance, the fatality risk incurred would be $3 \times 10^{-3}$ to $9 \times 10^{-2}$. This range is based on data for coal transport (DOE 1988).

\section{Radiation Exposures from Refining}

In the U.S.A., the National Council on Radiation Protection and Measurements (NCRP 1987) conducted a study of the annual effective dose equivalent from radiation exposure to nearby individuals for selected primary metal processing plants. Exposure levels were higher for nonferrous than for ferrous metals. Listing the organ with the highest dose, aluminum reduction plants expose about 3,400 local residents' kidneys to $12 \mu \mathrm{Sv}$, copper smelters expose 4,800 individuals' lungs to $2 \mu \mathrm{Sv}$, and lead smelters expose 14,000 individuals' lungs to $50 \mu \mathrm{Sv}$ annually. Other public health effects potentially result from exposure to trace metals and other pollutants that are released into the air, water, and ground from waste piles or through other refining processes.

\section{Chemical Exposures from Smelting}

Replacing RSM from ores would involve production of pig iron in a blast furnace operation, followed by carbon reduction in a smelter to produce steel. These activities produce stack emissions of hazardous chemicals released to the atmosphere, and potential releases to air and water from slag and emission control system dust/sludge. On the basis of conservative assumptions, the associated public health risks, which are detailed in Section 5.3.3.2, are about $2 \times 10^{-4}$ fatal cancers from production of 50,000 t of steel.

\subsubsection{Environmental Impacts of Metal Mining and Refining}

Steel production causes environmental impacts directly by changing land surfaces and water drainage patterns, and it also causes impacts through release of hazardous 
substances to air, land, and water, damaging resource quality. These impacts, as well as energy requirements for steel production activities, are discussed in this section.

\subsubsection{Air Impacts}

Most air emissions generated in the production of metals from virgin materials are from the ore-enhancement and smelting processes. However, some air emissions from mining also present a hazard to miners and to neighboring communities. Traffic from major mining and refining operations may also affect air quality in the vicinity, even though care is often taken to reduce dust production by sprinkling water on roads and other disturbed sites. This dust can be harmful to workers and residents near an operation, especially if it contains traces of toxic elements. Trace elements, gaseous emissions, and radiation are the major types of contaminants released to the atmosphere during the refining and smelting stages of metals production.

Trace metals released into the atmosphere from tailings piles at mines can be hazardous to the public if they enter the food chain and are ingested, especially by children. Hwang (1990) indicates that varying amounts of arsenic, cadmium, chromium, copper, lead, zinc, beryllium, silver, selenium, barium, molybdenum, manganese, nickel, iron, and silica can be blown as particulate matter from copper mine tailings piles, depending on the soil composition at the mine site. Amounts of trace elements released from smelting and refining processes are shown in Table 6.3. The low end of the range of emission estimates represents the more efficient combinations of production technology, pollution control, and raw material inputs with the lowest concentrations of contaminants. The high end represents the least efficient processes and highest contaminant concentrations. These estimates may underrepresent the global emissions rate because pollution-control requirements in developing countries can be less stringent than those in Europe and North America (Nriagu and Davidson 1986).

In addition to the hazards of trace element releases, sulfur dioxide $\left(\mathrm{SO}_{2}\right)$ emissions are a major concern because of their role in causing "acid rain." Worldwide, smelting of copper and other nonferrous metals results in the release of about $6 \times 10^{6} \mathrm{t}$ of $\mathrm{SO}_{2}$ into the atmosphere each year, which is about $8 \%$ of global $\mathrm{SO}_{2}$ emissions (Young 1992b). Smelting and converting a typical copper concentrate produces more than $0.5 \mathrm{t}$ of $\mathrm{SO}_{2}$ per ton of concentrate (Peacey 1992), which must be controlled to meet local emissions standards. With the installation of atmospheric emission control equipment in recent years, $\mathrm{SO}_{2}$ emissions in the U.S.A. have been controlled by more than 99\% (Jolly 1993). Use of emissions control equipment is becoming standard practice throughout the world, but such equipment is expensive and not always required by law.

Iron and steel production released $54,400 \mathrm{t}$ of nitrogen oxides $\left(\mathrm{NO}_{\mathrm{x}}\right), 144,400 \mathrm{t}$ of $\mathrm{SO}_{2}$, and 37,700 $\mathrm{t}$ of volatile organic compounds to the atmosphere in the U.S.A. in 1988 (Kohout et al. 1990). These values equated to about $0.270 \mathrm{~kg}$ of $\mathrm{NO}_{\mathrm{x}}, 0.717 \mathrm{~kg}$ of $\mathrm{SO}_{2}$, and $0.187 \mathrm{~kg}$ of volatile organic compounds for each ton of steel produced (using the same 
TABLE 6.3 Emissions of Trace Metals to the Atmosphere and Water from Metal Production Operations

\begin{tabular}{|c|c|c|c|c|c|}
\hline \multirow[b]{2}{*}{$\begin{array}{l}\text { Element } \\
\text { Released }\end{array}$} & \multicolumn{3}{|c|}{$\begin{array}{c}\text { Emissions from } \\
\text { Pyrometallurgical Metal } \\
\text { Production }^{2} \text { (g/t) }\end{array}$} & \multicolumn{2}{|c|}{$\begin{array}{l}\text { Liquid Effluents of } \\
\text { Smelting and } \\
\text { Refining }^{\mathrm{b}} \text { (ng/L) }\end{array}$} \\
\hline & $\begin{array}{l}\text { All } \\
\text { Nonferrous } \\
\text { Mining }\end{array}$ & $\begin{array}{l}\text { Steel and Iron } \\
\text { Manufacturing }\end{array}$ & $\begin{array}{c}\text { Copper } \\
\text { and Nickel } \\
\text { Production }\end{array}$ & $\begin{array}{c}\text { Iron } \\
\text { and } \\
\text { Steel }^{\mathrm{c}}\end{array}$ & $\begin{array}{l}\text { Nonferrous } \\
\text { Metals }^{\mathrm{d}}\end{array}$ \\
\hline Antimony & $1-10$ & $0.005-0.1$ & $50-200$ & $-^{e}$ & $0.04-3.8$ \\
\hline Arsenic & $5-10$ & $0.5-3.5$ & $1,000-1,500$ & - & $0.5-6.4$ \\
\hline Cadmium & $0.1-0.5$ & $0.04-0.4$ & $200-400$ & - & $0.004-1.8$ \\
\hline Chromium & - & $4-40$ & - & 一 & $1.5-10$ \\
\hline Copper & $20-100$ & $0.2-4.0$ & $1,700-3,600$ & - & $1.2-8.5$ \\
\hline Indium & - & - & $1-4$ & - & - \\
\hline Lead & $500-1,000$ & $1.5-20$ & $1,300-2,600$ & $0.2-0.4$ & $0.5-3.0$ \\
\hline Manganese & $50-100$ & $1.5-40.0$ & $100-500$ & $2.0-5.2$ & $1.0-7.5$ \\
\hline Mercury & - & - & $\dot{-}$ & 一 & $0.001-0.002$ \\
\hline Molybdenum & - & - & 一 & - & $0.003-0.2$ \\
\hline Nickel & $\sim 100$ & $0.05-10.0$ & 900 & 一 & $1-12$ \\
\hline Selenium & $1.0-2.5$ & $0.001-0.003$ & $50-150$ & 一 & $1.5-10$ \\
\hline Thallium & - & - & - & - & - \\
\hline Tin & - & - & $50-200$ & - & - \\
\hline Vanadium & - & $0.1-2.0$ & $5-10$ & - & $0-0.6$ \\
\hline Zinc & $50-100$ & $10-45$ & $500-1,000$ & $0.8-3.5$ & $1-10$ \\
\hline
\end{tabular}

a Based on the review of emission studies in Western Europe, the U.S.A., Canada, and the Soviet Union in 1983. The range is determined by (1) the concentration of the trace elements in the raw material, (2) the production technology employed in the emitting industry, and (3) the type and efficiency of pollution control.

b Based on a critical survey of the extensive databases on the trace metal concentrations in industrial and municipal solid wastes and aqueous effluents. Data are mostly from the 1970s and 1980s.

c Data include blast, basic oxygen, and electric arc furnace information.

d Data include primary and secondary smelter information.

e Negligible.

Source: Nriagu and Pacyna (1988). 
production information that was used by Kohout et al. [1990]). A total of 2,400 $\mathrm{t}$ of $\mathrm{NO}_{\mathrm{x}}$, $65,300 \mathrm{t}$ of $\mathrm{SO}_{2}$, and $400 \mathrm{t}$ of volatile organic compounds were released to the atmosphere by primary aluminum smelting; the equivalent of $0.608 \mathrm{~kg}$ of $\mathrm{NO}_{\mathrm{x}}, 16.5 \mathrm{~kg}$ of $\mathrm{SO}_{2}$, and $0.101 \mathrm{~kg}$ of volatile organic compounds per ton of primary aluminum. Primary copper smelting in the U.S.A. released $1,400 \mathrm{t}$ of $\mathrm{NO}_{\mathrm{x}}, 297,000 \mathrm{t}$ of $\mathrm{SO}_{2}$, and a negligible amount of volatile organic compounds to the atmosphere (Kohout et al. 1990), or $0.967 \mathrm{~kg}$ of $\mathrm{NO}_{\mathrm{x}}$ and $205 \mathrm{~kg}$ of $\mathrm{SO}_{2}$ emissions per ton of primary copper, a much lower value for $\mathrm{SO}_{2}$ production than given above by Peacey. The difference here is due to atmospheric controls in smelters. Primary lead and zinc smelters released $1,700 \mathrm{t}$ of $\mathrm{NO}_{\mathrm{x}}$ and $119,200 \mathrm{t}$ of $\mathrm{SO}_{2}$ to the atmosphere.

Fluoride particle control is the main atmospheric emission problem in the production of primary aluminum. Most primary smelters around the world have installed systems to collect and recycle the fluoride material to the production cells. These systems are typically at least $97 \%$ effective. About 0.5 to $1 \mathrm{~kg}$ of fluoride is produced per ton of aluminum. The improved equipment now used at many aluminum smelters has considerably reduced the environmental damage (particularly to trees and other vegetation) previously associated with fluoride emissions (Carwile 1993). Other potential air pollutants include $\mathrm{SO}_{2}$ from the boiler house and lime, bauxite, and alumina dust from the refineries. Absorbent filters and electrostatic precipitators can be effective in controlling these emissions.

Particulate emissions from steel manufacturing are a threat to the air quality around steel mills. At integrated steel mills, where steel is made from about $75 \%$ iron ore, $50 \mathrm{~kg}$ of dust is produced per tón of steel (Nriagu and Davidson 1986). For blast furnaces equipped with 99\%-efficient control devices, $580 \mathrm{~g}$ of particulate emissions are produced per ton of pig iron. Zinc ( 0.3 to $33 \mathrm{~g} / \mathrm{t})$, lead $(0.1$ to $8 \mathrm{~g} / \mathrm{t})$, and manganese ( 2.9 to $5.8 \mathrm{~g} / \mathrm{t})$ are among the trace elements found in this dust.

Steiner (1976) reports an average range of 7 to $30 \mathrm{~kg}$ of "dust and fume" generated by a basic oxygen furnace per ton of steel produced at the next stage in steel production. Table 6.4 lists the chemical composition of this dust by percentage of total mass for a noncombusted gas system typical of the majority of basic oxygen furnaces in the world. Iron is the predominant component, constituting $66.7 \%$ of this dust, and iron oxide is second at $21.4 \%$.

Radon gas poses a potential threat to workers in underground mining operations. Proper ventilation of mines alleviates this problem for workers, and occupational exposures attributable to
TABLE 6.4 Components as a Percentage of Total Mass of Particulate Emissions from Basic Oxygen Noncombusted Gas Systems

\begin{tabular}{lc}
\hline Component & Percentage \\
\hline $\mathrm{Fe}_{2} \mathrm{O}_{3}$ & 4.0 \\
$\mathrm{FeO}$ & 21.4 \\
$\mathrm{Iron}$ & 66.7 \\
$\mathrm{SiO}_{2}$ & 1.3 \\
$\mathrm{CaO}$ & 3.7 \\
$\mathrm{MgO}$ & trace \\
$\mathrm{P}_{2} \mathrm{O}_{5}$ & 0.4 \\
\hline
\end{tabular}

Source: Steiner (1976). 
radiation in nonuranium mines have been decreasing with time. However, radon vented from underground mines can then be released to the atmosphere and possibly expose the public to this radioactive gas. Annual atmospheric radon releases of 2,600 GBq were reported for one iron mine in the U.S.A. (United Nations 1988).

In the last two decades, studies of aluminum facilities in the U.S.A. have found emissions of radon to be much higher than those of other naturally occurring radionuclides. Among the particulates, $\mathrm{Pb}-210$ and $\mathrm{Po}-210$ were found to be the most important components of the releases, because of the high temperatures of the kilns and reduction cells (United Nations 1988). Estimates of radionuclides per gram of particulate emissions for alumina kilns and bauxite residue kilns at an alumina plant are given in Table 6.5. The values do not represent the total activity released because the high temperature of the kiln causes a large fraction of the radionuclides to be volatilized (USEPA 1984a).

TABLE 6.5 Radionuclides in Particulate Emissions from Reference Copper and Alumina Plants

\begin{tabular}{lccc}
\hline & \multicolumn{3}{c}{ Concentrations (Bq/g) } \\
\cline { 2 - 4 } Radionuclide & $\begin{array}{c}\text { Alumina } \\
\text { Kilns }\end{array}$ & $\begin{array}{c}\text { Bauxite } \\
\text { Residue } \\
\text { Kilns }\end{array}$ & $\begin{array}{c}\text { Copper } \\
\text { Smelter }\end{array}$ \\
\hline U-238 & 0.002 & $-{ }^{\mathrm{a}}$ & 0.026 \\
U-234 & 0.002 & - & 0.026 \\
Ra-226 & 0.001 & - & 0.001 \\
Rn-222 & - & 0.748 & - \\
Pb-210 & - & 0.013 & 0.043 \\
Po-210 & - & 0.011 & 0.020 \\
Th-228 & - & - & 0.001 \\
Th-230 & - & - & 0.001 \\
Th-232 & - & - & 0.001 \\
\hline a Negligible. & & & \\
Source: USEPA (1984a). & & &
\end{tabular}




\subsubsection{Land Use Impacts}

The impacts of metal mining and refining on land resources can be generally divided . into two major categories: impacts that result from changes in the physical structure of the land and impacts that result from release of toxic materials.

A major factor relative to the physical impacts from mining is the total amount of land used by mining operations. A larger iron-ore-mining operation, for example, requires from 1,200 to 4,000 ha of land for mining, waste dumps, plant operations, and tailings disposal (Klinger 1985). Another author estimated on the basis of 1980 data for worldwide land use that each year 500,000 ha of land is directly disturbed by nonfuel mining, including mines, waste disposal sites, and areas of subsidence over underground mines (Young 1992b). This estimate, however, excludes both previously mined land that remains ruined and the land used in refining the mined ores.

Impacts on land from surface and subsurface mining differ greatly. In 1988, overburden accounted for more than a third of the $3.3 \times 10^{9} \mathrm{t}$ of material handled at nonfuel surface mines (Young 1992a). Although subsurface mining produces less wastes, it poses the problem of subjecting the land above an underground mine to potential subsidence or collapse, which can seriously affect any land use or structures above the mine and cause financial losses.

Some lands, such as deserts and tundra, are particularly sensitive to mining impacts. Some arid lands are covered by a thin layer of pebbles over fine silt several centimeters thick. The layer of pebbles, called desert pavement, protects the finer material from wind erosion. When the pavement layer is disturbed by road building or other activity, the fine silts may be eroded, thus impairing physical, chemical, and biological properties of the soil in the immediate environment and scarring the land for many years. In other fragile areas, such as marshlands and the northern tundra, the presence of wet soils rich in organic materials makes the land sensitive to even light traffic (Miller 1991). Mining in tropical rain forests is likely to have substantial impacts on the ecosystem and native peoples that are dependent upon it. As the demand for metals increases, exploration and mining will likely increase in these previously avoided sensitive areas.

Mining wastes originate from two main sources in the mining and processing stages: (1) "overburden" or development waste rock, which is the material that must be removed to expose an ore body or develop a mine; and (2) "tailings," which are ore residuals that result from beneficiation of ores. (Beneficiation is the process of improving ore grade or concentration before smelting and includes such processes as floatation and drying.) Tailings comprise produce large quantities of waste because the desired metal generally is only a small percentage of the ore removed. Specialists at the U.S. Bureau of Mines have determined the worldwide average grades for certain metals as follows: 0.40 for iron ore, 0.23 for bauxite, 0.0091 for copper, and 0.025 for lead and nickel (Rogich 1992). Thus, for example, one ton of copper ore contains only $0.91 \%$ copper metal and $99.09 \%$ "waste" material. Because of these low natural concentrations of the metal, no practical means exist for reducing the volume of wastes generated. 
Mining and milling operations have a major impact because of the large volume of wastes they generate. These wastes are often piled many meters high and cover extensive land areas. The piles of waste degrade the natural environment and create serious physical hazards, such as rock and mud slides that can threaten life and property within the vicinity (Koren 1991). In the U.S.A. alone, the mining industry generates up to $2 \times 10^{9} \mathrm{t} / \mathrm{yr}$ of solid waste and accounts for about $40 \%$ of the total solid waste generated annually by all sources in the country (Hoye and Hubbard 1989). Although about 80 types of mineral industries generate substantial wastes, 8 are responsible for about $80 \%$ of the total. The copper industry is the largest contributor, followed by the iron and steel, bituminous coal, phosphate rock, lead, zinc, alumina, and anthracite industries (Koren 1991). In the U.S.A. alone, copper mining and milling wastes are accumulating at the rate of about $500 \times 10^{6} \mathrm{t} / \mathrm{yr}$, the greatest mass of solid wastes produced by any industry (Fitzgerald 1976).

The accumulations of overburden and tailings from mining operations inevitably change the original topography of the land, especially since much of the land is never reclaimed. Although some countries have laws requiring land reclamation, even in the U.S.A., which has enacted relatively strict laws, an average of less than $50 \%$ of mined land has been reclaimed. In 1980, for example, only $4.2 \%$ of the lands used by the iron ore mining industry and only $2.9 \%$ of the lands used by the copper mining industry were reclaimed there (Johnson and Paone 1982).

In addition to the physical disruption of land that mining and refining cause, the wastes also pose toxicity hazards. The following trace elements have been found to be common in copper mine tailings in concentrations ranging from a few parts per million: arsenic, cadmium, chromium, copper, lead, zinc, beryllium, and silica (Hwang 1990). Trace elements found in lead tailings may include arsenic, cadmium, chromium, copper, lead, zinc, beryllium, silica, silver, selenium, mercury, molybdenum, manganese, and iron (Hwang 1990). The presence of these trace elements poses substantial environmental and human health hazard associated with the dispersion or use of tailings from these and other mining operations. A summary of health hazards associated with some of these trace elements is provided in Appendix E.

Mining and refining wastes also have radioactive constituents. Copper ore often occurs in conjunction with elevated concentrations of uranium, thorium, and other radioactive elements. As a result, the potential impact of the large quantities of wastes from copper production involves hazards from the radioactivity released to soils and the food chain (Fitzgerald 1976). Radionuclide activity levels for materials involved in the production of alumina from bauxite ores are listed in Table 6.6. Radionuclide concentrations, for Ra-226, Th-232, and K-40 in steel slag, copper slag, nickel slag, and iron-chromium-carbon slag (from the production of stainless steel) are listed in Table 6.7.

In the metals refining process; slag from smelters and furnaces is often a waste product as well. In steel production, blast furnaces produce about $350 \mathrm{~kg}$ of slag for each ton of pig iron, resulting in about $265 \mathrm{~kg}$ of slag per ton of steel (if steel is produced from about $75 \%$ pig iron and 25\% scrap). Basic oxygen furnaces produce $75-120 \mathrm{~kg}$ of slag per ton of 
TABLE 6.6 Activity of Naturally Occurring Radionuclides in Alumina Plant Process Samples

\begin{tabular}{ccc}
\hline & \multicolumn{2}{c}{ Concentrations (Bq/g) } \\
\cline { 2 - 3 } Substance & $\mathrm{U}-238$ & Th-232 \\
\hline Bauxite ore & 0.250 & 0.200 \\
$\begin{array}{c}\text { Alumina kiln } \\
\text { feed }\end{array}$ & 0.002 & 0.002 \\
$\begin{array}{c}\text { Alumina } \\
\text { product }\end{array}$ & 0.010 & 0.07 \\
\begin{tabular}{c} 
Red mud \\
\hline
\end{tabular} & 0.280 & 0.180 \\
\hline
\end{tabular}

Source: United Nations (1988).
TABLE 6.7 Activity of Naturally Occurring Radionuclides in Metal Slags

\begin{tabular}{cccc}
\hline & \multicolumn{3}{c}{ Concentrations (Bq/g) } \\
\cline { 2 - 4 } Slag & Ra-226 & Th-232 & $\mathrm{K}-40$ \\
\hline Iron $^{\mathrm{a}}$ & 0.089 & 0.006 & 0.009 \\
Steel & 0.126 & 0.007 & 0.021 \\
Copper & 0.762 & 0.052 & 0.636 \\
Nickel & 0.518 & 0.778 & 0.076 \\
\hline
\end{tabular}

a Refers to iron-chromium-carbon slag.

Source: Ettenhuber and Lehmann (1986).

steel under the same assumptions (Steiner 1993b; Dehmel et al. 1992). Up to $4 \mathrm{t}$ of slag can be generated for each ton of copper produced (Jolly et al. 1993), but 2-3 $t$ are more typical. Slag can be a marketable by-product for uses such as railroad ballast or for incorporation into concrete. Typically, however, the slag is left in piles around the smelting site (Davenport 1993).

The principal solid waste in aluminum production is a caustic bauxite residue (often called "red mud") containing large amounts of iron, titanium, phosphorus, and other elements originally present in lateritic ores. For each ton of aluminum produced, about $2 \mathrm{t}$ of the bauxite residue is discharged (Carwile 1993). This residue is generally kept in large ponds until it settles and dries; the dried residue is then placed in a landfill. The U.S. Environmental Protection Agency (USEPA 1990a) recently ruled that the residues are not subject to regulation as hazardous waste. However, there is so much of this residue that the issue of its storage must be addressed. Attempts are being made to grow vegetation over these dried ponds to keep the caustic dust from damaging surrounding land and water.

\subsubsection{Water Use Impacts}

Mining and refining of iron ore, copper, aluminum (bauxite), lead, and nickel have serious impacts on water quality. However, a major problem involved in quantifying the effects of current metal mining is that about $60 \%$ of mine drainage is caused by abandoned mines (Koren 1991). Current mining may, therefore, affect water quality for many years in the future. In fact, the U.S. Environmental Protection Agency has determined that more than 80 old mining sites qualify for Superfund cleanup (Milius 1992). One of the primary problems with abandoned mines is that when mining operations cease, water is no longer 
pumped from them. The mines can then flood, and the overflowing water can contain harmful contaminants that can seep into groundwater.

Estimating the amount of wastewater generated by a mining site is difficult because of the many differences in mines. Copper mines exemplify this problem - estimates of wastewater production range from 0 to $300 \mathrm{~L}$ of water per ton of ore from open-pit mines and from 8 to $4,000 \mathrm{~L}$ water per ton of ore from underground mines. These values become especially significant on a per-ton-of-metal basis, because $99 \mathrm{t}$ of copper ore is needed to produce $1 \mathrm{t}$ of copper metal. The open-pit mine thus generates up to 29,850 L of wastewater per ton of copper metal, while the underground mine generates up to 398,000 L of wastewater per ton of metal (Syracuse Research Corp. 1990).

Water pollution from metal mining can affect both surface water and subsurface water (groundwater). These water sources are differentiated because the effects and treatment of contamination are somewhat different. Groundwater pollution is a special problem because reclamation of polluted groundwater is more difficult and expensive than reclamation of surface water (Keller 1988). Once groundwater is contaminated, it can be a long-term condition that may persist for hundreds of years.

Acid mine drainage affects subsurface mines especially, although it can also be a problem for surface mines. Acid mine drainage occurs when aerobic bacteria convert sulfide compounds found in mines, waste rock dumps, and tailings ponds to sulfuric acid. Because of their high sulfur concentrations, copper, lead, and nickel ores are most commonly associated with acid mine drainage problems (Young 1992a). Rain and melted snow seeping through the mine or mine tailings transfer the acid to nearby rivers and streams and into the groundwater, destroying aquatic life and contaminating water supplies (Miller 1991).

The sulfuric acid lowers the $\mathrm{pH}$ of the water, which in turn increases its capacity to carry metal ions. As the acidic water travels over or through soils, it strips other metals from exposed rock, adding to the acid mixture trace elements such as lead, mercury, manganese, cadmium, and arsenic (Darlington 1992) and metals such as copper, cobalt, zinc, aluminum, and iron (Connolly and Kealy 1990). When these elements are leached out, they may be concentrated in water, soil, or plants, and when ingested may be toxic or carcinogenic.

Recently the U.S. Bureau of Mines found that in the U.S.A., where mining regulations are stringent and relatively strictly enforced, more than $19,000 \mathrm{~km}$ of rivers and streams and 73,000 ha of lakes and reservoirs have been poisoned by acid mine drainage (Darlington 1992). In one case of pollution from abandoned mines in the U.S.A., over 100 years of copper mining near Butte, Montana, polluted drinking water and soil with arsenic and other trace metals and tainted approximately $225 \mathrm{~km}$ of waterways. The U.S. Environmental Protection Agency designated four Superfund sites in that region, the largest cleanup area in the country (Milius 1992). Such effects may be more serious in countries where mining regulations are either nonexistent or poorly enforced and where drinking water is not treated before use. 
In addition to the effects caused by acid in mining and milling water, problems can also occur because of the presence of naturally occurring radioactivity in the wastes. Copper and bauxite, especially, are associated with concentration of natural radiative elements. Acidic mine drainage can augment the level of radioactivity in surface waters by leaching out uranium and its radioactive decay products from waste storage piles. Radiological analysis of copper mine pumpout water at several sites in the U.S.A. shows a range of 0.056 to $1.01 \mathrm{~Bq} / \mathrm{L}$ for Ra-226 (Fitzgerald 1976). This phenomenon has not been extensively studied and thus remains a relatively unrecognized hazard to workers and the general public.

Surface mine sediment production can be 10 to 60 times the amount of sediment from lands used for agriculture (Koren 1991). Suspended sediment in rivers and lakes can be a serious problem, and is, by volume, the greatest surface water pollutant, reducing the quality of water resources and potentially depositing toxic elements on cropland (Keller 1988). The deposited sediment blocks waterways used for transportation and fills the area behind dams, requiring removal to maintain their usefulness.

Metal refining processes have been responsible for water quality problems as well, although these problems are significantly less now than in the past because of more stringent environmental regulation and technology improvements throughout the world. Also, smelting and refining impacts can be controlled somewhat better than mining impacts because the smelting and refining occur inside a structure rather than in open spaces. Liquid effluents from refining and smelting of nonferrous metals in Western Europe, North America, and the former Soviet Union have been found to contain a variety of toxic or carcinogenic trace elements (Nriagu and Pacyna 1988). These elements were listed in Table 6.3 (Section 6.2.3.1). The data presented are for both primary and secondary smelters. Primary nonferrous smelters process virgin ore almost exclusively, while secondary smelters process mostly scrap metal.

\subsubsection{Energy Use Impacts}

Estimates of energy use in production processes can vary widely among companies and countries, depending on such factors as the age of the plant and the energy sources available in the region. Regardless, for each metal, refining accounts for a majority of the energy used. Of the metals considered here, aluminum production uses the most energy and lead the least.

Energy requirements just for the extraction of iron from the ore to make steel, are about 19.4 MJ per ton of pig iron (St. Pierre 1992). Information from the American Iron and Steel Institute indicates that the total basic oxygen process in 1991 used $28.7 \mathrm{GJ}$ per ton of steel. Worldwide, the range is typically from 21 to 35 GJ or more per ton. Making steel from scrap requires approximately $10.5 \mathrm{GJ} /$ per ton, less than a third of the energy requirement when ore is the starting point (Steiner 1993a).

According to the U.S. Bureau of Mines, the final reduction stage of aluminum production is the most energy-intensive. Mining, breaking, loading, hauling, crushing, and 
drying collectively require only 1.16-3.49 GJ of the overall 132-170 GJ required per ton of primary aluminum metal (McCawley and Baumgardner 1985). The wide range of values is caused by many factors, including the age of the reduction cell, the type of anode system, the efficiency of the system, and the amount and type of transportation that is involved in the process. These energy requirements are slowly being reduced as new technology is discovered and implemented. Aluminum beverage containers made from scrap require $95 \%$ less energy than those made from ore (Lund 1993).

For typical ore grades and treatment of standard ore concentrates of copper, Castle (1989) found energy requirements for mining, beneficiation, and drying of copper to be 66.3 GJ per ton of metal. The total energy requirements for smelting and further refining ranged from 27.4 to 31.3 GJ per ton, depending on the process. Copper production from ore requires from two to six times more energy than production from scrap (Jolly et al. 1993). The Organization for Economic Cooperation and Development (OECD 1991) suggests that there is an $87 \%$ saving in energy use from substituting scrap for ore.

As of 1985, energy requirements for lead production, including mining, concentration, smelting, and refining processes, were the lowest of any of the major metals. Approximately 25.2 GJ is required for mining and concentrating one ton of lead. The total energy to mine, concentrate, and refine one ton of lead ranges from 39.8 to 42.2 GJ (Castle 1989).

The two major types of nickel deposits (sulphidic and lateritic) are mined and handled by different methods. For typical ore grades and treatment of standard ore concentrates of nickel, energy requirements can be as low as 84.4 GJ per ton for underground nickel sulphide mining and as high as $219.8 \mathrm{GJ}$ per ton for nickel laterite open-pit mining (Castle 1989). Energy requirements for smelting and refining of nickel are very high, depending on the ore type and process. For sulphide nickel, energy requirements are 152.4 GJ per ton for flash smelting, while requirements for laterites range from $249.8 \mathrm{GJ}$ per ton for acid pressure-leaching to $472.1 \mathrm{GJ}$ per ton for the ammonia leach process.

\subsubsection{Coal Mining and Coke Production Processes}

Production of steel involves the use of coke, which is produced from metallurgical (or coking) coal. Thus, the impacts of steel production include the environmental effects and risks associated with discharges from the mining, preparation, storage, and transportation of coking coal, as well as those from the production of the coke from that coal. These impacts and risks are summarized in the following subsections.

\subsubsection{Coal Mining}

Coal seams deeper than about $60 \mathrm{~m}$ usually require underground mining. The major underground mining methods currently used in the U.S.A are room-and-pillar and longwall panel mining. In room-and-pillar mining, coal is removed from intersecting tunnels in the coal seam; coal pillars are left in a checkerboard pattern to provide roof support and reduce 
subsidence. As mining depth increases, the size of the support pillars must also increase (DOE 1988). Panel mining, which can only be used where geological conditions are favorable and subsidence can be tolerated, eliminates the need to retain coal pillars for roof support. Longwall mining is the predominant method of panel mining; continuous mining equipment is used to cut two parallel operating tunnels into a coal seam. Room-and-pillar methods are used in $96 \%$ of all underground mines in the U.S.A. Longwall mining is widely used in Europe (DOE 1988), particularly in the United Kingdom and the Federal Republic of Germany. Continuous long-wall mining is the predominant coal mining method in Poland, where the mines are deep and the seams are thinning (Szpunar et al. 1990).

Surface mining of coal is accomplished by area, contour, auger, and open-pit methods. Topsoil and overburden are removed by cutting successive trenches (typically 30-60 m wide and $0.5 \mathrm{~km}$ or more long) to expose the top of the coal seam. Following coal extraction, another trench is cut to expose more coal; the new overburden (referred to as "spoil") is used to fill the mined-out trench. Spoil piles are then graded, topsoil (if segregated) is replaced, and the land is revegetated. Up to $40 \mathrm{t}$ of overburden may be handled for each ton of coal recovered (DOE 1988).

Coal preparation technologies may be physical or chemical. Both types of technologies are preceded by crushing to reduce the size of the coal, and screening to remove the fines. Physical coal cleaning processes remove impurities such as shale, clay, and pyrites. The technologies employed are mature and widely used in the eastern U.S.A., where most, if not all, of the metallurgical coal is mined. About $50 \%$ of underground-mined coals and about 25\% of surface-mined coals in the U.S.A. are physically cleaned. Physical cleaning processes primarily rely on differences in specific gravity, but may also use differences in surface properties, magnetic and electrical characteristics, or other attributes to separate impurities that are physically bound within the coal. Wet-cleaning methods account for about 98\% of physical cleaning activities (DOE 1988). More expensive chemical means must be used to remove additional impurities that are chemically bound in the coal, such as organically bound sulfur.

The major modes of transporting mined coal are railroad, truck, and barge. Trucks, conveyor belts, and pneumatic pipelines are economically used for short-haul coal transport. About $14 \%$ of the coal produced in the U.S.A. is moved by trucks, generally over intermediate distances of $80-120 \mathrm{~km}$. Truck transport is a relatively expensive mode. Conveyors and pneumatic pipelines typically are used to deliver smaller amounts of coal over shorter distances (less than $15 \mathrm{~km}$ ) (DOE 1988).

\subsubsection{Coke Production}

Coke is a premium fuel produced from a blend of two or more bituminous coals, because individual coal types do not possess all the properties required to produce highquality metallurgical coke. Coal is converted into coke, a porous, solid, carbonaceous material derived from the thermal decomposition of plastic or caking coals in the absence of air (DOE 1992a). Table 6.8 compares and summarizes U.S.A. coal and coke production and consumption statistics for 1970, 1980, and 1990 . 
TABLE 6.8 Consumption/Production Statistics for U.S.A. Coal and Coke, 1970, 1980, and 1990

\begin{tabular}{|c|c|c|c|}
\hline Category & 1970 & 1980 & 1990 \\
\hline Coking coal consumption $\left(10^{6} t\right)$ & 87.5 & 60.5 & 36.1 \\
\hline Coke production $\left(10^{6} t\right)$ & 60.3 & 41.8 & 25.0 \\
\hline Coke consumption (apparent) $\left(10^{6} \mathrm{t}\right)$ & 57.3 & 37.5 & 25.2 \\
\hline Coke used per ton of pig iron ${ }^{2}(t)$ & 0.63 & 0.58 & 0.50 \\
\hline Operating coke plants (number) ${ }^{b}$ & 69 & 60 & 34 \\
\hline
\end{tabular}

a See discussion in text regarding technological advances in blast furnace operations and increase in electric-arc furnace usage.

b Reduced to 28 coking plants by 1992 (USEPA 1992a).

Source: DOE (1992a).

A large fraction of the coal (vitrinite) softens when heated to about $400^{\circ} \mathrm{C}$ and decomposes, releasing volatiles. After a plastic or molten mass is formed in which individual coal particles lose their identities, a stage of minimum viscosity occurs, followed by a stage of increasing viscosity as a second group of volatiles is released. The mass solidifies into a carbon-rich material, referred to as semicoke. Continued application of heat in the range of $500-900^{\circ} \mathrm{C}$ converts the semicoke to coke by driving off essentially all elements except carbon, the inorganic mineral elements, and trace amounts of oxygen, nitrogen, hydrogen, and sulfur. The residual resolidifies as shiny, hard, black coke (Neavel and deMasi 1978).

Commercially, coals are coked in ovens called slot ovens. These ovens are refractorylined containers typically $0.5 \mathrm{~m}$ wide, $6 \mathrm{~m}$ high, and $40 \mathrm{~m}$ long. From 30 to more than 100 of these ovens are often aligned side-by-side into a battery, each oven separated from its neighbor by a narrow space referred to as a flue. Coal is charged through ports along the top of the oven until it fills the oven to within several feet of the top. Depending upon size, each oven holds 12-40 $t$ of coal. Heat is applied through the side walls by burning, in the flue, either natural gas or combustible gases derived from the pyrolysis of the coal itself (coke oven gas) (Neavel and deMasi 1978).

Flue temperatures are commonly controlled at $1200-1300^{\circ} \mathrm{C}$, which allows coking to proceed at $25 \mathrm{~mm}$ an hour. Since a typical slot oven is $0.5 \mathrm{~m}$ wide, a complete coking cycle , takes about 18 hours with the plastic zone, about $2.5 \mathrm{~mm}$ thick, moving progressively from the wall toward the center of the charge. Volatile products evolve toward the center and then upward, where they are removed from the head space through an offtake system composed of stand pipes and other piping. Tars and oils are then separated from aqueous liquor and gases. The gas. (rich in methane) is scrubbed and used to fire the oven; tars and oils are either burned as fuel or further processed into by-products. A small, positive back-pressure maintained on the oven prevents air from leaking into the ovens during coking (Neavel and deMasi 1978; American Iron and Steel Institute undated; USEPA 1992a). 
At the completion of the coking cycle, the hot, incandescent coke is transported by a rail car to a quenching shed where it is cooled with water sprays. The coke is then crushed and screened to produce pieces sized commonly between 1 and $5 \mathrm{~mm}$. Fine pieces of coke (breeze) are screened out and used as fuel (Neavel and deMasi 1978; USEPA 1992a).

\subsubsection{Health Risks of Coal Mining and Coke Production}

\subsubsection{Workers}

Coal mining has historically been a hazardous occupation. The incidence of injuries and deaths due to accidents in underground and surface coal mines and their associated coal preparation plants is listed in Table 6.9. Also listed is the health risk in fatalities on the basis of transport mode. The occupational fatalities include (1) fatal accidents in coal mines, (mainly from roof cave-ins and machinery); (2) miners' diseases (exposure to dust leading to pneumoconiosis, silicoses, bronchitis, vasoneurosis, vibration disease associated with equipment use leading to muscle and bone pains, bursitis, and Raynaud's syndrome); and (3) fatalities during transport (IAEA 1991).

The primary concerns for underground mine worker health and safety have been safe operating parameters, specifically for dust control, ventilation, and roof support. The prime health concern is coal worker pneumoconiosis. The incidence and severity of this disease is believed to be related to the levels of dust present in mines. Other occupational health problems, such as loss of hearing, nonrespiratory illness from coal exposure, and hypertension, are suggested from epidemiological studies, but the extent of these problems is not well known (DOE 1988).

The new chemical cleaning technologies may result in the release of chemicals such as iron pentacarbonyl, hydrogen sulfide, and organic solvents that can produce health effects ranging from eye irritation to serious illness or death, depending on exposure levels. The handling and conversion of coal that contains residual amounts of cleaning agents may also present both occupational and public health concerns (DOE 1988).

Potential occupational hazards have also been identified for coking operations. Epidemiological studies showed that U.S.A. steel workers most heavily exposed to mixtures of organic pollutants in coke oven emissions at by-product plants (e.g., at the topside of the coke oven) had an eightfold higher rate of respiratory cancer than the general U.S.A. population (USEPA 1984b, 1992b). ${ }^{3}$ Thus, coke oven emissions became regulated under the U.S. Occupational Safety and Health Administration (OSHA) to improve safety in the work environment (Shobert 1987).

3 The studies also showed that $90 \%$ of these workers were nonwhite. 
TABLE 6.9 Quantifiable Resource Requirements, Discharges, and Impacts from Coal Mining, Coal Preparation, Coal Storage, and Coal Transport per Ton of Steel Produced ${ }^{\mathrm{a}}$

\begin{tabular}{|c|c|c|}
\hline \multirow[b]{2}{*}{ Category } & \multicolumn{2}{|c|}{ Quantity, by Mine Type } \\
\hline & $\begin{array}{l}\text { Underground } \\
\text { Mining }\end{array}$ & $\begin{array}{l}\text { Surface } \\
\text { Mining }\end{array}$ \\
\hline \multicolumn{3}{|c|}{ Resource Requirements } \\
\hline Coke $^{b}(t)$ & 0.5 & 0.5 \\
\hline $\mathrm{Coal}^{\mathrm{b}}(\mathrm{t})$ & 0.72 & 0.72 \\
\hline Water (L) & 102 & 601 \\
\hline Land (ha) & $0.28 \times 10^{-6}$ & $6.5 \times 10^{-6}$ \\
\hline \multicolumn{3}{|c|}{ Atmospheric Emissions } \\
\hline Particulates (g) & 0.34 & 24 \\
\hline Hydrocarbons (g) & 0.34 & 30 \\
\hline $\mathrm{SO}_{2}(\mathrm{~g})$ & 0.42 & 34 \\
\hline $\mathrm{CO}(\mathrm{g})$ & 4.5 & 97 \\
\hline $\mathrm{NO}_{\mathrm{x}}(\mathrm{g})$ & Negligible & 466 \\
\hline Aldehydes (g) & Negligible & 7.2 \\
\hline Fugitive dust & Negligible & $1.3-2.2$ \\
\hline
\end{tabular}

\begin{tabular}{|c|c|c|c|c|}
\hline \multirow[b]{2}{*}{ Category } & \multicolumn{2}{|c|}{ Underground Mining } & \multicolumn{2}{|c|}{ Surface Mining } \\
\hline & Mine & $\begin{array}{l}\text { Prep } \\
\text { Plant }^{\mathrm{c}}\end{array}$ & Mine & $\begin{array}{l}\text { Prep } \\
\text { Plant }^{c}\end{array}$ \\
\hline \multicolumn{5}{|l|}{$\begin{array}{l}\text { Water Discharges } \\
\text { Appalachian }\end{array}$} \\
\hline $\mathrm{Fe}(\mathrm{g})$ & 5.7 & $1.8-4.1$ & 7.5 & $1.8-4.1$ \\
\hline $\mathrm{Mn}(\mathrm{g})$ & 3.2 & $1.0-2.3$ & 4.2 & $1.0-2.3$ \\
\hline $\begin{array}{l}\text { Total suspended } \\
\text { solids (g) }\end{array}$ & 57 & $18-41$ & 7.5 & $18-41$ \\
\hline \multicolumn{5}{|l|}{ Interior } \\
\hline $\mathrm{Fe}(\mathrm{g})$ & 3.9 & $1.8-4.1$ & 2.5 & $1.8-4.1$ \\
\hline $\operatorname{Mn}(g)$ & 2.2 & $1.0-2.3$ & 12.6 & $1.0-2.3$ \\
\hline $\begin{array}{l}\text { Total suspended } \\
\text { solids (g) }\end{array}$ & 39 & $18-41$ & 25 & $18-41$ \\
\hline \multicolumn{5}{|c|}{$\begin{array}{l}\text { Worker Health and Safety Impacts } \\
\text { (excluding transportation) }\end{array}$} \\
\hline Deaths $^{\mathrm{d}}$ & $2.8 \times 10^{-7}$ & $4.5 \times 10^{-9}$ & $3.6 \times 10^{-8}$ & $1.8 \times 10^{-8}$ \\
\hline Injuries & $3.5 \times 10^{-5}$ & $6.0 \times 10^{-7}$ & $3.8 \times 10^{-6}$ & $2.4 \times 10^{-6}$ \\
\hline
\end{tabular}


TABLE 6.9 (Cont.)

\begin{tabular}{lcccc}
\hline Category & Rail & Truck & Barge & Pipeline \\
\hline \multirow{2}{*}{$\begin{array}{c}\text { Coal Transport Deaths } \\
\text { Workers }\end{array}$} & $\begin{array}{r}5.4 \times 10^{-11} \text { to } \\
7.9 \times 10^{-9}\end{array}$ & $\begin{array}{c}5.0 \times 10^{-9} \text { to } \\
8.6 \times 10^{-7}\end{array}$ & $\begin{array}{c}2.2 \times 10^{-8} \text { to } \\
3.6 \times 10^{-7}\end{array}$ & $5.8 \times 10^{-8}$ \\
& & & & \\
Public & $1.3 \times 10^{-7}$ to & $2.2 \times 10^{-7}$ to & $2.5 \times 10^{-8}$ to & NA \\
& $1.9 \times 10^{-7}$ & $8.6 \times 10^{-7}$ & $1.0 \times 10^{-7}$ & \\
\hline
\end{tabular}

a Based on U.S.A. eastern coal mines; U.S.A. western coal mines generally do not produce metallurgical-grade coal.

b From DOE (1992a); $1 \mathrm{t}$ coal produces $0.69 \mathrm{t}$ coke; $0.5 \mathrm{t}$ coke is used to produce $1 \mathrm{t}$ pig iron; thus, assume $0.72 \mathrm{t}$ of mined coal is used to produce $1 \mathrm{t}$ steel.

c Associated coal preparation plant.

d IAEA (1991) gives a range of $8.6 \times 10^{-8}$ to $6.0 \times 10^{-7}$ for underground mines and $3.2 \times 10^{-8}$ to $6.1 \times 10^{-8}$ for surface mines.

e From IAEA (1991).

Source: DOE (1988), except as noted.

Coke oven emissions are highly variable and not easily measured since emissions escape from many different pieces of equipment, and leaks can change in size and location over time. Also, the tar component of coke oven emissions condenses on measurement equipment, causing erroneous results. For these reasons, proposed regulations address only visible emissions that are estimated (in terms of duration) by operators. Among the 10 states in the U.S.A. currently regulating by-product coke oven emissions, limits on charging operations range from 11 seconds to 60 seconds (on average) of visible emissions per charge (Hootman and Vernet 1991; USEPA 1992c).

Dust emissions have been measured from West German coke oven plants employing dust removal technology. These emission levels can be used to approximate the level per ton of U.S.A. steel produced (Table 6.10). Topside leak rates of POM can range from an average of $0.002 \mathrm{~kg} / \mathrm{h}$ to $0.013 \mathrm{~kg} / \mathrm{h}$ per oven, which may be equivalent to $36-234 \mathrm{~g}$ per oven per charge (Hootman and Vernet 1991; Elliott 1981).

To protect the worker, USEPA standards have been proposed for coke oven emissions. Industry experts have estimated that setting limits on cancer risks downwind of coke ovens would shut down nearly all of the nation's 28 plants (down from 69 in 1970 [Table 6.8]), eventually halting steel production in the U.S.A. Reportedly, it is uncertain 
TABLE 6.10 Types and Quantities of Environmental Impacts, Effects, and Risks from the Coking of Coal and Related Processing ${ }^{\mathrm{a}}$

\begin{tabular}{|c|c|c|c|c|}
\hline Category & Direct Impact & $\begin{array}{l}\text { Resultant Health/ } \\
\text { Environmental Effect }\end{array}$ & Quantifiable Effect ${ }^{b-i}$ & Value \\
\hline $\begin{array}{l}\text { Worker health } \\
\text { and safety }{ }^{\mathrm{g} j}\end{array}$ & $\begin{array}{l}\text { Emissions of benzene, } \\
\text { toluene, xylenes, } \\
\text { particulate POM, } \\
\text { trace elements - As, } \\
\mathrm{Be}, \mathrm{Cd}, \mathrm{Cr}, \mathrm{Pb} \text {, and } \\
\mathrm{Ni}-\text { and other VOCs } \\
\text { and HAPs. }\end{array}$ & $\begin{array}{l}\text { Death, injury, } \\
\text { respiratory (lung) and } \\
\text { kidney cancer, other } \\
\text { respiratory ailments } \\
\text { (such as bronchitis), and } \\
\text { heart disease from } \\
\text { occupational exposure. }\end{array}$ & $\begin{array}{l}\text { Topside coke oven POM } \\
\text { Carbon emissions (with } \\
\text { modern doors) } \\
\text { Total PAH } \\
\text { Dust emissions } \\
\text { Charging } \\
\text { Pushing } \\
\text { Quenching } \\
\text { Lung cancer risk: increase over } \\
\text { baseline risk. }\end{array}$ & $\begin{array}{r}0.65-4.2 \mathrm{~g} \\
2.2-7.1 \mathrm{~g} \\
\\
3.9 \mathrm{~g} \\
7.5 \mathrm{~g} \\
20 \mathrm{~g} \\
35 \mathrm{~g} \\
\\
0.4-15 \text { times }\end{array}$ \\
\hline $\begin{array}{l}\text { Public health } \\
\text { and safety }\end{array}$ & $\begin{array}{l}\text { Emissions of benzene, } \\
\text { toluene, xylenes, } \\
\text { particulate } \mathrm{POM} \text {, } \\
\text { trace elements - As, } \\
\mathrm{Be}, \mathrm{Cd}, \mathrm{Cr}, \mathrm{Pb} \text {, and } \\
\mathrm{Ni}-\text { and other VOCs } \\
\text { and HAPs. }\end{array}$ & $\begin{array}{l}\text { Death, respiratory } \\
\text { cancer, and other } \\
\text { ailments from public } \\
\text { exposure (sensitive } \\
\text { individuals). }\end{array}$ & $\begin{array}{l}\text { Excess lung cancer deaths } \\
\text { Excess total cancer deaths } \\
\text { Lost work days } \\
\text { Reduced activity days } \\
\text { Direct medical expenses }\end{array}$ & $\begin{array}{r}1.39 \times 10^{-6}(1972) \\
2.06 \times 10^{-8}(1991) \\
7.34 \times 10^{-8}(1985) \\
2.5 \times 10^{-5} \\
1.5 \times 10^{-3} \\
1.2 \text { mills }\end{array}$ \\
\hline Air quality & (Incorporated above in & blic health and safety.) & Benzo(a)pyrene & $1.33 \mathrm{~g}(1970 \mathrm{~s})$ \\
\hline Water quality & $\begin{array}{l}\text { Discharges from } \\
\text { coking operations. }\end{array}$ & $\begin{array}{l}\text { pH changes and levels of } \\
\text { pollutants in water sink } \\
\text { affecting quality and } \\
\text { availability for } \\
\text { terrestrial and aquatic } \\
\text { ecologies. }\end{array}$ & $\begin{array}{l}\text { Effluent standards } \\
\text { (West Germany) } \\
\text { Suspended solids } \\
\text { Chemical oxygen demand } \\
\text { Biological oxygen demand } \\
\text { Inorganic nitrogen } \\
\text { Total nitrogen } \\
\text { Phenol } \\
\text { Phosphorus } \\
\text { Cyanide } \\
\text { Thiocyanide } \\
\text { Benzene, toluene, xylenes } \\
\text { Benzo(a)pyrene } \\
\text { Sulfide }\end{array}$ & $\begin{array}{r}7.5 \mathrm{~g} \\
30 \mathrm{~g} \\
4.5 \mathrm{~g} \\
12 \mathrm{~g} \\
15 \mathrm{~g} \\
0.075 \mathrm{~g} \\
0.45 \mathrm{~g} \\
0.015 \mathrm{~g} \\
3.0 \mathrm{~g} \\
0.015 \mathrm{~g} \\
0.015 \mathrm{~g} \\
0.015 \mathrm{~g}\end{array}$ \\
\hline
\end{tabular}

a Sources of identified risk: coke (slot) oven (primary source), coke quenching process step, and blast furnace operation. Risks are calculated per ton of steel produced (where applicable). $\mathrm{POM}=$ polycyclic organic material, $\mathrm{VOCs}=$ volatile organic compounds, HAPs = hazardous air pollutants; $\mathrm{PAH}=$ polynuclear aromatic hydrocarbon.

b Dated, but illustrative, material - based on (1972) emissions: Suta (1977) from DOE (1980).

c EPA (1992a).

d Elliott (1981, p. 866).

e Anon. (1993).

f Dong et al. (1988); lifetime lung cancer risk to a U.S.A. or Canadian nonwhite male worker exposed to coke oven emissions for $\mathbf{4 0}$ years, beginning at age $\mathbf{2 0}$ (not given in terms of steel produced, but calculated on annual basis).

g USEPA (1990b).

h Fisher (1992).

i Friedrich and Hinz (1992).

j Minority workers estimated at $90 \%$, with an eightfold higher rate of respiratory cancer observed USEPA (1984b) from EPA (1992b). 
whether risks to the general public, which the Clean Air Act Amendments are designed to protect, are similar to those of exposed workers. However, it is generally agreed that coke production liberates a large amount of organic chemicals as by-products and that without emission control technology coke plants will continue to be serious air polluters (Shobert 1987).

\subsubsection{Public}

Coke oven emissions, characterized typically by oily, yellow-brown smoke, contain more than 10,000 individual compounds as gases and respirable particulate matter. The most critical components, in terms of public health concerns, appear to be the volatile organic compounds, benzene, and toluene. In addition, certain trace elements are also emitted from coke ovens. These elements - arsenic, beryllium, cadmium, chromium, lead, and nickel - pose health risk concerns over long-term exposure. Finally, certain gases such as methane $\left(\mathrm{CH}_{4}\right)$, hydrogen sulfide $\left(\mathrm{H}_{2} \mathrm{~S}\right), \mathrm{CO}$, and nitric oxide (NO) are also emitted (Hootman and Vernet 1991; Szpunar 1992; USEPA 1992c). Detailed descriptions of the health effects associated with these substances are included in Appendix E.

In 1992 , about $23 \times 10^{6}$ people were estimated to have been exposed to toxic emissions released from doors, topside, and charging at 28 coke oven plants. The cancer risk assessment indicates the following: 1.8 excess cancer cases per year due to baseline levels of coke oven emissions, 2,200 additional lost work days, 13,000 additional reduced activity days, and an extra $\$ 103,000$ ( $\$ 1991$ ) in direct medical expenses (EPA 1992a).

\subsubsection{Environmental Impacts of Coal Mining and Coal Production}

Coal mining, preparation, storage, and transportation impact air, water, solid waste and land use, noise, and health and safety. Many of the environmental impacts of coal mining and preparation are unavoidable. For instance, short-term loss of wildlife habitat and agricultural production is inherent in surface mining. Table 6.11 summarizes qualitatively by category the direct impacts, the resultant health and environmental effects, and the specific source and level of identified risk.

\subsubsection{Air Impacts}

Extraction, storage, transfer and transportation, and preparation and cleaning of coal and waste storage all produce some level of atmospheric emissions. Table 6.11 lists literature-derived estimates of atmospheric emissions in the eastern U.S. generated by underground and surface mines capable of producing metallurgical coal, calculated per ton of steel produced (DOE 1988). (Typically, U.S.A. western surface mines do not produce metallurgical-grade coal, only subbituminous and bituminous ranks of steam coal.) 
TABLE 6.11 Identification of Environmental Impacts, Effects, and Risks from Coal Mining, Coal Preparation, Coal Storage, and Coal Transportation ${ }^{a, b}$

\begin{tabular}{|c|c|c|c|c|}
\hline Category & Direct Impact & $\begin{array}{l}\text { Resultant Health/ } \\
\text { Environmental Effect }\end{array}$ & $\begin{array}{c}\text { Source of } \\
\text { Identified Risk }\end{array}$ & $\begin{array}{l}\text { Level of } \\
\text { Risk }\end{array}$ \\
\hline \multirow[t]{3}{*}{ Air quality } & \multirow{3}{*}{$\begin{array}{l}\text { Emissions of } \\
\text { particulates, } \mathrm{SO}_{2}, \mathrm{CO} \text {, } \\
\mathrm{NO}_{\mathrm{x}} \text {, ozone, airborne } \\
\mathrm{Pb} . \text {.VOCs, and } \\
\text { numerous other } \\
\mathrm{HAPs}^{\mathrm{c}, \mathrm{d}}\end{array}$} & \multirow{3}{*}{ 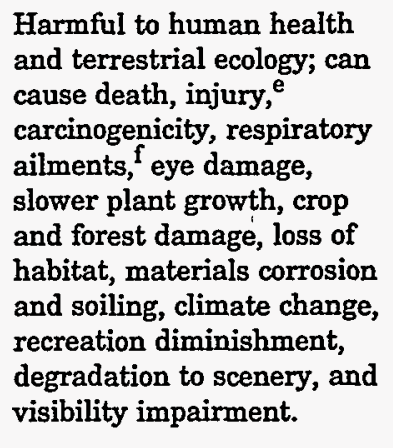 } & Surfäce mining & Low \\
\hline & & & $\begin{array}{l}\text { Uncontrolled fires from } \\
\text { abandoned mines and } \\
\text { storage/waste piles } \\
\text { Prep plant } \\
\text { (esp. thermal dryers) }\end{array}$ & $\begin{array}{l}\text { Low to } \\
\text { medium } \\
\text { Low }\end{array}$ \\
\hline & & & $\begin{array}{l}\text { Combustion products } \\
\text { from chemically cleaned } \\
\text { coal } \\
\text { Storage and transfer }\end{array}$ & Medium \\
\hline Water quality & $\begin{array}{l}\text { Discharges from mines, } \\
\text { prep plants, and slurry } \\
\text { pipelines; runoff from } \\
\text { storage/ waste piles } \\
\text { and reclaimed land. }\end{array}$ & $\begin{array}{l}\text { Can affect } \mathrm{pH} \text { and levels of } \\
\text { pollutants, harming water } \\
\text { quality and aquatic life. }\end{array}$ & $\begin{array}{l}\text { Surface-mine discharge } \\
\text { Underground-mine } \\
\text { discharge } \\
\text { Storage/waste-pile runoff } \\
\text { Prep-plant discharge } \\
\text { Aquifer modification }\end{array}$ & $\begin{array}{l}\text { Medium } \\
\text { Medium } \\
\text { Medium } \\
\text { Low } \\
\text { Low to high }\end{array}$ \\
\hline Water quantity & $\begin{array}{l}\text { Reduction/redirection of } \\
\text { surface water and } \\
\text { groundwater supplies. }\end{array}$ & $\begin{array}{l}\text { Can affect water } \\
\text { availability for terrestrial } \\
\text { and aquatic ecologies and } \\
\text { other uses. }\end{array}$ & $\begin{array}{l}\text { Surface-mine-drainage } \\
\text { modification } \\
\text { Aquifer modification } \\
\text { Consumptive uses }\end{array}$ & $\begin{array}{l}\text { Low } \\
\text { Low to high } \\
\text { Low to high }\end{array}$ \\
\hline $\begin{array}{l}\text { Land use/ } \\
\text { waste disposal }\end{array}$ & $\begin{array}{l}\text { Abuse of land during } \\
\text { and after mining; } \\
\text { aesthetic scarring, esp. } \\
\text { from surface mines; } \\
\text { formation and } \\
\text { collection of mine and } \\
\text { prep-plant wastes. }\end{array}$ & $\begin{array}{l}\text { Loss of wildlife habitat } \\
\text { ranges from temporary to } \\
\text { permanent. }\end{array}$ & $\begin{array}{l}\text { Surface-mine } \\
\text { reclamation } \\
\text { Subsidence } \\
\text { Wildlife habitat } \\
\text { destruction } \\
\text { Mine-waste and prep } \\
\text {-plant disposal }\end{array}$ & $\begin{array}{l}\text { Low to } \\
\text { medium } \\
\text { Low } \\
\text { Low to } \\
\text { medium } \\
\text { Low }\end{array}$ \\
\hline Noise & \multicolumn{2}{|c|}{$\begin{array}{l}\text { Temporary or permanent loss in hearing sensitivity, } \\
\text { physical, and psychological disorders; interference with } \\
\text { speech communications; changes in cardiovascular, } \\
\text { neurologic, and other functions (from machinery or } \\
\text { blasting). }\end{array}$} & $\begin{array}{l}\text { Surface mining } \\
\text { Underground mining } \\
\text { Prep plant } \\
\text { Storage }\end{array}$ & $\begin{array}{l}\text { Low to } \\
\text { medium } \\
\text { Low to } \\
\text { medium } \\
\text { Low } \\
\text { Low }\end{array}$ \\
\hline $\begin{array}{l}\text { Worker health and } \\
\text { safety; public health } \\
\text { and safety }\end{array}$ & \multicolumn{2}{|c|}{$\begin{array}{l}\text { Fatalities and disabling injuries from mining, prep- } \\
\text { plant, and transportation accidents; respiratory illness } \\
\text { from mining; nonrespiratory illness from coal exposure; } \\
\text { exposure to hazardous materials in prep plant; } \\
\text { hypertension; socioeconomic effects from increased } \\
\text { transportation. }\end{array}$} & $\begin{array}{l}\text { Surface mining } \\
\text { Underground mining } \\
\text { Prep-plant operation: } \\
\text { - physical and } \\
\text { - chemical } \\
\text { Storage } \\
\text { Transportation }\end{array}$ & $\begin{array}{l}\text { Low and } \\
\text { medium } \\
\text { Low } \\
\text { Low }\end{array}$ \\
\hline
\end{tabular}

See footnotes on next page. 
a DOE (1988).

b Szpunar and Gillette (1992).

c The list of hazardous air pollutants (HAPs) includes 189 chemical species, including specific organic compounds, inorganic elements and their compounds, and chemical classes or categories. The class of polycyclic organic matter (POM) is included in this list (U.S. Congress 1990).

d Szpunar (1992).

e Increased risks of injury (morbidity include: acute effects, exacerbation of chronic illness, and increased risk of developing chronic diseases from involuntary exposure.

f Specific respiratory ailments include impaired breathing, coughing, chest tightness, reduced productivity and activity, altered pulmonary ventilation, increased frequency and severity of asthmatic attacks, increased prevalence of chronic respiratory disease, and increased mortality.

Most of the atmospheric emissions from surface mines are fugitive dusts from access and haul roads and from coal loading, transfer, processing, and storage operations. Sources of fugitive dust can be controlled by spraying the coal with chemicals or water. Dust problems at transfer points may be reduced by the use of electrostatic precipitators, fabric filters, or even well-designed buffer zones. Emissions from conveyors are effectively eliminated by covers. Windbreaks can effectively reduce visible dust emissions from wind erosion of coal and overburden. Underground mining, because of the lower exposure of activities to surface winds and greater use of electrical equipment, generally produces fewer atmospheric emissions than does surface mining (DOE 1988).

Uncontrolled fires resulting from spontaneous combustion in abandoned mines and waste piles containing carbonaceous materials can smolder for years, producing toxic gases. Because such fires burn under oxygen-deficient conditions, the emissions differ from those generated during oxygen-rich combustion such as that typical of a coal-fired power plant boiler. By reducing air circulation in abandoned mines and by compacting and/or burying refuse piles, fires may be prevented (DOE 1988).

Sources of air pollution from coking plants may be broadly defined as either continuous or fugitive. The main sources of continuous emissions are those that originate from combustion processes such as battery underfiring, steam raising, and ammonia incineration. The main pollutants emanating therefrom include $\mathrm{SO}_{2}, \mathrm{NO}_{\mathrm{x}}$ (principally nitric oxide, NO), and particulates (Fisher 1992). The most widely applied $\mathrm{SO}_{2}$ control methods in Europe are ammonia-based removal processes. The control of $\mathrm{NO}_{\mathrm{x}}$ is achieved by the application of low- $\mathrm{NO}_{\mathrm{x}}$ burners and the incorporation of staged combustion. Particulates, primarily from incomplete combustion, can be controlled to some extent by adjusting and maintaining the burners (Fisher 1992).

In most countries, it is the fugitive emissions are generally the hardest to control. Fugitive emissions from the battery operations contain significant concentrations of particulates, $\mathrm{PAH}$, benzene, toluene, xylenes, $\mathrm{H}_{2} \mathrm{~S}$, and heavy metals. A German study has 
established that antimony, arsenic, beryllium, cobalt, chromium, copper, manganese, nickel, and vanadium are largely retained in the coke, whereas cadmium, lead, mercury, thallium and zinc are more concentrated in the tar (Eisenhut 1990; Fisher 1992).

Old coke ovens have been estimated to produce $7.8 \mathrm{~g}$ of PAH per ton of coke (equivalent to $3.9 \mathrm{~g}$ of PAH per ton of steel produced) attributed to door leakage (48\%) and leaking charge hole lids (42\%) (Fisher 1992). In the 1970s, coke oven emissions were reportedly one of the major sources of the organic compound, benzo(a)pyrene (one compound in the class of POM), accounting in 1972 for $154 \mathrm{t}$ of emissions, or about $20 \%$ of the nationwide benzo(a)pyrene emissions from all sources (Suta 1977; DOE 1980). This amount was equivalent to $1.33 \mathrm{~g}$ benzo(a)pyrene per ton of steel produced at that time. Actual downwind measurements indicate the influence of a coking plant on the background levels of PAH, benzene, toluene, and xylenes with a range of 1-2 km. However, recent European studies demonstrate reduction of $\mathrm{PAH}$ emissions to 1-2\% with modern self-sealing door designs. Battery emissions of benzene, toluene, and xylenes at well-maintained modern coke plants are estimated at less than $6 \%$ of those from older installations. At British Steel Corporation, for example, oven door and oven top-leakage control have averaged greater than 99\% since start up of its rebuilt ovens in 1984 (Fisher 1992).

\subsubsection{Land Use Impacts}

The effects of coal mining on land use are direct and site specific. Surface disruption, inadequate reclamation of surface mines, subsidence from underground mining, and disposal of wastes are the major impacts. The most obvious impact of surface mining is the temporary removal of land from its primary use as farmland, forest, or rangeland (DOE 1988).

Contour mining can create severe environmental problems if not properly performed. Spoil from improperly controlled mines can result in erosion and landslides, and unreclaimed highwalls are a major aesthetic problem. However, experience in most coal-producing regions suggests that once the coal has been extracted, the land can be successfully reclaimed to support its former uses (DOE 1988). Inadequate reclamation of surface-mine areas may leave the land unable to support desirable plant species and result in the loss of important farmland or wildlife habitat. Measures to mitigate these potential impacts will vary with the site, but can include segregation of topsoil and overburden, better compaction of refuse, revegetation with native species, combination planting, and soil enrichment (DOE 1988).

Although less conspicuous than the results of surface mining, subsidence from underground mines can have severe impacts on roads, water and gas lines, buildings, and local hydrology. The extent, severity, and timing of subsidence depend on the overburden composition and thickness, mining technique, and other factors. It has been estimated that about $25 \%$ of the $8 \times 10^{6}$ acres of undermined lands in the eastern U.S.A. have subsided (DOE 1988).

Another major land use impact from coal mining and preparation results from the disposing of mining wastes. In 1979 , there were an estimated $3,000-5,000$ waste piles in the 
eastern U.S.A. that together contained over $3 \times 10^{9} t$ of waste. In addition to degrading air and water quality, mine wastes can be a blight on property values and become a visual affront, unless they are properly disposed of and the land is reclaimed effectively. In 1971, improper disposal of such wastes was dramatized in Buffalo Creek, West Virginia, where a water impoundment that was constructed of mine wastes broke during a heavy rainstorm, killing more that 125 people and causing millions of dollars in property damage. Numerous other such impoundments in the eastern U.S.A. present similar dangers (DOE 1988).

Coal preparation plants are by far the largest producers of solid waste from underground mining. This waste consists of shale, pyrites, coal fines, and impurities. About $25 \%$ of the raw coal from both surface and underground mines that is cleaned becomes solid waste. Surface mines also generate large amounts of material from overburden removal. However, most of this material is returned during the mine area reclamation, with little net solid-waste generation (DOE 1988).

\subsubsection{Water Impacts}

Historically, water quality degradation has been one of the major environmental concerns associated with coal mining and preparation. Adverse impacts can result from water drainage from mines, preparation plant wastewater, leaching and erosion of solid wastes from mining and cleaning plants (rainwater runoff), slurry dewatering, and modifications of aquifers during mining. The water quality factors of greatest concern are alkalinity or acidity $(\mathrm{pH})$, dissolved and suspended solids, and the concentrations of various metals. Table 6.9 lists literature-derived estimates of water discharges by U.S.A. metallurgical region, calculated per ton of steel produced (DOE 1988). However, no discharge of process water from new coal preparation plants is allowed under the New Source Performance Standards (NSPS) (USEPA 1985).

Acid drainage from both underground and surface mines and from coal and refuse storage piles is a potentially severe environmental impact where the coal seams and overburden are rich in pyrites (sulfide impurities). During mining, pyrites may be exposed to air and water and may become oxidized to form sulfuric acid. The resulting lower $\mathrm{pH}$ increases the solubility of compounds containing toxic heavy metals such as arsenic, cadmium, chromium, lead, mercury, and nickel. The acidity and solubilized trace metal pollutants may become toxic to aquatic life and can render water unfit for municipal and domestic use. And although effluent limitations exist to control acid drainage from new mines, drainage from abandoned mines continues to be a lingering problem. Based on data collected in the 1960s, about 10,000 miles of streams, primarily in Appalachia, had been degraded by acid drainage and sedimentation; three-fourths of the total acidity was attributed to abandoned mines (DOE 1988).

Aquifer modification is another form of water quality degradation. It occurs from the interconnection of vertically adjacent aquifers and by seepage of contaminants from spoil or 
waste disposal piles. Adjacent aquifers can be contaminated by drainage through joints and fractures created during blasting or intrusion into the aquifers during mining (DOE 1988).

Groundwater impacts from mining in or near aquifers and recharge areas are site specific. Diversion of local surface water drainage may affect both regional hydrology and erosion patterns, which in some cases results in unacceptable levels of sedimentation and stream flows that are inadequate to sustain aquatic life. Where a mine is located below the water table, seepage of water into the mine can lower the water table and dry up wells in the area. The permeability and recharge capability of postreclamation soil may be significantly different from that of virgin soil; altered groundwater recharge and surface flooding are the potential results (DOE 1988).

Concentrations of pollutants in treated effluents from coal preparation plants can be comparable to those in effluents from active mines. The volume of discharges per ton of coal can also be similar. Therefore, the quantity of a pollutant that is discharged to a stream from cleaning a ton of coal may be about the same as the quantity from mining a ton of coal, resulting in double the discharge per single ton of coal. The types of effluents will depend on factors such as coal characteristics, the type of cleaning technology, control practices, and rainfall (DOE 1988). The annual water requirements for mining and preparing $1 \times 10^{6} \mathrm{t}$ of raw coal by eastern U.S.A. underground and surface mining are $1.5 \times 10^{8} \mathrm{~L}$ and $8.3 \times 10^{7} \mathrm{~L}$, respectively (DOE 1988). These water use requirements translate to 102 and $61 \mathrm{~L}$ per ton of steel produced.

Traditionally, the treatment of coke oven waste water has been a three-stage process involving pretreatment for the separation of oils and tars, steam stripping for the removal of ammonia, and biological oxidation and accompanying stages for the destruction of phenols, thiocyanates, cyanides, thiosulfates, and other compounds that contribute to the chemical oxygen demand of the effluent. Heavy metal concentrations in waste water are considered negligible (Fisher 1992).

\subsubsection{Noise Impacts}

The coal preparation crusher and other mining and transportation equipment are the major sources of noise from both surface and underground mining. Blasting, which is normally carried out intermittently at strip mines, results in a sharp peak superimposed on the normal background noise level. Heavy construction equipment typically generates noise at a level of 80-100 decibels (dB) at $15 \mathrm{~m}$. This noise level is reduced to 60-80 $\mathrm{dB}$ at distances of about $450-600 \mathrm{~m}$ from the noise source. As a reference, the American Conference of Governmental Industrial Hygienists has recommended maximum duration for noise exposure: a maximum daily exposure of $85 \mathrm{~dB}$ in an 8-hour shift and a maximum of 15 minutes at the 105-dB level (DOE 1988). 


\subsection{SUMMARY}

Tables 6.12 through 6.14 summarize the available quantitative estimates of discharge and effects per ton of metal produced for iron ore/steel, copper, and aluminum, respectively. Data on land, water, and atmospheric impacts are included, as well as data on energy use and some health effects. Impacts of producing fuel or energy required for metal production are not included.

Many types of impacts are not included in the tables because sufficiently detailed data are not available. Among the impact categories that could not be included are the amounts of overburden, tailings, sedimentation, acid mine drainage, and dust produced per ton of metal, as well as the amount of land required for mining and refining operations.

Public health effects also are not fully accounted for on a per-ton basis. Radiation doses to workers and the public could not be appropriately quantified because adequate information on exposures was lacking, as was information on exposure to toxic elements. Fatalities from miners' exposure to radon were excluded because of the difficulty of converting estimates to a per-ton basis. Radiation and vehicle accident fatalities associated with transportation are similarly excluded. In addition, health effect data for workers only address acute injuries, not illnesses due to chronic exposure to toxic substances. Thus, the summaries of effects given in Tables 6.11 through 6.13 provide an incomplete picture of the total impacts of replacing RSM.

As industrialization increases throughout the world, the demand for metals follows this pattern of increase. To meet the worldwide demand, more ore must be mined and processed. One of the results of this continual and increased mining is a general lowering of the average ore grade, because superior deposits are mined first. This situation, in turn, means that increased quantities of ore will have to be mined to fill the worldwide demand for metals, which will result in increased environmental impacts, energy use, and risks to workers and the public unless additional precautions are taken.

Mining and smelting also involve international equity issues that must be considered. For instance, if the U.S.A. and other highly industrialized nations strengthen environmental regulations, mineral industries may relocate to developing countries with less stringent or poorly enforced environmental, health, and safety regulations. Thus, equity issues are important if environmental impacts are shifted from developed to less developed countries. Equity issues can also arise if minority or impoverished populations are disproportionately employed in the riskiest metal processing fields. 
TABLE 6.12 Quantifiable Discharges and Impacts of Iron Ore/Steel Production per Ton of Steel Produced

\begin{tabular}{|c|c|c|}
\hline Category & Material/Quantity & Environmental or Health Effects \\
\hline Resource requirements & $\begin{aligned} \text { Ore }^{\mathrm{a}}: & 1.9 \mathrm{t} \\
\text { Fluxes: } & 110 \mathrm{~kg} \\
\text { Coke: } & 0.5 \mathrm{t}\end{aligned}$ & $\begin{array}{l}\text { Creates tailings piles; acid mine drainage (from ore, limestone, and coal } \\
\text { mining) releases heavy metals, and toxins; disturbs and pollutes land, air, } \\
\text { water, natural habitats; results in worker accidents, health risks. }\end{array}$ \\
\hline Residual slag & $\begin{array}{c}\mathrm{BF}^{\mathrm{b}}: 262 \mathrm{~kg} \\
\mathrm{BOF}^{\mathrm{c}}: 75-120 \mathrm{~kg}\end{array}$ & May require disposal. \\
\hline \multirow[t]{2}{*}{$\begin{array}{l}\text { Heavy metals in } \\
\text { wastewater from } \\
\text { smelting and refining }\end{array}$} & $\mathrm{Pb}: 0.2-0.4 \mathrm{ng} / \mathrm{L}$ & $\begin{array}{l}\text { Causes neurological and urinary tract disorders; anemia, reproductive and } \\
\text { respiratory dysfunctions; hearing loss; liver, kidney, and bone damage; } \\
\text { learning disabilities in children; cardiovascular disorders; blood } \\
\text { abnormalities. }\end{array}$ \\
\hline & Mn: $2.0-5.2 \mathrm{ng} / \mathrm{L}$ & $\begin{array}{l}\text { Toxic to infants; causes metabolic and intestinal problems, abnormalities and } \\
\text { suppressed growth in plants and animals. }\end{array}$ \\
\hline \multirow{8}{*}{$\begin{array}{l}\text { Heavy metals in air } \\
\text { emissions from smelting } \\
\text { and refining }\end{array}$} & $\mathrm{Sb}: 0.005-0.1 \mathrm{~g}$ & $\begin{array}{l}\text { Causes respiratory and circulatory dysfunction, gastrointestinal disorders; } \\
\text { suspected carcinogen. }\end{array}$ \\
\hline & As: $0.5-3.5 \mathrm{~g}$ & $\begin{array}{l}\text { Causes skin abnormalities, skin and lung cancers, lung dysfunction, } \\
\text { neurological disorders, hematological effects including anaemia. }\end{array}$ \\
\hline & Cd: $0.04-0.4 \mathrm{~g}$ & $\begin{array}{l}\text { Causes hypertension, sterility, testicular hemorrhage, renal dysfunction, } \\
\text { kidney damage, fibrosis, hypertension, pulmonary disorders such as } \\
\text { emphysema; suspected carcinogen (lung, prostate). }\end{array}$ \\
\hline & Cr: $4-40 \mathrm{~g}$ & $\begin{array}{l}\text { Causes respiratory dysfunction, papilloma of larynx and pharynx, lung and } \\
\text { gastrointestinal cancers. }\end{array}$ \\
\hline & $\mathrm{Cu}: 0.2-4.0 \mathrm{~g}$ & Causes respiratory irritation. \\
\hline & $\mathrm{Mn}: 1.5-40 \mathrm{~g}$ & $\begin{array}{l}\text { Toxic to infants; causes metabolic disorders, intestinal disorders, } \\
\text { abnormalities and suppressed growth in plants and animals, neurological } \\
\text { disorders, lung irritation and infections, impotence. }\end{array}$ \\
\hline & $\mathrm{Ni}: 0.05-10.0 \mathrm{~g}$ & $\begin{array}{l}\text { Causes pulmonary and immunological disorders, nasal and lung cancers, } \\
\text { birth defects and malformations. }\end{array}$ \\
\hline & $\begin{array}{l}\text { Se: } 0.001-0.003 \mathrm{~g} \\
\mathrm{~V}: 0.1-2.0 \mathrm{~g} \\
\mathrm{Zn}: 10-45 \mathrm{~g}\end{array}$ & $\begin{array}{l}\text { Causes neurological disorders, hair loss, respiratory dysfunction. } \\
\text { Causes respiratory distress, neurological dysfunction. } \\
\text { Toxic to plants. }\end{array}$ \\
\hline
\end{tabular}


TABLE 6.12 (Cont.)

\begin{tabular}{|c|c|c|}
\hline Category & Material/Quantity & Environmental or Health Effects \\
\hline \multirow[t]{3}{*}{$\begin{array}{l}\text { Gaseous emissions from } \\
\text { refining }\end{array}$} & & $\begin{array}{l}\text { Damages plants; aggravates asthma and other respiratory problems; } \\
\text { increases development of chronic lung injury and diseases. }\end{array}$ \\
\hline & $\mathrm{SO}_{2}: 0.717 \mathrm{~kg}$ & $\begin{array}{l}\text { Corrodes stone and metals; damages plants; increases asthma, other } \\
\text { respiratory problems; increases mortality among elderly, young, and } \\
\text { individuals with preexisting respiratory diseases. }\end{array}$ \\
\hline & VOC: $0.187 \mathrm{~kg}$ & $\begin{array}{l}\text { Contributes to lung and other cancers and respiratory problems; contributes } \\
\text { to ozone and smog production. }\end{array}$ \\
\hline $\begin{array}{l}\text { Particulate emissions } \\
\text { from refining }\end{array}$ & $\begin{array}{l}\text { BF: } 580 \mathrm{~g} \\
\text { BOF: } 7-30 \mathrm{~kg}\end{array}$ & $\begin{array}{l}\text { Contains lead, manganese, zinc, other elements. } \\
\text { Contains iron, iron oxide, other elements. }\end{array}$ \\
\hline Energy use & 21-35 GJ & $\begin{array}{l}\text { Causes } \mathrm{SO}_{2} \text { and other emissions from fuel combustion; increases land, air, } \\
\text { water impacts from coal and uranium mining, petroleum extraction, and } \\
\text { power generation; creates worker accidents and public health risks; causes } \\
\text { cancers. }\end{array}$ \\
\hline Mining health effects & $\begin{array}{l}\text { Fatalities: } 2 \times 10^{-7} \\
\text { Injuries: } 1.3 \times 10^{-5}\end{array}$ & $\begin{array}{l}\text { Includes death, loss of consciousness, restriction of work or motion, inability } \\
\text { to perform all job duties. }\end{array}$ \\
\hline $\begin{array}{l}\text { Refining health effects } \\
\text { (blast furnace) }\end{array}$ & $\begin{array}{l}\text { Fatalities and } \\
\text { injuries: } 1.4 \times 10^{-4}\end{array}$ & $\begin{array}{l}\text { Includes death, loss of consciousness, restriction of work or motion, inability } \\
\text { to perform all job duties. }\end{array}$ \\
\hline Foundry health effects & $\begin{array}{l}\text { Fatalities and } \\
\text { injuries: } 1.5 \times 10^{-4}\end{array}$ & $\begin{array}{l}\text { Includes death, loss of consciousness, restriction of work or motion, inability } \\
\text { to perform all job duties. }\end{array}$ \\
\hline
\end{tabular}

See next page for footnotes. 


\section{TABLE 6.12 (Cont.)}

a Computed on basis of a 2.5:1.0 ratio for iron ore to pig iron. Because steel produced from iron ore has approximately $25 \%$ scrap input, the 2.5 units of ore were multiplied by 0.75 .

b Blast furnace.

c Basic oxygen furnace.

d The low end of the range of emission estimates represents the more efficient combinations of production technology and pollution control and raw material inputs with the lowest concentrations of contaminants, while the high end represents the least efficient processes and highest contaminant concentrations.

Sources: Bhatti (1992); Dehmel (1992); Elsworth (1984); Friberg (1986); Graham (1990); Kohout et al. (1990); Nriagu and Pacyna (1988); OECD (1991); Rogich (1992); Steiner (1976, 1993a,b); U.S. Department of Labor (1989, 1991); Young (1992a). 
TABLE 6.13 Quantifiable Discharges and Impacts of Copper Production per Ton of Copper Produced

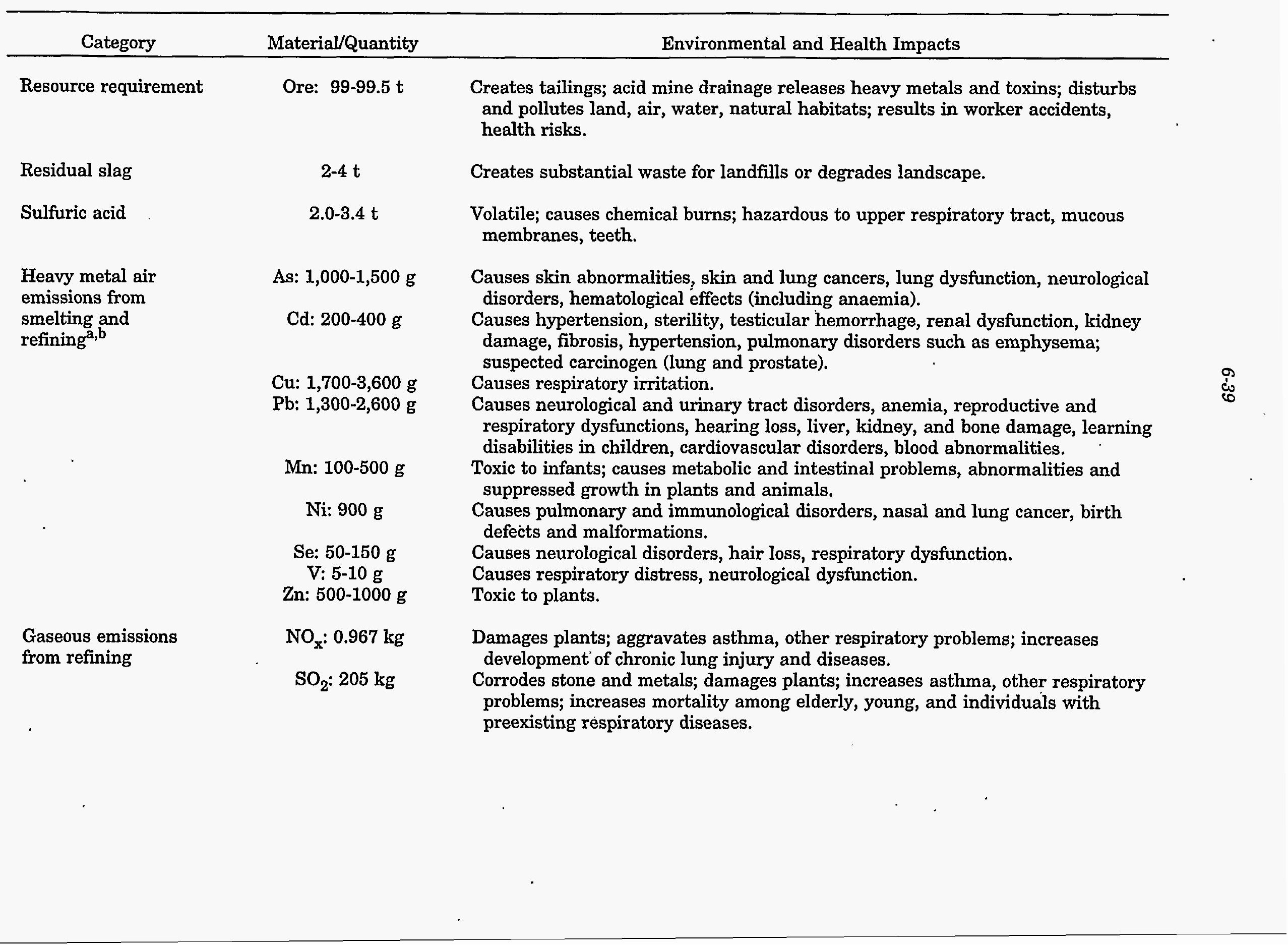


TABLE 6.13 (Cont.)

\begin{tabular}{lcc}
\hline \multicolumn{1}{c}{ Category } & Material/Quantity & Environmental and Health Impacts \\
\hline Energy use & $94-98 \mathrm{GJ}$ & $\begin{array}{c}\text { Causes } \mathrm{SO}_{2} \text { and other emissions from fuel combustion; increases land, air, water } \\
\text { impacts from coal and uranium mining, petroleum extraction, and power } \\
\text { generation; creates worker accidents, public health risks; causes cancers. }\end{array}$ \\
Mining health effects & $\begin{array}{c}\text { Fatalities: } 3.1 \times 10^{-6} \\
\text { Injuries: } 1.7 \times 10^{-4}\end{array}$ & $\begin{array}{c}\text { Includes death, loss of consciousness, restriction of work or motion, inability to } \\
\text { perform all job duties. }\end{array}$ \\
Refining health effects & $\begin{array}{c}\text { Fatalities and } \\
\text { injuries: } 3.7 \times 10^{-4}\end{array}$ & $\begin{array}{c}\text { Includes death, loss of consciousness, restriction of work or motion, inability to } \\
\text { perform all job duties. }\end{array}$ \\
\hline
\end{tabular}

a Data in this group are for copper and nickel production.

b The low end of the range of emission estimates represents the more efficient combinations of production technology and pollution control and raw material inputs with the lowest concentrations of contaminants. The high end represents the least efficient processes and highest contaminant concentrations.

Sources: Bhatti (1992); Castle (1989); Davenport (1993); Elsworth (1984); Friberg (1986); Graham (1990); Jolly (1993); Kohout et al. (1990); Nriagu and Pacyna (1988); OECD (1991); Rogich (1992); U.S. Department of Labor (1989, 1991); Young (1992a). 
TABLE 6.14 Quantifiable Discharges and Impacts of Aluminum Production per Ton of Aluminum Produced

\begin{tabular}{|c|c|c|}
\hline Category & Material/Quantity & Environmental or Health Impacts \\
\hline Resource requirement & Ore: $4 \mathrm{t}$ & $\begin{array}{l}\text { Creates tailings; acid mine drainage releases heavy metals, toxins; disturbs and } \\
\text { pollutes land, air, water, natural habitats; results in worker accidents, health } \\
\text { risks. }\end{array}$ \\
\hline Bauxite residue & $2 \mathrm{t}$ & Results in caustic solid waste for landfill. \\
\hline \multirow[t]{4}{*}{$\begin{array}{l}\text { Gaseous emissions } \\
\text { from refining }\end{array}$} & $\mathrm{NO}_{\mathrm{x}}: 0.608 \mathrm{~kg}$ & $\begin{array}{l}\text { Damages plants; aggravates asthma and other respiratory problems; increases } \\
\text { development of chronic lung injury and diseases. }\end{array}$ \\
\hline & $\mathrm{SO}_{2}: 16.5 \mathrm{~kg}$ & $\begin{array}{l}\text { Corrodes stone and metals; damages plants; increases asthma, and other } \\
\text { respiratory problems; increases mortality among elderly, young, and individuals } \\
\text { with pre-existing respiratory diseases. }\end{array}$ \\
\hline & VOC: $0.101 \mathrm{~kg}$ & $\begin{array}{l}\text { Contributes to lung and other cancers, respiratory problems; contributes to ozone } \\
\text { and smog production. }\end{array}$ \\
\hline & Fluoride: $0.5-1.0 \mathrm{~kg}$ & $\begin{array}{l}\text { Damages vegetation; toxic to animals; causes eye and skin irritation, } \\
\text { inflammation of the respiratory tract, breathing difficulty. }\end{array}$ \\
\hline Energy requirements & $133-174 \mathrm{GJ}$ & $\begin{array}{l}\text { Causes } \mathrm{SO}_{2} \text { and other emissions from fuel combustion; increases land, air, water } \\
\text { impacts from coal and uranium mining, petroleum extraction, and power } \\
\text { generation; creates worker accidents and public health risks; causes cancers. }\end{array}$ \\
\hline Refining health effects & $\begin{array}{l}\text { Fatalities and } \\
\text { injuries: } 5.7 \times 10^{-4}\end{array}$ & $\begin{array}{l}\text { Includes death, loss of consciousness, restriction of work or motion, inability to } \\
\text { perform all job duties. }\end{array}$ \\
\hline
\end{tabular}

Sources: Bhatti (1992); Carwile (1993); Castle (1989); Elsworth (1984); Friberg (1986); Graham (1990); Kohout et al. (1990); Koren (1991); McCawley and Baumgardner (1985); Nriagu and Pacyna (1988); OECD (1991); Rogich (1992); U.S. Department of Labor (1991); Young (1992a). 


\subsection{REFERENCES FOR SECTION 6}

American Iron and Steel Institute, undated, Steelmaking Flowlines, Washington, D.C.

Anon., 1993, 1993, "Health Risks of Work at Coking Plants and Allied Occupations," British Carbonisation Research Association Quarterly 39:31-65.

Bhatti, N., 1992, unpublished data, Argonne National Laboratory, Argonne, 111.

Brookins, D.G.,. 1990, Mineral and Energy Resources: Occurrence, Exploitation, and Environmental Impact, Merrill Publishing Co., Columbus, Ohio.

Carwile, R., 1993, personal communication from Carwile (Director, Environmental Affairs, Aluminum Association, Washington, D.C.) to S.E. Wilson (Argonne National Laboratory, Argonne, il.), March 18.

Castle, J.F., 1989, "Energy Consumption and Costs of Smelting," Engineering and Mining Journal 191(6):65-67, June.

Chem-Nuclear Systems, Inc., 1993, Barnwell Low-Level Radioactive Waste Management Facility Rate Schedule, Columbia, S.C.

Connolly, R.E., and C.D. Kealy, 1990, "Mining's Future -- Meeting the Environmental Challenge," in Environmental Issues and Waste Management in Energy and Minerals Production, Battelle Press, Columbus, Ohio.

Cross, J., 1993, letter from Cross (BNFL, Inc., Fairfax, Va.) to S. Wilson (Argonne National Laboratory, Argonne, II1.), June.

Darlington, D., 1992, "Copper Versus Grandeur: Mining British Columbia's Windy Craggy Mountain Would Compromise a Spectacular Ice Age Wilderness," Audubon 94(4):86-91, July/Aug.

Davenport, W., 1993, personal communication from Davenport (Arizona State University, Tempe, Ariz.) to S.E. Wilson (Argonne National Laboratory, Argonne, Ill.), March 23.

Dehmel, J.-C., et al., 1992, Scrap Metal Recycling of NORM Contaminated petroleum Equipment, Prepared by S. Cohen and Associates, McLean, Va., T.P. McNulty and Associates; Evergreen, Colo., and Hazen Research, Inc., Golden, Colo., for Petroleum Environmental Research Forum, Ponca City, Okla., Sept.

DOE - see U.S. Department of Energy.

Dong, M.H., et al., 1988, American Journal of Epidemiology, 128:4:860-873, from British Carbonisation Research Association Quarterly, 1993, 39:31-65. 
Ebasco, 1991, Design Services in Support of the ORO Environmental Restoration and Waste Management Program: Cost Estimate for D\&D of the Gaseous Diffusion Plant Task Summary Document, prepared for U.S. Department of Energy, Oak Ridge, Tenn., Apr.

EG\&G, 1987, Conceptual Design Report Alternative Concepts for Low-Level Radioactive Waste Disposal, DOE/LLW-60T, National Low-Level Radioactive Waste Management Program, EG\&G Idaho, Inc., Idaho Falls, Idaho.

Eisenhut, W., 1990, Trace Element Mass Balance in the Materials Flow in Coke Oven Plant, presented at the European Economic Community Information Days Meeting, sponsored by the European Coal and Steel Community, Nov.

Elliott, M.A., ed., 1981, Chemistry of Coal Utilization: Second Supplementary Volume, WileyInterscience Publication, New York, N.Y.

Elsworth, S., 1984, Acid Rain, Pluto Press, London.

Ettenhuber, E., and R. Lehmann, 1986, "The Collective Dose Equivalent Due to the Naturally Occurring Radionuclides in Building Materials in the German Democratic Republic. Part I: External Exposure," Health Physics 50(1):49-56, Jan.

Fisher, R., 1992, Progress in Pollution Abatement in the European Cokemaking Industry, 1:16-36, presented at the Second International Cokemaking Congress, sponsored by the Iron and Steel Division of The Institute of Materials, London, Sept. 28-30.

Fitzgerald, J.E., Jr., 1976, Radioactivity in the Copper Ore Mining and Dressing Industry: A Preliminary Assessment, Proc. of 10th Midyear Topical Symposium of the Health Physics Society, Saratoga Springs, N.Y., Oct.

Friberg, L., et al., 1986, Handbook of the Toxicology of Metals, Volume II: Specific Metals, Elsevier Science Publishers, New York, N.Y.

Friedrich, F., and D. Hinz, 1992, Emission Measurements on Coke Oven Doors with Various Sealing Systems, 1:376-390, presented at the Second International Cokemaking Congress, sponsored by the Iron and Steel Division of The Institute of Materials, London, Sept. 28-30.

Gardner, F, 1993, letter from Gardner (American Ecology, Houston, Texas) to S. Wilson (Argonne National Laboratory, Argonne, Ml.), June.

Graham, J.A., 1990, Direct Health Effects of Air Pollutants Associated with Acidic Precursor Emissions, Report 22, National Acid Precipitation Assessment Program, Washington, D.C.

Hootman, H.A., and J.E. Vernet, 1991, Air Toxics Provisions of the Clean Air Act: Potential Impacts on Energy, ANL/EAIS/TM-66, Argonne National Laboratory, Argonne, Il., Nov.

Hoye, R.L., and S.J. Hubbard, 1989, "Mining Wastes" in Standard Handbook of Hazardous Waste Treatment and Disposal, H.M. Freeman (ed.), McGraw-Hill Book Co., New York, N.Y. 
Hwang, S., 1990, "An Assessment of Health and Environmental Impact of Contaminant Releases from a Mine Tailings Pile," in Environmental Issues and Waste Management in Energy and Minerals Production, Battelle Press, Columbus, Ohio.

IAEA - see International Atomic Energy Agency.

International Atomic Energy Agency, 1991, "Health Effects of Different Energy Systems for Electricity Generation," Senior Expert Symposium on Electricity and the Environment: Key Issue Papers, May 13-17, Vienna.

International Commission of Radiological Protection, 1991, 1990, Recommendations of the International Commission on Radiological Protection, ICRP Publication 60, Annals of the ICRP 21(1-3), Pergamon Press, Oxford, England.

International Energy Agency, 1992, Coal Information 1992, in collaboration with the Organization for Economic Cooperation and Development, Paris, pp. 36-37.

Johnson, W., and J. Paone, 1982, Land Utilization and Reclamation in the Mining Industry, 1930-80, Information Circular 8862, U.S. Department of the Interior, Bureau of Mines, Washington, D.C.

Jolly, J.L.W., 1993, personal communication from Jolly (Copper Specialist, U.S. Bureau of Mines, Washington, D.C.) to S.E. Wilson (Argonne National Laboratory, Argonne, Ill.), March 16.

Jolly, J.L.W., et al., 1993, Recycling - Nonferrous Metals: 1991 Annual Report, U.S. Department of the Interior, Bureau of Mines, Washington, D.C., May.

Keller, E.A., 1988, Environmental Geology, 5th Ed., Merrill Publishing Co., Columbus, Ohio.

Klinger, F.L., 1985, "Iron Ore," in Mineral Facts and Problems, 1985 Edition, U.S. Department of the Interior, Bureau of Mines, Washington, D.C.

Kohout, E.J., et al., 1990, Current Emission Trends for Nitrogen Oxides, Sulfur Dioxide, and Volatile Organic Compounds by Month and State: Methodology and Results, ANL/EAIS/TM-25, Argonne National Laboratory, Argonne, III., Aug.

Koren, H., 1991, Handbook of Environmental Health and Safety: Principles and Practices, Vol. II, 2nd Ed., Lewis Publishers, Chelsea, Mich.

Kuck, P.H., 1993, personal communication from Kuck (Iron and Steel Specialist, U.S. Bureau of Mines, Washington, D.C.) to S.E. Wilson (Argonne National Laboratory, Argonne, Ill.), Mar. 31.

Lund, H., 1993, The McGraw-Hill Recycling Handbook, McGraw-Hill, Inc., New York, N.Y. 
McCabe, G.H., 1993, "Radioactive Waste: A View from Abroad," Forum for Applied Research and Public Policy 8(1):81-85.

McCawley, F.X., and L.H. Baumgardner, 1985, "Aluminum," in Mineral Facts and Problems, 1985 Edition, U.S. Department of the Interior, Bureau of Mines, Washington, D.C.

Milius, S., 1992, "The Dirty Face of Lady Luck," National Wildlife 30:43, Aug.-Sept.

Miller, G.T., 1991, Environmental Science, 3rd Ed., Wadsworth Publishing Co., Belmont, Calif.

MK-Ferguson Company, 1991, Waste Quantities Report 4/1/91-6/30/91, letter from J. R. Powers (MK-Ferguson Co., St. Charles, Missouri) to S. H. McCracken (U.S. Department of Energy, Weldon Spring Remedial Action Project, St. Charles, Mo.), April.

National Council on Radiation Protection and Measurement, 1987, Ionizing Radiation Exposure of the Population of the United States, NCRP Report No. 93:37, Bethesda, Md., Sept. 1.

NCRP - see National Council on Radiation Protection and Measurement.

Neavel, R.C., and J.E. deMasi, 1978, Metallurgical (Coking) Coals: A Study of Their Critical Properties and Utilization, Report COR.3KW.78, Exxon. Research and Engineering Co., Baytown, Texas, May.

Nriagu, J.O., and J.M. Pacyna, 1988, "Quantitative Assessment of Worldwide Contamination of Air, Water, and Soils by Trace Metals," Nature 333:134-139, May 12.

Nriagu, J.O., and C.I. Davidson (eds.), 1986, Toxic Metals in the Atmosphere, Vol. 17 of Wiley Series in Advances in Environmental Science and Technology, John Wiley and Sons, New York, N.Y.

Nuclear Energy Agency, 1991, Decommissioning of Nuclear Facilities: An Analysis of the Variability of Decommissioning Cost Estimates, Organization for Economic Cooperation and Development, Paris, France.

Oak Ridge National Laboratory, 1992, Integrated Data Base for 1992: U.S. Spent Fuel and Radioactive Waste Inventories, Projections, and Characteristics, DOE/RW-0006, Rev. 8, prepared for U.S. Department of Energy, Office of Environmental Restoration and Waste Management, Oct.

OECD - see Organization for Economic Cooperation and Development.

Organization for Economic Cooperation and Development, 1991, The State of the Environment, Paris, France.

ORNL - see Oak Ridge National Laboratory. 
Peacey, J.G., 1992, "Copper Metallurgy," in McGraw-Hill Encyclopedia of Science and Technology, 7th Ed., McGraw-Hill, Inc., New York, N.Y.

Rogich, D.G., 1992, unpublished data, U.S. Department of the Interior, Bureau of Mines, Division of Mineral Commodities, Washington, D.C., Apr.

Schneider, K., 1993, "New Approach to Old Peril: Abandoned Mines in West," The New York Times, Apr. 27.

Shobert, H.H., 1987, Coal, The Energy Source of the Past and Future, American Chemical Society, Washington, D.C.

St. Pierre, G.R., 1992, "Iron Metallurgy," in McGraw-Hill Encyclopedia of Science and Technology, 7th Ed., McGraw-Hill, Inc, New York, N.Y.

Steiner, B.A., 1976, "Air-Pollution Control in the Iron and Steel Industry," International Metals Reviews, pp. 171-191, Sept.

Steiner, B.A., 1993a, personal communication from Steiner (Vice President, Environment and Energy, American Iron and Steel Institute, Washington, D.C.) to S.E. Wilson (Argonne National Laboratory, Argonne, ח1.), Feb. 23.

Steiner, B.A., 1993b, personal communication from Steiner (Vice President, Environment and Energy, American Iron and Steel Institute, Washington, D.C.) to S.E. Wilson (Argonne National Laboratory, Argonne, Ml.), Mar. 18.

Suta, B.E., 1977, Human Population Exposures to Coke Oven Atmospheric Emissions, U.S. Environmental Protection Agency, Washington, D.C..

Syracuse Research Corp., 1990, Toxicological Profile for Copper, PB91-180513, U.S. Department of Health and Human Services, Public Health Service, Washington, D.C.

Szpunar, C.B., 1992, Air Toxic Emissions from the Combustion of Coal: Identifying and Quantifying Hazardous Air Pollutants from U.S. Coals, ANL/EAIS/TM-83, Argonne National Laboratory, Argonne, Ill., Sept.

Szpunar, C.B., and J.L. Gillette, 1992, Environmental Externalities: Applying the Concept to Asian Coal-Based Power Generation, ANL/EAIS/TM-90, Argonne National Laboratory, Argonne, IIl., Sept.

Szpunar, C.B., et al., 1990, Poland: An Energy and Environment Overview, U.S. Agency for International Development Report 90-12, Oct.

Teunckens, L., 1993, Letter from Teunckens (Belgoprocess, Dessel, Belgium) to S. Wilson (Argonne National Laboratory, Argonne, Ml.), June. 
United Nations, 1988, 1993, Sources, Effects, and Risks of Ionizing Radiation, United Nations Scientific Committee on the Effects of Atomic Radiation, New York, N.Y.

U.S. Congress, 1990, "Clean Air Act as Amended," Public Law 101-549.

U.S. Department of Energy, 1980, Comparative Assessment of Health and Safety Impacts of Coal Use, DOE/EV-0069, Washington, D.C., Mar.

U.S. Department of Energy, 1988, Energy Technologies and the Environment: Environmental Information Handbook, DOE/EH-0077, Washington, D.C., Oct.

U.S. Department of Energy, 1992a, The U.S. Coal Industry, 1970-1990: Two Decades of Change, DOE/EIA-0559, Energy Information Administration, Washington, D.C., Nov.

U.S. Department of Energy, 1992b, Feasibility Study for Remedial Action at the Chemical Plant Area of the Weldon Spring Site, DOE/OR/21548-148, Oak Ridge Field Office, Weldon Spring Site Remedial Action Project, Oak Ridge, Tenn., Nov.

U.S. Department of Energy, 1993, Operable Unit 3 Work Plan Addendum, Rev. 3, Final Report, Fernald Environmental Management Project, Fernald Field Office, Fernald, Ohio, June.

U.S. Department of Labor, 1989, Occupational Injuries and Illnesses in the United States by Industry, 1987, Bulletin 2328, Bureau of Labor Statistics, Washington, D.C.

U.S. Department of Labor, 1991, Injury Experience in Metallic Mineral Mining, 1990, Information Report 1201, Mine Safety and Health Administration, Denver, Colo.

U.S. Ecology, 1993, Washington Nuclear Center Radioactive Waste Disposal: Schedule A, Disposal Charges; Schedule B, Surcharges and Other Special Charges; Schedule C, Tax and Fee Rider, Houston, Texas.

U.S. Environmental Protection Agency, 1978, Natural Radioactivity Contamination Problems, EPA-520/4-77-015, Proc. of Conference of Radiation Control Program Directors, Inc., Washington, D.C., Feb.

U.S. Environmental Protection Agency, 1984a, Background Information Document (Integrated Risk Assessment): Final Rules for Radionuclides, Vol. II, EPA-520/1-84-022-2, Office of Radiation Programs, Washington, D.C., Oct. 22.

U.S. Environmental Protection Agency, 1984b, Carcinogen Assessment of Coke Oven Emissions, EPA-600/6-82-003F, Office of Health and Environmental Assessment, Washington, D.C. (as cited in Environmental Protection Agency 1992). 
U.S. Environmental Protection Agency, 1985, "Coal Mining Point Source Category: Effluent Limitations Guidelines for Existing Sources, Standards of Performance for New Sources and Pretreatment Standards, Final Rule," Federal Register, Vol. 50, No. 196, Washington, D.C., Oct. 9.

U.S. Environmental Protection Agency, 1990a, "Availability of Report to Congress on Special Wastes from Mineral Processing," Federal Register 55(152):32135-32137, Washington, D.C., Aug 7.

U.S. Environmental Protection Agency, 1990b, Cancer Risk from Outdoor Exposure to Air Toxics, EPA-450/1-90-004a, Office of Air Quality, Planning and Standards, Research Triangle Park, North Carolina, Sept.

U.S. Environmental Protection Agency, 1992a, Regulatory Impact Analysis of National Emissions Standards for Hazardous Air Pollutants for By-Product Coke Oven Charging, Door Leaks, and Topside Leaks, EPA 453/D-92-014, Research Triangle Park, North Carolina, Nov.

U.S. Environmental Protection Agency, 1992b, Environmental Equity: Reducing Risk for All Communities, EPA-230-R-92-008A, Office of Policy, Planning, and Evaluation, Washington, D.C., June.

U.S. Environmental Protection Agency, 1992c, "EPA National Emission Standards for Hazardous Air Pollutants for Source Categories; Coke Oven Batteries; Proposed Rule, Part II," Federal Register, Washington, D.C., Dec. 4.

USEPA - see U.S. Environmental Protection Agency.

U.S. Nuclear Regulatory Commission, 1990, "Standards for Protection against Radiation," Code of Federal Regulations, title 10, part 20, Washington, D.C.

U.S. Nuclear Regulatory Commission, 1993, "License Requirements for Land Disposal of Radioactive Waste," Code of Federal Regulations, title 10, part 61, revised, Washington, D.C.

World Resources Institute, 1992, World Resources 1992-93, prepared in collaboration with the U.N. Environment Programme and the U.N. Development Programme, Oxford University Press, New York, N.Y.

Young, J.E., 1992a, "Mining the Earth," in State of the World 1992, W.W. Norton and Co., New York, N.Y.

Young, J.E., 1992b, Mining the Earth, Worldwatch Paper 109, Worldwatch Institute, Washington, D.C.

Zaccai, H., 1990, Evaluation of Storage and Disposal Costs for Conditioned Radioactive Waste in Several European Countries, EUR 12871, Euradwaste Series No. 2, Commission of the European Communities, Luxembourg. 



\section{SOCIAL AND POLITICAL CONTEXT OF RADIOACTIVE SCRAP METAL RECYCLING}

This section assesses the context within which recycling of radioactive scrap metal (RSM) would occur and identifies cultural and institutional factors that are most likely to be relevant to the acceptability of RSM recycling. Regulation of radioactivity in consumer products is discussed in Section 7.1, followed in Section 7.2 by an overview of liability issues that may affect firms' decisions regarding participation in RSM recycling.

Cross-cultural studies of public attitudes toward radioactive substances are reviewed in Section 7.3 to determine commonalities and differences in public acceptance of nuclearrelated risks and, especially, of radioactivity in consumer products. This information provides the basis for identifying the characteristics of RSM that are most likely to influence the acceptability of recycling. Findings from a survey of key organizations regarding their positions on nuclear risks and RSM recycling are presented in Section 7.4.

The purpose of Section 7 is to characterize the social, institutional, and political factors that are likely to affect decisions regarding RSM recycling. Where such factors may constitute barriers to scrap metal recycling, the goal is to identify possible remedies that would reduce or eliminate these obstacles. The key factors and some potential remedies are discussed in Section 7.5.

\subsection{REGULATORY PRINCIPLES RELATED TO RADIOACTIVITY IN CONSUMER PRODUCTS}

Recycling of RSM into unrestricted uses will result in some increase in residual radioactivity in metal products that are readily accessible to the general population. Radioactive materials are presently accepted and used by the public virtually throughout the world, with varying degrees of public recognition of the associated risks. Radioactivity is incorporated intentionally, for its beneficial properties, in a variety of medical products, household products, and personal items. It also occurs naturally in some consumer products or can be an unintentional by-product of beneficial functions of products. Common radiation sources involved in consumer products and associated dose levels are presented in Appendix $E$ and are summarized here. In addition to intentional use of radioactivity, an unknown number of cases have occurred in which products have been accidentally contaminated with radioactivity before distribution. These situations are generally judged unacceptable, and when contaminated products are identified, they typically are removed from public use.

Radioactive materials are used routinely for medical diagnosis and treatment. Within this context, effort is made to limit exposures to the minimum efficacious dose. As suitable nonradioactive substitutes become available, the use of radioactive substances is generally curtailed. For instance, fetal risks have been reduced by substituting ultrasound for X-ray examinations (NCRP 1987). Also, when heart pacemakers were first developed, 
they were powered by radioactive source material, but the development of long-lasting nonnuclear batteries ended use of such material.

Numerous household and office products currently in use in industrialized countries produce some exposure to radioactivity. Some of these items (such as smoke detectors, fluorescent lamp starters, and gas lantern mantles) may be recognized by the public as containing a radioactive component. Other common exposure sources are probably not recognized by the public as radioactive. These other sources include such common items as appliance indicator lights and electric blanket thermostats. In addition, natural gas cooking ranges and domestic water supplies cause radon exposures, and mineral-based building materials may contain uranium, thorium, and potassium isotopes. Granite, which is commonly used in constructing public buildings in the U.S.A. and Europe, is one of the major sources of radiation exposure for building occupants. In addition, the public is exposed to products that, although they do not contain radioactivity, do produce X-rays as a by-product of operation. Both color television screens and video display terminals are in this category.

Radiation exposures also result from activities outside of the home or office. For instance, the X-rays used in airport luggage inspection systems cause slight exposures of some members of the public. Also, phosphate fertilizers used in both home gardens and commercial agriculture generally contain radioactive potassium, as well as naturally occurring uranium and thorium. While there is some public awareness of the X-ray output of luggage scanning devices (since they are usually clearly marked), there is little awareness of the radioactivity of commonly used fertilizers.

Possession, distribution, and disposal of all of these radiation-emitting products are exempt from government regulation because of their conformance with the principles of dose limitation discussed below.

\subsubsection{Regulatory Framework Affecting the Exemption Process}

The dose limitation principles endorsed by the International Atomic Energy Agency (IAEA) - justification of practice, optimization of protection, and limitation of individual risk - are adhered to by countries regardless of their regulatory structure or exemption process for consumer products containing radioactivity. Differences in the implementation of these principles, however, can result in disparate exemptions from country to country. Variation in social utility of products among countries may account for some differences of opinion among different cultures regarding exemptible products. Differences in regulatory frameworks among countries can also lead to these differences.

Regulatory processes can be relatively open or relatively closed. Open processes allow for extensive public participation through comment periods, give consideration to the public's comments, and encourage consultation and consensus development among domestic and international governmental entities. The disadvantage of an open system is the time and resources it demands; the advantage is greater probable acceptability of the exempted product because of public participation in the exemption process. Closed systems may reach exemption decisions more quickly because of limited participation. If the public has 
confidence in the regulatory process and the regulators, exemption decisions will probably be considered credible regardless of the closed nature of the process.

Regulators can make exemption decisions on a case-by-case basis or, additionally, by establishing a "de minimis" dose level for consumer products with radiation. A de minimis level is a low exposure level selected because the corresponding risk is generally considered trivial in comparison with other risks that the public typically accepts (Vance 1989). Consumer products containing radiation below the de minimis level would not require consideration for exemption because they are excluded from the universe of radiation sources subject to regulation. Products with radiation doses above the de minimis level would be subject to a case-by-case evaluation.

\subsubsection{Dose Limitation Principles Underlying the Exemption Process}

Exemptions to the normal system of notification, registration; and licensing required for products containing radiation are based on the principles of justification of practice, optimization of protection, and limitation of individual risk. These principles have been endorsed by the IAEA and the Organization for Economic Cooperation and Development, Nuclear Energy Agency (OECD/NEA).

Justification of practice means that deliberate public exposure to ionizing radiation in a specified usage is acceptable only if the exposure produces a positive net benefit. One factor that may justify a practice is the lack of other reasonable alternatives to the inclusion or use of the ionizing radiation. Justification of practice is the most elementary of the dose limitation principles (Webb 1989). If no positive net benefit arises from the practice or if an alternative to use of radioactive material exists, the practice will not be further considered for exemption.

Because the justification decision is based on perceived positive net benefit, it must reflect political, social, and economic values regarding what brings benefit to the society being protected. Production of a radiation-emitting item, even with a technically proven low dose, generally has not been deemed justified if the product has no, or very limited, social utility. Thus, smoke detectors are exempt; irradiated gem stones generally are not.

Optimization requires that doses resulting from the product be reduced to a level that is "as low as reasonably achievable" (the ALARA principle). Economic and social factors and the cost of any regulatory controls are included in determining what dose level is reasonably achievable. A product that cannot be made safer through reasonable regulatory controls is a candidate for exemption.

Individual risk levels are usually limited by controlling the doses received by the maximally exposed group. Regulators attempt to keep the annual individual dose to members of the high-risk group sufficiently low so that cumulative exposures from multiple exempted sources or practices will not exceed the annual maximum individual dose limit. 


\subsubsection{Regulatory Requirements}

A consumer product that has been exempted from the normal regulatory requirements may still be subject to some controls. Regulators may require product advertising or labeling to include explanatory information about the presence of radiation in the product. Although the product may be free from other requirements, the manufacturer may be subject to regulation involving production processes, worker health and safety, minimization of secondary waste streams, monitoring and sampling protocols to ensure that approved product radiation levels are not exceeded, and record keeping and reporting requirements.

\subsection{LIABILITY ISSUES}

Those engaged in the enterprise of RSM recycling will face a number of legal constraints; among them are compliance with domestic and foreign regulations relating to the handling of RSM and to health and safety in the work place, compliance with domestic and foreign environmental regulations, and compliance with trade restrictions and international agreements relating to radioactive materials and the transportation of hazardous materials. Apart from these concerns, parties involved in the RSM industry must consider the possibility that persons could be injured by exposure to radiation from products made from RSM if, for some reason, the system limiting exposures to prescribed levels should fail. Processors and manufacturers, both in the U.S.A. and abroad, could be held liable for these injuries.

Many parties could be involved in bringing RSM from the source or storage heap to the consumer, and these parties could be located in any country. In addition, a person injured by RSM radiation could be located in any country - not necessarily the same country as any of the responsible parties. As a result, it will be necessary to consider the substantive and procedural law of all potentially involved countries and the applicability of international agreements to potential liability related to RSM recycling. Thus, international trade in recycled RSM presents a number of domestic and international legal issues that may be considered obstacles by potential participants in the industry.

That area of law relating to injuries caused by defective products is known as "products liability" law. Whenever an injury to an individual is allegedly caused by the condition of a product, that individual may have a claim against the party who designed, manufactured, sold, or furnished the defective product. Product liability issues are discussed in Section 7.2.1 for the U.S.A. and Section 7.2.2 for other countries.

\subsubsection{Strict Liability in Tort - U.S.A. Law}

The dominant element of products liability law in the context of RSM recycling is the theory of strict liability in tort. Under the common law, this doctrine imposes liability on individuals, regardless of fault and of precautions taken, for injuries caused by 
"ultrahazardous"1 or "abnormally dangerous" 2 activities. In the absence of specific legal precedent, it is uncertain whether RSM recycling might be considered an ultrahazardous or abnormally dangerous activity. A detailed comparison of the potential hazards of RSM recycling and those of other activities to which strict liability has been applied would be needed to determine the likelihood that a court would apply strict liability to RSM recycling. ${ }^{3}$ However, the types of activities to which strict liability has been applied are generally orders of magnitude more hazardous than RSM recycling.

This doctrine imposes liability on a party or parties, regardless of fault, once a "defect" in the product is established as the cause of the injury, provided the product has left the control of the parties on whom liability is to be imposed. ${ }^{4}$ Three ways exist by which a product can be defective: (1) the defect could be in the design, (2) the defect could be in the production or manufacture, and (3) the defect could be in a failure to warn or to provide adequate directions. ${ }^{5}$ Each of the parties could be a defendant in a products liability suit because anyone "engaged in the business" of dealing in the product is a possible defendant. ${ }^{6}$ This view of strict products liability has been adopted by at least 40 states in the U.S.A. and is codified in the Restatement (Second) of Torts (Section 402A: Special Liability of Seller of Product for Physical Harm to User or Consumer) which provides:

(1) One who sells any product in a defective condition unreasonably dangerous to the user or consumer or to his property is subject to

1 Restatement of Torts $\S 519$ (1938).

2 Restatement of Torts $\S 519$ (1977).

3 A strict liability standard has been applied by courts in the U.S.A. to the following "abnormally dangerous" activities: blasting, crop dusting, the storage of explosives, the storage of certain quantities of inflammable liquids in an urban area, hazardous waste disposal, pile driving, and the handling of poisonous gases. See W.L. Prosser, J.W. Wade, and V.E. Schwartz, Cases and Materials on Torts 685-687 (8th Ed. 1988) and the cases cited therein.

A particularly significant application of the strict liability doctrine has been witnessed, in recent years, in the area of environmental torts. See, e.g., Sterling v. Velsicol Chem Corp., 647 F. Supp. 303 (W.D. Tenn. 1986) (chemical company strictly liable to neighbors for personal injuries and property damage resulting from inherently and abnormally dangerous activities in operating a hazardous waste dump). Generally cases arise from personal injuries that are caused by toxic substances in the environment, including groundwater contamination, airborne contamination (e.g., nuclear test fallout), pesticide exposure, and hazardous waste exposure. For a thorough discussion of environmental torts and the role of strict liability in such cases, see Brennan, Environmental Torts, 46 Vanderbilt L. Rev. 1, 58-61 (1993).

4 W. Freedman, International Products Liability $§ 1.17$ at 55 (1987 \& 1990 Supp.).

5 For a thorough discussion of possible defects see M. Shapo, The Law of Products Liability § 8 (1990).

6 See Restatement (Second) of Torts $\S 402(A)(1)(a)(1965)$. 
liability for physical harm thereby caused to the ultimate user or consumer, or to his property, if

(a) seller is engaged in the business of selling a product, and

(b) it is expected to and does reach the user or consumer without substantial change in the condition in which it is sold.

(2) The rule stated in subsection (1) applies although

(a) the seller has exercised all possible care in the preparation and sale of his product, and

(b) the user or consumer has not bought the product from or entered into any contractual arrangement with the seller. ${ }^{7}$

Under the strict products liability standard, the product that caused the injury will be deemed to be "unreasonably dangerous" if it is "defective."

A number of defenses are available to a defendant in a products liability suit. The two most important defenses focus on the conduct of the plaintiff. A party may not be liable if (1) the plaintiff used the product despite being aware of potential dangers (assumption of risk) or (2) the plaintiff used the product in a manner that was not foreseeable to the manufacturer (misuse). Similarly, an effective disclaimer or an effective product recall may protect the defendant from liability. If the defendant is the government or a quasigovernmental entity such as a utility, a number of defenses may apply, including sovereign immunity, ${ }^{8}$ the act-of-state doctrine, and the government contractor defense. The availability of any or all of these defenses will depend on the case and the jurisdiction in which it is brought.

All of the traditional tort remedies are available in a products liability context. ${ }^{9}$ All compensatory damages are available, including pain and suffering, emotional distress, and loss of consortium. Damages for loss of profits, a contract remedy, may also be available. Perhaps the most important remedy available in a products liability suit is punitive damages, a remedy based on a public policy of deterring similar future conduct. This remedy often accounts for large judgments in the U.S.A. Attorneys fees may also be available for

7 Restatement (Second) of Torts § 402(A) (1965).

8 A sovereign government is generally thought to be immune from suit unless it consents to the suit. See The Federalist No. 81, at 508 (A. Hamilton) (H. Lodge, ed., 1908). In the U.S.A., the Federal Tort Claims Act, 28 U.S.C. § 1346(b), 2671-2680, establishes the general circumstances under which the federal government has consented to suit. However, this waiver of sovereign immunity is limited by 13 exceptions.

9 See generally Prosser, Wade, and Schwartz, supra note 3. 
successful plaintiffs. The availability of any or all of these remedies will depend on the case and the jurisdiction in which it is brought.

\subsubsection{Products Liability in Other Countries}

It has long been argued that differences between the product liability system in the U.S.A., with its no-fault, strict liability standard, and the products liability systems of Europe, Asia, Africa, and Latin America result in higher products liability and insurance costs for U.S.A. manufacturers and give a competitive edge to non-U.S.A. manufacturers. ${ }^{10}$ However, a growing movement toward consumer protection outside the U.S.A. is expanding the role of products liability in the jurisprudence of many countries. The international trend toward consumer protection and the adoption of products liability norms comparable to those of the U.S.A. can, perhaps, best be seen by the products liability directive adopted by the European Economic Community (EC) in 1985. ${ }^{11}$ That this directive is meant to bring European products liability standards closer to those of the U.S.A. is demonstrated by the adoption of the strict liability doctrine in products liability cases. ${ }^{12,13}$

The growth of international trade and the proliferation of multinational corporations has made companies and consumers around the world aware of the dangers of using products that have traveled internationally. ${ }^{14}$ The ease with which merchandise and people can travel across borders also creates a number of legal difficulties. For instance, what is considered a sound manufacturing process in one country may be considered negligent in another. Or,

${ }^{10}$ Stayin, The U.S. Product Liability System: A Competitive Advantage to Foreign Manufacturers, 14 Canada-United States L. J. 193 (1988).

${ }^{11}$ Council Directive of 25 July 1985 on the Approximation of Laws, Regulations, and Administrative Provisions of Member States Concerning Liability for Defective Products (Directive), 28 O.J. Eur. Comm. (No. L 210) 29 (1985).

12 But see Stiefel, Resolution of International Products Liability Disputes: An Emerging Procedural Framework, 16 Brooklyn J. Int'l L. 267 (1990) (arguing that, even if the directive is implemented, the EC products liability system will not change drastically and, certainly, will not follow the U.S.A. procedure).

${ }^{13}$ Like all EC directives, this directive cannot come into force until it has been implemented within each state's national legislation. As of 1990, Belgium, France, Ireland, the Netherlands, Portugal and Spain had not yet implemented the directive. Stiefel, Resolution of International Products Liability Disputes: An Emerging Procedural Framework, 16 Brooklyn J. Int'1 L. 267, 269 (1990). For a thorough discussion of the provisions of the EC Directive and its possible effects see id. Havemann, The EC Directive on Product Liability: Its Background, Aims and System in R. Hulsenbek and D. Campbell, Product Liability: Prevention Practice and Process in Europe and the United States 17-30 (1989); Note, Products Liability: A Comparison of U.S. and EEC Approaches, 13 Syracuse J. Int'l L. and Com. 155, 174 (1986).

14 Freedman, supra note $4, \S 4.01$ at 206. 
what may be outside the parameters of strict liability in one country may be within the parameters of strict liability in another. ${ }^{15}$

Despite some movement of many of the world's nations toward the U.S.A. standard in products liability, a number of differences in the legal systems of other countries are likely to be maintained. ${ }^{16}$ First, it is unlikely that a products liability case in another country could result in the types of enormous judgments seen regularly in the U.S.A. because neither pain and suffering ${ }^{17}$ nor punitive damages are cognizable in most countries, and juries are not used in civil trials. ${ }^{18}$

Second, other legal systems do not possess the incentives to litigate that are inherent in the U.S.A. system. To begin with, contingent fees for lawyers are not allowed in many countries. In fact, plaintiffs in many countries are required to pay the defendant's attorney fee, in addition to their own, if they lose their products liability suit.

Third, and finally, procedural elements also discourage products liability cases. Pretrial discovery is much more limited elsewhere than in the U.S.A., and it is more difficult to obtain statistical and technical data in many countries. Furthermore, class action suits are not permitted under the civil procedure of many countries. ${ }^{19}$

On the basis of these factors, products liability is not as substantial a disincentive to RSM recycling in many jurisdictions outside of the U.S.A. The prevailing perception among products liability scholars is that the peculiarities of the U.S.A. system of jurisprudence accommodate the enormous damage awards that manufacturers and vendors dread. $^{20}$ Thus, the threat of a large judgment is substantially less in most other countries.

${ }^{15}$ See R. Hulsenbek and D. Cambell, Product Liability: Prevention Practice and Process in Europe and the United States 1 (1989).

16 These conclusions are based on a study of nations in Europe and Japan. See Stayin, The U.S. Product Liability System: A Competitive Advantage to Foreign Manufacturers, 14 Canada-United States L. Jrnl. 193, 193 (1988).

17 In some countries where pain and suffering is recognized, the amount of the award is limited by statute. This is not the case in the U.S.A. See generally, Freedman, supra note 4.

18 The study found that civil jury trials were only found in Ireland with, on average, damage awards four to six times higher than in England, where juries are not used for civil trials. It is also suggested that awards determined by judges, rather that juries, are less emotional, not based on sympathy, and unaffected by the "deep pocket syndrome."

${ }^{19}$ See W. Freedman, International Products Liability § 6-11 (1987 \& 1990 Supp.). See also W. Freedman, Products Liability: An International Manual of Practice (1990), wherein the author provides a comprehensive analysis of the substantive and procedural law of products liability in 28 countries.

${ }^{20}$ See W. Freedman supra note 4. 
Because an RSM products liability suit could be brought in any country and involve parties of any nationality, the likelihood of success of such a suit would depend on a number of complex legal factors. These important factors, which are beyond the current scope of this report, include jurisdiction, forum non conveniens (the inconvenient forum), ${ }^{21}$ discovery and the taking of evidence abroad, the applicability of international conventions and agreements, choice of law issues, immunity, and the recognition and enforcement of foreign judgments.

Another issue worthy of mention is the possibility that international standards may be developed that could affect eventual determinations of liability. If international standards relating to levels of radiation or manufacturing guidelines were developed and adhered to by parties involved in RSM recycling, those parties might be able to present a successful defense to liability in nonstrict liability jurisdictions. However, if strict products liability applies, then compliance with international standards would not act as a complete defense, but would merely serve as evidence that the design or manufacture of the product was not defective. Finally, the possibility always exists that an international agreement could be concluded that would limit or bar the liability of parties involved in the RSM recycling industry.

\subsection{ASSESSMENT OF RECYCLING ACCEPTABILITY TO THE PUBLIC}

This section compares attitudes and behavior related to risk perception in Asia, Europe, and North America with the goal of identifying cultural and risk characteristics that affect risk acceptability. Although the specific interest is in public perceptions of radioactivity in consumer products, that issue has not been the focus of any studies, but has only been addressed peripherally. Therefore, likely public responses to RSM recycling are inferred, in part, from more general studies of risk perception and acceptability of nuclear technologies and related activities.

\subsubsection{Cultural Context of Risk Perception and Risk Acceptability}

The perception of risk takes place within a cultural context that is affected by individual and societal values, the availability of risk information, the nature of personal experience with risks, and characteristics of the physical environment. Thus, the perception of risk associated with any particular hazard is likely to differ among countries and also to vary within countries, especially countries with relatively heterogeneous populations and conditions. This section first discusses the main characteristics of hazards that appear to determine risk perception and risk acceptability. That discussion is followed with information on the cultural determinants of preferences for societal risk taking (e.g., such as a decisions to recycle or to dispose of RSM).

21 For a discussion of how courts in the U.S.A. have used this doctrine to bar foreign plaintiffs in product liability actions see Miller, Forum Non Conveniens and State Control of Foreign Plaintiff Access in U.S. Courts in International Tort Action, 58 Univ. Chi. L. Rev. 1369 (1991). 


\subsubsection{Factors Affecting Risk Perception}

An objective of many studies has been to identify the specific characteristics of hazards that elicit a perception of risk on the part of the general public. This process first requires defining what is meant by "risk." Some measure of the probability of individual fatality is a common operational definition of "risk." Researchers, employing a variety of approaches in empirical studies, found that measures of "voluntariness of risk assumption," of "disaster potential," and of "benefit" are important in explaining risk perceptions.

From a comparative study of German and American (U.S.A.) students, Von Winterfeldt et al. (1981) concluded that perceptions of risk depend primarily on people's judgments of individual fatality probabilities. The total number of potential fatalities affects risk perceptions only for those activities with a high level of disaster potential. In this risk rating exercise, the perceptions of the Germans and Americans were quite similar and were consistent with the relative ranking of risks based on reported fatality rates.

A study of health-related risks conducted in England showed that people's perceptions of an activity's risk and benefit are largely independent of each other (Harding and Eiser 1984). While perceived risk levels were found to be lower for some activities with relatively high levels of perceived benefits, other factors (such as the probability of the hazardous event's actually occurring and the probability of fatalities if the event were to occur) influenced risk perception. Individual respondents' characteristics, including gender and knowledge base, also influenced risk perception, as they have in other studies.

From its beginnings, scientific research on factors influencing risk acceptability has focused on public evaluation of the benefits of hazardous activities and the degree of voluntariness of individual participation in risk exposure. On the basis of analysis of U.S.A. governmental decisions, Starr (1969) concluded that the acceptability to society of a given risk level increases with the benefits of the activity, that it is greater when participation is voluntary, and that it decreases as the number of persons exposed to the risk increases. Analyzing survey responses, Fischoff et al. (1979) also found that higher risk levels are acceptable if they are associated with greater benefits. Risk acceptability was also greater overall for voluntary activity participation. These basic findings have been confirmed by most of the extensive research on factors affecting risk acceptability that has followed.

\subsubsection{Cultural Patterns Linked to Variation in Risk-Related Attitudes}

Since about 1980, exploration of the cultural, historical, and political context of risk perception has been increasing. This research has focused on cultural patterns that are systematically linked to various issues, including perception of technological risks. On the basis of previous research, Dake (1991) related three major types of individual worldviews to respondents' concern with a broad range of contemporary issues, among them: "dangers associated with nuclear energy," "environmental pollution," and "dangers associated with technology." The three types of worldviews of interest are the hierarchical, individualist, and 
egalitarian. Respect for authority characterizes the hierarchical worldview, while the individualist is free-market oriented and supporting of self regulation. Egalitarians reject authority and espouse an equal sharing of an earth seen as fragile and finite.

Dake (1991) found distinctive patterns of concern with different types of issues, depending on whether individuals were characterized by a hierarchical, individualistic, or egalitarian worldview. For the hierarchical and individualistic worldviews, levels of concern with perceived dangers of nuclear energy, pollution, and technology were low. For egalitarianism, in contrast, the levels of concern were moderately strong, especially relative to concern with other issues included in the survey. These findings imply that acceptance of risks associated with nuclear power, environmental pollution, and technology will be greater in societies oriented toward hierarchical social relations or individual selfdetermination than in societies with a strong egalitarian worldview.

\subsubsection{Cross-Cultural Comparison of Attitudes toward Radioactivity}

Because risk perception is culturally determined, differences in attitudes toward risk taking and toward the distribution of risk within society are to be expected among countries. These attitudes are affected by environment, experience, and education, both formal and informal. Countering the forces that create differences in risk perception, however, is the increasing worldwide influence of the media and the flow of information across national boundaries. Because of the need for cross-cultural communication regarding risks, several studies have been conducted to examine the cognitive structures involved in risk evaluation.

Table 7.1 presents key findings of five different studies that employed the same methodology and basic questionnaire to assess risk perception by persons from different cultures. The original study was conducted by Slovic et al. in the U.S.A. in 1979 (and was replicated there in 1987). A comparable study in Hungary was reported by Englander et al. (1986), and results for a similar study in Norway are compared to the previous studies by Teigen et al. (1988). In addition, a similar study was conducted in France (Karpowicz-Lazreg and Mullet 1993), and a study using a subset of hazards from the original questionnaire was conducted in Hong Kong by Keown (1989).

In each study, college students were asked to rate a set of hazards according to the risk of dying faced by members of society as a whole due to each hazard. The scale extended from 0 (not risky) to 100 (extremely risky). Comparable items from the studies are summarized here. The mean risk rating for each hazard, the relative ranking of the six hazards involving some form of radioactivity, and the overall mean rating for the 86 hazard types in these four studies are shown in Table 7.1. The mean level of riskiness over all of the rated activities is considerably higher for the U.S.A. and French samples than for the others. Within the data ranges, the U.S.A., French, and Hong Kongese ratings are relatively high for all of the hazards that involve some exposure to radioactivity. While this result indicates greater risk sensitivity in the U.S.A. and French populations and heightened perception of nuclear risks in particular, the risk rankings show a general consistency across 
TABLE 7.1 Comparative Risk Ratings ${ }^{\mathfrak{a}}$ and Rankings for Norwegian, American, Hungarian, French, and Hong Kongese Populations

\begin{tabular}{|c|c|c|c|c|c|c|c|c|c|c|}
\hline \multirow[b]{2}{*}{ Hazard } & \multicolumn{2}{|c|}{ Norwegians } & \multicolumn{2}{|c|}{ Americans } & \multicolumn{2}{|c|}{ Hungarians } & \multicolumn{2}{|c|}{ French } & \multicolumn{2}{|c|}{ Hong Kongese } \\
\hline & Rating & Rank & Rating & Rank & Rating & Rank & Rating & Rank & Rating & Rank $^{\mathrm{b}}$ \\
\hline Nuclear power & 46.8 & 1 & 71.5 & 1 & 31.6 & 1 & 68.6 & 1 & 68 & 1 \\
\hline Radiation therapy & 38.5 & 2 & 52.7 & 3 & 13.2 & 3 & 47.2 & 2 & 48 & 2 \\
\hline Chemical fertilizers & 15.9 & 3 & 55.0 & 2 & 17.7 & 2 & 40.2 & 3 & 46 & 4 \\
\hline Sunbathing & 15.7 & 4 & 19.7 & 6 & 11.0 & 4 & 32.3 & 5 & 27 & 5 \\
\hline Diagnostic X-rays & 13.3 & 5 & 43.8 & 4 & 9.1 & 5 & 39.9 & 4 & 47 & 3 \\
\hline Fluorescent lights & 11.8 & 6 & 21.5 & 5 & 8.0 & 6 & 22.6 & 6 & $--^{c}$ & - \\
\hline Mean risk (86 hazards) & 27.2 & & 39.7 & & 20.9 & & 40.4 & & $\mathrm{NA}^{\mathrm{d}}$ & \\
\hline
\end{tabular}

a Average rating based on a risk scale of 0 (not risky) to 100 (extremely risky).

b Rank out of a total of 30 hazards.

c No data.

d Not applicable.

Sources: Teigen et al. (1988); Karpowicz-Lazreg and Mullet (1993); Keown (1989). 
all of the samples. Fluorescent lighting, in particular, appears to be viewed as presenting only minimal risks in all four countries where it was rated, in spite of the use of thorium in the starter mechanisms.

Factor analysis of the U.S.A. data by Slovic et al. (1985) identified two risk characteristics that, together, explained $75 \%$ of the variance in risk ratings. The first, designated "unknown risk," was associated with the hazard being unknown to those exposed, unknown to science, delayed in its effect, involuntary, and unfamiliar. The second, which the authors termed "dread risk," was associated with the perception of hazards as certain to be fatal, dreaded, and having catastrophic potential. Comparable analyses were conducted on data from each of the other study samples discussed above, except the French sample.

The Hungarian data (Englander et al. 1986) also showed evidence of two major factors influencing the perception of relative risks. These factors largely correspond to those found in the American study. Significant differences did, however, exist between the Hungarian and American studies in the apparent importance of some of the characteristics related to each factor. For instance, the Hungarians considered nuclear power to be high on the "dread" rating, but much less unknown than the Americans rated it. In general, the Hungarians sampled were less concerned about "high-tech" risks than the Americans and more concerned about risks from accidents, pregnancy and childbirth, poisonous mushrooms, and caffeine. Thus, there appear to be differences both in the importance of various characteristics of hazards and in the relative ranking of specific hazard risks between these populations.

Analysis of the Norwegian data showed a greater confidence in science, a perception of more risks as being familiar, and the hazard consequences as more delayed than the American data indicated. Factor analysis of the risk characteristics identified two major factors accounting for $74 \%$ of the variance in risk ratings. On the basis of their most strongly associated risk characteristic, these factors are called "fatal" risk and "involuntary" risk by the authors. While there is some commonality with the original factors developed by Slovic et al. (1985), the differences are greater than in the Hungarian study, and the primary focus in evaluating risks is clearly different.

Factor analysis of the data is not fully reported for the Hong Kong study, but, again, two main factors in risk perception were identified. The factor designated "unknown" risk was associated with involuntariness, delayed effect, and being unknown to those exposed. "Dread" risk was determined by catastrophic potential, dread, and certainty of fatality. While the same factor names are used as in the original American study, the association of involuntariness with "unknown" risks represents a difference in perception regarding risks.

Another study with a comparable methodology was conducted in 1988 by Kleinhesselink and Rosa (1991) among both American and Japanese students. In spite of the 10-year interval since the original (Slovic) study, the same factor structure was identified for the American student sample. The Japanese cognitive structure indicated by the factor analysis was similar, except that the characteristic of involuntariness carried less weight in determining the "dread" risk factor. Though the evaluative structure was comparable for the 
two groups, substantial differences existed in the perception of risk associated with specific hazards. In regard to nuclear-related risks in particular, the Japanese viewed these risks as more familiar, and known to both individuals and to science.

This body of research demonstrates that major similarities exist in nuclear-related attitudes between relatively well-educated U.S.A. and Asian populations and between U.S.A. and European populations.' The cognitive structures employed in evaluating risks are certainly comparable. However, numerous differences also exist among cultures in the relative ranking of specific societal risks. These differences appear to be mainly due to differences in the environmental and cultural context of the countries studied. In general, the relative ranking of various types of the subset of nuclear-related risks appears to be very similar.

A separate, and somewhat more complex, investigation of risk acceptability was conducted in the Netherlands by Vlek and Stallen (1981). They interviewed 673 subjects, representing both sexes, three age groups, and four categories of residential distance from Rotterdam Harbor, which has considerable heavy industrial activity. Respondents rated various aspects of 26 hazardous activities regarding their riskiness, beneficiality, and acceptability. Conceptions of riskiness, when no definition was provided by the interviewers, were found to depend on the magnitude of a potential accident and the degree of organized (i.e., regulatory) control. Considerable variation was noted in individual evaluations of the risk-related factors, with some consistency among population subgroups. For instance, risk ratings for "large-scale activities" increased with residential distance from the harbor, perhaps because those who perceived it as more risky located farther from it. The extent of individual variation in risk perception was such that Vlek and Stallen questioned the appropriateness of using any "average" measures. Individual scale values for beneficiality were found to correlate strongly with levels of acceptability, with riskiness apparently playing a secondary role in hazard acceptability.

\subsubsection{Implications for Acceptability of Radioactive Scrap Metal Recycling}

As discussed in the previous sections, both the characteristics of the hazard and the cultural context of risk perception affect societal decisions regarding risk acceptability. This section examines how RSM fits this framework.

\subsubsection{Radioactive Serap Metal Recycling Process Characteristics}

In regard to public perception of risk, RSM recycling is at a disadvantage (compared with some other activities with equally low probability of causing harm) because of the stigma currently associated with nuclear weapons and nuclear power in most industrialized countries. This stigma has largely been avoided by the metals, petroleum, phosphate, and coal industries, all of which release substantial quantities of naturally occurring radionuclides 
to the environment. Thus, development of a broadly based RSM recycling process may be more acceptable to the public than one that solely or primarily serves the nuclear industry.

It is unlikely that any direct benefit from including radionuclides in metal products will be perceived and, certainly, none has been claimed. This situation is a major drawback for public acceptance of RSM recycling because in virtually all existing uses of radioactivity in consumer products there is no adequate substitute for it. This factor has been one of the major premises for exempting such uses from regulation. In contrast, the main benefit of recycling RSM is the avoidance of environmental and health damages from replacing the metal. Since this benefit is an indirect one, it may render the recycling alternative less acceptable than if the benefit were direct.

Public acceptability of risk also depends on hazard characteristics, such as the probability of disaster and the voluntariness of participation in the activity leading to risk exposure. RSM recycling holds little potential for disaster because the levels of radioactivity involved would be very low and the radionuclides would primarily be bound into the metal. The resulting metal products would be as unlikely to cause a disaster as would the current global metal stock, which contains traces of naturally occurring uranium and thorium, traces of Co-60 from measurement devices used in steel production, and traces of fallout from nuclear weapons testing (Kuppers 1988). While disaster risks would be extremely low, assumption of the risks from metal exposure would be involuntary, as is the case for the present risks from radioactivity in metals. Unless the public is convinced that recycling is less risky than metal replacement, the involuntary nature of exposure is likely to cause public resistance to recycling.

\subsubsection{Cultural Characteristics}

The implications of the effects of cultural characteristics on risk acceptability are mixed in the case of RSM recycling. Recycling of RSM may be most acceptable in countries where a hierarchical worldview predominates, because of a greater tendency in such cultures to trust assurances of process safety and to accept decision making by regulatory agencies. Egalitarian-oriented cultures are likely to be more concerned about pollution and opposed to nuclear power, but they are also likely to see conservation of resources as desirable and to be sensitive to the issue of environmental and health impacts in less-developed countries from mining ores to replace RSM.

Regardless of the overall cultural orientation in a given country, there is substantial variation in attitudes among individuals, and antinuclear activist organizations exist in many industrialized countries. Among the strategies employed by antinuclear organizations have been opposition to any release of radioactivity, no matter how small, and opposition to any waste reprocessing or disposal alternatives that would increase the viability of nuclear power. Individuals who are committed to an antinuclear ideology are likely to oppose RSM recycling as a means of expressing their opposition to nuclear power. Given the nature of such opposition, information regarding the relative risks of recycling versus replacing the metal 
resources is unlikely to influence antinuclear groups regarding the acceptability of RSM recycling.

In the U.S.A., a somewhat unique hindrance to RSM recycling acceptability exists because of the development in recent years of an attitude that the government should protect people from all risks. This "zero-risk" mentality is demonstrated in the demand for protection from pollutants, even at levels where initial statistical risks are negligible. This attitude is reflected in the detailed investigation of accidents to assess responsibility and to institute preventive measures, almost regardless of the cost. In such a cultural atmosphere of risk avoidance and denial of the pervasiveness of risk, the acceptability of RSM recycling is questionable.

\subsection{RECYCLING ACCEPTABILITY TO STAKEHOLDER ORGANIZATIONS}

The formal and informal positions of institutions and organizations with primary interests in the scrap metal market and in the political arena affecting RSM (hereafter referred to as "stakeholder organizations") are summarized in this section. An understanding of the basis for these positions and the degree to which such groups may be willing to consider risk and cost trade-offs between recycling and disposal will provide a basis for policy development. The information available for this evaluation is primarily for the U.S.A. Efforts made to solicit information from groups in other countries were not successful.

\subsubsection{Identification of Stakeholder Organizations}

As shown in Table 7.2, the stakeholder organizations involved in the issue of acceptability of recycling RSM include groups concerned with general environmental and specific nuclear safety issues; trade unions whose members would be physically involved in RSM recycling or in the production of goods containing RSM; and industry trade associations that represent nonnuclear industries involved in or affected by RSM recycling. These industry groups include the mining and metals industries and the oil and gas industry. Each of these various groups has a different position that reflects the specific interests and needs of that group's constituent members.

Environmental and related groups that have expressed opinions regarding RSM recycling are largely issue-oriented advocacy organizations that derive support from the general public. Also interested are the dozens of local environmental and antinuclear citizen groups that have been organized around specific site or regional pollution issues. These regional and local groups are diverse, numerous, and (generally) volunteer organizations. The regional and local groups were not surveyed as part of this study, although many of them interact with the U.S. Department of Energy regarding nuclear issues. 
TABLE 7.2 Stakeholder Organizations Surveyed Regarding Radioactive Scrap Metal Recycling

\begin{tabular}{ll}
\hline \multicolumn{1}{c}{ Organization } & \multicolumn{1}{c}{ Major Focus } \\
\hline Environmental Groups (5) & \multicolumn{1}{c}{$\begin{array}{l}\text { General environmental advocacy } \\
\text { Nuclear-specific interest groups }\end{array}$} \\
Trade Unions (laborers) (1) & $\begin{array}{l}\text { Direct involvement in RSM recycling (handle RSM) } \\
\text { Indirect contact with RSM (manufacture products) }\end{array}$ \\
Industry Trade Associations (5) & $\begin{array}{l}\text { Metals and mining } \\
\text { Scrap and recycling } \\
\text { Oil and gas production }\end{array}$ \\
\hline
\end{tabular}

a Number of groups responding to survey questionnaires.

Several trade unions have a direct interest in RSM recycling issues. Workers involved in the smelting of iron and other metals, represented in the U.S.A. by the United Steelworkers, have a direct stake in RSM recycling because it may increase workplace risks, as well as create new job opportunities. The Oil, Chemical, and Atomic Workers Union has a stake because of the potential involvement of nuclear workers in RSM recycling. The Sheet Metal Workers Union is also actively involved in nuclear waste issues, with a functioning joint labor-management committee on hazardous and nuclear waste.

Industry representatives with a direct interest and role in RSM recycling include those directly involved in the smelting and manufacture of metals, such as the Aluminum Association and the Iron and Steel Institute, and the scrap and recycling industries represented by the Institute of Scrap Recycling Industries. Significant interest has also been voiced by the oil and gas industry, which has specific interests in recycling of drill pipe and other oil-field materials that become contaminated with naturally occurring radioactive materials (NORM). The phosphate mining industry has similar problems with NORMcontaminated equipment.

\subsubsection{Survey of Positions of Stakeholder Organizations}

To understand and compare the positions of these different groups, we identified and surveyed some representative organizations. The survey form, shown in Section F.1 of Appendix F, was designed and tested to encourage detailed responses to key questions, as well as to encourage expression of a full range of concerns related to RSM recycling. The survey solicited the following information:

1. Position on proposed U.S. Nuclear Regulatory Commission regulations designating radioactivity levels "below regulatory concern" (BRC), 
2. Position on RSM recycling and the rationale for that position,

3. Major concerns with RSM recycling,

4. Position on trace radiation levels as a factor in supporting/opposing RSM. recycling, and

5. Evaluation of the trade-offs between RSM recycling and disposal.

The groups' positions on these issues reflect a range of opinions, perceptions, and attitudes towards RSM recycling. Many of these responses are specific to each type of group and represent the types of concerns identified with the group's members or constituents. Groups that responded to the survey are listed in Section F.2 of Appendix F.

The positions of environmental groups on RSM recycling generally reflect skepticism about RSM recycling. Antinuclear groups constitute a core of opposition to all forms of RSM recycling, which they characterize as a form of deregulation of radioactive waste. At their extreme, these groups argue that "no level of ionizing radiation is safe." Several general environmental groups appear to take a somewhat more flexible position. While not stating its position on RSM recycling unequivocally, one recognized the need to set residual radioactivity standards for site cleanups and urged that the U.S. Environmental Protection Agency be given more authority to set and enforce such standards. Other general environmental organizations, although not of the stature of the national membership groups, also appear open-minded about RSM recycling, "provided that adequate safety standards are met."

In general, labor unions accept the need to recycle RSM and support some form of recycling "as a sound environmental approach." The trade unions could play an important role in supporting development of regulations for RSM recycling. While they have an overriding interest in ensuring worker safety, the unions also have an interest in job creation and market growth. Since RSM recycling represents a potential growth sector for some unions, they may favor of RSM recycling as long as it can be demonstrated that worker exposure is minimized. In a political context, the unions interested in this issue could provide important middle ground between the positions of environmental groups and those favoring RSM recycling in some form.

Industry trade associations and their individual members hold a broad range of positions on RSM recycling. On one extreme, the Aluminum Association strongly opposes RSM recycling and regularly advises its members to avoid all contaminated shipments. The Aluminum Association is concerned that RSM recycling will contaminate the recycling waste stream and also create confusion and fear on the part of consumers. However, at least one large member of the Aluminum Association has expressed conditional acceptance of RSM recycling, with a list of detailed concerns.

Nearly all other industry groups surveyed support some form of RSM recycling, although for varied reasons. The Iron and Steel Institute does not have a clear position on 
RSM recycling, but states that "for certain product lines, some small amounts of low-level radioactive material may be acceptable." The most active industry group supporting some form of RSM recycling is the Institute of Scrap Recycling Industries. It is recommending new U.S. Nuclear Regulatory Commission regulations to permit the recycling of RSM, including, but not limited to, NORM-contaminated scrap. The oil industry also has strong interest in recycling of NORM-contaminated RSM. Some major petroleum companies with NORM-contaminated scrap problems are considering establishing large-scale oil-field smelting operations since the RSM is rejected when identified by monitoring systems at commercial smelters.

\subsubsection{Major Concerns of Stakeholder Organizations}

Each major organization's position on RSM recycling presented above is based upon specific concerns that reflect the interests of the group's members. These concerns can be divided into several categories: liability, control of health/safety risks, and other concerns. Clearly, however, several specific concerns identified below fall into more than one category. It is important to note that all of the concerns expressed would be addressed in the normal course of the regulatory process.

\subsubsection{Liability Concerns}

Concerns with liability were not as common as expected, possibly as a result of a general lack of attention given to the RSM recycling issue by major industry groups. One environmental group voiced concern about "abuses of unverifiable, irretrievable contamination," which may indicate a general concern for health risks, accountability, and liability issues.

\subsubsection{Control of Health/Safety Risk Concerns}

Nearly all respondents expressed concerns about health and safety risks associated with RSM recycling and agreed on the need to ensure adequate safety standards and controls. Environmental groups, especially the major opponents of BRC regulations, voiced strong concerns about "unnecessary exposures to unconsenting people," and "the damage to human health caused by exposure to radiation." From the perspective of these groups, environmental impacts associated with RSM recycling make it undesirable.

The Sheet Metal Workers expressed detailed concerns relating to worker health and safety, including the need for material documentation, worker training, safety inspections, and proper disposal of residuals. The Iron and Steel Institute also expressed concern about specific health and safety-related issues: contamination of metals for certain product uses that may result in human exposure; contamination of melt shop operations, need for pollution control facilities, and disposal/hauling problems; and introduction of more dangerous isotopes. 


\subsubsection{Oil Industry Concerns with Recycling of NORM-Contaminated Equipment}

At least one major oil company with significant amounts of NORM-contaminated drill pipe has studied the issues and problems associated with RSM recycling in detail. Among the major findings presented by a recent oil-industry study (Dehmel et al. 1992) are the following:

- Given the evolving regulatory climate, oil industry practices have shifted away from conventional land disposal to decontamination and storage.

- A comprehensive recycling program is needed in order to convince the scrap recycling industry and regulatory agencies that recycling can be both viable and safe. Such a program must ensure the protection of the workers, general public, and the environment.

- Techniques to control radiation exposures in recycling processes are available and can be implemented.

\subsubsection{Other Concerns}

Several environmental groups and one industry group expressed concern that RSM recycling would harm conventional recycling programs by bringing confusion and fear into existing programs. One strongly antinuclear environmental group expressed concern over the impact of RSM recycling on economic competitiveness, although it is unclear what specific reasons motivate this concern. Finally, oil industry representatives and the Institute of Scrap Recycling Industries, two of the most informed supporters of RSM recycling, point to the need for a massive education and public relations campaign to improve public acceptance.

As a key participant in any RSM recycling scenario, the Institute of Scrap Recycling Industries in particular has expressed additional concerns regarding the problem of sealed radioactive sources entering the recycling stream and the associated costs of removal and disposal. The Institute is also concerned about NORM-contaminated scrap that is sufficiently radioactive to trigger radiation detection monitors but is unregulated in all but a few states. Concern was also expressed about the high cost of disposal under rules promulgated for higher levels of contamination.

\subsubsection{Evaluation of Trade-Offs by Stakeholder Organizations}

Several groups (including several industry trade associations and trade unions) recognized the benefits of RSM recycling compared with disposal and replacement. The Sheet Metal Workers' response was representative: "To the extent that recycling can be achieved while protecting human health and the environment, we support this approach. Disposal is a finite method with potential harm to health for many years if accidentally disturbed." One 
group reserved judgment on the trade-off question, without knowing specific details of the alternatives.

The major exception is the strong resistance of environmental and antinuclear groups to any alternative that causes radiation exposure. Typical of this position are comments such as "The only good solution is to stop generating the hazardous substance. Pollution prevention is the only successful means of environmental protection," and "isolate the waste from the environment and people." A more moderate position, balanced the inherent benefits of recycling with health and safety concerns: "Because reuse of scrap would present greater potential for exposure, adequate safety data and standards would become more essential."

The survey results indicate that the trade-offs between recycling and disposal have not generally been recognized or understood by many of the key organizations. Because of the critical importance of alternatives to RSM recycling, a good starting point for future study and education may be this particular issue of trade-offs between proposed alternatives.

\subsection{FACTORS AFFECTING SOCIAL AND POLITICAL IMPACTS OF RADIOACTIVE SCRAP METAL RECYCLING}

This section identifies factors that may be major impediments or keys to the success of an RSM recycling initiative. Although countries have identified release criteria that allow for RSM recycling, the requisite assessment and decontamination techniques are practicable, and a supply of RSM is readily available (see Section 3), recycling of RSM is currently impeded. The barriers to recycling include dissimilar national criteria for release, unsuitability of RSM for some uses, potential costs of compliance with the regulatory structure associated with RSM recycling, and possible lack of public acceptance of RSM recycling.

\subsubsection{Benefit and Risk Perceptions by Stakeholder Organizations and the Public}

Affected sectors of society must evaluate the impacts of both RSM recycling and of RSM disposal and replacement in order for the recycling concept to gain sufficient momentum for action and public support. In the U.S.A., the petroleum and mining industries are beginning to press for standards for decontamination and recycling of pipe and equipment contaminated with NORM. The Institute of Scrap Recycling Industries is calling for a national determination of a safe level of contamination in scrap metal. The U.S. Department of Energy and the commercial nuclear power industry have realized the need to consider recycling as an alternative to burial of millions of tons of minimally contaminated scrap. The public has already demonstrated its interest in the concept of RSM recycling and is likely to be active in the debate. The involvement of these differing institutions indicates that the time may be opportune for a comprehensive review of RSM recycling. 
In reaching an international consensus on RSM recycling, perceptions of the overall risks and benefits are of paramount importance. Public recognition that there are no "zero-risk" alternatives is essential. Process design and regulatory controls can be employed to keep such risks of recycling RSM to a very low level. Long-term storage and/or disposal of the RSM also presents risks, not only directly from those activities themselves, but also indirectly from the mining and smelting activities and energy production necessary to replace the discarded metal stock. These risks are considerably higher than the risks of recycling RSM. Indeed, avoidance of these risks and avoidance of the economic costs of producing replacement metal are the major benefits of the recycling option. Key organizations and the public must to be sufficiently informed about the alternatives to evaluate the risk/benefit trade-offs.

\subsubsection{Detectability of Radiation in Scrap Inputs and Finished Products}

People tend to be aware of and to try to avoid risks that give a clear signal of their impending occurrence. The public will accept RSM and products in which it is incorporated much more readily if the radioactivity level is sufficiently low that it does not set off standard radiation-detection alarms. In many industrialized countries, there are both fixed and mobile radiation detectors in scrap yards and a variety of other locations. As a result, numerous incidents have occurred around the world in which radiation has accidentally been discovered in metal scrap or metal products, with the discovery sometimes occurring after structural steel was incorporated in a building. Regardless of the country involved, these incidents have generally resulted in strong public demands for the government to find and remove all of the contaminated material. If the activity levels of RSM are high enough that the reused equipment or fabricated metal products trigger standard radiation detection systems, public acceptance of recycling will be unlikely. However, activity levels that are low enough to be protective of human health are unlikely to cause such alarms.

\subsubsection{Public Confidence in Institutional Controls}

When establishing release standards, regulators may base their decisions on the principle that the standard should correspond to the level at which individuals knowledgeable of the risk would not commit significant portions of their own resources to reduce the risk (Royal Society of London 1983). Or, they may define as a trivial dose one that is small in relation to the variation in naturally occurring background radiation (IAEA 1988). However sound these principles may be, regulators' assessments of risk may not be accepted by the public if those assessments do not relate to the way people perceive and evaluate risk.

For instance, in most Western countries, risk perception and risk acceptance are influenced, among other things, by the degree of voluntariness associated with the risk (Douglas and Wildavsky 1982). Thus, dosages that result from voluntary exposures, such as living at high altitude, will not necessarily be seen as comparable to involuntary risks, such as exposure to residual contamination in steel used in automobiles. Thus, aspects such as the involuntary nature of exposure to recycled RSM must be accounted for in establishing 
institutional controls. This "accounting" is usually accomplished by limiting risks to lower levels than those considered acceptable for voluntary hazard exposure.

The potential for public acceptance of RSM recycling will be affected by the general level of public trust in the regulatory institutions involved and in the nature of information received from various sources. For instance, statements in support of RSM recycling by knowledgeable persons who are generally well regarded will tend to increase public acceptance. In contrast, contradictory statements regarding the risks presented by competing teams of "experts" will tend to create public uncertainty about the accuracy of the risk assessment and result in concern that the regulatory organizations cannot be trusted. Thus, public acceptance of RSM recycling is likely to be increased by a high degree of consensus in the scientific community on its desirability and by effective communication of the low level of public risk.

\subsubsection{Nonuniformity of Release Standards among Countries}

Several countries have established or are proposing criteria for restricted or unrestricted release of contaminated scrap. Differences among countries in these domestic release criteria may interfere with the unrestricted transboundary movement of scrap metal that normally occurs in the international scrap market. Nonuniformity of countries' criteria means that RSM that meets one country's release levels for general melting in ordinary steel furnaces with inactive scrap (for example, in Germany the specific overall activity of each item cannot exceed $1 \mathrm{~Bq} / \mathrm{g}$ and the surface activity must not exceed $0.5 \mathrm{~Bq} / \mathrm{cm}^{2}$ [Neider 1992]) may not be accepted in other countries. This problem could make RSM recycling difficult and the market inefficient if the closest or most appropriate scrap use is in a neighboring country that does not allow RSM melting or has more restrictive release limits. End-use products made from recycled RSM may also be restricted to domestic use if the release standards vary. This restriction would occur if countries impose regulations that preclude the sale, transport, or use of products containing residual radioactive contamination other than that due to naturally occurring radiation.

Individual countries also regulate consumer products that contain radioactive substances or emit ionizing radiation. Although countries adhere to the principles of dose limitation - justification of a practice, optimization of radiation protection, and limitation of individual risk (IAEA 1988) - for the exemption of products from regulatory control, such adherence does not guarantee that all countries will reach compatible decisions regarding what products can be exempted. The cross-boundary movement of consumer products could be jeopardized by nonuniform exemption decisions.

The cost factors affecting RSM recycling include the economics of decontamination technologies, availability of decontamination and recycling facilities, market development, transportation systems, and management of secondary waste streams. The costs also include those of developing, implementing, monitoring, and complying with the regulations attendant to each activity associated with recycling. The costs of developing such a regulatory structure 
will be high but not prohibitive. Many countries have already developed a similar structure to manage hazardous wastes.

It is the cost of compliance with the regulatory structure that could become a barrier to $\mathrm{RSM}$ recycling. If the compliance costs associated with recycling appear to be prohibitive to participants in the scrap metal market, there will be no incentive to accept RSM. While the regulatory structure must be based on standards that protect human health and the environment, the urge to establish release standards that are as low as possible may increase the costs associated with measuring and verifying achievement of release levels. For example, modifying release levels from $4 \mathrm{~Bq} / \mathrm{cm}^{2}$ to $0.4 \mathrm{~Bq} / \mathrm{cm}^{2}$ for beta-gamma and from $0.4 \mathrm{~Bq} / \mathrm{cm}^{2}$ to $0.04 \mathrm{~Bq} / \mathrm{cm}^{2}$ for alpha emitters can increase monitoring and verification costs by as much as 50\% (OECD 1991). Significant monitoring and verification costs and associated record keeping may make RSM recycling unattractive to industry.

\subsection{REFERENCES FOR SECTION 7}

Dake, K. 1991, "Orienting Dispositions in the Perception of Risk," Journal of Cross Cultural Psychology 22(1):61-82.

Dehmel, J.-C., et al., 1992, Scrap Metal Recycling of NORM Contaminated Petroleum Equipment, prepared by S. Cohen \& Associates, McLean, Va., T.P. McNulty and Associates, Evergreen, Colo., and Hazen Research Inc., Golden, Colo., for Petroleum Environmental Research Forum, Ponca City, Okla., Sept.

Douglas, M., and A. Wildavsky, 1982, Risk and Culture: An Essay on the Selection of Technological and Environmental Dangers, University of California Press, Berkeley, Calif.

Englander, T., et al., 1986, "A Comparative Analysis of Risk Perception in Hungary and the United States," Social Behaviour 1:55-66.

Fischoff, B., et al., 1979, "Which Risks Are Acceptable?" Environment 21(4):17-20, 32-38.

Harding, C.M., and J.R. Eiser, 1984, "Characterizing the Perceived Risks and Benefits of Some Health Issues," Risk Analysis 4(2):131-141.

IAEA - see International Atomic Energy Agency.

International Atomic Energy Agency, 1988, Principles for the Exemption of Radiation Sources and Practices from Regulatory Control, IAEA Safety Guides, Safety Series No. 89, Vienna.

Karpowicz-Lazreg, C., and E. Mullet, 1993, "Societal Risk as Seen by the French Public," Risk Analysis 13(3):253-258.

Keown, C.F., 1989, "Risk Perceptions of Hong Kongese vs. Americans," Risk Analysis 9(3):401-405. 
Kleinhesselink, R.R., and E.A. Rosa, 1991, "Cognitive Representation of Risk Perceptions: A Comparison of Japan and the United States," Journal of Cross-Cultural Psychology 22(1):1-28.

Kuppers, C., 1988, Probleme der Wiederverwertung von Radioaktiv Kontaminiertem Stahlschrott aus Kerntechnischen Anlagen, IG Metall, Germany.

National Council on Radiation Protection and Measurements, 1987, Radiation Exposure of the U.S. Population from Consumer Products and Miscellaneous Sources, NCRP Report No. 95, Bethesda, Md.

NCRP - see National Council on Radiation Protection and Measurements.

Neider, R., 1992, "Exemption Limits for Contaminated Materials To Be Recycled and for Low Level Radioactive Waste from Nuclear Power Stations and Uranium Mining and Milling Areas in South-Eastern Germany," in Waste Management '92, Tucson, Ariz., March.

OECD - see Organization for Economic Cooperation and Development.

Organization for Economic Cooperation and Development, 1991, Decommissioning of Nuclear Facilities: Analysis of the Variability of Decommissioning Cost Estimates, Draft Report, Paris, France, June.

Royal Society of London, 1983, Risk Assessment: A Study Group Report by the Royal Society, London, England.

Slovic, P., et al., 1985, "Characterizing Perceived Risk," in Perilous Progress: Managing the Hazards of Technology, R.W. Kates et al. (eds.), Westview Press, Boulder, Colo.

Slovic, P., 1987, "Perception of Risk," Science 236:280-285.

Starr, C., 1969, "Social Benefit versus Technological Risk," Science 165:1232-1238.

Teigen, K.H., et al., 1988, "Societal Risks as Seen by a Norwegian Public," Journal of Behavioural Decision Making 1:111-130.

Vance, J., 1989, "EPRI Discussion Paper on BRC and De Minimis Concepts," in Workshop on Rules for Exemption from Regulatory Control, U.S. Nuclear Regulatory Commission, Washington, D.C.

Vlek, C., and P.J. Stallen, 1981, "Judging Risks and Benefits in the Small and in the Large," Organizational Behavior Human Performance 28:235-271.

Von Winterfeldt, D., et al., 1981, "Cognitive Components of Risk Ratings," Risk Analysis 1(4):277-287.

Webb, G., 1989, "International Commission on Radiological Protection (ICRP) Guidelines," in Residual Radioactivity and Recycling .Criteria, U.S. Environmental Protection Agency, Washington, D.C. 
$A-1$

\section{APPENDIX A:}

METHODOLOGY AND SUMMARY TABLES FOR POWER REACTOR REFERENCE PLANT DATA SETS 


$$
\text { A-2 }
$$




\section{APPENDIX A:}

\section{METHODOLOGY AND SUMMARY TABLES FOR POWER REACTOR REFERENCE PLANT DATA SETS}

\section{A.1 INTRODUCTION}

Appendix A documents the methods used to obtain the inventory parameters for nuclear power plants and presents the input data illustrating the application of the methodology. Descriptions of the categorizations of plants worldwide that were employed in deriving estimates of metal mass are contained in Section A.2. The tables that comprise Section A.3 present the listing of plant information and the metal mass values derived from the algorithms.

The quantities and types of metal scrap obtained from a dismantled reactor depend upon the class of reactor. Within each major reactor class, the amounts of material may also depend significantly upon a range of secondary characteristics, or identifiers, that are included in the plant input descriptor list. These identifiers includes country (effects of national differences in regulation), vendor (variations in design approach, such as the number of steam generators for a given power), architect-engineer (differences in balance-of-plant layout that affect the volume of concrete and mass of structural metals), period of construction (many extra systems were required after the Three Mile Island accident), number of steam turbines (combining smaller turbogenerator sets for a given power output requires more commodities), and cooling (the form of cooling water disposal or recycle, sea cooling or river cooling, and cooling towers of various designs, all require different amounts of commodities). The available databases are not sufficiently detailed to correlate all of these effects with the corresponding identifiers. If needed, however, additional correlations keyed to the existing identifiers can be added to the current spreadsheet methodology.

\section{A.2 REFERENCE NUCLEAR POWER PLANT METHODOLOGY}

\section{A.2.1 Background}

Reference plants of each reactor type were defined to form the basis for a range of simple algorithms that estimate waste-stream quantities from a minimum of input data. For each plant, the metal mass data are grouped into one of the four metal activity categories: (1) suspect radioactive, (2) surface-contaminated - removable, (3) surface-contaminated fixed, and (4) activated, as defined in Table 3.1. The algorithms take into account the wide range of plant sizes and types. For pressurized water reactor (PWR) and boiling water reactor (BWR) plants, adjustments are made to account for differences in size. United Kingdom gas-cooled reactors (GCRs) include Magnox reactors and advanced gas-cooled reactors (AGRs). Former Soviet Union VVERs are divided into 440-MWe and 1,000-MWe 
classes. This methodology is the basis for the annual increments in potential scrap metal inventories listed in Appendix B.

All metal masses for PWR and BWR plants are adjusted for design power levels scaled to the corresponding reference plant, on the basis that mass is proportional to the design electrical output to the $2 / 3$ power ([design electrical power] ${ }^{2 / 3}$ ). Because some plants have been derated, the electrical output values used are the original design power ratings. This scaling is based on PWR and BWR vessel mass data from Nuclear Engineering International (1991, 1993) and applies generally to the full range of vendors and countries. Although this scaling relationship has general validity, there is considerable scatter in the numerical multipliers, yielding vessel masses that tend to group by specific countries or vendors.

Published plant mass data show wide variations (Smith et al. 1978; Bryan and Dudley 1974; United Engineers and Constructors 1972; El-Bassioni 1980). The studies cited by El-Bassioni (1980) show estimated PWR steel masses varying by a factor of 5.4; although those studies were perhaps not highly detailed, the comparison indicates significant uncertainty in estimating mass data across the industry even for a single country. As another example of the potential uncertainty in any estimates of RSM masses, Lasch et al. (1984) present a generic estimate for a large light-water reactor (LWR) (in the 900- to 1,300-MWe range) of 1,100 metric tons ( $t$ ) of activated steel (plus $400 t$ of activated reinforced concrete). If $20 \%$ by weight of this reinforced concrete is steel (reinforcing bar, or rebar), the Lasch data imply about $1,200 \mathrm{t}$ of activated steel, only about $35-40 \%$ of the values used in the PWR and BWR reference plants of this report. Lasch et al. (1984) give a generic estimate of 7,800 $t$ of activated steel for an AGR; this can be compared with the total of 2,265 $t$ of activated carbon steel, iron, and stainless steel for the reference AGR plant based on the detailed tables of Regan et al. (1984).

Three reference reactors are used, without adjustment for electrical output rating, to develop scrap metal estimates for Magnox plants. However, the generic estimate by Lasch et al. (1984) (2,700 $\mathrm{t}$ of activated steel from each United Kingdom GCR, not counting activated steel rebar) is well in excess of the amount of activated iron and steel in each of these three reference plants.

Stainless steel is defined as described in Section 3.3.3; thus, nickel and nickel alloys are included in the stainless steel category. Zirconium is a significant component only in the Canadian deuterium-uranium (CANDU) and RBMK reactor types. The individual reference plants are described in the following subsection. 


\section{A.2.2 Plant-Specific Methodology}

\section{A.2.2.1 Advanced Gas-Cooled Reactor (AGR)}

The comprehensive description of components and activation calculations for the Torness and Heysham AGR plants by Regan et al. (1984) was used to provide the carbon steel and iron data and the stainless steel data for the reactor block of the AGR reference plant. This reference plant was used for all United Kingdom AGRs, without adjustment for electrical output rating. The generic PWR reference plant data were used for copper, aluminum, structural steel, and lead in the rest of the plant, with the exception of the nonradioactive copper value, which was reduced to $3,900 \mathrm{t}$.

\section{A.2.2.2 1,000-MWe Boiling-Water Reactor (BWR)}

The reference 1,000-MWe BWR was used to estimate scrap from all BWR plants. The quantities of iron and steel were estimated by adjusting the PWR reference plant data for BWR characteristics: less heat-transport piping and component material, absence of steam generators, more ex-vessel containment, and more ex-vessel structure. The BWR reference plant scrap carbon steel and iron is distributed as follows: $5,000 \mathrm{t}$ suspect radioactive, $6,700 \mathrm{t}$ surface-contaminated - removable, and 3,500 t activated. Scrap metal in the stainless steel category is allocated as follows: negligible quantities of suspect radioactive, $600 \mathrm{t}$ of surfacecontaminated - removable, and $670 \mathrm{t}$ of activated metal. In contrast, El-Bassioni (1980) gives a total mass of 10,000 $t$ of carbon steel and iron for a BWR. The copper, aluminum, and lead masses assigned to the reference $1,000-\mathrm{MWe} B W R$ plant were the same as those assigned to the reference 1,000-MWe PWR plant.

\section{A.2.2.3 Pressurized Heavy-Water Reactor (PHWR)}

Three different designs of heavy-water-moderated reactor are included in this category. The main group is the CANDU series. These reactors are distinguished by a lowpressure moderator in a calandria. The fuel channels are horizontal zirconium/niobium alloy pressure tubes designed to permit on-line refueling. The Indian Department of Atomic Energy now designs CANDU plants for domestic use. Variations on this design that are included in this category are reactors with light-water cooling or gas cooling, although demonstration plants of less than $100 \mathrm{MWe}$ are not included. Also, there are a few PHWRs that are essentially heavy-water-filled PWRs. Because of a lack of specific information, these types of reactors were treated as if they were CANDU PHWRs.

The mass estimates were based on reactor estimates for various plants representing design evolution; some equipment masses were taken from Nuclear Engineering International (1970); plant control information was from Nuclear Engineering International (1993) and the PWR structural/systems information. The reference plant chosen was Darlington ( $881 \mathrm{MWe)}$ as the most evolved unit, and all units were scaled by the 2/3 power rule. 
The calandria and all its related appurtenances were assumed to be stainless steel. The end shields, which permit the on-line refueling operations, include some carbon steel. However, the close interfaces with the calandria and heavy water suggest that these shields include several alloys, and, therefore, they were included with the calandria in the activated stainless steel values $(2,100 \mathrm{t})$. The steam generators are stainless, and the tubes are various high-nickel alloys; therefore, the component was treated as a unit. The whole mass was included with the cleanable stainless because some of the components typically fabricated from carbon steel for light-water reactors are made of stainless steel in heavy-water systems. The PHWR reference has a suspect radioactive stainless mass of $290 t, 2,000 t$ surfacecontaminated - removable stainless, and $200 \mathrm{t}$ of fixed, including an allowance for waste systems.

Two special add-ons were included in the stainless category. The Pickering reactors have 12 steam generators each, whereas each of the larger reactors has 4 generators. The scaling assumed that most reactors have four steam generators, including small reactors in the 200-MWe-range. To compensate for the scaling rule, an additional $440 \mathrm{t}$ of metal was included in the surface-contaminated - removable stainless category for the Pickering reactors. The Pickering A Station Units 1-4 have a dump tank for emergency shutdown. Some of the other early units are also described as including control by "moderator level" (Nuclear Engineering International 1993). Therefore, it was inferred that these units also included dump tanks (e.g., Douglas Point [Nuclear Engineering 1964]), which were closely associated with the reactor structure. For this reason, the Pickering Units 1-4 (1,500 t), Douglas Point, MAPS Units 1-2, RAPS Units 1-2 (all $825 \mathrm{t}$ ), and KANUPP (600 t) all include prescaled dump tank masses in the activated stainless steel component.

The carbon steel masses were based on the corresponding 1,000-MWe PWR values, except that some mass was transferred to the suspect radioactive and surface-contaminated - removable stainless steel categories because the fluid is heavy water. Because most of the activated carbon steel was for cell and containment liners and similar components, this value was left unchanged from that of the reference PWR. Although the PWR values are for a 1,000-MWe plant, while the reference PHWR is only $881 \mathrm{MWe}$, natural uranium reactors tend to be somewhat larger than those using slightly enriched uranium. Thus, the masses were not scaled down for the PHWR reference plant. Similarly, the copper, aluminum, and lead values and scaling treatments were as for the PWRs. This approach was also appropriate since the copper and aluminum values were based on the 900-MWe French PWR series. The pressure tubes are a zirconium-niobium alloy. Only a relatively small difference in masses was quoted for the Pickering and the Darlington units, and there are almost as many units larger than Pickering as there are units smaller than Pickering. A constant zirconium mass was used, equal to the Pickering value of $25 \mathrm{t}$.

\section{A.2.2.4 High-Temperature, Gas-Cooled Reactors (HTGRs)}

The only two high-temperature, gas-cooled reactors (HTGRs) in the data sheets are Fort St. Vrain and the THTR-300. Both of these had prestressed concrete pressure vessels, and the AGR materials data were used as a reasonable approximation for these HTGRs. 


\section{A.2.2.5 Magnox with Steel Vessels (Magnox I and II)}

The mass estimates for the Magnox stations were derived from several sources. In the Magnox stations' period of nuclear development, the basic design requirements were amply described, but the design details were clearly regarded as proprietary.

In the mass estimates, the base boiler (for example) was defined for the Dungeness nuclear power station by using shell information from an industry magazine issue devoted to the plant (Nuclear Power 1961), with tube masses approximated from Regan et al. (1984) and adjusted according to thermal power rating. This method partially allows for the temperature differences between the AGR and Magnox plants by considering unit thermal power rather than plant electrical ratings. All the tubes were assumed to be mild steel alloys. The total boiler mass per plant was then scaled from this base value according to plant output and number of boilers per plant. The duct length was estimated from the Nuclear Power wall chart for Dungeness (Nuclear Power 1961). The boiler masses tend to fall into two groups, the dividing line being about $200 \mathrm{MWe}$ per reactor. Consequently, the boiler and duct masses were averaged into two groups, designated in the tables as Magnox I (200 MWe or less) and Magnox II (more than $200 \mathrm{MWe}$ ). The power used in these calculations was the design rating, not the reduced operational rating given in the detailed data sheets.

The vessel mass used is an average of the Magnox steel vessels calculated from Nuclear Engineering International (1993). The vessel size ranges are relatively close (almost independent of reactor power), so an average was used. The structural steel values were scaled from those of the LWR reference plant by the 2/3-power rule, to $150 \mathrm{MWe}$ and 250 MWe for Magnox I and II, respectively. Because Magnox plants use natural uranium, a Magnox complex is larger than that of a comparable enriched-fuel reactor. Thus, the scaling factors were increased above those given by the $2 / 3$-power rule $(0.3$ and 0.4 , respectively), to 0.4 and 0.5 , respectively. The same ratios were used for the copper. For aluminum and lead, however, the reduced values were small and it was decided to exclude these metals. The Mágnox reactors contain relatively small quantities of stainless steel, primarily in instrumentation systems, and a nominal estimate was included. The turbine generator and condenser masses were estimated with data from Leclercq (1986) for the two reactor size groups. The specific reference plant values for Magnox I and II are given below.

\section{A.2.2.6 Magnox I}

The first reference reactor for the United Kingdom Magnox plants represents reactors of $200 \mathrm{MWe}$ or less. Estimates were obtained from evaluation of the specific components. Carbon steel and iron values are 3,800 $t$ of suspect radioactive, 4,950 $t$ of surface-contaminated - removable, negligible quantities of surface-contaminated - fixed, and 1,000 t of activated. An allowance of $100 \mathrm{t}$ for activated stainless steel is included. Copper is allocated as follows: $1,900 \mathrm{t}$ of suspect radioactive, $50 \mathrm{t}$ of surface-contaminated removable, and $50 \mathrm{t}$ of activated. Aluminum and lead quantities are negligible. Chinon A2 is included with Magnox I plants. 


\section{A.2.2.7 Magnox II}

Magnox II represents Magnox reactors greater than 200 MWe, without prestressed concrete pressure vessels. Estimates were obtained from evaluation of the specific components. Carbon steel and iron values are 4,690 $\mathrm{t}$ of suspect radioactive, 6,225 $\mathrm{t}$ of surface-contaminated - removable, negligible quantities of surface-contaminated - fixed, and 1,000 t of activated. An allowance of $100 \mathrm{t}$ is included for activated stainless steel. Copper is allocated as follows: $2,400 \mathrm{t}$ of suspect radioactive, $50 \mathrm{t}$ of surface-contaminated - removable, and $50 \mathrm{t}$ of activated. Aluminum and lead are negligible.

\section{A.2.2.8 Magnox with Prestressed Concrete Vessels (Magnox III)}

A third group of Magnox plants, designated Magnox III in the tables, was defined as those with prestressed concrete pressure vessels and internal boilers. They are the direct predecessors of the AGRs, and most of them have about the same rating as the AGRs. The AGRs are in the 500- to 700-MWe range, while most of the prestressed concrete vessel Magnox plants are in the 480- to 590-MWe range, including French and British units. The only exceptions are the two Oldbury units, at 300 MWe each. The French plants had boilers below the core (e.g. St. Laurent), and the British units have the annular boilers outboard of the graphite. For a useful first approximation, all the Magnox III plants are allocated the same metals distribution as the AGRs. Plants in this category include Bugey 1, Chinon A3, Oldbury 1 and 2, St. Laurent A1 and A2, and Wylfa 1 and 2.

\section{A.2.2.9 1,000-MWe Pressurized Water Reactor (PWR)}

The 1,000-MWe PWR reference plant was used to estimate scrap from all non-former Soviet Union PWR plants. The iron and steel data for this plant were based on a generic (but highly detailed) design study of a 1,000-MWe U.S.A. plant (Bryan and Dudley 1974, based on United Engineers and Constructors Inc. 1972), checked against French 900-MWe data (Chapuis et al. undated), a study on decommissioning a 1,095-MWe U.S.A. plant (Smith et al. 1978), and the El-Bassioni (1980) compilation. Estimates are consistent with IAEA figures (IAEA 1988).

Total carbon-steel and iron masses ranged from 25,000 t (the 900-MWe plant) to $33,000 \mathrm{t}$ (the 1,000-MWe plant). El-Bassioni (1980) quotes a range of 10,000 to 54,000 $\mathrm{t}$ for PWR plants. Of the 33,000 $t$ total in the generic 1,000-MWe plant, about $13,300 \mathrm{t}$ is rebar, which is difficult and expensive to recycle from concrete. Subtracting 15,000 t for rebar and other unavailable iron and steel yields a reference plant total of $18,000 \mathrm{t}$ of scrap carbon steel and iron. This steel and iron is distributed as follows: $8,290 \mathrm{t}$ of suspect radioactive, $6,700 \mathrm{t}$ of surface-contaminated - removable (Chapuis et al. [undated] suggest this category should be about $20 \%$ of the total), and $2,940 \mathrm{t}$ of activated.

Scrap metal in the stainless steel category is allocated on the basis of the detailed plant accounting sheets as follows: negligible quantities of suspect radioactive, $900 \mathrm{t}$ of 
surface-contaminated - removable, $300 \mathrm{t}$ of surface-contaminated - fixed, and $670 \mathrm{t}$ of activated. (Of these stainless steel masses, the steam generator accounts for $500 \mathrm{t}$ of surfacecontaminated - removable and all $300 \mathrm{t}$ of the surface-contaminated - fixed.) Copper and aluminum reference plant data were taken from Garbay and Chapuis (1989), who reference about 5,000 $\mathrm{t}$ of copper and about $100 \mathrm{t}$ of aluminum in the standard French 900-MWe plant. These metals are located primarily in the electrical and instrumentation and control systems. On the basis of Garbay and Chapuis' estimates of contamination and activation of cables, copper is allocated as follows: $4,900 \mathrm{t}$ of suspect radioactive, $80 \mathrm{t}$ of surface-contaminated removable, and $20 \mathrm{t}$ of activated. Aluminum is allocated as $80 \mathrm{t}$ of suspect radioactive, $15 \mathrm{t}$ of surface-contaminated - removable, and $5 \mathrm{t}$ of activated scrap. The El-Bassioni "model light-water reactor" value of $20 \mathrm{t}$ of lead is categorized as suspect radioactive and used for the reference PWR.

\section{A.2.2.10 RBMK (former Soviet Union)}

The reference RBMK plant is used for all former Soviet Union RBMK plants without adjustment for plant electrical output. Very little information has been published on details of former Soviet Union RBMK plants. The 1,000-MWe VVER reference plant data are used for all RBMK, with the addition of $100 \mathrm{t}$ of activated zirconium alloy to complete the rough estimate of metal per RBMK plant. (Emelyanov et al. [1982] indicate that an RBMK plant will contain about $90 \mathrm{t}$ or more of zirconium alloy in the form of activated pressure tubes from the in-core region.)

\section{A.2.2.11 440-MWe VVER (former Soviet Union PWR)}

The former Soviet Union deployed 440-MWe VVER plants as a class, followed, with overlap, by the 1,000-MWe VVER class. The 440-MWe VVER reference plant is used for all 440-MWe-class VVER plants, without adjustment for plant electrical output. A compilation of open literature data (DOE 1987) was the basic reference for the 440-MWe plants. Data for the mature Model 213 was used for the reference VVER 440-MWe plant. The copper, aluminum and lead data for the reference 1,000-MWe PWR were adjusted to 440-MWe nominal electrical output by applying the scaling relationship that mass is proportional to output to the two-thirds power. This calculation yields values of $2,840,46$, and $12 \mathrm{t}$ for suspect radioactive, surface-contaminated - removable, and activated copper, respectively; values of 46,9 , and $2 t$ for suspect radioactive, surface-contaminated - removable, and activated aluminum; and $12 \mathrm{t}$ of suspect radioactive lead.

\section{A.2.2.12 1,000-MWe VVER (former Soviet Union PWR)}

The 1,000-MWe VVER reference plant is used for all 1,000-MWe-class VVERs, without adjustment for plant electrical output. The U.S. Department of Energy (DOE 1987) presents additional data on specific systems of the 1,000-MWe VVER and also generic plant mass-to-capacity ratios of 43 and $30 \mathrm{t}$ of equipment/MWe for the 440-MWe Model 213 and 
1,000-MWe VVER, respectively. On the basis of these mass ratios, the 1,000-MWe VVER total metal mass is about 1.6 times that of the mature Model 213 VVER 440. That ratio was used to complete the VVER 1,000-MWe calculations. The actual scaling factor of 1.6 is in good agreement with that obtained by scaling total masses proportional to the generic relationship of (electrical output) ${ }^{2 / 3}$, which yields a total mass ratio of 1.7 for these two plant types. Reference 1,000-MWe PWR plant data for copper, aluminum and lead were used for the 1,000-MWe VVER.

\section{A.3 REFERENCE PLANT PARAMETERS AND ESTIMATED METAL MASSES}

This section presents summary tables listing the reference plant parameters and the estimated metal masses for each. In the plant information section at the top of each table, the row labelled "Identifier" consists of an identifying sequence number, a country identifier, and an abbreviated description of the reactor type. The "vendor" row identifies the main contractors for the reactor system and, in some cases, the hardware contributor. The architect/engineer row identifies the firm involved in laying out the reactor. In the metal quantities sections of the tables, the category "non-radioactive" is equivalent to "suspect radioactivity," the category "surf. contam.-cleanable" is equivalent to "surface-contaminated - removable," and the category "surf. contam.-non-clnbl." is equivalent to surfacecontaminated - fixed. 


\begin{tabular}{|c|c|c|c|c|c|c|c|c|c|c|c|c|c|c|}
\hline 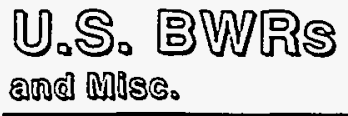 & $\begin{array}{l}\text { Browns } \\
\text { Forry } 1\end{array}$ & $\begin{array}{l}\text { Browns } \\
\text { Forry } 2\end{array}$ & $\begin{array}{l}\text { Browns } \\
\text { Forry } 3\end{array}$ & $\begin{array}{l}\text { Bruns- } \\
\text { wick } 1\end{array}$ & $\begin{array}{l}\text { Bruns- } \\
\text { wick } 2\end{array}$ & $\begin{array}{c}\text { Clinton } \\
1\end{array}$ & Cooper & $\begin{array}{c}\text { Dresden } \\
1\end{array}$ & $\begin{array}{c}\text { Dresden } \\
2\end{array}$ & $\begin{array}{c}\text { Dresden } \\
3\end{array}$ & $\begin{array}{l}\text { Duane } \\
\text { Arnold }\end{array}$ & $\begin{array}{l}\text { Edwin } 1 . \\
\text { Hatch } 1\end{array}$ & $\begin{array}{l}\text { Edwin } 1 . \\
\text { Hatch } 2\end{array}$ & $\begin{array}{c}\text { Formi } \\
2\end{array}$ \\
\hline Fuel cycle stage (FCD & Reactor & Reactor & Reacior & Reactor & Reactor & Peactor & Reactor & Reactor & Reactor & Reactor & Reactor & Reactor & Reactor & Reacior \\
\hline Identilior & 161USAB & 165USAB & 203USAB & 262USAB & 238USAB & 426USAB & 162USAB & 23 USAB & 129USAB & 132USAB & 237 USAB & 194USAB & 211USAB & 247 USAB \\
\hline Plant type & BWR & BWR & BWR & BWR & BWR & BWR & BWR & BWR & BWR & BWR & BWR & BWR & BWR & BWR \\
\hline Location & USA & LSA & USA & USA & USA & USA & USA & USA & USA & USA & USA & USA & USA & USA \\
\hline Start of operations & 1974 & 1975 & 1977 & 1977 & 1975 & 1987 & 1974 & 1960 & 1970 & 1971 & 1974 & 1975 & 1979 & 1988 \\
\hline Status & Operating & Operating & Operating & Operating & Operating & Operating & Operating & Shut down & Operating & Operating & Operating & Operating & Operating & Operating \\
\hline Size (MWO) (Net) & 1065 & 1065 & 1065 & 767 & 754 & 930 & 764 & 200 & 772 & 773 & 538 & 741 & 761 & 1075 \\
\hline Vendor & ⿷匚 & ⿷匚 & ⿷匚 & ⿷匚 & $\mathbb{E}$ & ⿷匚 & $\mathbb{G E}$ & & 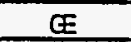 & ⿷匚 & GE & $\mathbb{E}$ & GE & $\mathrm{GE}$ \\
\hline AVE & Uilility & Utility & Utility & UE\&C & UE\&C & S\&L & B\&R & & S\&L & $S \& L$ & Bechtel & Util/Bcht| & Bechiel & Utility \\
\hline Pre or Post TMI & Pre & Pre & Pre & Pre & Pre & Post & Pre & Pre & Pre & Pre & Pre & Pre & Pre & Post \\
\hline No. of steam turbines & 1 & 1 & 1 & 1 & 1 & 1 & 1 & 1 & 1 & 1 & 1 & 2 & 2 & 1 \\
\hline Cooling & & & & River & Biver & Lake & River & & River & River & Tower & Ind.draft twr & Ind.draft twr & \\
\hline $\begin{array}{l}\text { Date EOL metal available } \\
\mathbb{Z Z Z}\end{array}$ & 2024 & 2025 & $\frac{2027}{Z Z Z Z}$ & 2027 & 2025 & 2037 & 2024 & 2010 & 2020 & 2021 & 2024 & 2025 & 2029 & 2038 \\
\hline \multicolumn{15}{|l|}{ Quantity of metal (tonnes): } \\
\hline Aluminum Non-radioactive & 83 & 83 & 83 & 67 & 66 & 76 & 67 & 27 & 67 & 67 & 53 & 66 & 67 & 84 \\
\hline Surl. contam.-cleanable & 16 & 16 & 16 & 13 & 12 & 14 & 13 & 5 & 13 & 13 & 10 & 12 & 13 & 16 \\
\hline Surl. contam.-non-cinbl & 0 & 0 & 0 & 0 & 0 & 0 & 0 & 0 & 0 & 0 & 0 & 0 & 0 & 0 \\
\hline Activated & 5 & 5 & 5 & 4 & 4 & 5 & 4 & 2 & 4 & 4 & 3 & 4 & 4 & 5 \\
\hline \begin{tabular}{|ll} 
Copper $\quad$ Non-radioactive \\
\end{tabular} & 5110 & 5110 & 5110 & 4106 & 4059 & 4669 & 4095 & 1676 & 4124 & 4127 & 3241 & 4012 & 4084 & 5142 \\
\hline Surl. conlam.-cleanable & 83 & 83 & 83 & 67 & 66 & 76 & 67 & 27 & 67 & 67 & 53 & 66 & 67 & 84 \\
\hline Surl. conlam.-non-cinbl & 0 & 0 & 0 & $\underline{0}$ & 0 & 0 & 0 & 0 & 0 & 0 & 0 & 0 & 0 & 0 \\
\hline Aclivated & 21 & 21 & 21 & 17 & 17 & 19 & 17 & 7 & 17 & 17 & 13 & 16 & 17 & 21 \\
\hline Non-radioactive & 20 & 20 & 20 & 20 & 20 & 20 & 20 & 20 & 20 & 20 & 20 & 20 & 20 & 20 \\
\hline Surl. contam.-cleanable & 0 & 0 & 0 & 0 & 0 & 0 & 0 & 0 & 0 & 0 & 0 & 0 & 0 & 0 \\
\hline Suri. contam.-non-cinbl & 0 & 0 & 0 & 0 & 0 & 0 & 0 & 0 & 0 & 0 & 0 & 0 & 0 & 0 \\
\hline Actlvated & $\underline{0}$ & 0 & 0 & $=0$ & 0 & 0 & 0 & 0 & 0 & 0 & 0 & 0 & 0 & 0 \\
\hline Stoel \& tron Non-radloactive & 5214 & 5214 & 5214 & 4190 & 4142 & 4764 & 4179 & 1710 & 4208 & 4211 & 3307 & 4094 & 4168 & 5247 \\
\hline Surf. contam.-cieanable & 6987 & 6987 & 6987 & 5614 & 5550 & 6384 & 5599 & 2291 & 5638 & 5643 & 4432 & 5486 & 5585 & 7031 \\
\hline Surf. contam.-non-clnbl & 0 & 0 & 0 & 0 & 0 & 0 & 0 & 0 & 0 & 0 & 0 & 0 & 0 & 0 \\
\hline Activaled & 3650 & 3650 & 3650 & 2933 & 2899 & 3335 & 2925 & 1197 & 2945 & 2948 & 2315 & 2866 & 2917 & 3673 \\
\hline Non-radioactive & 0 & 0 & 0 & 0 & 0 & $\underline{0}$ & 0 & 0 & 0 & 0 & 0 & 0 & 0 & 0 \\
\hline Surf. contam.-cleanablo & 626 & 626 & 626 & 503 & 497 & 572 & 501 & 205 & 505 & 505 & 397 & 491 & 500 & 630 \\
\hline Surf. contam.-non-clnbl & 0 & 0 & 0 & 0 & 0 & 0 & 0 & 0 & 0 & 0 & 0 & 0 & 0 & 0 \\
\hline Activaled & 699 & 699 & 699 & 561 & 555 & 638 & 560 & 229. & 564 & 564 & 443 & 549 & 558 & 703 \\
\hline Zirconium Non-radioactive & 0 & 0 & 0 & 0 & 0 & 0 & 0 & 0 & 0 & .0 & 0 & 0 & 0 & 0 \\
\hline Surf. conlam.-cleanable & 0 & 0 & $\underline{0}$ & 0 & 0 & 0 & 0 & 0 & 0 & 0 & 0 & 0 & 0 & 0 \\
\hline Surl. contam.-non-clnbl & 0 & 0 & 0 & 0 & 0 & 0 & 0 & 0 & 0 & 0 & 0 & 0 & 0 & 0 \\
\hline Activated & 0 & 0 & 0 & 0 & 0 & 0 & 0 & 0 & 0 & 0 & 0 & 0 & 0 & 0 \\
\hline
\end{tabular}




\begin{tabular}{|c|c|c|c|c|c|c|c|c|c|c|c|c|c|c|}
\hline 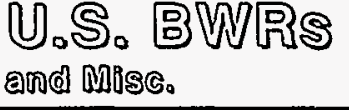 & $\begin{array}{l}\text { Grand } \\
\text { Gulf }\end{array}$ & $\begin{array}{l}\text { Hope } \\
\text { Creok }\end{array}$ & $\begin{array}{c}\text { James A. } \\
\text { Fitzpat. }\end{array}$ & $\begin{array}{l}\text { LaSalle } \\
\text { County } 1\end{array}$ & $\begin{array}{l}\text { LaSalle } \\
\text { County } 2\end{array}$ & $\begin{array}{c}\text { Limerlek } \\
1\end{array}$ & $\begin{array}{c}\text { Limerick } \\
2\end{array}$ & $\begin{array}{c}\text { Millstone } \\
1\end{array}$ & $\begin{array}{l}\text { Montl- } \\
\text { collo }\end{array}$ & $\begin{array}{c}\text { Nine Mllo } \\
\text { Point } 1\end{array}$ & $\begin{array}{l}\text { Nine Mile } \\
\text { Point } 2\end{array}$ & $\begin{array}{l}\text { Oyster } \\
\text { Creok }\end{array}$ & $\begin{array}{c}\text { Peach } \\
\text { Bottom } 2\end{array}$ & $\begin{array}{c}\text { Peach } \\
\text { Bottom } 3\end{array}$ \\
\hline Fuel cycle stage (FCT) & Reactor & Reacior & Reactor & Reacior & Reactor & Reactor & Reaclor & Reactor & Reactor & Reactor & Reactor & Reactor & Reactor & Reaclor \\
\hline Identifier & 359 USAB & 269USAB & 168USAB & 293USAB & 301 USAB & 272 USAB & 216 USAB & 131USAB & 151USAB & $108 \cup S A B$ & 333 USAB & g6USAB & 160USAB & 193USAB \\
\hline Plant type & BWR & BWR & BWR & BWA & BWA & BWR & BWA & BWA & BWA & BWA & BWR & BWR & BWR & BWR \\
\hline Location & USA & USA & USA & LSA & USA & USA & USA & USA & USA & USA & USA & USA & USA & USA \\
\hline Start of aperations & 1985 & 1986 & 1975 & 1984 & 1984 & 1986 & 1990 & 1971 & 1971 & 1969 & 1988 & 1969 & 1974 & 1974 \\
\hline Status & Operating & Operating & Operating & Operaling & Operating & Operating & Operating & Operating & Operating & Operating & Operating & Operating & Operating & Operating \\
\hline Size (MWe) (Net) & 1142 & 1031 & 757 & 1036 & 1036 & 1055 & 1055 & 660 & 536 & 610 & 1080 & 610 & 1100 & 1100 \\
\hline Vendor & $\underline{E}$ & $\Phi$ & $\underline{E}$ & ⿷匚 & ⿷匚 & 王 & ⿷匚 & $\underline{G}$ & $\underline{G}$ & GE & $G$ & $G$ & $E$ & $G$ \\
\hline$A E$ & Bechtel & Bechlel & S\&W & $S \& L$ & S\&L & Bechtel & Bechtel & Ebasco & Bechiel & Utility & S\&W & B\&PVGE & Bechtel & Bechlel \\
\hline Pre or Post TMI & Post & Post & Pre & Post & Post & Post & Post & Pre & Pre & Pre & Post & Pro & Pre & Pre \\
\hline No. of steam turbines & 1 & 1 & 1 & 1 & 1 & 1 & 1 & 1 & 1 & 1 & 1 & 1 & 1 & 1 \\
\hline Cooling & Tower & Tower & Lake & Lake & Lake & & & See & River & Lake & Tower & Cnl to bay & & \\
\hline $\begin{array}{l}\text { Date EOL metal available } \\
Z Z Z Z Z Z\end{array}$ & 2035 & 2036 & 2025 & 2034 & 2034 & 2036 & 2040 & 2021 & $\frac{2021}{\mathbb{Z} Z}$ & 2019 & 2038 & 2019 & $\frac{2024}{\mathbb{2} 2}$ & 2024 \\
\hline \multicolumn{15}{|l|}{ Quantity of metal (tonnes): } \\
\hline Aluminum Non-radioactive & 87 & 82 & 66 & 82 & 82 & 83 & 83 & 61 & 53 & 58 & 84 & 58 & 85 & 85 \\
\hline Surf. contam.-cleanable & 16 & 15 & 12 & 15 & 15 & 16 & 16 & 11 & 10 & 11 & .16 & 11 & 16 & 16 \\
\hline Surf. contam.-non-cinbl & 0 & 0 & 0 & 0 & 0 & 0 & 0 & 0 & 0 & 0 & 0 & 0 & 0 & 0 \\
\hline Activated & 5 & 5 & 4 & 5 & 5 & 5 & 5 & 4 & 3 & 4 & 5 & 4 & 5 & 5 \\
\hline Non-radioactive & 5354 & 5001 & 4070 & 5017 & 5017 & 5078 & 5078 & 3714 & 3233 & 3524 & 5158 & 3524 & 5221 & 5221 \\
\hline Surl. contam.-cleanable & 87 & 82 & 66 & 82 & 82 & 83 & 83 & 61 & 53 & 58 & 84 & 58 & 85 & 85 \\
\hline Surf. contam.-non-cinbl & 0 & 0 & 0 & 0 & 0 & 0 & 0 & 0 & 0 & 0 & 0 & 0 & 0 & 0 \\
\hline Activaled & 22 & 20 & 17 & 20 & 20 & 21 & 21 & 15 & 13 & 14 & 21 & 14 & 21 & 21 \\
\hline Non-radioactive & 20 & 20 & 20 & 20 & 20 & 20 & 20 & 20 & 20 & 20 & 20 & 20 & 20 & 20 \\
\hline Surl. contam.-cleanable & 0 & 0 & 0 & 0 & 0 & 0 & 0 & 0 & 0 & 0 & 0 & 0 & 0 & 0 \\
\hline Surf. contam.-non-cinbl & 0 & 0 & 0 & 0 & 0 & 0 & 0 & 0 & 0 & 0 & 0 & 0 & 0 & 0 \\
\hline Activaled & 0 & 0 & 0 & 0 & 0 & 0 & 0 & 0 & 0 & 0 & 0 & 0 & 0 & 0 \\
\hline \begin{tabular}{|l|} 
Stoel \& Iron Non-radioactive \\
\end{tabular} & 5463 & 5103 & 4153 & 5119 & 5119 & 5182 & 5182 & 3790 & 3299 & 3596 & 5263 & 3596 & 5328 & 5328 \\
\hline Surf. contam.-cleanable & 7320 & 6838 & 5565 & 6860 & 6860 & 6943 & 6943 & 5079 & 4421 & 4819 & 7053 & 4819 & 7140 & 7940 \\
\hline Surl. contam.-non-clnbl & 0 & 0 & 0 & 0 & 0 & 0 & 0 & 0 & 0 & 0 & 0 & 0 & 0 & 0 \\
\hline Aclivated & 3824 & 3572 & 2907 & 3584 & 3584 & 3627 & 3627 & 2653 & 2309 & 2517 & 3684 & 2517 & 3730 & 3730 \\
\hline \begin{tabular}{|ll} 
St. Steel Non-radioactive \\
\end{tabular} & 0 & 0 & 0 & 0 & 0 & 0 & 0 & 0 & 0 & 0 & 0 & 0 & 0 & $\underline{0}$ \\
\hline Surf. contam.-cleanable & 656 & 612 & 498 & 614 & 614 & 622 & 622 & 455 & 396 & 432 & 632 & 432 & 639 & 639 \\
\hline Surl. contam.-non-cinbl & 0 & 0 & 0 & 0 & 0 & 0 & 0 & 0 & 0 & 0 & 0 & 0 & 0 & 0 \\
\hline Activaled & 732 & 684 & 557 & 686 & 686 & 694 & 694 & 508 & 442 & 482 & 705 & 482 & 714 & 714 \\
\hline Zirconium Non-radioactive & 0 & 0 & 0 & 0 & 0 & 0 & 0 & 0 & 0 & 0 & 0 & 0 & 0 & $\underline{0}$ \\
\hline \begin{tabular}{|c|} 
Surl. contam.-cleanable \\
\end{tabular} & 0 & 0 & 0 & 0 & 0 & 0 & 0 & 0 & 0 & 0 & 0 & 0 & 0 & $\underline{0}$ \\
\hline Surl. contam.-non-clnbl & 0 & $\underline{0}$ & 0 & $\underline{0}$ & 0 & 0 & 0 & 0 & 0 & 0 & 0 & 0 & 0 & 0 \\
\hline Aclivated & 0 & 0 & 0 & 0 & 0 & 0 & 0 & 0 & 0 & 0 & 0 & 0 & 0 & 0 \\
\hline
\end{tabular}




\begin{tabular}{|c|c|c|c|c|c|c|c|c|c|c|c|c|}
\hline 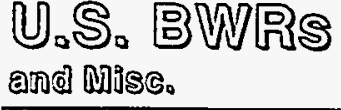 & $\begin{array}{c}\text { Perry } \\
1\end{array}$ & $\begin{array}{c}\text { Perry } \\
2\end{array}$ & Pilgrim & $\begin{array}{l}\text { Quad } \\
\text { Citles } 1\end{array}$ & $\begin{array}{l}\text { Quad } \\
\text { Citles } 2\end{array}$ & $\begin{array}{l}\text { River } \\
\text { Bend }\end{array}$ & $\begin{array}{l}\text { Susque- } \\
\text { hanna } 1\end{array}$ & $\begin{array}{l}\text { Susque- } \\
\text { hanna } 2\end{array}$ & $\begin{array}{l}\text { Vermont } \\
\text { Yankes }\end{array}$ & WNP-2 & $\begin{array}{l}\text { Fort } \\
\text { St. Vrain }\end{array}$ & $\begin{array}{l}\text { Hanford } \\
\qquad N\end{array}$ \\
\hline Fuel cycle stage (FCT) & Reactor & Reacior & Reaclor & Reactor & Reactor & Reactor & Reactor & Reacior & Reactor & Reactor & Reactor & Reactor \\
\hline Identifier & 360 USAB & 516 USAB & 18BUSAB & 154USAB & 155USAB & 374 USAB & 295USAB & 304USAB & 156USAB & 324 USAB & 137USAG & 58 USAG \\
\hline Plant type & BWR & BWR & BWA & BWR & BWR & BWR & BWR & BWR & BWR & BWA & HTGA & LWGR \\
\hline Location & USA & USA & USA & USA & USA & USA & USA & USA & USA & USA & USA & USA \\
\hline Start of operations & 1987 & - & 1972 & 1973 & 1973 & 1986 & 1983 & 1985 & 1972 & 1984 & 1979 & 1966 \\
\hline Status & Operating & Under Cons & Operating & Operating & Operating & Operating & Operating & Operating & Operating & Operating & Shut down & Shut down \\
\hline Size (MWo) (Net) & 1205 & 1205 & 670 & 769 & 769 & 936 & 1032 & 1038 & 504 & 1100 & 330 & 845 \\
\hline Vendor & $\underline{E}$ & $\mathbb{E}$ & $\mathbb{G E}$ & ⿷匚 & $\underline{\Phi}$ & GE & GE & $\mathbb{G}$ & GE & $\Phi$ & CSA & Kaiser \\
\hline AVE & Gilbert & Gilbert & Bechtel & S\&L & S\&L & S\&W & Bechtel & Bechiel & Ebasco & B\&A & Sarg.\&Lun & B\&FVGE \\
\hline Pre or Post TMI & Post & Post & Pro & Pro & Pre & Post & Post & Post & Pre & Post & Pro & Pre \\
\hline No. of steam turbines & 1 & 1 & 1 & 1 & 1 & 1 & 1 & 1 & 1 & 1 & 1 & 1 \\
\hline Cooling & Nat.dratt twr & Natoraft tur & & River & Piver & Tower & Nat.draft twer & Natdrati twr & & Frod ditt twr & Tower & Piver \\
\hline 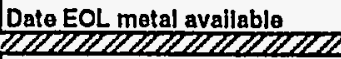 & 2037 & 2053 & $\frac{2022}{\mathbb{Z Z Z}}$ & 2023 & 2023 & 2036 & 2033 & 2035 & 2022 & 2034 & 2029 & 2016 \\
\hline \multicolumn{13}{|l|}{ Quantity of motal (tonnes): } \\
\hline Aluminum Non-radioactive & 91 & 91 & 61 & 67 & 67 & 77 & 82 & 82 & 51 & 85 & 80 & 80 \\
\hline Surf. contam.-cleanable & 17 & 17 & 11 & 13 & 13 & 14 & 15 & 15 & 9 & 16 & 15 & 15 \\
\hline Surl. contam.-non-clnbl & 0 & 0 & 0 & 0 & 0 & 0 & $\underline{0}$ & 0 & 0 & 0 & 0 & 0 \\
\hline Activated & 6 & 6 & 4 & 4 & 4 & 5 & 5 & 5 & 3 & 5 & 5 & 5 \\
\hline Non-radioactive & 5549 & 5549 & 3752 & 4113 & 4113 & 4689 & 5004 & 5023 & 3103 & 5221 & 3900 & 4900 \\
\hline Surf. contam.-cleanable & 91 & 91 & 61 & 67 & 67 & 77 & 82 & 82 & 51 & 85 & 80 & 80 \\
\hline Surl, contam.-non-cinbl & 0 & 0 & 0 & 0 & 0 & 0 & 0 & 0 & 0 & 0 & 0 & 0 \\
\hline Activated & 23 & 23 & 15 & 17 & 17 & 19 & 20 & 21 & 13 & 21 & 20 & 20 \\
\hline Non-radioactive & 20 & 20 & 20 & 20 & 20 & 20 & 20 & 20 & 20 & 20 & 20 & 0 \\
\hline Surl. contam.-cleanable & 0 & 0 & 0 & 0 & 0 & 0 & 0 & 0 & 0 & 0 & 0 & 0 \\
\hline Surf. contam.-non-cinbl & 0 & 0 & 0 & 0 & 0 & 0 & 0 & 0 & 0 & $\underline{0}$ & 0 & 0 \\
\hline Activated & 0 & 0 & 0 & 0 & 0 & 0 & 0 & 0 & 0 & 0 & 0 & 0 \\
\hline Steel \& Iron Non-radioactive & 5662 & 5662 & 3828 & 4197 & 4197 & 4784 & 5106 & 5126 & 3167 & 5328 & 12770 & . 19248 \\
\hline Suri. contam.-cleanable & 7587 & 7587 & 5130 & 5624 & 5624 & 6411 & 6842 & 6869 & 4243 & 7140 & 5630 & 7156 \\
\hline Surf. contam.-non-clnbl & 0 & 0 & 0 & 0 & 0 & $\underline{0}$ & 0 & 0 & 0 & 0 & 0 & 69 \\
\hline Activated & 3963 & 3963 & 2680 & 2938 & 2938 & 3349 & 3574 & 3588 & 2217 & 3730 & 2100 & 581 \\
\hline Non-radioactive & 0 & 0 & 0 & 0 & 0 & 0 & 0 & 0 & 0 & 0 & 60 & 0 \\
\hline Surf. contam.-cleanable & 679 & 679 & 459 & 504 & 504 & 574 & 613 & 615 & 380 & 639 & 900 & 2600 \\
\hline Surl. contam.-non-clnbl & 0 & 0 & 0 & 0 & 0 & 0 & 0 & 0 & 0 & 0 & 0 & 0 \\
\hline Activated & 759 & 759 & 513 & 562 & 562 & 641 & 684 & 687 & 424 & 714 & 165 & 406 \\
\hline Zirconium Non-radioactive & 0 & 0 & 0 & 0 & 0 & 0 & 0 & 0 & 0 & 0 & 0 & 0 \\
\hline Surl. contam.-cleanable & 0 & 0 & 0 & 0 & 0 & 0 & 0 & 0 & 0 & 0 & 0 & 0 \\
\hline Surl. contam.-non-clnbl & 0 & 0 & 0 & 0 & 0 & 0 & 0 & 0 & 0 & 0 & 0 & 0 \\
\hline Activated & 0 & 0 & 0 & 0 & 0 & 0 & 0 & 0 & 0 & 0 & 0 & 100 \\
\hline
\end{tabular}




\begin{tabular}{|c|c|c|c|c|c|c|c|c|c|c|c|c|}
\hline (U).S. DWD哟 & $\begin{array}{l}\text { Alvin W. } \\
\text { Voglle } 1\end{array}$ & $\begin{array}{l}\text { Alvin W. } \\
\text { Vogtle } 2\end{array}$ & $\begin{array}{l}\text { Arkansas } \\
\text { Nuclear } 1\end{array}$ & $\begin{array}{l}\text { Arkansas } \\
\text { Nuclear } 2 \\
\end{array}$ & $\begin{array}{l}\text { Beaver } \\
\text { Valloy } 1 \\
\end{array}$ & $\begin{array}{l}\text { Beaver } \\
\text { Valley } 2 \\
\end{array}$ & $\begin{array}{c}\text { Bellefonte } \\
1 \\
\end{array}$ & $\begin{array}{c}\text { Beltofonto } \\
2 \\
\end{array}$ & $\begin{array}{c}\text { Braldwood } \\
1 \\
\end{array}$ & $\begin{array}{c}\text { Braldwood } \\
2 \\
\end{array}$ & $\begin{array}{c}\text { Byron } \\
1 \\
\end{array}$ & $\begin{array}{c}\text { Byron } \\
2 \\
\end{array}$ \\
\hline Fuel cycle slage (FCT) & Reactor & Reactor & Reactor & Reactor & Reactor & Reacior & Reacior & Reactor & Peactor & Reactor & Peactor & Reactor \\
\hline Identifier & 334USAP & 520USAP & 197USAP & 288USAP & 205USAP & 327USAP & 294USAP & 298USAP & 424USAP & 440USAP & 326USAP & 435USAP \\
\hline Plant type & PWR & PWR & PWR & PWR & PWR & PWR & PWR & PWR & PWR & PWR & PWR & PWR \\
\hline Location & USA & USA & USA & USA & USA & USA & USA & USA & USA & USA & USA & USA \\
\hline Start of oparations & 1987 & 1989 & 1974 & 1980 & 1976 & 1987 & & & 1988 & 1988 & 1985 & 1987 \\
\hline Status & Operating & Operalling & Operating & Operating & Operaling & Operating & Under Const & Under Const & Operating & Operating & Operating & Operating \\
\hline Size (MWe) (Not) & 1100 & 1097 & 836 & 858 & 810 & 833 . & 1213 & 1213 & 1120 & 1120 & 1105 & 1105 \\
\hline Vendor & Wostinghouso & Wastinghouse & $B \& W$ & C-E & Westinghouso & Wostinghouse & $B \& W$ & $B \& W$ & Westinghouse & Wostinghouse & Westinghouse & Westinghouse \\
\hline$A E$ & Util.Bechtol & Util.Bochiol & Bechiol & Bechiel & S\&W & S\&W & Utillity & Uillity & S\&L & $S \& L$ & S\&L & S\&L \\
\hline Pre or Post TMI & Post & Post & Pre & Post & Pro. & Post & Post & Post & Post & Post & Post & Post \\
\hline No. of steam turbines & 1 & 1 & 1 & 1 & 1 & 1 & 1 & 1 & 1 & 1 & 1 & 1 \\
\hline Cooling & Tower & & Lake & Tower & River & & & & Lake & Lake & Tower & Tower \\
\hline Date EOL motal available & 2037 & 2039 & 2024 & 2030 & 2026 & 2037 & 2053 & 2053 & 2038 & 2038 & 2035 & 2037 \\
\hline \multicolumn{13}{|l|}{ Quantity of motal (tonnes): } \\
\hline Aluminum Non-radioactive & 85 & 85 & 71 & 72 & 70 & 71 & 91 & 91 & 86 & 86 & 86 & 86 \\
\hline Surf. contam.-cleanable & 16 & 16 & 13 & 14 & 13 & 13 & 17 & 17 & 16 & 16 & 16 & 16 \\
\hline Surf. contam.-non-cinbl & 0 & 0 & 0 & 0 & 0 & 0 & of & 0 & 0 & 0 & 0 & 0 \\
\hline Aclivaled & 5 & 5 & 4 & 5 & 4 & 4 & 6 & 6 & 5 & 5 & 5 & 5 \\
\hline Non-radioactive & 5221 & 5212 & 4348 & 4424 & 4258 & .4338 & 5573 & 5573 & 5285 & 5285 & 5237 & 5237 \\
\hline Surf. contam.-cleanable & 85 & 85 & 71 & 72 & 70 & 71 & 91 & 91 & 86 & 86 & 86 & 86 \\
\hline Surf. contam.-non-cinbl & 0 & 0 & 0 & 0 & 0 & 0 & 0 & 0 & 0 & 0 & 0 & 0 \\
\hline Activaled & 21 & 21 & 18 & 18 & 17 & 18 & 23 & 23 & 22 & 22 & 21 & 21 \\
\hline Non-radioactive & 20 & 20 & 20 & 20 & 20 & 20 & 20 & 20 & 20 & 20 & 20 & 20 \\
\hline Surl. contam. cleanable. & 0 & 0 & 0 & 0 & 0 & 0 & 0 & 0 & 0 & 0 & 0 & 0 \\
\hline Surl. contam.-non-clnbl & 0 & 0 & 0 & 0 & 0 & 0 & 0 & 0 & 0 & 0 & 0 & $\underline{0}$ \\
\hline Activaled & 0 & 0 & 0 & 0 & 0 & 0 & 0 & 0 & 0 & 요 & 0 & 0 \\
\hline Sleel \& Iron Non-radioactive & 8834 & 8818 & 7357 & 7485 & 7204 & 7339 & 9429 & 9429 & 8941 & 8941 & 8861 & 8861 \\
\hline Surl. contam.-cloanable & 7140 & 7127 & 5946 & 6050 & 5822 & 5932 & 7620 & 7620 & 7226 & 7226 & 7161 & 7161 \\
\hline Surf. conlam.-non-clnbl & 0 & 0 & 0 & 0 & 0 & 0 & 0 & 0 & 0 & 0 & 0 & 0 \\
\hline Activalod & 3133 & 3127 & 2609 & 2655 & 2555 & 2603 & 3344 & 3344 & 3171 & 3171 & 3142 & 3142 \\
\hline St. Steel Non-radioactive & 0 & 0 & 0 & 0 & 0 & 0 & 0 & 0 & 0 & 0 & 0 & $\underline{0}$ \\
\hline Surl. contam.-cleanable & 959 & 957 & 799 & 813 & 782 & 797 & 1024 & 1024 & 971 & 971 & 962 & 962 \\
\hline Surl. contam.-non-cinbl & 320 & 319 & 266 & 271 & 261 & 266 & 341 & 341 & 324 & 324 & 321 & 321 \\
\hline Activaled & 714 & 713 & 595 & 605 & 582 & 593 & 762 & 762 & 723 & 723 & 716 & 716 \\
\hline Zirconium Non-radioactive & 0 & 0 & $\underline{0}$ & 0 & $=0$ & 0 & 0 & 0 & 0 & 요 & 0 & $\underline{0}$ \\
\hline Surl. contarn.-cleanable & 0 & 0 & 0 & $\underline{0}$ & 0 & 0 & 0 & 0 & 요 & of & 0 & $\underline{0}$ \\
\hline Surt. contam.-non-clnbl & 0 & 0 & 0 & 0 & 0 & 0 & 0 & 0 & 0 & 0 & 0 & $\underline{0}$ \\
\hline Aclivated & 0 & 0 & 0 & 0 & 0 & 0 & 0 & 0 & 0 & 0. & 0 & 0 \\
\hline
\end{tabular}




\begin{tabular}{|c|c|c|c|c|c|c|c|c|c|c|c|c|}
\hline U.S。 PWD哟 & Callaway & $\begin{array}{l}\text { Calvert } \\
\text { Cllfts 1 }\end{array}$ & $\begin{array}{l}\text { Calvert } \\
\text { Cilffs } 2\end{array}$ & $\begin{array}{c}\text { Calawba } \\
1 \\
\end{array}$ & $\begin{array}{c}\text { Catawba } \\
2 \\
\end{array}$ & $\begin{array}{c}\text { Comanche } \\
\text { Peak1 } \\
\end{array}$ & $\begin{array}{c}\text { Comancho } \\
\text { Peak } 2 \\
\end{array}$ & $\begin{array}{l}\text { Crystal } \\
\text { River } 3 \\
\end{array}$ & $\begin{array}{l}\text { Davis- } \\
\text { Besse }\end{array}$ & $\begin{array}{c}\text { Dlablo } \\
\text { Canyon } 1 \\
\end{array}$ & $\begin{array}{c}\text { Dlablo } \\
\text { Canyon } 2 \\
\end{array}$ & $\begin{array}{c}\text { Donald C. } \\
\text { Cooky }\end{array}$ \\
\hline Fuel cycle stage (FCT) & Reactor & Reacior & Reacior & Reacior & Reacior & Reactor & Reactor & Reactor & Reactor & Reacior & Reaclor & Reactor \\
\hline Identifier & 427USAP & I99USAP & 206USAP & 299USAP & 302USAP & 358USAP & 367 USAP & 201USAP & 241USAP & 202USAP & 243USAP & 200USAP \\
\hline Plant type & PWR & PWR & PWR & PWR & PWR & PWR & PWR & PWR & PWR & PWR & PWR & PWR \\
\hline Location & USA & USA & USA & USA & USA & USA & USA & USA & USA & USA & USA & USA \\
\hline Start of operations & 1985 & 1975 & 1977 & 1985 & 1986 & 1990 & & 1977 & 1978 & 1985 & 1986 & 1975 \\
\hline Status & Operating & Operating & Operating & Operating & Operating & Operating & Under Const & Operating & Operating & Operating & Operating & Operating \\
\hline Size (MWo) (Net) & 1125 & 825 & 825 & 1129 & 1129 & 1150 & 1150 & 821 & 877 & 1073 & 1087 & 1020 \\
\hline Vendor & Westinghouse & $C-E$ & C.E & Westinghouse & Wostinghouse & Wastinghouse & Westinghouse & $B \& W$ & $B \& W$ & Wostinghouso & Westinghouse & Westinghouse \\
\hline AIE & Bechtel & Bechtel & Bechtel & Utility & Utility & Glbbs \& Hill & Gibbs \& Hill & Gilbert & Bechiel & Utility & Utility & Uilitity \\
\hline Pre or Post TMI & Post & Pre & Pre & Post & Post & Post & Post & Pre & Pro & Post & Post & Pre \\
\hline No. of steam turbines & 1 & 1 & 1 & 1 & 1 & 1 & 1 & 1 & 1 & 1 & 1 & 1 \\
\hline Cooling & Tower & Bay & & & & Lake & Lake & Sea & Nat.dratt tower & Sea & Sea & River \\
\hline Date EOL motal available & 2035 & 2025 & 2027 & 2035 & 2036 & 2040 & 2053 & 2027 & 2028 & 2035 & 2036 & 2025 \\
\hline Quantity of metal (tonnes): & & & & & & $\cdots$ & & & & & & \\
\hline Aluminum Non-radioactive & 87 & 70 & 70 & 87 & 87 & 88 & 88 & 70 & 73 & 84 & 85 & 81 \\
\hline Surl. contam.-cleanable & 16 & 13 & 13 & 16 & 16 & 16 & 16 & 13 & 14 & 16 & 16 & 15 \\
\hline Surl. contam.-non-clnbl & 0 & $\underline{0}$ & 0 & $\underline{0}$ & 0 & 0 & 0 & 0 & 0 & 0 & 0 & 0 \\
\hline Activatod & 5 & 4 & 4 & 5 & 5 & 5 & 5 & 4 & 5 & 5 & 5 & 5 \\
\hline Non-radioactive & 5300 & 4310 & 4310 & 5313 & 5313 & 5379 & 5379 & 4298 & 4489 & 5136 & 5180 & 4965 \\
\hline Surt. contam.-cleanable & 87 & 70 & 70 & 87 & 87 & 88 & 88 & 70 & 73 & 84 & 85 & 81 \\
\hline Surf. contam.-non-cinbl & 0 & 0 & 0 & 0 & 0 & 0 & 0 & 0 & 0 & 0 & 0 & 0 \\
\hline Activated & 22 & 18 & 18 & 22 & 22 & 22 & 22 & 18 & 18 & 21 & 21 & 20 \\
\hline Non-radioaclive & 20 & 20 & 20 & 20 & 20 & 20 & 20 & 20 & 20 & 20 & 20 & 20 \\
\hline Surl. contam.-cleanable & 0 & 0 & 0 & 0 & 0 & 0 & 0 & 0 & 0 & 0 & 0 & 0 \\
\hline Suri. contam.-non-c|nbl & 0 & 0 & 0 & $\underline{0}$ & 0 & 0 & 0 & 0 & 0 & 0 & 0 & $\cdot 0$ \\
\hline Activated & 0 & 0 & 0 & 0 & 0 & 0 & 0 & 0 & 0 & 0 & 0 & 0 \\
\hline \begin{tabular}{|l} 
Steel \& Iron Non-radioaclive \\
\end{tabular} & 8967 & 7292 & 7292 & 8988 & 8988 & 9100 & 9100 & 7269 & 7595 & 8689 & 8764 & 8400 \\
\hline Surl. contam.-cloanabla & 7247 & 5894 & 5894 & 7264 & 7264 & 7354 & 7354 & 5874 & 6139 & 7022 & 7083 & 6789 \\
\hline Surl. contam.-non-clnbl & 0 & 0 & 0 & 0 & 0 & 0 & 0 & 0 & 0 & 0 & 0 & 0 \\
\hline Activated & 3180 & 2586 & 2586 & 3188 & 3188 & 3227 & 3227 & 2578 & 2694 & 3081 & 3108 & 2979 \\
\hline \begin{tabular}{|ll} 
St. Steel Non-radioactive \\
\end{tabular} & 0 & 0 & 0 & 0 & 0 & 0 & 0 & 0 & 0 & 0 & 0 & 0 \\
\hline Surl. conlam.-cleanable & 974 & 792 & 792 & 976 & 976 & 988 & 988 & 789 & 825 & 943 & 951 & 912 \\
\hline Surl. contam.-non-cinbl & 325 & 264 & 264 & 325 & 325 & 329 & 329 & 263 & 275 & 314 & 317 & 304 \\
\hline Aclivaled & 725 & 589 & 589 & 726 & 726 & 735 & 735 & 587 & 614 & 702 & 708 & 679 \\
\hline Zirconium Non-radioactive & 0 & $\underline{0}$ & 0 & $\underline{0}$ & 0 & 0 & 0 & 0 & 0 & 0 & 0 & 0 \\
\hline Surl. contam.-cleanable & 0 & 0 & 0 & 0 & 0 & 0 & 0 & 0 & 0 & 0 & 0 & 0 \\
\hline Surl. contam.-non-clnbl & 0 & 0 & 0 & 0 & 0 & 0 & 0 & 0 & 0 & 0 & 0 & 0 \\
\hline Activatod & 0 & 0 & 0 & 0 & 0 & 0 & 0 & 0 & 0 & 0 & 0 & 0 \\
\hline
\end{tabular}




\begin{tabular}{|c|c|c|c|c|c|c|c|c|c|c|c|c|}
\hline U.S. DWW & $\begin{array}{c}\text { Donald C. } \\
\text { Cook } 2\end{array}$ & $\begin{array}{c}\text { Fort } \\
\text { Calhoun }\end{array}$ & $\begin{array}{c}\text { Haddam } \\
\text { Neck }\end{array}$ & $\begin{array}{l}\text { Indlan } \\
\text { Point } 1\end{array}$ & $\begin{array}{l}\text { Indlan } \\
\text { Point } 2\end{array}$ & $\begin{array}{l}\text { Indlan } \\
\text { Polnt } 3\end{array}$ & $\begin{array}{c}\text { Joseph M. } \\
\text { Farley } 1 \\
\end{array}$ & $\begin{array}{c}\text { Joseph M. } \\
\text { Farley } 2 \\
\end{array}$ & Kowaunes & $\begin{array}{l}\text { Malno } \\
\text { Yankeo }\end{array}$ & $\begin{array}{c}\text { Moculiro } \\
1 \\
\end{array}$ & $\begin{array}{c}\text { MeGuire } \\
2 \\
\end{array}$ \\
\hline Fuel cycle stage (FCD) & Reactor & Reactor & Reactor & Reactor & Reactor & Reactor & Reactor & Reacior & Reactor & Reactor & Reactor & Reactor \\
\hline Identifier & 20BUSAP & 166USAP & 94USAP & 24USAP & 135USAP & 234 USAP & 26IUSAP & 291 USAP & 192USAP & & & \\
\hline Plant type & PWR & PWR & PWR & PWA & PWA & PWR & PWR & PWR & PWR & PWR & PWR & PWR \\
\hline Location & USA & USA & USA & USA & LSA & USA & USA & USA & USA & USA & USA & USA \\
\hline Start of operations & 1978 & 1973 & 1968 & 1963 & 1974 & 1976 & 1977 & 1981 & 1974 & 1972 & 1981 & 1984 \\
\hline Status & Operating & Operating & Operating & Shut down & Operating & Operating & Operating & Operating & Operating & Operating & Operating & Operating \\
\hline Size (MWe) (Not) & 1060 & 478 & 590 & 257 & 970 & 965 & 814 & 824 & 503 & 840 & 1129 & 1129 \\
\hline Vendor & Westinghouse & C-E & Westinghouse & & Wostinghouse & Westinghouse & Wostinghouse & Westinghouse & Westinghouse & C.E & Westinghouse & Westinghouse \\
\hline ANE & Utility & Gibbs \& Hill & S\&W & & UE \& C & UE \& C & Uill JBchtl & Uiti/Bchll & Fluor & S\&W & Utility & Utility \\
\hline Pre or Post TMI & Pre & Pre & Pre & Pre & Pre & Pro & Pre & Post & Pre & Pre & Post & Post \\
\hline No. of steam turbines & 1 & 1 & & 1 & 1 & 1 & 1 & 1. & 1 & & & \\
\hline Cooling & Lake & & River & & River & & Forcod ditt twr & Forcod ditt thr & & & Lake & \\
\hline Date EOL metal available & 2028 & 2023 & 2018 & 2013 & 2024 & 2026 & 2027 & 2031 & 2024 & 2022 & 2031 & 2034 \\
\hline \multicolumn{13}{|l|}{ Quantity of melal (tonnes): } \\
\hline Aluminum Non-radioaclive & 83 & 49 & 56 & 32 & 78 & 78 & 70 & 70 & 51 & 71 & 87 & 87 \\
\hline Surt. contam.-cloanable & 16 & 9 & 11 & 6 & 15 & 15 & 13 & 13 & 9 & 13 & 16 & 16 \\
\hline Surl. contarn.-non-clnbl & 0 & 0 & 0 & 0 & 0 & 0 & 0 & 0 & 0 & D. & 0 & $\underline{0}$ \\
\hline Activated & 5 & 3 & 4 & 2 & 5 & 5 & 4 & 4 & 3 & 4 & 5 & 5 \\
\hline Copper Non-radioactive & 5094 & 2996 & 3447 & 1981 & 4802 & 4785 & 4272 & 4307 & 3099 & 4362 & 5313 & 5313 \\
\hline Surf. contam.-cleanable & 83 & 49 & 56 & 32 & 78 & 78 & 70 & 70 & 51 & 71 & 87 & 87 \\
\hline Surf. contam.-non-cinbl & 0 & 0 & of & 0 & 0 & 0 & 0 & 0 & 0 & 0 & 0 & 0 \\
\hline Activated & 21 & 12 & 14 & 8 & 20 & 20 & 17 & 18 & 13 & 18 & 22 & 22 \\
\hline Non-radioactive & 20 & 20 & 20 & 20 & 20 & 20 & 20 & 20 & 20 & 20 & 20 & 20 \\
\hline Surf. contam.-cleanable & 0 & 0 & 0 & 0 & 0 & 0 & 0 & 0 & 0 & 0 & 0 & 0 \\
\hline Surl. contam.-non-clnb! & 0 & 0 & 0 & 0 & 0 & 0 & 0 & 0 & 0 & 0 & 0 & 0 \\
\hline Activalod & 0 & a & 0 & 0 & 0 & 0 & 0 & 0 & 0 & 0 & 0 & 0 \\
\hline Steel \& Iron Non-radioactive & 8618 & 5068 & 5832 & 3351 & 8123 & 8095 & 7227 & 7286 & 5243 & 7380 & 8988 & 8988 \\
\hline Surf. contam.-cleanable & 6965 & 4096 & 4713 & 2708 & 6565 & 6543 & 5841 & 5889 & 4238 & 5965 & 7264 & 7264 \\
\hline Surf. contam.-non-cinbl & 0 & 0 & 0 & 0 & 0 & 0 & 0 & 0 & 0 & 0 & 0 & 0 \\
\hline Aclivaled & 3056 & 1797 & 2068 & 1188 & 2881 & 2871 & 2563 & 2584 & 1859 & 2617 & 3188 & 3188 \\
\hline St. Steel Non-radioaclive & 0 & 0 & 0 & 0 & 0 & 0 & 0 & 0 & 0 & 0 & 0 & 0 \\
\hline Surf. contam.-cleanable & 936 & 550 & 633 & 364 & 882 & 879 & 785 & 791 & 569 & 801 & 976 & 976 \\
\hline Surl. contam.-non-cinbl & 312 & 183 & 211 & 121 & 294 & 293 & 262 & 264 & 190 & 267 & 325 & 325 \\
\hline Activated & 697 & 410 & 471 & 271 & 657 & 654 & 584 & 589 & 424 & 596 & 726 & 726 \\
\hline Zirconium Non-radioactive & 0 & 0 & 0 & 0 & 0 & 0 & 0 & 0 & 0 & 0 & 0 & 0 \\
\hline Surl. contam.-cleanable & 0 & D. & 0 & 0 & 0 & 0 & 0 & 0 & 0 & 0 & 0 & 0 \\
\hline Surl. contam.non-clnbl & 0 & 0 & 0 & 0 & 0 & 0 & 0 & 0 & 0 & 0 & 0 & 0 \\
\hline Activated & 0 & 0 & 0 & 0 & 0 & 0 & 0 & 0 & 0 & 0 & 0 & 0 \\
\hline
\end{tabular}




\begin{tabular}{|c|c|c|c|c|c|c|c|c|c|c|c|c|}
\hline U].S。 & $\begin{array}{c}\text { Millstono } \\
2 \\
\end{array}$ & $\begin{array}{c}\text { Mlilstone } \\
3 \\
\end{array}$ & $\begin{array}{l}\text { North } \\
\text { Anna } 1 \\
\end{array}$ & $\begin{array}{c}\text { North } \\
\text { Anna } 2 \\
\end{array}$ & $\begin{array}{c}\text { Ocones } \\
1 \\
\end{array}$ & $\begin{array}{c}\text { Ocones } \\
2 \\
\end{array}$ & $\begin{array}{c}\text { Oconee } \\
3 \\
\end{array}$ & Pallsades & $\begin{array}{c}\text { Palo } \\
\text { Verde } 1\end{array}$ & $\begin{array}{c}\text { Palo } \\
\text { Verde } 2\end{array}$ & $\begin{array}{c}\text { Palo } \\
\text { Verde } 3\end{array}$ & $\begin{array}{c}\text { Point } \\
\text { Beach } 1\end{array}$ \\
\hline Fuel cycle stago (FCT) & Reactor & Reactor & Reacior & Reactor & Reactor & Reaclor & Reactor & Reactor & Reactor & Reactor & Reactor & Reacior \\
\hline Identifier & 239USAP & 528USAP & 207USAP & 209USAP & 158USAP & 163USAP & 196USAP & 153USAP & 431USAP & 44BUSAP & 461USAP & 130USAP \\
\hline Plant type & PWR & PWR & PWR & PWR & PWR & PWR & PWR & PWR & PWR & PWR & PWR & PWR \\
\hline Location & USA & USA & USA & USA & USA & USA & USA & USA & USA & USA & USA & USA \\
\hline Start of operations & 1975 & 1986 & 1978 & 1980 & 1973 & 1974 & 1974 & 1971 & 1986 & 1986 & 1988 & 1970 \\
\hline Status & Operating & Operating & Operating & Operating & Operating & Operating & Operating & Operating & Operating & Operating & Operating & Operating \\
\hline Size (MWe) (Net) & 862 & 1146 & 911 & 909 & 846 & 846 & 846 & 768 & 1221 & 1221 & 1221 & 485 \\
\hline Vendor & $C \cdot E$ & Westinghouse & Westinghouse & Westinghouse & $B \& W$ & $B \& W$ & $B \& W$ & $C-E$ & C-E & C-E & C.E & Wostinghouse \\
\hline$A E$ & Bechtel & S\&W & S\&W & S\&W & Util/Bchil & Util/Bcht1 & Util/Bchtl & Bechtel & Bechtel & Bechtel & Bechitel & Bechtel \\
\hline Pre or Post TMI & Pre & Post & Pre & Post & Pre & Pre & Pre & Pre & Post & Post & Post & Pre \\
\hline No. of steam turbines & 1 & 1 & 1 & 1 & 1 & 1 & 1 & 1 & 1 & 1 & 1 & 1 \\
\hline Cooling & Sen & Sen & Bay & River & & & & Tower & Tower & Tower & Tower & Lake \\
\hline Date EOL metal available & 2025 & 2036 & 2028 & 2030 & 2023 & 2024 & 2024 & 2021 & 2036 & 2036 & 2038 & 2020 \\
\hline \multicolumn{13}{|l|}{ Quantity of metal (tonnes): } \\
\hline Aluminum Non-radioactive & 72 & 88 & 75 & 75 & 72 & 72 & 72 & 67 & 91 & 91 & 91 & 49 \\
\hline Suri. contam.-cleanable & 14 & 16 & 14 & 14 & 13 & 13 & 13 & 13 & 17 & 17 & 17 & 9 \\
\hline Surl. contam.-non-clnbl & 0 & 0 & 0 & 0 & 0 & 0 & 0 & 0 & 0 & 0 & 0 & 0 \\
\hline Activated & 5 & 5 & 5 & 5 & 4 & 4 & 4 & 4 & 6 & 6 & 6 & 3 \\
\hline Non-radioactive & .4438 & 5366 & 4605 & 4598 & 4383 & 4383 & 4383 & 4109 & 5598 & 5598 & 5598 & 3025 \\
\hline Surf. contam.-cleanable & 72 & 88 & 75 & 75 & 72 & 72 & 72 & 67 & 91 & 91. & 91 & 49 \\
\hline Surl. contam.-non-cinbl & $\underline{0}$ & $\underline{0}$ & 0 & 0 & 0 & 0 & 0 & 0 & 0 & 0 & 0 & 0 \\
\hline Activatod & 18 & 22 & 19 & 19 & 18 & 18 & 18 & 17 & 23 & 23 & 23 & 12 \\
\hline Non-radioactive & 20 & 20 & 20 & 20 & 20 & 20 & 20 & 20 & 20 & 20 & 20 & 20 \\
\hline Surf. contam.-cleanable & 0 & 0 & 0 & 0 & 0 & 0 & 0 & 0 & 0 & 0 & 0 & 0 \\
\hline Surf. contam.-non-clnbl & 0 & 0 & $\underline{0}$ & 0 & 0 & 0 & 0 & 0 & 0 & 0 & 0 & 0 \\
\hline Activated & 0 & 0 & 0 & 0 & 0 & 0 & 0 & 0 & 0 & 0 & 0 & 0 \\
\hline Steol \& Iron Non-radioactive & 7509 & 9078 & 7791 & 7779 & 7415 & 7415 & 7415 & 6952 & 9470 & 9470 & 9470 & 5117 \\
\hline Surf. contam.-cleanable & 6068 & 7337 & 6296 & 6287 & 5993 & 5993 & 5993 & 5619 & 7654 & 7654 & 7654 & 4136 \\
\hline Surf. contam.-non-cinbl & 0 & 0 & 0 & 0 & 0 & 0 & 0 & 0 & $\underline{0}$ & 0 & 0 & 0 \\
\hline Activated & 2663 & 3220 & 2763 & 2759 & 2630 & 2630 & 2630 & 2466 & 3359 & 3359 & 3359 & 1815 \\
\hline Non-radioaclive & 0 & 0. & 0 & 0 & 0 & 0 & 0 & 0 & 0 & 0 & 0 & 0 \\
\hline Surl. contam.-cleanable & 815 & 986 & 846 & 845 & 805 & 805. & 805 & 755 & 1028 & 1028 & 1028 & 556 \\
\hline Surl. contam.-non-clnbl & 272 & 329 & 282 & 282 & 268 & 268 & 268 & 252 & 343 & 343 & 343 & 185 \\
\hline Aclivated & 607 & 734 & 630 & 629 & 599 & 599 & 599 & 562 & 765 & 765 & 765 & 414 \\
\hline Zirconium Non-radioaclive & 0 & 0 & 0 & 0 & 0 & 0 & 0 & 0 & 0 & 0 & 0 & 0 \\
\hline Surl. contam.-cleanable & 0 & 0 & 0 & 0 & 0 & 0 & 0 & 0 & 0 & 0 & 0 & $\underline{0}$ \\
\hline Surf, contam.-non-clnbl & 0 & 0 & 0 & 0 & 0 & 0 & 0 & 0 & 0 & 0 & 0 & 0 \\
\hline Activated & 0 & 0 & 0 & 0 & 0 & 0 & 0 & 0 & 0 & 0 & 0 & 0 \\
\hline
\end{tabular}




\begin{tabular}{|c|c|c|c|c|c|c|c|c|c|c|c|c|}
\hline U一, & $\begin{array}{c}\text { Point } \\
\text { Beach } 2\end{array}$ & $\begin{array}{l}\text { Prairio } \\
\text { Island } 1\end{array}$ & $\begin{array}{l}\text { Prairie } \\
\text { Island } 2\end{array}$ & $\begin{array}{c}\text { Pancho } \\
\text { Seco } \\
\end{array}$ & $\begin{array}{c}\text { Robinsan } \\
2 \\
\end{array}$ & $\begin{array}{l}\text { R.E. } \\
\text { Ginna } \\
\end{array}$ & $\begin{array}{c}\text { Saint } \\
\text { Lucie } 1 \\
\end{array}$ & $\begin{array}{c}\text { Saint } \\
\text { Lucie } 2 \\
\end{array}$ & $\begin{array}{c}\text { Salem } \\
1 \\
\end{array}$ & $\begin{array}{c}\text { Salem } \\
2 \\
\end{array}$ & $\begin{array}{c}\text { San } \\
\text { Onofre } 1 \\
\end{array}$ & $\begin{array}{c}\text { San } \\
\text { Onolro } 2 \\
\end{array}$ \\
\hline Fuel cycle slage (FCD & Reactor & Reactor & Reactor & Reactor & Reactor & Reactor & Reactor & Reactor & Reactor & Reactor & Peactor & Reactor \\
\hline Identilier & 157USAP & 191USAP & 198USAP & 167USAP & 150USAP & 128USAP & 242USAP & 375USAP & 169USAP & 170USAP & 95USAP & 296USAP \\
\hline Plant type & PWR & PWR & PWR & PWR & PWA & PWR & PWR & PWR & PWR & PWR & PWR & PWA \\
\hline Location & USA & USA & USA & USA & USA & USA & LSA & USA & USA & USA & USA & USA \\
\hline Start of operallons & 1972 & 1973 & 1974 & 1975 & 1971 & 1970 & 1976 & 1983 & 1977 & 1981 & 1968 & 1983 \\
\hline Status & Operating & Operating & Operating & Shur down & Operating & Operaling & Operating & Operating & Operating & Operating & Operating & Operating \\
\hline Size (MWe) (Net) & 485 & 503 & 500 & 913 & 683 & 470 & 839 & 839 & 1106 & 1106 & 436 & 1070 \\
\hline Vendor & Westinghouse & Wostinghouse & Westinghouse & & Wostinghouse & Wostinghouse & C-E & C-E & Wostinghouse & Westinghouse & Westinghouse & C-E \\
\hline ANE & Bechitel & Fluor & Fluor & & Ebasoo & Gillbert & Ebasco & Ebasco & Uilility & Utilliy & Bechtel & Bechitel \\
\hline Pre or Post TMI & Pro & Pre & Pre & Pre & Pre & Pre & Pre & Post & Pre & Post & Pre & Post \\
\hline No. of steam turbines & 1 & 1 & 1 & 1 & 1 & 1 & 1 & 1 & 1 & 1 & & 1 \\
\hline Cooling & Lake & & & Natdratilower & & Lake & Seg & Sea & River & River & Sen & Seg \\
\hline Date EOL metal available & 2022 & 2023 & 2024 & 2025 & 2021 & 2020 & 2026 & 2033 & 2027 & $\frac{2031}{211021}$ & 2018 & 2033 \\
\hline \multicolumn{13}{|l|}{ Quantity of metal (lonnes): } \\
\hline Aluminum Non-radioactive & 49 & 51 & 50 & 75 & 62 & 48 & 71 & 71 & 86 & 86 & 46 & 84 \\
\hline Surl. contam.-cleanable & 9 & 9 & 9 & 14 & 12 & 9 & 13 & 13 & 16 & 16 & 9 & 16 \\
\hline Surl. contam.-non-clnbl & 0 & 0 & O & 0 & 0 & 0 & 0 & 요 & 0 & 0 & 0 & 0 \\
\hline Activated & 3 & 3 & 3 & 5 & 4 & 3 & 4 & 4 & 5 & 5 & 3 & 5 \\
\hline Non-radioaclive & 3025 & 3099 & 3087 & 4612 & 3800 & 2962 & 4359 & 4359 & 5240 & 5240 & 2817 & 5126 \\
\hline Surl. contam.-cleanable & 49 & 51 & 50 & 75 & 62 & 48 & 71 & 71 & 86 & 86 & 46 & 84 \\
\hline Surf. contam.-non-clnbl & 0 & 0 & 0 & 0 & 0 & 0 & 0 & 0 & 0 & 0 & 의 & 0 \\
\hline Activated & 12 & 13 & 13 & 19 & 16 & 12 & 18 & 18 & 21 & 21 & 11 & 21 \\
\hline Non-radioactive & 20 & 20 & 20 & 20 & 20 & 20 & 20 & 20 & 20 & 20 & 20 & 20 \\
\hline Surf. contam.cleanable & 0 & 0 & 0 & 0 & 0 & 0 & 0 & 0 & 0 & 0. & of & 0 \\
\hline Surf. contam.-non-cinbl & 0 & 0 & 0 & 0 & 0 & of & 0. & 0 & 0 & 0 & 0 & 0 \\
\hline Activaled & 0 & 0 & 0 & 0 & 0 & 0 & 0 & a) & 0 & 0 & of & 0 \\
\hline Steel \& Iron Non-radioactive & 5117 & 5243 & 5222 & 7802 & 6429 & 5011 & 7374 & 7374 & 8866 & 8866 & 4767 & 8672 \\
\hline Surf. contam.-cleanable & 4136 & 4238 & 4221 & 6306 & 5196 & 4050 & 5960 & 5960 & 7165 & 7165 & 3852 & 7009 \\
\hline Surf. contam.-non-cinbl & 0 & 0 & D & 0 & 0 & 0 & 0 & 0 & 0 & 0 & 0 & 0 \\
\hline Activated & 1815 & 1859 & 1852 & 2767 & 2280 & 1777 & 2615 & 2615 & 3144 & 3144 & 1690 & 3076 \\
\hline St. Sleel Non-radioactive & 0 & 0 & 0 & 0 & 0 & 0 & 0 & 0 & 0 & of & of & 0 \\
\hline Surf. contam.-cleanable & 556 & 569 & 567 & 847 & 698 & 544 & 801 & 801 & 963 & 963 & 517 & 942 \\
\hline Surf. conlam.-non-clnbl & 185 & 190 & 189 & 282 & 233 & 181 & 267 & 267 & 321 & 321 & 172 & 314 \\
\hline Activated & 414 & 424 & 422 & 631 & 520 & 405 & 596 & 596 & 717 & 717 & 385 & 701 \\
\hline Zirconium Non-radioactive & 0 & 0 & $\underline{0}$ & 0 & 0 & 0 & 0 & 0 & 0 & 0 & 0 & 0 \\
\hline Surt. contam.-cleanable & 0 & 0 & 0 & 0 & 0 & 0 & 0 & 0 & 0 & 0 & 0 & 0 \\
\hline Surf. contam.-non-clnbl & 0 & 0 & 0 & 0 & 0 & 0 & 0 & 0 & 0 & 0 & 0 & 0 \\
\hline Activaled & 0 & 0 & 0 & 0 & 0 & 0 & 0 & 0 & 0 & 0 & 0 & 0 \\
\hline
\end{tabular}




\begin{tabular}{|c|c|c|c|c|c|c|c|c|c|c|c|c|}
\hline U。S. PND田 & $\begin{array}{c}\text { San } \\
\text { Onofre } 3 \\
\end{array}$ & Seabrook & $\begin{array}{c}\text { Sequoyah } \\
1 \\
\end{array}$ & $\begin{array}{c}\text { Sequoyah } \\
2 \\
\end{array}$ & $\begin{array}{l}\text { Shearon } \\
\text { Harris }\end{array}$ & $\begin{array}{c}\text { Surry } \\
1\end{array}$ & $\begin{array}{c}\text { Surry } \\
2 \\
\end{array}$ & $\begin{array}{l}\text { S. Texas } \\
\text { Project } 1\end{array}$ & $\begin{array}{l}\text { 5. Toxas } \\
\text { Projact } 2\end{array}$ & $\begin{array}{l}\text { Three Mile } \\
\text { Island } 1\end{array}$ & $\begin{array}{l}\text { Three Milo } \\
\text { Island } 2\end{array}$ & Trojan \\
\hline Fuel cycle stage (FCD) & Reactor & Reactor & Reactor & Reactor & Reactor & Reaclor & Reactor & Reactor & Peactor & Reactor & Reactor & Reactor \\
\hline Identifier & 306USAP & 371USAP & 244USAP & 245USAP & 335USAP & 152USAP & 159USAP & 422USAP & 434USAP & 164USAP & 263 USAP & 240USAP \\
\hline Plant type & PWR & PWR & PWR & PWR & PWR & PWA & PWA & PWR & PWR & PWR & PWR & PWR \\
\hline Location & USA & USA & USA & USA & USA & USA & USA & USA & USA & USA & USA & USA \\
\hline Start of operations & 1984 & 1990 & 1981 & 1982 & 1987 & 1972 & 1973 & 1988 & 1989 & 1974 & 1978 & 1976 \\
\hline Status & Operating & Operating & Operating & Operating & Operating & Operating & Operating & Operating & Operating & Operating & Shut down & Operating \\
\hline Size (MWe) (Net) & 1080 & 1150 & 1148 & 1148 & 860 & 781 & 781 & 1250 & 1250 & 786 & 792 & 1095 \\
\hline Vendor & $C-E$ & Westinghouse & Wastinghouse & Westinghouse & Westinghouse & Westinghouse & Westinghouse & Westinghouse & Wostinghouse & $B \& W$ & & Westinghouse \\
\hline AVE & Bechtel & UE \& C & Utilitiy & Uitility & Ebasco & S\&W & S\&W & Bechtel & Bechtel & Gilbert & & Bechitel \\
\hline Pre or Post TMI & Post & Post & Post & Post & Post & Pre & Pre & Post & Post & Pre & Pre & Pre \\
\hline No. of steam turbines & 1 & 1 & 1 & 1 & 1 & 1 & 1 & 1 & 1 & 1 & 1 & 1 \\
\hline Cooling & $\operatorname{sen}$ & & & & Tower & River & River & & & Nat.draft tower & & Tower \\
\hline 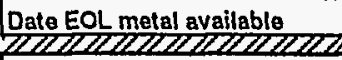 & 2034 & 2040 & 2031 & 2032 & 2037 & 2022 & 2023 & 2038 & 2039 & 2024 & 2028 & 2026 \\
\hline \multicolumn{13}{|l|}{ Quantity of metal (tonnes): } \\
\hline Aluminum Non-radioactive & 84 & 88 & 88 & 88 & 72 & 68 & 68 & 93 & 93 & 68 & 68 & 85 \\
\hline Surl. contam.-cleanable & 16 & 16 & 16 & 16 & 14 & 13 & 13 & 17 & 17 & 13 & 13 & 16 \\
\hline Surl. contam.-non-clnbl & 0 & 0 & 0 & $\therefore 0$ & 0 & 0 & 0 & 0 & 0 & 0 & 0 & 0 \\
\hline Activaled & 5 & 5 & 5 & 5 & 5 & 4 & 4 & 6 & 6 & 4 & 4 & 5 \\
\hline Non-radioactive & 5158 & 5379 & 5372 & 5372 & 4431 & 4156 & 4156 & 5686 & 5686 & 4173 & 4194 & 5206 \\
\hline Surl. contam.-cleanabla & 84 & 88 & 88 & 88 & 72 & 68 & 68 & 93 & 93 & 68 & 68 & 85 \\
\hline Surt. contam.-non-clnbl & 0 & 0 & 0 & 0 & 0 & 0 & 0 & 0 & 0 & 0 & 0 & 0 \\
\hline Activated & 21 & 22 & 22 & 22 & 18 & 17 & 17 & 23 & 23 & 17 & 17 & 21 \\
\hline Non-radioactive & 20 & 20 & 20 & 20 & 20 & 20 & 20 & 20 & 20 & 20 & 20 & 20 \\
\hline Surl. contam.-cleanable & 0 & 0 & 0 & 0 & 0 & 0 & 0 & 0 & 0 & 0 & 0 & 0 \\
\hline Surl. contam.-non-clnbl & 0 & 0 & 0 & 0 & 0 & 0 & 0 & 0 & 0 & 0 & 0 & 0 \\
\hline Activated & 0 & 0 & 0 & 0 & 0 & $\underline{0}$ & 0 & 0 & 0 & 0 & 0 & 0 \\
\hline Steel \& Iron Non-radioactive & 8726 & 9100 & 9089 & 9089 & 7497 & 7031 & 7031 & 9620 & 9620 & 7061 & 7096 & 8807 \\
\hline Surl. contam.-cleanable & 7053 & 7354 & 7346 & 7346 & 6059 & 5682 & 5682 & 7775 & 7775 & 5706 & 5735 & 7118 \\
\hline Surf. contam.-non-elnbl & 0 & 0 & $\underline{0}$ & 0 & 0 & 0 & 0 & 0 & 0 & 0 & 0 & 0 \\
\hline Activated & 3095 & 3227 & 3223 & 3223 & 2659 & 2493 & 2493 & 3412 & 3412 & 2504 & 2517 & 3123 \\
\hline Non-radioaclive & 0 & 0 & 0 & 0 & 0 & 0 & 0 & 0 & 0 & 0 & 0 & 0 \\
\hline Surf. contam.-cleanable & 947 & 988 & 987 & 987 & 814 & 763 & 763 & 1044 & 1044 & 767 & 770 & 956 \\
\hline Surf, contam.-non-cinbl & 316 & 329 & 329 & 329 & 271 & 254 & 254 & 348 & 348 & 256 & 257 & 319 \\
\hline Activaled & 705 & 735 & 735 & 735 & 606 & 568 & 568 & 777 & 777 & 571 & 574 & 712 \\
\hline Zirconium Non-radioactive & 0 & 0 & 0 & 0 & 0 & 0 & 0 & 0 & 0 & 0 & 0 & 0 \\
\hline Surf. contam.-deanablo & 0 & 0 & 0 & 0 & 0 & 0 & 0 & 0 & 0 & 0 & 0 & 0 \\
\hline Surf. conlam.-non-clnbl & 0 & 0 & 0 & 0 & 0 & 0 & 0 & $\underline{0}$ & 0 & 0 & 0 & 0 \\
\hline Aclivaled & 0 & 0 & 0 & 0 & 0 & 0 & 0 & 0 & 0 & 0 & 0 & 0 \\
\hline
\end{tabular}




\begin{tabular}{|c|c|c|c|c|c|c|c|c|c|c|c|c|}
\hline U.S్ PWW & $\begin{array}{l}\text { Turkey } \\
\text { Point } 3\end{array}$ & $\begin{array}{l}\text { Turkey } \\
\text { Point } 4\end{array}$ & $\begin{array}{l}\text { Virgil C. } \\
\text { Summer }\end{array}$ & $\begin{array}{c}\text { Waterford } \\
3 \\
\end{array}$ & $\begin{array}{l}\text { Watts } \\
\text { Bar } 1 \\
\end{array}$ & $\begin{array}{l}\text { Watts } \\
\text { Bar2 }\end{array}$ & WNP-1 & WNP-3 & $\begin{array}{l}\text { Wolt } \\
\text { Creek }\end{array}$ & $\begin{array}{c}\text { Yankee } \\
\text { Rowe } \\
\end{array}$ & $\begin{array}{c}\text { Zion } \\
1 \\
\end{array}$ & $\begin{array}{c}\text { Zion } \\
2 \\
\end{array}$ \\
\hline Fuel cyclo stago (FCT) & Reacior & Reactor & Reactor & Reaclor & Reacior & Reactor & Reaclor & Reactor & Reactor & Reactor & Reactor & Reactor \\
\hline Identifier & 134USAP & 136USAP & 325USAP & 297USAP & 292USAP & 300 USAP & 425USAP & 439USAP & 437USAP & 33USAP & 190USAP & 195USAP \\
\hline Plant type & PWR & PWR & PWR & PWR & PWR & PWR & PWR & PWR & PWR & PWR & PWR & PWR \\
\hline Location & USA & USA & USA & USA & USA & USA & USA & LSA & USA & LSA & USA & USA \\
\hline Start of operations & 1972 & 1973 & 1984 & 1985 & & & & & 1985 & 1961 & 1973 & 1974 \\
\hline Status & Operating & Operating & Operating & Operating & Under Const & Under Const & Under Const & Under Const & Operating & Shut down & Operaling & Operating \\
\hline Siza (MWe) (Net) & 666 & 686 & 885 & 1075 & 1177 & 1177 & 1259 & 1240 & 1135 & 167 & 1040 & 1040 \\
\hline Vendor & Westinghouse & Wostinghouse & Westinghouse & C-E & Westinghouse & Wostinghouso & $B \& W$ & C-E & Wostinghouse & & Westinghouse & Westinghouse \\
\hline NE & Bechiel & Bechtel & Gilbert & Ebasoo & Uilility & Utility & UE \& C & Ebasco & BechielsS\&L & & $S \& L$ & S\&L \\
\hline Pre or Post TMl & Pre & Pre & Post & Post & Post & Post & Post & Post & Post & Pre & Pre & Pre \\
\hline No. of steam turbines & 1 & 1 & 1 & 1 & 1 & 1 & 1 & 1 & 1 & 1. & 1 & 1 \\
\hline Cooling & Channels & Channels & Lake & & & & Forcod dittur & & & & Lake & Lake \\
\hline Date EOL metal available & 2022 & 2023 & 2034 & 2035 & 2053 & 2053 & 2053 & 2053 & 2035 & 2011 & 2023 & 2024 \\
\hline \multicolumn{13}{|l|}{ Quantily of metal (tonnes): } \\
\hline Aluminum Non-radioaclive & 61 & 61 & 74 & 84 & 89 & 89 & 93 & 92 & 87 & 24 & 82 & 82 \\
\hline Surf. contam.-cloanable & 11 & 11 & 14 & 16 & 17 & 17 & 17 & 17 & 16 & 5 & 15 & 15 \\
\hline Surl. contam.-nan-clnbl & 0 & 0 & 0 & 0 & 0 & 0 & 0 & 0 & 0 & 0 & 0 & 0 \\
\hline Activaled & 4 & 4 & 5 & 5 & 6 & 6 & 6 & 6 & 5 & 2 & 5 & 5 \\
\hline Non-radioactiva & 3737 & 3737 & 4517 & 5142 & 5462 & 5462 & 5713 & 5658 & 5332 & 1486 & 5030 & 5030 \\
\hline Surf. contam.-cloanable & 61 & 61 & 74 & 84 & 89 & 89 & 93 & 92 & 87 & 24 & 82 & 82 \\
\hline Surf. contam.-non-clnbl & 0 & 0 & 0 & 0 & 0 & 0 & 0 & 0 & 0 & 0 & 0 & 0 \\
\hline Activated & 15 & 15 & 18 & 21 & 22 & 22 & 23 & 23 & 22 & 6 & 21 & 21 \\
\hline Non-radioactive & 20 & 20 & 20 & 20 & 20 & 20 & 20 & 20 & 20 & 20 & 20 & 20 \\
\hline Surf. contam.-cleanable & 0 & 0 & 0 & 0 & 0 & 0 & 0 & 0 & 0 & 0 & 0 & 0 \\
\hline Surl. conlam,-non-cinbl & 0 & 0 & 0 & 0 & 0 & 0 & 0 & 0 & 0 & 0 & 0 & 0 \\
\hline Activated & 0 & 0 & 0 & 0 & 0 & 0 & 0 & 0 & 0 & 0 & 0 & 0 \\
\hline Steel \& lran Non-radioaclive & 6322 & 6322 & 7642 & 8699 & 9241 & 9241 & 9666 & 9568 & 9020 & 2514 & 8510 & 8510 \\
\hline Surl. contam.-cleanable & 5110 & 5110 & 6176 & 7031 & 7469 & 7469 & 7812 & 7733 & 7290 & 2032 & 6877 & 6877 \\
\hline Suri. contam.-non-clnbl & 0 & 0 & 0 & 0 & 0 & 0 & 0 & 0 & 0 & 0 & 0 & 0 \\
\hline Activatad & 2242 & 2242 & 2710 & 3085 & 3277 & 3277 & 3428 & 3393 & 3199 & 892 & 3018 & 3018 \\
\hline \begin{tabular}{|l} 
St. Stoel Non-radioaclive \\
\end{tabular} & 0 & 0 & 0 & 0 & 0 & 0 & 0 & 0 & 0 & 0 & 0 & 0 \\
\hline Surl contam-cleanable & 686 & 686 & 830 & 944 & 1003 & 1003 & 1049 & 1039 & 979 & 273 & 924 & 924 \\
\hline Surl. contam.-non-cinbl & 229 & 229 & 277 & 315 & 334 & 334 & 350 & 346 & 326 & 91 & 308 & 308 \\
\hline Activated & 511 & 511 & 618 & 703 & 747 & 747 & 781 & 773 & 729 & 203 & 688 & 688 \\
\hline Zirconium Non-radioactive & 0 & 0 & 0 & 0 & 0 & 0 & 0 & 0 & 0 & 0 & 0 & 0 \\
\hline Surf. contam.-cloanable & 0 & 0 & 0 & 0 & 0 & 0 & 0 & 0 & 0 & 0 & 0 & 0 \\
\hline Surf. contam.-non-cinbi & 0 & 0 & 0 & 0 & 0 & 0 & 0 & 0 & 0 & 0 & 0 & 0 \\
\hline Activated & 0 & 0 & 0 & 0 & 0 & 0 & 0 & 0 & 0 & 0 & 0 & 0 \\
\hline
\end{tabular}




\begin{tabular}{|c|c|c|c|c|c|c|c|c|c|c|c|c|}
\hline 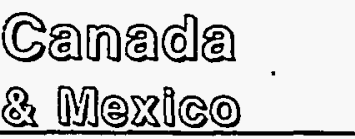 & $\begin{array}{c}\text { Bruce } \\
1 \\
\end{array}$ & $\begin{array}{c}\text { Bruce } \\
2 \\
\end{array}$ & $\begin{array}{c}\text { Bruce } \\
\mathbf{3} \\
\end{array}$ & $\begin{array}{c}\text { Bruce } \\
4 \\
\end{array}$ & $\begin{array}{c}\text { Bruce } \\
5 \\
\end{array}$ & $\begin{array}{c}\text { Bruce } \\
6 \\
\end{array}$ & $\begin{array}{c}\text { Bruce } \\
7 \\
\end{array}$ & $\begin{array}{c}\text { Bruce } \\
8 \\
\end{array}$ & $\begin{array}{c}\text { Darlington } \\
1 \\
\end{array}$ & $\begin{array}{c}\text { Darlington } \\
2 \\
\end{array}$ & $\begin{array}{c}\text { Darlington } \\
3 \\
\end{array}$ & $\begin{array}{c}\text { Darlington } \\
4 \\
\end{array}$ \\
\hline Fuel cycle stage (FCT) & Reactor & Reactor & Reactor & Reactor & Reactor & Reactor & Reactor & Reactor & Reactor & Reactor & Reactor & Reactor \\
\hline Identifier & $224 \mathrm{CDNH}$ & $225 \mathrm{CDNH}$ & $226 \mathrm{CONH}$ & $227 \mathrm{CDNH}$ & $402 \mathrm{CDNH}$ & 403 CDNH & $404 \mathrm{CDNH}$ & $405 \mathrm{CDNH}$ & $406 \mathrm{CDNH}$ & $407 \mathrm{CONH}$ & $409 \mathrm{CDNH}$ & $411 \mathrm{CDNH}$ \\
\hline Plant type & PHWR & PHWA & PHWR & PHWR & PHWR & PHWR & PHWR & PHWR & PHWR & PHWR & PHWR & PHWR \\
\hline Locatlon & Canada & Canada & Conada & Conada & Canada & Caneda & Canada & Carada & Cenada & Canada & Conada & Canada \\
\hline Start of operations & 1977 & 1977 & 1978 & 1979 & 1985 & 1984 & 1986 & 1987 & 1990 & 1990 & & \\
\hline Stalus & Operating & Operating & Operating & Operating & Operating & Operating & Operating & Operating & Operating & Operating & Under Const & Under Const \\
\hline Sizo $\left(M W_{0}\right)$ (Not) & 769 & 769 & 769 & 769 & 860 & 837 & 860 & 837 & 881 & 881 & 881 & 881 \\
\hline Vendor & AECUDB-S & AECUDB-S & AECUDBS & AECUDB-S & AECUMIL Vid & AECUMIL Vid & AECUMIL Vid & AECUMIL Vid & AECUDBS & AECUDB-S & AECUMIL Vid & AECUM!L Vie! \\
\hline A/E & Util/AECL & UtiUAECL & Utill/AECL & UtiVAECL & Ont. Hyd. & Ont. Hyd. & Ont. Hyd. & Ont. Hyd. & Ont. Hyd. & Ont. Hyd. & Ont. Hyd. & Ont. Hyd. \\
\hline Pre or Post TMI & Pro & Pre & Pre & Pre & Post & Post & Post & Post & Post & Post & Post & Post \\
\hline No. of steam turbines & 1 & 1 & 1 & 1 & 1 & 1 & 1 & 1 & 1 & 1 & 1 & 1 \\
\hline Coolling & Lake & Lake & Lake & Lake & Lake & Lake & Lake & Lake & Lake & Lake & Lake & Lake \\
\hline 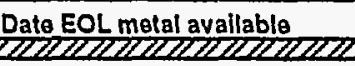 & 2027 & 2027 & 2028 & 2029 & 2035 & 2034 & 2036 & 2037 & 2040 & 2040 & 2053 & 2053 \\
\hline \multicolumn{13}{|l|}{ Quantity of metal (tonnes): } \\
\hline Aluminum Non-radioactive & 73 & 73 & 73 & 73 & .79 & 77 & 79 & 77 & 80 & 80 & 80 & 80 \\
\hline Surt. contam.cleanable & 14. & 14 & 14 & 14 & 15 & 14 & .15 & 14 & 15 & 15 & 15 & 15 \\
\hline Surt. conlam,-non-cinbl & 0 & 0 & 0 & 0 & 0 & 0 & 0 & 0 & 0 & 0 & 0 & 0 \\
\hline Activated & 5 & 5 & 5 & 5 & 5 & 5 & 5 & 5 & 5 & 5 & 5 & 5 \\
\hline Non-redioactive & 4475 & 4475 & 4475 & 4475 & 4822 & 4735 & 4822 & 4735 & 4900 & 4900 & 4900 & 4900 \\
\hline Surf. contam.-cleanable & 73 & 73 & 73 & 73 & 79 & 77 & 79 & 77 & 80 & 80 & 80 & 80 \\
\hline Surf. contam.-non-cinbl & 0 & 0 & 0 & af & 0 & 0 & 0 & 0 & 0 & 0 & 0 & 0 \\
\hline Activated & 18 & 18 & 18 & 18 & 20 & 19 & 20 & 19 & 20 & 20 & 20 & 20 \\
\hline Non-radioactive & 20 & 20 & 20 & 20 & 20 & 20 & 20 & 20 & 20 & 20 & 20 & 20 \\
\hline Surt. contam.-cleanable & 0 & 0 & 0 & 0 & 0 & 0 & 0 & 0 & 0 & 0 & 0 & 0 \\
\hline Surf. contam-non-cinbl & 0 & 0 & 0 & 0 & 0 & 0 & 0 & 0 & 0 & 0 & 0 & 0 \\
\hline Activated & 0 & 0 & 0 & 0 & 0 & 0 & 0 & 0 & 0 & 0 & 0 & 0 \\
\hline Steel \& Iron Non-radioaclive & 7307 & 7307 & 7307 & 7307 & 7872 & 7731 & 7872 & 7731 & 8000 & 8000 & 8000 & 8000 \\
\hline Surt. contam-cleanable & 5480 & 5480 & 5480 & 5480 & 5904 & 5799 & 5904 & 5799 & 6000 & 6000 & 6000 & 6000 \\
\hline Surt. contam.-non-clnbl & $\underline{0}$ & 0 & 0 & 0 & $\underline{0}$ & 0 & $\underline{0}$ & 0 & 0 & 0 & 0 & 0 \\
\hline Activated & 2685 & 2685 & 2685 & 2685 & 2893 & 2841 & 2893 & 2841 & 2940 & 2940 & 2940 & 2940 \\
\hline Non-radioactive & 265 & 265 & 265 & 265 & 285 & 280 & 285 & 280 & 290 & 290 & 290 & 290 \\
\hline Surf. contam.-cleanable & 1827 & 1827 & 1827 & 1827 & 1968 & 1933 & 1968 & 1933 & 2000 & 2000 & 2000 & 2000 \\
\hline Surt. contam.-non-cinbl & 183 & 183 & 183 & 183 & 197 & 193 & 197 & 193 & 200 & 200 & 200 & 200 \\
\hline Aclivated & 1918 & 1918 & 1918 & 1918 & 2066 & 2029 & 2066 & 2029 & 2100 & 2100 & 2100 & 2100 \\
\hline Zirconium Non-radioactive & 0 & 0 & 0 & $\underline{0}$ & 0 & 0 & 0 & 0 & 0 & 0 & 0 & 0 \\
\hline Surt. contam.-cleanable & 0 & 0 & 0 & 0 & $\underline{0}$ & 0 & 0 & 0 & $\underline{0}$ & 0 & 0 & 0 \\
\hline Surl. contam.non-cinbl & 0 & 0 & 0 & 0 & 0 & $\underline{0}$ & 0 & 0 & 0 & 0 & 0 & 0 \\
\hline Activated & 25 & 25 & 25 & 25 & 25 & 25 & 25 & 25 & 25 & 25 & 25 & 25 \\
\hline
\end{tabular}




\begin{tabular}{|c|c|c|c|c|c|c|c|c|c|c|c|c|}
\hline 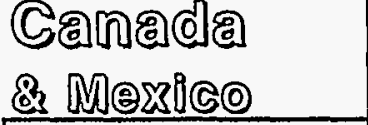 & $\begin{array}{c}\text { Douglas } \\
\text { Point }\end{array}$ & $\begin{array}{c}\text { Gentlliy } \\
1 \\
\end{array}$ & $\begin{array}{c}\text { Gentilly } \\
2 \\
\end{array}$ & $\begin{array}{c}\text { Plokering } \\
1 \\
\end{array}$ & $\begin{array}{c}\text { Plckering } \\
2 \\
\end{array}$ & $\begin{array}{c}\text { Plokering } \\
3 \\
\end{array}$ & $\begin{array}{c}\text { Pickering } \\
4 \\
\end{array}$ & $\begin{array}{c}\text { Plekering } \\
5 \\
\end{array}$ & $\begin{array}{c}\text { Plckering } \\
6 \\
\end{array}$ & $\begin{array}{c}\text { Plckering } \\
7 \\
\end{array}$ & $\begin{array}{c}\text { Plckering } \\
8 \\
\end{array}$ & $\begin{array}{l}\text { Polnt Le- } \\
\text { preau } 1 \\
\end{array}$ \\
\hline Fuel cycle slage (FCT) & Reactor & Reactor & Reactor & Reactor & Reactor & Reactor & Reactor & Reactor & Reactor & Peactor & Reactor & Reactor \\
\hline Identifler & $78 \mathrm{CDNH}$ & $119 \mathrm{CDNH}$ & $354 C D N H$ & $104 \mathrm{CDNH}$ & $105 \mathrm{CONH}$ & $120 \mathrm{CDNH}$ & $122 \mathrm{CDNH}$ & $228 \mathrm{CDNH}$ & $229 \mathrm{CDNH}$ & $399 \mathrm{CDNH}$ & $401 \mathrm{CDNH}$ & $514 C D N H$ \\
\hline Plant type & PHWR & PHWR & PHWR & PHWR & PHWR & PHWR & PHWR & PHWR & PHWR & PHWR & PHWR & PHWR \\
\hline Location & Canada & Canada & Canada & Canada & Canada & Canada & Canada & Canada & Canada & Canada & Canada & Canada \\
\hline Start of operatlons & 1968 & 1972 & 1983 & 1971 & 1971 & 1972 & 1973 & 1983 & 1984 & 1985 & 1986 & 1983 \\
\hline Slatús & Shut down & Shut down & Operating & Operating & Shut down & Operating & Operating & Operating & Operating & Operating & Operating & Operating \\
\hline Size (MWe) (Net) & 206 & 250 & 638 & 515 & 515 & 515 & 515 & 516 & 516 & 516 & 516 & 635 \\
\hline Yendor & AEC & AEQ & AEC & AECUDB-S & AECUDB-S & AECUDB-S & AECUDB-S & AECUDB-S & AECUDB-S & AECUDB-S & AECUDBS & AECL \\
\hline AIE & Util//AECL & AECL/UTil. & Hyd-Quebec & UIIVAECL & UtIIIAECL & UIIVAECL & UIII/AECL & UIIVAECL & UIII/AECL & UIIVAECL & UIII/AECL & Canalorn \\
\hline Pre or Post TMI & Pre & Pre & Post & Pre & Pro & Pre & Pre & Post & Post & Post & Post & Post \\
\hline No. of stoam turblnes & 1 & 1 & 1 & 1 & 1 & 1 & 1 & 1 & 1 & 1 & 1 & 1 \\
\hline Cooling & & & River & Lake & Lake & Lake & & Lake & Lake & Lake & Lake & SHt wer cond. \\
\hline 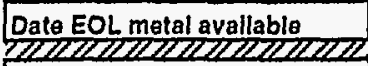 & 2018 & 2022 & 2033 & 2021 & 2021 & 2022 & 2023 & 2033 & 2034 & 2035 & 2036 & 2033 \\
\hline \multicolumn{13}{|l|}{ Quantity of metal (ionnes): } \\
\hline Aluminum Non-radioactive & 30 & 35 & 65 & 56 & 56 & 56 & 56 & 56 & 56 & 56 & 56 & 64 \\
\hline Surf. conlam.-cleanable & 6 & 6 & 12 & 10 & 10 & 10 & 10 & 10 & 10 & 10 & 10 & 12 \\
\hline Surf. contam.-non-cinbl & 0 & 0 & 0 & 0 & of & 0 & of & 0 & 0 & 0 & 0 & 0 \\
\hline Actlvated & 2 & 2 & 4 & 3 & 3 & 3 & 3 & 4 & 4 & 4 & 4 & 4 \\
\hline Non-radioactive & 1860 & 2116 & 3951 & 3426 & 3426 & 3426 & 3426 & 3430 & 3430 & 3430 & 3430 & 3939 \\
\hline Surf. contam.cleanable & 30 & 35 & 65 & 56 & 56 & 56 & 56 & 56 & 56 & 56 & 56 & 64 \\
\hline Surt. conlam.-non-clnbl & 0 & 0 & of & 0 & 0 & 0 & 0 & 0 & 0 & 0 & 0 & 0 \\
\hline Activated & 8 & 9 & 16 & 14 & 14 & 14 & 14 & 14 & 14 & 14 & 14 & 16 \\
\hline Non-radioactive & 20 & 20 & 20 & 20 & 20 & 20 & 20 & 20 & 20 & 20 & 20 & 20 \\
\hline Surt. contam.-cleanable & 0 & 0 & 0 & 0 & 0 & 0 & 0 & 0 & 0 & 0 & 0 & 0 \\
\hline Surf. contam.-non-clnbl & 요 & 0 & 0 & 0 & 0 & 0 & 0 & 0 & 0 & 0 & 0 & 0 \\
\hline Activaled & 0 & 0 & 0 & 0 & 0 & 0 & 0 & 0 & 0 & 0 & 0 & 0 \\
\hline Steol \& Iron Non-radioaclive & 3036 & 3455 & 6451 & 5593 & 5593 & 5593 & 5593 & 5600 & 5600 & 5600 & 5600 & 6431 \\
\hline Surt. contam.-cleanable & 2277 & 2591 & 4839 & 4195 & 4195 & 4195 & $\$ 4195$ & 4200 & 4200 & 4200 & 4200 & 4823 \\
\hline Surf. contam.-non-cinbl & 0 & 0 & 0 & 0 & 0 & 0 & $\therefore 0$ & 0 & 0 & 0 & 0 & 0 \\
\hline Activated & 1116 & 1270 & 2371 & 2055 & 2055 & 2055 & 2055 & 2058 & 2058 & 2058 & 2058 & 2363 \\
\hline \begin{tabular}{|ll} 
St. Steol Nón-radioactive \\
\end{tabular} & 110 & 125 & 234 & 203 & 203 & 203 & 203 & 203 & 203 & 203 & 203 & 233 \\
\hline Surf. contam.-cleanable & 759 & 864 & 1613 & 1398 & 1398 & 1398 & 1398 & 1400 & 1400 & 1400 & 1400 & 1608 \\
\hline Surt. contam.-non-c|nbl & 76 & 86 & 161 & 140 & 140 & 140 & 140 & 140 & 140 & 140 & 140 & 161 \\
\hline Activaled & 797 & 907 & 1693 & 1468 & 1468 & 1468 & 1468 & 1470 & 1470 & 1470 & 1470 & 1688 \\
\hline Zirconium Non-radioactive & 0 & 0 & 0 & 0 & 0 & 0 & 0 & 0 & 0 & 0 & 0 & 0 \\
\hline Surf. contam.-cleanable & 0 & 0 & 0 & 0 & 0 & 0 & 0 & $\underline{0}$ & 0 & 0 & $\underline{0}$ & 0 \\
\hline Suri. contam.-non-cinbl & $\underline{0}$ & 0 & 0 & 0 & 0 & 0 & $\underline{0}$ & 0 & 0 & 0 & 0 & 0 \\
\hline Activated & 25 & 25 & 25 & 25 & 25 & 25 & 25 & 25 & 25 & 25 & 25 & 25 \\
\hline
\end{tabular}




\begin{tabular}{|c|c|c|c|}
\hline 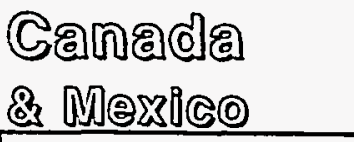 & $\begin{array}{l}\text { Point Le- } \\
\text { preau } 2\end{array}$ & $\begin{array}{l}\text { Laguna } \\
\text { Verde } 1 \\
\end{array}$ & $\begin{array}{l}\text { Laguna } \\
\text { Verde } 2 \\
\end{array}$ \\
\hline Fuel cycle stage (FCT) & Reactor & Reactor & Reactor \\
\hline Identifler & $860 \mathrm{CDNH}$ & $259 M \times B$ & $264 \mathrm{MXB}$ \\
\hline Plant type & PHWR & BWR & BWR \\
\hline Location & Canada & Mexico & Mexico \\
\hline Start of operations & & 1989 & \\
\hline Stalus & Planned & Operating & Under const. \\
\hline Size (MWe) (Net) & 400 & 654 & 654 \\
\hline Vendor & & $\Phi$ & $\Phi$ \\
\hline$A / E$ & & Ebasco/CFE & Ebasco/CFE \\
\hline Pre or Post TMI & Post & Post & Post \\
\hline No. of steam turbines & 1 & 1 & 1 \\
\hline \multicolumn{4}{|l|}{ Coollng } \\
\hline Date EOL motal available & $\begin{array}{l}\text { Unknown } \\
2\end{array}$ & 2039 & 2053 \\
\hline \multicolumn{4}{|l|}{ Quantity of metal (tonnes): } \\
\hline Aluminum Non-radioactive & 47 & 60 & 60 \\
\hline Surl. contam.-cleanable & 9 & 11 & 11 \\
\hline Surf. contam.-non-clnbl & 0 & 0 & $\underline{0}$ \\
\hline Activated & 3 & 4 & 4 \\
\hline Non-radioactive & 2895 & 3692 & 3692 \\
\hline Surt. contam.cleanable & 47 & 60 & 60 \\
\hline Surf. contam.-non-clnbl & 0 & 0 & 0 \\
\hline Activated & 12 & 15 & 15 \\
\hline Non-radioactive & 20 & 20 & 20 \\
\hline Surf. contam.-cleanable & 0 & 0 & 0 \\
\hline Surf. contam.-non-cinbl & 0 & 0 & $\underline{0}$ \\
\hline Activated & 0 & 0 & $\underline{0}$ \\
\hline Steel \& Iron Non-radioactive & 4726 & 3767 & 3767 \\
\hline Surf. contam.-cleanable & 3544 & 5048 & 5048 \\
\hline Surf. contam.-non-cinbl & 0 & 0 & 0 \\
\hline Activated & 1737 & 2637 & 2637 \\
\hline Non-radioactive & 171 & 0 & 0 \\
\hline Surf. contam.-cleanable & 1181 & 452 & 452 \\
\hline Surt. contam.-non-cinbl & 118 & 0 & 0 \\
\hline Activated & 1240 & 505 & 505 \\
\hline Zirconium Non-radioactive & $\underline{0}$ & 0 & 0 \\
\hline Surt. contam.-cleanable & 0 & 0 & 0 \\
\hline Surf. contam.-non-cinbl & 0 & 0 & 0 \\
\hline Activaled & 25 & 0 & 0 \\
\hline
\end{tabular}




\begin{tabular}{|c|c|c|c|c|c|c|c|c|c|c|c|c|}
\hline 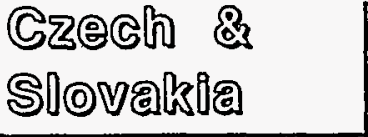 & $\begin{array}{c}\text { Bohunice } \\
\text { v2-2 }\end{array}$ & $\begin{array}{c}\text { Dukovany } \\
1\end{array}$ & $\begin{array}{c}\text { Dukovany } \\
2 \\
\end{array}$ & $\begin{array}{c}\text { Dukovany } \\
3 \\
\end{array}$ & $\begin{array}{c}\text { Dukovany } \\
4 \\
\end{array}$ & $\begin{array}{c}\text { Kecerovee } \\
1 \\
\end{array}$ & $\begin{array}{c}\text { Kecerovce } \\
2 \\
\end{array}$ & $\begin{array}{c}\text { Mochovce } \\
1 \\
\end{array}$ & $\begin{array}{c}\text { Mochovee } \\
2 \\
\end{array}$ & $\begin{array}{c}\text { Mochovce } \\
3\end{array}$ & $\begin{array}{c}\text { Mochover } \\
4\end{array}$ & $\begin{array}{c}\text { North Mo- } \\
\text { ravla } 1\end{array}$ \\
\hline Fuel cycle stage (FCT) & Reactor & Reactor & Reactor & Reactor & Reactor & Reactor & Reactor & Reactor & Reactor & Reactor & Reactor & Reactor \\
\hline Identifler & $287 \mathrm{CZP}$ & 319CZP & $320 \mathrm{CZP}$ & 574CZP & $497 \mathrm{CZP}$ & $806 \mathrm{CZP}$ & $807 \mathrm{CZP}$ & $673 \mathrm{CZP}$ & $674 C Z P$ & $675 \mathrm{CZP}$ & $826 \mathrm{CZP}$ & $840 C Z P$ \\
\hline Plant typo & WER & WER & WER & WER & WER & WER & WER & WER & WER & WER & WER & WER \\
\hline Location & Slovakia & Czech Rep. & Czech Res. & Czoch Rep. & Czech Rep. & Czochoslovakla & Czochosiovakia & Slovakla & Slovakia & Slovakla & Slovakia & Crechoslovakia \\
\hline Start of operatlons & 1984 & 1985 & 1985 & 1985 & 1985 & & & & & & & \\
\hline Status & Operating & Operating & Operating & Operating & Operating & Planned & Planned & Under Const & Under Const & Under Const & Under Const & Planned \\
\hline Size (MWe) (Net) & 408 & 390 & 390 & 390 & 390 & 918 & 918 & 408 & 408 & 408 & 408 & 908 \\
\hline Vendor & Skoda & Skoda & Skoda & Skoda & Skoda & & & Skoda & Skoda & Skoda & Skoda & \\
\hline A/E & $E-S-L$ & $E-S-L$ & E-S-L & E-S-L & E-S-L & $E-S-L$ & E-S-L & E-S-L & E-S-L & E-S-L & E-S-L & E-S.L \\
\hline Pre or Post TMI & Post & Post & Post & Post & Post & Post & Post & Post & Post & Post & Post & Post \\
\hline No. of steam turbines & 2 & 2 & 2 & 2 & 2 & 1 & 1 & 2 & 2 & 2 & 2 & 1 \\
\hline Cooling & & & & & & Tower & & & & & & \\
\hline Date EOL matal available & 2034 & 2035 & 2035 & 2035 & 2035 & Unknown & Unknown & 2053 & $\frac{2053}{211120}$ & 2053 & 2053 & Unknown \\
\hline \multicolumn{13}{|l|}{ Quantity of metal (tonnes): } \\
\hline Aluminum Non-radioactive & 46 & 46 & 46 & 46 & 46 & 80 & 80 & 46 & 46 & 46 & 46 & 80 \\
\hline Surf. contam.-cleanable & 9 & 9 & 9 & 9 & 9 & 15 & 15 & 9 & 9 & 9 & 9 & 15 \\
\hline Surf. contam.-non-cinbl & 0 & 0 & 0 & 0 & 0 & 0 & 0 & 0 & 0 & 0 & 0 & 0 \\
\hline Activated & 3 & 3 & 3 & 3 & 3 & 5 & 5 & 3 & 3 & 3 & 3 & 5 \\
\hline Copper Non-radioactive & 2840 & 2840 & 2840 & 2840 & 2840 & 4900 & 4900 & 2840 & 2840 & 2840 & 2840 & 4900 \\
\hline Surf. contam.cleanable & 46 & 46 & 46 & 46 & 46 & 80 & 80 & 46 & 46 & 46 & 46 & 80 \\
\hline Surt. contam.-non-cinbl & 0 & 0 & 0 & 0 & 0 & 0 & 0 & 0 & 0 & 0 & 0 & 0 \\
\hline Activated & 12 & 12 & 12 & 12 & 12 & 20 & 20 & 12 & 12 & 12 & 12 & 20 \\
\hline Non-radioactive & 20 & 20 & 20. & 20 & 20 & 20 & 20 & 20 & 20 & 20 & 20 & 20 \\
\hline Surt.contam.-cleanable & 0 & 0 & 0 & 0 & 0 & 0 & 0 & 0 & 0 & O. & 0 & 0 \\
\hline Surf.contam.-non-clnbl & 0 & 0 & 0 & 0 & 0 & 0 & 0 & 0 & 0 & 의 & 0 & 0 \\
\hline Activated & 0 & 0 & 0 & 0 & 0 & 0 & 0 & 0 & 0 & 0 & 0 & 0 \\
\hline Steol \& Iron Non-radioaclive & 12030 & 12030 & 12030 & 12030 & 12030 & 19248 & 19248 & 12030 & 12030 & 12030 & 12030 & 19248 \\
\hline Surl. contam.-cleanable & 4669 & 4669 & 4669 & 4669 & 4669 & 7156 & 7156 & 4669 & 4669 & 4669 & 4669 & 7156 \\
\hline Surf. contam.-non-cinbi & 46 & 46 & 46 & 46 & 46 & 69 & 69 & 46 & 46 & 46 & 46 & 69 \\
\hline Activated & 363 & 363 & 363 & 363 & 363 & 581 & 581 & 363 & 363 & 363 & 363 & 581 \\
\hline St. Steol Non-radioactive & 0 & of & 0 & 0 & 0 & 0 & 0 & 0 & 0 & 0 & 0 & 0 \\
\hline Surt. contam.-cleanable & 1599 & 1599 & 1599 & 1599 & 1599 & 2600 & 2600 & 1599 & 1599 & 1599 & 1599 & 2600 \\
\hline Surl. contam.-non-cinbl & 0 & 0 & 0 & 0 & $\therefore 0$ & of & 0 & 0 & 0 & 0 & 0 & 0 \\
\hline Activaled & 254 & 254 & 254 & 254 & 254 & 406 & 406 & 254 & 254 & 254 & 254 & 406 \\
\hline Zirconium Non-radioactive & 0 & 요 & 0 & 0 & 0 & 0 & 0 & 0 & 0 & 0 & 0 & $\underline{0}$ \\
\hline Surt. contam.-cleanable & 0 & 0 & 0 & 0 & 0 & 0 & 0 & 0 & 0 & 0 & 0 & 0 \\
\hline Surf. contam.-non-clnbl & 0 & 0 & 0 & 0 & 0 & 요 & 0 & 0 & 0 & 0 & 0 & 0 \\
\hline Aclivated & 0 & 0 & 0 & 0 & 0 & 0 & 0 & 01 & 0 & 0 & 0 & $\underline{0}$ \\
\hline
\end{tabular}




\begin{tabular}{|c|c|c|c|c|c|}
\hline 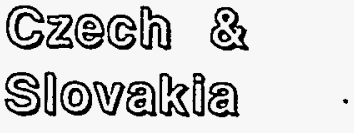 & $\begin{array}{l}\text { North Mo- } \\
\text { ravia } 2\end{array}$ & $\begin{array}{c}\text { South Bo. } \\
\text { hemia } 1\end{array}$ & $\begin{array}{l}\text { South Bo- } \\
\text { hemla } 2\end{array}$ & $\begin{array}{c}\text { Temelin } \\
1\end{array}$ & $\begin{array}{c}\text { Temelin } \\
2\end{array}$ \\
\hline Fuel cycle stage (FCT) & Reactor & Reactor & Reactor & Reactor & Reactor \\
\hline Identifler & $841 C Z P$ & $873 \mathrm{CZP}$ & $874 C Z P$ & 669CZP & $670 \mathrm{CZP}$ \\
\hline Plant type & WER & WER & WER & WER & WER \\
\hline Location & Czochosiovakia & Czochosbovaka & Czechoslovakia & Gzech Reg. & Czech Rep. \\
\hline \multicolumn{6}{|l|}{ Start of operations } \\
\hline Stalus & Planned & Planned & Planned & Under Const & Under Const \\
\hline Slze (MWe) (Net) & 918 & 918 & 918 & 918 & 918 \\
\hline Vendor & & & & Skoda/AEE & Skoda/AEE \\
\hline A/E & $E-S-L$ & $E-S-L$ & $E-S-L$ & E-S-L & E-S-L \\
\hline Pra or Post TMI & Post & Post & Post & Post & Post \\
\hline No. of sleam turbines & 1 & 1 & 1 & 1 & 1 \\
\hline \multicolumn{6}{|l|}{ Coolling } \\
\hline Date EOL metal avallable & Unknown & $\begin{array}{l}\text { Unknown } \\
\mathbb{Z Z Z Z Z Z Z}\end{array}$ & Unknown & 2053 & 2053 \\
\hline \multicolumn{6}{|l|}{ Quantity of metal (tonnes): } \\
\hline Aluminum Non-radioactive & 80 & 80 & 80 & 80 & 80 \\
\hline Surf. contam.cleanable & 15 & 15 & 15 & 15 & 15 \\
\hline Surf. contam.-non-clnbl & 0 & 0 & 0 & 0 & 0 \\
\hline Aclivated & 5 & 5 & 5 & 5 & .5 \\
\hline Non-radloactive & 4900 & 4900 & 4900 & 4900 & 4900 \\
\hline Surt. contam.-cleanable & 80 & 80 & 80 & 80 & 80 \\
\hline Surf. contam.-non-cinbl & 0 & 0 & 0 & 0 & 0 \\
\hline Activated & 20 & 20 & 20 & 20 & 20 \\
\hline Non-radioactlve & 20 & 20 & 20 & 20 & 20 \\
\hline Surt. contam.-cleanable & 0 & 0 & 0 & 0 & 0 \\
\hline Surf. contam.-nan-dnbl & 0 & 0 & 0 & 0 & 0 \\
\hline Activated & 0 & 0 & 0 & 요 & 0 \\
\hline Steol \& Iron Non-radioactive & 19248 & 19248 & 19248 & 19248 & 19248 \\
\hline Surf. contam.-cleanable & 7156 & 7156 & 7156 & 7156 & 7156 \\
\hline Surf. contam.non-clnbl & 69 & 69 & 69 & 69 & 69 \\
\hline Activated & 581 & 581 & 581 & 581 & 581 \\
\hline St. Steel Non-radioactive & 0 & 0 & 0 & 0 & 0 \\
\hline Surf. contam. cleanable & 2600 & 2600 & 2600 & 2600 & 2600 \\
\hline Suri. contam.-non-clnbl & 0 & 0 & 0 & 0 & $\underline{0}$ \\
\hline Activaled & 406 & 406 & 406 & 406 & 406 \\
\hline Zirconium Non-radioactive & 0 & 0 & 0 & 0 & 0 \\
\hline Surt. contam.cleanable & 0 & $\underline{0}$ & 0 & 0 & 0 \\
\hline Surf. contam.-non-cinbl & 0 & 0 & 0 & 0 & 0 \\
\hline Activated & 0 & 0 & 0 & 0 & 0 \\
\hline
\end{tabular}




\begin{tabular}{|c|c|c|c|c|c|c|c|c|c|c|c|c|}
\hline 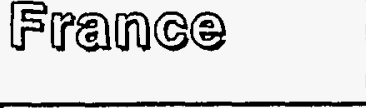 & $\begin{array}{c}\text { Belleville } \\
1 \\
\end{array}$ & $\begin{array}{c}\text { Belleville } \\
2 \\
\end{array}$ & $\begin{array}{l}\text { Bugey } \\
\cdot 2 \\
\end{array}$ & $\begin{array}{c}\text { Bugey } \\
3 \\
\end{array}$ & $\begin{array}{c}\text { Bugey } \\
4 \\
\end{array}$ & $\begin{array}{c}\text { Bugey } \\
5 \\
\end{array}$ & $\begin{array}{c}\text { Cattenom } \\
1 \\
\end{array}$ & $\begin{array}{c}\text { Cattenom } \\
2 \\
\end{array}$ & $\begin{array}{c}\text { Chinon } \\
\text { B1 }\end{array}$ & $\begin{array}{c}\text { Chinon } \\
\text { B2 } \\
\end{array}$ & $\begin{array}{c}\text { Chinon } \\
\text { B3 }\end{array}$ & $\begin{array}{c}\text { Chinon } \\
\mathrm{B} 4 \\
\end{array}$ \\
\hline Fuel cycle stage (FCT) & Reactor & Reactor & Reactor & Reactor & Reacior & Reactor & Reactor & Reactor & Reactor & Reactor & Reactor & Reactor \\
\hline Identllier & 609FP & 610FP & 323FP & $356 \mathrm{FP}$ & 415FP & 507FP & 630FP & 613FP & $578 \mathrm{FP}$ & 579FP & 633FP & 634FP \\
\hline Plant type & PWR & PWR & PWA & PWR & PWR & PWR & PWR & PWR & PWR & PWR & PWR & PWR \\
\hline Locatlon & France & France & France & France & France & France & France & France & France & France & France & France \\
\hline Start of operations & 1988 & 1988 & 1979 & 1979 & 1979 & 1980 & 1987 & 1988 & 1984 & 1984 & 1987 & 1988 \\
\hline Status & Operalling & Operating & Operallng & Operating & Operating & Operating & Operatling: & Operatlng & Operatlng & Operating & Operating & Operating \\
\hline Size (MWe) (Not) & 1310 & 1310 & 920 & 920 & 900 & 900 & 1300 & 1300 & 870 & 870 & 920 & 920 \\
\hline Vendor & Framatome & Framatome & Framatome & Framatome & Framatome & Framalome & Framatome & Framatome & Framatome & Framatome & Framalome & Framatome \\
\hline AVE & EdF & EdF & EdF & EdF & EdF & EdF & EOF & EdF & EdF & EdF & EdF & EdF \\
\hline Pre or Post TMI & Post & Post & Pre & Pre & Pre & Post & Post & Post & Post & Post & Post & Post \\
\hline No. of steam turbines & 1 & 1 & 1 & 1 & 1 & 1 & 1 & 1 & 1 & 1 & 1 & 1 \\
\hline Cooling & & & & & & & & & Tower & Tower & Tower & Tower \\
\hline 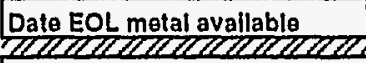 & 2038 & 2038 & 2029 & 2029 & 2029 & 2030 & 2037 & 2038 & 2034 & 2034 & 2037 & 2038 \\
\hline \multicolumn{13}{|l|}{ Quantity of metal (tonnes): } \\
\hline Aluminum Non-radioaclive & 96 & 96 & 76 & 76 & 75 & 75 & 95 & 95 & 73 & 73 & 76 & 76 \\
\hline Surf. contam.-cleanable & 18 & 18 & 14 & 14 & 14 & 14 & 18 & 18 & 14 & 14 & 14 & 14 \\
\hline Surf. contam.-non-cinbl & $\underline{0}$ & 0 & 0 & 0 & 0 & 0 & 0 & 0 & 0 & 0 & 0 & 0 \\
\hline Activated & 6 & 6 & 5 & 5 & 5 & 5 & 6 & 6 & 5 & 5 & 5 & 5 \\
\hline Copper Non-radioactive & 5866 & 5866 & 4635 & 4635 & 4568 & 4568 & 5837 & 5837 & 4466 & 4466 & 4635 & 4635 \\
\hline Surf. contam.cleanable & 96 & 96 & 76 & 76 & 75 & 75 & 95 & 95 & 73 & 73 & 76 & 76 \\
\hline Surf. contam.-non-clnbl & 0 & 0 & 0 & 0 & 0 & 0 & 0 & 0 & 0 & 요 & 0 & 0 \\
\hline Activated & 24 & 24 & 19 & 19 & 19 & 19 & 24 & 24 & 18 & 18 & 19 & 19 \\
\hline Non-radjoactive & 20 & 20 & 20 & 20 & 20 & 20 & 20 & 20 & 20 & 20 & 20 & 20 \\
\hline Suri. contam.-cleanable & 0 & 0 & 0 & 0 & 0 & 0 & 0 & 0 & 0 & 0 & 0 & 0 \\
\hline Surf. contam.-non-cinbl & 0 & 0 & 0 & 0 & 0 & 0 & 0 & 0 & 0 & 0. & 0 & 0 \\
\hline Activated & 0 & 0 & 0 & 0 & 0 & 0 & 0 & 0 & 0 & 0 & 0 & 0 \\
\hline Steol \& Iron Non-radioactive & 9925 & 9925 & 7842 & 7842 & 7728 & 7728 & 9875 & 9875 & 7555 & 7555 & 7842 & 7842 \\
\hline Surf. contam.cleanable & 8022 & 8022 & 6338 & 6338 & 6246 & 6246 & 7981 & 7981 & 6106 & 6106 & 6338 & 6338 \\
\hline Surf. contam.-non-clnbl & 0 & 0 & 0 & 0 & 0 & 0 & 0 & 0 & 0 & 0 & 0 & 0 \\
\hline Activated & 3520 & 3520 & 2781 & 2781 & 2741 & 2741 & 3502 & 3502 & 2679 & 2679 & 2781 & 2781 \\
\hline Non-radioactive & 0 & 0 & 0 & 0 & 0 & 0 & 0 & 0 & 0 & 0 & 0 & 0 \\
\hline Surf. contam.cleanable & 1078 & 1078 & 851 & 851 & 839 & 839 & 1072 & 1072 & 820 & 820 & 851 & 851 \\
\hline Surf. contam.-non-clnbl & 359 & 359 & 284 & 284 & 280 & 280 & 357 & 357 & 273 & 273 & 284 & 284 \\
\hline Activated & 802 & 802 & 634 & 634 & 625 & 625 & 798 & 798 & 611 & 611 & 634 & 634 \\
\hline Zlrconium Non-radioaclive & 0 & 0 & 0 & 0 & 0 & 0 & 0 & 0 & 0 & 0 & 0 & $\underline{0}$ \\
\hline Surf. contam.-cleanable & 0 & 0 & 0 & 0 & 0 & 0 & 0 & 0 & 0 & 0 & 0 & 0 \\
\hline Surt. conlam.-non-cinbl & 0 & 0 & 0 & 0 & 0 & 0 & 0 & 0 & 0 & .0 & 0 & 0 \\
\hline Activated & 0 & 0 & 0 & 0 & 0 & 0 & 0 & 0 & 0 & 0 & 0 & 0 \\
\hline
\end{tabular}




\begin{tabular}{|c|c|c|c|c|c|c|c|c|c|c|c|c|}
\hline 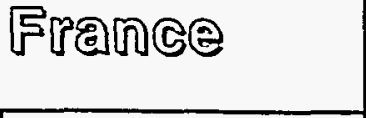 & $\begin{array}{l}\text { ChOoz } \\
\text { SENA }\end{array}$ & $\begin{array}{c}\text { Cruas } \\
\text { Meysse } 1 \\
\end{array}$ & $\begin{array}{c}\text { Cruas } \\
\text { Meysse } 2 \\
\end{array}$ & $\begin{array}{c}\text { Cruas } \\
\text { Meysse } 3\end{array}$ & $\begin{array}{c}\text { Cruas } \\
\text { Meysse } 4\end{array}$ & $\begin{array}{c}\text { Damplerre } \\
1 \\
\end{array}$ & $\begin{array}{c}\text { Damplerre } \\
2 \\
\end{array}$ & $\begin{array}{c}\text { Damplerre } \\
\mathbf{3} \\
\end{array}$ & $\begin{array}{c}\text { Damplerre } \\
\mathbf{4} \\
\end{array}$ & $\begin{array}{l}\text { Fessen- } \\
\text { heim } 1\end{array}$ & $\begin{array}{l}\text { Fessen- } \\
\text { heim } 2\end{array}$ & $\begin{array}{c}\text { Flaman- } \\
\text { ville } 1\end{array}$ \\
\hline Fuel cycle stage (FCT) & Reaclor & Reactor & Reactor & Reactor & Reactor & Reactor & Reactor & Reactor & Reactor & Reactor & Reactor & Reactor \\
\hline Identilier & 85FP & 590FP & 591FP & 629FP & 592FP & 418FP & 509FP & 512FP & $513 F P$ & 289FP & $290 \mathrm{FP}$ & 555FP \\
\hline Plant type & PWR & PWR & PWR & PWR & PWR & PWR & PWR & PWR & PWR & PWR & PWR & PWR \\
\hline Locatlon & France & France & France & France & France & France & France & France & France & France & France & France \\
\hline Start of operatlons & 1967 & 1984 & 1985 & 1984 & 1985 & 1980 & 1981 & 1981 & 1981 & 1977 & 1978 & 1986 \\
\hline Status & Shut down & Operating & Operating & Operating & Operating & Operalling & Operating & Operating & Operating & Operating & Operating & Operating \\
\hline Size $\left(M W_{e}\right)$ (Net) & 305 & 880 & 915 & 915 & 880 & 890 & 890 & 890 & 890 & 880 & 880 & 1350 \\
\hline Vendor & Aceco/Fram & Framatome & Framatome & Framatome & Framatome & Framatome & Framatome & Framatome & Framatome & Framatom $\theta$ & Framatome & Framatome \\
\hline AVE & G\&H/Spie & EdF & EdF & EdF & $\mathrm{EdF}$ & EdF & $\mathrm{EdF}$ & EdF & EdF & EdF & EdF & EdF \\
\hline Pre or Post TMI & Pre & Post & Post & Post & Post & Post & Post & Post & Post & Pre & Pre & Post \\
\hline No. of steam turbines & 1 & 1 & 1 & 1 & 1 & 1 & 1 & 1 & 1 & 1 & 1 & 1 \\
\hline \multicolumn{13}{|l|}{ Cooling } \\
\hline 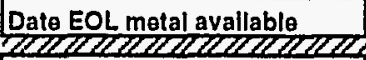 & 2017 & $\frac{2034}{2202}$ & $\frac{2035}{2120}$ & $\frac{2034}{202012}$ & $\frac{2035}{2120}$ & 2030 & 2031 & $2031 \cdot$ & 2031 & 2027 & $\cdot 2028$ & 2036 \\
\hline \multicolumn{13}{|l|}{ Quantity of metal (tonnes): } \\
\hline Aluminum Non-radioactive & 36 & 73 & 75 & 75 & 73 & 74 & 74 & 74 & 74 & 73 & 73 & 98 \\
\hline Surf. contam. cleanable & 7 & 14 & 14 & 14 & 14 & 14 & 14 & 14 & 14 & 14 & 14 & 18 \\
\hline Surl. contam.-non-cinbl & 0 & 0 & 0 & 0 & 0 & 0 & 0 & 0 & 0 & 0 & 0 & $\underline{0}$ \\
\hline Activaled & 2 & 5 & 5 & 5 & 5 & 5 & 5 & 5 & 5 & 5 & 5 & 6 \\
\hline \begin{tabular}{|ll} 
Copper $\quad$ Non-radioactive \\
\end{tabular} & 2220 & 4500 & 4618 & 4618 & 4500 & 4534 & 4534 & 4534 & 4534 & 4500 & 4500 & 5985 \\
\hline Surf. contam. cleanable & 36 & 73 & 75 & 75 & 73 & 74 & 74 & 74 & 74 & 73 & 73 & 98 \\
\hline Surf. contam.-non-clnbl & 0 & 0 & 0 & 0 & 0 & 0 & 0 & 0 & 0 & 0 & 0 & 0 \\
\hline Activated & 9 & 18 & 19 & 19 & 18 & 19 & 19 & 19 & 19 & 18 & 18 & 24 \\
\hline Non-radioactive & 20 & 20 & 20 & 20 & 20 & 20 & 20 & 20 & 20 & 20 & 20 & 20 \\
\hline Surf. contam.cleanable & 0 & 0 & 요 & 0 & 0 & 0 & $\underline{0}$ & 0 & 0 & 0 & 0 & 0 \\
\hline Surt. contam.-non-cinbl & 0 & 0 & 0 & 0 & 0 & 0 & 0 & 0 & 0 & 0 & 0 & 0 \\
\hline Activated & 0 & 0 & 0 & 0 & 0 & 0 & 0 & 0 & 0 & 0 & 0 & 0 \\
\hline Stoel \& Iron Non-radioactive & 3756 & 7613 & 7813 & 7813 & 7613 & 7670 & 7670 & 7670 & 7670 & 7613 & 7613 & 10126 \\
\hline Surf. contam.-cleanable & 3036 & 6153 & 6315 & 6315 & 6153 & 6199 & 6199 & 6199 & 6199 & 6153 & 6153 & 8184 \\
\hline Surt. contam.non-clnbl & 0 & 0 & 0 & 0 & 0 & 0 & 0 & 0 & 0 & 0 & 0 & 0 \\
\hline Activated & 1332 & 2700 & 2771 & 2771 & 2700 & 2720 & 2720 & 2720 & 2720 & 2700. & 2700 & 3591 \\
\hline \begin{tabular}{|ll} 
St. Steel Non-radioactive \\
\end{tabular} & 0 & 0 & 0 & 0 & 0 & 0 & 0 & 0 & 0 & 0 & 0 & 0 \\
\hline Surt.contam.-cleanable & 408 & 826 & 848 & 848 & 826 & 833 & 833 & 833 & 833 & 826 & 826 & 1099 \\
\hline Surf. contam.-non-cinbl & 136 & 275 & 283 & 283 & 275 & 278 & 278 & 278 & 278 & 275 & 275 & 366 \\
\hline Activated & 304 & 615 & 631 & 631 & 615 & 620 & 620 & 620 & 620 & 615 & 615 & 818 \\
\hline Zlirconium Non-radioactive & 0 & 0 & 0 & 0 & 0 & 0 & 0 & 0 & 0 & 0 & 0 & 0 \\
\hline Surf. contam.-cleanable & 0 & 0 & 0 & 0 & 0 & 0 & 0 & 0 & $\underline{0}$ & 0 & 0 & 0 \\
\hline Surf. contam.-non-clnbl & 0 & 0 & 0 & 0 & 0 & 0 & 0 & 0 & $\underline{0}$ & 0 & 0 & 0 \\
\hline Activated & 0 & 0 & 이 & 0 & 0 & 0 & 0 & 0 & 0 & 0 & 0 & 0 \\
\hline
\end{tabular}




\begin{tabular}{|c|c|c|c|c|c|c|c|c|c|c|c|c|}
\hline 5pQn日อ & $\begin{array}{l}\text { Flaman- } \\
\text { ville } 2 \\
\end{array}$ & $\begin{array}{c}\text { Gravellnes } \\
1 . \\
\end{array}$ & $\begin{array}{c}\text { Gravellnes } \\
2 \\
\end{array}$ & $\begin{array}{c}\text { Gravelines } \\
3 \\
\end{array}$ & $\begin{array}{c}\text { Gravelines } \\
4 \\
\end{array}$ & $\begin{array}{c}\text { Gravelines } \\
5 \\
\end{array}$ & $\begin{array}{c}\text { Gravellnes } \\
6 \\
\end{array}$ & $\begin{array}{c}\text { LeBlayais } \\
1 \\
\end{array}$ & $\begin{array}{c}\text { LeBlayals } \\
2 \\
\end{array}$ & $\begin{array}{c}\text { LeBlayais } \\
3 \\
\end{array}$ & $\begin{array}{c}\text { LeBlayais } \\
4 \\
\end{array}$ & $\begin{array}{c}\text { Nogent } \\
1 \\
\end{array}$ \\
\hline Fuel cycle stage (FCT) & Reactor & Reactor & Reactor & Reactor & Reactor & Reactor & Reactor & Reactor & Reactor & Reactor & Reaclor & Reactor \\
\hline Identillor & $556 \mathrm{FP}$ & $416 \mathrm{FP}$ & 417FP & 419FP & 423FP & $631 \mathrm{FP}$ & 632FP & 551FP & 553FP & 586FP & 587FP & 614FP \\
\hline Plant type & PWR & PWR & PWR & PWR & PWR & PWA & PWR & PWR & PWR & PWR & PWR & PWR \\
\hline Locallon & France & France & France & France & France & Franco & France & France & France & France & France & France \\
\hline Start of operations & 1987 & 1980 & 1980 & 1981 & 1981 & 1985 & 1985 & 1981 & 1983 & 1983 & 1983 & 1988 \\
\hline Status & Operating & Operating & Operating & Operating & Operating & Operating & Operating & Operating & Operating & Operating & Operating & Operating \\
\hline Slze (MWo) (Net) & 1300 & 910 & 910 & 910 & 910 & 910 & 910 & 910 & 910 & 910 & 910 & 1310 \\
\hline Vendor & Framatome & Framatome & Framatome & Framatome & Framalome & Framatome & Framatome & Framatome & Framatome & Framatome & Framatome & Framatome \\
\hline$A / E$ & EdF & $E \mathrm{dF}$ & EdF & EdF & EdF & EdF & EdF & EdF & $\mathrm{EdF}$ & $\mathrm{EdF}$ & EdF & EdF \\
\hline Pre or Post TMI & Post & Post & Post & Post & Post & Post & Post & Post & Post & Post & Post & Post \\
\hline No. of steam furbines & 1 & 1 & 1 & 1 & 1 & 1 & 1 & 1 & 1 & 1 & 1 & 1 \\
\hline \multicolumn{13}{|l|}{ Coollng } \\
\hline Date EOL motal avallable & 2037 & 2030 & 2030 & 2031 & 2031 & 2035 & 2035 & 2031 & 2033. & $2033^{\circ}$ & 2033 & 2038 \\
\hline \multicolumn{13}{|l|}{ Quantlly of motal (lonnes): } \\
\hline Aluminum Non-radloactive & 95 & 75 & 75 & 75 & 75 & 75 & 75 & 75 & 75 & 75 & 75 & 96 \\
\hline Surt. contam.-cleanable & 18 & 14 & 14 & 14 & 14 & 14 & 14 & 14 & 14 & 14 & 14 & 18 \\
\hline Surt. contam.-non-clnbl & 0 & 0 & 0 & 0 & 0 & 0 & of & of & 0 & 0 & 으 & 0 \\
\hline Activated & 6 & 5 & 5 & 5 & 5 & 5 & 5 & 5 & 5 & 5 & 5 & 6 \\
\hline Copper Non-radioactive & 5837 & 4601 & 4601 & 4601 & 4601 & 4601 & 4601 & 4601 & 4601 & 4601 & 4601 & 5866 \\
\hline Surt. contam.-cleanable & 95 & 75 & 75 & 75 & 75 & 75 & 75 & 75 & 75 & 75 & 75 & 96 \\
\hline Surf. contam.-non-cinbl & 0 & 0 & 0 & 0 & 0. & 0 & 0 & 0 & ㅇ. & 0 & 0 & $\underline{0}$ \\
\hline Activaled & 24 & 19 & 19 & 19 & 19 & 19 & 19 & 19 & 19 & 19 & 19 & 24 \\
\hline Non-radioactive & 20 & 20 & 20 & 20 & 20 & 20 & 20 & 20 & 20 & 20 & 20 & 20 \\
\hline Sur. contam.-cleanable & 0 & 0 & 0 & 0 & 0 & 0 & 0 & 0 & 0 & 0 & 0 & 0 \\
\hline Surt. contam.-non-clnbl & 0 & 0 & 0 & 0 & 0 & 0 & 0 & 0 & 0 & 아 & 0 & 0 \\
\hline Activaled & 0 & 0 & 0 & 0 & 0 & 0 & a & 0 & of & of & 0 & 0 \\
\hline Steol \& Iron Non-radioactive & 9875 & 7785 & 7785 & 7785 & 7785 & 7785 & 7785 & 7785 & 7785 & 7785 & 7785 & 9925 \\
\hline Surf contam.-cleanable & 7981 & 6292 & 6292 & 6292 & 6292 & 6292 & 6292 & 6292 & 6292 & 6292 & 6292 & 8022 \\
\hline Surf. contam.-non-clnbl & 0 & 0 & 0 & 0 & 0 & 0 & 0 & 0 & 0 & 0 & 0 & 0 \\
\hline Aclivated & 3502 & 2761 & 2761 & 2761 & 2761 & 2761 & 2761 & 2761 & 2761 & .2761 & 2761 & 3520 \\
\hline St. Steol Non-radioactive & 0 & 0 & 0 & 0 & 0 & 0 & 0 & 0 & 0 & 0 & 0 & 0 \\
\hline Surt. contam.-cleanable & 1072 & 845 & 845 & 845 & 845 & 845 & 845 & 845 & 845 & 845 & 845 & 1078 \\
\hline Surf. contam.non-cinbl & 357 & 282 & 282 & 282 & 282 & 282 & 282 & 282 & 282 & 282 & 282 & 359 \\
\hline Activated & 798 & 629 & 629 & 629 & 629 & 629 & 629 & 629 & 629 & 629 & 629 & 802 \\
\hline Zirconium Non-radioactive & 0 & 0 & 0 & 0 & 0 & 0 & 0 & 0 & 0 & 0 & 0 & 0 \\
\hline Surf. contam.cleanable & 0 & 0 & 0 & 0 & 0 & 0 & 0 & 0 & 0 & 0 & 0 & 0 \\
\hline Surl. contam.-non-clnbl & 0 & $\underline{0}$ & 0 & 0 & 0 & 0 & 0 & 0 & 0 & 0 & 0 & 0 \\
\hline Activated & 01 & 0 & 0 & 0 & 0 & 0 & 0 & 0 & 0 & 01 & 0 & 0 \\
\hline
\end{tabular}




\begin{tabular}{|c|c|c|c|c|c|c|c|c|c|c|c|c|}
\hline 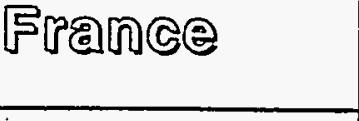 & $\begin{array}{c}\text { Nogent } \\
2 \\
\end{array}$ & $\begin{array}{c}\text { Paluel } \\
1 \\
\end{array}$ & $\begin{array}{c}\text { Paluel } \\
2 \\
\end{array}$ & $\begin{array}{c}\text { Paluel } \\
3 \\
\end{array}$ & $\begin{array}{c}\text { Paluel } \\
4 \\
\end{array}$ & $\begin{array}{c}\text { Saint } \\
\text { Alban } 1 \\
\end{array}$ & $\begin{array}{c}\text { Saint } \\
\text { Alban } 2 \\
\end{array}$ & $\begin{array}{c}\text { St Laurent } \\
\text { B1 } \\
\end{array}$ & $\begin{array}{c}\text { St Laurent } \\
\mathrm{B} 2 \\
\end{array}$ & $\begin{array}{c}\text { Tricastin } \\
7 \\
\end{array}$ & $\begin{array}{c}\text { Tricastin } \\
2 \\
\end{array}$ & $\begin{array}{c}\text { Tricastin } \\
3 \\
\end{array}$ \\
\hline F́uel cycle stago (FCT) & Reactor & Reactor & Reactor & Reactor & Reaclor & Reactor & Reactor & Reactor & Reactor & Reactor & Reactor & Reactor \\
\hline Identifier & 615FP & $554 \mathrm{FP}$ & $585 \mathrm{FP}$ & $588 \mathrm{FP}$ & 589FP & 611FP & 612FP & 550FP & 552FP & 503FP & 505FP & 420FP \\
\hline Plant type & PWR & PWR & PWR & PWR & PWR & PWR & PWR & PWR & PWR & PWR & PWR & PWR \\
\hline Location & France & France & France & France & France & France & France & France & France & France & France & France \\
\hline Start of operations & 1989 & 1985 & 1985 & 1986 & 1986 & 1986 & 1987 & 1983 & 1983 & 1980 & 1980 & 1981 \\
\hline Status & Operating & Operating & Operating & Operating & Operating & Operating & Operating & Operating & Operating & Operating & Operating & Operating \\
\hline Size (MWo) (Nat) & 1310 & 1330 & 1330 & 1330 & 1330 & 1335 & 1335 & 880 & 880 & 915 & 915 & 915 \\
\hline Vendor & Framatome & Framatome & Framatome & Framatome & Framatome & Framalome & Framatome & Framatome & Framatome & Framatome & Framatome & Framatome \\
\hline AIE & EdF & EdF & EdF & EdF & EdF & EdF & EdF & EdF & EdF & EdF & EdF & EdF \\
\hline Pre or Post TMI & Post & Post & Post & Post & Post & Post & Post & Post & Post & Post & Post & Post \\
\hline No. of steam turbines & 1 & 1 & 1 & 1 & 1 & 1 & 1 & 1 & 1 & 1 & 1 & 1 \\
\hline Coolling & & & & & & & & & & River & River & River \\
\hline $\begin{array}{l}\text { Date EOL motal avallablo } \\
\mathbb{Z Z Z W Z}\end{array}$ & 2039 & 2035 & 2035 & 2036 & $2036^{\circ}$ & 2036 & 2037 & $\frac{2033}{2120}$ & 2033 & 2030 & 2030 & $\frac{2031}{2221}$ \\
\hline \multicolumn{13}{|l|}{ Quantity of matal (tonnes): } \\
\hline Aluminum Non-radioactive & 96 & 97 & 97 & 97 & 97 & 97 & 97 & 73 & 73 & 75 & 75 & 75 \\
\hline Surf. contam.-cleanable & 18 & 18 & 18 & 18 & 18 & 18 & 18 & 14 & 14 & 14 & 14 & 14 \\
\hline Surt. contam.-non-cinbl & 0 & 0 & 0 & 0 & 요 & 0 & 0 & 0 & 0 & 0 & 0 & 0 \\
\hline Activated & 6 & 6 & 6 & 6 & 6 & 6 & 6 & 5 & 5 & 5 & 5 & 5 \\
\hline Non-radjoactive & 5866 & 5926 & 5926 & 5926 & 5926 & 5941 & 5941 & 4500 & 4500 & 4618 & 4618 & 4618 \\
\hline Surf. contam.-cleanable & 96 & 97 & 97 & 97 & 97 & 97 & 97 & 73 & 73 & 75 & 75 & 75 \\
\hline Surf. contam.-non-clnbl & 의 & 0 & 0 & 0 & 0 & 0 & 요 & 0 & 0 & 0 & 0 & 0 \\
\hline Activated & 24 & 24 & 24 & 24 & 24 & 24 & 24 & 18 & 18 & 19 & 19 & 19 \\
\hline Non-radioactive & 20 & 20 & 20 & 20 & 20 & 20 & 20 & 20 & 20 & 20 & 20 & 20 \\
\hline Surt. contam.-cleanable & 0 & 0 & 0. & 0 & 0 & 0 & 0 & 0 & 0 & 0 & 0 & 0 \\
\hline Surt. contam.-non-clnbl & of & 0 & 0 & 0 & 0 & 0 & 0 & 0 & 0 & 0 & 0 & 0 \\
\hline Activated & of & 0 & of & 0 & 0 & 0 & 0 & 0 & 0 & 0 & 0 & 0 \\
\hline Steol \& Iron Non-radioactive & 9925 & 10026 & 10026 & 10026 & 10026 & 10051 & 10051 & 7613 & 7613 & 7813 & 7813 & 7813 \\
\hline Surt. contam. cleanable & 8022 & 8103 & 8103 & 8103 & 8103 & 8123 & 8123 & 6153 & 6153 & 6315 & 6315 & 6315 \\
\hline Surl. contam.-non-clnbl & of & 0 & 0 & 0 & 0 & 0 & 0 & 0 & 0 & .0 & 0 & 0 \\
\hline Activaled & 3520 & 3556 & 3556 & 3556 & 3556 & 3565 & 3565 & 2700 & 2700 & 2771 & 2771 & 2771 \\
\hline Non-radioactive & 0 & 0 & 0 & 0 & 0 & 0 & 0 & 0 & 0 & 0 & 0 & 0 \\
\hline Surf.contam.-cleanable & 1078 & 1088 & 1088 & 1088 & 1088 & 1091 & 1091 & 826 & 826 & 848 & 848 & 848 \\
\hline Surf. contam.-non-cinbl & 359 & 363 & 363 & 363 & 363 & 364 & 364 & 275 & 275 & 283 & 283 & 283 \\
\hline Activaled & 802 & 810 & 810 & 810 & 810 & 812 & 812 & 615 & 615 & 631 & 631 & 631 \\
\hline Zirconlum Non-radioactive & 0 & 0 & of & 0 & 0 & 0 & 0 & 0 & 0 & 0 & 0 & 0 \\
\hline Surf. contam.-cleanable & 0 & 0 & 0. & 의 & 0 & 0 & 0 & 0 & 0 & 0 & 0 & 0 \\
\hline Surf. contam.-non-cinbl & 0 & 운 & of & 0 & 0 & 요 & 0 & 0 & 0 & 0 & 0 & 0 \\
\hline Activated & 0 & 0 & 0 & 0 & 0 & 0 & 0 & 0 & 0 & 0 & 0 & 0 \\
\hline
\end{tabular}




\begin{tabular}{|c|c|c|c|c|c|c|c|c|}
\hline 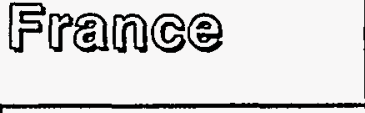 & $\begin{array}{c}\text { Tricastin } \\
4 \\
\end{array}$ & $\begin{array}{c}\text { Bugey } \\
1 \\
\end{array}$ & $\begin{array}{c}\text { ChInon } \\
\text { A2 } \\
\end{array}$ & $\begin{array}{c}\text { Chinon } \\
\mathrm{A3} \\
\end{array}$ & $\begin{array}{c}\text { St Laurent } \\
\text { A1 } \\
\end{array}$ & $\begin{array}{c}\text { St Laurent } \\
\mathrm{A2} \\
\end{array}$ & Phenix & $\begin{array}{c}\text { Super } \\
\text { Phenix } 1 \\
\end{array}$ \\
\hline Fuel cycle stage (FCT) & Reactor & Reactor & Reactor & Reactor & Reactor & Reactor & Reactor & Reactor \\
\hline Identifler & $421 \mathrm{FP}$ & $139 \mathrm{FG}$ & 50FG. & $81 F G$ & $97 F G$ & $138 \mathrm{FG}$ & 210FF & 357FF \\
\hline Plant type & PWR & Magnox IIII & Magnox 1 & Magnox III & Magnox III & Magnox III & LMA & LMR \\
\hline Location & France & France & France & France & France & France & France & France \\
\hline Start of operations & 1981 & 1972 & 1965 & 1967 & 1969 & 1971 & 1974 & 1986 \\
\hline Status & Operating & Operating & Shut down & Shut down & Shut down & Shut down & Operating & Operating \\
\hline Size (MWe) (Net) & 915 & 540 & 180 & 360 & 390 & 450 & 233 & 1200 \\
\hline Vendor & Framalome & Various & Various & Various & Various & Various & CEANEDFIGAAA & Nvtme/Nira \\
\hline $\mathrm{A} / \mathrm{E}$ & EdF & $\mathrm{EdF}$ & EdF/CEA & EdF/CEA & EdF & EdF & CEAGAAAEEOF & Nersa \\
\hline Pre or Post TMI & Post & Pre & Pre & Pre & Pro & Pre & Pre & Post \\
\hline No. of steam turbines & 1 & 2 & 2 & 2 & 2 & 2 & 1 & \\
\hline Cooling & River & & & & & & & \\
\hline Date EOL motal avaliable & 2031 & 2022 & 2015 & 2017 & 2019 & 2021 & 2024 & 2036 \\
\hline \multicolumn{9}{|l|}{ Quantity of metal (tonnes): } \\
\hline Aluminum Non-radioactive & 75 & 80 & 0 & 80 & 80 & 80 & & \\
\hline Surt. contam.-cleanable & 14 & 15 & 0 & 15 & 15 & 15 & & \\
\hline Surf. conlam.-non-clnbl & 0 & 0 & 0 & 0 & 0 & 0 & & \\
\hline Activated & 5 & 5 & 0 & 5 & 5 & 5 & & \\
\hline Non-radloactive & 4618 & 3900 & 1900 & 3900 & 3900 & 3900 & & \\
\hline Surt. contam.-cleanable & 75 & 80 & 50 & 80 & 80 & 80 & & \\
\hline Surf. contam.-non-clnbl & 0 & 0 & 0 & 0 & 0 & 0 & & \\
\hline Activated & 19 & 20 & 50 & 20 & 20 & 20 & & \\
\hline Non-radioactive & 20 & 20 & 0 & 20 & 20 & 20 & & \\
\hline Surl. contam.-cleanable & 0 & 0 & 0 & 0 & 0 & 0 & & \\
\hline Surt. contam.non-cinbl & 0 & 0 & 0 & 0 & 0 & 요 & & \\
\hline Activated & 0 & 0 & 0 & 0 & 0 & 0 & & \\
\hline Steol \& Iroin Non-radioactive & 7813 & 12770 & 3800 & 12770 & 12770 & 12770 & & \\
\hline Surf.contam.cleanable & 6315 & 5630 & 4950 & 5630 & 5630 & 5630 & & \\
\hline Surf. contam.-non-cinbl & 0 & 0 & 0 & 0 & 0 & 0 & & \\
\hline Aclivated & 2771 & 2100. & 1000 & 2100 & 2100 & 2100 & & \\
\hline St.Steol Non-radioactive & 0 & 60 & 100 & 60 & 60 & 60 & & \\
\hline Surt. contam.-cleanable & 848 & 900 & 0 & 900 & 900 & 900 & & \\
\hline Surf. contam.-non-clnbl & 283 & 0 & 0 & 0 & 0 & 0 & & \\
\hline Aclivated & 631 & 165 & 0 & 165 & 165 & 165 & & \\
\hline Zirconium Non-radioactive & 0 & 0 & 0 & 0 & 0 & 0 & & \\
\hline Surf. contam.-cleanable & 0 & 0 & 0 & 0 & 요 & 요 & & \\
\hline Surt. contam.-non-clnbl & 0 & 0 & 0 & 0 & 0 & 0 & & \\
\hline Activated & 0 & 0. & 0 & 0 & 0 & 0 & & \\
\hline
\end{tabular}




\begin{tabular}{|c|c|c|c|c|c|c|c|c|c|c|c|c|}
\hline 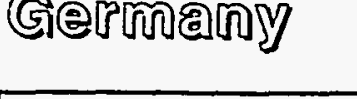 & $\begin{array}{c}\text { Brunsbuet } \\
\text { tel KKB }\end{array}$ & $\begin{array}{l}\text { Gundrem- } \\
\text { mingen A }\end{array}$ & $\begin{array}{l}\text { Gundrem- } \\
\text { mingen } \mathbf{B}\end{array}$ & $\begin{array}{l}\text { Gundrem- } \\
\text { mingen C }\end{array}$ & $\begin{array}{r}\text { Isar } \\
\text { KKI1 } \\
\end{array}$ & $\begin{array}{l}\text { Kahl } \\
\text { VAK } \\
\end{array}$ & $\begin{array}{c}\text { Kruemmel } \\
\text { KKK }\end{array}$ & $\begin{array}{c}\text { Lingen } \\
\text { KWL }\end{array}$ & $\begin{array}{c}\text { Phillipps- } \\
\text { burg } 1\end{array}$ & $\begin{array}{l}\text { Wuergas- } \\
\text { sen KWW }\end{array}$ & $\begin{array}{c}\text { Biblis } \\
\text { A } \\
\end{array}$ & $\begin{array}{c}\text { Biblis } \\
\mathrm{B} \\
\end{array}$ \\
\hline Fuel cycle stage (FCT) & Reactor & Reactor & Reactor & Reactor & Reactor & Reactor & Reactor & Reactor & Reactor & Reactor & Reactor & Reactor \\
\hline Identifler & $274 D B$ & 91DB & $5220 B$ & 526DB & $3390 \mathrm{DB}$ & $620 \mathrm{~B}$ & $385 \mathrm{DB}$ & $110 D B$ & $341 \mathrm{DB}$ & $214 \mathrm{DB}$ & $2730 B$ & $3380 \mathrm{~B}$ \\
\hline Plant type & BWR & BWR & BWR & BWR & BWR & BWR & BWR & BWR & BWR & BWR & PWR & PWR \\
\hline Localion & Gemany,FR & Germany,FR & Germany,FR & Germany,FR & Germany,FR & Germany,FR & Germany,FR & Germany, FR & Germany,FR & Germany,FR & Germany,FR & Gormany,FR \\
\hline Start of operations & 1977 & 1967 & 1984 & 1985 & 1979 & 1962 & 1984 & 1968 & 1980 & 1975 & 1875 & 1977 \\
\hline Status & Operating & Shut down & Operaling & Operating & Operating & Shut down & Operating & Shut down & Operating & Operating & Operating & Operating \\
\hline Slze (MWe) (Not) & $\pi 1$ & 237 & 1240 & 1248 & 870 & 15 & 1260 & 256 & 864 & 640 & 1146 & 1240 \\
\hline Vendor & KWU & GE/Ruhrst. & KWU & & KWU & ⿷E & KWU & AEG & KWR/AEG & AEG & Siemens & Siemens \\
\hline$A / E$ & KWU & AEG/Hochtief & KWU & KWU & KWU & $A B G$ & KWU & AEG/Hochtie & KWU & Siemens & KWU & KWU \\
\hline Pre or Post TMI & Pre & Pre & Post & Post & Pre & Pro & Post & Pre & Post & Pre & Pre & Pre \\
\hline No. of steam turbines & 1 & 1 & 1 & 2 & 1 & 1 & 1 & 1 & 1 & 1 & 1 & 1 \\
\hline Cooling & River & & Tower & Tower & River & & River & & River & & RveAwr & RurAwr \\
\hline Date EOL matal available & 2027 & 2017 & 2034 & 2035 & 2029 & 2012 & 2034 & 2018 & 2030 & 2025 & 1925 & 2027 \\
\hline \multicolumn{13}{|l|}{ Quantity of motal (tonnes): } \\
\hline Aluminum Non-radioactive & 67 & 31 & 92 & 93 & 73 & 5 & 93 & 32 & 73 & 59 & 88 & 92 \\
\hline Surf. contam.-cleanable & 13 & 6 & 17 & 17 & 14 & 1 & 17 & 6 & 14 & 11 & 16 & 17 \\
\hline Surt. contam.-non-clnbl & 0 & 0 & 0 & 0 & 0 & 0 & 0 & 0 & 0 & 0 & $\underline{0}$ & $\underline{0}$ \\
\hline Activated & 4 & 2 & 6 & 6 & 5 & 0 & 6 & 2 & 5 & 4 & 5 & 6 \\
\hline Non-radioactive & 4120 & 1877 & 5656 & 5680 & $\therefore \quad 4466$ & 298 & 5716 & 1976 & 4445 & 3639 & 5366 & 5656 \\
\hline Surf. contam. cleanable & 67 & 31 & 92 & 93 & 73 & 5 & 93 & 32 & 73 & 59 & 88 & 92 \\
\hline Surf. contam.-non-clnbl & 0 & 0 & 0 & 0 & 0 & 0 & 0 & 0 & 0 & 0 & 0 & 0 \\
\hline Activaled & 17 & 8 & 23 & 23 & 18 & 1 & 23 & 8 & 18 & 15 & 22 & 23 \\
\hline Lead $\quad$ Non-radioactive & 20 & 20 & 20 & 20 & 20 & 20 & 20 & 20 & 20 & 20 & 20 & 20 \\
\hline Surf. contam.-cleanable & 0 & 0 & 0 & 0 & 0 & 0 & 0 & 0 & 0 & 0 & 0 & 0 \\
\hline Surf. contam.-non-clnbl & 0 & 0 & 0 & 0 & 0 & 0 & 0 & 0 & 0 & 0 & 0 & 0 \\
\hline Activated & 0 & 0 & $\underline{0}$ & 0 & 0 & 0 & 0 & 0 & 0 & 0 & 0 & 0 \\
\hline Steel \& iron Non-radioactive & 4204 & 1915 & 5771 & 5796 & 4557 & 304 & 5833 & 2016 & 4536 & 3713 & 9078 & 9568 \\
\hline Surt. contam.cleanable & 5633 & 2566 & 7733 & 7766 & 6106 & 408 & 7816 & 2701 & 6078 & 4976 & 7337 & 7733 \\
\hline Surt. contam.-non-clnbl & 0 & 0 & 0 & 0 & 0 & 0 & 0 & 0 & 0 & 0 & 0 & 0 \\
\hline Activated & 2943 & 1340 & 4040 & 4057 & 3190 & 213 & 4083 & 1411 & 3175 & 2599 & 3220 & 3393 \\
\hline St. Stoel Non-radioactive & 0 & 0 & 0 & 0 & 0 & 0 & 0 & 0 & 0 & 0 & 0 & 0 \\
\hline Surt. contam.cleanable & 504 & 230 & 693 & 695 & 547 & 36 & 700 & 242 & 544 & 446 & 986 & 1039 \\
\hline Surf. contam.-non-clnbl & 0 & 0 & 0 & 0 & 0 & 0 & 0 & 0 & 0 & 0 & 329 & 346 \\
\hline Activated & 563 & 257 & 773 & 777 & 611 & 41 & 782 & 270 & 608 & 498 & 734 & 773 \\
\hline Zirconlum Non-radloactive & 0 & 0 & 0 & 0 & 0 & 0 & 0 & 0 & 0 & 0 & 0 & 0 \\
\hline Surl, contam.-cleanable & 0 & 0 & $\underline{0}$ & $\underline{0}$ & 0 & 0 & 0 & 0 & 0 & 0 & 0 & 0 \\
\hline Surf, contam.non-cinbl & 0 & $\underline{0}$ & 0 & 0 & 0. & 0 & 0 & 0 & 0 & 0 & 0 & 0 \\
\hline Activated & 0 & 0 & 0 & 0 & 0 & 0 & 0 & 0 & 0 & 0 & 0 & 0 \\
\hline
\end{tabular}




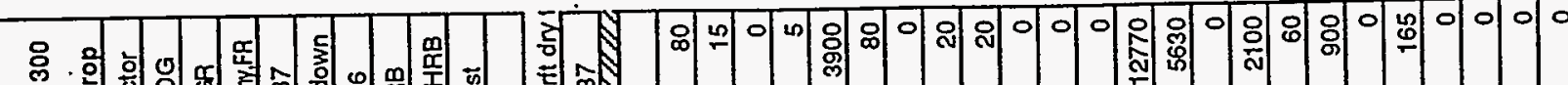

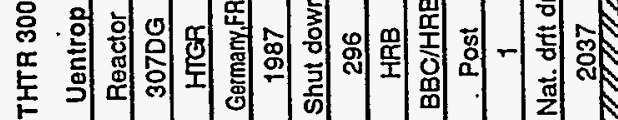

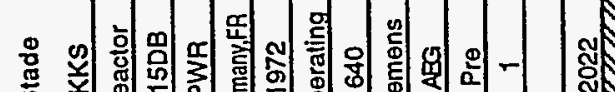

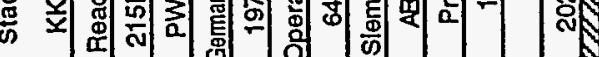

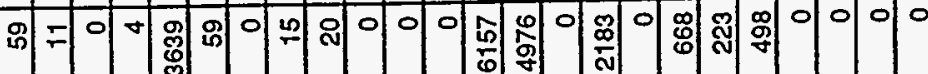

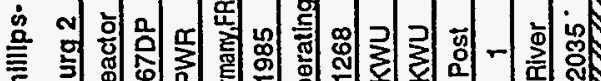

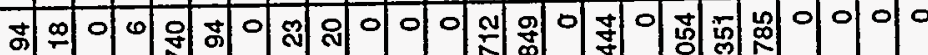

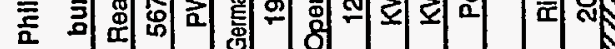

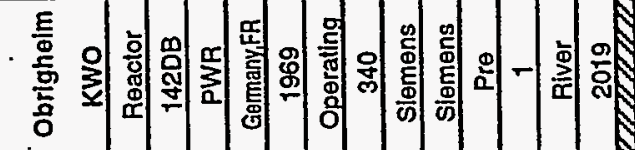

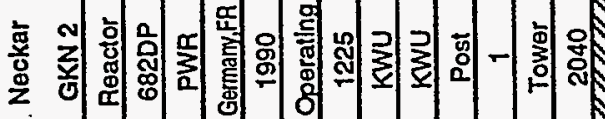

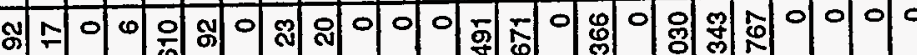

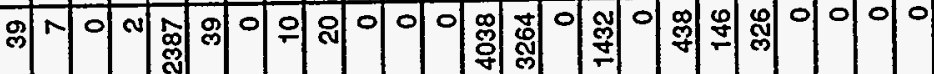

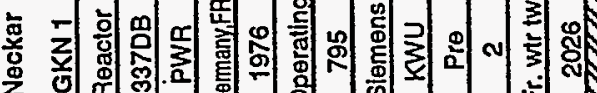

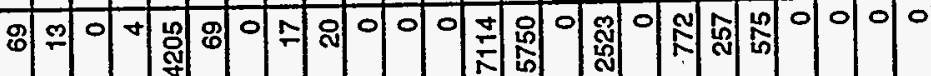

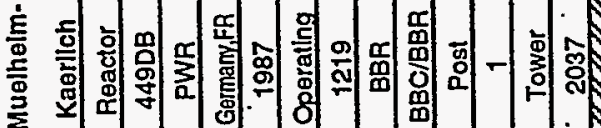

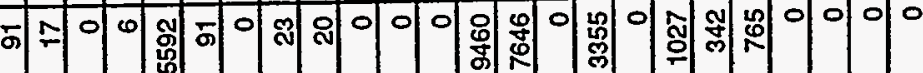

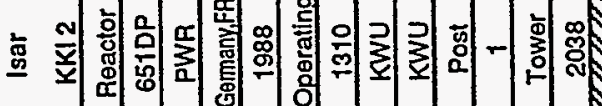

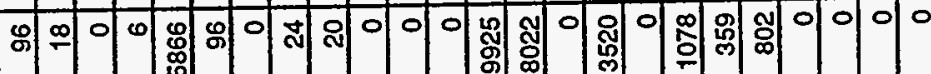

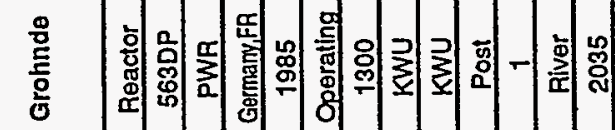

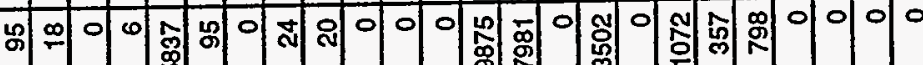

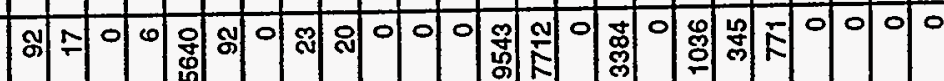

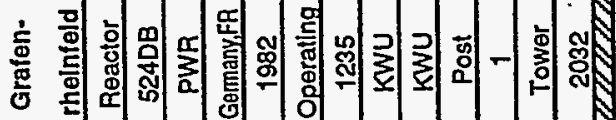

豆

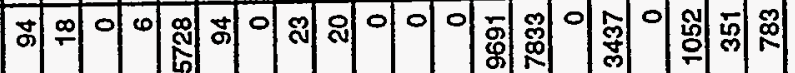

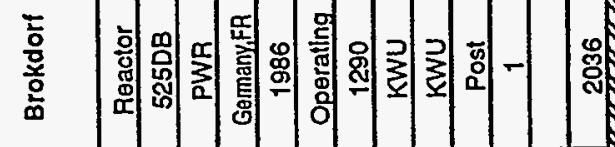

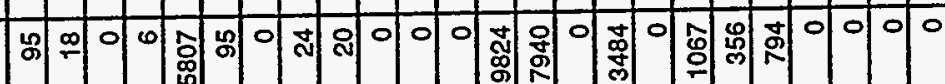

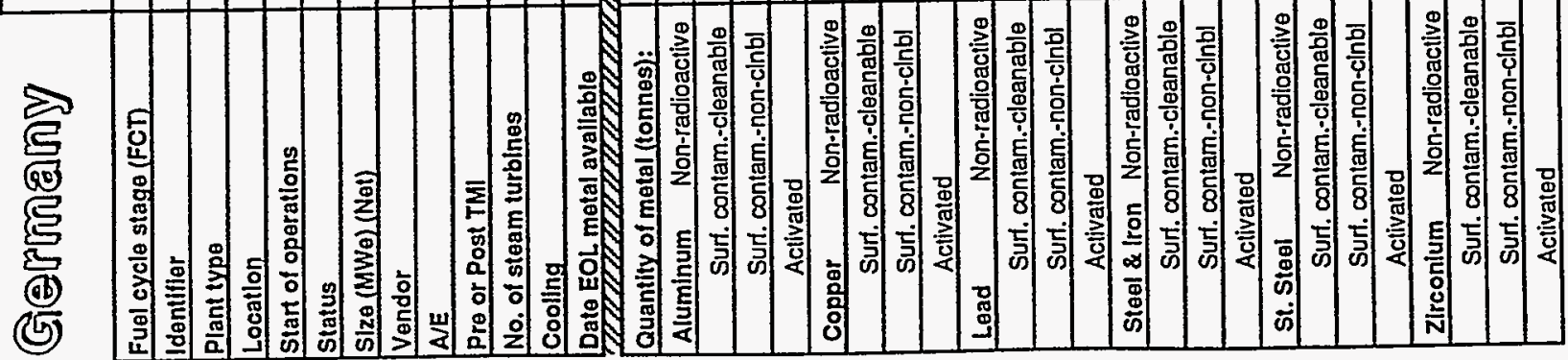




\begin{tabular}{|c|c|c|c|c|c|c|c|c|c|c|c|}
\hline Gㅁำณy & $\begin{array}{l}\text { Unterwe- } \\
\text { ser fKKU }\end{array}$ & $\begin{array}{l}\text { Grelfswald } \\
1 \text { (Lubmin) }\end{array}$ & $\begin{array}{l}\text { Grelfswald } \\
2 \text { (Lubmin) } \\
\end{array}$ & $\begin{array}{l}\text { Greliswald } \\
\mathbf{3} \text { (Lubmin) }\end{array}$ & $\begin{array}{l}\text { Grellswald } \\
4 \text { (Lubmin) }\end{array}$ & $\begin{array}{l}\text { Greilswaid } \\
5 \text { (Lubmin) } \\
\end{array}$ & $\begin{array}{l}\text { Grelfswald } \\
6 \text { (Lubmin) } \\
\end{array}$ & $\begin{array}{l}\text { Greilswaid } \\
7 \text { (Lubmin) } \\
\end{array}$ & $\begin{array}{r}\text { Greifswald } \\
.8 \text { (Lubmin) } \\
\end{array}$ & $\begin{array}{c}\text { Stendal } \\
1 \\
\end{array}$ & $\begin{array}{c}\text { Stendal } \\
2 \\
\end{array}$ \\
\hline Fuel cycle stage (FCT) & Reacior & Reactor & Reactor & Reactor & Reactor & Reactor & Reactor & Reactor & Reactor & Reactor & Reactor \\
\hline Identifler & $340 \mathrm{DB}$ & 174DDRP & 218DDRP & 389DDRP & 390DDRP & 622DDRP & 623DDRP & 6240RP & 625DDRP & 705DDRP & 706DDRP \\
\hline Plant type & PWR & WER & WER & WER & WER & WER & WER & WER & WER & WER & WER \\
\hline Location & Germany,FR & Germam,DR & Germany,DA & Germany, DR & Gemany,DR & Germany,DR & Germany,OR & Germany,DR & Germany,DR & Germany.DR & Germany,DR \\
\hline Start of operations & 1979 & 1974 & 1975 & 1978 & 1979 & 1990 & & & & & \\
\hline Status & Operating & Shut down & Shut down & Shut down & Shut down & Shut down & Opsraling & Under Const & Under Const & Under Const & Under Const \\
\hline Size (MWo) (Nat) & 1230 & 440 & 440 & 440 & 440 & 440 & 440 & 440 & 440 & 1000 & 1000 \\
\hline Vendor & KWU & AEI & AEE & AEE & AEI & AEI & AEI & AEE & AEE & AEE & AEE \\
\hline A/E & KWU & & $\cdot$ & & & TEP/KKAB & TEP/KKAB & TEP/KKAB & TEP/KKAB & TEP/KKAB & TEP/KKAB \\
\hline Pre or Post TMI & Pro & Pre & Pre & Pre & Pre & Post & Post & Post & Post & Post & Post \\
\hline No. of steam turbines & 1 & 2 & 2 & 2 & 2 & 2 & 2 & 2 & 2 & 1 & 1 \\
\hline Coolling & wr & & & & & & & & & Tower & Tower \\
\hline $\begin{array}{l}\text { Date EOL motal avallabla } \\
\mathbb{Z Z Z}\end{array}$ & 2029 & 2024 & 2025 & $\frac{2028}{21202}$ & :2029 & 2040 & 2053 & 2053 & 2053 & 2053 & 2053 \\
\hline \multicolumn{12}{|l|}{ Quantity of matal (tonnes): } \\
\hline Aluminum Non-radioactive & 92 & 46 & 46 & 46 & 46 & 46 & 46 & 46 & 46 & 80 & 80 \\
\hline Surf. contam.-cleanable & 17 & 9 & 9 & 9 & 9 & 9 & 9 & 9 & 9 & 15 & 15 \\
\hline Surf. contam.-non-cinbl & 0 & 0 & 0 & 0 & 요 & $\underline{0}$ & 0 & 0 & 0 & 0 & 0 \\
\hline Activated & 6 & 3 & 3 & 3 & 3 & 3 & 3 & 3 & 3 & 5 & 5 \\
\hline Non-radioaclive & 5625 & 2840 & 2840 & 2840 & 2840 & 2840 & 2840 & 2840 & 2840 & 4900 & 4900 \\
\hline Surf. contam.-cleanable & 92 & 46 & 46 & 46 & 46 & 46 & 46 & 46 & 46 & 80 & 80 \\
\hline Surt. contam.-non-cinbl & 0 & 0 & 0 & 0 & 의 & 0 & 0 & 0 & 0 & 0 & 0 \\
\hline Activated & 23 & 12 & 12 & 12 & 12 & 12 & 12 & 12 & 12 & 20 & 20 \\
\hline Non-radioactive & 20 & 20 & 20 & 20 & 20 & 20 & 20 & 20 & 20 & 20 & 20 \\
\hline Surf. contam.cleanable & of & 0 & 0 & $\underline{0}$ & o & 0 & 0 & 0 & 0 & $\underline{0}$ & 0 \\
\hline Surt. contam,-non-clnbl & of & 0 & 0 & 0 & 우 & $\underline{0}$ & 0 & 0 & 0 & 0 & 0 \\
\hline Activated & of & 0 & $\underline{0}$ & 0 & 0 & 0 & 0 & 0 & 0 & 0 & 0 \\
\hline Steol \& Iron Non-radioactive & 9517 & 12030 & 12030 & 12030 & 12030 & 12030 & 12030 & 12030 & 12030 & 19248 & 19248 \\
\hline Surf. contam.-cleanable & 7692 & 4669 & 4669 & 4669 & 4669 & 4669 & 4669 & 4669 & 4669 & 7156 & 7156 \\
\hline Surt. contam.-non-cinbl & 0 & 46 & 46 & 46 & 46 & $\cdot 46$ & 46 & 46 & 46 & 69 & 69 \\
\hline Activated & 3375 & 363 & 363 & 363 & 363 & 363 & 363 & 363 & 363 & 581 & 581 \\
\hline Non-radioactive & 0 & 0 & 0 & 0 & 0 & 0 & 0 & 0 & 0 & 0 & 0 \\
\hline Surf. contam.-cleanable & 1033 & 1599 & 1599 & 1599 & 1599 & 1599 & 1599 & 1599 & 1599 & 2600 & 2600 \\
\hline Surt. contam.-non-clnbl & 344 & 0 & 0 & 0 & 0 & 0 & 0 & 0 & 0 & 0 & 0 \\
\hline Activated & 769 & 254 & 254 & 254 & 254 & 254 & 254 & 254 & 254 & 406 & 406 \\
\hline Zirconjum Non-radioactive & 0 & 0 & $\underline{0}$ & $\underline{0}$ & 0 & 0 & 0 & 0 & 0 & 0 & 0 \\
\hline Surf. contam.-cleanable & 0 & 0 & $\underline{0}$ & 0 & 요 & 0 & 0 & 0 & 0 & 0 & 0 \\
\hline Surf. contam.-non-cinbl & 요 & 0 & 0 & 0 & 아 & 0 & 0 & 0 & 0 & 0 & 0 \\
\hline Activated & 이 & 0 & 0 & 0 & 0 & 0 & 0 & 0 & 0 & 0 & 0 \\
\hline
\end{tabular}




\begin{tabular}{|c|c|c|c|c|c|c|c|c|c|c|c|c|}
\hline (U) & $\begin{array}{c}\text { Dungeness } \\
\mathrm{B1} \\
\end{array}$ & $\begin{array}{c}\text { Dungeness } \\
\mathrm{B2} \\
\end{array}$ & $\begin{array}{c}\text { Hartlepool } \\
1\end{array}$ & $\begin{array}{c}\text { Harllepool } \\
2 \\
\end{array}$ & $\begin{array}{c}\text { Heysham } \\
1-1 \\
\end{array}$ & $\begin{array}{c}\text { Heysham } \\
1-2 \\
\end{array}$ & $\begin{array}{c}\text { Heysham } \\
2-1 \\
\end{array}$ & $\begin{array}{c}\text { Heysham } \\
2.2 \\
\end{array}$ & $\begin{array}{l}\text { Hinkley } \\
\text { Polnt B1 }\end{array}$ & $\begin{array}{l}\text { Hinkley } \\
\text { Point B2 }\end{array}$ & $\begin{array}{l}\text { Hunter- } \\
\text { ston B1 }\end{array}$ & $\begin{array}{l}\text { Hunter- } \\
\text { ston } 82\end{array}$ \\
\hline Fuel cycle stage (FCT) & Reactor & Reactor & Reactor & Reactor & Reactor & Reaclor & Peactor & Reactor & Reactor & Reactor & Reactor & Reactor \\
\hline Identifier & 116GBG & $117 \mathrm{GBG}$ & $180 \mathrm{GBG}$ & $181 \mathrm{GBQ}$ & 182GBG & $183 \mathrm{GBQ}$ & 641GBG & 642GBG & $175 \mathrm{GBG}$ & $177 \mathrm{GBG}$ & $178 \mathrm{GBG}$ & $179 \mathrm{GBG}$ \\
\hline Plant type & AGR & $A C A$ & $A C R$ & $A C R$ & $A G R$ & $A G R$ & $A G R$ & $A G R$ & $A C R$ & $A C R$ & $A C R$ & $A G R$ \\
\hline Location & UK & UK & UK & UK & UK & UK & UK & UK & UK & UK & UK & UK \\
\hline Stant of operations & 1985 & 1988 & 1984 & 1985 & 1984 & 1985 & 1988 & 1989 & 1978 & 1976 & 1976 & 1977 \\
\hline Status & Sperating & Operating & Oporating & Operating & Operating & Operating & Operating & Operating & Operating & Operating & Operating & Operating \\
\hline Slze (MWe) (Net) & 600 & 600 & 625 & 625 & 625 & 625 & 615 & 615 & 625 & 625 & 624 & 624 \\
\hline Vendor & APC & APC & NNC & MC & NNC & NO & NC & NNC & INPG & TNPG & TNPG & TNPG \\
\hline A/E & $A P C$ & $A P C$ & MNC & No & NO & NC & MC & NNC & INPG & TNPG & TNPG & TNPG \\
\hline Pre or Post TMI & Post & Post & Post & Post & Post & Post & Post & Post & Pre & Pre & Pre & Pre \\
\hline No. of stoam furbines & 1 & 1 & 1 & 1 & 1 & 1 & 1 & 1 & 1 & 1 & 1 & 1 \\
\hline \multicolumn{13}{|l|}{ Coolling } \\
\hline Date EOL matal avallablo & $2035^{\circ}$ & 2038 & 2034 & 2035 & 2034 & 2035 & 2038 & 2039 & 2028 & 2026 & 2026 & 2027 \\
\hline \multicolumn{13}{|l|}{ Quantity of motal (tonnes): } \\
\hline Aluminum Non-radioactive & 80 & 80 & 80 & 80 & 80 & 80 & 80 & 80 & 80 & 80 & 80 & 80 \\
\hline Surt. contam.-cleanable & 15 & 15 & 15 & 15 & 15 & 15 & 15 & 15 & 15 & 15 & 15 & 15 \\
\hline Surt. contam.-non-cinbl & 0 & 0 & 0 & 0 & 0 & 0 & 0 & 0 & 0 & 0 & 0 & $\underline{0}$ \\
\hline Aclivated & 5 & 5 & 5 & 5 & 5 & 5 & 5 & 5 & 5 & 5 & 5 & 5 \\
\hline Non-radioactlve & 3900 & 3900 & 3900 & 3900 & 3900 & 3900 & 3900 & 3900 & 3900 & 3900 & 3900 & 3900 \\
\hline Surt contam. cleanable & 80 & 80 & 80 & 80 & 80 & 80 & 80 & 80 & 80 & 80 & 80 & 80 \\
\hline Suri. contam.-non-cinbl & 0 & 0 & 0 & 0 & 0 & 0 & 0 & 0 & 0 & 0 & 0 & 0 \\
\hline Activated & 20 & 20 & 20 & 20 & 20 & 20 & 20 & 20 & 20 & 20 & 20 & 20 \\
\hline Non-radioactive & 20 & 20 & 20 & 20 & 20 & 20 & 20 & 20 & 20 & 20 & 20 & 20 \\
\hline Suri. contam. cleanable & 0 & 0 & 0 & 0 & 0 & 0 & 0 & 0 & 0 & 0 & 0 & 0 \\
\hline Surf. contam.-non-cinbl & 0 & 0 & 요 & 0 & 0 & 0 & 0 & 요 & 0 & 0 & 0 & 0 \\
\hline Activated & 0 & 0 & 0 & 0 & 0 & 0 & 0 & O) & 0 & 0 & 0 & 0 \\
\hline Steol \& Iron Non-radioactiva & 12770 & 12770 & 12770 & 12770 & 12770 & 12770 & 12770 & 12770 & 12770 & 12770 & 12770 & 12770 \\
\hline Surl. contam.cleanable & 5630 & 5630 & 5630 & 5630 & 5630 & 5630 & 5630 & 5630 & 5630 & 5630 & 5630 & 5630 \\
\hline Suri. contam.-non-clnbi & 0 & 0 & 0 & 0 & 0 & 0 & 0 & 0 & 0 & 0 & 0 & 0 \\
\hline Activated & 2100 & 2100 & 2100 & 2100 & 2100 & 2100 & 2100 & 2100 & 2100 & 2100 & 2100 & 2100 \\
\hline Non-radioactive & 60 & 60 & 60 & 60 & 60 & 60 & 60 & 60 & 60 & 60 & 60 & 60 \\
\hline Surt. contam.-cleanable & 900 & 900 & 900 & 900 & 900 & 900 & 900 & 900 & 900 & 900 & 900 & 900 \\
\hline Surf. contam.-non-clnbl & 0 & 0 & 0 & 0 & 0 & 0 & 0 & 0 & 0 & 0 & 0 & 0 \\
\hline Activated & 165 & 165 & 165 & 165 & 165 & 165 & 165 & 165 & 165 & 165 & 165 & 165 \\
\hline Zirconium Non-radioactive & 0 & 0 & 0 & 0 & 0 & 0 & 0 & 0 & 0 & 0 & 0 & 0 \\
\hline Surf. contam.-cleanable & 0 & 0 & 0 & 0 & 0 & 0 & 0 & 0 & 0 & 0 & 0 & 0 \\
\hline Surf. contam.-non-cinbl & 0 & 0 & 0 & 요 & 0 & 0 & 0 & 0 & 0 & 0 & 0 & 0 \\
\hline Activated & 0 & 0 & 0 & 0 & 0 & 0 & 0 & 0 & 0 & 0 & 0 & 0 \\
\hline
\end{tabular}




\begin{tabular}{|c|c|c|c|c|c|c|c|c|c|c|c|c|}
\hline (U) 0 & $\begin{array}{c}\text { Torness } \\
1 \\
\end{array}$ & $\begin{array}{c}\text { Torness } \\
2 \\
\end{array}$ & $\begin{array}{c}\text { Berkeley } \\
1 \\
\end{array}$ & $\begin{array}{c}\text { Berkeley } \\
2 \\
\end{array}$ & $\begin{array}{c}\text { Bradwell } \\
1 \\
\end{array}$ & $\begin{array}{c}\text { Bradwell } \\
2 \\
\end{array}$ & $\begin{array}{c}\text { Dungeness } \\
\text { A1 } \\
\end{array}$ & $\begin{array}{c}\text { Dungeness } \\
\mathrm{A2} \\
\end{array}$ & $\begin{array}{l}\text { Hinkley } \\
\text { Point A1 }\end{array}$ & $\begin{array}{c}\text { Hinkley } \\
\text { Point A2 } \\
\end{array}$ & $\begin{array}{l}\text { Hunter } \\
\text { ston A1 }\end{array}$ & $\begin{array}{l}\text { Hunter } \\
\text { ston A2 }\end{array}$ \\
\hline Fuel cycle stage (FCT) & Reactor & Reactor & Reactor & Reactor & Reactor & Reactor & Reactor & Reactor & Reactor & Reactor & Reactor & Reactor \\
\hline Identliler & 639GBG & $640 \mathrm{GBG}$ & $39 G B G$ & 4OGBG & $41 G B G$ & 42GBG & 75 GBG & $76 G B G$ & 52GBG & $53 G B G$ & 43GBG & 44GBG \\
\hline Plant type & ACR & $A C R$ & Magnox I & Magnox 1 & Magnox 1 & Magnox I & Magnox II & Magnox II & Magnox II & Magnox II & Magnox II & Magnox II \\
\hline Location & UK & UK & UK & UK & UK & UK & UK & UK & UK & UK & UK & UK \\
\hline Start of operations & 1988 & 1989 & 1962 & 1962 & 1962 & 1962 & 1965 & 1965 & 1965 & 1965 & 1962 & 1964 \\
\hline Status & Operating & Operating & Shut down & Shut down & Operating & Operating & Operating & Operating & Operating & Operaling & Shut down & Shut down \\
\hline Size (MWe) (Net) & 625 & 625 & 138 & 138 & 150 & 150 & 275 & 275 & 250 & 250 & 150 & 150 \\
\hline Vendor & $\mathrm{NNC}$ & $\mathrm{NC}$ & TNPG & TNPG & TNPG & TNPG & TNPG & TNPG & EE/BW/TW & EE/BW/TW & $\operatorname{CEC}$ & $\csc$ \\
\hline AJE & MC & NNC & TNPG & TNPG & TNPG & TNPG & TNPG & TNPG & EE/BW/TW & EE/BW/TW & & \\
\hline Pre or Post TMI & Post & Post & Pro & Pre & Pro & Pre & Pre & Pre & Pre & Pro & Pre & Pre \\
\hline No. of steam turbines & 1 & 1 & 4 & 4 & 3 & 3 & 2 & 2 & 3 & 3 & 3 & 3 \\
\hline \multicolumn{13}{|l|}{ Cooling } \\
\hline Date EOL motal available & 2038 & 2039 & 2012 & 2012 & 2012 & 2012 & 2015 & $\frac{2015}{212}$ & 2015 & 2015 & 2012 & $2014 \cdot$ \\
\hline \multicolumn{13}{|l|}{ Quantity of metal (tonnes): } \\
\hline Aluminum Non-radioactive & 80 & 80 & 0 & 0 & 0 & 0 & 0 & 0 & 0 & $\underline{0}$ & 0 & 0 \\
\hline Surt. contam.-cleanable & 15 & 15 & 0 & 0 & 0 & 0 & 0 & 0 & 0 & $\underline{0}$ & 0 & $\underline{0}$ \\
\hline Surf. contam-non-cinbl & $\underline{0}$ & 0 & 0 & $\underline{0}$ & 0 & 0 & 0 & 0 & $\underline{0}$ & 0 & 0 & 은 \\
\hline Activated & 5 & 5 & .0 & 0 & 0 & 0 & 0 & 0 & 0 & 0 & 0 & 0 \\
\hline Copper Non-radioactive & 3900 & 3900 & 1900 & 1900 & 1900 & 1900 & 2400 & 2400 & 2400 & 2400 & 2400 & 2400 \\
\hline Surt. contam.-cleanable & 80 & 80 & 50 & 50 & 50 & 50 & 50 & 50 & 50 & 50 & 50 & 50 \\
\hline Surt. contam.-non-cinbl & 0 & 0 & 0 & 0 & 0 & 0 & 0 & 0 & 0 & $\underline{0}$ & $\underline{0}$ & 0 \\
\hline Aclivated & 20 & 20 & 50 & 50 & 50 & 50 & 50 & 50 & 50 & 50 & 50 & 50 \\
\hline Non-radioactive & 20 & 20 & 0 & 0 & 0 & 0 & 0 & o. & 0 & 0 & 0 & 0 \\
\hline Surt. contam.-cleanable & 0 & 0 & 0 & 0 & 0 & 0 & 0 & 0 & 0 & 0 & 0 & 0 \\
\hline Surt. contam.-non-cinbl & 0 & 0 & 0 & 0 & 0 & 0 & 0 & ㅇ. & 0 & 0 & 0 & $\underline{0}$ \\
\hline Activated & 0 & 0 & 0 & 0 & 0 & $\underline{0}$ & 0 & 요 & $\underline{0}$ & 0 & 0 & 0 \\
\hline Steol \& Iron Non-radioactive & 12770 & 12770 & 3800 & 3800 & 3800 & 3800 & 4690 & 4690 & 4690 & 4690 & 4690 & 4690 \\
\hline Surf contam. cleanable & 5630 & 5630 & 4950 & 4950 & 4950 & 4950 & 6225 & 6225 & 6225 & 6225 & 6225 & 6225 \\
\hline Sur. contam.-non-clnbl & 0 & 0 & 0 & 0 & 0 & 0 & 0 & 0 & 0 & 0 & 0 & 0 \\
\hline Activated & 2100 & 2100 & 1000 & 1000 & 1000 & 1000 & 1000 & 1000 & 1000 & 1000 & 1000 & 1000 \\
\hline Non-radioaclive & 60 & 60 & 100 & 100 & 100 & 100 & 100 & 100 & 100 & 100 & 100 & 100 \\
\hline Suri. contam.-cleanable & 900 & 900 & 0 & 0 & 0 & $\underline{a}$ & 0 & 0 & 0 & 0 & 0 & 0 \\
\hline Surl. contam.-non-cinbl & 0 & $\underline{0}$ & 0 & $\underline{0}$ & 0 & 0 & 0 & 요 & 0 & 0 & 0 & 0 \\
\hline Activated & 165 & 165 & 0 & $\underline{0}$ & 0 & 0 & 0 & 요 & 0 & 0 & 0 & 0 \\
\hline Zirconlum Non-radioactive & 0 & 0 & 0 & 0 & 0 & 0 & 0 & 0 & 0 & 0 & 0 & $\underline{0}$ \\
\hline Surt. contam.-cleanable & 0 & 0 & 0 & 0 & 0 & $\underline{0}$ & 0 & 0 & 0 & 0 & 0 & $\underline{0}$ \\
\hline Surf. contam.non-cinbl & 0 & 0 & 0 & 0 & 0 & 0 & $\underline{0}$ & of & 0 & $\underline{0}$ & $\underline{0}$ & $\underline{0}$ \\
\hline Activated & $\underline{0}$ & 0 & 0 & 0 & 0 & 0 & $\underline{0}$ & of & 0 & 0 & 0 & 0 \\
\hline
\end{tabular}




\begin{tabular}{|c|c|c|c|c|c|c|c|c|c|c|}
\hline (U) & $\begin{array}{c}\text { Oldbury } \\
1 \\
\end{array}$ & $\begin{array}{c}\text { Oldbury } \\
\quad 2 \\
\end{array}$ & $\begin{array}{c}\text { Slzewell } \\
\text { A1 }\end{array}$ & $\begin{array}{c}\text { Sizewell. } \\
\mathrm{A} 2 \\
\end{array}$ & $\begin{array}{c}\text { Traws. } \\
\text { lynydd } 1\end{array}$ & $\begin{array}{l}\text { Traws- } \\
\text { fynydd } 2 \\
\end{array}$ & $\begin{array}{c}\text { Wylfa } \\
\text { A1 } \\
\end{array}$ & $\begin{array}{c}\text { Wylla } \\
\text { A2 } \\
\end{array}$ & $\begin{array}{c}\text { Dounreay } \\
\text { PFR } \\
\end{array}$ & $\begin{array}{c}\text { Sizewell } \\
\mathrm{B} \\
\end{array}$ \\
\hline Fuel cycle stage (FCT) & Reactor & Reactor & Reactor & Reactor & Reactor & Reactor & Reactor & Reactor & Reactor & Reactor \\
\hline Identifler & $87 G B G$ & $88 \mathrm{GBG}$ & $82 B G B$ & $83 G B G$ & $64 \mathrm{GBO}$ & 65GBO & 102GBG & $103 G B G$ & 145GBF & $733 \mathrm{GBP}$ \\
\hline Plant type & Magnox III & Magnox III & Magnox 11. & Magnox 1 & Magnox II & Magnox II & Magnox III & Magnox III & LMR & PWR \\
\hline Location & UK & UK & UK & UK & UK & UK & UK & UK & UK & UK \\
\hline Start of oparallons & 1966 & 1968 & 1965 & 1966 & 1965 & 1965 & 1971 & 1972 & 1976 & \\
\hline Status & Operating & Operating & Operating & Operating & Operalling & Operating & Operating & Operating & Operating & Under Const \\
\hline Size (MWe) (Net) & 300 & 300 & 290 & 290 & 250 & 250 & 590 & 590 & 250 & 1188 \\
\hline Vendor & TNPG & TNPG & EE/BW/TW & EE/BW/TW & APC & APC & EE/BW/TW & EE/BW/TW & UKAEATNPG & Westinghouse \\
\hline$A / E$ & TNPG & TNPG & EE/BW/TW & EE/BW/TW & $A P C$ & APC & EE/BW/TW & EE/BW/TW & AEA Tch $\pi$ NPG & \\
\hline Pre or Post TMI & Pre & Pre & Pre & Pre & Pre & Pre & Pre & Pre & Pie & Post \\
\hline No. of steam turbines & 1 & 1 & 1 & 1 & 2 & 2 & 2 & 2 & 1 & 1 \\
\hline Cooling & & & Nuc Elec & & & & & & Sea & \\
\hline Date EOL molal avallable & 2016 & 2018 & 2015 & 2016 & 2015 & 2015 & $2021^{\circ}$ & 2022 & 2026 & 2053 \\
\hline Quantily of metal (tonnes): & & & & & & & $n$ & & & \\
\hline Aluminum Non-radloactive & 80 & 80 & 0 & 0 & 0 & 0 & 80 & 80 & & 90 \\
\hline Surf. contam.-cleanable & 15 & 15 & 0 & 0 & 0 & 0 & 15 & 15 & & 17 \\
\hline Surf. contam.-non-clnbl & 0 & 0 & of & 0 & 0 & 0 & 0 & 0 & & 0 \\
\hline Activated & 5 & 5 & 0 & 0 & 0 & 0 & 5 & 5 & & 6 \\
\hline Non-radioactive & 3900 & 3900 & 2400 & 1900 & 2400 & 2400 & 3900 & 3900 & & 5496 \\
\hline Surt. contam.-cleanable & 80 & 80 & 50 & 50 & 50 & 50 & 80 & 80. & & 90 \\
\hline Surf. contam.-non-cinbl & 0 & 0 & 0 & 0 & 0 & 0 & 0 & 0 & & 0 \\
\hline Activated & 20 & 20 & 50 & 50 & 50 & 50 & 20 & 20 & & 22 \\
\hline Lead . Non-radioactive & 20 & 20 & 으 & 0 & 0 & 0 & 20 & 20 & & 20 \\
\hline Suri. contam.-cleanable & 0 & 0 & 0 & 0 & 0 & 0 & 0 & 0 & & 0 \\
\hline Surf. contam.-non-clnbl & 0 & 0 & 0 & 0 & 0 & 0 & 0 & 0 & & $\underline{0}$ \\
\hline Activated & 0 & 0 & 0 & 0 & 0 & 0 & 0 & 0 & & 0 \\
\hline Steel \& Iron Non-radioactive & 12770 & 12770 & 4690 & 3800 & 4690 & 4690 & 12770 & 12770 & & 9299 \\
\hline Surt. contam.-cleanable & 5630 & 5630 & 6225 & 4950 & 6225 & 6225 & 5630 & 5630 & & 7515 \\
\hline Surl. contam.non-clnbl & 0 & 0 & 0 & 0 & 0 & 0 & .0 & 0 & & 0 \\
\hline Activated & 2100 & 2100 & 1000 & 1000 & 1000 & 1000 & 2100 & 2100 & & 3298 \\
\hline Non-radioactive & 60 & 60 & 100 & 100 & 100 & 100 & 60 & 60 & & 0 \\
\hline Surf. contam.-cleanable & 900 & 900 & 0 & 0 & 0 & $\therefore \quad 0$ & 900 & 900 & $\dot{-}$ & 1010 \\
\hline Surf. contam.-non-clnbl & 0 & 0 & 0 & 0 & 0 & of & 0 & 0 & & 337 \\
\hline Aclivated & 165 & 165 & 0 & 0 & 0 & of & 165 & 165 & & 752 \\
\hline Non-radioactive & 0 & 0 & 0 & 0 & 0 & 0 & 0 & 0 & & 0 \\
\hline Surt. contam.-cleanable & 0 & 0 & 0 & 0 & 0 & 0 & 0 & 0 & & 0 \\
\hline Surt. conlam.nnon-clnbl & 0 & 0 & 0 & 0 & 0 & 0 & 0 & 0 & & 0 \\
\hline Activated & 0 & 0 & 0 & 0 & 0 & 0 & 0 & 0 & & 0 \\
\hline
\end{tabular}




\begin{tabular}{|c|c|c|c|c|c|c|c|c|c|c|c|c|}
\hline 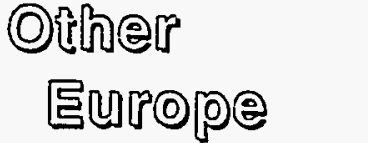 & $\begin{array}{c}\text { Doel } \\
1\end{array}$ & $\begin{array}{l}\text { Doel } \\
2\end{array}$ & $\begin{array}{l}\text { Doel } \\
3\end{array}$ & $\begin{array}{l}\text { Doel } \\
4\end{array}$ & $\begin{array}{c}\text { Tihange } \\
1\end{array}$ & $\begin{array}{c}\text { Tihange } \\
2\end{array}$ & $\begin{array}{c}\text { Tihange } \\
3\end{array}$ & $\begin{array}{c}\text { Belene } \\
1\end{array}$ & $\begin{array}{l}\text { Belene } \\
2\end{array}$ & $\begin{array}{c}\text { Belene } \\
3\end{array}$ & $\begin{array}{c}\text { Belene } \\
4\end{array}$ & $\begin{array}{c}\text { Kozloduy } \\
1\end{array}$ \\
\hline Fuel cycle stage (FCT) & Reactor & Reactor & Reactor & Reactor & Reacior & Reactor & Reactor & Reactor & Reactor & Reactor & Reactor & Reactor \\
\hline Identifler & 220BP & 222BP & 482BP & 545BP & $221 \mathrm{BP}$ & 483BP & $546 \mathrm{BP}$ & 687BULP & $716 B U L P$ & 768BULP & 769BULP & 184BULP \\
\hline Plant type & PWR & PWR & PWR & PWR & PWR & PWR & PWR & WER & WER & WER & WER & WER \\
\hline Location & Belgium & Belgium & Belgium & Bolgium & Belgium & Belgium & Bolgium & Bulgaria & Bulgaria & Bulgaria & Bulgaria & Bulgaria \\
\hline Start of operatlons & 1975 & 1975 & 1982 & 1985 & 1975 & 1983 & 1985 & & & 1998 & 2000 & 1974 \\
\hline Status & Operating & Operating & Operating & Operating & Operating & Operating & Operating & Under Const & Under Const & Planned & Planned & Operating \\
\hline Slze (MWe) (Net) & 392 & 392 & 900 & 1010 & 870 & 900 & 1020 & 953 & 953 & 953 & 953 & 405 \\
\hline Vendor & Acocowen & Acecowen & Framaceco & Acecowen & Framacoco & Framaco $\infty$ & Acocowen & AEE & AEI & AE & AEI & AEI \\
\hline AEE & Tractebel & Tractebel & Tractebol & Tractebol & Tractebel & Tractobol & Tractebel & SEU/IC & SEU/IC & SEU/IC & SEU/IC & SEU/IC \\
\hline Pre or Post TMI & Pre & Pro & Post & Post & Pre & Post & Post & Post & Post & Post & Post & Pre \\
\hline No. of steam lurblnes & 1 & 1 & 1 & 1 & 2 & 1 & 1 & 1 & 1 & 1 & 1 & 2 \\
\hline Coolling & Lake & Riveritower & Rlveritower & Rlvertower & Alvernower & Rlvartower & Riveritower & $\dot{-}$ & - & $\dot{-}$ & & \\
\hline Date EOL molal avallabie & 2025 & 2025 & 2032 & 2035 & 2025 & 2033 & 2035 & 2053 & 2053 & Unknown & Unknown & $\frac{2024}{21212 X 2}$ \\
\hline \multicolumn{13}{|l|}{ Quantity of metal (tonnes): } \\
\hline Aluminum Non-radloactive & 43 & 43 & 75 & 81 & 73 & 75 & 81 & 80 & 80 & 80 & 80 & 46 \\
\hline Surt. contam. cleanable & 8 & 8 & 14 & 15 & 14 & 14 & 15 & 15 & 15 & 15 & 15 & 9 \\
\hline Surl. contam.non-clnbl & 0 & 0 & 0 & 0 & 0 & 0 & 0 & 0 & 0 & 0 & 0 & 0 \\
\hline Activaled & 3 & 3 & 5 & 5 & 5 & 5 & 5. & 5 & 5 & 5 & 5 & 3 \\
\hline Copper Non-radloactlve & 2625 & 2625 & 4568 & 4933 & 4466 & 4568 & 4965 & 4900 & 4900 & 4900 & 4900 & 2840 \\
\hline Surl. contam. cleanable & 43 & 43 & 75 & 81 & 73 & 75 & 81 & 80 & 80 & 80 & 80 & 46 \\
\hline Surf. contam.non-clnbl & 0 & 0 & 0 & 0 & 0 & 0 & 0 & 0 & 0 & 0 & 0 & 0 \\
\hline Aclivated & 11 & 11 & 19 & 20 & 18 & 19 & 20 & 20 & 20 & 20 & 20 & 12 \\
\hline Non-radioactlve & 20 & 20 & 20 & 20 & 20 & 20 & 20 & 20 & 20 & 20 & 20 & 20 \\
\hline Surl. contam. cleanable & 0 & 0 & 0 & 0 & 요 & 0 & 0 & 0 & 0 & 0 & 0 & 0 \\
\hline Surl. contam.non-clnbl & 0 & 0 & 0 & 0 & 0 & 0 & 0 & 0 & 0 & 0 & 0 & 0 \\
\hline Actlvated & 0 & 0 & of & 0 & of & 0 & 0 & 0 & 0 & 0 & 0 & 0 \\
\hline Steel \& Iron Non-radloaclive & 4440 & 4440 & 7728 & 8345 & 7555 & 7728 & 8400 & 19248 & 19248 & 19248 & 19248 & 12030 \\
\hline Surl. contam. cleanable & 3589 & 3589 & 6246 & 6745 & 6106 & 6246 & 6789 & 7156 & 7156 & 7156 & 7156 & 4669 \\
\hline Surl. contam.-non-clnbl & 0 & 0 & 0 & 0 & 0 & 0 & 0 & 69 & 69 & 69 & 69 & 46 \\
\hline Actlvated & 1575 & 1575 & 2741 & 2960 & 2679 & 2741 & 2979 & 581 & 581 & 581 & 581 & 363 \\
\hline Non-radioacilve & 0 & 0 & 0 & 0 & 0 & $\underline{0}$ & 0 & of & $\underline{0}$ & 0 & 0 & 0 \\
\hline Surf. contam.-cleanable & 482 & 482 & 839 & 906 & 820 & 839 & 912 & 2600 & 2600 & .2600 & 2600 & 1599 \\
\hline Surl. contam.-non-cinbl & 161 & 161 & 280 & 302 & 273 & 280 & 304 & 0 & 0 & 0 & 0 & 0 \\
\hline Acllvated & 359 & 359 & 625 & 674 & 611 & 625 & 679 & 406 & 406 & 406 & 406 & 254 \\
\hline Zlrconlum Non-radloactlive & $\underline{0}$ & 0 & 0 & 0 & 0 & 0 & 0 & 0 & 0 & 0 & 0 & 0 \\
\hline Surl. contam. cleanable & $\underline{0}$ & 0 & 0 & $\underline{0}$ & 0 & 0 & 0 & 0 & 0 & 0 & 0 & 0 \\
\hline Surl. contam.-non-clnbl & 0 & 0 & 0 & 0 & 0 & 0 & 0 & 0 & 0 & 0 & 0 & 0 \\
\hline Activated & 0 & 0 & 0 & 0 & 0 & 0 & 0 & 01 & 0 & 0 & 0 & 0 \\
\hline
\end{tabular}




\begin{tabular}{|c|c|c|c|c|c|c|c|c|c|c|c|c|}
\hline 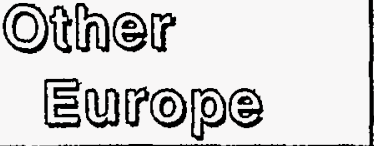 & $\begin{array}{c}\text { Kozloduy } \\
2\end{array}$ & $\begin{array}{c}\text { Kozloduy } \\
3\end{array}$ & $\begin{array}{c}\text { Kozloduy } \\
4\end{array}$ & $\begin{array}{l}\text { Kozloduy } \\
5 \\
\end{array}$ & $\begin{array}{c}\text { Kozloduy } \\
6\end{array}$ & $\begin{array}{c}\text { Olklluoto } \\
1\end{array}$ & $\begin{array}{c}\text { Olkiluoto } \\
2\end{array}$ & $\begin{array}{l}\text { Lovlisa } \\
1\end{array}$ & $\begin{array}{l}\text { Lovlisa } \\
2 \\
\end{array}$ & $\begin{array}{c}\text { Hungary } \\
7 \\
\end{array}$ & $\begin{array}{l}\text { Hungary } \\
8 \\
\end{array}$ & $\begin{array}{c}\text { Hungary } \\
9 \\
\end{array}$ \\
\hline Fuel cycle stage (FCT) & Reactor & Reactor & Reactor & Reactor & Reactor & Reactor & Roactor & Reactor & Reactor & Reactor & Reactor & Reactor \\
\hline Identifler & 185BULP & 352BULP & 353BULP & 626BULP & 652BULP & $355 \mathrm{SFB}$ & 502SFB & 260SFP & 322SFP & $784 \mathrm{HP}$ & $785 \mathrm{HP}$ & $786 \mathrm{HP}$ \\
\hline Plant type & WER & WER & WER & WER & WER & BWR & BWR & PWR & PWR & WEA & WER & WER \\
\hline Location & Bulgaria & Bulgaria & Bulgaria & Bulgaria & Buigaria & Finland & Finland & Finland & Finland & Hungary & Hungary & Hungary \\
\hline Start of operatrons & 1975 & 1981 & 1982 & 1988 & 1990 & 1979 & 1982 & 1977 & 1981 & & & \\
\hline Status & Operating & Operating & Operating & Operaling & Under Const & Operafing & Operating & Operaling & Oporating & Planned & Planned & Planned \\
\hline Slze (MWo) (Nol) & 405 & 405 & 405 & 953 & 953 & 710 & 710 & 445 & 445 & 953 & 953 & 953 \\
\hline Vendor & AEE & AEE & AEE & AEE & A匡 & ABB-Atom & ABB-Atom & V-O/AEE & V-O/AEE & AEEISSSR & AEESSSSR & AEESSSSR \\
\hline ANE & SEU/IC & SEU/IC & SEU/IC & SEU/C & SEU/IC & ABB Atom & ABB-Atom & AEE & No & ERBE & ERBE & ERBE \\
\hline Pre or Post TMI & Pro & Post & Post & Post & Post & Pre & Post & Pre & Post & Post & Post & Post \\
\hline No. of steam turblnes & 1 & & & 1 & 1 & 1 & 1 & 2 & 2 & 1 & 1 & 1 \\
\hline Cooling & & & & & - & sea & Sea & & & $\dot{-}$ & & $\dot{-}$ \\
\hline Date EOL motal avallable & 2025 & 2031 & 2032 & 2038 & 2040 & 2029 & $\frac{2032}{2 Z Z Z Z}$ & 2027 & 2031 & Unknown & Unknown & Unknown \\
\hline \multicolumn{13}{|l|}{ Quantiliy of metal(tonnes): } \\
\hline Aluminum Non-radioactive & 46 & 46 & 46 & 80 & 80 & 64 & 64 & 47 & 47 & 80 & 80 & 80 \\
\hline Surf. contam.-cleanable & 9 & 9 & 9 & 15 & 15 & 12 & 12 & 9 & 9 & 15 & 15 & 15 \\
\hline Surl. contam.-non-cinbl & 0 & 0 & 0 & 0 & 0 & 0 & $\because 0$ & 0 & 0 & 0 & 0 & 0 \\
\hline Acilvated & 3. & 3 & 3 & 5 & 5 & 4 & $\because 4$ & 3 & 3 & 5 & 5 & 5 \\
\hline Non-radloactlve & 2840 & 2840 & 2840 & 4900 & 4900 & 3900 & 3900 & 2856 & 2856 & 4900 & 4900 & 4900 \\
\hline Surf. contam.-cleanable & 46 & 46 & 46 & 80 & 80 & 64 & 64 & 47 & 47 & 80 & 80 & 80 \\
\hline Surl. contam.-non-cinbl & 0 & $\underline{0}$ & 0 & 0 & 0 & 0 & 0 & 0 & 0 & 0 & 0 & 0 \\
\hline Activaled & 12 & 12 & 12 & 20 & 20 & 16 & 16 & 12 & 12 & 20 & 20 & 20 \\
\hline Non-radioacilve & 20 & 20 & 20 & 20 & 20 & 20 & 20 & 20 & 20 & 20 & 20 & 20 \\
\hline Surl. contam.cleanable & 0 & 0 & 0 & 0 & 0 & 0 & 0 & 0 & 0 & 0 & 0 & 0 \\
\hline Surl. contam.-non-cinol & 0 & 0 & 0 & 0 & 0 & 0 & 0 & 0 & 0 & 0 & 0 & 0 \\
\hline Activated & 0 & 0 & 0 & 0 & 0 & 0 & 0 & 0 & 0 &.$\quad 0$ & 0 & 0 \\
\hline Steel \& Iron Non-radloactive & 12030 & 12030 & 12030 & 19248 & 19248 & 3979 & 3979 & 4832 & 4832 & 19248 & 19248 & 19248 \\
\hline Surt. contam.-cloanable & 4669 & 4669 & 4669 & 7156 & 7156 & 5332 & 5332 & 3905 & 3905 & 7156 & 7156 & 7156 \\
\hline Surl conlam-non-clnbl & 46 & 46 & 46 & 69 & 69 & 0 & 0 & 0 & 0 & 69 & 69 & 69 \\
\hline Activated & 363 & 363 & 363 & 581 & 581 & 2786 & 2786 & 1714 & 1714 & 581 & 581 & 581 \\
\hline St. Stoel Non-radioaclive & 0 & 0 & 0 & 0 & 0 & 0 & 0 & 0 & 0 & 0. & 0 & 0 \\
\hline Surf. contam.-cieanable & 1599 & 1599 & 1599 & 2600 & 2600 & 478 & 478 & 525 & 525 & 2600 & 2600 & 2600 \\
\hline Surf. contam--non-cinbl & 0 & 0 & 0 & 0 & ㅇ. & 0 & 0 & 175 & 175 & 0 & 0 & $\underline{0}$ \\
\hline Activaled & 254 & 254 & 254 & 406 & 406 & 533 & 533 & 391 & 391 & 406 & 406 & 406 \\
\hline Zlrconlum Non-radioacilve & 0 & 0 & 0 & 0 & 0 & 0 & 0 & 0 & 0 & 0 & 0 & 0 \\
\hline Surl. contam.cleanable & 0 & 0 & 0 & 0 & 0 & 0 & 0 & 0 & 0 & 0 & 0 & 0 \\
\hline Surf. contam-non-cinbl & $\underline{0}$ & 0 & 0 & 0 & 0 & 0 & 0 & 0 & 0 & 0 & $\underline{0}$ & $\underline{0}$ \\
\hline Activaled & 0 & 0 & 0 & 0 & 0 & 0 & 0 & 0 & 0 & 0 & 0 & 0 \\
\hline
\end{tabular}




\begin{tabular}{|c|c|c|c|c|c|c|c|c|c|c|c|c|}
\hline 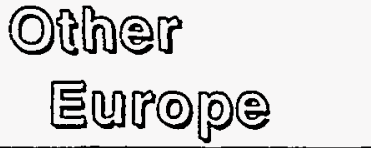 & $\begin{array}{l}\text { Paks } \\
1\end{array}$ & $\begin{array}{l}\text { Paks } \\
2\end{array}$ & $\begin{array}{l}\text { Paks } \\
3\end{array}$ & $\begin{array}{l}\text { Paks } \\
4\end{array}$ & $\begin{array}{l}\text { Paks } \\
5\end{array}$ & $\begin{array}{l}\text { Paks } \\
6\end{array}$ & Caorso & Garigllano & Latina & $\begin{array}{c}\text { Trino } \\
\text { Vercellese }\end{array}$ & Borssele & $\begin{array}{c}\text { Kujawy } \\
1\end{array}$ \\
\hline Fuel cycle stage (FCT) & Reactor & Reactor & Reactor & Reactor & Reactor & Reactor. & Reactor & Reactor & Reactor & Reactor & Reactor & Reactor \\
\hline Identifter & $346 \mathrm{HP}$ & $347 \mathrm{HP}$ & 595HP & $596 \mathrm{HP}$ & 745HP & 746HP & $2521 \mathrm{~B}$ & 5518 & $541 \mathrm{G}$ & $321 \mathrm{P}$ & $266 N L P$ & 811 PLP \\
\hline Plant type & WER & WER & WER & WER & WER & WER & BWR & BWR & Magnox 1 & PWR & PWR & WER \\
\hline Locatlon & Hungary & Hungary & Hungary & Hungary & Hungary & Hungary & ltaly & Italy & Italy & Italy & Notherlands & Poland \\
\hline Start of operallons & 1983 & 1984 & 1986 & 1987 & & & 1981 & 1964 & 1964 & 1965 & 1973 & \\
\hline Status & Operating & Operating & Oporating & Oporating & Planned & Planned & Shut down & Shut down & Shut down & Shut down & Operating & Planned \\
\hline $\mathrm{S} \mid z \theta(\mathrm{MWo})(\mathrm{Nel})$ & 408 & 408 & 408 & 408 & 953 & 953 & 860 & 150 & 153 & 260 & 452 & 950 \\
\hline Vendor & AEESSSR & AEE/SSSR & AEESSSR & AEE/SSSR & AEESSSSR & AEESSSSR & AMNGotsco & $\mathbb{E}$ & TNPQ & Wstnghse & KWU & \\
\hline ANE & ERBE & ERBE & ERBE & ERBE & ERBE & ERBE & Gibos \& Hill & Exasco & TNPG & Gibbs \& Hill & KWU & VO/AEE \\
\hline Pre or Post TMI & Post & Post & Post & Post & Post & Post & Post & Pre & Pre & Pre & Pro & Post \\
\hline No. of steam turbines & 2 & 2 & $\underline{2}$ & 2 & 1 & 1 & 1 & 1 & 3 & 2 & 1 & 1 \\
\hline Coolling & River & River & River & River & & & River & River & Sea. & River & River & . \\
\hline 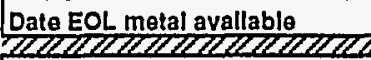 & 2033 & 2034 & 2036 & 2037 & Unknown & Unknown & $\frac{2031}{Z Z Z Z}$ & 2014 & 2014 & 2015 & 2023 & Unknown \\
\hline \multicolumn{13}{|l|}{ Quantlly of metal (tonnes): } \\
\hline Aluminum Non-radioactive & 46 & 46 & 46 & 46 & 80 & 80 & 72 & 23 & 0 & 33 & 47 & 80 \\
\hline Surf. contam.-cleanable & 9 & 9 & 9 & 9 & 15 & 15 & 14 & 4 & 0 & 6 & 9 & 15 \\
\hline Surt. contam-non-clnbl & 0 & 0 & 0 & 0 & 0 & 0 & 0 & 0 & 0 & 0 & $\underline{0}$ & $\underline{0}$ \\
\hline Activaled & 3 & 3 & 3 & 3 & 5 & 5 & 5 & 1 & $\underline{0}$ & 2 & 3 & 5 \\
\hline Copper $\quad$ Non-radioactive & 2840 & 2840 & 2840 & 2840 & 4900 & 4900 & 4431 & 1383 & 1900 & 1996 & 2886 & 4900 \\
\hline Surf. contam.-claanable & 46 & 46 & 46 & 46 & 80 & 80 & 72 & 23 & 50 & 33 & 47 & 80 \\
\hline Surl. contam.-non-clnbl & 0 & 0 & 0 & 0 & 0 & 0 & 0 & 0 & 0 & 0 & 0 & $\underline{0}$ \\
\hline Activated & 12 & 12 & 12 & 12 & 20 & 20 & 18 & 6 & 50 & 8 & 12 & 20 \\
\hline Non-radioacilve & 20 & 20 & 20 & 20 & 20 & 20 & 20 & 20 & 0 & 20 & 20 & 20 \\
\hline Surl. contam.-cleanable & 0 & 0 & 0 & 0 & 욤 & 0 & 0 & 0 & 0 & 0 & 0 & $\underline{0}$ \\
\hline Surl. contàm.-non-cinbl & 0 & 0 & 0 & 0 & 0 & 0 & 0 & 0 & 0 & 0 & 0 & $\underline{0}$ \\
\hline Acllvated & 0 & 0 & 0 & 0 & 0 & 0 & 0 & 0 & 0 & 0 & 0 & $\underline{0}$ \\
\hline Steel \& Iron Non-radloactive & 12030 & 12030 & 12030 & 12030 & 19248 & 19248 & 4522 & 1412 & 3800 & 3377 & 4883 & 19248 \\
\hline Surt. contam.-cleanable & 4669 & 4669 & 4669 & 4669 & 7156 & 7156 & 6059 & 1891 & 4950 & 2729 & 3946 & 7156 \\
\hline Surf. contam.-non-cinbl & 46 & 46 & 46 & 46 & 69 & 69 & 0 & 0 & $\underline{0}$ & 0 & 0 & 69 \\
\hline Actlvated & 363 & 363 & 363 & 363 & 581 & 581 & 3165 & 988 & 1000 & 1198 & 1732 & 581 \\
\hline Non-radloactive & 0 & 0 & 0 & 0 & 0 & 0 & 0 & 0 & 100 & 0 & 0 & $\underline{0}$ \\
\hline Surf. contam. cleanable & 1599 & 1599 & 1599 & 1599 & 2600 & 2600 & 543 & 169 & 0 & 367 & 530 & 2600 \\
\hline Surf. contam.-non-clnbl & 0 & 0 & 0 & 0 & 0 & 0 & 0 & 0 & $\underline{0}$ & 122 & 177 & 0 \\
\hline Activaled & 254 & 254 & 254 & 254 & 406 & 406 & 606 & 189 & 0 & 273 & 395 & 406 \\
\hline Zlrconlum Non-radioactlve & 0 & 0 & 0 & 0 & 0 & $\underline{0}$ & 0 & 0 & 0 & 0 & 0 & $\underline{0}$ \\
\hline Surf. contam.-cleanable & 0 & 0 & 0 & 0 & 0 & 0 & 0 & 0 & 0 & 0 & 0 & $\underline{0}$ \\
\hline Surf. contam.-non-cinbl & 0 & 0 & 0 & 0 & 0 & 0 & 0 & 0 & 0 & 0 & 0 & $\underline{0}$ \\
\hline Actlvated & 0 & 0 & 0 & 0 & 0 & 0 & 0 & 0 & 0 & 0 & 0 & 0 \\
\hline
\end{tabular}




\begin{tabular}{|c|c|c|c|c|c|c|c|c|c|c|c|c|}
\hline 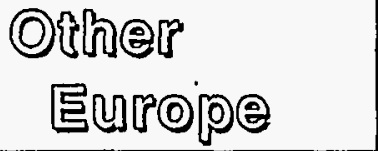 & $\begin{array}{c}\text { Kujawy } \\
2\end{array}$ & $\begin{array}{c}\text { Kujawy } \\
3\end{array}$ & $\begin{array}{c}\text { Kujawy } \\
4\end{array}$ & $\begin{array}{c}\text { Warta } \\
1\end{array}$ & $\begin{array}{c}\text { Warta } \\
2 \\
\end{array}$ & $\begin{array}{l}\text { Warta } \\
3\end{array}$ & $\begin{array}{l}\text { Warta } \\
4 \\
\end{array}$ & $\begin{array}{c}\text { Zarnowlec } \\
1\end{array}$ & $\begin{array}{c}\text { Zarnowlec } \\
2\end{array}$ & $\begin{array}{c}\text { Zarnowlec } \\
3\end{array}$ & $\begin{array}{c}\text { Zarnowlec } \\
4 \\
\end{array}$ & $\begin{array}{c}\text { Cernavoda } \\
1\end{array}$ \\
\hline Fuel cycle stage (FCT) & Reactor & Reactor & Reactor & Reactor & Reactor & Reactor & Reactor & Reactor & Reactor & Reactor & Reactor & Reactor \\
\hline Identlfier & 812PLP & $813 P L P$ & 814PLP & $897 P L P$ & 898PLP & 899PLP & 900PLP & $506 \mathrm{PLP}$ & 508PLP & 510PLP & 511PLP & $608 \mathrm{RH}$ \\
\hline Plant type & WEA & WER & WER & WER & WER & WER & WER & WER & WER & WER & WER & PHWR \\
\hline Locatlon & Poland & Poland & Poland & Poland & Poland & Poland & Poland & Poland & Poland & Poland & Poland & Romania \\
\hline \multicolumn{13}{|l|}{ Start of operatlons } \\
\hline Slatus & Planned & Planned & Planned & Planned & Planned & Planned & Planned & Under Const & Under Const & Under Const & Under Const & Under Const \\
\hline Slze (MWe) (Net) & 950 & 950 & 950 & 950 & 950 & 950 & 950 & 424 & 424 & 424 & 424 & 620 \\
\hline Vendor & & & & & & & & Skoda/Praha & Skoda/Praha & Skoda/Praha & Skoda/Praha & $A E Q$ \\
\hline AVE & VO/AEE & VOIAEE & VO/AEE & EPWILOATEP & EPWROATEP & EPWROATEP & EPWILOATEP & \begin{tabular}{|l|} 
EPWILOATEP \\
\end{tabular} & EPWLOATEP & EPWROATEP & EPWILOATEP & Inst.Pwr S\&D \\
\hline Pre or Post TMI & Post & Post & Post & Post & Post & Post & Post & Post & Post & Post & Post & Post \\
\hline No. of steam turbines & 1 & 1 & 1 & 1 & 1 & 1 & 1 & 1 & 1 & 1 & 1 & 1 \\
\hline Coollng & & & & Tower & Tower & Tower & Tower & Lake & $\therefore$ Lake. & Lake & Lake & River \\
\hline Date EOL metal avallable & Unknown & Unknown & Unknown & Unknown & Unknown & Unknown & Unknown & 2053 & 2053 & 2053 & 2053 & 2053 \\
\hline \multicolumn{13}{|l|}{ Quantlty of metal (tonnes): } \\
\hline Alumlnum Non-radloactive & 80 & 80 & 80 & 80 & 80 & 80 & 80 & 46 & 46 & 46 & 46 & 63 \\
\hline \begin{tabular}{|c|} 
Surt. contam.-cleanable \\
\end{tabular} & 15 & 15 & 15 & 15 & 15 & 15 & 15 & 9 & 9 & 9 & 9 & 12 \\
\hline Surl. contam.-non-cinbl & 0 & 0 & 0 & 0 & 0 & 0 & 0 & 0 & 0 & 0 & 0 & 0 \\
\hline Activaled & 5 & 5 & 5 & 5 & 5 & 5 & 5 & 3 & 3 & 3 & 3 & 4 \\
\hline Non-radioactlve & 4900 & 4900 & 4900 & 4900 & 4900 & 4900 & 4900 & 2840 & 2840 & 2840 & 2840 & 3877 \\
\hline Surl. contam.-cleanable & 80 & 80 & 80 & 80 & 80 & 80 & 80 & 46 & 46 & 46 & 46 & 63 \\
\hline Surl. contam.-non-clnbl & 0 & 0 & 0 & 0 & 0 & 0 & 요 & 0 & 0 & 0 & 0 & 0 \\
\hline Acllyated & 20 & 20 & 20 & 20 & 20 & 20 & 20 & 12 & 12 & 12 & 12 & 16 \\
\hline Non-radloactlve & 20 & 20 & 20 & 20 & 20 & 20 & 20 & 20 & 20 & 20 & 20 & 20 \\
\hline Suri. contam.-cleanable & 0 & 0 & 0 & 0 & 0 & 0 & 0 & 0 & 0 & 0 & 0 & 0 \\
\hline Surl. contam.-non-cinbl & 0 & 0 & 0 & 0 & 0 & 0 & 0 & 0 & 0 & 0 & 0 & 0 \\
\hline Aclivated & 0 & 0 & 0 & 0 & 0 & 0 & 0 & 0 & 0 & 0 & 0 & 0 \\
\hline Steel \& Iron Non-radloaclive & 19248 & 19248 & 19248 & 19248 & 19248 & 19248 & 19248 & 12030 & 12030 & 12030 & 12030 & 6329 \\
\hline Surl. contam. cleanable & 7156 & 7156 & 7156 & 7156 & 7156 & 7156 & 7156 & 4669 & 4669 & 4669 & 4669 & 4747 \\
\hline Surl.contam.-non-cinbl & 69 & 69 & 69 & 69 & 69 & 69 & 69 & 46 & 46 & 46 & 46 & 0 \\
\hline Actlvated & 581 & 581 & 581 & 581 & 581 & 581 & 581 & 363 & 363 & 363 & 363 & 2326 \\
\hline St. Steel Non-radioactive & 0 & 0 & 0 & 0 & 0 & 0 & 0 & 0 & 0 & 0 & 0 & 229 \\
\hline Surl. contam.cleanable & 2600 & 2600 & 2600 & 2600 & 2600 & 2600 & 2600 & 1599 & 1599 & 1599 & 1599 & 1582 \\
\hline Surl. contam.-non-cinb! & 0 & 0 & 0 & 0 & 0 & 0 & 0 & 0 & 0 & 0 & 0 & 158 \\
\hline Aclivated & 406 & 406 & 406 & 406 & 406 & 406 & .406 & 254 & 254 & 254 & 254 & 1661 \\
\hline Non-radioactive & 0 & 0 & 0 & 0 & 0 & 0 & 0 & 0 & 0 & 0 & 0 & 0 \\
\hline Surl. contam.-cleanable & 0 & 0 & 0 & 0 & 0 & 0 & 0 & 0 & 0 & 0 & 0 & 0 \\
\hline Surf. coniam.-non-dinbl & 0 & 0 & $\underline{0}$ & 0 & 0 & 0 & 0 & 0 & 0 & 0 & 0 & 0 \\
\hline Activated & 0 & 0 & 0 & 0 & 0 & 0 & 0 & 0 & 0 & 0 & 0 & 25 \\
\hline
\end{tabular}




\begin{tabular}{|c|c|c|c|c|c|c|c|c|c|c|c|c|}
\hline 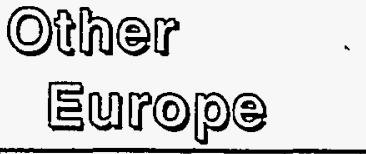 & $\begin{array}{c}\text { Cernavoda } \\
2 \\
\end{array}$ & $\begin{array}{c}\text { Cernavoda } \\
3 \\
\end{array}$ & $\begin{array}{c}\text { Cernavoda } \\
4 \\
\end{array}$ & $\begin{array}{c}\text { Cernavoda } \\
5 \\
\end{array}$ & Cofrentes & $\begin{array}{l}\text { Santa Marla } \\
\text { de Garnọa }\end{array}$ & $\begin{array}{c}\text { Vandellos } \\
1\end{array}$ & $\begin{array}{c}\text { Almaraz } \\
1\end{array}$ & $\begin{array}{c}\text { Almaraz } \\
2\end{array}$ & $\begin{array}{c}\text { Asco } \\
1\end{array}$ & $\begin{array}{c}\text { Asco } \\
2 \\
\end{array}$ & $\begin{array}{l}\text { Jose } \\
\text { Cabrera }\end{array}$ \\
\hline Fuel cycle stage (FCT) & Reactor & Reactor & Reactor & Reactor & Reactor & Reactor & Reactor & Reactor & Reactor & Reactor & Reactor & Reactor \\
\hline Identifler & 662RH & $704 \mathrm{RH}$ & $708 \mathrm{RH}$ & 722RH & $428 \mathrm{~EB}$ & $141 \mathrm{~EB}$ & 171EG & 328EP & 362EP & $363 \mathrm{EP}$ & 429EP & 133EP \\
\hline Plant type & PHWR & PHWR & PHWR & PHWR & BWR & BWR & Magnox III & PWR & PWR & PWR & PWR & PWR \\
\hline Locatlon & Romania & Romania & Romania & Romania & Spain & Spain & Spain & Spain & Spain & Spain & Spain & Spain \\
\hline Stant of operatlons & & & & & 1985 & 1971 & 1972 & 1981 & 1984 & 1984 & 1986 & 1969 \\
\hline Status & Under Const & Under Const & Under Const & Under Const & Operating & Operating & Shut down & Operating & Operating & Operating & Operating & Operating \\
\hline Slze (MWe) (Net) & 620 & 620 & 620 & 620 & 958 & 440 & 480 & 900 & 902 & 887 & 887 & 153 \\
\hline Vendor & AECL & MICM & MIGM & MICM & ⿷匚E & 壬 & GEASFAC & Westinghouse & Westinghouse & Westinghouse & Westlaghouse & Westinghouse \\
\hline AVE & Inst.Pwr S\&D & Inst.Pwir S\&D & Inst.Pwr S\&D & Inst.Pwr S\&D & E. AJG\&H & Exasoo & Socia & & & Bechtel, etc. & Bechlel, etc. & Gibbs \& Hill \\
\hline Pre or Post TMI & Post & Post & Post & Post & Post & Pre & Pre & Post & Post & Post & Post & Pre \\
\hline No. of steam turbines & 1 & 1 & 1 & 1 & 1 & 1 & 2 & 1 & 1 & 1 & 1 & 1 \\
\hline Coolling & River & River & River & River & Tower & -River & & $\dot{-}$ & & & & \\
\hline Date EOL metal avallable & 2053 & 2053 & $\frac{2053}{\text { ZXXI }}$ & 2053 & 2035 & 2021 & 2022 & 2031 & 2034 & 2034 & 2036 & 2019 \\
\hline \multicolumn{13}{|l|}{ Quantity of metal (tonnes): } \\
\hline Aluminum Non-radloactive & 63 & 63 & 63 & 63 & 78 & 46 & 80 & 75 & 75 & 74 & 74 & 23 \\
\hline Surt. contam.-claanable & 12 & 12 & 12 & 12 & 15 & 9 & 15 & 14 & 14 & 14 & 14 & 4 \\
\hline Surl. contam.-non-clnbl & 0 & 0 & 0 & 0 & 0 & 0 & 0 & 0 & 0 & 0 & 0 & 0 \\
\hline Activated & 4 & 4 & 4 & 4 & 5 & 3 & 5 & 5 & 5 & 5 & 5 & 1 \\
\hline Non-radloactlve & 3877 & 3877 & 3877 & 3877 & 4762 & 2835 & 3900 & 4568 & 4574 & 4524 & 4524 & 1402 \\
\hline Surl. contam.-cleanable & 63 & 63 & 63 & 63 & 78 & 46 & 80 & 75 & 75 & 74 & 74 & 23 \\
\hline Surl. contam.non-clnbl & 0 & 0 & 0 & 0 & 0 & 0 & 0 & 0 & 0 & 0 & 0 & 0 \\
\hline Activated & 16 & 16 & 16 & 16 & 19 & 12 & 20 & 19 & 19 & 18 & 18 & 6 \\
\hline Non-radloactive & 20 & 20 & 20 & 20 & 20 & 20 & 20 & 20 & 20 & 20 & 20 & 20 \\
\hline Surl. contam.-cleanable & 0 & 0 & 0 & 0 & 0 & 0 & 0 & 0 & 0 & 0 & 0 & 0 \\
\hline Surl. contam.non-cinbl & 0 & 0 & 0 & 0 & 0 & 0 & 0 & 0 & 0 & 0 & 0 & 0 \\
\hline Actlvated & 0 & 0 & 0 & 0 & 0 & 0 & 0 & 0 & 0 & 0 & 0 & 0 \\
\hline Steel \& Iron Non-radloactive & 6329 & 6329 & 6329 & 6329 & 4859 & 2892 & 12770 & 7728 & 7739 & 7653 & 7653 & 2371 \\
\hline Suri. contam.-cleanable & 4747 & 4747 & 4747 & 4747 & 6511 & 3876 & 5630 & 6246 & 6255 & 6185 & 6185 & 1917 \\
\hline Surf. contam.-non-clnbl & 0 & 0 & 0 & 0 & 0 & 0 & 0 & 0 & 0 & $\underline{0}$ & 0 & 0 \\
\hline Actlvated & 2326 & 2326 & 2326 & 2326 & 3401 & 2025 & 2100 & 2741 & 2745 & 2714 & 2714 & 841 \\
\hline Non-radloactlve & 229 & 229 & 229 & 229 & 0 & 0 & 60 & 0 & 0 & 0 & 0 & 0 \\
\hline Surl. contam.-cleanable & 1582 & 1582 & 1582 & 1582 & 583 & 347 & 900 & 839 & 840 & 831 & 831 & 257 \\
\hline Surf. contam.-non-cinbl & 158 & 158 & 158 & 158 & 0 & 0 & 0 & 280 & 280 & 277 & 277 & 86 \\
\hline Acllvated & 1661 & 1661 & 1661 & 1661 & 651 & 388 & 165 & 625 & 625 & 619 & 619 & 192 \\
\hline Non-radioactlve & 0 & 0 & 0 & $\underline{0}$ & 0 & 0 & 0 & 0 & 0 & $\underline{0}$ & 0 & 0 \\
\hline Surf. contam.-cleanable & 0 & 0 & 0 & 0 & 0 & 0 & 0 & 0 & 0 & 0 & 0 & 0 \\
\hline Surl. contam.-non-cinbl & 0 & 0 & 0 & 0 & 0 & 0 & 0 & 0 & 0 & 0 & 0 & 0 \\
\hline Activated & 25 & 25 & 25 & 25 & 0 & 0 & 0 & 0 & 0 & 0 & 0 & 0 \\
\hline
\end{tabular}




\begin{tabular}{|c|c|c|c|c|c|c|c|c|c|c|c|c|}
\hline 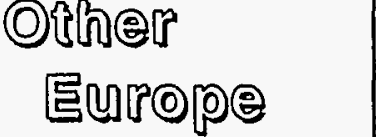 & $\begin{array}{c}\text { Trlllo } \\
1\end{array}$ & $\begin{array}{c}\text { Vandellos } \\
2\end{array}$ & $\begin{array}{c}\text { Barsebaeck } \\
1\end{array}$ & $\begin{array}{c}\text { Barsobaeck } \\
2\end{array}$ & $\begin{array}{c}\text { Forsmark } \\
1\end{array}$ & $\begin{array}{c}\text { Forsmark } \\
2\end{array}$ & $\begin{array}{c}\text { Forsmark } \\
3 \\
3\end{array}$ & $\begin{array}{l}\text { Oskar- } \\
\text { shamn } y\end{array}$ & $\begin{array}{c}\text { Oskar. } \\
\text { shamn } 2\end{array}$ & $\begin{array}{l}\text { Oskar- } \\
\text { shamn } 3\end{array}$ & $\begin{array}{l}\text { Ringhals } \\
1\end{array}$ & $\begin{array}{l}\text { Rlnghals } \\
2\end{array}$ \\
\hline Fuel cycle stage (FCI) & Reactor & Reactor & Peactor & Reactor & Reactor & Reactor & Reactor & Reactor & Reactor & Reactor & Reactor & Reactor \\
\hline Identlifer & 560EP & 558EP & 267SB & $450 \mathrm{SB}$ & $342 S B$ & $277 \mathrm{SB}$ & 565SB & 143SB & 275SB & $581 \mathrm{SB}$ & 248SB & 249SP \\
\hline Plant type & PWR & PWR & BWR & BWR & BWR & BWR & BWR & BWR & BWR & BWR & BWR & PWR \\
\hline Locatlon & Spain & Spain & Swedon & Swoden & Swaden & Swadan & Swaden & Swodan & Swaden & Swaden & Sweden & Swoden \\
\hline Start of operatlons & 1989 & 1988 & 1975 & 1977 & 980 & 1981 & 1985 & 1972 & 1974 & 1985 & 1976 & 1975 \\
\hline Status & Operating & Operating & Operating & Operating & Operating & Operating & Operating & Operating & Operating & Operating & Oporating & Operating \\
\hline Size (MWe) (Nel) & 991 & 951 & 600 & 585 & 970 & 970 & 1050 & 440 & 595 & 1160 & 750 & 800 \\
\hline Vendor & KWU & Westinghouse & Asea-Atom & Assa-Atom & Asea-Atom & Asea-Atom & Assa-Atom & ABB-Atom & ABB-Alom & ABB-Atom & Asea-Alom & Weslinghouse \\
\hline AVE & & Initec/Bochite & VBB & VBB & SSPB & SSPB & SSPB & & VBB & & A-AVSSPB & SSPB/G\&H \\
\hline Pre or Post TMI & Post & Post & Pre & Pre & Pre & Post & Post & Pre & Pre & Post & Pre & Pro \\
\hline No. of steam turbines & 1 & 1 & 1 & 1 & 2 & 2 & 1 & 1 & 1 & 1 & 2 & 2 \\
\hline Coolling & & sea & & & & & & & & . & & $\therefore$ \\
\hline 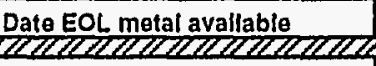 & 2039 & 2038 & 2025 & 2027 & 1030 & 2031 & 2035 & 2022 & 2024 & 2035 & 2026 & 2025 \\
\hline \multicolumn{13}{|l|}{ Quaniliy of metal (tonnes): } \\
\hline Aluminum Non-radioactlve & 80 & 77 & 57 & 56 & 78 & 78 & 83 & 46 & 57 & 88 & 66 & 69 \\
\hline Surf. contam.-cleanable & 15. & 15 & 11 & 10 & 15 & 15 & 15 & 9 & 11 & 17 & 12 & 13 \\
\hline Surt. contam.-non-cinbl & 0 & 0 & 0 & 0 & 0 & 0 & 0 & 의 & of & 0 & 0 & 0 \\
\hline Actlvated & 5 & 5 & 4 & 3 & 5 & 5 & 5 & $\begin{array}{l}.3 \\
\end{array}$ & 4 & 6 & 4 & 4 \\
\hline Non-radloactive & 4871 & 4739 & 3486 & 3427 & 4802 & 4802 & 5062 & 2835 & 3466 & 5410 & 4045 & 4223 \\
\hline Surl. contam.-cleanable & 80 & 77 & 57 & 56 & 78 & 78 & 83 & 46 & 57 & 88 & 66 & 69 \\
\hline Surl. contam.-non-clnbl & 0 & 0 & of & 0 & 0.1 & 0 & 0 & 0 & 0 & 0 & 0 & 0 \\
\hline Acllvated & 20 & 19 & 14 & 14 & 20 & 20 & 21 & 12 & 14 & 22 & 17 & 17 \\
\hline Non-radioactive & 20 & 20 & 20 & 20 & 20 & 20 & 20 & 20 & 20 & 20 & 20 & 20 \\
\hline Surt. contam.-cleanable & 0 & 0 & 0 & 0 & 0 & 0 & 0 & 0 & 0 & 0 & 0 & 0 \\
\hline Surl. contam.-non-cinbl & 0 & 0 & 요 & 0 & 0 & 0 & 0 & 0 & 0 & 0 & 0 & 0 \\
\hline Actlvated & 0 & 0 & 0 & 0 & 0 & 0 & 0 & 0 & 0 & 0 & 0 & 0 \\
\hline Steol \& Iron Non-radioactive & 8240 & 8017 & 3557 & 3497 & 4899 & 4899 & 5165 & 2892 & 3537 & 5520 & 4127 & 7144 \\
\hline Surt. contam.-cleanable & 6660 & 6479 & 4766 & 4686 & 6565 & 6565 & 6922 & 3876 & 4740 & 7397 & 5531 & 5774 \\
\hline Surl. contam.-non-clnbl & 0 & 0 & 0 & 0 & 0 & 0 & 0 & 0 & 0 & 0 & 0 & 0 \\
\hline Actlvated & 2922 & 2843 & 2490 & 2448 & 3430 & 3430 & 3616 & 2025 & 2476 & 3864 & 2889 & 2534 \\
\hline St. Steel Non-radloactive & 0 & 0 & 0 & 0 & 0 & 0 & 0 & 0 & 0 & 0 & 0 & 0 \\
\hline Suri. contam-cleanable & 895 & 870 & 427 & 420 & 588 & 588 & 620 & 347 & 424 & 662 & 495 & 776 \\
\hline Surt. contam.-non-clnbl & 298 & 290 & 0 & 0 & 0 & 0 & 0 & 0 & 0 & 0 & 0 & 259 \\
\hline Activated & 666 & 648 & 477 & 469 & 657 & 657 & 692 & 388 & 474 & 740 & 553 & 577 \\
\hline Zlrconlum Non-radioactive & 0 & 0 & 0 & 0 & 0 & 0 & 0 & 0 & 0 & 0 & 0 & 0 \\
\hline Surf. contam.-cleanable & 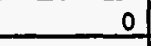 & 0 & 0 & 0 & 0 & 0 & 0 & 0 & 0 & 0 & 0 & 0 \\
\hline Surf. contam.-non-cinbl & 0 & 0 & 0 & 0 & 0 & 0 & 0 & 0 & 0 & 0 & 0 & 0 \\
\hline Activated & 0 & 0 & 0 & 0 & 0 & 0 & 0 & 0 & 0 & 0 & 0 & 0 \\
\hline
\end{tabular}




\begin{tabular}{|c|c|c|c|c|c|c|c|c|c|c|c|c|}
\hline 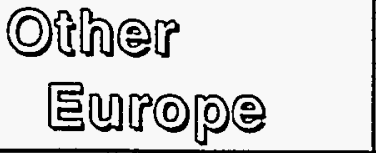 & $\begin{array}{c}\text { Ringhals } \\
3\end{array}$ & $\begin{array}{c}\text { Rlnghals } \\
4\end{array}$ & Lelbstadt & $\begin{array}{l}\text { Muehle- } \\
\text { berg } 1\end{array}$ & Beznau & $\begin{array}{l}\text { Beznau } \\
\text { CNL } \\
\end{array}$ & $\begin{array}{c}\text { Goesgen } \\
2\end{array}$ & SInop & $\begin{array}{c}\text { Akkuyu } \\
1 \\
\end{array}$ & $\begin{array}{l}\text { Akkuyu } \\
2\end{array}$ & Krsko & Prevlaka \\
\hline Fuel cycle stage (FCT) & Reactor & Reactor & Reactor & Reactor & Reactor & Reactor & Reactor & Reactor & Reactor & Reactor & Reactor & Reactor \\
\hline Identifler & $381 \mathrm{SP}$ & $382 S P$ & $4757 \mathrm{CHB}$ & $173 \mathrm{CHB}$ & $217 \mathrm{CHP}$ & 144CHP & $455 \mathrm{CHP}$ & 871TRB & 752TRH & 753TRP & $412 Y U P$ & $862 Y U P$ \\
\hline Plant type & PWR & PWR & BWR & BWR & PWR & PWR & PWR & BWR & PHWR & PWR & PWR & WER \\
\hline Location & Swaden & Swodan & Switzerland & Switzerland & Switzerland & Switzerland & 'Switzerland & Turkey & Turkey & Turkey & Slovenla & Slovenia \\
\hline Start of operatlons & 1981 & 983 & 1984 & 1972 & 1972 & 1989 & 1979 & & & & & \\
\hline Status & Operating & Operating & Operating & Operating & Operating & Operating & Operating & Planned & Planned & Planned & Operating & Planned \\
\hline Slzo (MWe) (Net) & 915 & 915 & 990 & 320 & 264 & 350 & 920 & 1200 & 600 & 950 & 632 & 900 \\
\hline Vendor & Westinghouse & Westinghouse & Getsoo & Getsos & Westinghouse & Westinghouse & KWU & & & & Westinghouse & \\
\hline AVE & SSPB & SSPB & BBC/Eletrutt & $\mathrm{BBC} / \mathrm{E} \& \mathrm{~B} / \mathrm{GE}$ & G\&H/BBC & G\&H/BBC & KWU & & & & Gilbert & \\
\hline Pre or Post TMI & Post & Pro & Post & Pro & Pre & Post & Pro & Post & Post & Post & Post & Post \\
\hline No. of steam turblnes & 2 & 2 & 1. & 2 & 2 & 2 & 1 & 1 & 1 & 1 & 1 & 1 \\
\hline Coolling & Sea & Sea & Nat dift twr & River & & & Tower & & $\dot{.}$ & & & Forced circ. \\
\hline Date EOL metal avallable & 2031 & 1033 & 2034 & 2022 & 2022 & 2039 & 2029 & Unknown & Unknown & Unknown & 2053 & Unknown \\
\hline \multicolumn{13}{|l|}{ Quantlty of metal (tonnes): } \\
\hline Non-radloactlve & 75 & 75 & 79 & 37 & 33 & 40 & 76 & 90 & 62 & 77 & 59 & 80 \\
\hline Surt. contam.-cleanable & 14 & 14 & 15 & 7 & 6 & 7 & 14 & 17 & 12 & 14 & 11 & 15 \\
\hline Surf. contam.-non-cinbl & 0 & 0 & 0 & 0 & 0 & 0 & 0 & 0 & 0 & 0 & 0 & 0 \\
\hline Aclivated & 5 & 5 & 5 & 2 & 2 & 2 & 5 & 6 & 4 & 5 & 4 & 5 \\
\hline Copper Non-radloactive & 4618 & 4618 & 4867 & 2292 & 2017 & 2434 & 4635 & 5533 & 3793 & 4735 & 3609 & 4900 \\
\hline Surf. conlam.-cleanable & 75 & 75 & 79 & 37 & 33 & 40 & 76 & 90 & 62 & 77 & 59 & 80 \\
\hline Surl. contam.-non-clnbl & 0 & 0 & 0 & 0 & 0 & 0 & 0 & 0 & 0 & 0 & 0 & 0 \\
\hline Activated & 19 & 19 & 20 & 9 & 8 & 10 & 19 & 23 & 15 & 19 & 15 & 20 \\
\hline Non-radioactlve & 20 & 20 & 20 & 20 & 20 & 20 & 20 & 20 & 20 & 20 & 20 & 20 \\
\hline Surt. contam.-cleanable & 0 & 0 & 0 & 0 & 0 & 0 & 0 & 0 & 0 & 0 & 0 & 0 \\
\hline Surf. contam.-non-clnbl & 0 & 0 & 0 & 0 & 0 & 0 & 0 & 0 & 0 & 0 & 0 & 0 \\
\hline Actlvated & 0 & 0 & 0 & 0 & 0 & 0 & 0 & 0 & 0 & 0 & 0 & 0 \\
\hline Steel \& Iron Non-radioactlve & 7813 & 7813 & 4967 & 2339 & 3412 & $4117^{\circ}$ & 7842 & 5646 & 6193 & 8011 & 6105 & 19248 \\
\hline Surf. contam.-cleanable & 6315 & 6315 & 6655 & 3135 & 2757 & 3328 & 6338 & 7566 & 4644 & 6475 & 4934 & 7156 \\
\hline Surf. contam.-non-clnbl & 0 & 0 & 0 & 0 & 0 & 0 & 0 & 0 & 0 & 0 & 0 & 69 \\
\hline Actlvated & 2771 & 2771 & 3477 & 1637 & 1210 & 1460 & 2781 & 3952 & 2276 & 2841 & 2165 & 581 \\
\hline Non-radioactive & 0 & 0 & 0 & 0 & 0 & 0 & 0 & 0 & 224 & 0 & 0 & 0 \\
\hline Surf. contam.-cleanable & 848 & 848 & 596 & 281 & 370 & 447 & 851 & 678 & 1548 & 870 & 663 & 2600 \\
\hline Suri. contam.-non-cinbl & 283 & 283 & 0 & 0 & 123 & 149 & 284 & 0 & 155 & 290 & 221 & 0 \\
\hline Activated & 631 & 631 & 666 & 313 & 276 & 333 & 634 & 757 & 1626 & 647 & 493 & 406 \\
\hline Zirconlum Non-radioactive & 0 & 0 & 0 & 0 & 0 & 0 & 0 & 0 & 0 & 0 & 0 & 0 \\
\hline Surf. contam.-cleanable & 0 & 0 & 0 & 0 & 0 & 0 & 0 & 0 & 0 & 0 & 0 & 0 \\
\hline Suri. contam.-non-clnbl & 0 & 0 & 0 & 0 & $\underline{0}$ & $\underline{0}$ & 0 & 0 & 0 & 0 & 0 & 0 \\
\hline Activated & 0 & 0 & 0 & 0 & 0 & 0 & 0 & 0 & 25 & 0 & 0 & 0 \\
\hline
\end{tabular}




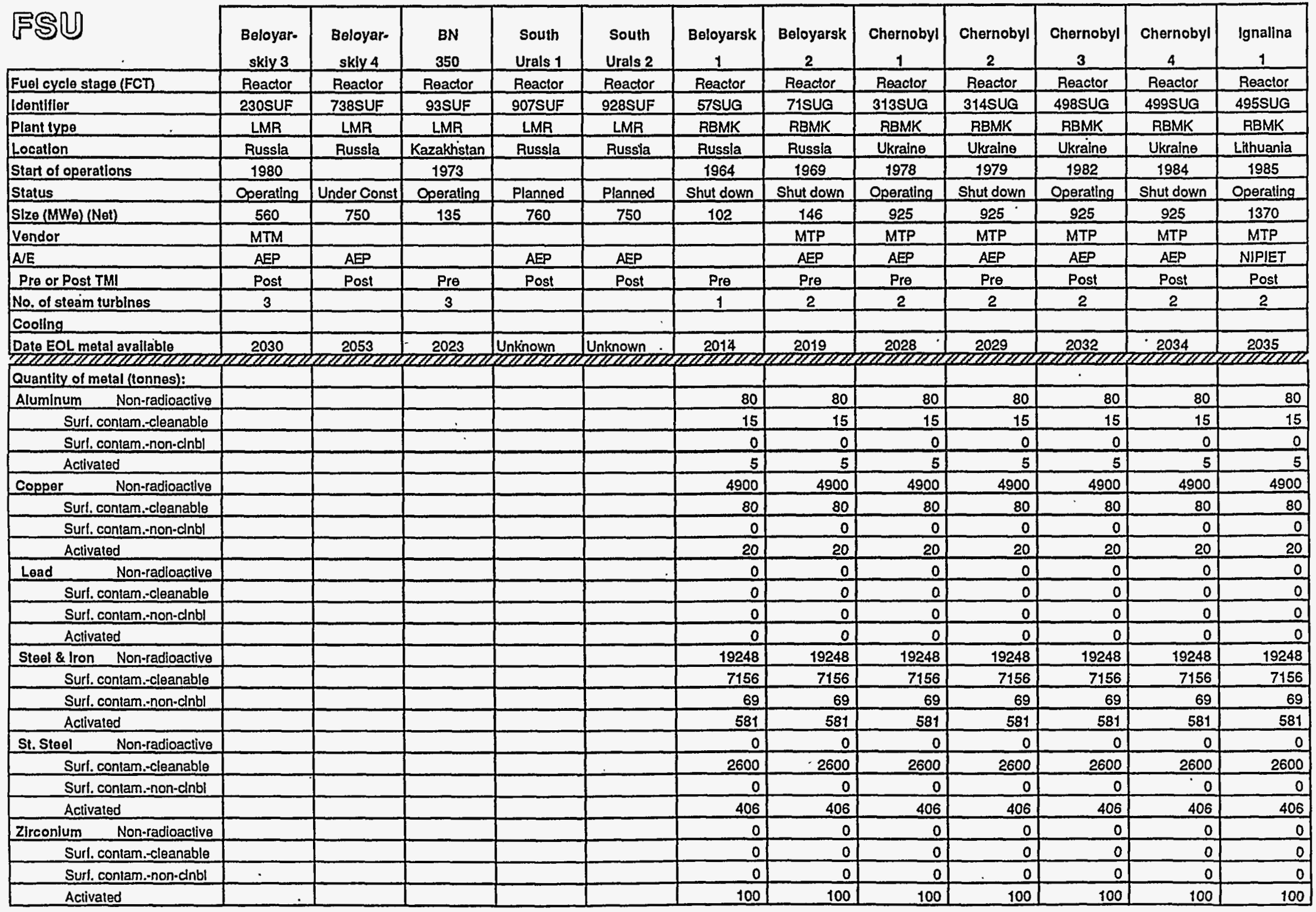




\begin{tabular}{|c|c|c|c|c|c|c|c|c|c|c|c|c|}
\hline Бதலை & $\begin{array}{c}\text { Ignalina } \\
2 \\
\end{array}$ & $\begin{array}{c}\text { Kursk } \\
1 \\
\end{array}$ & $\begin{array}{c}\text { Kursk } \\
2 \\
\end{array}$ & $\begin{array}{c}\text { Kursk } \\
3 \\
\end{array}$ & $\begin{array}{c}\text { Kursk } \\
4 \\
\end{array}$ & $\begin{array}{c}\text { Leningrad } \\
1\end{array}$ & $\begin{array}{c}\text { Leningrad } \\
2 \\
\end{array}$ & $\begin{array}{c}\text { Leningrad } \\
3 \\
\end{array}$ & $\begin{array}{c}\text { Leningrad } \\
4 \\
\end{array}$ & $\begin{array}{c}\text { Smolensk } \\
1\end{array}$ & $\begin{array}{c}\text { Smolensk } \\
2 \\
\end{array}$ & $\begin{array}{c}\text { Smolensk } \\
3 \\
\end{array}$ \\
\hline Fuel cycle slage (FCT) & Reactor & Reactor & Reactor & Reactor & Reactor & Reactor & Reactor & Reactor & Reactor & Reactor & Reactor & Reactor \\
\hline Identlfier & 496SUG & 232SUG & 235SUG & 235SUG & 501SUG & 231SUG & 234SUG & 548SUG & 549SUG & 311SUG & 312SUG & 667SUG \\
\hline Plant type & RBMK & RBMK & RBMK & RBMK & RBMK & RBMK & RBMK & RBMK & RBMK & RBMK & RBMK & RBMK \\
\hline Location & Lithuania & Russia & Russia & Russia & Russla & Russia & Russia & Russia & Russia & Russia & Russia & Russia \\
\hline Start of oparations & 1987 & 1977 & 1979 & 1984 & 1986 & 1974 & 1976 & 1980 & 1981 & 1983 & 1985 & 1990 \\
\hline Status & Oporating & Operating & Operating & Operating & Operating & Operating & Operating & Operating & Operating & Operating & Operating & Operating \\
\hline Slze (MWe) (Not) & 1370 & 925 & 925 & 925 & 925 & 925. & 925 & 925 & 925 & 925 & 925 & 925 \\
\hline Vendor & MTP & MTP & MTP & MTP & MTP & MTP & MTP & MTP & MTP & MTP & MTP & MTP \\
\hline A/E & NIPIET & AEP & AEP & AEP & AEP & AEP & AEP & AEP & AEP & AEP & AEP & AEP \\
\hline Pre or Post TMI & Post & Pre & Pre & Post & Post & Pre & Pre & Post & Post & Post & Post & Post \\
\hline No. of steam turbines & 2 & 2 & 2 & 2 & 2 & 2 & 2 & 2 & 2 & 2 & 2 & 2 \\
\hline \multicolumn{13}{|l|}{ Cooling } \\
\hline Date EOL melal avallable & 2037 & 2027 & 2029 & 2034 & 2036 & 2024 & 2026 & 2030 & 2031 & $2033 \cdots$ & $\frac{2035}{22 Z}$ & 2040 \\
\hline \multicolumn{13}{|l|}{ Quantity of motal (tonnes): } \\
\hline Non-radioaclive & 80 & 80 & 80 & 80 & 80 & 80 & 80 & 80 & 80 & 80 & 80 & 80 \\
\hline Surl. contam.-cleanable & 15 & 15 & 15 & 15 & 15 & 15 & 15 & 15 & 15 & 15 & 15 & 15 \\
\hline Surf. contam.-non-cinbl & 0 & 0 & 0 & 0 & 0 & 0 & 0 & 0 & 0 & 0 & 0 & 0 \\
\hline Activated & 5 & 5 & 5 & 5 & 5 & 5 & 5 & 5 & 5 & 5 & 5 & 5 \\
\hline Non-radioactive & 4900 & 4900 & 4900 & 4900 & 4900 & 4900 & 4900 & 4900 & 4900 & 4900 & 4900 & 4900 \\
\hline Surl. contam.-cleanable & 80 & 80 & 80 & 80 & 80 & 80 & 80 & 80 & 80 & 80 & 80 & 80 \\
\hline Surl. contam.-non-clnbl & 0 & 0 & 0 & 0 & 0 & 0 & 0 & 0 & 0 & 0 & 0 & 0 \\
\hline Activated & 20 & 20 & 20 & 20 & 20 & 20 & 20 & 20 & 20 & 20 & 20 & 20 \\
\hline Load $\quad$ Non-radioactive & 0 & 0 & 0 & 0 & 0 & 0 & 0 & 0 & 0 & 0 & 0 & 0 \\
\hline Surf. contam.-cleanable & 0 & 0 & 0 & 0 & 0 & 0 & 0 & 0 & 0 & 0 & 0 & 0 \\
\hline Surl. contam.-non-cinb! & 0 & 0 & $\underline{0}$ & 0 & 0 & 0 & 0 & 0 & 0 & 0 & 0 & 0 \\
\hline Activated & 0 & 0 & 0 & 0 & 0 & $\therefore$ & 0 & 0 & 0 & 0 & 0 & 0 \\
\hline Steol \& Iron Non-radioactive & 19248 & 19248 & 19248 & 19248 & 19248 & 19248 & 19248 & 19248 & 19248 & 19248 & 19248 & 19248 \\
\hline Surf. contam.-cleanable & 7156 & 7156 & 7156 & 7156 & 7156 & 7156 & 7156 & 7156 & .7156 & 7156 & 7156 & 7156 \\
\hline Surl. contam.-non-dnbl & 69 & 69 & 69 & 69 & 69 & 69 & 69 & 69 & 69 & 69 & 69 & 69 \\
\hline Aclivated & 581 & 581 & 581 & 581 & 581 & 581 & 581 & 581 & 581 & 581 & 581 & 581 \\
\hline St.Steel Non-radioactive & 0 & 0 & 0 & 0 & 0 & 0 & 0 & 0 & 0 & 0 & 0 & 0 \\
\hline Surl. contam.-cleanable & 2600 & 2600 & 2600 & 2600 & 2600 & 2600 & 2600 & 2600 & 2600 & 2600 & 2600 & 2600 \\
\hline Surl. contam.-non-clnbl & 0 & 0 & 0 & 0 & 0 & 0 & 0 & 0 & 0 & 0 & 0 & 0 \\
\hline Activated & 406 & 406 & 406 & 406 & 406 & 406 & 406 & 406 & 406 & 406 & 406 & 406 \\
\hline Non-radioactive & 0 & 0 & 0 & 0 & 0 & 0 & 0 & 0 & 0 & 0 & 0 & 0 \\
\hline Surl. contam.-cleanable & 0 & 0 & 0 & 0 & 0 & 0 & 0 & 0 & 0 & 0 & 0 & 0 \\
\hline Surl. conlam.-non-clnbl & 0 & 0 & 0 & 0 & 0 & 0 & 0 & 0 & 0 & 0 & 0 & 0 \\
\hline Activated & 100 & 100 & 100 & 100 & 100 & 100 & 100 & 100 & 100 & 100 & 100 & 100 \\
\hline
\end{tabular}




\begin{tabular}{|c|c|c|c|c|c|c|c|c|c|c|c|c|}
\hline 5@ీ & $\begin{array}{c}\text { Aktash } \\
1 \\
\end{array}$ & $\begin{array}{c}\text { Aktash } \\
2 \\
\end{array}$ & $\begin{array}{l}\text { Arkhan- } \\
\text { gelsk } 1\end{array}$ & $\begin{array}{l}\text { Arkhan- } \\
\text { gelsk } 2 \text { - }\end{array}$ & $\begin{array}{c}\text { Armonia } \\
1 \\
\end{array}$ & $\begin{array}{c}\text { Armonla } \\
2 \\
\end{array}$ & $\begin{array}{c}\text { Balakovo } \\
1 \\
\end{array}$ & $\begin{array}{c}\text { Balakovo } \\
2 \\
\end{array}$ & $\begin{array}{c}\text { Balakovo } \\
3 \\
\end{array}$ & $\begin{array}{c}\text { Balakovo } \\
4 \\
\end{array}$ & $\begin{array}{c}\text { Balakovo } \\
5 \\
\end{array}$ & $\begin{array}{c}\text { Balakovo } \\
6 \\
\end{array}$ \\
\hline Fuel cycle stage (FCT) & Reactor & Reactor & Reactor & Reactor & Reactor & Reactor & Reactor & Reactor & Reactor & Reactor & Reactor & Reaclor \\
\hline Identifier & 603SUP & 644SUP & 759SUP & 760 SUP & 233 SUP & 258SUP & 604SUP & 678SUP & 699SUP & 763SUP & 764 SUP & 765SUP \\
\hline Plant type & WER & WER & WER & WER & WER & WER & WER & WER & WER & WER & WER & WER \\
\hline Location & FSU & FSU & Russla & Russla & Armenla & Armenia & Russla & Russla & Russia & Russia & Russla & Russia \\
\hline Start of operatlons & & & & & 1976 & 1980 & 1986 & 1988 & 1990 & & & \\
\hline Status & Under Const & Under Const & Planned & Plannod & Shut down & Shut down & Operating & Operating & Operating & Under Const & Under Const & Under Const \\
\hline$S \mid z \theta$ (MWO) (Not) & 953 & 953 & 950 & 950 & 376 & 376 & $950^{\circ}$ & 950 & 950 & 950 & 950 & 950 \\
\hline Vendor & & & & & MTM & MTM & MTM & MTM & MTM & MTM & MTM & MTM \\
\hline A/E & AEP & AEP & & & AEP & AEP & AEP & AEP & AEP & AEP & AEP & AEP \\
\hline Pre or Post TMI & Post & Post & Post & Post & Pre & Post & Post & Post & Post & Post & Post & Post \\
\hline No. of steam turbines & 1 & 1 & 1 & 1 & 2 & 2 & 1 & 1 & 1 & 1 & 1 & 1 \\
\hline \multicolumn{13}{|l|}{ Cooling } \\
\hline Dato EOL matal available & 2053 & 2053 & Unknown & Unknown & 2026 & 2030 & 2036 & 2038 & 2040 & 2053 & 2053 & 2053 \\
\hline \multicolumn{13}{|l|}{ Quantlty of motal (tonnes): } \\
\hline Aluminum Non-radioactive & 80 & 80 & 80 & 80 & 46 & 46 & 80 & 80 & 80 & 80 & 80 & 80 \\
\hline Surl. conlam.-cleanable & 15 & 15 & 15 & 15 & 9 & 9 & 15 & 15 & 15 & 15 & 15 & 15 \\
\hline Surl. contam.-non-cinbl & 0 & 0 & 0 & 0 & 0 & 0 & 0 & 0 & 0 & 0 & 0 & 0 \\
\hline Activated & 5 & 5 & 5 & 5 & 3 & 3 & 5 & 5 & 5 & 5 & 5 & 5 \\
\hline Copper Non-radioactive & 4900 & 4900 & 4900 & 4900 & 2840 & 2840 & 4900 & 4900 & 4900 & 4900 & 4900 & 4900 \\
\hline Surf. contam.-cleanable & 80 & 80 & 80 & 80 & 46 & 46 & 80 & 80 & 80 & 80 & 80 & 80 \\
\hline Surf. contam.-non-clnbl & 0 & 0 & 0 & 0 & 0 & 0 & 0 & 0 & 0 & 0 & 0 & 0 \\
\hline Activaled & 20 & 20 & 20 & 20 & 12 & 12 & 20 & 20 & 20 & 20 & 20 & 20 \\
\hline Lead $\quad$ Non-radloaclive & 20 & 20 & 20 & 20 & 20 & 20 & 20 & 20 & 20 & 20 & 20 & 20 \\
\hline Surf. contam.-cleanable & 0 & 0 & 0 & 0 & 0 & 0 & 0 & 0 & 0 & 0 & 0 & 0 \\
\hline Surf. contam.-non-cInbl & 0 & 0 & 0 & 0 & 0 & 0 & 0 & 0 & 0 & 0 & 0 & 0 \\
\hline Activated & 0 & 0 & 0 & 0 & 0 & 0 & 0 & 0 & 0 & 0 & 0 & 0 \\
\hline Steel \& Iron Non-radioactive & 19248 & 19248 & 19248 & 19248 & 12030 & 12030 & 19248 & 19248 & 19248 & 19248 & 19248 & 19248 \\
\hline Surl. contam-cleanable & 7156 & 7156 & 7156 & 7156 & 4669 & 4669 & 7156 & 7156 & 7156 & 7156 & 7156 & 7156 \\
\hline Surl. contam.-non-clnbl & 69 & 69 & 69 & 69 & 46 & 46 & 69 & 69 & 69 & 69 & 69 & 69 \\
\hline Activated & 581 & 581 & 581 & 581 & 363 & 363 & 581 & 581 & 581 & 581 & 581 & 581 \\
\hline Non-radioactive & 0 & 0 & 0 & 0 & 0 & 0 & 0 & 0 & 0 & 0 & 0 & 0 \\
\hline Surl. contam.-cleanable & 2600 & 2600 & 2600 & 2600 & 1599 & 1599 & 2600 & 2600 & 2600 & 2600 & 2600 & 2600 \\
\hline Surl. contam.-non-dnbl & 0 & 0 & 0 & 0 & 0 & 0 & 0 & 0 & 0 & .0 & 0 & 0 \\
\hline Activated & 406 & 406 & 406 & 406 & 254 & 254 & 406 & 406 & 406 & 406 & 406 & 406 \\
\hline Zirconlum Non-radioactive & 0 & 0 & 0 & 0 & 0 & 0 & 0 & 0 & 0 & 0 & 0 & 0 \\
\hline Surl. contam.-cleanable & 0 & 0 & 0 & 0 & 0 & 0 & 0 & 0 & 0 & 0 & 0 & 0 \\
\hline Surl. contam.-non-clnbl & 0 & 0 & 0 & 0 & 0 & 0 & 0 & 0 & 0 & 0 & 0 & 0 \\
\hline Activated & 0 & 0 & 0 & 0 & 0 & 0 & 0 & 0 & 0 & 0 & 0 & 0 \\
\hline
\end{tabular}




\begin{tabular}{|c|c|c|c|c|c|c|c|c|c|c|c|c|}
\hline కS్రు & $\begin{array}{c}\text { Bryansk } \\
1 \\
\end{array}$ & $\begin{array}{c}\text { Kalinin } \\
1 \\
\end{array}$ & $\begin{array}{c}\text { Kalinin } \\
2 \\
\end{array}$ & $\begin{array}{c}\text { Kalinin } \\
3 \\
\end{array}$ & $\begin{array}{c}\text { Kalinln } \\
4 \\
\end{array}$ & $\begin{array}{c}\text { Khmeinitskly } \\
2 \\
\end{array}$ & $\begin{array}{c}\text { Khmoinitskly } \\
3 \\
\end{array}$ & $\begin{array}{c}\text { Khmelnitskity } \\
1 \\
\end{array}$ & $\begin{array}{c}\text { Khmernitsky } \\
4 \\
\end{array}$ & $\begin{array}{c}\text { Kola } \\
1 \\
\end{array}$ & $\begin{array}{c}\text { Kola } \\
2 \\
\end{array}$ & $\begin{array}{c}\text { Kola } \\
3 \\
\end{array}$ \\
\hline Fuel cycle stage (FCT) & Reactor & Reactor & Reactor & Reactor & Reactor & Reactor & Roactor & Reactor & Reactor & Reactor & Peactor & Reactor \\
\hline Identiller & 915SUP & 317SUP & 318SUP & 802SUP & 803SUP & 627SUP & 688SUP & 573SUP & 72GSUP & 148SUP & 149SUP & 493SUP \\
\hline Plant typo & WER & WER & WER & WER & WER & WER & WER & WER & WER & WER & WER & WER \\
\hline Location & FSU & Russia & Russia & Russla & Russia & Ukraine & Ukraine & Ukraine & Ukraine & Russia & Russia & Russia \\
\hline Start of operallons & & 1985 & 1987 & & & & & & & 1973 & 1973 & 1982 \\
\hline Stalus & Planned & Operating & Operating & Under Const & Under Const & Under Const & Under Const & Operating & Under Const & Operating & Operating & Operating \\
\hline Slzo (MWe) (Net) & 950 & 950 & 950 & 950 & 950 & 950 & 950 & 950 & 950 & 411 & 411 & 411 \\
\hline Vendor & & MTM & MTM & MTM & MTM & MTM & MTM & MTM & MTM & MTM & MTM & MTM \\
\hline$A / E$ & & AEP & AEP & AEP & AEP & AEP & AEP & AEP & AEP & AEP & AEP & AEP \\
\hline Pre or Post TMI & Post & Post & Post & Post. & Post & Post & Post & Post & Post & Pre & Pre & Post \\
\hline No. of steam turbines & 2 & 1 & 1 & 1 & 1 & 1 & 1 & 1 & 1 & 2 & 2 & 2 \\
\hline Cooling & & & & & & & & & & & - & \\
\hline 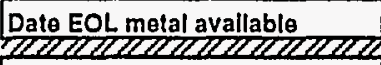 & Unknown & 2035 & 2037 & 2053 & 2053 & 2053 & 2053 & 2053 & 2053 & 2023 & 2023 & 2032 \\
\hline Quantity of metal (tonnes): & & & & & & & & & & & & \\
\hline Aluminum Non-radioactive & 80 & 80 & 80 & 80 & 80 & 80 & 80 & 80 & 80 & 46 & 46 & 46 \\
\hline Surl. contam.-cleanable & 15 & 15 & 15 & 15 & 15 & 15 & 15 & 15 & 15 & 9 & 9 & 9 \\
\hline Suri. contam.-non-clnbl & 0 & 0 & 0 & 0 & 0 & 0 & 0 & 0 & 0 & 0 & 0 & 0 \\
\hline Activated & 5 & 5 & 5 & 5 & 5 & 5 & 5 & 5 & 5 & 3 & 3 & 3 \\
\hline Non-radioective & 4900 & 4900 & 4900 & 4900 & 4900 & 4900 & 4900 & 4900 & 4900 & 2840 & 2840 & 2840 \\
\hline Surf. contam.cleanable & 80 & 80 & 80 & 80 & 80 & 80 & 80 & 80 & 80 & 46 & 46 & 46 \\
\hline Surt. contam-non-clnbl & 0 & 0 & 0 & 0 & 0 & 0 & 0 & 0 & 0 & 0 & 0 & 0 \\
\hline Aclivated & 20 & 20 & 20 & 20 & 20 & 20 & 20 & 20 & 20 & 12 & 12 & 12 \\
\hline Non-radioactive & 20 & 20 & 20 & 20 & 20 & 20 & 20 & 20 & 20 & 20 & 20 & 20 \\
\hline Surf. contam.-cleanable & 0 & 0 & 0 & ? & 0 & 0 & 0 & 0 & 0 & 0 & 0 & 0 \\
\hline Surl contam.-non-cinbl & 0 & 0 & 0 & 0 & 0 & 0 & 요 & 0 & 0 & 0 & 0 & 0 \\
\hline Activated & 0 & $0^{\circ}$ & 0 & 0 & 0 & 0 & 0 & 0 & 0 & 0 & 0 & 0 \\
\hline Steol \& Iron Non-radioactive & 19248 & 19248 & 19248 & 19248 & 19248 & 19248 & 19248 & 19248 & 19248 & 12030 & 12030 & 12030 \\
\hline Surl. contam. cleanable & 7156 & 7156 & 7156 & 7156 & 7156 & 7156 & 7156 & 7156 & 7156 & 4669 & 4669 & 4669 \\
\hline Surl. contam.-non-cinbl & 69 & 69 & 69 & 69 & 69 & 69 & 69 & 69 & 69 & 46 & 46 & 46 \\
\hline Activated & 581 & 581 & 581 & 581 & 581 & 581 & 581 & 581 & 581 & 363 & 363 & 363 \\
\hline Non-radioactive & 0 & 0 & 0 & 0 & 0 & 0 & 0 & $\underline{0}$ & 0 & 0 & 0 & 0 \\
\hline Surf. contam.-cleanable & 2600 & 2600 & 2600 & 2600 & 2600 & 2600 & 2600 & 2600 & 2600 & 1599 & 1599 & 1599 \\
\hline Surl. contam.non-dnbl & 0 & 0 & 0 & 0 & 0 & 0 & 0 & 0 & 0 & 0 & 0 & 0 \\
\hline Activated & 406 & 406 & 406 & 406 & 406 & 406 & 406 & 406 & 406 & 254 & 254 & 254 \\
\hline Non-radioactive & 0 & 0 & 0 & 0 & 0 & 0 & 0 & 0 & 0 & 0 & 0 & 0 \\
\hline - $\quad$ Surl. coniam.-cleanable & 0 & 0 & 0 & 0 & 0 & 0 & 0 & 0 & 0 & 0 & 0 & 0 \\
\hline Surl. contam.-non-clnbl & 0 & 0 & 0 & 0 & 0 & 0 & 0 & 0 & 0 & 0 & 0 & 0 \\
\hline Activated & 0 & 0 & 0 & 0 & 0 & 0 & 0 & $\underline{0}$ & 0 & 0 & 0 & 0 \\
\hline
\end{tabular}




\begin{tabular}{|c|c|c|c|c|c|c|c|c|c|c|c|c|}
\hline | & $\begin{array}{c}\text { Kola } \\
4 \\
\end{array}$ & $\begin{array}{c}\text { Kola } \\
5 \\
\end{array}$ & $\begin{array}{c}\text { Kola } \\
6 \\
\end{array}$ & $\begin{array}{c}\text { Kostroma } \\
1 \\
\end{array}$ & $\begin{array}{c}\text { Kostroma } \\
2 \\
\end{array}$ & $\begin{array}{c}\text { Kostroma } \\
3 \\
\end{array}$ & $\begin{array}{c}\text { Kostroma } \\
4 \\
\end{array}$ & $\begin{array}{c}\text { Novovoro- } \\
\text { nezh } 1\end{array}$ & $\begin{array}{c}\text { Novovoro- } \\
\text { nezh } 2\end{array}$ & $\begin{array}{c}\text { Novovoro- } \\
\text { nezh } 3 \\
\end{array}$ & $\begin{array}{c}\text { Novovoro- } \\
\text { nezh } 4 \\
\end{array}$ & $\begin{array}{c}\text { Novovoro- } \\
\text { nezh } 5\end{array}$ \\
\hline Fuel cycle stage (FCT) & Roactor & Reactor & Reactor & Reactor & Reactor & Reactor & Reactor & Reactor & Reactor & Reactor & Reactor & Reactor \\
\hline Identlfier & 494SUP & 926SUP & 927SUP & 659SUP & 690SUP & 736 SUP & 737SUP & 69SUP & 106SUP & 121SUP & 123SUP & 256SUP \\
\hline Plant type & WER & WER & WER & WER & WER & WER & WER & WER & WER & WER & WER & WER \\
\hline Locatlon & Russla & Russia & Russia & Russia & Russia & Russia & Russia & Russia & Russia & Russia & Russia & Russia \\
\hline Start of operations & 1984 & & & & & & & 1964 & 1970 & 1972 & 1973 & 1981 \\
\hline Status & Operating & Planned & Planned & Under Const & Under Const & Under Const & Under Const & Shut down & Shut down & Operating & Operating & Operating \\
\hline Slze (MWe) (Net) & 411 & 950 & 950 & 950 & 950 & 950 & 950 & 200 & 336 & 385 & 385 & 950 \\
\hline Vendor & MTM & MTM & MTM & MTM & MTM & MTM & MTM & MTM & MTM & MTM & MTM & MTM \\
\hline A/E & AEP & AEP & AEP & AEP & AEP & AEP & AEP & AEP & AEP & AEP & AEP & AEP \\
\hline Pre or Post TMI & Post & Posi & Post & Post & Post & Post & Post & Pre & Pre & Pre & Pre & Post \\
\hline No. of steam turbines & 2 & & & 1 & 1 & 1 & 1 & 1 & 5 & 2 & 2 & 2 \\
\hline Coolling & & & & & & & & & & & & \\
\hline 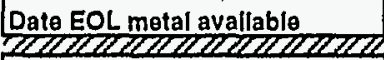 & 2034 & Unknown & Unknown & 2053 & 2053 & 2053 & 2053 & 2014 & $2020^{\circ}$ & $\frac{2022}{2120}$ & 2023 & 2031 \\
\hline Quantity of metal (tonnes): & & & & & & & & & & & & \\
\hline Aluminum Non-radioactive & 46 & 80 & 80 & 80 & 80 & 80 & 80 & 46 & 46 & 46 & 46 & 80 \\
\hline Surf. contam.-cleanable & 9 & 15 & 15 & 15 & 15 & 15 & 15 & 9 & 9 & 9 & 9 & 15 \\
\hline Surf. contam.-non-cinbl & 0 & 0 & 0 & 0 & 0 & 0 & 0 & 0 & 0 & 0 & 0 & 0 \\
\hline Aclivaled & 3 & 5 & 5 & 5 & 5 & 5 & 5 & 3 & 3 & 3 & 3 & 5 \\
\hline Non-radioactive & 2840 & 4900 & 4900 & 4900 & 4900 & 4900 & 4900 & 2840 & 2840 & 2840 & 2840 & 4900 \\
\hline Surf. contam.-cleanable & 46 & 80 & 80 & 80 & 80 & 80 & 80 & 46 & 46 & 46 & 46 & 80 \\
\hline Suri. contam.-non-clnbl & 0 & 0 & 0 & 0 & 0 & 0 & 0 & 0 & 0 & 0 & 0 & $\underline{0}$ \\
\hline Activated & 12 & 20 & 20 & 20 & 20 & 20 & 20 & 12 & 12 & 12 & 12 & 20 \\
\hline Non-radloactive & 20 & 20 & 20 & 20 & 20 & 20 & 20 & 20 & 20 & 20 & 20 & 20 \\
\hline Surl. contam.-cleanable & 0 & 0 & 0 & 0. & 0 & 0 & 0 & 0 & 0 & 0 & 0 & 0 \\
\hline Surl contam.non-dnbl & 0 & 0 & 0 & 0 & 0 & 0 & .0 & 0 & 0 & 0 & 0 & 0 \\
\hline Activated & 0 & 0 & 0 & 0 & 0 & 0 & 0 & 0 & 0 & 0 & 0 & 0 \\
\hline \begin{tabular}{|l} 
Steol \& Iron Non-radioactive \\
\end{tabular} & 12030 & 19248 & 19248 & 19248 & 19248 & 19248 & 19248 & 12030 & 12030 & 12030 & 12030 & 19248 \\
\hline Surf. contam.-cleanable & 4669 & 7156 & 7156 & 7156 & 7156 & 7156 & 7156 & 4669 & 4669 & 4669 & 4669 & 7156 \\
\hline Surl. contam.non-dnbl & 46 & 69 & 69 & 69 & 69 & 69 & 69 & 46 & 46 & 46 & 46 & 69 \\
\hline Activated & 363 & 581 & 581 & 581 & 581 & 581 & 581 & 363 & 363 & 363 & 363 & 581 \\
\hline \begin{tabular}{|ll} 
St. Steel Non-radioactive \\
\end{tabular} & 0 & 0 & 0 & 0 & 0 & 0 & 0 & 0 & 0 & 0 & 0 & 0 \\
\hline Surl. contam.-cleanable & 1599 & 2600 & 2600 & 2600 & 2600 & 2600 & 2600 & 1599 & 1599 & 1599 & 1599 & 2600 \\
\hline Surl. contam.-non-clnbl & 0 & 0 & 0 & 0 & 0 & 0 & 0 & 0 & 0 & 0 & 0 & 0 \\
\hline Activaled & 254 & 406 & 406 & 406 & 406 & 406 & 406 & 254 & 254 & 254 & 254 & 406 \\
\hline Zirconium Non-radioactive & 0 & 0 & 0 & 0 & 0 & 0 & $\underline{0}$ & 0 & 0 & 0 & 0 & 0 \\
\hline Surl. contam.-cleanable & 0 & 0 & 0 & 0 & 0 & 0 & 0 & 0 & 0 & 0 & 0 & 0 \\
\hline Surl. contam.-non-cinbl & 0 & 0 & 0 & 0 & 0 & 0 & 0 & 0 & 0 & 0 & 0 & 0 \\
\hline Activated & 0 & 0 & 0 & 0 & 0 & 0 & 0 & 0 & 0 & 0 & 0 & 0 \\
\hline
\end{tabular}




\begin{tabular}{|c|c|c|c|c|c|c|c|c|c|c|c|c|}
\hline БSU & $\begin{array}{c}\text { Rostov } \\
1\end{array}$ & $\begin{array}{c}\text { Rostov } \\
2 \\
\end{array}$ & $\begin{array}{c}\text { Rostov } \\
3 \\
\end{array}$ & $\begin{array}{c}\text { Rostov } \\
4 \\
\end{array}$ & $\begin{array}{c}\text { Rovno } \\
1 \\
\end{array}$ & $\begin{array}{c}\text { Rovno } \\
2 \\
\end{array}$ & $\begin{array}{c}\text { Rovno } \\
3 \\
\end{array}$ & $\begin{array}{c}\text { Rovno } \\
4 \\
\end{array}$ & $\begin{array}{c}\text { South } \\
\text { Ukraine } 1 \\
\end{array}$ & $\begin{array}{c}\text { South } \\
\text { Ukraine } 2 \\
\end{array}$ & $\begin{array}{c}\text { South } \\
\text { Ukraine } 3 \\
\end{array}$ & $\begin{array}{c}\text { South } \\
\text { Ukraino } 4 \\
\end{array}$ \\
\hline Fual cycle staga (FC) & Reactor & Reactor & Reactor & Reaclor & Reactor & Reactor & Reactor & Reactor & Reactor & Reactor & Reactor & Reactor \\
\hline Identlfier & 605SUP & 646SUP & $7015 U P$ & $702 S U P$ & 315 SUP & 316 SUP & 628SUP & 692SUP & 491SUP & 492SUP & 653SUP & 691SUP \\
\hline Plant type & WER & WER & WER & WER & WER & WER & WER & WER & WER & WER & WER & WER \\
\hline Location & Russia & Russia & Russia & Russia & Ukraine & Ukraine & Ukraine & Ukraine & Ukraine & Ukraine & Ukraine & Ukraine \\
\hline Start of operations & & & & & 1980 & 1982 & 1987 & - & 1983 & 1985 & & \\
\hline Status & Under Const & Operating & Under Const & Under Const & Operating & Operaling & Operating & Under Const & Operating & Operating & Operating & Under Const \\
\hline Sizo $\left(M W_{\theta}\right)$ (Not) & 950 & 950 & 950 & 950 & 361 & 384 & 950 & 950 & 950 & 950 & 950 & 950 \\
\hline Vendor & MTM & MTM & MTM & MTM & MTM & MTM & MTM & MTM & MTM & MTM & MTM & MTM \\
\hline AE & AEP & $\mathrm{AEP}$ & AEP & AEP & AEP & AEP & AEP & AEP & AEP & AEP & AEP & AEP \\
\hline Pre or Post TMI & Post & Post & Post & Post & Post & Post & Post & Post & Post & Post & Post & Post \\
\hline No. of steam turblnes & 1 & 1 & 1 & 1 & 2 & 2 & 1 & 1 & 1 & 1 & 1 & 1 \\
\hline \multicolumn{13}{|l|}{ Coolling } \\
\hline 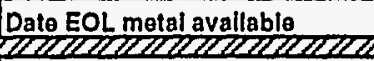 & $\frac{2053}{2 x+212}$ & $\frac{2053}{2120}$ & 2053 & 2053 & 2030 & 2032 & 2037 & 2053 & 2033 & 2035 & 2053 & 2053 \\
\hline \multicolumn{13}{|l|}{ Quantily of metal (tonnes): } \\
\hline Non-radioactive & 80 & 80 & 80 & 80 & 46 & 46 & 80 & 80 & 80 & 80 & 80 & 80 \\
\hline Surl. contam. cleanable & 15 & 15 & 15 & 15 & 9 & 9 & 15 & 15 & 15 & 15 & 15 & 15 \\
\hline Surl. contam.-non-clnbl & 0 & 0 & 0 & 0 & 0 & 0 & 0 & 0 & 0 & 0 & 0 & 0 \\
\hline Aclivated & 5 & 5 & 5 & 5 & 3 & 3 & 5 & 5 & 5 & 5 & 5 & 5 \\
\hline Non-radioactlve & 4900 & 4900 & 4900 & 4900 & 2840 & 2840 & 4900 & 4900 & 4900 & 4900 & 4900 & 4900 \\
\hline Surf. contam.-cloanable & 80 & 80 & 80 & 80 & 46 & 46 & 80 & 80 & 80 & 80 & 80 & 80 \\
\hline Surl. contam.-non-clnbl & 0 & 0 & 0 & 0 & 0 & 0 & 0 & 0 & 0 & 0 & 0 & 0 \\
\hline Activated & 20 & 20 & 20 & 20 & 12 & 12 & 20 & 20 & 20 & 20 & 20 & 20 \\
\hline Non-radioactive & 20 & 20 & 20 & 20 & 20 & 20 & 20 & 20 & 20 & 20 & 20 & 20 \\
\hline Surl. contam.-cleanable & 0 & 0 & 0 & 0 & 0 & $\underline{0}$ & 0 & 0 & 0 & $\dot{0}$ & 0 & 0 \\
\hline Surl. contam-non-clnbl & 0 & 0 & 0 & 0 & $\underline{0}$ & 0 & 0 & 0 & 0 & 0 & 0 & 0 \\
\hline Activated & 0 & 0 & 0 & 0 & 0 & 0 & 0 & 0 & 0 & 0 & 0 & 0 \\
\hline Stoel \& Iron Non-radioactive & 19248 & 19248 & 19248 & 19248 & 12030 & 12030 & 19248 & 19248 & 19248 & 19248 & 19248 & 19248 \\
\hline Surl. contam.-cleanable & 7156 & 7156 & 7156 & 7156 & 4669 & 4669 & 7156 & 7156 & 7156 & 7156 & 7156 & 7156 \\
\hline Surf. contam.-non-clnbl & 69 & 69 & 69 & $69^{\circ}$ & 46 & 46 & 69 & 69 & 69 & 69 & 69 & 69 \\
\hline Activated & 581 & 581 & 581 & 581 & 363 & 363 & 581 & 581 & 581 & 581 & 581 & 581 \\
\hline Non-radioactive & 0 & 0 & 0 & 0 & 0 & 0 & 0 & 0 & 0 & 0. & 0 & 0 \\
\hline Surl. contam.-cleanable & 2600 & 2600 & 2600 & 2600 & 1599 & 1599 & 2600 & 2600 & 2600 & 2600 & 2600 & 2600 \\
\hline Surf. contam.-non-clnbl & 0 & 0 & 0 & 0 & 0 & 0 & 0 & 0 & 0 & 0 & 0 & 0 \\
\hline Activated & 406 & 406 & 406 & 406 & 254 & 254 & 406 & 406 & 406 & 406 & 406 & 406 \\
\hline Non-radioactive & 0 & 0 & 0 & 0 & 0 & 0 & 0 & 으 & 0 & 0 & 0 & 0 \\
\hline Surf. contam.-cleanable & 0 & 0 & 0 & 0 & 0 & 0 & 0 & 0 & 0 & 0 & 0 & 0 \\
\hline Surl. contam.-non-clnbl & 0 & 0 & 0 & 0 & 0 & 0 & 0 & 0 & 0 & 0 & 0 & 0 \\
\hline - Activated & 0 & 0 & 0 & 0 & 0 & 0 & 0 & 0 & 0 & 0 & 0 & 0 \\
\hline
\end{tabular}




\begin{tabular}{|c|c|c|c|c|c|c|c|c|c|c|c|c|}
\hline 15S0 & $\begin{array}{c}\text { Tatar } \\
1\end{array}$ & $\begin{array}{c}\text { Tatar } \\
2\end{array}$ & $\begin{array}{c}\text { Tatar } \\
\dot{3}\end{array}$ & $\begin{array}{c}\text { Tatar } \\
4\end{array}$ & $\begin{array}{c}\text { Voronezh } \\
1 \text { [Ho] }\end{array}$ & $\begin{array}{c}\text { Voronezh } \\
2[\mathrm{HO}\end{array}$ & $\begin{array}{l}\text { Zapo- } \\
\text { rozhye } 1\end{array}$ & $\begin{array}{c}\text { Zapo- } \\
\text { rozhye } 2\end{array}$ & $\begin{array}{c}\text { Zapo- } \\
\text { rozhye } 3\end{array}$ & $\begin{array}{c}\text { Zapo- } \\
\text { rozhye } 4\end{array}$ & $\begin{array}{c}\text { Zapo. } \\
\text { rozhye } 5 \\
\end{array}$ & $\begin{array}{c}\text { Zapo- } \\
\text { rozhye } 6\end{array}$ \\
\hline Fuel cycle stage (FCT) & Reactor & Reactor & Reactor & Reactor & Reactor & Reactor & Reactor & Reactor & Reactor & Reactor & Reactor & Reactor \\
\hline Identifier & 677SUP & 879SUP & 880SUP & 881\$UP & 657SUP & 656SUP & 606SUP & 607SUP & 647SUP & 648SUP & 697SUP & 700SUP \\
\hline Plant type & WER & WER & WER & WER & WER & WER & WER & WER & WER & WER & WER & WER \\
\hline Locatlon & Russia & Russia & Russia & Russia & Russia & Russia & Ukraine & Ukraine & Ukraine & Ukraine & Ukraine & Ukraine \\
\hline Start of operations & & & & & & & 1985 & 1985 & 1987 & 1988 & 1990 & \\
\hline Status & Under Const & Under Const & Planned & Planned & Under Const & Under Const & Operating & Operating & Operating & Operating & Operating & Under Const \\
\hline Slze (MWe) (Net) & 950 & 950 & 950 & 950 & 150 & 150 & 950 & 950 & 950 & 950 & 950 & 950 \\
\hline Vendor & MTM & MTM & MTM & MTM & MTM & MTM & MTM & MTM & MTM & MTM & MTM & MTM \\
\hline ANE & AEP & AEP & AEP & AEP & AEP & AEP & AEP & AEP & AEP & AEP & AEP & AEP \\
\hline Pre or Post TMI & Post & Post & Post & Post & Post & Post & Post & Post & Post & Post & Post & Post \\
\hline No. of steam turbines & 1 & 1 & 1 & 1 & 1 & 1 & 1 & 1 & 1 & 1 & 1 & 1 \\
\hline \multicolumn{13}{|l|}{ Cooling } \\
\hline Date EOL metal avallablo & 2053 & 2053 & Unknown & Unknown & 2053 & 2053 & 2035 & 2035 & 2037 & $\frac{2038}{\mathbb{2} 2 \mathbb{Z Z}}$ & 2040 & 2053 \\
\hline \multicolumn{13}{|l|}{ Quantity of metal (tonnes): } \\
\hline Aluminum Non-radioactive & 80 & 80 & 80 & 80 & 46 & 46 & 80 & 80 & 80 & 80 & 80 & 80 \\
\hline Suri. contam.cleanable & 15 & 15 & 15 & 15 & 9 & 9 & 15 & 15 & 15 & 15 & 15 & 15 \\
\hline Surf. contam.-non-clnbl & 0 & 0 & 0 & 0 & 0 & 0 & 0 & 0 & 0 & 0 & 0 & 0 \\
\hline Activated & 5 & 5 & 5 & 5 & 3 & 3 & 5 & 5 & 5 & 5 & 5 & 5 \\
\hline Non-radioactive & 4900 & 4900 & 4900 & 4900 & 2840 & 2840 & 4900 & 4900 & 4900 & 4900 & 4900 & 4900 \\
\hline Surf. contam.-cleanable & 80 & 80 & 80 & 80 & 46 & 46 & 80 & 80 & 80 & 80 & 80 & 80 \\
\hline Surl, contam.-non-clnbl & 0 & 0 & 0 & 0 & 0 & 0 & 0 & 0 & 0 & 0 & 0 & 0 \\
\hline Activated & 20 & 20 & 20 & 20 & 12 & 12 & 20 & 20 & 20 & 20 & 20 & 20 \\
\hline Non-radjoactive & 20 & 20 & 20 & 20 & 20 & 20 & 20 & 20 & 20 & 20 & 20 & 20 \\
\hline Surl. contam.-cleanable & 0 & $\cdot 0$ & 0 & 0 & 0 & 0 & .0 & 0 & 0 & 0 & 0 & 0 \\
\hline Surl. contam.-non-cinbl & 0 & 0 & 0 & 0 & 0 & 0 & 0 & 0 & 0 & 0 & 0 & 0 \\
\hline Activaled & 0 & 0 & 0 & 0 & 0 & 0 & 0 & 0 & 0 & 0 & 0 & 0 \\
\hline Steel \& Iron Non-radioactive & 19248 & 19248 & 19248 & 19248 & 12030 & 12030 & 19248 & 19248 & 19248 & 19248 & 19248 & 19248 \\
\hline Suri. contam.-cleanable & 7156 & 7156 & 7156 & 7156 & 4669 & 4669 & 7156 & 7156 & 7156 & 7156 & 7156 & 7156 \\
\hline - Suri. contam.-non-cinbl & 69 & 69 & 69 & 69 & 46 & 46 & 69 & 69 & 69 & 69 & 69 & 69 \\
\hline Activated & 581 & 581 & 581 & 581 & 363 & 363 & 581 & 581 & 581 & 581 & 581 & 581 \\
\hline Non-radioactive & 0 & 0 & 0 & 0 & 0 & 0 & 0 & 0 & 0 & 0 & 0 & 0 \\
\hline Surt. contam.-cleanable & 2600 & 2600 & 2600 & 2600 & 1599 & 1599 & 2600 & 2600 & 2600 & 2600 & 2600 & 2600 \\
\hline Surf. contam.-non-cinbl & 0 & 0 & 0 & 0 & 0 & 0 & 0 & 0 & 0 & 0 & 0 & 0 \\
\hline Activaled & 406 & 406 & 406 & 406 & 254 & 254 & 406 & 406 & 406 & 406 & 406 & 406 \\
\hline Non-radioactive & 0 & 0 & 0 & 0 & 0 & 0 & 0 & 0 & 0 & 0 & 0 & 0 \\
\hline Surl. contam.-cleanable & 0 & 0 & 0 & 0 & 0 & 0 & 0 & 0 & 0 & 0 & 0 & 0 \\
\hline Surt. contam.-non-clnbl & 0 & 0 & 0 & 0 & 0 & 0 & 0 & 0 & 0 & 0 & 0 & 0 \\
\hline Activaled & 0 & 0 & 0 & 0 & 0 & 0 & 0 & 0 & 0 & 0 & 0 & 0 \\
\hline
\end{tabular}




\begin{tabular}{|c|c|c|c|c|c|c|c|c|c|c|c|c|c|}
\hline ป回国同 & $\begin{array}{c}\text { Fukushlma } \\
\text { Dallchl } 1\end{array}$ & $\begin{array}{c}\text { Fukushlma } \\
\text { Dallchl } 2 \\
\end{array}$ & $\begin{array}{c}\text { Fukushlma } \\
\text { Dallchl } 3\end{array}$ & $\begin{array}{c}\text { Fukushima } \\
\text { Dallchl } 4\end{array}$ & $\begin{array}{c}\text { Fukushima } \\
\text { Dallchl } 5\end{array}$ & $\begin{array}{c}\text { Fukushlma } \\
\text { Dallchl } 6 \\
\end{array}$ & $\begin{array}{c}\text { Fukushima } \\
\text { Dalnl } 1 \\
\end{array}$ & $\begin{array}{c}\text { Fukushlma } \\
\text { Dalnl } 2 \\
\end{array}$ & $\begin{array}{c}\text { Fukushima } \\
\text { Dainl } 3 \\
\end{array}$ & $\begin{array}{c}\text { Fukushima } \\
\text { Dainl } 4 \\
\end{array}$ & $\begin{array}{c}\text { Genkal } \\
1 \\
\end{array}$ & $\begin{array}{c}\text { Hamaoka } \\
1 \\
\end{array}$ & $\begin{array}{c}\text { Hamaoka } \\
2 \\
\end{array}$ \\
\hline Fuel cycle stage (FCT) & Reactor & Reactor & Reactor & Reactor & Reactor & Reactor & Reactor & Reactor & Reaclor & Reactor & Reactor & Reactor & Reactor \\
\hline Identifler & $147 \mathrm{JB}$ & 223.JB & $284 \mathrm{JB}$ & $369 J \mathrm{JB}$ & $321 \mathrm{JB}$ & $372 \mathrm{JB}$ & $561 \mathrm{JB}$ & $621 \mathrm{JB}$ & $649 \mathrm{JB}$ & $650 \mathrm{JB}$ & $236 \mathrm{JP}$ & $255 \mathrm{JB}$ & $370 \mathrm{JB}$ \\
\hline Plant type & BWR & BWR & BWR & BWR & BWR & BWR & BWR & BWR & BWR & BWR & BWR & BWR & BWR \\
\hline Location & Japan & Japan & Japan & Japan & Japan & Japan & Japan & Japan & Japan & Japan & Japan & Japan & Japan \\
\hline Start of operations & 1971 & 1974 & 1976 & 1978 & 1978 & 1979 & 1982 & 1984 & 1985 & 1987 & 1975 & 1976 & 1978 \\
\hline Status & Operating & Operating & Operating & Operating & Operating & Operating & Operating & Operating & Operating & Operating & Operating & Operating & Operating \\
\hline Size (MWO) (Not) & 439 & 760 & 760 & 760 & 760 & 1067 & 1067 & 1067 & 1067 & 1067 & 529 & 515 & 815 \\
\hline Vendor & GE & GE/Toshiba & Toshiba & Hilachi & Toshiba & GE Toshiba & Toshiba & Hltachi & Toshiba & Hilachi & $\mathrm{MHI}$ & Toshiba & Toshiba \\
\hline AEE & ⿷匚 & Ebasso & Toshiba & Hilachi & Toshiba & Ebasco & Toshiba & Hitachi & Toshiba & Hitachi & Mapi & Toshiba & Tshba/Htchi \\
\hline Pre or Post TMI & Pre & Pre & Pre & Pro & Pre & Pre & Post & Post & Post & Post & Pre & Pre & Pre \\
\hline No. of steam turbines & 1 & 1 & 1 & 1 & 1 & 1 & 1 & 1 & 1 & 1 & 1 & 1 & 1 \\
\hline Coolling & Sea & Sea & Sea & Sea & Sea & Sea & Saa & Sea & Sea & Sea & Sea & & \\
\hline Date EOL metal avallablo & 2021 & 2024 & 2026 & 2028 & 2028 & 2029 & 2032 & 2034 & 2035 & 2037 & 2025 & 2026 & 2028 \\
\hline \multicolumn{14}{|l|}{ Quantily of motal (lonnes): } \\
\hline Non-radloactlve & 46 & 67 & 67 & 67 & 67 & 84 & 84 & 84 & 84 & 84 & 52 & 51 & 70 \\
\hline Surf. contam. cleanable & 9 & 12 & 12 & 12 & 12 & 16 & 16 & 16 & 16 & 16 & 10 & $10^{\circ}$ & 13 \\
\hline Surl. contam.-non-clnbl & 0 & 0 & o) & of & 의 & 0. & 0 & 0 & 0 & 0 & $\underline{0}$ & 0 & $\underline{0}$ \\
\hline Actlvated & 3 & 4 & 4 & 4 & 4 & 5 & 5 & 5 & 5 & 5 & 3 & 3 & 4 \\
\hline Non-radioactlve & 2830 & 4081 & 4081 & 4081 & 4081 & 5116 & 5116 & 5116 & 5116 & 5116 & 3205 & 3148 & 4275 \\
\hline Surt. contam.-cleanable & -46 & 67 & 67 & 67 & 67 & 84 & 84 & 84) & 84 & 84 & 52 & 51 & 70 \\
\hline Surt. contam.-non-cinbl & $\underline{0}$ & 0 & of & of & 요 & 0 & 0 & 0 & a & 0 & 0 & 0 & 0 \\
\hline Activated & 12 & 17 & 17 & 17 & 17 & 21 & 21 & 21 & 21 & 21 & 13 & 13 & 17 \\
\hline Non-radloactive & 20 & 20 & 20 & 20 & 20 & 20 & 20 & 20 & 20 & 20 & 20 & 20 & 20 \\
\hline Surt. contam.-cleanable & 0 & 0 & 0 & 요 & 0 & 0 & 0 & 0 & 0 & 0 & 0 & 0 & 0 \\
\hline Surt. contam.-non-cinbl & 0 & 0 & 0 & 0 & 0 & 0 & 0 & 0 & 0 & 0 & 0 & 0 & 0 \\
\hline Activated & 0 & 0 & 0 & 0 & 0 & 0 & 0 & 0 & 요 & 0 & 0 & 0 & $\underline{0}$ \\
\hline Steol \& Iron Non-radloactive & 2888 & 4164 & 4164 & 4164 & 4164 & 5221 & 5221 & 5221 & 5221 & 5221 & 3270 & 3212 & 4363 \\
\hline Surf. contam.-cleanable & 3870 & 5580 & 5580 & 5580 & 5580 & 6996 & 6996 & 6996 & 6996 & 6996 & 4382 & 4305 & 5846 \\
\hline Surf, contam.-non-cinbl & 0 & of & 0 & of & of & 0 & of & 0 & 요 & 0 & 0 & 0 & $\underline{0}$ \\
\hline Actlvated & 2022 & 2915 & 2915 & 2915 & 2915 & 3655 & 3655 & 3655 & 3655 & 3655 & 2289 & 2249 & 3054 \\
\hline Non-radloactive & 0 & 0 & of & of & of & 0 & 요 & 0 & of & 0 & 0 & 0 & 0 \\
\hline Surt. contam.-cleanable & 347 & 500 & 500 & 500 & 500 & 627 & 627 & 627 & 627 & 627 & 392 & 385 & 524 \\
\hline Surt. contam.-non-clnbl & 0 & 0 & 0 & 0 & 0 & 0 & 0 & 0 & 0 & 0 & 0 & 0 & 0 \\
\hline Acllvated & 387. & 558 & 558 & 558 & 558 & 700 & 700 & 700 & 700 & 700 & 438 & 430 & 585 \\
\hline Zlrconium Non-radioaclive & 0 & 0 & of & 0 & 0 & 0 & D & $\underline{0}$ & of & $\underline{0}$ & 0 & 0 & 0 \\
\hline Surt. contam.-cleanable & 0 & 0 & 0 & 요 & 요 & $\underline{0}$ & 으 & 0 & 0 & 0 & 0 & 0 & $\underline{0}$ \\
\hline Surt. contam.-non-cinbl & 0 & 0 & of & 의 & 0 & 0 & 0 & 0 & a & 0 & 0 & 0 & $\underline{0}$ \\
\hline Activated & 0 & o) & 0] & 0] & 0 & 0 & 0 & 0 & 01 & 0 & 0 & 0 & $\underline{0}$ \\
\hline
\end{tabular}




\begin{tabular}{|c|c|c|c|c|c|c|c|c|c|c|c|c|c|}
\hline 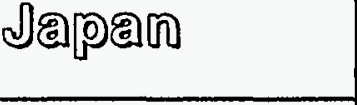 & $\begin{array}{c}\text { Hamaoka } \\
3 \\
\end{array}$ & $\begin{array}{c}\text { Hamaoka } \\
4 \\
\end{array}$ & $\begin{array}{c}\text { Higashldor } \\
1 \\
\end{array}$ & $\begin{array}{c}\text { Kashiwazak! } \\
\text { Karkwa } 1\end{array}$ & $\begin{array}{c}\text { Kashwwazokj } \\
\text { Karhwa } 2 \\
\end{array}$ & $\begin{array}{c}\text { Kashlwazool } \\
\text { Kartwa } 3\end{array}$ & $\begin{array}{c}\text { Kashwwazakl } \\
\text { Karfwa 4 }\end{array}$ & $\begin{array}{l}\text { Kashiwazakl } \\
\text { Kartwa } 5\end{array}$ & $\begin{array}{c}\text { Kashiwazold } \\
\text { Kethwa } 6 \\
\end{array}$ & $\begin{array}{c}\text { Kashwwazakl } \\
\text { Kartwa } 7\end{array}$ & Makl & $\begin{array}{l}\text { Namla- } \\
\text { Odaka }\end{array}$ & $\begin{array}{c}\text { Onagawa } \\
2 \\
\end{array}$ \\
\hline Fuel cycle stage (FCT) & Reactor & Reaclor & Reaclor & Reaclor & Reaclor & Reactor & Reactor & Reactor & Reactor & Reaclor & Reactor & Reactor & Reactor \\
\hline Identlfier & $679 \mathrm{JB}$ & $782 \mathrm{JB}$ & $783 \mathrm{JB}$ & 620.JB & $712 \mathrm{JB}$ & $804 \mathrm{JB}$ & $805 \mathrm{JB}$ & $707 \mathrm{JB}$ & $739 \mathrm{JB}$ & $740 \mathrm{JB}$ & $825 \mathrm{JB}$ & $832 \mathrm{JB}$ & $847 \mathrm{JB}$ \\
\hline Plant type & BWR & BWA & BWR & BWR & BWR & BWR & BWR & BWR & BWR & BWR & $B \dot{W R}$ & BWR & BWR \\
\hline Locatlon & Japan & Japan & Japan & Japan & Japan & Japan & Japan & Japan & Japan & Japan & Japan & Japan & Japan \\
\hline Start of operatlons & 1987 & & & 1985 & 1990 & & & 1990 & & & & & 1995 \\
\hline Status & Operating & Under Const & Planned & Operating & Opersting & Under Const & Under Const & Operating & Planned & Planned & Planned & Planned & Operating \\
\hline Size (MWo) (Not) & 1066 & 1092 & 1067 & 1067 & TCO: & 1067 & 1067 & 1067 & 1311 & 1311 & 796 & 796 & 796 \\
\hline Vendor & Toshiba & & & Toshiba & Toshiba & Toshiba & Hilachi & Hitachi & & & & & \\
\hline$A E$ & Tshba/Hichi & & & Toshiba & Toshiba & Toshiba & Hilachi & Hitachi & & & & & \\
\hline Pre or Post TMI & Post & Post & Post & Post & Post & Post & Post & Post & Post & Post & Post & Post & Post \\
\hline No. of steam turbines & .1 & 1 & 1 & 1 & 1 & 1 & 1 & 1 & 1 & 1 & 1 & 1 & 1 \\
\hline Coolling & & & & Sea & Sea & Sea & Sea & Sea & Sea & Sea & & & Sea \\
\hline Date EOL motal available & 2037 & 2053 & Unknown & 2035 & 2040 & 2053 & $\frac{2053}{2212}$ & 2040 & Unknown & Unknown & Unknown & $\begin{array}{l}\text { Unknown } \\
Z Z Z Z Z\end{array}$ & 2045 \\
\hline \multicolumn{14}{|l|}{ Quantity of motal (lonnes): } \\
\hline Aluminum Non-radioactive & 83 & 85 & 84 & 84 & 84 & 84 & 84 & 84 & 96 & 96 & 69 & 69 & 69 \\
\hline Surt. contam.-cleanable & 16 & 16 & 16 & 16 & 16 & 16 & 16 & 16 & 18 & 18 & 13 & 13 & 13 \\
\hline Surf. contam.-non-clnbl & 0 & 0 & 0. & of & 0 & 0 & 0 & 0 & 0 & 0 & 0 & 0 & $\underline{0}$ \\
\hline Activated & 5 & 5 & 5 & 5 & 5 & 5 & 5 & 5 & 6 & 6 & 4 & 4 & 4 \\
\hline Copper $\quad$ Non-radioactlve & 5113 & 5196 & 5116 & 5116 & 5116 & 5116 & 5116 & 5116 & 5869 & 5869 & 4209 & 4209 & 4209 \\
\hline Surf. contam.-cleanable & 83 & 85 & 84 & 84 & 84 & 84 & 84 & 84 & 96 & 96 & 69 & 69 & 69 \\
\hline Surt. contam.-non-cinbl & 0 & 0 & 요 & 0 & 0 & 0 & 0 & 0 & 0 & 0 & 0 & 0 & 0 \\
\hline Actlyated & 21 & 21 & 21 & 21 & 21 & 21 & 21 & 21 & 24 & 24 & 17 & 17 & 17 \\
\hline Non-radioaclive & 20 & 20 & 20 & 20 & 20 & 20 & 20 & 20 & 20 & 20 & 20 & 20 & 20 \\
\hline Surf. contam.-cleanable & 0 & 0 & 0 & 0 & 0 & of & 0 & 0 & 0 & 0 & of & 0 & 0 \\
\hline Surt. contam.-non-clnbl & 0 & 0 & 0 & 0 & 0 & 0 & 0 & of & 0 & 0 & 0 & 0 & 0 \\
\hline Activated & 0 & 0 & 0 & 0 & 0 & 0 & 0 & 0 & 0 & 0 & 0 & 0 & 0 \\
\hline Steol \& Iron Non-radioactive & 5218 & 5302 & 5221 & 5221 & 5221 & 5221 & 5221 & 5221 & 5989 & 5989 & 4294 & 4294 & 4294 \\
\hline Surt, contam. cloanable & 6992 & 7105 & 6996 & 6996 & 6996 & 6996 & 6996 & 6996 & 8026 & 8026 & 5755 & 5755 & 5755 \\
\hline Surl. contam.-non-clnbl & 0 & 0 & 0 & 0 & 0 & 0 & 0 & 0 & 0 & 0 & 0 & 0 & 0 \\
\hline Activaled & 3652 & 3712 & 3655 & 3655 & 3655 & 3655 & 3655 & 3655 & 4192 & 4192 & 3006 & 3006 & 3006 \\
\hline Non-radloactive & 0 & 0 & 0 & 0 & 0 & 0 & 0 & 0 & 0 & 0 & 0 & 0 & 0 \\
\hline Surt. contam.-cleanable & 626 & 636 & 627 & 627 & 627 & 627 & 627 & 627 & 719 & 719 & 515 & 515 & 515 \\
\hline Surt. contam.-non-clnbl & 0 & 0 & 0 & 0 & 0 & 0 & 0 & 0 & 0 & 0 & 0 & 0 & 0 \\
\hline Actlvaled & 699 & 710 & 700 & 700 & 700 & 700 & 700 & 700 & 803 & $\mathrm{BD3}$ & 575 & 575 & 575 \\
\hline Zlrconium Non-radloactive & 0 & 0 & 0 & 0 & 0 & 0 & 0 & 0 & 0 & 0 & 0 & 0 & 0 \\
\hline Surf. contam.-cleanable & 0 & 0 & 0 & 0 & 0 & 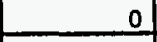 & 0 & 0 & 0 & 0 & 0 & 0 & 0 \\
\hline Surt. contam.-non-cinbl & 0 & 0 & 0 & 0 & 0 & 0 & 0 & 0 & 0 & 0 & 0 & 0 & $\underline{0}$ \\
\hline Aclivated & 0 & 0 & 0 & 0 & 0 & 0 & 0 & 0 & 0 & 0 & 0 & 0 & 0 \\
\hline
\end{tabular}




\begin{tabular}{|c|c|c|c|c|c|c|c|c|c|c|c|c|c|}
\hline ปஃฺด & $\begin{array}{c}\text { Onagawa } \\
3 \\
\end{array}$ & $\begin{array}{c}\text { Onogawa } \\
1 \\
\end{array}$ & $\begin{array}{c}\text { Shlka } \\
1 \\
\end{array}$ & $\begin{array}{c}\text { Shimane } \\
1 \\
\end{array}$ & $\begin{array}{c}\text { Shlmane } \\
2 \\
\end{array}$ & $\begin{array}{c}\text { Tokal } \\
2 \\
\end{array}$ & $\begin{array}{c}\text { Toyoklta } \\
1 \\
\end{array}$ & $\begin{array}{c}\text { Toyoklta } \\
2 \\
\end{array}$ & $\begin{array}{c}\text { Tsuruga } \\
1 \\
\end{array}$ & $\begin{array}{c}\text { Genkal } \\
2 \\
\end{array}$ & $\begin{array}{c}\text { Genkal } \\
3 \\
\end{array}$ & $\begin{array}{c}\text { Genkal } \\
4 \\
\end{array}$ & $\begin{array}{c}\text { Ikata } \\
1 \\
\end{array}$ \\
\hline Fuel cycle stage (FCT) & Reaclor & Reactor & Reactor & Reactor & Reactor & Peactor & Reactor & Reactor & Reactor & Reactor & Reactor & Reactor & Reaclor \\
\hline Identilier & $848 . \mathrm{BB}$ & $271 \mathrm{JB}$ & $844 \mathrm{JB}$ & $283 \mathrm{JB}$ & $713 \mathrm{JB}$ & 368.JB & $882 \mathrm{JB}$ & 883. 8 & $118 \mathrm{JB}$ & 580.JP & 719JP & 720JP & 436JP \\
\hline Plant type & BWR & BWR & BWR & BWR & BWR & BWR & BWR & BWR & BWR & PWR & PWR & PWR & PWR \\
\hline Location & Japan & Japan & Japan & Japan & Japan & Japan & Japan & Japan & Japan & Japan & Japan & Japan & Japan \\
\hline Start of operations & & 1984 & 1992 & 1974 & 1989 & 1978 & & & 1970 & 1981 & 1993 & 1995 & 1978 \\
\hline Status & Planned & Operating & Under Const & Operating & Operating & Operating & Planned & Planned & Operating & Operating & Under Const & Under Const & Operating \\
\hline Size (MWo) (Not) & 796 & 497 & 515 & 439 & 791 & 1056 & 1067 & 1067 & 340 & 529 & 1127 & 1127 & 538 \\
\hline Vendor & & Toshiba & Hitachi & Hitachi & Hilachi & GE/Hitachi & & & GE/Hitachi & MHI & MHI & MHI & $\mathrm{MHI}$ \\
\hline AE & & Kajima & & Hitachl & Hllachi & Ebason & & & Ebasco & Hiltachi & Mapi & Mapi & Mapi \\
\hline Pre or Post TMl & Post & Post & Post & Pro & Post & Pro & Post & Post & Pre & Post & Post & Post & Pre \\
\hline No. of steam turbines & 1 & 1 & 1 & 1 & 1 & 1 & 1 & 1 & 1 & 1 & 1 & 1 & 1 \\
\hline Coolling & & Sea & Sea & & & & & & & Sea & Sea & Sea & \\
\hline Date EOL motal availablo & Unknown & 2034 & 2042 & 2024 & 2039 & 2028 & Unknown & $\begin{array}{l}\text { Unknown } \\
\text { ZnZZZ }\end{array}$ & 2020 & 2031 & 2043 & 2045 & 2028 \\
\hline \multicolumn{14}{|l|}{ Quantity of metal (1onnes): } \\
\hline Aluminum Non-radioactlve & 69 & 50 & 51 & 46 & 68 & 83 & 84 & 84 & 39 & 52 & 87 & 87 & 53 \\
\hline Surf. contam.-cleanable & 13 & 9 & 10 & 9 & 13 & 16 & 16 & 16 & 7 & 10 & 16 & 16 & 10 \\
\hline Surl. contam.-non-chnbl & 0 & 0 & 0 & 0 & 0 & 0 & 0 & 0 & 0 & 0 & 0 & 0 & 0 \\
\hline Activated & 4 & 3 & 3 & 3 & 4 & 5 & 5 & 5 & 2 & 3 & 5 & 5 & 3 \\
\hline Non-radloactive & 4209 & 3074 & 3148 & 2830 & 4191 & 5081 & 5116 & 5118 & 2387 & 3205 & 5307 & 5307 & 3241 \\
\hline Surt contam.-cleanable & 69 & 50 & 51 & 46 & 88 & 83 & 84 & 84 & 39 & 52 & 87 & 87 & 53 \\
\hline Sur. contam.-non-cinbl & 0 & 0 & 0 & 0 & 0 & 0 & 0 & 0 & 0 & 0 & 0 & 0 & 0 \\
\hline Actlvatod & 17 & 13. & 13 & 12 & 17 & 21 & 21 & 21 & 10 & 13 & 22 & 22 & 13 \\
\hline Non-radioactlve & 20 & 20. & 20 & 20 & 20 & 20 & 20 & 20 & 20 & 20 & 20 & 20 & 20 \\
\hline Suri. contam.-cleanable & 0 & 0 & 0 & 0 & 0 & 0 & 0 & 0 & 0 & 0 & 0 & 0 & 0 \\
\hline Surt contam.-non-cinbl & 0 & $\underline{0}$ & 0 & $0^{\circ}$ & 0 & 0 & 0 & 0 & of & 0 & 0 & 0 & 0 \\
\hline Actlvated & 0 & 0 & 0 & 0 & 0 & 0 & 0 & 0 & 0. & $\underline{0}$ & 0 & 0 & 0 \\
\hline Steol \& Iron Non-radioactlve & 4294 & 3137 & 3212 & 2888 & 4276 & 5185 & 5221 & 5221 & 2436 & 5422 & 8978 & 8978 & 5484 \\
\hline Surl. conlam.-cleanable & 5755 & 4204 & 4305 & 3870 & 5730 & 6948 & 6996 & 6996 & 3264 & 4382 & 7256 & 7256 & 4432 \\
\hline Surt. contam.-non-cinbl & 0 & 0 & 0 & 0 & 0 & 0 & 0 & 0 & 0 & 0 & 0 & 0 & 0 \\
\hline Actlvated & 3006 & 2196 & 2249 & 2022 & 2994 & 3629 & 3655 & 3655 & 1705 & 1923 & 3184 & 3184 & 1945 \\
\hline Non-radloactlve & 0 & 0 & 0 & 0 & 0 & 0 & 0 & 0 & 0 & 0 & 0 & 0 & 0 \\
\hline Surt. contam. cleanable & 515 & 376 & 385 & 347 & 513 & 622 & 627 & 627 & 292 & 589 & 975 & 975 & 595 \\
\hline Surf. contam.-non-clnbl & 0 & 0 & 0 & 0 & 0 & 0 & 0 & 0 & 0 & 196 & 325 & 325 & 198 \\
\hline Activated & 575 & 420 & 430 & 387 & 573 & 695 & 700 & 700 & 326 & 438 & 726 & 726 & 443 \\
\hline Zirconium Non-radioactlve & 0 & 0 & 0 & 0 & 0 & 0 & 0 & 0 & 0 & 0 & 0 & 0 & 0 \\
\hline Surt. contam.-cleanable & 0 & 0 & 0 & 0 & 0 & $\underline{0}$ & 0 & 0 & of & 0 & 0 & 0 & 0 \\
\hline Surt. contam.-non-clnbl & 0 & 0 & 0 & 0 & 0 & 0 & 0 & 0 & of & O & 0 & 0 & 0 \\
\hline Aclivated & 0 & 0 & 0 & 0 & 0 & 0 & 0 & 0 & 0 & 0 & 0 & 0 & 0 \\
\hline
\end{tabular}




\begin{tabular}{|c|c|c|c|c|c|c|c|c|c|c|c|c|c|}
\hline 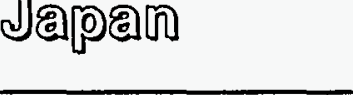 & $\begin{array}{c}\text { Ikata } \\
2 \\
\end{array}$ & $\begin{array}{c}\text { Ikata } \\
3\end{array}$ & $\begin{array}{c}\text { Mihama } \\
2\end{array}$ & $\begin{array}{c}\text { Mihama } \\
\quad 3\end{array}$ & $\begin{array}{c}\text { Mlhama } \\
+\quad \\
\end{array}$ & N1 & $\begin{array}{c}\text { OhI } \\
1\end{array}$ & $\begin{array}{c}\text { OhI } \\
2\end{array}$ & $\begin{array}{c}\text { Ohl } \\
3\end{array}$ & $\begin{array}{c}\text { Ohl } \\
4 \\
\end{array}$ & $\begin{array}{c}\text { Oura } \\
1 \\
\end{array}$ & $\begin{array}{c}\text { Sendal } \\
1 \\
\end{array}$ & $\begin{array}{c}\text { Sendal } \\
2 \\
\end{array}$ \\
\hline Fuel cycle stage (FCT) & Reactor & Reactor & Reactor & Reactor & Reaclor & Reactor & Reactor & Reactor & Reactor & Reactor & Reactor & Reactor & Reactor \\
\hline Identifier & 593JP & 723JP & $186 \mathrm{JP}$ & 332.JP & $146 \mathrm{JP}$ & $827 \mathrm{JP}$ & $303 . J P$ & $305 . \mathrm{JP}$ & 729JP & 730.JP & $851 \mathrm{JP}$ & 636JP & 666.JP \\
\hline Plant lypo & PWR & PWR & PWR & PWR & PWR & PWR & PWR & PWR & PWA & PWR & PWR & PWR & PWR \\
\hline Location & Japan & Japan & Japan & Japan & Japan & Japan & Japan & Japan & Japan & Japan & Japan & Japan & Japan \\
\hline Start of operatlons & 1982 & 1995 & 1972 & 1976 & 1970 & & 1979 & 1979 & 1991 & 1992 & 1999 & 1984 & 1985 \\
\hline Status & Operating & Under Const & Operating & Operating & Operating & Planned & Operating & Operating & Under Const & Under Const & Planned & Operating & Operating \\
\hline Slze (MWe) (Net) & 538 & 846 & 470 & 780 & 320 & 1300 & 1120 & 1120 & 1127 & 1127 & 1300 & 846 & 846 \\
\hline Vendor & $\mathrm{MHI}$ & & MHIMest & $\mathrm{MHI}$ & West/MHI & & Wstnghse & Wstnghse & $\mathrm{MHI}$ & $\mathrm{MHI}$ & & Mhi & $\mathrm{MHI}$ \\
\hline AE & Mapi & & Kepco/Mapi & Kepco/Mapi & Kepco/Glbrt & & Glbrt/Kpeo & Glbrt/Kpco & Kepco/Mapi & Kepco/Mapi & & Mapi & Mapi \\
\hline Pro or Post TMI & Post & Post & Pre & Pre & Pre & Post & Pre & Pre & Post & Post & Post & Post & Post \\
\hline No. of steam turbines & 1 & 1 & 1 & 1 & 1 & 1 & 1 & 1 & 1 & 1 & 1 & 1 & 1 \\
\hline \multicolumn{14}{|l|}{ Cooling } \\
\hline Date EOL metal avallable & 2032 & 2045 & 2022 & 2026 & 2020 & Unknown & 2029 & 2029 & 2041 & 2042 & Unknown & 2034 & 2035 \\
\hline \multicolumn{14}{|l|}{ Quantlty of motal (tonnes): } \\
\hline Aluminum Non-radloactive & 53 & 72 & 48 & 68 & 37 & 95 & 86 & 86 & 87 & 87 & 95 & 72 & 72 \\
\hline Surt. contam.-cioanable & 10 & 13 & 9 & 13 & 7 & 18 & 16 & 16 & 16 & 16 & 18 & 13 & 13 \\
\hline Surt. contam.-non-c|nbl & 0 & 0 & 0 & 0 & 0 & 0 & 0 & 0 & 0 & 0 & 0 & 0 & 0 \\
\hline Actlyated & 3 & 4 & 3 & 4 & 2 & 6 & 5 & 5 & 5 & 5 & 6 & 4 & 4 \\
\hline Non-radioactive & 3241 & 4383 & 2962 & 4152 & 2292 & 5837 & 5285 & 5285 & 5307 & 5307 & 5837 & 4383 & 4383 \\
\hline Surt. contam.-cleanable & 53 & 72 & 48 & 68 & 37 & 95 & 86 & 86 & 87 & 87 & 95 & 72 & 72 \\
\hline Surt. contam.-non-cinbl & 0 & 0 & 0 & 0 & 0 & 0 & 0 & 0 & 0 & 0 & 0 & 0 & 0 \\
\hline Actlvated & 13 & 18 & 12 & 17 & 9 & 24 & 22 & 22 & 22 & 22 & 24 & 18 & 18 \\
\hline Non-radloactlve & 20 & 20 & 20 & 20 & 20 & 20 & 20 & 20 & 20 & 20 & 20 & 20 & 20 \\
\hline Surf. contam.-cleanable & 0 & 0 & 0 & 0 & 0 & 0 & 0 & 0 & 0 & 0 & 0 & of & 0 \\
\hline Surt. contam.-non-clnbl & 0 & 0 & 0 & 0 & 0 & 0 & 0 & of & 0 & 0 & 0 & 0 & O \\
\hline Acllvated & 0 & 0 & 0 & 0 & 0 & 0 & 0 & 0 & 0 & 0 & 0 & 0 & 0 \\
\hline Steol \& Iron Non-radloactive & 5484 & 7415 & 5011 & 7025 & 3878 & 9875 & 8941 & 8941 & 8978 & 8978 & 9875 & 7415 & 7415 \\
\hline Surt. contam.-cleanable & 4432 & 5993 & 4050 & 5677 & 3135 & 7981 & 7226 & 7226 & 7256 & 7256 & 7981 & 5993 & 5993 \\
\hline Surt. contam.-non-cinbl & 0 & 0 & 0 & 0 & 0 & 0 & 0 & 0 & 0 & 0 & 0 & 0 & 0 \\
\hline Activated & 1945 & 2630 & 1777 & 2491 & 1375 & 3502 & 3171 & 3171 & 3184 & 3184 & 3502 & 2630 & 2630 \\
\hline St.Steol Non-radloactlve & 0 & 0 & 0 & 0 & 0 & 0 & 0 & 0 & 0 & 0 & 0 & 0 & 0 \\
\hline Surt. contam.-cloanable & 595 & 805 & 544 & 763 & 421 & 1072 & 971 & 971 & 975 & 975 & 1072 & 805 & 805 \\
\hline Surt. contam.-non-clnbl & 198 & 268 & 181 & 254 & 140 & 357 & 324 & 324 & 325 & 325 & 357 & 268 & 268 \\
\hline Aclivated & 443 & 599 & 405 & 568 & 313 & 798 & 723 & 723 & 726 & 726 & 798 & 599 & 599 \\
\hline Zlrconium Non-radloactlve & 0 & 0 & 0 & 0 & 0 & 0 & 0 & 0 & 0 & 0 & 0 & 0 & 0 \\
\hline Surt. contam.-cleanable & 0 & 0 & 0 & 0 & 0 & 0 & 0 & 0 & 0 & 0 & 0 & 0 & $\underline{0}$ \\
\hline Surt. contam.-non-cinbl & 0 & 0 & 0 & 0 & 0 & 0 & 0 & 0 & 0 & 0 & 0 & 0 & $\underline{0}$ \\
\hline Activated & 0 & 0 & 0 & 0 & 0 & 0 & 0 & 0 & 0 & 0 & 0 & 0 & 0 \\
\hline
\end{tabular}




\begin{tabular}{|c|c|c|c|c|c|c|c|c|c|c|c|c|}
\hline 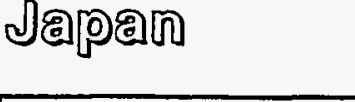 & $\begin{array}{c}\text { Takshama } \\
1 \\
\end{array}$ & $\begin{array}{c}\text { Takahama } \\
2 \\
\end{array}$ & $\begin{array}{c}\text { Takahama } \\
3 \\
\end{array}$ & $\begin{array}{c}\text { Takahama } \\
4 \\
\end{array}$ & $\begin{array}{c}\text { Tomari } \\
1 \\
\end{array}$ & $\begin{array}{c}\text { Tomar } \\
2 \\
\end{array}$ & $\begin{array}{c}\text { Tsuruga } \\
2 \\
\end{array}$ & $\begin{array}{l}\text { Tokal } \\
\text { Japco }\end{array}$ & $\begin{array}{l}\text { Joyo } \\
\text { [HOI }\end{array}$ & Monju & $\begin{array}{c}\text { Fugen } \\
\text { ATR }\end{array}$ & $\begin{array}{c}\text { Ohma } \\
\text { Demo ATR }\end{array}$ \\
\hline Fuel cycle stage (FCT) & - Reactor & Reactor & Reactor & Reactor & Reaclor & Reactor & Reactor & Reactor & Reactor & Reactor & Reactor & Reactor \\
\hline Identiflor & 254JP & 285.JP & 663JP & 664JP & 6BOJP & 681JP & $665 \mathrm{JP}$ & $66 \mathrm{JG}$ & 172JF & $711 \mathrm{JF}$ & 213JH & $845 \mathrm{JH}$ \\
\hline Plant type & PWR & PWR & PWR & PWR & PWR & PWR & PWR & Magnox 1 & LMR & LMR & LWCHWR & LWCHWR \\
\hline Location & Japan & Japan & Japan & Japan & Japan & Japan & Japan & Japan & Japan & Japan & Japan & Japan \\
\hline Start of operations & 1974 & 1975 & 1985 & 1985 & 1989 & 1991 & 1987 & 1966 & 1978 & 1993 & 1979 & \\
\hline Status & Operating & Operaling & Operating & Operating & Operating & Under Const & Operating & Operating & Operating & Under Const & Operating & Planned \\
\hline Size (MWo) (Not) & 780 & 780 & 830 & 830 & 550 & 550 & 1115 & 159 & 33 & 280 & 148 & 556 \\
\hline Vendor & WestMHI & MHI & MHI & MH! & $\mathrm{MHI}$ & $\mathrm{MHI}$ & MHI & $\mathrm{CEC}$ & Tshba, olc. & Tshba, etc. & PNC & \\
\hline AE & Kepco/Glbrt & Kepco/Mapi & Kepco/Mapi & Kepco/Mapi & Mapi & Mapi & Ob/Sh/Tak & $\mathbb{C E C}$ & Takenaka & & PNC & \\
\hline Pre or Post TMI & Pre & Pre & Post & Post & Post & Post & Post & Pre & Pre & Post & Pre & Post \\
\hline No. of steam turbines & 1 & 1 & 1 & 1 & 1 & 1 & 1 & 2 & & 1 & 1 & 1 \\
\hline Cooling & & & & & Sea & Sea & & $\operatorname{sen}$ & & & Sea & \\
\hline Date EOL motal avallable & 2024 & 2025 & 2035 & 2035 & 2039 & 2041 & 2037 & 2016 & 2028 & 2043 & 2029 & Unknown \\
\hline \multicolumn{13}{|l|}{ Quantity of metal (lonnes): } \\
\hline Aluminum Non-radloacilve & 68 & 68 & 71 & 71 & 54 & 54 & 86 & 0 & & & 24 & 59 \\
\hline Surt. contam.-cleanable & 13 & 13 & 13 & 13 & 10 & 10 & 16 & 0 & & & 5 & 11 \\
\hline Surl. contam.-non-clnbl & 0 & 0 & 0 & 0 & 0 & 0 & 0 & 0 & $\dot{-}$ & & 0 & 0 \\
\hline Acllvatod & 4 & 4 & 4 & 4 & 3 & 3 & 5 & 0 & & & 2 & 4 \\
\hline Non-radioactive & 4152 & 4152 & 4328 & 4328 & 3289 & 3289 & 5269 & 1900 & & & 1492 & 3605 \\
\hline Surt. contam.-cleanable & 68 & 68 & 71 & 71 & 54 & 54 & 86 & 50 & & & 24 & 59 \\
\hline Surt. contam.-non-clnbl & 0 & 0 & 0 & 0 & 0 & 0 & 0 & 0 & & & 0 & 0 \\
\hline Acllvated & 17 & 17 & 18 & 18 & 13 & 13 & 22 & 50 & & & 6 & 15 \\
\hline Non-radloactlve & 20 & 20 & 20 & 20 & 20 & 20 & 20 & 0 & & & 20 & 20 \\
\hline Surt contam.-cleanable & 0 & 0 & 0 & 0 & 0 & 0 & 0 & 0 & & & 0 & 0 \\
\hline Surf, contam.-non-cinbl & 0 & 0 & 0 & 0 & 0 & 0 & 0 & 0 & & & 0 & 0 \\
\hline Activated & 0 & 0 & 0 & 0 & 0 & 0 & 0 & 0 & & & 0 & 0 \\
\hline Steel \& Iron Non-radloactlve & 7025 & 7025 & 7322 & 7322 & 5565 & 5565 & 8914 & 3800 & & & 2436 & 5886 \\
\hline Surt. contam.-cleanable & 5677 & 5677 & 5917 & 5917 & 4498 & 4498 & 7204 & 4950 & & & 1827 & 4415 \\
\hline Surf. contam.-nan-clnbl & 0 & 0 & 0 & 0 & 0 & 0 & 0 & 0 & & & 0 & 0 \\
\hline Activated & 2491 & 2491 & 2597 & 2597 & 1974 & 1974 & 3161 & 1000 & & & 895 & 2163 \\
\hline Non-radloactive & 0 & 0 & 0 & 0 & 0 & 0 & 0 & 100 & & & 88 & 213 \\
\hline Suri. contam.-cleanable & 763 & 763 & 795 & 795 & 604 & 604 & 968 & 0 & & & 609 & 1472 \\
\hline Surt. contam.-non-clnbl & 254 & 254 & 265 & 265 & 201 & 201 & 323 & 0 & & & 61 & 147 \\
\hline Aclivated & 568 & 568 & 592 & 592 & 450 & 450 & 720 & 0 & & & 639 & 1545 \\
\hline Zirconlum Non-radioactlve & 0 & 0 & 0 & 0 & 0 & 0 & 0 & 0 & & & 0 & 0 \\
\hline Surt. contam.-cloanable & 0 & 0 & 0 & 0 & 0 & 0 & 0 & 0 & & & 0 & 0 \\
\hline Surl. contam.-non-clnbl & 0 & 0 & 0 & 0 & o & 0 & $\therefore 0$ & 0 & & & 0 & 0 \\
\hline Activated & 0 & 0 & 0 & 0 & 0 & 0 & 0 & 0 & & & 25 & 25 \\
\hline
\end{tabular}




\begin{tabular}{|c|c|c|c|c|c|c|c|c|c|c|c|c|c|}
\hline 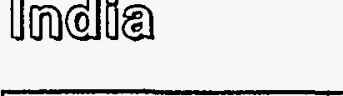 & $\begin{array}{c}\text { Kalga } \\
1\end{array}$ & $\begin{array}{c}\text { Kalga } \\
2 \\
\end{array}$ & $\begin{array}{c}\text { Kalga } \\
3 \\
\end{array}$ & $\begin{array}{c}\text { Kalga } \\
4 \\
\end{array}$ & $\begin{array}{c}\text { Kalga } \\
5\end{array}$ & $\begin{array}{c}\text { Kalga } \\
6 \\
\end{array}$ & $\begin{array}{c}\text { Kakrapar } \\
1 \\
\end{array}$ & $\begin{array}{c}\text { Kakrapar } \\
2 \\
\end{array}$ & $\begin{array}{l}\text { Madras } \\
\text { MAPS } 1 \\
\end{array}$ & $\begin{array}{l}\text { Madras } \\
\text { MAPS } 2 \\
\end{array}$ & $\begin{array}{c}\text { Narora } \\
1 \\
\end{array}$ & $\begin{array}{c}\text { Narora } \\
2 \\
\end{array}$ & $\begin{array}{c}\text { Rajasthan } \\
\text { RAPS } 1 \\
\end{array}$ \\
\hline Fuel cycle stage (FCI) & Reactor & Reaclor & Reactor & Reactor & Reaclor & Reactor & Reactor & Reactor & Reactor & Reactor & Reactor & Reactor & Reactor \\
\hline Identifier & $724 ! \mathrm{NDH}$ & $7251 \mathrm{NDH}$ & $7981 \mathrm{NDH}$ & $7991 \mathrm{NDH}$ & $8001 N D H$ & 913|NDH & 685INDH & 686INDH & $2501 \mathrm{NDH}$ & $2511 \mathrm{NDH}$ & 542INDH & $5431 \mathrm{NDH}$ & $115 \mathrm{INDH}$ \\
\hline Plant type & PHWR & PHWR & PHWR & PHWR & PHWR. & PHWR & PHWR & PHWR & PHWR & PHWR & PHWR & PHWR & PHWR \\
\hline Locatlon & India & India & India & India & India & India & India & India & India & India & Indla & India & India \\
\hline Start of operatlons & 1995 & 1996 & & & & & 1991 & 1992 & 1984 & 1986 & 1990 & 1991 & 1973 \\
\hline Status & Under Const & Under Const & Planned & Planned & Planned & Planned & Under Const & Under Const & Operating & Operating & Operating & Under Const & Operating \\
\hline Size (MWo) (Not) & 220 & 220 & 220 & 220 & 220 & 220 & 220 & $220^{\circ}$ & 220 & 220 & 220 & 220 & 207 \\
\hline Vendor. & NPC & $\mathrm{NPC}$ & NPC & $\mathrm{NPC}$ & NPC & NPC & DAE/NPC & DAENNPC & DAE & DAE & DAENAPC & DAE/NPC & AECLDAE \\
\hline ANE & DAE/NPC & DAE/NPC & DAE/NPC & DAENPC & DAENNPC & DAE/NPC & DAENPC & DAENAPC & DAE & DAE & DAENNPC & DAE/NPC & AECLME \\
\hline Pre or Post TMI & Post & Post & Post & Post & Post & Post & Post & Post & Post & Post & Post & Post & Pre \\
\hline No. of steam turbines & 1 & 1 & 1 & 1 & 1 & 1 & 1 & 1 & 1 & 1 & 1 & 1. & 1 \\
\hline Coolling & River & River & River & River & Piver & Biver & Tower & Tower & Sea & Sea & Tower & Tower & Lake \\
\hline 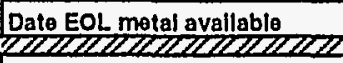 & 2045 & 2046 & Unknown & Unknown & Unknown & Unknown & 2041 & 2042 & 2034 & 2036 & 2040 & 2041 & 2023 \\
\hline \multicolumn{14}{|l|}{ Quantity of matal (tonnes): } \\
\hline Aluminum Non-radloactlve & 32 & 32 & 32 & 32 & 32 & 32 & 32 & 32 & 32 & 32 & 32 & 32 & 30 \\
\hline Surf. contam.-cloanable & 6 & 6 & 6 & 6 & 6 & 6 & 6 & 6 & 6 & 6 & 6 & 6 & 6 \\
\hline Surt. contam.-non-clnbl & 0 & 0 & 0 & 0 & 0 & 0 & 0 & .0 & 0 & 0 & 0 & 0 & 0 \\
\hline Activatod & 2 & 2 & 2 & 2 & 2 & 2 & 2 & 2 & 2 & 2 & 2 & 2. & 2 \\
\hline Copper Non-radloactive & 1943 & 1943 & 1943 & 1943 & 1943 & 1943 & 1943 & 1943 & 1943 & 1843 & 1943 & 1943 & 1866 \\
\hline Surl, contam.-cloanable & 32 & 32 & 32 & $\therefore \quad 32$ & 32 & 32 & 32 & 32 & 32 & 32 & 32 & 32 & 30 \\
\hline Surl. contam.-non-clnbl & 0 & 0 & 0 & 0 & 0 & 0 & 0 & 0 & 0 & 0 & 0 & 0 & 0 \\
\hline Aclivaled & 8 & 8 & 8 & 8 & 8 & 8 & 8 & 8 & 8 & 8 & 8 & 8 & 8 \\
\hline Non-radloactlve & 20 & 20 & 20 & 20 & 20 & 20 & 20 & 20 & 20 & 20 & 20 & 20 & 20 \\
\hline Surl. contam.-cloanablo & 0 & 0 & 0 & 0 & 0 & 0 & 0 & 0 & .0 & 0 & 0 & 0 & 0 \\
\hline Surf. contam.-non-clnbl & 0 & 0 & 0 & 0 & 0 & 0 & 0 & 0 & 0 & 0 & 0 & 0 & 0 \\
\hline Actlvated & 0 & 0 & 0 & 0 & 0 & 0 & 0 & 0 & 0 & 0 & 0 & 0 & 0 \\
\hline Steel \& Iron Non-radloactive & 3172 & 3172 & 3172 & 3172 & 3172 & 3172 & 3172 & 3172 & 3172 & 3172 & 3172 & 3172 & 3046 \\
\hline Surl. contam.-cloanable & 2379 & 2379 & 2379 & 2379 & 2379 & 2379 & 2379 & 2379 & 2379 & 2379 & 2379 & 2379 & 2285 \\
\hline Surl. contam.-non-clnbl & 0 & 0 & 0 & 0 & 0 & 0 & 0 & 0 & 0 & 0 & 0 & 0 & 0 \\
\hline Activated & 1166 & 1166 & 1168 & 1166 & 1166 & 1166 & 1166 & 1166 & 1166 & 1166 & 1166 & 1166 & 1119 \\
\hline St.Stool Non-radloactive & 115 & 115 & 115 & 115 & 115 & 115 & 115 & 115 & 115 & $\$ 15$ & 115 & 115 & 110 \\
\hline Surf. contam.-cloanable & 793 & 793 & 793 & 793 & 793 & 793 & 793 & 793 & 793 & 793 & 793 & 793 & 762 \\
\hline Surl. contam.-non-clnbl & 79 & 79 & 79 & 79 & 79 & 79 & 79 & 79 & 79 & 79 & $79^{\circ}$ & 79 & 76 \\
\hline Actlvatod & 833 & 833 & 833 & 833 & 833 & 833 & 833 & 833 & 833 & 833 & 833 & 833 & 800 \\
\hline Zirconium Non-radloactlue & 0 & 0 & 0 & 0 & 0 & 0 & 0 & 0 & 0 & 0 & 0 & 0 & 0 \\
\hline Surf. contam.-cleanable & 0 & 0 & 0 & 0 & 0 & 0 & 0 & 0 & 0 & 0 & 0 & 0 & 0 \\
\hline Surf. contam.-non-clnbl & 0 & 0 & 0 & 0 & 0 & 0 & 0 & 0 & 0 & 0 & 0 & 0 & 0 \\
\hline Activated & 25 & 25 & 25 & 25 & 25 & 25 & 25 & 25 & 25 & 25 & 25 & 25 & 25 \\
\hline
\end{tabular}




\begin{tabular}{|c|c|c|c|c|c|c|c|c|c|c|c|c|c|}
\hline ดกำ]อ & $\begin{array}{c}\text { Rajasthan } \\
\text { RAPS } 2\end{array}$ & $\begin{array}{c}\text { Rajasthan } \\
\text { RAPS } 3 \\
\end{array}$ & $\begin{array}{c}\text { Rajasthan } \\
\text { RAPS } 4 \\
\end{array}$ & $\begin{array}{c}\text { Ralasthan } \\
\text { RAPS } 5\end{array}$ & $\begin{array}{c}\text { Rajasthan } \\
\text { RAPS } 6 \\
\end{array}$ & $\begin{array}{c}\text { Rajasthan } \\
\text { RAPS } 7\end{array}$ & $\begin{array}{c}\text { Rajasthan } \\
\text { RAPS } 8 \\
\end{array}$ & $\begin{array}{c}\text { Tarapur } \\
\mathbf{3} \\
\end{array}$ & $\begin{array}{c}\text { Tarapur } \\
4 \\
\end{array}$ & $\begin{array}{c}\text { Koodang- } \\
\text { ulam } 1\end{array}$ & $\begin{array}{c}\text { Koodang- } \\
\text { ulam } 2\end{array}$ & $\begin{array}{c}\text { Tarapur } \\
1 \\
\end{array}$ & $\begin{array}{c}\text { Tarapur } \\
\mathbf{2} \\
\end{array}$ \\
\hline Fuel cycle stage (FCT) & Reactor & Reactor & Reactor & Reaclor & Reactor & Reaclor & Reactor & Reactor & Reactor & Reactor & Reactor & Reactor & Reaclor \\
\hline Identifier & 219INOH & 718INOH & $717 \mathrm{NOH}$ & 922INDH & 9231NDH & 924INDH & 925INH & 920INDH & $9211 \mathrm{NDH}$ & $9111 N D P$ & 912INDP & 113INDB & 114 INDB \\
\hline Plant type & PHWR & PHWR & PHWR & PHWR & PHWR & PHWR & PHWR & PHWR & PHWR & PWR & PWR & BWR & BWR \\
\hline Location & India & India & India & India & India & India & India & india & India & India & India & India & India \\
\hline Start of operations & 1981 & 1995 & 1996 & & & & & & & & & 1969 & 1969 \\
\hline Status & Operating & Under Const & Under Const & Planned & Planned & Planned & Planned & Planned & Planned & Planned & Planned & Operating & Operating \\
\hline Sizo (MWO) (Net) & 207 & 220 & 220 & 450 & 450 & 450 & 450 & 450 & 450 & 953 & 953 & 150 & 150 \\
\hline Vendor & AECLDAE & NPC & $\mathrm{NPC}$ & NPC & $\mathrm{NPC}$ & NPC & NPC & NPC & NPC & AEE & AEE & $G$ & $\underline{E}$ \\
\hline NE & AECLMME & DAENNPC & DAE/NPC & DAENNPC & DAENNPC & DAENPC & DAE INPC & DAE/NPC & DAENPC & & & Bechtel & Bechtel \\
\hline Pre or Post TMI & Post & Post & Post & Post & Post & Post & Post & Post & Post & Post & Post & Pre & Pre \\
\hline No. of steam turbines & 1 & 1 & 1 & 1 & 1 & 1 & 1 & 1 & 1 & 2 & 2 & 1 & 1 \\
\hline Cooling & Lake & Tower & Tower & Sea & Sea & Sea & Sea & Sea & $\operatorname{sen}$ & & & Sea & Sea \\
\hline $\begin{array}{l}\text { Date EOL motal available } \\
2\end{array}$ & 2031 & 2045 & 2046 & Unknown & Unknown & Unknown & Unknown & Unknown & Unknown & Unknown & Unknown & 2019 & 2019 \\
\hline \multicolumn{14}{|l|}{ Quantity of metal (tonnes): } \\
\hline Aluminum Non-radioactlve & 30 & 32 & 32 & 51 & 51 & 51 & 51 & 51 & 51 & 77 & 77 & 23 & 23 \\
\hline Surl. contam.-cleanable & 6 & 6 & 6 & 10 & 10 & 10 & 10 & 10 & 10 & 15 & 15 & 4 & 4 \\
\hline Surf. contam.-non-cinbl & 0 & 0 & 0 & 0 & 0 & 0 & 0 & 0 & 0 & 0 & 0 & 0 & 0 \\
\hline Actlvated & 2 & 2 & 2 & 3 & 3 & 3 & 3 & 3 & 3 & 5 & 5 & 1 & 1 \\
\hline Non-radloactlve & 1866 & 1943 & 1943 & 3131 & 3131 & 3131 & 3131 & 3131 & 3131 & 4745 & 4745 & 1383 & 1383 \\
\hline Surt. contam.-cleanable & 30 & 32 & 32 & 51 & 51 & 51 & 51 & 51 & 51 & 77 & 77 & 23 & 23 \\
\hline Surl. contam.-non-cinbl & 0 & 0 & 0 & 0 & 0 & 0 & 0 & 0 & 0 & 0 & 0 & 0 & 0 \\
\hline Aclivalod & 8 & 8 & 8 & 13 & 13 & 13 & 13 & 13 & 13 & 19 & 19 & 6 & 6 \\
\hline Non-radioactive & 20 & 20 & 20 & 20 & 20 & 20 & 20 & 20 & 20 & 20 & 20 & 20 & 20 \\
\hline Suri. contam. cleanable & 0 & 0 & 0 & 0 & 0 & 0 & 0 & 0 & 0 & 0 & 0 & 0 & 0 \\
\hline Surf. contam.-non-cinbl & 0 & 0 & 0 & 0 & 0 & 0 & 0 & 0 & 0 & 0 & 0 & 0 & 0 \\
\hline Activated & 0 & 0 & 0 & 0 & 0 & 0 & 0 & 0 & 0 & 0 & 0 & 0 & 0 \\
\hline Steol \& Iron Non-radloactive & 3046 & 3172 & 3172 & 5112 & 5112 & 5112 & 5112 & 5112 & 5112 & 8028 & 8028 & 1412 & 1412 \\
\hline Surf. contam.-cleanable & 2285 & 2379 & 2379 & 3834 & 3834 & 3834 & 3834 & 3834 & 3834 & 6488 & 6488 & 1891 & 1891 \\
\hline Surl. contam.-non-cinbl & 0 & 0 & 0 & 0 & 0 & 0 & 0 & 0 & 0 & 0 & 0 & 0 & 0 \\
\hline Actlvated & 1119 & 1166 & 1166 & 1879 & 1879 & 1879 & 1879 & 1879 & 1879 & 2847 & 2847 & 988 & 988 \\
\hline St. Steol Non-radloactive & 110 & 115 & 115 & 185 & 185 & 185 & 185 & 185 & 185 & 0 & 0 & 0 & 0 \\
\hline Surl. contam.-claanablo & 762 & 793 & 793 & 1278 & 1278 & 1278 & 1278 & 1278 & 1278 & 872 & 872 & 169 & 169 \\
\hline Surl. contam.-non-cinbl & 76 & 79 & 79 & 128 & 128 & 128 & 128 & 128 & 128 & 291 & 291 & 0 & 0 \\
\hline Activated & 800 & 833 & 833 & 1342 & 1342 & 1342 & 1342 & 1342 & 1342 & 649 & 649 & 189 & 189 \\
\hline Zirconium Non-radloactlve & 0 & 0 & 0 & 0 & 0 & 0 & 0 & 0 & 0 & 0 & 0 & 0 & 0 \\
\hline Surl. contam.cleanable & 0 & 0 & 0 & 0 & 0 & 0 & 0 & 0 & 0 & 0 & 0 & 0 & 0 \\
\hline Surl. conlam. + non-clnbl & 0 & 0 & 0 & 0 & 0 & 0 & 0 & 0 & 0 & 0 & 0 & 0 & 0 \\
\hline Activaled & 25 & 25 & 25 & 25 & 25 & 25 & 25 & 25 & 25 & 0 & 0 & 0 & 0 \\
\hline
\end{tabular}




\begin{tabular}{|c|c|c|c|c|c|c|c|c|c|c|c|c|}
\hline ASIa & $\begin{array}{c}\text { Guangdong } \\
1\end{array}$ & $\begin{array}{c}\text { Guangdong } \\
2\end{array}$ & $\begin{array}{c}\text { Qlnshan } \\
1\end{array}$ & $\begin{array}{c}\text { Qinshan } \\
2\end{array}$ & $\begin{array}{c}\text { Qinshan } \\
3\end{array}$ & $\begin{array}{c}\text { Bushehr } \\
1\end{array}$ & $\begin{array}{c}\text { Bushohr } \\
2\end{array}$ & $\begin{array}{c}\text { Iraq } \\
1\end{array}$ & $\begin{array}{c}\text { Israel } \\
1\end{array}$ & $\begin{array}{c}\text { Wolsong } \\
1\end{array}$ & $\begin{array}{c}\text { Wolsong } \\
2\end{array}$ & $\begin{array}{c}\text { Kori } \\
1\end{array}$ \\
\hline Fuel cycle stage (FCT) & Reactor & Reactor & Reactor & Reactor & Reactor & Reactor & Reactor & Reactor & Reactor & Reactor & Reactor & Reactor \\
\hline Identiller & $727 \mathrm{CNP}$ & 728CNP & 689CNP & 904CNP & 905CNP & & & 787IQP & 7891LP & $400 \mathrm{KH}$ & $917 \mathrm{KH}$ & $257 \mathrm{KP}$ \\
\hline Plant typo & PWR & PWR & PWR & PWR & PWR & PWR & PWR & PWR & PWR & PHWR & PHWA & PWR \\
\hline Locatlon & China & China & China & China & China & Iran & Iran & Iraq & Israel & Korea & Korea & Korea \\
\hline Start of operations & & & & & & & & 1991 & 1994 & 1982 & 1997 & 1977 \\
\hline Status & Under Const & Under Const & Under Const & Planned & Planned & On hold & On hold & Planned & Planned & Operating & Under Constr & Operating \\
\hline Size (MWe) (Net) & 900 & 900 & 288 & 600 & 600 & 1300 & 1300 & 600 & 900 & 629 & 629 & 556 \\
\hline Vendor & Framalome & Framatome & & & & KWU & KWU & & & AEQ & & Wstnghse \\
\hline A/E & & & & & & & & & & AEQ & AECL & Gilbert \\
\hline Pre or Post TMI & Post & Post & Post & Post & Post & Post & Post & Post & Post & Post & Post & Pre \\
\hline No. of steam turbines & 1 & 1 & 1 & & 2 & & & 1 & 1 & 1 & 1 & 1 \\
\hline \multicolumn{13}{|l|}{ Coolling } \\
\hline Date EOL motal availablo & 2053 & 2053 & 2053 & Unknown & Unknown & Unknown & Unknown & Unknown & Unknown & 2032 & 2047 & 2027 \\
\hline \multicolumn{13}{|l|}{ Quantity of motal (tonnes): } \\
\hline Aluminum Non-radioactive & 75 & 75 & 35 & 57 & 57 & 95 & 95 & 57 & 75 & 64 & 64 & 54 \\
\hline Surf. contam.-cleanable & 14 & 14 & 7 & 11 & 11 & 18 & 18 & 11 & 14 & 12 & 12 & 10 \\
\hline Surf. contam.-non-clnbl & 0 & 0 & 0 & 0 & 0 & 0 & 0 & 0 & 0 & 0 & 0 & 0 \\
\hline Activated & 5 & 5 & 2 & 4 & 4 & 6 & 6 & 4 & 5 & 4 & 4 & 3 \\
\hline Non-radloactlive & 4568 & 4568 & 2137 & 3486 & 3486 & 5837 & 5837 & 3486 & 4568 & 3914 & 3914 & 3313 \\
\hline Surl. contam.-cleanable & 75 & 75 & 35 & 57 & 57 & 95 & 95 & 57 & 75 & 64 & 64 & 54 \\
\hline Surl. contam-non-clnbl & 0 & 0 & 0 & 0 & 0 & 0 & 0 & 0 & 0 & 0 & 0 & 0 \\
\hline Activated & 19 & 19 & 9 & 14 & 14 & 24 & 24 & 14 & 19 & 16 & 16 & 14 \\
\hline Non-radioactive & 20 & 20 & 20 & 20 & 20 & 20 & 20 & 20 & 20 & 20 & 20 & 20 \\
\hline Surf. conlam.-cleanable & 0 & 0 & 0 & 0 & 0 & 0 & 0 & 0 & 0 & 0 & 0 & 0 \\
\hline Surf. contam.-non-clnbl & 0 & 0 & 0 & 0 & 0 & 0 & 0 & 0 & 0 & 0 & 0 & 0 \\
\hline Activaled & 0 & 0 & 0 & 0 & 0 & 0 & 0 & 0 & 0 & 0 & 0 & 0 \\
\hline Steel \& Iron Non-radioactive & 7728 & 7728 & 3615 & 5897 & 5897 & 9875 & 9875 & 5897 & 7728 & 6391 & 6391 & 5605 \\
\hline Surf. contam.-cleanable & 6246 & 6246 & 2922 & 4766 & 4766 & 7981 & 7981 & 4766 & 6246 & 4793 & 4793 & 4530 \\
\hline Surl. contam.-non-cinbl & 0 & 0 & 0 & 0 & 0 & 0 & 0 & 0 & 0 & 0 & 0 & 0 \\
\hline Activated & 2741 & 2741 & 1282 & 2091 & 2091 & 3502 & 3502 & 2091 & 2741 & 2348 & 2348 & 1988 \\
\hline Non-radioactive & 0 & 0 & 0 & 0 & 0 & 0 & 0 & 0 & 0 & 232 & 232 & 0 \\
\hline Surf. contam.cleanable & 839 & 839 & 392 & 640 & 640 & 1072 & 1072 & 640 & 839 & 1598 & 1598 & 609 \\
\hline Surf. contam.-non-cinbl & 280 & 280 & 131 & 213 & 213 & 357 & 357 & 213 & 280 & 160 & 160 & 203 \\
\hline Activated & 625 & 625 & 292 & 477 & 477 & 798 & 798 & 477 & 625 & 1677 & 1677 & 453 \\
\hline Zirconlum Non-radioaclive & 0 & 0 & 0 & 0 & 0 & 0 & 0 & 0 & 0 & 0 & 0 & 0 \\
\hline Surl. contam.-cleanable & 0 & 0 & 0 & 0 & 0 & 0 & 0 & 0 & 0 & 0 & 0 & 0 \\
\hline Surf. contam.-non-clnbl & 0 & 0 & 0 & 0 & 0 & $\underline{0}$ & 0 & 0 & 0 & 0 & 0 & 0 \\
\hline Activated & 0 & 0 & 0 & 0 & 0 & 0 & 0 & 0 & 0 & 25 & 25 & $\underline{0}$ \\
\hline
\end{tabular}




\begin{tabular}{|c|c|c|c|c|c|c|c|c|c|c|c|c|}
\hline 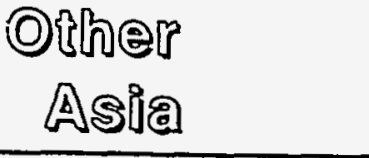 & $\begin{array}{c}\text { Korl } \\
2 \\
\end{array}$ & $\begin{array}{c}\text { Kori } \\
3 \\
\end{array}$ & $\begin{array}{l}\text { Kori } \\
4 \\
\end{array}$ & $\begin{array}{l}\text { Uljin } \\
1\end{array}$ & $\begin{array}{l}\text { UJjin } \\
2 \\
\end{array}$ & $\begin{array}{l}\text { Uljin } \\
3 \\
\end{array}$ & Uijin & $\begin{array}{l}\text { Yeong- } \\
\text { gwang } 1\end{array}$ & $\begin{array}{l}\text { Yeong- } \\
\text { gwang } 2\end{array}$ & $\begin{array}{l}\text { Yeong- } \\
\text { gwang } 3\end{array}$ & $\begin{array}{l}\text { Yeong- } \\
\text { gwang } 4\end{array}$ & Kanupp \\
\hline Fuel cycle stage (FCT) & Reactor & Reactor & Reactor & Reactor & Reactor & Reactor & Reactor & Reactor & Reactor & Reactor & Reactor & Reactor \\
\hline Identifler & $490 \mathrm{KP}$ & $602 \mathrm{KP}$ & 601kP & $643 \mathrm{KP}$ & $637 \mathrm{KP}$ & 918KP & $919 \mathrm{KP}$ & $600 \mathrm{KP}$ & 599KP & $731 \mathrm{KP}$ & $735 \mathrm{KP}$ & 140PKH \\
\hline Plant type & PWR & PWR & PWR & PWR & PWR & PWR & PWR & PWR & PWR & PWR & PWR & PHWR \\
\hline Location & Korea & Korea & Korea & Korea & Korea & Korea & Korea & Korea & Korea & Korea & Korea & Pakistan \\
\hline Start of operatlons & 1983 & 1985 & 1985 & 1988 & 1989 & 1998 & 1999 & 1986 & 1986 & 1995 & 1996 & 1972 \\
\hline Status & Operating & Operating & Operating & Operating & Operating & Under Constr & Under Constr & Operating & Operating & Under Const & Under Const & Operating \\
\hline Size (MWe) (Net) & 605 & 895 & 895 & 943 & 943 & 943 & 943 & 900 & 900 & 900 & 900 & 125 \\
\hline Vendor & Wstnghse & Wsinghse & Wstnghse & Framatome & Framatome & $\mathrm{ABB}-\mathrm{CE}$ & ABB-CE & Westinghouse & Westinghouse & $A B B-C E$ & $\mathrm{ABB} \cdot \mathrm{CE}$ & CanGE \\
\hline AVE & Gilbert & Bechtel & Bechtel & Framalome & Framalome & Sarg \& Lun & Sarg \& Lun & Bechtel & Bechtel & Sarg \& Lun & Sarg \& Lun & Can $\mathrm{Ge}_{0}$ \\
\hline Pre or Post TMI & Post & Post & Post & Post & Post & Post & Post & Post & Post & Post & Post & Pre \\
\hline No. of steam turblnes & 1 & 1 & 1 & 1 & 1 & & & 1 & 1 & 1 & 1 & 1 \\
\hline Coolling & & & & & & & & & & & & \\
\hline Date EOL motal avallablo & 2033 & 2035 & 2035 & 2038 & 2039 & 2048 & 2049 & 2036 & 2036 & 2045 & 2046 & 2022 \\
\hline Quantlty of metal (tonnes): & & & & & & & & & & & & \\
\hline Alumlnum Non-radioactive & 57 & 74 & 74 & 77 & 77 & 77 & 77 & 75 & 75 & 75 & 75 & 22 \\
\hline Surl. contam.-cleanable & 11 & 14 & 14 & 14 & 14 & 14 & 14 & 14 & 14 & 14 & 14 & 4 \\
\hline Surl. conlam.-non-cinbl & 0 & 0 & 0 & 0 & 0 & 0 & 0 & 0 & 0 & 0 & 0 & 0 \\
\hline Activated & 4 & 5 & 5 & 5 & 5 & 5 & 5 & 5 & 5 & 5 & 5 & 1 \\
\hline Non-radloaclive & 3505 & 4551 & 4551 & 4712 & 4712 & 4712 & 4712 & 4568 & 4568 & 4568 & 4568 & 1333 \\
\hline Surl. contam.-cleanable & 57 & 74 & 74 & 77 & 77 & 77 & 77 & 75 & 75 & 75 & 75 & 22 \\
\hline Surl. contam.-non-dnbl & 0 & 0 & 0 & 0 & 0 & 0 & 0 & 0 & 0 & 0 & 0 & 0 \\
\hline Activalod & 14 & 19 & 19 & 19 & 19 & 19 & 19 & 19 & 19 & 19 & 19 & 5 \\
\hline Non-radioactive & 20 & 20 & 20 & 20 & 20 & 20 & 20 & 20 & 20 & 20 & 20 & 20 \\
\hline Surf. contam.-cleanable & 0 & 0 & 0 & 0 & 0 & 0 & 0 & 0 & 0 & 0 & 0 & 0 \\
\hline Surf. contam.non-dnbl & 0 & 0 & 0 & 0 & 0 & 0 & 0 & 0 & 0 & 0 & 0 & 0 \\
\hline Activaled & 0 & 0 & 0 & 0 & 0 & 0 & 0 & 0 & 0 & 0 & 0 & 0 \\
\hline Steol \& Iron Non-radioactive & 5930 & 7699 & 7699 & 7972 & 7972 & 7972 & 7972 & 7728 & 7728 & 7728 & 7728 & 2176 \\
\hline Surt. conlam.-cleanable & 4793 & 6222 & 6222 & 6443 & 6443 & 6443 & 6443 & 6246 & 6246 & 6246 & 6246 & 1632 \\
\hline Surf. conlam.-nan-c|nbl & 0 & 0 & 0 & 0 & 0 & 0 & 0 & 0 & 0 & 0. & 0 & 0 \\
\hline Activated & 2103 & 2730 & 2730 & 2827 & 2827 & 2827 & 2827 & 2741 & 2741 & 2741 & 2741 & 800 \\
\hline Non-radloaclive & 0 & 0 & 0 & 0 & 0 & 0 & 0 & 0 & 0 & 0 & 0 & 79 \\
\hline Surl. contam.-cleanable & 644 & 836 & 836 & 865 & 865 & 865 & 865 & 839 & 839 & 839. & 839 & 544 \\
\hline Surf. contam.non-clnbl & 215 & 279 & 279 & 288 & 288 & 288 & 288 & 280 & 280 & 280 & 280 & 54 \\
\hline Activated & 479 & 622 & 622 & 644 & 644 & 644 & 644 & 625 & 625 & 625 & 625 & 571 \\
\hline Zirconium Non-radioactive & 0 & 0 & 0 & 0 & 0 & 0 & 0 & 0 & 0 & 0 & 0 & 0 \\
\hline Surf. contam.-cleanable & 0 & 0 & 0 & 0 & 0 & 0 & 0 & of & 0 & 0 & 0 & 0 \\
\hline Surf. contam.-non-dnbl & 0 & 0 & 0 & 0 & 0 & 0 & 0 & 0 & 0 & 0 & 0 & 0 \\
\hline Activated & 0 & 0 & 0 & 0 & 0 & 0 & 0 & 0 & 0 & 01 & 01 & 25 \\
\hline
\end{tabular}




\begin{tabular}{|c|c|c|c|c|c|c|c|c|}
\hline 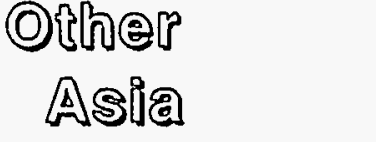 & Chasnupp & Chashma & $\begin{array}{c}\text { Chin-shan } \\
1\end{array}$ & $\begin{array}{c}\text { Chin-shan } \\
2\end{array}$ & $\begin{array}{c}\text { Kuosheng } \\
1\end{array}$ & $\begin{array}{c}\text { Kuosheng } \\
2\end{array}$ & $\begin{array}{c}\text { Maanshan } \\
1\end{array}$ & $\begin{array}{c}\text { Maanshan } \\
2 \\
\end{array}$ \\
\hline Fuel cycle stage (FCT) & Reactor & Reactor & Reactor & Reaclor & Reaclor & Reactor & Reactor & Reactor \\
\hline Identifier & & 772PKP & $279 R O C B$ & $280 \mathrm{AOCB}$ & 458ROCB & 460ROCB & 531ROCP & 594ROCP \\
\hline Plant type & PWR & PWR & BWR & BWR & BWR & BWR & PWR & PWR \\
\hline Location & Pakistan & Pakistan & Taiwan & Taiwan & Taiwan & Taiwan & Taiwan & Taiwan \\
\hline Start of operations & & 1995 & 1978 & 1979 & 1981 & 1983 & 1986 & 1985 \\
\hline Status & Under Const & Planned & Operating & Operating & Operating & Operating & Operating & Operating \\
\hline Size (MWe) (Nel) & 300 & 864 & 604 & 604 & 948 & 948 & 890 & 890 \\
\hline Vendor & $a N D$ & & $\Phi$ & ⿷匚 & $\underline{G}$ & $G$ & Westinghouse & Westinghouse \\
\hline AVE & avoc & & Ebasco & Ebasoo & Bechtel & Bechtel & Bechtel & Bechtel \\
\hline Pre or Post TMI & Post & Post & Pre & Pre & Post & Post & Post & Post \\
\hline No. of steam lurbines & & 1 & 1 & 1 & 1 & 1 & 1 & 1 \\
\hline Coolling & & & Sea & Sea & sea & See & Sea & Sea \\
\hline Date EOL motal avallable & 2053 & Unknown & 2028 & 2029 & 2031 & 2033 & 2036 & 2035 \\
\hline \multicolumn{9}{|l|}{ Quantity of metal (lonnes): } \\
\hline Aluminum ${ }^{\circ}$ Non-radioactive & 36 & 73 & 57 & 57 & 77 & 77 & 74 & 74 \\
\hline Surf. contam.-cleanable & 7 & 14 & 11 & 11 & 14 & 14 & 14 & 14 \\
\hline Sulf. contam.-non-clnbl & 0 & 0 & 0 & 0 & 0 & 0 & 0 & 0 \\
\hline Activated & 2 & 5 & 4 & 4 & 5 & 5 & 5 & 5 \\
\hline Copper Non-radioactive & 2196 & 4445 & 3501 & 3501 & 4729 & 4729 & 4534 & 4534 \\
\hline $\begin{array}{l}\text { Suri. contam.-cleanable } \\
\end{array}$ & 36 & 73 & 57 & 57 & 77 & 77 & 74 & 74 \\
\hline Surl. contam.-non-cinbl & 0 & 0 & 0 & 0 & 0 & 0 & 0 & 0 \\
\hline Activated & 9 & 18 & 14 & 14 & 19 & 19 & 19 & 19 \\
\hline \begin{tabular}{|ll} 
Lead & Non-radioactive \\
\end{tabular} & 20 & 20 & 20 & 20 & 20 & 20 & 20 & 20 \\
\hline Surf. contam.-cleanable & 0 & 0 & 0 & 0 & 0 & 0 & 0 & 0 \\
\hline Surf. contam.-non-cinbl & 0 & 0 & 0 & 0 & 0 & 0 & 0 & 0 \\
\hline Activaled & 0 & 0 & 0 & 0 & 0 & 0 & 0 & 0 \\
\hline \begin{tabular}{|l} 
Steol \& Iron Non-radioactive \\
\end{tabular} & 3715 & 7520 & 3573 & 3573 & 4825 & 4825 & 7670 & 7670 \\
\hline \begin{tabular}{|c|} 
Surf. contam.-cleanable \\
\end{tabular} & 3003 & 6078 & 4787 & 4787 & 6466 & 6466 & 6199 & 6199 \\
\hline Surf. contam.non-clnbl & 0 & 0 & 0 & 0 & 0 & 0 & 0 & 0 \\
\hline Activated & 1318 & 2667 & 2501 & 2501 & 3378 & 3378 & 2720 & 2720 \\
\hline St.Stoel Non-radioactive & 0 & 0 & 0 & 0 & 0 & 0 & 0 & 0 \\
\hline Surl. contam.cleanable & 403 & 816 & 429 & 429 & 579 & 579 & 833 & 833 \\
\hline Surf. contam.-non-cinbl & 134 & 272 & 0 & 0 & 0 & 0 & 278 & 278 \\
\hline Activated & 300 & 608 & 479 & 479 & 647 & 647 & 620 & 620 \\
\hline \begin{tabular}{|l|l} 
Zirconium Non-radioactive \\
\end{tabular} & 0 & 0 & 0 & 0 & 0 & 0 & 0 & $\underline{0}$ \\
\hline Surl. contam.-cleanable & 0 & 0 & 0 & 0 & 0 & 0 & 0 & 0 \\
\hline Surl. contam.-non-cinbl & 0 & 0 & 0 & 0 & 0 & 0 & 0 & 0 \\
\hline Activated & 0 & 0 & 0 & 0 & 0 & 0 & 0 & 0 \\
\hline
\end{tabular}




\begin{tabular}{|c|c|c|c|c|c|c|c|c|c|c|c|c|}
\hline $\begin{array}{l}\text { Rest @if } \\
\text { WOLी@ }\end{array}$ & $\begin{array}{c}\text { Atucha } \\
1\end{array}$ & $\begin{array}{c}\text { Atucha } \\
2\end{array}$ & Embalse & $\begin{array}{c}\text { Angra } \\
1\end{array}$ & $\begin{array}{l}\text { Angra } \\
2\end{array}$ & $\begin{array}{c}\text { Angra } \\
3\end{array}$ & $\begin{array}{l}\text { Furnas } \\
\qquad 4\end{array}$ & $\begin{array}{l}\text { Furnas } \\
5\end{array}$ & $\begin{array}{c}\text { Juragua } \\
1\end{array}$ & $\begin{array}{c}\text { Juragua } \\
2\end{array}$ & $\begin{array}{c}\text { Juragua } \\
\qquad 3\end{array}$ & $\begin{array}{c}\text { Juragua } \\
4\end{array}$ \\
\hline Fuel cycle stage (FCT) & Reactor & Reactor & Reactor & Reactor & Reactor & Reactor & Reactor & Reactor & Reactor & Reactor & Reactor & Reactor \\
\hline Identifler & 176RAH & 638RAH & 282RAH & 309BRP & 488BRP & 489BRP & 779BRP & 780BRP & 694CUP & 690CUP & 796CUP & 797CUP \\
\hline Plant type & PHWR & PHWR & PHWR & PWR & PWR & PWR & PWR & PWR & WER & WER & WER & WER \\
\hline Location & Argentlina & Argentina & Argentina & Brazil & Brazil & Brazll & Brazil & Brazil & aba & aba & aba & aba \\
\hline Start of operations & 1974 & 1994 & 1984 & 1985 & 1992 & 1995 & & & & & & \\
\hline Status & Operating & Under Const & Operating & Operating & Under Const & Under Const & Planned & Planned & Under Const & Under Const & Planned & Planned \\
\hline Size $\left(\mathrm{MWO}_{\theta}\right)(\mathrm{Net})$ & 335 & 692 & 600 & 626 & 1245 & 1245 & 1245 & 1245 & 408 & 408 & 408 & 408 \\
\hline Vendor & Slemens & KWU & AEC & Wsinghse & KWU & KWU & KWU & KWU & & & & \\
\hline AVE. & Siemens & ENACE & AECL/ltalimp & G\&H/Prmn & Nuclen & Nucien & & & & & & \\
\hline Pre or Post TMI & Pre & Post & Post & Post & Post & Post & Post & Post & Post & Post & Post & Post \\
\hline No. of steam turbines & 1 & 1 & 1 & 1 & 1 & 1 & 1 & 1 & 1 & 1 & 1 & 1 \\
\hline \multicolumn{13}{|l|}{ Coolling } \\
\hline Date EOL metal avallable & 2024 & 2053 & 2034 & 2035 & $\frac{2042}{21227}$ & $2045^{\circ}$ & $\begin{array}{l}\text { Unknown } \\
\text { ZZZZZZZZZ }\end{array}$ & Unknown & 2053 & 2053 & Unknown & Unknown \\
\hline \multicolumn{13}{|l|}{ Quantity of motal (lonnes): } \\
\hline Aluminum Non-radioactive & 42 & 68 & 62 & 59 & 93 & 93 & 93 & 93 & 46 & 46 & 46 & 46 \\
\hline \begin{tabular}{|l|} 
Surl. contam.-cleanable \\
\end{tabular} & 8 & 13 & 12 & 11 & 17 & 17 & 17 & 17 & 9 & 9 & 9 & 9 \\
\hline Surt. contam.-non-clnbl & 0 & 0 & 0 & of & 0 & 0 & 0 & 0 & of & 0 & 0 & 0 \\
\hline Activaled & 3 & 4 & 4 & 4 & 6. & 6 & 6. & 6 & 3 & 3 & 3 & 3 \\
\hline Copper Non-radioactive & 2572 & 4171 & 3793 & 3586 & 5671 & 5671 & 5671 & 5671 & 2840 & 2840 & 2840 & 2840 \\
\hline Surf. contam.-cleanable & 42 & 68 & 62 & 59 & 93 & 93 & 93 & 93 & 46 & 46 & 46 & 46 \\
\hline Surt. contam.-non-cinbl & 0 & 0 & 0 & 0 & 0 & 0 & 0 & 0 & 0 & 0 & 0 & 0 \\
\hline Activated & 10 & 17 & 15 & 15 & 23 & 23 & 23 & 23 & 12 & 12 & 12 & 12 \\
\hline Non-radioactive & 20 & 20 & 20 & 20 & 20 & 20 & 20 & 20 & 20 & 20 & 20 & 20 \\
\hline Suri. contam.-cleanable & 0 & 0 & 0 & 0 & 0 & 0 & 0 & 0 & 0 & 0 & 0 & 0 \\
\hline Surf. contam.non-cinbl & 0 & 0 & 0 & 0 & 0 & 0 & 0 & 0 & of & 0 & of & 0 \\
\hline Activated & 0 & 0 & 0 & 0 & 0 & 0 & 0 & 0 & 0 & 0 & 0 & 0 \\
\hline Steel \& Iron Non-radioactive & 4199 & 6810 & 6193 & 6066 & 9594 & 9594 & 9594 & 9594 & 12030 & 12030 & 12030 & 12030 \\
\hline Surf. contam.-cleanable & 3149 & 5108 & 4644 & 4903 & 7754 & 7754 & 7754 & 7754 & 4669 & 4669 & 4669 & 4669 \\
\hline Surf. contam.-non-clnbl & 0 & 0 & 0 & 0 & 0 & 0 & 0 & 0 & 46 & 46 & 46 & 46 \\
\hline Activated & 1543 & 2503 & 2276 & 2151 & 3402 & 3402 & 3402 & 3402 & 363 & 363 & 363 & 363 \\
\hline St. Steel Non-radioactive & 152 & 247 & 224 & 0 & 0 & 0 & 0 & 0 & 0 & 0 & 요 & 0 \\
\hline Surf. contam.-cleanable & 1050 & 1703 & 1548 & 659 & 1042 & 1042 & 1042 & 1042 & 1599 & 1599 & 1599 & 1599 \\
\hline Surf. contam.-non-clnbl & 105 & 170 & 155 & 220 & 347 & 347 & 347 & 347 & 0 & 0 & 0 & 0 \\
\hline Activated & 1102 & 1788 & 1626 & 490 & 775 & 775 & 775 & 775 & 254 & 254 & 254 & 254 \\
\hline Zirconium Non-radioactive & 0 & 0 & 0 & 0 & 0 & 0 & 0 & 0 & 0 & 0 & 0 & 0 \\
\hline Surf. contam.-cleanable & 0 & 0 & 0 & 0 & 0 & 0 & 0 & 0 & 0 & 0 & 0 & 0 \\
\hline Surf. contam.-non-clnbl & 0 & 0 & 0 & 0 & of & 0 & 0 & 0 & 0 & 0 & 0 & 0 \\
\hline Activated & 25 & 25 & 25 & 0 & 0 & 0 & 0 & 0 & 01 & 0 & 0 & 0 \\
\hline
\end{tabular}




\begin{tabular}{|c|c|c|c|c|c|c|c|c|c|c|c|c|}
\hline $\begin{array}{l}\text { Res\} @f } \\
\text { By@[ी@ }\end{array}$ & $\begin{array}{c}\text { Orlente } \\
1\end{array}$ & $\begin{array}{l}\text { Orlente } \\
2\end{array}$ & $\begin{array}{c}\text { Plunardel } \\
\text { RIO } 2\end{array}$ & $\begin{array}{c}\text { Plunardel } \\
\text { RlO1 }\end{array}$ & $\begin{array}{c}\text { El Dabaa } \\
1\end{array}$ & $\begin{array}{c}\text { El Dabaa } \\
2\end{array}$ & $\begin{array}{c}\text { El Dabaa } \\
3\end{array}$ & $\begin{array}{c}\text { El Dabaa } \\
4\end{array}$ & $\begin{array}{c}\text { Libya } \\
1\end{array}$ & $\begin{array}{l}\text { Libya } \\
2\end{array}$ & $\begin{array}{c}\text { Koeberg } \\
1\end{array}$ & $\begin{array}{c}\text { Koagerg } \\
2\end{array}$ \\
\hline Fuel cycle slage (FCM) & Reactor & Reactor & Reactor & Reactor & Reactor & Reactor & Reactor & Reactor & Reactor & Reactor & Reactor & Reactor \\
\hline Identifler & 849CUP & 8500 UP & 857CUP & 856CUP & 774EGP & 775EGP & 776EGP & T77EGP & 817LP & 818LYP & 576ZAP & 577ZAP \\
\hline Plant type & WER & WEA & WER & WER & PWR & PWR & PWA & PWR & PWR & PWR & PWR & PINR \\
\hline Location & aba & aba & aba & aba & Egypl & Egypt & Egypt & Egypt & Libya & Llbya & South Airica & South Alrica \\
\hline Stant of operations & & & & & & & & & 1991 & 1993 & 1984 & 1985 \\
\hline Status & Planned & Planned & Planned & Planned & Planned & Planned & Planned & Plánned & Planned & Planned & Operating & Operating \\
\hline Size (MWe) (Nel) & 408 & 408 & 408 & 408 & 900 & 900 & 900 & 900 & .408 & 408 & 920 & 920 \\
\hline Vendor & & & & & & & & & & & Framatome & Framatome \\
\hline$A / E$ & & & & & & & & & & & Framatome & Framatome \\
\hline Pre or Post TMI & Post & Post & Post & Post & Post & Post & Post & Post & Post & Post & Post & Post \\
\hline No. of steam turblines & 1 & 1 & 1 & 1 & 1 & 1 & 1 & 1 & 1 & 1 & 1 & 1 \\
\hline Cooling & & & & & & & & & & & Sea & Sea \\
\hline 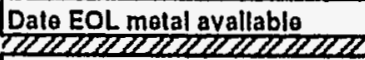 & Unknown & Unknown & Unknown & Unknown & Unknown & Unknown & Unknown & Unknown & Unknown & Unknown & 2034 & 2035 \\
\hline \multicolumn{13}{|c|}{ 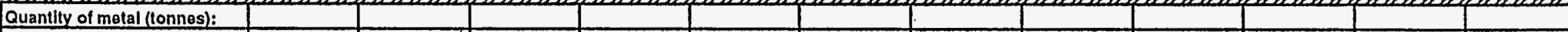 } \\
\hline Aluminum Non-radioactive & 46 & 46 & 46 & 46 & 75 & 75 & 75 & 75 & 44 & 44 & 76 & 76 \\
\hline Surf. conlam.cleanable & 9 & 9 & 9 & 9 & 14 & 14 & 14 & 14 & 8 & 8 & 14 & 14 \\
\hline Surt. conlam.-non-clnbl & $\underline{0}$ & 0 & $\underline{0}$ & 0 & 0 & 0 & 0 & $\underline{0}$ & 0 & 0 & 0 & 0 \\
\hline Activated & 3 & 3 & 3 & 3 & 5 & 5 & 5 & 5 & 3 & 3 & 5 & 5 \\
\hline Copper Non-radioactive & 2840 & 2840 & 2840 & 2840 & 4568 & 4568 & 4568 & 4568 & 2695 & 2695 & 4635 & 4635 \\
\hline Surf.contam.-cleanable & 46 & 46 & 46 & 46 & 75 & 75 & 75 & 75 & 44 & 44 & 76 & 76 \\
\hline Surf. conlam.-non-clnbl & 0 & 0 & 0 & 0 & 0 & 0 & 0 & 0 & 0 & 0 & 0 & 0 \\
\hline Acilvated & 12 & 12 & 12 & 12 & 19 & 19 & 19 & 19 & 11 & 11 & 19 & 19 \\
\hline Lead Non-radloactive & 20 & 20 & 20 & 20 & 20 & 20 & 20 & 20 & 20 & 20 & 20 & 20 \\
\hline Surl. conlam.cleanable & 0 & 0 & 0 & 0 & 0 & 0 & 0 & $\therefore 0$ & 0 & 0 & 0 & 0 \\
\hline Surl. contam.-non-cinbl & 0 & 0 & 0 & 0 & 0 & 0 & 0 & 0 & 0 & 0 & 0 & $\underline{0}$ \\
\hline Aclivaled & 0 & 0 & 0 & 0 & 0 & 0 & 0 & 0 & 0 & 0 & 0 & 0 \\
\hline Steol \& Iron Non-radloacive & 12030 & 12030 & 12030 & 12030 & 7728 & 7728 & 7728 & 7728 & 4560 & 4560 & 7842 & 7842 \\
\hline Surl. contam. cleanable & 4669 & 4669 & 4669 & 4669 & 6246 & 6246 & 6246 & 6246 & 3686 & 3686 & 6338 & 6338 \\
\hline Surf. contam.-non-clnbl & 46 & 46 & 46 & 46 & 0 & 0 & 0 & 0 & 0 & 0 & 0 & 0 \\
\hline Activaled & 363 & 363 & 363 & 363 & 2741 & 2741 & 2741 & 2741 & 1617 & 1617 & 2781 & 2781 \\
\hline S1.Stoel Non-radioactive & 0 & 0 & 0 & 0 & 0 & 0 & 0 & 0 & 0 & 0 & 0 & 0 \\
\hline Surf. conlam.cleanable & 1599 & 1599 & 1599 & 1599 & 839 & 839 & 839 & 839 & 495 & 495 & 851 & 851 \\
\hline Surt. conlam.non-cinbl & 0 & 0 & 0 & 0 & 280 & 280 & 280 & 280 & 165 & 165 & 284 & 284 \\
\hline Activaled & 254 & 254 & 254 & 254 & 625 & 625 & 625 & 625 & 369 & 369 & 634 & 634 \\
\hline Zirconium Non-radioactive & 0 & 0 & 0 & 0 & 0 & 0 & 0 & 0 & 0 & 0 & 0 & 0 \\
\hline Surt. contam.-cleanable & 0 & 0 & 0 & 0 & 0 & 0 & 0 & 0 & 0 & 0 & 0 & 0 \\
\hline Surf. contam.-non-clnbl & 0 & 0 & 0 & 0 & 0 & 0 & 0 & 0 & 0 & 0 & 0 & 0 \\
\hline Activated & 0 & 0 & 0 & 0 & 0 & 0 & 0 & 0 & 0 & 0 & 0 & 0 \\
\hline
\end{tabular}




\begin{tabular}{|c|c|c|c|c|}
\hline $\begin{array}{l}\text { R日S: (0f } \\
\text { WORlo }\end{array}$ & Kanupp & Chashma & $\begin{array}{c}\text { Kooberg } \\
1\end{array}$ & $\begin{array}{c}\text { Koegerg } \\
2\end{array}$ \\
\hline Fuel cycle stage (FCT) & Reactor & Reactor & Reactor & Reactor \\
\hline Identifler & 140PKH & 772PKP & 576ZAP & 577ZAP \\
\hline Plant type & PHWR & PWR & PWR & PWR \\
\hline Location & Pakistan & Pakistan & South Africa & South Africa \\
\hline Start of operations & 1972 & 1995 & 1984 & 1985 \\
\hline Status & Operating & Planned & Operating & Operating \\
\hline$S i z \theta$ (MWe) (Net) & 125 & 864 & 920 & 920 \\
\hline Vendor & CanGE & & Framatome & Framatome \\
\hline ANE & $C_{n} \mathrm{C}_{\theta}$ & & Framatome & Framatome \\
\hline Pre or Post TMI & Pre & Post & Post & Post \\
\hline No. of steam turbines & 1 & 1 & 1 & 1 \\
\hline Cooling & & & Sea & Sea \\
\hline Date EOL melal avallable & 2022 & $\begin{array}{l}\text { Unknown } \\
\text { UZZZZZZ }\end{array}$ & 2034 & 2035 \\
\hline \multicolumn{5}{|l|}{ Quantity of motal (tonnes): } \\
\hline Aluminum Non-radioactive & 22 & 73 & 76 & 76 \\
\hline Surf. contam.-cleanable & 4 & 14 & 14 & 14 \\
\hline Surf. contam.-non-clnbl & 0 & 0 & 0 & 0 \\
\hline Activated & 1 & 5 & 5 & 5 \\
\hline Copper Non-radioactive & 1333 & 4445 & 4635 & 4635 \\
\hline Surf. contam.-cleanable & 22 & 73 & 76 & 76 \\
\hline Suri. contam.-non-clnbl & 0 & 0 & 0 & 0 \\
\hline Activated & 5 & 18 & 19 & 19 \\
\hline Non-radioactive & 20 & 20 & 20 & 20 \\
\hline Surt. contam.-cleanable & 0 & 0 & 0 & 0 \\
\hline Surt. contam.-non-clnbl & $\underline{0}$ & $\underline{0}$ & 0 & 0 \\
\hline Activaled & 0 & 0 & 0 & 0 \\
\hline Steel \& Iron Non-radioactive & 2176 & 7520 & 7842 & 7842 \\
\hline Surt contam.-cleanable & 1632 & 6078 & 6338 & 6338 \\
\hline Surl. contam.-non-clnbl & $\underline{0}$ & 0 & 0 & 0 \\
\hline Activated & 800 & 2667 & 2781 & 2781 \\
\hline Non-radioactive & 79 & 0 & 0 & 0 \\
\hline Surf. contam.cleanable & 544 & 816 & 851 & 851 \\
\hline Surt. contam.-non-clnbl & 54 & 272 & 284 & 284 \\
\hline Activated & 571 & 608 & 634 & 634 \\
\hline Zlrconlum Non-radioactive & 0 & 0 & 0 & 0 \\
\hline Surf. contam.-cleanable & 0 & 0 & 0 & 0 \\
\hline Surf. contam.-non-clnbl & 0 & $\underline{0}$ & 0 & 0 \\
\hline Activated & 25 & 0 & 0 & 0 \\
\hline
\end{tabular}




\section{A.4 REFERENCES}

Bryan, R.S., and I.T. Dudley, 1974, Estimated Quantities of Materials Contained in a 1000-MW(e) PWR Power Plant, ORNL-TM-4515, Oak Ridge National Laboratory, Oak Ridge, Tenn., June.

Chapuis, A.M., et al., undated, Exemption Limits for the Recycling of Materials from the Dismantling of Nuclear Installations, CEA, Fontenay-aux Roses, France.

DOE - See U.S. Department of Energy.

El-Bassioni, A.A., 1980, A Methodology and a Preliminary Data Base for Examining the Health Risks of Electricity Generation from Uranium and Coal Fuels, NUREG/CR-1539, U.S. Nuclear Regulatory Commission, Washington, D.C., Aug.

Emelyanov, I.Y., et al., 1982, Designs of Nuclear Reactors, Energoizdat, Moscow.

Garbay, H., and A.M. Chapuis, 1989, "Radiological Impact of Very Slightly Radioactive Copper and Aluminum Recovered from Dismantled Nuclear Facilities," in Decommissioning of Nuclear Installations, Proceedings of an International Conference Held in Brussels, Oct. 24-27, Commission of the European Communities, Luxembourg, p. 755.

International Atomic Energy Agency, 1988, Factors Relevant to the Recycling or Reuse of Components Arising from the Decommissioning and Refurbishment of Nuclear Facilities, Technical Reports Series No. 293, Vienna.

Lasch, M., et al., 1984, "Estimation of Radioactive Waste Quantities Arising during Decommissioning," in Decommissioning of Nuclear Power Plants, Proceedings of a European Conference held in Luxembourg, May 22-24, Commission of the European Communities, Luxembourg, p. 75.

Leclercq, J., 1986, The Nuclear Age, Hachette, France.

Nuclear Engineering, 1964, "CANDU-Douglas Point Nuclear Power Station," Aug., p. 289. Nuclear Engineering International, 1970, "Pickering Generating Station," June, p. 501.

-Nuclear Engineering International, 1991, World Nuclear Industry Handbook 1991, Surrey, .England.

Nuclear Engineering International, 1993, World Nuclear Industry Handbook 1993, Surrey, England.

Nuclear Power, 1961, "Dungeness Nuclear Power Station," April.

Regan, J.D., et al., 1984, Design Features Facilitating the Decommissioning of Advanced GasCooled Reactors, " Commission of the European Communities, Luxembourg. 
Smith, R.I., et al., 1978, Technology, Safety and Costs of Decommissioning a Reference Pressurized Water Reactor Power Station," NUREG/CR-0130, U.S. Nuclear Regulatory Commission, Washington, D.C., June.

United Engineers and Constructors, Inc., 1972, Pressurized Water Reactor Plant, 1000-MWe Central Station Power Plants Investment Cost Study, Vol. I, WASH-1230, prepared for U.S. Atomic Energy Commission, Washington, D.C., June.

U.S. Department of Energy, 1987, Overall Plant Design Description VVER Water Cooled, Water Moderated Energy Reactor, DOE/NE-0084, Washington, D.C., May. 


\section{APPENDIX B:}

ANNUAL INCREMENTS IN POTENTIAL SCRAP METAL INVENTORY FROM NUCLEAR POWER PLANTS 


\section{APPENDIX B:}

\section{ANNUAL INCREMENTS IN POTENTIAL SCRAP METAL INVENTORY FROM NUCLEAR POWER PLANTS}

This appendix presents tables listing annual increments in potential scrap metal inventory from nuclear power plants for various regions of the world. Each table is given in three parts - A, B, and C. Table B.1A, for example, summarizes the U.S.A. annual metal mass increments for the calendar years 2010 through 2043. Reactor metal masses are included in the appropriate year for dismantlement occurring 50 years after start-up. Table B.1B represents the same information for an additional 50-year delay, allowing for isotope decay and the transfer of metals from one activity category to another. Table B.1C shows the status after an additional 50 years decay (i.e., start-up plus 150 years).

The subsequent tables are for North America (Table B.2), Europe (Table B.3), the former Soviet Union (Table B.4), Asia (Table B.5), the rest of the world (Table B.6) and a worldwide total (Table B.7).

Following the tables are Figures B.1 through B.7, which present the data graphically. Figure B.1 gives annual iron and steel increments estimated for the U.S.A., while Figure B.2 gives total annual increments estimated for North America (U.S.A., Canada, and Mexico, excluding $\mathrm{Cuba).} \mathrm{Figure} \mathrm{B.3} \mathrm{gives} \mathrm{annual} \mathrm{increments} \mathrm{estimated} \mathrm{for} \mathrm{Europe,} \mathrm{including} \mathrm{eastern}$ Europe (Bulgaria, Czech Republic, Finland, Hungary, Poland, Romania, Slovakia, and Slovenia). Figure B.4 gives annual increments for the former Soviet Union (including Asian portions), and Figure B.5 gives annual increments estimated for Asia (excluding Asian parts of the former Soviet Union). Figure B.6 gives annual increments estimated for the remainder of the world. Worldwide summations of the annual increment estimates are presented in Figure B.7.

Each figure has three parts - A, B, and C. Figure B.1A, for example, provides a summary of the U.S.A. annual iron and steel mass increments for the calendar years 2010 through 2043. Reactors are included in each year as appropriate for 50 years after start-up. Figure B.1B represents the same information for an additional 50-year delay, allowing for isotope decay and the transfer of metals from one activity category to another. Figure B.1C shows the status after an additional 50 years decay (i.e., at start-up plus 150 years). 
TABLE B.1 Annual Increments in Scrap-Metal Inventory from Nuclear Power Plants for the U.S.A.; Part A: Start-Up Plus

\begin{tabular}{|c|c|c|c|c|c|c|c|c|c|c|c|c|}
\hline \multirow[b]{2}{*}{$\begin{array}{c}50 \text { Years } \\
\text { Year } \\
\text { avall. } \\
\text { able }\end{array}$} & \multicolumn{4}{|c|}{ 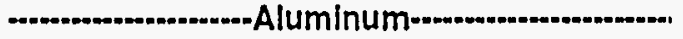 } & \multicolumn{4}{|c|}{ 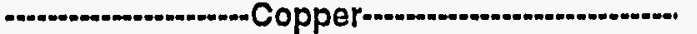 } & \multicolumn{4}{|c|}{ 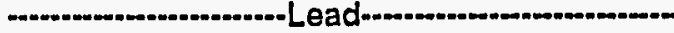 } \\
\hline & $\begin{array}{l}\text { Non- } \\
\text { active }\end{array}$ & $\begin{array}{c}\text { Clean- } \\
\text { able }\end{array}$ & $\begin{array}{l}\text { Non- } \\
\text { clean- } \\
\text { able }\end{array}$ & $\begin{array}{l}\text { Actl- } \\
\text { vated }\end{array}$ & $\begin{array}{l}\text { Non- } \\
\text { actlve }\end{array}$ & $\begin{array}{l}\text { Clean- } \\
\text { ablé }\end{array}$ & $\begin{array}{l}\text { Non- } \\
\text { clean- } \\
\text { able }\end{array}$ & $\begin{array}{l}\text { Acti- } \\
\text { vated }\end{array}$ & $\begin{array}{l}\text { Non- } \\
\text { active }\end{array}$ & $\begin{array}{c}\text { Clean- } \\
\text { able }\end{array}$ & $\begin{array}{l}\text { Non- } \\
\text { clean- } \\
\text { able }\end{array}$ & $\begin{array}{l}\text { Actl- } \\
\text { vated }\end{array}$ \\
\hline 2010 & 27 & 5 & 0 & 2 & 1676 & 27 & 0 & 7 & 20 & 0 & 0 & 0 \\
\hline 2011 & 24 & 5 & 0 & 2 & 1486 & 24 & 0 & 6 & 20 & 0 & 0 & 0 \\
\hline 2012 & 0 & 0 & 0 & 0 & 0 & 0 & 0 & 0 & 0 & 0 & 0 & 0 \\
\hline 2013 & 32 & 6 & 0 & 2 & 1981 & 32 & 0 & 8 & 20 & 0 & 0 & 0 \\
\hline 2014 & 0 & 0 & 0 & 0 & 0 & 0 & 0 & 0. & 0 & 0 & 0 & 0 \\
\hline 2015 & 0 & 0 & 0 & 0 & 0 & 0 & 0 & 0 & 0 & 0 & 0 & 0 \\
\hline 2016 & 80 & 15 & 0 & 5 & 4900 & 80 & 0 & 20 & 0 & 0 & 0 & 0 \\
\hline 2017 & 0 & 0 & 0 & 0 & 0 & 0 & 0 & 0 & 0 & 0 & 0 & 0 \\
\hline 2018 & 102 & 19 & 0 & 6 & 6264 & 102 & 0 & 26 & 40 & 0 & 0 & 0 \\
\hline 2019 & 115 & 22 & 0 & 7 & 7049 & 115 & 0 & 29 & 40 & 0 & 0 & 0 \\
\hline 2020 & 165 & 31 & 0 & 10 & 10110 & 165 & 0 & 41 & 60 & 0 & 0 & 0 \\
\hline 2021 & 310 & 58 & 0 & 19 & 18984 & 310 & 0 & 77 & 100 & 0 & 0 & 0 \\
\hline 2022 & 361 & 68 & 0 & 23 & 22135 & 361 & 0 & 90 & 120 & 0 & 0 & 0 \\
\hline 2023 & 516 & 97 & 0 & 32 & 31626 & 516 & 0 & 129 & 160 & 0 & 0 & 0 \\
\hline 2024 & 917 & 172 & 0 & 67 & 56194 & 917 & 0 & 229 & 260 & 0 & 0 & 0 \\
\hline 2025 & 581 & 109 & 0 & 36 & 35577 & 581 & 0 & 145 & 160 & 0 & 0 & 0 \\
\hline 2026 & 304 & 57 & 0 & 19 & 18607 & 304 & 0 & 76 & 80 & 0 & 0 & 0 \\
\hline 2027 & 446 & 84 & 0 & 28 & 27335 & 446 & 0 & 112 & 120 & 0 & 0 & 0 \\
\hline 2028 & 300 & 56 & 0 & 19 & 18383 & 300 & 0 & 75 & 80 & $0^{\circ}$ & 0 & 0 \\
\hline 2029 & 147 & 28 & 0 & 9 & 7984 & 147 & 0 & 37 & 40 & 0 & 0 & 0 \\
\hline 2030 & 147 & 28 & 0 & 9 & 9022 & 147 & 0 & 37 & 40 & 0 & 0 & 0 \\
\hline 2031 & 330 & 62 & 0 & 21 & 20232 & 330 & 0 & 83 & 80 & 0 & 0 & 0 \\
\hline 2032 & 88 & 16 & 0 & 5 & 5372 & 88 & 0 & 22 & 20 & 0 & 0 & 0 \\
\hline 2033 & 237 & 44 & 0 & 15 & 14489 & 237 & 0 & 59 & 60 & 0 & 0 & 0 \\
\hline 2034 & $4 \dot{9} 4$ & 93 & 0 & 31 & 30243 & 494 & 0 & 123 & 120 & 0 & 0 & 0 \\
\hline 2035 & 683 & 128 & 0 & 43 & 41837 & 683 & 0 & 171 & 160 & 0 & 0 & 0 \\
\hline 2036 & 683 & 128 & 0 & 43 & 41822 & 683 & 0 & 171 & 160 & 0 & 0 & 0 \\
\hline 2037 & 481 & 90 & 0 & 30 & 29445 & 481 & 0 & 120 & 120 & 0 & 0 & 0 \\
\hline 2038 & 525 & 98 & 0 & 33 & 32153 & 525 & 0 & 131 & 120 & 0 & 0 & 0 \\
\hline 2039 & 178 & 33 & 0 & 11 & 10898 & 178 & 0 & 44 & 40 & 0 & 0 & 0 \\
\hline 2040 & 259 & 48 & 0 & 16 & 15835 & 259 & 0 & 65 & 60 & 0 & 0 & 0 \\
\hline 2041 & 0 & 0 & 0 & 0 & 0 & 0 & 0 & 0 & 0 & 0 & 0 & 0 \\
\hline 2042 & 0 & 0 & 0 & 0 & 0 & 0 & 0 & 0 & 0 & 0 & 0 & 0 \\
\hline 2043 & 0 & 0 & 0 & 0 & 0 . & 0 & 0 & 0 & 0 & 0 & 0 & 0 \\
\hline \multicolumn{13}{|l|}{ Under } \\
\hline const. & 724 & 136 & 0 & 45 & 44367 & 724 & 0 & 181 & 160 & 0 & 0 & 0 \\
\hline
\end{tabular}


TABLe B.1 (Cont.); Part A (Cont.)

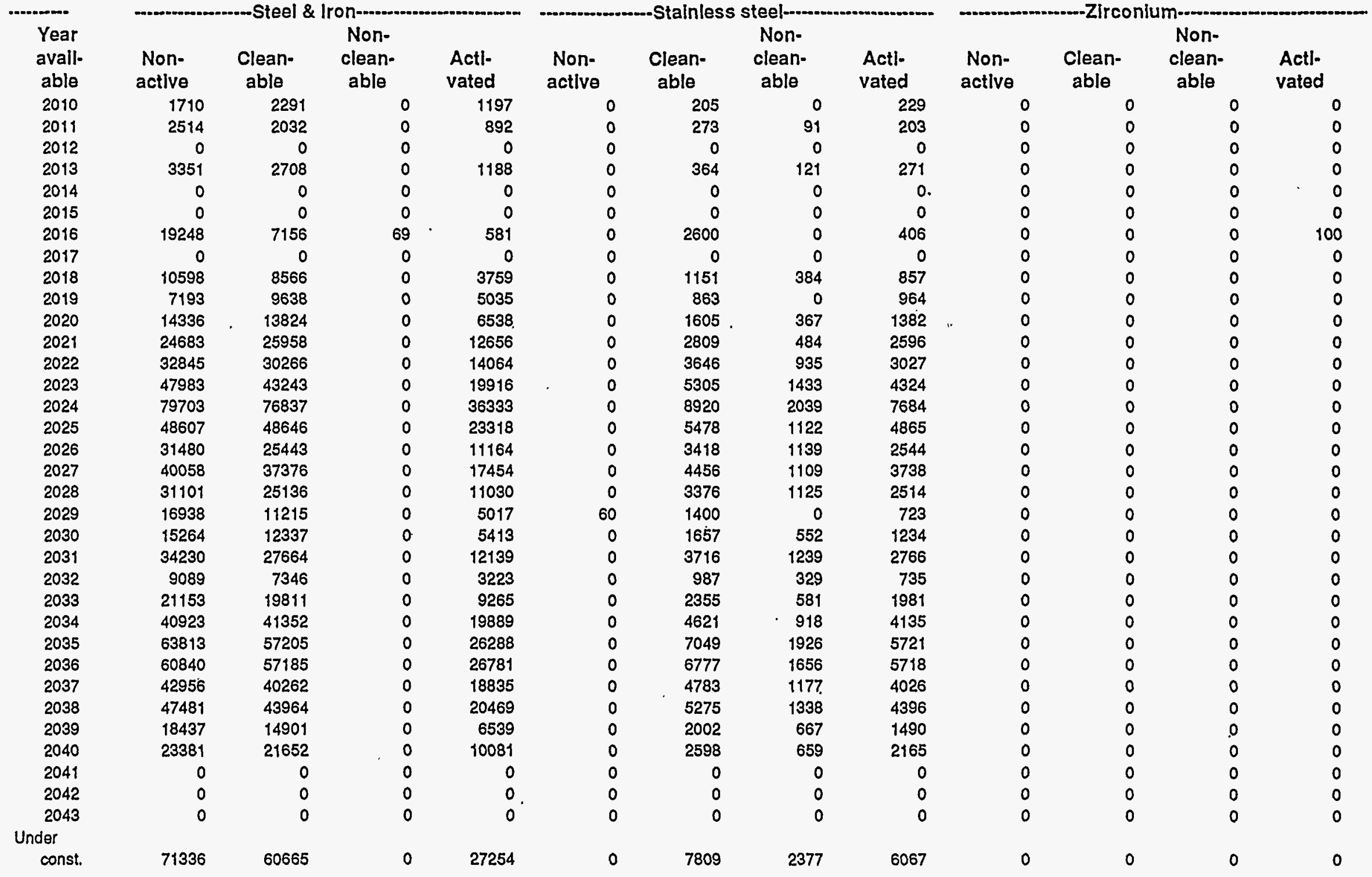


TABLE B.1 (Cont.); Part B: Start-Up Plus 100 Years

\begin{tabular}{|c|c|c|c|c|c|c|c|c|c|c|c|c|}
\hline & & -..-Alur & -1 & 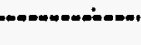 & & Copp & 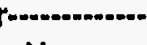 & 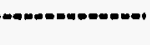 & $n-\infty$ & Le & & \\
\hline $\begin{array}{c}\text { Year } \\
\text { avall- } \\
\text { able }\end{array}$ & $\begin{array}{l}\text { Non- } \\
\text { active }\end{array}$ & $\begin{array}{c}\text { Clean- } \\
\text { able }\end{array}$ & $\begin{array}{l}\text { Non- } \\
\text { clean- } \\
\text { able }\end{array}$ & $\begin{array}{l}\text { Acti- } \\
\text { vated }\end{array}$ & $\begin{array}{l}\text { Non- } \\
\text { active }\end{array}$ & $\begin{array}{c}\text { Clean- } \\
\text { able }\end{array}$ & $\begin{array}{l}\text { Non- } \\
\text { clean- } \\
\text { able }\end{array}$ & $\begin{array}{l}\text { Actl- } \\
\text { vated }\end{array}$ & $\begin{array}{l}\text { Non- } \\
\text { active }\end{array}$ & $\begin{array}{c}\text { Clean- } \\
\text { able }\end{array}$ & $\begin{array}{l}\text { Non- } \\
\text { clean- } \\
\text { able }\end{array}$ & $\begin{array}{l}\text { Actl- } \\
\text { vated }\end{array}$ \\
\hline 2060 & 31 & 3 & 0 & 1 & 1689 & 14 & 0 & 7 & 20 & 0 & 0 & 0 \\
\hline 2061 & 27 & 2 & 0 & 1 & 1498 & 12 & 0 & 6 & 20 & 0 & 0 & 0 \\
\hline 2062 & .0 & 0 & 0 & 0 & 0 & 0 & 0 & 0 & 0 & 0 & 0 & 0 \\
\hline 2063 & 36 & 3 & 0 & 1 & 1997 & 16 & 0 & 8 & 20 & 0 & 0 & 0 \\
\hline 2064 & 0 & 0 & 0 & 0 & .0 & 0 & 0 & 0 & 0 & 0 & 0 & 0 \\
\hline 2065 & 0 & 0 & 0 & 0 & 0 & 0 & $0^{\circ}$ & 0 & 0 & 0 & 0 & 0 \\
\hline 2066 & 90 & 8 & 0 & 3 & 4940 & 40 & 0 & 20 & 0 & 0 & 0 & 0 \\
\hline 2067 & 0 & 0 & 0 & 0 & 0 & 0 & 0 & 0 & 0 & 0 & 0 & 0 \\
\hline 2068 & 115 & 10 & 0 & 3 & 6315 & 51 & 0 & 26 & 40 & 0 & 0 & 0 \\
\hline 2069 & 129 & 11 & 0 & 4 & 7106 & 58 & 0 & 29 & 40 & 0 & 0 & 0 \\
\hline 2070 & 186 & 15 & 0 & 5 & 10193 & 83 & 0 & 41 & 60 & 0 & 0 & 0 \\
\hline 2071 & 349 & 29 & 0 & 10 & 19139 & 155 & 0 & 77 & 100 & 0 & 0 & 0 \\
\hline 2072 & 407 & 34 & 0 & 11 & 22315 & 181 & 0 & 90 & 120 & 0 & 0 & 0 \\
\hline 2073 & 581 & 48 & 0 & 16 & 31884 & 258 & 0 & 129 & 160 & 0 & 0 & 0 \\
\hline 2074 & 1032 & 86 & 0 & 29 & 56653 & 459 & 0 & 229 & 260 & 0 & 0 & 0 \\
\hline 2075 & 653 & 54 & 0 & 18 & 35867 & 290 & 0 & 145 & 160 & 0 & 0 & 0 \\
\hline 2076 & 342 & 28 & 0 & 9 & 18759 & 152 & 0 & 76 & 80 & 0 & 0 & 0 \\
\hline 2077 & 502 & 42 & 0 & 14 & 27558 & 223 & 0 & 112 & 120 & 0 & 0 & 0 \\
\hline 2078 & 338 & 28 & 0 & 9 & 18533 & 150 & 0 & 75 & 80 & 0 & 0 & 0 \\
\hline 2079 & 165 & 14 & 0 & 5 & 8058 & 73 & 0 & 37 & 40 & 0 & 0 & 0 \\
\hline 2080 & 166 & 14 & 0 & 5 & 9096 & 74 & 0 & 37 & 40 & 0 & 0 & 0 \\
\hline 2081 & 372 & 31 & 0 & 10 & 20397 & 165 & 0 & 83 & 80 & 0 & 0 & 0 \\
\hline 2082 & 99 & 8 & 0 & 3 & 5416 & 44 & 0 & 22 & 20 & 0 & 0 & 0 \\
\hline 2083 & 266 & 22 & 0 & 7 & 14607 & 118 & 0 & 59 & 60 & 0 & 0 & 0 \\
\hline 2084 & 555 & 46 & 0 & 15 & 30490 & 247 & 0 & 123 & 120 & 0 & 0 & 0 \\
\hline 2085 & 768 & 64 & 0 & 21 & 42178 & 342 & 0 & 171 & $160^{\circ}$. & 0 & 0 & 0 \\
\hline 2086 & 768 & 64 & 0 & 21 & 42163 & 341 & 0 & 171 & $160^{\circ}$ & 0 & 0 & 0 \\
\hline 2087 & 541 & 45 & 0 & 15 & 29686 & 240 & 0 & 120 & 120 & 0 & 0 & 0 \\
\hline 2088 & 591 & 49 & 0 & 16 & 32415 & 262 & 0 & 131 & 120 & 0 & 0 & 0 \\
\hline 2089 & 200 & 17 & 0 & 6 & 10987 & 89 & 0 & 44 & 40 & 0 & 0 & 0 \\
\hline 2090 & 291 & 24 & 0 & 8 & 15964 & 129 & 0 & 65 & 60 & 0 & 0 & 0 \\
\hline 2091 & 0 & 0 & 0 & 0 & 0 & 0 & 0 & 0 & 0 & 0 & 0 & 0 \\
\hline 2092 & 0 & 0 & 0 & 0 & 0 & 0 & 0 & 0 & 0 & 0 & 0 & 0 \\
\hline 2093 & 0 & 0 & 0 & 0 & 0 & 0 & 0 & 0 & 0 & 0 & 0 & 0 \\
\hline Under & & & & & & & & & & & & \\
\hline const. & 815 & 68 & 0 & 23 & 44729 & 362 & 0 & 181 & 160 & 0 & 0 & 0 \\
\hline
\end{tabular}


TABLE B.1 (Cont.); Part B (Cont.)

\begin{tabular}{|c|c|c|c|c|c|c|c|c|c|c|c|c|}
\hline \multirow[b]{2}{*}{$\begin{array}{c}\text { Year } \\
\text { avall- } \\
\text { able }\end{array}$} & \multicolumn{4}{|c|}{ 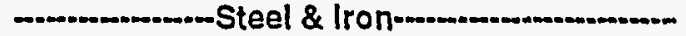 } & \multicolumn{4}{|c|}{ Stainless steel } & \multicolumn{4}{|c|}{ 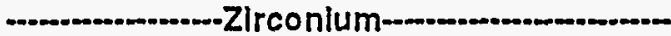 } \\
\hline & $\begin{array}{l}\text { Non- } \\
\text { actlve }\end{array}$ & $\begin{array}{l}\text { Clean- } \\
\text { able }\end{array}$ & $\begin{array}{l}\text { Non- } \\
\text { clean- } \\
\text { able }\end{array}$ & $\begin{array}{l}\text { Actl- } \\
\text { vated }\end{array}$ & $\begin{array}{l}\text { Non- } \\
\text { active }\end{array}$ & $\begin{array}{l}\text { Clean- } \\
\text { able }\end{array}$ & $\begin{array}{l}\text { Non- } \\
\text { clean- } \\
\text { able }\end{array}$ & $\begin{array}{l}\text { Acti- } \\
\text { vated }\end{array}$ & $\begin{array}{l}\text { Non- } \\
\text { actlve }\end{array}$ & $\begin{array}{c}\text { Clean- } \\
\text { able }\end{array}$ & $\begin{array}{l}\text { Non- } \\
\text { clean- } \\
\text { able }\end{array}$ & $\begin{array}{l}\text { Actl- } \\
\text { vated }\end{array}$ \\
\hline 2060 & 3454 & 1146 & 0 & 598 & 103 & 103 & 0 & 229 & 0 & 0 & 0 & 0 \\
\hline 2061 & 3976 & 1016 & 0 & 446 & 182 & 136 & 45 & 203 & 0 & 0 & 0 & 0 \\
\hline 2062 & 0 & 0 & 0 & 0 & 0 & 0 & 0 & 0 & 0 & 0 & 0 & 0 \\
\hline 2063 & 5299 & 1354 & 0 & 594 & 243 & 182 & 61 & 271 & 0 & 0 & 0 & 0 \\
\hline 2064 & 0 & 0 & 0 & 0 & 0 & 0 & 0 & 0 & 0 & 0 & 0 & 0 \\
\hline 2065 & 0 & 0 & 0 & 0 & 0 & 0 & 0 & 0 & 0 & 0 & 0 & 0 \\
\hline 2066 & 23151 & 3578 & 35 & 291 & 1300 & 1300 & 0 & 406 & 50 & 0 & 0 & 50 \\
\hline 2067 & 0 & 0 & 0 & 0 & 0 & 0 & 0 & 0 & 0 & 0 & 0 & 0 \\
\hline 2068 & 16760 & 4283 & 0 & 1879 & 767 & 575 & 192 & 857 & 0 & 0 & 0 & 0 \\
\hline 2069 & 14529 & 4819 & 0 & 2517 & 432 . & 432 & 0 & 964 & 0 & .0 & 0 & 0 \\
\hline 2070 & 24517 & 6912 & 0 & 3269 & 986 & 802 & 183 & 1382 & 0 & .0 & 0 & 0 \\
\hline 2071 & 43990 & 12979 & 0 & 6328 & 1647 & 1404 & 242 & 2596 & 0 & 0 & 0 & 0 \\
\hline 2072 & 55010 & 15133 & 0 & 7032 & 2291 & 1823 & 468 & 3027 & 0 & 0 & 0 & 0 \\
\hline 2073 & 79562 & 21622 & 0 & 9958 & 3369 & 2653 & 716 & 4324 & 0 & 0 & 0 & 0 \\
\hline 2074 & 136288 & 38419 & 0 & 18166 & 5480 & 4460 & 1020 & 7684 & 0 & 0 & 0 & 0 \\
\hline 2075 & 84588 & 24323 & 0 & 11659 & 3300 & 2739 & 561 & 4865 & 0 & 0 & 0 & 0 \\
\hline 2076 & 49784 & 12721 & 0 & 5582 & 2278 & 1709 & 570 & 2544 & 0 & 0 & 0 & 0 \\
\hline 2077 & 67473 & 18688 & 0 & 8727 & 2783 & 2228 & 555 & 3738 & 0 & 0 & 0 & 0 \\
\hline 2078 & 49183 & 12568 & 0 & 5515 & 2251 & 1688 & 563 & 2514 & 0 & 0 & 0 & 0 \\
\hline 2079 & 25054 & 5607 & 0 & 2509 & 760 & 700 & 0 & 723 & 0 & 0 & 0 & 0 \\
\hline 2080 & 24140 & 6168 & 0 & 2707 & 1105 & 829 & 276 & 1234 & 0 & 0 & 0 & 0 \\
\hline 2081 & 54132 & 13832 & 0 & 6070 & 2477 & 1858 & 619 & 2766 & 0 & 0 & 0 & 0 \\
\hline 2082 & 14374 & 3673 & 0 & 1612 & 658 & 493 & 164 & 735 & 0 & 0 & 0 & 0 \\
\hline 2083 & 35691 & 9906 & 0 & 4633 & 1468 & 1177 & 290 & 1981 & 0 & 0 & 0 & 0 \\
\hline 2084 & 71544 & 20676 & 0 & 9945 & 2769 & 2310 & 459 & 4135 & 0 & 0 & 0 & 0 \\
\hline 2085 & 105560 & 28603 & 0 & 13144 & 4488 & 3524 & 963 & $5721^{\circ}$ & 0 & 0 & 0 & 0 \\
\hline 2086 & 102823 & 28592 & 0 & 13390 & 4217 & 3389 & 828 & 5718 & 0 & 0 & 0 & 0 \\
\hline 2087 & 72505 & 20131 & 0 & 9417 & 2980 & 2391 & 589 & 4026 & 0 & 0 & 0 & 0 \\
\hline 2088 & 79698 & 21982 & 0 & 10234 & 3306 & 2637 & 669 & 4396 & 0 & 0 & 0 & 0 \\
\hline 2089 & 29157 & 7451 & 0 & 3269 & 1334 & 1001 & 334 & 1490 & 0 & 0 & 0 & 0 \\
\hline 2090 & 39247 & 10826 & 0 & 5041 & 1628 & 1299 & 329 & 2165 & 0 & 0 & 0 & 0 \\
\hline 2091 & 0 & 0 & 0 & 0 & 0 & 0 & 0 & 0 & 0 & 0 & 0 & 0 \\
\hline - 2092 & 0 & 0 & 0 & 0 & 0 & 0 & 0 & 0 & 0 & 0 & 0 & 0 \\
\hline 2093 & 0 & 0 & 0 & 0 & 0 & 0 & 0 & 0 & 0 & 0 & 0 & 0 \\
\hline \multicolumn{13}{|l|}{ Under } \\
\hline const. & 115296 & 30333 & 0 & 13627 & 5093 & 3905 & 1188 & 6067 & 0 & 0 & 0 & 0 \\
\hline
\end{tabular}


TABLE B.1 (Cont.); Part C: Start-Up Plus 150 Years

\begin{tabular}{|c|c|c|c|c|c|c|c|c|c|c|c|c|}
\hline \multirow{2}{*}{$\begin{array}{c}\text { Year } \\
\text { avall- } \\
\text { able }\end{array}$} & \multicolumn{4}{|c|}{ Aluminum } & \multicolumn{4}{|c|}{ י-Copper } & \multicolumn{4}{|c|}{ 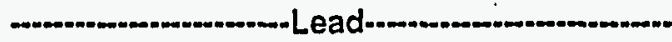 } \\
\hline & $\begin{array}{l}\text { Non- } \\
\text { active }\end{array}$ & $\begin{array}{c}\text { Clean- } \\
\text { able }\end{array}$ & $\begin{array}{l}\text { Non- } \\
\text { clean- } \\
\text { able }\end{array}$ & $\begin{array}{l}\text { Actl- } \\
\text { vated }\end{array}$ & $\begin{array}{l}\text { Non- } \\
\text { active }\end{array}$ & $\begin{array}{c}\text { Clean- } \\
\text { able }\end{array}$ & $\begin{array}{l}\text { Non- } \\
\text { clean- } \\
\text { able }\end{array}$ & $\begin{array}{l}\text { Actl- } \\
\text { vated }\end{array}$ & $\begin{array}{l}\text { Non- } \\
\text { actlve }\end{array}$ & $\begin{array}{c}\text { Clean- } \\
\text { able }\end{array}$ & $\begin{array}{c}\text { Non- } \\
\text { clean- } \\
\text { able }\end{array}$ & $\begin{array}{l}\text { Acti- } \\
\text { vated }\end{array}$ \\
\hline 2110 & 32 & 1 & 0 & 0 & 1696 & 7 & 0 & 2 & 20 & 0 & 0 & 0 \\
\hline 2111 & 29 & 1 & 0 & 0 & 1504 & 6 & 0 & 2 & 20 & 0 & 0 & 0 \\
\hline 2112 & 0 & 0 & 0 & 0 & 0 & 0 & 0 & 0 & 0 & 0 & 0 & 0 \\
\hline 2113 & 38 & 2 & 0 & 1 & 2005 & 8 & 0 & 2 & 20 & 0 & 0 & 0 \\
\hline 2114 & 0 & 0 & 0 & 0 & 0 & 0 & 0 & 0. & 0 & 0 & 0 & 0 \\
\hline 2115 & 0 & 0 & 0 & 0 & 0 & 0 & 0 & 0 & 0 & 0 & 0 & 0 \\
\hline 2116 & 95 & 4 & 0 & 1 & 4960 & 20 & 0 & 5 & 0 & 0 & 0 & 0 \\
\hline 2117 & 0 & 0 & 0 & 0 & .0 & 0 & 0 & 0 & 0 & 0 & 0 & 0 \\
\hline 2118 & 121 & 5 & 0 & 2 & 6341 & 26 & 0 & 6 & 40 & 0 & 0 & 0 \\
\hline 2119 & 137 & 5 & 0 & 2 & 7135 & 29 & 0 & 7 & 40 & 0 & 0 & 0 \\
\hline 2120 & 196 & 8 & 0 & 3 & 10234 & 41 & 0 & 10 & 60 & 0 & 0 & 0 \\
\hline 2121 & 368 & 15 & 0 & 5 & 19217 & 77 & 0 & 19 & 100 & 0 & 0 & 0 \\
\hline 2122 & 429 & 17 & 0 & 6 & 22406 & 90 & 0 & 23 & 120 & 0 & 0 & 0 \\
\hline 2123 & 613 & 24 & 0 & 8 & 32013 & 129 & 0 & 32 & 160 & 0 & 0 & 0 \\
\hline 2124 & 1089 & 43 & 0 & 14 & 56883 & 229 & 0 & 57 & 260 & 0 & 0 & 0 \\
\hline 2125 & 690 & 27 & 0 & 9 & 36012 & 145 & 0 & 36 & 160 & 0 & 0 & 0 \\
\hline 2126 & 361 & 14 & 0 & 5 & 18835 & 76 & 0 & 19 & 80 & 0 & 0 & 0 \\
\hline 2127 & 530 & 21 & 0 & 7 & 27.669 & 112 & 0 & 28 & 120 & 0 & 0 & 0 \\
\hline 2128 & 356 & 14 & 0 & 5 & 18608 & 75 & 0 & 19 & 80 & 0 & 0 & 0 \\
\hline 2129 & 174 & 7 & 0 & 2 & 8094 & 37 & 0 & 9 & 40 & 0 & 0 & 0 \\
\hline 2130 & 175 & 7 & 0 & 2 & 9133 & 37 & 0 & 9 & 40 & 0 & 0 & 0 \\
\hline 2131 & 392 & 15 & 0 & 5 & 20480 & 83 & 0 & 21 & 80 & 0 & 0 & 0 \\
\hline 2132 & 104 & 4 & 0 & 1 & 5438 & 22 & 0 & 5 & 20 & 0 & 0 & 0 \\
\hline 2133 & 281 & .11 & 0 & 4 & 14666 & 59 & 0 & 15 & 60 & 0 & 0 & 0 \\
\hline 2134 & 586 & 23 & 0 & 8 & 30613 & 123 & 0 & 31. & 120 & 0 & 0 & 0 \\
\hline 2135 & 811 & 32 & 0 & 11 & 42349 & 171 & 0 & 43 & 160 & 0 & 0 & 0 \\
\hline 2136 & 811 & 32 & 0 & 11 & 42334 & 171 & 0 & 43 & 160 & 0 & 0 & 0 \\
\hline 2137 & 571 & 23 & 0 & 8 & 29806 & 120 & 0 & 30 & 120 & 0 & 0 & 0 \\
\hline 2138 & 623 & 25 & 0 & 8 & 32546 & 131 & 0 & 33 & 120 & 0 & 0 & 0 \\
\hline 2139 & 211 & 8 & 0 & 3 & 11031 & 44 & $\dot{0}$ & 11 & 40 & 0 & 0 & 0 \\
\hline 2140 & 307 & 12 & 0 & 4 & 16029 & 65 & 0 & 16 & 60 & 0 & 0 & 0 \\
\hline 2141 & 0 & 0 & 0 & 0 & 0 & 0 & 0 & 0 & 0 & 0 & 0 & 0 \\
\hline 2142 & 0 & 0 & 0 & 0 & 0 & 0 & 0 & 0 & 0 & 0 & 0 & 0 \\
\hline 2143 & 0 & 0 & 0 & 0 & 0 & 0 & 0 & 0 & 0 & 0 & 0 & 0 \\
\hline \multicolumn{13}{|l|}{ Under } \\
\hline const. & 860 & 34 & 0 & 11 & 44910 & 181 & 0 & 45 & 160 & 0 & 0 & 0 \\
\hline
\end{tabular}


TABLE B.1 (Cont.); Part C (Cont.)

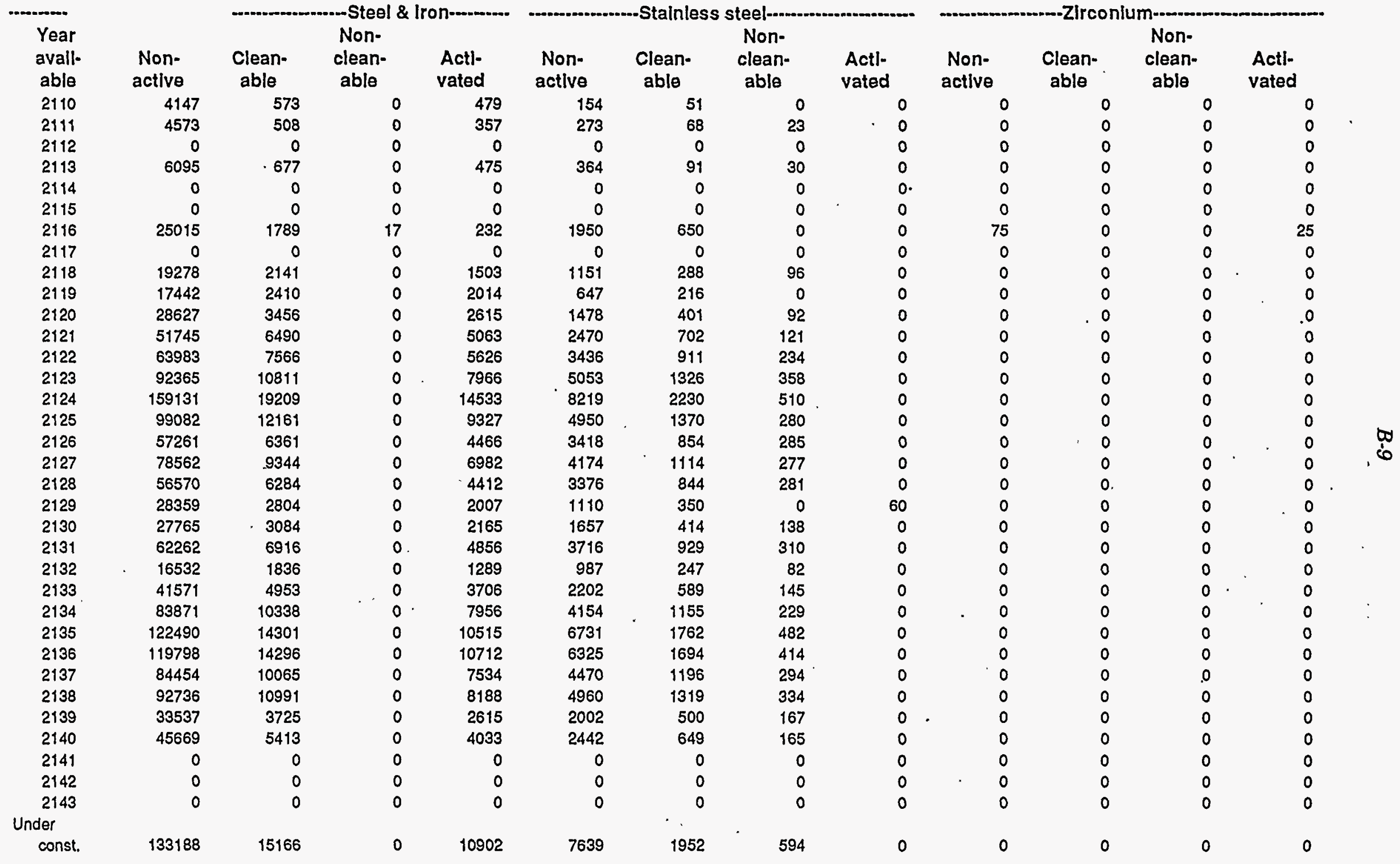


TABLE B.2 Annual Increments in Scrap-Metal Inventory from Nuclear Power Plants for North America (U.S.A., Canada, and Mexico, excludes Cuba); Part A: Start-Up Plus 50 Years

\begin{tabular}{|c|c|c|c|c|c|c|c|c|c|c|c|c|}
\hline $\begin{array}{l}\text { Year } \\
\text { avall- } \\
\text { able }\end{array}$ & $\begin{array}{l}\text { Non- } \\
\text { active }\end{array}$ & $\begin{array}{l}\text { Clean- } \\
\text { able }\end{array}$ & $\begin{array}{l}\text { Non- } \\
\text { clean- } \\
\text { able }\end{array}$ & $\begin{array}{l}\text { Actl- } \\
\text { vated }\end{array}$ & $\begin{array}{l}\text { Non- } \\
\text { active }\end{array}$ & $\begin{array}{c}\text { Clean- } \\
\text { able }\end{array}$ & $\begin{array}{l}\text { Non- } \\
\text { clean- } \\
\text { able }\end{array}$ & $\begin{array}{l}\text { Actl- } \\
\text { vated }\end{array}$ & $\begin{array}{l}\text { Non- } \\
\text { actlve }\end{array}$ & $\begin{array}{c}\text { Clean- } \\
\text { able }\end{array}$ & $\begin{array}{l}\text { Non- } \\
\text { clean- } \\
\text { able }\end{array}$ & $\begin{array}{l}\text { Acti- } \\
\text { vated }\end{array}$ \\
\hline 2010 & 27 & 5 & 0 & 2 & 1676 & 27 & 0. & 7 & 20 & 0 & 0 & 0 \\
\hline 2011 & 24 & 5 & 0 & 2 & 1486 & 24 & $0^{\circ}$ & 6 & 20 & 0 & 0 & 0 \\
\hline 2012 & 0 & 0 & 0 & 0 & 0 & 0 & 0 & 0 & 0 & 0 & 0 & 0 \\
\hline 2013 & 32 & 6 & 0 & 2 & 1981 & 32 & 0 & 8 & 20 & 0 & 0 & 0 \\
\hline 2014 & 0 & 0 & 0 & 0 & 0 & 0 & 0 & 0 & 0 & 0 & 0 & 0 \\
\hline 2015 & 0 & 0 & 0 & 0 & 0 & 0 & 0 & 0 & 0 & 0 & 0 & 0 \\
\hline 2016 & 80 & 15 & 0 & 5 & 4900 & 80 & 0 & 20 & 0 & 0 & 0 & 0 \\
\hline 2017 & 0 & 0 & ' & 0 & 0 & 0 & 0 & 0 & 0 & 0 & 0 & 0 \\
\hline 2018 & 133 & 25 & 0 & 8 & 8124 & 133 & 0 & 33 & 60 & 0 & 0 & 0 \\
\hline 2019 & 115 & 22 & 0 & 7 & 7049 & 115 & 0 & 29 & 40 & 0 & 0 & 0 \\
\hline 2020 & 165 & $3 i$ & 0 & 10 & 10110 & 165 & 0 & 41 & 60 & 0 & 0 & 0 \\
\hline 2021 & 422 & 79 & 0 & 26 & 25836 & 422 & 0 & 105 & 140 & 0 & 0 & 0 \\
\hline 2022 & 452 & 85 & 0 & 28 & 27676 & 452 & 0 & 113 & 160 & 0 & 0 & 0 \\
\hline 2023 & 572 & 107 & 0 & 36 & 35052 & 572 & 0 & 143 & 180 & 0 & 0 & 0 \\
\hline 2024 & 917 & 172 & 0 & 57 & 56194 & 917 & 0 & 229 & 260 & 0 & 0 & 0 \\
\hline 2025 & 581 & 109 & 0 & 36 & 35577 & 581 & 0 & 145 & 160 & 0 & 0 & 0 \\
\hline 2026 & 304 & 57 & 0 & 19 & 18607 & 304 & 0 & 76 & 80 & 0 & 0 & 0 \\
\hline 2027 & 592 & 111 & 0 & 37 & 36285 & 592 & 0 & 148 & 160 & 0 & 0 & 0 \\
\hline 2028 & 373 & 70 & 0 & 23 & 22858 & 373 & 0 & 93 & 100 & 0 & 0 & 0 \\
\hline 2029 & 220 & 41 & 0 & 14 & 12460 & 220 & 0 & 55 & 60 & 0 & 0 & 0 \\
\hline 2030 & 147 & 28 & 0 & 9 & 9022 & 147 & 0 & 37 & 40 & 0 & 0 & 0 \\
\hline 2031 & 330 & 62 & 0 & 21 & 20232 & 330 & 0 & 83 & 80 & 0 & 0 & 0 \\
\hline 2032 & 88 & 16 & 0 & 5 & 5372 & 88 & 0 & 22 & 20 & 0 & 0 & 0 \\
\hline 2033 & 421 & 79 & 0 & 26 & 25810 & 421 & 0 & 105 & 120 & 0 & 0 & 0 \\
\hline 2034 & 627 & 118 & 0 & 39 & 38408 & 627 & 0 & 157 & 160 & 0 & 0 & 0 \\
\hline 2035 & 818 & 153 & 0 & 51 & 50089 & 818 & 0 & 204 & 200 & 0 & 0 & 0 \\
\hline 2036 & 818 & 153 & 0 & 51 & 50074 & 818 & 0 & 204 & 200 & 0 & 0 & 0 \\
\hline 2037 & 558 & 105 & 0 & 35 & 34181 & 558 & 0 & 140 & 140 & 0 & 0 & 0 \\
\hline 2038 & 525 & 98 & 0 & 33 & 32153 & 525 & 0 & 131 & 120 & 0 & 0 & 0 \\
\hline 2039 & 238 & 45 & . & 15 & 14590 & 238 & 0 & 60 & 60 & 0 & 0 & 0 \\
\hline 2040 & 419 & 78 & 0 & 26 & 25635 & 419 & 0 & 105 & 100 & 0 & 0 & 0 \\
\hline 2041 & 0 & 0 & 0 & 0 & 0 & 0 & 0 & 0 & 0 & .0 & 0 & 0 \\
\hline 2042 & 0 & 0 & 0 & 0 & 0 & 0 & 0 & 0 & 0 & 0 & 0 & 0 \\
\hline 2043 & 0 & 0 & 0 & 0 & 0 & 0 & 0 & 0 & 0 & 0 & 0 & 0 \\
\hline \multicolumn{13}{|l|}{ Under } \\
\hline const. & 945 & 177 & 0 & 59 & 57859 & 945 & 0 & 236 & 220 & 0 & 0 & 0 \\
\hline
\end{tabular}


TABLE B.2 (Cont.); Part A (Cont.)

\begin{tabular}{|c|c|c|c|c|c|c|c|c|c|c|c|c|}
\hline \multirow{2}{*}{$\begin{array}{c}\text { Year } \\
\text { avail- } \\
\text { able }\end{array}$} & \multicolumn{4}{|c|}{ 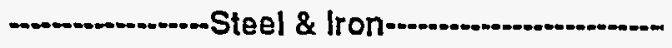 } & \multicolumn{4}{|c|}{ 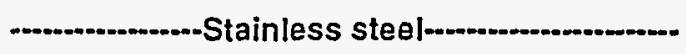 } & \multicolumn{4}{|c|}{ 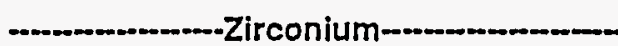 } \\
\hline & $\begin{array}{l}\text { Non- } \\
\text { active }\end{array}$ & $\begin{array}{c}\text { Clean- } \\
\text { able }\end{array}$ & $\begin{array}{l}\text { Non- } \\
\text { clean- } \\
\text { able }\end{array}$ & $\begin{array}{l}\text { Acti: } \\
\text { vated }\end{array}$ & $\begin{array}{l}\text { Non- } \\
\text { active }\end{array}$ & $\begin{array}{l}\text { Clean- } \\
\text { able }\end{array}$ & $\begin{array}{l}\text { Non- } \\
\text { clean- } \\
\text { able }\end{array}$ & $\begin{array}{l}\text { Acti- } \\
\text { vated }\end{array}$ & $\begin{array}{l}\text { Non- } \\
\text { active }\end{array}$ & $\begin{array}{l}\text { Clean- } \\
\text { able }\end{array}$ & $\begin{array}{l}\text { Non- } \\
\text { clean- } \\
\text { able }\end{array}$ & $\begin{array}{l}\text { Acti- } \\
\text { vated }\end{array}$ \\
\hline 2010 & 1710 & 2291 & 0 & 1197 & 0 & 205 & 0 & 229 & 0 & 0 & 0 & 0 \\
\hline 2011 & 2514 & 2032 & 0 & 892 & 0 & 273 & 91 & 203 & 0 & 0 & 0 & 0 \\
\hline 2012 & 0 & 0 & 0 & 0 & 0 & 0 & 0 & 0 & 0 & 0 & 0 & 0 \\
\hline 2013 & 3351 & 2708 & 0 & 1188 & 0 & 364 & 121 & 271 & 0 & 0 & 0 & 0 \\
\hline 2014 & 0 & 0 & 0 & 0 & 0 & 0 & 0 & 0 & 0 & 0 & 0 & 0 \\
\hline 2015 & 0 & 0 & 0 & 0 & 0 & 0 & 0 & 0 & 0 & 0 & 0 & 0 \\
\hline 2016 & 19248 & 7156 & 69 & 581 & 0 & 2600 & 0 & 406 & 0 & 0 & 0 & 100 \\
\hline 2017 & 0 & 0 & 0 & 0 & 0 & 0 & 0 & 0 & 0 & 0 & 0 & 0 \\
\hline 2018 & 13635 & 10843 & 0 & 4874 & 110 & 1910 & 459 & 1654 & 0 & 0 & 0 & 25 \\
\hline 2019 & 7193 & 9638 & 0 & 5035 & 0 & 863 & 0 & 964 & 0 & 0 & 0 & 0 \\
\hline 2020 & 14336 & 13824 & 0 & 6538 & 0 & 1605 & 367 & 1382 & 0 & 0 & 0 & 0 \\
\hline 2021 & 35869 & 34348 & 0 & 16767 & 405 & 5605 & 764 & 5532 & 0 & 0 & 0 & 50 \\
\hline 2022 & 41893 & 37051 & 0 & 17389 & 328 & 5908 . & 1162 & 5401 & 0 & 0 & 0 & 50 \\
\hline 2023 & 53576 & 47438 & 0 & 21971 & 203 & 6703 & 1572 & 5792 & 0 & 0 & 0 & 25 \\
\hline 2024 & 79703 & 76837 & 0 & 36333 & 0 & 8920 & 2039 & 7684 & 0 & 0 & 0 & 0 \\
\hline 2025 & 48607 & 48646 & 0 & 23318 & 0 & 5478 & 1122 & 4865 & 0 & 0 & 0 & 0 \\
\hline 2026 & 3.1480 & 25443 & 0 & 11164 & 0 & 3418 & 1139 & 2544 & 0 & 0 & 0 & 0 \\
\hline 2027 & 54671 & 48336 & 0 & 22824 & 530 & 8110 & 1475 & 7573 & 0 & 0 & 0 & 50 \\
\hline 2028 & 38408 & 30616 & 0 & 13715 & 265 & 5203 & 1308. & 4432 & 0 & 0 & 0 & 25 \\
\hline 2029 & 24244 & 16695 & 0 & 7702 & 325 & 3227 & 183 & 2641 & 0 & 0 & 0 & 25 \\
\hline 2030 & 15264 & 12337 & 0 & 5413 & 0 & 1657 & 552 & 1234 & 0 & 0 & 0 & 0 \\
\hline 2031 & 34230 & 27664 & 0 & 12139 & 0 & 3716 & 1239 & 2766 & 0 & 0 & 0 & 0 \\
\hline 2032 & 9089 & 7346 & 0 & 3223 & 0 & 987 & 329 & 735 & 0 & 0 & 0 & 0 \\
\hline 2033 & 39636 & 33673 & 0 & 16057 & 670 & 6976 & 1043 & 6833 & 0 & 0 & 0 & 75 \\
\hline 2034 & 54255 & 51351 & 0 & 24788 & 483 & 7954 & 1251 & 7635 & 0 & 0 & 0 & 50 \\
\hline 2035 & 77286 & 67310 & 0 & 31239 & 488 & 10417 & 2263 & 9257 & 0 & 0 & 0 & 50 \\
\hline 2036 & 74313 & 67289 & 0 & 31732 & 488 & 10146 & 1993 & 9255 . & 0 & 0 & 0 & 50 \\
\hline 2037 & 50688 & 46060 & 0 & 21676 & 280 & 6716 & 1371 & 6056 & 0 & 0 & 0 & 25 \\
\hline 2038 & 47481 & 43964 & 0 & 20469 & 0 & 5275 & 1338 & 4396 & 0 & 0 & 0 & 0 \\
\hline 2039 & 22205 & 19949 & 0 & 9176 & 0 & 2454 & 667 & 1995 & 0. & 0 & 0 & 0 \\
\hline 2040 & 39381 & 33652 & 0 & 15961 & 580 & 6598 & 1059 & 6365 & 0 & 0 & 0 & 50 \\
\hline 2041 & 0 & 0 & 0 & 0 & 0 & 0 & 0 & 0 & 0 & 0 & 0 & 0 \\
\hline 2042 & 0 & 0 & 0 & 0 & 0 & 0 & 0 & 0 & 0 & 0 & 0 & 0 \\
\hline 2043 & 0 & 0 & 0 & 0 & 0 & 0 & 0 & 0 & 0 & 0 & 0 & 0 \\
\hline \multicolumn{13}{|l|}{ Under } \\
\hline const. & 91104 & 77713 & 0 & 35771 & 580 & 12261 & 2777 & 10771 & 0 & 0 & 0 & 50 \\
\hline
\end{tabular}


TABLE B.2 (Cont.); Part B: Start-Up Plus 100 Years

\begin{tabular}{|c|c|c|c|c|c|c|c|c|c|c|c|c|}
\hline \multirow{2}{*}{$\begin{array}{l}\text { Year } \\
\text { avall- } \\
\text { able }\end{array}$} & \multicolumn{4}{|c|}{ 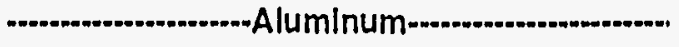 } & \multicolumn{4}{|c|}{ 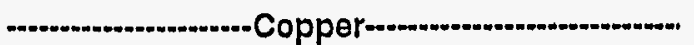 } & \multicolumn{4}{|c|}{ nead } \\
\hline & $\begin{array}{l}\text { Non- } \\
\text { active }\end{array}$ & $\begin{array}{l}\text { Clean- } \\
\text { able }\end{array}$ & $\begin{array}{l}\text { Non- } \\
\text { clean- } \\
\text { able }\end{array}$ & $\begin{array}{l}\text { Actl- } \\
\text { vated }\end{array}$ & $\begin{array}{l}\text { Non- } \\
\text { active }\end{array}$ & $\begin{array}{l}\text { Clean- } \\
\text { able }\end{array}$ & $\begin{array}{l}\text { Non- } \\
\text { clean- } \\
\text { able }\end{array}$ & $\begin{array}{l}\text { Actl- } \\
\text { vated }\end{array}$ & $\begin{array}{l}\text { Non- } \\
\text { actlive }\end{array}$ & $\begin{array}{l}\text { Clean- } \\
\text { able }\end{array}$ & $\begin{array}{l}\text { Non- } \\
\text { clean- } \\
\text { able }\end{array}$ & $\begin{array}{l}\text { Acti- } \\
\text { vated }\end{array}$ \\
\hline 2060 & 31 & 3 & 0 & 1 & 1689 & 14 & 0 & 7 & 20 & 0 & 0 & 0 \\
\hline 2061 & 27 & 2 & 0 & 1 & 1498 & 12 & 0 & 6 & 20 & 0 & 0 & 0 \\
\hline 2062 & 0 & 0 & 0 & 0 & 0 & 0 & 0 & 0 & 0 & 0 & 0 & 0 \\
\hline 2063 & 36 & 3 & 0 & 1 & 1997 & 16 & 0 & 8 & 20 & 0 & 0 & 0 \\
\hline 2064 & 0 & 0 & 0 & 0 & 0 & 0 & 0 & 0 & 0 & 0 & 0 & 0 \\
\hline 2065 & 0 & 0 & 0 & 0 & 0 & 0 & 0 & 0 & 0 & 0 & 0 & 0 \\
\hline 2066 & 90 & 8 & 0 & 3 & 4940 & 40 & 0 & 20 & 0 & 0 & 0 & 0 \\
\hline 2067 & 0 & 0 & 0 & 0 & 0 & 0 & 0 & 0 & 0 & 0 & 0 & 0 \\
\hline 2068 & 149 & 12 & 0 & 4 & 8190 & 66 & 0 & 33 & 60 & 0 & 0 & 0 \\
\hline 2069 & 129 & 11 & 0 & 4 & 7106 & 58 & 0 & 29 & 40 & 0 & 0 & 0 \\
\hline 2070 & 186 & 15 & 0 & 5 & 10193 & 83 & 0 & 41 & 60 & 0 & 0 & 0 \\
\hline 2071 & 475 & 40 & 0 & 13 & 26047 & 211 & 0 & 105 & 140 & 0 & 0 & 0 \\
\hline 2072 & 508 & 42 & 0 & 14 & 27902 & 226 & 0 & 113 & 160 & 0 & 0 & 0 \\
\hline 2073 & 644 & 54 & 0 & 18 & 35338 & 286 & 0 & 143 & 180 & 0 & 0 & 0 \\
\hline 2074 & 1032 & 86 & 0 & 29 & 56653 & 459 & 0 & 229 & 260 & 0 & 0 & 0 \\
\hline 2075 & 653 & 54 & 0 & 18 & 35867 & 290 & 0 & 145 & 160 & 0 & 0 & 0 \\
\hline 2076 & 342 & 28 & 0 & 9 & 18759 & 152 & 0 & 76 & 80 & 0 & 0 & 0 \\
\hline 2077 & 666 & 56 & 0 & 19 & 36582 & 296 & 0 & 148 & 160 & 0 & 0 & 0 \\
\hline 2078 & 420 & 35 & 0 & 12 & 23045 & 187 & 0 & 93 & 100 & 0 & 0 & 0 \\
\hline 2079 & 247 & 21 & 0 & 7 & 12570 & 110 & 0 & 55 & 60 & 0 & 0 & 0 \\
\hline 2080 & 166 & 14 & 0 & 5 & 9096 & 74 & 0 & 37 & 40 & 0 & 0 & 0 \\
\hline 2081 & 372 & 31 & 0 & 10 & 20397 & 165 & 0 & 83 & 80 & 0 & 0 & 0 \\
\hline 2082 & 99 & 8 & 0 & 3 & 5416 & 44 & 0 & 22 & 20 & 0 & 0 & 0 \\
\hline 2083 & 474 & 40 & 0 & 13 & 26020 & 211 & 0 & 105 & 120 & 0 & 0 & 0 \\
\hline 2084 & 705 & 59 & 0 & 20 & 38722 & 314 & 0 & 157 & 160 & 0 & 0 & 0 \\
\hline 2085 & 920 & 77 & 0 & 26 & 50497 & 409 & 0 & 204 & 200 & 0 & 0 & 0 \\
\hline 2086 & 920 & 77 & 0 & 26 & 50483 & 409 & 0 & 204 & 200 & 0 & 0 & 0 \\
\hline 2087 & 628 & 52 & 0 & 17 & 34460 & 279 & 0 & 140 & 140 & 0 & 0 & 0 \\
\hline 2088 & 591 & 49 & 0 & 16 & 32415 & 262 & 0 & 131 & 120 & 0 & 0 & 0 \\
\hline 2089 & 268 & 22 & 0 & 7 & 14709 & 119 & 0 & 60 & 60 & 0 & 0 & 0 \\
\hline 2090 & 471 & 39 & 0 & 13 & 25844 & 209 & $0^{\circ}$ & 105 & 100 & 0 & 0 & 0 \\
\hline 2091 & 0 & 0 & 0 & 0 & 0 & 0 & 0 & 0 & 0 & 0 & 0 & 0 \\
\hline 2092 & 0 & 0 & 0 & 0 & 0 & 0 & 0 & 0 & 0 & 0 & 0 & 0 \\
\hline 2093 & 0 & 0 & 0 & 0 & 0 & 0 & 0 & 0 & 0 & 0 & 0 & 0 \\
\hline Under & & & & & & & & & & & & \\
\hline const. & 1063 & 89 & 0 & 30 & 58331 & 472 & 0 & 236 & 220 & 0 & 0 & 0 \\
\hline
\end{tabular}


TABLE B.2 (Cont.); Part B (Cont.)

\begin{tabular}{|c|c|c|c|c|c|c|c|c|c|c|c|c|}
\hline \multirow{2}{*}{$\begin{array}{l}\text { Year } \\
\text { avail-- } \\
\text { able }\end{array}$} & \multicolumn{4}{|c|}{ 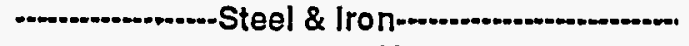 } & \multicolumn{4}{|c|}{ 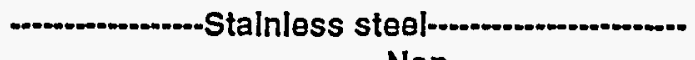 } & \multicolumn{4}{|c|}{ 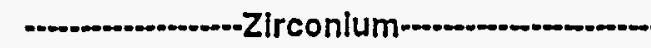 } \\
\hline & $\begin{array}{l}\text { Non- } \\
\text { actlve }\end{array}$ & $\begin{array}{c}\text { Clean- } \\
\text { able }\end{array}$ & $\begin{array}{l}\text { Non- } \\
\text { clean- } \\
\text { able }\end{array}$ & $\begin{array}{l}\text { Actl- } \\
\text { vated }\end{array}$ & $\begin{array}{l}\text { Non- } \\
\text { active }\end{array}$ & $\begin{array}{c}\text { Clean- } \\
\text { able }\end{array}$ & $\begin{array}{l}\text { Non: } \\
\text { clean- } \\
\text { able }\end{array}$ & $\begin{array}{l}\text { Acti- } \\
\text { vated }\end{array}$ & $\begin{array}{l}\text { Non- } \\
\text { actlve }\end{array}$ & $\begin{array}{c}\text { Clean- } \\
\text { able }\end{array}$ & $\begin{array}{l}\text { Non- } \\
\text { clean- } \\
\text { able }\end{array}$ & $\begin{array}{l}\text { Actl- } \\
\text { vated }\end{array}$ \\
\hline 2060 & 3454 & 1146 & 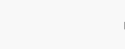 & 598 & 103 & 103 & 0 & 229 & 0 & 0 & c & 0 \\
\hline 2061 & 3976 & 1016 & 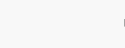 & 446 & 182 & 136 & 45 & 203 & 0 & 0 & $\mathrm{c}$ & 0 \\
\hline 2062 & 0 & 0 & 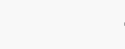 & 0 & 0 & 0 & 0 & 0 & 0 & 0 & c & 0 \\
\hline 2063 & 5299 & 1354 & 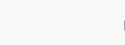 & 594 & 243 & 182 & 61 & 271 & 0 & 0 & 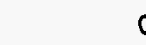 & 0 \\
\hline 2064 & 0 & $\cdot 0$ & & 0 & 0 & 0 & 0 & 0 & 0 & 0 & $c$ & 0 \\
\hline 2065 & 0 & 0 & - & 0 & 0 & 0 & 0 & 0 & 0. & 0 & c & 0 \\
\hline 2066 & 23151 & 3578 & 3 & 291 & 1300 & 1300 & 0 & 406 & 50 & 0 & $c$ & 50 \\
\hline 2067 & 0 & 0 & 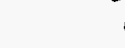 & 0 & 0 & 0 & 0 & 0 & 0 & 0 & c & 0 \\
\hline 2068 & 21493 & 5421 & 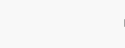 & 2437 & 1295 & 955 & 230 & 1654 & 13 & 0 & 0 & 13 \\
\hline 2069 & 14529 & 4819 & 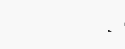 & 2517 & 432 & 432 & 0 & 964 & 0 & 0 & 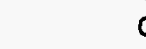 & 0 \\
\hline 2070 & 24517 & 6912 & 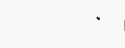 & 3269 & 986 & 802 & 183 & 1382 & 0 & 0 & $c$ & 0 \\
\hline 2071 & 61426 & 17174 & & 8384 & 3590 & 2803 & 382 & 5532 & 25 & 0 & c & 25 \\
\hline 2072 & 69113 & 18526 & & 8695 & 3863 & 2954 & 581 & 5401 & 25 & 0 & $c$ & 25 \\
\hline 2073 & 88280 & 23719 & & 10985 & 4341 & 3352 & 786 & 5792 & 13 & 0 & c & 13 \\
\hline 2074 & 136288 & 38419 & 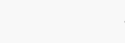 & 18166 & 5480 & 4460 & 1020 & 7684 & 0 & 0 & $c$ & 0 \\
\hline 2075 & 84588 & 24323 & 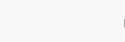 & 11659 & 3300 & 2739 & 561 & 4865 & 0. & 0 & $c$ & .0 \\
\hline 2076 & 49784 & 12721 & 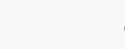 & 5582 & 2278 & 1709 & 570 & 2544 & 0 & 0 & 0 & 0 \\
\hline 2077 & 90251 & 24168 & 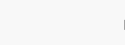 & 11412 & 5322 & 4055 & 737 & 7573 & 25 & 0 & 0 & 25 \\
\hline 2078 & 60573 & 15308 & & 6857 & 3521 & 2602 & 654 & 4432 & 13 & 0 & 0 & 13 \\
\hline 2079 & 36443 & 8347 & . & 3851 & 2030 & 1613 & 91 & 2641 & 13 & 0 & 0 & 13 \\
\hline 2080 & 24140 & 6168 & & 2707 & 1105 & 829 & 276 & 1234 & 0 & 0 & 0 & 0 \\
\hline 2081 & 54132 & 13832 & & 6070 & 2477 & 1858 & 619 & 2766 & 0 & 0 & . & 0 \\
\hline 2082 & 14374 & 3673 & & 1612 & 658 & 493 & 164 & 735 & 0 & 0 & 0 & 0 \\
\hline 2083 & 64501 & 16837 & . & 8029 & 4679 & 3488 & 521 & 6833 & 38 & 0 & 0 & 38 \\
\hline 2084 & 92324 & 25676 & 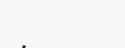 & 12394 & 5086 & 3977 & 625 & 7635 & 25 & 0 & 0 & 25 \\
\hline 2085 & 126560 & 33655 & 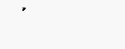 & 15619 & 6828 & 5209 & 1131 & 9257 & 25 & 0 & . & 25 \\
\hline 2086 & 123824 & 33645 & 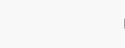 & 15866 & 66558 & 5073 & .997 & 9255 & 25 & 0 & 0 & 25 \\
\hline 2087 & 84556 & 23030 & & 10838 & 4323 & 3358 & 685 & 6056 & 13 & 0 & 0 & 13 \\
\hline 2088 & 79698 & 21982 & & 10234 & 3306 & 2637 & 669 & 4396 & 0 & 0 & 0 & 0 \\
\hline 2089 & 36767 & 9975 & 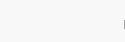 & 4588 & 1560 & 1227 & 334 & 1995 & 0 & 0 & 0 & 0 \\
\hline 2090 & 64187 & 16826 & 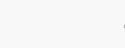 & 7981 & 4408 & 3299 & 529 & 6365 & 25 & 0 & 0 & 25 \\
\hline 2091 & 0 & 0 & & 0 & 0 & 0 & 0 & 0 & 0 & 0 & 0 & 0 \\
\hline 2092 & 0 & 0 & & 0 & 0 & 0 & 0 & 0 & 0 & 0 & 0 & 0 \\
\hline 2093 & 0 & 0 & 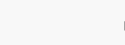 & 0 & 0 & 0 & 0 & 0 & 0 & 0 & 0 & 0 \\
\hline Under & & & & & & & & & & & & \\
\hline const. & 147846 & 38857 & . & 17886 & 8099 & 6131 & 1388 & 10771 & 25 & 0 & 0 & 25 \\
\hline
\end{tabular}




\begin{tabular}{|c|c|c|c|}
\hline 0 & 0 & 0 & 022 \\
\hline 0 & 0 & 0 & 0 \\
\hline 0 & 0 & 0 & 0 \\
\hline 0 & 0 & 0 & 0 \\
\hline 0 & 0 & 0 & 001 \\
\hline 0 & 0 & 0 & 09 \\
\hline 0 & 0 & 0 & 021 \\
\hline 0 & 0 & 0 & Op1 \\
\hline 0 & 0 & 0 & 002 \\
\hline 0 & 0 & 0 & $002^{\circ}$ \\
\hline 0 & 0 & 0 & 091 \\
\hline 0 & 0 & 0 & 021 \\
\hline 0 & 0 & 0 & $0 z$ \\
\hline 0 & 0 & 0 & 08 \\
\hline 0 & 0 & 0 & ob \\
\hline 0 & 0 & 0 & .09 \\
\hline 0 & 0 & 0 & ool \\
\hline 0 & 0 & 0 & 091 \\
\hline$\underset{4}{\sharp}$ & 0 & 0 & 08 \\
\hline 0 & 0 & 0 & 091 \\
\hline 0 & 0 & 0 & 092 \\
\hline 0 & 0 & 0 & 081 \\
\hline 0 & 0 & 0 & 091 \\
\hline 0 & 0 & 0 & opt \\
\hline 0 & 0 & 0 & 09 \\
\hline 0 & 0 & 0 & ot \\
\hline 0 & 0 & 0 & 09 \\
\hline 0 & 0 & 0 & 0 \\
\hline 0 & 0 & 0 & 0 \\
\hline 0 & 0 & 0 & 0 \\
\hline 0 & 0 & 0 & 0 \\
\hline 0 & 0 & 0 & 02 \\
\hline 0 & 0 & 0 & 0 \\
\hline 0 & 0 & 0 & 02 \\
\hline 0 & 0 & 0 & 02 \\
\hline pөjen & elge & ө|qe & oxltoe \\
\hline-1108 & $-4 e \theta j 0$ & $-40 e 10$ & $-U O N$ \\
\hline & $-4 O N$ & & \\
\hline
\end{tabular}

\begin{tabular}{|c|c|c|c|}
\hline 69 & 0 & 982 & L9S8S \\
\hline 0 & 0 & 0 & 0 \\
\hline 0 & 0 & 0 & 0 \\
\hline 0 & 0 & 0 & 0 \\
\hline 92 & 0 & sol & $6 \nabla 692$ \\
\hline st & 0 & 09 & $89 \angle \nabla t$ \\
\hline$\varepsilon \varepsilon$ & $\therefore \quad 0$ & $|\varepsilon|$ & $9 ๑ 92 \varepsilon$ \\
\hline SE & 0 & 001 & $66 S t \varepsilon$ \\
\hline IS & $\therefore 0$ & $D 02$ & $\angle 8909^{\circ}$ \\
\hline IS & $\cdot 0$ & +02 & $20 \angle 0 S$ \\
\hline $6 \varepsilon$ & .0 & LSt & $6 \angle 88 \varepsilon$ \\
\hline 92 & . 0 & SOL & 92192 \\
\hline$s$ &.$\quad .0$ & $2 Z$ & $8 \varepsilon b 9$ \\
\hline 12 & 0 & $\varepsilon \dot{8}$ & $08+02$ \\
\hline 6 & 0 & $\angle \varepsilon$ & $\varepsilon \varepsilon\llcorner 6$ \\
\hline t) & 0 & S9 & s292! \\
\hline$\varepsilon 己$ & 0 & 86 & 8Eเยट \\
\hline$\angle \varepsilon$ & 0 & 801 & $0 \varepsilon \angle 9 \varepsilon$ \\
\hline 61 & 0 & $9 L$ & . 98881 \\
\hline $9 \varepsilon$ & 0 & spt & 2l09ع \\
\hline$\angle S$ & 0 & 622 & $\varepsilon 8899$ \\
\hline $9 \varepsilon$ & 0 & $\varepsilon p \downarrow$ & $18+98$ \\
\hline 82 & 0 & Et) & S1082 \\
\hline 92 & 0 & SOL & 29192 \\
\hline Or & 0 & 10 & ๑८20। \\
\hline$L$ & 0 & 62 & $S \varepsilon+L$ \\
\hline 8 & 0 & $\varepsilon \varepsilon$ & D2Z8 \\
\hline 0 & 0 & 0 & 0 \\
\hline$s$ & 0 & 02 & 0968 \\
\hline 0 & 0 & 0 & 0 \\
\hline 0 & 0 & 0 & 0 \\
\hline 2 & 0 & 8 & 9002 \\
\hline 0 & 0 & 0 & 0 \\
\hline 2 & 0 & 9 & DOSL \\
\hline 2 & 0 & $L$ & 9691 \\
\hline рөзеn & ө|qe & olqe & ox!loe \\
\hline$-120 \forall$ & $\begin{array}{l}\text {-UEelo } \\
\text { unoN }\end{array}$ & -4eelo & $-L O N$ \\
\hline
\end{tabular}

\begin{tabular}{|c|c|c|c|}
\hline St & 0 & $\Delta t$ & 22.1 \\
\hline 0 & 0 & 0 & 0 \\
\hline 0 & 0 & 0 & 0 \\
\hline 0 & 0 & 0 & 0 \\
\hline$L$ & 0 & 02 & $\angle 6 b$ \\
\hline$\downarrow$ & 0 & H & $\varepsilon 82$ \\
\hline 8 & 0 & 92 & ८ट૭ \\
\hline 6 & 0 & 92 & $\varepsilon 99$ \\
\hline$\varepsilon$. & 0 & $8 \varepsilon$ & $1<6$ \\
\hline$\varepsilon l$ & 0 & $8 \varepsilon$ & $1<66$ \\
\hline Ol & 0 & 62 & $s+L$ \\
\hline$L$ & 0 & $O Z$ & $00 s$ \\
\hline 1 & 0 & $b$ & tol \\
\hline s & 0 & st & $26 \varepsilon^{\circ}$ \\
\hline 2 & 0 & $L$ & SLI \\
\hline$\varepsilon$ & 0 & 01 & 192 \\
\hline 9 & 0 & $\angle 1$ & Ett \\
\hline 6 & 0 & 82 & $80 L$ \\
\hline g. & 0 & $\$ b$ & $19 \varepsilon$ \\
\hline 6 & 0 & $\angle Z$ & 069 \\
\hline+1 & 0 & $\varepsilon b$ & 6801 \\
\hline 6 & 0 & $\angle Z$ & 089 \\
\hline$L$ & 0 & 12 & $\angle \varepsilon S$ \\
\hline$L$ & 0 & $0 Z$ & 109 \\
\hline$\varepsilon$ & 0 & 8 & 961 \\
\hline 2 & 0 & s & $\angle \varepsilon t$ \\
\hline 2 & 0 & 9 & 891 \\
\hline 0 & 0 & 0 & 0 \\
\hline 1 & 0 & $\nabla$ & s6 \\
\hline 0 & 0 & 0 & 0 \\
\hline 0 & 0 & 0 & 0 \\
\hline 1 & 0 & 2 & $8 \varepsilon$ \\
\hline 0 & 0 & 0 & 0 \\
\hline 0 & 0 & 1 & 62 \\
\hline 0 & 0 & 1 & 乙E \\
\hline рө|ел & өlqe & өाqe & өヘlfoe \\
\hline \multirow[t]{2}{*}{$-110 \forall$} & -UE⿰ן三人 & -LBelo & $-H O N$ \\
\hline & $-4 O N$ & & \\
\hline
\end{tabular}

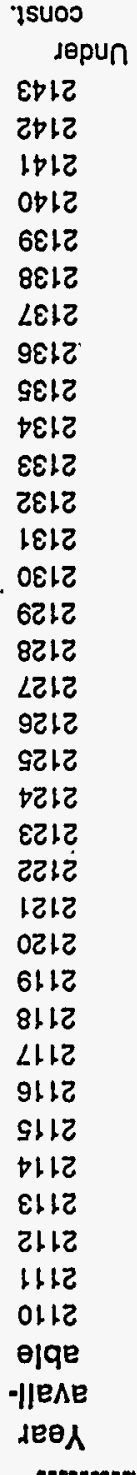


TABLE B.2 (Cont.); Part C (Cont.)

\begin{tabular}{|c|c|c|c|c|c|c|c|c|c|c|c|c|}
\hline - mos. & & -Steel \& & on-............... & C................. & .................... & -Stailnles & steol-............ & ...................... & & ...-Zlrcor & $m \cdots$ & m....... \\
\hline $\begin{array}{c}\text { Year } \\
\text { avall- } \\
\text { able }\end{array}$ & $\begin{array}{l}\text { Non- } \\
\text { actlve }\end{array}$ & $\begin{array}{c}\text { Clean- } \\
\text { ablo }\end{array}$ & $\begin{array}{l}\text { Non- } \\
\text { clean- } \\
\text { able }\end{array}$ & $\begin{array}{l}\text { Actl- } \\
\text { vated }\end{array}$ & $\begin{array}{l}\text { Non- } \\
\text { actlve }\end{array}$ & $\begin{array}{l}\text { Clean- } \\
\text { able }\end{array}$ & $\begin{array}{l}\text { Non- } \\
\text { clean- } \\
\text { able }\end{array}$ & $\begin{array}{l}\text { Actl- } \\
\text { vated }\end{array}$ & $\begin{array}{l}\text { Non- } \\
\text { actlve }\end{array}$ & $\begin{array}{c}\text { Clean- } \\
\text { able }\end{array}$ & $\begin{array}{l}\text { Non- } \\
\text { clean- } \\
\text { able }\end{array}$ & $\begin{array}{l}\text { Acti- } \\
\text { vated }\end{array}$ \\
\hline 2110 & 4147 & 573 & 0 & 479 & 154 & 51 & 0 & 0 & 0 & 0 & 0 & 0 \\
\hline 2111 & 4573 & 508 & 0 & 357 & 273 & 68 & 23 & 0 & 0 & 0 & 0 & 0 \\
\hline 2112 & 0 & 0 & 0 & 0. & 0 & 0 & 0 & 0 & 0 & 0 & 0 & 0 \\
\hline 2113 & 6095 & 677 & 0 & 475 & 364 & 91 & 30 & 0 & 0 & 0 & 0 & 0 \\
\hline 2114 & 0 & 0 & 0 & 0 & 0 & 0 & 0 & 0 & 0 & 0 & 0 & 0 \\
\hline 2115 & 0 & 0 & 0 & 0 & 0 & 0 & 0 & 0 & 0 & 0 & 0 & . \\
\hline 2116 & 25015 & . 1789 & 17 & 232 & 1950 & 650 & 0 & 0 & .75 & 0 & 0 & 25 \\
\hline 2117 & 0 & 0 & 0 & 0 & 0 & 0 & 0 & 0 & 0 & 0 & 0 & 0 \\
\hline 2118 & 24691 & 2711 & 0 & 1950 & 1887 & 477 & 115 & 110 & 19 & 0 & 0 & 6 \\
\hline 2119 & 17442 & 2410 & 0 & 2014 & 647 & 216 & 0 & 0 & 0 & 0 & 0 & 0 \\
\hline 2120 & 28627 & 3456 & 0 & 2615 & 1478 & 401 & 92 & 0 & 0 & 0 & 0 & 0 \\
\hline 2121 & 71689 & 8587 & 0 & 6707 & 5182 & 1401 & 191 & 405 & 38 & 0 & 0 & 13 \\
\hline 2122 & 80115 & 9263 & 0 & 6956 & 5630 & 1477 & 290 & 328 & 38 & 0 & 0 & 13 \\
\hline 2123 & 102337 & 11860 & 0 & 8788 & 6410 & 1676 & 393 & 203 & 19 & $0^{\circ}$ & 0 & 6 \\
\hline 2124 & 159131 & 19209 & 0 & 14533 & 8219 & 2230 & 510 & 0 & 0 & 0 & 0 & 0 \\
\hline 2125 & 99082 & 12161 & 0 & 9327 & 4950 & 1370 & 280 & 0 & 0 & 0 & 0 & 0 \\
\hline 2126 & 57261 & 6361 & 0 & 4466 & 3418 & 854 & 285 & 0 & 0 & 0 & 0 & 0 \\
\hline 2127 & 104618 & 12084 & 0 & 9130 & 7718 & 2027 & 369 & 530 & 38 & 0 & 0 & 13 \\
\hline 2128 & 69598 & 7654 & 0 & 5486 & 5148 & 1301 & 327 & 265 & 19 & 0 & 0 & 6 \\
\hline 2129 & 41387 & 4174 & 0 & 3081 & 2882 & 807 & 46 & 325 & 19 & 0 & 0 & 6 \\
\hline 2130 & 27765 & 3084 & 0 & 2165 & 1657 & 414 & 138 & 0 & 0 & 0 & 0 & 0 \\
\hline 2131 & 62262 & 6916 & 0 & 4856. & 3716 & 929 & 310 & 0 & 0 & 0 & 0 & 0 \\
\hline 2132 & 16532 & 1836 & 0 & $1289^{\circ}$ & 987 & 247 & 82 & 0 & 0 & 0 & 0 & 0 \\
\hline 2133 & 74525 & 8418 & 0 & 6423 & 6684 & 1744 & 261 & 670 & 56 & 0 & 0 & 19 \\
\hline 2134 & 107641 & 12838 & 0 & 9915 & 7387 & 1988 & 313 & 483 & 38 & 0 & 0 & 13 \\
\hline 2135 & 146511 & 16827 & 0 & 12496 & 9998 & 2604 & 566 & 488 & 38 & 0 & 0 & 13 \\
\hline 2136 & 143819 & 16822 & 0 & 12693 & 9592 & 2536 & 498 & 488 & 38 & 0 & 0 & 13 \\
\hline$\quad 2137$ & 98239 & 11515 & 0 & 8670 & 6345 & 1679 & 343 & 280 & 19 & 0 & 0 & 6 \\
\hline 2138 & 92736 & 10991 & .0 & 8188 & 4960 & 1319 & 334 & 0 & 0 & 0 & 0 & . \\
\hline 2139 & 42672 & 4987 & 0 & 3670 & 2341 & 613 & 167 & 0 & 0 & 0 & 0 & 0 \\
\hline 2140 & 74197 & 8413 & 0 & 6384 & 6322 & 1649 & 265 & 580 & 38 & 0 & 0 & 13 \\
\hline 2141 & 0 & 0 & 0 & 0 & 0 & 0 & .0 & 0 & 0 & 0 & 0 & 0 \\
\hline 2142 & 0 & 0 & 0 & 0 & 0 & 0 & 0 & 0 & 0 & 0 & 0 & 0 \\
\hline 2143 & 0 & 0 & 0 & 0 & 0 & 0 & 0 & 0 & 0 & 0 & 0 & 0 \\
\hline \multicolumn{13}{|l|}{ Under } \\
\hline const. & 170851 & 19428 & 0 & 14308 & 11859 & 3065 & 694 & 580 & 38 & 0 & 0 & 13 \\
\hline
\end{tabular}


TABLE B.3 Annual Increments in Scrap-Metal Inventory from Nuclear Power Plants for Europe (includes eastern Europe: Bulgaria, Czech Republic, Finland, Hungary, Poland, Romania, Slovakia, and Slovenia); Part A: Start-Up Plus 50 Years

\begin{tabular}{|c|c|c|c|c|c|c|c|c|c|c|c|c|}
\hline \multirow{3}{*}{$\begin{array}{l}\text { Year } \\
\text { avall- } \\
\text { able } \\
2010\end{array}$} & \multicolumn{4}{|c|}{ 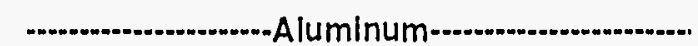 } & \multicolumn{4}{|c|}{ r................................... } & \multicolumn{4}{|c|}{ 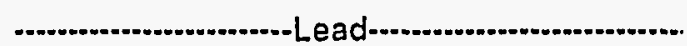 } \\
\hline & $\begin{array}{l}\text { Non- } \\
\text { active }\end{array}$ & $\begin{array}{l}\text { Clean. } \\
\text { able }\end{array}$ & $\begin{array}{c}\text { Non- } \\
\text { clean- } \\
\text { able }\end{array}$ & $\begin{array}{l}\text { Actl- } \\
\text { vated }\end{array}$ & $\begin{array}{l}\text { Non- } \\
\text { actlve }\end{array}$ & $\begin{array}{l}\text { Clean- } \\
\text { able }\end{array}$ & $\begin{array}{l}\text { Non- } \\
\text { clean- } \\
\text { able }\end{array}$ & $\begin{array}{l}\text { Actl- } \\
\text { vated }\end{array}$ & $\begin{array}{l}\text { Non- } \\
\text { active }\end{array}$ & $\begin{array}{l}\text { Clean- } \\
\text { able }\end{array}$ & $\begin{array}{l}\text { Non- } \\
\text { clean- } \\
\text { able }\end{array}$ & $\begin{array}{l}\text { Actl- } \\
\text { vated }\end{array}$ \\
\hline & 0 & 0 & 0 & 0 & 0 & 0 & 0 & 0 & 0 & 0 & 0 & 0 \\
\hline 2011 & 0 & 0 & 0 & 0 & 0 & 0 & 0 & 0 & 0 & 0 & 0 & 0 \\
\hline 2012 & 5 & 1 & 0 & 0 & 10298 & 255 & 0 & 251 & 20 & 0 & 0 & 0 \\
\hline 2013. & 0 & 0 & 0 & 0 & 0 & 0 & 0 & 0 & 0 & 0 & 0 & 0 \\
\hline 2014 & 23 & 4 & 0 & 1 & 5683 & 123 & 0 & 106 & 20 & 0 & 0 & 0 \\
\hline 2015 & 33 & 6 & 0 & 2 & 20696 & 433 & 0 & 408 & 20 & 0 & 0 & 0 \\
\hline 2016 & 80 & 15 & 0 & 5 & 5800 & 130 & 0 & 70 & 20 & 0 & 0 & 0 \\
\hline 2017 & 147 & 28 & 0 & 9 & 7997 & 147 & 0 & 37 & 60 & 0 & 0 & 0 \\
\hline 2018 & 112 & 21 & 0 & 7 & 5876 & 112 & 0 & 28 & 40 & 0 & 0 & 0 \\
\hline 2019 & 142 & 27 & 0 & 9 & 7689 & 142 & 0 & 35 & 60 & 0 & 0 & 0 \\
\hline 2020 & 0 & 0 & 0 & 0 & 0 & 0 & 0 & 0 & 0 & 0 & 0 & 0 \\
\hline 2021 & 206 & 39 & 0 & 13 & 10635 & 206 & 0 & 52 & 60 & 0 & 0 & 0 \\
\hline 2022 & 416 & 78 & 0 & 26 & 22483 & 416 & 0 & 104 & 140 & 0 & 0 & 0 \\
\hline 2023 & 47 & 9 & 0 & 3 & 2886 & 47 & 0 & 12 & 20 & 0 & 0 & 0 \\
\hline 2024 & 149 & 29 & 0 & 10 & 9146 & 149 & 0 & 38 & 60 & 0 & 0 & 0 \\
\hline 2025 & 436 & 82 & 0 & 27 & 26742 & $43 \dot{6}$ & 0 & 110 & 160 & 0 & 0 & 0 \\
\hline 2026 & 295 & 55 & 0 & 18 & 16050 & 295 & 0 & 74 & 80 & 0 & 0 & 0 \\
\hline 2027 & 416 & 78 & 0 & 26 & 24459 & 416 & 0 & 104 & 120 & 0 & 0 & 0 \\
\hline 2028 & 199 & 38 & 0 & 13 & 11240 & 199 & 0 & 50 & 60 & 0 & 0 & 0 \\
\hline 2029 & 576 & 108 & 0 & 36 & 35303 & 576 & 0 & 145 & 160 & 0 & 0 & 0 \\
\hline 2030 & 522 & 98 & 0 & 33 & 31986 & 522 & 0 & 131 & 140 & 0 & 0 & 0 \\
\hline 2031 & 992 & 186 & 0 & 62 & 60757 & 992 & 0 & 248 & 280 & 0 & 0 & 0 \\
\hline 2032 & 276 & 52 & 0 & 17 & 16948 & 276 & 0. & 70 & 80 & 0 & 0 & 0 \\
\hline 2033 & 493 & 93 & 0 & 31 & 30211 & 493 & 0 & 124 & 140 & 0 & 0 & 0 \\
\hline 2094 & 960 & 181 & 0 & 60 & 56866 & 960 & 0 & 241 & 260 & 0 & 0 & 0 \\
\hline 2035 & 1609 & 303 & 0 & 101 & 95621 & 1609 & 0 & 404 & 420 & 0 & 0 & 0 \\
\hline 2036 & 603 & 1.13 & 0 & 38 & 36948 & 603 & 0. & 151 & 140 & 0 & 0 & 0 \\
\hline 2037 & 581 & 109 & 0 & 36 & 34581 & 581 & 0 & 146 & 140 & 0 & 0 & 0 \\
\hline 2038 & 1045 & 196 & 0 & 65 & 61004 & 1045 & 0 & 261 & 240 & 0 & 0 & 0 \\
\hline 2039 & 375 & .70 & 0 & 23 & 20971 & 375 & 0 & 94 & 100 & 0 & 0 & 0 \\
\hline 2040 & 138 & 26 & 0 & 9 & 8450 & 138 & 0 & 35 & 40 & 0 & 0 & . \\
\hline 2041 & 0 & 0 & 0 & 0 & 0 & 0 & 0 & 0 & 0 & 0 & 0 & 0 \\
\hline 2042 & 0 & 0 & 0 & 0 & 0 & 0 & 0 & 0 & 0 & 0 & 0 & 0 \\
\hline 2043 & 0 & 0 & 0 & 0 & 0 & 0 & 0 & 0 & 0 & 0 & 0 & 0 \\
\hline Inder & & & & & & & & & & & & \\
\hline const. & 1531 & 291 & 0 & 97 & 94029 & 1531 & 0 & 388 & 500 & 0 & 0 & 0 \\
\hline
\end{tabular}


TABLE B.3 (Cont.); Part A (Cont.)

\begin{tabular}{|c|c|c|c|c|c|c|c|c|c|c|c|c|}
\hline \multirow{2}{*}{$\begin{array}{l}\text { Year } \\
\text { avail- } \\
\text { able }\end{array}$} & \multicolumn{4}{|c|}{ 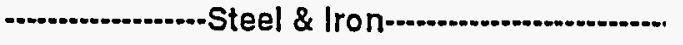 } & \multicolumn{4}{|c|}{--Stainless steel-o...................... } & \multicolumn{4}{|c|}{ 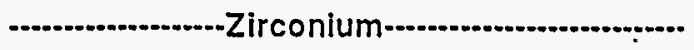 } \\
\hline & $\begin{array}{l}\text { Non- } \\
\text { active }\end{array}$ & $\begin{array}{l}\text { Clean- } \\
\text { able }\end{array}$ & $\begin{array}{l}\text { Non- } \\
\text { clean- } \\
\text { able }\end{array}$ & $\begin{array}{l}\text { Acti- } \\
\text { vated }\end{array}$ & $\begin{array}{l}\text { Non- } \\
\text { active }\end{array}$ & $\begin{array}{l}\text { Clean- } \\
\text { able }\end{array}$ & $\begin{array}{l}\text { Non- } \\
\text { clean- } \\
\text { able }\end{array}$ & $\begin{array}{l}\text { Acti- } \\
\text { vated }\end{array}$ & $\begin{array}{l}\text { Non- } \\
\text { active }\end{array}$ & $\begin{array}{l}\text { Clean- } \\
\text { able }\end{array}$ & $\begin{array}{l}\text { Non- } \\
\text { clean- } \\
\text { able }\end{array}$ & $\begin{array}{l}\text { Acti- . } \\
\text { vated }\end{array}$ \\
\hline 2010 & 0 & 0 & 0 & 0 & 0 & 0 & 0 & 0 & 0 & 0 & 0 & 0 \\
\hline 2011 & 0 & 0 & 0 & 0 & 0 & 0 & 0 & 0 & 0 & 0 & 0 & 0 \\
\hline 2012 & 20194 & 26433 & 0 & $5213^{\circ}$ & 500 & 36 . & 0 & 41 & 0 & 0 & 0 & 0 \\
\hline 2013 & 0 & 0 & 0 & 0 & 0 & 0 & 0 & $0^{\circ}$ & 0 & 0 & 0 & 0 \\
\hline 2014 & 9902 & 13066 & 0 & 2988 & 200 & 169 & 0 & 189 & 0 & 0 & 0 & 0 \\
\hline 2015 & 40007 & 51254 & 0 & 9198 & 800 & 367 & 122 & 273 & 0 & 0. & 0 & 0 \\
\hline 2016 & 16570 & 10580 & 0 & 3100 & 160 & 900 & 0 & 165 & 0 & 0 & 0 & 0 \\
\hline 2017 & 18441 & 11232 & 0 & 4773 & 60 & 1538 & 136 & 725 & 0 & 0 & 0 & 0 \\
\hline 2018 & 14786 & 8331 & 0 & 3511 & 60 & 1142 & 0 & $435^{\circ}$ & 0 & 0 & 0 & 0 \\
\hline 2019 & 19180 & 10810 & 0 & 4373 & 60 & 1596 & 232 & 683 & 0 & 0 & 0 & 0 \\
\hline 2020 & .0 & 0 & 0 & 0 & 0 & 0 & 0 & 0 & 0 & 0 & 0 & 0 \\
\hline 2021 & 28432 & 15136 & 0 & 6225 & 120 & 2147 & 0 & 718 & 0 & 0 & 0 & 0 \\
\hline 2022 & 53110 & 31634 & 0 & 13355 & 180 & 4367 & 346 & 1969 & 0 & 0 & 0 & 0 \\
\hline 2023 & 4883 & 3946 & 0 & 1732 & 0 & 530 & 177 & 395 & 0 & 0 & 0 & 0 \\
\hline 2024 & 27597 & 14078 & 92 & 3202 & 0 & 3622 & 0 & 982 & 0 & 0 & 0 & 0 \\
\hline 2025 & 54910 & 38137 & 92 & 14178 & 0 & 6630 & 853 & 3388 & 0 & 0 & 0 & 0 \\
\hline 2026 & 36782 & 22541 & 0 & 9612 & 120 & 3068 & 257 & 1458 & 0 & 0 & 0 & 0 \\
\hline 2027 & 42485 & 33741 & 0 & 15298 & 60 & 4214 & 797 & 2976 & 0 . & 0 & 0 & 0 \\
\hline 2028 & 32413 & 16452 & 46 & 5163 & 60 & 3325 & 275 & 1034 & 0 & 0 & 0 & 0 \\
\hline 2029 & 61336 & 49057 & 46 & 20797 & 0 & 7049 & 1475 & 4693 & 0 & 0 & 0 & 0 \\
\hline 2030 & 51130 & 43735 & 0 & 19699 & 0 & 5603 & 1686 & 4374 & 0 & 0 & 0 & 0 \\
\hline 2031 & 103816 & 8386.1 & 46 & 36168 & 0 & 11671 & 2981 & 8173 & 0 & 0 & 0 & 0 \\
\hline 2032 & 33280 & 23959 & 46 & 9273 & 0 & 3951 & 625 & 2183 & 0 & 0 & 0 & 0 \\
\hline 2033 & 58338 & 42095 & 46 & 16786 & 0 & 6626 & 1676 & 3997 & 0 & 0 & 0 & 0 \\
\hline 2034 & 112099 & 79922 & 92 & 32814 & 120 & 11973 & 1662 & 6770 & 0 & 0 & 0 & 0 \\
\hline 2035 & 195149 & 134782 & 184 & 53679 & 180 & 21143 & 3162 & 11433 & 0 & 0 & 0 & 0 \\
\hline 2036 & 69736 & 51307 & 46 & 20828 & 0 & 7864 & 2088 & 4918 & 0 & 0 & 0 & 0 \\
\hline 2037 & 71902 & 48367 & 46 & 19167 & 60 & 7613 & 1705 & 4226 & 0 & 0 & 0 & 0 \\
\hline 2038 & 132683 & 84762 & 69 & 33524 & 180 & 13456 & 2719 & 6973 & 0 & 0 & 0 & 0 \\
\hline 2039 & 47822 & 29269 & 0 & 12102 & 120 & 4219 & 806 & 2131 & 0 & 0 & 0 & 0 \\
\hline 2040 & 21521 & 12340 & 46 & 3729 & 0 & 2629 & 343 & 1021 & 0 & 0 & 0 & 0 \\
\hline 2041 & 0 & 0 & 0 & 0 & 0 & 0 & 0 & 0 & 0 & 0 & 0 & 0 \\
\hline 2042 & 0 & 0 & 0 & 0 & 0 & 0 & 0 & 0 & 0 & 0 & 0 & 0 \\
\hline 2043 & 0 & 0 & 0 & 0 & 0 & 0 & 0 & 0 & 0 & 0 & 0 & 0 \\
\hline \multicolumn{13}{|l|}{ Under } \\
\hline const. & 314118 & 137636 & 989 & 25153 & 1147 & 45373 & 1349 & 15188 & 0 & 0 & 0 & 125 \\
\hline
\end{tabular}


TABLE B.3 (Cont.); Part B: Start-Up Plus 100 Years

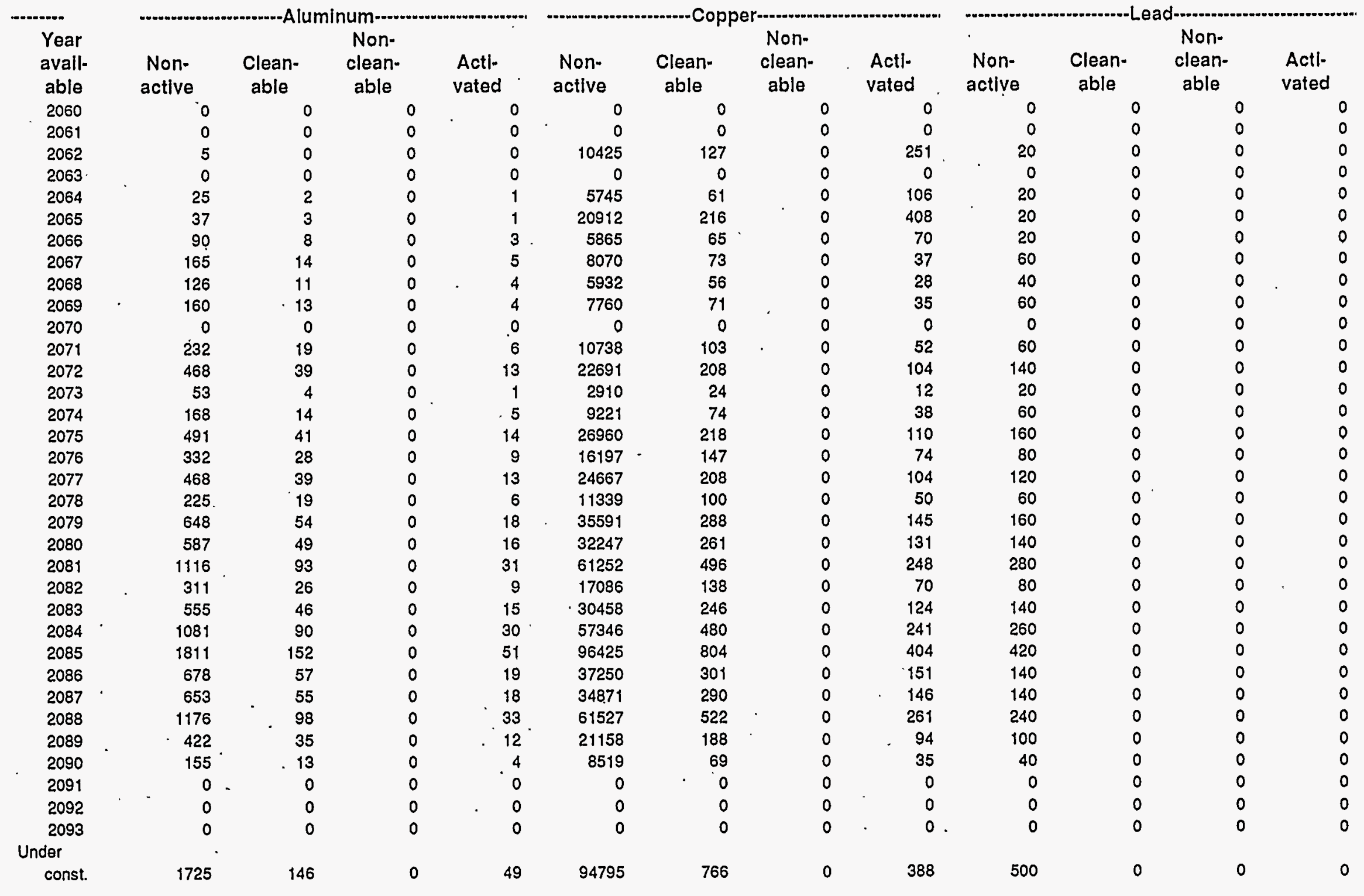


TABLE B.3 (Cont.); Part B (Cont.)

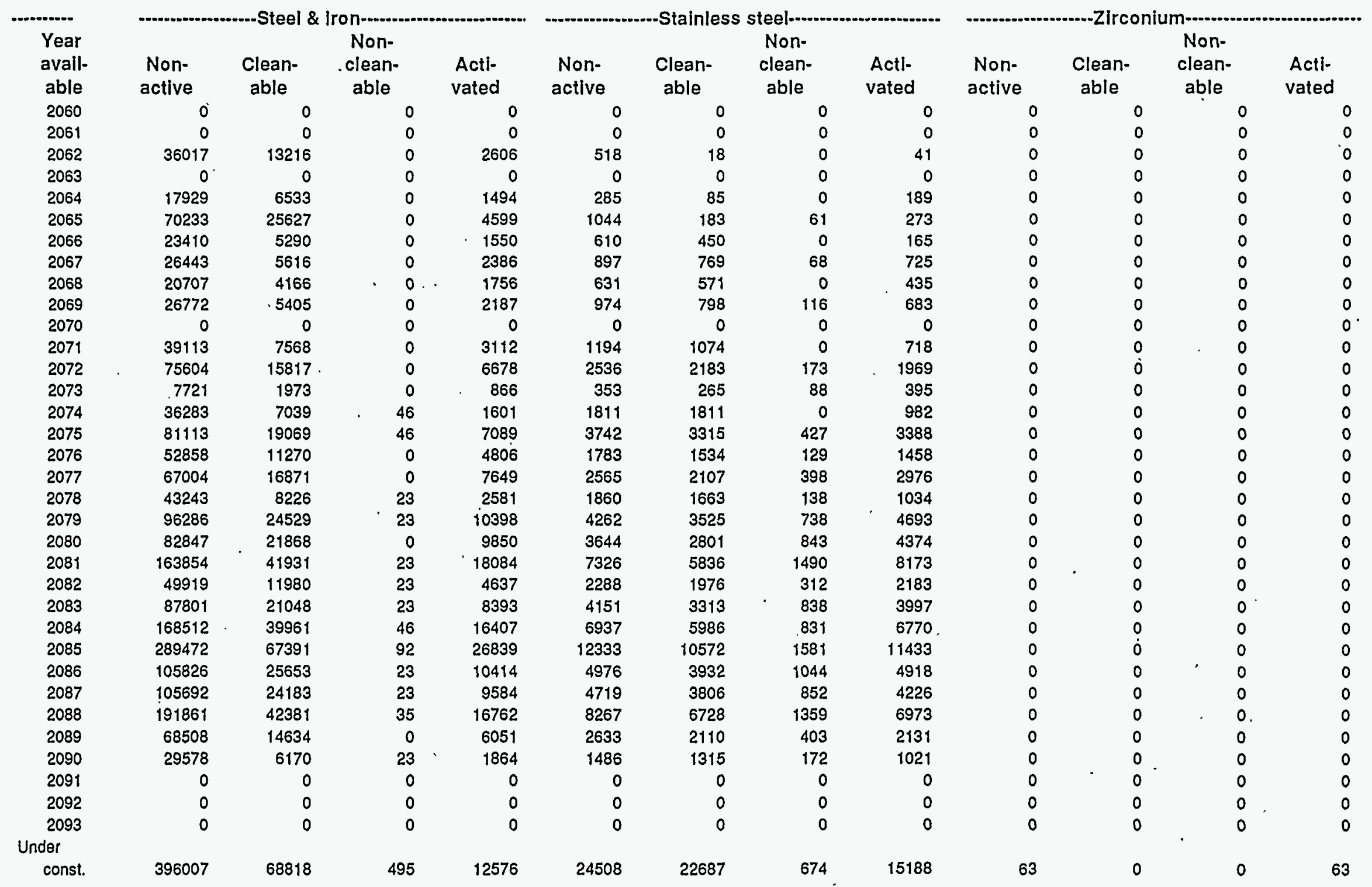


TABLE B.3 (Cont.); Part C: Start-Up Plus 150 Years

\begin{tabular}{|c|c|c|c|c|c|c|c|c|c|c|c|c|}
\hline \multirow[b]{2}{*}{$\begin{array}{l}\text { Year } \\
\text { avall. } \\
\text { able }\end{array}$} & \multicolumn{4}{|c|}{ Aluminum } & \multicolumn{4}{|c|}{ 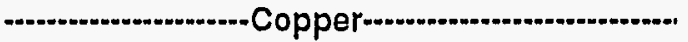 } & \multicolumn{4}{|c|}{ 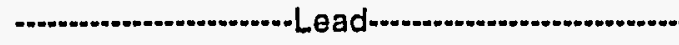 } \\
\hline & $\begin{array}{l}\text { Non- } \\
\text { active }\end{array}$ & $\begin{array}{l}\text { Clean- } \\
\text { able }\end{array}$ & $\begin{array}{l}\text { Non- } \\
\text { clean- } \\
\text { able }\end{array}$ & $\begin{array}{l}\text { Acti- } \\
\text { vated }\end{array}$ & $\begin{array}{l}\text { Non- } \\
\text { active }\end{array}$ & $\begin{array}{c}\text { Clean- } \\
\text { able }\end{array}$ & $\begin{array}{l}\text { Non- } \\
\text { clean- } \\
\text { able }\end{array}$ & $\begin{array}{l}\text { Actl- } \\
\text { vated }\end{array}$ & $\begin{array}{l}\text { Non- } \\
\text { active }\end{array}$ & $\begin{array}{c}\text { Clean- } \\
\text { able }\end{array}$ & $\begin{array}{l}\text { Non- } \\
\text { clean- } \\
\text { able }\end{array}$ & $\begin{array}{l}\text { Acti- } \\
\text { vated }\end{array}$ \\
\hline 2110 & 0 & 0 & 0 & 0 & 0 & 0 & 0 & 0 & 0 & 0 & 0 & 0 \\
\hline 2111 & 0 & 0 & 0 & 0 & 0 & 0 & 0 & 0 & 0 & 0 & 0 & 0 \\
\hline 2112 & 6 & 0 & 0 & 0 & 10489 & 64 & 0 & 63 & 20 & 0 & 0 & 0 \\
\hline 2113 & 0 & 0 & 0 & 0 & 0 & 0 & 0 & 0 & 0 & 0 & 0 & 0 \\
\hline 2114 & 27 & 1 & 0 & 0 & 5775 & 31 & 0 & 26 & 20 & 0 & 0 & 0 \\
\hline 2115 & 39 & $\dot{2}$ & 0 & 1 & 21021 & 108 & 0 & 102 & 20 & 0 & 0 & 0 \\
\hline 2116 & 95 & 4 & 0 & 1 & 5898 & 33 & 0 & 18 & 20 & 0 & 0 & $0^{\circ}$ \\
\hline 2117 & 174 & 7 & 0 & 2 & 8107 & 37 & 0 & 9 & 60 & 0 & 0 & 0 \\
\hline 2118 & 133 & 5 & 0 & 2 & 5960 & 28 & 0 & 7 & 40 & 0 & 0 & 0 \\
\hline 2119 & 168 & 7 & 0 & 2 & 7795 & 35 & 0 & 9 & 60 & 0 & 0 & 0 \\
\hline 2120 & 0 & 0 & 0 & 0 & 0 & 0 & 0 & 0 & 0 & 0 & 0 & 0 \\
\hline 2121 & 245 & 10 & 0 & 3 & 10789 & 52 & 0 & 13 & 60 & 0 & 0 & 0 \\
\hline 2122 & 494 & 20 & 0 & 7 & 22795 & 104 & 0 & 26 & 140 & 0 & 0 & 0 \\
\hline 2123 & 56 & 2 & 0 & 1 & 2921 & 12 & 0 & 3 & 20 & 0 & 0 & 0 \\
\hline 2124 & 177 & 7 & 0 & 2 & 9258 & 37 & 0 & 10 & 60 & 0 & 0 & 0 \\
\hline 2125 & 518 & 21 & 0 & 7 & 27069 & 109 & 0 & 27 & 160 & 0 & 0 & 0 \\
\hline 2126 & 350 & 14 & 0 & 5 & 16271 & 74 & 0 & 18 & 80 & 0 & 0 & 0 \\
\hline 2127 & 494 & 19 & 0 & 6 & 24771 & 104 & 0 & 26 & 120 & 0 & 0 & 0 \\
\hline 2128 & 237 & 9 & 0 & 3 & 11389 & 50 & 0 & 13 & 60 & 0 & 0 & 0 \\
\hline 2129 & 684 & 27 & 0 & 9 & 35735 & 144 & 0 & 36 & 160 & 0 & 0 & 0 \\
\hline 2130 & 620 & 24 & 0 & 8 & 32377 & 131 & 0 & 33 & 140 & 0 & 0 & 0 \\
\hline 2131 & 1178 & 47 & 0 & 16 & 61500 & 248 & 0 & 62 & 280 & 0 & 0 & 0 \\
\hline 2132 & 329 & 13 & 0 & 4 & 17155 & 69 & 0 & 17 & 80 & 0 & 0 & 0 \\
\hline 2133 & 586 & 23 & 0 & 8 & 30581 & 123 & 0 & 31 & 140 & 0 & 0 & 0 \\
\hline 2134 & 1141 & 45 & 0 & 15 & 57586 & 240 & 0 & 60 & 260 & 0 & 0 & 0 \\
\hline 2135 & 1912 & 76 & 0 & 25 & 96827 & 402 & 0 & 101 & 420 & 0 & 0 & 0 \\
\hline 2136 & 716 & 28 & 0 & 9 & 37401 & 151 & 0 & 38 & 140 & 0 & 0 & 0 \\
\hline 2137 & 690 & 27 & 0 & 9 & 35016 & 145 & 0 & 36 & 140 & 0 & 0 & 0 \\
\hline 2138 & . 1241 & 49 & 0 & 16 & 61788 & 261 & 0 & 65 & 240 & 0 & 0 & 0 \\
\hline 2139 & 445 & 18 & 0 & 6 & 21252 & 94 & 0 & 23 & 100 & 0 & 0 & 0 \\
\hline 2140 & 164 & 7 & 0 & 2 & 8553 & 34 & 0 & 9 & 40 & 0 & 0 & 0 \\
\hline 2141 & 0 & 0 & 0 & 0 & 0 & 0 & 0 & 0 & 0 & 0 & 0 & 0 \\
\hline 2142 & 0 & 0 & 0 & 0 & 0 & 0 & 0 & 0 & 0 & 0 & 0 & 0 \\
\hline 2143 & 0 & 0 & 0 & 0 & 0 & 0 & 0 & 0 & 0 & 0 & 0 & 0 \\
\hline \multicolumn{13}{|l|}{ Under } \\
\hline const. & 1822 & 73 & 0 & 24 & 95177 & 383 & 0 & 97 & 500 & 0 & 0 & 0 \\
\hline
\end{tabular}


TABLE B.3 (Cont.); Part C (Cont.)

\begin{tabular}{|c|c|c|c|c|c|c|c|c|c|c|c|c|}
\hline \multirow{2}{*}{$\begin{array}{c}\text { Year } \\
\text { avall- } \\
\text { able }\end{array}$} & \multicolumn{4}{|c|}{ 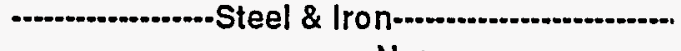 } & \multicolumn{4}{|c|}{ 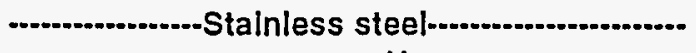 } & \multicolumn{4}{|c|}{ Zlrconlum } \\
\hline & $\begin{array}{l}\text { Non- } \\
\text { actlve }\end{array}$ & $\begin{array}{l}\text { Clean- } \\
\text { able }\end{array}$ & $\begin{array}{l}\text { Non- } \\
\text { clean- } \\
\text { able }\end{array}$ & $\begin{array}{l}\text { Actl- } \\
\text { vated }\end{array}$ & $\begin{array}{c}\text { Non- } \\
\text { active }\end{array}$ & $\begin{array}{l}\text { Clean- } \\
\text { able }\end{array}$ & $\begin{array}{l}\text { Non- } \\
\text { clean- } \\
\text { able }\end{array}$ & $\begin{array}{l}\text { Acti- } \\
\text { vated }\end{array}$ & $\begin{array}{l}\text { Non- } \\
\text { active }\end{array}$ & $\begin{array}{l}\text { Clean- } \\
\text { able }\end{array}$ & $\begin{array}{l}\text { Non- } \\
\text { clean- } \\
\text { able }\end{array}$ & $\begin{array}{l}\text { Acti- } \\
\text { vated }\end{array}$ \\
\hline 2110 & . 0 & 0 & 0 & 0 & 0 & 0 & 0 & 0 & 0 & 0 & 0 & 0 \\
\hline 2111 & 0 & 0 & 0 & 0 & 0 & 0 & 0 & 0 & 0 & 0 & 0 & 0 \\
\hline 2112 & 43146 & 6608 & 0 & 2085 & 527 & 9 & 0 & 500 & 0 & 0 & 0 & 0 \\
\hline 2113 & 0 & 0 & 0 & 0 & 0 & 0 & 0 & 0 & 0 & 0 & 0 & 0 \\
\hline 2114 & 21494 & 3267 & 0 & 1195 & 327 & 42 & 0 & 200 & 0 & 0 & 0 & 0 \\
\hline 2115 & 83966 & 12814 & 0 & 3679 & 1167 & 92 & 31 & 800 & 0 & 0 & 0 & 0 \\
\hline 2116 & 26365 & 2645 & 0 & 1240 & 835 & 225 & 0 & 160 & 0 & 0 & 0 & 0 \\
\hline 2117 & 29728 & 2808 & 0 & 1909 & 1315 & 384 & 34 & 60 & 0 & .0 & 0 & 0 \\
\hline 2118 & 23141 & 2083 & 0 & 1404 & 916 & 285 & 0 & 60 & 0 & 0 & 0 & 0 \\
\hline 2119 & 29912 & 2703 & 0 & 1749 & 1431 & 399 & 58 & 60 & 0 & 0 & 0 & 0 \\
\hline 2120 & 0 & 0 & 0 & 0 & 0 & 0 & 0 & 0 & 0 & 0 & 0 & 0 \\
\hline 2121 & 43519 & 3784 & 0 & 2490 & 1730 & 537 & 0 & 120 & 0 & 0 & 0 & 0 \\
\hline 2122 & 84848 & 7908 & 0 & 5342 & 3715 & 1092 & 87 & 180 & 0 & 0 & 0 & 0 \\
\hline 2123 & 8881 & 987 & 0 & 693 & 536 & 133 & 44 & 0 & 0 & 0 & 0 & 0 \\
\hline 2124 & 40146 & 3519 & 23 & 1281 & 2717 & 906 & 0 & 0 & 0 & 0 & 0 & 0 \\
\hline 2125 & 92088 & 9534 & 23 & 5671 & 5613 & 1658 & 213 & 0 & 0 & 0 & 0 & 0 \\
\hline 2126 & 59454 & 5635 & 0 & 3845 & 2614 & 767 & 64 & 120 & 0 & 0 & 0 & 0 \\
\hline 2127 & 76969 & 8435 & 0 & 6119 & 3818 & 1054 & 199 & 60 & 0 & 0 & 0 & 0 \\
\hline 2128 & 47884 & 4113 & 12 & 2065 & 2761 & 831 & 69 & 60 & 0 & 0 & 0 & 0 \\
\hline 2129. & 110642 & 12264 & 12 & 8319 & 6394 & 1762 & 369 & 0 & 0 & 0 & 0 & 0 \\
\hline 2130 & 95751 & 10934 & 0 & 7880 & 5467 & 1401 & 422 & 0 & 0 & 0 & 0 & 0 \\
\hline 2131 & 188448 & 20965 & 12 & 14467 & 10989 & 2918 & 745 & 0 & 0 & 0 & 0 & 0 \\
\hline 2132 & 56847 & 5990 & 12 & 3709 & 3432 & 988 & . 156 & 0 & 0 & 0 & 0 & 0 \\
\hline 2133 & 100015 & 10524 & 12 & 6714 & 6227 & 1657 & 419 & 0 & 0 & 0 & 0 & 0 \\
\hline 2134 & 191797 & 19980 & 23 & 13125 & 10346 & 2993 & 416 & 120 & 0 & 0 & 0 & 0 \\
\hline 2135 & 328581 & 33695 & 46 & 21471 & 18409 & 5286 & 791 & 180 & 0 & 0 & 0 & 0 \\
\hline 2136 & 120747 & 12827 & 12 & 8331 & 7464 & 1966 & 522 & 0 & 0 & 0 & 0 & 0 \\
\hline 2137 & 119712 & 12092 & 12 & 7667 & 7048 & 1903 & 426. & 60 & 0 & 0 & 0 & 0 \\
\hline 2138 & 216421 & 21191 & 17 & 13409 & 12311 & 3364 & $680^{\circ}$ & 180 & 0 & 0 & 0 & 0 \\
\hline 2139 & 77035 & 7317 & 0 & 4841 & 3889 & 1055 & 202 & 120 & 0 & 0 & 0 & 0 \\
\hline 2140 & 33048 & 3085 & 12 & 1492 & 2230 & 657 & 86 & 0 & 0 & 0 & 0 & 0 \\
\hline 2141 & 0 & 0 & 0 & 0 & 0 & 0 & 0 & 0 & 0 & 0 & 0 & 0 \\
\hline 2142 & 0 & 0 & 0 & 0 & 0 & 0 & 0 & 0 & 0 & 0 & 0 & 0 \\
\hline 2143 & 0 & 0 & 0 & 0 & 0 & 0 & 0 & 0 & 0 & 0 & 0 & 0 \\
\hline Under & & & & & & & & & & & & \\
\hline const. & 433178 & 34409 & 247 & 10061 & 36189 & 11343 & 337 & 1147. & 94 & 0 & 0 & 31 \\
\hline
\end{tabular}


TABLE B.4 Annual Increments in Scrap-Metal Inventory from Nuclear Power Plants for the Former Soviet Union (includes Asian part of the former Spviet Union); Part A: Start-Up Plus 50 Years

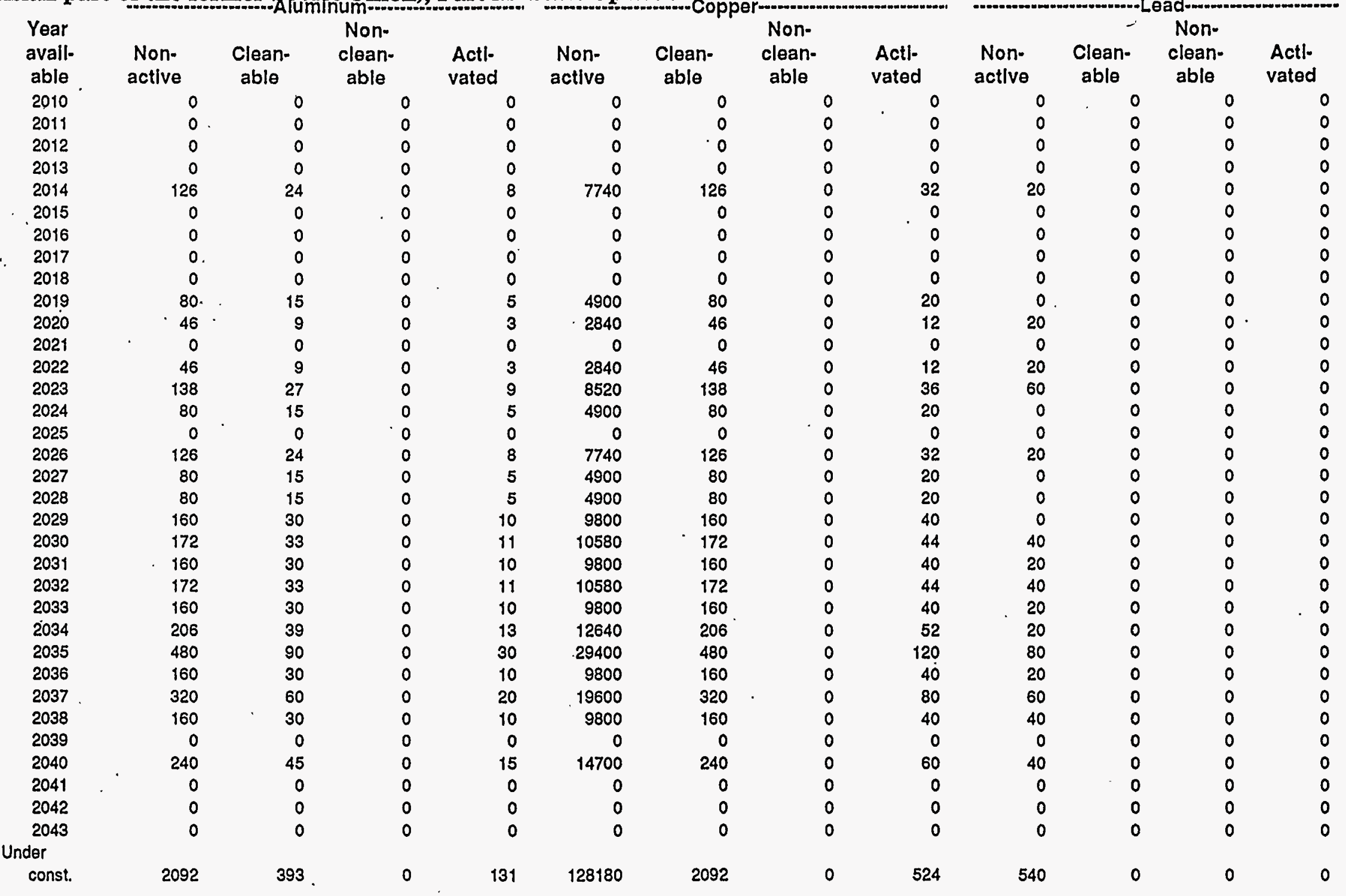


TABLE B.4 (Cont.); Part A (Cont.)

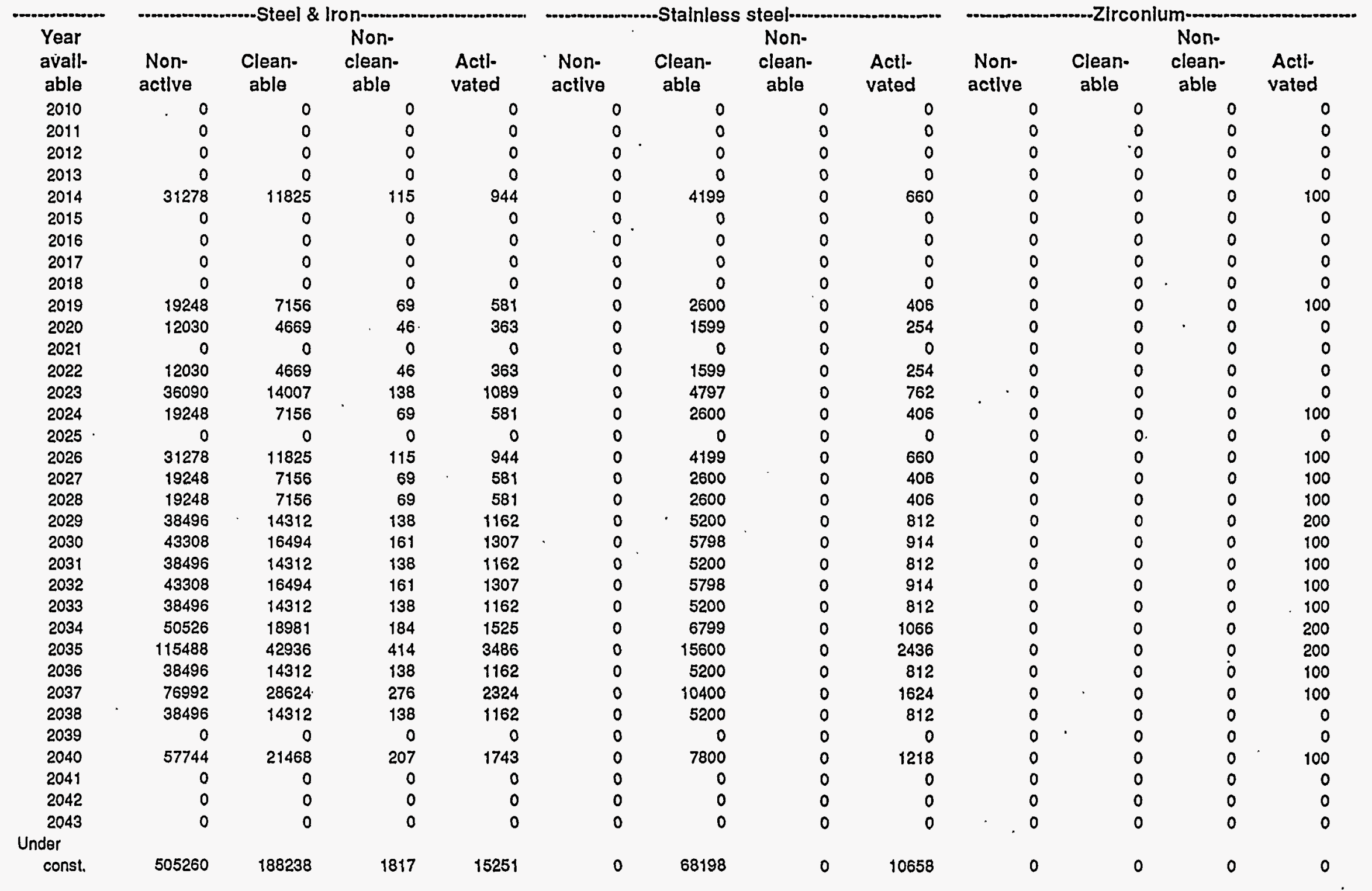


TABLE B.4 (Cont.); Part B: Start-Up Plus 100 Years

\begin{tabular}{|c|c|c|c|c|c|c|c|c|c|c|c|c|}
\hline \multirow{2}{*}{$\begin{array}{l}\text { Year } \\
\text { avall- } \\
\text { able }\end{array}$} & \multicolumn{4}{|c|}{ 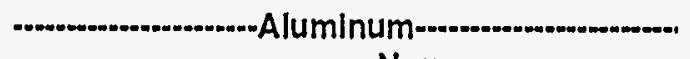 } & \multicolumn{4}{|c|}{ Copper } & \multicolumn{4}{|c|}{ 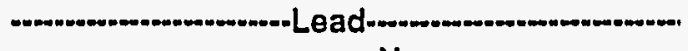 } \\
\hline & $\begin{array}{l}\text { Non- } \\
\text { actlve }\end{array}$ & $\begin{array}{l}\text { Clean- } \\
\text { able }\end{array}$ & $\begin{array}{l}\text { Non- } \\
\text { clean- } \\
\text { able }\end{array}$ & $\begin{array}{l}\text { Acti- } \\
\text { vated }\end{array}$ & $\begin{array}{l}\text { Non- } \\
\text { active }\end{array}$ & $\begin{array}{l}\text { Clean- } \\
\text { able }\end{array}$ & $\begin{array}{l}\text { Non- } \\
\text { clean- } \\
\text { able }\end{array}$ & $\begin{array}{l}\text { Actl- } \\
\text { vated }\end{array}$ & $\begin{array}{l}\text { Non- } \\
\text { actlve }\end{array}$ & $\begin{array}{c}\text { Clean- } \\
\text { able }\end{array}$ & $\begin{array}{l}\text { Non- } \\
\text { clean- } \\
\text { able }\end{array}$ & $\begin{array}{l}\text { Actl- } \\
\text { vated }\end{array}$ \\
\hline 2060 & 0 & 0 & 0 & 0 & 0 & 0 & 0 & 0 & 0 & 0 & 0 & 0 \\
\hline 2061 & 0 & 0 & 0 & 0 & 0 & 0 & 0 & 0 & 0 & 0 & 0 & 0 \\
\hline 2062 & 0 & 0 & 0 & 0 & 0 & 0 & 0 & 0 & 0 & 0 & 0 & 0 \\
\hline 2063 & 0 & 0 & 0 & 0 & 0 & 0 & 0 & 0 & 0 & 0 & 0 & 0 \\
\hline 2064 & 142 & 12 & 0 & 4 & 7803 & 63 & 0 & 32 & 20 & 0 & 0 & 0 \\
\hline 2065 & $\cdot \quad 0$ & 0 & 0 & 0 & 0 & 0 & 0 & 0 & 0 & 0 & 0 & 0 \\
\hline 2066 & 0 & 0 & 0 & 0 & 0 & 0 & 0 & 0 & 0 & 0 & 0 & 0 \\
\hline 2067 & 0 & 0 & 0 & 0 & 0 & 0 & 0 & 0 & 0 & 0 & 0 & 0 \\
\hline 2068 & 0 & 0 & 0 & 0 & 0 & 0 & 0 & 0 & 0 & 0 & 0 & 0 \\
\hline 2069 & 90 & 8 & 0 & 3 & 4940 & 40 & 0 & 20 & 0 & 0 & 0 & 0 \\
\hline 2070 & 52 & 5 & 0 & 2 & 2863 & 23 & 0 & 12 & 20 & 0 & 0 & 0 \\
\hline .2071 & 0 & 0 & 0 & 0 & 0 & 0 & 0 & 0 & 0 & 0 & 0 & 0 \\
\hline 2072 & 52 & 5 & 0 & 2 & 2863 & 23 & 0 & 12 & 20 & 0 & 0 & 0 \\
\hline 2073 & 156 & 14 & 0 & 5 & 8589 & 69 & 0 & 36 & 60 & 0 & 0 & 0 \\
\hline 2074 & 90 & 8 & 0 & 3 & 4940 & 40 & 0 & 20 & 0 & 0 & 0 & 0 \\
\hline 2075 & 0 & 0 & 0 & 0 & 0 & 0 & 0 & 0 & 0 & 0 & 0 & 0 \\
\hline 2076 & 142 & 12 & 0 & 4 & 7803 & 63 & 0 & 32 & 20 & 0 & 0 & 0 \\
\hline 2077 & 90 & 8 & 0 & 3 & 4940 & 40 & 0 & 20 & 0 & 0 & 0 & 0 \\
\hline 2078 & 90 & 8 & 0 & 3 & 4940 & 40 & 0 & 20 & 0 & 0 & 0 & 0 \\
\hline 2079 & 180 & 15 & 0 & 5 & 9880 & 80 & 0 & 40 & 0 & 0 & 0 & 0 \\
\hline 2080 & 194 & 17 & 0 & 6 & 10666 & 86 & 0 & 44 & 40 & 0 & 0 & 0 \\
\hline 2081 & 180 & 15 & 0 & 5 & 9880 & 80 & 0 & 40 & 20 & 0 & 0 & 0 \\
\hline 2082 & 194 & 17 & 0 & 6 & 10666 & 86 & 0 & 44 & 40 & 0 & 0 & 0 \\
\hline 2083 & 180 & 15 & 0 & 5 & 9880 & 80 & 0 & 40 & 20 & 0 & 0 & 0 \\
\hline 2084 & 232 & 20 & 0 & 7 & 12743 & 103 & 0 & 52 & 20 & 0 & 0 & 0 \\
\hline 2085 & 540 & 45 & 0 & 15 & 29640 & 240 & 0 & 120 & 80 & 0 & 0 & 0 \\
\hline 2086 & 180 & 15 & 0 & 5 & 9880 & 80 & 0 & 40 & 20 & 0 & 0 & 0 \\
\hline 2087 & 360 & 30 & 0 & 10 & 19760 & 160 & 0 & 80 & 60 & 0 & 0 & 0 \\
\hline 2088 & 180 & 15 & 0 & 5 & 9880 & 80 & 0 & 40 & 40 & 0 & 0 & 0 \\
\hline 2089 & 0 & 0 & .0 & 0 & 0 & 0 & 0 & 0 & 0 & 0 & 0 & 0 \\
\hline 2090 & 270 & 23 & 0 & 8 & $14820 \ldots$ & 120 & 0 & 60 & 40 & 0 & 0 & 0 \\
\hline 2091 & 0 & 0 & 0 & 0 & 0 & 0 & 0 & 0 & 0 & 0 & 0 & 0 \\
\hline 2092 & 0 & 0 & 0 & 0 & 0 & 0 & 0 & 0 & 0 & 0 & 0 & 0 \\
\hline 2093 & 0 & 0 & 0 & 0 & 0 & 0 & 0 & 0 & 0 & 0 & 0 & 0 \\
\hline Under & & & & & & & & & & & & \\
\hline const. & 2354 & 197 & 0 & 66 & 129226 & 1046 & 0 & 524 & 540 & 0 & 0 & 0 \\
\hline
\end{tabular}


TABLE B.4 (Cont.); Part B (Cont.)

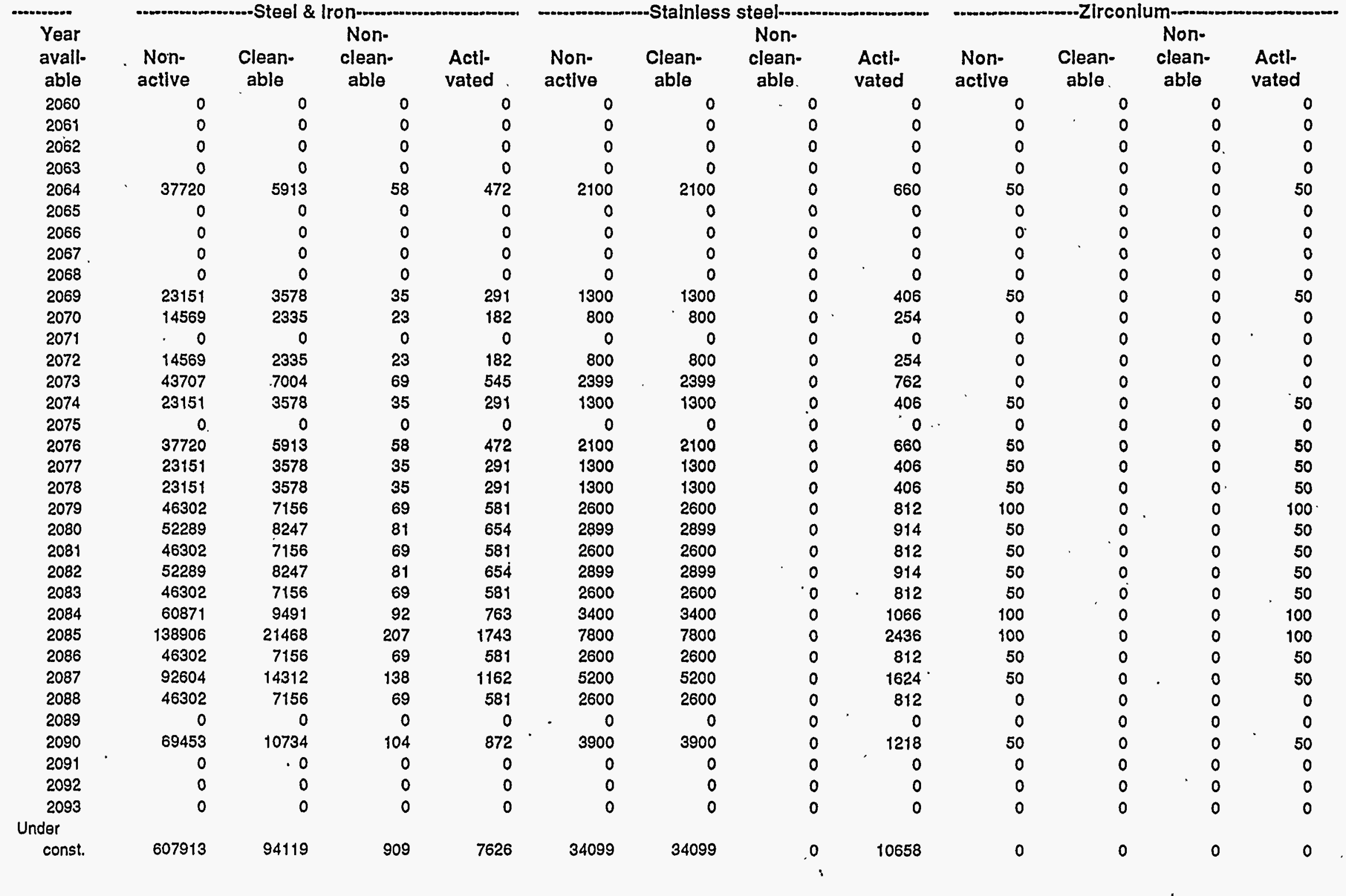


TABLE B.4 (Cont.); Part C: Start-Up Plus 150 Years

\begin{tabular}{|c|c|c|c|c|c|c|c|c|c|c|c|c|}
\hline \multirow{2}{*}{$\begin{array}{c}\text { Year } \\
\text { avall- } \\
\text { able }\end{array}$} & \multirow[b]{2}{*}{$\begin{array}{l}\text { Non- } \\
\text { actlve }\end{array}$} & \multirow{2}{*}{\multicolumn{2}{|c|}{$\begin{array}{l}\text { Non- } \\
\text { clean- } \\
\text { able }\end{array}$}} & \multirow[b]{2}{*}{$\begin{array}{l}\text { Actl- } \\
\text { vated }\end{array}$} & \multirow[b]{2}{*}{$\begin{array}{l}\text { Non- } \\
\text { active }\end{array}$} & \multirow{2}{*}{\multicolumn{2}{|c|}{$\begin{array}{l}\text { Non- } \\
\text { clean- } \\
\text { able }\end{array}$}} & \multirow[b]{2}{*}{$\begin{array}{l}\text { Actl- } \\
\text { vated }\end{array}$} & \multirow[b]{2}{*}{$\begin{array}{l}\text { Non- } \\
\text { actlve }\end{array}$} & \multirow{2}{*}{\multicolumn{2}{|c|}{$\begin{array}{c}\text { Non- } \\
\text { clean- } \\
\text { able }\end{array}$}} & \multirow{3}{*}{$\begin{array}{l}\text { Actl. } \\
\text { vated }\end{array}$} \\
\hline & & & & & & & & & & & & \\
\hline 2110 & 0 & 0 & 0 & 0 & 0 & 0 & 0 & 0 & 0 & 0 & 0 & \\
\hline 2111 & 0 & 0 & 0 & 0 & 0 & 0 & 0 & 0 & 0 & 0 & 0 & 0 \\
\hline 2112 & 0 & 0 & 0 & 0 & 0 & 0 & 0 & 0 & 0 & 0 & 0 & 0 \\
\hline 2113 & 0 & 0 & 0 & 0 & 0 & 0 & 0 & 0 & 0 & 0 & 0 & 0 \\
\hline 2114 & 150 & 6 & 0 & 2 & 7835 & 32 & 0 & 8 & 20 & 0 & 0 & 0 \\
\hline 2115 & 0 & 0 & 0 & 0 & 0 & 0 & 0 & 0 & 0 & 0 & 0 & 0 \\
\hline 2116 & 0 & 0 & 0 & 0 & 0 & 0 & 0 & 0 & 0 & 0 & 0 & 0 \\
\hline 2117 & 0 & 0 & 0 & 0 & 0 & 0 & 0 & 0 & 0 & 0 & 0 & 0 \\
\hline 2118 & 0 & 0 & 0 & 0 & 0 & 0 & 0 & 0 & 0 & 0 & 0 & 0 \\
\hline 2119 & 95 & 4 & 0 & 1 & 4960 & 20 & 0 & 5 & 0 & 0 & 0 & 0 \\
\hline 2120 & 55 & 2 & 0 & 1 & $287 \dot{5}$ & 12 & 0 & 3 & 20 & 0 & 0 & 0 \\
\hline 2121 & 0 & 0 & 0 & 0 & 0 & 0 & 0 & 0 & 0 & 0 & 0 & 0 \\
\hline 2122 & 55 & 2 & 0 & 1 & 2875 & 12 & 0 & 3 & 20 & 0 & 0 & 0 \\
\hline 2123 & 165 & 7 & 0 & 2 & 8624 & 35 & 0 & 9 & 60 & 0 & 0 & 0 \\
\hline 2124 & 95 & 4 & 0 & 1 & 4960 & 20 & 0 & 5 & 0 & 0 & 0 & 0 \\
\hline 2125 & 0 & 0 & 0 & 0 & 0 & 0 & 0 & 0 & 0 & 0 & 0 & 0 \\
\hline 2126 & 150 & 6 & 0 & 2 & 7835 & 32 & 0 & 8 & 20 & 0 & 0 & 0 \\
\hline 2127 & 95 & 4 & 0 & 1 & 4960 & 20 & 0 & 5 & 0 & 0 & 0 & 0 \\
\hline 2128 & 95 & 4 & 0 & 1 & 4960 & 20 & 0 & 5 & 0 & 0 & 0 & 0 \\
\hline 2129 & 190 & 8 & 0 & 3 & 9920 & 40 & 0 & 10 & 0 & 0 & 0 & 0 \\
\hline 2130 & 205 & 8 & 0 & 3 & 10709 & 43 & 0 & 11 & 40 & 0 & 0 & 0 \\
\hline 2131 & 190 & 8 & 0 & 3 & 9920 & 40 & 0 & 10 & 20 & 0 & 0 & 0 \\
\hline 2132 & 205 & 8 & 0 & 3 & 10709 & 43 & 0 & 11 & 40 & 0 & 0 & 0 \\
\hline 2133 & 190 & 8 & 0 & 3 & 9920 & 40 & 0 & 10 & 20 & 0 & 0 & 0 \\
\hline 2134 & 245 & 10 & 0 & 3 & 12795 & 52 & 0 & 13 & 20 & 0 & 0 & 0 \\
\hline 2135 & 570 & 23 & 0 & 8 & 29760 & 120 & 0 & 30 & 80 & 0 & 0 & 0 \\
\hline 2136 & 190 & 8 & 0 & 3 & 9920 & 40 & 0 & 10 & 20 & 0 & 0 & 0 \\
\hline 2137 & 380 & 15 & 0 & 5 & 19840 & 80 & 0 & 20 & 60 & 0 & 0 & 0 \\
\hline 2138 & 190 & 8 & 0 & 3 & 9920 & 40 & 0 & 10 & 40 & 0 & 0 & 0 \\
\hline 2139 & 0 & 0 & 0 & 0 & 0 & 0 & 0 & 0 & 0 & 0 & 0 & 0 \\
\hline 2140 & 285 & 11 & 0 & .4 & 14880 & 60 & 0 & 15 & 40 & 0 & 0 & 0 \\
\hline 2141 & 0 & 0 & 0 & 0 & 0 & 0 & 0 & 0 & 0 & 0 & 0 & 0 \\
\hline 2142 & 0 & 0 & 0 & 0 & 0 & 0 & 0 & 0 & 0 & 0 & 0 & 0 \\
\hline 2143 & 0 & 0 & 0 & 0 & 0 & 0 & 0 & 0 & 0 & 0 & 0 & 0 \\
\hline \multicolumn{13}{|l|}{ Under } \\
\hline const. & 2485 & 98 & 0 & 33 & 129749 & 523 & 0 & 131 & 540 & 0 & 0 & 0 \\
\hline
\end{tabular}


TABLE B.4 (Cont.); Part C (Cont.)

\begin{tabular}{|c|c|c|c|c|c|c|c|c|c|c|c|c|}
\hline .......... & -............... & ...-Steel \& & on-............. & . & 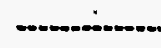 & --Stainles & steel-...... & - & - & --Zlrco & Im-n...... & - \\
\hline $\begin{array}{c}\text { Year } \\
\text { avail- } \\
\text { able }\end{array}$ & $\begin{array}{l}\text { Non- } \\
\text { actlve }\end{array}$ & $\begin{array}{c}\text { Clean- } \\
\text { able }\end{array}$ & $\begin{array}{l}\text { Non- } \\
\text { clean- } \\
\text { able }\end{array}$ & $\begin{array}{l}\text { Actl- } \\
\text { vated }\end{array}$ & $\begin{array}{l}\text { Non- } \\
\text { actlve }\end{array}$ & $\begin{array}{c}\text { Clean- } \\
\text { able }\end{array}$ & $\begin{array}{l}\text { Non- } \\
\text { clean- } \\
\text { able }\end{array}$ & $\begin{array}{l}\text { Acti- } \\
\text { vated }\end{array}$ & $\begin{array}{l}\text { Non- } \\
\text { actlve }\end{array}$ & $\begin{array}{l}\text { Clean- } \\
\text { able }\end{array}$ & $\begin{array}{c}\text { Non- } \\
\text { clean- } \\
\text { able }\end{array}$ & $\begin{array}{l}\text { Actl- } \\
\text { vated }\end{array}$ \\
\hline 2110 & 0 & 0 & 0 & 0 & 0 & 0 & 0 & 0 & 0 & 0 & 0 & 0 \\
\hline 2111 & 0 & 0 & 0 & 0 & 0 & 0 & 0 & 0 & 0 & 0 & 0 & 0 \\
\hline 2112 & 0 & 0 & 0 & 0 & 0 & 0 & 0 & 0 & 0 & 0 & 0 & 0 \\
\hline $2113^{-}$ & 0 & 0 & 0 & 0 & 0 & 0 & 0 & 0 & 0 & 0 & 0 & 0 \\
\hline 2114 & 40799 & 2956 & 29 & 378 & 3149 & 1050 & 0 & 0 & 75 & 0 & 0 & 25 \\
\hline 2115 & 0 & 0 & 0 & 0 & 0 & 0 & 0 & 0 & 0 & 0 & 0 & 0 \\
\hline 2116 & 0 & 0 & 0 & 0 & 0 & 0 & 0 & 0 & 0 & 0 & 0 & 0 \\
\hline 2117 & 0 & 0 & 0 & 0 & 0 & 0 & 0 & 0 & 0 & 0 & 0 & 0 \\
\hline 2118 & 0 & 0 & 0 & 0 & 0 & 0 & 0 & 0 & 0 & 0 & 0 & 0 \\
\hline 2119 & 25015 & 1789 & 17 & 232 & 1950 & 650 & 0 & 0 & 75 & 0 & 0 & 25 \\
\hline 2120 & 15784 & 1167 & 12 & 145 & 1199 & 400 & 0 & 0 & 0 & 0 & 0 & 0 \\
\hline 2121 & 0 & 0 & 0 & 0 & 0 & 0 & 0 & 0 & 0 & 0 & 0 & 0 \\
\hline 2122 & 15784 & 1167 & 12 & 145 & 1199 & 400 & 0 & 0 & 0 & 0 & 0 & 0 \\
\hline 2123 & 47352 & 3502 & 35 & 436 & 3598 & 1199 & 0 & 0 & 0 & 0 & 0 & 0 . \\
\hline 2124 & 25015 & 1789 & 17 & 232 & 1950 & 650 & 0 & 0 & 75 & 0 & 0 & 25 \\
\hline 2125 & 0 & 0 & 0 & 0 & 0 & 0 & 0 & 0 & 0 & 0 & 0 & 0 \\
\hline 2126 & 40799 & 2956 & 29 & 378 & 3149 & 1050 & 0 & 0 & 75 & 0 & 0 & 25 \\
\hline 2127 & 25015 & 1789 & 17 & 232 & 1950 & 650 & 0 & 0 & 75 & 0 & 0 & 25 \\
\hline 2128 & 25015 & 1789 & 17 & 232 & 1950 & 650 & 0 & 0 & 75 & 0 & 0 & 25 \\
\hline 2129 & 50031 & 3578 & 35 & 465 & 3900 & 1300 & 0 & 0 & 150 & 0 & 0 & 50 \\
\hline 2130 & 56583 & 4124 & 40 & 523 & 4349 & 1450 & 0 & 0 & 75 & 0 & 0 & 25 \\
\hline 2131 & 50031 & 3578 & 35 & 465 & 3900 & 1300 & 0 & 0 & 75 & 0 & 0 & 25 \\
\hline 2132 & 56583 & 4124 & 40 & 523 & 4349 & 1450 & 0 & 0 & .75 & 0 & 0 & 25 \\
\hline 2133 & 50031 & 3578 & 35 & 465 & 3900 & 1300 & 0 & 0 & 75 & 0 & 0 & 25 \\
\hline 2134 & 65815 & 4745 & 46 & 610 & 5099 & 1700 & 0 & 0 & 150 & 0 & 0 & 50 \\
\hline 2135 & 150092 & 10734 & 104 & 1394 & 11700 & 3900 & 0 & 0 & 150 & 0 & 0 & 50 \\
\hline 2136 & 50031 & 3578 & 35. & 465 & 3900 & 1300 & 0 & 0 & 75 & 0 & 0 & 25 \\
\hline 2137 & 100061 & 7156 & 69 & 930 & 7800 & 2600 & 0 & 0 & 75 & 0 & 0 & 25 \\
\hline 2138 & 50031 & 3578 & 35 & 465 & 3900 & 1300 & 0 & 0 & 0 & 0 & 0 & 0 \\
\hline 2139 & 0 & 0 & 0 & 0 & 0 & $0^{\circ}$ & 0 & 0 & 0 & 0 & 0 & 0 \\
\hline 2140 & 75046 & 5367 & 52 & 697 & 5850 & 1950 & 0 & 0 & 75 & 0 & 0 & 25 \\
\hline 2141 & 0 & 0 & 0 & 0 & 0 & 0 & 0 & 0 & 0 & 0 & 0 & 0 \\
\hline 2142 & 0 & 0 & 0 & 0 & 0 & 0 & 0 & 0 & 0 & 0 & 0 & 0 \\
\hline 2143 & 0 & 0 & 0 & 0 & 0 & 0 & 0 & 0 & 0 & 0 & 0 & 0 \\
\hline Under & & & & & & & & & & & & \\
\hline const. & 656952 & 47060 & 454 & 6100 & 51149 & 17050 & 0 & 0 & 0 & 0 & 0 & 0 \\
\hline
\end{tabular}

iู 
TABLE B.5 Annual Increments in Scrap-Metal Inventory from Nuclear Power Plant for Asia (excludes Asian parts of the former Soviet Union); Part A: Start-Up Plus 50 Years

\begin{tabular}{|c|c|c|c|c|c|c|c|c|c|c|c|c|}
\hline \multirow[b]{2}{*}{$\begin{array}{l}\text { Year } \\
\text { avall- } \\
\text { able }\end{array}$} & \multicolumn{4}{|c|}{ 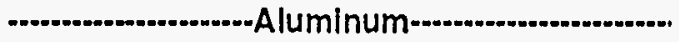 } & \multicolumn{4}{|c|}{ 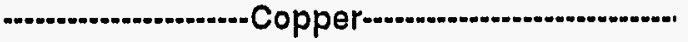 } & \multicolumn{4}{|c|}{ 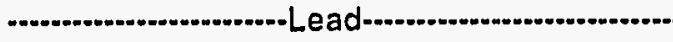 } \\
\hline & $\begin{array}{l}\text { Non- } \\
\text { active }\end{array}$ & $\begin{array}{l}\text { Clean- } \\
\text { able }\end{array}$ & $\begin{array}{l}\text { Non- } \\
\text { clean- } \\
\text { able }\end{array}$ & $\begin{array}{l}\text { Actl- } \\
\text { vated }\end{array}$ & $\begin{array}{l}\text { Non- } \\
\text { actlve }\end{array}$ & $\begin{array}{l}\text { Clean- } \\
\text { able }\end{array}$ & $\begin{array}{l}\text { Non- } \\
\text { clean- } \\
\text { able }\end{array}$ & $\begin{array}{l}\text { Actj- } \\
\text { vated }\end{array}$ & $\begin{array}{l}\text { Non- } \\
\text { active }\end{array}$ & $\begin{array}{l}\text { Clean. } \\
\text { able }\end{array}$ & $\begin{array}{l}\text { Non- } \\
\text { clean- } \\
\text { able }\end{array}$ & $\begin{array}{l}\text { Acti- } \\
\text { vated }\end{array}$ \\
\hline 2010 & 0 & 0 & 0 & 0 & 0 & 0 & 0 & 0 & 0 & 0 & 0 & 0 \\
\hline 2011 & 0 & 0 & 0 & 0 & 0 & 0 & 0 & 0 & 0 & 0 & 0 & 0 \\
\hline 2012 & 0 & 0 & 0 & 0 & 0 & 0 & 0 & 0 & 0 & 0 & 0 & 0 \\
\hline 2013 & 0 & 0 & 0 & 0 & 0 & 0 & 0 & 0 & 0 & 0 & 0 & 0 \\
\hline 2014 & 0 & 0 & 0 & 0 & 0 & 0 & 0 & 0 & 0 & 0 & 0 & 0 \\
\hline 2015 & 0 & 0 & 0 & 0 & 0 & 0 & 0 & 0 & 0 & 0 & 0 & 0 \\
\hline 2016 & 0 & 0 & 0 & 0 & 1900 & 50 & 0 & 50 & 0 & 0 & 0 & 0 \\
\hline 2017 & 0 & 0 & 0 & 0 & 0 & 0 & 0 & 0 & 0 & 0 & 0 & 0 \\
\hline 2018 & 0 & 0 & 0 & 0 & 0 & 0 & 0 & 0 & 0 & 0 & 0 & 0 \\
\hline 2019 & 45 & 8 & 0 & 3 & 27.67 & 45 & 0 & 11 & 40 & 0 & 0 & 0 \\
\hline 2020 & 76 & 14 & 0 & 5 & 4679 & 76 & 0 & 19 & 40 & 0 & 0 & 0 \\
\hline 2021 & 46 & 9 & 0 & 3 & 2830 & 46 & 0 & 12 & 20 & 0 & 0 & , \\
\hline 2022 & 70 & 13 & 0 & 4 & 4295 & 70 & 0 & 18 & 40 & 0 & 0 & 0 \\
\hline 2023 & 30 & 6 & 0 & 2 & 1866 & 30 & 0 & 8 & 20 & 0 & 0 & 0 \\
\hline 2024 & 181 & 34 & 0 & 11 & 11063 & 181 & 0 & 45 & 60 & 0 & 0 & 0 \\
\hline 2025 & 120 & 23 & 0 & 8 & 7357 & 120 & 0 & 30 & 40 & 0 & 0 & 0 \\
\hline 2026 & 186 & 35 & 0 & 12 & 11381 & 186 & 0 & 46 & 60 & 0 & 0 & 0 \\
\hline 2027 & 54 & 10 & $0^{\circ}$ & 3 & 3313 & 54 & 0 & 14 & 20 & 0 & 0 & 0 \\
\hline 2028 & 396 & 74 & 0 & 25 & 24261 & 396 & 0 & 99 & 120 & 0 & 0 & 0 \\
\hline 2029 & 338 & 63 & 0 & 21 & 20679 & 338 & 0 & 84 & 100 & 0 & 0 & 0 \\
\hline 2030 & $0^{:}$ & 0 & 0 & 0 & 0 & 0 & 0 & 0 & 0 & 0 & 0 & 0 \\
\hline 2031 & 160 & 30 & 0 & 10 & 9799 & 160 & 0 & 40 & 60 & 0 & 0 & 0 \\
\hline 2032 & 200 & 38 & 0 & 13 & 12272 & 200 & 0 & 50 & 60 & 0 & 0 & 0 \\
\hline 2033 & 134 & 25. & 0 & 8 & 8234 & 134 & 0 & 34 & 40 & 0 & 0 & 0 \\
\hline 2034 & 237 & 44 & 0 & 15 & 14517 & 237 & 0 & 59 & 80 & 0 & 0 & 0 \\
\hline 2035 & 603 & 113 & 0 & 38 & 36906 & 603 & 0 & 151 & 160 & 0 & 0 & 0 \\
\hline 2036 & 255 & 48 & 0 & 16 & 15612 & 255 & 0 & 64 & 80 & 0 & 0 & 0 \\
\hline 2037 & $253^{\circ}$ & 47 & 0 & 16 & 15499 & 253 & 0 & 63 & 60 & 0 & 0 & 0 \\
\hline 2038 & 77 & 14 & 0 & 5 & 4712 & 77 & 0 & 19 & 20 & 0 & 0 & 0 \\
\hline 2039 & 199 & 37 & 0 & 12 & 12192 & 199 & 0 & 50 & 60 & 0 & 0 & 0 \\
\hline 2040 & 199 & 37 & 0 & 12 & 12176 & 199 & 0 & 50 & 60 & 0 & 0 & 0 \\
\hline 2041 & 172 & 32 & 0 & 11 & 10539 & 172 & 0 & 43 & 60 & 0 & 0 & 0 \\
\hline 2042 & 0 & 0 & 0 & 0 & 0 & 0 & 0 & 0 & 0 & 0 & 0 & 0 \\
\hline 2043 & 0 & 0 & 0 & 0 & 0 & 0 & 0 & 0 & 0 & 0 & 0 & 0 \\
\hline Inder & & & & & & & . & & & & & \\
\hline const. & 1412 & 265 & 0 & 88 & 86480 & 1412 & 0 & 353 & 460 & 0 & 0 & 0 \\
\hline
\end{tabular}


TABLE B.5 (Cont.); Part A (Cont.)

\begin{tabular}{|c|c|c|c|c|c|c|c|c|c|c|c|c|}
\hline \multirow{2}{*}{$\begin{array}{c}\text { Year } \\
\text { avall- } \\
\text { able }\end{array}$} & \multicolumn{4}{|c|}{ 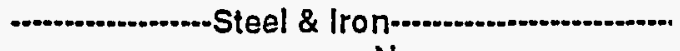 } & \multicolumn{4}{|c|}{ 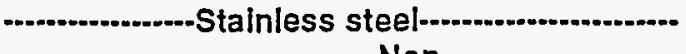 } & \multicolumn{4}{|c|}{ 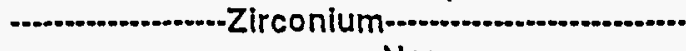 } \\
\hline & $\begin{array}{l}\text { Non- } \\
\text { actlve }\end{array}$ & $\begin{array}{l}\text { Clean- } \\
\text { able }\end{array}$ & $\begin{array}{l}\text { Non- } \\
\text { clean- } \\
\text { able }\end{array}$ & $\begin{array}{l}\text { Acti- } \\
\text { vated }\end{array}$ & $\begin{array}{l}\text { Non- } \\
\text { actlve }\end{array}$ & $\begin{array}{l}\text { Clean- } \\
\text { able }\end{array}$ & $\begin{array}{l}\text { Non- } \\
\text { clean- } \\
\text { able }\end{array}$ & $\begin{array}{l}\text { Acti- } \\
\text { vated }\end{array}$ & $\begin{array}{l}\text { Non- } \\
\text { active }\end{array}$ & $\begin{array}{l}\text { Clean- } \\
\text { able }\end{array}$ & $\begin{array}{l}\text { Non- } \\
\text { clean- } \\
\text { able }\end{array}$ & $\begin{array}{l}\text { Acti- } \\
\text { vated }\end{array}$ \\
\hline 2010 & 0 & 0 & 0 & 0 & 0 & 0 & 0 & 0 & 0 & 0 & 0 & 0 \\
\hline 2011 & 0 & 0 & 0 & 0 & 0 & 0 & 0 & 0 & 0 & 0 & 0 & 0 \\
\hline 2012 & 0 & 0 & 0 & 0 & 0 & 0 & 0 & 0 & 0 & 0 & 0 & 0 \\
\hline 2013 & 0 & 0 & 0 & 0 & 0 & 0 & 0 & 0 & 0 & 0 & 0 & 0 \\
\hline 2014 & 0 & 0 & 0 & 0 & 0 & 0 & 0 & 0 & 0 & 0 & 0 & 0 \\
\hline 2015 & 0 & 0 & 0 & 0 & 0 & 0 & 0 & 0 & 0 & 0 & 0 & 0 \\
\hline 2016 & 3800 & 4950 & 0 & 1000 & 100 & 0 & 0 & 0 & 0 & 0 & 0 & 0 \\
\hline 2017 & 0 & 0 & 0 & 0 & 0 & 0 & 0 & 0 & 0 & 0 & 0 & 0 \\
\hline 2018 & 0 & 0 & 0 & 0 & 0 & 0 & 0 & 0 & 0 & 0 & 0 & 0 \\
\hline 2019 & 2823 & 3783 & 0 & 1976 & 0 & 339 & 0 & 378 & 0 & 0 & 0 & 0 \\
\hline 2020 & 6314 & 6398 & 0 & 3080 & 0 & 713 & 140 & 640 & 0 & 0 & 0 & 0 \\
\hline 2021 & 2888 & 3870 & 0 & 2022 & 0 & 347 & 0 & 387 & 0 & 0 & 0 & 0 \\
\hline 2022 & 7188 & 5682 & 0 & 2577 & 79 & 1088 & 236 & 976 & 0 & 0 & 0 & 25 \\
\hline 2023 & 3046 & 2285 & 0 & 1119 & 110 & 762 & 76 & 800 & 0 & 0 & 0 & 25 \\
\hline 2024 & 14077 & 15127 & 0 & 7428 & 0 & 1609 & 254 & 1513 & 0 & 0 & 0 & 0 \\
\hline 2025 & 10295 & 10060 & 0 & 4781 & 0 & 1155 & 254 & 1006 & 0 & 0 & 0 & 0 \\
\hline 2026 & 14401 & 15562 & 0 & 7655 & 0 & 1648 & 254 & 1556 & 0 & 0 & 0 & 0 \\
\hline 2027 & 5605. & 4530 & 0 & 1988 & 0 & 609 & 203 & 453 & 0 & 0 & 0 & 0 \\
\hline 2028 & 26932 & 33173 & 0 & 16959 & 0 & 3169 & 198 & 3317 & 0 & 0 & 0 & 0 \\
\hline 2029 & 29110 & 28062 & 0 & 13392 & 88 & 3605 & 708 & 3263 & 0 & 0 & 0 & 25 \\
\hline 2030 & 0 & 0 & 0 & 0 & 0 & 0 & 0 & 0 & 0 & 0 & 0 & 0 \\
\hline 2031 & 13294 & 13133 & 0 & 6420 & 110 & 1929 & 272 & 1884 & 0 & 0 & 0 & 25 \\
\hline 2032 & 17095 & 16221 & 0 & 7948 & 232 & 2819 & 358 & 2820 & 0 & 0 & 0 & 25 \\
\hline 2033 & 10755 & 11258 & 0 & 5481 & 0 & 1223 & 215 & 1126 & 0 & 0 & 0 & 0 \\
\hline 2034 & 18946 & 19572 & 0 & 9646 & 115 & 2601 & 348 & 2552 & 0 & 0 & 0 & 25 \\
\hline 2035 & 55569 & 50464 & 0 & 23313 & 0 & 6152 & 1633 & 5046 & 0 & 0 & 0 & 0 \\
\hline 2036 & 26298 & 21070 & 0 & 9367 & 115 & 3304 & 916 & 2702 & 0 & 0 & 0 & 25 \\
\hline 2037 & 19353 & 21192 & 0 & 10468 & 0 & 2220 & 323 & 2119 & 0 & 0 & 0 & 0 \\
\hline 2038 & 7972 & 6443 & 0 & 2827 & 0 & 865 & 288 & 644 & 0 & 0 & 0 & 0 \\
\hline 2039 & 17813 & 16671 & 0 & 7794 & 0 & 1983 & 490 & 1667 & 0 & 0 & 0 & 0 \\
\hline 2040 & 13614 & 16371 & 0 & 8475 & 115 & 2046 & 79 & 2232 & 0 & 0 & 0 & 25 \\
\hline 2041 & 17715 & 14133 & 0 & 6323 & 115 & 2372 & 606 & 2008 & 0 & 0 & 0 & 25 \\
\hline 2042 & 0 & 0 & 0 & 0 & 0 & 0 & 0 & 0 & 0 & 0 & 0 & 0 \\
\hline 2043 & 0 & 0 & 0 & 0 & 0 & 0 & 0 & 0 & 0 & 0 & 0 & 0 \\
\hline \multicolumn{13}{|l|}{ Under } \\
\hline const. & 132915 & 116024 & 0 & 54011 & 922 & 18243 & 3840 & 16369 & 0 & 0 & 0 & 175 \\
\hline
\end{tabular}


TABLE B.5 (Cont.); Part B: Start-Up Plus 100 Years

\begin{tabular}{|c|c|c|c|c|c|c|c|c|c|c|c|c|}
\hline \multirow{2}{*}{$\begin{array}{l}\text { Year } \\
\text { avall- } \\
\text { able }\end{array}$} & \multicolumn{4}{|c|}{.............................Aluminum } & \multicolumn{4}{|c|}{ 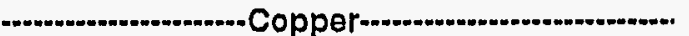 } & \multicolumn{4}{|c|}{ 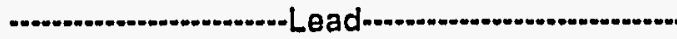 } \\
\hline & $\begin{array}{l}\text { Non- } \\
\text { actlve }\end{array}$ & $\begin{array}{c}\text { Clean- } \\
\text { able }\end{array}$ & $\begin{array}{l}\text { Non- } \\
\text { clean- } \\
\text { able }\end{array}$ & $\begin{array}{l}\text { Actl- } \\
\text { vated }\end{array}$ & $\begin{array}{l}\text { Non- } \\
\text { active }\end{array}$ & $\begin{array}{l}\text { Clean- } \\
\text { able }\end{array}$ & $\begin{array}{c}\text { Non- } \\
\text { clean- } \\
\text { able }\end{array}$ & $\begin{array}{l}\text { Acti- } \\
\text { vated }\end{array}$ & $\begin{array}{l}\text { Non- } \\
\text { active }\end{array}$ & $\begin{array}{c}\text { Clean- } \\
\text { able }\end{array}$ & $\begin{array}{l}\text { Non- } \\
\text { clean- } \\
\text { able }\end{array}$ & $\begin{array}{l}\text { Actl. } \\
\text { vated }\end{array}$ \\
\hline 2060 & 0 & 0 & 0 & 0 & 0 & 0 & 0 & 0 & 0 & 0 & 0 & 0 \\
\hline 2061 & 0 & 0 & 0 & 0 & 0 & 0 & 0 & 0 & 0 & 0 & 0 & 0 \\
\hline 2062 & 0 & 0 & 0 & 0 & 0 & 0 & 0 & 0 & 0 & 0 & 0 & 0 \\
\hline 2063 & 0 & 0 & 0 & 0 & 0 & 0 & 0 & 0 & 0 & 0 & 0 & 0 \\
\hline 2064 & 0 & 0 & 0 & 0 & 0 & 0 & 0 & 0 & 0 & 0 & 0 & 0 \\
\hline 2065 & 0 & 0 & 0 & 0 & 0 & 0 & 0 & 0 & 0 & 0 & 0 & 0 \\
\hline 2066 & 0 & 0 & 0 & 0 & 1925 & 25 & 0 & 50 & 0 & 0 & 0 & 0 \\
\hline 2067 & 0 & 0 & 0 & 0 & 0 & 0 & 0 & 0 & 0 & 0 & 0 & 0 \\
\hline 2068 & 0 & 0 & 0 & 0 & 0 & 0 & 0 & 0 & 0 & 0 & 0 & 0 \\
\hline 2069 & 51 & 4 & 0 & 1 & 2789 & 23 & 0 & 11 & 40 & 0 & 0 & 0 \\
\hline 2070 & 86 & 7 & 0 & 2 & 4718 & 38 & 0 & 19 & 40 & 0 & 0 & 0 \\
\hline 2071 & 52 & 4 & 0 & 1 & 2853 & 23 & 0 & 12 & 20 & 0 & 0 & 0 \\
\hline 2072 & 79 & 7 & 0 & 2 & 4330 & 35 & 0 & 18 & 40 & 0 & 0 & 0 \\
\hline 2073 & 34 & 3 & 0 & 1 & 1881 & 15 & 0 & 8 & 20 & 0 & 0 & 0 \\
\hline 2074 & 203 & 17 & 0 & 6 & 11153 & 90 & 0 & 45 & 60 & 0 & 0 & 0 \\
\hline 2075 & 135 & 11 & 0 & 4 & 7417 & 60 & 0 & 30 & 40 & 0 & 0 & 0 \\
\hline 2076 & 209 & 17 & 0 & 6 & 11474 & 93 & 0 & 46 & 60 & 0 & 0 & 0 \\
\hline 2077 & 61 & 5 & 0 & 2 & 3340 & 27 & 0 & 14 & 20 & 0 & 0 & 0 \\
\hline 2078 & 446 & 37 & 0 & 12 & 24459 & . $\quad 198$ & 0 & 99 & 120 & 0 & 0 & 0 \\
\hline 2079 & 380 & 32 & 0 & 11 & 20847 & 169 & 0 & 84 & 100 & 0 & 0 & 0 \\
\hline 2080 & 0 & 0 & 0 & 0 & 0 & 0 & 0 & 0 & 0 & 0 & 0 & 0 \\
\hline 2081 & 180 & 15 & 0 & 5 & 9879 & 80 & 0 & 40 & 60 & 0 & 0 & 0 \\
\hline 2082 & 225 & 19 & 0 & 6 & 12372 & 100 & 0 & 50 & 60 & 0 & 0 & 0 \\
\hline 2083 & 151 & 13 & 0 & 4 & 8301 & 67 & 0 . & 34 & 40 & 0 & 0 & 0 \\
\hline 2084 & 267 & 22 & 0 & 7 & 14636 & 119 & 0 & 59 & 80 & 0 & 0 & 0 \\
\hline 2085 & 678 & 56 & 0 & 19 & 37208 & 301 & 0 & 151 & 160 & 0 & 0 & 0 \\
\hline 2086 & 287 & 24 & 0 & 8 & 15740 & 127 & 0 & 64 & 80 & 0 & 0 & 0 \\
\hline 2087 & 285 & 24 & 0 & 8 & 15625 & 127 & 0 & 63 & 60 & 0 & 0 & 0 \\
\hline 2088 & 87 & 7 & 0 & 2 & 4750 & 38 & 0 & 19 & 20 & 0 & 0 & 0 \\
\hline 2089 & 224 & 19 & 0 & 6 & 12292 & 100 & 0 & 50 & 60 & 0 & 0 & 0 \\
\hline 2090 & 224 & 19 & 0 & 6 & 12275 & 99 & 0 & 50 & 60 & 0 & 0 & 0 \\
\hline 2091 & 194 & 16 & 0 & 5 & 10625 & 86 & 0 & 43 & 60 & 0 & 0 & 0 \\
\hline 2092 & 0 & 0 & 0 & 0 & 0 & 0 & 0 & 0 & 0 & 0 & 0 & 0 \\
\hline 2093 & 0 & 0 & . 0 & 0 & 0 & 0 & 0 & 0 & 0 & 0 & 0 & 0 \\
\hline Under & & & & & & & & & & & & \\
\hline const. & 1588 & 132 & 0 & 44 & 87186 & 706 & 0 & 353 & 460 & 0 & 0 & 0 \\
\hline
\end{tabular}


TABLE B.5 (Cont.); Part B (Cont.)

\begin{tabular}{|c|c|c|c|c|c|c|c|c|c|c|c|c|}
\hline \multirow{2}{*}{$\begin{array}{c}\text { Year } \\
\text { avail- } \\
\text { able }\end{array}$} & \multicolumn{4}{|c|}{ 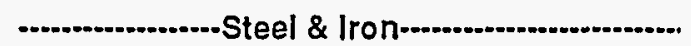 } & \multicolumn{4}{|c|}{ 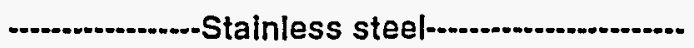 } & \multicolumn{4}{|c|}{-Zirconium } \\
\hline & $\begin{array}{l}\text { Non- } \\
\text { active }\end{array}$ & $\begin{array}{c}\text { Clean- } \\
\text { able }\end{array}$ & $\begin{array}{l}\text { Non- } \\
\text { clean- } \\
\text { able }\end{array}$ & $\begin{array}{l}\text { Acti- } \\
\text { vated }\end{array}$ & $\begin{array}{l}\text { Non- } \\
\text { active }\end{array}$ & $\begin{array}{l}\text { Clean- } \\
\text { able }\end{array}$ & $\begin{array}{l}\text { Non- } \\
\text { clean- } \\
\text { able }\end{array}$ & $\begin{array}{l}\text { Acti- } \\
\text { vated }\end{array}$ & $\begin{array}{l}\text { Non- } \\
\text { active }\end{array}$ & $\begin{array}{c}\text { Clean- } \\
\text { able }\end{array}$ & $\begin{array}{l}\text { Non- } \\
\text { clean- } \\
\text { able }\end{array}$ & $\begin{array}{l}\text { Actl- } \\
\text { vated }\end{array}$ \\
\hline 2060 & 0 & 0 & 0 & 0 & 0 & 0 & 0 & 0 & 0 & 0 & 0 & 0 \\
\hline 2061 & 0 & 0 & 0 & 0 & 0 & 0 & 0 & 0 & 0 & 0 & 0 & 0 \\
\hline 2062 & 0 & 0 & 0 & 0 & 0 & 0 & 0 & 0 & 0 & 0 & 0 & 0 \\
\hline 2063 & 0 & 0 & 0 & 0 & 0 & 0 & 0 & 0 & 0 & 0 & 0 & 0 \\
\hline 2064 & 0 & 0 & 0 & 0 & 0 & 0 & 0 & 0 & 0 & 0 & 0 & 0 \\
\hline 2065 & 0 & 0 & 0 & 0 & 0 & 0 & 0 & 0 & 0 & 0 & 0 & 0 \\
\hline 2066 & 6775 & 2475 & 0 & 500 & 100 & 0 & 0 & .0 & 0 & 0 & 0 & 0 \\
\hline 2067 & 0 & 0 & 0 & 0 & 0 & 0 & 0 & 0 & 0 & 0 & 0 & 0 \\
\hline 2068 & 0 & 0 & 0 & 0 & 0 & 0 & 0 & 0 & 0 & 0 & 0 & 0 \\
\hline 2069 & 5703 & 1891 & 0 & 988 & 169 & 169 & 0 & $\dot{3} 78$ & 0 & 0 & 0 & 0 \\
\hline 2070 & 11054 & 3199 & 0 & 1540 & 427 & 357 & 70 & 640 & 0 & 0 & 0 & 0 \\
\hline 2071 & 5834 & 1935 & 0 & 1011 & 173 & 173 & 0 & 387 & 0 & 0 & 0 & 0 \\
\hline 2072 & 11317 & 2841 & 0 & 1288 & 741 & 544 & 118 & 976 & 13 & 0 & 0 & 13 \\
\hline 2073 & 4748 & 1142 & 0 & 560 & 529 & 381 & 38 & 800 & 13 & 0 & 0 & 13 \\
\hline 2074 & 25354 & 7564 & 0 & 3714 & 932 & 804 & 127 & 1513 & 0 & 0 & 0 & 0 \\
\hline 2075 & 17715 & 5030 & 0 & 2390 & 705 & 578 & 127 & 1006 & 0 & 0 & 0 & 0 \\
\hline 2076 & 26009 & 7781 & 0 & 3827 & 951 & 824 & 127 & 1556 & 0 & 0 & 0 & 0 \\
\hline 2077 & 8864 & 2265 & 0 & 994 & 406 & 304 & 101 & 453 & 0 & 0 & 0 & 0 \\
\hline 2078 & 51998 & 16586 & 0 & 8479 & 1684 & 1585 & 99 & 3317 & 0 & 0 & 0 & 0 \\
\hline 2079 & 49837 & 14031 & 0 & 6696 & 2245 & 1803 & 354 & 3263 & 13 & 0 & 0 & 13 \\
\hline 2080 & 0 & 0 & 0 & 0 & 0 & 0 & 0 & 0 & 0 & 0 & 0 & 0 \\
\hline 2081 & 23070 & 6566 & 0 & 3210 & 1211 & 965 & 136 & 1884 & 13 & 0 & 0 & 13 \\
\hline 2082 & 29180 & 8110 & 0 & 3974 & 1821 & 1410 & 179 & 2820 & 13 & 0 & 0 & 13 \\
\hline 2083 & 19125 & 5629 & 0 & 2740 & 719 & 611 & 107 & 1126 & 0 & 0 & 0 & 0 \\
\hline 2084 & 33555 & 9786 & 0 & 4823 & 1589 & 1301 & 174 & 2552 & 13 & 0 & 0 & 13 \\
\hline 2085 & 92457 & 25232 & 0 & 11657 & 3893 & 3076 & 817 & 5046 & 0 & 0 & 0 & 0 \\
\hline 2086 & 41517 & 10535 & 0 & 4684 & 2225 & 1652 & 458 & 2702 & 13 & 0 & 0 & 13 \\
\hline 2087 & 35183 & 10596 & 0 & 5234 & 1271 & 1110 & 161 & 2119 & 0 & 0 & 0 & 0 \\
\hline 2088 & 12607 & 3221 & 0 & 1414 & 577 & 433 & 144 & 644 & 0 & 0 & 0 & 0 \\
\hline 2089 & 30046 & 8336 & 0 & 3897 & 1236 & 991 & 245 & 1667 & 0 & 0 & 0 & 0 \\
\hline 2090 & 26037 & 8186 & 0 & 4238 & 1178 & 1023 & 40 & 2232 & 13 & 0 & 0 & 13 \\
\hline 2091 & 27943 & 7066 & 0 & 3162 & 1604 & 1186 & 303 & 2008 & 13 & 0 & 0 & 13 \\
\hline 2092 & 0 & 0 & 0 & 0 & 0 & 0 & 0 & 0 & 0 & 0 & 0 & 0 \\
\hline 2093 & 0 & 0 & 0 & 0 & 0 & 0 & 0 & 0 & 0 & 0 & 0 & 0 \\
\hline \multicolumn{13}{|l|}{ Under } \\
\hline const. & 217933 & 58012 & 0 & 27005 & 11963 & 9121 & 1920 & 16369 & 88 & 0 & 0 & 88 \\
\hline
\end{tabular}


TABLE B.5 (Cont.); Part C: Start-Up Plus 150 Years

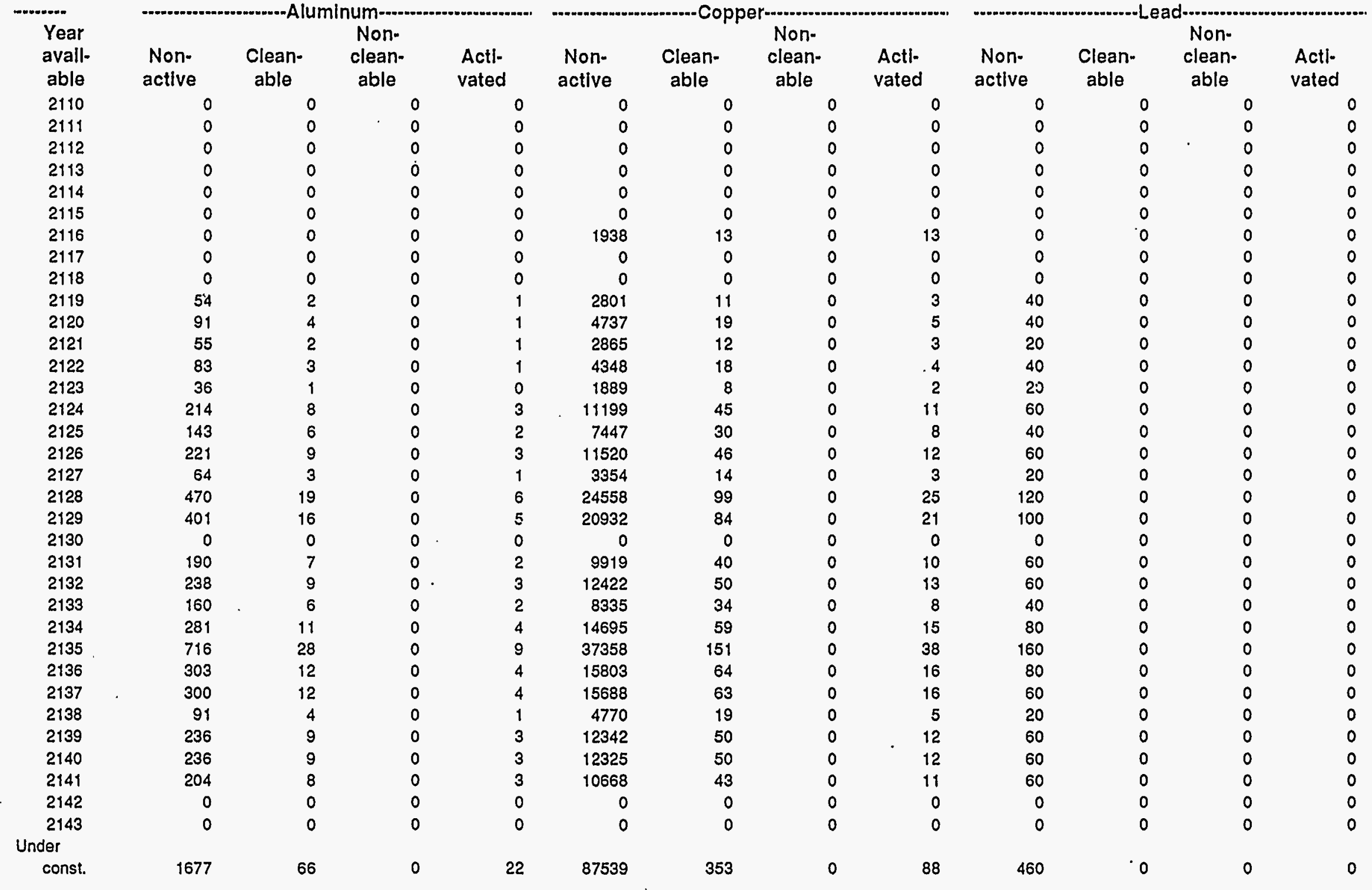


TABLE B.5 (Cont.); Part C (Cont.)

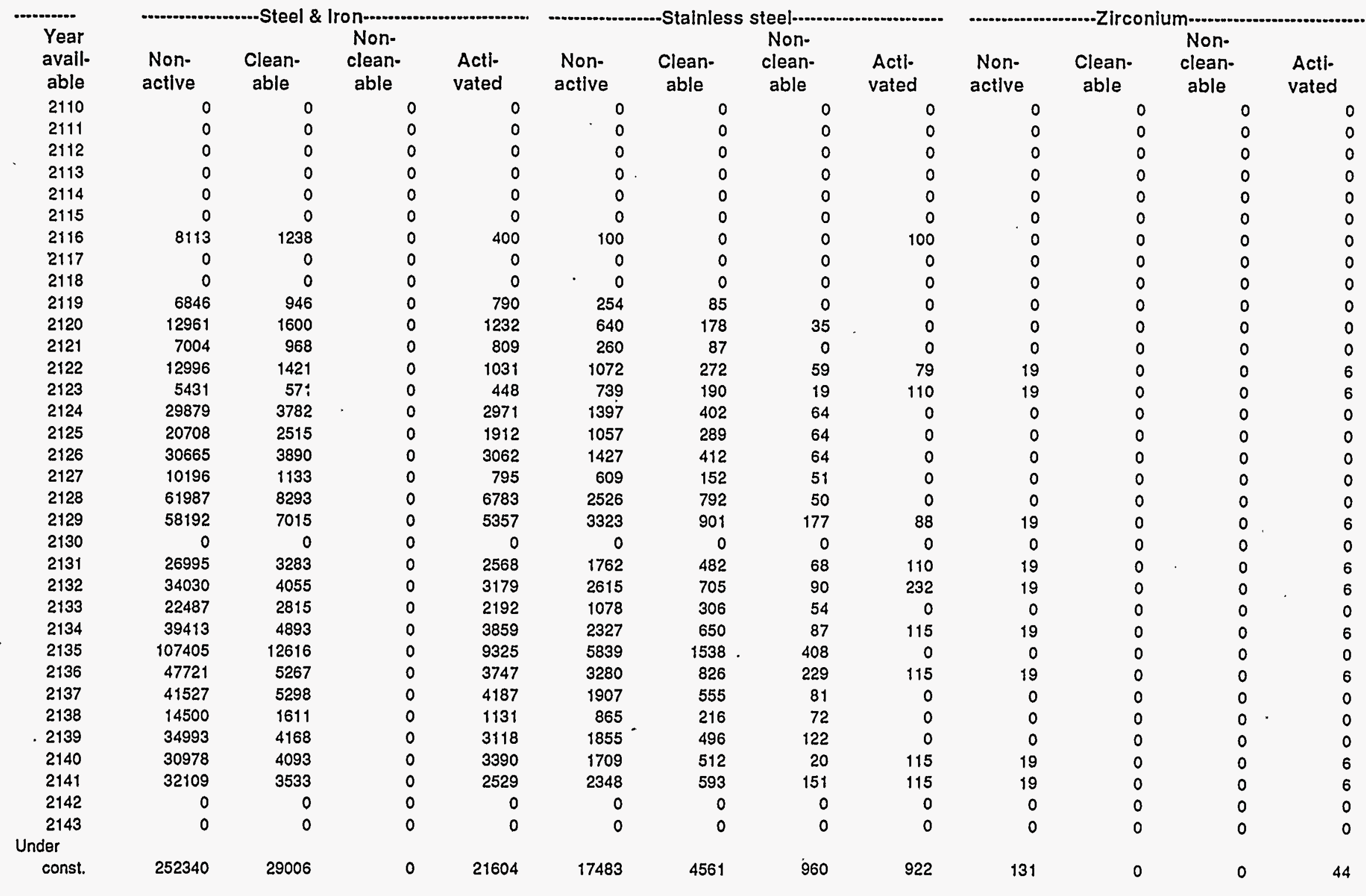




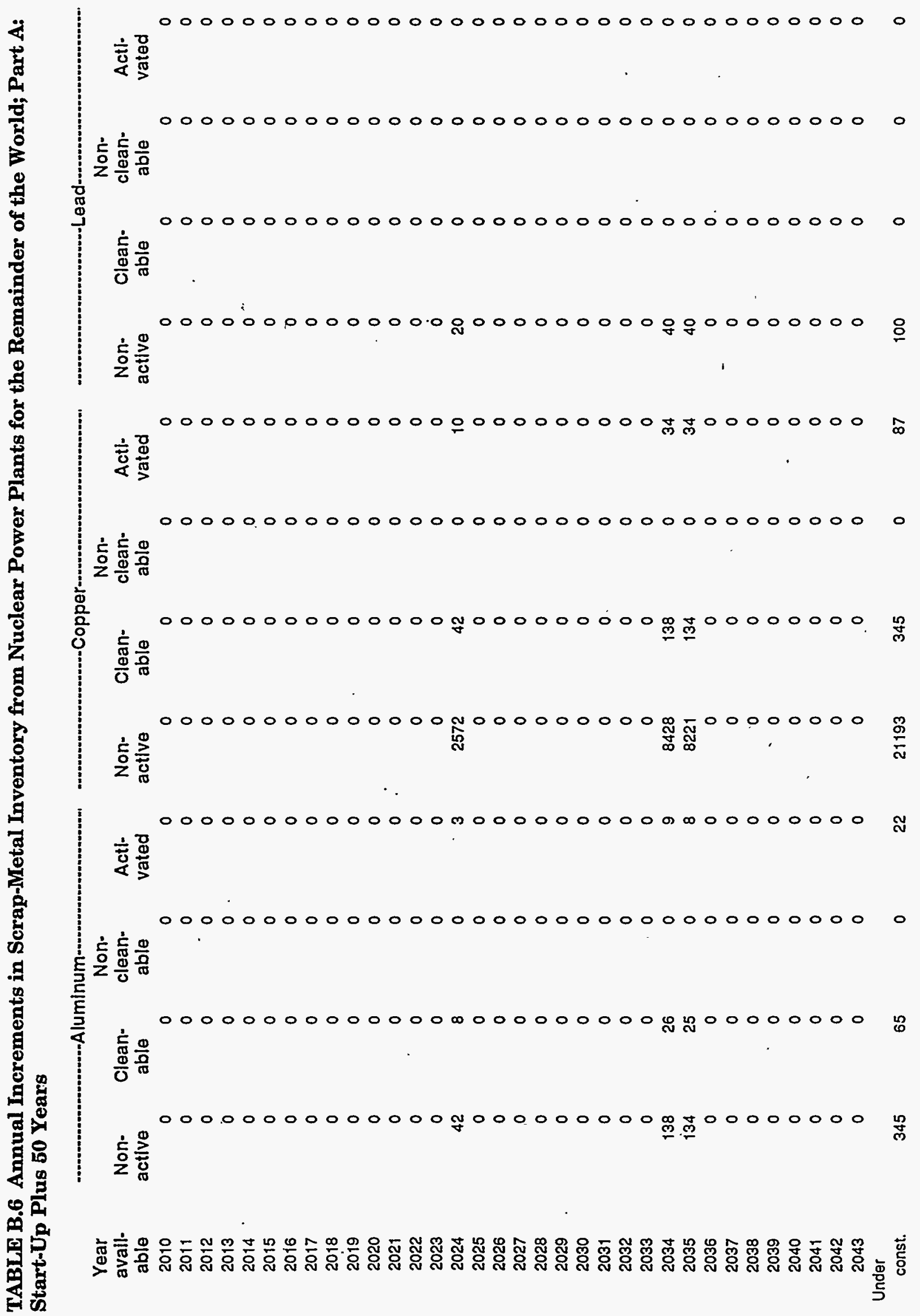




\section{TABLE B.6 (Cont.); Part A (Cont.)}

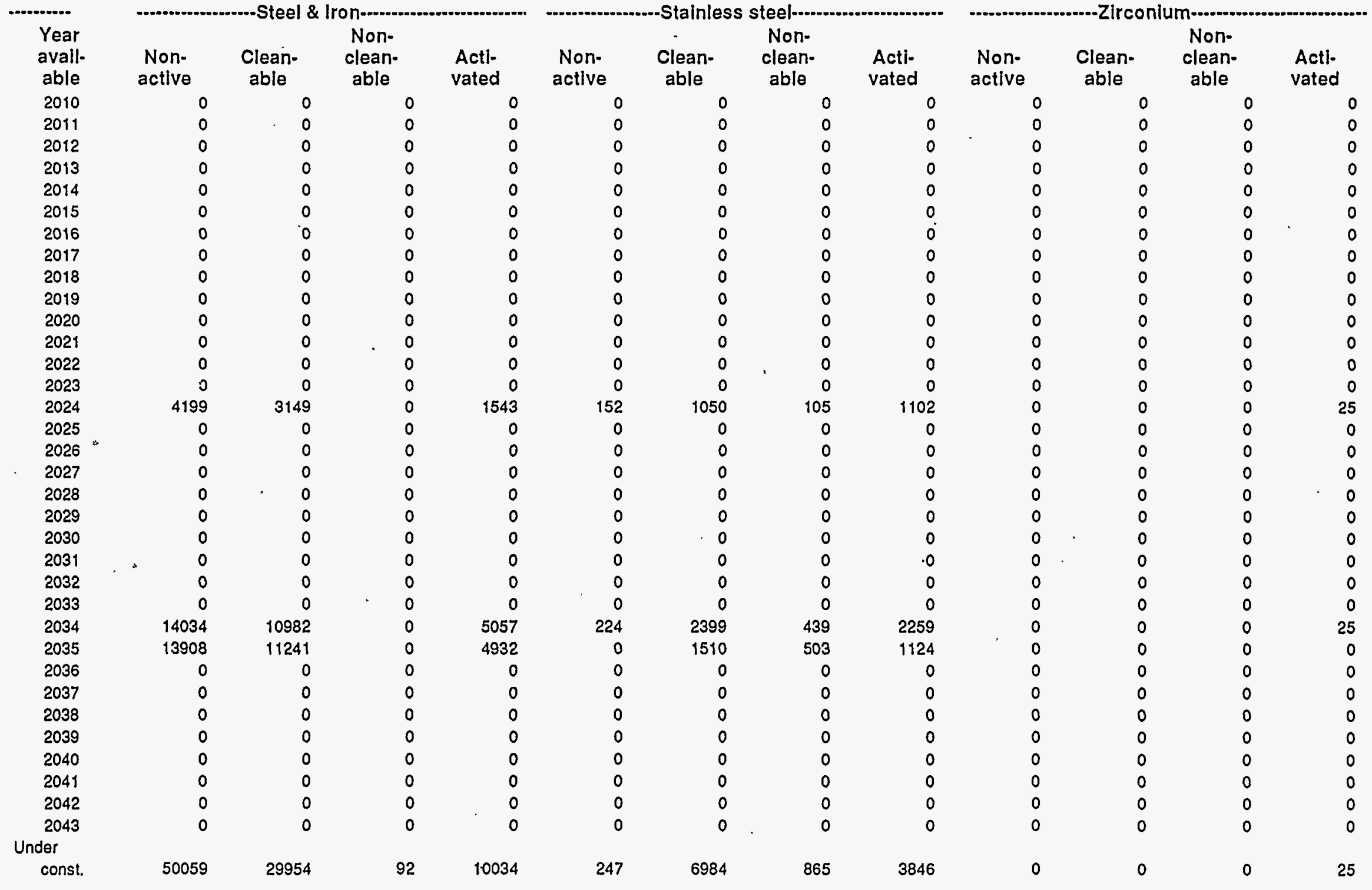


TABLE B.6 (Cont.); Part B: Start-Up Plus 100 Years

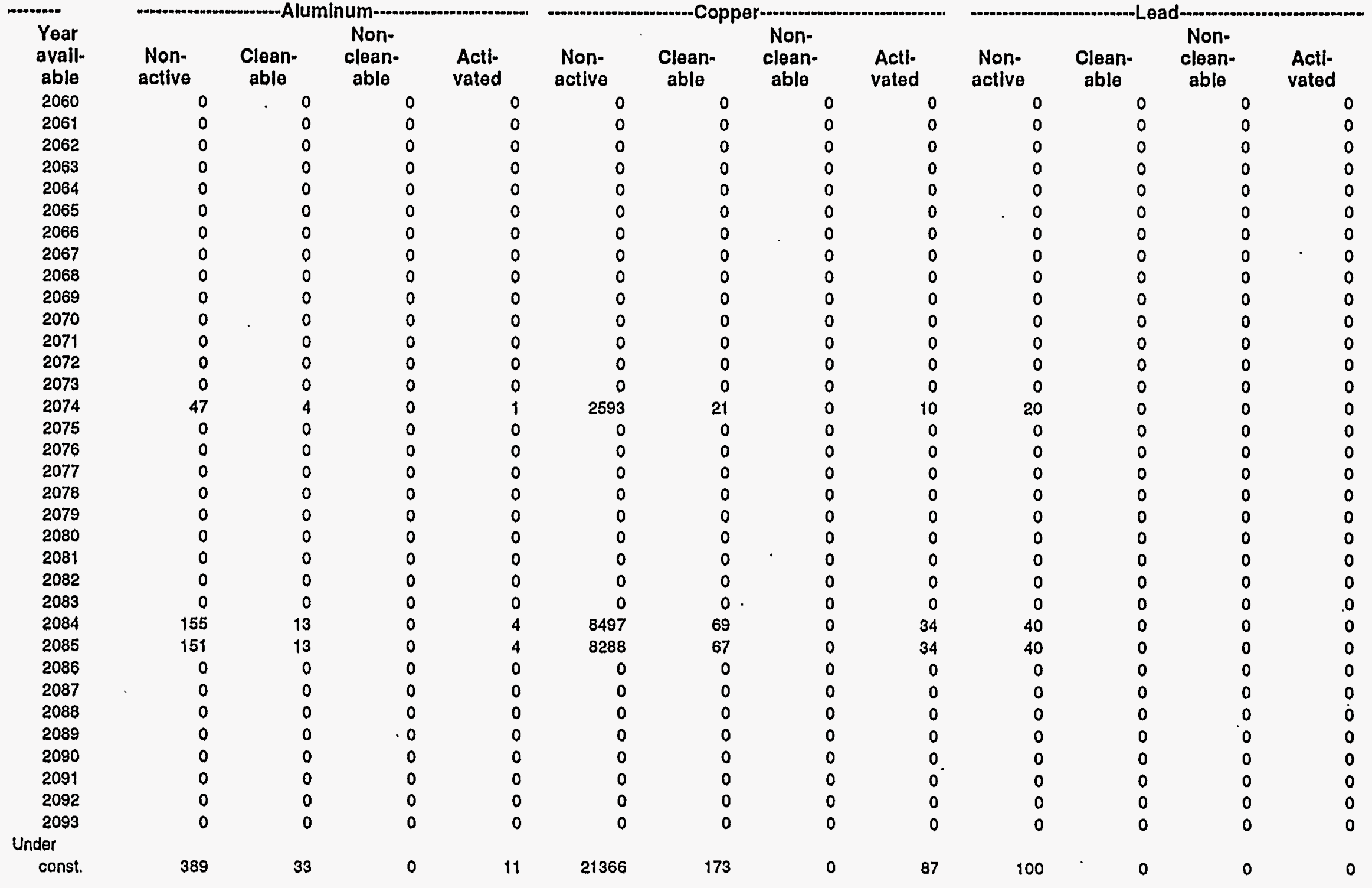


TABLE B.6 (Cont.); Part B (Cont.)

\begin{tabular}{|c|c|c|c|c|c|c|c|c|c|c|c|c|}
\hline -........... & -............. & ...-Steel \& & on............... & י.................. & -............... & -Stainles & steel-....... & . & ................ & -.--Zircor & m................... & .................. \\
\hline $\begin{array}{c}\text { Year } \\
\text { avail- } \\
\text { able }\end{array}$ & $\begin{array}{l}\text { Non- } \\
\text { active }\end{array}$ & $\begin{array}{l}\text { Clean- } \\
\text { able }\end{array}$ & $\begin{array}{l}\text { Non- } \\
\text { clean- } \\
\text { able }\end{array}$ & $\begin{array}{l}\text { Acti- } \\
\text { vated }\end{array}$ & $\begin{array}{l}\text { Non- } \\
\text { active }\end{array}$ & $\begin{array}{l}\text { Clean- } \\
\text { able }\end{array}$ & $\begin{array}{l}\text { Non- } \\
\text { clean- } \\
\text { able }\end{array}$ & $\begin{array}{l}\text { Acti- } \\
\text { vated }\end{array}$ & $\begin{array}{l}\text { Non- } \\
\text { active }\end{array}$ & $\begin{array}{l}\text { Clean- } \\
\text { able }\end{array}$ & $\begin{array}{l}\text { Non- } \\
\text { clean- } \\
\text { able }\end{array}$ & $\begin{array}{l}\text { Acti- } \\
\text { vated }\end{array}$ \\
\hline 2060 & 0 & 0 & 0 & 0 & 0 & 0 & 0 & 0 & 0 & 0 & 0 & 0 \\
\hline 2061 & 0 & 0 & 0 & 0 & 0 & 0 & 0 & 0 & 0 & 0 & 0 & 0 \\
\hline 2062 & 0 & 0 & 0 & 0 & 0 & 0 & 0 & 0 & 0 & 0 & 0 & 0 \\
\hline 2063 & 0 & 0 & 0 & 0 & 0 & 0 & 0 & 0 & 0 & 0 & 0 & 0 \\
\hline 2064 & 0 & 0 & 0 & 0 & 0 & 0 & 0 & 0 & 0 & 0 & 0 & 0 \\
\hline 2065 & 0 & 0 & 0 & 0 & 0 & 0 & 0 & 0 & 0 & 0 & 0 & 0 \\
\hline 2066 & 0 & 0 & 0 & 0 & 0 & 0 & 0 & 0 & 0 & 0 & 0 & 0 \\
\hline 2067 & 0 & 0 & 0 & 0 & 0 & 0 & 0 & 0 & 0 & 0 & 0 & 0 \\
\hline 2068 & 0 & 0 & 0 & 0 & 0 & 0 & 0 & 0 & 0 & 0 & 0 & 0 \\
\hline 2069 & 0 & 0 & 0 & 0 & 0 & 0 & 0 & 0 & 0 & 0 & 0 & 0 \\
\hline 2070 & 0 & 0 & 0 & 0 & 0 & 0 & 0 & 0 & 0 & 0 & 0 & 0 \\
\hline 2071 & 0 & 0 & 0 & 0 & 0 & 0 & 0 & 0 & 0 & 0 & 0 & 0 \\
\hline 2072 & 0 & 0 & 0 & 0 & 0 & 0 & 0 & 0 & 0 & 0 & 0 & 0 \\
\hline 2073 & 0 & 0 & 0 & 0 & 0 & .0 & 0 & $c$ & 0 & 0 & 0 & 0 \\
\hline 2074 & 6545 & 1575 & 0 & 772 & 730 & 525 & 52 & 1102 & 13 & 0 & 0 & 13 \\
\hline 2075 & 0 & 0 & 0 & 0 & 0 & 0 & 0 & 0 & 0 & 0 & 0 & 0 \\
\hline 2076 & 0 & 0 & 0. & 0 & 0 & 0 & 0 & 0 & 0 & 0 & 0 & 0 \\
\hline 2077 & 0 & 0 & 0 & 0 & 0 & 0 & 0 & 0 & 0 & 0 & 0 & 0 \\
\hline 2078 & 0 & 0 & 0 & 0 & 0 & 0 & 0 & 0 & 0 & 0 & 0 & 0 \\
\hline 2079 & 0 & 0 & 0 & $0^{\prime}$ & 0 & 0 & 0 & 0 & 0 & 0 & 0 & 0 \\
\hline 2080 & 0 & 0 & 0 & 0 & 0 & 0 & 0 & 0 & 0 & 0 & 0 & 0 \\
\hline .2081 & 0 & 0 & 0 & 0 & 0 & 0 & 0 & 0 & 0 & 0 & 0 & 0 \\
\hline 2082 & 0 & 0 & 0 & 0 & 0 & 0 & 0. & 0 & 0 & 0 & 0 & 0 \\
\hline 2083 & 0 & 0 & 0 & 0 & 0 & 0 & 0 & 0 & 0 & 0 & 0 & 0 \\
\hline 2084 & 22054 & 5491 & 0 & 2528 & 1644 & 1200 & 219 & 2259 & 13 & 0 & 0 & 13 \\
\hline 2085 & 21995 & 5620 & 0 & 2466 & 1007 & 755 & 252 & 1124 & 0 & 0 & 0 & 0 \\
\hline 2086 & 0 & 0 & 0 & 0 & 0 & 0 & 0 & 0 & 0 & 0 & 0 & 0 \\
\hline 2087 & 0 & 0 & 0 & 0 & 0 & 0 & 0 & 0 & 0 & 0 & 0 & 0 \\
\hline 2088 & 0 & 0. & 0 & 0 & 0 & 0 & 0 & 0 & 0 & 0 & 0 & 0 \\
\hline 2089 & 0 & 0 & 0 & 0 & 0 & 0 & 0 & 0 & 0 & 0 & 0 & 0 \\
\hline 2090 & 0 & 0 & 0 & 0 & 0 & 0 & 0 & 0 & 0 & 0 & 0 & 0 \\
\hline 2091 & 0 & 0 & 0 & 0 & 0 & 0 & 0 & 0 & 0 & 0 & 0 & 0 \\
\hline 2092 & 0 & 0 & 0 & 0 & 0 & 0 & 0 & 0 & 0 & 0 & 0 & 0 \\
\hline 2093 & 0 & 0 & 0 & 0 & 0 & 0 & 0 & 0 & 0 & 0 & 0 & 0 \\
\hline \multicolumn{13}{|l|}{ Under } \\
\hline const. & 70098 & 14977 & 46 & 5017 & 4171 & 3492 & 432 & 3846 & 13 & 0 & 0 & 13 \\
\hline
\end{tabular}


TABLE B.6 (Cont.); Part C: Start-Up Plus 150 Years

\begin{tabular}{|c|c|c|c|c|c|c|c|c|c|c|c|c|}
\hline \multirow{2}{*}{$\begin{array}{c}\text { Year } \\
\text { avall- } \\
\text { able }\end{array}$} & \multicolumn{4}{|c|}{ 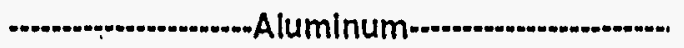 } & \multicolumn{4}{|c|}{ 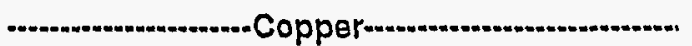 } & \multicolumn{4}{|c|}{$\ldots$} \\
\hline & $\begin{array}{l}\text { Non- } \\
\text { active }\end{array}$ & $\begin{array}{l}\text { Clean- } \\
\text { able }\end{array}$ & $\begin{array}{l}\text { Non- } \\
\text { clean- } \\
\text { able }\end{array}$ & $\begin{array}{l}\text { Acti- } \\
\text { vated }\end{array}$ & $\begin{array}{l}\text { Non- } \\
\text { active }\end{array}$ & $\begin{array}{l}\text { Clean- } \\
\text { able }\end{array}$ & $\begin{array}{l}\text { Non- } \\
\text { clean- } \\
\text { able }\end{array}$ & $\begin{array}{l}\text { Actl- } \\
\text { vated }\end{array}$ & $\begin{array}{l}\text { Non- } \\
\text { active }\end{array}$ & $\begin{array}{l}\text { Clean- } \\
\text { able }\end{array}$ & $\begin{array}{l}\text { Non- } \\
\text { clean- } \\
\text { able }\end{array}$ & $\begin{array}{l}\text { Acti- } \\
\text { vated }\end{array}$ \\
\hline 2110 & 0 & 0 & 0 & 0 & 0 & 0 & 0 & 0 & 0 & 0 & 0 & 0 \\
\hline 2111 & 0 & 0 & 0 & 0 & 0 & 0 & 0 & 0 & 0 & 0 & 0 & 0 \\
\hline 2112 & 0 & 0 & 0 & 0 & 0 & 0 & 0 & 0 & 0 & 0 & 0 & 0 \\
\hline 2113 & 0 & 0 & 0 & 0 & 0 & 0 & 0 & 0 & 0 & 0 & 0 & 0 \\
\hline 2114 & 0 & 0 & 0 & 0 & 0 & 0 & 0 & 0 & 0 & 0 & 0 & 0 \\
\hline 2115 & 0 & 0 & 0 & 0 & 0 & 0 & 0 & 0 & 0 & 0 & 0 & 0 \\
\hline 2116 & 0 & 0 & 0 & 0 & 0 & 0 & 0 & 0 & 0 & 0 & 0 & 0 \\
\hline 2117 & 0 & 0 & 0 & 0 & 0 & 0 & 0 & 0 & 0 & 0 & 0 & 0 \\
\hline 2118 & 0 & 0 & 0 & 0 & 0 & 0 & 0 & 0 & 0 & 0 & 0 & 0 \\
\hline 2119 & 0 & 0 & 0 & 0 & 0 & 0 & 0 & 0 & 0 & 0 & 0 & 0 \\
\hline 2120 & 0 & 0 & 0 & 0 & 0 & 0 & 0 & 0 & 0 & 0 & 0 & 0 \\
\hline 2121 & 0 & 0 & 0 & 0 & 0 & 0 & 0 & 0 & 0 & 0 & 0 & 0 \\
\hline 2122 & 0 & 0 & 0 & 0 & 0 & 0 & 0 & 0 & 0 & 0 & 0 & 0 \\
\hline 2123 & 0 & 0 & 0 & 0 & 0 & 0 & 0 & 0 & 0 & 0 & 0 & 0 \\
\hline 2124 & 50 & 2 & 0 & 1 & 2603 & 10 & 0 & 3 & 20 & 0 & 0 & 0 \\
\hline 2125 & 0 & 0 & 0 & 0 & 0 & 0 & 0 & 0 & 0 & 0 & 0 & 0 \\
\hline 2126 & 0 & 0 & 0 & 0 & 0 & 0 & 0 & 0 & 0 & 0 & 0 & 0 \\
\hline 2127 & 0 & 0 & 0 & 0 & 0 & 0 & 0 & 0 & 0 & 0 & 0 & 0 \\
\hline 2128 & 0 & 0 & 0 & 0 & 0 & 0 & 0 & 0 & 0 & 0 & 0 & 0 \\
\hline 2129 & 0 & 0 & 0 & 0 & 0 & 0 & 0 & 0 & 0 & 0 & 0 & 0 \\
\hline 2130 & 0 & 0 & 0 & 0 & 0 & 0 & 0 & 0 & 0 & 0 & 0 & 0 \\
\hline 2131 & 0 & 0 & 0 & 0 & 0 & 0 & 0 & 0 & 0 & 0 & 0 & 0 \\
\hline 2132 & 0 & 0 & 0 & 0 & 0 & 0 & 0 & 0 & 0 & 0 & 0 & 0 \\
\hline 2133 & 0 & 0 & 0 & 0 & 0 & 0 & 0 & 0 & 0 & 0 & 0 & 0 \\
\hline 2134 & 163 & 6 & 0 & 2 & 8531 & 34 & 0 & 9 & 40 & 0 & 0 & 0 \\
\hline 2135 & 159 & 6 & 0 & 2 & 8321 & 34 & 0 & 8 & 40 & 0 & 0 & 0 \\
\hline 2136 & 0 & 0 & 0 & 0 & 0 & 0 & 0 & 0 & 0 & 0 & 0 & 0 \\
\hline 2137 & 0 & 0 & 0 & 0 & 0 & 0 & 0 & 0 & 0 & 0 & 0 & 0 \\
\hline 2138 & 0 & 0 & 0 & 0 & 0 & 0 & 0 & 0 & 0 & 0 & 0 & 0 \\
\hline 2139 & 0 & 0 & 0 & 0 & 0 & 0 & 0 & 0 & 0 & 0 & 0 & 0 \\
\hline 2140 & 0 & 0 & 0 & 0 & 0 & 0 & 0 & 0 & 0 & 0 & 0 & 0 \\
\hline 2141 & 0 & 0 & 0 & 0 & 0 & 0 & 0 & 0 & 0 & 0 & 0 & 0 \\
\hline 2142 & 0 & 0 & 0 & 0 & 0 & 0 & 0 & 0 & 0 & 0 & 0 & 0 \\
\hline 2143 & 0 & 0 & 0 & 0 & 0 & 0 & 0 & 0 & 0 & 0 & 0 & 0 \\
\hline Under & & & & & & & & & & & & \\
\hline const. & 411 & 16 & 0 & 5 & 21452 & 86 & 0 & 22 & 100 & 0 & 0 & 0 \\
\hline
\end{tabular}




\section{TABLE B.6 (Cont.); Part C (Cont.)}

\begin{tabular}{|c|c|c|c|c|c|c|c|c|c|c|c|c|}
\hline $\begin{array}{c}\text { Year } \\
\text { avail- } \\
\text { able }\end{array}$ & $\begin{array}{l}\text { Non- } \\
\text { active }\end{array}$ & $\begin{array}{l}\text { Clean- } \\
\text { able }\end{array}$ & $\begin{array}{l}\text { Non- } \\
\text { clean- } \\
\text { able }\end{array}$ & $\begin{array}{l}\text { Acti- } \\
\text { vated }\end{array}$ & $\begin{array}{l}\text { Non- } \\
\text { active }\end{array}$ & $\begin{array}{l}\text { Clean- } \\
\text { able }\end{array}$ & $\begin{array}{l}\text { Non- } \\
\text { clean- } \\
\text { able }\end{array}$ & $\begin{array}{l}\text { Acti- } \\
\text { vated }\end{array}$ & $\begin{array}{l}\text { Non- } \\
\text { active }\end{array}$ & $\begin{array}{l}\text { Clean- } \\
\text { able }\end{array}$ & $\begin{array}{l}\text { Non- } \\
\text { clean- } \\
\text { able }\end{array}$ & $\begin{array}{l}\text { Acti- } \\
\text { vated }\end{array}$ \\
\hline 2110 & 0 & 0 & 0 & 0 & 0 & 0 & 0 & 0 & 0 & 0 & 0 & 0 \\
\hline 2111 & 0 & 0 & 0 & 0 & 0 & 0 & 0 & 0 & 0 & 0 & 0 & 0 \\
\hline 2112 & 0 & 0 & 0 & 0 & 0 & 0 & 0 & 0 & 0 & 0 & 0 & 0 \\
\hline 2113 & 0 & 0 & 0 & 0 & 0 & 0 & 0 & 0 & 0 & 0 & 0 & 0 \\
\hline 2114 & 0 & 0 & 0 & 0 & 0 & 0 & 0 & 0 & 0 & 0 & 0 & 0 \\
\hline 2115 & 0 & 0 & 0 & 0 & 0 & 0 & 0 & 0 & 0 & 0 & 0 & 0 \\
\hline 2116 & 0 & 0 & 0 & 0 & 0 & 0 & 0 & 0 & 0 & 0 & 0 & 0 \\
\hline 2117 & 0 & 0 & 0 & 0 & 0 & 0 & 0 & 0 & 0 & 0 & 0 & 0 \\
\hline 2118 & 0 & 0 & 0 & 0 & 0 & 0 & 0 & 0 & 0 & 0 & 0 & 0 \\
\hline 2119 & 0 & 0 & 0 & 0 & 0 & 0 & 0 & 0 & 0 & 0 & 0 & 0 \\
\hline 2120 & 0 & 0 & 0 & 0 & 0 & 0 & 0 & 0 & 0 & 0 & 0 & 0 \\
\hline 2121 & 0 & 0 & 0 & 0 & 0 & 0 & 0 & 0 & 0 & 0 & 0 & 0 \\
\hline 2122 & 0 & 0 & 0 & 0 & 0 & 0 & 0 & 0 & 0 & 0 & 0 & 0 \\
\hline 2123 & 0 & 0 & 0 & 0 & 0 & 0 & 0 & 0 & 0 & 0 & 0 & 0 \\
\hline 2124 & 7487 & 787 & 0 & 617 & 1018 & 262 & 26 & 152 & 19 & 0 & 0 & 6 \\
\hline 2125 & 0 & 0 & 0 & 0 & 0 & 0 & 0 & 0 & 0 & 0 & 0 & 0 \\
\hline 2126 & 0 & 0 & 0 & 0 & 0 & 0 & 0 & 0 & 0 & 0 & 0 & 0 \\
\hline 2127 & 0 & 0 & 0 & 0 & 0 & 0 & 0 & 0 & 0 & 0 & 0 & 0 \\
\hline 2128 & 0 & 0 & 0 & 0 & 0 & 0 & 0 & 0 & 0 & 0 & 0 & 0 \\
\hline 2129 & 0 & 0 & 0 & 0 & 0 & 0 & 0 & 0 & 0 & 0 & 0 & 0 \\
\hline 2130 & 0 & 0 & 0 & 0 & 0 & 0 & 0 & 0 & 0 & 0 & 0 & 0 \\
\hline 2131 & 0 & 0 & 0 & 0 & 0 & 0 & 0 & 0 & 0 & 0 & 0 & 0 \\
\hline 2132 & 0 & 0 & 0 & 0 & 0 & 0 & 0 & 0 & 0 & 0 & 0 & 0 \\
\hline 2133 & 0 & 0 & 0 & 0 & 0 & 0 & 0 & 0 & 0 & 0 & 0 & 0 \\
\hline 2134 & 25305 & 2746 & 0 & 2023 & 2353 & 600 & 110 & 224 & 19 & 0 & 0 & 6 \\
\hline 2135 & 25298 & 2810 & 0 & 1973 & 1510 & 377 & 126 & 0 & 0 & 0 & 0 & 0 \\
\hline 2136 & 0 & 0 & 0 & 0 & 0 & 0 & 0 & 0 & 0 & 0 & 0 & 0 \\
\hline 2137 & 0 & 0 & 0 & 0 & 0 & 0 & 0 & 0 & 0 & 0 & 0 & 0 \\
\hline 2138 & 0 & 0 & 0 & 0 & 0 & 0 & 0 & 0 & 0 & 0 & 0 & 0 \\
\hline 2139 & 0 & 0 & 0 & 0 & 0 & 0 & 0 & 0 & 0 & 0 & $0^{\circ}$ & 0 \\
\hline 2140 & 0 & 0 & 0 & 0 & 0 & 0 & 0 & 0 & 0 & 0 & 0 & 0 \\
\hline 2141 & 0 & 0 & 0 & 0 & 0 & 0 & 0 & 0 & 0 & 0 & 0 & 0 \\
\hline 2142 & 0 & 0 & 0 & 0 & 0 & 0 & 0 & 0 & 0 & 0 & 0 & 0 \\
\hline 2143 & 0 & 0 & 0 & 0 & 0 & 0 & 0 & 0 & 0 & 0 & 0 & 0 \\
\hline \multicolumn{13}{|l|}{ Under } \\
\hline const. & 78613 & 7488 & 23 & 4013 & 6133 & 1746 & 216 & 247 & 19 & 0 & 0 & 6 \\
\hline
\end{tabular}


TABLE B.7 Worldwide Summations of the Annual Increments in Scrap-Metal Inventory from the Nuclear Power Plants; Part A: Start-Up Plus 50 Years

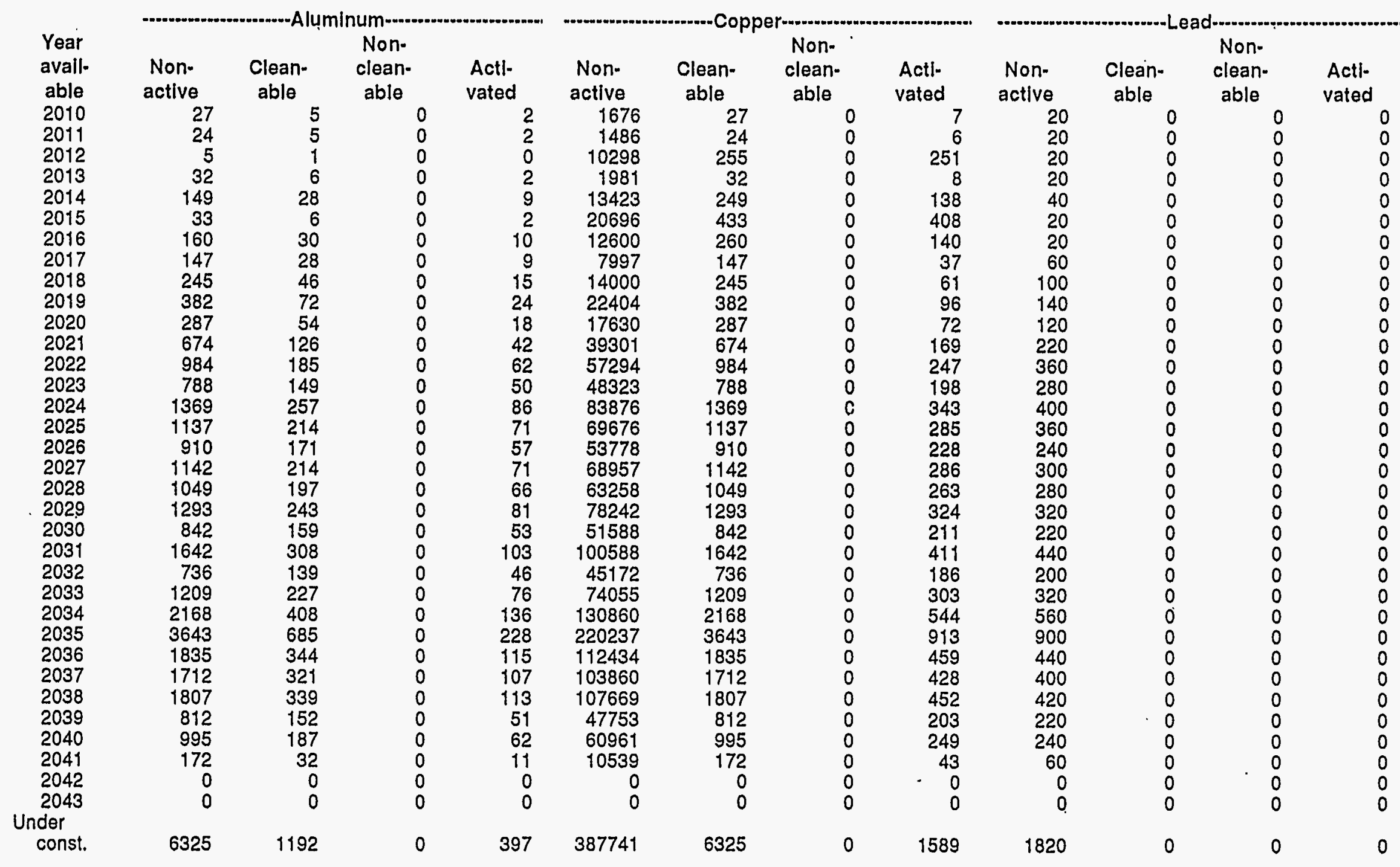




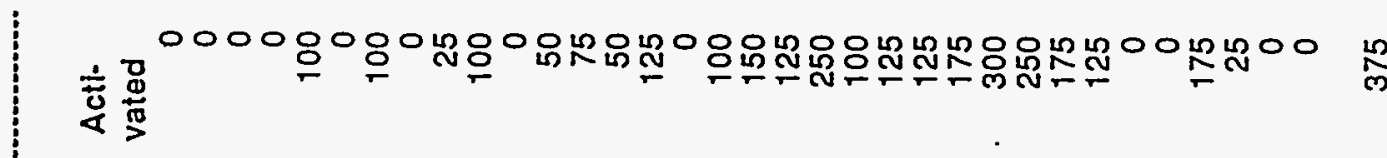

它察

0000000000000000000000000000000000

$z \frac{0}{0} \div$

迹 $\frac{0}{0}$

0000000000000000000000000000000000.

0

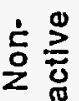

00000000000000000000000000000000000

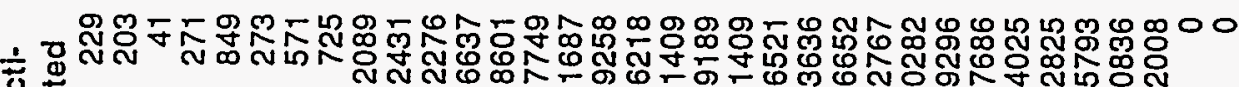

$\stackrel{0}{>}$

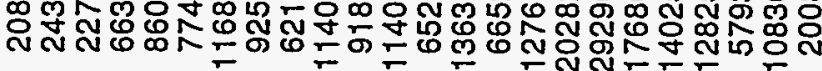

芯

它

นกํำ

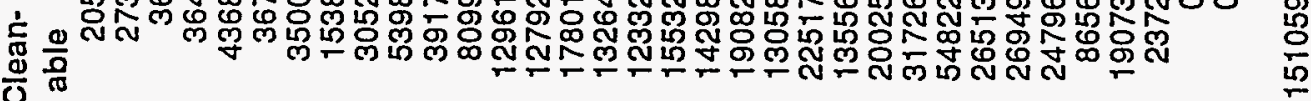

논

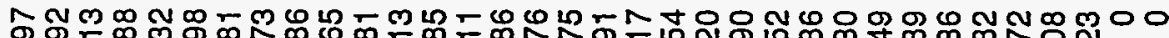

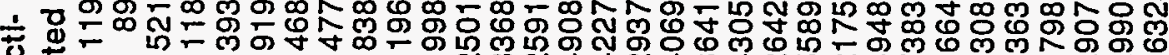

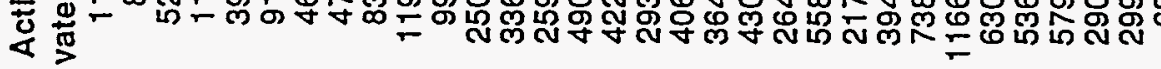

ญัญ

2

|

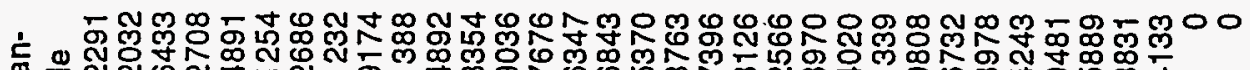

西. N

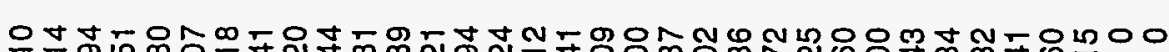

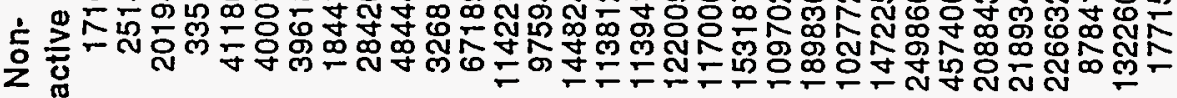

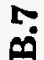

| 
TABLE B.7 (Cont.); Part B: Start-Up Plus 100 Years

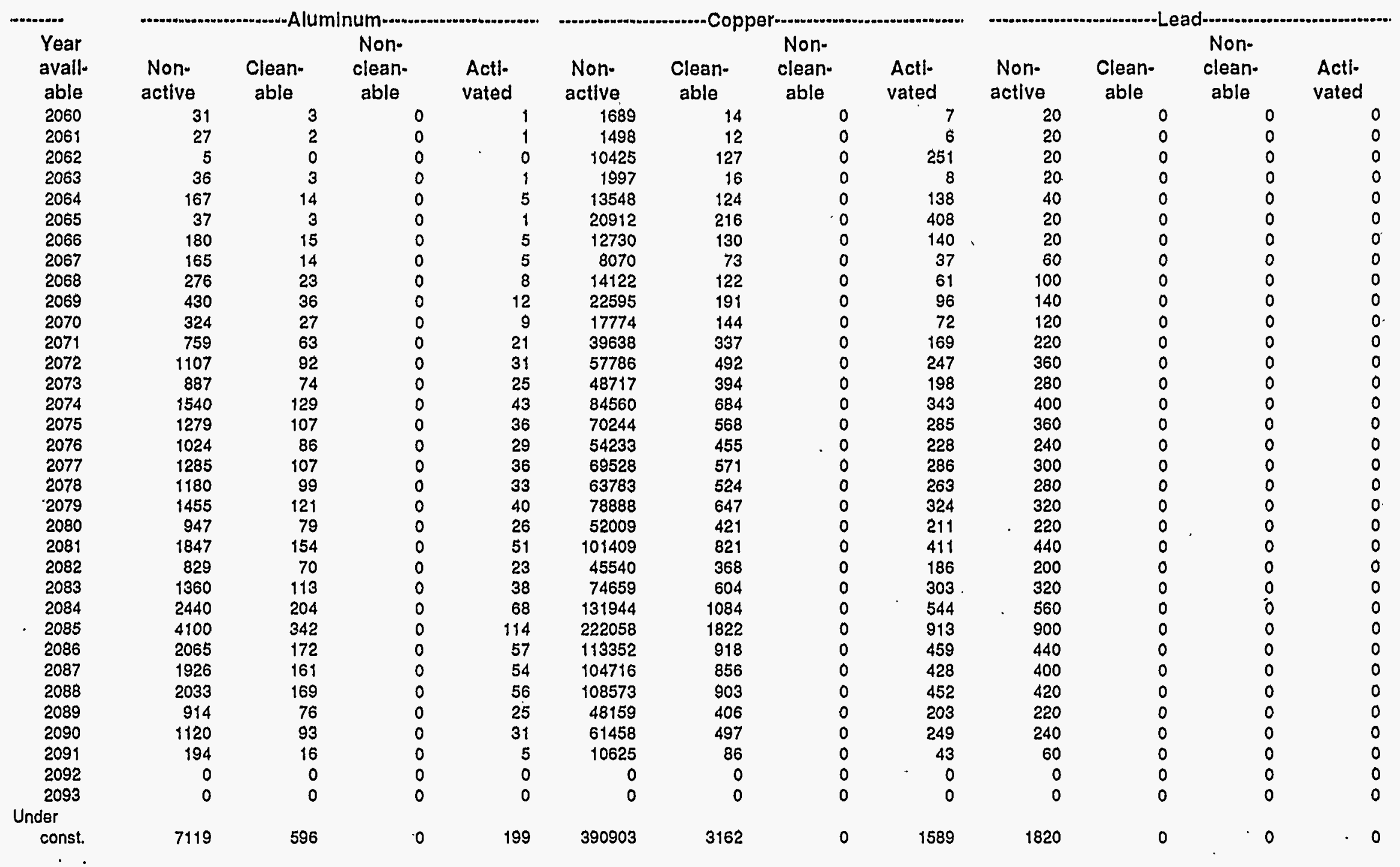


TABLE B.7 (Cont.); Part B (Cont.)

\begin{tabular}{|c|c|c|c|c|c|c|c|c|c|c|c|c|}
\hline \multirow[b]{2}{*}{$\begin{array}{l}\text { Year } \\
\text { avail- } \\
\text { able }\end{array}$} & \multirow[b]{2}{*}{$\begin{array}{l}\text { Non- } \\
\text { active }\end{array}$} & \multirow{2}{*}{\multicolumn{2}{|c|}{$\begin{array}{l}\text { Non- } \\
\text { clean- } \\
\text { able }\end{array}$}} & \multirow[b]{2}{*}{$\begin{array}{l}\text { Acti- } \\
\text { vated }\end{array}$} & \multirow[b]{2}{*}{$\begin{array}{l}\text { Non- } \\
\text { active }\end{array}$} & \multirow{2}{*}{\multicolumn{2}{|c|}{$\begin{array}{l}\text { Noel--...-. } \\
\text { Non- } \\
\text { clean- } \\
\text { able }\end{array}$}} & \multirow[b]{2}{*}{$\begin{array}{l}\text { Acti- } \\
\text { vated }\end{array}$} & \multirow[b]{2}{*}{$\begin{array}{l}\text { Non- } \\
\text { active }\end{array}$} & \multirow{2}{*}{\multicolumn{2}{|c|}{$\begin{array}{l}\text { Non- } \\
\text { clean- } \\
\text { able }\end{array}$}} & \multirow{3}{*}{$\begin{array}{l}\text { Acti- } \\
\text { vated } \\
0\end{array}$} \\
\hline & & & & & & & & & & & & \\
\hline 2060 & 3454 & 1146 & 0 & 598 & 103 & 103 & 0 & 229 & 0 & 0 & 0 & \\
\hline 2061 & 3976 & 1016 & 0 & 446 & 182 & 136 & 45 & 203 & 0 & 0 & 0 & 0 \\
\hline 2062 & 36017 & 13216 & 0 & 2606 & 518 & 18 & 0 & 41 & 0 & 0 & 0 & 0 \\
\hline 2063 & 5299 & 1354 & 0 & 594 & 243 & 182 & 61 & 271 & 0 & 0 & 0 & 0 \\
\hline 2064 & 55649 & 12446 & 58 & 1966 & 2384 & 2184 & 0 & 849 & 50 & 0 & 0 & 50 \\
\hline 2065 & 70233 & 25627 & 0 & 4599 & 1044 & 183 & 61 & 273 & 0 & 0 & 0 & 0 \\
\hline 2066 & 53336 & 11343 & 35 & 2341 & 2010 & 1750 & 0 & 571 & 50 & 0 & 0 & 50 \\
\hline 2067 & 26443 & 5616 & 0 & 2386 & 897 & 769 & 68 & 725 & 0 & 0 & 0 & 0 \\
\hline 2068 & 42200 & 9587 & 0 & 4193 & 1926 & 1526 & 230 & 2089 & 13 & 0 & 0 & 13 \\
\hline 2069 & 70154 & 15694 & 35 & 5983 & 2875 & 2699 & 116 & 2431 & 50 & 0 & 0 & 50 \\
\hline 2070 & 50140 & 12446 & 23 & 4990 & 2212 & 1958 & 253 & 2276 & 0 & 0 & 0 & 0 \\
\hline 2071 & 106373 & 26677 & 0 & 12507 & 4957 & 4050 & 382 & 6637 & 25 & 0 & 0 & 25 \\
\hline 2072 & 170604 & 39518 & 23 & 16842 & 7939 & 6481 & 872 & 8601 & 38 & 0 & 0 & 38 \\
\hline 2073 & 144457 & 33838 & 69 & 12955 & 7622 & 6396 & 913 & 7749 & 25 & 0 & 0 & 25 \\
\hline 2074 & 227621 & 58174 & 81 & 24543 & 10252 & 8901 & 1199 & 11687 & 63 & 0 & 0 & 63 \\
\hline 2075 & 183417 & 48421 & 46 & 21138 & 7747 & 6632 & 1115 & 9258 & 0 & 0 & 0 & 0 \\
\hline 2076 & 166371 & 37685 & 58 & 14688 & 7111 & 6166 & 825 & 6218 & 50 & 0 & 0 & 50 \\
\hline 2077 & 189271 & 46882 & 35 & 20345 & 9593 & 7766 & 1237 & 11409 & 75 & 0 & 0 & 75 \\
\hline 2078 & 178964 & .43698 & 58 & 18209 & 8365 & 7149 & 891 & 9189 & 63 & 0 & 0 & 63 \\
\hline 2079 & 228868 & 54063 & 92 & 21527 & 11137 & 9541 & 1183 & 11409 & 125 & 0 & 0 & 125 \\
\hline 2080 & 159276 & 36283 & 81 & 13210 & 7648 & 6529 & 1119 & 6521 & 50 & 0 & 0 & 50 \\
\hline 2081 & 287358 & 69485 & 92 & 27945 & 13615 & 11258 & 2246 & 13636 & 63 & 0 & 0 & 63 \\
\hline 2082 & 145761 & 32010 & 104 & 10876 & 7666 & 6778 & 656 & 6652 & 63 & 0 & 0 & 63 \\
\hline 2083 & 217729 & 50669 & 92 & 19743 & 12149 & 10012 & 1467 & 12767 & 88 & 0 & 0 & 88 \\
\hline 2084 & 377317 & 90404 & 138 & 36915 & 18655 & 15863 & 1850 & 20282 & 150 & 0 & 0 & 150 \\
\hline 2085 & 669390 & 153366 & 299 & 58325 & 31860 & 27411 & 3781 & 29296 & 125 & 0 & 0 & 125 \\
\hline 2086 & 317468 & 76989 & 92 & 31545 & 16359 & 13257 & 2499 & 17686 & 88 & 0 & 0 & 88 \\
\hline 2087 & 318035 & 72122 & 161 & 26818 & 15513 & 13474 & 1699 & 14025 & 63 & 0 & 0 & 63 \\
\hline 2088 & 330467 & 74741 & 104 & 28991 & 14751 & 12398 & 2173 & 12825 & 0 & 0 & 0 & 0 \\
\hline 2089 & 135321 & 32945 & 0 & 14536 & 5430 & 4328 & 982 & 5793 & 0 & 0 & 0 & 0 \\
\hline 2090 & 189256 & 41915 & 127 & 14954 & 10972 & 9537 & 741 & 10836 & 88 & 0 & 0 & 88 \\
\hline 2091 & 27943 & 7066 & 0 & 3162 & 1604 & 1186 & 303 & 2008 & 13 & 0 & 0 & 13 \\
\hline 2092 & 0 & 0 & 0 & 0 & 0 & 0 & 0 & 0 & 0 & 0 & 0 & 0 \\
\hline 2093 & 0 & 0 & 0 & 0 & 0 & 0 & 0 & 0 & 0 & 0 & 0 & 0 \\
\hline \multicolumn{13}{|l|}{ Under } \\
\hline const. & 1439796 & 274782 & 1449 & 70110 & 82840 & 75529 & 4415 & 56833 & 188 & 0 & 0 & 188 \\
\hline
\end{tabular}


TABLE B.7 (Cont.); Part C: Start-Up Plus 150 Years

\begin{tabular}{|c|c|c|c|c|c|c|c|c|c|c|c|c|}
\hline \multicolumn{5}{|c|}{ - } & \multicolumn{4}{|c|}{ 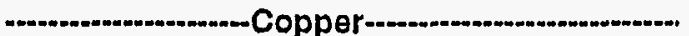 } & \multicolumn{4}{|c|}{-Lead- } \\
\hline $\begin{array}{l}\text { Year } \\
\text { avall- } \\
\text { able }\end{array}$ & $\begin{array}{l}\text { Non- } \\
\text { active }\end{array}$ & $\begin{array}{c}\text { Clean- } \\
\text { able }\end{array}$ & $\begin{array}{l}\text { Non- } \\
\text { clean- } \\
\text { able }\end{array}$ & $\begin{array}{l}\text { Acti- } \\
\text { vated }\end{array}$ & $\begin{array}{l}\text { Non- } \\
\text { active }\end{array}$ & $\begin{array}{c}\text { Clean- } \\
\text { able }\end{array}$ & $\begin{array}{l}\text { Non- } \\
\text { clean- } \\
\text { able }\end{array}$ & $\begin{array}{l}\text { Acti- } \\
\text { vated }\end{array}$ & $\begin{array}{l}\text { Non- } \\
\text { active }\end{array}$ & $\begin{array}{c}\text { Clean- } \\
\text { able }\end{array}$ & $\begin{array}{c}\text { Non- } \\
\text { clean- } \\
\text { able }\end{array}$ & $\begin{array}{l}\text { Acti- } \\
\text { vated }\end{array}$ \\
\hline 2110 & 32 & 1 & 0 & 0 & 1696 & 7 & 0 & 2 & 20 & 0 & 0 & 0 \\
\hline 2111 & 29 & 1 & 0 & 0 & 1504 & 6 & 0 & 2 & 20 & 0 & 0 & 0 \\
\hline 2112 & 6 & 0 & 0 & 0 & 10489 & 64 & 0 & 63 & 20 & 0 & 0 & 0 \\
\hline 2113 & 38 & 2 & 0 & 1 & 2005 & 8 & 0 & 2 & 20 & 0 & 0 & 0 \\
\hline 2114 & 177 & 7 & 0 & 2 & 13610 & 62 & 0 & 34 & 40 & 0 & 0 & 0 \\
\hline 2115 & 39 & 2 & 0 & $i$ & 21021 & 108 & 0 & 102 & 20 & 0 & 0 & 0 \\
\hline 2116 & 190 & 8 & 0 & 3 & 12795 & 65 & 0 & 35 & 20 & 0 & 0 & 0 \\
\hline 2117 & 174 & 7 & 0 & 2 & 8107 & 37 & 0 & 9 & 60 & 0 & 0 & 0 \\
\hline 2118 & 291 & 11 & 0 & 4 & 14183 & 61 & 0 & 15 & 100 & 0 & 0 & 0 \\
\hline 2119 & 454 & 18 & 0 & 6 & 22691 & 96 & 0 & 24 & 140 & 0 & 0 & 0 \\
\hline 2120 & 342 & 14 & 0 & 5 & 17845 & 72 & 0 & 18 & 120 & 0 & 0 & 0 \\
\hline 2121 & 801 & 32 & 0 & 11 & 39806 & 169 & 0 & 42 & 220 & 0 & 0 & 0 \\
\hline 2122 & 1169 & 46 & 0 & 15 & 58032 & 246 & 0 & 62 & 360 & 0 & 0 & 0 \\
\hline 2123 & 937 & 37 & 0 & 12 & 48914 & 197 & 0 & 50 & 280 & 0 & 0 & 0 \\
\hline 2124 & 1626 & 64 & 0 & 21 & 84902 & 342 & 0 & 86 & 400 & 0 & 0 & 0 \\
\hline 2125 & 1351 & 53 & 0 & 18 & 70529 & 284 & 0 & 71 & 360 & 0 & 0 & 0 \\
\hline 2126 & 1081 & 43 & 0 & 14 & 54461 & 228 & 0 & 57 & 240 & 0 & 0 & 0 \\
\hline 2127 & 1356 & 54 & 0 & 18 & 69814 & 286 & 0 & 71 & 300 & 0 & 0 & 0 \\
\hline 2128 & 1246 & 49 & 0 & 16 & 64045 & 262 & 0 & 66 & 280 & 0 & 0 & 0 \\
\hline 2129 & 1536 & 61 & 0 & 20 & 79212 & 323 & 0 & 81 & 320 & 0 & 0 & 0 \\
\hline 2130 & 1000 & 40 & 0 & 13 & 52219 & 210 & 0 & 53 & 220 & 0 & 0 & 0 \\
\hline 2131 & 1950 & 77 & 0 & 26 & 101820 & 410 & 0 & 103 & 440 & 0 & 0 & 0 \\
\hline 2132 & 876 & 35 & 0 & 12 & 45724 & 184 & 0 & 46 & 200 & 0 & 0 & 0 \\
\hline 2133 & 1436 & 57 & 0 & 19 & 74961 & 302 & 0 & 76 & 320. & 0 & 0 & 0 \\
\hline 2134 & 2576 & 102 & 0 & 34 & 132486 & 542 & 0 & 136 & 560 & 0 & 0 & 0 \\
\hline 2135 & 4328 & 171 & 0 & 57 & 222969 & 911 & 0 & 228 & 900 & 0 & 0 & 0 \\
\hline 2136 & 2180 & 86 & 0 & 29 & 113811 & 459 & 0 & 115 & 440 & 0 & 0 & 0 \\
\hline 2137 & 2033 & 80 & 0 & 27 & 105144 & 428 & 0 & 107 & 400 & 0 & 0 & 0 \\
\hline 2138 & 2146 & 85 & 0 & 28 & 109024 & 452 & 0 & 113 & 420 & 0 & 0 & 0 \\
\hline 2139 & 965 & 38 & 0 & 13 & 48362 & 203 & 0 & 51 & 220 & 0 & 0 & 0 \\
\hline 2140 & 1182 & 47 & 0 & 16 & 61707 & 249 & 0 & 62 & 240 & 0 & 0 & 0 \\
\hline 2141 & 204 & 8 & 0 & 3 & 10668 & 43 & 0 & 11 & 60 & 0 & 0 & 0 \\
\hline 2142 & 0 & 0 & 0 & 0 & 0 & 0 & 0 & 0 & 0 & 0 & 0 & 0 \\
\hline 2143 & 0 & 0 & 0 & 0 & 0 & 0 & 0 & 0 & 0 & 0 & 0 & 0 \\
\hline Under & & & & & & & & & & & & \\
\hline const. & 7516 & 298 & 0 & 99 & 392485 & 1581 & 0 & 397 & 1820 & 0 & 0 & 0 \\
\hline
\end{tabular}


TABLE B.7 (Cont.); Part C (Cont.)

\begin{tabular}{|c|c|c|c|c|c|c|c|c|c|c|c|c|}
\hline $\begin{array}{c}\text { Year } \\
\text { avail- } \\
\text { able }\end{array}$ & $\begin{array}{l}\text { Non- } \\
\text { active }\end{array}$ & $\begin{array}{c}\text { Clean- } \\
\text { able }\end{array}$ & $\begin{array}{l}\text { Non- } \\
\text { clean- } \\
\text { able }\end{array}$ & $\begin{array}{l}\text { Acti- } \\
\text { vated }\end{array}$ & $\begin{array}{l}\text { Non- } \\
\text { active }\end{array}$ & $\begin{array}{l}\text { Clean- } \\
\text { able }\end{array}$ & $\begin{array}{l}\text { Non- } \\
\text { clean-.... } \\
\text { able }\end{array}$ & $\begin{array}{l}\text { Acti- } \\
\text { vated }\end{array}$ & $\begin{array}{c}\text { Non- } \\
\text { active }\end{array}$ & $\begin{array}{l}\text { Clean- } \\
\text { able }\end{array}$ & $\begin{array}{l}\text { Non- } \\
\text { clean- } \\
\text { able }\end{array}$ & $\begin{array}{l}\text { Acti- } \\
\text { vated }\end{array}$ \\
\hline 2110 & 4147 & 573 & 0 & 479 & 154 & 51 & 0 & 0 & 0 & 0 & 0 & 0 \\
\hline 2111 & 4573 & 508 & 0 & 357 & 273 & 68 & 23 & 0 & 0 & 0 & 0 & 0 \\
\hline 2112 & 43146 & 6608 & 0 & 2085 & 527 & 9 & 0 & 500 & 0 & 0 & 0 & 0 \\
\hline 2113 & 6095 & 677 & 0 & 475 & 364 & 91 & 30 & 0 & 0 & 0 & 0 & 0 \\
\hline 2114 & 62294 & 6223 & 29 & 1573 & 3476 & 1092 & 0 & 200 & 75 & 0 & 0 & 25 \\
\hline 2115 & 83966 & 12814 & 0 & 3679 & 1167 & 92 & 31 & 800 & 0 & 0 & 0 & 0 \\
\hline 2116 & 59493 & 5672 & 17 & 1872 & 2885 & 875 & 0 & 260 & 75 & 0 & 0 & 25 \\
\hline 2117 & 29728 & 2808 & 0 & 1909 & 1315 & 384 & 34 & 60 & 0 & 0 & 0 & 0 \\
\hline 2118 & 47832 & 4794 & 0 & 3354 & 2803 & 763 & 115 & 170 & 19 & 0 & 0 & 6 \\
\hline 2119 & 79215 & 7847 & 17 & 4786 & 4282 & 1349 & 58 & 60 & 75 & 0 & 0 & 25 \\
\hline 2120 & 57372 & 6223 & 12 & 3992 & 3318 & 979 & 127 & 0 & 0 & 0 & 0 & 0 \\
\hline 2121 & 122212 & 13338 & 0 & 10005 & 7173 & 2025 & 191 & 525 & 38 & 0 & 0 & 13 \\
\hline 2122 & 193743 & 19759 & 12 & 13474 & 11616 & 3240 & 436 & 587 & 56 & 0 & 0 & 19 \\
\hline 2123 & 164001 & 16919 & 35 & 10364 & 11276 & 3198 & 456 & 313 & .38 & 0 & 0 & 13 \\
\hline 2124 & 261657 & 29087 & 40 & 19635 & 15302 & 4450 & 600 & 152 & 94 & 0 & 0 & 31 \\
\hline 2125 & 211878 & 24211 & 23 & 16910. & 11620 & 3316 & 557 & 0 & 0 & 0 & 0 & 0 \\
\hline 2126 & 188180 & 18842 & 29 & 11750 & 10607 & 3083 & 413 & 120 & 75 & 0 & 0 & 25 \\
\hline 2127 & 216798 & 23441 & 17 & 16276 & 14095 & 3883 & 619 & 590 & 113 & 0 & 0 & 38 \\
\hline 2128 & 204484 & 21849 & 29 & 14567 & 12385 & 3574 & 446 & 325 & 94 & 0 & 0 & 31 \\
\hline 2129 & 260251 & 27031 & 46 & 17221 & 16499 & 4770 & 592 & 413 & 188 & 0 & 0 & 63 \\
\hline 2130 & 180100 & 18142 & 40 & 10568 & 11472 & 3264 & 560 & 0 & 75 & 0 & 0 & 25 \\
\hline 2131 & 327735 & 34743 & 46 & 22356 & 20367 & 5629 & 1123 & 110 & 94 & 0 & 0 & 31 \\
\hline 2132 & 163993 & 16005 & 52 & 8701 & 11383 & 3389 & 328 & 232 & 94 & 0 & 0 & 31 \\
\hline 2133 & 247058 & 25335 & 46 & 15794 & 17888 & 5006 & 733 & 670 & 131 & 0 & 0 & 44 \\
\hline 2134 & 429971 & 45202 & 69 & 29532 & 27512 & 7931 & 925 & 943 & 225 & 0 & 0 & 75 \\
\hline 2135 & 757887 & 76683 & 150 & 46660 & 47456 & 13706 & 1890 & 668 & 188 & 0 & 0 & 63 \\
\hline 2136 & 362318 & 38494 & 46 & 25236 & 24236 & 6628 & 1249 & 603 & 131 & 0 & 0 & 44 \\
\hline 2137 & 359539 & .36061 & 81 & 21454 & 23100 & 6737 & 849 & 340 & 94 & 0 & 0 & 31 \\
\hline 2138 & 373687 & 37370 & 52 & 23193 & 22036 & 6199 & 1086 & 180 & 0 & 0 & 0 & 0 \\
\hline 2139 & 154701 & 16472 & 0 & 11629 & 8084 & 2164 & 491 & 120 & 0 & 0 & 0 & 0 \\
\hline 2140 & 213268 & 20958 & 63 & 11963 & 16111 & 4768 & 370 & 695 & 131 & 0 & 0 & 44 \\
\hline 2141 & 32109 & 3533 & 0 & 2529 & 2348 & 593 & 151 & 115 & 19 & 0 & 0 & 6 \\
\hline 2142 & 0 & 0 & 0 & 0 & 0 & 0 & 0 & 0 & 0 & 0 & 0 & 0 \\
\hline 2143 & 0 & 0 & 0 & 0 & 0 & 0 & 0 & 0 & 0 & 0 & 0 & 0 \\
\hline Under & & & & & & & & & & & & \\
\hline const. & 1591934 & 137391 & 725 & 56088 & 122812 & 37765 & 2207 & 2896 & 281 & 0 & 0 & 94 \\
\hline
\end{tabular}




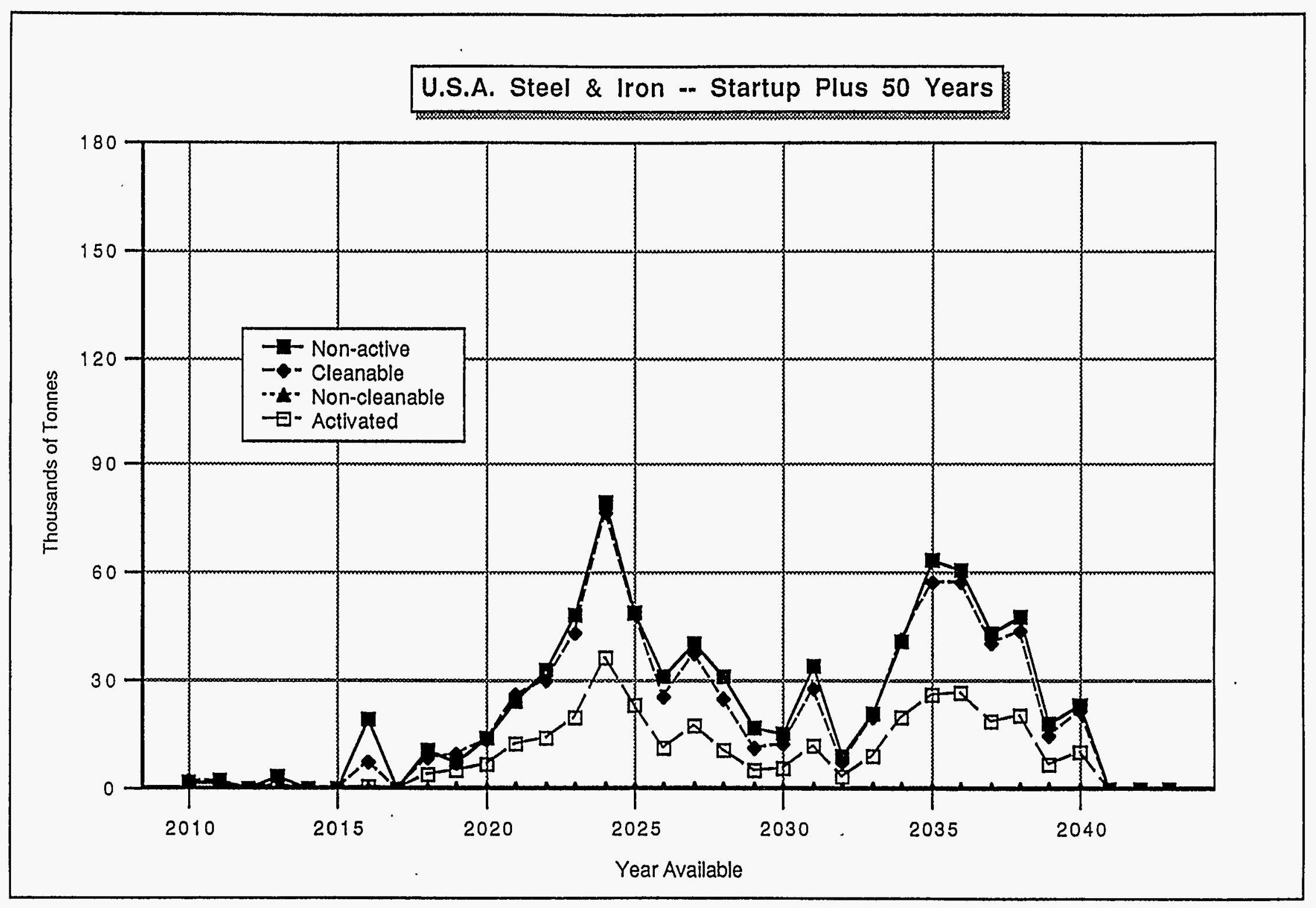

FIGURE B.1 Annual Increments in Scrap-Metal Inventory from Nuclear Power Plants for the U.S.A.; Part A: Start-Up Plus 50 Years 


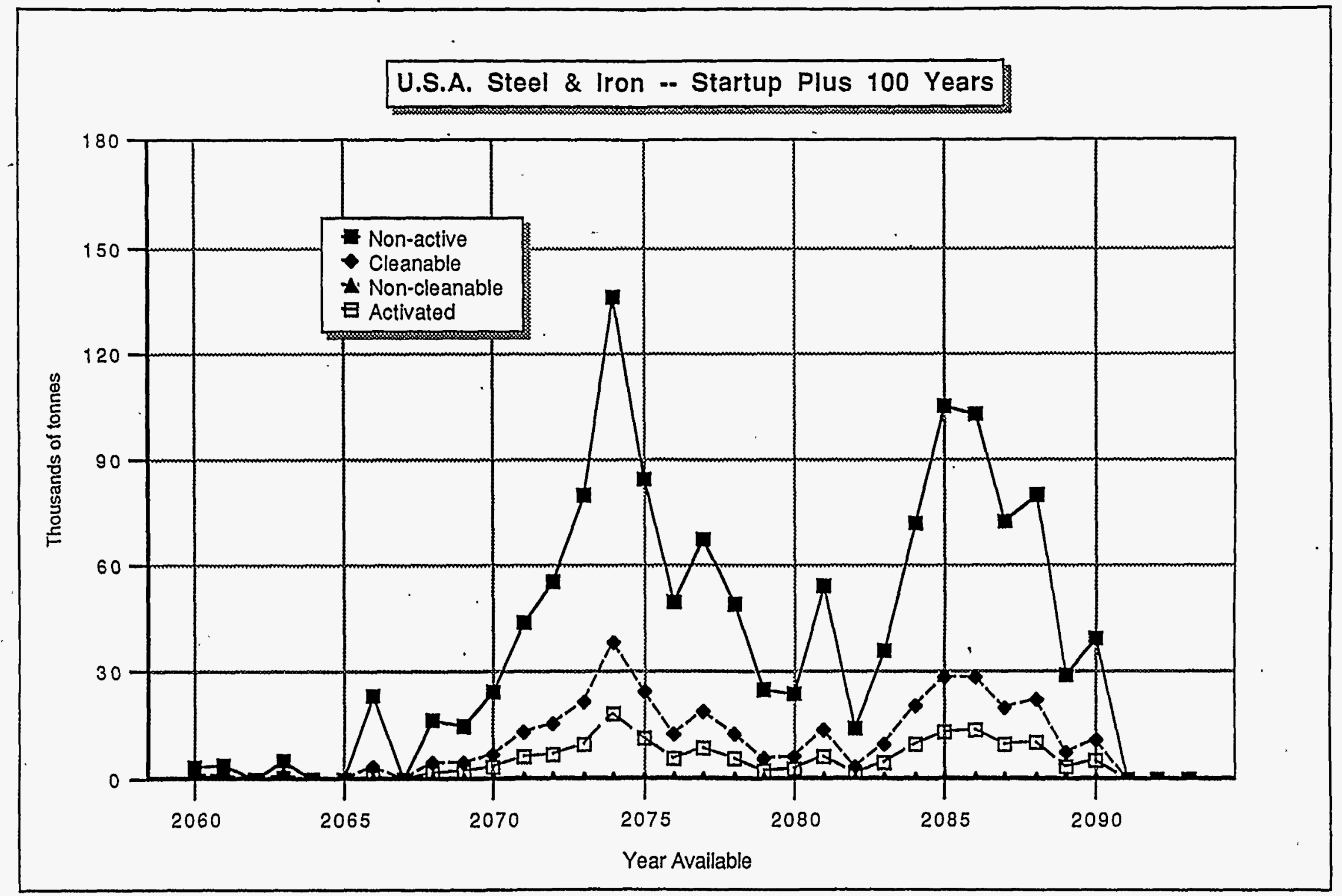

FIGURE B.1 (Cont.) Part B: Start-Up Plus 100 Years 


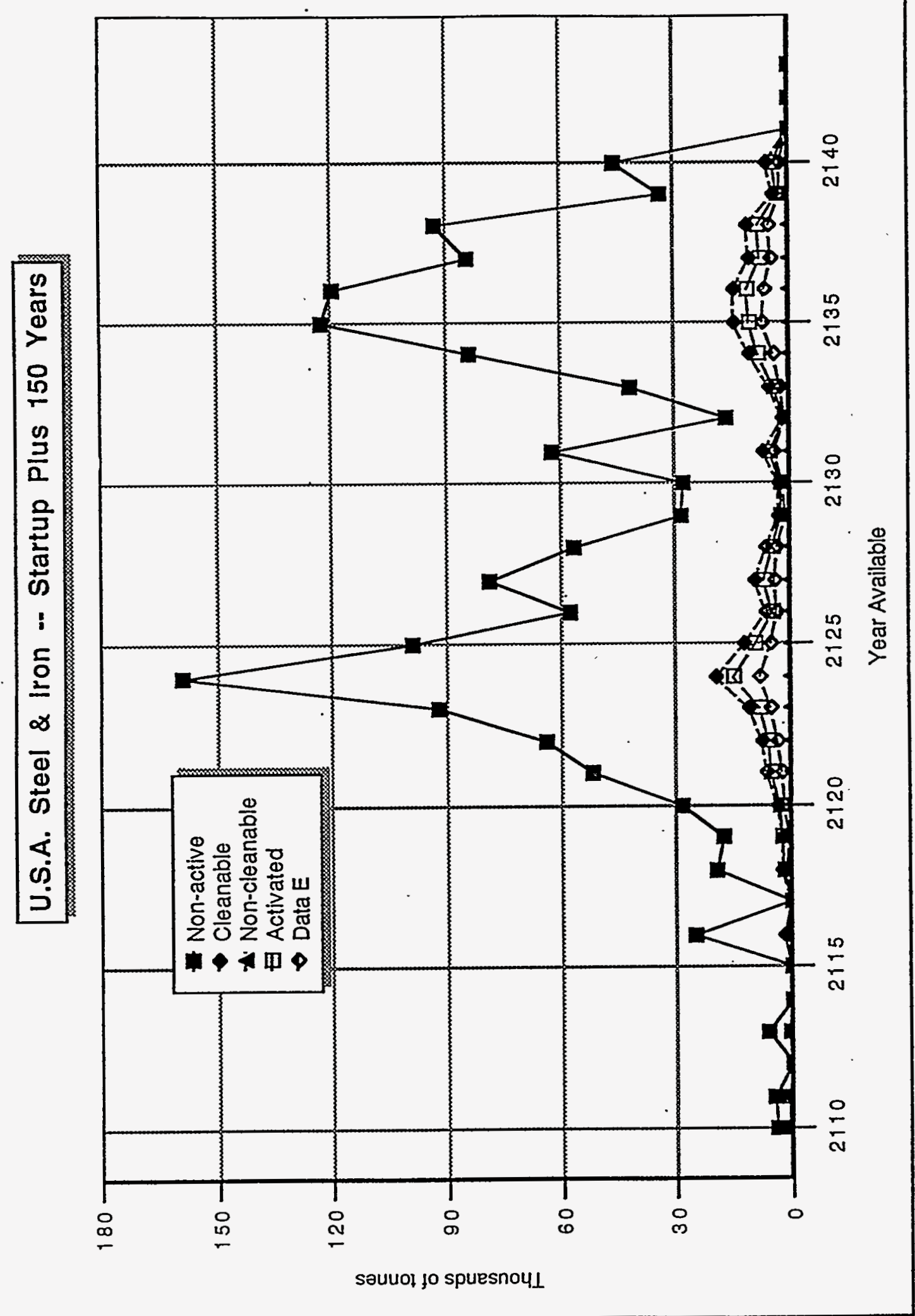

ن 


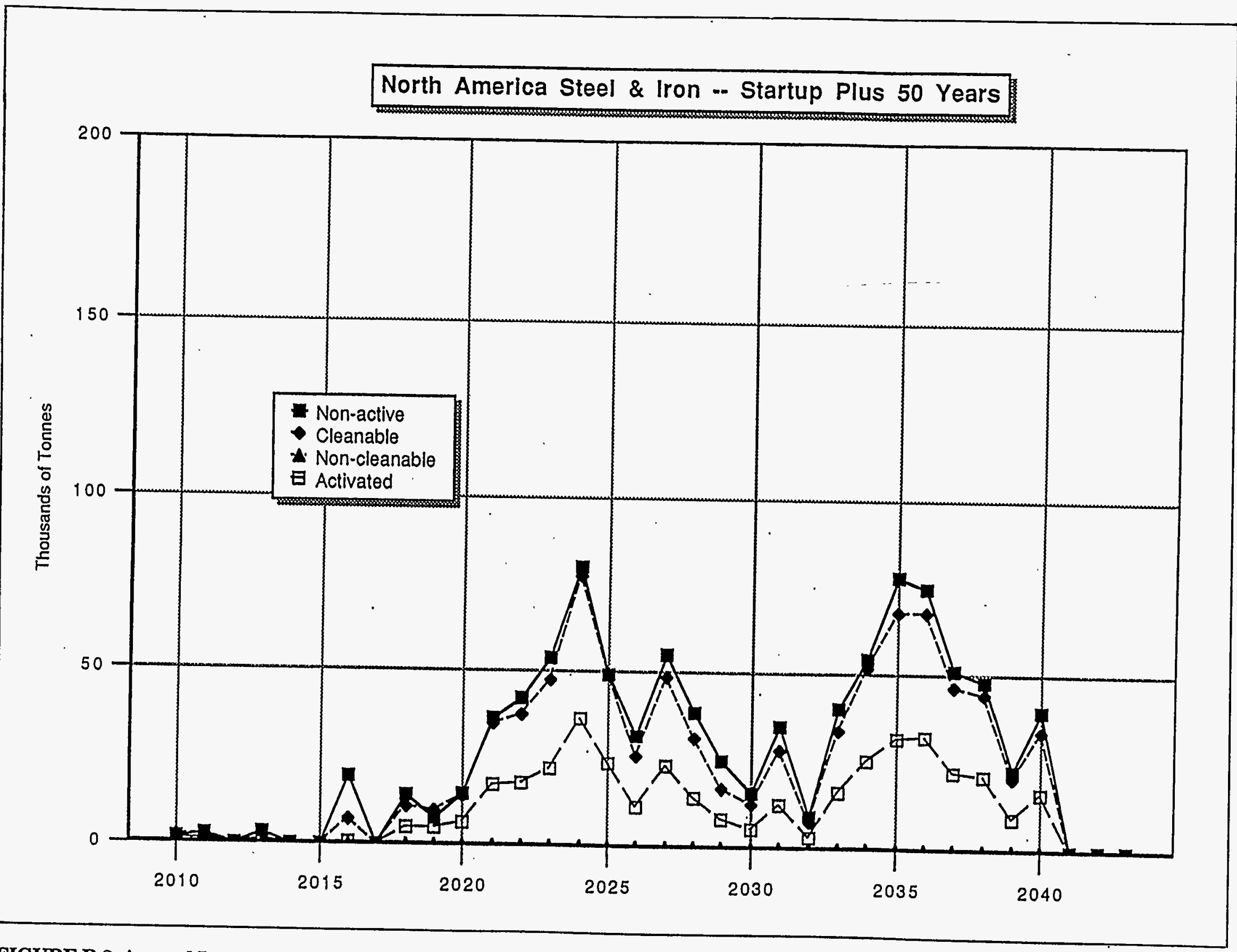

FIGURE B.2 Annual Increments in Scrap-Metal Inventory from Nuclear Power Plants for North America (U.S.A., Canada, and
Mexico, excludes Cuba); Part A: Start-Up Plus 50 Years 


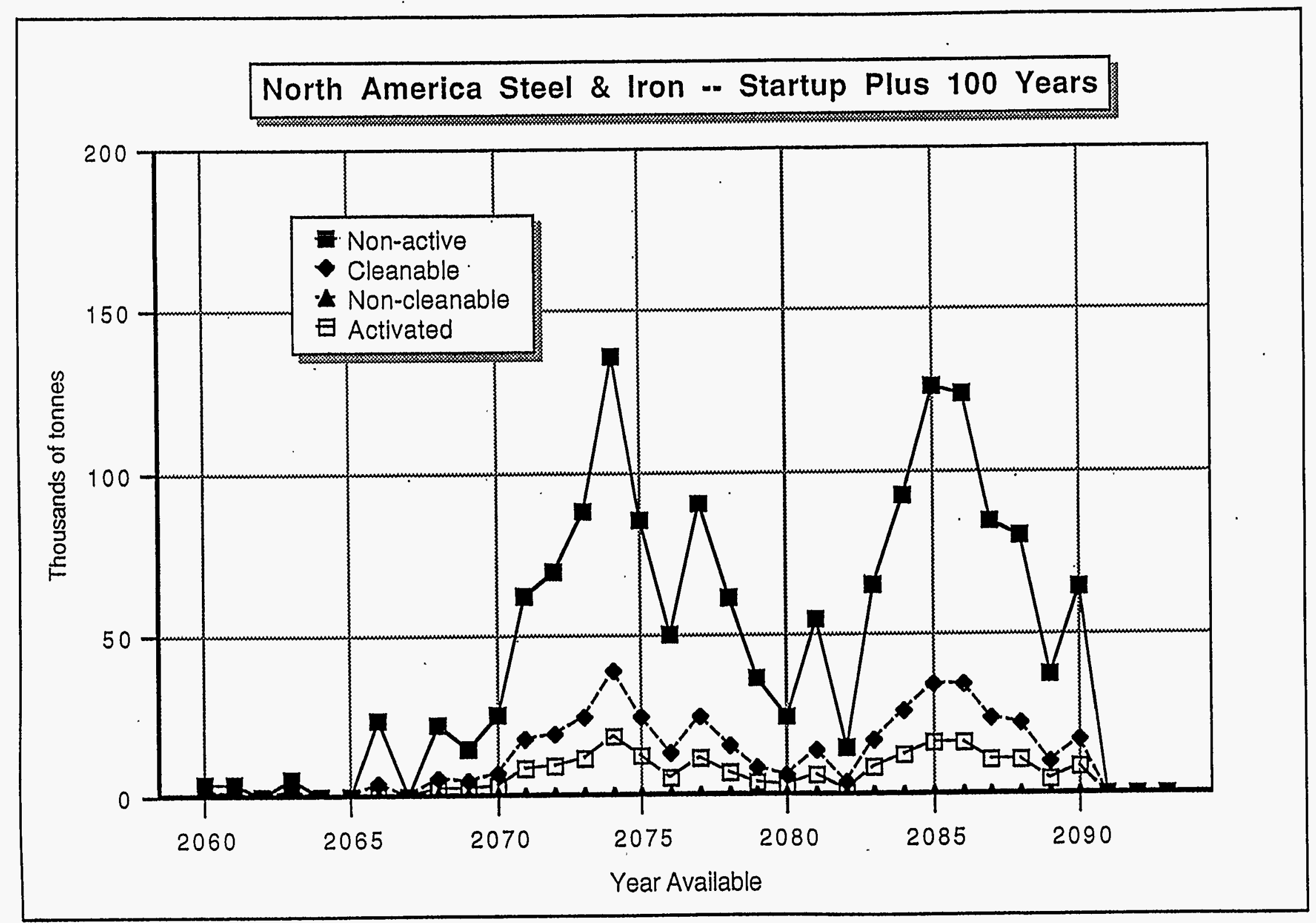




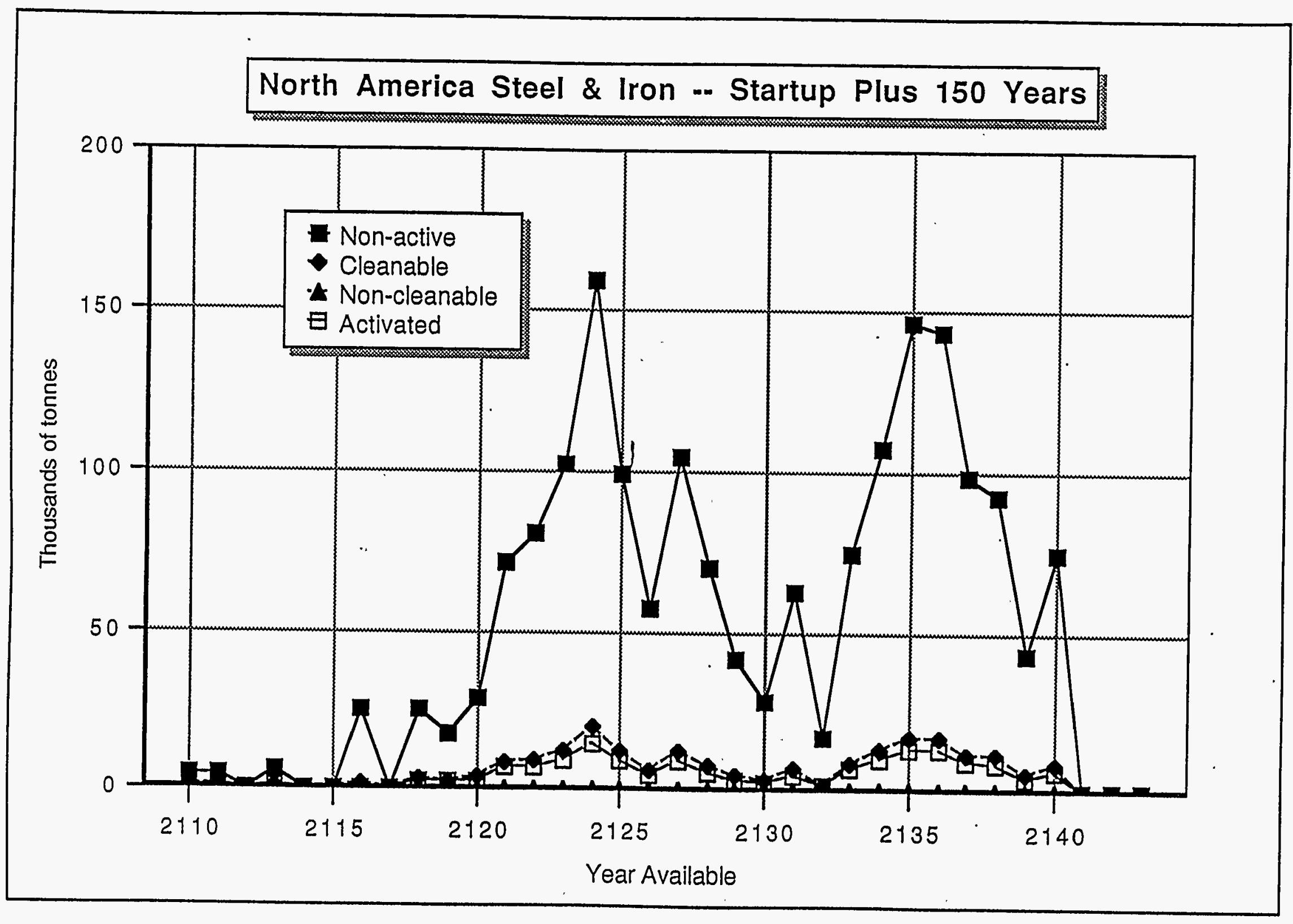




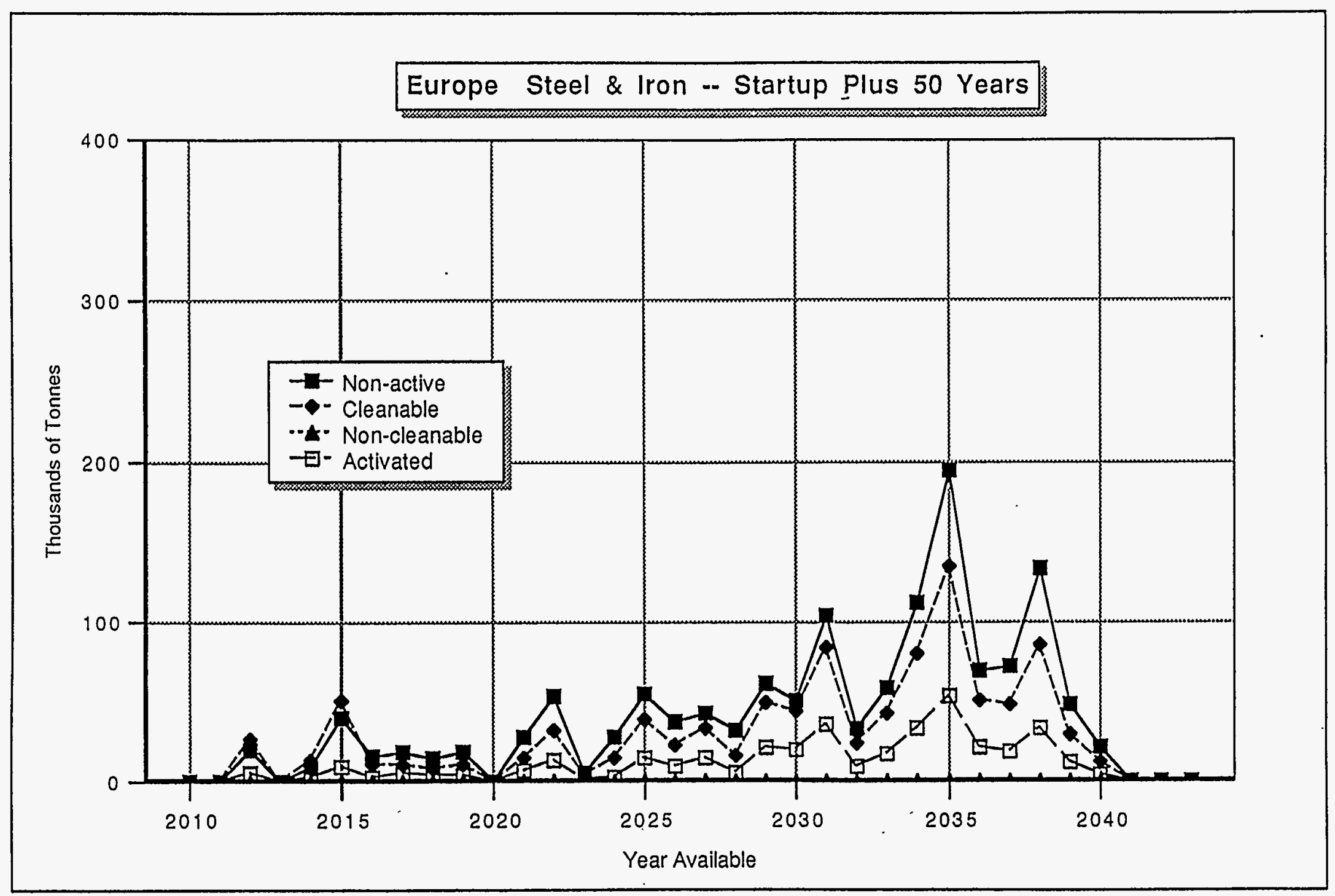

FIGURE B.3 Annual Increments in Scrap-Metal Inventory from Nuclear Power Plants for Europe (includes eastern Europe: Bulgaria, Czech Republic, Finland, Hungary, Poland, Romania, Slovakia, and Slovenia); Part A: Start-Up Plus 50 Years 


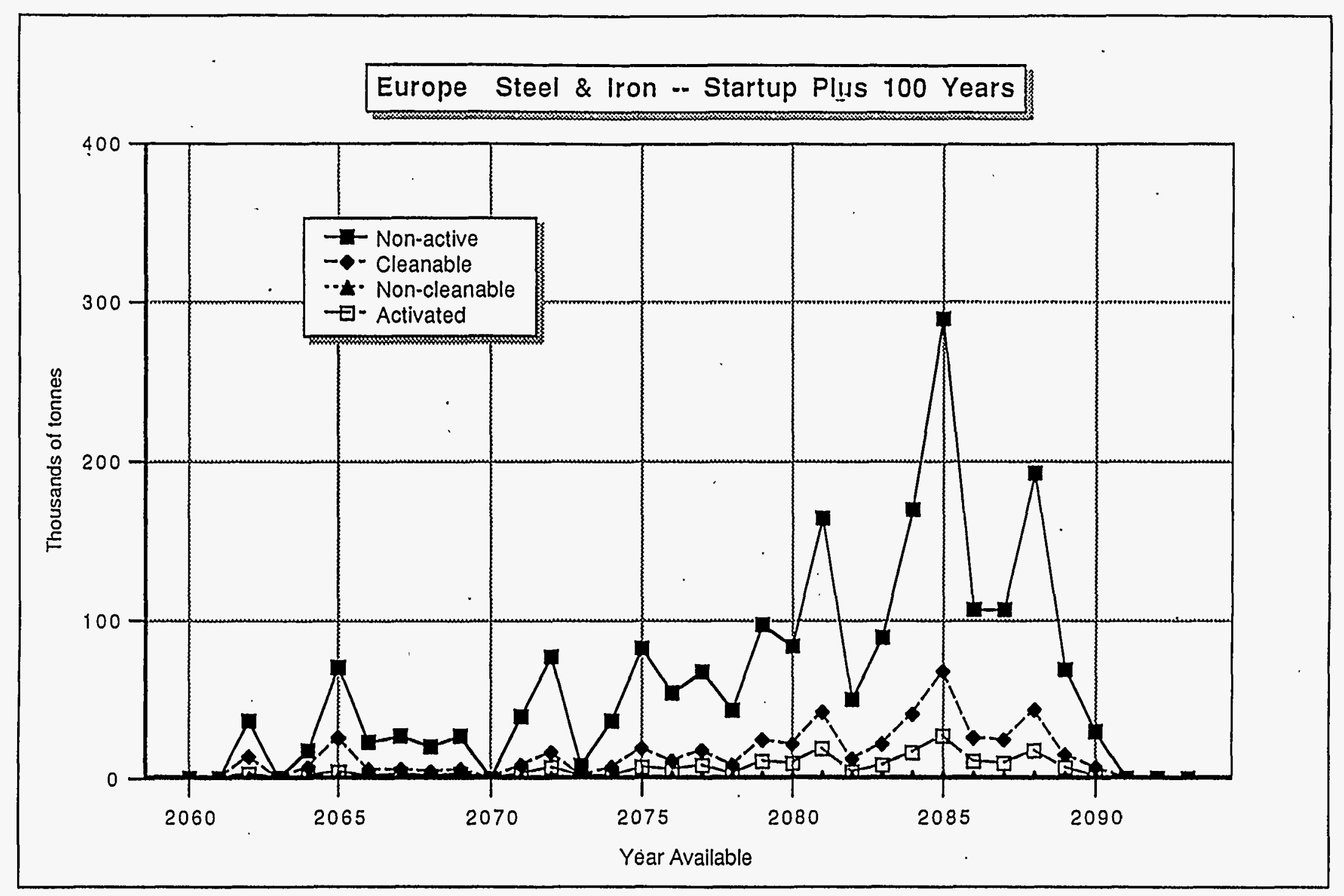




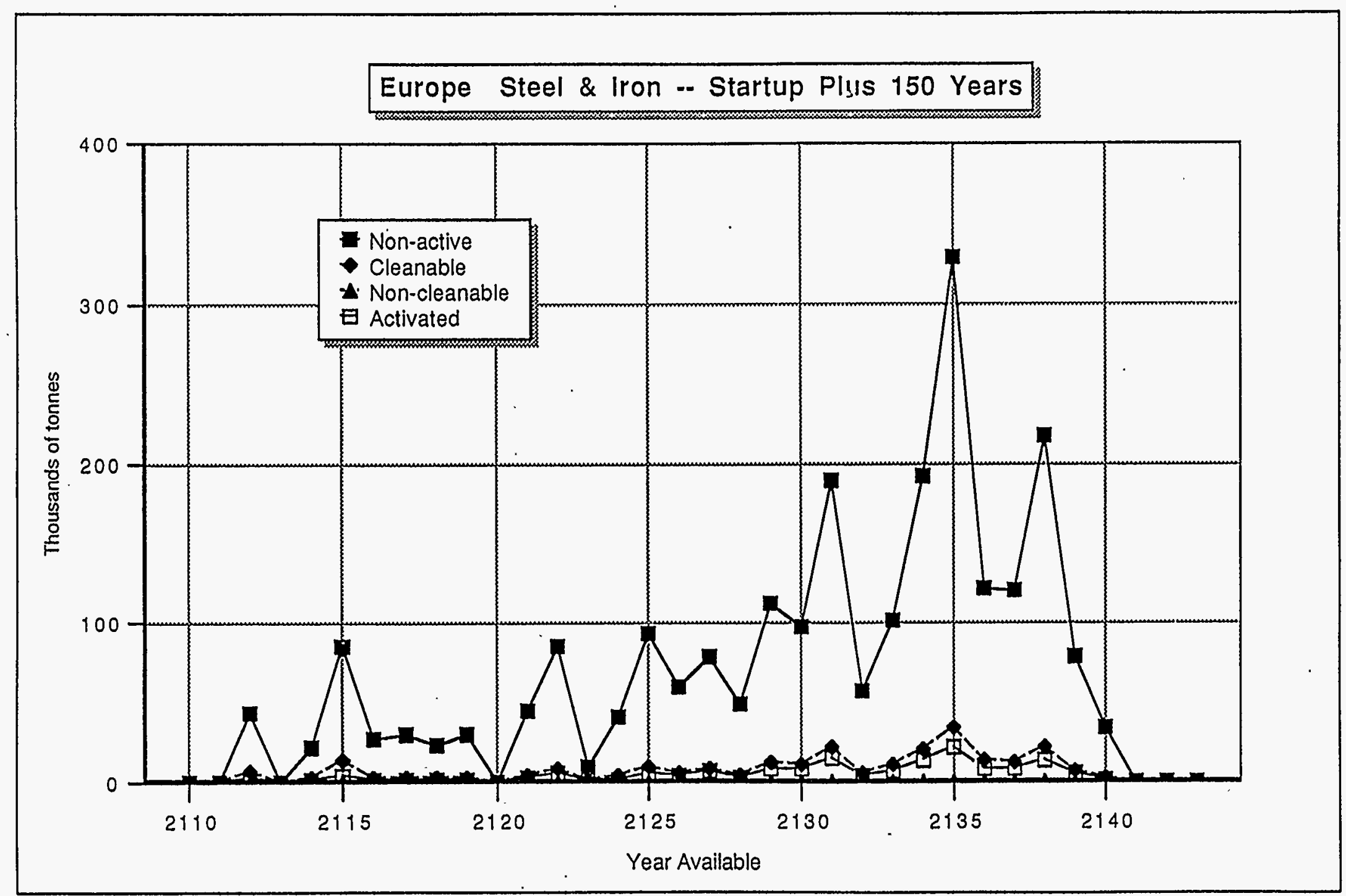




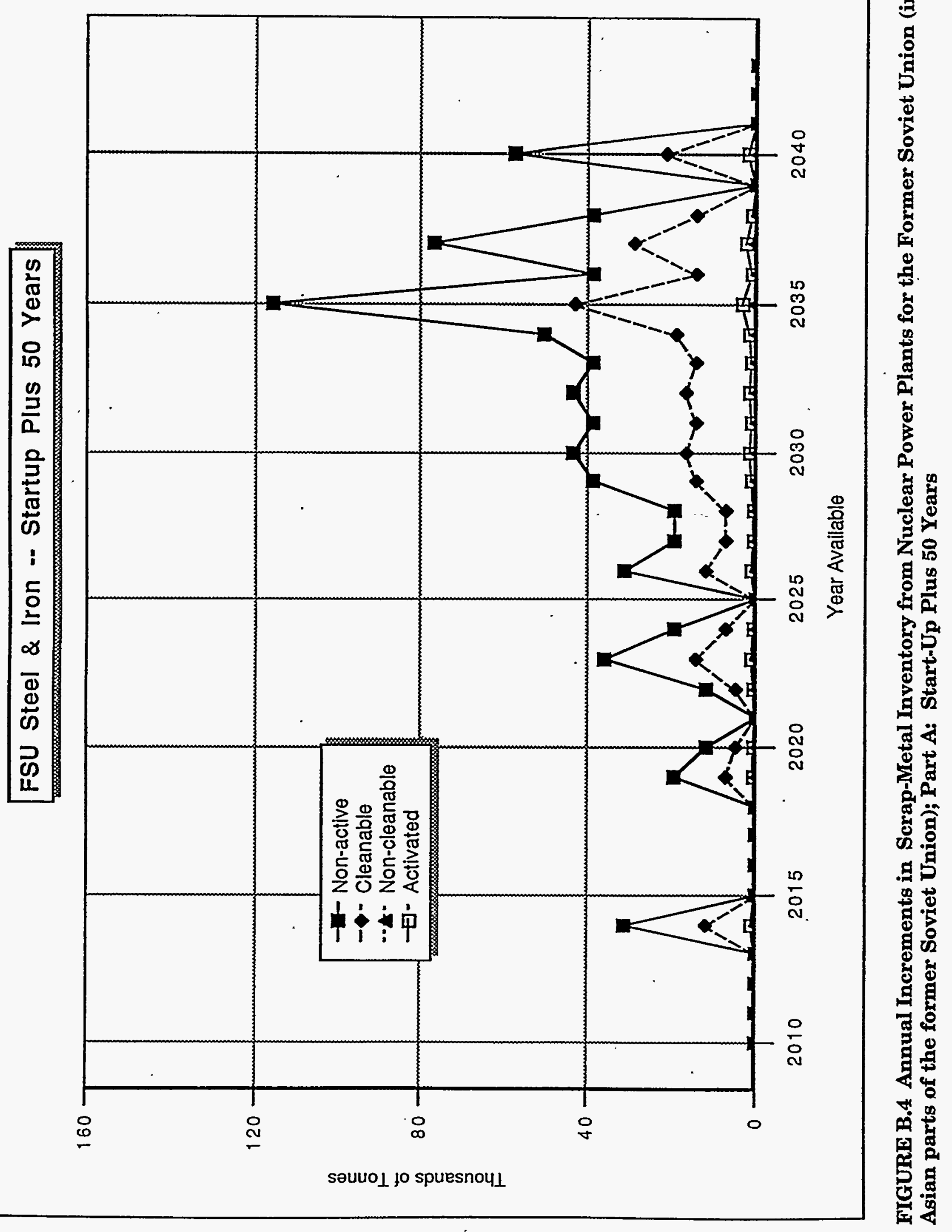




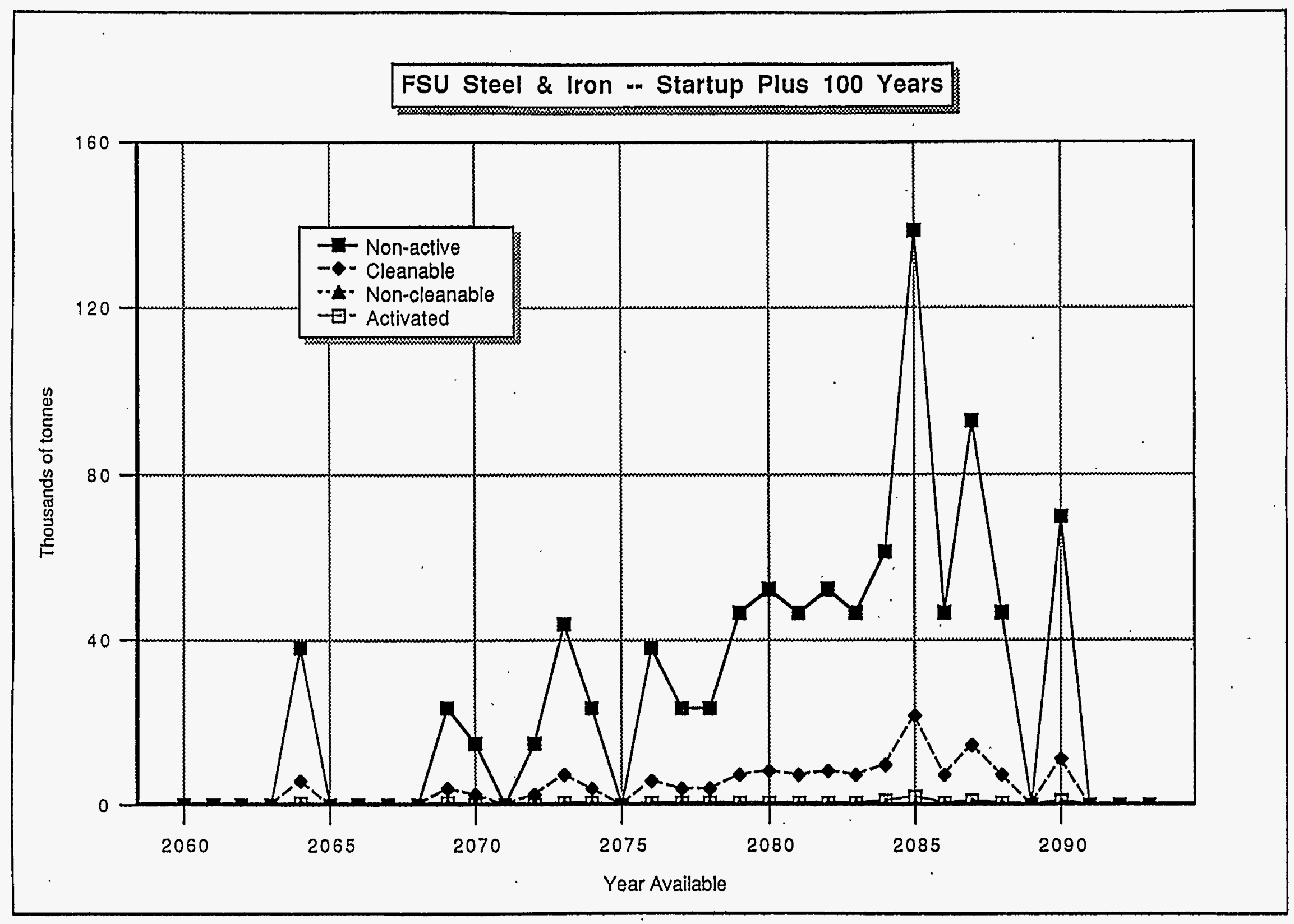




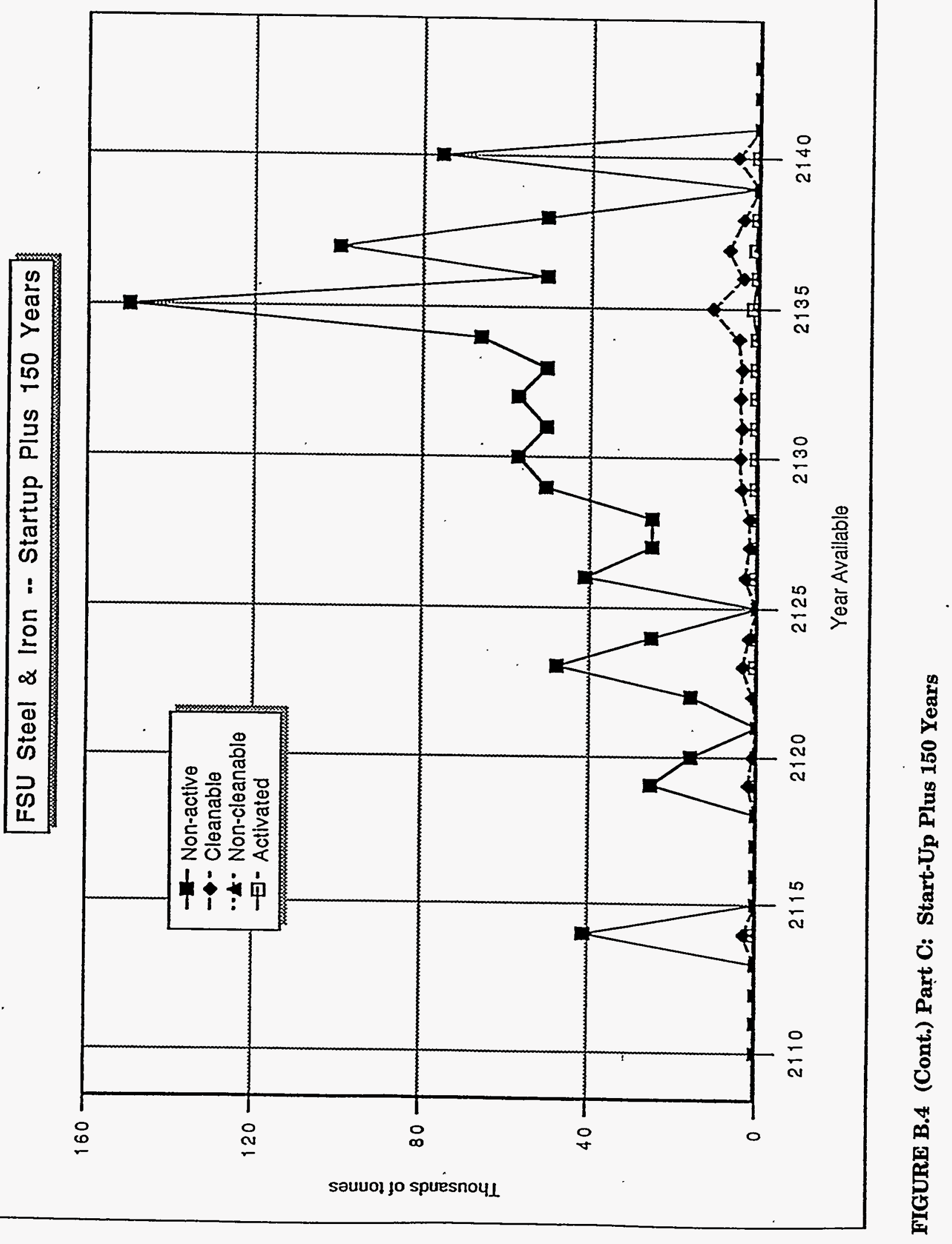




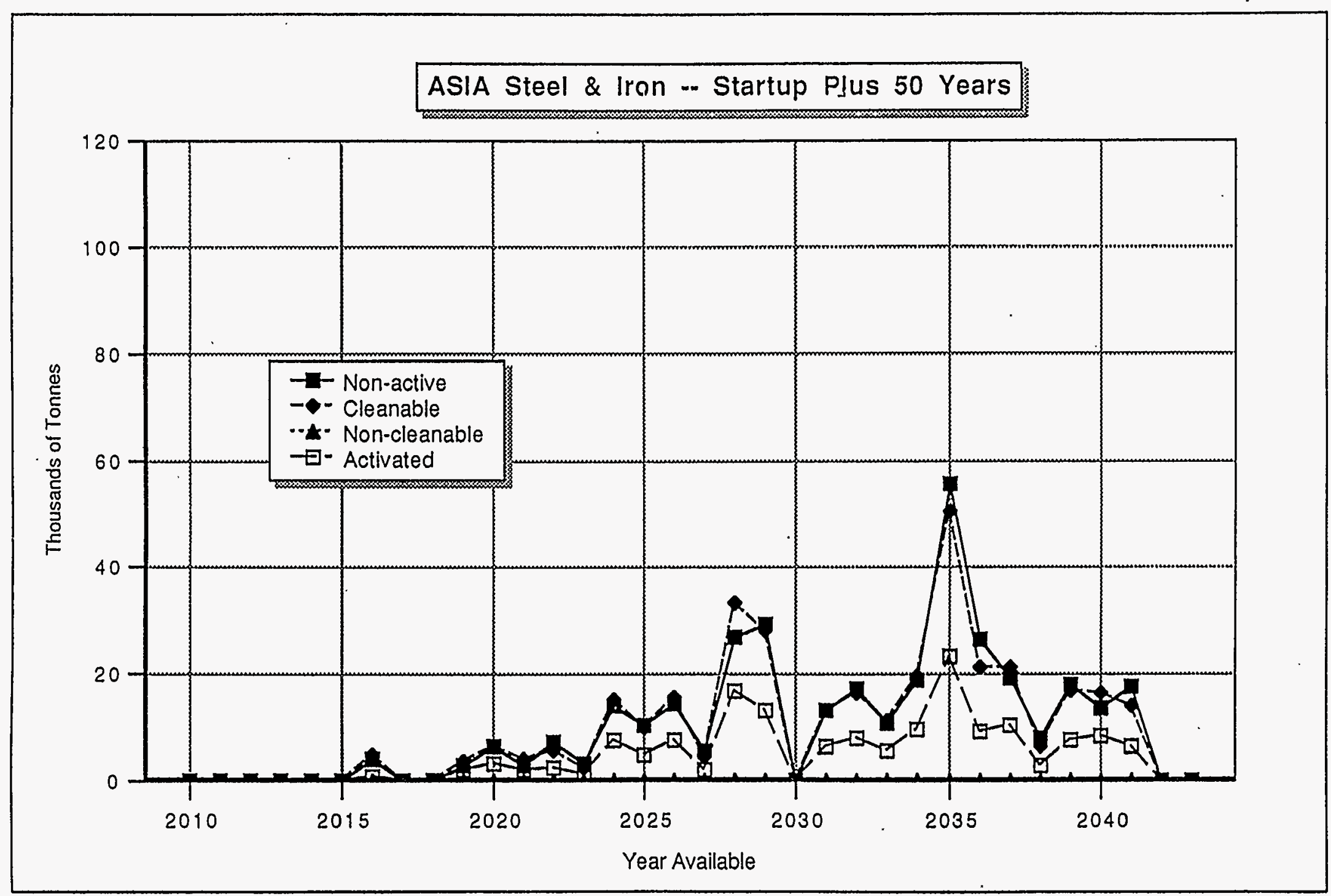

FIGURE B.5 Annual Increments in Scrap-Metal Inventory from Nuclear Power Plants for Asia (excludes Asian parts of the former Soviet Union); Part A: Start-Up Plus 50 Years 


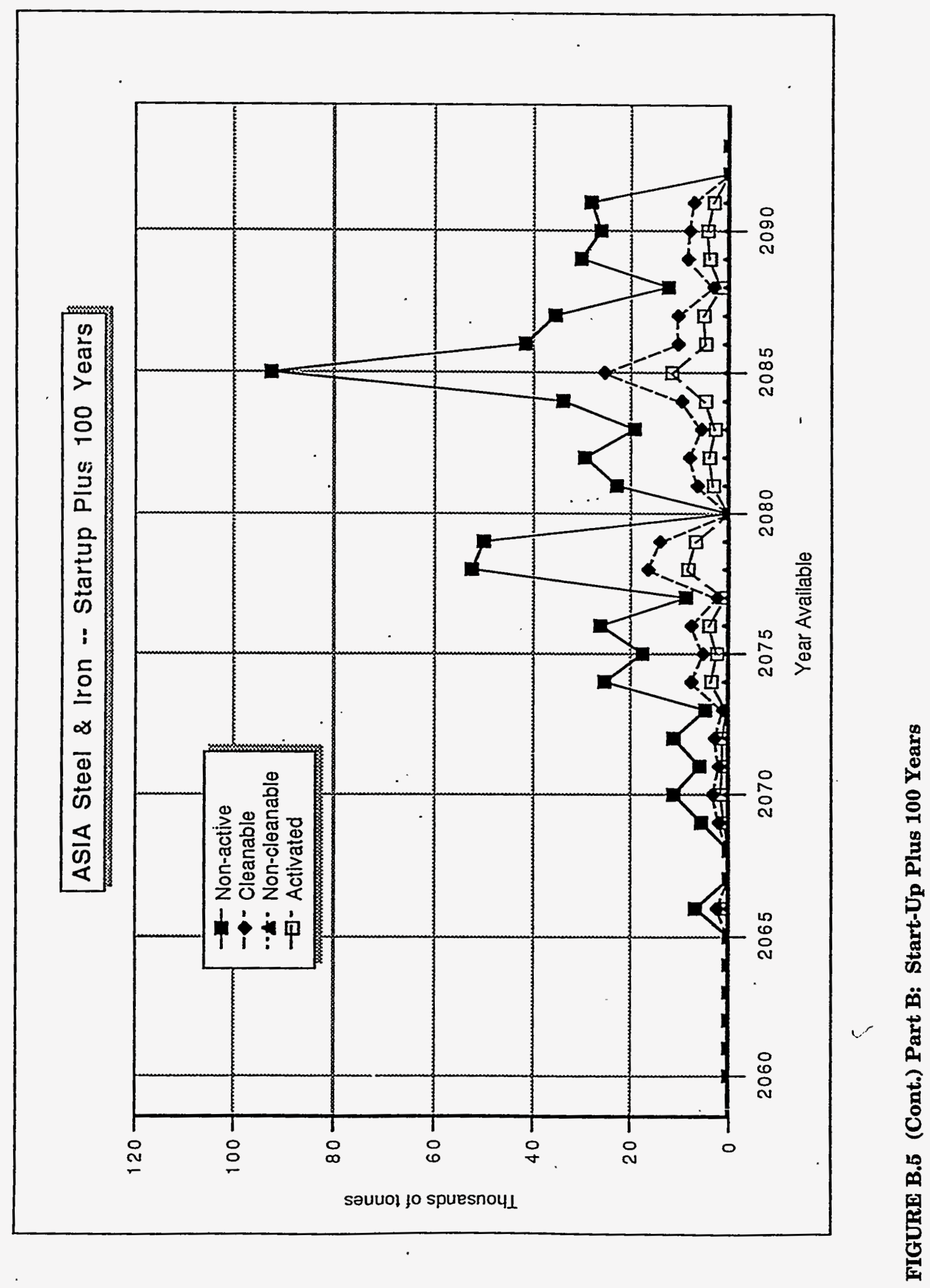




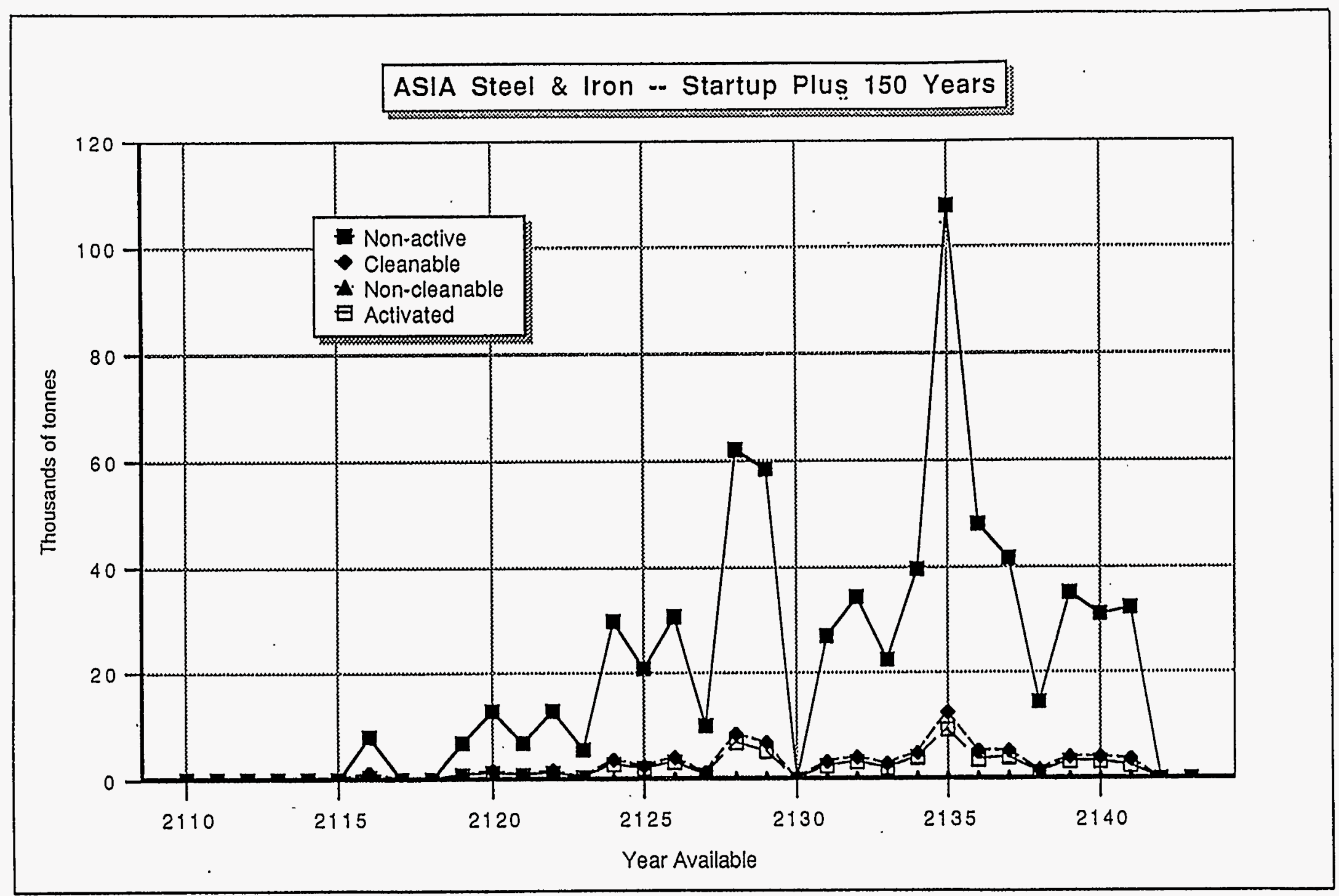




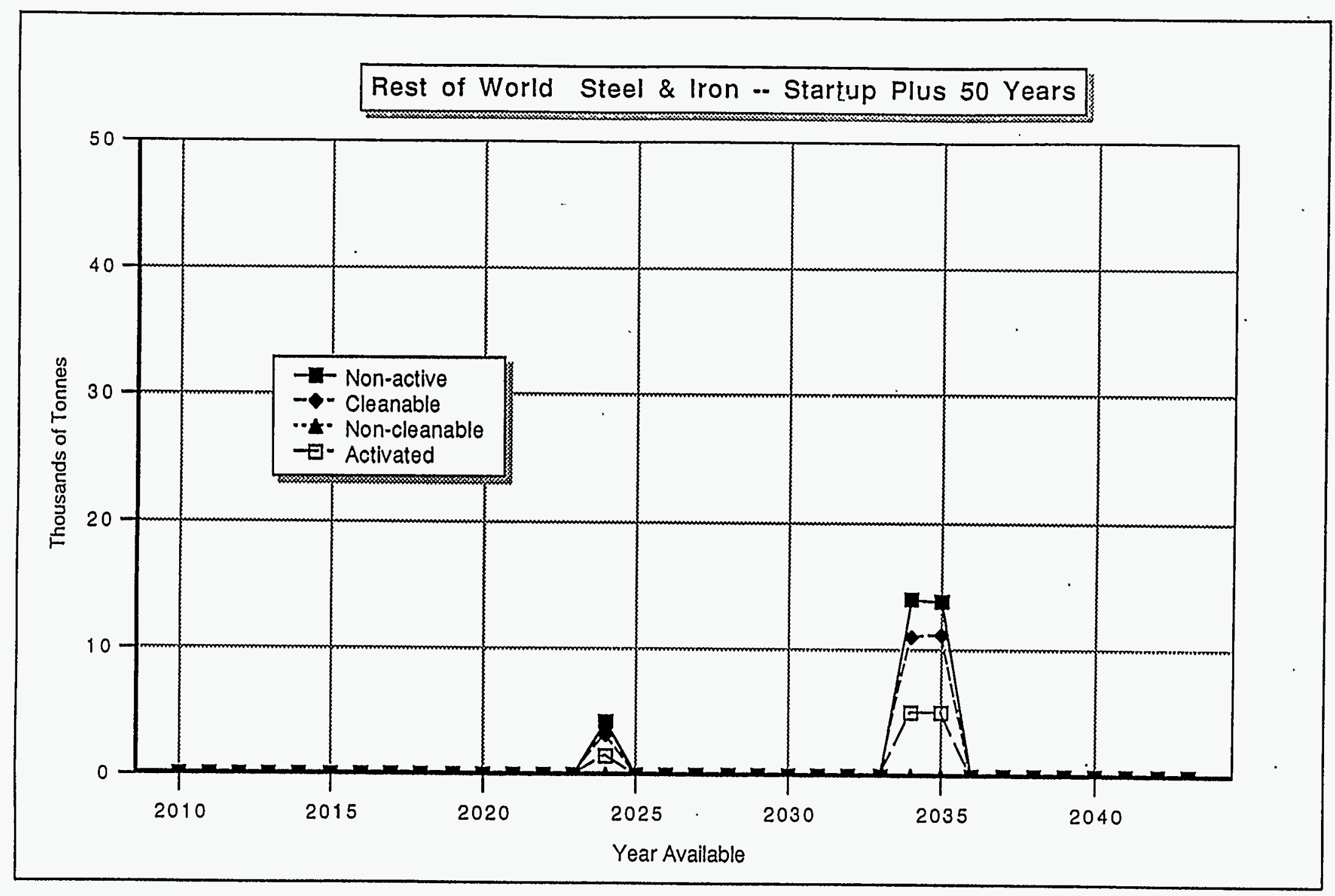
FIGURE B.6 Annual Increments in Scrap-Metal Inventory from Nuclear Power Plants for the Remainder of the World; Part A:
Start-Up Plus 50 Years 


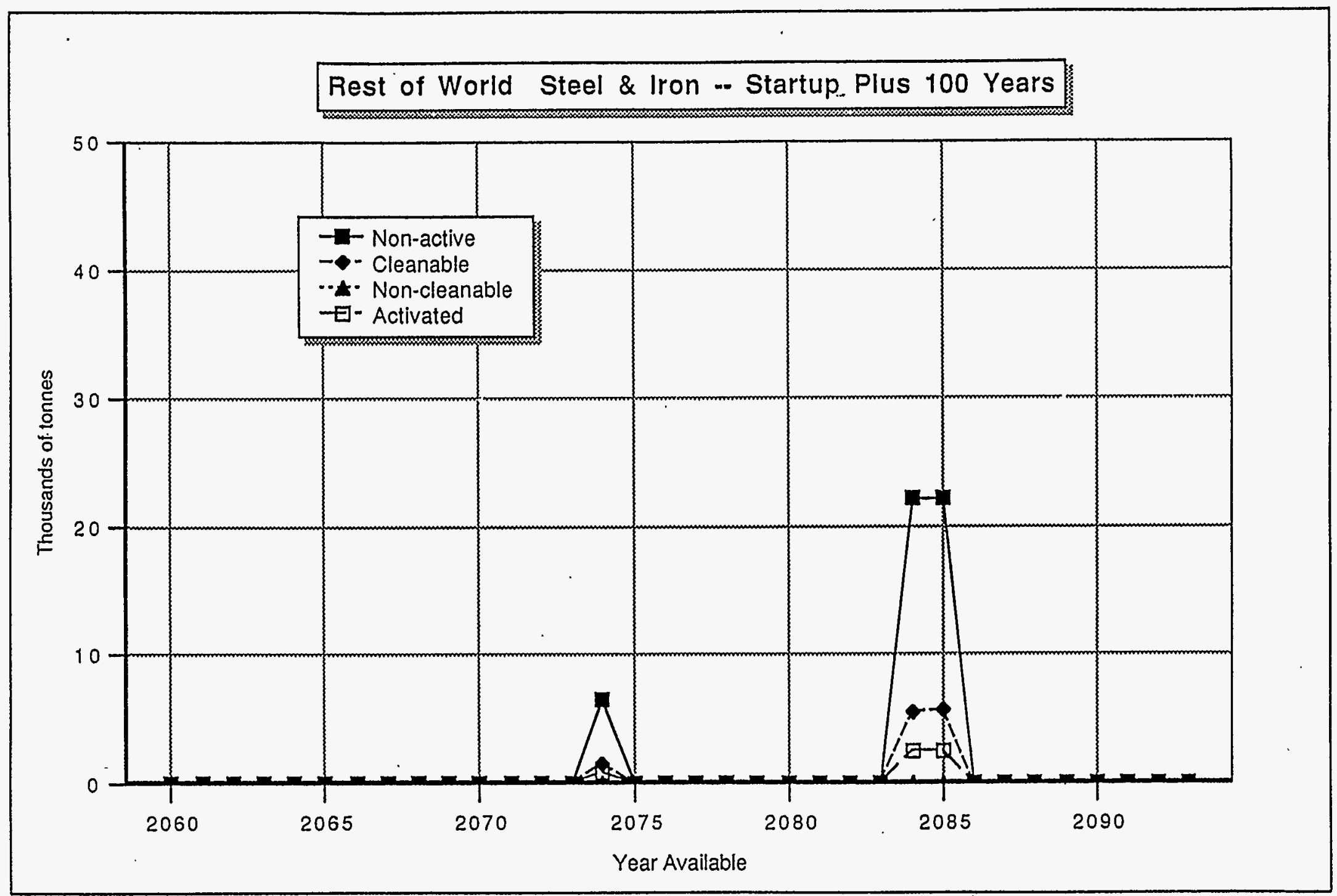




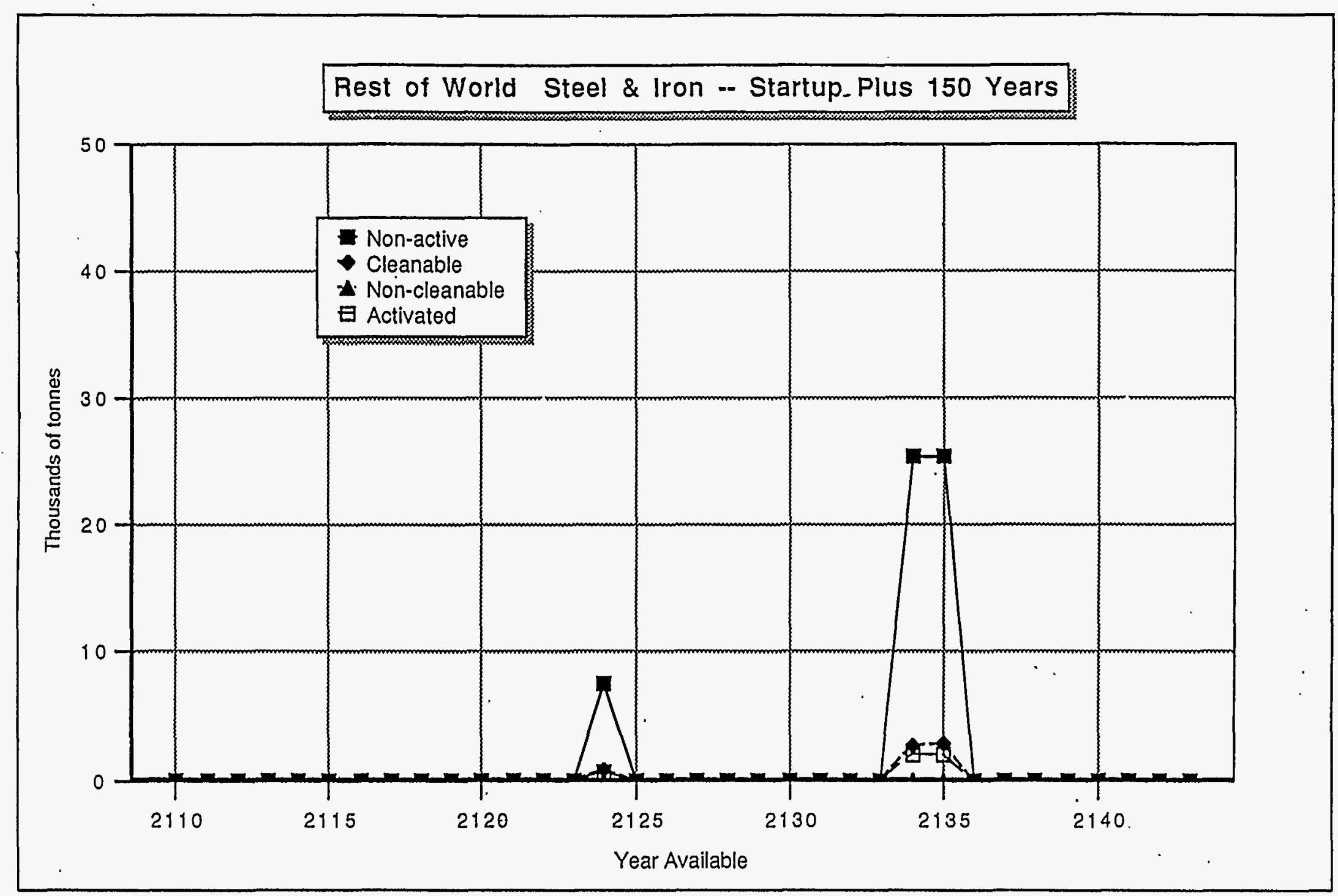




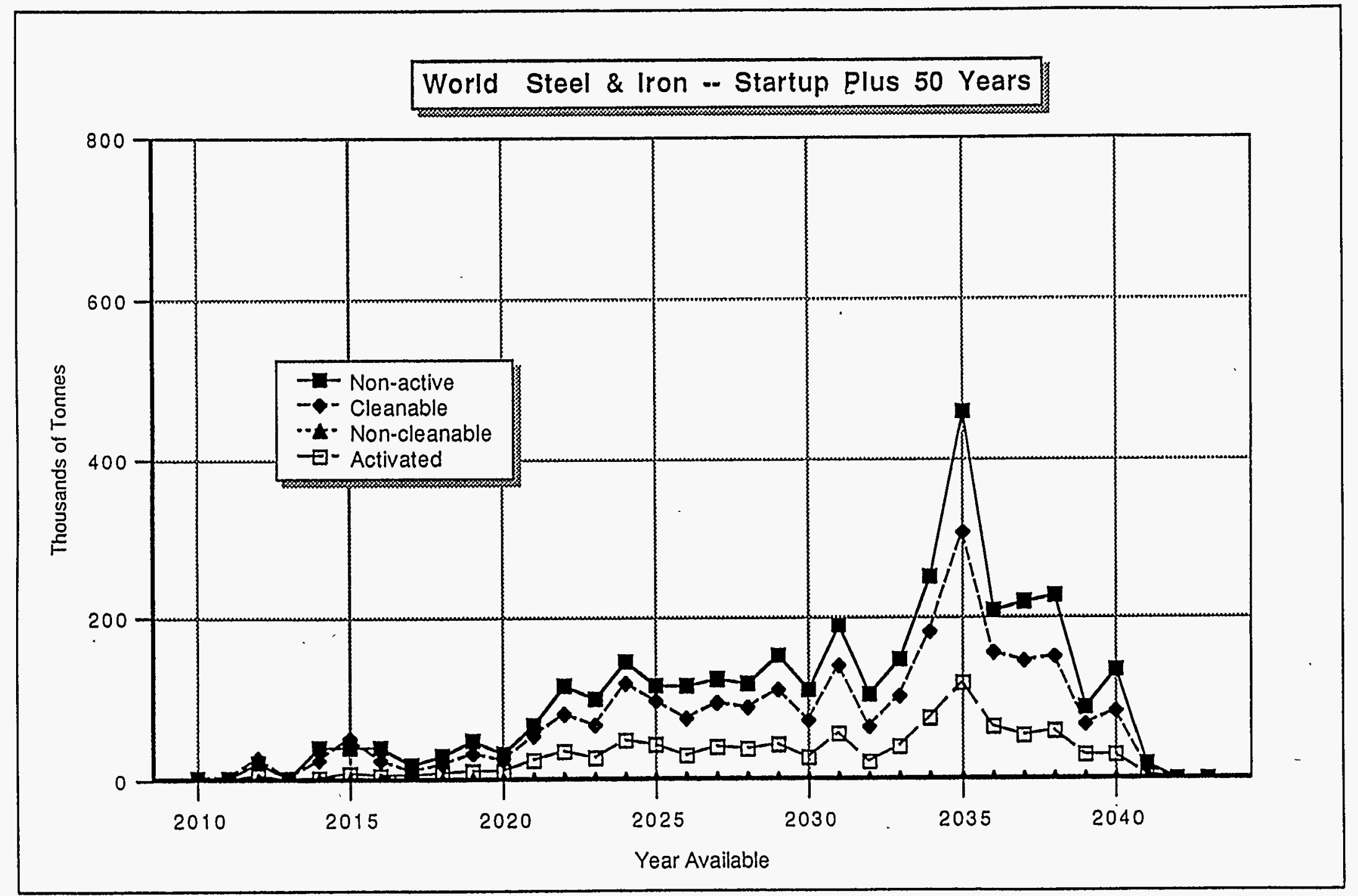




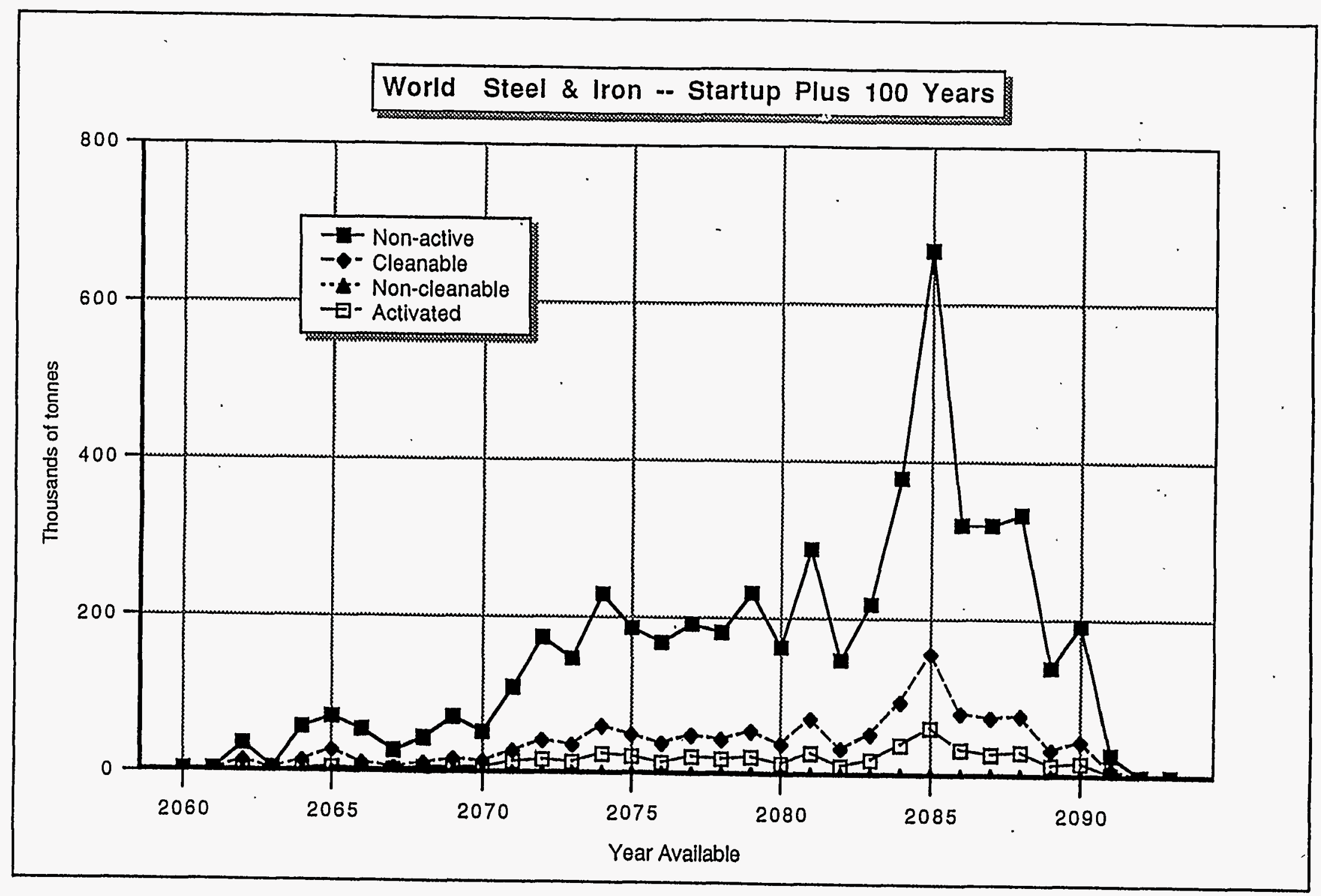




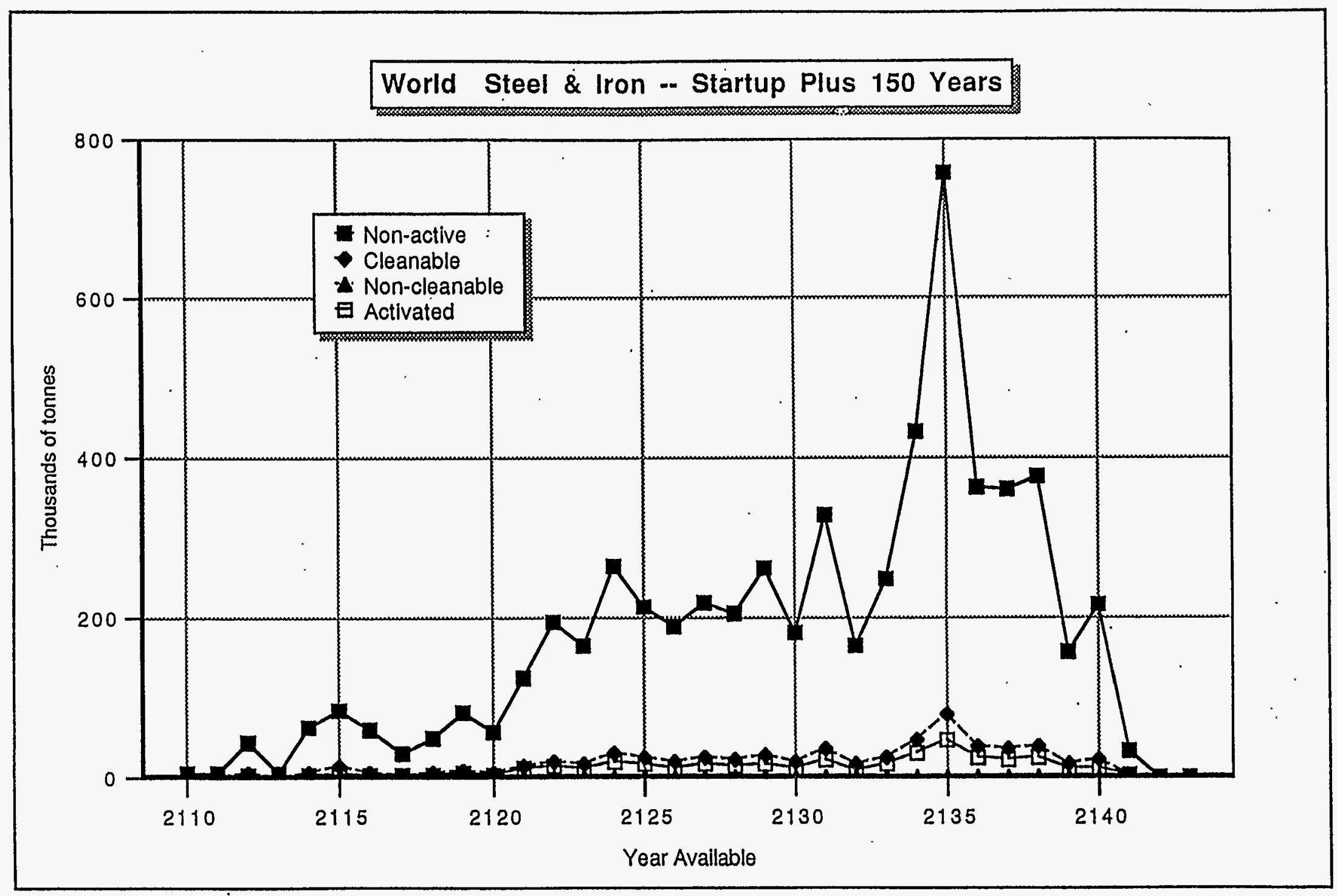


C-1

APPENDIX C:

RADIOLOGICAL RISK ASSESSMENT METHODOLOGY AND SENSITIVITY ANALYSIS 


\section{APPENDIX C:}

\section{RADIOLOGICAL RISK ASSESSMENT METHODOLOGY AND SENSITIVITY ANALYSIS}

This appendix first describes the methodology used to calculate doses from radioactive scrap metal (RSM) recycling for the potential release tiers (i.e., Tiers $A, B, C$, and $\mathrm{D}$ ). Then the scenarios employed to analyze each tier are described in detail. The method of deriving release levels from the dose estimates is then discussed, followed by an analysis of the sensitivity of dose estimates to important model parameters. Finally, a simulated probabilistic analysis is presented to illustrate the advantages of a Monte Carlo approach in dose assessment.

\section{C.1 RISK ASSESSMENT METHODOLOGY}

The basic methodology used for this analysis employs the methods in the U.S. Nuclear Regulatory Commission's (USNRC's) NUREG/CR-5512 publication (USNRC 1992) and the RESRAD-BUILD code developed at Argonne National Laboratory (Yu et al. 1994). While NUREG/CR-5512 is designed to serve as a generic screening model, the RESRAD-BUILD code assesses exposures ${ }^{1}$ in a more detailed environmental setting for decontamination and decommissioning activities. For this evaluation, the following pathways were analyzed: inhalation of particulates, radon and its decay progeny, tritium, and volatile elements; ingestion; and external exposure. Exposure assessments for radon, tritium, and volatile elements (such as iodine) were limited to Tier A (reuse scenarios) because of the complexity of assessing these exposures after melting of RSM, which would apply to Tier B and $\mathrm{C}$ releases.

For this analysis, consideration was given to radionuclides that have short half-lives. An average decay factor was used to account for radioactive decay over a one-year period in the dose calculations for the public and the workers (Table C.1). The decay factor represents the average fraction of activity present over the course of one year. Inhalation and ingestion doses were calculated with committed effective dose equivalent conversion factors (DCFs) obtained from the U.S. Environmental Protection Agency, Federal Guidance Report No. 11 (Eckerman et al. 1988). These DCFs, which are listed in Table C.1, are based on recommendations in the International Commission on Radiological Protection's (ICRP's) Publication 30 (ICRP 1979-1988), and ICRP Publication 48 (ICRP.1986) for plutonium and related elements. The external effective dose equivalent factors were based on the recent report published by USEPA, Federal Guidance Report No. 12 (USEPA 1993).

1 Detailed recycling scenarios and calculation methods have since been incorporated into the RESRAD-RECYCLE code that is under development at Argonne National Laboratory. 
TABLE C.1 Inhalation and Ingestion Dose Conversion Factors (DCFs) ${ }^{2}$

\begin{tabular}{|c|c|c|c|c|}
\hline Nuclide & $\begin{array}{l}\text { Half-Life } \\
(\mathrm{yr})\end{array}$ & $\begin{array}{c}\text { Average Decay } \\
\text { Factor }\end{array}$ & $\begin{array}{c}\text { Ingestion DCF } \\
(\mathrm{Sv} / \mathrm{Bq})\end{array}$ & $\begin{array}{c}\text { Inhalation DCF } \\
(\mathrm{Sv} / \mathrm{Bq})\end{array}$ \\
\hline Ac-227 & $2.18 \mathrm{E}+01$ & $9.84 \mathrm{E}-01$ & $3.80 \mathrm{E}-06$ & 1.81E-03 \\
\hline Ag-110m & $6.84 \mathrm{E}-01$ & $6.29 \mathrm{E}-01$ & 2.92E-09 & 2.17E-08 \\
\hline Am-241 & $4.33 \mathrm{E}+02$ & 9.99E-01 & $9.84 \mathrm{E}-07$ & $1.20 \mathrm{E}-04$ \\
\hline Am-243 & $7.37 \mathrm{E}+03$ & $1.00 \mathrm{E}+00$ & 9.79E-07 & $1.19 \mathrm{E}-04$ \\
\hline $\mathrm{Ca}-41$ & $1.03 \mathrm{E}+05$ & $1.00 \mathrm{E}+00$ & 3.44E-10 & 3.64E-10 \\
\hline Ce-144 & $7.79 \mathrm{E}-01$ & $6.62 \mathrm{E}-01$ & $5.68 \mathrm{E}-09$ & $1.01 \mathrm{E}-07$ \\
\hline $\mathrm{Cl}-36$ & $3.01 E+05$ & $1.00 \mathrm{E}+00$ & 8.18E-10 & 5.93E-09 \\
\hline $\mathrm{Cm}-243$ & $2.85 \mathrm{E}+01$ & $9.88 \mathrm{E}-01$ & $6.79 \mathrm{E}-07$ & 8.30E-05 \\
\hline $\mathrm{Cm}-244$ & $1.81 \mathrm{E}+01$ & 9.81E-01 & $5.45 \mathrm{E}-07$ & 6.70E-05 \\
\hline $\mathrm{Cm}-245$ & $8.50 \mathrm{E}+03$ & $1.00 \mathrm{E}+00$ & 1.01E-06 & 1.23E-04 \\
\hline $\mathrm{Cm}-246$ & $4.75 \mathrm{E}+03$ & $1.00 \mathrm{E}+00$ & 1.00E-06 & 1.22E-04 \\
\hline $\mathrm{Cm}-247$ & $1.56 \mathrm{E}+07$ & $1.00 \mathrm{E}+00$ & 9.24E-07 & 1.12E-04 \\
\hline Co-57 & 7.97E-01 & $6.68 \mathrm{E}-01$ & $3.20 \mathrm{E}-10$ & 2.45E-09 \\
\hline Co-60 & $5.27 \mathrm{E}+00$ & 9.37E-01 & $7.28 \mathrm{E}-09$ & 5.91E-08 \\
\hline Cs-134 & $2.06 \mathrm{E}+00$ & 8.49E-01 & $1.98 \mathrm{E}-08$ & $1.25 \mathrm{E}-08$ \\
\hline Cs-135 & $2.30 \mathrm{E}+06$ & $1.00 \mathrm{E}+00$ & 1.91E-09 & 1.23E-09 \\
\hline Cs-137 & $3.02 \mathrm{E}+01$ & $9.89 \mathrm{E}-01$ & 1.35E-08 & 8.63E-09 \\
\hline Eu-152 & $1.36 \mathrm{E}+01$ & $9.75 \mathrm{E}-01$ & $1.75 \mathrm{E}-09$ & 5.97E-08 \\
\hline Eu-154 & $8.80 \mathrm{E}+00$ & 9.62E-01 & 2.58E-09 & 7.73E-08 \\
\hline Fe-55 & $2.70 \mathrm{E}+00$ & 8.82E-01 & 1.64E-10 & $7.26 \mathrm{E}-10$ \\
\hline $\mathrm{Mn}-54$ & 8.57E-01 & $6.86 \mathrm{E}-01$ & 7.48E-10 & 1.81E-09 \\
\hline $\mathrm{Na}-22$ & $2.60 \mathrm{E}+00$ & $8.78 \mathrm{E}-01$ & 3.10E-09 & 2.07E-09 \\
\hline $\mathrm{Nb}-94$ & $2.03 \mathrm{E}+04$ & $1.00 \mathrm{E}+00$ & 1.93E-09 & 1.12E-07 \\
\hline $\mathrm{Ni}-59$ & $7.50 \mathrm{E}+04$ & $1.00 \mathrm{E}+00$ & 5.67E-11 & 7.31E-10 \\
\hline $\mathrm{Ni}-63$ & $1.00 \mathrm{E}+02$ & 9.97E-01 & $1.56 \mathrm{E}-10$ & $1.70 \mathrm{E}-09$ \\
\hline Np-237 & $2.14 \mathrm{E}+06$ & $1.00 \mathrm{E}+00$ & $1.20 \mathrm{E}-06$ & $1.46 \mathrm{E}-04$ \\
\hline $\mathrm{Pb}-210$ & $2.23 \mathrm{E}+01$ & 9.85E-01 & 1.45E-06 & 3.67E-06 \\
\hline Pm-147 & $2.62 \mathrm{E}+00$ & 8.79E-01 & 2.83E-10 & $1.06 \mathrm{E}-08$ \\
\hline $\mathrm{Pu}-238$ & $8.78 \mathrm{E}+01$ & 9.96E-01 & 8.65E-07 & 1.06E-04 \\
\hline Pu-239 & $2.41 \mathrm{E}+04$ & $1.00 \mathrm{E}+00$ & 9.56E-07 & $1.16 \mathrm{E}-04$ \\
\hline Pu-240 & $6.54 \mathrm{E}+03$ & $1.00 \mathrm{E}+00$ & 9.56E-07 & $1.16 \mathrm{E}-04$ \\
\hline Pu-241 & $1.44 \mathrm{E}+01$ & $9.76 \mathrm{E}-01$ & $1.85 \mathrm{E}-08$ & 2.23E-06 \\
\hline Pu-242 & $3.76 \mathrm{E}+05$ & $1.00 \mathrm{E}+00$ & 9.08E-07 & 1.11E-04 \\
\hline $\mathrm{Ru}-106$ & $1.01 \mathrm{E}+00$ & 7.23E-01 & 7.40E-09 & $1.29 \mathrm{E}-07$ \\
\hline Sb-125 & $2.77 \mathrm{E}+00$ & 8.85E-01 & 7.59E-10 & 3.30E-09 \\
\hline Se-79 & $6.50 \mathrm{E}+04$ & $1.00 \mathrm{E}+00$ & 2.35E-09 & 2.66E-09 \\
\hline $\mathrm{Sm}-151$ & $9.00 \mathrm{E}+01$ & $9.96 \mathrm{E}-01$ & $1.05 \mathrm{E}-10$ & 8.10E-09 \\
\hline Sr-90 & $2.86 \mathrm{E}+01$ & $9.88 \mathrm{E}-01$ & $3.85 \mathrm{E}-08$ & 3.51E-07 \\
\hline Tc-99 & $2.13 E+05$ & $1.00 \mathrm{E}+00$ & 3.95E-10 & 2.25E-09 \\
\hline Th-228 & $1.90 \mathrm{E}+00$ & $8.38 \mathrm{E}-01$ & $1.07 \mathrm{E}-07$ & 9.23E-05 \\
\hline Th-229 & $7.30 \mathrm{E}+03$ & $1.00 \mathrm{E}+00$ & $9.54 \mathrm{E}-07$ & 5.80E-04 \\
\hline Th-230 & $7.50 \mathrm{E}+04$ & $1.00 \mathrm{E}+00$ & $1.48 \mathrm{E}-07$ & 8.80E-05 \\
\hline Th-232 & $1.40 \mathrm{E}+10$ & $1.00 \mathrm{E}+00$ & $7.38 \mathrm{E}-07$ & 4.43E-04 \\
\hline U-232 & $6.89 E+01$ & 9.95E-01 & $3.54 \mathrm{E}-07$ & $1.78 \mathrm{E}-04$ \\
\hline U-233 & $1.60 \mathrm{E}+05$ & $1.00 \mathrm{E}+00$ & 7.81E-08 & $3.66 \mathrm{E}-05$ \\
\hline U-234 & $2.44 \mathrm{E}+05$ & $1.00 \mathrm{E}+00$ & 7.66E-08 & 3.58E-05 \\
\hline
\end{tabular}


TABLE C.1 (Cont.)

\begin{tabular}{lcccc}
\hline Nuclide & $\begin{array}{c}\text { Half-Life } \\
(\mathrm{yr})\end{array}$ & $\begin{array}{c}\text { Average Decay } \\
\text { Factor }\end{array}$ & $\begin{array}{c}\text { Ingestion DCF } \\
(\mathrm{Sv} / \mathrm{Bq})\end{array}$ & $\begin{array}{c}\text { Inhalation DCF } \\
(\mathrm{Sv} / \mathrm{Bq})\end{array}$ \\
\hline $\mathrm{U}-235$ & $7.04 \mathrm{E}+08$ & $1.00 \mathrm{E}+00$ & $7.19 \mathrm{E}-08$ & $3.32 \mathrm{E}-05$ \\
$\mathrm{U}-238$ & $4.47 \mathrm{E}+09$ & $1.00 \mathrm{E}+00$ & $6.88 \mathrm{E}-08$ & $3.20 \mathrm{E}-05$ \\
Zn-65 & $6.70 \mathrm{E}-01$ & $6.23 \mathrm{E}-01$ & $3.90 \mathrm{E}-09$ & $5.51 \mathrm{E}-09$ \\
Zr-93 & $1.50 \mathrm{E}+06$ & $1.00 \mathrm{E}+00$ & $4.48 \mathrm{E}-10$ & $8.67 \mathrm{E}-08$ \\
\hline
\end{tabular}

a Internal dose conversion factors were taken from USEPA Federal. Guidance Report No. 11 (Eckerman et al. 1988).

b Represents the average fraction of activity present over one year.

\section{C.1.1 Radionuclide Selection}

Analyses were initially conducted for a comprehensive list of potential contaminants (more than 200 radionuclides). Because of the difficulty of conducting a full analysis for the complete list, representative radionuclides were selected on the basis of the following criteria: (1) radionuclides analyzed in the IAEA and Commission of the European Communities (CEC) reports (CEC 1988) were included; (2) radionuclides with a half-life of less than one year were not included, with the exception of those that were expected to be prevalent in RSM (e.g., $\mathrm{Zn}-65$ and $\mathrm{Mn}-54$ ); (3) radionuclides with relatively low internal or external dose conversion factors were excluded from the analysis; and (4) results of an analysis of smelted metal from decontaminated reactors were used to focus the selection (Scientific Ecology Group 1993). While it is recognized that the final list of radionuclides presented in this report does not represent the full inventory of radionuclides that may be present in RSM, the results can be used to estimate doses from other radionuclides with similar DCFs.

\section{C.1.2 Surface Contamination Methodology}

The reuse scenarios assess exposures to a surface contaminated room or small tool. A room compartment that is $5 \times 5 \times 3 \mathrm{~m}$ is assumed. For extensive contamination, all four walls of the room are assumed to be uniformly contaminated. For small tools/motors, or equipment, a representative area of $1 \mathrm{~m}^{2}$ is assumed in the same room environment. The RESRAD-BUILD code ( $\mathrm{Yu}$ et al. 1994) was used to perform the calculations.

\section{C.1.2.1 Inhalation}

In calculating the inhalation dose from surface contamination, the RESRAD-BUILD code applies an emission rate of $10^{-6}$ per hour (Healy 1971) rather than a resuspension factor and accounts for air ventilation rate and total area of the contaminated surface as follows: 


$$
C E D E_{i}=C_{i} \times E R \times I R \times F \times E D \times D C F_{i} \times A_{s} \times W /(V \times k),
$$

where

$$
\begin{aligned}
C E D E_{i}= & \begin{array}{l}
\text { committed effective dose equivalent from intake of } \\
\text { radionuclide } \mathrm{i}(\mathrm{Sv}),
\end{array} \\
C_{i}= & \begin{array}{c}
\text { concentration of radionuclide } \mathrm{i} \text { on } \mathrm{RSM} \text { (assumed to be } \\
\left.1 \mathrm{~Bq} / \mathrm{cm}^{2}\right),
\end{array} \\
E R= & \text { emission rate (assumed to be } 10^{-6} / \mathrm{h} \text { [Healy 1971]), } \\
I R= & \text { inhalation rate (assumed to be } 1.2 \mathrm{~m}^{3} / \mathrm{h} \text { [ICRP 1975]), } \\
F= & \text { average decay factor (unitless), } \\
E D= & \text { exposure duration (h), } \\
D C F_{i}= & \text { inhalation dose conversion factor for radionuclide } \mathrm{i} \\
& (\text { Sv/Bq), } \\
A_{s}= & \text { surface area of the source (cm } \left.{ }^{2}\right), \\
W= & \text { fraction of airborne dust originating from the } \\
& \text { contaminated source (unitless, assumed to be } 1.0), \\
V= & \text { volume of the room (cm } \left.{ }^{3}\right), \text { and } \\
k= & \text { ventilation rate (assumed to be } 1 / \mathrm{h}) .
\end{aligned}
$$

\section{C.1.2.2 Ingestion} equation:

The ingestion dose from surface contamination was calculated with the following

$$
C E D E_{i}=C_{i} \times I G \times E D \times D C F_{i} \times F \times W
$$

where

$$
\begin{aligned}
& I G=\text { rate of ingestion of removable surface contamination, } \\
& D C F_{i}=\text { ingestion dose conversion factor for radionuclide } \mathrm{i} \text {, } \\
& W \text { = fraction of ingested material originating from the } \\
& \text { contaminated surface (unitless, assumed to be 1). }
\end{aligned}
$$


For the tool reuse scenario, the ingestion dose was multiplied by the ratio of contaminated surface area of the tool to that of the room.

\section{C.1.2.3 Radon}

Exposure to radon and its decay progeny is likely to affect workers as well as the public under the reuse scenario. The concentration of radon in air was calculated as follows:

$$
C_{r a}(t)=r S(A / V)[\lambda(\lambda+k)],
$$

where

$$
\begin{aligned}
C_{r a}(t)= & \text { radon concentration in air at time }(\mathrm{t})\left(\mathrm{Bq} / \mathrm{cm}^{3}\right), \\
r= & \text { radon emanation factor, } \\
S= & \text { radium surface concentration from either direct contamination } \\
& \text { or ingrowth from a parent of radium }\left(1 \mathrm{~Bq} / \mathrm{cm}^{2}\right), \\
A= & \text { area of the source }\left(\mathrm{cm}^{2}\right), \\
V= & \text { the volume of the room, } \\
\lambda= & \text { radon decay constant, and } \\
k= & \text { building ventilation rate }\left(\mathrm{h}^{-1}\right) .
\end{aligned}
$$

The working level is derived from the concentrations of radon decay products, which are obtained from the concentration and building ventilation rates. $\mathrm{A}$ time-averaged concentration is used to evaluate the first-year dose.

\section{C.1.2.4 Volatile Elements}

The air concentration of tritium and volatile elements was calculated using the following equation:

$$
C_{i}(t)=S_{i}\left(\frac{A}{V}\right) \frac{\gamma}{k} e^{-\lambda_{i} t}
$$

where

$$
\begin{aligned}
C_{i}(t) & =\text { concentration of radionuclide } i \text { in air at time }(\mathrm{t})\left(\mathrm{Bq} / \mathrm{cm}^{3}\right), \\
S_{i} & =\text { surface concentration of radionuclide } \mathrm{i} \text { in } \mathrm{RSM}\left(\mathrm{Bq} / \mathrm{cm}^{2}\right),
\end{aligned}
$$




$$
\begin{aligned}
\gamma & =\text { emission rate }\left(h^{-1}\right), \text { and } \\
\lambda_{i} & =\text { decay constant of radionuclide } i\left(h^{-1}\right)
\end{aligned}
$$

In this calculation, the radioactivity is assumed to be released in one year.

\section{C.1.2.5 External Exposure}

Each contaminated surface in a scenario contributes to the external exposure. The exposure rate depends upon the geometry of the surface relative to the point at which the dose is to be evaluated. This geometry is determined by the area of the source, the distance (parallel and perpendicular to the surface) between the source and receptor, and the shielding between the source and receptor. The Federal Guidance Report 12 (USEPA 1993) surface dose conversion factors for infinite plane sources with the receptor $1 \mathrm{~m}$ from the plane and without shielding were used as reference points. The external exposure from surface contamination was derived as:

$$
E D E_{i}=C_{i} \times T \times \sum_{\text {surfaces }} D_{\infty i} \times F_{G i}
$$

where

$$
\begin{aligned}
E D E= & \text { effective dose equivalent for radionuclide }(i), \\
T= & \text { time exposed to surfaces, } \\
D_{\infty}= & \begin{array}{l}
\text { Federal Guidance Report } 12 \text { dose conversion factor for } \\
\text { infinite plane source, and }
\end{array} \\
F_{G}= & \begin{array}{l}
\text { geometrical factor for finite area, shielding, and position of } \\
\text { receptor relative to the surface. }
\end{array}
\end{aligned}
$$

The geometrical factors are obtained by finding the ratio of dose integrals over the source. These dose integrals considered source energy, attenuation, and buildup through cover material and air. Each energy from a radionuclide's decay was considered separately and weighted by its yield. The integral is one-dimensional, assuming the source is cylindrical. Therefore, the dimension to be integrated is the perpendicular distance from the cylinder's axis. This is done as follows: 


$$
F_{G}=\frac{\sum_{\text {Energies: } j} y_{j} E_{j} \int_{0}^{R} \frac{B\left(x^{\prime}\right) \times e^{-\mu x^{\prime}}}{\left(x^{\prime}\right)^{2}} d A}{\sum_{\text {Energies: } j} y_{j} E_{j} \int_{0}^{\infty} \frac{B_{a}(x) \times e^{-p_{a} x}}{x^{2}} d A}
$$

where

$$
\begin{aligned}
x^{2} & =r^{2}+(1 m)^{2} \\
\left(x^{\prime}\right)^{2} & =r^{2}+\left(d_{a}+d_{c}\right)^{2} \\
\mu & =\frac{d_{a} \mu_{a}+d_{c} \mu_{c}}{d_{a}+d_{c}} \\
B(x) & =B_{a}\left(\frac{d_{a}}{d_{a}+d_{c}} x\right) B_{c}\left(\frac{d_{c}}{d_{a}+d_{c}} x\right)
\end{aligned}
$$

( $\mu$ and B are the appropriate energy and material (a: air, c: cover material) attenuation coefficient and buildup factor).

\section{C.1.3 Volume Contamination Methodology}

\section{C.1.3.1 Inhalation}

The dose from inhalation of contaminated airborne particulates from volumecontaminated RSM was calculated as follows:

$$
C E D E_{i}=C_{i} \times F \times I R \times A D \times W \times E D \times D C F_{i},
$$

where

$$
\begin{aligned}
C_{i}= & \text { concentration of nuclide } \mathrm{i} \text { in } \mathrm{RSM} \text { (assumed to be } 1 \mathrm{~Bq} / \mathrm{g} \text { ), } \\
A D= & \text { airborne dust concentration }\left(\mathrm{g} / \mathrm{m}^{3}\right), \\
W= & \text { the fraction of airborne dust originating from the contaminated } \\
& \text { source (unitless, assumed to be } 1.0) .
\end{aligned}
$$

The critical parameter in this equation is the concentration of respirable dust in air $(A D)$. The value for this parameter depends on a multitude of factors, including ventilation, particle-size distribution, and quantity of material being handled. Because little is known about the amount of respirable dust in air, the parameter is estimated with a mass airborne 
dust-loading factor. As a conservative screening approach, the IAEA Safety Series No. 111 report (IAEA 1992) limit for indoor dust (i.e., $1 \times 10^{-3} \mathrm{~g} / \mathrm{m}^{3}$ ) was used as an upper-bound limit for indoor worker scenarios. A factor of 10 lower was used for scenarios having less potential for resuspension.

\section{C.1.3.2 Ingestion}

The CEDE for ingestion was calculated as explained for surface contamination (Section C.1.2.2):

$$
C E D E_{i}=C_{i} \times F \times I G \times E D \times D C F_{i}
$$

where

$$
I G=\text { ingestion rate }(\mathrm{g} / \mathrm{h})
$$

\section{C.1.3.3 External Exposure}

Each contaminated volume in a scenario contributes to the external exposure. The exposure rate depends upon the geometry of the volume relative to the point where the dose is to be evaluated. Each volume is represented either as a full or half cylinder. The geometry is determined by the area of the source, thickness of the source, the distance (parallel and perpendicular to the surface) between the source and receptor, and the shielding between the source and receptor. The Federal Guidance Report 12 semi-infinite slab volume dose conversion factors (USEPA 1993) with the receptor $1 \mathrm{~m}$ from the plane without shielding were used as reference points. Corrections for finite thickness of the source were made on the basis of the methodology in Chen $(1991 \mathrm{a}, \mathrm{b})$. The external exposure from contaminated volumes was derived as:

$$
E D E_{i}=C_{i} \times T \times \sum_{\text {surfaces }} D_{\infty i} \times F_{G i}
$$

where

$$
\begin{aligned}
& E D E=\text { effective dose equivalent for radionuclide (i), } \\
& T=\text { time exposed to surfaces, } \\
& D_{\infty}=\text { Federal Guidance Report } 12 \text { dose conversion factor 'for } \\
& \text { semi-infinite volume source, } \\
& F_{G}=\text { geometrical factor for finite area, source thickness, } \\
& \text { shielding, and position of receptor relative to the surface } \\
& \text { for radionuclide } \mathrm{i} \text {. }
\end{aligned}
$$




\section{C.1.4 Disposal Scenario Methodology}

The RESRAD code was used to evaluate doses from disposal of surface-contaminated material ( $\mathrm{Yu}$ et al. 1993b). For volume-contaminated material, the radionuclides are not immediately available for leaching but instead become available for leaching throughout a 100-year corrosion process. This scenario cannot be directly modeled with RESRAD. Instead, the dose was estimated for this scenario by separating the exposure into components from the uneroded material, $Q$, and the eroding material $d Q / d t$. The intact material contributes to the dose only through the external pathway, while the eroding material contributes through all pathways. Ingrowth and decay must be considered in both of these components. The time-dependent total dose profile $\left(D_{i}(t)\right)$ for a unit source of radionuclide $i$ available for leaching can be calculated from RESRAD. The external component of this at time of deposition is $D^{\text {ext }}$. The dose from contamination of radionuclide $j$ with a decay chain that includes radionuclides $i$ can be expressed as:

$$
D(t)=\sum_{i: \text { chain }}\left[D_{i}^{E x t} Q(t) C_{j} B_{i j}(t)+D_{i} *\left(\frac{d Q}{d t} C_{j} B_{i j}(t)\right)\right],
$$

where the B function is the Bateman's ingrowth ( $\mathrm{Yu}$ et al. 1993b), decay factor $\mathrm{C}$ is the original concentration of contamination, and the symbol "**" designates a time convolution between the two time-dependent functions.

\section{C.1.5 Collective Dose as a Function of Throughput}

The number of full-time workers (working $2,000 \mathrm{~h}$ per year) used in the collective dose calculations can be modified to account for variation in the amount of RSM to be recycled, according to the following equation:

$$
N=N_{0} \times\left(E D_{0} / 2000 h\right) \times\left(M / M_{0}\right),
$$

where

$$
\begin{aligned}
N= & \text { the number of full time workers, } \\
N_{0}= & \text { the number of workers in the baseline calculation, } \\
E D_{0}= & \text { worker exposure duration used in the baseline } \\
& \text { calculation }(\mathrm{h}), \\
M= & \text { amount of RSM to be recycled (t), and } \\
M_{0}= & \text { amount of RSM used in the baseline calculation }(100 \mathrm{t}) .
\end{aligned}
$$


For example, to recycle 50,000 t of RSM, the number of full-time workers (working $2,000 \mathrm{~h}$ per year) can be calculated with the above equation as shown in Table C.2. For enduse scenarios, the number of exposed consumers can be modified to account for variation in the amount of RSM recycled by multiplying the number in the baseline calculation by the ratio of the new amount to the baseline amount of $100 \mathrm{t}$. For example, to obtain the number of exposed individuals from recycling 50,000 $\mathrm{t}$ of RSM, the baseline numbers are multiplied by 500 .

\section{C.2 DESCRIPTION OF SCENARIOS}

This section describes the scenarios considered for each recycling activity. Representative exposure scenarios were considered for each step in the recycle process and for each major type of steel end use. In general, the exposure scenarios are similar to those presented in the International Atomic Energy Agency (IAEA) Safety Series 111 report (IAEA 1992). The worker scenarios were developed to model potential exposures associated with the transport of RSM from the place of origin to the smelter, the smelting process, and the fabrication and distribution of products. A modified conservative case (described in Section C.4.1) was developed to provide results under realistic assumptions.

The consumer scenarios were developed to model potential doses associated with the unrestricted release tiers. Tier A is represented by a building reuse scenario, which models potential exposures from reuse of a surface-contaminated room, and by a scenario for reuse of a small object or item of equipment. Eight consumer product scenarios are modeled under Tier B, and two scenarios were developed to model potential exposures from specified-initialuse products for Tier C. For the restricted recycle option, Tier D, three end-use exposure scenarios were developed.

\section{C.2.1 Worker Scenarios}

The parameter assumptions used in modeling each scenario are listed in Table C.2. The results of the analysis are presented for each scenario in Tables D.1 through D.22 (Appendix D). The results are represented in terms of individual dose and also collective dose for a 100-t throughput.

\section{C.2.1.1 Scrap Delivery}

Two scenarios are considered for the scrap delivery recycle step: loader and truck driver. The loader scenario models the potential doses to an individual who loads the RSM (which has met release limits) onto trucks for transport to the smelter. Standard mechanical loading equipment is assumed to be used for this operation. The truck driver scenario models the potential doses to an individual who transports the RSM from the place of origin to the processing facility. Because the driver would not be directly in contact with the scrap metal, 
TABLE C.2 Exposure Parameters Used to Model Worker Scenarios

\begin{tabular}{|c|c|c|c|c|c|c|c|c|c|c|c|c|}
\hline Recycle Shop & Scenario & $\begin{array}{c}\text { Source } \\
\text { Geometry }\end{array}$ & $\begin{array}{l}\text { Density } \\
\left(\mathrm{g} / \mathrm{cm}^{3)}\right.\end{array}$ & $\begin{array}{c}\cdot \\
\text { Thickness } \\
\text { (cm) }\end{array}$ & $\begin{array}{c}\text { Radius } \\
(\mathrm{cm})\end{array}$ & $\begin{array}{l}\text { Distance } \\
\text { (cm) }\end{array}$ & $\begin{array}{l}\text { Time } \\
\text { (h) }\end{array}$ & $\begin{array}{c}\text { Concentration } \\
(\mathrm{Bq} / \mathrm{g})\end{array}$ & $\begin{array}{c}\text { Internal } \\
\text { Pathway }\end{array}$ & $\begin{array}{c}\text { Air } \\
\text { Concentration } \\
\left(\mathrm{g} / \mathrm{m}^{3}\right)\end{array}$ & $\begin{array}{l}\text { No. of } \\
\text { Workers } \\
\text { for } 100 t\end{array}$ & $\begin{array}{l}\text { No. of Full- } \\
\text { Time Workers } \\
\text { for } 50,000 \mathrm{t}\end{array}$ \\
\hline Scrap & Loader & 1 half cylinder & 3.93 & 253 & 127 & 400 & 4 & 1 & inh, ing & 1.E-04 & 2 & 2 \\
\hline delivery & Truck driver & 1 half cylinder & 3.93 & 900 & 60 & 200 & 4 & 1 & $\cdots$ & $\cdots$ & 5 & 5 \\
\hline $\begin{array}{l}\text { Scrap seg- } \\
\text { menting }\end{array}$ & Cutter & 1 half cylinder & 3.93 & 60 & 30 & 200 & 12 & 1 & inh, ing & 1.E-04 & 3 & 9 \\
\hline $\begin{array}{l}\text { Scrap } \\
\text { processing }\end{array}$ & Processor & 1 half cylinder & 5.90 & 60 & 30 & 200 & 12 & 1 & inh, ing & 1.E-04 & 3 & 9 \\
\hline \multirow[t]{3}{*}{ Smelting } & Worker & 1 half cylinder & 5.90 & 351 & 175 & 1,000 & 80 & 1 & inh, ing & 1.E-04 & 10 & 200 \\
\hline & Loader & 1 half cylinder & 5.90 & 279 & 139 & 400 & 4 & 1 & inh, ing & 1.E-03 & 5 & 5 \\
\hline & Operator & 1 full cylinder & 7.86 & 253 & 127 & 300 & 5 & 1 & inh, ing & 1.E-03 & 3 & 3.75 \\
\hline Baghouse & Processor & 1 full cylinder & 2.00 & 100 & 40 & 200 & 0.16 & 100 & inh, ing & 1.E-03 & 1 & 0.04 \\
\hline Industrial & Ingot caster & 1 full cylinder & 7.86 & 100 & 64 & 150 & 2.5 & 1 & inh, ing & 1.E-03 & 2 & 1.25 \\
\hline \multirow[t]{4}{*}{ products } & $\begin{array}{l}\text { Small objects } \\
\text { Caster }\end{array}$ & 1 full cylinder & 7.86 & 1 & 201 & 100 & 50 & 1 & inh, ing & $1 . \mathrm{E}-03$ & 2 & 25 \\
\hline & Slag worker & 1 half cylinder & 2.70 & 45.5 & 228 & 150 & 25 & 10 & inh, ing & 1.E-03 & 1 & 6.25 \\
\hline & Loader & 1 half cylinder & 7.86 & 100 & 201 & 400 & 2 & 1 & $\ldots$ & $\ldots$ & 2 & 1 \\
\hline & Truck driver & 1 full cylinder & 7.86 & 200 & 64 & 200 & 5 & 1 & $\cdots$ & $\cdots$ & 5 & 6.25 \\
\hline Initial & Yard worker & 1 half cylinder & 7.86 & 100 & 201 & 1,000 & 40 & 1 & $\cdots$ & $\ldots$ & 10 & 100 \\
\hline \multirow[t]{2}{*}{ fabrication } & Sheet worker & 1 half cylinder & 7.86 & 0.2 & 138 & 100 & 1 & 1 & inh, ing & 1.E-04 & 15 & 3.75 \\
\hline & Coil worker & 1 full cylinder & 7.86 & 122 & 60 & 150 & 1 & 1 & inh, ing & $1 . \mathrm{E} .04$ & 1 & 0.25 \\
\hline Final & Sheet worker & 1 half cylinder & 7.86 & 0.2 & 138 & 100 & 1 & 1 & $\ldots$ & $\cdots$ & 20 & 5 \\
\hline fabrication & Coil worker & 1 full cylinder & 7.86 & 122 & 60 & 160 & 80 & 1 & $\cdots$ & $\cdots$ & 5 & 100 \\
\hline \multirow[t]{4}{*}{ Distribution } & Loader & 1 half cylinder & 7.86 & 100 & 201 & 400 & 20 & 1 & $\ldots$ & ...- & 2 & 10 \\
\hline & Truck driver & 1 full cylinder & 7.86 & 200 & 64 & 200 & 8 & 1 & $\cdots$ & $\ldots$ & 5 & 10 \\
\hline & Sheet worker & 1 half cylinder & 7.86 & 0.2 & 138 & 100 & 20 & 1 & $\cdots$ & $\ldots$ & 20 & 100 \\
\hline & $\begin{array}{l}\text { Warehouse } \\
\text { worker }\end{array}$ & 1 half cylinder & 7.86 & 1.2 & 138 & 600 & 2,000 & 1 & $\cdots$ & $\cdots$ & 5 & 2,500 \\
\hline
\end{tabular}

a inh $=$ inhalation; ing $=$ ingestion. 
only the external gamma pathway is considered. The calculations do not account for shielding provided by the truck cab.

\section{C.2.1.2 Scrap Cutting}

An initial cutting step is modelled when the scrap first enters the processing facility. It is estimated that three individuals would work 12 hours each to process 100 tons of scrap metal. Cutters are assumed to work in an open area. Therefore, the average dust concentration is not expected to be high, although localized high concentrations may occur. Individuals using a torch to perform cutting operations are likely to be wearing some protective equipment. Although a respirable fraction of 1 is assumed, a high percentage of the particulates are expected to be above the respirable range (greater than $10 \mu \mathrm{m}$ ).

\section{C.2.1.3 Scrap Processing}

The scrap processing step is represented by an individual who prepares the scrap for input to the furnace. This individual's activities include shredding, cutting, smashing, chopping, bailing, and banding the scrap metal.

\section{C.2.1.4 Smelting of Scrap Metal}

Three scenarios are considered for the smelting process: a yard worker, loader, and an operator. The yard worker scenario models potential doses to an individual who works at the storage yard at the smelter. The loader scenario models the potential doses to a crane operator who loads scrap metal into the smelter. The operator scenario models the potential doses to an operator who works at a 100-t furnace.

\section{C.2.1.5 Baghouse Processor}

A baghouse processor scenario (based on Elert and Wiborgh [1992]) is evaluated to model potential doses to a worker handling smelter baghouse contents. The dust in the baghouse is assumed to be sprayed with water before handling to reduce the possibility of baghouse dust resuspension and inhalation. The baghouse processor is assumed to conduct his or her activity in the general area of smelting operations, and the dust concentration in the facility is assumed for the calculation of inhalation dose.

The volume of dust generated at a smelter is typically about $1 \%$ of the throughput. Thus for a 100-ton throughput, 1 ton of dust is expected to accumulate in the baghouse. Because of the concentrated activity in the dust, the processor is exposed to an activity concentration as high as 100 times the concentration in the scrap metal. The content of the baghouse is typically loaded in 1-ton bags for processing or storage. One processor is assumed to spend 0.16 hour processing dust bags for dust generated from a throughput of $100 \mathrm{t}$ of radioactive scrap metal. This operation will not require a full-time worker for 
$50,000 \mathrm{t}$ and is conducted at various times per year, depending on the annual throughput. In addition, the quantity handled is small (1\%) compared with the quantity of slag (10\%).

\section{C.2.1.6 Industrial Products/By-Product}

For the industrial products/by-product step, exposures from casting metal ingots or small objects are evaluated, as is exposure to the by-product material (slag). Also included in this step are exposures to those workers involved in transport of the industrial products from the smelting facility to the fabrication plant. The ingot caster scenario is evaluated to model potential doses to a worker casting 10-ton ingots. This scenario is the same as the Caster 1 scenario in the IAEA Safety Series 111 (IAEA 1992). The small objects caster scenario models potential doses to a worker casting industrial or consumer products. This scenario corresponds to the Caster 3 scenario in IAEA Safety Series 111.

The slag worker scenario models the potential doses to a worker who handles the slag. It is estimated that $10 \mathrm{t}$ of slag will be generated from smelting $100 . t$ of RSM. In the base case, the radionuclide concentration in the slag is estimated to be $10 \mathrm{~Bq} / \mathrm{g}$, based on the assumption that $10 \%$ of the initial charge becomes slag and that all of the radionuclides are concentrated in the slag. This assumption is only valid for some of the radionuclides, and partitioning factors are applied in the modified-conservative case. The loader scenario models the potential doses to a worker at the smelter who loads the industrial products for transport to the fabrication plant. The truck driver scenario models the potential doses to an individual who transports the ingots to the fabrication facility. Shielding from the truck cab is not considered in the dose calculations.

\section{C.2.1.7 Fabrication}

The process of fabricating sheet steel materials is divided into initial fabrication and final fabrication. The initial fabrication recycle step considers a yard worker at the fabrication plant, a sheet worker, and a coil worker. A sheet worker and a coil worker were also evaluated for the final fabrication process. The yard worker scenario models the potential exposures to a worker who processes the metal ingots at the steel fabrication plant. The coil worker scenario evaluates the potential doses to a worker who handles coils of sheet steel. Because of the different exposure conditions, inhalation and ingestion are considered plausible and evaluated under the initial fabrication step only.

\section{C.2.1.8 Distribution of Final Products}

This recycle step considers the transport and distribution of the final products made at the fabrication facility. Since this recycle step involves the finished product, only external gamma exposure is considered. The loader scenario models potential exposures to an individual who loads and unloads trucks for distribution of the final products. The truck driver scenario models potential exposures to an individual who transports the finished 
products for distribution. The sheet worker scenario models potential exposures to an individual who assembles the sheets of steel for a building. The warehouse worker scenario models potential exposures to an individual who is responsible for distribution of consumer products.

\section{C.2.2 Description of End-Use Scenarios}

This section describes the end-use scenarios considered. Table C.3 lists the parameter assumptions used in modeling each scenario for Tiers $A, B, C$, and D. The results of this analysis, which are reported in Appendix D, Tables D.23 through D.35, are given as individual annual committed effective dose equivalent. The committed collective dose equivalent is also reported.

\section{C.2.2.1 Tier A: Unrestricted Reuse}

Tool reuse and building occupancy scenarios are modeled for Tier A and shown in Tables D.23 and D.24. The tool reuse scenario considers the use of a small surfacecontaminated tool. The tool is treated as having a total surface area of $1 \mathrm{~m}^{2}$. A building ventilation rate of $1 / \mathrm{h}$ is applied. The building occupancy scenario considers the use of a surface-contaminated room. The room size is $5 \times 5 \times 3 \mathrm{~m}$. Each wall is modeled as a half cylinder with a 3-m radius. An individual is assumed to be located $1 \mathrm{~m}$ from one wall, $4 \mathrm{~m}$ from the opposite wall, and $1.5 \mathrm{~m}$ from the two adjacent walls. The radon emanation factor is conservatively taken to be 1.0 in these scenarios.

\section{C.2.2.2 Tier B: Unrestricted Recycle End-Use Scenarios}

This section describes the consumer products scenarios considered under Tier $B$ and the assumptions for the population dose calculations. The amount of steel available for manufacturing consumer products from recycling $100 \mathrm{t}$ of RSM is taken to be $90 \mathrm{t}$, and the amount of slag is taken to be $10 \mathrm{t}$ (i.e., $10 \%$ of the recycled RSM). The steel is assumed to be distributed to various industries in the following proportions (U.S. Bureau of Mines 1985): office/room, 38\%; appliance, $8 \%$; automobile, $30 \%$; office furniture, $8 \%$; home furniture, $8 \%$; frying pan, $8 \%$.

The total collective dose from all consumer products scenarios (see Tables D.25-D.29 in Appendix D) is based on a 100-t RSM throughput. Dilution of steel is not in the baseline analysis except for the use of slag (by a factor of 100 with concrete). In the modifiedconservative case, both dilution and partitioning factors are included. 
TABLE C.3 Exposure Parameters Used to Model Surface Reuse, Consumer Products, Specified Initial Use, and Controlled Recycle Scenarios

\begin{tabular}{|c|c|c|c|c|c|c|c|c|c|c|c|}
\hline Recycle Step & Scenario & Source Geometry & $\begin{array}{l}\text { Density } \\
\left(\mathrm{g} / \mathrm{cm}^{3}\right)\end{array}$ & $\begin{array}{l}\text { Thickness } \\
\text { (cm) }\end{array}$ & $\begin{array}{l}\text { Radius } \\
\text { (cm) }\end{array}$ & $\begin{array}{l}\text { Distance from } \\
\text { Source }(\mathrm{cm})\end{array}$ & $\begin{array}{c}\text { Time } \\
\text { (h) }\end{array}$ & $\begin{array}{c}\text { Concentration } \\
(\mathrm{Bq} / \mathrm{g})^{\mathrm{a}}\end{array}$ & $\begin{array}{l}\text { Internal } \\
\text { Pathway }\end{array}$ & $\begin{array}{l}\text { No. of } \\
\text { Individuals } \\
\text { for } 100 \mathrm{t}^{\mathrm{c}}\end{array}$ & $\begin{array}{l}\text { No. of } \\
\text { Individuals } \\
\text { for } 50,000 \mathrm{t}\end{array}$ \\
\hline Tier A: & Tool Reuse & 1 full disk & $\ldots \ldots^{d}$ & $\ldots$ & 56.4 & 60 & 2,000 & 1 & inh, ing & 1 & 500 \\
\hline Surface Reuse & Building Occupancy & 4 half disks & $\ldots$ & $\ldots$ & 300 & 100 & 2,000 & 1 & inh, ing & 4 & 2,000 \\
\hline Tier B: & Parking Lot & 1 full cylinder & 2.70 & 10 & $\mathbf{3 , 4 3 3}$ & 100 & 62 & 0.1 & $\ldots$ & 1,050 & 525,000 \\
\hline Consumer & Room/Onice & 4 half cylinders & 7.86 & 0.2 & 300 & 100 & 2,000 & 1 & $\ldots$ & 144 & 72,000 \\
\hline \multirow[t]{6}{*}{ Products } & Appliance & 1 half cylinder & 7.86 & 0.1 & 92 & 100 & 730 & $\mathbf{1}$ & $\ldots$ & 343 & 171,500 \\
\hline & Automobile & 4 full cylinders & 7.86 & 0.1 & 150 & 50 & 668 & 1 & $\ldots$ & 252 & 126,000 \\
\hline & Office Furniture & 1 half cylinder & 7.86 & 0.1 & 103 & 15 & 2,000 & 1 & $\cdots$ & $554^{\circ}$ & 277,000 \\
\hline & Home Furniture & 1 half cylinder & 7.86 & 0.1 & 110 & 15 & 3,650 & 1 & .... & 480 & 240,000 \\
\hline & Frying Pan & 1 full cylinder & 7.86 & 0.4 & 15 & 30 & 180 & 1 & ing & 3,272 & $1,636,000$ \\
\hline & Pavement & 1 full cylinder & 2.7 & 10 & 3,433 & 100 & 3.7 & 0.1 & $\cdots$ & $8,234,400$ & $4,117,200,000$ \\
\hline Tier C: & Public Building ${ }^{\circ}$ & 4 half cylinders & 7.86 & 0.5 & 300 & 100 & 2,000 & 1 & $\cdots$ & 164 & 82,000 \\
\hline $\begin{array}{l}\text { Specified } \\
\text { Initial Use }\end{array}$ & Bridge & 2 half cylinders & 7.86 & 1.2 & 1,800 & 100 & 1 & 1 & $\cdots$ & $8,234,400$ & $4,117,200,000$ \\
\hline Tier D: & Shielding Block & 1 half cylinder & 7.86 & 132 & 105 & 100 & 2,000 & 1 & -... & $\ldots$ & $\cdots$ \\
\hline Controlled & Reactor Tank & 1 half cylinder & 7.86 & 0.2 & 300 & 100 & 2,000 & 1 & $\ldots$ & -- & $\cdots$ \\
\hline Recycle & Radwaste Container & 1 half cylinder & 7.86 & 0.27 & 100 & 100 & 2,000 & 1 & $+\cdots$ & $\ldots$ & $\ldots$ \\
\hline
\end{tabular}

a Unit is $\mathrm{Bq} / \mathrm{cm}^{2}$ for Tier A surface reuse scenarios.

b inh = inhalation; ing = ingestion.

c Number of individuals for consumer products includes the following mass distribution of ingots among the products: room/ofice $38 \%$, appliance $8 \%$, automobile $30 \%$, office furniture $8 \%$, house furniture 8\%, and frying pan 8\% (U.S. Bureau of Mines 1985). Parking lot and pavement scenarios use 10 tons of slag (10\% of $100 \mathrm{t}$ RSM).

d ...- means not applicable.

- Shielded by $15 \mathrm{~cm}$ of concrote. 


\section{Consumer Product Scenarios}

Eight consumer product scenarios are considered in this section - parking lot, office/room, appliance, automobile, office furniture, home furniture, frying pan, and pavement scenarios. The parking lot scenario considers the use of slag in the construction of a parking lot. The slag is assumed to be diluted with concrete by a factor of 100 , resulting in a radionuclide concentration of $0.1 \mathrm{~Bq} / \mathrm{g}$. Because the slag is assumed to be $10 \%$ of the total mass of steel being recycled and the dilution factor is 100 , the estimated total mass of the mixture is $1,000 \mathrm{t}$. The average individual is assumed to spend 10 minutes a day in the parking lot, for an annual exposure time of 62.1 hours. For the collective dose calculation, the number of exposed individuals is estimated to be 1,050. This calculation is based on the surface area of the parking lot, the base area of an average automobile, and an average occupancy of two individuals per automobile.

The office/room scenario considers the use of sheet metal to construct the four walls of a $5 \times 5 \times 3 \mathrm{~m}$ office. If $940 \mathrm{~kg}$ of steel is used to construct one room, about 36 rooms could be built from recycling $100 \mathrm{t}$ of $\mathrm{RSM}$, (assuming that $38 \%$ is used in the construction industry). An average occupancy of four persons per room is assumed.

The appliance scenario considers the use of steel in manufacturing appliances for home use. Refrigerators, stoves, and dishwashers have been investigated for modeling. The refrigerator yields the most conservative results because of its large size. The average mass of a refrigerator is about $21 \mathrm{~kg}$. If about $8 \%$ of available steel is used in the appliance industry, 343 refrigerators could be made from recycling $100 \mathrm{t}$ of RSM. The number of exposed individuals applied for the collective dose calculation is 343 .

The automobile scenario considers the use of steel in the body of automobiles. If about $30 \%$ of available steel is used in the transportation industry and $222 \mathrm{~kg}$ of steel is used in the body of an average car, about 126 automobiles could be manufactured from recycling of $100 \mathrm{t}$ of RSM. An average occupancy of two persons per automobile is assumed.

The office furniture scenario considers the use of steel in office furniture. Desks, book cases, and file cabinets have been investigated for modeling this scenario. Use of the desk in the modeling yields the most conservative results because of the proximity of the desk to the office worker and the long period that the average worker could be exposed to the source. About $13 \mathrm{~kg}$ of steel is estimated to be used in making a desk. If $8 \%$ of available steel is used in the office furniture industry, about 554 desks could be manufactured from recycling $100 \mathrm{t}$ of RSM. One person would be exposed per desk.

The home furniture scenario considers the use of steel in home furniture, such as wire bed springs. The amount of steel used in a bed is estimated to be about $15 \mathrm{~kg}$. If $8 \%$ of available steel is used in the home furniture industry, 480 beds could be manufactured from recycling $100 \mathrm{t}$ of $\mathrm{RSM}$. One person is assumed to be exposed per bed.

The frying pan scenario considers the use of steel in frying pans for household use. The amount of steel used in a pan is $2.2 \mathrm{~kg}$. If $8 \%$ of available steel is used to make frying 
pans, about 3,272 pans could be produced from recycling $100 \mathrm{t}$ of RSM. For the frying pan scenario, the ingestion rate was based on a corrosion rate of $0.13 \mathrm{~mm} / \mathrm{yr}$ (IAEA 1988). For a frying pan with an area of $710 \mathrm{~cm}^{2}$ and the assumed corrosion rate, approximately $1.2 \mathrm{~g} / \mathrm{yr}$ of metal would be corroded. It was assumed that $50 \%$ of the corroded material would be ingested. For the collective dose calculation it is assumed that one person is exposed per pan.

The pavement scenario considers the slag to be used in highway pavement. Parameters are the same as for the parking lot, but individual exposure time differs. The average individual spends about six hours per year on the pavement, driving twice a day at a speed of $50 \mathrm{~km} / \mathrm{h}$. For the collective dose calculation, it is assumed that the traffic count is 470 cars per hour, a typical rural highway traffic frequency (Neuhauser and Kanipe 1992). Each car is assumed to have two passengers.

\section{Other Tier B Scenarios}

The use of recycled steel containing residual radioactivity for use as a surgically implanted bone prosthesis was investigated by the U.S. Nuclear Regulatory Commission in NUREG-0518 (USNRC 1980). A concentration of $17.5 \mathrm{ppm}(0.21 \mathrm{~Bq} / \mathrm{g})$ uranium and $5 \mathrm{ppm}$ $\left(6.4 \times 10^{5} \mathrm{~Bq} / \mathrm{g}\right) \mathrm{Tc}-99$ was assumed for the analysis (on the basis of a representative sampling of smelted alloys). The resulting dose was estimated to be $40 \mu \mathrm{Sv}$ per year, a factor of four higher than the assumed limit of $10 \mu \mathrm{pv} / \mathrm{yr}$ (IAEA 1988). These radionuclides are considered to be representative of other long-lived alpha/beta emitters investigated in this report. The use of scrap for medical implants is not considered a probable scenario, given the stringent material requirements and liability for damages associated with such practices. Hence, such a scenario should not be used to derive exemption limits.

\section{Maximally Exposed Individual Scenarios}

The following annual exposure durations were used to calculate the dose to a maximally exposed individual: 2,000 hours for the parking lot scenario (parking lot attendant), 2,000 hours for the office/room scenario, 1,000 hours for the appliance scenario, 2,000 hours for the automobile scenario (taxi driver), 180 hours for the frying pan scenario, 2,000 hours for the office furniture scenario, and 3,650 hours for the home furniture scenario.

\section{C.2.2.3 Tier C: Recycle to Specified Initial-Use}

The specified public use scenarios considered under Tier $\mathbf{C}$ are described in this section. The results of the analysis are presented for each scenario in Table D.30 in Appendix D.

The public building scenario considers the use of reinforcement bars in the structure of public buildings. Four walls of a $5 \times 5 \times 3-\mathrm{m}$ room are assumed to be constructed with reinforcement bars placed $15 \mathrm{~cm}$ deep inside concrete. The average individual is assumed 
to be located $1 \mathrm{~m}$ from one wall, $4 \mathrm{~m}$ from the opposite wall, and $1.5 \mathrm{~m}$ from the two adjacent walls. If $2.2 \mathrm{t}$ of steel is needed to construct one room, about 41 rooms could be built from recycling $100 \mathrm{t}$ of RSM. Thus, for an average occupancy of four persons per room, the number of exposed individuals for collective dose assessment is 164 .

The bridge scenario considers the use of recycled steel for support beams in bridges. The bridge is assumed to be $5 \mathrm{~m}$ wide and $100 \mathrm{~m}$ long, with a beam height of $5 \mathrm{~m}$. An individual is assumed to be located $1 \mathrm{~m}$ from one upright and $4 \mathrm{~m}$ from the other upright support beam of the bridge. If an average individual drives under the bridge twice per day at a speed of $50 \mathrm{~km} / \mathrm{h}$, the total exposure time is estimated to be $1 \mathrm{~h} / \mathrm{yr}$. If 100 people pass under the bridge per hour and one bridge is built from recycling of $100 \mathrm{t}$ of RSM, the number of exposed individuals used for the collective dose calculation is 876,000 per year.

\section{C.2.3 Stack Emission Scenario}

The stack emission scenario (see Table D.31) considers the release of radionuclides from a smelting facility through a stack. The CAP88-PC (Version 1.0) computer code (Parks 1992) was used to perform dose assessment calculations for the maximally exposed individual. The code was developed by the USEPA to perform risk and dose assessments to evaluate compliance with 40 CFR 61.93(a). The baseline calculation is based on processing $100 \mathrm{t} / \mathrm{yr}$ of RSM with a concentration of $1 \mathrm{~Bq} / \mathrm{g}$ and includes partitioning of radionuclides due to the smelting operations. On the basis of the partitioning factors listed in Table C.4, only the airborne fraction is released through the stack. The partitioning factors are based on a comprehensive review of available data in the literature, including the Safety Series 111 report (IAEA 1992), CEC Report-43 (CEC 1988), Chapuis et al. (undated), and Johnson (1993).

The maximally exposed individual is assumed to be beyond a 100-m radius from the release point. Doses are adjusted for the use of a high-efficiency particulate air filter. A decontamination factor of 2,000 (99.95\% efficiency) is applied (Lee and Stoddard 1979). Other assumptions used in CAP88 calculations are shown in Table C.5 and are similar to those used by O'Donnell et al (1978).

\section{C.2.4 Disposal Scenario}

In the disposal scenario, it is assumed that 50,000 $t$ of RSM is disposed of in an area of $11,400 \mathrm{~m}^{2}$. The RSM is mixed with soil in a 1:1 volume concentration to form a 1-m-thick layer and is covered with $0.5 \mathrm{~m}$ of clean soil. For volume contamination the concentration of activity in the RSM is $1 \mathrm{~Bq} / \mathrm{g}$. For surface contamination the concentration of activity is $1 \mathrm{~Bq} / \mathrm{cm}^{2}$, with the average thickness of material being $10 \mathrm{~cm}$. These values yield an average concentration in the RSM of $0.0125 \mathrm{~Bq} / \mathrm{g}$. 
TABLE C.4 Partitioning Factors

\begin{tabular}{lrrrr}
\hline Nuclide & Ingot & Air & Slag & $\begin{array}{c}\text { Source } \\
(\mathrm{Bq} / \mathrm{yr})\end{array}$ \\
\hline Ac-227 & 10.0 & 0.5 & 100.0 & $5.0 \mathrm{E}+05$ \\
Am-241 & 10.0 & 0.5 & 100.0 & $5.0 \mathrm{E}+05$ \\
Pu-239 & 10.0 & 0.5 & 100.0 & $5.0 \mathrm{E}+05$ \\
U-238 & 10.0 & 0.5 & 100.0 & $5.0 \mathrm{E}+05$ \\
Sr-90 & 10.0 & 10.0 & 100.0 & $1.0 \mathrm{E}+07$ \\
Tc-99 & 10.0 & 100.0 & 10.0 & $1.0 \mathrm{E}+08$ \\
Co-60 & 100.0 & 0.5 & 1.0 & $5.0 \mathrm{E}+05$ \\
Cs-137 & 0.1 & 100.0 & 100.0 & $1.0 \mathrm{E}+08$ \\
Zn-65 & 1.0 & 100.0 & 1.0 & $1.0 \mathrm{E}+08$ \\
H-3 & 0.0 & 100.0 & 0.0 & $1.0 \mathrm{E}+08$ \\
C-14 & 0.0 & 100.0 & 0.0 & $1.0 \mathrm{E}+08$ \\
I-129 & 0.0 & 100.0 & 0.0 & $1.0 \mathrm{E}+08$ \\
Rn-220 & 0.0 & 100.0 & 0.0 & $1.0 \mathrm{E}+08$ \\
Rn-222 & 0.0 & 100.0 & 0.0 & $1.0 \mathrm{E}+08$ \\
Th-228 & 10.0 & 0.5 & 100.0 & $1.0 \mathrm{E}+08$ \\
Th-232 & 10.0 & 0.5 & 100.0 & $1.0 \mathrm{E}+08$ \\
Ra-224 & 10.0 & 0.5 & 100.0 & $1.0 \mathrm{E}+08$ \\
Ra-226 & 10.0 & 0.5 & 100.0 & $1.0 \mathrm{E}+08$ \\
\hline
\end{tabular}

TABLE C.5 Assumptions Used in CAP88 Calculations

\begin{tabular}{ll}
\hline \multicolumn{1}{c}{ Parameter } & \multicolumn{1}{c}{ Value } \\
\hline Stack Height & $43 \mathrm{~m}$ \\
Exit Velocity & $3 \mathrm{~m} / \mathrm{s}$ \\
Stack Diameter & $6 \mathrm{~m}$ \\
Population Data File & Argonne.pop \\
Wind Data File & ORD0452.wnd \\
Food Consumption & Urban \\
\hline
\end{tabular}


The two different contamination types affect the assumptions about the availability of the radionuclides to leach from the contaminated zone. For surface contamination, it is assumed that the radionuclides are bound to the RSM until released through erosion processes. A simplified erosion process was adopted by assuming linear erosion over 100 years. This erosion process cannot be directly simulated with the RESRAD code. The methodology section details how the doses were estimated.

For dose calculations, two maximally exposed individuals were defined - a worker at the site after disposal and a resident living on the disposal site. Dose estimates are given in Tables D.32 and D.33. The site is released to the public 30 years after the disposal of the RSM. The worker is only exposed to external ground shine. The resident is subject to the environmental pathways (including radon inhalation). The disposal scenarios can be classified according to three parameters: site type (managed or unrestricted), exposed individual type (worker or resident), and RSM contamination type (surface or volume contamination).

\section{C.3 DERIVATION OF RELEASE LEVELS}

The activity level $\left(\mathrm{L}\right.$, in $\mathrm{Bq} / \mathrm{cm}^{2}$ or $\left.\mathrm{Bq} / \mathrm{g}\right)$ that is protective of workers or the public can be derived for a particular radionuclide from unit dose factors according to the following equation:

$$
L=\frac{D_{0}}{D}
$$

where $D_{0}$ (in $\mu \mathrm{Sv} / \mathrm{yr}$ ) is the dose constraint to an individual (assumed to be $10 \mu \mathrm{Sv} / \mathrm{yr}$ for release level derivation) for the release, and $D$ (in $\mu \mathrm{Sv} / \mathrm{yr}$ per $\mathrm{Bq} / \mathrm{cm}^{2}$ or $\mu \mathrm{Sv} / \mathrm{yr}$ per $\mathrm{Bq} / \mathrm{g}$ ) is the worker or public dose per unit activity concentration (e.g., $1 \mathrm{~Bq} / \mathrm{cm}^{2}$ or $1 \mathrm{~Bq} / \mathrm{g}$ ). .The cumulative population dose (DP) resulting from radioactive scrap metal release is obtained by:

$$
D P_{k}=N_{k} \times D_{i}^{k} \times F_{i} \times T
$$

where $N_{k}$ is the number of exposed individuals for population subgroup $k ; D_{i}^{k}$ is the first annual dose received by population subgroup $k$ based on a unit nuclide concentration (person-Sv/yr per $\mathrm{Bq} / \mathrm{g}$ or per $\mathrm{Bq} / \mathrm{cm}^{2}$ ); $F$ and $T$ are factors pertaining to the accumulation of dose over time (which are discussed further below); and $i$ represents the radionuclide contained in the metal.

The factors $F$ and $T$ in Equation C.2 represent the nuclide average decay factor and the time multiplier of population dose, respectively, over the long-term use of radioactive scrap metal products. Both factors pertain to the useful life of the products, after which time portions of the radioactive scrap metal will be recycled in a continual process, although the dose contribution from the same radioactive scrap metal will diminish over time. These two factors only apply in the Tier $\mathrm{B}$ and $\mathrm{C}$ analyses. If the product life is $T_{r}$ years and the 
fraction returned for future recycle is $f_{r}$, the average decay factor of each nuclide over the product life is:

$$
F_{i}=\frac{1-E X P\left(-\lambda_{i} \times T_{r}\right)}{\lambda_{i} T_{r}}
$$

and the time multiplier can be shown to be:

$$
T=\frac{T_{r}}{\left(1-f_{r}\right)} \text {, }
$$

where $\lambda_{i}$ is the nuclide decay constant. For Tier B the product life $T_{r}$ is assumed to be 10 years for consumer products (including slag used for public pavement), and for Tier $\mathrm{C}$ it is assumed to be 30 years for public structures (e.g., buildings or bridges). According to IAEA Safety Series No. 111-P-1.1 (IAEA 1992), $\mathrm{f}_{\mathrm{r}}$ is about 0.2 , (i.e., about $20 \%$ of the scrap metal gets recycled every year). Recent rates in the U.S.A. are about 0.25 per year. Repeated recycling is not assumed for slag used in pavement.

\section{C.4 SENSITIVITY ANALYSIS}

A sensitivity analysis was conducted to identify major areas of uncertainty and to guide the assumptions used as a basis for defining cases for dose estimation. The case definitions are presented for conservative, modified-conservative, and protected cases.

\section{C.4.1 Case Assumptions}

On the basis of the sensitivity analysis findings, three analytical cases were developed to apply to volumetric and surface contamination, which are defined below. Results for the modified-conservative case are shown in Chapter 5.

\section{- Volumetric Contamination}

- Conservative Case - Uses a partitioning factor of 1 for all scenarios and a dilution factor of 1 . This case is similar to the Safety Series No. 111-P-1.1 (IAEA 1992) baseline case except that updated information has been used for some parameters.

- Modified-Conservative Case - Uses empirical data for partitioning factors (Table B.3) and a dilution factor of 0.1 .

- Protected Case - Uses empirical data for partitioning factors, a dilution factor of 0.1 , and a protection factor of 0.01 (affecting inhalation and ingestion pathways). The protection factor assumes that workers wear gloves and coveralls and use respiratory 
protection. Shielding could provide virtually complete protection from external exposure, but that factor is not modeled because processing is assumed to occur in a commercial smelter.

\section{- Surface Contamination}

- Conservative Case - Surface transfer factor is 1.

- Modified-Conservative Case - Surface transfer factor is 0.01, which is similar to the IAEA Safety Series No. 111-P-1.1 (IAEA 1992) assumption regarding transfer of contamination from the surface to the room air.

- Protected Case - Surface transfer factor is assumed to be $1 \times 10^{-4}$ based on the capability of decontamination techniques for removal of nonfixed contamination.

These cases were used to establish the range of doses and derived activity levels generated by modeling assumptions that range from conservative to realistic. From this range, the modified-conservative case was selected for presentation of the study findings. This case has a strong empirical basis, and it substantially reduces the level of conservatism in derived activity levels relative to previous studies.

Conservative assumptions are typically employed in various dose assessment steps because of uncertainty regarding appropriate parameter values. Sensitivity of dose estimates to the parameter assumptions and the ramifications for release standards are discussed below. The calculational framework within which parameter sensitivity was analyzed is presented in Figure C.1 for volumetric contamination and Figure C.2 for surface contamination. These diagrams show the major computational steps and the parameter values employed in the modified-conservative case. The parameters analyzed and the dose estimates affected by each parameter are indicated in Table C.6. The parameters vary in importance from those, such as the dilution and partitioning factors, that substantially affect multiple scenarios to those that only affect one exposure pathway for one scenario. Baseline values and an estimate of the level of conservatism represented by that value are indicated for each parameter. The relevant parameters are discussed below in relation to each category of dose calculation (e.g. Tier B individual public dose), and the availability and effectiveness of protective measures are indicated.

\section{C.4.2 Doses to Workers}

Worker scenarios for each step in the recycle process are adapted from Safety Series No. 111-P-1.1 (IAEA 1992). For Tier B-1, worker scenarios are included for scrap delivery, scrap processing, smelting, product fabrication, and distribution; just fabrication and distribution are included for Tier B-2. Exposure pathways for workers include inhalation, 


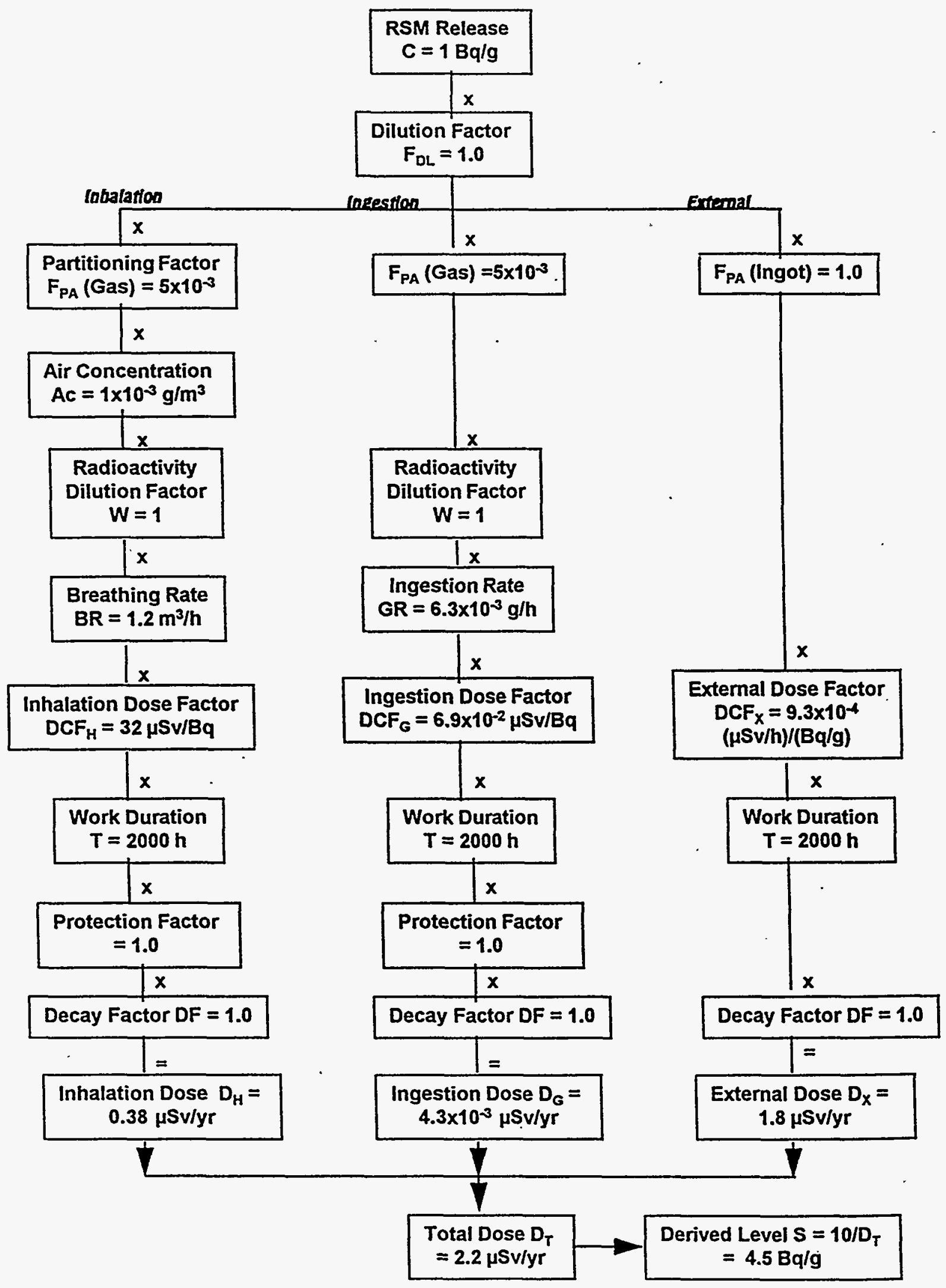

FIGURE C.1 Computational Process for Volumetric Release Levels (U-238, Slag Worker Scenario) 


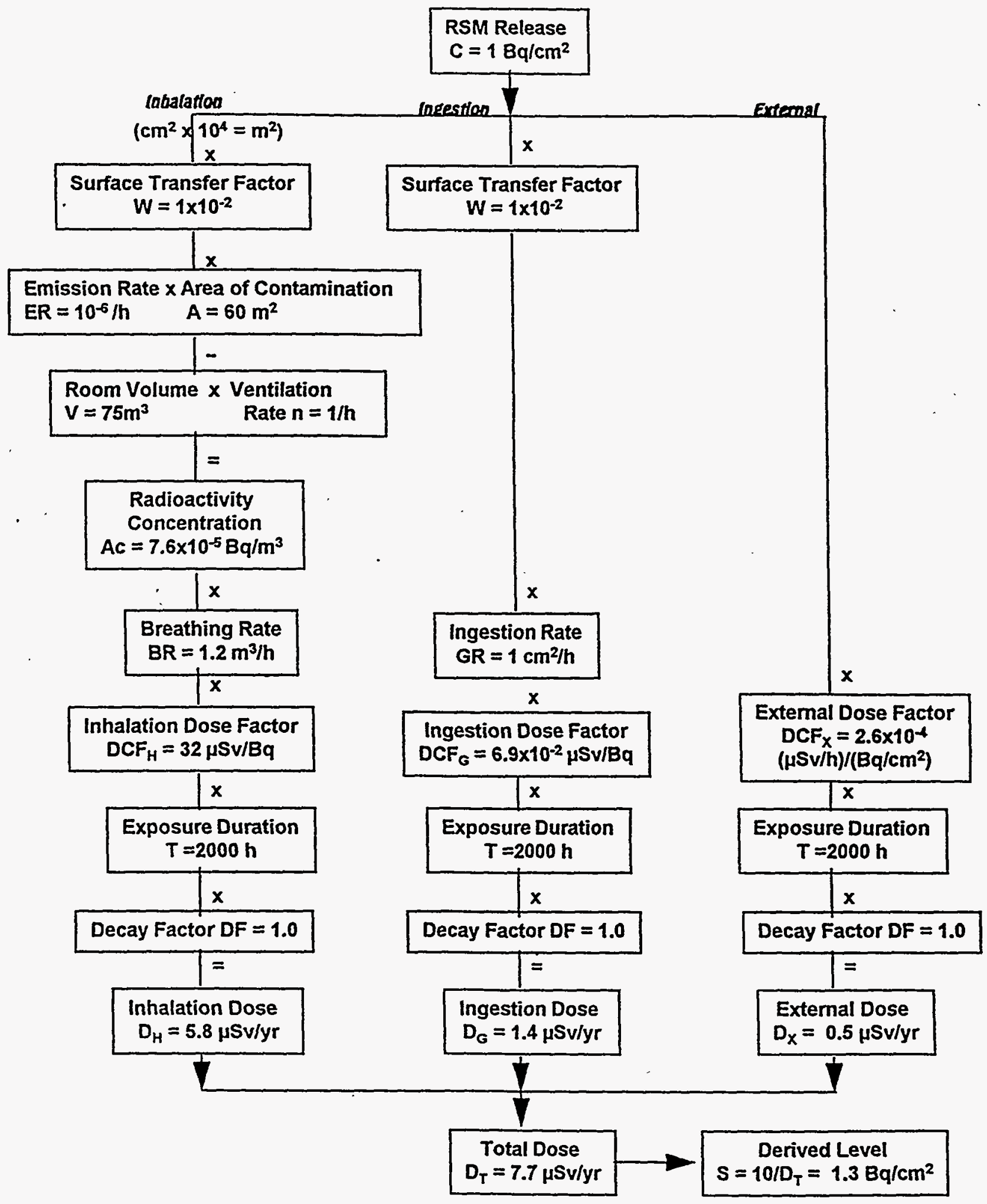

FIGURE C.2 Computational Process for Surface Release Levels (U-238, Room Occupancy Scenario) 
TABLE C.6 Key Parameters in Dose Estimation for Radioactive Scrap Metal Reuse or Recycling

\begin{tabular}{|c|c|c|c|c|c|}
\hline Parameter & $\begin{array}{c}\text { Tier } \\
\text { Affected }\end{array}$ & $\begin{array}{c}\text { Dose } \\
\text { Affected }\end{array}$ & $\begin{array}{c}\text { Group } \\
\text { Affected }\end{array}$ & $\begin{array}{c}\text { Baseline } \\
\text { Value }\end{array}$ & $\begin{array}{c}\text { Range of } \\
\text { Conservatism }\end{array}$ \\
\hline Dilution factor & B-1 & $\begin{array}{l}\text { Individual } \\
\text { Population }\end{array}$ & $\begin{array}{l}\text { Worker } \\
\text { Public }\end{array}$ & 1.0 & $10-10^{2}$ \\
\hline Partitioning factor & B-1 & $\begin{array}{l}\text { Individual } \\
\text { Population }\end{array}$ & $\begin{array}{l}\text { Worker } \\
\text { Public }\end{array}$ & 1.0 & $\begin{array}{l}1-10^{2} \text { (depending } \\
\text { on the nuclide) }\end{array}$ \\
\hline Air concentration & B-1 & $\begin{array}{l}\text { Individual } \\
\text { Population }\end{array}$ & Worker & $10^{-3} \mathrm{~g} / \mathrm{m}^{3}$ & $10+$ \\
\hline Ingestion rate & B-1 & $\begin{array}{l}\text { Individual } \\
\text { Population }\end{array}$ & Worker & $6.25 \times 10^{-3} \mathrm{~g} / \mathrm{h}$ & $10-10^{3}$ \\
\hline Surface transfer factor & A-1 & Individual & Public & 0.01 & $10^{2}$ \\
\hline Emission rate & A-1 & Individual & Public & $10^{-6} / \mathrm{h}$ & $10+$ \\
\hline Air exchange & A-1 & Individual & Public & $1 / \mathrm{h}$ & - \\
\hline Surface ingestion rate & A-1 & Individual & Public & $10^{-4} \mathrm{~m}^{2} / \mathrm{h}$ & $10-10^{2}$ \\
\hline $\begin{array}{l}\text { Radon emanation and } \\
\text { plate out }\end{array}$ & A-1 & Individual & Public & 1.0 & $10+$ \\
\hline Steel corrosion rate & B & $\begin{array}{l}\text { Individual } \\
\text { Population }\end{array}$ & Public & $0.13 \mathrm{~mm} / \mathrm{yr}$ & $10+$ \\
\hline
\end{tabular}

ingestion, and external exposures from metal preparation, smelting, and processing activities. Annual doses for workers were estimated on the basis of 2,000 hours of exposure, although fewer hours might be required for some worker categories to process 50,000 t of RSM without dilution.

\section{C.4.2.1 Dilution Factor}

Assuming no dilution of RSM in commercial smelters is unrealistic because the total RSM inventory is only a fraction of the entire scrap metal stock and the RSM is likely to be recycled over many years. In practice, the dilution factor would vary substantially with parameters such as RSM quantities in each region, furnace technology, scrap throughput, and mill capacity. The potential range of dilution proportions is considered for an annual throughput of 50,000 t per foundry (i.e., three foundries processing the projected annual RSM inventory flow of about 150,000 t from years 2010 to 2043 in North America (see Section 3). Dilution proportions are derived in Table C.7 assuming that the RSM is mixed with other scrap inputs in processing. The proportion of RSM in products if all RSM goes to just three 
TABLE C.7 Steel Mill Technology and Capacity Relative to Potential 50,000 t Annual Radioactive Scrap Metal Throughput in North America

\begin{tabular}{|c|c|c|c|c|c|c|}
\hline \multirow[b]{2}{*}{ Parameter } & \multicolumn{3}{|c|}{ Basic Oxygen Furnace } & \multicolumn{3}{|c|}{ Electric Arc Furnace } \\
\hline & Low & Average & High & Low & Average & High \\
\hline $\begin{array}{l}\text { Mill capacity } \\
\left(10^{6} \mathrm{t} / \mathrm{yx}\right)\end{array}$ & 0.9 & 2.4 & 4.5 & 0.4 & 0.8 & $2.7^{\circ}$ \\
\hline $\begin{array}{l}\text { Radioactive scrap } \\
\text { metal dilution } \\
\text { rate }^{\mathbf{a}}\end{array}$ & 0.19 & 0.07 & 0.04 & 0.13 & 0.06 & 0.02 \\
\hline
\end{tabular}

a Projected radioactive scrap metal quantity available annually, divided by furnace capacity (based on Table 4.1).

commercial smelters ranges from as high as 0.19 in a low-capacity basic oxygen furnace to a low of 0.02 in a high-capacity electric arc furnace. The average dilution is more than tenfold, and the doses would be reduced accordingly because all dose estimates are linearly proportional to the dilution factor. This dose reduction from dilution applies to commercial smelter worker doses and public doses from products after commercial smelting.

\section{C.4.2.2 Partitioning Factors}

The nuclide partitioning factors reflect the fraction of the original radionuclide activity in the various end products of the steel smelting processes (ingots, slag) and the work environment (dust, offgas). These factors, which affect all pathways and all scenarios, are each assumed to have a value of 1.0 in the conservative case estimates (i.e., the ingot, slag, and offgas/dust each have the same activity as the original scrap metal) (IAEA 1992). This conservative approach is applied because of the large variation in partitioning rates, depending on melt conditions. Some typical radionuclide partitioning values have been suggested by IAEA (1992) and by Chapuis et al. (undated]. Reviews by Hertzler et al. (1993) and Otis (1995) indicate a range of partitioning factors among nuclide such that nearly $100 \%$ of the original activity may remain in the ingot (e.g., Co-60) or nearly 100\% may be incorporated in slag (e.g., Am-241). Because of uncertainty, a high estimate is used for some nuclides (e.g., 100\% in slag for Cs-137), even though most of the mass would likely end up in the offgas or baghouse dust. Partitioning rates vary with furnace type, melt temperature, flux chemistry, and other factors. The range of values for representative nuclide is summarized in Table C.8. Use of such data, where available, reduces dose estimates for metal product scenarios by two orders of magnitude in some cases. However, it should be noted that because partitioning factors affect each pathway, the effect on total dose of variation in partitioning factors is highly dependent on scenario definitions. This effect also applies to commercial smelter worker doses and public doses from products after commercial smelting. 
TABLE C.8 Steel Melt Partitioning Factors of Representative Radionuclides ${ }^{\text {a }}$

\begin{tabular}{|c|c|c|c|c|c|c|}
\hline \multirow[b]{2}{*}{$\begin{array}{l}\text { Radio- } \\
\text { nuclide }\end{array}$} & \multicolumn{2}{|c|}{ Ingot } & \multicolumn{2}{|c|}{ Slag } & \multicolumn{2}{|c|}{ Offgas } \\
\hline & $\begin{array}{l}\text { Assumed } \\
\text { Value }\end{array}$ & Range & $\begin{array}{l}\text { Assumed } \\
\text { Value }\end{array}$ & Range & $\begin{array}{l}\text { Assumed } \\
\text { Value }\end{array}$ & Range \\
\hline $\mathrm{H}-3$ & 0 & 0 & 0 & 0 & 1 & 1 \\
\hline $\mathrm{Co}-60$ & 1 & $0.2-1$ & 0.01 & $0-0.75$ & 0.005 & $0.005-0.1$ \\
\hline $\mathrm{Zn}-65$ & 0.01 & $0-1$ & 0.01 & $0-0.13$ & 1 & $0.01-1$ \\
\hline Sr-90 & 0.1 & $0.1-1$ & 1 & $0.8-1$ & 0.1 & 0.1 \\
\hline Tc-99 & 0.1 & 0.1 & 0.1 & 0.1 & 1 & 1 \\
\hline Cs-137 & 0.001 & $0-0.001$ & 1 & $0.02-1$ & 1 & $0.03-1$ \\
\hline Pu-239 & 0.1 & $0.01-0.1$ & 1 & 1 & 0.005 & $0-0.01$ \\
\hline
\end{tabular}

a Alpha emitters such as Ac-227, Am-241, and U-238 are assumed to have the same partitioning factors as Pu-239.

Sources: Assumed values are from Chapuis et al. (undated) and IAEA (1992); ranges are from Hertzler et al. (1993), Johnson (1993), and Sanford Cohen and Associates (1995).

\section{C.4.2.3 Air Concentration}

The air concentration of a radionuclide in the work environment directly affects inhalation dose in a manner similar to the partitioning factor. The dust loading factor of $10^{-3} \mathrm{~g} / \mathrm{m}^{3}$ (IAEA 1992) assumed for all three cases is at the high end of the range for uncontrolled work environments. Particulate air concentrations generally range from $5 \times 10^{-5}$ (residential scenario in NUREG CCR-5512 [USNRC 1992]) to $1.8 \times 10^{-3} \mathrm{~g} / \mathrm{m}^{3}$ (for coal mining [Oztunali 1981]). With effective ventilation, dust loading can be substantially decreased (proportionally to the ventilation rate), which would reduce potential doses to workers. Reducing the air concentration by a factor of 10 (i.e., to $10^{-4} \mathrm{~g} / \mathrm{m}^{3}$ ) would reduce the overall dose by about a factor of 10 for alpha emitters and a factor of 2 for beta emitters, but would have almost no impact for gamma emitters.

\section{C.4.2.4 Ingestion Rate}

For ingestion doses, the key parameters are the ingestion rate and the partitioning factors. An ingestion rate of $6.25 \times 10^{-2} \mathrm{~g} / \mathrm{h}$ (USEPA 1991), derived from the dirt ingestion rate for children, is applied for all cases. This value is recommended by the U.S. Environmental Protection Agency (EPA) for adults in an occupational setting but is very conservative because workers are generally well trained to avoid ingesting dust and are likely to wear gloves. With such protective measures, dust ingestion can be substantially curtailed or even eliminated. However, since the worker doses (see Figure C.3a) are not dominated by the ingestion pathway, the total dose is not especially sensitive to the ingestion rate. 


\section{C.4.2.5 Factors Related to External Dose}

Factors controlling external exposure include the distance of workers from materials, effectiveness of shielding, and work duration. No shielding for workers was assumed because personal shielding may disrupt the work procedure.

\section{C.4.2.6 Protection Factor}

Protective equipment, such as masks, protective suits, and gloves, is ordinarily required for workplace hazards. For radioactive scrap metal smelting in a commercial foundry or mill, protection against radiation would not be required because the smelter is not expected to be licensed as a nuclear facility. If desired, however, respirators (usually available with an efficiency range from 99 to $99.9 \%$ ) could be employed, thereby reducing the inhalation dose by a factor of 100 to 1,000. A protection factor of 0.01 is assumed in the protected case. Sensitivity of the total dose to inhalation protection is similar to that for the partitioning factor. Wearing gloves would virtually eliminate ingestion but would not significantly reduce total doses. The major impact would be on beta emitters, but the dose reduction would be no more than $50 \%$. Unfortunately, no effective means exist to protect against external gamma radiation except, perhaps, remote control.

\section{C.4.2.7 Sensitivity of Key Parameters}

Figure C.3 illustrates parameter relationships to dose estimates for the Tier B-1 slag worker scenario. The relative magnitude of dose pathway contributions to total dose is shown in Figure C.3a, and the effect on dose estimates of varying each of the key parameters separately by $10 \%$ is shown in Figure C. $3 \mathrm{~b}$. Dose estimates are clearly most sensitive to partitioning and dilution factors. The effect on dose estimates of dilution and partitioning information, separately and combined, is shown in Figure C.3c.

Figure C.3b shows worker dose sensitivity to partitioning factors for the most constraining worker scenario, slag workers. The conservative case doses are dominated by the inhalation pathway for alpha emitters (above $90 \%$ of total effective dose) and for beta emitters (slightly above 50\%) and by the external exposure pathway for gamma emitters (nearly 100\%). Application of partitioning factors reduces total dose estimates considerably. Relative to conservative case dose estimates, partitioning reduces doses for alpha emitters by up to $99 \%$, up to $70 \%$ for beta emitters; and up to $99 \%$ for some gamma emitters. Dose reduction for alpha emitters is most substantial because these elements tend to concentrate in slag, thus reducing the inhalation dose from dust and offgas.

Although partitioning factor data are available for offgas and dust combined, partitioning rates between offgas and dust in the work area are unknown. Additional conservatism is introduced by assuming the same partitioning factors for the dust as for the offgas, although it is likely that dust would have lower radioactivity concentrations. 


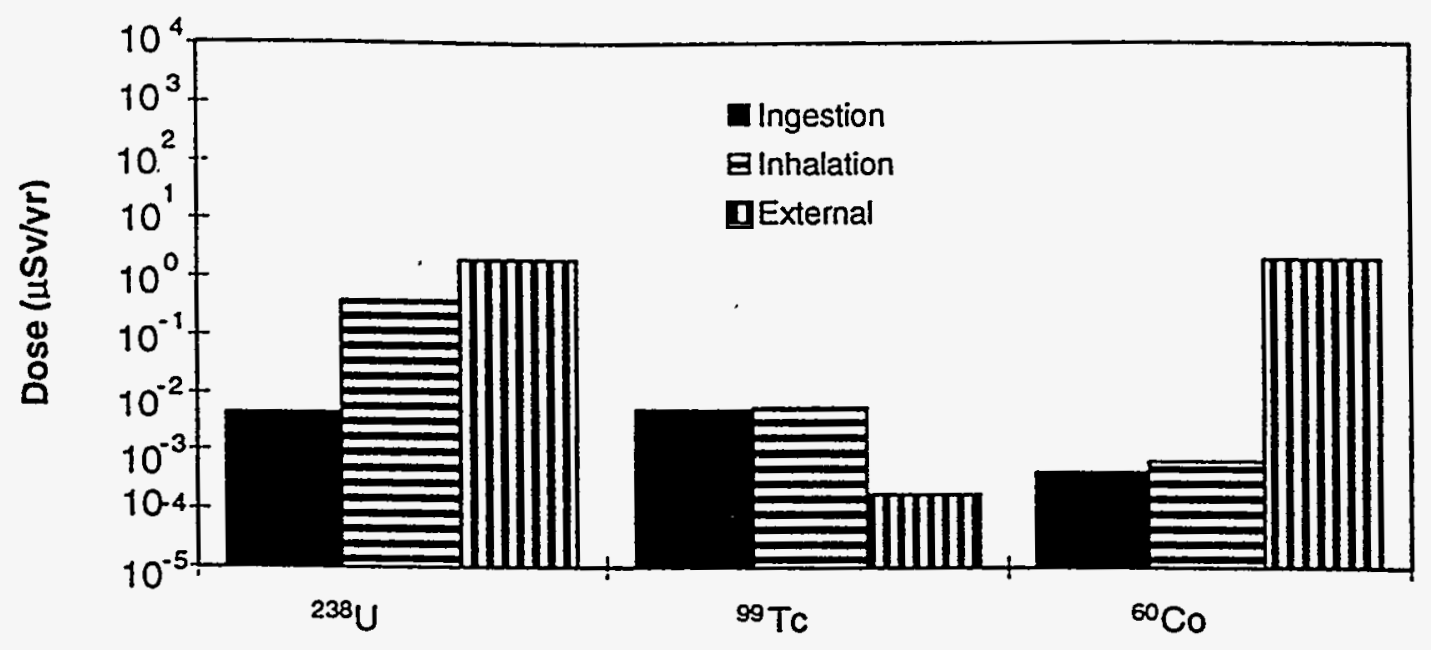

(a) Relative Contribution of Dose Pathways to Total Dose under Modified-Conservative Case Assumptions

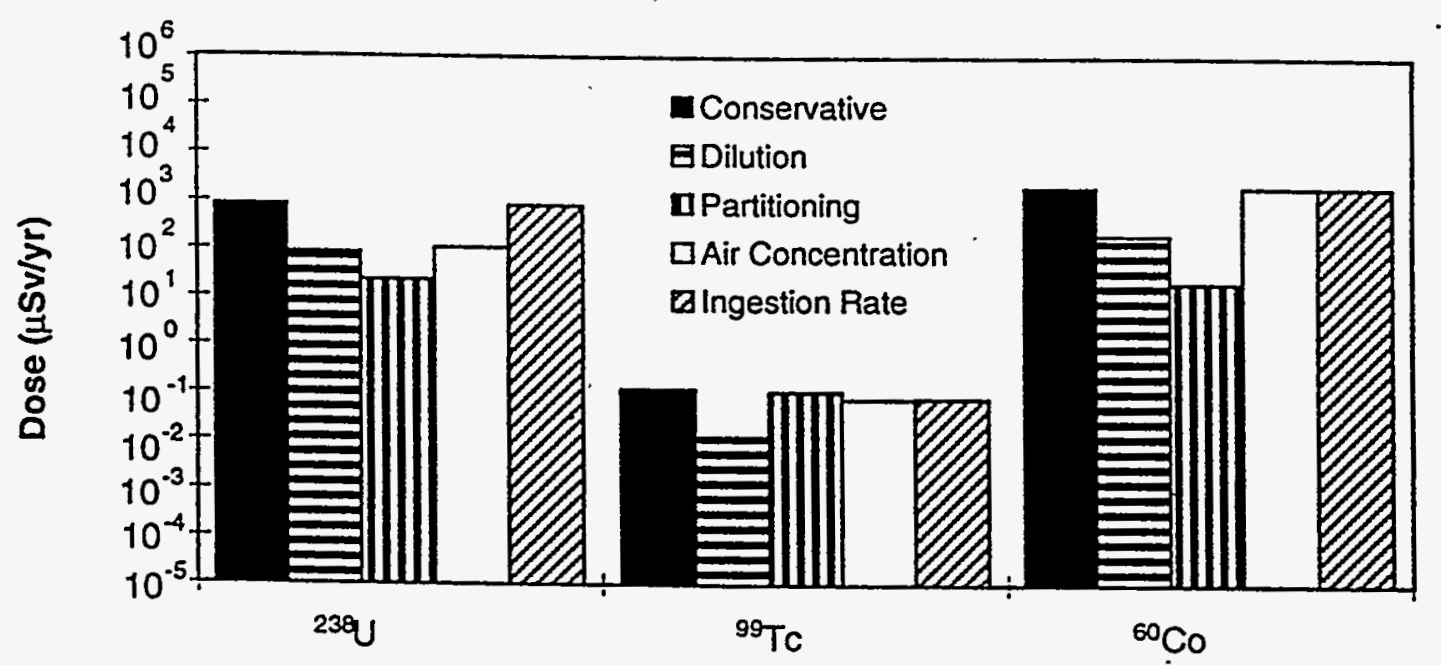

(b) Slag Worker Sensitivity Analysis (partitioning factors included and other factors multiplied by 10\%)

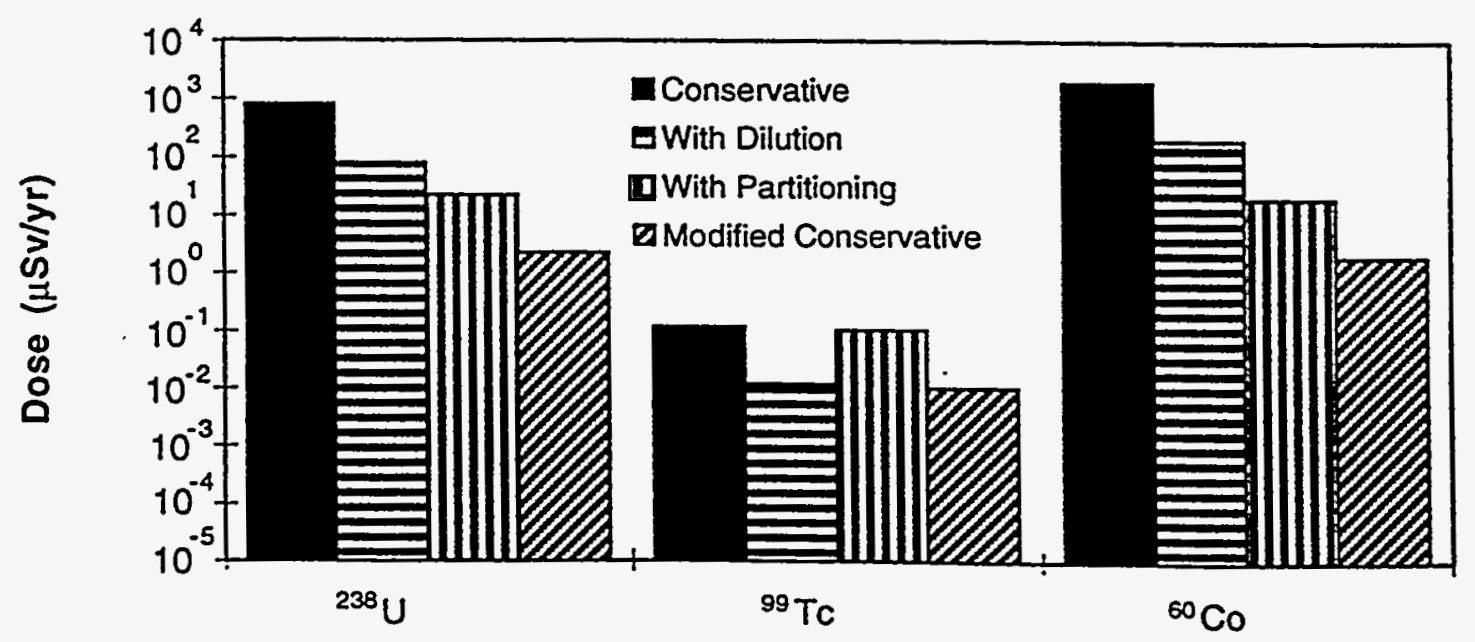

(c) Effects on Dose Estimates of Incoporating Dilution and Partitioning Information

FIGURE C.3 Parameter Relationships to Worker Dose Estimates for the Slag Worker Scenario 


\section{C.4.2.8 Level of Conservatism}

From this analysis, the baseline level of conservatism in dose estimates for alpha emitters (inhalation dominant) ranges from a factor of 10 to $10^{4}$. With dilution, partitioning, and protection factors, the conservative case dose estimates for alpha emitters are reduced by a total factor of $10^{3}$ to $10^{7}$. For ingestion-dominant nuclides (some beta emitters), dose estimates are reduced by a factor of 10 to 100 by use of realistic dilution and partitioning factors. In addition, with proper training and clothing, worker ingestion doses could potentially be eliminated. For gamma emitters (external exposure), the baseline conservatism level is about 10 to $10^{4}$, depending on the nuclide. External doses can be controlled with remote operations, as can all worker doses from other pathways and other toxic exposures associated with normal smelting operations. Worker doses could also be decreased by other factors, such as lower radioactive scrap metal throughput, worker rotation, and as low as reasonably achievable (ALARA) practices.

\section{C.4.3 Doses to Public}

The public exposure scenarios cover the three reuse/recycle tiers (Tiers A, B, and C) of potential product end uses. These scenarios are discussed in Sections C.4.3.1, C.4.3.2, and C.4.3.3.

\section{C.4.3.1 Public Reuse Scenarios - Tier A}

For Tier A-1, a room occupancy scenario (USNRC 1992) was analyzed for reuse of a building or of large equipment with surface contamination. The conservative case assumes uniform contamination of the four walls of a $5 \times 5 \times 3 \mathrm{~m}$ room. An additional scenario was developed for reuse of small tools or equipment, with an area of $1 \mathrm{~m}^{2}$ assumed. Doses from surface contamination could occur through inhalation (including radon and its progeny), ingestion, and external pathways.

The modified-conservative dose components for the tool and room reuse scenarios of Tier A-1 are shown in. Figures C.4a and C.4b, respectively. Doses from alpha emitters are dominated (more than $50 \%$ ) by inhalation dose; beta emitters by ingestion; gamma emitters by the external pathway; and radon parents by inhalation of radon. Several key factors affecting total dose are discussed below. The effect on the dose estimate of separately varying each of the key factors by $10 \%$ is shown in Figure C.4c. The importance of these factors differs depending on the dominant exposure pathway.

Tier A-2 is for reuse of a tool or equipment with volumetric contamination and assumes an object $1 \mathrm{~m}$ in height with radius of $64 \mathrm{~cm}$ and an activity concentration of $1 \mathrm{~Bq} / \mathrm{g}$. Only external exposure is included in the dose calculation. 


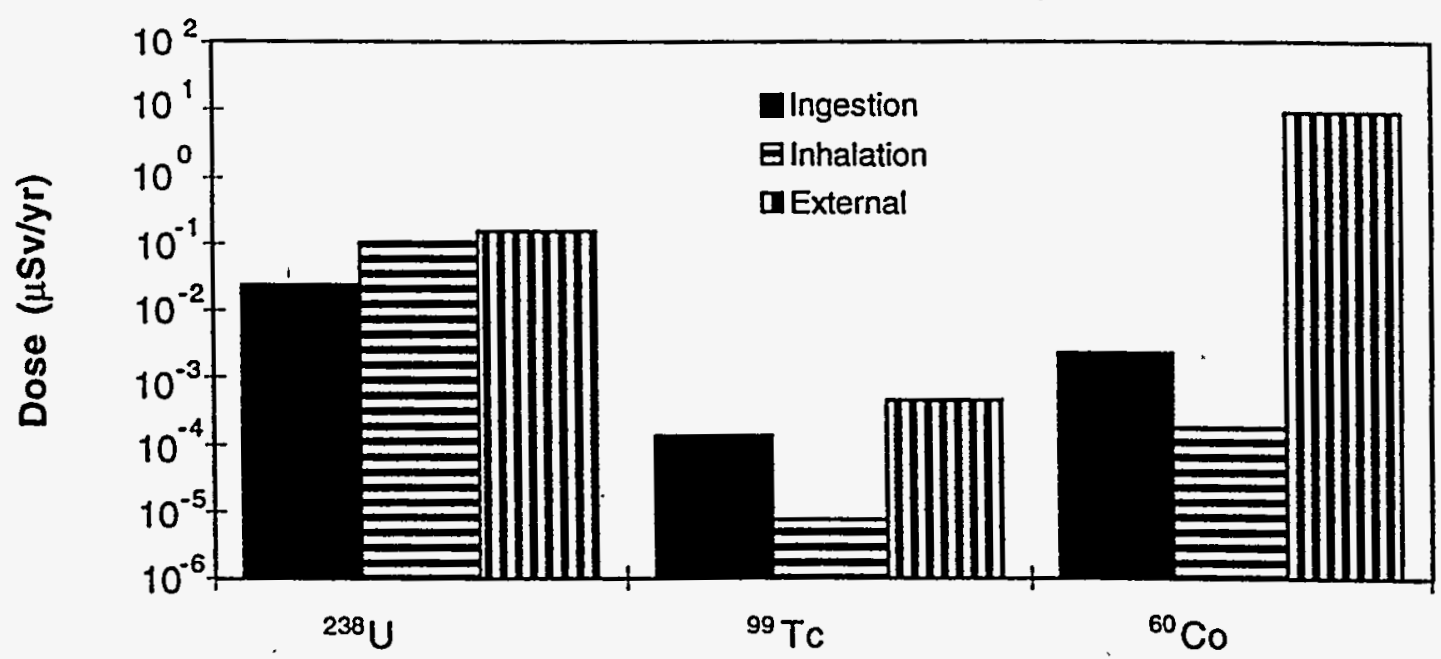

(a) Tool Use

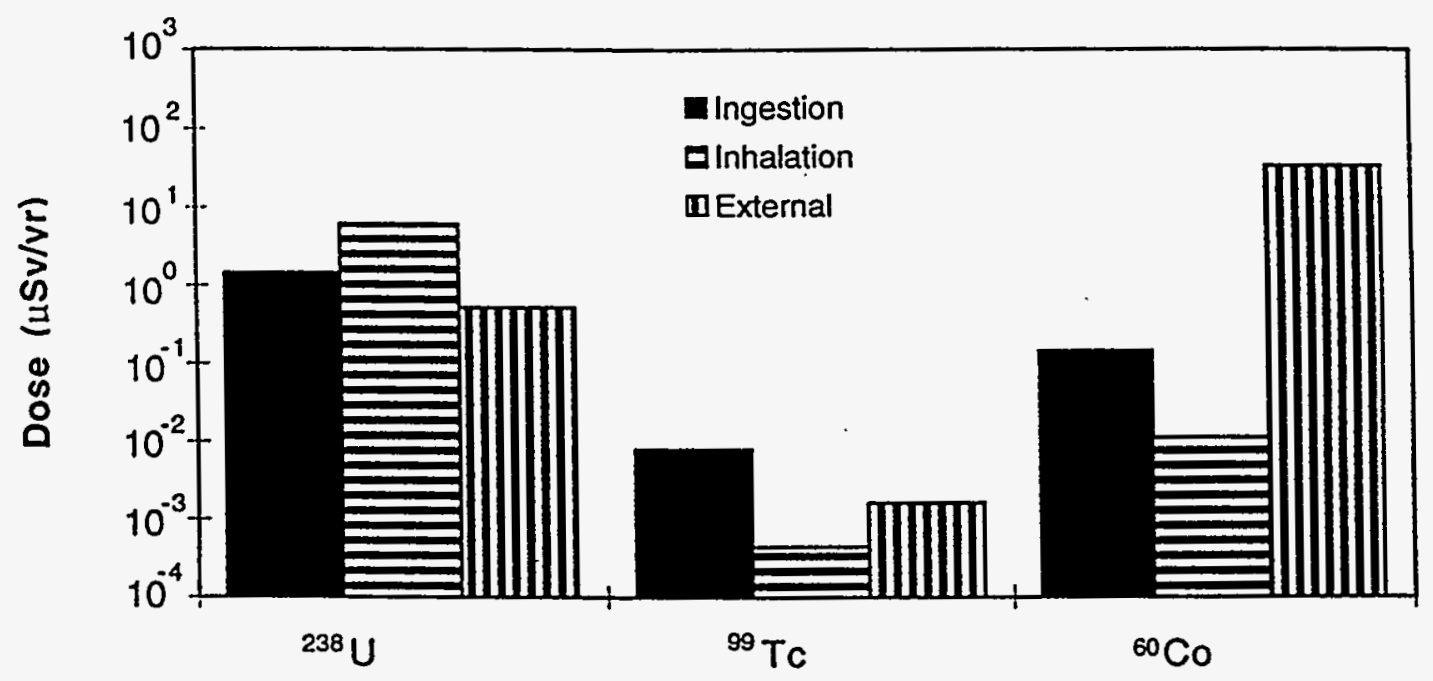

(b) Room Occupancy

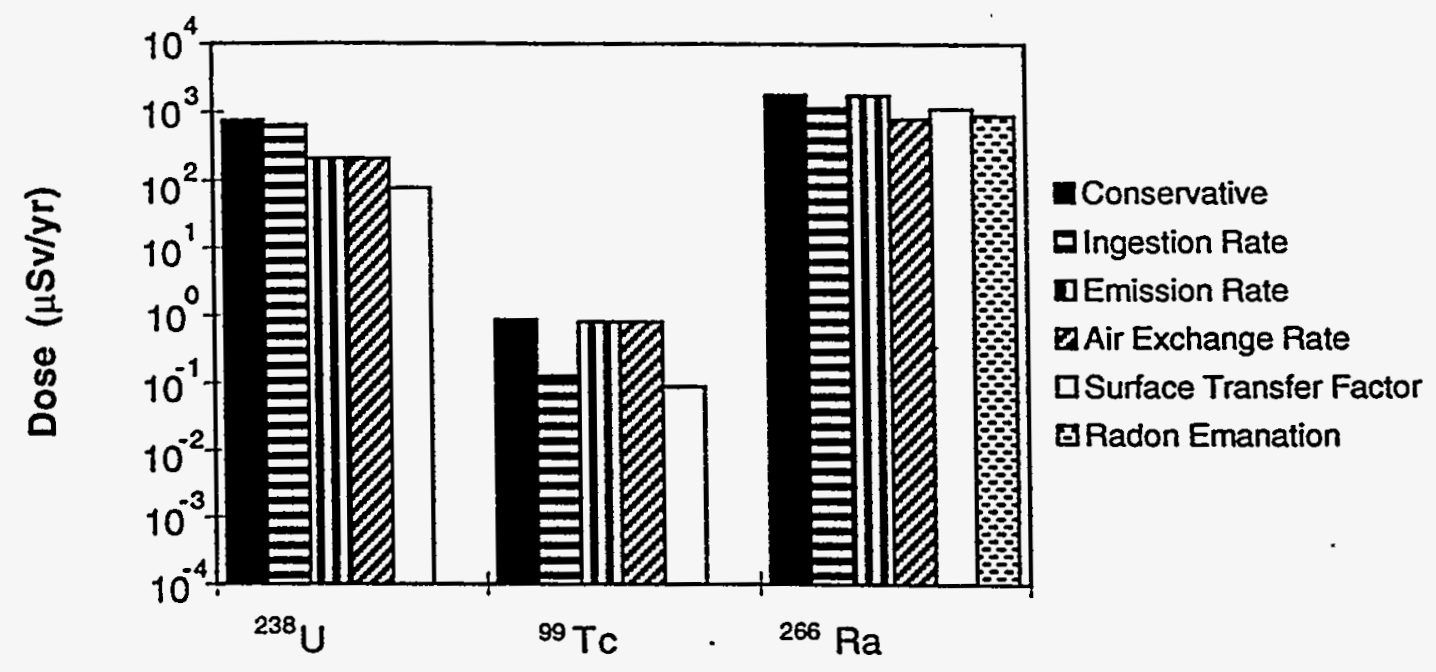

(c) Room Occupancy - Sensitivity Analysis (factors multiplied by 10\%)

FIGURE C.4 Relative Contribution of Dose Pathways for Tier A-1 Reuse Scenarios under Modified-Conservative Case Assumptions 


\section{Surface Transfer Factor}

To account for dilution of radioactive particles with other dust particles on material surfaces, a "surface transfer factor" (assigned a value of 0.01) was used in Safety Series No. 111-P-1.1 (IAEA 1992) and applied to both inhalation and ingestion doses. This is not included in conservative case doses because it is omitted from NUREG/CR-5512 (USNRC 1992); it is included in the modified-conservative case.

\section{Emission Rate}

The radionuclide emission rate used for RESRAD-BUILD $\left(10^{-6} / \mathrm{h}\right)$ is suggested by Healy (1971) for room occupancy. Because the mobility of surface contaminants is likely to be curtailed through rigorous decontamination processes and surface painting before release for reuse, the level of conservatism in this parameter could be substantial. The inhalation dose estimate is directly proportional to the emission rate. For alpha emitters, reduction of the emission rate by a factor of 10 would reduce total doses by about a factor of 5 . The reduction is less for nuclides whose doses are not dominated by the inhalation pathway.

\section{Air Exchange Rate}

A typical room air exchange rate of $1 / \mathrm{h}$ was assumed. Forced air circulation could reduce the contaminant concentration in air and thereby reduce inhalation doses, especially the radon dose. Although forced ventilation is an effective means of reducing inhalation doses, such mitigation cannot be ensured once the building is released for public use. This approach results in inhalation doses comparable to the use of the $10^{-6} / \mathrm{m}$ surface resuspension factor suggested in NUREG/CR-5512 (USNRC 1992) or Safety Series No. 111-P-1.1 (IAEA 1992).

\section{Surface Ingestion Rate}

The surface ingestion rate of $1 \mathrm{~cm}^{2} / \mathrm{h}$ (IAEA 1992; USNRC 1992) is based on nonfixed surface contamination, and assumes that during each hour of exposure all the activity associated with a given $\mathrm{cm}^{2}$ would be ingested. This value is extremely high considering the thorough decontamination process that would be likely before radioactive scrap metal release. Further, the scenario assumes transfer of contaminants from surface to hand to ingested foods, which is not a likely event in the general office setting to which the room occupancy scenario pertains. Thus, the level of conservatism in the ingestion dose is at least a factor of 100 . This primarily affects dose estimates for beta emitters (such as Sr-90) for which ingestion contributes $90 \%$ or more of total dose. 


\section{Factors for External Dose}

Dose is reduced by a factor of 2 to 4 if only one wall is contaminated. Also, room size and receptor location (assumed at $1 \mathrm{~m}$ from a wall) would affect the dose estimate. Such general factors would change the results by a factor of 2 to 3 . Shielding could further reduce dose estimates. The level of conservatism in resulting dose estimates is a factor of about 5 to 10 .

\section{Factors Related to Radon}

Radon is assumed to be immediately released (i.e., an emanation factor or release fraction of 1) by the decay of its parent nuclide. However, radon may be actually attached to particles on the surface, allowing only a fraction of the radon present to be freely released. Plate out (e.g., on furniture or drapes) of particulates may also reduce the air concentration of radon progeny. In addition, room ventilation is effective in reducing radon concentration. Radon emanation factors generally vary from 0.1 to 0.3 in soil ( $Y u$ et al. 1993a), but no data were found for surface contamination of materials. Use of a realistic value reduces all radon dose estimates by about factor of 10 or more and the total doses for Ra-226 and Th-230 accordingly.

\section{Protection Factor}

Following decontamination, sealant or paint could be applied over the surface of objects. By this means, doses from ingestion and inhalation can be largely eliminated (total doses reduced by a factor of $10^{3}$ or more for alpha and beta emitters and for radon parents). This could leave gamma emitters as the constraining nuclides for Tier A-1. However, although effective in the short run, the long-term effectiveness of painting is questionable because the protection could be degraded over time.

\section{Level of Conservatism}

Overall, the level of conservatism in conservative case doses from Tier A-1 metal reuse is estimated to be about a factor of 10 to 1,000 for alpha and beta emitters and a factor of 1 to 10 for gamma emitters. For ingestion-dominant nuclides, the level is highly uncertain. For radon, assuming a normal room ventilation rate, the level of conservatism is a factor of 10 or more.

\section{C.4.3.2 Consumer Product and Prescribed Initial-Use Scenarios - Tiers $\mathbf{B}$ and $\mathbf{C}$}

Scenarios for the use of consumer products predominantly result in external exposures, except in the case of frying pans for which ingestion is the primary pathway for some nuclides. For Tier B, unrestricted metal recycling, basic scenarios and assumptions 
follow Safety Series No. 111-P-1.1 (IAEA 1992). Tier B-1 assumes commercial remelting, with resulting radionuclide partitioning and dilution, while B-2 assumes fabrication into products without remelting. Tier B-1 also includes use of slag in pavement. External exposure is the only identifiable pathway to the public for the Tier C-specified initial use scenarios, which include use of structural steel and reinforcing bars in bridges and public buildings.

Key parameters for Tier B-I include the ingot partitioning factor and the dilution factor. Figure C.5 illustrates the sensitivity of dose to the dilution and partitioning factors for the constraining taxi driver scenario for Tier B-1. The modified-conservative case includes both partitioning and dilution factors.

\section{Dilution Factor}

The metal dilution factor is linearly proportional to public doses, and including this factor reduces doses in all Tier B-1 scenarios by a factor of 10 or more.

\section{Partitioning Factor}

As discussed for worker scenarios, the partitioning factor is also a key parameter for consumer products made from remelted metal or from slag (Tier B-1). Except for Co-60, dose estimates generally decrease by more than a factor of 10 because of the effect of the partitioning factor, and dose reduction from the conservative case by a factor up to 100 is possible. Because Co-60 has a partitioning factor of 1 for ingots, no dose reduction would occur for public end uses from partitioning.

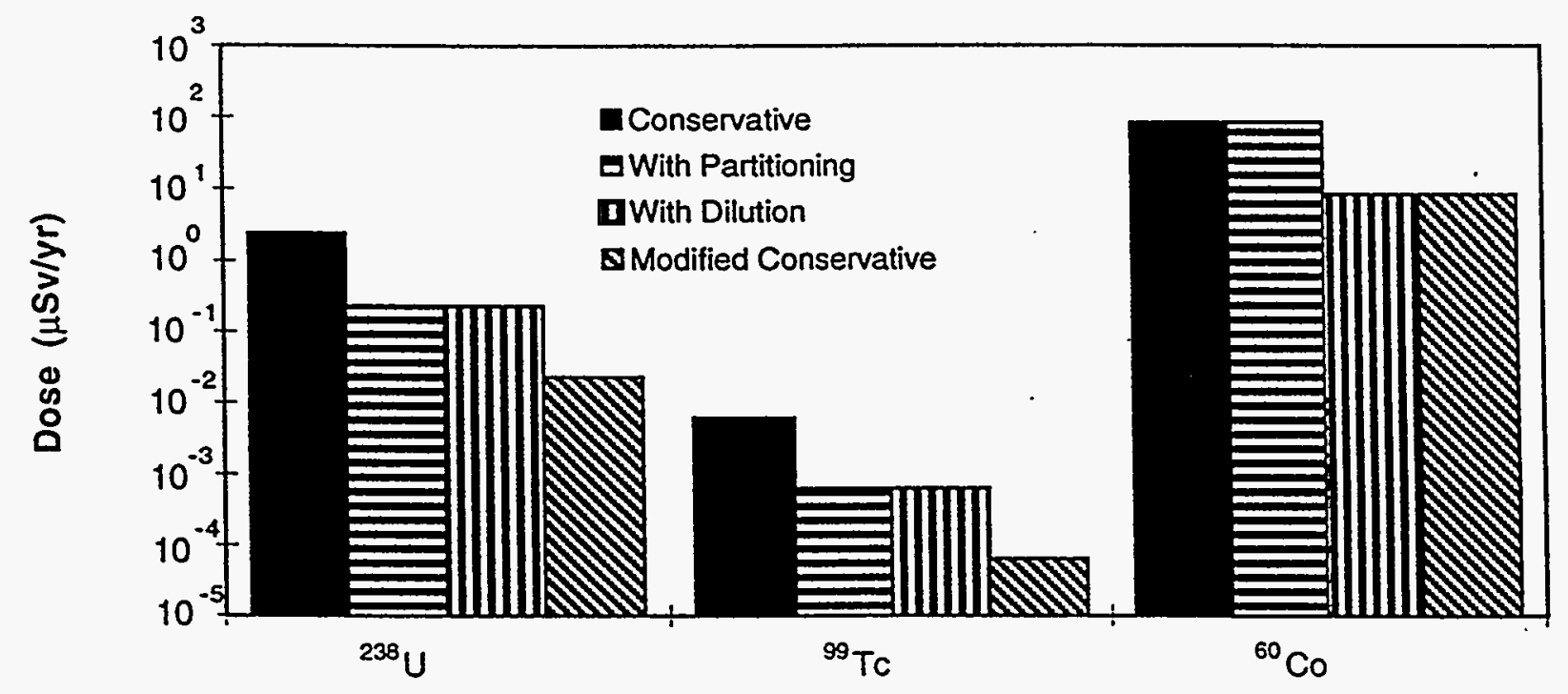

FIGURE C.5 Effects on Dose Estimates of Incorporating Dilution and Partitioning Information under the Tier B-1 Taxi Driver Scenario 
Sensitivity of Tier B-1 dose estimates to partitioning is similar for all scenarios except the frying pan scenario because all other exposures are external. For the frying pan scenario, ingestion dose is the major component of total dose for most of the alpha and beta emitters.

\section{Steel Corrosion Rate}

For the frying pan scenario, a corrosion rate of $0.13 \mathrm{~mm} / \mathrm{yr}$ was assumed (derived from the natural iron corrosion rate of $1.3 \mathrm{~mm} / \mathrm{yr}$ ). The corrosion rate only affects dose via. the ingestion pathway, which is significant (more than $70 \%$ of total dose) for nuclides such as Ac-227, Am-241, Pu-239, and Sr-90. The level of conservatism in the corrosion rate is a factor of 10 or more because a corroded utensil would probably not be used for cooking and, if used, it is unlikely that all corrosion products would be retained in prepared foods.

\section{Level of Conservatism}

Summing over the dilution, partitioning, and corrosion factors, the combined level of conservatism in public dose estimates is from a factor of 10 to $10^{3}$, depending on the radionuclide considered.

\section{C.4.4 Effect of Case Assumptions on Dose Estimates}

The effect of the case assumptions on dose estimates is illustrated in Figures C.6 and C.7. Figure C.6 shows the dose estimates for the various cases for the Tier B-1 slag worker and taxi driver scenarios. In both scenarios, the employment of dilution and nuclide partitioning information reduces dose estimates and increases activity levels by at least one order of magnitude for all categories of nuclides. For nuclides that primarily partition to slag (e.g., U-238), derived levels increase by up to two orders of magnitude relative to the conservative case. For nuclides that primarily partition to offgas (e.g., Tc-99), respiratory protection of workers (Figure C.6a) reduces doses and increases levels by up to two orders of magnitude relative to the modified-conservative case. In the case of Co-60 and other nuclides that primarily partition to the ingot, derived levels for scenarios involving metal exposure are increased only by diluting the radioactive scrap metal in the melt batch or reducing exposure time.

Figure C.7 presents a similar dose estimate comparison for Tier A-1 scenarios. For the surface contaminated tool reuse scenario shown in Figure C.7a, use of a realistic assumption for the rate of contamination transfer from the tool surface to room air reduces dose estimates by more than one order of magnitude relative to the conservative case for nuclides with dominant inhalation and ingestion pathways (e.g., U-238 and Tc-99). In the room occupancy scenario, this effect is magnified by the spatial geometry. Assuming greater decontamination effectiveness (protected case) also has greater impact on doses in the room 


\section{C-38}

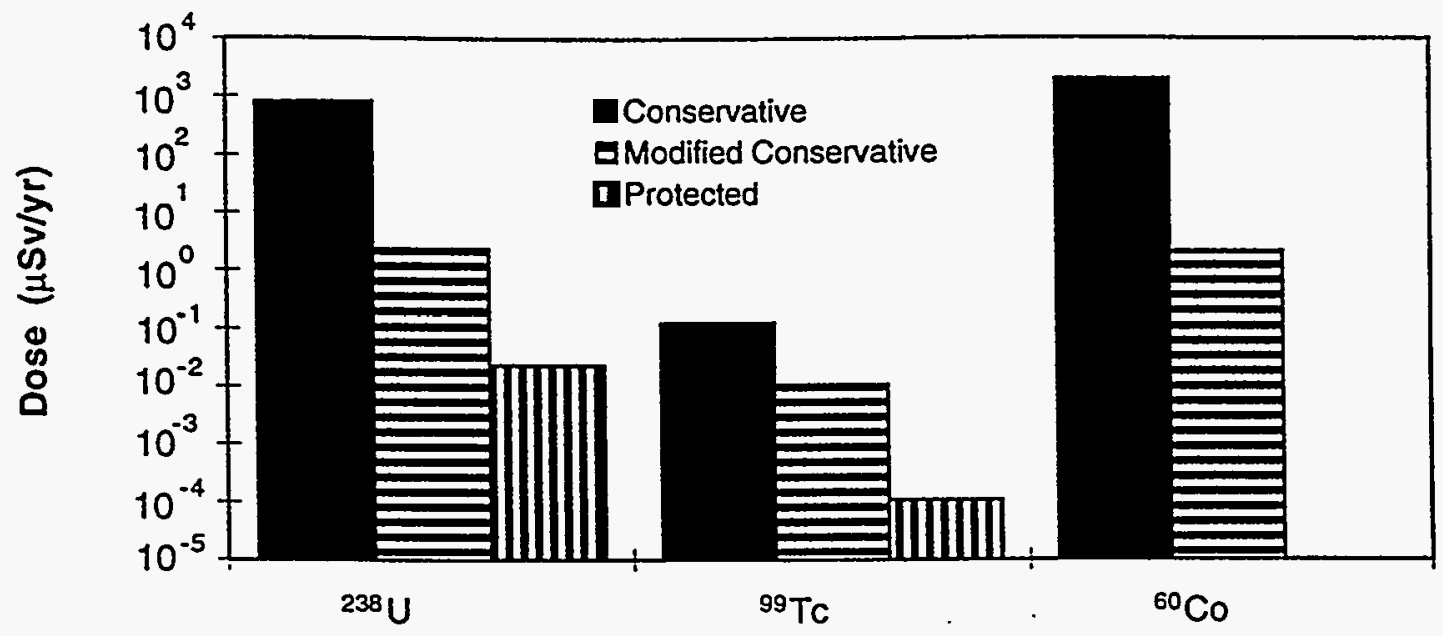

(a) Slag Worker Scenario

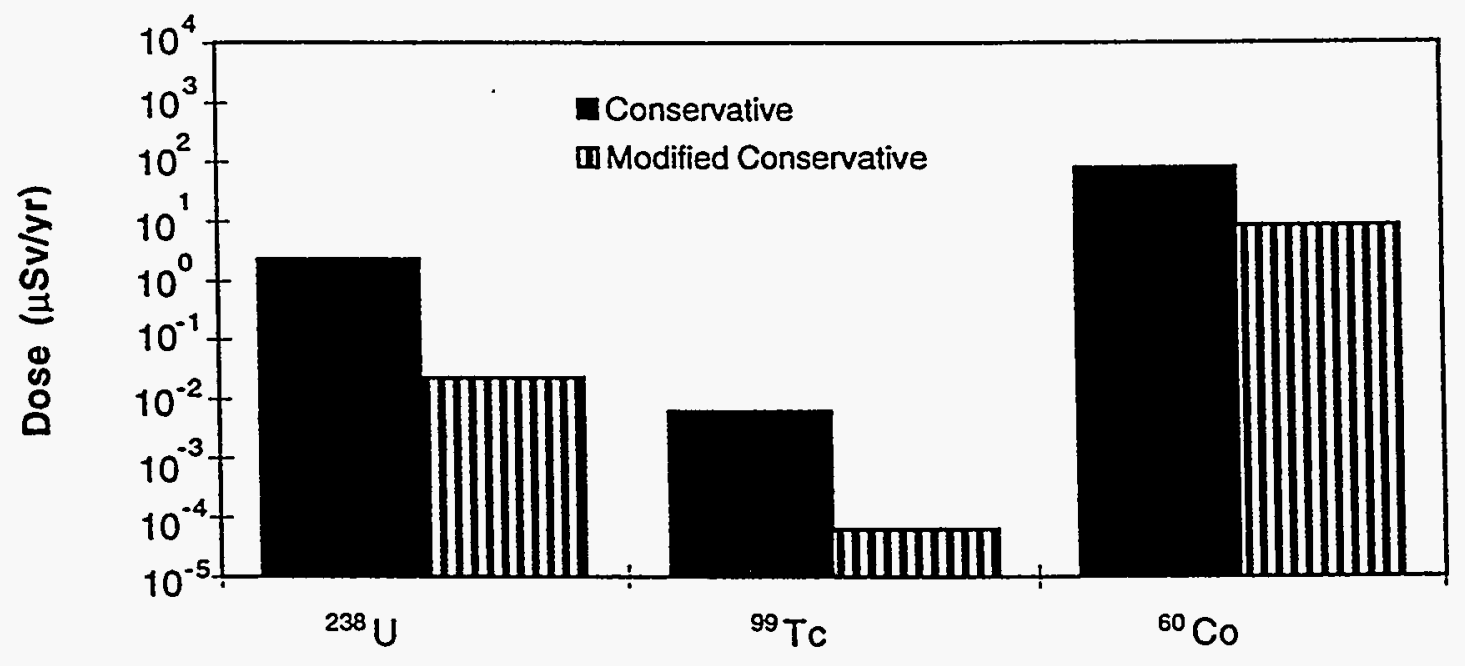

(b) Taxi Driver Scenario

FIGURE C.6 Dose Estimate Variation for Tier B-1 under Parameter Assumptions for Each Case 


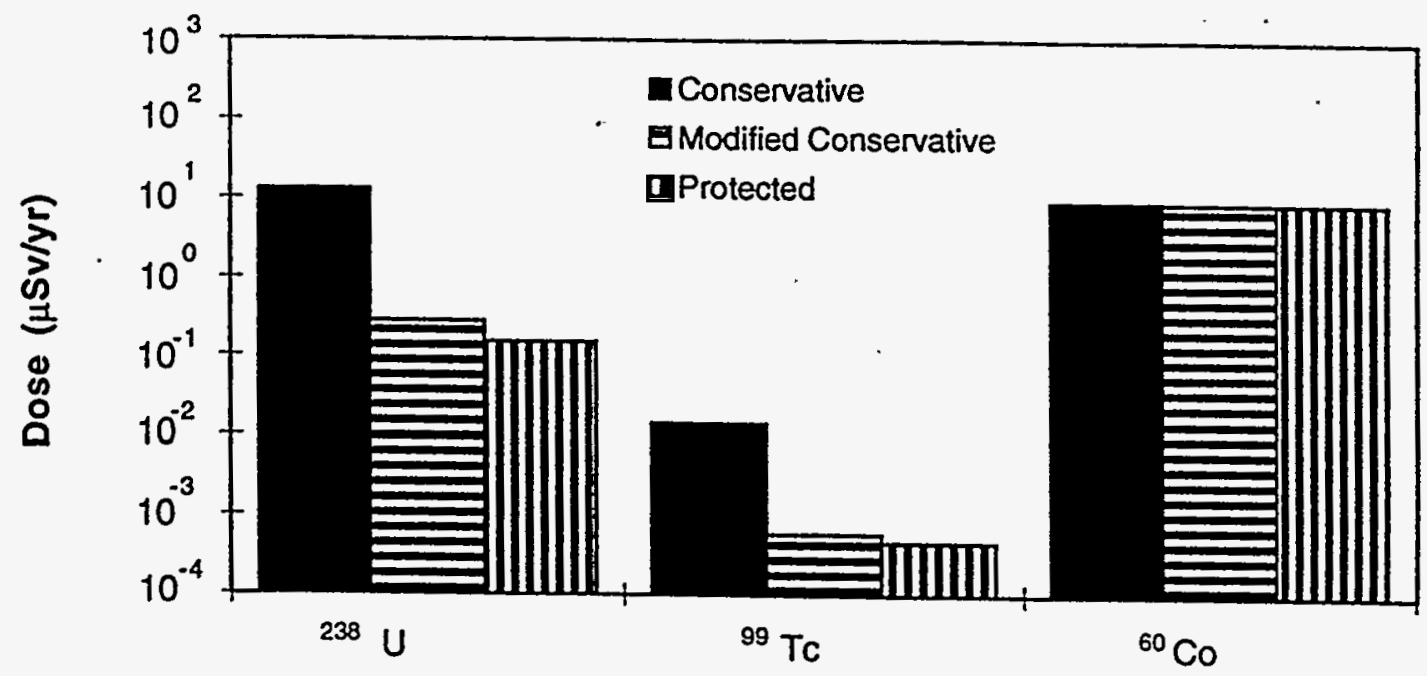

(a) Tool Reuse Scenario

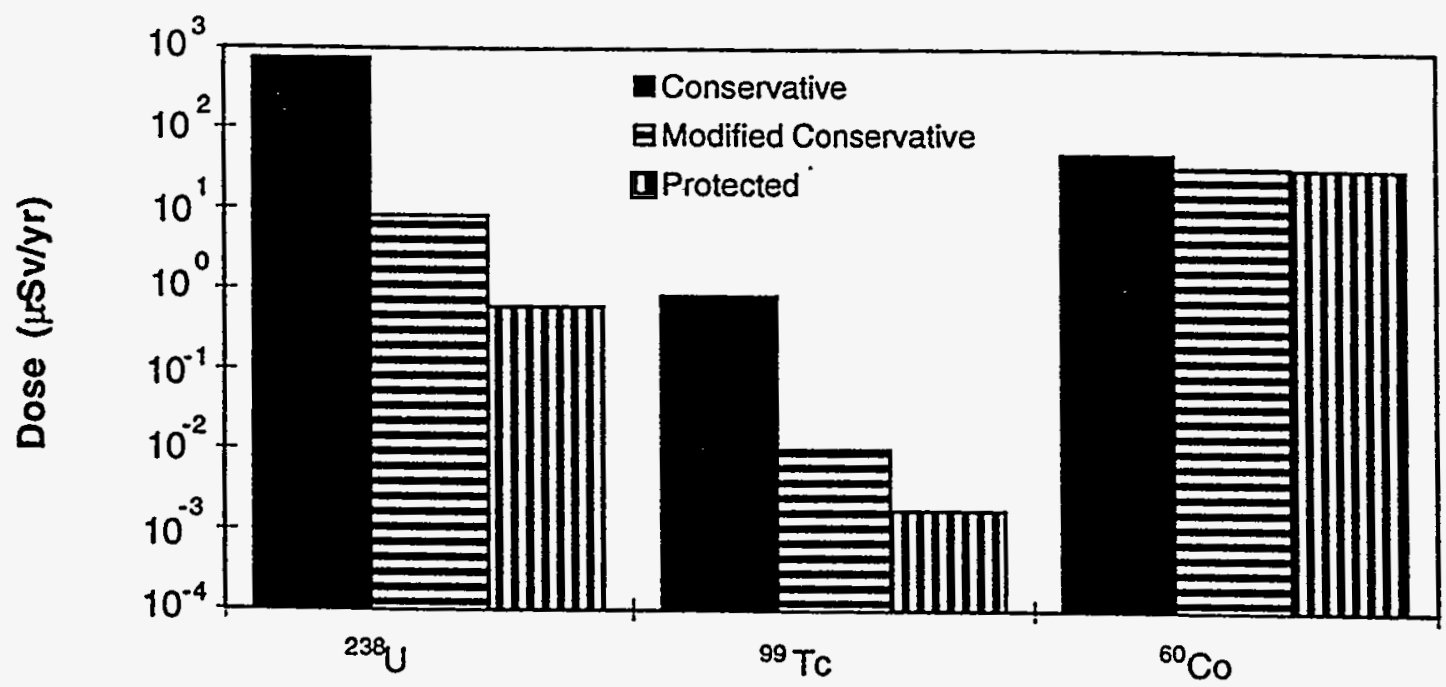

(b) Room Occupancy Scenario

FIGURE C.7 Dose Estimate Variation for Tier A-1 under Parameter Assumptions for Each Case 
scenario. Dose estimates and derived levels for nuclides where external exposure dominates dose (e.g., Co-60) are largely unaffected by these assumptions.

\section{C.5 PROBABILISTIC ANALYSIS}

A simulated probabilistic analysis of dose estimates was conducted to examine the effect of this approach for setting release standards. Figure C.8 shows the cumulative probability of a given individual dose lying within the range of estimated doses, from the minimum dose to the maximum. Both a linear and a normal distribution of dose estimates are shown to indicate that the dose level, and therefore the derived release level, that protects $90 \%$ of the exposed population can differ substantially substantially ( $\mathrm{X}_{90}^{\mathrm{N}}$ versus $\mathrm{X}_{90}^{\mathrm{L}}$ in Figure C.8), depending on distributions of parameter values.

The parameter value assumptions for this analytical example are listed in Table C.9, and the calculated flow is shown in Figure C.9, with the parameters indicated that are treated probabilistically. Based on 100 Monte Carlo runs, the mean dose estimate is $4.2 \mu \mathrm{Sv} / \mathrm{yr}$ and the mean derived level is $2.9 \mathrm{~Bq} / \mathrm{g}$. Dose estimates from the runs are plott ed in Figure C.10, which has a line drawn to indicate the 50th percentile in the dose distribution. Under the assumed parameter ranges, all of the doses would be less than $9 \mu \mathrm{Sv} / \mathrm{yr}$, with a release level of about $1 \mathrm{~Bq} / \mathrm{g}$ for Co-60.

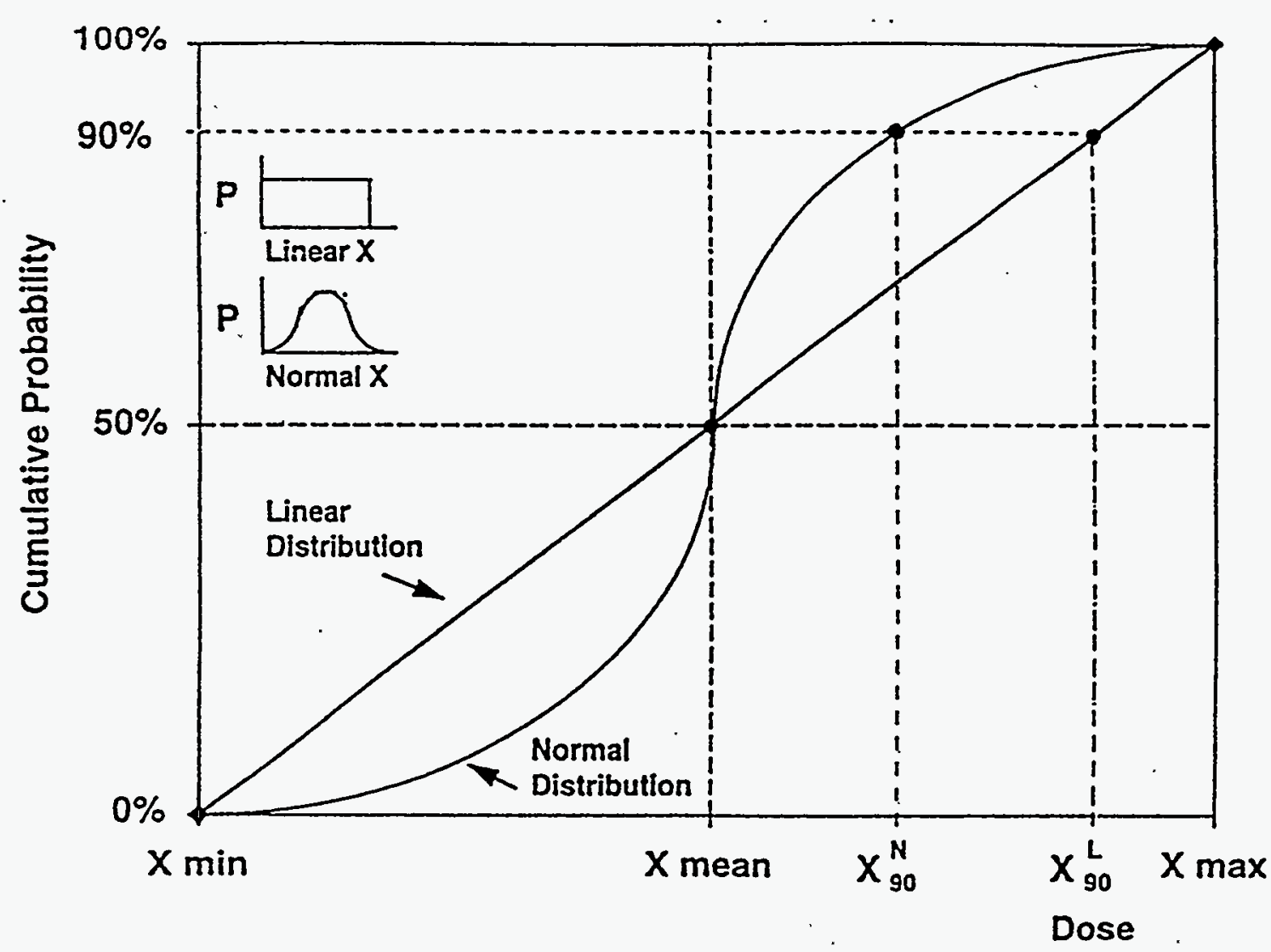

FIGURE C.8 Parameter Range and Shape of Distribution in Probabilistic Analysis 


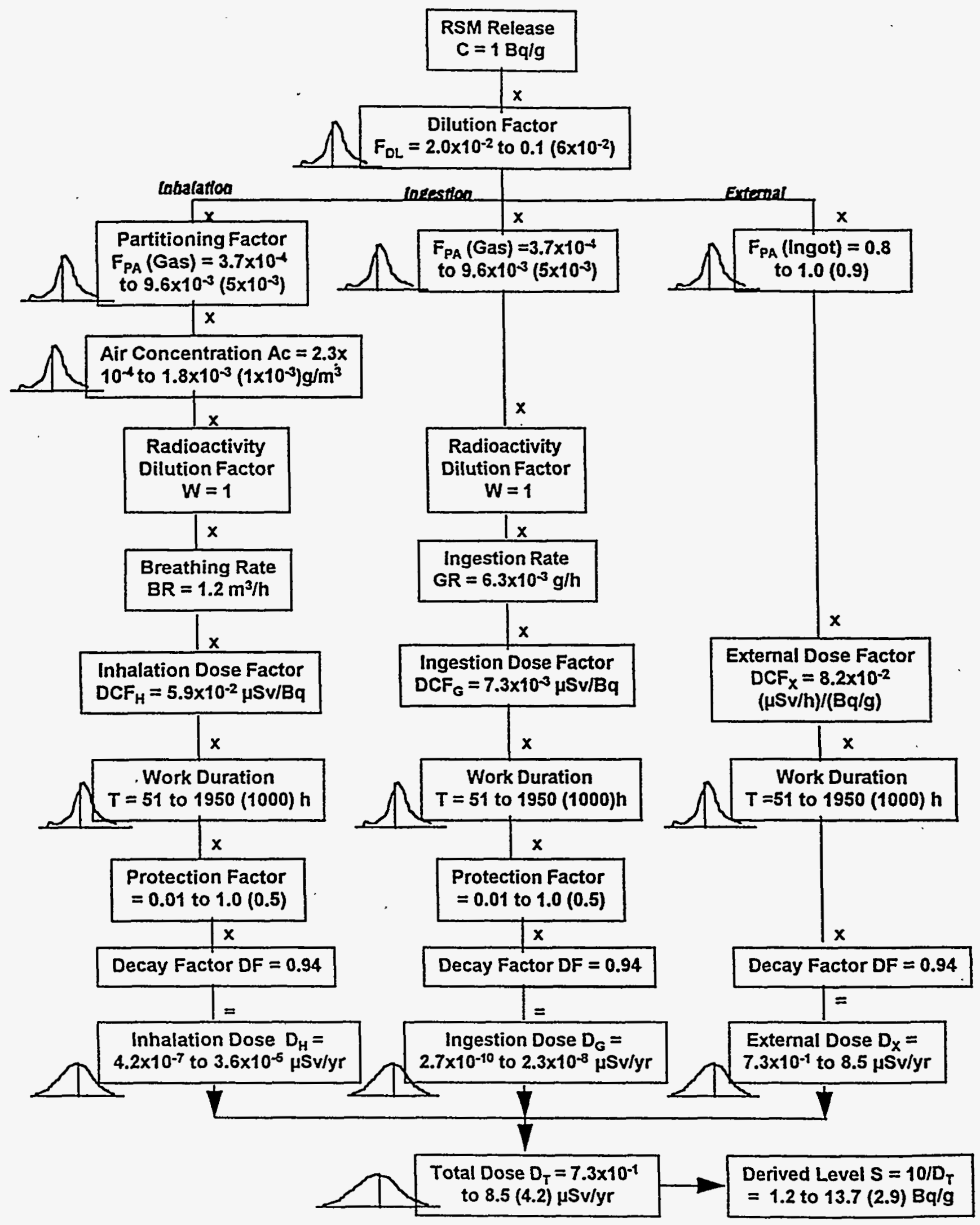

FIGURE C.9 Probabilistic Parameters in Worker Dose Calculation for Co-60 by Using Simulated Data (mean values in parentheses) 
TABLE C.9 Assumptions Used in Probabilistic Analysis of Dose Estimates for Co-60

\begin{tabular}{lccc}
\hline \multicolumn{1}{c}{ Variable } & Range & $\begin{array}{c}\text { Assumed } \\
\text { Mean }\end{array}$ & Distribution \\
\hline Dilution factor & $2.0 \times 10^{-2}-0.1$ & $6 \times 10^{-2}$ & Normal \\
Air dust loading & $2.3 \times 10^{-4}-1.8 \times 10^{-3}$ & $1 \times 10^{-3}$ & Normal \\
Exposure duration & $5.1 \times 10^{1}-1.95 \times 10^{3}$ & $1 \times 10^{3}$ & Normal \\
$\begin{array}{l}\text { Inhalation and ingestion } \\
\text { protection factor }\end{array}$ & $1 \times 10^{-2}-1 \times 10^{0}$ & $5.1 \times 10^{-1}$ & Uniform \\
$\begin{array}{l}\text { Partitioning to ingot } \\
\text { Partitioning to air }\end{array}$ & $8 \times 10^{-1}-1 \times 10^{0}$ & $9 \times 10^{-1}$ & Normal \\
\hline
\end{tabular}

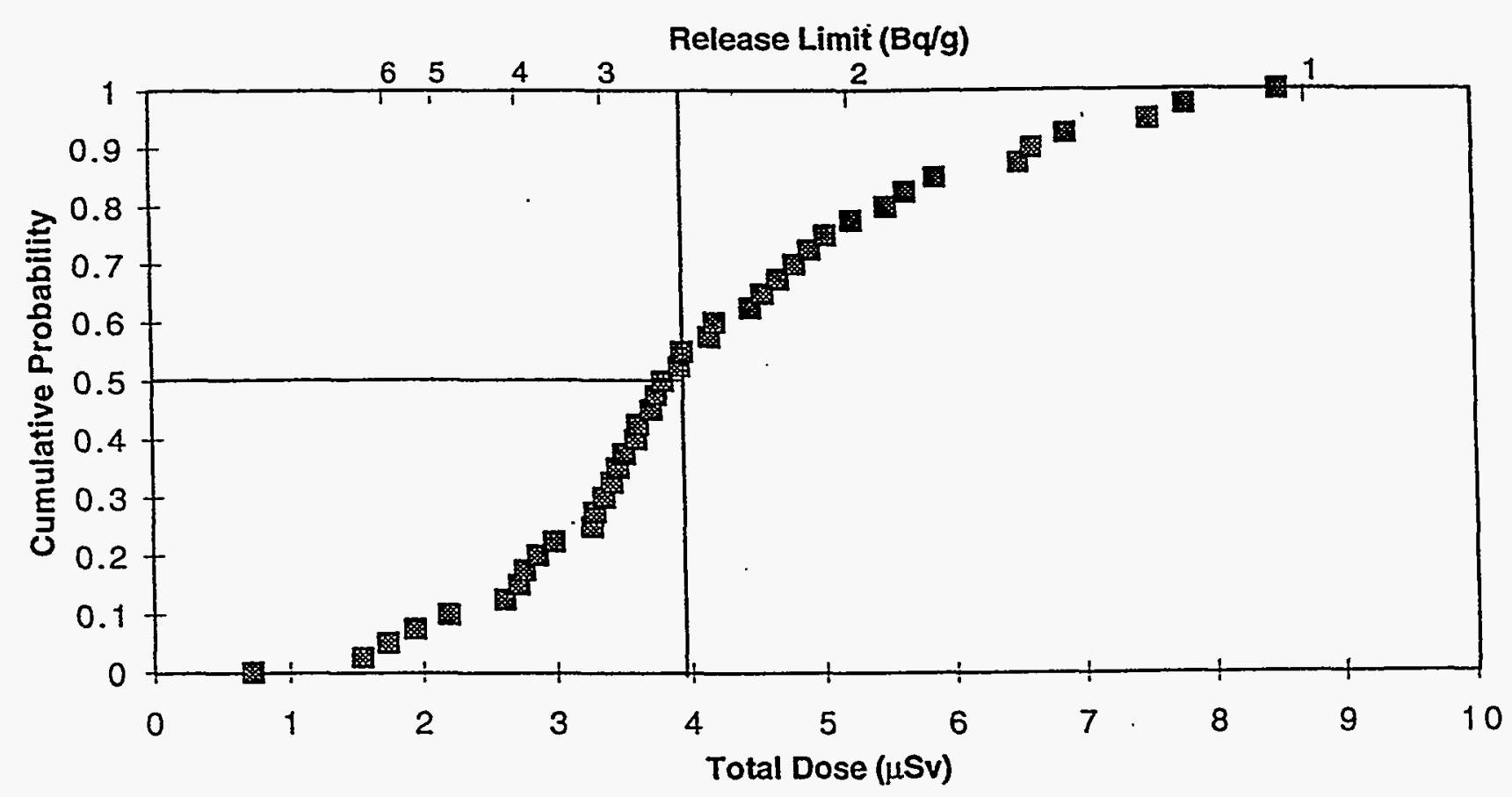

FIGURE C.10 Cumulative Probability for Co-60 Small Object Caster Dose 
Because the parameter values were constructed rather than empirically based, the estimated values are not valid. However, the example demonstrates that probabilistic analysis offers a substantial advantage for development of standards in that the degree of conservatism can be controlled if parameter values are well known. In cases like that of scrap metals, where unintended conservatism is very costly, further research to characterize parameters is certainly warranted.

\section{C.6 REFERENCES FOR APPENDIX C}

Chapuis, A.M., et al., Undated, Exemption Limits for the Recycling of Materials from the Dismantling of Nuclear Installations, Commissariat a' L'Energie Atomique, Fontenay-aux Roses, France.

- Chen, S.Y., 1991a, "Calculation of Effective Dose Equivalent Responses for External Exposure from Residual Photon Emitters in Soil," Health Physics 60(3):411-426.

Chen, S.Y., 1991b, "SOILD: A Computer Model for Calculating the Effective Dose Equivalent from External Exposure to Distributed Gamma Sources in Soil," Environmental Remediation '91 - Cleanup the Environment for the 21 st Century, symposium sponsored by the U.S. Department of Energy, Pasco, Wash.

Commission of the European Communities, 1981, Radiation Protection Criteria for the Recycling of Materials from the Dismantling of Nuclear Materials, Radiation Protection No. 43, Luxembourg, Belgium.

Eckerman, K.F., et al., 1988, Limiting Values of Radionuclide Intake and Air Concentration and Dose Conversion Factors for Inhalation, Submersion, and Ingestion, Federal Guidance Report No. 11, EPA-520/1-88-020, 'U.S. Environmental Protection Agency, Washington, D.C.

Elert, M., and M. Wiborgh, 1992, Basis for Criteria for Exemption of Decommissioning Waste: Reprocessing of Dust from Recycling of Steel, prepared for Swedish Radiation Protection Institute, KEMAKTA Konsalt AB.

Healy, J.W., 1971, Surface Contamination: Decision Levels, LA-4558-MS, Los Alamos Scientific Laboratory, Los Alamos, N.M.

Hertzler, T., et al., 1993, Recycle of DOE Radiologically Contaminated Metal - A Scoping Study, Draft, Science Application International Corp., Idaho Falls, Idaho.

IAEA - See International Atomic Energy Agency.

ICRP - See International Commission on Radiation Protection.

International Atomic Energy Agency, 1988, Principles for the Exemption of Radiation Sources and Practices form Regulatory Control, IAEA Safety Series No. 89, Vienna, Austria.

International Atomic Energy Agency, 1992, Application of Exemption Principles to the Recycle and Reuse of Materials from Nuclear Facilities, IAEA Safety Series No. 111, Vienna, Austria. 
International Commission on Radiological Protection, 1975, Reference Man: Anatomical, Physiological and Metabolic Characteristics, ICRP Publication 23, Pergamon Press, Oxford, United Kingdom.

International Commission on Radiation Protection, 1979-1988, Limits for Intake of Radionuclides by Workers, ICRP 30, Part 1 (and subsequent parts and supplements), Pergamon Press, Oxford, United Kingdom.

International Commission on Radiation Protection, 1986, The Metabolism of Plutonium and Related Elements, ICRP 48, Pergamon Press, Oxford, United Kingdom.

International Commission on Radiation Protection, 1991, Recommendations of the International Commission on Radiological Protection, ICRP 60, Pergamon Press, Oxford, United Kingdom.

Johnson, A., 1993, "Estimated Isotope Partitioning," transmittal from Johnson (Scientific Ecology Group, Oak Ridge, Tenn.) to S.Y. Chen (Argonne National Laboratory, Argonne, Ill.).

Lee, M.W., and D.H. Stoddard, 1979, Statistical Analysis of HEPA Filtration Services, DPST-79-359, Westinghouse Savannah River Co., Savannah River Site, Aiken, S.C.

Moghissi, A.A., et al., (eds.), 1986, Radioactive Waste Technology, American Society of Mechanical Engineers, New York, N.Y.

Neuhauser, K.S., and F.L. Kanipe, 1992, RADTRAN 4: Volume 3, User Guide, SAND89-2370, Sandia National Laboratories, Albuquerque, N.M.

O'Donnell, F.R., et al., 1978, Potential Radiation Dose to Man from Recycle of Metals Reclaimed from a Decommissioned Nuclear Power Plant, NUREG/CR-0134, ORNL/NUREG/TM-215, prepared by Oak Ridge National Laboratory, Oak Ridge, Tenn., for U.S. Department of Energy, Washington, D.C.

Otis, M., 1995, memorandum from Otis (Science Applications International Corporation, Idaho Falls, Idaho) to R.A. Meck (U.S. Nuclear Regulatory Commission, Bethesda, Md.), Aug. 30.

Oztunali, O.I., et al., 1981, Data Base for Radioactive Waste Management: Impacts Analyses Methodology Report, NUREG/CR-1759, Vol. 3, U.S. Nuclear Regulatory Commission, Washington, D.C.

Parks, B.S., 1992, User's Guide for CAP88-PC, Version 1.0, 402-B-92-001, prepared by U.S. Environmental Protection Agency for the U.S. Department of Energy, Las Vegas, Nev.

Sanford Cohen and Associates, Inc., 1995, Analysis of the Potential Recycling of Department of Energy Radioactive Scrap Metal, prepared for U.S. Environmental Protection Agency, Office of Radiation and Indoor Air, McLean, Va., Aug.

Scientific Ecology Group, 1993, Specification for Cast Steel Shield Blocks, Oak Ridge, Tenn., Feb. 17. 
U.S. Bureau of Mines, 1985, Mineral Facts and Problems, 1985 Edition, Bulletin 675, Washington, D.C.

USEPA - see U.S. Environmental Protection Agency.

U.S. Environmental Protection Agency, 1991, Risk Assessment Guidance for Superfund, Vol. I: Human Health Evaluation Manual, Supplemental Guidance; Standard Default Exposure Factors, OSWER Directive 9285.6-03 Interim Final, Office of Emergency and Remedial Response, Washington, D.C., March.

U.S. Environmental Protection Agency, 1993, External Exposure to Radionuclides in Air, Water, and Soil, Federal Guidance Report No. 12, EPA 402-R-93-081, Washington, D.C.

USNRC - see U.S. Nuclear Regulatory Commission.

U.S. Nuclear Regulatory Commission, 1980, Draft Environmental Statement Concerning Proposed Rule Making Exemption from Licensing Requirements for Smelted Alloys Containing Residual Technetium-99 and Low-Enriched Uranium, NUREG-0518, Office of Standards Development, Washington, D.C., Oct.

U.S. Nuclear Regulatory Commission, 1992, Residual Radioactive Contamination from Decommissioning: Volume 1, Technical Basis for Translating Contamination Levels to Annual Total Effective Dose Equivalent, NUREG/CR-5512, Washington, D.C.

Yu., C., et al., 1993a, Data Collection Handbook to Support Modeling the Impacts of Radioactive Material in Soil, ANL/EAIS-8, Environmental Assessment and Information Sciences Division, Argonne National Laboratory, Argonne, Ml., April.

Yu, C., et al., 1993b, Manual for Implementing Residual Radioactive Material Guidelines Using RESRAD, Version 5.0, Working Draft for Comment, ANL/EAD/LD-2, Argonne National Laboratory, Argonne, חll., Sept.

Yu, C., et al., 1994, Computer Model for Analyzing the Radiological Doses Resulting from the Remediation and Occupancy of Buildings Contaminated with Radioactive Material, ANL/EAD/LD-3, Environmental Assessment Division, Argonne National Laboratory, Argonne, Ill., Nov. 
$D-1$

\section{APPENDIX D:}

\section{BASELINE DOSE ESTIMATES FOR WORKER} AND PUBLIC SCENARIOS 


\section{APPENDIX D: \\ BASELINE DOSE ESTIMATES FOR WORKER AND PUBLIC SCENARIOS}

The calculations presented in this appendix (Tables D.1-D.33) have been separated into worker and consumer exposures. The calculational methodology and scenarios are described in Appendix C. Individual doses have been calculated with a unit concentration of $1 \mathrm{~Bq} / \mathrm{g}$ for each radionuclide on the basis of 2,000 hours of work. The worker doses presented in Tables D.1-D.22 are based on the parameters described in Table C.2. The public doses presented in Tables D.23-D.30 are based on the parameters described in Table C.3. Collective doses are based on $100 \mathrm{t}$ of RSM. These baseline doses follow the scenarios and assumptions discussed in Appendix $\mathrm{C}$ but do not account for scrap dilution or radionuclide partitioning during melt operations, as do the modified-conservative case results given in Section 5. Doses are for an annual practice and do not include potential increases in exposures from recycling operations over time. 
TABLE D.1 Baseline Worker Doses for a 2,000-h Scrap Delivery Loader ${ }^{\text {a }}$

\begin{tabular}{|c|c|c|c|c|c|}
\hline Nuclide & $\begin{array}{r}\text { Ingestion } \\
(\mu \mathrm{Sv} / \mathrm{yr})\end{array}$ & $\begin{array}{c}\text { Inhalation } \\
(\mu \mathrm{Sv} / \mathrm{yr})\end{array}$ & $\begin{array}{c}\text { External } \\
(\mu \mathrm{Sv} / \mathrm{yr})\end{array}$ & $\begin{array}{c}\text { Total Dose } \\
(\mu \mathrm{Sv} / \mathrm{yr})\end{array}$ & $\begin{array}{l}\text { Collective Dose } \\
\text { (person-Sv/yr) }\end{array}$ \\
\hline Ac-227 & $4.70 \mathrm{E}+01$ & $4.30 \mathrm{E} \div 02$ & $2.60 \mathrm{E}+00$ & $4.80 \mathrm{E}+02$ & $9.50 \mathrm{E}-04$ \\
\hline $\mathrm{Ag}-110 \mathrm{~m}$ & $2.30 \mathrm{E}-02$ & $3.30 \mathrm{E}-03$ & $1.40 \mathrm{E}+01$ & $1.40 \mathrm{E}+01$ & $2.80 \mathrm{E}-05$ \\
\hline Am-241 & $1.20 \mathrm{E}+01$ & $2.90 \mathrm{E}+01$ & $6.10 \mathrm{E}-02$ & $4.10 \mathrm{E}+01$ & $8.20 \mathrm{E}-05$ \\
\hline Am-243 & $1.20 \mathrm{E}+01$ & $2.90 \mathrm{E}+01$ & $1.20 \mathrm{E}+00$ & $4.20 \mathrm{E}+01$ & $8.40 \mathrm{E}-05$ \\
\hline $\mathrm{Ca}-41$ & $4.30 \mathrm{E}-03$ & $8.70 \mathrm{E}-05$ & $0.00 \mathrm{E}+00$ & $4.40 \mathrm{E}-03$ & $8.80 \mathrm{E}-09$ \\
\hline Ce-144 & $4.70 \mathrm{E}-02$ & $1.60 \mathrm{E}-02$ & $2.80 \mathrm{E}-01$ & 3.40E-01 & $6.80 \mathrm{E}-07$ \\
\hline $\mathrm{Cl}-36$ & $1.00 \mathrm{E}-02$ & $1.40 \mathrm{E}-03$ & 3.10E-03 & $1.50 \mathrm{E}-02$ & $2.90 \mathrm{E}-08$ \\
\hline $\mathrm{Cm}-243$ & $8.40 \mathrm{E}+00$ & $2.00 \mathrm{E}+01$ & $7.80 \mathrm{E}-01$ & $2.90 \mathrm{E}+01$ & 5.80E-05 \\
\hline $\mathrm{Cm}-244$ & $6.70 \mathrm{E}+00$ & $1.60 \mathrm{E}+01$ & $1.50 \mathrm{E}-04$ & $2.20 \mathrm{E}+01$ & $4.50 \mathrm{E}-05$ \\
\hline $\mathrm{Cm}-245$ & $1.30 \mathrm{E}+01$ & $3.00 \mathrm{E}+01$ & $4.60 \mathrm{E}-01$ & $4.30 \mathrm{E}+01$ & $8.50 \mathrm{E}-05$ \\
\hline $\mathrm{Cm}-246$ & $1.30 \mathrm{E}+01$ & $2.90 \mathrm{E}+01$ & 1.30E-04 & $4.20 \mathrm{E}+01$ & $8.40 \mathrm{E}-05$ \\
\hline Cm-247 & $1.20 \mathrm{E}+01$ & $2.70 \mathrm{E}+01$ & $2.40 \mathrm{E}+00$ & $4.10 \mathrm{E}+01$ & $8.20 \mathrm{E}-05$ \\
\hline $\mathrm{Co}-57$ & $2.70 \mathrm{E}-03$ & $3.90 \mathrm{E}-04$ & $4.60 \mathrm{E}-01$ & $4.60 \mathrm{E}-01$ & $9.20 \mathrm{E}-07$ \\
\hline $\mathrm{Co}-60$ & $8.50 \mathrm{E}-02$ & $1.30 \mathrm{E}-02$ & $1.90 E+01$ & $1.90 E+01$ & $3.90 \mathrm{E}-05$ \\
\hline Cs-134 & $2.10 \mathrm{E}-01$ & $2.50 \mathrm{E}-03$ & $1.00 E+01$ & $1.10 \mathrm{E}+01$ & $2.10 \mathrm{E}-05$ \\
\hline Cs-135 & $2.40 \mathrm{E}-02$ & $3.00 \mathrm{E}-04$ & $0.00 \mathrm{E}+00$ & $2.40 \mathrm{E}-02$ & $4.80 \mathrm{E}-08$ \\
\hline Cs-137 & $1.70 \mathrm{E}-01$ & 2.00E-03 & $4.30 \mathrm{E}+00$ & $4.50 \mathrm{E}+00$ & $9.00 \mathrm{E}-06$ \\
\hline Eu-152 & 2.10E-02 & $1.40 \mathrm{E}-02$ & $8.70 \mathrm{E}+00$ & $8.80 \mathrm{E}+00$ & $1.80 \mathrm{E}-05$ \\
\hline Eu-154 & $3.10 \mathrm{E}-02$ & $1.80 \mathrm{E}-02$ & $9.50 \mathrm{E}+00$ & $9.50 \mathrm{E}+00$ & $1.90 \mathrm{E}-05$ \\
\hline $\mathrm{Fe}-55$ & $1.80 \mathrm{E}-03$ & $1.50 \mathrm{E}-04$ & $0.00 \mathrm{E}+00$ & $2.00 \mathrm{E}-03$ & $3.90 \mathrm{E}-09$ \\
\hline $\mathrm{Mn}-54$ & $6.40 \mathrm{E}-03$ & $3.00 \mathrm{E}-04$ & $4.50 \mathrm{E}+00$ & $4.50 \mathrm{E}+00$ & 9.10E-06 \\
\hline $\mathrm{Na}-22$ & $3.40 \mathrm{E}-02$ & $4.40 \mathrm{E}-04$ & $1.50 \mathrm{E}+01$ & $1.50 \mathrm{E}+01$ & 3.10E-05 \\
\hline $\mathrm{Nb}-94$ & 2.40E-02 & 2.70E-02 & $1.20 \mathrm{E}+01$ & $1.20 \mathrm{E}+01$ & 2.50E-05 \\
\hline $\mathrm{Ni}-59$ & 7.10E-04 & $1.80 \mathrm{E}-04$ & $0.00 \mathrm{E}+00$ & $8.80 \mathrm{E}-04$ & $1.80 \mathrm{E}-09$ \\
\hline $\mathrm{Ni}-63$ & $1.90 \mathrm{E}-03$ & $4.10 \mathrm{E}-04$ & $0.00 \mathrm{E}+00$ & $2.40 \mathrm{E}-03$ & $4.70 \mathrm{E}-09$ \\
\hline Np-237 & $1.50 \mathrm{E}+01$ & $3.50 \mathrm{E}+01$ & $1.50 \mathrm{E}+00$ & $5.10 \mathrm{E}+01$ & $1.00 \mathrm{E}-04$ \\
\hline $\mathrm{Pb}-210$ & $1.80 \mathrm{E}+01$ & $8.70 \mathrm{E}-01$ & $3.30 \mathrm{E}-03$ & $1.90 \mathrm{E}+01$ & $3.70 \mathrm{E}-05$ \\
\hline Pm-147 & $3.10 \mathrm{E}-03$ & $2.20 \mathrm{E}-03$ & $6.00 \mathrm{E}-05$ & $5.40 \mathrm{E}-03$ & $1.10 \mathrm{E}-08$ \\
\hline $\mathrm{Pu}-238$ & $1.10 \mathrm{E}+01$ & $2.50 \mathrm{E}+01$ & $1.80 \mathrm{E}-04$ & $3.60 \mathrm{E}+01$ & $7.20 \mathrm{E}-05$ \\
\hline $\mathrm{Pu}-239$ & $1.20 \mathrm{E}+01$ & $2.80 \mathrm{E}+01$ & $4.00 \mathrm{E}-04$ & $4.00 \mathrm{E}+01$ & $8.00 \mathrm{E}-05$ \\
\hline $\mathrm{Pu}-240$ & $1.20 \mathrm{E}+01$ & $2.80 \mathrm{E}+01$ & $1.80 \mathrm{E}-04$ & $4.00 \mathrm{E}+01$ & $8.00 \mathrm{E}-05$ \\
\hline $\mathrm{Pu}-241$ & 2.30E-01 & $5.20 \mathrm{E}-01$ & 2.50E-05 & $7.50 \mathrm{E}-01$ & $1.50 \mathrm{E}-06$ \\
\hline $\mathrm{Pu}-242$ & $1.10 \mathrm{E}+01$ & $2.70 \mathrm{E}+01$ & $1.60 \mathrm{E}-04$ & $3.80 \mathrm{E}+01$ & $7.60 \mathrm{E}-05$ \\
\hline Ru-106 & $6.70 \mathrm{E}-02$ & $2.20 \mathrm{E}-02$ & $1.20 \mathrm{E}+00$ & $1.30 \mathrm{E}+00$ & $2.60 \mathrm{E}-06$ \\
\hline $\mathrm{Sb}-125$ & $8.40 \mathrm{E}-03$ & $7.00 \mathrm{E}-04$ & $2.80 \mathrm{E}+00$ & $2.80 \mathrm{E}+00$ & $5.60 \mathrm{E}-06$ \\
\hline Se-79 & $2.90 \mathrm{E}-02$ & $6.40 \mathrm{E}-04$ & $0.00 \mathrm{E}+00$ & $3.00 \mathrm{E}-02$ & $6.00 \mathrm{E}-08$ \\
\hline $\mathrm{Sm}-151$ & $1.30 \mathrm{E}-03$ & $1.90 \mathrm{E}-03$ & $1.30 \mathrm{E}-06$ & $3.20 \mathrm{E}-03$ & $6.50 \mathrm{E}-09$ \\
\hline Sr-90 & $4.80 \mathrm{E}-01$ & $8.30 \mathrm{E}-02$ & $3.00 \mathrm{E}-02$ & 5.90E-01 & $1.20 \mathrm{E}-06$ \\
\hline Tc-99 & $4.90 \mathrm{E}-03$ & $5.40 \mathrm{E}-04$ & $1.70 \mathrm{E}-04$ & $5.70 \mathrm{E}-03$ & $1.10 \mathrm{E}-08$ \\
\hline Th-228 & $1.10 \mathrm{E}+00$ & $1.90 \mathrm{E}+01$ & $1.10 \mathrm{E}+01$ & $3.10 \mathrm{E}+01$ & $6.10 \mathrm{E}-05$ \\
\hline Th-229 & $1.20 \mathrm{E}+01$ & $1.40 \mathrm{E}+02$ & $2.10 \mathrm{E}+00$ & $1.50 \mathrm{E}+02$ & 3.10E-04 \\
\hline Th-230 & $1.90 \mathrm{E}+00$ & $2.10 \mathrm{E}+01$ & $1.60 \mathrm{E}-03$ & $2.30 \mathrm{E}+01$ & $4.60 \mathrm{E}-05$ \\
\hline Th-232 & $9.20 \mathrm{E}+00$ & $1.10 \mathrm{E}+02$ & $7.10 \mathrm{E}-04$ & $1.20 \mathrm{E}+02$ & 2.30E-04 \\
\hline U-232 & $4.40 \mathrm{E}+00$ & $4.30 \mathrm{E}+01$ & $1.20 \mathrm{E}-03$ & $4.70 \mathrm{E}+01$ & $9.40 \mathrm{E}-05$ \\
\hline U-233 & $9.80 \mathrm{E}-01$ & $8.80 \mathrm{E}+00$ & $1.90 \mathrm{E}-03$ & $9.80 \mathrm{E}+00$ & 2.00E-05 \\
\hline U-234 & $9.60 \mathrm{E}-01$ & $8.60 \mathrm{E}+00$ & $5.40 \mathrm{E}-04$ & $9.60 \mathrm{E}+00$ & $1.90 \mathrm{E}-05$ \\
\hline U-235 & 9.00E-01 & $8.00 \mathrm{E}+00$ & $1.00 \mathrm{E}+00$ & $9.90 \mathrm{E}+00$ & $2.00 \mathrm{E}-05$ \\
\hline U-238 & $8.60 \mathrm{E}-01$ & $7.70 \mathrm{E}+00$ & $1.70 \mathrm{E}-01$ & $8.70 \mathrm{E}+00$ & $1.70 \mathrm{E}-05$ \\
\hline Zn-65 & $3.00 \mathrm{E}-02$ & $8.20 \mathrm{E}-04$ & $2.90 \mathrm{E}+00$ & $3.00 \mathrm{E}+00$ & $5.90 \mathrm{E}-06$ \\
\hline $\mathrm{Zr}-93$ & $5.60 \mathrm{E}-03$ & 2.10E-02 & $0.00 \mathrm{E}+00$ & $2.60 \mathrm{E}-02$ & 5.30E-08 \\
\hline
\end{tabular}

a Doses do not account for scrap dilution or radionuclide partitioning; collective doses based on $100 \mathrm{t}$. 
TABLE D.2 Baseline Worker Doses for a 2,000-h Scrap Delivery Truck Driver ${ }^{a}$

\begin{tabular}{|c|c|c|c|c|c|}
\hline Nuclide & $\begin{array}{r}\text { Ingestion } \\
(\mu \mathrm{Sv} / \mathrm{yr})\end{array}$ & $\begin{array}{c}\text { Inhalation } \\
(\mu \mathrm{Sv} / \mathrm{yr})\end{array}$ & $\begin{array}{l}\text { External } \\
(\mu S v / y r)\end{array}$ & $\begin{array}{c}\text { Total Dose } \\
(\mu \mathrm{Sv} / \mathrm{yr})\end{array}$ & $\begin{array}{r}\text { Collective Dose } \\
\text { (person-Sv/yr) }\end{array}$ \\
\hline Ac-227 & $0.00 \mathrm{E}+00$ & $0.00 \mathrm{E}+00$ & $2.30 \mathrm{E}+00$ & $2.30 \mathrm{E}+00$ & $1.20 \mathrm{E}-05$ \\
\hline Ag-110m & $0.00 \mathrm{E}+00$ & $0.00 \mathrm{E}+00$ & $1.20 \mathrm{E}+01$ & $1.20 \mathrm{E}+01$ & $6.10 \mathrm{E}-05$ \\
\hline $\mathrm{Am}-241$ & $0.00 \mathrm{E}+00$ & $0.00 \mathrm{E}+00$ & 5.70E-02 & $5.70 \mathrm{E}-02$ & 2.80E-07 \\
\hline Am-243 & $0.00 \mathrm{E}+00$ & $0.00 \mathrm{E}+00$ & $1.10 \mathrm{E}+00$ & $1.10 \mathrm{E}+00$ & $5.50 \mathrm{E}-06$ \\
\hline Ca-41 & $0.00 \mathrm{E}+00$ & $0.00 \mathrm{E}+00$ & $0.00 \mathrm{E}+00$ & $0.00 \mathrm{E}+00$ & $0.00 \mathrm{E}+00$ \\
\hline Ce-144 & $0.00 \mathrm{E}+00$ & $0.00 \mathrm{E}+00$ & 2.50E-01 & 2.50E-01 & $1.20 \mathrm{E}-06$ \\
\hline Cl-36 & $0.00 \mathrm{E}+00$ & $0.00 \mathrm{E}+00$ & $2.80 \mathrm{E}-03$ & $2.80 \mathrm{E}-03$ & $1.40 \mathrm{E}-08$ \\
\hline $\mathrm{Cm}-243$ & $0.00 \mathrm{E}+00$ & $0.00 \mathrm{E}+00$ & $7.00 \mathrm{E}-01$ & $7.00 \mathrm{E}-01$ & $3.50 \mathrm{E}-06$ \\
\hline $\mathrm{Cm}-244$ & $0.00 \mathrm{E}+00$ & $0.00 \mathrm{E}+00$ & 1.70E-04 & 1.70E-04 & $8.60 \mathrm{E}-10$ \\
\hline $\mathrm{Cm}-245$ & $0.00 \mathrm{E}+00$ & $0.00 \mathrm{E}+00$ & $4.20 \mathrm{E}-01$ & $4.20 \mathrm{E}-01$ & 2.10E-06 \\
\hline $\mathrm{Cm}-246$ & $0.00 \mathrm{E}+00$ & $0.00 \mathrm{E}+00$ & $1.70 \mathrm{E}-04$ & $1.70 \mathrm{E}-04$ & $8.30 \mathrm{E}-10$ \\
\hline $\mathrm{Cm}-247$ & $0.00 \mathrm{E}+00$ & $0.00 \mathrm{E}+00$ & $2.20 \mathrm{E}+00$ & $2.20 \mathrm{E}+00$ & $1.10 \mathrm{E}-05$ \\
\hline Co-57 & $0.00 \mathrm{E}+00$ & $0.00 \mathrm{E}+00$ & $4.20 \mathrm{E}-01$ & $4.20 \mathrm{E}-01$ & $2.10 \mathrm{E}-06$ \\
\hline Co-60 & $0.00 \mathrm{E}+00$ & $0.00 \mathrm{E}+00$ & $1.70 \mathrm{E}+01$ & $1.70 \mathrm{E}+01$ & 8.60E-05 \\
\hline Cs-134 & $0.00 \mathrm{E}+00$ & $0.00 \mathrm{E}+00$ & $9.20 \mathrm{E}+00$ & $9.20 \mathrm{E}+00$ & $4.60 \mathrm{E}-05$ \\
\hline Cs-135 & $0.00 \mathrm{E}+00$ & $0.00 \mathrm{E}+00$ & $0.00 \mathrm{E}+00$ & $0.00 \mathrm{E}+00$ & $0.00 \mathrm{E}+00$ \\
\hline Cs-137 & $0.00 \mathrm{E}+00$ & $0.00 \mathrm{E}+00$ & $3.80 \mathrm{E}+00$ & $3.80 \mathrm{E}+00$ & $1.90 \mathrm{E}-05$ \\
\hline Eu-152 & $0.00 \mathrm{E}+00$ & $0.00 \mathrm{E}+00$ & $7.80 \mathrm{E}+00$ & $7.80 \mathrm{E}+00$ & $3.90 \mathrm{E}-05$ \\
\hline Eu-154 & $0.00 \mathrm{E}+00$ & $0.00 \mathrm{E}+00$ & $8.40 \mathrm{E}+00$ & $8.40 \mathrm{E}+00$ & 4.20E-05 \\
\hline $\mathrm{Fe}-55$ & $0.00 \mathrm{E}+00$ & $0.00 \mathrm{E}+00$ & $0.00 \mathrm{E}+00$ & $0.00 \mathrm{E}+00$ & $0.00 \mathrm{E}+00$ \\
\hline Mn-54 & $0.00 \mathrm{E}+00$ & $0.00 \mathrm{E}+00$ & $4.00 \mathrm{E}+00$ & $4.00 \mathrm{E}+00$ & $2.00 \mathrm{E}-05$ \\
\hline $\mathrm{Na}-22$ & $0.00 \mathrm{E}+00$ & $0.00 \mathrm{E}+00$ & $1.40 \mathrm{E}+01$ & $1.40 \mathrm{E}+01$ & $6.80 \mathrm{E}-05$ \\
\hline $\mathrm{Nb}-94$ & $0.00 \mathrm{E}+00$ & $0.00 \mathrm{E}+00$ & $1.10 \mathrm{E}+01$ & $1.10 \mathrm{E}+01$ & $5.50 \mathrm{E}-05$ \\
\hline Ni-59 & $0.00 \mathrm{E}+00$ & $0.00 \mathrm{E}+00$ & $0.00 \mathrm{E}+00$ & $0.00 \mathrm{E}+00$ & $0.00 \mathrm{E}+00$ \\
\hline $\mathrm{Ni}-63$ & $0.00 \mathrm{E}+00$ & $0.00 \mathrm{E}+00$ & $0.00 \mathrm{E}+00$ & $0.00 \mathrm{E}+00$ & $0.00 \mathrm{E}+00$ \\
\hline $\mathrm{Np}-237$ & $0.00 \mathrm{E}+00$ & $0.00 \mathrm{E}+00$ & $1.30 \mathrm{E}+00$ & $1.30 \mathrm{E}+00$ & $6.60 \mathrm{E}-06$ \\
\hline $\mathrm{Pb}-210$ & $0.00 \mathrm{E}+00$ & $0.00 \mathrm{E}+00$ & $3.20 \mathrm{E}-03$ & $3.20 \mathrm{E}-03$ & $1.60 \mathrm{E}-08$ \\
\hline Pm-147 & $0.00 \mathrm{E}+00$ & $0.00 \mathrm{E}+00$ & $5.50 \mathrm{E}-05$ & $5.50 \mathrm{E}-05$ & $2.70 \mathrm{E}-10$ \\
\hline $\mathrm{Pu}-238$ & $0.00 \mathrm{E}+00$ & $0.00 E+00$ & 2.10E-04 & 2.10E-04 & $1.00 \mathrm{E}-09$ \\
\hline Pu-239 & $0.00 \mathrm{E}+00$ & $0.00 \mathrm{E}+00$ & $3.80 \mathrm{E}-04$ & $3.80 \mathrm{E}-04$ & $1.90 \mathrm{E}-09$ \\
\hline $\mathrm{Pu}-240$ & $0.00 \mathrm{E}+00$ & $0.00 \mathrm{E}+00$ & $2.00 \mathrm{E}-04$ & $2.00 \mathrm{E}-04$ & 1.00E-09 \\
\hline $\mathrm{Pu}-241$ & $0.00 \mathrm{E}+00$ & $0.00 \mathrm{E}+00$ & 2.30E-05 & 2.30E-05 & $1.10 \mathrm{E}-10$ \\
\hline $\mathrm{Pu}-242$ & $0.00 \mathrm{E}+00$ & $0.00 \mathrm{E}+00$ & $1.70 \mathrm{E}-04$ & $1.70 \mathrm{E}-04$ & $8.70 \mathrm{E}-10$ \\
\hline Ru-106 & $0.00 \mathrm{E}+00$ & $0.00 \mathrm{E}+00$ & $1.10 \mathrm{E}+00$ & $1.10 \mathrm{E}+00$ & $5.40 \mathrm{E}-06$ \\
\hline Sb-125 & $0.00 \mathrm{E}+00$ & $0.00 \mathrm{E}+00$ & $2.50 \mathrm{E}+00$ & $2.50 \mathrm{E}+00$ & $1.20 \mathrm{E}-05$ \\
\hline Se-79 & $0.00 \mathrm{E}+00$ & $0.00 \mathrm{E}+00$ & $0.00 \mathrm{E}+00$ & $0.00 \mathrm{E}+00$ & $0.00 \mathrm{E}+00$ \\
\hline Sm-151 & $0.00 \mathrm{E}+00$ & $0.00 \mathrm{E}+00$ & $1.40 \mathrm{E}-06$ & $1.40 \mathrm{E}-06$ & $6.80 \mathrm{E}-12$ \\
\hline Sr-90 & $0.00 \mathrm{E}+00$ & $0.00 \mathrm{E}+00$ & $2.60 \mathrm{E}-02$ & $2.60 \mathrm{E}-02$ & $1.30 \mathrm{E}-07$ \\
\hline Tc-99 & $0.00 \mathrm{E}+00$ & $0.00 \mathrm{E}+00$ & $1.60 \mathrm{E}-04$ & $1.60 \mathrm{E}-04$ & $8.10 \mathrm{E}-10$ \\
\hline Th-228 & $0.00 \mathrm{E}+00$ & $0.00 \mathrm{E}+00$ & $9.60 \mathrm{E}+00$ & $9.60 \mathrm{E}+00$ & $4.80 \mathrm{E}-05$ \\
\hline Th-229 & $0.00 \mathrm{E}+00$ & $0.00 \mathrm{E}+00$ & $1.90 \mathrm{E}+00$ & $1.90 \mathrm{E}+00$ & $9.40 \mathrm{E}-06$ \\
\hline Th-230 & $0.00 \mathrm{E}+00$ & $0.00 \mathrm{E}+00$ & $1.50 \mathrm{E}-03$ & $1.50 \mathrm{E}-03$ & $7.60 \mathrm{E}-09$ \\
\hline Th-232 & $0.00 \mathrm{E}+00$ & $0.00 \mathrm{E}+00$ & $6.60 \mathrm{E}-04$ & $6.60 \mathrm{E}-04$ & 3.30E-09 \\
\hline U-232 & $0.00 \mathrm{E}+00$ & $0.00 \mathrm{E}+00$ & 1.10E-03 & $1.10 \mathrm{E}-03$ & 5.70E-09 \\
\hline U-233 & $0.00 \mathrm{E}+00$ & $0.00 \mathrm{E}+00$ & $1.80 \mathrm{E}-03$ & $1.80 \mathrm{E}-03$ & $8.80 \mathrm{E}-09$ \\
\hline U-234 & $0.00 \mathrm{E}+00$ & $0.00 \mathrm{E}+00$ & $5.10 \mathrm{E}-04$ & $5.10 \mathrm{E}-04$ & 2.60E-09 \\
\hline U-235 & $0.00 \mathrm{E}+00$ & $0.00 \mathrm{E}+00$ & $9.20 \mathrm{E}-01$ & $9.20 \mathrm{E}-01$ & $4.60 \mathrm{E}-06$ \\
\hline U-238 & $0.00 \mathrm{E}+00$ & $0.00 \mathrm{E}+00$ & $1.50 \mathrm{E}-01$ & $1.50 \mathrm{E}-01$ & $7.70 \mathrm{E}-07$ \\
\hline $\mathrm{Zn}-65$ & $0.00 \mathrm{E}+00$ & $0.00 \mathrm{E}+00$ & $2.60 \mathrm{E}+00$ & $2.60 \mathrm{E}+00$ & 1.30E-05 \\
\hline $\mathrm{Zr}-93$ & $0.00 \mathrm{E}+00$ & $0.00 \mathrm{E}+00$ & $0.00 \mathrm{E}+00$ & $0.00 \mathrm{E}+00$ & $0.00 \mathrm{E}+00$ \\
\hline
\end{tabular}

a Doses do not account for scrap dilution or radionuclide partitioning; collective doses based on $100 \mathrm{t}$. 
TABLE D.3 Baseline Worker Doses for a 2,000-h Scrap Cutter ${ }^{\text {a }}$

\begin{tabular}{|c|c|c|c|c|c|}
\hline Nuclide & $\begin{array}{r}\text { Ingestion } \\
(\mu \mathrm{Sv} / \mathrm{yr})\end{array}$ & $\begin{array}{l}\text { Inhalation } \\
\text { ( } \mu \mathrm{S} v / \mathrm{yr})\end{array}$ & $\begin{array}{r}\text { External } \\
(\mu \mathrm{Sv} / \mathrm{yr})\end{array}$ & $\begin{array}{l}\text { Total Dose } \\
\text { ( } \mu \mathrm{Sv} / \mathrm{yr})\end{array}$ & $\begin{array}{r}\text { Collective Dose } \\
\text { (person-Sv/yr) }\end{array}$ \\
\hline Ac-227 & $4.90 \mathrm{E}+01$ & $4.30 \mathrm{E}+02$ & $6.00 \mathrm{E}-01$ & $4.80 \mathrm{E}+02$ & $8.60 \mathrm{E}-04$ \\
\hline Ag-110m & $2.30 \mathrm{E}-02$ & 3.30E-03 & $3.50 \mathrm{E}+00$ & $3.50 \mathrm{E}+00$ & 6.30E-06 \\
\hline Am-241 & $1.20 \mathrm{E}+01$ & $2.90 \mathrm{E}+01$ & 3.90E-03 & $4.10 \mathrm{E}+01$ & $7.40 \mathrm{E}-05$ \\
\hline Am-243 & $1.20 \mathrm{E}+01$ & $2.90 \mathrm{E}+01$ & 5.50E-02 & 4.10E+01 & $7.40 \mathrm{E}-05$ \\
\hline $\mathrm{Ca}-41$ & 4.30E-03 & 8.70E-05 & $0.00 \mathrm{E}+00$ & 4.40E-03 & 7.90E-09 \\
\hline $\mathrm{Ce}-144$ & $4.70 \mathrm{E}-02$ & 1.60E-02 & $6.20 \mathrm{E}-02$ & $1.30 \mathrm{E}-01$ & 2.30E-07 \\
\hline Cl-36 & 1.00E-02 & $1.40 \mathrm{E}-03$ & 7.70E-04 & 1.20E-02 & 2.20E-08 \\
\hline $\mathrm{Cm}-243$ & $8.40 \mathrm{E}+00$ & $2.00 \mathrm{E}+01$ & $1.60 \mathrm{E}-01$ & $2.80 \mathrm{E}+01$ & $5.10 \mathrm{E}-05$ \\
\hline $\mathrm{Cm}-244$ & $6.70 \mathrm{E}+00$ & $1.60 \mathrm{E}+01$ & 5.70E-06 & $2.30 \mathrm{E}+01$ & $4.00 \mathrm{E}-05$ \\
\hline $\mathrm{Cm}-245$ & $1.30 E+01$ & $3.00 E+01$ & $7.40 \mathrm{E}-02$ & $4.20 \mathrm{E}+01$ & $7.60 \mathrm{E}-05$ \\
\hline $\mathrm{Cm}-246$ & $1.30 \mathrm{E}+01$ & $2.90 \mathrm{E}+01$ & $9.20 \mathrm{E}-06$ & $4.20 \mathrm{E}+01$ & $7.50 \mathrm{E}-05$ \\
\hline $\mathrm{Cm}-247$ & 1.20E+01 & $2.70 \mathrm{E}+01$ & $1.50 \mathrm{E}-02$ & $3.80 \mathrm{E}+01$ & $6.90 \mathrm{E}-05$ \\
\hline Co-57 & 2.60E-03 & $3.80 \mathrm{E}-04$ & $7.60 \mathrm{E}-02$ & 7.90E-02 & $1.40 \mathrm{E}-07$ \\
\hline Co-60 & $8.50 \mathrm{E}-02$ & 1.30E-02 & $4.90 \mathrm{E}+00$ & $5.00 \mathrm{E}+00$ & 8.90E-06 \\
\hline Cs-134 & $2.10 \mathrm{E}-01$ & $2.60 \mathrm{E}-03$ & $2.60 \mathrm{E}+00$ & $2.80 \mathrm{E}+00$ & 5.00E-06 \\
\hline Cs-135 & 2.40E-02 & $3.00 \mathrm{E}-04$ & $0.00 \mathrm{E}+00$ & 2.40E-02 & 4.40E-08 \\
\hline Cs-137 & $1.70 \mathrm{E}-01$ & $2.10 \mathrm{E}-03$ & $1.10 \mathrm{E}+00$ & $1.30 \mathrm{E}+00$ & 2.20E-06 \\
\hline Eu-152 & $2.10 \mathrm{E}-02$ & $1.40 \mathrm{E}-02$ & $2.20 \mathrm{E}+00$ & $2.20 \mathrm{E}+00$ & $4.00 \mathrm{E}-06$ \\
\hline Eu-154 & $3.10 \mathrm{E}-02$ & $1.80 \mathrm{E}-02$ & $2.30 \mathrm{E}+00$ & $2.40 \mathrm{E}+00$ & 4.30E-06 \\
\hline $\mathrm{Fe}-55$ & $1.80 \mathrm{E}-03$ & $1.50 \mathrm{E}-04$ & $0.00 \mathrm{E}+00$ & 2.00E-03 & 3.50E-09 \\
\hline$M n-54$ & $6.40 \mathrm{E}-03$ & $3.00 \mathrm{E}-04$ & 1.10E+00 & $1.10 \mathrm{E}+00$ & $2.00 \mathrm{E}-06$ \\
\hline $\mathrm{Na}-22$ & $3.40 \mathrm{E}-02$ & 4.40E-04 & $3.90 \mathrm{E}+00$ & $3.90 \mathrm{E}+00$ & 7.00E-06 \\
\hline $\mathrm{Nb}-94$ & $2.40 \mathrm{E}-02$ & 2.70E-02 & $.3 .10 \mathrm{E}+00$ & $3.20 \mathrm{E}+00$ & 5.70E-06 \\
\hline $\mathrm{Ni}-59$ & 7.10E-04 & $1.80 \mathrm{E}-04$ & $0.00 \mathrm{E}+00$ & 8.80E-04 & $1.60 \mathrm{E}-09$ \\
\hline Ni-63 & $1.90 \mathrm{E}-03$ & $4.10 \mathrm{E}-04$ & $0.00 \mathrm{E}+00$ & $2.40 \mathrm{E}-03$ & 4.20E-09 \\
\hline $\mathrm{Np}-237$ & $1.50 \mathrm{E}+01$ & $3.50 \mathrm{E}+01$ & 3.20E-01 & $5.00 \mathrm{E}+01$ & 9.10E-05 \\
\hline $\mathrm{Pb}-210$ & $2.40 \mathrm{E}+01$ & $1.50 \mathrm{E}+00$ & $4.70 \mathrm{E}-04$ & $2.60 \mathrm{E}+01$ & $4.60 \mathrm{E}-05$ \\
\hline Pm-147 & $3.10 \mathrm{E}-03$ & $2.20 \mathrm{E}-03$ & $9.90 \mathrm{E}-06$ & $5.40 \mathrm{E}-03$ & 9.60E-09 \\
\hline $\mathrm{Pu}-238$ & $1.10 \mathrm{E}+01$ & $2.50 \mathrm{E}+01$ & $1.30 \mathrm{E}-05$ & $3.60 \mathrm{E}+01$ & $6.50 \mathrm{E}-05$ \\
\hline Pu-239 & $1.20 \mathrm{E}+01$ & $2.80 \mathrm{E}+01$ & 7.30E-05 & $4.00 \mathrm{E}+01$ & 7.20E-05 \\
\hline Pu-240 & $1.20 \mathrm{E}+01$ & $2.80 \mathrm{E}+01$ & 1.30E-05 & $4.00 \mathrm{E}+01$ & $7.20 \mathrm{E}-05$ \\
\hline $\mathrm{Pu}-241$ & $2.30 \mathrm{E}-01$ & $5.20 \mathrm{E}-01$ & $1.40 \mathrm{E}-01$ & $8.90 \mathrm{E}-01$ & $1.60 \mathrm{E}-06$ \\
\hline $\mathrm{Pu}-242$ & $1.10 \mathrm{E}+01$ & $2.70 \mathrm{E}+01$ & $1.30 \mathrm{E}-05$ & $3.80 \mathrm{E}+01$ & $6.80 \mathrm{E}-05$ \\
\hline Ru-106 & $6.70 \mathrm{E}-02$ & 2.20E-02 & $4.20 \mathrm{E}+00$ & $4.30 \mathrm{E}+00$ & 7.80E-06 \\
\hline $\mathrm{Sb}-125$ & $8.40 \mathrm{E}-03$ & $7.00 \mathrm{E}-04$ & $6.90 \mathrm{E}-01$ & $7.00 \mathrm{E}-01$ & 1.30E-06 \\
\hline Se-79 & $2.90 \mathrm{E}-02$ & $6.40 \mathrm{E}-04$ & $0.00 \mathrm{E}+00$ & 3.00E-02 & 5.40E-08 \\
\hline Sm-151 & $1.30 \mathrm{E}-03$ & $1.90 \mathrm{E}-03$ & 5.10E-08 & $3.20 \mathrm{E}-03$ & 5.80E-09 \\
\hline Sr-90 & 5.10E-01 & 8.40E-02 & $7.60 \mathrm{E}-03$ & $6.00 \mathrm{E}-01$ & $1.10 \mathrm{E}-06$ \\
\hline Tc-99 & $4.90 \mathrm{E}-03$ & $5.40 \mathrm{E}-04$ & $2.00 \mathrm{E}-05$ & 5.50E-03 & 9.90E-09 \\
\hline Th-228 & $2.30 \mathrm{E}+00$ & $1.90 \mathrm{E}+01$ & $2.60 \mathrm{E}+00$ & $2.40 \mathrm{E}+01$ & $4.30 \mathrm{E}-05$ \\
\hline Th-229 & 1.40E+01 & $1.40 \mathrm{E}+02$ & $4.70 \mathrm{E}-01$ & $1.50 \mathrm{E}+02$ & $2.80 \mathrm{E}-04$ \\
\hline Th-230 & $1.90 \mathrm{E}+00$ & $2.10 \mathrm{E}+01$ & $2.40 \mathrm{E}-04$ & $2.30 \mathrm{E}+01$ & 4.10E-05 \\
\hline Th-232 & $9.20 \mathrm{E}+00$ & $1.10 \mathrm{E}+02$ & $8.80 \mathrm{E}-05$ & $1.20 \mathrm{E}+02$ & 2.10E-04 \\
\hline U-232 & $4.40 \mathrm{E}+00$ & $4.30 \mathrm{E}+01$ & $1.90 \mathrm{E}-04$ & $4.70 \mathrm{E}+01$ & $8.50 \mathrm{E}-05$ \\
\hline U-233 & $9.80 \mathrm{E}-01$ & $8.80 \mathrm{E}+00$ & 3.70E-04 & $9.80 \mathrm{E}+00$ & $1.80 \mathrm{E}-05$ \\
\hline U-234 & $9.60 \mathrm{E}-01$ & $8.60 \mathrm{E}+00$ & $6.80 \mathrm{E}-05$ & $9.60 \mathrm{E}+00$ & $1.70 \mathrm{E}-05$ \\
\hline U-235 & $9.00 \mathrm{E}-01$ & $8.00 \mathrm{E}+00$ & 2.10E-01 & $9.10 \mathrm{E}+00$ & $1.60 \mathrm{E}-05$ \\
\hline U-238 & $9.10 \mathrm{E}-01$ & $7.70 \mathrm{E}+00$ & $3.90 \mathrm{E}-02$ & $8.60 \mathrm{E}+00$ & $1.60 \mathrm{E}-05$ \\
\hline $\mathrm{Zn}-65$ & $3.00 \mathrm{E}-02$ & 8.20E-04 & $7.40 \mathrm{E}-01$ & 7.70E-01 & 1.40E-06 \\
\hline $\mathrm{Zr}-93$ & $5.60 \mathrm{E}-03$ & 2.10E-02 & $0.00 \mathrm{E}+00$ & $2.60 \mathrm{E}-02$ & 4.80E-08 \\
\hline
\end{tabular}

a Doses do not account for scrap dilution or radionuclide partitioning; collective doses based on $100 t$. 
TABLE D.4 Baseline Worker Doses for a 2,000-h Scrap Processor ${ }^{\text {a }}$

\begin{tabular}{|c|c|c|c|c|c|}
\hline Nuclide & $\begin{array}{l}\text { Ingestion } \\
(\mu \mathrm{Sv} / \mathrm{yr})\end{array}$ & $\begin{array}{c}\text { Inhalation } \\
(\mu \mathrm{Sv} / \mathrm{yr})\end{array}$ & $\begin{array}{r}\text { External } \\
(\mu \mathrm{Sv} / \mathrm{yr})\end{array}$ & $\begin{array}{c}\text { Total Dose } \\
(\mu \mathrm{Sv} / \mathrm{yr})\end{array}$ & $\begin{array}{r}\text { Collective Dose } \\
\text { (person-Sv/yr) }\end{array}$ \\
\hline Ac-227 & $4.70 \mathrm{E}+01$ & $4.30 \mathrm{E}+02$ & 6.10E-01 & $4.70 \mathrm{E}+02$ & $1.40 \mathrm{E}-03$ \\
\hline $\mathrm{Ag}-110 \mathrm{~m}$ & 2.30E-02 & $3.30 \mathrm{E}-03$ & $3.20 \mathrm{E}+00$ & $3.30 \mathrm{E}+00$ & $9.80 \mathrm{E}-06$ \\
\hline Am-241 & $1.20 \mathrm{E}+01$ & $2.90 \mathrm{E}+01$ & $1.50 \mathrm{E}-02$ & $4.10 \mathrm{E}+01$ & 1.20E-04 \\
\hline Am-243 & $1.20 \mathrm{E}+01$ & $2.90 \mathrm{E}+01$ & 2.90E-01 & $4.10 E+01$ & $1.20 \mathrm{E}-04$ \\
\hline $\mathrm{Ca}-41$ & 4.30E-03 & 8.70E-05 & $0.00 \mathrm{E}+00$ & $4.40 \mathrm{E}-03$ & 1.30E-08 \\
\hline $\mathrm{Ce}-144$ & $4.70 \mathrm{E}-02$ & $1.60 \mathrm{E}-02$ & 6.50E-02 & $1.30 \mathrm{E}-01$ & 3.80E-07 \\
\hline $\mathrm{Cl}-36$ & $1.00 \mathrm{E}-02$ & $1.40 \mathrm{E}-03$ & 7.30E-04 & $1.20 \mathrm{E}-02$ & 3.70E-08 \\
\hline $\mathrm{Cm}-243$ & $8.40 \mathrm{E}+00$ & $2.00 \mathrm{E}+01$ & $1.80 \mathrm{E}-01$ & $2.80 \mathrm{E}+01$ & $8.50 \mathrm{E}-05$ \\
\hline Cm-244 & $6.70 \mathrm{E}+00$ & $1.60 \mathrm{E}+01$ & $4.50 \mathrm{E}-05$ & $2.20 \mathrm{E}+01$ & 6.70E-05 \\
\hline $\mathrm{Cm}-245$ & $1.30 \mathrm{E}+01$ & $3.00 \mathrm{E}+01$ & $1.10 \mathrm{E}-01$ & $4.20 \mathrm{E}+01$ & $1.30 \mathrm{E}-04$ \\
\hline $\mathrm{Cm}-246$ & $1.30 \mathrm{E}+01$ & $2.90 \mathrm{E}+01$ & $4.40 \mathrm{E}-05$ & $4.20 \mathrm{E}+01$ & $1.30 \mathrm{E}-04$ \\
\hline $\mathrm{Cm}-247$ & $1.20 \mathrm{E}+01$ & $2.70 \mathrm{E}+01$ & $5.70 \mathrm{E}-01$ & $3.90 \mathrm{E}+01$ & $1.20 \mathrm{E}-04$ \\
\hline Co-57 & $2.70 \mathrm{E}-03$ & $3.90 \mathrm{E}-04$ & $1.10 \mathrm{E}-01$ & 1.10E-01 & 3.40E-07 \\
\hline Co.60 & 8.50E-02 & $1.30 \mathrm{E}-02$ & $4.50 \mathrm{E}+00$ & $4.60 \mathrm{E}+00$ & $1.40 \mathrm{E}-05$ \\
\hline Cs-134 & 2.10E-01 & $2.50 \mathrm{E}-03$ & $2.40 \mathrm{E}+00$ & $2.60 \mathrm{E}+00$ & $7.90 \mathrm{E}-06$ \\
\hline Cs-135 & $2.40 \mathrm{E}-02$ & $3.00 \mathrm{E}-04$ & $0.00 \mathrm{E}+00$ & $2.40 \mathrm{E}-02$ & 7.30E-08 \\
\hline Cs-137 & $1.70 \mathrm{E}-01$ & $2.00 \mathrm{E}-03$ & $1.00 \mathrm{E}+00$ & $1.20 \mathrm{E}+00$ & $3.50 \mathrm{E}-06$ \\
\hline Eu-152 & 2.10E-02 & $1.40 \mathrm{E}-02$ & $2.00 \mathrm{E}+00$ & $2.10 \mathrm{E}+00$ & $6.20 \mathrm{E}-06$ \\
\hline Eu-154 & $3.10 \mathrm{E}-02$ & $1.80 \mathrm{E}-02$ & $2.20 \mathrm{E}+00$ & $2.30 \mathrm{E}+00$ & $6.80 \mathrm{E}-06$ \\
\hline $\mathrm{Fe}-55$ & $1.80 \mathrm{E}-03$ & $1.50 \mathrm{E}-04$ & $0.00 \mathrm{E}+00$ & 2.00E-03 & $5.90 \mathrm{E}-09$ \\
\hline$M n-54$ & $6.40 \mathrm{E}-03$ & $3.00 \mathrm{E}-04$ & $1.10 \mathrm{E}+00$ & $1.10 \mathrm{E}+00$ & $3.20 \mathrm{E}-06$ \\
\hline $\mathrm{Na}-22$ & $3.40 \mathrm{E}-02$ & 4.40E-04 & $3.60 \mathrm{E}+00$ & $3.60 \mathrm{E}+00$ & $1.10 \mathrm{E}-05$ \\
\hline $\mathrm{Nb}-94$ & 2.40E-02 & 2.70E-02 & $2.90 \mathrm{E}+00$ & $3.00 \mathrm{E}+00$ & 8.90E-06 \\
\hline $\mathrm{Ni}-59$ & 7.10E-04 & $1.80 \mathrm{E}-04$ & $0.00 \mathrm{E}+00$ & $8.80 \mathrm{E}-04$ & 2.70E-09 \\
\hline $\mathrm{Ni}-63$ & $1.90 \mathrm{E}-03$ & $4.10 \mathrm{E}-04$ & $0.00 \mathrm{E}+00$ & 2.40E-03 & 7.10E-09 \\
\hline $\mathrm{Np}-237$ & $1.50 \mathrm{E}+01$ & $3.50 \mathrm{E}+01$ & $3.40 \mathrm{E}-01$ & $5.00 \mathrm{E}+01$ & $1.50 \mathrm{E}-04$ \\
\hline $\mathrm{Pb}-210$ & 1.80E+01 & 8.70E-01 & 8.30E-04 & $1.90 \mathrm{E}+01$ & 5.60E-05 \\
\hline Pm-147 & $3.10 \mathrm{E}-03$ & 2.20E-03 & $1.40 \mathrm{E}-05$ & 5.40E-03 & 1.60E-08 \\
\hline $\mathrm{Pu}-238$ & $1.10 \mathrm{E}+01$ & $2.50 \mathrm{E}+01$ & $5.40 \mathrm{E}-05$ & $3.60 \mathrm{E}+01$ & 1.10E-04 \\
\hline Pu-239 & $1.20 \mathrm{E}+01$ & $2.80 \mathrm{E}+01$ & $9.80 \mathrm{E}-05$ & $4.00 \mathrm{E}+01$ & $1.20 \mathrm{E}-04$ \\
\hline $\mathrm{Pu}-240$ & $1.20 \mathrm{E}+01$ & $2.80 \mathrm{E}+01$ & $5.20 \mathrm{E}-05$ & $4.00 E+01$ & 1.20E-04 \\
\hline Pu-241 & $2.30 \mathrm{E}-01$ & 5.20E-01 & $6.00 \mathrm{E}-06$ & $7.50 \mathrm{E}-01$ & 2.20E-06 \\
\hline $\mathrm{Pu}-242$ & $1.10 \mathrm{E}+01$ & $2.70 \mathrm{E}+01$ & $4.60 \mathrm{E}-05$ & $3.80 \mathrm{E}+01$ & 1.10E-04 \\
\hline Ru-106 & 6.70E-02 & 2.20E-02 & $2.80 \mathrm{E}-01$ & 3.70E-01 & 1.10E-06 \\
\hline $\mathrm{Sb}-125$ & $8.40 \mathrm{E}-03$ & $7.00 \mathrm{E}-04$ & $6.60 \mathrm{E}-01$ & 6.60E-01 & 2.00E-06 \\
\hline Se-79 & 2.90E-02 & $6.40 \mathrm{E}-04$ & $0.00 \mathrm{E}+00$ & 3.00E-02 & 9.00E-08 \\
\hline Sm-151 & $1.30 \mathrm{E}-03$ & $1.90 \mathrm{E}-03$ & $3.60 \mathrm{E}-07$ & $3.20 \mathrm{E}-03$ & $9.70 \mathrm{E}-09$ \\
\hline Sr-90 & $4.80 \mathrm{E}-01$ & 8.30E-02 & $7.00 \mathrm{E}-03$ & 5.70E-01 & 1.70E-06 \\
\hline Tc-99 & 4.90E-03 & 5.40E-04 & $4.20 \mathrm{E}-05$ & $5.50 \mathrm{E}-03$ & 1.70E-08 \\
\hline Th-228 & $1.10 \mathrm{E}+00$ & $1.90 \mathrm{E}+01$ & $2.50 \mathrm{E}+00$ & $2.20 \mathrm{E}+01$ & $6.70 \mathrm{E}-05$ \\
\hline Th-229 & $1.20 \mathrm{E}+01$ & $1.40 \mathrm{E}+02$ & $4.90 \mathrm{E}-01$ & $1.50 \mathrm{E}+02$ & $4.50 \mathrm{E}-04$ \\
\hline Th-230 & $1.90 \mathrm{E}+00$ & $2.10 \mathrm{E}+01$ & $4.00 \mathrm{E}-04$ & $2.30 \mathrm{E}+01$ & $6.90 \mathrm{E}-05$ \\
\hline Th-232 & $9.20 \mathrm{E}+00$ & $1.10 \mathrm{E}+02$ & 1.70E-04 & $1.20 \mathrm{E}+02$ & 3.50E-04 \\
\hline U-232 & $4.40 \mathrm{E}+00$ & $4.30 E+01$ & 3.00E-04 & $4.70 \mathrm{E}+01$ & 1.40E-04 \\
\hline U-233 & $9.80 \mathrm{E}-01$ & $8.80 \mathrm{E}+00$ & $4.60 \mathrm{E}-04$ & $9.80 \mathrm{E}+00$ & 2.90E-05 \\
\hline U-234 & $9.60 \mathrm{E}-01$ & $8.60 \mathrm{E}+00$ & 1.30E-04 & $9.50 \mathrm{E}+00$ & 2.90E-05 \\
\hline U-235 & $9.00 \mathrm{E}-01$ & $8.00 \mathrm{E}+00$ & $2.40 \mathrm{E}-01$ & $9.10 \mathrm{E}+00$ & 2.70E-05 \\
\hline U-238 & $8.60 \mathrm{E}-01$ & $7.70 \mathrm{E}+00$ & 4.00E-02 & $8.60 \mathrm{E}+00$ & 2.60E-05 \\
\hline $\mathrm{Zn}-65$ & $3.00 \mathrm{E}-02$ & 8.20E-04 & $6.90 \mathrm{E}-01$ & $7.20 \mathrm{E}-01$ & 2.10E-06 \\
\hline $\mathrm{Zr}-93$ & $5.60 \mathrm{E}-03$ & 2.10E-02 & $0.00 \mathrm{E}+00$ & 2.60E-02 & $7.90 \mathrm{E}-08$ \\
\hline
\end{tabular}

a Doses do not account for scrap dilution or radionuclide partitioning; collective doses based on $100 \mathrm{t}$. 
TABLE D.5 Baseline Worker Doses for a 2,000-h Smelting Worker ${ }^{\text {a }}$

\begin{tabular}{|c|c|c|c|c|c|}
\hline Nuclide & $\begin{array}{l}\text { Ingestion } \\
(\mu \mathrm{Sv} / \mathrm{yr})\end{array}$ & $\begin{array}{c}\text { Inhalation } \\
\text { ( } \mu \mathrm{Sv} / \mathrm{yr})\end{array}$ & $\begin{array}{r}\text { External } \\
(\mu \mathrm{Sv} / \mathrm{yr})\end{array}$ & $\begin{array}{c}\text { Total Dose } \\
(\mu \mathrm{Sv} / \mathrm{yr})\end{array}$ & $\begin{array}{r}\text { Collective Dose } \\
\text { (person-Sv/yr) }\end{array}$ \\
\hline Ac-227 & $4.70 \mathrm{E}+01$ & $4.30 \mathrm{E}+02$ & $8.00 \mathrm{E}-01$ & $4.70 \mathrm{E}+02$ & 4.70E-03 \\
\hline $\mathrm{Ag}-110 \mathrm{~m}$ & 2.30E-02 & $3.30 \mathrm{E}-03$ & $4.40 \mathrm{E}+00$ & $4.40 \mathrm{E}+00$ & 4.40E-05 \\
\hline Am-241 & $1.20 \mathrm{E}+01$ & $2.90 \mathrm{E}+01$ & 1.70E-02 & $4.10 \mathrm{E}+01$ & 4.10E-04 \\
\hline Am-243 & $1.20 \mathrm{E}+01$ & $2.90 \mathrm{E}+01$ & $3.70 \mathrm{E}-01$ & $4.10 \mathrm{E}+01$ & $4.10 \mathrm{E}-04$ \\
\hline $\mathrm{Ca}-41$ & - 4.30E-03. & 8.70E-05 & $0.00 \mathrm{E}+00$ & 4.40E-03 & 4.40E-08 \\
\hline $\mathrm{Ce}-144$ & $4.70 \mathrm{E}-02$ & $1.60 \mathrm{E}-02$ & $8.70 \mathrm{E}-02$ & 1.50E-01 & 1.50E-06 \\
\hline Cl-36 & 1.00E-02 & $1.40 \mathrm{E}-03$ & $9.80 \mathrm{E}-04$ & $1.30 \mathrm{E}-02$ & 1.30E-07 \\
\hline $\mathrm{Cm}-243$ & $8.40 \mathrm{E}+00$ & $2.00 \mathrm{E} \div 01$ & 2.40E-01 & $2.80 \mathrm{E}+01$ & 2.80E-04 \\
\hline $\mathrm{Cm}-244$ & $6.70 \mathrm{E}+00$ & $1.60 \mathrm{E}+01$ & 2.80E-05 & $2.20 \mathrm{E}+01$ & 2.20E-04 \\
\hline $\mathrm{Cm}-245$ & $1.30 \mathrm{E}+01$ & $3.00 \mathrm{E}+01$ & $1.40 \mathrm{E}-01$ & $4.20 \mathrm{E}+01$ & $4.20 \mathrm{E}-04$ \\
\hline $\mathrm{Cm}-246$ & $1.30 \mathrm{E}+01$ & $2.90 \mathrm{E}+01$ & $1.90 \mathrm{E}-05$ & $4.20 \mathrm{E}+01$ & $4.20 \mathrm{E}-04$ \\
\hline $\mathrm{Cm}-247$ & $1.20 \mathrm{E}+01$ & $2.70 \mathrm{E}+01$ & $7.60 \mathrm{E}-01$ & $3.90 \mathrm{E}+01$ & $3.90 \mathrm{E}-04$ \\
\hline Co-57 & $2.70 \mathrm{E}-03$ & 3.90E-04 & $1.40 \mathrm{E}-01$ & $1.40 \mathrm{E}-01$ & $1.40 \mathrm{E}-06$ \\
\hline Co-60 & 8.50E-02 & $1.30 \mathrm{E}-02$ & $6.20 \mathrm{E}+00$ & $6.30 \mathrm{E}+00$ & $6.30 \mathrm{E}-05$ \\
\hline Cs-134 & 2.10E-01 & $2.50 \mathrm{E}-03$ & $3.30 \mathrm{E}+00$ & $3.50 \mathrm{E}+00$ & 3.50E-05 \\
\hline Cs-135 & 2.40E-02 & 3.00E-04 & $0.00 \mathrm{E}+00$ & 2.40E-02 & $2.40 \mathrm{E}-07$ \\
\hline Cs-137 & $1.70 \mathrm{E}-01$ & $2.00 \mathrm{E}-03$ & $1.40 \mathrm{E}+00$ & $1.50 \mathrm{E}+00$ & 1.50E-05 \\
\hline Eu-152 & 2.10E-02 & $1.40 \mathrm{E}-02$ & $2.80 \mathrm{E}+00$ & $2.80 \mathrm{E}+00$ & 2.80E-05 \\
\hline Eu-154 & 3.10E-02 & $1.80 \mathrm{E}-02$ & $3.00 \mathrm{E}+00$ & $3.00 \mathrm{E}+00$ & 3.00E-05 \\
\hline $\mathrm{Fe}-55$ & $1.80 \mathrm{E}-03$ & $1.50 \mathrm{E}-04$ & $0.00 \mathrm{E}+00$ & $2.00 \mathrm{E}-03$ & $2.00 \mathrm{E}-08$ \\
\hline $\mathrm{Mn}-54$ & 6.40E-03 & $3.00 \mathrm{E}-04$ & $1.40 \mathrm{E}+00$ & $1.40 \mathrm{E}+00$ & $1.40 \mathrm{E}-05$ \\
\hline $\mathrm{Na}-22$ & 3.40E-02 & $4.40 \mathrm{E}-04$ & $4.90 \mathrm{E}+00$ & $4.90 \mathrm{E}+00$ & 4.90E-05 \\
\hline $\mathrm{Nb}-94$ & $2.40 \mathrm{E}-02$ & 2.70E-02 & $3.90 \mathrm{E}+00$ & $4.00 \mathrm{E}+00$ & $4.00 \mathrm{E}-05$ \\
\hline $\mathrm{Ni}-59$ & 7.10E-04 & $1.80 \mathrm{E}-04$ & $0.00 \mathrm{E}+00$ & 8.80E-04 & 8.80E-09 \\
\hline $\mathrm{Ni}-63$ & $1.90 \mathrm{E}-03$ & $4.10 \mathrm{E}-04$ & $0.00 \mathrm{E}+00$ & 2.40E-03 & 2.40E-08 \\
\hline$N p-237$ & $1.50 \mathrm{E}+01$ & $3.50 \mathrm{E}+01$ & $4.50 \mathrm{E}-01$ & $5.00 \mathrm{E}+01$ & 5.00E-04 \\
\hline $\mathrm{Pb}-210$ & $1.80 \mathrm{E}+01$ & 8.70E-01 & $9.20 \mathrm{E}-04$ & $1.90 \mathrm{E}+01$ & $1.90 \mathrm{E}-04$ \\
\hline $\mathrm{Pm}-147$ & $3.10 \mathrm{E}-03$ & 2.20E-03 & 1:80E-05 & 5.40E-03 & 5.40E-08 \\
\hline Pu-238 & $1.10 \mathrm{E}+01$ & $2.50 \mathrm{E}+01$ & $4.00 \mathrm{E}-05$ & $3.60 \mathrm{E}+01$ & 3.60E-04 \\
\hline Pu-239 & $1.20 \mathrm{E}+01$ & $2.80 \mathrm{E}+01$ & $1.20 \mathrm{E}-04$ & $4.00 \mathrm{E}+01$ & $4.00 \mathrm{E}-04$ \\
\hline $\mathrm{Pu}-240$ & $1.20 \mathrm{E}+01$ & $2.80 \mathrm{E}+01$ & $4.00 \mathrm{E}-05$ & $4.00 \mathrm{E}+01$ & 4.00E-04 \\
\hline $\mathrm{Pu}-241$ & 2.30E-01 & $5.20 \mathrm{E}-01$ & $7.60 \mathrm{E}-06$ & $7.50 \mathrm{E}-01$ & 7.50E-06 \\
\hline $\mathrm{Pu}-242$ & $1.10 \mathrm{E}+01$ & $2.70 \mathrm{E}+01$ & $3.60 \mathrm{E}-05$ & $3.80 \mathrm{E}+01$ & 3.80E-04 \\
\hline Ru-106 & $6.70 \mathrm{E}-02$ & $2.20 \mathrm{E}-02$ & $3.80 \mathrm{E}-01$ & 4.70E-01 & 4.70E-06 \\
\hline $\mathrm{Sb}-125$ & 8.40E-03 & 7.00E-04 & 8.80E-01 & $8.90 \mathrm{E}-01$ & 8.90E-06 \\
\hline Se-79 & $2.90 \mathrm{E}-02$ & 6.40E-04 & $0.00 \mathrm{E}+00$ & $3.00 \mathrm{E}-02$ & 3.00E-07 \\
\hline Sm-151 & $1.30 \mathrm{E}-03$ & 1.90E-03 & 2.50E-07 & 3.20E-03 & 3.20E-08 \\
\hline Sr-90 & 4.80E-01 & 8.30E-02 & $9.50 \mathrm{E}-03$ & $5.70 \mathrm{E}-01$ & 5.70E-06 \\
\hline Tc-99 & $4.90 \mathrm{E}-03$ & 5.40E-04 & $5.10 \mathrm{E}-05$ & $5.50 \mathrm{E}-03$ & $5.50 \mathrm{E}-08$ \\
\hline Th-228 & $1.10 \mathrm{E}+00$ & $1.90 \mathrm{E}+01$ & $3.50 \mathrm{E}+00$ & $2.30 \mathrm{E}+01$ & 2.30E-04 \\
\hline Th-229 & $1.20 \mathrm{E}+01$ & $1.40 \mathrm{E} \div 02$ & $6.50 \mathrm{E}-01$ & $1.50 \mathrm{E}+02$ & $1.50 \mathrm{E}-03$ \\
\hline Th-230 & $1.90 \mathrm{E}+00$ & $2.10 \mathrm{E}+01$ & $4.90 \mathrm{E}-04$ & $2.30 \mathrm{E}+01$ & 2.30E-04 \\
\hline Th-232 & $9.20 \mathrm{E}+00$ & $1.10 \mathrm{E}+02$ & 2.10E-04 & $1.20 \mathrm{E}+02$ & $1.20 \mathrm{E}-03$ \\
\hline U-232 & $4.40 \mathrm{E}+00$ & $4.30 \mathrm{E}+01$ & $3.60 \mathrm{E}-04$ & $4.70 \mathrm{E}+01$ & 4.70E-04 \\
\hline U-233 & $9.80 \mathrm{E}-01$ & $8.80 \mathrm{E}+00$ & 5.70E-04 & $9.80 \mathrm{E}+00$ & 9.80E-05 \\
\hline U-234 & $9.60 \mathrm{E}-01$ & $8.60 \mathrm{E}+00$ & $1.60 \mathrm{E}-04$ & $9.50 \mathrm{E}+00$ & $9.50 \mathrm{E}-05$ \\
\hline U-235 & $9.00 \mathrm{E}-01$ & $8.00 \mathrm{E}+00$ & 3.10E-01 & $9.20 \mathrm{E}+00$ & $9.20 \mathrm{E}-05$ \\
\hline U-238 & $8.60 \mathrm{E}-01$ & $7.70 \mathrm{E}+00$ & $5.30 \mathrm{E}-02$ & $8.60 \mathrm{E}+00$ & $8.60 \mathrm{E}-05$ \\
\hline $\mathrm{Zn}-65$ & 3.00E-02 & 8.20E-04 & $9.30 \mathrm{E}-01$ & 9.70E-01 & 9.70E-06 \\
\hline Zr-93 & $5.60 \mathrm{E}-03$ & $2.10 \mathrm{E}-02$ & $0.00 \mathrm{E}+00$ & 2.60E-02 & $2.60 \mathrm{E}-07$ \\
\hline
\end{tabular}

a Doses do not account for scrap dilution or radionuclide partitioning; collective doses based on $100 \mathrm{t}$. 
TABLE D.6 Baseline Worker Doses for a 2,000-h Smelting Loader ${ }^{\mathrm{a}}$

\begin{tabular}{|c|c|c|c|c|c|}
\hline Nuclide & $\begin{array}{r}\text { Ingestion } \\
(\mu \mathrm{Sv} / \mathrm{yr})\end{array}$ & $\begin{array}{c}\text { Inhalation } \\
(\mu \mathrm{Sv} / \mathrm{yr})\end{array}$ & $\begin{array}{r}\text { External } \\
(\mu \mathrm{Sv} / \mathrm{yr}) \\
\end{array}$ & $\begin{array}{c}\text { Total Dose } \\
(\mu \mathrm{Sv} / \mathrm{yr})\end{array}$ & $\begin{array}{r}\text { Collective Dose } \\
\text { (person-Sv/yr) }\end{array}$ \\
\hline Ac-227 & $4.70 \mathrm{E}+01$ & $4.30 \mathrm{E}+03$ & $3.10 \mathrm{E}+00$ & $4.30 \mathrm{E}+03$ & $2.20 \mathrm{E}-02$ \\
\hline $\mathrm{Ag}-110 \mathrm{~m}$ & 2.30E-02 & 3.30E-02 & $1.60 \mathrm{E}+01$ & $1.70 \mathrm{E}+01$ & $8.30 \mathrm{E}-05$ \\
\hline Am-241 & $1.20 \mathrm{E}+01$ & $2.90 \mathrm{E}+02$ & 7.10E-02 & $3.00 \mathrm{E}+02$ & $1.50 \mathrm{E}-03$ \\
\hline Am-243 & $1.20 \mathrm{E}+01$ & $2.90 \mathrm{E}+02$ & $1.40 \mathrm{E}+00$ & $3.00 \mathrm{E}+02$ & $1.50 \mathrm{E}-03$ \\
\hline $\mathrm{Ca}-41$ & $4.30 \mathrm{E}-03$ & 8.70E-04 & $0.00 \mathrm{E}+00$ & $5.20 \mathrm{E}-03$ & 2.60E-08 \\
\hline $\mathrm{Ce}-144$ & 4.70E-02 & $1.60 \mathrm{E}-01$ & $3.30 \mathrm{E}-01$ & 5.40E-01 & 2.70E-06 \\
\hline $\mathrm{Cl}-36$ & 1.00E-02 & $1.40 \mathrm{E}-02$ & 3.70E-03 & 2.80E-02 & $1.40 \mathrm{E}-07$ \\
\hline $\mathrm{Cm}-243$ & $8.40 \mathrm{E}+00$ & $2.00 \mathrm{E}+02$ & $9.20 \mathrm{E}-01$ & $2.10 \mathrm{E}+02$ & $1.00 \mathrm{E}-03$ \\
\hline $\mathrm{Cm}-244$ & $6.70 \mathrm{E}+00$ & $1.60 \mathrm{E}+02$ & 1.70E-04 & $1.60 \mathrm{E}+02$ & 8.20E-04 \\
\hline $\mathrm{Cm}-245$ & $1.30 \mathrm{E}+01$ & $3.00 \mathrm{E}+02$ & $5.50 \mathrm{E}-01$ & $3.10 \mathrm{E}+02$ & $1.50 \mathrm{E}-03$ \\
\hline $\mathrm{Cm}-246$ & $1.30 \mathrm{E}+01$ & $2.90 \mathrm{E}+02$ & $1.50 \mathrm{E}-04$ & $3.10 \mathrm{E}+02$ & $1.50 \mathrm{E}-03$ \\
\hline $\mathrm{Cm}-247$ & $1.20 \mathrm{E}+01$ & $2.70 \mathrm{E}+02$ & $2.90 \mathrm{E}+00$ & $2.80 \mathrm{E}+02$ & $1.40 \mathrm{E}-03$ \\
\hline Co-57 & 2.70E-03 & 3.90E-03 & $5.40 \mathrm{E}-01$ & $5.50 \mathrm{E}-01$ & $2.70 \mathrm{E}-06$ \\
\hline Co-60 & 8.50E-02 & $1.30 \mathrm{E}-01$ & $2.30 \mathrm{E}+01$ & $2.30 \mathrm{E}+01$ & 1.20E-04 \\
\hline Cs-134 & 2.10E-01 & $2.50 \mathrm{E}-02$ & $1.20 \mathrm{E}+01$ & $1.30 \mathrm{E}+01$ & $6.30 \mathrm{E}-05$ \\
\hline Cs-135 & $2.40 \mathrm{E}-02$ & $3.00 \mathrm{E}-03$ & $0.00 \mathrm{E}+00$ & 2.70E-02 & 1.30E-07 \\
\hline Cs-137 & $1.70 \mathrm{E}-01$ & 2.00E-02 & $5.10 \mathrm{E}+00$ & $5.30 \mathrm{E}+00$ & 2.70E-05 \\
\hline Eu-152 & $2.10 \mathrm{E}-02$ & $1.40 \mathrm{E}-01$ & $1.00 \mathrm{E}+01$ & $1.10 \mathrm{E}+01$ & 5.30E-05 \\
\hline Eu-154 & 3.10E-02 & $1.80 \mathrm{E}-01$ & $1.10 \mathrm{E}+01$ & $1.10 \mathrm{E}+01$ & $5.70 \mathrm{E}-05$ \\
\hline $\mathrm{Fe}-55$ & $1.80 \mathrm{E}-03$ & $1.50 \mathrm{E}-03$ & $0.00 \mathrm{E}+00$ & $3.30 \mathrm{E}-03$ & $1.70 \mathrm{E}-08$ \\
\hline $\mathrm{Mn}-54$ & $6.40 \mathrm{E}-03$ & $3.00 \mathrm{E}-03$ & $5.40 \mathrm{E}+00$ & $5.40 \mathrm{E}+00$ & 2.70E-05 \\
\hline $\mathrm{Na}-22$ & $3.40 \mathrm{E}-02$ & $4.40 \mathrm{E}-03$ & $1.80 \mathrm{E}+01$ & $1.80 \mathrm{E}+01$ & $9.20 \mathrm{E}-05$ \\
\hline $\mathrm{Nb}-94$ & $2.40 \mathrm{E}-02$ & 2.70E-01 & $1.50 \mathrm{E}+01$ & $1.50 \mathrm{E}+01$ & 7.50E-05 \\
\hline $\mathrm{Ni}-59$ & $7.10 \mathrm{E}-04$ & $1.80 \mathrm{E}-03$ & $0.00 \mathrm{E}+00$ & $2.50 \mathrm{E}-03$ & $1.20 \mathrm{E}-08$ \\
\hline $\mathrm{Ni}-63$ & $1.90 \mathrm{E}-03$ & 4.10E-03 & $0.00 \mathrm{E}+00$ & $6.00 \mathrm{E}-03$ & 3.00E-08 \\
\hline Np-237 & $1.50 \mathrm{E}+01$ & $3.50 \mathrm{E}+02$ & $1.70 \mathrm{E}+00$ & $3.70 \mathrm{E}+02$ & $1.80 \mathrm{E}-03$ \\
\hline $\mathrm{Pb}-210$ & $1.80 \mathrm{E}+01$ & $8.70 \mathrm{E}+00$ & $3.90 \mathrm{E}-03$ & $2.70 \mathrm{E}+01$ & 1.30E-04 \\
\hline Pm-147 & $3.10 \mathrm{E}-03$ & 2.20E-02 & 7.10E-05 & $2.60 \mathrm{E}-02$ & 1.30E-07 \\
\hline $\mathrm{Pu}-238$ & $1.10 \mathrm{E}+01$ & $2.50 \mathrm{E}+02$ & $2.10 \mathrm{E}-04$ & $2.60 \mathrm{E}+02$ & $1.30 \mathrm{E}-03$ \\
\hline $\mathrm{Pu}-239$ & $1.20 \mathrm{E}+01$ & $2.80 \mathrm{E}+02$ & 4.80E-04 & $2.90 \mathrm{E}+02$ & $1.50 \mathrm{E}-03$ \\
\hline $\mathrm{Pu}-240$ & $1.20 \mathrm{E}+01$ & $2.80 \mathrm{E}+02$ & 2.10E-04 & $2.90 \mathrm{E}+02$ & $1.50 \mathrm{E}-03$ \\
\hline $\mathrm{Pu}-241$ & 2.30E-01 & $5.20 \mathrm{E}+00$ & $3.00 \mathrm{E}-05$ & $5.40 \mathrm{E}+00$ & 2.70E-05 \\
\hline $\mathrm{Pu}-242$ & $1.10 \mathrm{E}+01$ & $2.70 \mathrm{E}+02$ & 1.90E-04 & $2.80 \mathrm{E}+02$ & 1.40E-03 \\
\hline Ru-106 & $6.70 \mathrm{E}-02$ & $2.20 \mathrm{E}-01$ & $1.40 \mathrm{E}+00$ & $1.70 \mathrm{E}+00$ & 8.60E-06 \\
\hline Sb-125 & $8.40 \mathrm{E}-03$ & $7.00 \mathrm{E}-03$ & $3.30 \mathrm{E}+00$ & $3.30 \mathrm{E}+00$ & $1.70 \mathrm{E}-05$ \\
\hline Se-79 & 2.90E-02 & $6.40 \mathrm{E}-03$ & $0.00 \mathrm{E}+00$ & 3.60E-02 & 1.80E-07 \\
\hline Sm-151 & 1.30E-03 & $1.90 \mathrm{E}-02$ & 1.50E-06 & 2.10E-02 & 1.00E-07 \\
\hline Sr-90 & $4.80 \mathrm{E}-01$ & 8.30E-01 & $3.60 \mathrm{E}-02$ & $1.30 \mathrm{E}+00$ & 6.70E-06 \\
\hline Tc-99 & $4.90 \mathrm{E}-03$ & $5.40 \mathrm{E}-03$ & 2.10E-04 & 1.10E-02 & 5.30E-08 \\
\hline Th-228 & $1.10 \mathrm{E}+00$ & $1.90 \mathrm{E}+02$ & $1.30 \mathrm{E}+01$ & $2.00 \mathrm{E}+02$ & $1.00 \mathrm{E}-03$ \\
\hline Th-229 & $1.20 \mathrm{E}+01$ & $1.40 \mathrm{E}+03$ & $2.50 \mathrm{E}+00$ & $1.40 \mathrm{E}+03$ & 7.00E-03 \\
\hline Th-230 & $1.90 \mathrm{E}+00$ & $2.10 \mathrm{E}+02$ & $1.90 \mathrm{E}-03$ & $2.10 \mathrm{E}+02$ & 1.10E-03 \\
\hline Th-232 & $9.20 \mathrm{E}+00$ & $1.10 \mathrm{E}+03$ & $8.40 \mathrm{E}-04$ & $1.10 \mathrm{E}+03$ & $5.40 \mathrm{E}-03$ \\
\hline U-232 & $4.40 \mathrm{E}+00$ & $4.30 \mathrm{E}+02$ & $1.40 \mathrm{E}-03$ & $4.30 \mathrm{E}+02$ & 2.10E-03 \\
\hline U-233 & $9.80 \mathrm{E}-01$ & $8.80 \mathrm{E}+01$ & $2.30 \mathrm{E}-03$ & $8.90 \mathrm{E}+01$ & $4.40 \mathrm{E}-04$ \\
\hline U-234 & $9.60 \mathrm{E}-01$ & $8.60 \mathrm{E}+01$ & $6.40 \mathrm{E}-04$ & $8.70 \mathrm{E}+01$ & $4.30 \mathrm{E}-04$ \\
\hline U-235 & $9.00 \mathrm{E}-01$ & $8.00 \mathrm{E}+01$ & $1.20 \mathrm{E}+00$ & $8.20 \mathrm{E}+01$ & $4.10 \mathrm{E}-04$ \\
\hline U-238 & 8.60E-01 & $7.70 \mathrm{E}+01$ & 2.00E-01 & $7.80 \mathrm{E}+01$ & 3.90E-04 \\
\hline $\mathrm{Zn}-65$ & $3.00 \mathrm{E}-02$ & 8.20E-03 & $3.50 \mathrm{E}+00$ & $3.50 \mathrm{E}+00$ & $1.80 \mathrm{E}-05$ \\
\hline Zr-93 & $5.60 \mathrm{E}-03$ & $2.10 \mathrm{E}-01$ & $0.00 \mathrm{E}+00$ & 2.10E-01 & 1.10E-06 \\
\hline
\end{tabular}

a Doses do not account for scrap dilution or radionuclide partitioning; collective doses based on $100 \mathrm{t}$. 
TABLE D.7 Baseline Worker Doses for a 2,000-h Smelting Operator ${ }^{a}$

\begin{tabular}{|c|c|c|c|c|c|}
\hline Nuclide & $\begin{array}{r}\text { Ingestion } \\
(\mu \mathrm{Sv} / \mathrm{yr})\end{array}$ & $\begin{array}{c}\text { Inhalation } \\
(\mu \mathrm{Sv} / \mathrm{yr})\end{array}$ & $\begin{array}{l}\text { External } \\
(\mu \mathrm{Sv} / \mathrm{yr})\end{array}$ & $\begin{array}{l}\text { Total Dose } \\
(\mu \mathrm{Sv} / \mathrm{yr})\end{array}$ & $\begin{array}{l}\text { Collective Dose } \\
\text { (person-Sv/yr) }\end{array}$ \\
\hline Ac-227 & $4.70 \mathrm{E}+01$ & $4.30 \mathrm{E}+03$ & 2.00E-02 & $4.30 \mathrm{E}+03$ & $1.30 \mathrm{E}-02$ \\
\hline $\mathrm{Ag}-110 \mathrm{~m}$ & $2.30 \mathrm{E}-02$ & $3.30 \mathrm{E}-02$ & $9.20 \mathrm{E}-01$ & $9.70 \mathrm{E}-0 \mathrm{I}$ & 2.90E-06 \\
\hline Am-241 & $1.20 \mathrm{E}+01$ & $2.90 \mathrm{E}+02$ & 1.10E-10 & $3.00 \mathrm{E}+02$ & $9.00 \mathrm{E}-04$ \\
\hline Am-243 & $1.20 \mathrm{E}+01$ & $2.90 \mathrm{E}+02$ & $1.20 \mathrm{E}-03$ & $3.00 \mathrm{E}+02$ & 8.90E-04 \\
\hline $\mathrm{Ca}-41$ & $4.30 \mathrm{E}-03$ & $8.70 \mathrm{E}-04$ & $0.00 \mathrm{E}+00$ & $5.20 \mathrm{E}-03$ & $1.60 \mathrm{E}-08$ \\
\hline Ce-144 & $4.70 \mathrm{E}-02$ & $1.60 \mathrm{E}-01$ & 3.30E-02 & $2.40 \mathrm{E}-01$ & 7.20 E-07 \\
\hline Cl-36 & $1.00 \mathrm{E}-02$ & $1.40 \mathrm{E}-02$ & $5.30 \mathrm{E}-05$ & $2.50 \mathrm{E}-02$ & 7.40E-08 \\
\hline $\mathrm{Cm}-243$ & $8.40 \mathrm{E}+00$ & $2.00 \mathrm{E}+02$ & 8.50E-04 & $2.10 \mathrm{E}+02$ & $6.20 \mathrm{E}-04$ \\
\hline $\mathrm{Cm}-244$ & $6.70 \mathrm{E}+00$ & $1.60 \mathrm{E}+02$ & $3.10 \mathrm{E}-14$ & $1.60 \mathrm{E}+02$ & $4.90 \mathrm{E}-04$ \\
\hline $\mathrm{Cm}-245$ & $1.30 \mathrm{E}+01$ & $3.00 \mathrm{E}+02$ & $3.00 \mathrm{E}-05$ & $3.10 \mathrm{E}+02$ & $9.20 \mathrm{E}-04$ \\
\hline $\mathrm{Cm}-246$ & $1.30 \mathrm{E}+01$ & $2.90 \mathrm{E}+02$ & $1.80 \mathrm{E}-19$ & $3.10 \mathrm{E}+02$ & $9.20 \mathrm{E}-04$ \\
\hline $\mathrm{Cm}-247$ & $1.20 \mathrm{E}+01$ & $2.70 \mathrm{E}+02$ & $1.90 \mathrm{E}-02$ & $2.80 \mathrm{E}+02$ & 8.40E-04 \\
\hline Co-57 & $2.70 \mathrm{E}-03$ & $3.90 \mathrm{E}-03$ & $2.70 \mathrm{E}-04$ & $6.90 \mathrm{E}-03$ & 2.10E-08 \\
\hline Co-60 & $8.50 \mathrm{E}-02$ & $1.30 \mathrm{E}-01$ & $2.10 \mathrm{E}+00$ & $2.30 \mathrm{E}+00$ & $6.90 \mathrm{E}-06$ \\
\hline Cs-134 & $2.10 \mathrm{E}-01$ & $2.50 \mathrm{E}-02$ & $4.20 \mathrm{E}-01$ & $6.50 \mathrm{E}-01$ & $2.00 \mathrm{E}-06$ \\
\hline Cs-135 & $2.40 \mathrm{E}-02$ & $3.00 \mathrm{E}-03$ & $0.00 E+00$ & 2.70E-02 & $8.00 \mathrm{E}-08$ \\
\hline Cs-137 & $1.70 \mathrm{E}-01$ & $2.00 \mathrm{E}-02$ & $1.40 \mathrm{E}-01$ & 3.30E-01 & $9.80 \mathrm{E}-07$ \\
\hline Eu-152 & $2.10 \mathrm{E}-02$ & 1.40E-01 & $6.80 \mathrm{E}-01$ & $8.50 \mathrm{E}-01$ & $2.50 \mathrm{E}-06$ \\
\hline Eu-154 & $3.10 \mathrm{E}-02$ & $1.80 \mathrm{E}-01$ & $7.50 \mathrm{E}-01$ & $9.60 \mathrm{E}-01$ & $2.90 \mathrm{E}-06$ \\
\hline $\mathrm{Fe}-55$ & $1.80 \mathrm{E}-03$ & $1.50 \mathrm{E}-03$ & $0.00 \mathrm{E}+00$ & $3.30 \mathrm{E}-03$ & 1.00E-08 \\
\hline $\mathrm{Mn}-54$ & $6.40 \mathrm{E}-03$ & $3.00 \mathrm{E}-03$ & $2.40 \mathrm{E}-01$ & 2.50E-01 & $7.40 \mathrm{E}-07$ \\
\hline $\mathrm{Na}-22$ & $3.40 \mathrm{E}-02$ & $4.40 \mathrm{E}-03$ & $1.10 \mathrm{E}+00$ & $1.10 \mathrm{E}+00$ & 3.40E-06 \\
\hline $\mathrm{Nb}-94$ & $2.40 \mathrm{E}-02$ & $2.70 \mathrm{E}-01$ & $6.00 \mathrm{E}-01$ & $8.90 \mathrm{E}-01$ & $2.70 \mathrm{E}-06$ \\
\hline $\mathrm{Ni}-59$ & $7.10 \mathrm{E}-04$ & $1.80 \mathrm{E}-03$ & $0.00 \mathrm{E}+00$ & $2.50 \mathrm{E}-03$ & 7.40E-09 \\
\hline $\mathrm{Ni}-63$ & $1.90 \mathrm{E}-03$ & $4.10 \mathrm{E}-03$ & $0.00 \mathrm{E}+00$ & $6.00 \mathrm{E}-03$ & $1.80 \mathrm{E}-08$ \\
\hline $\mathrm{Np}-237$ & $1.50 \mathrm{E}+01$ & $3.50 \mathrm{E}+02$ & $4.50 \mathrm{E}-03$ & $3.70 \mathrm{E}+02$ & $1.10 \mathrm{E}-03$ \\
\hline $\mathrm{Pb}-210$ & $1.80 \mathrm{E}+01$ & $8.70 \mathrm{E}+00$ & 2.10E-16 & $2.70 \mathrm{E}+01$ & 8.00E-05 \\
\hline$P m-147$ & $3.10 \mathrm{E}-03$ & $2.20 \mathrm{E}-02$ & $1.80 \mathrm{E}-09$ & 2.50E-02 & $7.60 \mathrm{E}-08$ \\
\hline $\mathrm{Pu}-238$ & $1.10 \mathrm{E}+01$ & $2.50 \mathrm{E}+02$ & $1.90 \mathrm{E}-14$ & $2.60 \mathrm{E}+02$ & $7.90 \mathrm{E}-04$ \\
\hline Pu-239 & $1.20 \mathrm{E}+01$ & $2.80 \mathrm{E}+02$ & $6.80 \mathrm{E}-09$ & $2.90 \mathrm{E}+02$ & $8.70 \mathrm{E}-04$ \\
\hline $\mathrm{Pu}-240$ & $1.20 \mathrm{E}+01$ & $2.80 \mathrm{E}+02$ & $9.50 \mathrm{E}-15$ & $2.90 \mathrm{E}+02$ & 8.70E-04 \\
\hline Pu-241 & $2.30 \mathrm{E}-01$ & $5.20 \mathrm{E}+00$ & $1.00 \mathrm{E}-08$ & $5.40 \mathrm{E}+00$ & $1.60 \mathrm{E}-05$ \\
\hline $\mathrm{Pu}-242$ & $1.10 \mathrm{E}+01$ & $2.70 \mathrm{E}+02$ & $3.60 \mathrm{E}-14$ & $2.80 \mathrm{E}+02$ & $8.30 \mathrm{E}-04$ \\
\hline $\mathrm{Ru}-106$ & $6.70 \mathrm{E}-02$ & $2.20 \mathrm{E}-01$ & $4.00 \mathrm{E}-02$ & 3.30E-01 & $9.90 \mathrm{E}-07$ \\
\hline Sb-125 & 8.40E-03 & $7.00 \mathrm{E}-03$ & $5.40 \mathrm{E}-02$ & $7.00 \mathrm{E}-02$ & 2.10E-07 \\
\hline Se-79 & $2.90 \mathrm{E}-02$ & $6.40 \mathrm{E}-03$ & $0.00 \mathrm{E}+00$ & $3.60 \mathrm{E}-02$ & 1.10E-07 \\
\hline Sm-151 & 1.30E-03 & $1.90 \mathrm{E}-02$ & $0.00 \mathrm{E} \div 00$ & $2.10 \mathrm{E}-02$ & $6.20 \mathrm{E}-08$ \\
\hline Sr-90 & $4.80 \mathrm{E}-01$ & $8.30 \mathrm{E}-01$ & 5.10E-03 & $1.30 \mathrm{E}+00$ & $3.90 \mathrm{E}-06$ \\
\hline Tc-99 & $4.90 \mathrm{E}-03$ & $5.40 \mathrm{E}-03$ & 3.70E-10 & 1.00E-02 & $3.10 \mathrm{E}-08$ \\
\hline Th-228 & $1.10 \mathrm{E}+00$ & $1.90 \mathrm{E}+02$ & $2.10 \mathrm{E}+00$ & $1.90 \mathrm{E}+02$ & $5.70 \mathrm{E}-04$ \\
\hline Th-229 & $1.20 \mathrm{E}+01$ & $1.40 \mathrm{E}+03$ & $5.60 \mathrm{E}-02$ & $1.40 \mathrm{E}+03$ & $4.20 \mathrm{E}-03$ \\
\hline Th-230 & $1.90 \mathrm{E}+00$ & $2.10 \mathrm{E}+02$ & $1.80 \mathrm{E}-07$ & $2.10 \mathrm{E}+02$ & $6.40 \mathrm{E}-04$ \\
\hline Th-232 & $9.20 \mathrm{E}+00$ & $1.10 \mathrm{E}+03$ & $1.50 \mathrm{E}-08$ & $1.10 \mathrm{E}+03$ & $3.20 \mathrm{E}-03$ \\
\hline U-232 & $4.40 \mathrm{E}+00$ & $4.30 \mathrm{E}+02$ & $7.40 \mathrm{E}-08$ & $4.30 \mathrm{E}+02$ & $1.30 \mathrm{E}-03$ \\
\hline U-233 & $9.80 \mathrm{E}-01$ & $8.80 \mathrm{E}+01$ & 3.70E-08 & $8.90 \mathrm{E}+01$ & 2.70E-04 \\
\hline U-234 & $9.60 \mathrm{E}-01$ & $8.60 \mathrm{E}+01$ & $1.20 \mathrm{E}-08$ & $8.70 \mathrm{E}+01$ & $2.60 \mathrm{E}-04$ \\
\hline U-235 & $9.00 \mathrm{E}-01$ & $8.00 \mathrm{E}+01$ & $3.00 \mathrm{E}-04$ & $8.10 \mathrm{E}+01$ & $2.40 \mathrm{E}-04$ \\
\hline U-238 & $8.60 \mathrm{E}-01$ & $7.70 \mathrm{E}+01$ & $8.70 \mathrm{E}-03$ & $7.80 \mathrm{E}+01$ & 2.30E-04 \\
\hline Zn-65 & $3.00 \mathrm{E}-02$ & $8.20 \mathrm{E}-03$ & $2.50 \mathrm{E}-01$ & $2.90 \mathrm{E}-01$ & $8.60 \mathrm{E}-07$ \\
\hline $\mathrm{Zr}-93$ & $5.60 \mathrm{E}-03$ & $2.10 \mathrm{E}-01$ & $0.00 \mathrm{E}+00$ & $2.10 \mathrm{E}-01$ & $6.40 \mathrm{E}-07$ \\
\hline
\end{tabular}

a Doses do not account for scrap dilution or radionuclide partitioning; collective doses based on $100 \mathrm{t}$. 
TABLE D.8 Baseline Worker Doses for a 2,000-h Baghouse Processor ${ }^{a}$

\begin{tabular}{|c|c|c|c|c|c|}
\hline Nuclide & $\begin{array}{r}\text { Ingestion } \\
(\mu \mathrm{Sv} / \mathrm{yr})\end{array}$ & $\begin{array}{c}\text { Inhalation } \\
(\mu \mathrm{Sv} / \mathrm{yr})\end{array}$ & $\begin{array}{c}\text { External } \\
(\mu \mathrm{Sv} / \mathrm{yr})\end{array}$ & $\begin{array}{c}\text { Total Dose } \\
(\mu \mathrm{Sv} / \mathrm{yr})\end{array}$ & $\begin{array}{r}\text { Collective Dose } \\
\text { (person-Sv/yr) }\end{array}$ \\
\hline Ac-227 & $4.90 \mathrm{E}+01$ & $4.30 \mathrm{E}+03$ & $2.00 \mathrm{E}+02$ & $4.60 \mathrm{E}+03$ & $2.30 \mathrm{E}-04$ \\
\hline $\mathrm{Ag}-110 \mathrm{~m}$ & $2.30 \mathrm{E}-02$ & 3.30E-02 & $1.20 \mathrm{E}+03$ & $1.20 \mathrm{E}+03$ & $5.70 \mathrm{E}-05$ \\
\hline Am-241 & $1.20 \mathrm{E}+01$ & $2.90 \mathrm{E}+02$ & $1.40 \mathrm{E}+00$ & $3.00 \mathrm{E}+02$ & 1.50E-05 \\
\hline Am-243 & $1.20 \mathrm{E}+01$ & $2.90 \mathrm{E}+02$ & $1.90 \mathrm{E}+01$ & $3.20 \mathrm{E}+02$ & 1.60E-05 \\
\hline $\mathrm{Ca}-41$ & 4.30E-03 & $8.70 \mathrm{E}-04$ & $0.00 \mathrm{E}+00$ & $5.20 \mathrm{E}-03$ & $2.60 \mathrm{E}-10$ \\
\hline Ce-144 & $4.70 \mathrm{E}-02$ & $1.60 \mathrm{E}-01$ & $2.10 \mathrm{E}+01$ & $2.10 \mathrm{E}+01$ & $1.00 \mathrm{E}-06$ \\
\hline Cl-36 & $1.00 \mathrm{E}-02$ & $1.40 \mathrm{E}-02$ & 2.60E-01 & $2.80 \mathrm{E}-01$ & $1.40 \mathrm{E}-08$ \\
\hline $\mathrm{Cm}-243$ & $8.40 \mathrm{E}+00$ & $2.00 \mathrm{E}+02$ & $5.50 \mathrm{E}+01$ & $2.60 \mathrm{E}+02$ & $1.30 \mathrm{E}-05$ \\
\hline $\mathrm{Cm}-244$ & $6.70 \mathrm{E}+00$ & $1.60 \mathrm{E}+02$ & $2.00 \mathrm{E}-03$ & $1.60 \mathrm{E}+02$ & $8.20 \mathrm{E}-06$ \\
\hline $\mathrm{Cm}-245$ & $1.30 \mathrm{E}+01$ & $3.00 \mathrm{E}+02$ & $2.60 \mathrm{E}+01$ & $3.30 \mathrm{E}+02$ & $1.70 \mathrm{E}-05$ \\
\hline $\mathrm{Cm}-246$ & $1.30 \mathrm{E}+01$ & $2.90 \mathrm{E}+02$ & $3.20 \mathrm{E}-03$ & $3.10 \mathrm{E}+02$ & $1.50 \mathrm{E}-05$ \\
\hline $\mathrm{Cm}-247$ & $1.20 \mathrm{E}+01$ & $2.70 \mathrm{E}+02$ & $5.10 \mathrm{E}+00$ & $2.90 \mathrm{E}+02$ & $1.40 \mathrm{E}-05$ \\
\hline $\mathrm{Co}-57$ & 2.60E-03 & $3.80 \mathrm{E}-03$ & $2.60 \mathrm{E}+01$ & $2.60 \mathrm{E}+01$ & $1.30 \mathrm{E}-06$ \\
\hline Co-60 & $8.50 \mathrm{E}-02$ & $1.30 \mathrm{E}-01$ & $1.60 \mathrm{E}+03$ & $1.60 \mathrm{E}+03$ & $8.00 \mathrm{E}-05$ \\
\hline Cs-134 & $2.10 \mathrm{E}-01$ & $2.60 \mathrm{E}-02$ & $8.60 \mathrm{E}+02$ & $8.60 \mathrm{E}+02$ & $4.30 \mathrm{E}-05$ \\
\hline Cs-135 & $2.40 \mathrm{E}-02$ & $3.00 \mathrm{E}-03$ & $0.00 \mathrm{E}+00$ & $2.70 \mathrm{E}-02$ & $1.30 \mathrm{E}-09$ \\
\hline Cs-137 & $1.70 \mathrm{E}-01$ & $2.10 \mathrm{E}-02$ & $3.60 \mathrm{E}+02$ & $3.60 \mathrm{E}+02$ & $1.80 \mathrm{E}-05$ \\
\hline Eu-152 & 2.10E-02 & $1.40 \mathrm{E}-01$ & $7.20 \mathrm{E}+02$ & $7.20 \mathrm{E}+02$ & $3.60 \mathrm{E}-05$ \\
\hline Eu-154 & $3.10 \mathrm{E}-02$ & $1.80 \mathrm{E}-01$ & $7.80 \mathrm{E}+02$ & $7.80 \mathrm{E}+02$ & $3.90 \mathrm{E}-05$ \\
\hline $\mathrm{Fe}-55$ & $1.80 \mathrm{E}-03$ & $1.50 \mathrm{E}-03$ & $0.00 \mathrm{E}+00$ & 3.30E-03 & $1.70 \mathrm{E}-10$ \\
\hline $\mathrm{Mn}-54$ & $6.40 \mathrm{E}-03$ & $3.00 \mathrm{E}-03$ & $3.80 \mathrm{E}+02$ & $3.80 \mathrm{E}+02$ & $1.90 \mathrm{E}-05$ \\
\hline $\mathrm{Na}-22$ & $3.40 \mathrm{E}-02$ & $4.40 \mathrm{E}-03$ & $1.30 \mathrm{E}+03$ & $1.30 \mathrm{E}+03$ & $6.40 \mathrm{E}-05$ \\
\hline $\mathrm{Nb}-94$ & $2.40 \mathrm{E}-02$ & $2.70 \mathrm{E}-01$ & $1.00 \mathrm{E}+03$ & $1.00 \mathrm{E}+03$ & $5.20 \mathrm{E}-05$ \\
\hline $\mathrm{Ni}-59$ & $7.10 \mathrm{E}-04$ & $1.80 \mathrm{E}-03$ & $0.00 \mathrm{E}+00$ & 2.50E-03 & $1.20 \mathrm{E}-10$ \\
\hline $\mathrm{Ni}-63$ & $1.90 \mathrm{E}-03$ & $4.10 \mathrm{E}-03$ & $0.00 \mathrm{E}+00$ & $6.00 \mathrm{E}-03$ & $3.00 \mathrm{E}-10$ \\
\hline $\mathrm{Np}-237$ & $1.50 \mathrm{E}+01$ & $3.50 \mathrm{E}+02$ & $1.10 \mathrm{E}+02$ & $4.80 \mathrm{E}+02$ & $2.40 \mathrm{E}-05$ \\
\hline $\mathrm{Pb}-210$ & $2.40 \mathrm{E}+01$ & $1.50 \mathrm{E}+01$ & $1.60 \mathrm{E}-01$ & $3.90 \mathrm{E}+01$ & $2.00 \mathrm{E}-06$ \\
\hline Pm-147 & $3.10 \mathrm{E}-03$ & $2.20 \mathrm{E}-02$ & $3.40 \mathrm{E}-03$ & $2.90 \mathrm{E}-02$ & $1.40 \mathrm{E}-09$ \\
\hline Pu-238 & $1.10 \mathrm{E}+01$ & $2.50 \mathrm{E}+02$ & $4.60 \mathrm{E}-03$ & $2.60 \mathrm{E}+02$ & $1.30 \mathrm{E}-05$ \\
\hline Pu-239 & $1.20 \mathrm{E}+01$ & $2.80 \mathrm{E}+02$ & 2.50E-02 & $2.90 \mathrm{E}+02$ & $1.50 \mathrm{E}-05$ \\
\hline $\mathrm{Pu}-240$ & $1.20 \mathrm{E}+01$ & $2.80 \mathrm{E}+02$ & $4.60 \mathrm{E}-03$ & $2.90 \mathrm{E}+02$ & $1.50 \mathrm{E}-05$ \\
\hline $\mathrm{Pu}-241$ & 2.30E-01 & $5.20 \mathrm{E}+00$ & $4.90 \mathrm{E}+01$ & $5.50 \mathrm{E}+01$ & 2.70E-06 \\
\hline $\mathrm{Pu}-242$ & $1.10 \mathrm{E}+01$ & $2.70 \mathrm{E}+02$ & $4.40 \mathrm{E}-03$ & $2.80 \mathrm{E}+02$ & $1.40 \mathrm{E}-05$ \\
\hline Ru-106 & $6.70 \mathrm{E}-02$ & $2.20 \mathrm{E}-01$ & $1.40 \mathrm{E}+03$ & $1.40 \mathrm{E}+03$ & $7.10 \mathrm{E}-05$ \\
\hline Sb-125 & $8.40 \mathrm{E}-03$ & $7.00 \mathrm{E}-03$ & $2.30 \mathrm{E}+02$ & $2.30 \mathrm{E}+02$ & $1.20 \mathrm{E}-05$ \\
\hline Se-79 & $2.90 \mathrm{E}-02$ & $6.40 \mathrm{E}-03$ & $0.00 E+00$ & $3.60 \mathrm{E}-02$ & $1.80 \mathrm{E}-09$ \\
\hline Sm-151 & $1.30 \mathrm{E}-03$ & $1.90 \mathrm{E}-02$ & $1.80 \mathrm{E}-05$ & $2.10 \mathrm{E}-02$ & $1.00 \mathrm{E}-09$ \\
\hline $\mathrm{Sr}-90$ & 5.10E-01 & $8.40 \mathrm{E}-01$ & $2.50 \mathrm{E}+00$ & $3.80 \mathrm{E}+00$ & $1.90 \mathrm{E}-07$ \\
\hline Tc-99 & $4.90 \mathrm{E}-03$ & $5.40 \mathrm{E}-03$ & $6.80 \mathrm{E}-03$ & $1.70 \mathrm{E}-02$ & $8.60 \mathrm{E}-10$ \\
\hline Th-228 & $2.30 \mathrm{E}+00$ & $1.90 \mathrm{E}+02$ & $8.60 \mathrm{E}+02$ & $1.10 \mathrm{E}+03$ & $5.20 \mathrm{E}-05$ \\
\hline Th-229 & $1.40 \mathrm{E}+01$ & $1.40 \mathrm{E}+03$ & $1.60 \mathrm{E} \div 02$ & $1.60 \mathrm{E}+03$ & $7.90 \mathrm{E}-05$ \\
\hline Th-230 & $1.90 \mathrm{E}+00$ & $2.10 \mathrm{E}+02$ & $8.20 \mathrm{E}-02$ & $2.10 \mathrm{E}+02$ & $1.10 \mathrm{E}-05$ \\
\hline Th-232 & $9.20 \mathrm{E}+00$ & $1.10 \mathrm{E}+03$ & $3.10 \mathrm{E}-02$ & $1.10 \mathrm{E}+03$ & $5.40 \mathrm{E}-05$ \\
\hline U-232 & $4.40 \mathrm{E}+00$ & $4.30 \mathrm{E}+02$ & $6.50 \mathrm{E}-02$ & $4.30 \mathrm{E}+02$ & $2.20 \mathrm{E}-05$ \\
\hline U-233 & $9.80 \mathrm{E}-01$ & $8.80 \mathrm{E}+01$ & 1.30E-01 & $8.90 \mathrm{E}+01$ & $4.50 \mathrm{E}-06$ \\
\hline U-234 & $9.60 \mathrm{E}-01$ & $8.60 \mathrm{E}+01$ & $2.40 \mathrm{E}-02$ & $8.70 \mathrm{E}+01$ & $4.40 \mathrm{E}-06$ \\
\hline U-235 & $9.00 \mathrm{E}-01$ & $8.00 \mathrm{E}+01$ & $7.20 \mathrm{E}+01$ & $1.50 \mathrm{E}+02$ & $7.60 \mathrm{E}-06$ \\
\hline U-238 & $9.10 \mathrm{E}-01$ & $7.70 \mathrm{E}+01$ & $1.30 \mathrm{E}+01$ & $9.10 \mathrm{E}+01$ & $4.50 \mathrm{E}-06$ \\
\hline $\mathrm{Zn}-65$ & $3.00 \mathrm{E}-02$ & $8.20 \mathrm{E}-03$ & $2.40 \mathrm{E}+02$ & $2.40 \mathrm{E}+02$ & $1.20 \mathrm{E}-05$ \\
\hline $\mathrm{Zr}-93$ & $5.60 \mathrm{E}-03$ & $2.10 \mathrm{E}-01$ & $0.00 \mathrm{E}+00$ & $2.10 \mathrm{E}-01$ & $1.10 \mathrm{E}-08$ \\
\hline
\end{tabular}

a Doses do not account for scrap dilution or radionuclide partitioning; collective doses based on $100 \mathrm{t}$. 
TABLE D.9 Baseline Worker Doses for a 2,000-h Industrial Products Caster $\mathbf{1}^{\mathrm{a}}$

\begin{tabular}{|c|c|c|c|c|c|}
\hline Nuclide & $\begin{array}{r}\text { Ingestion } \\
(\mu \mathrm{S} v / \mathrm{yr})\end{array}$ & $\begin{array}{c}\text { Inhalation } \\
(\mu S v / y r)\end{array}$ & $\begin{array}{l}\text { External } \\
(\mu \mathrm{Sv} / \mathrm{yr})\end{array}$ & $\begin{array}{c}\text { Total Dose } \\
(\mu \mathrm{Sv} / \mathrm{yr})\end{array}$ & $\begin{array}{r}\text { Collective Dose } \\
\text { (person-Sv/yr) }\end{array}$ \\
\hline Ac-227 & $4.70 \mathrm{E}+01$ & $4.30 \mathrm{E}+03$ & $9.00 \mathrm{E}+00$ & $4.30 \mathrm{E}+03$ & $8.70 \mathrm{E}-03$ \\
\hline $\mathrm{Ag}-110 \mathrm{~m}$ & 2.30E-02 & 3.30E-02 & $4.80 \mathrm{E}+01$ & $4.80 \mathrm{E}+01$ & $9.60 \mathrm{E}-05$ \\
\hline Am-241 & $1.20 \mathrm{E}+01$ & $2.90 \mathrm{E}+02$ & 2.20E-01 & $3.00 \mathrm{E}+02$ & $6.00 \mathrm{E}-04$ \\
\hline $\mathrm{Am}-243$ & $1.20 \mathrm{E}+01$ & $2.90 \mathrm{E}+02$ & $4.20 \mathrm{E}+00$ & $3.00 \mathrm{E}+02$ & $6.00 \mathrm{E}-04$ \\
\hline $\mathrm{Ca}-41$ & $4.30 \mathrm{E}-03$ & $8.70 \mathrm{E}-04$ & $0.00 \mathrm{E}+00$ & $5.20 \mathrm{E}-03$ & $1.00 \mathrm{E}-08$ \\
\hline Ce-144 & $4.70 \mathrm{E}-02$ & $1.60 \mathrm{E}-01$ & $9.60 \mathrm{E}-01$ & $1.20 \mathrm{E}+00$ & $2.30 \mathrm{E}-06$ \\
\hline Cl-36 & $1.00 \mathrm{E}-02$ & $1.40 \mathrm{E}-02$ & $1.10 \mathrm{E}-02$ & $3.50 \mathrm{E}-02$ & $7.00 \mathrm{E}-08$ \\
\hline $\mathrm{Cm}-243$ & $8.40 \mathrm{E}+00$ & $2.00 \mathrm{E}+02$ & $2.70 \mathrm{E}+00$ & $2.10 \mathrm{E}+02$ & $4.20 \mathrm{E}-04$ \\
\hline $\mathrm{Cm}-244$ & $6.70 \mathrm{E}+00$ & $1.60 \mathrm{E}+02$ & $7.00 \mathrm{E}-04$ & $1.60 \mathrm{E}+02$ & $3.30 \mathrm{E}-04$ \\
\hline $\mathrm{Cm}-245$ & $1.30 \mathrm{E}+01$ & $3.00 E+02$ & $1.60 \mathrm{E}+00$ & $3.10 \mathrm{E}+02$ & $6.20 \mathrm{E}-04$ \\
\hline $\mathrm{Cm}-246$ & $1.30 E+01$ & $2.90 E+02$ & $6.90 \mathrm{E}-04$ & $3.10 \mathrm{E}+02$ & $6.10 \mathrm{E}-04$ \\
\hline $\mathrm{Cm}-247$ & $1.20 \mathrm{E}+01$ & $2.70 \mathrm{E}+02$ & $8.40 \mathrm{E}+00$ & $2.90 \mathrm{E}+02$ & $5.80 \mathrm{E}-04$ \\
\hline Co-57 & $2.70 \mathrm{E}-03$ & $3.90 \mathrm{E}-03$ & $1.60 \mathrm{E}+00$ & $1.60 \mathrm{E}+00$ & $3.20 \mathrm{E}-06$ \\
\hline Co 60 & $8.50 \mathrm{E}-02$ & $1.30 \mathrm{E}-01$ & $6.70 \mathrm{E}+01$ & $6.70 \mathrm{E}+01$ & 1.30E-04 \\
\hline Cs-134 & $2.10 \mathrm{E}-01$ & $2.50 \mathrm{E}-02$ & $3.60 \mathrm{E}+01$ & $3.60 \mathrm{E}+01$ & $7.20 \mathrm{E}-05$ \\
\hline Cs-135 & $2.40 \mathrm{E}-02$ & $3.00 \mathrm{E}-03$ & $0.00 \mathrm{E}+00$ & $2.70 \mathrm{E}-02$ & $5.40 \mathrm{E}-08$ \\
\hline Cs-137 & $1.70 \mathrm{E}-01$ & $2.00 \mathrm{E}-02$ & $1.50 \mathrm{E}+01$ & $1.50 \mathrm{E} \div 01$ & $3.00 \mathrm{E}-05$ \\
\hline Eu-152 & $2.10 \mathrm{E}-02$ & $1.40 \mathrm{E}-01$ & $3.00 \mathrm{E}+01$ & $3.00 \mathrm{E}+01$ & $6.10 \mathrm{E}-05$ \\
\hline Eu-154 & $3.10 \mathrm{E}-02$ & $1.80 \mathrm{E}-01$ & $3.30 \mathrm{E}+01$ & $3.30 \mathrm{E} \div 01$ & $6.60 \mathrm{E}-05$ \\
\hline $\mathrm{Fe}-55$ & $1.80 \mathrm{E}-03$ & $1.50 \mathrm{E}-03$ & $0.00 \mathrm{E}+00$ & 3.30E-03 & $6.70 \mathrm{E}-09$ \\
\hline $\mathrm{Mn}-54$ & $6.40 \mathrm{E}-03$ & $3.00 \mathrm{E}-03$ & $1.60 \mathrm{E}+01$ & $1.60 \mathrm{E}+01$ & 3.10E-05 \\
\hline $\mathrm{Na}-22$ & 3.40E-02 & $4.40 \mathrm{E}-03$ & $5.30 \mathrm{E}+01$ & $5.30 \mathrm{E}+01$ & $1.10 \mathrm{E}-04$ \\
\hline $\mathrm{Nb}-94$ & $2.40 \mathrm{E}-02$ & $2.70 \mathrm{E}-01$ & $4.30 \mathrm{E}+01$ & $4.30 \mathrm{E}+01$ & $8.60 \mathrm{E}-05$ \\
\hline Ni-59 & $7.10 \mathrm{E}-04$ & $1.80 \mathrm{E}-03$ & $0.00 \mathrm{E}+00$ & $2.50 \mathrm{E}-03$ & 4.90E-09 \\
\hline $\mathrm{Ni}-63$ & $1.90 \mathrm{E}-03$ & $4.10 \mathrm{E}-03$ & $0.00 \mathrm{E}+00$ & $6.00 \mathrm{E}-03$ & $1.20 \mathrm{E}-08$ \\
\hline $\mathrm{Np}-237$ & $1.50 \mathrm{E}+01$ & $3.50 \mathrm{E}+02$ & $5.00 \mathrm{E}+00$ & $3.70 \mathrm{E}+02$ & $7.40 \mathrm{E}-04$ \\
\hline $\mathrm{Pb}-210$ & $1.80 \mathrm{E}+01$ & $8.70 \mathrm{E}+00$ & $1.20 \mathrm{E}-02$ & $2.70 \mathrm{E}+01$ & 5.30E-05 \\
\hline Pm-147 & $3.10 \mathrm{E}-03$ & $2.20 \mathrm{E}-02$ & 2.10E-04 & $2.60 \mathrm{E}-02$ & $5.10 \mathrm{E}-08$ \\
\hline $\mathrm{Pu}-238$ & $1.10 \mathrm{E}+01$ & $2.50 \mathrm{E}+02$ & $8.40 \mathrm{E}-04$ & $.2 .60 \mathrm{E}+02$ & $5.30 \mathrm{E}-04$ \\
\hline $\mathrm{Pu}-239$ & $1.20 \mathrm{E}+01$ & $2.80 \mathrm{E}+02$ & 1.40E-03 & $2.90 \mathrm{E}+02$ & $5.80 \mathrm{E}-04$ \\
\hline $\mathrm{Pu}-240$ & $1.20 \mathrm{E}+01$ & $2.80 \mathrm{E}+02$ & $8.10 \mathrm{E}-04$ & $2.90 \mathrm{E}+02$ & $5.80 \mathrm{E}-04$ \\
\hline $\mathrm{Pu}-241$ & $2.30 \mathrm{E}-01$ & $5.20 \mathrm{E}+00$ & $8.80 \mathrm{E}-05$ & $5.40 \mathrm{E}+00$ & 1.10E-05 \\
\hline $\mathrm{Pu}-242$ & $1.10 \mathrm{E}+01$ & $2.70 E+02$ & $7.00 \mathrm{E}-04$ & $2.80 \mathrm{E}+02$ & $5.60 \mathrm{E}-04$ \\
\hline $\mathrm{Ru}-106$ & $6.70 \mathrm{E}-02$ & $2.20 \mathrm{E}-01$ & $4.20 \mathrm{E}+00$ & $4.40 \mathrm{E}+00$ & 8.90E-06 \\
\hline $\mathrm{Sb}-125$ & $8.40 \mathrm{E}-03$ & $7.00 \mathrm{E}-03$ & $9.60 \mathrm{E}+00$ & $9.70 \mathrm{E}+00$ & $1.90 \mathrm{E}-05$ \\
\hline Se-79 & $2.90 \mathrm{E}-02$ & $6.40 \mathrm{E}-03$ & $0.00 \mathrm{E}+00$ & $3.60 \mathrm{E}-02$ & $7.20 \mathrm{E}-08$ \\
\hline Sm-151 & $1.30 \mathrm{E}-03$ & $1.90 \mathrm{E}-02$ & $5.40 \mathrm{E}-06$ & 2.10E-02 & $4.10 \mathrm{E}-08$ \\
\hline Sr-90 & $4.80 \mathrm{E}-01$ & $8.30 \mathrm{E}-01$ & $1.00 \mathrm{E}-01$ & $1.40 \mathrm{E}+00$ & $2.80 \mathrm{E}-06$ \\
\hline Tc-99 & $4.90 \mathrm{E}-03$ & $5.40 \mathrm{E}-03$ & $6.20 \mathrm{E}-04$ & 1.10E-02 & $2.20 \mathrm{E}-08$ \\
\hline Th-228 & $1.10 \mathrm{E}+00$ & $1.90 \mathrm{E}+02$ & $3.70 \mathrm{E}+01$ & $2.20 \mathrm{E}+02$ & $4.50 \mathrm{E}-04$ \\
\hline Th-229 & $1.20 \mathrm{E}+01$ & $1.40 \mathrm{E}+03$ & $7.30 \mathrm{E}+00$ & $1.40 \mathrm{E}+03$ & $2.80 \mathrm{E}-03$ \\
\hline Th-230 & $1.90 \mathrm{E}+00$ & $2.10 \mathrm{E}+02$ & $5.80 \mathrm{E}-03$ & $2.10 \mathrm{E}+02$ & $4.30 \mathrm{E}-04$ \\
\hline Th-232 & $9.20 E+00$ & $1.10 \mathrm{E}+03$ & $2.60 \mathrm{E}-03$ & $1.10 \mathrm{E}+03$ & $2.10 \mathrm{E}-03$ \\
\hline U-232 & $4.40 \mathrm{E}+00$ & $4.30 \mathrm{E}+02$ & $4.40 \mathrm{E}-03$ & $4.30 \mathrm{E}+02$ & $8.60 \mathrm{E}-04$ \\
\hline U-233 & $9.80 \mathrm{E}-01$ & $8.80 \mathrm{E}+01$ & $6.80 \mathrm{E}-03$ & $8.90 \mathrm{E}+01$ & $1.80 \mathrm{E}-04$ \\
\hline U-234 & $9.60 \mathrm{E}-01$ & $8.60 \mathrm{E}+01$ & $2.00 \mathrm{E}-03$ & $8.70 \mathrm{E}+01$ & $1.70 \mathrm{E}-04$ \\
\hline U-235 & $9.00 \mathrm{E}-01$ & $8.00 E+01$ & $3.60 \mathrm{E}+00$ & $8.40 E+01$ & 1.70E-04 \\
\hline U-238 & $8.60 \mathrm{E}-01$ & $7.70 E+01$ & $6.00 \mathrm{E}-01$ & $7.80 \mathrm{E}+01$ & $1.60 \mathrm{E}-04$ \\
\hline $\mathrm{Zn-65}$ & $3.00 \mathrm{E}-02$ & 8.20E-03 & $1.00 \mathrm{E}+01$ & $1.00 \mathrm{E}+01$ & $2.00 \mathrm{E}-05$ \\
\hline $\mathrm{Zr}-93$ & $5.60 \mathrm{E}-03$ & $2.10 \mathrm{E}-01$ & $0.00 \mathrm{E}+00$ & $2.10 \mathrm{E}-01$ & $4.30 \mathrm{E}-07$ \\
\hline
\end{tabular}

a Doses do not account for scrap dilution or radionuclide partitioning; collective doses based on $100 \mathrm{t}$. 
TABLE D.10 Baseline Worker Doses for a 2,000-h Industrial Products Caster $2^{a}$

\begin{tabular}{|c|c|c|c|c|c|}
\hline Nuclide & $\begin{array}{r}\text { Ingestion } \\
(\mu \mathrm{Sv} / \mathrm{yr})\end{array}$ & $\begin{array}{l}\text { Inhalation } \\
.(\mu \mathrm{Sv} / \mathrm{yr})\end{array}$ & $\begin{array}{l}\text { External } \\
(\mu \mathrm{Sv} / \mathrm{yr})\end{array}$ & $\begin{array}{c}\text { Total Dose } \\
(\mu \mathrm{Sv} / \mathrm{yr})\end{array}$ & $\begin{array}{r}\text { Collective Dose } \\
\text { (person-Sv/yr) }\end{array}$ \\
\hline Ac-227 & $4.70 \mathrm{E}+01$ & $4.30 \mathrm{E}+03$ & $3.20 \mathrm{E}+01$ & $4.40 \mathrm{E}+03$ & $8.70 \mathrm{E}-03$ \\
\hline $\mathrm{Ag}-110 \mathrm{~m}$ & 2.30E-02 & $3.30 \mathrm{E}-02$ & $1.10 \mathrm{E}+02$ & $1.10 \mathrm{E}+02$ & 2.30E-04 \\
\hline Am-241 & $1.20 \mathrm{E}+01$ & $2.90 \mathrm{E}+02$ & $1.60 \mathrm{E}+00$ & $3.00 \mathrm{E}+02$ & $6.00 \mathrm{E}-04$ \\
\hline Am-243 & $1.20 \mathrm{E}+01$ & $2.90 \mathrm{E}+02$ & $2.20 \mathrm{E}+01$ & $3.20 \mathrm{E}+02$ & $6.40 \mathrm{E}-04$ \\
\hline $\mathrm{Ca}-41$ & $4.30 \mathrm{E}-03$ & 8.70E-04 & $0.00 \mathrm{E}+00$ & $5.20 \mathrm{E}-03$ & $1.00 \mathrm{E}-08$ \\
\hline Ce-144 & $4.70 \mathrm{E}-02$ & $1.60 \mathrm{E}-01$ & $2.90 \mathrm{E}+00$ & $3.10 \mathrm{E}+00$ & $6.10 \mathrm{E}-06$ \\
\hline $\mathrm{Cl}-36$ & 1.00E-02 & $1.40 \mathrm{E}-02$ & $3.00 \mathrm{E}-02$ & 5.40E-02 & 1.10E-07 \\
\hline $\mathrm{Cm}-243$ & $8.40 \mathrm{E}+00$ & $2.00 \mathrm{E}+02$ & $1.20 \mathrm{E}+01$ & $2.20 \mathrm{E}+02$ & $4.40 \mathrm{E}-04$ \\
\hline $\mathrm{Cm}-244$ & $6.70 \mathrm{E}+00$ & $1.60 \mathrm{E}+02$ & 5.10E-03 & $1.60 \mathrm{E}+02$ & 3.30E-04 \\
\hline $\mathrm{Cm}-245$ & $1.30 \mathrm{E}+01$ & $3.00 \mathrm{E}+02$ & $9.90 \mathrm{E}+00$ & $3.20 \mathrm{E}+02$ & $6.40 \mathrm{E}-04$ \\
\hline $\mathrm{Cm}-246$ & $1.30 \mathrm{E}+01$ & $2.90 \mathrm{E}+02$ & $5.00 \mathrm{E}-03$ & $3.10 \mathrm{E}+02$ & $6.10 \mathrm{E}-04$ \\
\hline $\mathrm{Cm}-247$ & $1.20 \mathrm{E}+01$ & $2.70 \mathrm{E}+02$ & $2.60 \mathrm{E}+01$ & $3.10 \mathrm{E}+02$ & $6.10 \mathrm{E}-04$ \\
\hline Co-57 & $2.70 \mathrm{E}-03$ & $3.90 \mathrm{E}-03$ & $9.50 \mathrm{E}+00$ & $9.50 \mathrm{E}+00$ & $1.90 \mathrm{E}-05$ \\
\hline Co-60 & $8.50 \mathrm{E}-02$ & $1.30 \mathrm{E}-01$ & $1.50 \mathrm{E}+02$ & $1.50 \mathrm{E}+02$ & $2.90 \mathrm{E}-04$ \\
\hline Cs-134 & $2.10 \mathrm{E}-01$ & 2.50E-02 & $9.10 \mathrm{E}+01$ & $9.10 \mathrm{E}+01$ & $1.80 \mathrm{E}-04$ \\
\hline Cs-135 & $2.40 \mathrm{E}-02$ & $3.00 \mathrm{E}-03$ & $0.00 \mathrm{E}+00$ & $2.70 \mathrm{E}-02$ & $5.40 \mathrm{E}-08$ \\
\hline Cs-137 & 1.70E-01 & $2.00 \mathrm{E}-02$ & $3.90 \mathrm{E}+01$ & $3.90 \mathrm{E}+01$ & $7.90 \mathrm{E}-05$ \\
\hline Eu-152 & $2.10 \mathrm{E}-02$ & $1.40 \mathrm{E}-01$ & $7.50 \mathrm{E}+01$ & $7.50 \mathrm{E}+01$ & $1.50 \mathrm{E}-04$ \\
\hline Eu-154 & 3.10E-02 & $1.80 \mathrm{E}-01$ & $8.00 \mathrm{E}+01$ & $8.00 \mathrm{E}+01$ & 1.60E-04 \\
\hline $\mathrm{Fe}-55$ & $1.80 \mathrm{E}-03$ & $1.50 \mathrm{E}-03$ & $0.00 \mathrm{E}+00$ & 3.30E-03 & $6.70 \mathrm{E}-09$ \\
\hline $\mathrm{Mn}-54$ & $6.40 \mathrm{E}-03$ & $3.00 \mathrm{E}-03$ & $3.70 \mathrm{E}+01$ & $3.70 \mathrm{E}+01$ & 7.30E-05 \\
\hline $\mathrm{Na}-22$ & $3.40 \mathrm{E}-02$ & $4.40 \mathrm{E}-03$ & $1.30 \mathrm{E}+02$ & $1.30 \mathrm{E}+02$ & 2.50E-04 \\
\hline $\mathrm{Nb}-94$ & $2.40 \mathrm{E}-02$ & $2.70 \mathrm{E}-01$ & $1.00 \mathrm{E} \div 02$ & $1.00 \mathrm{E}+02$ & $2.10 \mathrm{E}-04$ \\
\hline Ni-59 & $7.10 \mathrm{E}-04$ & $1.80 \mathrm{E}-03$ & $0.00 \mathrm{E}+00$ & $2.50 \mathrm{E}-03$ & $4.90 \mathrm{E}-09$ \\
\hline $\mathrm{Ni}-63$ & $1.90 \mathrm{E}-03$ & 4.10E-03 & $0.00 \mathrm{E}+00$ & $6.00 \mathrm{E}-03$ & $1.20 \mathrm{E}-08$ \\
\hline Np-237 & $1.50 \mathrm{E}+01$ & $3.50 \mathrm{E}+02$ & $1.90 \mathrm{E}+01$ & $3.80 \mathrm{E}+02$ & $7.70 \mathrm{E}-04$ \\
\hline $\mathrm{Pb}-210$ & $1.80 \mathrm{E}+01$ & $8.70 \mathrm{E}+00$ & $8.70 \mathrm{E}-02$ & $2.70 \mathrm{E}+01$ & $5.30 \mathrm{E}-05$ \\
\hline Pm-147 & 3.10E-03 & $2.20 \mathrm{E}-02$ & $1.30 \mathrm{E}-03$ & $2.70 \mathrm{E}-02$ & $5.40 \mathrm{E}-08$ \\
\hline $\mathrm{Pu}-238$ & $1.10 \mathrm{E}+01$ & $2.50 \mathrm{E}+02$ & $6.10 \mathrm{E}-03$ & $2.60 \mathrm{E}+02$ & 5.30E-04 \\
\hline $\mathrm{Pu}-239$ & $1.20 \mathrm{E}+01$ & $2.80 \mathrm{E}+02$ & $9.20 \mathrm{E}-03$ & $2.90 \mathrm{E}+02$ & $5.80 \mathrm{E}-04$ \\
\hline $\mathrm{Pu}-240$ & $1.20 \mathrm{E}+01$ & $2.80 \mathrm{E}+02$ & $5.90 \mathrm{E}-03$ & $2.90 \mathrm{E}+02$ & 5.80E-04 \\
\hline Pu-241 & $2.30 \mathrm{E}-01$ & $5.20 \mathrm{E}+00$ & $4.90 \mathrm{E}-04$ & $5.40 \mathrm{E}+00$ & $1.10 \mathrm{E}-05$ \\
\hline Pu-242 & $1.10 \mathrm{E}+01$ & $2.70 \mathrm{E}+02$ & $5.10 \mathrm{E}-03$ & $2.80 \mathrm{E}+02$ & $5.60 \mathrm{E}-04$ \\
\hline Ru-106 & $6.70 \mathrm{E}-02$ & $2.20 \mathrm{E}-01$ & $1.10 \mathrm{E}+01$ & $1.10 \mathrm{E}+01$ & 2.30E-05 \\
\hline Sb-125 & $8.40 \mathrm{E}-03$ & $7.00 \mathrm{E}-03$ & $2.70 \mathrm{E}+01$ & $2.70 \mathrm{E}+01$ & $5.40 \mathrm{E}-05$ \\
\hline Se-79 & $2.90 \mathrm{E}-02$ & $6.40 \mathrm{E}-03$ & $0.00 \mathrm{E}+00$ & $3.60 \mathrm{E}-02$ & $7.20 \mathrm{E}-08$ \\
\hline Sm-151 & $1.30 \mathrm{E}-03$ & $1.90 \mathrm{E}-02$ & 3.90E-05 & $2.10 \mathrm{E}-02$ & $4.10 \mathrm{E}-08$ \\
\hline Sr-90 & $4.80 \mathrm{E}-01$ & $8.30 \mathrm{E}-01$ & $2.10 \mathrm{E}-01$ & $1.50 \mathrm{E}+00$ & $3.00 \mathrm{E}-06$ \\
\hline Tc-99 & $4.90 \mathrm{E}-03$ & $5.40 \mathrm{E}-03$ & $4.30 \mathrm{E}-03$ & $1.50 \mathrm{E}-02$ & $2.90 \mathrm{E}-08$ \\
\hline Th-228 & $1.10 \mathrm{E}+00$ & $1.90 \mathrm{E}+02$ & $8.30 \mathrm{E}+01$ & $2.70 \mathrm{E}+02$ & 5.40E-04 \\
\hline Th-229 & $1.20 \mathrm{E}+01$ & $1.40 \mathrm{E}+03$ & $2.70 \mathrm{E}+01$ & $1.40 \mathrm{E}+03$ & $2.90 \mathrm{E}-03$ \\
\hline Th-230 & $1.90 \mathrm{E}+00$ & $2.10 \mathrm{E}+02$ & $3.50 \mathrm{E}-02$ & $2.10 \mathrm{E}+02$ & $4.30 \mathrm{E}-04$ \\
\hline Th-232 & $9.20 \mathrm{E}+00$ & $1.10 \mathrm{E}+03$ & $1.60 \mathrm{E}-02$ & $1.10 \mathrm{E}+03$ & $2.10 \mathrm{E}-03$ \\
\hline U-232 & $4.40 \mathrm{E}+00$ & $4.30 \mathrm{E}+02$ & $2.60 \mathrm{E}-02$ & $4.30 \mathrm{E}+02$ & 8.60E-04 \\
\hline U-233 & $9.80 \mathrm{E}-01$ & $8.80 \mathrm{E}+01$ & $4.30 \mathrm{E}-02$ & $8.90 \mathrm{E}+01$ & $1.80 \mathrm{E}-04$ \\
\hline U-234 & $9.60 \mathrm{E}-01$ & $8.60 \mathrm{E}+01$ & 1.30E-02 & $8.70 \mathrm{E}+01$ & 1.70E-04 \\
\hline U-235 & $9.00 \mathrm{E}-01$ & $8.00 \mathrm{E}+01$ & $1.70 \mathrm{E}+01$ & $9.80 E+01$ & $2.00 \mathrm{E}-04$ \\
\hline U-238 & 8.60E-01 & $7.70 \mathrm{E}+01$ & $2.00 \mathrm{E}+00$ & $8.00 \mathrm{E}+01$ & $1.60 \mathrm{E}-04$ \\
\hline $\mathrm{Zn}-65$ & $3.00 \mathrm{E}-02$ & $8.20 \mathrm{E}-03$ & $2.40 \mathrm{E}+01$ & $2.40 \mathrm{E}+01$ & $4.80 \mathrm{E}-05$ \\
\hline Zr-93 & $5.60 \mathrm{E}-03$ & 2.10E-01 & $0.00 \mathrm{E}+00$ & 2.10E-01 & 4.30E-07 \\
\hline
\end{tabular}

a Doses do not account for scrap dilution or radionuclide partitioning; collective doses based on $100 \mathrm{t}$. 
TABLE D.11 Baseline Worker Doses for a 2,000-h Industrial Products Slag Worker ${ }^{a}$

\begin{tabular}{|c|c|c|c|c|c|}
\hline Nuclide & $\begin{array}{r}\text { Ingestion } \\
(\mu \mathrm{Sv} / \mathrm{yr})\end{array}$ & $\begin{array}{c}\text { Inhalation } \\
\text { ( } \mu \mathrm{Sv} / \mathrm{yr})\end{array}$ & $\begin{array}{r}\text { External } \\
(\mu \mathrm{Sv} / \mathrm{yr})\end{array}$ & $\begin{array}{c}\text { Total Dose } \\
(\mu \mathrm{Sv} / \mathrm{yr})\end{array}$ & $\begin{array}{r}\text { Collective Dose } \\
\text { (person-Sv/yr) }\end{array}$ \\
\hline Ac-227 & $4.70 \mathrm{E}+02$ & $4.30 \mathrm{E}+04$ & $2.90 \mathrm{E}+02$ & $4.40 \mathrm{E}+04$ & $4.40 \mathrm{E}-02$ \\
\hline $\mathrm{Ag}-110 \mathrm{~m}$ & 2.30E-01 & $3.30 \mathrm{E}-01$ & $1.60 \mathrm{E}+03$ & $1.60 \mathrm{E}+03$ & 1.60E-03 \\
\hline Am-241 & $1.20 \mathrm{E}+02$ & $2.90 \mathrm{E}+03$ & $6.80 \mathrm{E}+00$ & $3.00 \mathrm{E}+03$ & - 3.00E-03 \\
\hline Am-243 & 1.20E+02 & $2.90 \mathrm{E}+03$ & 1.40E+02 & $3.10 \mathrm{E}+03$ & 3.10E-03 \\
\hline $\mathrm{Ca}-41$ & 4.30E-02 & 8.70E-03 & $0.00 \mathrm{E}+00$ & 5.20E-02 & 5.20E-08 \\
\hline Ce-144 & $4.70 \mathrm{E}-01$ & $1.60 \mathrm{E}+00$ & $3.10 \mathrm{E}+01$ & $3.30 \mathrm{E}+01$ & 3.30E-05 \\
\hline $\mathrm{Cl}-36$ & $1.00 \mathrm{E}-01$ & $1.40 \mathrm{E}-01$ & $3.60 \mathrm{E}-01$ & 6.00E-01 & 6.00E-07 \\
\hline $\mathrm{Cm}-243$ & $8.40 \mathrm{E}+01$ & $2.00 \mathrm{E}+03$ & $8.70 \mathrm{E}+01$ & $2.10 \mathrm{E}+03$ & 2.10E-03 \\
\hline $\mathrm{Cm}-244$ & $6.70 \mathrm{E}+01$ & $1.60 \mathrm{E}+03$ & $2.10 \mathrm{E}-02$ & $1.60 \mathrm{E}+03$ & 1.60E-03 \\
\hline $\mathrm{Cm}-245$ & $1.30 \mathrm{E}+02$ & $3.00 \mathrm{E}+03$ & $5.20 \mathrm{E}+01$ & $3.10 \mathrm{E}+03$ & 3.10E-03 \\
\hline $\mathrm{Cm}-246$ & $1.30 \mathrm{E}+02$ & $2.90 \mathrm{E}+03$ & $2.00 \mathrm{E}-02$ & $3.10 \mathrm{E}+03$ & 3.10E-03 \\
\hline $\mathrm{Cm}-247$ & $1.20 \mathrm{E}+02$ & $2.70 \mathrm{E}+03$ & $2.80 \mathrm{E}+02$ & $3.10 \mathrm{E}+03$ & $3.10 \mathrm{E}-03$ \\
\hline Co-57 & 2.70E-02 & $3.90 \mathrm{E}-02$ & $5.10 \mathrm{E}+01$ & $5.10 \mathrm{E}+01$ & 5.10E-05 \\
\hline Co-60 & $8.50 \mathrm{E}-01$ & $1.30 \mathrm{E}+00$ & $2.20 \mathrm{E}+03$ & $2.20 \mathrm{E}+03$ & 2.20E-03 \\
\hline Cs-134 & $2.10 \mathrm{E}+00$ & 2.50E-01 & $1.20 \mathrm{E}+03$ & $1.20 \mathrm{E} \div 03$ & 1.20E-03 \\
\hline Cs-135 & $2.40 \mathrm{E}-01$ & $3.00 \mathrm{E}-02$ & $0.00 \mathrm{E}+00$ & $2.70 \mathrm{E}-01$ & 2.70E-07 \\
\hline Cs-137 & $1.70 \mathrm{E}+00$ & $2.00 \mathrm{E}-01$ & $5.00 \mathrm{E}+02$ & $5.00 \mathrm{E}+02$ & 5.00E-04 \\
\hline Eu-152 & 2.10E-01 & $1.40 \mathrm{E}+00$ & $9.90 \mathrm{E}+02$ & $1.00 \mathrm{E}+03$ & 1.00E-03 \\
\hline Eu-154 & $3.10 \mathrm{E}-01$ & $1.80 \mathrm{E}+00$ & $1.10 \mathrm{E}+03$ & $1.10 \mathrm{E}+03$ & 1.10E-03 \\
\hline $\mathrm{Fe}-55$ & $1.80 \mathrm{E}-02$ & $1.50 \mathrm{E}-02$ & $0.00 \mathrm{E}+00$ & $3.30 \mathrm{E}-02$ & 3.30E-08 \\
\hline$M n-54$ & $6.40 \mathrm{E}-02$ & $3.00 \mathrm{E}-02$ & $5.20 \mathrm{E}+02$ & $5.20 \mathrm{E}+02$ & 5.20E-04 \\
\hline $\mathrm{Na}-22$ & $3.40 \mathrm{E}-01$ & $4.40 \mathrm{E}-02$ & $1.70 \mathrm{E}+03$ & $1.70 \mathrm{E}+03$ & 1.70E-03 \\
\hline Nb-94 & $2.40 \mathrm{E}-01$ & $2.70 \mathrm{E}+00$ & $1.40 \mathrm{E}+03$ & $1.40 \mathrm{E}+03$ & $1.40 \mathrm{E}-03$ \\
\hline $\mathrm{Ni}-59$ & 7.10E-03 & $1.80 \mathrm{E}-02$ & $0.00 \mathrm{E}+00$ & 2.50E-02 & 2.50E-08 \\
\hline $\mathrm{Ni}-63$ & $1.90 \mathrm{E}-02$ & 4.10E-02 & $0.00 \mathrm{E}+00$ & $6.00 \mathrm{E}-02$ & $6.00 \mathrm{E}-08$ \\
\hline Np-237 & $1.50 \mathrm{E}+02$ & $3.50 \mathrm{E}+03$ & $1.70 \mathrm{E}+02$ & $3.80 \mathrm{E}+03$ & 3.80E-03 \\
\hline $\mathrm{Pb}-210$ & $1.80 \mathrm{E}+02$ & $8.70 E+01$ & $3.80 \mathrm{E}-01$ & $2.70 \mathrm{E}+02$ & 2.70E-04 \\
\hline $\mathrm{Pm}-147$ & 3.10E-02 & 2.20E-01 & $6.70 \mathrm{E}-03$ & 2.60E-01 & 2.60E-07 \\
\hline $\mathrm{Pu}-238$ & 1.10E+02 & $2.50 E+03$ & 2.50E-02 & $2.60 \mathrm{E}+03$ & 2.60E-03 \\
\hline $\mathrm{Pu}-239$ & 1.20E+02 & $2.80 \mathrm{E}+03$ & $4.50 \mathrm{E}-02$ & $2.90 \mathrm{E}+03$ & 2.90E-03 \\
\hline $\mathrm{Pu}-240$ & $1.20 E+02$ & $2.80 \mathrm{E}+03$ & $2.40 \mathrm{E}-02$ & $2.90 \mathrm{E}+03$ & $2.90 \mathrm{E}-03$ \\
\hline $\mathrm{Pu}-241$ & $2.30 \mathrm{E}+00$ & $5.20 \mathrm{E}+01$ & $2.80 \mathrm{E}-03$ & $5.40 \mathrm{E}+01$ & 5.40E-05 \\
\hline Pu-242 & $1.10 E+02$ & $2.70 \mathrm{E}+03$ & $2.10 \mathrm{E}-02$ & $2.80 \mathrm{E}+03$ & 2.80E-03 \\
\hline Ru-106 & $6.70 \mathrm{E}-01$ & $2.20 \mathrm{E}+00$ & $1.40 \mathrm{E}+02$ & $1.40 \mathrm{E}+02$ & 1.40E-04 \\
\hline $\mathrm{Sb}-125$ & $8.40 \mathrm{E}-02$ & $7.00 \mathrm{E}-02$ & $3.20 \mathrm{E}+02$ & $3.20 \mathrm{E}+02$ & $3.20 \mathrm{E}-04$ \\
\hline Se-79 & $2.90 \mathrm{E}-01$ & $6.40 \mathrm{E}-02$ & $0.00 \mathrm{E}+00$ & $3.60 \mathrm{E}-01$ & 3.60E-07 \\
\hline$S m-151$ & $1.30 \mathrm{E}-02$ & $1.90 \mathrm{E}-01$ & $1.60 \mathrm{E}-04$ & 2.10E-01 & 2.10E-07 \\
\hline Sr-90 & $4.80 \mathrm{E}+00$ & $8.30 \mathrm{E}+00$ & $3: 30 \mathrm{E}+00$ & $1.60 \mathrm{E}+01$ & $1.60 \mathrm{E}-05$ \\
\hline Tc-99 & $4.90 \mathrm{E}-02$ & 5.40E-02 & $1.90 \mathrm{E}-02$ & 1.20E-01 & 1.20E-07 \\
\hline Th-228 & $1.10 \mathrm{E}+01$ & $1.90 \mathrm{E}+03$ & $1.20 \mathrm{E}+03$ & $3.10 \mathrm{E}+03$ & $3.10 \mathrm{E}-03$ \\
\hline Th-229 & $1.20 \mathrm{E}+02$ & $1.40 \mathrm{E}+04$ & $2.40 \mathrm{E}+02$ & $1.40 \mathrm{E}+04$ & $1.40 \mathrm{E}-02$ \\
\hline Th-230 & $1.90 \mathrm{E}+01$ & $2.10 \mathrm{E}+03$ & $1.90 \mathrm{E}-01$ & $2.10 \mathrm{E}+03$ & $2.10 \mathrm{E}-03$ \\
\hline Th-232 & $9.20 \mathrm{E}+01$ & $1.10 \mathrm{E}+04$ & $8.00 \mathrm{E}-02$ & $1.10 \mathrm{E}+04$ & $1.10 \mathrm{E}-02$ \\
\hline U-232 & $4.40 \mathrm{E}+01$ & $4.30 \mathrm{E}+03$ & $1.40 \mathrm{E}-01$ & $4.30 \mathrm{E}+03$ & 4.30E-03 \\
\hline U-233 & $9.80 \mathrm{E}+00$ & $8.80 \mathrm{E}+02$ & 2.10E-01 & $8.90 \mathrm{E}+02$ & 8.90E-04 \\
\hline U-234 & $9.60 \mathrm{E}+00$ & $8.60 \mathrm{E}+02$ & $6.20 \mathrm{E}-02$ & $8.70 \mathrm{E}+02$ & 8.70E-04 \\
\hline U-235 & $9.00 \mathrm{E}+00$ & $8.00 \mathrm{E}+02$ & $1.20 \mathrm{E}+02$ & $9.20 \mathrm{E}+02$ & 9.20E-04 \\
\hline U-238 & $8.60 \mathrm{E}+00$ & $7.70 \mathrm{E}+02$ & $2.00 \mathrm{E}+01$ & $8.00 \mathrm{E}+02$ & $8.00 \mathrm{E}-04$ \\
\hline $\mathrm{Zn}-65$ & $3.00 \mathrm{E}-01$ & $8.20 \mathrm{E}-02$ & $3.30 \mathrm{E}+02$ & $3.30 \mathrm{E}+02$ & 3.30E-04 \\
\hline Zr-93 & $5.60 \mathrm{E}-02$ & $2.10 E+00$ & $0.00 \mathrm{E}+00$ & $2.10 \mathrm{E}+00$ & 2.10E-06 \\
\hline
\end{tabular}

a Doses do not account for scrap dilution or radionuclide partitioning; collective doses based on $100 \mathrm{t}$. 
TABLE D.12 Baseline Worker Doses for a 2,000-h Industrial Products Loader ${ }^{a}$

\begin{tabular}{|c|c|c|c|c|c|}
\hline Nuclide & $\begin{array}{r}\text { Ingestion } \\
(\mu \mathrm{Sv} / \mathrm{yr})\end{array}$ & $\begin{array}{c}\text { Inhalation } \\
(\mu \mathrm{Sv} / \mathrm{yr})\end{array}$ & $\begin{array}{l}\text { External } \\
(\mu \mathrm{Sv} / \mathrm{yr})\end{array}$ & $\begin{array}{c}\text { Total Dose } \\
(\mu \mathrm{Sv} / \mathrm{yr})\end{array}$ & $\begin{array}{r}\text { Collective Dose } \\
\text { (person-Sv/yr) }\end{array}$ \\
\hline Ac-227 & $0.00 \mathrm{E}+00$ & $0.00 \mathrm{E}+00$ & $6.00 \mathrm{E}+00$ & $6.00 \mathrm{E}+00$ & $1.20 \mathrm{E}-05$ \\
\hline $\mathrm{Ag}-110 \mathrm{~m}$ & $0.00 \mathrm{E}+00$ & $0.00 \mathrm{E}+00$ & $3.20 \mathrm{E}+01$ & $3.20 \mathrm{E}+01$ & $6.40 \mathrm{E}-05$ \\
\hline $\mathrm{Am}-241$ & $0.00 \mathrm{E}+00$ & $0.00 \mathrm{E}+00$ & $1.40 \mathrm{E}-01$ & $1.40 \mathrm{E}-01$ & $2.80 \mathrm{E}-07$ \\
\hline Am-243 & $0.00 \mathrm{E}+00$ & $0.00 \mathrm{E}+00$ & $2.80 \mathrm{E}+00$ & $2.80 \mathrm{E}+00$ & $5.50 \mathrm{E}-06$ \\
\hline Ca-41 & $0.00 \mathrm{E}+00$ & $0.00 \mathrm{E}+00$ & $0.00 \mathrm{E}+00$ & $0.00 \mathrm{E}+00$ & $0.00 \mathrm{E}+00$ \\
\hline Ce-144 & $0.00 \mathrm{E}+00$ & $0.00 \mathrm{E}+00$ & $6.40 \mathrm{E}-01$ & $6.40 \mathrm{E}-01$ & $1.30 \mathrm{E}-06$ \\
\hline Cl-36 & $0.00 \mathrm{E}+00$ & $0.00 \mathrm{E}+00$ & $7.20 \mathrm{E}-03$ & $7.20 \mathrm{E}-03$ & $1.40 \mathrm{E}-08$ \\
\hline $\mathrm{Cm}-243$ & $0.00 \mathrm{E}+00$ & $0.00 \mathrm{E}+00$ & $1.80 \mathrm{E}+00$ & $1.80 \mathrm{E}+00$ & $3.60 \mathrm{E}-06$ \\
\hline $\mathrm{Cm}-244$ & $0.00 \mathrm{E}+00$ & $0.00 \mathrm{E}+00$ & 3.30E-04 & 3.30E-04 & $6.60 \mathrm{E}-10$ \\
\hline $\mathrm{Cm}-245$ & $0.00 \mathrm{E}+00$ & $0.00 \mathrm{E}+00$ & $1.10 \mathrm{E}+00$ & $1.10 \mathrm{E}+00$ & $2.10 \mathrm{E}-06$ \\
\hline $\mathrm{Cm}-246$ & $0.00 \mathrm{E}+00$ & $0.00 \mathrm{E}+00$ & $2.90 \mathrm{E}-04$ & $2.90 \mathrm{E}-04$ & $5.80 \mathrm{E}-10$ \\
\hline $\mathrm{Cm}-247$ & $0.00 \mathrm{E}+00$ & $0.00 \mathrm{E}+00$ & $5.60 \mathrm{E}+00$ & $5.60 \mathrm{E}+00$ & $1.10 \mathrm{E}-05$ \\
\hline Co-57 & $0.00 \mathrm{E}+00$ & $0.00 \mathrm{E}+00$ & $1.00 \mathrm{E}+00$ & $1.00 \mathrm{E}+00$ & $2.10 \mathrm{E}-06$ \\
\hline Co-60 & $0.00 \mathrm{E}+00$ & $0.00 \mathrm{E}+00$ & $4.50 \mathrm{E}+01$ & $4.50 \mathrm{E}+01$ & $9.00 \mathrm{E}-05$ \\
\hline Cs-134 & $0.00 \mathrm{E}+00$ & $0.00 \mathrm{E}+00$ & $2.40 \mathrm{E}+01$ & $2.40 \mathrm{E}+01$ & $4.80 \mathrm{E}-05$ \\
\hline Cs-135 & $0.00 \mathrm{E}+00$ & $0.00 \mathrm{E}+00$ & $0.00 \mathrm{E}+00$ & $0.00 \mathrm{E}+00$ & $0.00 \mathrm{E}+00$ \\
\hline Cs-137 & $0.00 \mathrm{E}+00$ & $0.00 \mathrm{E}+00$ & $1.00 \mathrm{E}+01$ & $1.00 \mathrm{E}+01$ & 2.00E-05 \\
\hline Eu-152 & $0.00 \mathrm{E}+00$ & $0.00 \mathrm{E}+00$ & $2.00 \mathrm{E}+01$ & $2.00 \mathrm{E}+01$ & 4.10E-05 \\
\hline Eu-154 & $0.00 \mathrm{E}+00$ & $0.00 \mathrm{E}+00$ & $2.20 \mathrm{E}+01$ & $2.20 \mathrm{E}+01$ & $4.40 \mathrm{E}-05$ \\
\hline Fe-55 & $0.00 \mathrm{E}+00$ & $0.00 \mathrm{E}+00$ & $0.00 \mathrm{E}+00$ & $0.00 \mathrm{E}+00$ & $0.00 \mathrm{E}+00$ \\
\hline Mn-54 & $0.00 \mathrm{E}+00$ & $0.00 \mathrm{E}+00$ & $1.00 \mathrm{E}+01$ & $1.00 \mathrm{E}+01$ & 2.10E-05 \\
\hline $\mathrm{Na}-22$ & $0.00 \mathrm{E}+00$ & $0.00 \mathrm{E}+00$ & $3.60 \mathrm{E}+01$ & $3.60 \mathrm{E}+01$ & 7.10E-05 \\
\hline $\mathrm{Nb}-94$ & $0.00 \mathrm{E}+00$ & $0.00 \mathrm{E}+00$ & $2.90 \mathrm{E}+01$ & $2.90 \mathrm{E}+01$ & $5.80 \mathrm{E}-05$ \\
\hline Ni-59 & $0.00 \mathrm{E}+00$ & $0.00 \mathrm{E}+00$ & $0.00 \mathrm{E}+00$ & $0.00 \mathrm{E}+00$ & $0.00 \mathrm{E}+00$ \\
\hline $\mathrm{Ni}-63$ & $0.00 \mathrm{E}+00$ & $0.00 \mathrm{E}+00$ & $0.00 \mathrm{E}+00$ & $0.00 \mathrm{E}+00$ & $0.00 \mathrm{E}+00$ \\
\hline $\mathrm{Np}-237$ & $0.00 \mathrm{E}+00$ & $0.00 \mathrm{E}+00$ & $3.40 \mathrm{E}+00$ & $3.40 \mathrm{E}+00$ & $6.70 \mathrm{E}-06$ \\
\hline $\mathrm{Pb}-210$ & $0.00 \mathrm{E}+00$ & $0.00 \mathrm{E}+00$ & $7.60 \mathrm{E}-03$ & $7.60 \mathrm{E}-03$ & $1.50 \mathrm{E}-08$ \\
\hline Pm-147 & $0.00 \mathrm{E}+00$ & $0.00 \mathrm{E}+00$ & $1.40 \mathrm{E}-04$ & $1.40 \mathrm{E}-04$ & $2.70 \mathrm{E}-10$ \\
\hline $\mathrm{Pu}-238$ & $0.00 \mathrm{E}+00$ & $0.00 \mathrm{E}+00$ & $4.10 \mathrm{E}-04$ & $4.10 \mathrm{E}-04$ & $8.20 \mathrm{E}-10$ \\
\hline $\mathrm{Pu}-239$ & $0.00 \mathrm{E}+00$ & $0.00 \mathrm{E}+00$ & $9.20 \mathrm{E}-04$ & $9.20 \mathrm{E}-04$ & $1.80 \mathrm{E}-09$ \\
\hline $\mathrm{Pu}-240$ & $0.00 E+00$ & $0.00 \mathrm{E}+00$ & $4.00 \mathrm{E}-04$ & $4.00 \mathrm{E}-04$ & $8.00 \mathrm{E}-10$ \\
\hline Pu-241 & $0.00 \mathrm{E}+00$ & $0.00 \mathrm{E}+00$ & $5.80 \mathrm{E}-05$ & $5.80 \mathrm{E}-05$ & $1.20 \mathrm{E}-10$ \\
\hline $\mathrm{Pu}-242$ & $0.00 \mathrm{E}+00$ & $0.00 \mathrm{E}+00$ & 3.50E-04 & $3.50 \mathrm{E}-04$ & 7.10E-10 \\
\hline Ru-106 & $0.00 \mathrm{E}+00$ & $0.00 \mathrm{E}+00$ & $2.80 \mathrm{E}+00$ & $2.80 \mathrm{E}+00$ & $5.60 \mathrm{E}-06$ \\
\hline Sb-125 & $0.00 \mathrm{E}+00$ & $0.00 \mathrm{E}+00$ & $6.50 \mathrm{E}+00$ & $6.50 \mathrm{E}+00$ & 1.30E-05 \\
\hline Se-79 & $0.00 \mathrm{E}+00$ & $0.00 \mathrm{E}+00$ & $0.00 \mathrm{E}+00$ & $0.00 \mathrm{E}+00$ & $0.00 \mathrm{E}+00$ \\
\hline Sm-151 & $0.00 \mathrm{E}+00$ & $0.00 \mathrm{E}+00$ & $2.80 \mathrm{E}-06$ & $2.80 \mathrm{E}-06$ & $5.70 \mathrm{E}-12$ \\
\hline Sr-90 & $0.00 \mathrm{E}+00$ & $0.00 \mathrm{E}+00$ & $7.00 \mathrm{E}-02$ & $7.00 \mathrm{E}-02$ & $1.40 \mathrm{E}-07$ \\
\hline Tc-99 & $0.00 \mathrm{E}+00$ & $0.00 \mathrm{E}+00$ & $4.00 \mathrm{E}-04$ & $4.00 \mathrm{E}-04$ & $7.90 \mathrm{E}-10$ \\
\hline Th-228 & $0.00 \mathrm{E}+00$ & $0.00 \mathrm{E}+00$ & $2.50 \mathrm{E}+01$ & $2.50 \mathrm{E}+01$ & $5.10 \mathrm{E}-05$ \\
\hline Th-229 & $0.00 \mathrm{E}+00$ & $0.00 \mathrm{E}+00$ & $4.80 \mathrm{E}+00$ & $4.80 E+00$ & $9.70 \mathrm{E}-06$ \\
\hline Th-230 & $0.00 \mathrm{E}+00$ & $0.00 \mathrm{E}+00$ & $3.80 \mathrm{E}-03$ & 3.80E-03 & $7.50 \mathrm{E}-09$ \\
\hline Th-232 & $0.00 \mathrm{E}+00$ & $0.00 \mathrm{E}+00$ & $1.60 \mathrm{E}-03$ & 1.60E-03 & $3.20 \mathrm{E}-09$ \\
\hline U-232 & $0.00 \mathrm{E}+00$ & $0.00 \mathrm{E}+00$ & $2.80 \mathrm{E}-03$ & $2.80 \mathrm{E}-03$ & $5.60 \mathrm{E}-09$ \\
\hline U-233 & $0.00 \mathrm{E}+00$ & $0.00 \mathrm{E}+00$ & $4.40 \mathrm{E}-03$ & $4.40 \mathrm{E}-03$ & $8.80 \mathrm{E}-09$ \\
\hline U-234 & $0.00 \mathrm{E}+00$ & $0.00 \mathrm{E}+00$ & $1.20 \mathrm{E}-03$ & $1.20 \mathrm{E}-03$ & $2.50 \mathrm{E}-09$ \\
\hline U-235 & $0.00 \mathrm{E}+00$ & $0.00 \mathrm{E}+00$ & $2.30 \mathrm{E}+00$ & $2.30 \mathrm{E}+00$ & 4.70E-06 \\
\hline U-238 & $0.00 \mathrm{E}+00$ & $0.00 \mathrm{E}+00$ & $4.00 \mathrm{E}-01$ & $4.00 \mathrm{E}-01$ & $7.90 \mathrm{E}-07$ \\
\hline Zn-65 & $0.00 \mathrm{E}+00$ & $0.00 \mathrm{E}+00$ & $6.80 \mathrm{E}+00$ & $6.80 \mathrm{E}+00$ & $1.40 \mathrm{E}-05$ \\
\hline $\mathrm{Zr}-93$ & $0.00 \mathrm{E}+00$ & $0.00 \mathrm{E}+00$ & $0.00 \mathrm{E}+00$ & $0.00 \mathrm{E}+00$ & $0.00 \mathrm{E}+00$ \\
\hline
\end{tabular}

a Doses do not account for scrap dilution or radionuclide partitioning; collective doses based on $100 \mathrm{t}$. 
TABLE D.13 Baseline Worker Doses for a 2,000-h Industrial Products Truck Driver ${ }^{a}$

\begin{tabular}{|c|c|c|c|c|c|}
\hline Nuclide & $\begin{array}{r}\text { Ingestion } \\
(\mu \mathrm{Sv} / \mathrm{yr})\end{array}$ & $\begin{array}{c}\text { Inhalation } \\
(\mu \mathrm{Sv} / \mathrm{yr})\end{array}$ & $\begin{array}{l}\text { External } \\
(\mu \mathrm{Sv} / \mathrm{yr})\end{array}$ & $\begin{array}{c}\text { Total Dose } \\
(\mu \mathrm{Sv} / \mathrm{yr})\end{array}$ & $\begin{array}{r}\text { Collective Dose } \\
\text { (person-Sv/yr) }\end{array}$ \\
\hline Ac-227 & $0.00 \mathrm{E}+00$ & $0.00 \mathrm{E}+00$ & $5.30 \mathrm{E}+00$ & $5.30 \mathrm{E}+00$ & $2.60 \mathrm{E}-05$ \\
\hline $\mathrm{Ag}-110 \mathrm{~m}$ & $0.00 \mathrm{E}+00$ & $0.00 \mathrm{E}+00$ & $2.80 \mathrm{E}+01$ & $2.80 \mathrm{E}+01$ & $1.40 \mathrm{E}-04$ \\
\hline Am-241 & $0.00 \mathrm{E}+00$ & $0.00 \mathrm{E}+00$ & $1.30 \mathrm{E}-01$ & 1.30E-01 & $6.40 \mathrm{E}-07$ \\
\hline Am-243 & $0.00 \mathrm{E}+00$ & $0.00 \mathrm{E}+00$ & $2.50 \mathrm{E}+00$ & $2.50 \mathrm{E}+00$ & $1.20 \mathrm{E}-05$ \\
\hline $\mathrm{Ca}-41$ & $0.00 \mathrm{E}+00$ & $0.00 \mathrm{E}+00$ & $0.00 \mathrm{E}+00$ & $0.00 \mathrm{E}+00$ & $0.00 \mathrm{E}+00$ \\
\hline Ce-144 & $0.00 \mathrm{E}+00$ & $0.00 \mathrm{E}+00$ & $5.70 \mathrm{E}-01$ & $5.70 \mathrm{E}-01$ & $2.80 \mathrm{E}-06$ \\
\hline Cl-36 & $0.00 \mathrm{E}+00$ & $0.00 \mathrm{E}+00$ & $6.30 \mathrm{E}-03$ & $6.30 \mathrm{E}-03$ & $3.20 \mathrm{E}-08$ \\
\hline $\mathrm{Cm}-243$ & $0.00 \mathrm{E}+00$ & $0.00 \mathrm{E}+00$ & $1.60 \mathrm{E}+00$ & $1.60 \mathrm{E}+00$ & $8.00 \mathrm{E}-06$ \\
\hline $\mathrm{Cm}-244$ & $0.00 \mathrm{E}+00$ & $0.00 \mathrm{E}+00$ & $3.90 \mathrm{E}-04$ & $3.90 \mathrm{E}-04$ & $1.90 \mathrm{E}-09$ \\
\hline $\mathrm{Cm}-245$ & $0.00 \mathrm{E}+00$ & $0.00 \mathrm{E}+00$ & $9.60 \mathrm{E}-01$ & $9.60 \mathrm{E}-01$ & $4.80 \mathrm{E}-06$ \\
\hline $\mathrm{Cm}-246$ & $0.00 \mathrm{E}+00$ & $0.00 \mathrm{E}+00$ & $3.70 \mathrm{E}-04$ & $3.70 \mathrm{E}-04$ & $1.90 \mathrm{E}-09$ \\
\hline $\mathrm{Cm}-247$ & $0.00 \mathrm{E}+00$ & $0.00 \mathrm{E}+00$ & $4.90 \mathrm{E}+00$ & $4.90 \mathrm{E} \div 00$ & 2.50E-05 \\
\hline Co-57 & $0.00 \mathrm{E}+00$ & $0.00 \mathrm{E}+00$ & $9.50 \mathrm{E}-01$ & $9.50 \mathrm{E}-01$ & $4.70 \mathrm{E}-06$ \\
\hline Co-60 & $0.00 \mathrm{E}+00$ & $0.00 \mathrm{E}+00$ & $4.00 \mathrm{E}+01$ & $4.00 \mathrm{E}+01$ & $2.00 \mathrm{E}-04$ \\
\hline Cs-134 & $0.00 \mathrm{E}+00$ & $0.00 \mathrm{E}+00$ & $2.10 \mathrm{E}+01$ & $2.10 \mathrm{E}+01$ & $1.10 \mathrm{E}-04$ \\
\hline Cs-135 & $0.00 \mathrm{E}+00$ & $0.00 \mathrm{E}+00$ & $0.00 \mathrm{E}+00$ & $0.00 \mathrm{E}+00$ & $0.00 \mathrm{E}+00$ \\
\hline Cs-137 & $0.00 \mathrm{E}+00$ & $0.00 \mathrm{E}+00$ & $8.80 \mathrm{E}+00$ & $8.80 E+00$ & $4.40 \mathrm{E}-05$ \\
\hline Eu-152 & $0.00 \mathrm{E}+00$ & $0.00 \mathrm{E}+00$ & $1.80 \mathrm{E}+01$ & $1.80 \mathrm{E}+01$ & $8.90 \mathrm{E}-05$ \\
\hline Eu-154 & $0.00 \mathrm{E}+00$ & $0.00 \mathrm{E}+00$ & $1.90 \mathrm{E}+01$ & $1.90 \mathrm{E}+01$ & $9.70 \mathrm{E}-05$ \\
\hline Fe-55 & $0.00 \mathrm{E}+00$ & $0.00 \mathrm{E}+00$ & $0.00 \mathrm{E}+00$ & $0.00 \mathrm{E}+00$ & $0.00 \mathrm{E}+00$ \\
\hline$M n-54$ & $0.00 \mathrm{E}+00$ & $0.00 \mathrm{E}+00$ & $9.30 \mathrm{E}+00$ & $9.30 \mathrm{E}+00$ & $4.60 \mathrm{E}-05$ \\
\hline $\mathrm{Na}-22$ & $0.00 \mathrm{E}+00$ & $0.00 \mathrm{E}+00$ & $3.20 \mathrm{E}+01$ & $3.20 \mathrm{E}+01$ & $1.60 \mathrm{E}-04$ \\
\hline $\mathrm{Nb}-94$ & $0.00 \mathrm{E}+00$ & $0.00 \mathrm{E}+00$ & $2.50 \mathrm{E}+01$ & $2.50 \mathrm{E}+01$ & 1.30E-04 \\
\hline Ni-59 & $0.00 \mathrm{E}+00$ & $0.00 \mathrm{E}+00$ & $0.00 \mathrm{E}+00$ & $0.00 \mathrm{E}+00$ & $0.00 \mathrm{E}+00$ \\
\hline $\mathrm{Ni}-63$ & $0.00 \mathrm{E}+00$ & $0.00 \mathrm{E}+00$ & $0.00 \mathrm{E}+00$ & $0.00 \mathrm{E}+00$ & $0.00 \mathrm{E}+00$ \\
\hline Np-237 & $0.00 \mathrm{E}+00$ & $0.00 \mathrm{E}+00$ & $3.00 \mathrm{E}+00$ & $3.00 \mathrm{E}+00$ & $1.50 \mathrm{E}-05$ \\
\hline $\mathrm{Pb}-210$ & $0.00 \mathrm{E}+00$ & $0.00 E+00$ & $7.10 \mathrm{E}-03$ & 7.10E-03 & $3.60 \mathrm{E}-08$ \\
\hline $\mathrm{Pm}-147$ & $0.00 \mathrm{E}+00$ & $0.00 \mathrm{E}+00$ & $1.20 \mathrm{E}-04$ & $1.20 \mathrm{E}-04$ & $6.20 \mathrm{E}-10$ \\
\hline $\mathrm{Pu}-238$ & $0.00 \mathrm{E}+00$ & $0.00 \mathrm{E}+00$ & $4.70 \mathrm{E}-04$ & $4.70 \mathrm{E}-04$ & 2.30E-09 \\
\hline Pu-239 & $0.00 \mathrm{E}+00$ & $0.00 \mathrm{E}+00$ & $8.50 \mathrm{E}-04$ & 8.50E-04 & $4.20 \mathrm{E}-09$ \\
\hline $\mathrm{Pu}-240$ & $0.00 \mathrm{E}+00$ & $0.00 \mathrm{E}+00$ & $4.50 \mathrm{E}-04$ & $4.50 \mathrm{E}-04$ & $2.30 \mathrm{E}-09$ \\
\hline $\mathrm{Pu}-241$ & $0.00 \mathrm{E}+00$ & $0.00 \mathrm{E}+00$ & $5.20 \mathrm{E}-05$ & $5.20 \mathrm{E}-05$ & $2.60 \mathrm{E}-10$ \\
\hline $\mathrm{Pu}-242$ & $0.00 \mathrm{E}+00$ & $0.00 \mathrm{E}+00$ & $3.90 \mathrm{E}-04$ & $3.90 \mathrm{E}-04$ & 2.00E-09 \\
\hline Ru-106 & $0.00 \mathrm{E}+00$ & $0.00 \mathrm{E}+00$ & $2.50 \mathrm{E}+00$ & $2.50 \mathrm{E}+00$ & $1.20 \mathrm{E}-05$ \\
\hline Sb-125 & $0.00 \mathrm{E}+00$ & $0.00 \mathrm{E}+00$ & $5.70 \mathrm{E}+00$ & $5.70 \mathrm{E}+00$ & $2.90 \mathrm{E}-05$ \\
\hline Se-79 & $0.00 E+00$ & $0.00 \mathrm{E}+00$ & $0.00 \mathrm{E}+00$ & $0.00 \mathrm{E}+00$ & $0.00 \mathrm{E}+00$ \\
\hline Sm-151 & $0.00 \mathrm{E}+00$ & $0.00 \mathrm{E}+00$ & $3.10 \mathrm{E}-06$ & 3.10E-06 & $1.50 \mathrm{E}-11$ \\
\hline Sr-90 & $0.00 \mathrm{E}+00$ & $0.00 \mathrm{E}+00$ & $6.10 \mathrm{E}-02$ & $6.10 \mathrm{E}-02$ & $3.00 \mathrm{E}-07$ \\
\hline Tc-99 & $0.00 \mathrm{E}+00$ & $0.00 \mathrm{E}+00$ & $3.60 \mathrm{E}-04$ & 3.60E-04 & $1.80 \mathrm{E}-09$ \\
\hline Th-228 & $0.00 \mathrm{E}+00$ & $0.00 \mathrm{E}+00$ & $2.20 \mathrm{E}+01$ & $2.20 \mathrm{E}+01$ & $1.10 \mathrm{E}-04$ \\
\hline Th-229 & $0.00 \mathrm{E}+00$ & $0.00 \mathrm{E}+00$ & $4.30 \mathrm{E}+00$ & $4.30 \mathrm{E}+00$ & $2.20 \mathrm{E}-05$ \\
\hline Th-230 & $0.00 \mathrm{E}+00$ & $0.00 \mathrm{E}+00$ & $3.40 \mathrm{E}-03$ & $3.40 \mathrm{E}-03$ & $1.70 \mathrm{E}-08$ \\
\hline Th-232 & $0.00 \mathrm{E}+00$ & $0.00 \mathrm{E}+00$ & $1.50 \mathrm{E}-03$ & $1.50 \mathrm{E}-03$ & $7.50 \mathrm{E}-09$ \\
\hline U-232 & $0.00 \mathrm{E}+00$ & $0.00 \mathrm{E}+00$ & 2.60E-03 & $2.60 \mathrm{E}-03$ & $1.30 \mathrm{E}-08$ \\
\hline U-233 & $0.00 \mathrm{E}+00$ & $0.00 \mathrm{E}+00$ & $4.00 \mathrm{E}-03$ & $4.00 \mathrm{E}-03$ & $2.00 \mathrm{E}-08$ \\
\hline U-234 & $0.00 \mathrm{E}+00$ & $0.00 \mathrm{E}+00$ & $1.20 \mathrm{E}-03$ & $1.20 \mathrm{E}-03$ & $5.80 \mathrm{E}-09$ \\
\hline U-235 & $0.00 \mathrm{E}+00$ & $0.00 \mathrm{E}+00$ & $2.10 \mathrm{E}+00$ & $2.10 \mathrm{E}+00$ & $1.10 \mathrm{E}-05$ \\
\hline U-238 & $0.00 \mathrm{E}+00$ & $0.00 \mathrm{E}+00$ & $3.50 \mathrm{E}-01$ & $3.50 \mathrm{E}-01$ & $1.80 \mathrm{E}-06$ \\
\hline $\mathrm{Zn}-65$ & $0.00 \mathrm{E}+00$ & $0.00 \mathrm{E}+00$ & $6.00 \mathrm{E}+00$ & $6.00 \mathrm{E}+00$ & $3.00 \mathrm{E}-05$ \\
\hline $\mathrm{Zr}-93$ & $0.00 \mathrm{E}+00$ & $0.00 \mathrm{E}+00$ & $0.00 \mathrm{E}+00$ & $0.00 \mathrm{E}+00$ & $0.00 \mathrm{E}+00$ \\
\hline
\end{tabular}

a Doses do not account for scrap dilution or radionuclide partitioning; collective doses based on $100 \mathrm{t}$. 
TABLE D.14 Baseline Worker Doses for a 2,000-h Initial Fabrication Yard Worker ${ }^{\mathrm{a}}$

\begin{tabular}{|c|c|c|c|c|c|}
\hline Nuclide & $\begin{array}{r}\text { Ingestion } \\
(\mu \mathrm{Sv} / \mathrm{yr})\end{array}$ & $\begin{array}{c}\text { Inhalation } \\
(\mu \mathrm{Sv} / \mathrm{yr})\end{array}$ & $\begin{array}{c}\text { External } \\
(\mu \mathrm{Sv} / \mathrm{yr})\end{array}$ & $\begin{array}{c}\text { Total Dose } \\
(\mu \mathrm{Sv} / \mathrm{yr})\end{array}$ & $\begin{array}{r}\text { Collective Dose } \\
\text { (person-Sv/yr) }\end{array}$ \\
\hline Ac-227 & $0.00 \mathrm{E}+00$ & $0.00 \mathrm{E}+00$ & $1.10 \mathrm{E}+00$ & $1.10 \mathrm{E}+00$ & $1.10 \mathrm{E}-05$ \\
\hline $\mathrm{Ag}-110 \mathrm{~m}$ & $0.00 \mathrm{E}+00$ & $0.00 \mathrm{E}+00$ & $5.80 \mathrm{E}+00$ & $5.80 \mathrm{E}+00$ & $5.80 \mathrm{E}-05$ \\
\hline Am-241 & $0.00 \mathrm{E}+00$ & $0.00 \mathrm{E}+00$ & $2.20 \mathrm{E}-02$ & $2.20 \mathrm{E}-02$ & $2.20 \mathrm{E}-07$ \\
\hline Am-243 & $0.00 \mathrm{E}+00$ & $0.00 \mathrm{E}+00$ & $4.80 \mathrm{E}-01$ & $4.80 \mathrm{E}-01$ & $4.80 \mathrm{E}-06$ \\
\hline $\mathrm{Ca}-41$ & $0.00 \mathrm{E}+00$ & $0.00 \mathrm{E}+00$ & $0.00 \mathrm{E}+00$ & $0.00 E+00$ & $0.00 \mathrm{E}+00$ \\
\hline Ce-144 & $0.00 \mathrm{E}+00$ & $0.00 \mathrm{E}+00$ & $1.10 \mathrm{E}-01$ & $1.10 \mathrm{E}-01$ & $1.10 \mathrm{E}-06$ \\
\hline $\mathrm{Cl}-36$ & $0.00 \mathrm{E}+00$ & $0.00 \mathrm{E}+00$ & $1.30 \mathrm{E}-03$ & $1.30 \mathrm{E}-03$ & 1.30E-08 \\
\hline $\mathrm{Cm}-243$ & $0.00 \mathrm{E}+00$ & $0.00 \mathrm{E}+00$ & $3.10 \mathrm{E}-01$ & $3.10 \mathrm{E}-01$ & 3.10E-06 \\
\hline $\mathrm{Cm}-244$ & $0.00 \mathrm{E}+00$ & $0.00 \mathrm{E}+00$ & 3.60E-05 & $3.60 \mathrm{E}-05$ & 3.60E-10 \\
\hline $\mathrm{Cm}-245$ & $0.00 \mathrm{E}+00$ & $0.00 \mathrm{E}+00$ & $1.80 \mathrm{E}-01$ & $1.80 \mathrm{E}-01$ & $1.80 \mathrm{E}-06$ \\
\hline $\mathrm{Cm}-246$ & $0.00 \mathrm{E}+00$ & $0.00 E+00$ & 2.50E-05 & 2.50E-05 & $2.50 \mathrm{E}-10$ \\
\hline $\mathrm{Cm}-247$ & $0.00 \mathrm{E}+00$ & $0.00 \mathrm{E}+00$ & $1.00 \mathrm{E} \div 00$ & $1.00 \mathrm{E}+00$ & $1.00 \mathrm{E}-05$ \\
\hline Co-57 & $0.00 \mathrm{E}+00$ & $0.00 \mathrm{E}+00$ & 1.80E-01 & 1.80E-01 & $1.80 \mathrm{E}-06$ \\
\hline Co-60 & $0.00 \mathrm{E}+00$ & $0.00 \mathrm{E}+00$ & $8.10 \mathrm{E}+00$ & $8.10 \mathrm{E}+00$ & $8.10 \mathrm{E}-05$ \\
\hline Cs-134 & $0.00 \mathrm{E}+00$ & $0.00 \mathrm{E}+00$ & $4.30 \mathrm{E}+00$ & $4.30 \mathrm{E}+00$ & 4.30E-05 \\
\hline Cs-135 & $0.00 \mathrm{E}+00$ & $0.00 \mathrm{E}+00$ & $0.00 \mathrm{E}+00$ & $0.00 \mathrm{E}+00$ & $0.00 \mathrm{E}+00$ \\
\hline Cs-137 & $0.00 \mathrm{E}+00$ & $0.00 \mathrm{E}+00$ & $1.80 \mathrm{E}+00$ & $1.80 \mathrm{E}+00$ & $1.80 \mathrm{E}-05$ \\
\hline Eu-152 & $0.00 \mathrm{E}+00$ & $0.00 \mathrm{E}+00$ & $3.60 \mathrm{E}+00$ & $3.60 \mathrm{E}+00$ & $3.60 \mathrm{E}-05$ \\
\hline Eu-154 & $0.00 \mathrm{E}+00$ & $0.00 \mathrm{E}+00$ & $3.90 \mathrm{E}+00$ & $3.90 \mathrm{E}+00$ & 3.90E-05 \\
\hline $\mathrm{Fe}-55$ & $0.00 \mathrm{E}+00$ & $0.00 \mathrm{E}+00$ & $0.00 \mathrm{E}+00$ & $0.00 \mathrm{E}+00$ & $0.00 \mathrm{E}+00$ \\
\hline $\mathrm{Mn}-54$ & $0.00 \mathrm{E}+00$ & $0.00 \mathrm{E}+00$ & $1.90 \mathrm{E}+00$ & $1.90 \mathrm{E}+00$ & $1.90 \mathrm{E}-05$ \\
\hline $\mathrm{Na}-22$ & $0.00 \mathrm{E}+00$ & $0.00 \mathrm{E}+00$ & $6.40 \mathrm{E}+00$ & $6.40 \mathrm{E}+00$ & $6.40 \mathrm{E}-05$ \\
\hline $\mathrm{Nb}-94$ & $0.00 \mathrm{E}+00$ & $0.00 \mathrm{E}+00$ & $5.10 \mathrm{E}+00$ & $5.10 \mathrm{E}+00$ & 5.10E-05 \\
\hline Ni-59 & $0.00 \mathrm{E}+00$ & $0,00 \mathrm{E}+00$ & $0.00 \mathrm{E}+00$ & $0.00 \mathrm{E}+00$ & $0.00 \mathrm{E}+00$ \\
\hline $\mathrm{Ni}-63$ & $0.00 \mathrm{E}+00$ & $0.00 \mathrm{E}+00$ & $0.00 E+00$ & $0.00 \mathrm{E}+00$ & $0.00 \mathrm{E}+00$ \\
\hline Np-237 & $0.00 \mathrm{E}+00$ & $0.00 \mathrm{E}+00$ & 5.90E-01 & $5.90 \mathrm{E}-01$ & $5.90 \mathrm{E}-06$ \\
\hline $\mathrm{Pb}-210$ & $0.00 \mathrm{E}+00$ & $0.00 \mathrm{E}+00$ & $1.20 \mathrm{E}-03$ & $1.20 \mathrm{E}-03$ & $1.20 \mathrm{E}-08$ \\
\hline Pm-147 & $0.00 \mathrm{E}+00$ & $0.00 \mathrm{E}+00$ & $2.40 \mathrm{E}-05$ & 2.40E-05 & 2.40E-10 \\
\hline $\mathrm{Pu}-238$ & $0.00 \mathrm{E}+00$ & $0.00 \mathrm{E}+00$ & $5.20 \mathrm{E}-05$ & $5.20 \mathrm{E}-05$ & $5.20 \mathrm{E}-10$ \\
\hline Pu-239 & $0.00 \mathrm{E}+00$ & $0.00 \mathrm{E}+00$ & $1.50 \mathrm{E}-04$ & $1.50 \mathrm{E}-04$ & 1.50E-09 \\
\hline $\mathrm{Pu}-240$ & $0.00 \mathrm{E}+00$ & $0.00 \mathrm{E}+00$ & $5.20 \mathrm{E}-05$ & $5.20 \mathrm{E}-05$ & $5.20 \mathrm{E}-10$ \\
\hline $\mathrm{Pu}-241$ & $0.00 \mathrm{E}+00$ & $0.00 \mathrm{E}+00$ & $9.90 \mathrm{E}-06$ & $9.90 \mathrm{E}-06$ & $9.90 \mathrm{E}-11$ \\
\hline $\mathrm{Pu}-242$ & $0.00 \mathrm{E}+00$ & $0.00 \mathrm{E}+00$ & $4.70 \mathrm{E}-05$ & 4.70E-05 & $4.70 \mathrm{E}-10$ \\
\hline Ru-106 & $0.00 \mathrm{E}+00$ & $0.00 \mathrm{E}+00$ & $5.00 \mathrm{E}-01$ & $5.00 \mathrm{E}-01$ & $5.00 \mathrm{E}-06$ \\
\hline $\mathrm{Sb}-125$ & $0.00 \mathrm{E}+00$ & $0.00 \mathrm{E}+00$ & $1.20 \mathrm{E}+00$ & $1.20 \mathrm{E}+00$ & $1.20 \mathrm{E}-05$ \\
\hline Se-79 & $0.00 \mathrm{E} \div 00$ & $0.00 \mathrm{E}+00$ & $0.00 \mathrm{E}+00$ & $0.00 \mathrm{E}+00$ & $0.00 \mathrm{E}+00$ \\
\hline Sm-151 & $0.00 \mathrm{E}+00$ & $0.00 \mathrm{E}+00$ & 3.30E-07 & 3.30E-07 & 3.30E-12 \\
\hline Sr-90 & $0.00 \mathrm{E}+00$ & $0.00 \mathrm{E}+00$ & $1.30 \mathrm{E}-02$ & 1.30E-02 & $1.30 \mathrm{E}-07$ \\
\hline Tc-99 & $0.00 \mathrm{E}+00$ & $0.00 \mathrm{E}+00$ & $6.60 \mathrm{E}-05$ & $6.60 \mathrm{E}-05$ & $6.60 \mathrm{E}-10$ \\
\hline Th-228 & $0.00 \mathrm{E}+00$ & $0.00 \mathrm{E}+00$ & $4.50 \mathrm{E}+00$ & $4.50 \mathrm{E}+00$ & $4.50 \mathrm{E}-05$ \\
\hline Th-229 & $0.00 \mathrm{E}+00$ & $0.00 \mathrm{E}+00$ & $8.50 \mathrm{E}-01$ & $8.50 \mathrm{E}-01$ & $8.50 \mathrm{E}-06$ \\
\hline Th-230 & $0.00 \mathrm{E}+00$ & $0.00 \mathrm{E}+00$ & $6.40 \mathrm{E}-04$ & $6.40 \mathrm{E}-04$ & $6.40 \mathrm{E}-09$ \\
\hline Th-232 & $0.00 \mathrm{E}+00$ & $0.00 \mathrm{E}+00$ & $2.70 \mathrm{E}-04$ & $2.70 \mathrm{E}-04$ & 2.70E-09 \\
\hline U-232 & $0.00 \mathrm{E}+00$ & $0.00 \mathrm{E}+00$ & 4.70E-04 & $4.70 \mathrm{E}-04$ & 4.70E-09 \\
\hline U-233 & $0.00 \mathrm{E}+00$ & $0.00 \mathrm{E}+00$ & $7.50 \mathrm{E}-04$ & 7.50E-04 & $7.50 \mathrm{E}-09$ \\
\hline U-234 & $0.00 \mathrm{E}+00$ & $0.00 \mathrm{E}+00$ & 2.10E-04 & $2.10 \mathrm{E}-04$ & 2.00E-09 \\
\hline U-235 & $0.00 \mathrm{E}+00$ & $0.00 \mathrm{E}+00$ & $4.10 \mathrm{E}-01$ & $4.10 \mathrm{E}-01$ & $4.10 \mathrm{E}-06$ \\
\hline U-238 & $0.00 \mathrm{E}+00$ & $0.00 \mathrm{E}+00$ & $7.00 \mathrm{E}-02$ & $7.00 \mathrm{E}-02$ & 7.00E-07 \\
\hline $\mathrm{Zn}-65$ & $0.00 \mathrm{E}+00$ & $0.00 \mathrm{E}+00$ & $1.20 \mathrm{E}+00$ & $1.20 \mathrm{E}+00$ & $1.20 \mathrm{E}-05$ \\
\hline Zr-93 & $0.00 \mathrm{E}+00$ & $0.00 \mathrm{E}+00$ & $0.00 \mathrm{E}+00$ & $0.00 \mathrm{E}+00$ & $0.00 \mathrm{E}+00$ \\
\hline
\end{tabular}

a Doses do not account for scrap dilution or radionuclide partitioning; collective doses based on $100 \mathrm{t}$. 
TABLE D.15 Baseline Worker Doses for a 2,000-h Initial Fabrication Sheet Worker ${ }^{\mathrm{a}}$

\begin{tabular}{|c|c|c|c|c|c|}
\hline Nuclide & $\begin{array}{r}\text { Ingestion } \\
(\mu \mathrm{Sv} / \mathrm{yr})\end{array}$ & $\begin{array}{l}\text { Inhalation } \\
\text { ( } \mu \mathrm{S} v / \mathrm{yr})\end{array}$ & $\begin{array}{c}\text { External } \\
(\mu \mathrm{Sv} / \mathrm{yr})\end{array}$ & $\begin{array}{c}\text { Total Dose } \\
(\mu \mathrm{S} v / \mathrm{yr})\end{array}$ & $\begin{array}{r}\text { Collective Dose } \\
\text { (person-Sv/yr) }\end{array}$ \\
\hline Ac- 227 & $4.70 \mathrm{E}+01$ & $4.30 \mathrm{E}+02$ & $2.70 E+00$ & $4.80 E+02$ & 7.20E-03 \\
\hline $\mathrm{Ag}-110 \mathrm{~m}$ & 2.30E-02 & 3.30E-03 & $7.90 \mathrm{E}+00$ & $8.00 \mathrm{E}+00$ & 1.20E-04 \\
\hline$A m-241$ & $1.20 \mathrm{E}+01$ & $2.90 \mathrm{E}+01$ & $5.30 \mathrm{E}-01$ & $4.20 \mathrm{E}+01$ & $6.20 \mathrm{E}-04$ \\
\hline Am-243 & $1.20 \mathrm{E}+01$ & $2.90 \mathrm{E}+01$ & $2.80 \mathrm{E}+00$ & $4.40 \mathrm{E}+01$ & 6.50E-04 \\
\hline $\mathrm{Ca}-41$ & $4.30 \mathrm{E}-03$ & 8.70E-05 & $0.00 \mathrm{E}+00$ & 4.40E-03 & $6.60 \mathrm{E}-08$ \\
\hline $\mathrm{Ce}-144$ & $4.70 \mathrm{E}-02$ & $1.60 \mathrm{E}-02$ & $2.50 \mathrm{E}-01$ & 3.10E-01 & $4.60 \mathrm{E}-0.6$ \\
\hline $\mathrm{Cl}-36$ & $1.00 \mathrm{E}-02$ & $1.40 \mathrm{E}-03$ & 2.10E-03 & $1.40 \mathrm{E}-02$ & 2.10E-07 \\
\hline $\mathrm{Cm}-243$ & $8.40 \mathrm{E}+00$ & $2.00 \mathrm{E}+01$ & $1.10 \mathrm{E}+00$ & $2.90 \mathrm{E}+01$ & $4.40 \mathrm{E}-04$ \\
\hline $\mathrm{Cm}-244$ & $6.70 \mathrm{E}+00$ & $1.60 E+01$ & $1.90 \mathrm{E}-03$ & $2.20 \mathrm{E}+01$ & 3.40E-04 \\
\hline $\mathrm{Cm}-245$ & $1.30 \mathrm{E}+01$ & $3.00 \mathrm{E}+01$ & $1.10 \mathrm{E}+00$ & $4.30 \mathrm{E}+01$ & 6.50E-04 \\
\hline $\mathrm{Cm}-246$ & $1.30 \mathrm{E}+01$ & $2.90 \mathrm{E}+01$ & $1.90 \mathrm{E}-03$ & $4.20 \mathrm{E}+01$ & $6.30 \mathrm{E}-04$ \\
\hline $\mathrm{Cm}-247$ & $1.20 \mathrm{E}+01$ & $2.70 \mathrm{E}+01$ & $1.90 \mathrm{E}+00$ & $4.00 \mathrm{E}+01$ & 6.00E-04 \\
\hline Co-57 & 2.70E-03 & $3.90 \mathrm{E}-04$ & $9.50 \mathrm{E}-01$ & $9.50 \mathrm{E}-01$ & $1.40 \mathrm{E}-05$ \\
\hline Co-60 & 8.50E-02 & $1.30 \mathrm{E}-02$ & $1.00 \mathrm{E}+01$ & $1.00 \mathrm{E}+01$ & 1.50E-04 \\
\hline Cs-134 & $2.10 \mathrm{E}-01$ & $2.50 \mathrm{E}-03$ & $6.30 \mathrm{E}+00$ & $6.50 \mathrm{E}+00$ & 9.70E-05 \\
\hline Cs-135 & 2.40E-02 & 3.00E-04 & $0.00 \mathrm{E}+00$ & $2.40 \mathrm{E}-02$ & $3.60 \mathrm{E}-07$ \\
\hline Cs-137 & $1.70 \mathrm{E}-01$ & $2.00 \mathrm{E}-03$ & $2.70 \mathrm{E}+00$ & $2.80 \mathrm{E}+00$ & $4.30 \mathrm{E}-05$ \\
\hline Eu-152 & 2.10E-02 & $1.40 \mathrm{E}-02$ & $5.50 \mathrm{E}+00$ & $5.50 \mathrm{E}+00$ & 8.30E-05 \\
\hline Eu-154 & $3.10 \mathrm{E}-02$ & $1.80 \mathrm{E}-02$ & $5.80 \mathrm{E}+00$ & $5.90 \mathrm{E}+00$ & $8.80 \mathrm{E}-05$ \\
\hline Fe-55 & $1.80 \mathrm{E}-03$ & $1.50 \mathrm{E}-04$ & $0.00 \mathrm{E}+00$ & $2.00 \mathrm{E}-03$ & $2.90 \mathrm{E}-08$ \\
\hline $\mathrm{Mn}-54$ & 6.40E-03 & 3.00E-04 & $2.60 E+00$ & $2.60 \mathrm{E}+00$ & 3.90E-05 \\
\hline $\mathrm{Na}-22$ & $3.40 \mathrm{E}-02$ & $4.40 \mathrm{E}-04$ & $8.90 \mathrm{E}+00$ & $8.90 \mathrm{E}+00$ & 1.30E-04 \\
\hline $\mathrm{Nb}-94$ & $2.40 \mathrm{E}-02$ & $2.70 \mathrm{E}-02$ & $7.20 E+00$ & $7.30 \mathrm{E}+00$ & 1.10E-04 \\
\hline $\mathrm{Ni}-59$ & 7.10E-04 & $1.80 \mathrm{E}-04$ & $0.00 \mathrm{E}+00$ & 8.80E-04 & 1.30E-08 \\
\hline $\mathrm{Ni}-63$ & $1.90 \mathrm{E}-03$ & 4.10E-04 & $0.00 \mathrm{E}+00$ & $2.40 \mathrm{E}-03$ & $3.50 \mathrm{E}-08$ \\
\hline Np-237 & $1.50 \mathrm{E}+01$ & $3.50 \mathrm{E}+01$ & $1.80 \mathrm{E}+00$ & $5.20 \mathrm{E}+01$ & $7.80 \mathrm{E}-04$ \\
\hline $\mathrm{Pb}-210$ & $1.80 \mathrm{E}+01$ & 8.70E-01 & 3.20E-02 & $1.90 \mathrm{E}+01$ & 2.80E-04 \\
\hline $\mathrm{Pm}-147$ & 3.10E-03 & $2.20 \mathrm{E}-03$ & 1.30E-04 & 5.50E-03 & 8.20E-08 \\
\hline $\mathrm{Pu}-238$ & $1.10 \mathrm{E}+01$ & $2.50 \mathrm{E}+01$ & $2.20 \mathrm{E}-03$ & $3.60 \mathrm{E}+01$ & 5.40E-04 \\
\hline Pu-239 & $1.20 \mathrm{E}+01$ & $2.80 \mathrm{E}+01$ & $1.20 \mathrm{E}-03$ & $4.00 \mathrm{E}+01$ & $6.00 \mathrm{E}-04$ \\
\hline $\mathrm{Pu}-240$ & $1.20 \mathrm{E}+01$ & $2.80 \mathrm{E}+01$ & $2.20 \mathrm{E}-03$ & $4.00 \mathrm{E}+01$ & 6.00E-04 \\
\hline $\mathrm{Pu}-241$ & 2.30E-01 & $5.20 \mathrm{E}-01$ & $5.90 \mathrm{E}-05$ & 7.50E-01 & 1.10E-05 \\
\hline $\mathrm{Pu}-242$ & $1.10 \mathrm{E}+01$ & $2.70 \mathrm{E}+01$ & $1.80 \mathrm{E}-03$ & $3.80 \mathrm{E}+01$ & 5.70E-04 \\
\hline Ru-106 & 6.70E-02 & 2.20E-02 & $7.70 \mathrm{E}-01$ & $8.60 \mathrm{E}-01$ & $1.30 \mathrm{E}-05$ \\
\hline $\mathrm{Sb}-125$ & $8.40 \mathrm{E}-03$ & $7.00 \mathrm{E}-04$ & $1.90 \mathrm{E}+00$ & $1.90 \mathrm{E}+00$ & $2.80 \mathrm{E}-05$ \\
\hline $\mathrm{Se}-79$ & 2.90E-02 & $6.40 \mathrm{E}-04$ & $0.00 \mathrm{E}+00$ & 3.00E-02 & 4.50E-07 \\
\hline Sm-151 & $1.30 \mathrm{E}-03$ & $1.90 \mathrm{E}-03$ & $1.50 \mathrm{E}-05$ & 3.30E-03 & $4.90 \mathrm{E}-08$ \\
\hline $\mathrm{Sr}-90$ & $4.80 \mathrm{E}-01$ & $8.30 \mathrm{E}-02$ & $1.40 \mathrm{E}-02$ & 5.70E-01 & 8.60E-06 \\
\hline Tc-99 & $4.90 \mathrm{E}-03$ & $5.40 \mathrm{E}-04$ & $6.90 \mathrm{E}-04$ & 6.20E-03 & 9.30E-08 \\
\hline Th-228 & $1.10 \mathrm{E}+00$ & $1.90 \mathrm{E}+01$ & $5.90 \mathrm{E}+00$ & $2.60 \mathrm{E}+01$ & 3.80E-04 \\
\hline Th-229 & $1.20 \mathrm{E}+01$ & $1.40 \mathrm{E}+02$ & $2.70 \mathrm{E}+00$ & $1.50 \mathrm{E}+02$ & 2.30E-03 \\
\hline Th-230 & $1.90 \mathrm{E}+00$ & $2.10 \mathrm{E}+01$ & $6.80 \mathrm{E}-03$ & $2.30 \mathrm{E}+01$ & $3.40 \mathrm{E}-04$ \\
\hline Th-232 & $9.20 \mathrm{E}+00$ & $1.10 \mathrm{E}+02$ & $3.60 \mathrm{E}-03$ & $1.20 \mathrm{E}+02$ & 1.70E-03 \\
\hline U-232 & $4.40 \mathrm{E}+00$ & $4.30 \mathrm{E}+01$ & $4.50 \mathrm{E}-03$ & $4.70 \mathrm{E}+01$ & 7.00E-04 \\
\hline U-233 & $9.80 \mathrm{E}-01$ & $8.80 \mathrm{E}+00$ & $4.80 \mathrm{E}-03$ & $9.80 \mathrm{E}+00$ & $1.50 \mathrm{E}-04$ \\
\hline U-234 & $9.60 \mathrm{E}-01$ & $8.60 \mathrm{E}+00$ & 2.40E-03 & $9.60 \mathrm{E}+00$ & $1.40 \mathrm{E}-04$ \\
\hline U-235 & $9.00 \mathrm{E}-01$ & $8.00 E+00$ & $1.50 \mathrm{E}+00$ & $1.00 \mathrm{E}+01$ & $1.50 \mathrm{E}-04$ \\
\hline U-238 & $8.60 \mathrm{E}-01$ & $7.70 \mathrm{E}+00$ & 2.40E-01 & $8.80 \mathrm{E}+00$ & 1.30E-04 \\
\hline Zn-65 & $3.00 \mathrm{E}-02$ & $8.20 \mathrm{E}-04$ & $1.70 \mathrm{E}+00$ & $1.70 \mathrm{E}+00$ & 2.60E-05 \\
\hline $\mathrm{Zr}-93$ & $5.60 \mathrm{E}-03$ & 2.10E-02 & $0.00 \mathrm{E}+00$ & $2.60 \mathrm{E}-02$ & $4.00 \mathrm{E}-07$ \\
\hline
\end{tabular}

a Doses do not account for scrap dilution or radionuclide partitioning; collective doses based on $100 \mathrm{t}$. 
TABLE D.16 Baseline Worker Doses for a 2,000-h Initial Fabrication Coil Worker ${ }^{\mathrm{a}}$

\begin{tabular}{|c|c|c|c|c|c|}
\hline Nuclide & $\begin{array}{r}\text { Ingestion } \\
(\mu \mathrm{Sv} / \mathrm{yr})\end{array}$ & $\begin{array}{c}\text { Inhalation } \\
(\mu \mathrm{Sv} / \mathrm{yr})\end{array}$ & $\begin{array}{c}\text { External } \\
(\mu \mathrm{Sv} / \mathrm{yr})\end{array}$ & $\begin{array}{l}\text { Total Dose } \\
(\mu \mathrm{Sv} / \mathrm{yr})\end{array}$ & $\begin{array}{r}\text { Collective Dose } \\
\text { (person-Sv/yr) }\end{array}$ \\
\hline Ac-227 & $4.70 \mathrm{E}+01$ & $4.30 \mathrm{E}+02$ & $8.00 \mathrm{E}+00$ & $4.80 \mathrm{E}+02$ & $4.80 \mathrm{E}-04$ \\
\hline $\mathrm{Ag}-110 \mathrm{~m}$ & $2.30 \mathrm{E}-02$ & $3.30 \mathrm{E}-03$ & $4.30 \mathrm{E}+01$ & $4.30 \mathrm{E}+01$ & $4.30 \mathrm{E}-05$ \\
\hline Am-241 & $1.20 \mathrm{E}+01$ & $2.90 \mathrm{E}+01$ & $2.00 \mathrm{E}-01$ & $4.10 \mathrm{E}+01$ & 4.10E-05 \\
\hline Am-243 & $1.20 \mathrm{E}+01$ & $2.90 \mathrm{E}+01$ & $3.80 \mathrm{E}+00$ & $4.50 \mathrm{E}+01$ & $4.50 \mathrm{E}-05$ \\
\hline $\mathrm{Ca}-41$ & $4.30 \mathrm{E}-03$ & 8.70E-05 & $0.00 \mathrm{E}+00$ & $4.40 \mathrm{E}-03$ & 4.40E-09 \\
\hline Ce-144 & $4.70 \mathrm{E}-02$ & $1.60 \mathrm{E}-02$ & $8.50 \mathrm{E}-01$ & $9.20 \mathrm{E}-01$ & $9.20 \mathrm{E}-07$ \\
\hline Cl-36 & $1.00 \mathrm{E}-02$ & $1.40 \mathrm{E}-03$ & $9.60 \mathrm{E}-03$ & 2.10E-02 & 2.10E-08 \\
\hline $\mathrm{Cm} \cdot 243$ & $8.40 \mathrm{E}+00$ & $2.00 \mathrm{E}+01$ & $2.40 \mathrm{E}+00$ & $3.00 \mathrm{E}+01$ & $3.00 \mathrm{E}-05$ \\
\hline $\mathrm{Cm}-244$ & $6.70 \mathrm{E}+00$ & $1.60 \mathrm{E}+01$ & $6.30 \mathrm{E}-04$ & $2.20 \mathrm{E}+01$ & 2.20E-05 \\
\hline $\mathrm{Cm}-245$ & $1.30 \mathrm{E}+01$ & $3.00 \mathrm{E}+01$ & $1.50 \mathrm{E}+00$ & $4.40 \mathrm{E}+01$ & 4.40E-05 \\
\hline $\mathrm{Cm}-246$ & $1.30 \mathrm{E}+01$ & $2.90 \mathrm{E}+01$ & $6.20 \mathrm{E}-04$ & $4.20 \mathrm{E}+01$ & $4.20 \mathrm{E}-05$ \\
\hline $\mathrm{Cm}-247$ & $1.20 \mathrm{E}+01$ & $2.70 \mathrm{E}+01$ & $7.50 \mathrm{E}+00$ & $4.60 \mathrm{E}+01$ & $4.60 \mathrm{E}-05$ \\
\hline Co-57 & $2.70 \mathrm{E}-03$ & $3.90 \mathrm{E}-04$ & $1.40 \mathrm{E}+00$ & $1.40 \mathrm{E}+00$ & $1.40 \mathrm{E}-06$ \\
\hline Co-60 & $8.50 \mathrm{E}-02$ & $1.30 \mathrm{E}-02$ & $6.00 \mathrm{E}+01$ & $6.00 \mathrm{E}+01$ & $6.00 \mathrm{E}-05$ \\
\hline Cs-134 & $2.10 \mathrm{E}-01$ & $2.50 \mathrm{E}-03$ & $3.20 \mathrm{E}+01$ & $3.20 \mathrm{E}+01$ & $3.20 \mathrm{E}-05$ \\
\hline Cs-135 & $2.40 \mathrm{E}-02$ & 3.00E-04 & $0.00 \mathrm{E}+00$ & $2.40 \mathrm{E}-02$ & $2.40 \mathrm{E}-08$ \\
\hline Cs-137 & $1.70 \mathrm{E}-01$ & $2.00 \mathrm{E}-03$ & $1.30 \mathrm{E}+01$ & $1.30 \mathrm{E}+01$ & $1.30 \mathrm{E}-05$ \\
\hline Eu-152 & 2.10E-02 & $1.40 \mathrm{E}-02$ & $2.70 \mathrm{E}+01$ & $2.70 \mathrm{E}+01$ & $2.70 \mathrm{E}-05$ \\
\hline Eu-154 & 3.10E-02 & $1.80 \mathrm{E}-02$ & $2.90 \mathrm{E}+01$ & $2.90 \mathrm{E}+01$ & $2.90 \mathrm{E}-05$ \\
\hline $\mathrm{Fe}-55$ & $1.80 \mathrm{E}-03$ & $1.50 \mathrm{E}-04$ & $0.00 \mathrm{E}+00$ & $2.00 \mathrm{E}-03$ & $2.00 \mathrm{E}-09$ \\
\hline$M n-54$ & $6.40 \mathrm{E}-03$ & $3.00 \mathrm{E}-04$ & $1.40 \mathrm{E}+01$ & $1.40 \mathrm{E}+01$ & $1.40 \mathrm{E}-05$ \\
\hline $\mathrm{Na}-22$ & $3.40 \mathrm{E}-02$ & $4.40 \mathrm{E}-04$ & $4.70 \mathrm{E}+01$ & $4.70 \mathrm{E}+01$ & 4.70E-05 \\
\hline $\mathrm{Nb}-94$ & $2.40 \mathrm{E}-02$ & 2.70E-02 & $3.80 \mathrm{E}+01$ & $3.80 \mathrm{E}+01$ & $3.80 \mathrm{E}-05$ \\
\hline $\mathrm{Ni}-59$ & $7.10 \mathrm{E}-04$ & $1.80 \mathrm{E}-04$ & $0.00 \mathrm{E}+00$ & $8.80 \mathrm{E}-04$ & $8.80 \mathrm{E}-10$ \\
\hline $\mathrm{Ni}-63$ & $1.90 \mathrm{E}-03$ & $4.10 \mathrm{E}-04$ & $0.00 \mathrm{E}+00$ & $2.40 \mathrm{E}-03$ & $2.40 \mathrm{E}-09$ \\
\hline $\mathrm{Np}-237$ & $1.50 \mathrm{E}+01$ & $3.50 \mathrm{E}+01$ & $4.50 \mathrm{E}+00$ & $5.50 \mathrm{E}+01$ & $5.50 \mathrm{E}-05$ \\
\hline $\mathrm{Pb}-210$ & $1.80 \mathrm{E}+01$ & 8.70E-01 & $1.10 \mathrm{E}-02$ & $1.90 \mathrm{E}+01$ & $1.90 \mathrm{E}-05$ \\
\hline Pm-147 & $3.10 \mathrm{E}-03$ & $2.20 \mathrm{E}-03$ & $1.90 \mathrm{E}-04$ & $5.50 \mathrm{E}-03$ & $5.50 \mathrm{E}-09$ \\
\hline Pu-238 & $1.10 \mathrm{E}+01$ & $2.50 \mathrm{E}+01$ & $7.50 \mathrm{E}-04$ & $3.60 \mathrm{E}+01$ & 3.60E-05 \\
\hline Pu-239 & $1.20 \mathrm{E}+01$ & $2.80 \mathrm{E}+01$ & $1.30 \mathrm{E}-03$ & $4.00 \mathrm{E}+01$ & $4.00 \mathrm{E}-05$ \\
\hline Pu-240 & $1.20 \mathrm{E}+01$ & $2.80 \mathrm{E}+01$ & 7.30E-04 & $4.00 \mathrm{E}+01$ & $4.00 \mathrm{E}-05$ \\
\hline $\mathrm{Pu}-241$ & 2.30E-01 & $5.20 \mathrm{E}-01$ & $7.90 \mathrm{E}-05$ & $7.50 \mathrm{E}-01$ & $7.50 \mathrm{E}-07$ \\
\hline $\mathrm{Pu}-242$ & $1.10 \mathrm{E}+01$ & $2.70 \mathrm{E}+01$ & 6.30E-04 & $3.80 \mathrm{E}+01$ & $3.80 \mathrm{E}-05$ \\
\hline$R u-106$ & $6.70 \mathrm{E}-02$ & $2.20 \mathrm{E}-02$ & $3.70 \mathrm{E}+00$ & $3.80 \mathrm{E}+00$ & $3.80 \mathrm{E}-06$ \\
\hline Sb-125 & $8.40 \mathrm{E}-03$ & $7.00 \mathrm{E}-04$ & $8.60 \mathrm{E}+00$ & $8.60 \mathrm{E}+00$ & 8.60E-06 \\
\hline Șe-79 & $2.90 \mathrm{E}-02$ & $6.40 \mathrm{E}-04$ & $0.00 \mathrm{E}+00$ & $3.00 \mathrm{E}-02$ & $3.00 \mathrm{E}-08$ \\
\hline Śm-151 & $1.30 \mathrm{E}-03$ & $1.90 \mathrm{E}-03$ & $4.80 \mathrm{E}-06$ & $3.20 \mathrm{E}-03$ & $3.20 \mathrm{E}-09$ \\
\hline Sr-90 & $4.80 \mathrm{E}-01$ & 8.30E-02 & $9.20 \mathrm{E}-02$ & $6.50 \mathrm{E}-01$ & $6.50 \mathrm{E}-07$ \\
\hline Tc-99 & $4.90 \mathrm{E}-03$ & 5.40E-04 & $5.50 \mathrm{E}-04$ & $6.00 \mathrm{E}-03$ & $6.00 \mathrm{E}-09$ \\
\hline Th-228 & $1.10 \mathrm{E}+00$ & $1.90 \mathrm{E}+01$ & $3.30 \mathrm{E}+01$ & $5.30 \mathrm{E}+01$ & $5.30 \mathrm{E}-05$ \\
\hline Th-229 & $1.20 \mathrm{E}+01$ & $1.40 \mathrm{E}+02$ & $6.50 \mathrm{E}+00$ & $1.60 \mathrm{E}+02$ & $1.60 \mathrm{E}-04$ \\
\hline Th-230 & $1.90 \mathrm{E}+00$ & $2.10 \mathrm{E}+01$ & $5.20 \mathrm{E}-03$ & $2.30 \mathrm{E}+01$ & $2.30 \mathrm{E}-05$ \\
\hline Th-232 & $9.20 \mathrm{E}+00$ & $1.10 \mathrm{E}+02$ & 2.30E-03 & $1.20 \mathrm{E}+02$ & $1.20 \mathrm{E}-04$ \\
\hline U-232 & $4.40 \mathrm{E}+00$ & $4.30 \mathrm{E}+01$ & $3.90 \mathrm{E}-03$ & $4.70 E+01$ & $4.70 \mathrm{E}-05$ \\
\hline U-233 & $9.80 \mathrm{E}-01$ & $8.80 \mathrm{E}+00$ & $6.00 \mathrm{E}-03$ & $9.80 \mathrm{E}+00$ & $9.80 \mathrm{E}-06$ \\
\hline U-234 & $9.60 \mathrm{E}-01$ & $8.60 \mathrm{E}+00$ & $1.80 \mathrm{E}-03$ & $9.60 \mathrm{E}+00$ & $9.60 \mathrm{E}-06$ \\
\hline U-235 & $9.00 \mathrm{E}-01$ & $8.00 \mathrm{E}+00$ & $3.20 \mathrm{E}+00$ & $1.20 \mathrm{E}+01$ & $1.20 \mathrm{E}-05$ \\
\hline U-238 & $8.60 \mathrm{E}-01$ & $7.70 \mathrm{E}+00$ & $5.30 \mathrm{E}-01$ & $9.10 \mathrm{E}+00$ & $9.10 \mathrm{E}-06$ \\
\hline $\mathrm{Zn}-65$ & $3.00 \mathrm{E}-02$ & $8.20 \mathrm{E}-04$ & $9.00 \mathrm{E}+00$ & $9.10 \mathrm{E}+00$ & $9.10 \mathrm{E}-06$ \\
\hline Zr-93 & $5.60 \mathrm{E}-03$ & 2.10E-02 & $0.00 \mathrm{E}+00$ & $2.60 \mathrm{E}-02$ & $2.60 \mathrm{E}-08$ \\
\hline
\end{tabular}

a Doses do not account for scrap dilution or radionuclide partitioning; collective doses based on $100 \mathrm{t}$. 
TABLE D.17 Baseline Worker Doses for a 2,000-h Final Fabrication Sheet Worker ${ }^{2}$

\begin{tabular}{|c|c|c|c|c|c|}
\hline Nuclide & $\begin{array}{r}\text { Ingestion } \\
(\mu \mathrm{Sv} / \mathrm{yr})\end{array}$ & $\begin{array}{l}\text { Inhalation } \\
(\mu \mathrm{Sv} / \mathrm{yr})\end{array}$ & $\begin{array}{c}\text { External } \\
(\mu S v / y r)\end{array}$ & $\begin{array}{c}\text { Total Dose } \\
(\mu \mathrm{Sv} / \mathrm{yr})\end{array}$ & $\begin{array}{r}\text { Collective Dose } \\
\text { (person-Sv/yr) }\end{array}$ \\
\hline Ac-227 & $0.00 \mathrm{E}+00$ & $0.00 \mathrm{E}+00$ & $2.70 \mathrm{E}+00$ & $2.70 \mathrm{E}+00$ & $5.50 \mathrm{E}-05$ \\
\hline $\mathrm{Ag}-110 \mathrm{~m}$ & $0.00 \mathrm{E}+00$ & $0.00 \mathrm{E}+00$ & $7.90 \mathrm{E}+00$ & $7.90 \mathrm{E}+00$ & $1.60 \mathrm{E}-04$ \\
\hline Am-241 & $0.00 \mathrm{E}+00$ & $0.00 \mathrm{E}+00$ & $5.30 \mathrm{E}-01$ & $5.30 \mathrm{E}-01$ & $1.10 \mathrm{E}-05$ \\
\hline Am-243 & $0.00 \mathrm{E}+00$ & $0.00 \mathrm{E}+00$ & $2.80 \mathrm{E}+00$ & $2.80 \mathrm{E}+00$ & $5.50 \mathrm{E}-05$ \\
\hline $\mathrm{Ca}-41$ & $0.00 \mathrm{E}+00$ & $0.00 \mathrm{E}+00$ & $0.00 \mathrm{E}+00$ & $0.00 \mathrm{E}+00$ & $0.00 \mathrm{E}+00$ \\
\hline Ce-144 & $0.00 E+00$ & $0.00 E+00$ & $2.50 \mathrm{E}-01$ & $2.50 \mathrm{E}-01$ & $4.90 \mathrm{E}-06$ \\
\hline Cl-36 & $0.00 \mathrm{E}+00$ & $0.00 \mathrm{E}+00$ & $2.10 \mathrm{E}-03$ & $2.10 \mathrm{E}-03$ & $4.10 \mathrm{E}-08$ \\
\hline $\mathrm{Cm}-243$ & $0.00 \mathrm{E}+00$ & $0.00 \mathrm{E}+00$ & $1.10 \mathrm{E}+00$ & $1.10 \mathrm{E}+00$ & $2.30 \mathrm{E}-05$ \\
\hline $\mathrm{Cm}-244$ & $0.00 \mathrm{E}+00$ & $0.00 \mathrm{E}+00$ & $1.90 \mathrm{E}-03$ & $1.90 \mathrm{E}-03$ & $3.70 \mathrm{E}-08$ \\
\hline $\mathrm{Cm}-245$ & $0.00 \mathrm{E}+00$ & $0.00 \mathrm{E}+00$ & $1.10 \mathrm{E}+00$ & $1.10 \mathrm{E}+00$ & $2.20 \mathrm{E}-05$ \\
\hline $\mathrm{Cm}-246$ & $0.00 \mathrm{E}+00$ & $0.00 \mathrm{E}+00$ & $1.90 \mathrm{E}-03$ & $1.90 \mathrm{E}-03$ & $3.80 \mathrm{E}-08$ \\
\hline $\mathrm{Cm}-247$ & $0.00 \mathrm{E}+00$ & $0.00 \mathrm{E}+00$ & $1.90 \mathrm{E}+00$ & $1.90 \mathrm{E}+00$ & $3.80 \mathrm{E}-05$ \\
\hline Co-57 & $0.00 E+00$ & $0.00 \mathrm{E}+00$ & 9.50E-01 & $9.50 \mathrm{E}-01$ & $1.90 \mathrm{E}-05$ \\
\hline Co-60 & $0.00 \mathrm{E}+00$ & $0.00 \mathrm{E}+00$ & $1.00 \mathrm{E}+01$ & $1.00 \mathrm{E}+01$ & 2.00E-04 \\
\hline Cs-134 & $0.00 \mathrm{E}+00$ & $0.00 \mathrm{E}+00$ & $6.30 \mathrm{E}+00$ & $6.30 \mathrm{E}+00$ & 1.30E-04 \\
\hline Cs-135 & $0.00 \mathrm{E}+00$ & $0.00 \mathrm{E}+00$ & $0.00 \mathrm{E}+00$ & $0.00 \mathrm{E}+00$ & $0.00 \mathrm{E}+00$ \\
\hline Cs-137 & $0.00 \mathrm{E}+00$ & $0.00 \mathrm{E}+00$ & $2.70 E+00$ & $2.70 E+00$ & 5.30E-05 \\
\hline Eu-152 & $0.00 \mathrm{E}+00$ & $0.00 \mathrm{E}+00$ & $5.50 \mathrm{E}+00$ & $5.50 \mathrm{E}+00$ & 1.10E-04 \\
\hline Eu-154 & $0.00 \mathrm{E}+00$ & $0.00 \mathrm{E}+00$ & $5.80 \mathrm{E}+00$ & $5.80 \mathrm{E}+00$ & 1.20E-04 \\
\hline Fe-55 & $0.00 E+00$ & $0.00 \mathrm{E}+00$ & $0.00 \mathrm{E}+00$ & $0.00 \mathrm{E}+00$ & $0.00 E+00$ \\
\hline $\mathrm{Mn}-54$ & $0.00 \mathrm{E}+00$ & $0.00 \mathrm{E}+00$ & $2.60 \mathrm{E}+00$ & $2.60 \mathrm{E}+00$ & $5.20 \mathrm{E}-05$ \\
\hline $\mathrm{Na}-22$ & $0.00 \mathrm{E}+00$ & $0.00 \mathrm{E}+00$ & $8.90 \mathrm{E}+00$ & $8.90 \mathrm{E}+00$ & 1.80E-04 \\
\hline $\mathrm{Nb}-94$ & $0.00 \mathrm{E}+00$ & $0.00 \mathrm{E}+00$ & $7.20 \mathrm{E}+00$ & $7.20 \mathrm{E}+00$ & 1.40E-04 \\
\hline $\mathrm{Ni}-59$ & $0.00 \mathrm{E}+00$ & $0.00 \mathrm{E}+00$ & $0.00 \mathrm{E}+00$ & $0.00 \mathrm{E}+00$ & $0.00 \mathrm{E}+00$ \\
\hline $\mathrm{Ni}-63$ & $0.00 \mathrm{E}+00$ & $0.00 \mathrm{E}+00$ & $0.00 \mathrm{E}+00$ & $0.00 \mathrm{E}+00$ & $0.00 \mathrm{E}+00$ \\
\hline $\mathrm{Np}-237$ & $0.00 \mathrm{E}+00$ & $0.00 \mathrm{E}+00$ & $1.80 \mathrm{E}+00$ & $1.80 \mathrm{E}+00$ & $3.50 \mathrm{E}-05$ \\
\hline $\mathrm{Pb}-210$ & $0.00 \mathrm{E}+00$ & $0.00 \mathrm{E}+00$ & $3.20 \mathrm{E}-02$ & $3.20 \mathrm{E}-02$ & $6.40 \mathrm{E}-07$ \\
\hline $\mathrm{Pm}-147$ & $0.00 \mathrm{E}+00$ & $0.00 \mathrm{E}+00$ & $1.30 \mathrm{E}-04$ & $1.30 \mathrm{E}-04$ & $2.60 \mathrm{E}-09$ \\
\hline $\mathrm{Pu}-238$ & $0.00 \mathrm{E}+00$ & $0.00 \mathrm{E}+00$ & $2.20 \mathrm{E}-03$ & $2.20 \mathrm{E}-03$ & $4.40 \mathrm{E}-08$ \\
\hline Pu-239 & $0.00 \mathrm{E}+00$ & $0.00 \mathrm{E}+00$ & $1.20 \mathrm{E}-03$ & $1.20 \mathrm{E}-03$ & $2.30 \mathrm{E}-08$ \\
\hline $\mathrm{Pu}-240$ & $0.00 \mathrm{E}+00$ & $0.00 \mathrm{E}+00$ & $2.20 \mathrm{E}-03$ & 2.20E-03 & $4.30 \mathrm{E}-08$ \\
\hline $\mathrm{Pu}-241$ & $0.00 \mathrm{E}+00$ & $0.00 \mathrm{E}+00$ & $5.90 \mathrm{E}-05$ & $5.90 \mathrm{E}-05$ & $1.20 \mathrm{E}-09$ \\
\hline $\mathrm{Pu}-242$ & $0.00 \mathrm{E}+00$ & $0.00 \mathrm{E}+00$ & $1.80 \mathrm{E}-03$ & $1.80 \mathrm{E}-03$ & $3.70 \mathrm{E}-08$ \\
\hline Ru-106 & $0.00 \mathrm{E}+00$ & $0.00 \mathrm{E}+00$ & $7.70 \mathrm{E}-01$ & $7.70 \mathrm{E}-01$ & 1.50E-05 \\
\hline $\mathrm{Sb}-125$ & $0.00 \mathrm{E}+00$ & $0.00 \mathrm{E}+00$ & $1.90 \mathrm{E}+00$ & $1.90 \mathrm{E}+00$ & 3.70E-05 \\
\hline Se-79 & $0.00 \mathrm{E}+00$ & $0.00 \mathrm{E}+00$ & $0.00 \mathrm{E}+00$ & $0.00 \mathrm{E}+00$ & $0.00 \mathrm{E}+00$ \\
\hline Sm-151 & $0.00 \mathrm{E}+00$ & $0.00 \mathrm{E}+00$ & 1.50E-05 & $1.50 \mathrm{E}-05$ & $2.90 \mathrm{E}-10$ \\
\hline Sr-90 & $0.00 \mathrm{E}+00$ & $0.00 \mathrm{E}+00$ & $1.40 \mathrm{E}-02$ & 1.40E-02 & $2.80 \mathrm{E}-07$ \\
\hline Tc-99 & $0.00 \mathrm{E}+00$ & $0.00 E+00$ & $6.90 \mathrm{E}-04$ & $6.90 \mathrm{E}-04$ & $1.40 \mathrm{E}-08$ \\
\hline Th-228 & $0.00 \mathrm{E}+00$ & $0.00 \mathrm{E}+00$ & $5.90 \mathrm{E}+00$ & $5.90 \mathrm{E}+00$ & 1.20E-04 \\
\hline Th-229 & $0.00 \mathrm{E}+00$ & $0.00 \mathrm{E}+00$ & $2.70 \mathrm{E}+00$ & $2.70 \mathrm{E}+00$ & $5.30 \mathrm{E}-05$ \\
\hline Th-230 & $0.00 \mathrm{E}+00$ & $0.00 \mathrm{E}+00$ & $6.80 \mathrm{E}-03$ & $6.80 \mathrm{E}-03$ & 1.40E-07 \\
\hline Th-232 & $0.00 \mathrm{E}+00$ & $0.00 \mathrm{E}+00$ & $3.60 \mathrm{E}-03$ & $3.60 \mathrm{E}-03$ & 7.10E-08 \\
\hline U-232 & $0.00 \mathrm{E}+00$ & $0.00 \mathrm{E}+00$ & $4.50 \mathrm{E}-03$ & $4.50 \mathrm{E}-03$ & $9.00 \mathrm{E}-08$ \\
\hline U-233 & $0.00 \mathrm{E}+00$ & $0.00 \mathrm{E}+00$ & $4.80 \mathrm{E}-03$ & $4.80 \mathrm{E}-03$ & $9.50 \mathrm{E}-08$ \\
\hline U-234 & $0.00 E+00$ & $0.00 E+00$ & $2.40 \mathrm{E}-03$ & $2.40 \mathrm{E}-03$ & $4.80 \mathrm{E}-08$ \\
\hline U-235 & $0.00 \mathrm{E}+00$ & $0.00 \mathrm{E}+00$ & $1.50 \mathrm{E}+00$ & $1.50 \mathrm{E}+00$ & $2.90 \mathrm{E}-05$ \\
\hline U-238 & $0.00 \mathrm{E}+00$ & $0.00 \mathrm{E}+00$ & $2.40 \mathrm{E}-01$ & $2.40 \mathrm{E}-01$ & $4.80 \mathrm{E}-06$ \\
\hline $\mathrm{Zn}-65$ & $0.00 \mathrm{E}+00$ & $0.00 \mathrm{E}+00$ & $1.70 \mathrm{E}+00$ & $1.70 E+00$ & $3.40 \mathrm{E}-05$ \\
\hline Zr-93 & $0.00 \mathrm{E}+00$ & $0.00 \mathrm{E}+00$ & $0.00 \mathrm{E}+00$ & $0.00 \mathrm{E}+00$ & $0.00 \mathrm{E}+00$ \\
\hline
\end{tabular}

a Doses do not account for scrap dilution or radionuclide partitioning; collective doses based on $100 \mathrm{t}$. 
TABLE D.18 Baseline Worker Doses for a 2,000-h Final Fabrication Coil Worker ${ }^{a}$

\begin{tabular}{|c|c|c|c|c|c|}
\hline Nuclide & $\begin{array}{r}\text { Ingestion } \\
(\mu \mathrm{Sv} / \mathrm{yr}) \\
\end{array}$ & $\begin{array}{c}\text { Inhalation } \\
(\mu \mathrm{Sv} / \mathrm{yr})\end{array}$ & $\begin{array}{r}\text { External } \\
(\mu \mathrm{Sv} / \mathrm{yr}) \\
\end{array}$ & $\begin{array}{c}\text { Total Dose } \\
(\mu \mathrm{Sv} / \mathrm{yr})\end{array}$ & $\begin{array}{r}\text { Collective Dose } \\
\text { (person-Sv/yr) }\end{array}$ \\
\hline Ac-227 & $0.00 \mathrm{E}+00$ & $0.00 \mathrm{E}+00$ & $8.00 \mathrm{E}+00$ & $8.00 \mathrm{E}+00$ & $4.00 \mathrm{E}-05$ \\
\hline $\mathrm{Ag}-110 \mathrm{~m}$ & $0.00 \mathrm{E}+00$ & $0.00 \mathrm{E}+00$ & $4.30 \mathrm{E}+01$ & $4.30 \mathrm{E}+01$ & $2.10 \mathrm{E}-04$ \\
\hline Am-241 & $0.00 \mathrm{E}+00$ & $0.00 \mathrm{E}+00$ & $2.00 \mathrm{E}-01$ & $2.00 \mathrm{E}-01$ & $9.80 \mathrm{E}-07$ \\
\hline $\mathrm{Am}-243$ & $0.00 \mathrm{E}+00$ & $0.00 \mathrm{E}+00$ & $3.80 \mathrm{E}+00$ & $3.80 \mathrm{E}+00$ & 1.90E-05 \\
\hline $\mathrm{Ca}-41$ & $0.00 \mathrm{E}+00$ & $0.00 \mathrm{E}+00$ & $0.00 \mathrm{E}+00$ & $0.00 \mathrm{E}+00$ & $0.00 \mathrm{E}+00$ \\
\hline Ce-144 & $0.00 \mathrm{E}+00$ & $0.00 \mathrm{E}+00^{\circ}$ & 8.50E-01 & $8.50 \mathrm{E}-01$ & $4.30 \mathrm{E}-06$ \\
\hline Cl-36 & $0.00 \mathrm{E}+00$ & $0.00 \mathrm{E}+00$ & $9.60 \mathrm{E}-03$ & $9.60 \mathrm{E}-03$ & $4.80 \mathrm{E}-08$ \\
\hline $\mathrm{Cm}-243$ & $0.00 \mathrm{E}+00$ & $0.00 \mathrm{E}+00$ & $2.40 \mathrm{E}+00$ & $2.40 \mathrm{E}+00$ & $1.20 \mathrm{E}-05$ \\
\hline $\mathrm{Cm}-244$ & $.0 .00 \mathrm{E}+00$ & $0.00 \mathrm{E}+00$ & 6.30E-04 & $6.30 \mathrm{E}-04$ & $3.10 \mathrm{E}-09$ \\
\hline $\mathrm{Cm}-245$ & $0.00 \mathrm{E}+00$ & $0.00 \mathrm{E}+00$ & $1.50 \mathrm{E}+00$ & $1.50 \mathrm{E}+00$ & 7.30E-06 \\
\hline $\mathrm{Cm}-246$ & $0.00 \mathrm{E}+00$ & $0.00 \mathrm{E}+00$ & $6.20 \mathrm{E}-04$ & $6.20 \mathrm{E}-04$ & $3.10 \mathrm{E}-09$ \\
\hline $\mathrm{Cm}-247$ & $0.00 \mathrm{E}+00$ & $0.00 \mathrm{E}+00$ & $7.50 \mathrm{E}+00$ & $7.50 \mathrm{E}+00$ & 3.70E-05 \\
\hline Co-57 & $0.00 \mathrm{E}+00$ & $0.00 \mathrm{E}+00$ & $1.40 \mathrm{E}+00$ & $1.40 \mathrm{E}+00$ & $7.20 \mathrm{E}-06$ \\
\hline Co-60 & $0.00 \mathrm{E}+00$ & $0.00 \mathrm{E}+00$ & $6.00 \mathrm{E}+01$ & $6.00 \mathrm{E}+01$ & $3.00 \mathrm{E}-04$ \\
\hline Cs-134 & $0.00 \mathrm{E}+00$ & $0.00 \mathrm{E}+00$ & $3.20 \mathrm{E}+01$ & $3.20 \mathrm{E}+01$ & $1.60 \mathrm{E}-04$ \\
\hline Cs-135 & $0.00 \mathrm{E}+00$ & $0.00 \mathrm{E}+00$ & $0.00 \mathrm{E}+00$ & $0.00 \mathrm{E}+00$ & $0.00 \mathrm{E}+00$ \\
\hline Cs-137 & $0.00 \mathrm{E}+00$ & $0.00 \mathrm{E}+00$ & $1.30 \mathrm{E}+01$ & $1.30 \mathrm{E}+01$ & $6.60 \mathrm{E}-05$ \\
\hline Eu-152 & $0.00 \mathrm{E}+00$ & $0.00 \mathrm{E}+00$ & $2.70 \mathrm{E}+01$ & $2.70 \mathrm{E}+01$ & $1.30 \mathrm{E}-04$ \\
\hline Eu-154 & $0.00 \mathrm{E}+00$ & $0.00 \mathrm{E}+00$ & $2.90 \mathrm{E}+01$ & $2.90 \mathrm{E}+01$ & $1.50 \mathrm{E}-04$ \\
\hline $\mathrm{Fe}-55$ & $0.00 \mathrm{E}+00$ & $0.00 \mathrm{E}+00$ & $0.00 \mathrm{E}+00$ & $0.00 \mathrm{E}+00$ & $0.00 \mathrm{E}+00$ \\
\hline Mn-54 & $0.00 \mathrm{E}+00$ & $0.00 \mathrm{E}+00$ & $1.40 \mathrm{E}+01$ & $1.40 \mathrm{E}+01$ & $7.00 \mathrm{E}-05$ \\
\hline $\mathrm{Na}-22$ & $0.00 \mathrm{E}+00$ & $0.00 \mathrm{E}+00$ & $4.70 \mathrm{E}+01$ & $4.70 \mathrm{E}+01$ & $2.40 \mathrm{E}-04$ \\
\hline $\mathrm{Nb}-94$ & $0.00 \mathrm{E}+00$ & $0.00 \mathrm{E}+00$ & $3.80 \mathrm{E}+01$ & $3.80 \mathrm{E}+01$ & $1.90 \mathrm{E}-04$ \\
\hline $\mathrm{Ni}-59$ & $0.00 \mathrm{E}+00$ & $0.00 \mathrm{E}+00$ & $0.00 \mathrm{E}+00$ & $0.00 \mathrm{E}+00$ & $0.00 \mathrm{E}+00$ \\
\hline $\mathrm{Ni}-63$ & $0.00 \mathrm{E}+00$ & $0.00 \mathrm{E}+00$ & $0.00 \mathrm{E}+00$ & $0.00 \mathrm{E}+00$ & $0.00 \mathrm{E}+00$ \\
\hline Np-237 & $0.00 \mathrm{E}+00$ & $0.00 \mathrm{E}+00$ & $4.50 \mathrm{E}+00^{\circ}$ & $4.50 \mathrm{E}+00$ & $2.30 \mathrm{E}-05$ \\
\hline $\mathrm{Pb}-210$ & $0.00 \mathrm{E}+00$ & $0.00 \mathrm{E}+00$ & $1.10 \mathrm{E}-02$ & $1.10 \mathrm{E}-02$ & $5.50 \mathrm{E}-08$ \\
\hline Pm-147 & $0.00 \mathrm{E}+00$ & $0.00 \mathrm{E}+00$ & $1.90 \mathrm{E}-04$ & $1.90 \mathrm{E}-04$ & $9.40 \mathrm{E}-10$ \\
\hline $\mathrm{Pu}-238$ & $0.00 \mathrm{E}+00$ & $0.00 \mathrm{E}+00$ & $7.50 \mathrm{E}-04$ & $7.50 \mathrm{E}-04$ & 3.70E-09 \\
\hline Pu-239 & $0.00 \mathrm{E}+00$ & $0.00 \mathrm{E}+00$ & $1.30 \mathrm{E}-03$ & $1.30 \mathrm{E}-03$ & $6.50 \mathrm{E}-09$ \\
\hline $\mathrm{Pu}-240$ & $0.00 \mathrm{E}+00$ & $0.00 \mathrm{E}+00$ & 7.30E-04 & 7.30E-04 & $3.60 \mathrm{E}-09$ \\
\hline $\mathrm{Pu}-241$ & $0.00 \mathrm{E}+00$ & $0.00 \mathrm{E}+00$ & $7.90 \mathrm{E}-05$ & $7.90 \mathrm{E}-05$ & $3.90 \mathrm{E}-10$ \\
\hline $\mathrm{Pu}-242$ & $0.00 \mathrm{E}+00$ & $0.00 \mathrm{E}+00$ & $6.30 \mathrm{E}-04$ & $6.30 \mathrm{E}-04$ & 3.10E-09 \\
\hline Ru-106 & $0.00 \mathrm{E}+00$ & $0.00 \mathrm{E}+00$ & $3.70 \mathrm{E}+00$ & $3.70 \mathrm{E}+00$ & 1.80E-05 \\
\hline Sb-125 & $0.00 \mathrm{E}+00$ & $0.00 \mathrm{E}+00$ & $8.60 \mathrm{E}+00$ & $8.60 \mathrm{E}+00$ & $4.30 \mathrm{E}-05$ \\
\hline Se-79 & $0.00 \mathrm{E}+00$ & $0.00 \mathrm{E}+00$ & $0.00 \mathrm{E}+00$ & $0.00 \mathrm{E}+00$ & $0.00 \mathrm{E}+00$ \\
\hline Sm-151 & $0.00 \mathrm{E}+00$ & $0.00 \mathrm{E}+00$ & $4.80 \mathrm{E}-06$ & $4.80 \mathrm{E}-06$ & $2.40 \mathrm{E}-11$ \\
\hline Sr-90 & $0.00 \mathrm{E}+00$ & $0.00 \mathrm{E}+00$ & $9.20 \mathrm{E}-02$ & $9.20 \mathrm{E}-02$ & $4.60 \mathrm{E}-07$ \\
\hline Tc-99 & $0.00 \mathrm{E}+00$ & $0.00 \mathrm{E}+00$ & $5.50 \mathrm{E}-04$ & $5.50 \mathrm{E}-04$ & $2.80 \mathrm{E}-09$ \\
\hline Th-228 & $0.00 \mathrm{E}+00$ & $0.00 \mathrm{E}+00$ & $3.30 \mathrm{E}+01$ & $3.30 \mathrm{E}+01$ & 1.70E-04 \\
\hline Th-229 & $0.00 \mathrm{E}+00$ & $0.00 \mathrm{E}+00$ & $6.50 \mathrm{E}+00$ & $6.50 \mathrm{E}+00$ & 3.30E-05 \\
\hline Th-230 & $0.00 \mathrm{E}+00$ & $0.00 \mathrm{E}+00$ & $5.20 \mathrm{E}-03$ & $5.20 \mathrm{E}-03$ & $2.60 \mathrm{E}-08$ \\
\hline Th-232 & $0.00 \mathrm{E}+00$ & $0.00 \mathrm{E}+00$ & $2.30 \mathrm{E}-03$ & 2.30E-03 & $1.20 \mathrm{E}-08$ \\
\hline U-232 & $0.00 \mathrm{E}+00$ & $0.00 \mathrm{E}+00$ & $3.90 \mathrm{E}-03$ & $3.90 \mathrm{E}-03$ & $2.00 \mathrm{E}-08$ \\
\hline U-233 & $0.00 \mathrm{E}+00$ & $0.00 \mathrm{E}+00$ & $6.00 \mathrm{E}-03$ & $6.00 \mathrm{E}-03$ & $3.00 \mathrm{E}-08$ \\
\hline U-234 & $0.00 \mathrm{E}+00$ & $0.00 \mathrm{E}+00$ & $1.80 \mathrm{E}-03$ & $1.80 \mathrm{E}-03$ & 8.90E-09 \\
\hline U-235 & $0.00 \mathrm{E}+00$ & $0.00 \mathrm{E}+00$ & $3.20 \mathrm{E}+00$ & $3.20 \mathrm{E}+00$ & $1.60 \mathrm{E}-05$ \\
\hline U-238 & $0.00 \mathrm{E}+00$ & $0.00 \mathrm{E}+00$ & $5.30 \mathrm{E}-01$ & $5.30 \mathrm{E}-01$ & 2.70E-06 \\
\hline Zn-65 & $0.00 \mathrm{E}+00$ & $0.00 \mathrm{E}+00$ & $9.00 \mathrm{E}+00$ & $9.00 \mathrm{E}+00$ & $4.50 \mathrm{E}-05$ \\
\hline Zr-93 & $0.00 \mathrm{E}+00$ & $0.00 \mathrm{E}+00$ & $0.00 \mathrm{E}+00$ & $0.00 \mathrm{E}+00$ & $0.00 \mathrm{E}+00$ \\
\hline
\end{tabular}

a Doses do not account for scrap dilution or radionuclide partitioning; collective doses based on $100 \mathrm{t}$. 
TABLE D.19 Baseline Worker Doses for a 2,000-h Distribution Loader ${ }^{a}$

\begin{tabular}{|c|c|c|c|c|c|}
\hline Nuclide & $\begin{array}{c}\text { Ingestion } \\
(\mu \mathrm{Sv} / \mathrm{yr})\end{array}$ & $\begin{array}{c}\text { Inhalation } \\
(\mu \mathrm{Sv} / \mathrm{yr})\end{array}$ & $\begin{array}{l}\text { External } \\
(\mu \mathrm{Sv} / \mathrm{yr})\end{array}$ & $\begin{array}{c}\text { Total Dose } \\
(\mu \mathrm{Sv} / \mathrm{yr})\end{array}$ & $\begin{array}{l}\text { Collective Dose } \\
\text { (person-Sv/yr) }\end{array}$ \\
\hline Ac-227 & $0.00 \mathrm{E}+00$ & $0.00 \mathrm{E}+00$ & $6.00 \mathrm{E}+00$ & $6.00 \mathrm{E}+00$ & $1.20 \mathrm{E}-05$ \\
\hline $\mathrm{Ag}-110 \mathrm{~m}$ & $0.00 \mathrm{E}+00$ & $0.00 \mathrm{E}+00$ & $3.20 \mathrm{E}+01$ & $3.20 \mathrm{E}+01$ & $6.40 \mathrm{E}-05$ \\
\hline Am-241 & $0.00 \mathrm{E}+00$ & $0.00 \mathrm{E}+00$ & $1.40 \mathrm{E}-01$ & $1.40 \mathrm{E}-01$ & $2.80 \mathrm{E}-07$ \\
\hline Am-243 & $0.00 \mathrm{E}+00$ & $0.00 \mathrm{E}+00$ & $2.80 \mathrm{E}+00$ & $2.80 \mathrm{E}+00$ & 5.50E-06 \\
\hline $\mathrm{Ca}-41$ & $0.00 \mathrm{E}+00$ & $0.00 \mathrm{E}+00$ & $0.00 \mathrm{E}+00$ & $0.00 \mathrm{E}+00$ & $0.00 E+00$ \\
\hline Ce-144 & $0.00 \mathrm{E}+00$ & $0.00 \mathrm{E}+00$ & $6.40 \mathrm{E}-01$ & $6.40 \mathrm{E}-01$ & 1.30E-06 \\
\hline Cl-36 & $0.00 \mathrm{E}+00$ & $0.00 \mathrm{E}+00$ & $7.20 \mathrm{E}-03$ & $7.20 \mathrm{E}-03$ & $1.40 \mathrm{E}-08$ \\
\hline $\mathrm{Cm}-243$ & $0.00 \mathrm{E}+00$ & $0.00 \mathrm{E}+00$ & $1.80 \mathrm{E}+00$ & $1.80 \mathrm{E}+00$ & $3.60 \mathrm{E}-06$ \\
\hline $\mathrm{Cm}-244$ & $0.00 \mathrm{E}+00$ & $0.00 \mathrm{E}+00$ & $3.30 \mathrm{E}-04$ & $3.30 \mathrm{E}-04$ & $6.60 \mathrm{E}-10$ \\
\hline $\mathrm{Cm}-245$ & $0.00 \mathrm{E}+00$ & $0.00 \mathrm{E}+00$ & $1.10 \mathrm{E}+00$ & $1.10 \mathrm{E}+00$ & $2.10 \mathrm{E}-06$ \\
\hline $\mathrm{Cm}-246$ & $0.00 \mathrm{E}+00$ & $0.00 \mathrm{E}+00$ & $2.90 \mathrm{E}-04$ & 2.90E-04 & $5.80 \mathrm{E}-10$ \\
\hline $\mathrm{Cm}-247$ & $0.00 \mathrm{E}+00$ & $0.00 \mathrm{E}+00$ & $5.60 \mathrm{E}+00$ & $5.60 \mathrm{E}+00$ & $1.10 \mathrm{E}-05$ \\
\hline Co-57 & $0.00 \mathrm{E}+00$ & $0.00 \mathrm{E}+00$ & $1.00 \mathrm{E}+00$ & $1.00 \mathrm{E}+00$ & 2.10E-06 \\
\hline $\mathrm{Co}-60$ & $0.00 \mathrm{E}+00$ & $0.00 \mathrm{E}+00$ & $4.50 \mathrm{E}+01$ & $4.50 \mathrm{E}+01$ & $9.00 \mathrm{E}-05$ \\
\hline Cs-134 & $0.00 \mathrm{E}+00$ & $0.00 \mathrm{E} \div 00$ & $2.40 \mathrm{E}+01$ & $2.40 \mathrm{E}+01$ & $4.80 \mathrm{E}-05$ \\
\hline Cs-135 & $0.00 \mathrm{E}+00$ & $0.00 \mathrm{E}+00$ & $0.00 \mathrm{E}+00$ & $0.00 \mathrm{E}+00$ & $0.00 \mathrm{E}+00$ \\
\hline Cs-137 & $0.00 \mathrm{E}+00$ & $0.00 \mathrm{E}+00$ & $1.00 E+01$ & $1.00 \mathrm{E}+01$ & $2.00 \mathrm{E}-05$ \\
\hline Eu-152 & $0.00 \mathrm{E}+00$ & $0.00 \mathrm{E}+00$ & $2.00 \mathrm{E}+01$ & $2.00 \mathrm{E}+01$ & 4.10E-05 \\
\hline $\mathrm{Eu}-154$ & $0.00 \mathrm{E}+00$ & $0.00 E+00$ & $2.20 \mathrm{E}+01$ & $2.20 \mathrm{E}+01$ & $4.40 \mathrm{E}-05$ \\
\hline $\mathrm{Fe}-55$ & $0.00 \mathrm{E}+00$ & $0.00 \mathrm{E}+00$ & $0.00 \mathrm{E}+00$ & $0.00 E+00$ & $0.00 \mathrm{E}+00$ \\
\hline $\mathrm{Mn}-54$ & $0.00 \mathrm{E}+00$ & $0.00 \mathrm{E}+00$ & $1.00 \mathrm{E}+01$ & $1.00 \mathrm{E}+01$ & $2.10 \mathrm{E}-05$ \\
\hline $\mathrm{Na}-22$ & $0.00 \mathrm{E}+00$ & $0.00 \mathrm{E}+00$ & $3.60 \mathrm{E}+01$ & $3.60 \mathrm{E}+01$ & 7.10E-05 \\
\hline $\mathrm{Nb}-94$ & $0.00 \mathrm{E}+00$ & $0.00 \mathrm{E}+00$ & $2.90 \mathrm{E}+01$ & $2.90 \mathrm{E}+01$ & $5.80 \mathrm{E}-05$ \\
\hline Ni-59 & $0.00 \mathrm{E}+00$ & $0.00 \mathrm{E}+00$ & $0.00 \mathrm{E}+00$ & $0.00 \mathrm{E}+00$ & $0.00 \mathrm{E}+00$ \\
\hline $\mathrm{Ni}-63$ & $0.00 \mathrm{E}+00$ & $0.00 \mathrm{E}+00$ & $0.00 \mathrm{E}+00$ & $0.00 \mathrm{E}+00$ & $0.00 \mathrm{E}+00$ \\
\hline Np-237 & $0.00 \mathrm{E}+00$ & $0.00 \mathrm{E}+00$ & $3.40 \mathrm{E}+00$ & $3.40 \mathrm{E}+00$ & $6.70 \mathrm{E}-06$ \\
\hline $\mathrm{Pb}-210$ & $0.00 \mathrm{E}+00$ & $0.00 \mathrm{E}+00$ & $7.60 \mathrm{E}-03$ & $7.60 \mathrm{E}-03$ & $1.50 \mathrm{E}-08$ \\
\hline $\mathrm{Pm}-147$ & $0.00 \mathrm{E}+00$ & $0.00 \mathrm{E}+00$ & $1.40 \mathrm{E}-04$ & $1.40 \mathrm{E}-04$ & $2.70 \mathrm{E}-10$ \\
\hline $\mathrm{Pu}-238$ & $0.00 \mathrm{E}+00$ & $0.00 \mathrm{E}+00$ & $4.10 \mathrm{E}-04$ & $4.10 \mathrm{E}-04$ & $8.20 \mathrm{E}-10$ \\
\hline Pu-239 & $0.00 E+00$ & $0.00 \mathrm{E}+00$ & $9.20 \mathrm{E}-04$ & $9.20 \mathrm{E}-04$ & $1.80 \mathrm{E}-09$ \\
\hline $\mathrm{Pu}-240$ & $0.00 \mathrm{E}+00$ & $0.00 \mathrm{E}+00$ & $4.00 \mathrm{E}-04$ & $4.00 \mathrm{E}-04$ & $8.00 \mathrm{E}-10$ \\
\hline $\mathrm{Pu}-241$ & $0.00 \mathrm{E}+00$ & $0.00 \mathrm{E}+00$ & $5.80 \mathrm{E}-05$ & $5.80 \mathrm{E}-05$ & $1.20 \mathrm{E}-10$ \\
\hline $\mathrm{Pu}-242$ & $0.00 \mathrm{E}+00$ & $0.00 \mathrm{E}+00$ & $3.50 \mathrm{E}-04$ & $3.50 \mathrm{E}-04$ & $7.10 \mathrm{E}-10$ \\
\hline Ru-106 & $0.00 \mathrm{E}+00$ & $0.00 \mathrm{E}+00$ & $2.80 \mathrm{E}+00$ & $2.80 \mathrm{E}+00$ & 5.60E-06 \\
\hline Sb-125. & $0.00 \mathrm{E}+00$ & $0.00 \mathrm{E}+00$ & $6.50 \mathrm{E}+00$ & $6.50 \mathrm{E}+00$ & $1.30 \mathrm{E}-05$ \\
\hline Se-79 & $0.00 \mathrm{E}+00$ & $0.00 \mathrm{E}+00$ & $0.00 \mathrm{E}+00$ & $0.00 \mathrm{E}+00$ & $0.00 \mathrm{E}+00$ \\
\hline $\mathrm{Sm}-151$ & $0.00 E+00$ & $0.00 \mathrm{E}+00$ & $2.80 \mathrm{E}-06$ & $2.80 \mathrm{E}-06$ & $5.70 \mathrm{E}-12$ \\
\hline $\mathrm{Sr}-90$ & $0.00 \mathrm{E}+00$ & $0.00 \mathrm{E}+00$ & $7.00 \mathrm{E}-02$ & $7.00 \mathrm{E}-02$ & $1.40 \mathrm{E}-07$ \\
\hline Tc-99 & $0.00 \mathrm{E}+00$ & $0.00 \mathrm{E}+00$ & $4.00 \mathrm{E}-04$ & $4.00 \mathrm{E}-04$ & $7.90 \mathrm{E}-10$ \\
\hline Th-228 & $0.00 \mathrm{E}+00$ & $0.00 \mathrm{E}+00$ & $2.50 \mathrm{E}+01$ & $2.50 \mathrm{E}+01$ & 5.10E-05 \\
\hline Th-229 & $0.00 \mathrm{E}+00$ & $0.00 \mathrm{E}+00$ & $4.80 \mathrm{E}+00$ & $4.80 \mathrm{E}+00$ & 9.70E-06 \\
\hline Th-230 & $0.00 \mathrm{E}+00$ & $0.00 \mathrm{E}+00$ & $3.80 \mathrm{E}-03$ & $3.80 \mathrm{E}-03$ & $7.50 \mathrm{E}-09$ \\
\hline $\mathrm{Th}-232$ & $0.00 \mathrm{E}+00$ & $0.00 \mathrm{E}+00$ & $1.60 \mathrm{E}-03$ & $1.60 \mathrm{E}-03$ & $3.20 \mathrm{E}-09$ \\
\hline $\mathrm{U}-232$ & $0.00 E+00$ & $0.00 E+00$ & $2.80 \mathrm{E}-03$ & $2.80 \mathrm{E}-03$ & $5.60 \mathrm{E}-09$ \\
\hline U-233 & $0.00 \mathrm{E}+00$ & $0.00 \mathrm{E}+00$ & $4.40 \mathrm{E}-03$ & $4.40 \mathrm{E}-03$ & $8.80 \mathrm{E}-09$ \\
\hline U-234 & $0.00 \mathrm{E}+00$ & $0.00 \mathrm{E}+00$ & $1.20 \mathrm{E}-03$ & $1.20 \mathrm{E}-03$ & 2.50E-09 \\
\hline U-235 & $0.00 \mathrm{E}+00$ & $0.00 \mathrm{E}+00$ & $2.30 \mathrm{E}+00$ & $2.30 \mathrm{E}+00$ & $4.70 \mathrm{E}-06$ \\
\hline U-238 & $0.00 \mathrm{E}+00$ & $0.00 \mathrm{E}+00$ & $4.00 \mathrm{E}-01$ & $4.00 \mathrm{E}-01$ & $7.90 \mathrm{E}-07$ \\
\hline $\mathrm{Zn}-65$ & $0.00 \mathrm{E}+00$ & $0.00 \mathrm{E}+00$ & $6.80 \mathrm{E}+00$ & $6.80 \mathrm{E}+00$ & $1.40 \mathrm{E}-05$ \\
\hline Zr-93 & $0.00 \mathrm{E}+00$ & $0.00 \mathrm{E}+00$ & $0.00 \mathrm{E}+00$ & $0.00 \mathrm{E}+00$ & $0.00 \mathrm{E}+00$ \\
\hline
\end{tabular}

a Doses do not account for scrap dilution or radionuclide partitioning; collective doses based on $100 \mathrm{t}$. 
TABLE D.20 Baseline Worker Doses for a 2,000-h Distribution Truck Driver ${ }^{\mathrm{a}}$

\begin{tabular}{|c|c|c|c|c|c|}
\hline Nuclide & $\begin{array}{r}\text { Ingestion } \\
(\mu \mathrm{Sv} / \mathrm{yr})\end{array}$ & $\begin{array}{c}\text { Inhalation } \\
(\mu \mathrm{Sv} / \mathrm{yr})\end{array}$ & $\begin{array}{c}\text { External } \\
(\mu \mathrm{Sv} / \mathrm{yr})\end{array}$ & $\begin{array}{l}\text { Total Dose } \\
(\mu \mathrm{Sv} / \mathrm{yr})\end{array}$ & $\begin{array}{r}\text { Collective Dose } \\
\text { (person-Sv/yr) }\end{array}$ \\
\hline Ac-227 & $0.00 \mathrm{E}+00$ & $0.00 \mathrm{E}+00$ & $5.30 \mathrm{E}+00$ & $5.30 \mathrm{E}+00$ & $2.60 \mathrm{E}-05$ \\
\hline Ag- $110 \mathrm{~m}$ & $0.00 \mathrm{E}+00$ & $0.00 \mathrm{E}+00$ & $2.80 \mathrm{E}+01$ & $2.80 \mathrm{E}+01$ & $1.40 \mathrm{E}-04$ \\
\hline Am-241 & $0.00 \mathrm{E}+00$ & $0.00 \mathrm{E}+00$ & 1.30E-01 & $1.30 \mathrm{E}-01$ & $6.40 \mathrm{E}-07$ \\
\hline $\mathrm{Am}-243$ & $0.00 \mathrm{E}+00$ & $0.00 \mathrm{E}+00$ & $2.50 \mathrm{E}+00$ & $2.50 \mathrm{E}+00$ & 1.20E-05 \\
\hline $\mathrm{Ca}-41$ & $0.00 \mathrm{E}+00$ & $0.00 \mathrm{E}+00$ & $0.00 \mathrm{E}+00$ & $0.00 \mathrm{E}+00$ & $0.00 \mathrm{E}+00$ \\
\hline Ce-144 & $0.00 \mathrm{E}+00$ & $0.00 \mathrm{E}+00$ & $5.70 \mathrm{E}-01$ & $5.70 \mathrm{E}-01$ & $2.80 \mathrm{E}-06$ \\
\hline $\mathrm{Cl}-36$ & $0.00 \mathrm{E}+00$ & $0.00 \mathrm{E}+00$ & $6.30 \mathrm{E}-03$ & $6.30 \mathrm{E}-03$ & $3.20 \mathrm{E}-08$ \\
\hline $\mathrm{Cm}-243$ & $0.00 \mathrm{E}+00$ & $0.00 \mathrm{E}+00$ & $1.60 \mathrm{E}+00$ & $1.60 \mathrm{E}+00$ & 8.00E-06 \\
\hline $\mathrm{Cm}-244$ & $0.00 \mathrm{E}+00$ & $0.00 \mathrm{E}+00$ & $3.90 \mathrm{E}-04$ & $3.90 \mathrm{E}-04$ & $1.90 \mathrm{E}-09$ \\
\hline $\mathrm{Cm}-245$ & $0.00 \mathrm{E}+00$ & $0.00 \mathrm{E}+00$ & $9.60 \mathrm{E}-01$ & $9.60 \mathrm{E}-01$ & $4.80 \mathrm{E}-06$ \\
\hline $\mathrm{Cm}-246$ & $0.00 \mathrm{E}+00$ & $0.00 \mathrm{E}+00$ & $3.70 \mathrm{E}-04$ & 3.70E-04 & $1.90 \mathrm{E}-09$ \\
\hline $\mathrm{Cm}-247$ & $0.00 \mathrm{E}+00$ & $0.00 \mathrm{E}+00$ & $4.90 \mathrm{E}+00$ & $4.90 \mathrm{E}+00$ & $2.50 \mathrm{E}-05$ \\
\hline Co-57 & $0.00 \mathrm{E}+00$ & $0.00 \mathrm{E}+00$ & $9.50 \mathrm{E}-01$ & $9.50 \mathrm{E}-01$ & 4.70E-06 \\
\hline Co-60 & $0.00 \mathrm{E}+00$ & $0.00 \mathrm{E}+00$ & $4.00 \mathrm{E}+01$ & $4.00 \mathrm{E}+01$ & $2.00 \mathrm{E}-04$ \\
\hline Cs-134 & $0.00 \mathrm{E}+00$ & $0.00 \mathrm{E}+00$ & $2.10 \mathrm{E}+01$ & $2.10 \mathrm{E}+01$ & $1.10 \mathrm{E}-04$ \\
\hline Cs-135 & $0.00 \mathrm{E}+00$ & $0.00 \mathrm{E}+00$ & $0.00 \mathrm{E}+00$ & $0.00 \mathrm{E}+00$ & $0.00 \mathrm{E}+00$ \\
\hline Cs-137 & $0.00 \mathrm{E}+00$ & $0.00 \mathrm{E}+00$ & $8.80 \mathrm{E}+00$ & $8.80 \mathrm{E}+00$ & $4.40 \mathrm{E}-05$ \\
\hline Eu-152 & $0.00 \mathrm{E}+00$ & $0.00 \mathrm{E}+00$ & $1.80 \mathrm{E}+01$ & $1.80 \mathrm{E}+01$ & 8.90E-05 \\
\hline Eu-154 & $0.00 \mathrm{E}+00$ & $0.00 \mathrm{E}+00$ & $1.90 \mathrm{E}+01$ & $1.90 \mathrm{E}+01$ & $9.70 \mathrm{E}-05$ \\
\hline Fe-55 & $0.00 \mathrm{E}+00$ & $0.00 \mathrm{E}+00$ & $0.00 \mathrm{E}+00$ & $0.00 \mathrm{E}+00$ & $0.00 \mathrm{E}+00$ \\
\hline $\mathrm{Mn}-54$ & $0.00 \mathrm{E}+00$ & $0.00 E+00$ & $9.30 \mathrm{E}+00$ & $9.30 \mathrm{E}+00$ & 4.60E-05 \\
\hline $\mathrm{Na}-22$ & $0.00 \mathrm{E}+00$ & $0.00 \mathrm{E}+00$ & $3.20 \mathrm{E}+01$ & $3.20 \mathrm{E}+01$ & $1.60 \mathrm{E}-04$ \\
\hline $\mathrm{Nb}-94$ & $0.00 \mathrm{E}+00$ & $0.00 \mathrm{E}+00$ & $2.50 \mathrm{E}+01$ & $2.50 \mathrm{E}+01$ & 1.30E-04 \\
\hline Ni-59 & $0.00 \mathrm{E}+00$ & $0.00 \mathrm{E}+00$ & $0.00 \mathrm{E}+00$ & $0.00 \mathrm{E}+00$ & $0.00 \mathrm{E}+00$ \\
\hline $\mathrm{Ni}-63$ & $0.00 \mathrm{E}+00$ & $0.00 \mathrm{E}+00$ & $0.00 \mathrm{E}+00$ & $0.00 \mathrm{E}+00$ & $0.00 \mathrm{E}+00$ \\
\hline $\mathrm{Np}-237$ & $0.00 \mathrm{E}+00$ & $0.00 \mathrm{E}+00$ & $3.00 \mathrm{E}+00$ & $3.00 \mathrm{E}+00$ & $1.50 \mathrm{E}-05$ \\
\hline $\mathrm{Pb}-210$ & $0.00 \mathrm{E}+00$ & $0.00 \mathrm{E}+00$ & 7.10E-03 & $7.10 \mathrm{E}-03$ & $3.60 \mathrm{E}-08$ \\
\hline Pm-147 & $0.00 \mathrm{E}+00$ & $0.00 \mathrm{E}+00$ & $1.20 \mathrm{E}-04$ & $1.20 \mathrm{E}-04$ & $6.20 \mathrm{E}-10$ \\
\hline $\mathrm{Pu}-238$ & $0.00 \mathrm{E}+00$ & $0.00 \mathrm{E}+00$ & $4.70 \mathrm{E}-04$ & $4.70 \mathrm{E}-04$ & 2.30E-09 \\
\hline $\mathrm{Pu}-239$ & $0.00 \mathrm{E}+00$ & $0.00 \mathrm{E}+00$ & $8.50 \mathrm{E}-04$ & 8.50E-04 & $4.20 \mathrm{E}-09$ \\
\hline $\mathrm{Pu}-240$ & $0.00 \mathrm{E}+00$ & $0.00 \mathrm{E}+00$ & $4.50 \mathrm{E}-04$ & $4.50 \mathrm{E}-04$ & 2.30E-09 \\
\hline $\mathrm{Pu}-241$ & $0.00 \mathrm{E}+00$ & $0.00 \mathrm{E}+00$ & $5.20 \mathrm{E}-05$ & $5.20 \mathrm{E}-05$ & $2.60 \mathrm{E}-10$ \\
\hline Pu-242 & $0.00 \mathrm{E}+00$ & $0.00 \mathrm{E}+00$ & $3.90 \mathrm{E}-04$ & $3.90 \mathrm{E}-04$ & $2.00 \mathrm{E}-09$ \\
\hline Ru-106 & $0.00 \mathrm{E}+00$ & $0.00 \mathrm{E}+00$ & $2.50 \mathrm{E}+00$ & $2.50 \mathrm{E}+00$ & $1.20 \mathrm{E}-05$ \\
\hline Sb-125 & $0.00 \mathrm{E}+00$ & $0.00 \mathrm{E}+00$ & $5.70 \mathrm{E}+00$ & $5.70 \mathrm{E}+00$ & $2.90 \mathrm{E}-05$ \\
\hline Se-79 & $0.00 \mathrm{E}+00$ & $0.00 \mathrm{E}+00$ & $0.00 \mathrm{E}+00$ & $0.00 \mathrm{E}+00$ & $0.00 \mathrm{E}+00$ \\
\hline $\mathrm{Sm}-151$ & $0.00 \mathrm{E}+00$ & $0.00 \mathrm{E}+00$ & $3.10 \mathrm{E}-06$ & $3.10 \mathrm{E}-06$ & $1.50 \mathrm{E}-11$ \\
\hline Sr-90 & $0.00 \mathrm{E}+00$ & $0.00 \mathrm{E}+00$ & $6.10 \mathrm{E}-02$ & $6.10 \mathrm{E}-02$ & $3.00 \mathrm{E}-07$ \\
\hline Tc-99 & $0.00 \mathrm{E}+00$ & $0.00 \mathrm{E}+00$ & $3.60 \mathrm{E}-04$ & $3.60 \mathrm{E}-04$ & $1.80 \mathrm{E}-09$ \\
\hline Th-228 & $0.00 \mathrm{E}+00$ & $0.00 \mathrm{E}+00$ & $2.20 E+01$ & $2.20 \mathrm{E}+01$ & 1.10E-04 \\
\hline Th-229 & $0.00 \mathrm{E}+00$ & $0.00 \mathrm{E}+00$ & $4.30 \mathrm{E}+00$ & $4.30 \mathrm{E}+00$ & $2.20 \mathrm{E}-05$ \\
\hline Th-230 & $0.00 \mathrm{E}+00$ & $0.00 \mathrm{E}+00$ & $3.40 \mathrm{E}-03$ & $3.40 \mathrm{E}-03$ & $1.70 \mathrm{E}-08$ \\
\hline Th-232 & $0.00 \mathrm{E}+00$ & $0.00 \mathrm{E}+00$ & $1.50 \mathrm{E}-03$ & $1.50 \mathrm{E}-03$ & $7.50 \mathrm{E}-09$ \\
\hline U-232 & $0.00 \mathrm{E}+00$ & $0.00 \mathrm{E}+00$ & $2.60 \mathrm{E}-03$ & $2.60 \mathrm{E}-03$ & 1.30E-08 \\
\hline U-233 & $0.00 \mathrm{E}+00$ & $0.00 \mathrm{E}+00$ & $4.00 \mathrm{E}-03$ & $4.00 \mathrm{E}-03$ & $2.00 \mathrm{E}-08$ \\
\hline U-234 & $0.00 \mathrm{E}+00$ & $0.00 \mathrm{E}+00$ & $1.20 \mathrm{E}-03$ & $1.20 \mathrm{E}-03$ & $5.80 \mathrm{E}-09$ \\
\hline U-235 & $0.00 \mathrm{E}+00$ & $0.00 \mathrm{E}+00$ & $2.10 \mathrm{E}+00$ & $2.10 \mathrm{E}+00$ & $1.10 \mathrm{E}-05$ \\
\hline U-238 & $0.00 \mathrm{E}+00$ & $0.00 \mathrm{E}+00$ & $3.50 \mathrm{E}-01$ & $3.50 \mathrm{E}-01$ & $1.80 \mathrm{E}-06$ \\
\hline $\mathrm{Zn}-65$ & $0.00 \mathrm{E}+00$ & $0.00 \mathrm{E}+00$ & $6.00 \mathrm{E}+00$ & $6.00 \mathrm{E}+00$ & $3.00 \mathrm{E}-05$ \\
\hline $\mathrm{Zr}-93$ & $0.00 \mathrm{E}+00$ & $0.00 \mathrm{E}+00$ & $0.00 \mathrm{E}+00$ & $0.00 \mathrm{E}+00$ & $0.00 \mathrm{E}+00$ \\
\hline
\end{tabular}

a Doses do not account for scrap dilution or radionuclide partitioning; collective doses based on $100 \mathrm{t}$. 
TABLE D.21 Baseline Worker Doses for a 2,000-h Distribution Sheet Worker ${ }^{a}$

\begin{tabular}{|c|c|c|c|c|c|}
\hline Nuclide & $\begin{array}{r}\text { Ingestion } \\
(\mu \mathrm{Sv} / \mathrm{yr}) \\
\end{array}$ & $\begin{array}{l}\text { Inhalation } \\
(\mu \mathrm{Sv} / \mathrm{yr})\end{array}$ & $\begin{array}{r}\text { External } \\
(\mu \mathrm{Sv} / \mathrm{yr})\end{array}$ & $\begin{array}{c}\text { Total Dose } \\
(\mu \mathrm{Sv} / \mathrm{yr})\end{array}$ & $\begin{array}{r}\text { Collective Dose } \\
\text { (person-Sv/yr) }\end{array}$ \\
\hline Ac-227 & $0.00 \mathrm{E}+00$ & $0.00 \mathrm{E}+00$ & $2.70 \mathrm{E}+00$ & $2.70 \mathrm{E}+00$ & $5.50 \mathrm{E}-05$ \\
\hline $\mathrm{Ag}-110 \mathrm{~m}$ & $0.00 \mathrm{E}+00$ & $0.00 \mathrm{E}+00$ & $7.90 \mathrm{E}+00$ & $7.90 \mathrm{E}+00$ & $1.60 \mathrm{E}-04$ \\
\hline Am-241 & $0.00 \mathrm{E}+00$ & $0.00 \mathrm{E}+00$ & 5.30E-01 & 5.30E-01 & $1.10 \mathrm{E}-05$ \\
\hline Am-243 & $0.00 \mathrm{E}+00$ & $0.00 \mathrm{E}+00$ & $2.80 \mathrm{E}+00$ & $2.80 \mathrm{E}+00$ & 5.50E-05 \\
\hline $\mathrm{Ca}-41$ & $0.00 \mathrm{E}+00$ & $0.00 \mathrm{E}+00$ & $0.00 \mathrm{E}+00$ & $0.00 \mathrm{E}+00$ & $0.00 \mathrm{E}+00$ \\
\hline $\mathrm{Ce}-144$ & $0.00 \mathrm{E}+00$ & $0.00 \mathrm{E}+00$ & 2.50E-01 & $2.50 \mathrm{E}-01$ & $4.90 \mathrm{E}-06$ \\
\hline $\mathrm{Cl}-36$ & $0.00 \mathrm{E}+00$ & $0.00 \mathrm{E}+00$ & 2.10E-03 & 2.10E-03 & $4.10 \mathrm{E}-08$ \\
\hline $\mathrm{Cm}-243$ & $0.00 \mathrm{E}+00$ & $0.00 \mathrm{E}+00$ & $1.10 \mathrm{E}+00$ & $1.10 \mathrm{E}+00$ & 2.30E-05 \\
\hline $\mathrm{Cm}-244$ & $0.00 \mathrm{E}+00$ & $0.00 \mathrm{E}+00$ & $1.90 \mathrm{E}-03$ & $1.90 \mathrm{E}-03$ & $3.70 \mathrm{E}-08$ \\
\hline $\mathrm{Cm}-245$ & $0.00 \mathrm{E}+00$ & $0.00 \mathrm{E}+00$ & $1.10 \mathrm{E}+00$ & $1.10 \mathrm{E}+00$ & 2.20E-05 \\
\hline $\mathrm{Cm}-246$ & $0.00 \mathrm{E}+00$ & $0.00 \mathrm{E}+00$ & $1.90 \mathrm{E}-03$ & $1.90 \mathrm{E}-03$ & $3.80 \mathrm{E}-08$ \\
\hline $\mathrm{Cm}-247$ & $0.00 \mathrm{E}+00$ & $0.00 \mathrm{E}+00$ & $1.90 \mathrm{E}+00$ & $1.90 \mathrm{E}+00$ & $3.80 \mathrm{E}-05$ \\
\hline Co-57 & $0.00 \mathrm{E}+00$ & $0.00 \mathrm{E}+00$ & $9.50 \mathrm{E}-01$ & $9.50 \mathrm{E}-01$ & 1.90E-05 \\
\hline $\mathrm{Co}-60$ & $0.00 \mathrm{E}+00$ & $0.00 \mathrm{E}+00$ & $1.00 \mathrm{E}+01$ & $1.00 \mathrm{E}+01$ & $2.00 \mathrm{E}-04$ \\
\hline Cs-134 & $0.00 \mathrm{E}+00$ & $0.00 \mathrm{E}+00$ & $6.30 \mathrm{E}+00$ & $6.30 \mathrm{E}+00$ & $1.30 \mathrm{E}-04$ \\
\hline Cs-135 & $0.00 \mathrm{E}+00$ & $0.00 \mathrm{E}+00$ & $0.00 \mathrm{E}+00$ & $0.00 \mathrm{E}+00$ & $0.00 \mathrm{E}+00$ \\
\hline Cs-137 & $0.00 \mathrm{E}+00$ & $0.00 \mathrm{E}+00$ & $2.70 \mathrm{E}+00$ & $2.70 \mathrm{E}+00$ & $5.30 \mathrm{E}-05$ \\
\hline Eu-152 & $0.00 \mathrm{E}+00$ & $0.00 \mathrm{E}+00$ & $5.50 \mathrm{E}+00$ & $5.50 \mathrm{E}+00$ & 1.10E-04 \\
\hline Eu-154 & $0.00 \mathrm{E}+00$ & $0.00 \mathrm{E}+00$ & $5.80 \mathrm{E}+00$ & $5.80 \mathrm{E}+00$ & $1.20 \mathrm{E}-04$ \\
\hline $\mathrm{Fe}-55$ & $0.00 \mathrm{E}+00$ & $0.00 \mathrm{E}+00$ & $0.00 \mathrm{E}+00$ & $0.00 \mathrm{E}+00$ & $0.00 \mathrm{E}+00$ \\
\hline $\mathrm{Mn}-54$ & $0.00 \mathrm{E}+00$ & $0.00 \mathrm{E}+00$ & $2.60 \mathrm{E}+00$ & $2.60 \mathrm{E}+00$ & $5.20 \mathrm{E}-05$ \\
\hline $\mathrm{Na}-22$ & $0.00 \mathrm{E}+00$ & $0.00 \mathrm{E}+00$ & $8.90 \mathrm{E}+00$ & $8.90 E+00$ & $1.80 \mathrm{E}-04$ \\
\hline $\mathrm{Nb}-94$ & $0.00 \mathrm{E}+00$ & $0.00 \mathrm{E}+00$ & $7.20 \mathrm{E}+00$ & $7.20 \mathrm{E}+00$ & $1.40 \mathrm{E}-04$ \\
\hline $\mathrm{Ni}-59$ & $0.00 \mathrm{E}+00$ & $0.00 \mathrm{E}+00$ & $0.00 \mathrm{E}+00$ & $0.00 \mathrm{E}+00$ & $0.00 \mathrm{E}+00$ \\
\hline $\mathrm{Ni}-63$ & $0.00 \mathrm{E}+00$ & $0.00 \mathrm{E}+00$ & $0.00 \mathrm{E}+00$ & $0.00 \mathrm{E}+00$ & $0.00 \mathrm{E}+00$ \\
\hline$N p-237$ & $0.00 \mathrm{E}+00$ & $0.00 \mathrm{E}+00$ & $1.80 \mathrm{E}+00$ & $1.80 \mathrm{E}+00$ & $3.50 \mathrm{E}-05$ \\
\hline $\mathrm{Pb}-210$ & $0.00 \mathrm{E}+00$ & $0.00 \mathrm{E}+00$ & $3.20 \mathrm{E}-02$ & $3.20 \mathrm{E}-02$ & $6.40 \mathrm{E}-07$ \\
\hline Pm-147 & $0.00 \mathrm{E}+00$ & $0.00 \mathrm{E}+00$ & 1.30E-04 & $1.30 \mathrm{E}-04$ & $2.60 \mathrm{E}-09$ \\
\hline $\mathrm{Pu}-238$ & $0.00 \mathrm{E}+00$ & $0.00 \mathrm{E}+00$ & 2.20E-03 & $2.20 \mathrm{E}-03$ & $4.40 \mathrm{E}-08$ \\
\hline $\mathrm{Pu}-239$ & $0.00 E+00$ & $0.00 \mathrm{E}+00$ & 1.20E-03 & $1.20 \mathrm{E}-03$ & 2.30E-08 \\
\hline $\mathrm{Pu}-240$ & $0.00 \mathrm{E}+00$ & $0.00 \mathrm{E}+00$ & $2.20 \mathrm{E}-03$ & $2.20 \mathrm{E}-03$ & $4.30 \mathrm{E}-08$ \\
\hline Pu-241 & $0.00 \mathrm{E}+00$ & $0.00 \mathrm{E}+00$ & $5.90 \mathrm{E}-05$ & $5.90 \mathrm{E}-05$ & $1.20 \mathrm{E}-09$ \\
\hline $\mathrm{Pu}-242$ & $0.00 \mathrm{E}+00$ & $0.00 \mathrm{E}+00$ & $1.80 \mathrm{E}-03$ & $1.80 \mathrm{E}-03$ & 3.70E-08 \\
\hline Ru-106 & $0.00 \mathrm{E}+00$ & $0.00 \mathrm{E}+00$ & $7.70 \mathrm{E}-01$ & 7.70E-01 & $1.50 \mathrm{E}-05$ \\
\hline Sb-125 & $0.00 \mathrm{E}+00$ & $0.00 \mathrm{E}+00$ & $1.90 \mathrm{E}+00$ & $1.90 \mathrm{E}+00$ & 3.70E-05 \\
\hline Se-79 & $0.00 \mathrm{E}+00$ & $0.00 \mathrm{E}+00$ & $0.00 \mathrm{E}+00$ & $0.00 \mathrm{E}+00$ & $0.00 \mathrm{E}+00$ \\
\hline Sm-151 & $0.00 \mathrm{E}+00$ & $0.00 \mathrm{E}+00$ & $1.50 \mathrm{E}-05$ & $1.50 \mathrm{E}-05$ & $2.90 \mathrm{E}-10$ \\
\hline Sr-90 & $0.00 \mathrm{E}+00$ & $0.00 \mathrm{E}+00$ & $1.40 \mathrm{E}-02$ & 1.40E-02 & $2.80 \mathrm{E}-07$ \\
\hline Tc-99 & $0.00 \mathrm{E}+00$ & $0.00 \mathrm{E}+00$ & $6.90 \mathrm{E}-04$ & $6.90 \mathrm{E}-04$ & $1.40 \mathrm{E}-08$ \\
\hline Th-228 & $0.00 \mathrm{E}+00$ & $0.00 \mathrm{E}+00$ & $5.90 \mathrm{E}+00$ & $5.90 \mathrm{E}+00$ & $1.20 \mathrm{E}-04$ \\
\hline Th-229 & $0.00 \mathrm{E}+00$ & $0.00 \mathrm{E}+00$ & $2.70 \mathrm{E}+00$ & $2.70 \mathrm{E}+00$ & 5.30E-05 \\
\hline Th-230 & $0.00 \mathrm{E}+00$ & $0.00 \mathrm{E}+00$ & $6.80 \mathrm{E}-03$ & 6.80E-03 & 1.40E-07 \\
\hline Th-232 & $0.00 \mathrm{E}+00$ & $0.00 \mathrm{E}+00$ & $3.60 \mathrm{E}-03$ & $3.60 \mathrm{E}-03$ & $7.10 \mathrm{E}-08$ \\
\hline U-232 & $0.00 \mathrm{E}+00$ & $0.00 \mathrm{E}+00$ & $4.50 \mathrm{E}-03$ & $4.50 \mathrm{E}-03$ & $9.00 \mathrm{E}-08$ \\
\hline U-233 & $0.00 \mathrm{E}+00$ & $0.00 \mathrm{E}+00$ & $4.80 \mathrm{E}-03$ & $4.80 \mathrm{E}-03$ & $9.50 \mathrm{E}-08$ \\
\hline U-234 & $0.00 \mathrm{E}+00$ & $0.00 \mathrm{E}+00$ & 2.40E-03 & 2.40E-03 & $4.80 \mathrm{E}-08$ \\
\hline U-235 & $0.00 \mathrm{E}+00$ & $0.00 \mathrm{E}+00$ & $1.50 \mathrm{E}+00$ & $1.50 \mathrm{E}+00$ & 2.90E-05 \\
\hline $\mathrm{U}-238$ & $0.00 \mathrm{E}+00$ & $0.00 \mathrm{E}+00$ & 2.40E-01 & 2.40E-01 & $4.80 \mathrm{E}-06$ \\
\hline $\mathrm{Zn}-65$ & $0.00 \mathrm{E}+00$ & $0.00 \mathrm{E}+00$ & $1.70 \mathrm{E}+00$ & $1.70 \mathrm{E}+00$ & 3.40E-05 \\
\hline Zr-93 & $0.00 \mathrm{E}+00$ & $0.00 \mathrm{E}+00$ & $0.00 \mathrm{E}+00$ & $0.00 \mathrm{E}+00$ & $0.00 \mathrm{E}+00$ \\
\hline
\end{tabular}

a Doses do not account for scrap dilution or radionuclide partitioning; collective doses based on $100 \mathrm{t}$. 
TABLE D.22 Baseline Worker Doses for a 2,000-h Distribution Warehouse Worker ${ }^{a}$

\begin{tabular}{|c|c|c|c|c|c|}
\hline Nuclide & $\begin{array}{r}\text { Ingestion } \\
(\mu \mathrm{Sv} / \mathrm{yr}) \\
\end{array}$ & $\begin{array}{c}\text { Inhalation } \\
(\mu \mathrm{Sv} / \mathrm{yr})\end{array}$ & $\begin{array}{c}\text { External } \\
(\mu \mathrm{Sv} / \mathrm{yr})\end{array}$ & $\begin{array}{c}\text { Total Dose } \\
(\mu \mathrm{Sv} / \mathrm{yr})\end{array}$ & $\begin{array}{l}\text { Collective Dose } \\
\text { (person-Sv/yr) }\end{array}$ \\
\hline Ac-227 & $0.00 \mathrm{E}+00$ & $0.00 \mathrm{E}+00$ & $6.50 \mathrm{E}-01$ & $6.50 \mathrm{E}-01$ & $3.20 \mathrm{E}-06$ \\
\hline $\mathrm{Ag}-110 \mathrm{~m}$ & $0.00 \mathrm{E}+00$ & $0.00 \mathrm{E}+00$ & $2.20 \mathrm{E}+00$ & $2.20 \mathrm{E}+00$ & $1.10 \mathrm{E}-05$ \\
\hline Am-241 & $0.00 \mathrm{E}+00$ & $0.00 \mathrm{E}+00$ & $3.10 \mathrm{E}-02$ & $3.10 \mathrm{E}-02$ & $1.60 \mathrm{E}-07$ \\
\hline Am-243 & $0.00 \mathrm{E}+00$ & $0.00 \mathrm{E}+00$ & $4.50 \mathrm{E}-01$ & $4.50 \mathrm{E}-01$ & $2.20 \mathrm{E}-06$ \\
\hline $\mathrm{Ca}-41$ & $0.00 \mathrm{E}+00$ & $0.00 \mathrm{E}+00$ & $0.00 \mathrm{E}+00$ & $0.00 \mathrm{E}+00$ & $0.00 \mathrm{E}+00$ \\
\hline Ce-144 & $0.00 \mathrm{E}+00$ & $0.00 \mathrm{E}+00$ & $5.70 \mathrm{E}-02$ & $5.70 \mathrm{E}-02$ & 2.90E-07 \\
\hline $\mathrm{Cl}-36$ & $0.00 \mathrm{E}+00$ & $0.00 \mathrm{E}+00$ & $5.90 \mathrm{E}-04$ & 5.90E-04 & $3.00 \mathrm{E}-09$ \\
\hline $\mathrm{Cm}-243$ & $0.00 \mathrm{E}+00$ & $0.00 \mathrm{E}+00$ & $2.60 \mathrm{E}-01$ & $2.60 \mathrm{E}-01$ & $1.30 \mathrm{E}-06$ \\
\hline $\mathrm{Cm}-244$ & $0.00 \mathrm{E}+00$ & $0.00 \mathrm{E}+00$ & $6.40 \mathrm{E}-05$ & $6.40 \mathrm{E}-05$ & $3.20 \mathrm{E}-10$ \\
\hline $\mathrm{Cm}-245$ & $0.00 \mathrm{E}+00$ & $0.00 \mathrm{E}+00$ & $2.10 \mathrm{E}-01$ & 2.10E-01 & $1.00 \mathrm{E}-06$ \\
\hline $\mathrm{Cm}-246$ & $0.00 \mathrm{E}+00$ & $0.00 \mathrm{E}+00$ & $5.20 \mathrm{E}-05$ & $5.20 \mathrm{E}-05$ & $2.60 \mathrm{E}-10$ \\
\hline $\mathrm{Cm}-247$ & $0.00 \mathrm{E}+00$ & $0.00 \mathrm{E}+00$ & 5.10E-01 & $5.10 \mathrm{E}-01$ & 2.60E-06 \\
\hline Co-57 & $0.00 \mathrm{E}+00$ & $0.00 \mathrm{E}+00$ & $2.00 \mathrm{E}-01$ & $2.00 \mathrm{E}-01$ & $1.00 \mathrm{E}-06$ \\
\hline Co-60 & $0.00 \mathrm{E}+00$ & $0.00 \mathrm{E}+00$ & $2.80 \mathrm{E}+00$ & $2.80 \mathrm{E}+00$ & $1.40 \mathrm{E}-05$ \\
\hline Cs-134 & $0.00 \mathrm{E}+00$ & $0.00 \mathrm{E}+00$ & $1.80 \mathrm{E}+00$ & $1.80 \mathrm{E}+00$ & 8.90E-06 \\
\hline Cs-135 & $0.00 \mathrm{E}+00$ & $0.00 \mathrm{E}+00$ & $0.00 \mathrm{E}+00$ & $0.00 \mathrm{E}+00$ & $0.00 \mathrm{E}+00$ \\
\hline Cs-137 & $0.00 \mathrm{E}+00$ & $0.00 \mathrm{E}+00$ & 7.70E-01 & 7.70E-01 & $3.80 \mathrm{E}-06$ \\
\hline Eu-152 & $0.00 \mathrm{E}+00$ & $0.00 \mathrm{E}+00$ & $1.50 \mathrm{E}+00$ & $1.50 \mathrm{E}+00$ & $7.30 \mathrm{E}-06$ \\
\hline Eu-154 & $0.00 \mathrm{E}+00$ & $0.00 \mathrm{E}+00$ & $1.50 \mathrm{E}+00$ & $1.50 \mathrm{E}+00$ & $7.70 \mathrm{E}-06$ \\
\hline $\mathrm{Fe}-55$ & $0.00 \mathrm{E}+00$ & $0.00 \mathrm{E}+00$ & $0.00 \mathrm{E}+00$ & $0.00 \mathrm{E}+00$ & $0.00 \mathrm{E}+00$ \\
\hline $\mathrm{Mn}-54$ & $0.00 \mathrm{E}+00$ & $0.00 \mathrm{E}+00$ & $7.20 \mathrm{E}-01$ & 7.20E-01 & $3.60 \mathrm{E}-06$ \\
\hline $\mathrm{Na}-22$ & $0.00 \mathrm{E}+00$ & $0.00 \mathrm{E}+00$ & $2.50 \mathrm{E}+00$ & $2.50 \mathrm{E}+00$ & $1.20 \mathrm{E}-05$ \\
\hline $\mathrm{Nb}-94$ & $0.00 \mathrm{E}+00$ & $0.00 \mathrm{E}+00$ & $2.00 \mathrm{E}+00$ & $2.00 \mathrm{E}+00$ & $1.00 \mathrm{E}-05$ \\
\hline Ni-59 & $0.00 \mathrm{E}+00$ & $0.00 \mathrm{E}+00$ & $0.00 \mathrm{E}+00$ & $0.00 \mathrm{E}+00$ & $0.00 \mathrm{E}+00$ \\
\hline $\mathrm{Ni}-63$ & $0.00 \mathrm{E}+00$ & $0.00 \mathrm{E}+00$ & $0.00 \mathrm{E}+00$ & $0.00 \mathrm{E}+00$ & $0.00 \mathrm{E}+00$ \\
\hline Np-237 & $0.00 \mathrm{E}+00$ & $0.00 \mathrm{E}+00$ & $4.00 \mathrm{E}-01$ & $4.00 \mathrm{E}-01$ & $2.00 \mathrm{E}-06$ \\
\hline $\mathrm{Pb}-210$ & $0.00 \mathrm{E}+00$ & $0.00 \mathrm{E}+00$ & $1.70 \mathrm{E}-03$ & $1.70 \mathrm{E}-03$ & $8.60 \mathrm{E}-09$ \\
\hline $\mathrm{Pm}-147$ & $0.00 \mathrm{E}+00$ & $0.00 \mathrm{E}+00$ & $2.70 \mathrm{E}-05$ & 2.70E-05 & $1.40 \mathrm{E}-10$ \\
\hline $\mathrm{Pu}-238$ & $0.00 \mathrm{E}+00$ & $0.00 \mathrm{E}+00$ & 8.30E-05 & 8.30E-05 & $4.20 \mathrm{E}-10$ \\
\hline $\mathrm{Pu}-239$ & $0.00 \mathrm{E}+00$ & $0.00 \mathrm{E}+00$ & $1.90 \mathrm{E}-04$ & $1.90 \mathrm{E}-04$ & $9.50 \mathrm{E}-10$ \\
\hline Pu-240 & $0.00 \mathrm{E}+00$ & $0.00 \mathrm{E}+00$ & 8.30E-05 & $8.30 \mathrm{E}-05$ & $4.10 \mathrm{E}-10$ \\
\hline $\mathrm{Pu}-241$ & $0.00 \mathrm{E}+00$ & $0.00 \mathrm{E}+00$ & $1.00 \mathrm{E}-05$ & $1.00 \mathrm{E}-05$ & $5.20 \mathrm{E}-11$ \\
\hline $\mathrm{Pu}-242$ & $0.00 \mathrm{E}+00$ & $0.00 \mathrm{E}+00$ & $7.40 \mathrm{E}-05$ & $7.40 \mathrm{E}-05$ & $3.70 \mathrm{E}-10$ \\
\hline Ru-106 & $0.00 \mathrm{E}+00$ & $0.00 \mathrm{E}+00$ & 2.20E-01 & $2.20 \mathrm{E}-01$ & $1.10 \mathrm{E}-06$ \\
\hline Sb-125 & $0.00 \mathrm{E}+00$ & $0.00 \mathrm{E}+00$ & $5.40 \mathrm{E}-01$ & $5.40 \mathrm{E}-01$ & $2.70 \mathrm{E}-06$ \\
\hline Se-79 & $0.00 \mathrm{E}+00$ & $0.00 \mathrm{E}+00$ & $0.00 \mathrm{E}+00$ & $0.00 \mathrm{E}+00$ & $0.00 \mathrm{E}+00$ \\
\hline Sm-151 & $0.00 \mathrm{E}+00$ & $0.00 \mathrm{E}+00$ & 5.80E-07 & 5.80E-07 & $2.90 \mathrm{E}-12$ \\
\hline Sr-90 & $0.00 \mathrm{E}+00$ & $0.00 \mathrm{E}+00$ & $3.90 \mathrm{E}-03$ & $3.90 \mathrm{E}-03$ & $2.00 \mathrm{E}-08$ \\
\hline Tc-99 & $0.00 \mathrm{E}+00$ & $0.00 \mathrm{E}+00$ & $9.00 \mathrm{E}-05$ & $9.00 \mathrm{E}-05$ & $4.50 \mathrm{E}-10$ \\
\hline Th-228 & $0.00 \mathrm{E}+00$ & $0.00 \mathrm{E}+00$ & $1.60 \mathrm{E}+00$ & $1.60 \mathrm{E}+00$ & $8.10 \mathrm{E}-06$ \\
\hline Th-229 & $0.00 \mathrm{E}+00$ & $0.00 \mathrm{E}+00$ & $5.40 \mathrm{E}-01$ & $5.40 \mathrm{E}-01$ & $2.70 \mathrm{E}-06$ \\
\hline Th-230 & $0.00 \mathrm{E}+00$ & $0.00 \mathrm{E}+00$ & 7.10E-04 & 7.10E-04 & $3.50 \mathrm{E}-09$ \\
\hline Th-232 & $0.00 \mathrm{E}+00$ & $0.00 \mathrm{E}+00$ & $3.30 \mathrm{E}-04$ & $3.30 \mathrm{E}-04$ & 1.70E-09 \\
\hline U-232 & $0.00 \mathrm{E}+00$ & $0.00 \mathrm{E}+00$ & 5.20E-04 & $5.20 \mathrm{E}-04$ & 2.60E-09 \\
\hline U-233 & $0.00 \mathrm{E}+00$ & $0.00 \mathrm{E}+00$ & $9.10 \mathrm{E}-04$ & $9.10 \mathrm{E}-04$ & $4.50 \mathrm{E}-09$ \\
\hline U-234 & $0.00 \mathrm{E}+00$ & $0.00 \mathrm{E}+00$ & 2.50E-04 & 2.50E-04 & 1.30E-09 \\
\hline U-235 & $0.00 \mathrm{E}+00$ & $0.00 \mathrm{E}+00$ & $3.50 \mathrm{E}-01$ & $3.50 \mathrm{E}-01$ & $1.80 \mathrm{E}-06$ \\
\hline U-238 & $0.00 \mathrm{E}+00$ & $0.00 \mathrm{E}+00$ & $4.10 \mathrm{E}-02$ & $4.10 \mathrm{E}-02$ & $2.00 \mathrm{E}-07$ \\
\hline $\mathrm{Zn}-65$ & $0.00 \mathrm{E}+00$ & $0.00 \mathrm{E}+00$ & $4.60 \mathrm{E}-01$ & $4.60 \mathrm{E}-01$ & $2.30 \mathrm{E}-06$ \\
\hline $\mathrm{Zr}-93$ & $0.00 \mathrm{E}+00$ & $0.00 \mathrm{E}+00$ & $0.00 \mathrm{E}+00$ & $0.00 \mathrm{E}+00$ & $0.00 \mathrm{E}+00$ \\
\hline
\end{tabular}

a Doses do not account for scrap dilution or radionuclide partitioning; collective doses based on $100 \mathrm{t}$. 
TABLE D.23 Baseline Public Doses for Tool Reuse ${ }^{a}$

\begin{tabular}{|c|c|c|c|c|c|}
\hline Nuclide & $\begin{array}{r}\text { Ingestion } \\
(\mu \mathrm{Sv} / \mathrm{yr})\end{array}$ & $\begin{array}{c}\text { Inhalation } \\
(\mu S v / y r)\end{array}$ & $\begin{array}{r}\text { External } \\
(\mu \mathrm{Sv} / \mathrm{yr})\end{array}$ & $\begin{array}{l}\text { Total Dose } \\
(\mu \mathrm{Sv} / \mathrm{yr})\end{array}$ & $\begin{array}{r}\text { Collective Dose } \\
\text { (person-Sv/yr) }\end{array}$ \\
\hline Ac-227 & $1.30 \mathrm{E}+02$ & $5.70 \mathrm{E}+02$ & $7.30 \mathrm{E}-01$ & $7.10 \mathrm{E}+02$ & 7.10E-04 \\
\hline $\mathrm{Ag}-110 \mathrm{~m}$ & $6.10 \mathrm{E}-02$ & 4.40E-03 & $3.10 \mathrm{E}+00$ & $3.20 \mathrm{E}+00$ & 3.20E-06 \\
\hline Am-241 & $3.30 \mathrm{E}+01$ & $3.80 \mathrm{E}+01$ & 8.90E-02 & $7.10 \mathrm{E}+01$ & $7.10 \mathrm{E}-05$ \\
\hline Am-243 & $3.30 \mathrm{E}+01$ & $3.80 \mathrm{E}+01$ & $5.00 \mathrm{E}-01$ & $7.10 \mathrm{E}+01$ & 7.10E-05 \\
\hline $\mathrm{Ca}-41$ & $1.10 \mathrm{E}-02$ & $1.20 \mathrm{E}-04$ & $0.00 \mathrm{E}+00$ & 1.20E-02 & $1.20 \mathrm{E}-08$ \\
\hline $\mathrm{Ce}-144$ & $1.30 \mathrm{E}-01$ & 2.10E-02 & 7.90E-02 & 2.30E-01 & 2.30E-07 \\
\hline Cl-36 & 2.70E-02 & $1.90 \mathrm{E}-03$ & $1.30 \mathrm{E}-03$ & $3.00 \mathrm{E}-02$ & 3.00E-08 \\
\hline $\mathrm{Cm}-243$ & $2.20 \mathrm{E}+01$ & $2.60 \mathrm{E}+01$ & 2.60E-01 & $4.90 \mathrm{E}+01$ & 4.90E-05 \\
\hline $\mathrm{Cm}-244$ & $1.80 \mathrm{E}+01$ & $2.10 \mathrm{E}+01$ & 5.90E-03 & $3.90 \mathrm{E}+01$ & 3.90E-05 \\
\hline $\mathrm{Cm}-245$ & $3.40 \mathrm{E}+01$ & $3.90 \mathrm{E}+01$ & $2.10 \mathrm{E}-01$ & $7.30 \mathrm{E}+01$ & 7.30E-05 \\
\hline $\mathrm{Cm}-246$ & $3.30 \mathrm{E}+01$ & $3.90 \mathrm{E}+01$ & $5.40 \mathrm{E}-03$ & $7.20 \mathrm{E}+01$ & $7.20 \mathrm{E}-05$ \\
\hline $\mathrm{Cm}-247$ & $3.10 \mathrm{E}+01$ & $3.60 \mathrm{E}+01$ & $6.10 \mathrm{E}-01$ & $6.70 \mathrm{E}+01$ & $6.70 \mathrm{E}-05$ \\
\hline $\mathrm{Co}-57$ & $7.10 \mathrm{E}-03$ & $5.20 \mathrm{E}-04$ & $1.80 \mathrm{E}-01$ & $1.80 \mathrm{E}-01$ & $1.80 \mathrm{E}-07$ \\
\hline Co-60 & $2.30 \mathrm{E}-01$ & $1.80 \mathrm{E}-02$ & $4.10 \mathrm{E}+00$ & $4.30 \mathrm{E}+00$ & $4.30 \mathrm{E}-06$ \\
\hline Cs-134 & 5.60E-01 & $3.40 \mathrm{E}-03$ & $2.40 \mathrm{E}+00$ & $2.90 \mathrm{E}+00$ & 2.90E-06 \\
\hline Cs-135 & 6.40E-02 & 3.90E-04 & $0.00 \mathrm{E}+00$ & $6.40 \mathrm{E}-02$ & $6.40 \mathrm{E}-08$ \\
\hline Cs-137 & $4.50 \mathrm{E}-01$ & 2.70E-03 & $1.00 \mathrm{E}+00$ & $1.50 \mathrm{E}+00$ & $1.50 \mathrm{E}-06$ \\
\hline Eu-152 & $5.70 \mathrm{E}-02$ & $1.90 \mathrm{E}-02$ & $2.00 \mathrm{E}+00$ & $2.10 \mathrm{E}+00$ & 2.10E-06 \\
\hline Eu-154 & $8.30 \mathrm{E}-02$ & 2.40E-02 & $2.10 \mathrm{E}+00$ & $2.30 \mathrm{E}+00$ & 2.30E-06 \\
\hline $\mathrm{Fe}-55$ & $4.80 \mathrm{E}-03$ & 2.00E-04 & $0.00 E+00$ & 5.00E-03 & $5.00 \mathrm{E}-09$ \\
\hline $\mathrm{Mn}-54$ & 1.70E-02 & $4.00 \mathrm{E}-04$ & $1.00 \mathrm{E}+00$ & $1.00 \mathrm{E}+00$ & $1.00 \mathrm{E}-06$ \\
\hline $\mathrm{Na}-22$ & $9.10 \mathrm{E}-02$ & $5.80 \mathrm{E}-04$ & $3.40 \mathrm{E}+00$ & $3.50 \mathrm{E}+00$ & $3.50 \mathrm{E}-06$ \\
\hline $\mathrm{Nb}-94$ & $6.40 \mathrm{E}-02$ & $3.60 \mathrm{E}-02$ & $2.80 \mathrm{E}+00$ & $2.90 \mathrm{E}+00$ & 2.90E-06 \\
\hline $\mathrm{Ni}-59$ & $1.90 \mathrm{E}-03$ & 2.30E-04 & $0.00 \mathrm{E}+00$ & $2.10 \mathrm{E}-03$ & 2.10E-09 \\
\hline $\mathrm{Ni}-63$ & $5.20 \mathrm{E}-03$ & 5.40E-04 & $0.00 \mathrm{E}+00$ & $5.70 \mathrm{E}-03$ & 5.70E-09 \\
\hline $\mathrm{Np}-237$ & $4.00 \mathrm{E}+01$ & $4.70 \mathrm{E}+01$ & 4.60E-01 & $8.70 \mathrm{E}+01$ & $8.70 \mathrm{E}-05$ \\
\hline $\mathrm{Pb}-210$ & $4.80 \mathrm{E}+01$ & $1.20 \mathrm{E}+00$ & $9.70 \mathrm{E}-03$ & $4.90 \mathrm{E}+01$ & $4.90 \mathrm{E}-05$ \\
\hline Pm-147 & 8.30E-03 & $3.00 \mathrm{E}-03$ & $6.80 \mathrm{E}-05$ & 1.10E-02 & $1.10 \mathrm{E}-08$ \\
\hline $\mathrm{Pu}-238$ & $2.90 E+01$ & $3.40 \mathrm{E}+01$ & $6.50 \mathrm{E}-03$ & $6.30 \mathrm{E}+01$ & $6.30 \mathrm{E}-05$ \\
\hline $\mathrm{Pu}-239$ & $3.20 \mathrm{E}+01$ & $3.70 \mathrm{E}+01$ & 2.40E-03 & $6.90 \mathrm{E}+01$ & $6.90 \mathrm{E}-05$ \\
\hline $\mathrm{Pu}-240$ & $3.20 \mathrm{E}+01$ & $3.70 \mathrm{E}+01$ & 6.20E-03 & $6.90 \mathrm{E}+01$ & $6.90 \mathrm{E}-05$ \\
\hline $\mathrm{Pu}-241$ & $6.00 \mathrm{E}-01$ & $7.00 \mathrm{E}-01$ & 1.30E-05 & $1.30 \mathrm{E}+00$ & 1.30E-06 \\
\hline $\mathrm{Pu}-242$ & $3.00 \mathrm{E}+01$ & $3.60 \mathrm{E}+01$ & $5.10 \mathrm{E}-03$ & $6.60 \mathrm{E}+01$ & $6.60 \mathrm{E}-05$ \\
\hline $\mathrm{Ru}-106$ & $1.80 \mathrm{E}-01$ & $3.00 \mathrm{E}-02$ & $2.80 \mathrm{E}-01$ & 4.90E-01 & $4.90 \mathrm{E}-07$ \\
\hline $\mathrm{Sb}-125$ & $2.20 \mathrm{E}-02$ & $9.30 \mathrm{E}-04$ & 7.20E-01 & $7.50 \mathrm{E}-01$ & 7.50E-07 \\
\hline $\mathrm{Se}-79$ & $7.80 \mathrm{E}-02$ & 8.50E-04 & $0.00 \mathrm{E}+00$ & 7.90E-02 & 7.90E-08 \\
\hline Sm-151 & $3.50 \mathrm{E}-03$ & 2.60E-03 & 2.80E-05 & $6.10 \mathrm{E}-03$ & 6.10E-09 \\
\hline $\mathrm{Sr}-90$ & $1.40 \mathrm{E}+00$ & $1.10 \mathrm{E}-01$ & $9.80 \mathrm{E}-03$ & $1.50 \mathrm{E}+00$ & $1.50 \mathrm{E}-06$ \\
\hline Tc-99 & $1.30 \mathrm{E}-02$ & $7.20 \mathrm{E}-04$ & 2.00E-04 & $1.40 \mathrm{E}-02$ & $1.40 \mathrm{E}-08$ \\
\hline Th-228 & $3.00 \mathrm{E}+00$ & $2.50 \mathrm{E}+01$ & $2.20 \mathrm{E}+00$ & $3.00 \mathrm{E}+01$ & 3.00E-05 \\
\hline Th-229 & $3.20 \mathrm{E}+01$ & $1.90 \mathrm{E}+02$ & 6.70E-01 & $2.20 \mathrm{E}+02$ & 2.20E-04 \\
\hline Th-230 & $4.90 \mathrm{E}+00$ & $2.80 \mathrm{E}+01$ & 3.60E-03 & $3.30 \mathrm{E}+01$ & 3.30E-05 \\
\hline Th-232 & $2.50 \mathrm{E}+01$ & $1.40 \mathrm{E}+02$ & 3.40E-03 & $1.70 \mathrm{E}+02$ & 1.70E-04 \\
\hline U-232 & $1.20 \mathrm{E}+01$ & $5.70 \mathrm{E}+01$ & 6.30E-03 & $6.80 \mathrm{E}+01$ & $6.80 \mathrm{E}-05$ \\
\hline U-233 & $2.60 \mathrm{E}+00$ & $1.20 \mathrm{E}+01$ & 3.20E-03 & $1.40 \mathrm{E}+01$ & 1.40E-05 \\
\hline U-234 & $2.60 \mathrm{E}+00$ & $1.10 \mathrm{E}+01$ & 5.30E-03 & $1.40 \mathrm{E}+01$ & $1.40 \mathrm{E}-05$ \\
\hline $\mathrm{U}-235$ & $2.40 \mathrm{E}+00$ & $1.10 \mathrm{E}+01$ & 3.70E-01 & 1.30E+01 & $1.30 \mathrm{E}-05$ \\
\hline U-238 & $2.30 \mathrm{E}+00$ & $1.00 \mathrm{E}+01$ & 6.20E-02 & $1.30 \mathrm{E}+01$ & $1.30 \mathrm{E}-05$ \\
\hline $\mathrm{Zn}-65$ & 8.10E-02 & $1.10 \mathrm{E}-03$ & $6.40 \mathrm{E}-01$ & 7.20E-01 & $7.20 \mathrm{E}-07$ \\
\hline $\mathrm{Zr}-93$ & $1.50 \mathrm{E}-02$ & $2.80 \mathrm{E}-02$ & $0.00 \mathrm{E}+00$ & 4.30E-02 & 4.30E-08 \\
\hline
\end{tabular}

a Doses do not account for scrap dilution or radionuclide partitioning; collective doses based on $100 t$. 
TABLE D.24 Baseline Public Doses for Building Occupancy Scenario ${ }^{a}$

\begin{tabular}{|c|c|c|c|c|c|}
\hline Nuclide & $\begin{array}{r}\text { Ingestion } \\
(\mu \mathrm{Sv} / \mathrm{yr})\end{array}$ & $\begin{array}{c}\text { Inhalation } \\
(\mu \mathrm{Sv} / \mathrm{yr})\end{array}$ & $\begin{array}{l}\text { External } \\
(\mu S v / y r)\end{array}$ & $\begin{array}{l}\text { Total Dose } \\
(\mu \mathrm{Sv} / \mathrm{yr})\end{array}$ & $\begin{array}{r}\text { Collective Dose } \\
\text { (person-Sv/yr) }\end{array}$ \\
\hline Ac-227 & $8.00 \mathrm{E}+03$ & $3.40 \mathrm{E}+04$ & $7.20 \mathrm{E}+00$ & $4.20 \mathrm{E}+04$ & $1.70 \mathrm{E}-01$ \\
\hline $\mathrm{Ag}-110 \mathrm{~m}$ & $3.70 \mathrm{E}+00$ & $2.60 \mathrm{E}-01$ & $4.70 \mathrm{E}+01$ & $5.10 \mathrm{E}+01$ & $2.00 \mathrm{E}-04$ \\
\hline $\mathrm{Am}-241$ & $2.00 \mathrm{E}+03$ & $2.30 \mathrm{E}+03$ & $4.80 \mathrm{E}-01$ & $4.30 \mathrm{E}+03$ & $1.70 \mathrm{E}-02$ \\
\hline Am-243 & $2.00 \mathrm{E}+03$ & $2.30 \mathrm{E}+03$ & $6.60 \mathrm{E}+00$ & $4.20 \mathrm{E}+03$ & $1.70 \mathrm{E}-02$ \\
\hline $\mathrm{Ca}-41$ & $6.90 \mathrm{E}-01$ & $7.00 \mathrm{E}-03$ & $0.00 \mathrm{E}+00$ & $6.90 \mathrm{E}-01$ & 2.80E-06 \\
\hline Ce-144 & $7.50 \mathrm{E}+00$ & $1.30 \mathrm{E}+00$ & $1.10 \mathrm{E}+00$ & $9.90 \mathrm{E}+00$ & $4.00 \mathrm{E}-05$ \\
\hline Cl-36 & $1.60 \mathrm{E}+00$ & $1.10 \mathrm{E}-01$ & $1.90 \mathrm{E}-02$ & $1.80 \mathrm{E}+00$ & 7.10E-06 \\
\hline $\mathrm{Cm}-243$ & $1.30 \mathrm{E}+03$ & $1.60 \mathrm{E}+03$ & $3.70 \mathrm{E}+00$ & $2.90 \mathrm{E}+03$ & $1.20 \mathrm{E}-02$ \\
\hline $\mathrm{Cm}-244$ & $1.10 \mathrm{E}+03$ & $1.30 \mathrm{E}+03$ & $6.60 \mathrm{E}-02$ & $2.30 \mathrm{E}+03$ & $9.30 \mathrm{E}-03$ \\
\hline $\mathrm{Cm}-245$ & $2.00 \mathrm{E}+03$ & $2.40 \mathrm{E}+03$ & $2.70 \mathrm{E}+00$ & $4.40 \mathrm{E}+03$ & $1.80 \mathrm{E}-02$ \\
\hline $\mathrm{Cm}-246$ & $2.00 \mathrm{E}+03$ & $2.30 \mathrm{E}+03$ & $6.00 \mathrm{E}-02$ & $4.30 \mathrm{E}+03$ & $1.70 \mathrm{E}-02$ \\
\hline $\mathrm{Cm}-247$ & $1.80 \mathrm{E}+03$ & $2.20 \mathrm{E}+03$ & $9.50 \mathrm{E}+00$ & $4.00 \mathrm{E}+03$ & $1.60 \mathrm{E}-02$ \\
\hline Co-57 & $4.30 \mathrm{E}-01$ & $3.10 \mathrm{E}-02$ & $2.30 \mathrm{E}+00$ & $2.70 \mathrm{E}+00$ & $1.10 \mathrm{E}-05$ \\
\hline Co-60 & $1.40 \mathrm{E}+01$ & $1.10 \mathrm{E}+00$ & $4.20 \mathrm{E}+01$ & $5.70 \mathrm{E}+01$ & 2.30E-04 \\
\hline Cs-134 & $3.40 \mathrm{E}+01$ & $2.00 \mathrm{E}-01$ & $3.60 \mathrm{E}+01$ & $7.00 \mathrm{E}+01$ & $2.80 \mathrm{E}-04$ \\
\hline Cs-135 & $3.80 \mathrm{E}+00$ & $2.40 \mathrm{E}-02$ & $0.00 \mathrm{E}+00$ & $3.80 \mathrm{E}+00$ & $1.50 \mathrm{E}-05$ \\
\hline Cs-137 & $2.70 \mathrm{E}+01$ & $1.60 \mathrm{E}-01$ & $1.00 \mathrm{E}+01$ & $3.70 \mathrm{E}+01$ & 1.50E-04 \\
\hline Eu-152 & $3.40 \mathrm{E}+00$ & $1.10 \mathrm{E}+00$ & $3.00 \mathrm{E}+01$ & $3.50 \mathrm{E}+01$ & $1.40 \mathrm{E}-04$ \\
\hline Eu-154 & $5.00 \mathrm{E}+00$ & $1.40 \mathrm{E}+00$ & $3.20 \mathrm{E}+01$ & $3.80 \mathrm{E}+01$ & $1.50 \mathrm{E}-04$ \\
\hline $\mathrm{Fe}-55$ & $2.90 \mathrm{E}-01$ & $1.20 \mathrm{E}-02$ & $0.00 \mathrm{E}+00$ & $3.00 \mathrm{E}-01$ & $1.20 \mathrm{E}-06$ \\
\hline $\mathrm{Mn}-54$ & $1.00 \mathrm{E}+00$ & $2.40 \mathrm{E}-02$ & $1.60 \mathrm{E}+01$ & $1.70 \mathrm{E}+01$ & $6.70 \mathrm{E}-05$ \\
\hline $\mathrm{Na}-22$ & $5.40 \mathrm{E}+00$ & $3.50 \mathrm{E}-02$ & $5.20 \mathrm{E}+01$ & $5.70 \mathrm{E}+01$ & $2.30 \mathrm{E}-04$ \\
\hline $\mathrm{Nb}-94$ & $3.90 \mathrm{E}+00$ & $2.20 \mathrm{E}+00$ & $4.30 \mathrm{E}+01$ & $4.90 \mathrm{E}+01$ & $2.00 \mathrm{E}-04$ \\
\hline $\mathrm{Ni}-59$ & 1.10E-01 & $1.40 \mathrm{E}-02$ & $0.00 \mathrm{E}+00$ & $1.30 \mathrm{E}-01$ & 5.10E-07 \\
\hline $\mathrm{Ni}-63$ & 3.10E-01 & $3.30 \mathrm{E}-02$ & $0.00 \mathrm{E}+00$ & $3.40 \mathrm{E}-01$ & $1.40 \mathrm{E}-06$ \\
\hline Np-237 & $2.40 \mathrm{E}+03$ & $2.80 \mathrm{E}+03$ & $6.70 \mathrm{E}+00$ & $5.20 \mathrm{E}+03$ & 2.10E-02 \\
\hline $\mathrm{Pb}-210$ & $2.90 \mathrm{E}+03$ & $6.90 \mathrm{E}+01$ & $1.10 \mathrm{E}-01$ & $2.90 \mathrm{E}+03$ & $1.20 \mathrm{E}-02$ \\
\hline Pm-147 & $5.00 \mathrm{E}-01$ & $1.80 \mathrm{E}-01$ & 8.70E-04 & $6.80 \mathrm{E}-01$ & $2.70 \mathrm{E}-06$ \\
\hline $\mathrm{Pu}-238$ & $1.70 \mathrm{E}+03$ & $2.00 \mathrm{E}+03$ & $6.50 \mathrm{E}-02$ & $3.80 \mathrm{E}+03$ & $1.50 \mathrm{E}-02$ \\
\hline Pu-239 & $1.90 \mathrm{E}+03$ & $2.20 \mathrm{E}+03$ & $2.50 \mathrm{E}-02$ & $4.10 \mathrm{E}+03$ & $1.70 \mathrm{E}-02$ \\
\hline $\mathrm{Pu}-240$ & $1.90 \mathrm{E}+03$ & $2.20 \mathrm{E}+03$ & $6.30 \mathrm{E}-02$ & $4.10 \mathrm{E}+03$ & 1.70E-02 \\
\hline $\mathrm{Pu}-241$ & $3.60 \mathrm{E}+01$ & $4.20 \mathrm{E}+01$ & $1.70 \mathrm{E}-04$ & $7.80 \mathrm{E}+01$ & 3.10E-04 \\
\hline $\mathrm{Pu}-242$ & $1.80 \mathrm{E}+03$ & $2.10 \mathrm{E}+03$ & $5.20 \mathrm{E}-02$ & $3.90 \mathrm{E}+03$ & $1.60 \mathrm{E}-02$ \\
\hline Ru-106 & $1.10 \mathrm{E}+01$ & $1.80 \mathrm{E}+00$ & $4.30 \mathrm{E}+00$ & $1.70 \mathrm{E}+01$ & $6.70 \mathrm{E}-05$ \\
\hline Sb-125 & $1.30 \mathrm{E}+00$ & $5.60 \mathrm{E}-02$ & $1.10 \mathrm{E}+01$ & $1.30 \mathrm{E}+01$ & $5.00 \mathrm{E}-05$ \\
\hline Se-79 & $4.70 \mathrm{E}+00$ & $5.10 \mathrm{E}-02$ & $0.00 \mathrm{E}+00$ & $4.80 \mathrm{E}+00$ & $1.90 \mathrm{E}-05$ \\
\hline Sm-151 & 2.10E-01 & $1.50 \mathrm{E}-01$ & 3.10E-04 & $3.60 \mathrm{E}-01$ & $1.50 \mathrm{E}-06$ \\
\hline Sr-90 & $8.30 \mathrm{E}+01$ & $6.70 \mathrm{E}+00$ & $9.50 \mathrm{E}-02$ & $9.00 \mathrm{E}+01$ & $3.60 \mathrm{E}-04$ \\
\hline Tc-99 & 7.90E-01 & $4.30 \mathrm{E}-02$ & 1.50E-03 & 8.30E-01 & $3.30 \mathrm{E}-06$ \\
\hline Th-228 & $1.80 \mathrm{E}+02$ & $1.50 \mathrm{E}+03$ & $3.20 \mathrm{E}+01$ & $1.70 \mathrm{E}+03$ & $6.80 \mathrm{E}-03$ \\
\hline Th-229 & $1.90 \mathrm{E}+03$ & $1.10 \mathrm{E}+04$ & $9.40 \mathrm{E}+00$ & $1.30 \mathrm{E}+04$ & $5.20 \mathrm{E}-02$ \\
\hline Th-230 & $3.00 \mathrm{E}+02$ & $1.70 \mathrm{E}+03$ & 3.60E-02 & $2.00 \mathrm{E}+03$ & $7.90 \mathrm{E}-03$ \\
\hline Th-232 & $1.50 \mathrm{E}+03$ & $8.50 E+03$ & 3.30E-02 & $1.00 \mathrm{E}+04$ & $4.00 \mathrm{E}-02$ \\
\hline U-232 & $7.00 \mathrm{E}+02$ & $3.40 E+03$ & $6.30 \mathrm{E}-02$ & $4.10 \mathrm{E}+03$ & $1.60 \mathrm{E}-02$ \\
\hline U-233 & $1.60 \mathrm{E}+02$ & $7.00 \mathrm{E}+02$ & $3.40 \mathrm{E}-02$ & $8.60 \mathrm{E}+02$ & $3.40 \mathrm{E}-03$ \\
\hline U-234 & $1.50 \mathrm{E}+02$ & $6.90 \mathrm{E}+02$ & $5.20 \mathrm{E}-02$ & $8.40 \mathrm{E}+02$ & $3.40 \mathrm{E}-03$ \\
\hline U-235 & $1.40 \mathrm{E}+02$ & $6.40 \mathrm{E}+02$ & $5.00 \mathrm{E}+00$ & $7.90 \mathrm{E}+02$ & 3.10E-03 \\
\hline U-238 & $1.40 \mathrm{E}+02$ & $6.10 \mathrm{E}+02$ & $5.40 \mathrm{E}-01$ & $7.50 \mathrm{E}+02$ & $3.00 \mathrm{E}-03$ \\
\hline $\mathrm{Zn}-65$ & $4.90 \mathrm{E}+00$ & $6.60 \mathrm{E}-02$ & $6.30 \mathrm{E}+00$ & $1.10 \mathrm{E}+01$ & $4.30 \mathrm{E}-05$ \\
\hline Zr-93 & $9.00 \mathrm{E}-01$ & $1.70 \mathrm{E}+00$ & $0.00 \mathrm{E}+00$ & $2.60 \mathrm{E}+00$ & $1.00 \mathrm{E}-05$ \\
\hline
\end{tabular}

a Doses do not account for scrap dilution or radionuclide partitioning; collective doses based on $100 \mathrm{t}$. 
TABLE D.25 Baseline Public Doses for a 100-t Batch - Parking Lot Scenario and Room/Office Scenario ${ }^{2}$

\begin{tabular}{|c|c|c|c|c|}
\hline \multirow[b]{2}{*}{ Nuclide } & \multicolumn{2}{|c|}{ Parking Lot Scenario } & \multicolumn{2}{|c|}{ Room/Office Scenario } \\
\hline & $\begin{array}{l}\text { External }^{b} \\
(\mu \mathrm{Sv} / \mathrm{yr})\end{array}$ & $\begin{array}{c}\text { Collective Dose } \\
\text { (person-Sv/yr) }\end{array}$ & $\begin{array}{l}\text { External }^{b} \\
(\mu \mathrm{S} \text { Sv/yr) }\end{array}$ & $\begin{array}{l}\text { Collective Dose } \\
\text { (person-Sv/yr) }\end{array}$ \\
\hline Ac-227 & $3.50 \mathrm{E}-01$ & 3.70E-04 & $9.20 \mathrm{E}+00$ & $1.30 \mathrm{E}-03$ \\
\hline $\mathrm{Ag}-110 \mathrm{~m}$ & $1.70 \mathrm{E}+00$ & $1.80 \mathrm{E}-03$ & $2.70 \mathrm{E}+01$ & 3.90E-03 \\
\hline Am-241 & $8.30 \mathrm{E}-03$ & 8.70E-06 & $1.60 \mathrm{E}+00$ & 2.30E-04 \\
\hline Am-243 & $1.70 \mathrm{E}-01$ & 1.70E-04 & $8.90 \mathrm{E}+00$ & $1.30 \mathrm{E}-03$ \\
\hline $\mathrm{Ca}-41$ & $0.00 \mathrm{E}+00$ & $0.00 \mathrm{E}+00$ & $0.00 \mathrm{E}+00$ & $0.00 \mathrm{E}+00$ \\
\hline $\mathrm{Ce}-144$ & $3.40 \mathrm{E}-02$ & $3.60 \mathrm{E}-05$ & $8.20 \mathrm{E}-01$ & $1.20 \mathrm{E}-04$ \\
\hline Cl-36 & $4.20 \mathrm{E}-04$ & 4.40E-07 & $7.10 \mathrm{E}-03$ & $1.00 \mathrm{E}-06$ \\
\hline $\mathrm{Cm}-243$ & $1.10 \mathrm{E}-01$ & 1.10E-04 & $3.80 \mathrm{E}+00$ & $5.50 \mathrm{E}-04$ \\
\hline $\mathrm{Cm}-244$ & $2.40 \mathrm{E}-05$ & 2.50E-08 & $4.80 \mathrm{E}-03$ & 6.90E-07 \\
\hline $\mathrm{Cm}-245$ & $6.40 \mathrm{E}-02$ & $6.80 \mathrm{E}-05$ & $3.60 \mathrm{E}+00$ & $5.20 \mathrm{E}-04$ \\
\hline $\mathrm{Cm}-246$ & $2.20 \mathrm{E}-05$ & 2.30E-08 & 4.70E-03 & $6.80 \mathrm{E}-07$ \\
\hline $\mathrm{Cm}-247$ & $3.20 \mathrm{E}-01$ & 3.40E-04 & $6.50 \mathrm{E}+00$ & $9.30 \mathrm{E}-04$ \\
\hline $\mathrm{Co}-57$ & $6.40 \mathrm{E}-02$ & $6.70 \mathrm{E}-05$ & $3.20 \mathrm{E}+00$ & $4.50 \mathrm{E}-04$ \\
\hline Co-60 & $2.30 \mathrm{E}+00$ & $2.50 \mathrm{E}-03$ & $3.50 \mathrm{E}+01$ & $5.00 \mathrm{E}-03$ \\
\hline Cs-134 & $1.30 \mathrm{E}+00$ & $1.40 \mathrm{E}-03$ & $2.10 \mathrm{E}+01$ & 3.10E-03 \\
\hline Cs-135 & $0.00 \mathrm{E}+00$ & $0.00 \mathrm{E}+00$ & $0.00 \mathrm{E}+00$ & $0.00 \mathrm{E}+00$ \\
\hline Cs-137 & 5.70E-01 & 6.00E-04 & $9.10 \mathrm{E}+00$ & $1.30 \mathrm{E}-03$ \\
\hline Eu-152 & $1.10 \mathrm{E}+00$ & $1.20 \mathrm{E}-03$ & $1.90 \mathrm{E}+01$ & 2.70E-03 \\
\hline Eu-154 & $1.20 \mathrm{E}+00$ & $1.30 \mathrm{E}-03$ & $2.00 \mathrm{E}+01$ & $2.90 \mathrm{E}-03$ \\
\hline $\mathrm{Fe}-55$ & $0.00 \mathrm{E}+00$ & $0.00 \mathrm{E}+00$ & $0.00 \mathrm{E}+00$ & $0.00 \mathrm{E}+00$ \\
\hline $\mathrm{Mn}-54$ & $5.70 \mathrm{E}-01$ & $6.00 \mathrm{E}-04$ & $8.80 \mathrm{E}+00$ & $1.30 \mathrm{E}-03$ \\
\hline $\mathrm{Na}-22$ & $1.90 \mathrm{E}+00$ & 2.00E-03 & $3.10 \mathrm{E}+01$ & $4.40 \mathrm{E}-03$ \\
\hline $\mathrm{Nb}-94$ & $1.60 \mathrm{E}+00$ & $1.70 \mathrm{E}-03$ & $2.50 \mathrm{E}+01$ & $3.60 \mathrm{E}-03$ \\
\hline Ni-59 & $0.00 \mathrm{E}+00$ & $0.00 \mathrm{E}+00$ & $0.00 \mathrm{E}+00$ & $0.00 \mathrm{E}+00$ \\
\hline Ni-63 & $0.00 \mathrm{E}+00$ & $0.00 \mathrm{E}+00$ & $0.00 \mathrm{E}+00$ & $0.00 \mathrm{E}+00$ \\
\hline $\mathrm{Np}-237$ & 2.00E-01 & 2.10E-04 & $5.90 \mathrm{E}+00$ & 8.40E-04 \\
\hline $\mathrm{Pb}-210$ & $4.60 \mathrm{E}-04$ & $4.80 \mathrm{E}-07$ & $9.40 \mathrm{E}-02$ & $1.30 \mathrm{E}-05$ \\
\hline Pm-147 & $8.40 \mathrm{E}-06$ & 8.80E-09 & $4.30 \mathrm{E}-04$ & $6.30 \mathrm{E}-08$ \\
\hline Pu-238 & $2.90 \mathrm{E}-05$ & $3.00 \mathrm{E}-08$ & $5.80 \mathrm{E}-03$ & $8.30 \mathrm{E}-07$ \\
\hline $\mathrm{Pu}-239$ & 5.60E-05 & $5.90 \mathrm{E}-08$ & $3.60 \mathrm{E}-03$ & $5.20 \mathrm{E}-07$ \\
\hline $\mathrm{Pu}-240$ & 2.80E-05 & 3.00E-08 & $5.70 \mathrm{E}-03$ & $8.20 \mathrm{E}-07$ \\
\hline $\mathrm{Pu}-241$ & 3.50E-06 & 3.60E-09 & $1.90 \mathrm{E}-04$ & 2.80E-08 \\
\hline $\mathrm{Pu}-242$ & 2.40E-05 & 2.60E-08 & $4.90 \mathrm{E}-03$ & 7.00E-07 \\
\hline Ru-106 & $1.60 \mathrm{E}-01$ & $1.70 \mathrm{E}-04$ & $2.60 \mathrm{E}+00$ & 3.80E-04 \\
\hline $\mathrm{Sb}-125$ & 3.70E-01 & $3.90 \mathrm{E}-04$ & $6.40 \mathrm{E}+00$ & $9.20 \mathrm{E}-04$ \\
\hline Se-79 & $0.00 \mathrm{E}+00$ & $0.00 \mathrm{E}+00$ & $0.00 \mathrm{E}+00$ & $0.00 \mathrm{E}+00$ \\
\hline Sm-151 & $1.90 \mathrm{E}-07$ & $2.00 \mathrm{E}-10$ & $4.00 \mathrm{E}-05$ & 5.70E-09 \\
\hline Sr-90 & $3.50 \mathrm{E}-03$ & 3.70E-06 & $4.80 \mathrm{E}-02$ & $6.90 \mathrm{E}-06$ \\
\hline Tc-99 & 2.40E-05 & 2.50E-08 & $2.20 \mathrm{E}-03$ & $3.20 \mathrm{E}-07$ \\
\hline Th-228 & $1.30 \mathrm{E}+00$ & $1.40 \mathrm{E}-03$ & $2.00 \mathrm{E}+01$ & $2.90 \mathrm{E}-03$ \\
\hline Th-229 & 2.80E-01 & 2.90E-04 & $8.70 \mathrm{E}+00$ & $1.30 \mathrm{E}-03$ \\
\hline Th-230 & 2.30E-04 & 2.40E-07 & $2.10 \mathrm{E}-02$ & $3.00 \mathrm{E}-06$ \\
\hline Th-232 & $9.90 \mathrm{E}-05$ & $1.00 \mathrm{E}-07$ & $1.10 \mathrm{E}-02$ & $1.50 \mathrm{E}-06$ \\
\hline U-232 & $1.70 \mathrm{E}-04$ & $1.80 \mathrm{E}-07$ & $1.40 \mathrm{E}-02$ & $2.00 \mathrm{E}-06$ \\
\hline U-233 & 2.70E-04 & 2.80E-07 & $1.60 \mathrm{E}-02$ & 2.20E-06 \\
\hline U-234 & $7.70 \mathrm{E}-05$ & 8.00E-08 & $7.20 \mathrm{E}-03$ & $1.00 \mathrm{E}-06$ \\
\hline U-235 & $1.40 \mathrm{E}-01$ & 1.50E-04 & $4.90 \mathrm{E}+00$ & 7.10E-04 \\
\hline U-238 & $2.30 \mathrm{E}-02$ & 2.40E-05 & $7.70 \mathrm{E}-01$ & $1.10 \mathrm{E}-04$ \\
\hline $\mathrm{Zn}-65$ & $3.80 \mathrm{E}-01$ & $4.00 \mathrm{E}-04$ & $5.80 \mathrm{E}+00$ & 8.30E-04 \\
\hline $\mathrm{Zr}-93$ & $0.00 \mathrm{E}+00$ & $0.00 \mathrm{E}+00$ & $0.00 \mathrm{E}+00$ & $0.00 \mathrm{E}+00$ \\
\hline
\end{tabular}

a Doses do not account for scrap dilution or radionuclide partitioning; collective doses based on $100 \mathrm{t}$.

b Ingestion and inhalation doses do not apply for these.scenarios. 
TABLE D.26 Baseline Public Doses for a 100-t Batch - Appliance Scenario and Automobile Scenario ${ }^{a}$

\begin{tabular}{|c|c|c|c|c|}
\hline \multirow[b]{2}{*}{ Nuclide } & \multicolumn{2}{|c|}{ Appliance Scenario } & \multicolumn{2}{|c|}{ Automobile Scenario } \\
\hline & $\begin{array}{l}\text { External }^{\mathrm{b}} \\
(\mu \mathrm{Sv} / \mathrm{yr})\end{array}$ & $\begin{array}{l}\text { Collective Dose } \\
\text { (person-Sv/yr) }\end{array}$ & $\begin{array}{l}\text { External }^{b} \\
(\mu \mathrm{Sv} / \mathrm{yr})\end{array}$ & $\begin{array}{l}\text { Collective Dose } \\
\text { (person-Sv/yr) }\end{array}$ \\
\hline Ac-227 & 2.90E-01 & 1.00E-04 & $3.50 \mathrm{E}+00$ & 8.80E-04 \\
\hline $\mathrm{Ag}-110 \mathrm{~m}$ & $7.80 \mathrm{E}-01$ & $2.70 \mathrm{E}-04$ & $9.50 \mathrm{E}+00$ & $2.40 \mathrm{E}-03$ \\
\hline Am-241 & $8.50 \mathrm{E}-02$ & 2.90E-05 & $9.10 \mathrm{E}-01$ & 2.30E-04 \\
\hline Am-243 & $3.10 \mathrm{E}-01$ & $1.10 \mathrm{E}-04$ & $3.70 \mathrm{E}+00$ & $9.20 \mathrm{E}-04$ \\
\hline $\mathrm{Ca}-41$ & $0.00 \mathrm{E}+00$ & $0.00 \mathrm{E}+00$ & $0.00 E+00$ & $0.00 \mathrm{E}+00$ \\
\hline Ce-144 & $2.70 \mathrm{E}-02$ & $9.30 \mathrm{E}-06$ & $3.20 \mathrm{E}-01$ & 8.00E-05 \\
\hline Cl-36 & $2.10 \mathrm{E}-04$ & $7.10 \mathrm{E}-08$ & $2.50 \mathrm{E}-03$ & $6.40 \mathrm{E}-07$ \\
\hline $\mathrm{Cm}-243$ & $1.20 \mathrm{E}-01$ & $4.10 \mathrm{E}-05$ & $1.50 \mathrm{E}+00$ & $3.70 \mathrm{E}-04$ \\
\hline $\mathrm{Cm}-244$ & $4.00 \mathrm{E}-04$ & $1.40 \mathrm{E}-07$ & $4.10 \mathrm{E}-03$ & $1.00 \mathrm{E}-06$ \\
\hline $\mathrm{Cm}-245$ & $1.20 \mathrm{E}-01$ & $4.10 \mathrm{E}-05$ & $1.40 \mathrm{E}+00$ & $3.60 \mathrm{E}-04$ \\
\hline $\mathrm{Cm}-246$ & $4.40 \mathrm{E}-04$ & $1.50 \mathrm{E}-07$ & $4.50 \mathrm{E}-03$ & 1.10E-06 \\
\hline $\mathrm{Cm}-247$ & $1.90 \mathrm{E}-01$ & $6.70 \mathrm{E}-05$ & $2.30 \mathrm{E}+00$ & 5.90E-04 \\
\hline Co-57 & $9.80 \mathrm{E}-02$ & 3.30E-05 & $1.20 \mathrm{E}+00$ & $3.00 \mathrm{E}-04$ \\
\hline Co-60 & $1.00 \mathrm{E}+00$ & 3.50E-04 & $1.20 \mathrm{E}+01$ & 3.10E-03 \\
\hline Cs-134 & $6.20 \mathrm{E}-01$ & 2.10E-04 & $7.60 \mathrm{E}+00$ & $1.90 \mathrm{E}-03$ \\
\hline Cs-135 & $0.00 \mathrm{E}+00$ & $0.00 \mathrm{E}+00$ & $0.00 \mathrm{E}+00$ & $0.00 \mathrm{E}+00$ \\
\hline Cs-137 & 2.70E-01 & 9.10E-05 & $3.20 \mathrm{E}+00$ & 8.10E-04 \\
\hline Eu-152 & 5.70E-01 & $2.00 \mathrm{E}-04$ & $6.90 \mathrm{E}+00$ & $1.70 \mathrm{E}-03$ \\
\hline Eu-154 & $5.90 \mathrm{E}-01$ & $2.00 \mathrm{E}-04$ & $7.10 \mathrm{E}+00$ & $1.80 \mathrm{E}-03$ \\
\hline $\mathrm{Fe}-55$ & $0.00 \mathrm{E}+00$ & $0.00 \mathrm{E}+00$ & $0.00 \mathrm{E}+00$ & $0.00 \mathrm{E}+00$ \\
\hline Mn-54 & $2.60 \mathrm{E}-01$ & 8.90E-05 & $3.10 \mathrm{E}+00$ & $7.90 \mathrm{E}-04$ \\
\hline $\mathrm{Na}-22$ & $8.90 \mathrm{E}-01$ & $3.00 \mathrm{E}-04$ & $1.10 \mathrm{E}+01$ & 2.70E-03 \\
\hline $\mathrm{Nb}-94$ & $7.10 \mathrm{E}-01$ & 2.40E-04 & $8.70 \mathrm{E}+00$ & 2.20E-03 \\
\hline $\mathrm{Ni}-59$ & $0.00 \mathrm{E}+00$ & $0.00 \mathrm{E}+00$ & $0.00 \mathrm{E}+00$ & $0.00 \mathrm{E}+00$ \\
\hline $\mathrm{Ni}-63$ & $0.00 \mathrm{E}+00$ & $0.00 \mathrm{E}+00$ & $0.00 \mathrm{E}+00$ & $0.00 \mathrm{E}+00$ \\
\hline Np-237 & $1.90 \mathrm{E}-01$ & $6.40 \mathrm{E}-05$ & $2.30 \mathrm{E}+00$ & $5.70 \mathrm{E}-04$ \\
\hline $\mathrm{Pb}-210$ & $6.60 \mathrm{E}-03$ & $2.20 \mathrm{E}-06$ & $6.60 \mathrm{E}-02$ & $1.70 \mathrm{E}-05$ \\
\hline Pm-147 & $1.40 \mathrm{E}-05$ & $4.60 \mathrm{E}-09$ & $1.60 \mathrm{E}-04$ & $4.10 \mathrm{E}-08$ \\
\hline Pu-238 & $4.50 \mathrm{E}-04$ & $1.60 \mathrm{E}-07$ & $4.80 \mathrm{E}-03$ & $1.20 \mathrm{E}-06$ \\
\hline $\mathrm{Pu}-239$ & $1.50 \mathrm{E}-04$ & 5.00E-08 & $1.70 \mathrm{E}-03$ & $4.30 \mathrm{E}-07$ \\
\hline $\mathrm{Pu}-240$ & $4.40 \mathrm{E}-04$ & $1.50 \mathrm{E}-07$ & $4.60 \mathrm{E}-03$ & $1.20 \mathrm{E}-06$ \\
\hline $\mathrm{Pu}-241$ & 7.00E-06 & 2.40E-09 & $8.20 \mathrm{E}-05$ & 2.10E-08 \\
\hline $\mathrm{Pu}-242$ & $3.60 \mathrm{E}-04$ & $1.20 \mathrm{E}-07$ & $3.80 \mathrm{E}-03$ & $9.70 \mathrm{E}-07$ \\
\hline Ru-106 & 7.60E-02 & 2.60E-05 & $9.30 \mathrm{E}-01$ & $2.30 \mathrm{E}-04$ \\
\hline $\mathrm{Sb}-125$ & $1.90 \mathrm{E}-01$ & $6.60 \mathrm{E}-05$ & $2.30 \mathrm{E}+00$ & $5.90 \mathrm{E}-04$ \\
\hline Se-79 & $0.00 \mathrm{E}+00$ & $0.00 \mathrm{E}+00$ & $0.00 \mathrm{E}+00$ & $0.00 \mathrm{E}+00$ \\
\hline $\mathrm{Sm}-151$ & 3.40E-06 & 1.20E-09 & 3.40E-05 & $8.60 \mathrm{E}-09$ \\
\hline Sr-90 & $1.40 \mathrm{E}-03$ & 4.70E-07 & $1.70 \mathrm{E}-02$ & 4.20E-06 \\
\hline Tc-99 & $8.00 \mathrm{E}-05$ & $2.80 \mathrm{E}-08$ & $9.40 \mathrm{E}-04$ & $2.40 \mathrm{E}-07$ \\
\hline Th-228 & 5.90E-01 & 2.00E-04 & $7.10 \mathrm{E}+00$ & $1.80 \mathrm{E}-03$ \\
\hline Th-229 & $3.00 \mathrm{E}-01$ & $1.00 \mathrm{E}-04$ & $3.50 \mathrm{E}+00$ & 8.90E-04 \\
\hline Th-230 & $8.80 \mathrm{E}-04$ & 3.00E-07 & $1.00 \mathrm{E}-02$ & 2.50E-06 \\
\hline Th-232 & 5.40E-04 & $1.90 \mathrm{E}-07$ & $5.90 \mathrm{E}-03$ & $1.50 \mathrm{E}-06$ \\
\hline U-232 & 6.70E-04 & 2.30E-07 & $7.40 \mathrm{E}-03$ & $1.90 \mathrm{E}-06$ \\
\hline U-233 & 5.30E-04 & $1.80 \mathrm{E}-07$ & $6.30 \mathrm{E}-03$ & $1.60 \mathrm{E}-06$ \\
\hline U-234 & $3.90 \mathrm{E}-04$ & $1.30 \mathrm{E}-07$ & $4.20 \mathrm{E}-03$ & $1.10 \mathrm{E}-06$ \\
\hline U-235 & $1.50 \mathrm{E}-01$ & 5.20E-05 & $1.80 \mathrm{E}+00$ & $4.60 \mathrm{E}-04$ \\
\hline U-238 & 2.80E-02 & $9.60 \mathrm{E}-06$ & $3.30 \mathrm{E}-01$ & $8.20 \mathrm{E}-05$ \\
\hline $\mathrm{Zn}-65$ & $1.70 \mathrm{E}-01$ & $5.80 \mathrm{E}-05$ & $2.00 \mathrm{E}+00$ & $5.20 \mathrm{E}-04$ \\
\hline $\mathrm{Zr}-93$ & $0.00 \mathrm{E}+00$ & $0.00 \mathrm{E}+00$ & $0.00 \mathrm{E}+00$ & $0.00 \mathrm{E}+00$ \\
\hline
\end{tabular}

a Doses do not account for scrap dilution or radionuclide partitioning; collective doses based on $100 \mathrm{t}$.

b Ingestion and inhalation doses do not apply for these scenarios. 
TABLE D.27 Baseline Public Doses for a 100-t Batch - Office Furniture Scenario and Home Furniture Scenario ${ }^{a}$

\begin{tabular}{|c|c|c|c|c|}
\hline \multirow[b]{2}{*}{ Nuclide } & \multicolumn{2}{|c|}{ Office Furniture Scenario } & \multicolumn{2}{|c|}{ Home Furniture Scenario } \\
\hline & $\begin{array}{c}\text { External }^{\mathrm{b}} \\
(\mu \mathrm{Sv} / \mathrm{yr})\end{array}$ & $\begin{array}{r}\text { Collective Dose } \\
\text { (person-Sv/yr) }\end{array}$ & $\begin{array}{l}\text { External }^{\mathrm{b}} \\
\text { (pSv/yr) }\end{array}$ & $\begin{array}{r}\text { Collective Dose } \\
\text { (person-Sv/yr) }\end{array}$ \\
\hline Ac-227 & $1.10 \mathrm{E}+02$ & $6.10 \mathrm{E}-04$ & $8.60 \mathrm{E}+00$ & $4.20 \mathrm{E}-03$ \\
\hline $\mathrm{Ag}-110 \mathrm{~m}$ & $3.40 \mathrm{E}+02$ & $1.90 \mathrm{E}-03$ & $2.50 \mathrm{E}+01$ & $1.20 \mathrm{E}-02$ \\
\hline Am-241 & $1.50 \mathrm{E}+01$ & 8.10E-05 & $1.80 \mathrm{E}+00$ & 8.50E-04 \\
\hline Am-243 & $1.10 \mathrm{E}+00$ & $5.90 \mathrm{E}-04$ & $8.50 \mathrm{E}+00$ & $4.10 \mathrm{E}-03$ \\
\hline $\mathrm{Ca}-41$ & $0.00 \mathrm{E}+00$ & $0.00 \mathrm{E}+00$ & $0.00 \mathrm{E}+00$ & $0.00 \mathrm{E}+00$ \\
\hline $\mathrm{Ce}-144$ & $1.00 \mathrm{E}-01$ & $5.60 \mathrm{E}-05$ & $7.70 \mathrm{E}-01$ & $3.70 \mathrm{E}-04$ \\
\hline $\mathrm{Cl}-36$ & 8.70E-04 & $4.80 \mathrm{E}-07$ & $6.60 \mathrm{E}-03$ & 3.20E-06 \\
\hline $\mathrm{Cm}-243$ & $4.70 \mathrm{E}-01$ & 2.60E-04 & $3.70 \mathrm{E}+00$ & $1.80 \mathrm{E}-03$ \\
\hline $\mathrm{Cm}-244$ & $5.60 \mathrm{E}-04$ & 3.10E-07 & 8.00E-03 & 3.80E-06 \\
\hline $\mathrm{Cm}-245$ & $4.50 \mathrm{E}-01$ & 2.50E-04 & $3.50 \mathrm{E}+00$ & $1.70 \mathrm{E}-03$ \\
\hline $\mathrm{Cm}-246$ & $5.80 \mathrm{E}-04$ & $3.20 \mathrm{E}-07$ & 8.60E-03 & 4.10E-06 \\
\hline $\mathrm{Cm}-247$ & $7.90 \mathrm{E}-01$ & $4.40 \mathrm{E}-04$ & $6.00 \mathrm{E}+00$ & 2.90E-03 \\
\hline Co-57 & 3.90E-01 & $2.20 \mathrm{E}-04$ & $3.00 \mathrm{E}+00$ & $1.40 \mathrm{E}-03$ \\
\hline $\mathrm{Co}-60$ & $4.40 \mathrm{E}+00$ & $2.50 \mathrm{E}-03$ & $3.20 \mathrm{E}+01$ & $1.50 \mathrm{E}-02$ \\
\hline Cs-134 & $2.70 \mathrm{E}+00$ & $1.50 \mathrm{E}-03$ & $2.00 \mathrm{E}+01$ & $9.40 \mathrm{E}-03$ \\
\hline Cs-135 & $0.00 \mathrm{E}+00$ & $0.00 \mathrm{E}+00$ & $0.00 \mathrm{E}+00$ & $0.00 \mathrm{E}+00$ \\
\hline Cs-137 & $1.10 \mathrm{E}+00$ & $6.40 \mathrm{E}-04$ & $8.40 \mathrm{E}+00$ & $4.00 \mathrm{E}-03$ \\
\hline Eu-152 & $2.30 \mathrm{E}+00$ & $1.30 \mathrm{E}-03$ & $1.70 \mathrm{E}+01$ & 8.30E-03 \\
\hline Eu-154 & $2.50 \mathrm{E}+00$ & $1.40 \mathrm{E}-03$ & $1.80 \mathrm{E}+01$ & 8.80E-03 \\
\hline $\mathrm{Fe}-55$ & $0.00 \mathrm{E}+00$ & $0.00 \mathrm{E}+00$ & $0.00 \mathrm{E}+00$ & $0.00 \mathrm{E}+00$ \\
\hline Mn-54 & $1.10 \mathrm{E}+00$ & $6.20 \mathrm{E}-04$ & $8.20 \mathrm{E}+00$ & $3.90 \mathrm{E}-03$ \\
\hline $\mathrm{Na}-22$ & $3.80 \mathrm{E}+00$ & $2.10 \mathrm{E}-03$ & $2.80 \mathrm{E}+01$ & $1.30 \mathrm{E}-02$ \\
\hline $\mathrm{Nb}-94$ & $3.10 \mathrm{E}+00$ & $1.70 \mathrm{E}-03$ & $2.30 \mathrm{E}+01$ & $1.10 \mathrm{E}-02$ \\
\hline $\mathrm{Ni}-59$ & $0.00 \mathrm{E}+00$ & $0.00 \mathrm{E}+00$ & $0.00 \mathrm{E}+00$ & $0.00 \mathrm{E}+00$ \\
\hline $\mathrm{Ni}-63$ & $0.00 \mathrm{E}+00$ & $0.00 \mathrm{E}+00$ & $0.00 \mathrm{E}+00$ & $0.00 \mathrm{E}+00$ \\
\hline Np-237 & 7.10E-01 & $3.90 \mathrm{E}-04$ & $5.60 \mathrm{E}+00$ & $2.70 \mathrm{E}-03$ \\
\hline $\mathrm{Pb}-210$ & $8.40 \mathrm{E}-03$ & $4.60 \mathrm{E}-06$ & $1.20 \mathrm{E}-01$ & 5.70E-05 \\
\hline $\mathrm{Pm}-147$ & $5.30 \mathrm{E}-05$ & $3.00 \mathrm{E}-08$ & $4.10 \mathrm{E}-04$ & $2.00 \mathrm{E}-07$ \\
\hline $\mathrm{Pu}-238$ & $6.70 \mathrm{E}-04$ & 3.70E-07 & $9.30 \mathrm{E}-03$ & $4.50 \mathrm{E}-06$ \\
\hline Pu-239 & $4.60 \mathrm{E}-04$ & 2.60E-07 & $4.00 \mathrm{E}-03$ & $1.90 \mathrm{E}-06$ \\
\hline Pu-240 & $6.40 \mathrm{E}-04$ & $3.60 \mathrm{E}-07$ & $9.00 \mathrm{E}-03$ & $4.30 \mathrm{E}-06$ \\
\hline $\mathrm{Pu}-241$ & $2.30 \mathrm{E}-05$ & $1.30 \mathrm{E}-08$ & $1.90 \mathrm{E}-04$ & $9.10 \mathrm{E}-08$ \\
\hline Pu-242 & $5.50 \mathrm{E}-04$ & 3.00E-07 & $7.50 \mathrm{E}-03$ & $3.60 \mathrm{E}-06$ \\
\hline Ru-106 & $3.20 \mathrm{E}-01$ & $1.80 \mathrm{E}-04$ & $2.40 \mathrm{E}+00$ & $1.20 \mathrm{E}-03$ \\
\hline $\mathrm{Sb}-125$ & $7.80 \mathrm{E}-01$ & 4.30E-04 & $6.00 \mathrm{E}+00$ & $2.90 \mathrm{E}-03$ \\
\hline Se-79 & $0.00 \mathrm{E}+00$ & $0.00 \mathrm{E}+00$ & $0.00 \mathrm{E}+00$ & $0.00 \mathrm{E}+00$ \\
\hline $\mathrm{Sm}-151$ & 4.10E-06 & 2.30E-09 & $6.20 \mathrm{E}-05$ & 3.00E-08 \\
\hline Sr-90 & $6.10 \mathrm{E}-04$ & 3.40E-07 & $4.30 \mathrm{E}-02$ & 2.10E-05 \\
\hline Tc-99 & 2.70E-04 & 1.50E-08 & $2.20 \mathrm{E}-03$ & $1.00 \mathrm{E}-06$ \\
\hline Th-228 & $2.50 \mathrm{E}+00$ & $1.40 \mathrm{E}-03$ & $1.80 \mathrm{E}+01$ & $8.80 \mathrm{E}-03$ \\
\hline Th-229 & $1.10 \mathrm{E}+00$ & $5.80 \mathrm{E}-04$ & $8.40 \mathrm{E}+00$ & $4.00 \mathrm{E}-03$ \\
\hline Th-230 & $2.20 \mathrm{E}-03$ & 1.20E-06 & $2.10 \mathrm{E}-02$ & $1.00 \mathrm{E}-05$ \\
\hline Th-232 & $1.10 \mathrm{E}-03$ & $6.10 \mathrm{E}-07$ & $1.20 \mathrm{E}-02$ & 5.80E-06 \\
\hline U-232 & $1.50 \mathrm{E}-03$ & 8.10E-07 & $1.50 \mathrm{E}-02$ & 7.40E-06 \\
\hline U-233 & $2.00 \mathrm{E}-03$ & $1.10 \mathrm{E}-05$ & $5.00 \mathrm{E}-01$ & 7.40E-06 \\
\hline $\mathrm{U}-234$ & $7.90 \mathrm{E}-04$ & $4.40 \mathrm{E}-08$ & $7.00 \mathrm{E}-02$ & $4.20 \mathrm{E}-06$ \\
\hline U-235 & $6.00 \mathrm{E}-01$ & $3.30 \mathrm{E}-05$ & $6.00 \mathrm{E}+01$ & $2.20 \mathrm{E}-03$ \\
\hline U-238 & $9.20 \mathrm{E}-02$ & $5.10 \mathrm{E}-06$ & $5.00 \mathrm{E}+00$ & 3.60E-04 \\
\hline $\mathrm{Zn}-65$ & $7.40 \mathrm{E}-01$ & $4.10 \mathrm{E}-05$ & $3.00 \mathrm{E}+01$ & 2.50E-03 \\
\hline Zr-93 & $0.00 \mathrm{E}+00$ & $0.00 E \div 00$ & $0.00 \mathrm{E}+00$ & $0.00 \mathrm{E}+00$ \\
\hline
\end{tabular}

a Doses do not account for scrap dilution or radionuclide partitioning; collective doses based on $100 t$.

b Ingestion and inhalation doses do not apply for these scenarios. 
TABLE D.28 Baseline Public Doses for a 100-t Batch Frying Pan Scenario a,b

\begin{tabular}{|c|c|c|c|c|}
\hline Nuclide & $\begin{array}{r}\text { Ingestion } \\
(\mu \mathrm{Sv} / \mathrm{yr})\end{array}$ & $\begin{array}{r}\text { External } \\
(\mu \mathrm{Sv} / \mathrm{yr})\end{array}$ & $\begin{array}{l}\text { Total Dose } \\
(\mu \mathrm{Sv} / \mathrm{yr})\end{array}$ & $\begin{array}{r}\text { Collective Dose } \\
\text { (person-Sv/yr) }\end{array}$ \\
\hline Ac-227 & $2.20 \mathrm{E}+00$ & $8.80 \mathrm{E}-01$ & $3.10 \mathrm{E}+00$ & $1.00 \mathrm{E}-02$ \\
\hline $\mathrm{Ag}-110 \mathrm{~m}$ & $1.10 \mathrm{E}-03$ & $2.50 \mathrm{E}+00$ & $2.50 \mathrm{E}+00$ & $8.20 \mathrm{E}-03$ \\
\hline Am-241 & $5.80 \mathrm{E}-01$ & $1.80 \mathrm{E}-01$ & $7.50 \mathrm{E}-01$ & $2.50 \mathrm{E}-03$ \\
\hline $\mathrm{Am}-243$ & $5.70 \mathrm{E}-01$ & $8.60 \mathrm{E}-01$ & $1.40 \mathrm{E}+00$ & $4.70 \mathrm{E}-03$ \\
\hline $\mathrm{Ca}-41$ & 2.00E-04 & $0.00 \mathrm{E}+00$ & 2.00E-04 & $6.60 \mathrm{E}-07$ \\
\hline $\mathrm{Ce}-144$ & $2.20 \mathrm{E}-03$ & $7.90 \mathrm{E}-02$ & 8.10E-02 & 2.60E-04 \\
\hline Cl-36 & $4.80 \mathrm{E}-04$ & 6.70E-04 & 1.20E-03 & 3.80E-06 \\
\hline $\mathrm{Cm}-243$ & $3.90 \mathrm{E}-01$ & $3.70 \mathrm{E}-01$ & $7.60 \mathrm{E}-01$ & 2.50E-03 \\
\hline $\mathrm{Cm}-244$ & 3.10E-01 & $7.90 \mathrm{E}-04$ & $3.10 \mathrm{E}-01$ & $1.00 \mathrm{E}-03$ \\
\hline $\mathrm{Cm}-245$ & $5.90 \mathrm{E}-01$ & $3.50 \mathrm{E}-01$ & $9.50 \mathrm{E}-01$ & $3.10 \mathrm{E}-03$ \\
\hline $\mathrm{Cm}-246$ & $5.80 \mathrm{E}-01$ & $8.60 \mathrm{E}-04$ & $5.90 \mathrm{E}-01$ & $1.90 \mathrm{E}-03$ \\
\hline $\mathrm{Cm}-247$ & $5.40 \mathrm{E}-01$ & $6.10 \mathrm{E}-01$ & $1.20 \mathrm{E}+00$ & $3.80 \mathrm{E}-03$ \\
\hline Co-57 & $1.30 \mathrm{E}-04$ & 3.00E-01 & $3.00 \mathrm{E}-01$ & $9.90 \mathrm{E}-04$ \\
\hline Co-60 & $4.00 \mathrm{E}-03$ & $3.20 \mathrm{E}+00$ & $3.20 \mathrm{E}+00$ & $1.10 \mathrm{E}-02$ \\
\hline Cs-134 & $9.80 \mathrm{E}-03$ & $2.00 \mathrm{E}+00$ & $2.00 \mathrm{E}+00$ & $6.60 \mathrm{E}-03$ \\
\hline Cs-135 & 1.10E-03 & $0.00 \mathrm{E}+00$ & $1.10 \mathrm{E}-03$ & 3.70E-06 \\
\hline Cs-137 & 7.80E-03 & $8.50 \mathrm{E}-01$ & $8.60 \mathrm{E}-01$ & $2.80 \mathrm{E}-03$ \\
\hline Eu-152 & $1.00 \mathrm{E}-03$ & $1.80 \mathrm{E}+00$ & $1.80 \mathrm{E}+00$ & $5.80 \mathrm{E}-03$ \\
\hline Eu-154 & $1.50 \mathrm{E}-03$ & $1.90 \mathrm{E}+00$ & $1.90 \mathrm{E}+00$ & $6.10 \mathrm{E}-03$ \\
\hline $\mathrm{Fe}-55$ & 8.50E-05 & $0.00 \mathrm{E}+00$ & $8.50 \mathrm{E}-05$ & $2.80 \mathrm{E}-07$ \\
\hline Mn-54 & $3.00 \mathrm{E}-04$ & $8.30 \mathrm{E}-01$ & 8.30E-01 & 2.70E-03 \\
\hline $\mathrm{Na}-22$ & $1.60 \mathrm{E}-03$ & $2.90 \mathrm{E}+00$ & $2.90 \mathrm{E}+00$ & 9.30E-03 \\
\hline $\mathrm{Nb}-94$ & 1.10E-03 & $2.30 \mathrm{E}+00$ & $2.30 \mathrm{E}+00$ & 7.60E-03 \\
\hline $\mathrm{Ni}-59$ & $3.30 \mathrm{E}-05$ & $0.00 \mathrm{E}+00$ & 3.30E-05 & $1.10 \mathrm{E}-07$ \\
\hline $\mathrm{Ni}-63$ & $9.10 \mathrm{E}-05$ & $0.00 \mathrm{E}+00$ & $9.10 \mathrm{E}-05$ & 3.00E-07 \\
\hline $\mathrm{Np}-237$ & $7.00 \mathrm{E}-01$ & $5.70 \mathrm{E}-01$ & $1.30 \mathrm{E}+00$ & $4.20 \mathrm{E}-03$ \\
\hline $\mathrm{Pb}-210$ & 8.40E-01 & $1.20 \mathrm{E}-02$ & $8.50 \mathrm{E}-01$ & 2.80E-03 \\
\hline Pm-147 & $1.50 \mathrm{E}-04$ & $4.20 \mathrm{E}-05$ & $1.90 \mathrm{E}-04$ & $6.10 \mathrm{E}-07$ \\
\hline Pu-238 & $5.00 \mathrm{E}-01$ & $9.30 \mathrm{E}-04$ & $5.00 \mathrm{E}-01$ & $1.70 \mathrm{E}-03$ \\
\hline $\mathrm{Pu}-239$ & $5.60 \mathrm{E}-01$ & $4.00 \mathrm{E}-04$ & $5.60 \mathrm{E}-01$ & $1.80 \mathrm{E}-03$ \\
\hline $\mathrm{Pu}-240$ & $5.60 \mathrm{E}-01$ & 8.90E-04 & $5.60 \mathrm{E}-01$ & $1.80 \mathrm{E}-03$ \\
\hline Pu-241 & $1.10 \mathrm{E}-02$ & $1.90 \mathrm{E}-05$ & $1.10 \mathrm{E}-02$ & $3.50 \mathrm{E}-05$ \\
\hline $\mathrm{Pu}-242$ & 5.30E-01 & 7.50E-04 & $5.30 \mathrm{E}-01$ & $1.70 \mathrm{E}-03$ \\
\hline Ru-106 & 3.10E-03 & $2.50 \mathrm{E}-01$ & $2.50 \mathrm{E}-01$ & 8.20E-04 \\
\hline Sb-125 & 3.90E-04 & 6.10E-01 & $6.10 \mathrm{E}-01$ & 2.00E-03 \\
\hline Se-79 & $1.40 \mathrm{E}-03$ & $0.00 \mathrm{E}+00$ & $1.40 \mathrm{E}-03$ & $4.50 \mathrm{E}-06$ \\
\hline Sm-151 & 6.10E-05 & $6.10 \mathrm{E}-06$ & $6.70 \mathrm{E}-05$ & 2.20E-07 \\
\hline Sr-90 & 2.20E-02 & $4.40 \mathrm{E}-03$ & 2.70E-02 & 8.70E-05 \\
\hline Tc-99 & 2.30E-04 & 2.20E-04 & $4.50 \mathrm{E}-04$ & 1.50E-06 \\
\hline Th-228 & $5.20 \mathrm{E}-02$ & $1.90 \mathrm{E}+00$ & $1.90 \mathrm{E}+00$ & $6.20 \mathrm{E}-03$ \\
\hline Th-229 & $5.60 \mathrm{E}-01$ & 8.50E-01 & $1.40 \mathrm{E}+00$ & $4.60 \mathrm{E}-03$ \\
\hline Th-230 & $8.70 \mathrm{E}-02$ & 2.10E-03 & $8.90 \mathrm{E}-02$ & 2.90E-04 \\
\hline Th-232 & $4.30 \mathrm{E}-01$ & $1.20 \mathrm{E}-03$ & 4.30E-01 & 1.40E-03 \\
\hline U-232 & $2.10 \mathrm{E}-01$ & $1.60 \mathrm{E}-03$ & 2.10E-01 & $6.80 \mathrm{E}-04$ \\
\hline U-233 & $4.60 \mathrm{E}-02$ & $1.60 \mathrm{E}-03$ & $4.70 \mathrm{E}-02$ & $1.50 \mathrm{E}-04$ \\
\hline U-234 & $4.50 \mathrm{E}-02$ & $8.70 \mathrm{E}-04$ & $4.60 \mathrm{E}-02$ & $1.50 \mathrm{E}-04$ \\
\hline U-235 & $4.20 \mathrm{E}-02$ & 4.70E-01 & 5.10E-01 & $1.70 \mathrm{E}-03$ \\
\hline U-238 & $4.00 \mathrm{E}-02$ & 7.60E-02 & $1.20 \mathrm{E}-01$ & 3.80E-04 \\
\hline Zn-65 & $1.40 \mathrm{E}-03$ & 5.40E-01 & 5.40E-01 & $1.80 \mathrm{E}-03$ \\
\hline Zr-93 & 2.60E-04 & $0.00 \mathrm{E}+00$ & 2.60E-04 & 8.60E-07 \\
\hline
\end{tabular}

a Doses do not account for scrap dilution or radionuclide partitioning; collective doses based on $100 t$.

b Inhalation doses do not apply for these scenarios. 
TABLE D.29 Baseline Public Doses

for a 100-t Batch - Highway

Pavement Scenario ${ }^{a}$

\begin{tabular}{|c|c|c|}
\hline Nuclide & $\begin{array}{l}\text { External }^{b} \\
(\mu \mathrm{Sv} / \mathrm{yr})\end{array}$ & $\begin{array}{l}\text { Collective Dose } \\
\text { (person-Sv/yr) }\end{array}$ \\
\hline Ac- 227 & $3.40 \mathrm{E}-02$ & $5.60 \mathrm{E}-04$ \\
\hline $\mathrm{Ag}-110 \mathrm{~m}$ & $1.40 \mathrm{E}-01$ & $2.30 \mathrm{E}-03$ \\
\hline Am-241 & $1.10 \mathrm{E}-03$ & $1.90 \mathrm{E}-05$ \\
\hline Am-243 & $1.90 \mathrm{E}-02$ & 3.10E-04 \\
\hline $\mathrm{Ca}-41$ & $0.00 \mathrm{E}+00$ & $0.00 \mathrm{E}+00$ \\
\hline $\mathrm{Ce}-144$ & $3.00 \mathrm{E}-03$ & $5.00 \mathrm{E}-05$ \\
\hline $\mathrm{Cl}-36$ & 3.60E-05 & $5.90 \mathrm{E}-07$ \\
\hline $\mathrm{Cm}-243$ & $1.20 \mathrm{E}-02$ & $1.90 \mathrm{E}-04$ \\
\hline $\mathrm{Cm}-244$ & 2.80E-06 & $4.60 \mathrm{E}-08$ \\
\hline $\mathrm{Cm}-245$ & $8.10 \mathrm{E}-03$ & 1.30E-04 \\
\hline $\mathrm{Cm}-246$ & $2.50 \mathrm{E}-06$ & $4.20 \mathrm{E}-08$ \\
\hline $\mathrm{Cm}-247$ & $2.90 \mathrm{E}-02$ & $4.80 \mathrm{E}-04$ \\
\hline Co-57 & $7.90 \mathrm{E}-03$ & 1.30E-04 \\
\hline Co-60 & $1.80 \mathrm{E}-01$ & $2.90 \mathrm{E}-03$ \\
\hline Cs-134 & $1.10 \mathrm{E}-01$ & $1.80 \mathrm{E}-03$ \\
\hline Cs-135 & $0.00 \mathrm{E}+00$ & $0.00 \mathrm{E}+00$ \\
\hline Cs-137 & $4.80 \mathrm{E}-02$ & $7.90 \mathrm{E}-04$ \\
\hline Eu-152 & $9.00 \mathrm{E}-02$ & $1.50 \mathrm{E}-03$ \\
\hline Eu-154 & $9.60 \mathrm{E}-02$ & $1.60 \mathrm{E}-03$ \\
\hline $\mathrm{Fe}-55$ & $0.00 \mathrm{E}+00$ & $0.00 \mathrm{E}+00$ \\
\hline $\mathrm{Mn}-54$ & $4.60 \mathrm{E}-02$ & 7.60E-04 \\
\hline $\mathrm{Na}-22$ & $1.60 \mathrm{E}-01$ & $2.60 \mathrm{E}-03$ \\
\hline Nb-94 & 1.30E-01 & 2.10E-03 \\
\hline $\mathrm{Ni}-59$ & $0.00 \mathrm{E}+00$ & $0.00 \mathrm{E}+00$ \\
\hline $\mathrm{Ni}-63$ & $0.00 \mathrm{E}+00$ & $0.00 \mathrm{E}+00$ \\
\hline $\mathrm{Np}-237$ & $2.00 \mathrm{E}-02$ & 3.30E-04 \\
\hline Pb-210 & $6.20 \mathrm{E}-05$ & $1.00 \mathrm{E}-06$ \\
\hline Pm-147 & $1.00 \mathrm{E}-06$ & $1.70 \mathrm{E}-08$ \\
\hline $\mathrm{Pu}-238$ & $3.50 \mathrm{E}-06$ & $5.80 \mathrm{E}-08$ \\
\hline Pu-239 & $7.20 \mathrm{E}-06$ & $1.20 \mathrm{E}-07$ \\
\hline $\mathrm{Pu}-240$ & 3.50E-06 & 5.70E-08 \\
\hline $\mathrm{Pu}-241$ & 4.20E-07 & $6.90 \mathrm{E}-09$ \\
\hline Pu-242 & $3.00 \mathrm{E}-06$ & 5.00E-08 \\
\hline Ru-106 & $1.40 \mathrm{E}-02$ & 2.20E-04 \\
\hline Sb-125 & $3.20 \mathrm{E}-02$ & 5.30E-04 \\
\hline Se-79 & $0.00 \mathrm{E}+00$ & $0.00 \mathrm{E}+00$ \\
\hline $\mathrm{Sm-151}$ & $2.30 \mathrm{E}-08$ & 3.90E-10 \\
\hline Sr-90 & $2.60 \mathrm{E}-04$ & $4.30 \mathrm{E}-06$ \\
\hline Tc-99 & $3.20 \mathrm{E}-06$ & 5.30E-08 \\
\hline Th-228 & $1.00 \mathrm{E}-01$ & 1.70E-03 \\
\hline Th-229 & 2.70E-02 & 4.50E-04 \\
\hline Th-230 & $2.80 \mathrm{E}-05$ & 4.60E-07 \\
\hline Th-232 & $1.30 \mathrm{E}-05$ & 2.10E-07 \\
\hline U-232 & 2.10E-05 & 3.40E-07 \\
\hline U-233 & $3.40 \mathrm{E}-05$ & 5.60E-07 \\
\hline U-234 & $9.70 \mathrm{E}-06$ & $1.60 \mathrm{E}-07$ \\
\hline U-235 & $1.60 \mathrm{E}-02$ & 2.60E-04 \\
\hline U-238 & 2.10E-03 & 3.40E-05 \\
\hline $\mathrm{Zn}-65$ & $2.90 \mathrm{E}-02$ & $4.80 \mathrm{E}-04$ \\
\hline Zr-93 & $0.00 \mathrm{E}+00$ & $0.00 \mathrm{E}+00$ \\
\hline
\end{tabular}

a Doses do not account for scrap dilution or radionuclide partitioning; collective doses based on $100 \mathrm{t}$.

b Ingestion and inhalation doses do not apply for these scenarios. 
TABLE D.30 Baseline Public Doses for a 100-t Batch - Public Building Scenario and Bridge Scenario ${ }^{a}$

\begin{tabular}{|c|c|c|c|c|}
\hline \multirow[b]{2}{*}{ Nuclide } & \multicolumn{2}{|c|}{ Public Building Scenario } & \multicolumn{2}{|c|}{ Bridge Scenario } \\
\hline & $\begin{array}{l}\text { External }^{b} \\
(\mu \mathrm{Sv} / \mathrm{yr})\end{array}$ & $\begin{array}{r}\text { Collective Dose } \\
\text { (person-Sv/yr) }\end{array}$ & $\begin{array}{c}\text { External }^{b} \\
(\mu \mathrm{Sv} / \mathrm{yr})\end{array}$ & $\begin{array}{r}\text { Collective Dose } \\
\text { (person-Sv/yr) }\end{array}$ \\
\hline Ac-227 & $2.00 \mathrm{E}-02$ & 3.30E-04 & $9.70 \mathrm{E}-01$ & $1.60 \mathrm{E}-04$ \\
\hline $\mathrm{Ag}-110 \mathrm{~m}$ & $1.00 \mathrm{E}-01$ & $1.70 \mathrm{E}-03$ & $1.30 \mathrm{E}+01$ & $2.20 \mathrm{E}-03$ \\
\hline Am-241 & 4.90E-04 & $8.00 \mathrm{E}-06$ & $4.80 \mathrm{E}-06$ & $7.80 \mathrm{E}-10$ \\
\hline Am-243 & $9.60 \mathrm{E}-03$ & $1.60 \mathrm{E}-04$ & $1.90 \mathrm{E}-01$ & $3.00 \mathrm{E}-05$ \\
\hline $\mathrm{Ca}-41$ & $0.00 \mathrm{E}+00$ & $0.00 \mathrm{E}+00$ & $0.00 \mathrm{E}+00$ & $0.00 \mathrm{E}+00$ \\
\hline $\mathrm{Ce}-144$ & $2.00 \mathrm{E}-03$ & 3.30E-05 & 2.50E-01 & $4.00 \mathrm{E}-05$ \\
\hline Cl-36 & 2.50E-05 & 4.00E-07 & $2.00 \mathrm{E}-03$ & 3.30E-07 \\
\hline $\mathrm{Cm}-243$ & $6.20 \mathrm{E}-03$ & $1.00 \mathrm{E}-04$ & $1.40 \mathrm{E}-01$ & 2.30E-05 \\
\hline $\mathrm{Cm}-244$ & $1.40 \mathrm{E}-06$ & 2.30E-08 & 2.50E-09 & 4.10E-13 \\
\hline $\mathrm{Cm}-245$ & 3.70E-03 & $6.20 \mathrm{E}-05$ & $2.30 \mathrm{E}-02$ & 3.70E-06 \\
\hline $\mathrm{Cm}-246$ & $1.30 \mathrm{E}-06$ & 2.20E-08 & $1.30 \mathrm{E}-12$ & 2.10E-16 \\
\hline $\mathrm{Cm}-247$ & $1.90 \mathrm{E}-02$ & 3.10E-04 & $1.10 \mathrm{E}+00$ & $1.80 \mathrm{E}-04$ \\
\hline Co-57 & 3.70E-03 & $6.10 \mathrm{E}-05$ & $2.70 \mathrm{E}-02$ & 4.40E-06 \\
\hline Co-60 & $1.40 \mathrm{E}-01$ & 2.30E-03 & $2.20 \mathrm{E}+01$ & 3.50E-03 \\
\hline Cs-134 & $7.90 \mathrm{E}-02$ & $1.30 \mathrm{E}-03$ & $8.90 \mathrm{E}+00$ & $1.50 \mathrm{E}-03$ \\
\hline Cs-135 & $0.00 \mathrm{E}+00$ & $0.00 \mathrm{E}+00$ & $0.00 \mathrm{E}+00$ & $0.00 \mathrm{E}+00$ \\
\hline Cs-137 & $3.30 \mathrm{E}-02$ & 5.50E-04 & $3.60 \mathrm{E}+00$ & $5.90 \mathrm{E}-04$ \\
\hline Eu-152 & $6.50 \mathrm{E}-02$ & $1.10 \mathrm{E}-03$ & $8.50 \mathrm{E}+00$ & 1.40E-03 \\
\hline Eu-154 & 7.10E-02 & $1.20 \mathrm{E}-03$ & $9.50 \mathrm{E}+00$ & $1.60 \mathrm{E}-03$ \\
\hline $\mathrm{Fe}-55$ & $0.00 \mathrm{E}+00$ & $0.00 \mathrm{E}+00$ & $0.00 \mathrm{E}+00$ & $0.00 \mathrm{E}+00$ \\
\hline $\mathrm{Mn}-54$ & 3.30E-02 & 5.50E-04 & $4.20 \mathrm{E}+00$ & $6.90 \mathrm{E}-04$ \\
\hline $\mathrm{Na}-22$ & 1.10E-01 & $1.90 \mathrm{E}-03$ & $1.40 \mathrm{E}+01$ & 2.30E-03 \\
\hline $\mathrm{Nb}-94$ & $9.30 \mathrm{E}-02$ & $1.50 \mathrm{E}-03$ & $1.10 \mathrm{E}+01$ & $1.80 \mathrm{E}-03$ \\
\hline $\mathrm{Ni}-59$ & $0.00 \mathrm{E}+00$ & $0.00 \mathrm{E}+00$ & $0.00 \mathrm{E}+00$ & $0.00 \mathrm{E}+00$ \\
\hline $\mathrm{Ni}-63$ & $0.00 \mathrm{E}+00$ & $0.00 \mathrm{E}+00$ & $0.00 \mathrm{E}+00$ & $0.00 \mathrm{E}+00$ \\
\hline $\mathrm{Np}-237$ & $1.10 \mathrm{E}-02$ & 1.90E-04 & $4.50 \mathrm{E}-01$ & $7.40 \mathrm{E}-05$ \\
\hline $\mathrm{Pb}-210$ & 2.70E-05 & $4.40 \mathrm{E}-07$ & $4.60 \mathrm{E}-10$ & 7.60E-14 \\
\hline Pm-147 & $4.90 \mathrm{E}-07$. & 8.00E-09 & $2.60 \mathrm{E}-06$ & $4.20 \mathrm{E}-10$ \\
\hline $\mathrm{Pu}-238$ & $1.70 \mathrm{E}-06$ & $2.80 \mathrm{E}-08$ & $2.20 \mathrm{E}-09$ & $3.60 \mathrm{E}-13$ \\
\hline Pu-239 & 3.30E-06 & $5.40 \mathrm{E}-08$ & $1.30 \mathrm{E}-05$ & 2.10E-09 \\
\hline $\mathrm{Pu}-240$ & 1.70E-06 & 2.70E-08 & $1.40 \mathrm{E}-09$ & 2.30E-13 \\
\hline $\mathrm{Pu}-241$ & $2.00 \mathrm{E}-07$ & 3.30E-09 & 2.30E-06 & $3.80 \mathrm{E}-10$ \\
\hline $\mathrm{Pu}-242$ & $1.40 \mathrm{E}-06$ & 2.40E-08 & 3.20E-09 & $5.20 \mathrm{E}-13$ \\
\hline $\mathrm{Ru}-106$ & $9.40 \mathrm{E}-03$ & $1.50 \mathrm{E}-04$ & $9.30 \mathrm{E}-01$ & $1.50 \mathrm{E}-04$ \\
\hline $\mathrm{Sb}-125$ & 2.20E-02 & 3.60E-04 & $1.80 \mathrm{E}+00$ & 3.00E-04 \\
\hline Se-79 & $0.00 \mathrm{E}+00$ & $0.00 \mathrm{E}+00$ & $0.00 \mathrm{E}+00$ & $0.00 E+00$ \\
\hline $\mathrm{Sm}-151$ & 1.10E-08 & $1.80 \mathrm{E}-10$ & $0.00 \mathrm{E}+00$ & $0.00 \mathrm{E}+00$ \\
\hline Sr-90 & $2.10 \mathrm{E}-04$ & 3.40E-06 & 3.70E-02 & $6.00 \mathrm{E}-06$ \\
\hline Tc-99 & $1.40 \mathrm{E}-06$ & 2.30E-08 & $1.60 \mathrm{E}-06$ & 2.60E-10 \\
\hline Th-228 & $7.50 \mathrm{E}-02$ & $1.20 \mathrm{E}-03$ & $1.30 \mathrm{E}+01$ & 2.10E-03 \\
\hline Th-229 & $1.60 \mathrm{E}-02$ & 2.70E-04 & $1.00 \mathrm{E}+00$ & $1.70 \mathrm{E}-04$ \\
\hline Th-230 & $1.30 \mathrm{E}-05$ & $2.20 \mathrm{E}-07$ & $1.00 \mathrm{E}-04$ & $1.70 \mathrm{E}-08$ \\
\hline Th-232 & $5.80 \mathrm{E}-06$ & $9.50 \mathrm{E}-08$ & $2.00 \mathrm{E}-05$ & $3.20 \mathrm{E}-09$ \\
\hline $\mathrm{U}-232$ & $9.90 \mathrm{E}-06$ & $1.60 \mathrm{E}-07$ & $6.50 \mathrm{E}-05$ & $1.10 \mathrm{E}-08$ \\
\hline U-233 & $1.60 \mathrm{E}-05$ & $2.60 \mathrm{E}-07$ & $6.40 \mathrm{E}-05$ & 1.10E-08 \\
\hline U-234 & $4.50 \mathrm{E}-06$ & $7.40 \mathrm{E}-08$ & $1.70 \mathrm{E}-05$ & 2.80E-09 \\
\hline U-235 & $8.30 \mathrm{E}-03$ & 1.40E-04 & $1.20 \mathrm{E}-01$ & $2.00 \mathrm{E}-05$ \\
\hline U-238 & $1.30 \mathrm{E}-03$ & 2.20E-05 & 1.40E-01 & 2.30E-05 \\
\hline $\mathrm{Zn}-65$ & 2.20E-02 & 3.70E-04 & $3.20 \mathrm{E}+00$ & 5.30E-04 \\
\hline $\mathrm{Zr}-93$ & $0.00 \mathrm{E}+00$ & $0.00 \mathrm{E}+00$ & $0.00 \mathrm{E}+00$ & $0.00 \mathrm{E}+00$ \\
\hline
\end{tabular}

a Doses do not account for scrap dilution or radionuclide partitioning; collective doses based on $100 \mathrm{t}$.

b Ingestion and inhalation doses do not apply for these scenarios. 
TABLE D.31 Public Doses for Stack Emission Scenario

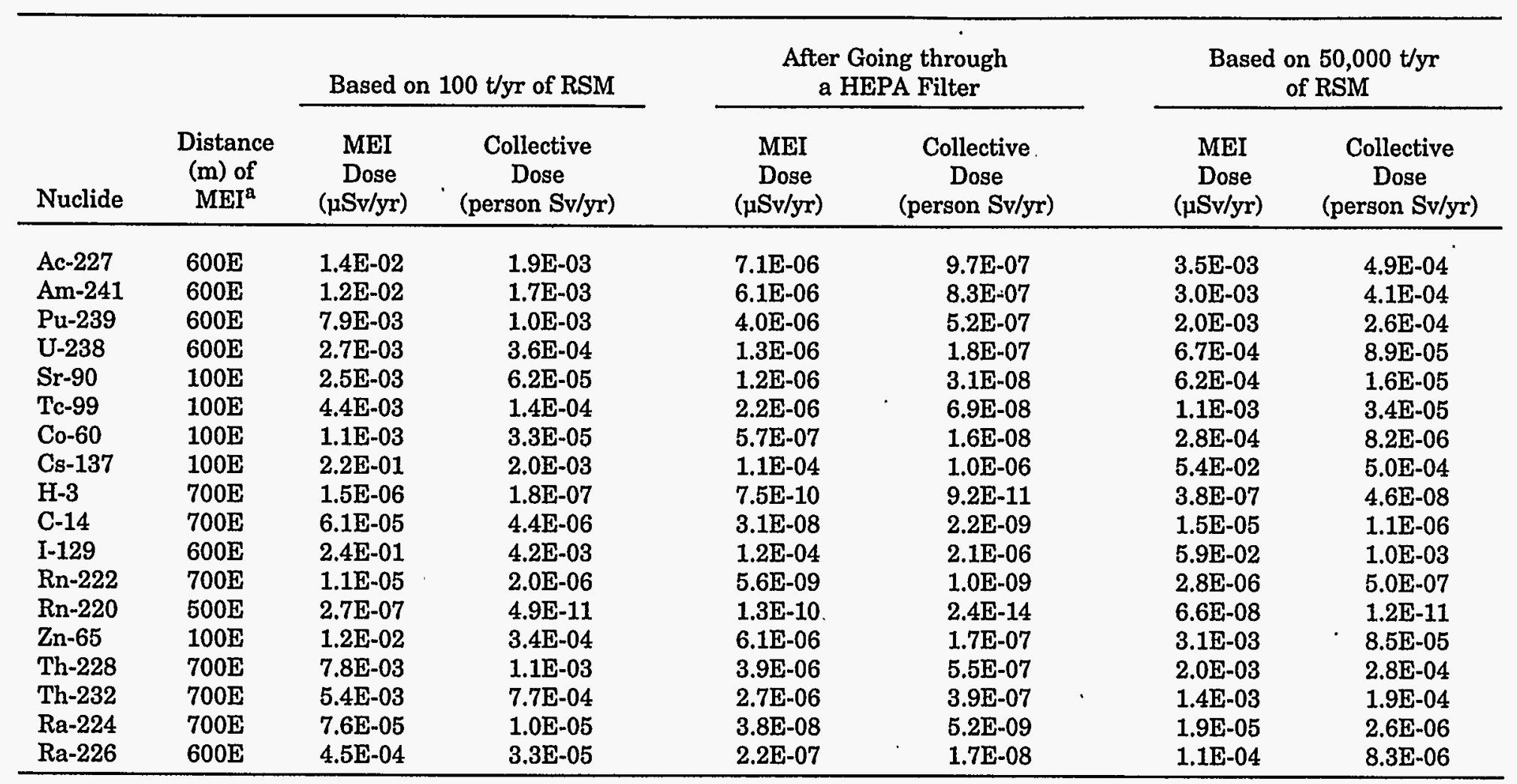

a $\mathrm{MEI}=$ maximally exposed individual. 
TABLE D.32 Doses for Disposal Worker Scenario

\begin{tabular}{|c|c|c|c|c|}
\hline \multirow[b]{3}{*}{ Nuclide } & \multicolumn{4}{|c|}{ Dose ( $\mu \mathrm{Sv} / \mathrm{yr})$} \\
\hline & \multicolumn{2}{|c|}{$\begin{array}{c}\text { Volume-Contaminated } \\
\text { RSM } \\
\end{array}$} & \multicolumn{2}{|c|}{$\begin{array}{c}\text { Surface-Contaminated } \\
\text { RSM }\end{array}$} \\
\hline & $\begin{array}{c}\text { Managed } \\
\text { Landfill }\end{array}$ & $\begin{array}{c}\text { Unrestricted } \\
\text { Landfill } \\
\end{array}$ & $\begin{array}{c}\text { Managed } \\
\text { Landfill } \\
\end{array}$ & $\begin{array}{c}\text { Unrestricted } \\
\text { Landfill } \\
\end{array}$ \\
\hline Ac- 227 & 5.30E-02 & $1.10 \mathrm{E}+02$ & $6.60 \mathrm{E}-04$ & $1.40 \mathrm{E}+00$ \\
\hline Am-241 & 3.90E-06 & $1.70 \mathrm{E}+00$ & $4.90 \mathrm{E}-08$ & 2.10E-02 \\
\hline C-14 & $0.00 \mathrm{E}+00$ & $0.00 \mathrm{E}+00$ & $0.00 \mathrm{E}+00$ & $0.00 \mathrm{E}+00$ \\
\hline Co-60 & $1.80 \mathrm{E}+00$ & $8.90 \mathrm{E}+02$ & $2.30 \mathrm{E}-02$ & $1.10 \mathrm{E}+01$ \\
\hline Cs-137 & $1.70 \mathrm{E}-01$ & $2.00 \mathrm{E}+02$ & $2.10 \mathrm{E}-03$ & $2.50 \mathrm{E}+00$ \\
\hline $\mathrm{H}-3$ & $0.00 \mathrm{E}+00$ & $0.00 \mathrm{E}+00$ & $0.00 \mathrm{E}+00$ & $0.00 \mathrm{E}+00$ \\
\hline$I-129$ & $9.60 \mathrm{E}-09$ & $1.20 \mathrm{E}+00$ & $1.20 \mathrm{E}-10$ & $1.50 \mathrm{E}-02$ \\
\hline $\mathrm{Pu}-239$ & $9.10 \mathrm{E}-08$ & 1.40E-02 & 1.10E-09 & $1.80 \mathrm{E}-03$ \\
\hline Ra-226 & $2.30 \mathrm{E}+00$ & $6.20 \mathrm{E}+02$ & $2.80 \mathrm{E}-02$ & $7.80 \mathrm{E}+00$ \\
\hline $\mathrm{Ra}-228$ & 7.30E-01 & $3.20 \mathrm{E}+02$ & $9.10 \mathrm{E}-03$ & $4.00 \mathrm{E}+00$ \\
\hline Sr-90 & $0.00 \mathrm{E}+00$ & $0.00 \mathrm{E}+00$ & $0.00 \mathrm{E}+00$ & $0.00 \mathrm{E}+00$ \\
\hline Tc-99 & $2.20 \mathrm{E}-11$ & $6.80 \mathrm{E}-05$ & $2.80 \mathrm{E}-13$ & $8.50 \mathrm{E}-07$ \\
\hline Th-228 & $3.80 \mathrm{E}+00$ & $5.40 \mathrm{E}+02$ & $4.80 \mathrm{E}-02$ & $6.80 \mathrm{E}+00$ \\
\hline Th-230 & 3.10E-02 & $7.90 \mathrm{E}+00$ & $3.90 \mathrm{E}-04$ & $1.00 \mathrm{E}-01$ \\
\hline Th-232 & $5.60 \mathrm{E}+00$ & $8.20 \mathrm{E}+02$ & $7.00 \mathrm{E}-02$ & $1.00 \mathrm{E}+01$ \\
\hline U-238 & $5.40 \mathrm{E}-03$ & $4.90 \mathrm{E}+00$ & $6.80 \mathrm{E}-05$ & $6.10 \mathrm{E}-02$ \\
\hline $\mathrm{Zn}-65$ & $1.80 \mathrm{E}-01$ & $1.50 \mathrm{E}+02$ & 2.30E-03 & $1.90 \mathrm{E}+00$ \\
\hline
\end{tabular}


TABLE D.33 Doses for Disposal Resident Scenario

\begin{tabular}{|c|c|c|c|c|}
\hline \multirow[b]{3}{*}{ Nuclide } & \multicolumn{4}{|c|}{ Dose ( $\mu \mathrm{Sv} / \mathrm{yr})$} \\
\hline & \multicolumn{2}{|c|}{$\begin{array}{l}\text { Volume-Contaminated } \\
\text { RSM }\end{array}$} & \multicolumn{2}{|c|}{$\begin{array}{c}\text { Surface-Contaminated } \\
\text { RSM }\end{array}$} \\
\hline & $\begin{array}{l}\text { Managed } \\
\text { Landfill }\end{array}$ & $\begin{array}{l}\text { Unrestricted } \\
\text { Landfill }\end{array}$ & $\begin{array}{c}\text { Managed } \\
\text { Landfill }\end{array}$ & $\begin{array}{l}\text { Unrestricted } \\
\text { Landfill }\end{array}$ \\
\hline Ac-227 & $4.00 \mathrm{E}+01$ & $4.50 \mathrm{E}+02$ & $1.40 \mathrm{E}+00$ & $8.30 \mathrm{E}+00$ \\
\hline Am-241 & $1.20 \mathrm{E}+01$ & $6.00 \mathrm{E}+01$ & $4.40 \mathrm{E}-01$ & $2.00 \mathrm{E}+00$ \\
\hline C-14 & $1.40 \mathrm{E}+02$ & $1.10 \mathrm{E}+03$ & $0.00 \mathrm{E}+00$ & $0.00 \mathrm{E}+00$ \\
\hline Co-60 & $3.00 \mathrm{E}-01$ & $1.70 \mathrm{E}+01$ & $1.30 \mathrm{E}-02$ & 2.50E-01 \\
\hline Cs-137 & $3.00 \mathrm{E}+00$ & $2.00 \mathrm{E}+02$ & $2.50 \mathrm{E}-01$ & $1.80 \mathrm{E}+00$ \\
\hline $\mathrm{H}-3$ & $1.50 \mathrm{E}+00$ & $1.30 \mathrm{E}+00$ & $0.00 \mathrm{E}+00$ & $0.00 \mathrm{E}+00$ \\
\hline I-129 & $3.80 \mathrm{E}+03$ & $3.00 \mathrm{E}+03$ & $0.00 \mathrm{E}+00$ & $6.30 \mathrm{E}-04$ \\
\hline Pu-239 & $1.30 \mathrm{E}+01$ & $5.60 E+01$ & $5.00 \mathrm{E}-01$ & $2.30 \mathrm{E}+00$ \\
\hline $\mathrm{Ra}-226$ & $1.30 \mathrm{E}+04$ & $1.20 \mathrm{E}+03$ & $4.50 \mathrm{E}+02$ & $3.80 \mathrm{E}+01$ \\
\hline $\mathrm{Ra}-228$ & $3.00 \mathrm{E}+00$ & $3.00 \mathrm{E}+01$ & $1.30 \mathrm{E}-01$ & $8.30 \mathrm{E}-01$ \\
\hline Sr-90 & $7.00 \mathrm{E}+01$ & $1.50 \mathrm{E}+02$ & $2.60 \mathrm{E}+00$ & $5.80 \mathrm{E}+00$ \\
\hline Tc-99 & $1.30 \mathrm{E}+01$ & $1.30 \mathrm{E}+02$ & $0.00 \mathrm{E}+00$ & $0.00 \mathrm{E}+00$ \\
\hline Th-228 & $0.00 \mathrm{E}+00$ & $1.00 \mathrm{E}-02$ & $0.00 \mathrm{E}+00$ & $1.90 \mathrm{E}-04$ \\
\hline Th-230 & $4.90 \mathrm{E}+02$ & $3.00 \mathrm{E}+01$ & $6.10 \mathrm{E}+00$ & $1.30 \mathrm{E}+00$ \\
\hline Th-232 & $1.70 \mathrm{E}+02$ & $7.50 \mathrm{E}+02$ & $6.30 \mathrm{E}+00$ & $3.00 \mathrm{E}+01$ \\
\hline U-238 & $1.80 \mathrm{E}+00$ & $1.10 \mathrm{E}+01$ & $6.90 \mathrm{E}-02$ & $5.00 \mathrm{E}-01$ \\
\hline $\mathrm{Zn}-65$ & $0.00 \mathrm{E}+00$ & $0.00 \mathrm{E}+00$ & $0.00 \mathrm{E}+00$ & $0.00 E+00$ \\
\hline
\end{tabular}


APPENDIX E:

ENVIRONMENTAL RISK CONTEXT AND PROFILES OF TOXIC SUBSTANCES AND ASSOCIATED HEALTH EFFECTS 


\section{APPENDIX E: \\ ENVIRONMENTAL RISK CONTEXT AND PROFILES OF TOXIC SUBSTANCES AND ASSOCIATED HEALTH EFFECTS}

Section E.1 presents information regarding the environmental risk context within which decisions will be made regarding radioactive scrap metal (RSM) management. This material is intended to provide perspective on the risk levels associated with the RSM alternatives. Section E.2 presents risk profiles of chemicals that would be released from processes associated with the RSM alternatives.

\section{E.1 ENVIRONMENTAL RISK CONTEXT}

Information regarding public and worker risks associated with the possible recycling of contaminated metals should be considered in the context of risks from common hazards and activities. Such a comparison of relative risks provides a basis for determining which risk-reduction efforts should be given priority and which costs of reducing, or avoiding, risks are worth incurring. This section presents an overview of risks to workers and to the public from common substances and activities. It also indicates the range of costs incurred in the U.S.A. per fatality averted as a result of recent regulations to reduce risk.

\section{E.1.1 Radiation-Related Risks}

Health risks associated with radiation exposures of the general population occur from radiation sources ranging from cosmic radiation and terrestrial materials, to diagnostic and therapeutic medical treatment, to industrial and medical occupational activities. Nonmedical sources of exposure to major segments of the population are identified in this section.

\section{E.1.1.1 Industrial Activities}

Occupational exposure to radiation occurs among several groups other than nuclear workers. The occupational categories of exposed workers, the sources of the exposure, and the average dose levels are shown in Table E.1. The groups receiving the largest annual exposures are industrial radiographers and well-loggers working in the oil industry. Next are aircraft crews and workers in rock phosphate production. For comparison, the average dose to nuclear power workers in Great Britain is about $1 \mathrm{mSv} / \mathrm{yr}$, with just a few workers receiving doses greater than $5 \mathrm{mSv} / \mathrm{yr}$ (Health and Safety Executive 1992). 
TABLE E.1 Occupational Exposure of Nonnuclear Workers

$\because$

\begin{tabular}{|c|c|c|c|c|}
\hline Occupational Category & Radiation Source & $\begin{array}{l}\text { Number } \\
\text { Exposed } \\
\text { in U.S.A } \\
\end{array}$ & $\begin{array}{c}\text { Mean Annual } \\
\text { Effective Dose } \\
\text { Equivalent (mSv) }\end{array}$ & $\begin{array}{l}\text { Risk of Fatal } \\
\text { Cancer from } \\
\text { Annual Exposure }\end{array}$ \\
\hline Medical $^{b}$ & Diagnostic X-ray machines & 584,000 & $0.7-1.5$ & $4 \times 10^{-5}-8 \times 10^{-5}$ \\
\hline U.S. Public Health Service ${ }^{b}$ & Various sources & 5,000 & $0.07-0.47$ & $4 \times 10^{-6}-2 \times 10^{-5}$ \\
\hline Industrial radiographers ${ }^{b}$ & Co- 60 or Ir-192 & 8,500 & $2.8-4.3$ & $1 \times 10^{-4}-2 \times 10^{-4}$ \\
\hline Well loggers ${ }^{b}$ & Co-60 or Ir-192 & 8,700 & $3.5-4.2$ & $2 \times 10^{-4}$ \\
\hline $\begin{array}{l}\text { Phosphate fertilizer production } \\
\text { plant and storehouse workers }\end{array}$ & $\begin{array}{l}\text { Uranium-natural, Ra-226, } \\
\text { thorium-natural, } \mathrm{K}-40\end{array}$ & $N A^{d}$ & $0.11-0.45$ & $6 \times 10^{-6}-2 \times 10^{-5}$ \\
\hline $\begin{array}{l}\text { Rock phosphate production } \\
\text { and transport workers }\end{array}$ & $\begin{array}{l}\text { Uranium-natural, } \mathrm{Ra}-226 \text {, } \\
\text { thorium-natural, } \mathrm{K}-40\end{array}$ & NA & $0.3-3.0$ & $2 \times 10^{-5}-2 \times 10^{-4}$ \\
\hline Aircraft crew ${ }^{b}$ & Cosmic radiation & 97,000 & 1.7 & $9 \times 10^{-5}$ \\
\hline
\end{tabular}

a From NCRP (1989); low end of range represents all professionals in field, while high end represents those operating equipment.

b From Wehner (1978).

c $\mathrm{NA}=$ data not available.

d The risk of fatal cancer was calculated with a risk factor of $5.0 \times 10^{-2} / \mathrm{Sv}$ for the general public (ICRP 1990). 


\section{E.1.1.2 Consumer Products}

Radiation is associated with consumer products in both intentionally added and naturally occurring forms and as an unintended by-product of product operation. Some of the major types of products with which the public in industrialized countries is likely to come into contact are listed in Table E.2. Among these products, the highest doses are associated with use of tobacco products, in which the radioactivity occurs naturally. The next largest doses, which are substantially smaller, are by-products of color TV and video display terminal operation.

Watches with luminescent displays are probably the most common personal products to which radioactivity is intentionally added. Historically, radium was painted on watch hands or dials to render them luminous. This practice has been replaced by the use of tritium in liquid crystal display devices. The watch casing shields the wearer from any exposure, and the only way that potential exposure could occur is through ingestion or inhalation of the liquid tritium if the casing breaks.

Uranium may be added to the material used for ceramic dentures and dental prostheses in order to impart a natural-looking color. The annual effective equivalent dose to the exposed population is relatively low, on the order of $0.7 \mu \mathrm{Sv}$. This dose is in addition to the 1.4-1.9 mSv dose equivalent from $\mathrm{K}-40$ in the ceramic material. While as many as $45,000,000$ people in the U.S.A are estimated to be using this material (National Council on Radiation Protection and Measurements [NCRP] 1987a), it is unlikely that many are aware of the uranium content. Recently, this use has been largely phased out by the introduction of acrylic products.

\section{E.1.1.3 Environmental Radiation Exposure}

Small quantities of radioactive elements occur naturally in rock, soil, water, and air and are incorporated into living organisms. The concentrations of these radioactive materials range from trace levels to levels sufficient to cause measurable cell damage in humans. Even the materials with higher levels of activity are generally used without regard for their radioactivity and in a few cases are considered by local populations to have therapeutic value.

Table E.3 includes both commonly used substances that give rise to radiation exposures and some that are relatively unusual. Mineral-based building materials, domestic water supplies, and agricultural fertilizers have average annual dose equivalents ranging up to 50-70 $\mu \mathrm{Sv}$ for the exposed population. The doses from these substances are considerably larger than those from any of the consumer products, in which the radiation is man-made.

The radioactivity level in seawater is about the same as the high-end level for drinking water, but the activity is due to the presence of $\mathrm{K}-40$ rather than dissolved radon. In buildings made of granite, $\mathrm{K}-40$ raises dose levels due to external exposure for building occupants. These levels are likely to be higher than those listed in Table E.3 for concrete or 
TABLE E.2 Population Exposure from Consumer Products in the U.S.A.

\begin{tabular}{|c|c|c|c|c|}
\hline Product & Radiation Source & $\begin{array}{l}\text { U.S.A. } \\
\text { Population } \\
\text { Exposed }\end{array}$ & $\begin{array}{c}\text { Mean Annual } \\
\text { Effective Dose } \\
\text { Equivalent to an } \\
\text { Exposed Individual } \\
(\mu \mathrm{SV})\end{array}$ & $\begin{array}{c}\text { Risk of Fatal } \\
\text { Cancer from } \\
\text { Annual } \\
\text { Exposure }^{\mathrm{a}}\end{array}$ \\
\hline Color TV screens & By-product X-rays & $230,000,000$ & $<10$ & $<5 \times 10^{-7}$ \\
\hline Video display terminals & By-product X-rays & $50,000,000$ & $<10$ & $<5 \times 10^{-7}$ \\
\hline $\begin{array}{l}\text { Airport luggage } \\
\text { inspection systems }\end{array}$ & Intentional X-rays & $30,000,000$ & 0.021 & $1 \times 10^{-9}$ \\
\hline $\begin{array}{l}\text { Luminescent watches } \\
\text { and clocks }\end{array}$ & Tritium & $10,750,000$ & 1 & $5 \times 10^{-8}$ \\
\hline $\begin{array}{l}\text { Electron tubes, appliance } \\
\text { indicator lights, electric } \\
\text { blanket thermostats }\end{array}$ & $\begin{array}{l}\text { Various isotopes } \\
\text { with activities } \\
<37 \mathrm{kBq} \text { per unit }\end{array}$ & $230,000,000$ & 0.04 & $2 \times 10^{-9}$ \\
\hline Smoke detectors & Am-241 & $-^{b}$ & 0.08 & $4 \times 10^{-9}$ \\
\hline Tobacco products & Po-210 & $50,000,000$ & 13,000 & $7 \times 10^{-4}$ \\
\hline $\begin{array}{l}\text { Natural gas cooking } \\
\text { ranges }\end{array}$ & Radon & $125,000,000$ & 4 & $2 \times 10^{-7}$ \\
\hline Ophthalmic glass & $\begin{array}{l}\text { Thorium and } \\
\text { uranium }\end{array}$ & $50,000,000$ & $<4$ & $<2 \times 10^{-7}$ \\
\hline Gas lantern mantles & Thorium & $50,000,000$ & 2 & $1 \times 10^{-7}$ \\
\hline $\begin{array}{l}\text { Fluorescent lamp } \\
\text { starters }\end{array}$ & Thorium & $50,000,000$ & 0.0002 & $1 \times 10^{-11}$ \\
\hline
\end{tabular}

a The risk of fatal cancer was calculated with a risk factor of $5.0 \times 10^{-2} / \mathrm{Sv}$ for the general public (ICRP 1990).

b About 100 million units in use.

Source: NCRP (1987a). 
TABLE E.3 Naturally Occurring Radioactive Concentrations in the Environment

\begin{tabular}{|c|c|c|c|c|}
\hline Substance & Radiation Source & Concentration & $\begin{array}{c}\text { Mean Annual } \\
\text { Effective Dose } \\
\text { Equivalent to an } \\
\text { Exposed } \\
\text { Individual ( } \mu \mathrm{Sv} \text { ) }\end{array}$ & $\begin{array}{l}\text { Risk of Fatal } \\
\text { Cancer from } \\
\text { Annual } \\
\text { Exposure }^{a}\end{array}$ \\
\hline $\begin{array}{l}\text { Domestic water supplies } \\
\text { (U.S.A.) }^{\text {b }}\end{array}$ & Radon & $1,400-8,100 \mathrm{~Bq} / \mathrm{L}^{\mathrm{c}}$ & $10-60$ & $5 \times 10^{-7}-3 \times 10^{-6}$ \\
\hline Concrete or brick home $\mathrm{e}^{\mathrm{b}}$ & $\begin{array}{l}\text { Uranium, thorium, } \\
\text { potassium }\end{array}$ & $-^{d}$ & 70 & $4 \times 10^{-6}$ \\
\hline Agriculture fertilizer ${ }^{b}$ & $\begin{array}{l}\text { Uranium, thorium, } \\
\text { potassium }\end{array}$ & - & $5-50$ & $3 \times 10^{-7}-3 \times 10^{-6}$ \\
\hline Seawater ${ }^{e}$ & Potassium & $8,100 \mathrm{~Bq} / \mathrm{L}$ & - & - \\
\hline Granite $^{f}$ & Potassium & $1,100 \mathrm{~Bq} / \mathrm{g}$ & - & - \\
\hline Shale ${ }^{e}$ & Potassium & $590 \mathrm{~Bq} / \mathrm{g}$ & 一 & 一 \\
\hline Pre-World War II steel ${ }^{\mathrm{e}}$ & Uranium & $0.01-0.2 \mathrm{ppm}$ & - & - \\
\hline Human skeleton ${ }^{\mathbf{e}}$ & $\mathrm{Ra}-226$ & $0.62 \mathrm{~Bq} / \mathrm{g} \mathrm{Ca}$ in bone & - & $\dot{-}$ \\
\hline Brazil nuts $^{e}$ & Radium & $380 \mathrm{~Bq} / \mathrm{g}$ & - & - \\
\hline Cereals $^{e}$ & Radium & $16 \mathrm{~Bq} / \mathrm{g}$ & - & - \\
\hline $\begin{array}{l}\text { Mineral springse } \\
\text { - Saratoga, N.Y. } \\
\text { - Bad Gastein, } \\
\text { Austria }\end{array}$ & $\begin{array}{l}\text { Radium } \\
\text { Radium }\end{array}$ & $\begin{array}{c}7,600-14,000 \mathrm{~Bq} / \mathrm{L} \\
2,700 \mathrm{~Bq} / \mathrm{L}\end{array}$ & $\begin{array}{l}- \\
-\end{array}$ & $\begin{array}{l}- \\
-\end{array}$ \\
\hline \multicolumn{5}{|l|}{ b NCRP (1987a). } \\
\hline d - denotes data not available. & \multicolumn{4}{|c|}{ Population-weighted average. } \\
\hline e Eisenbud (1987). & & & & \\
\hline f Conference of Radiatio & trol Program Dire & c. (1978). & & \\
\hline
\end{tabular}


brick houses. Samples of steel produced before World War II, and the release of man-made radioactivity, showed traces (0.01-0.2 ppm) of natural uranium content. Traces of radium, which is chemically similar to calcium, occur in many foods. Cereals are at the high end of the range of concentrations found in common types of foods.

Finally, Table E.3 presents radium concentrations in mineral spring waters that are renowned for their putative health benefits. People both drink the waters and immerse themselves in them, seeking their curative effects. In addition to the springs listed, similar sites are located in Greece (springs) and in Brazil (sands) with relatively long histories of therapeutic use.

People experience much more significant (in terms of magnitude) exposures from environmental radiation than from consumer products (other than tobacco). As shown in Table E.4, the largest exposure source is inhalation of radon and its 'decay products. This

TABLE E.4 Sources of Population Exposure to Environmental Radiation

\begin{tabular}{lcc}
\hline \multicolumn{1}{c}{ Source } & $\begin{array}{c}\text { Annual Dose } \\
\text { Equivalent ( } \mu \mathrm{Sv})\end{array}$ & $\begin{array}{c}\text { Risk of Fatal Cancer } \\
\text { from Annual } \\
\text { Exposure }^{\mathrm{a}}\end{array}$ \\
\hline $\begin{array}{l}\text { Cosmic radiation, including air travel } \\
\text { Terrestrial gamma radiation }\end{array}$ & 270 & $1 \times 10^{-5}$ \\
$\begin{array}{l}\text { Inhaled radon and its daughters } \\
\text { Radionuclides incorporated in body } \\
\text { tissues }\end{array}$ & $280^{\mathrm{b}}$ & $1 \times 10^{-5}$ \\
Coal combustion & $2,000^{\mathrm{c}}$ & $1 \times 10^{-4}$ \\
Fallout from nuclear weapons testing & 390 & $2 \times 10^{-5}$ \\
Nuclear fuel cycle & $<1$ & $2 \times 10^{-8}-2 \times 10^{-7}$ \\
\hline
\end{tabular}

a The risk of fatal cancer was calculated with a risk factor of $5 \times 10^{-2} / \mathrm{Sv}$ for the general public (ICRP 1990).

b In the U.S.A., the range is from $160 \mu \mathrm{Sv}$ on the Atlantic and Gulf coasts to $630 \mu \mathrm{Sv}$ on the eastern slopes of the Rocky Mountains.

c Average estimated at $1 \mathrm{mSv}$ in the United Kingdom (Health and Safety Executive 1992).

Source: NCRP (1987b). 
hazard varies geographically with area geology and also varies with indoor air circulation. Terrestrial gamma radiation levels also differ greatly around the world, with about 200-600 mSv/yr being considered the normal range (United Nations Scientific Committee on the Effects of Atomic Radiation [UNSCEAR] 1982). In the U.S.A., the range is approximately from 160 to $630 \mu \mathrm{Sv}$. Additional doses are received from cosmic radiation and from isotopes that have been incorporated into body tissues, especially K-40. Man-made sources contribute much smaller increments to the total annual dose equivalent. Of these activities, coal combustion is one of the main radioactive emission sources.

\section{E.1.2 Nonnuclear Risks to Life and Health}

Risks from common hazards and activities that are nonnuclear in nature also provide an indication of the baseline level of societal risk. A range of these hazards is summarized in the next section, followed by a brief summary of some risks that have been considered sufficiently substantial to require regulation, and the expenditure levels per fatality averted by the regulation.

\section{E.1.2.1 Risk Associated with Common Hazards}

To the degree that the public is informed about risks, the activities and investments chosen by a society provide some indication of the risk levels that are considered acceptable, given the benefits of participating in the activity. Fatality risks from participation of broad segments of the U.S.A. population in normal, daily activities are shown in Table E.5. The figures indicate the average risk to an exposed individual per year and the uncertainty level associated with that estimate. These activities were selected to present a range of voluntary and involuntary risks involving consumption decisions and common household and business activities. The risk levels range from a high of $3.6 \times 10^{-3}$ fatalities for persons smoking a pack of cigarettes per day to a low of $6 \times 10^{-7}$ fatalities from drinking water that contains chloroform at the upper limit of the U.S. Environmental Protection Agency (USEPA) standard.

\section{E.1.2.2 Regulated Risk Reduction and Associated Costs}

During the past 20 years, risk regulation has been a major emphasis in the U.S.A, especially at the federal level. Table E.6 provides information on a few of the standards, specifically related to hazardous materials or consumer products, developed during this period. Generally, annual residual risk levels of $10^{-4}$ to $10^{-6}$ are considered "acceptable"; however, three of the listed regulations addressed baseline risk levels that were well within the "acceptable" level. Of these three, one involved protection of children, at a relatively low cost per fatality avoided. The other two were developed during the last five years and involve very high costs for the decrease in fatality risks. This development is a clear break from the previous trend and indicates a very strong demand for reduction of even minimal risk levels. 
TABLE E.5 Fatality Risks Associated with Common Activities in the U.S.A.

\begin{tabular}{lcc}
\hline \multicolumn{1}{c}{ Activity } & $\begin{array}{c}\text { Mean Annual } \\
\text { Risk of } \\
\text { Fatality }\end{array}$ & Uncertainty \\
\hline $\begin{array}{l}\text { Cigarette smoking (one } \\
\text { pack/day) }\end{array}$ & $3.6 \times 10^{-3}$ & Factor of 3 \\
$\begin{array}{l}\text { Motor vehicle accident (total) } \\
\begin{array}{l}\text { Alcohol consumption (light } \\
\text { drinker) }\end{array}\end{array}$ & $2.4 \times 10^{-4}$ & $10 \%$ \\
$\begin{array}{l}\text { Home accidents } \\
\text { Frequent air travel }\end{array}$ & $4.2 \times 10^{-5}$ & Factor of 10 \\
$\begin{array}{l}\text { Eating peanut butter } \\
\text { (4 tablespoons/day) }\end{array}$ & $5 \times 10^{-5}$ & $5 \%$ \\
$\begin{array}{l}\text { Drinking water with EPA limit } \\
\text { of chloroform }\end{array}$ & $6 \times 10^{-7}$ & $50 \%$ \\
\hline
\end{tabular}

Source: Wilson and Crouch (1987).

\section{E.2 PROFILES OF TOXIC SUBSTANCES AND ASSOCIATED HEALTH EFFECTS}

Many different toxic substances may be released as a result of the process alternatives for RSM management. This section indicates some of the health risks associated with substances identified as of potential concern for the RSM alternatives.

\section{E.2.1 Benzene}

Benzene is toxic by ingestion, inhalation, and skin absorption. Single oral or inhalation exposures to benzene at $20,000 \mathrm{ppm}$ have proven to be fatal in humans. Industrial air concentrations of benzene have been reported to give rise to giddiness, drowsiness, dizziness, headache, nausea, convulsions, unconsciousness, and paralysis (U.S, Department of Health and Human Services [DHHS] 1989d; National Research Council 1977). Long-term exposures to benzene may affect normal blood production, possibly resulting in severe anemia and internal bleeding. Benzene has been found harmful to the immune system, increasing the chance for infections and perhaps lowering the body's defense against tumors. Exposure to benzene has also been linked with genetic changes (DHHS 1989d; Szpunar 1993). 
TABLE E.6 Baseline Mortality Risk Levels and Costs Associated with Selected U.S.A Regulations

\begin{tabular}{lcc}
\hline \multicolumn{1}{c}{ Regulation } & $\begin{array}{c}\text { Initial Lifetime } \\
\text { Morality Risk for } \\
\text { Exposed } \\
\text { Population }\end{array}$ & $\begin{array}{c}\text { Estimated Cost } \\
\text { per Premature } \\
\text { Death Avoided } \\
\left(\$ 10^{6} 1990\right)\end{array}$ \\
\hline Ban on flammable children's sleepwear & $2.9 \times 10^{-5}$ & 0.6 \\
$\begin{array}{l}\text { Standards for radionuclides in uranium } \\
\text { mines }\end{array}$ & $6.3 \times 10^{-3}$ & 3.4 \\
$\begin{array}{l}\text { Arsenic emission standards for glass plants } \\
\begin{array}{l}\text { Treatment of petroleum refining sludge as } \\
\text { hazardous waste }\end{array}\end{array}$ & $2.7 \times 10^{-3}$ & 13.5 \\
$\begin{array}{l}\text { Cover/move inactive uranium mill tailings } \\
\text { sites }\end{array}$ & $3.0 \times 10^{-2}$ & 27.6 \\
$\begin{array}{l}\text { Hazardous waste land disposal ban } \\
\begin{array}{l}\text { Treatment of wood-preserving chemical as } \\
\text { hazardous waste }\end{array}\end{array}$ & $<1.0 \times 10^{-6}$ & 31.7 \\
\hline
\end{tabular}

Source: U.S. Government Printing Office (1991, p. 370).

From overwhelming human evidence and supporting animal studies, benzene is known to be a human carcinogen. Leukemia (cancer of the tissues that form the white blood cells) and subsequent death from cancer have occurred in some workers exposed to benzene for periods of less than 5 years. The California Department of Health Services, in addition to the U.S. Environmental Protection Agency, has assumed that there is no threshold for benzene-induced carcinogenicity (DHHS 1989d; USEPA 1993).

\section{E.2.2 Toluene}

Toluene is toxic by ingestion, inhalation, and skin absorption. Information on acute human exposure to toluene suggests a narcotic effect at approximately $200 \mathrm{ppm}$. Irritation to eyes and the upper respiratory tract may occur at $100 \mathrm{ppm}$. Industrial exposure for several years at a mean atmospheric toluene concentration of $125 \mathrm{ppm}$ has not produced any detectable change in blood characteristics or in liver function, although workers exposed to toluene at $100-1,100 \mathrm{ppm}$ from two weeks to five years have demonstrated evidence of mild red-cell decrease, enlarged liver, and increased mean corpuscular hemoglobin concentration. However, a literature search failed to confirm any clinical or laboratory evidence of altered 
liver function in workers exposed to $80-300$ ppm over many years (National Research Council 1977; DHHS 1989a; Szpunar 1992).

Short-term exposure affects the nervous system, producing lightheadedness and euphoria at first, followed by fatigue, confusion, general weakness, dizziness, sleepiness, drunken-type actions, memory loss, nausea, loss of appetite, unconsciousness, and (in some cases) death because the person cannot breathe. These symptoms disappear when exposure is stopped. Long-term exposure has been linked with permanent damage to the brain, affecting speech, vision, and hearing and resulting in loss of muscle control, memory, and balance (DHHS 1989a; Szpunar 1992).

\section{E.2.3 Polycyclic Organic Matter}

Polycyclic organic matter (POM), a chemical class including numerous organic compounds, primarily large, fused-ring, polynuclear aromatic hydrocarbons (PAHs), is listed as a single category in the 1990 Clean Air Act Amendments (CAAA). (The 1990 CAAA listing contains 170 individual organic compounds, plus the generic class of POM.) Although benzidine, dibenzofuran, and naphthalene are singled out as individual Clean Air Act hazardous air pollutants, they are typically considered in the class of POM, which may include more than 100 compounds. The POM compounds tend to be toxic by inhalation or skin absorption, and over long periods of exposure some have been determined to be carcinogenic. Specifically, benzidine (as a carcinogen) and dibenzofuran (as a noncarcinogen) are cited by the U.S. Environmental Protection Agency (Hassett-Sipple 1991) as high-risk pollutants (Szpunar 1993).

Some of the most powerful carcinogens are derivatives of 1,2-benzanthracene (four fused, aromatic rings). These may include 5,10-dimethyl-1,2-benzanthracene, 1,2,5,6dibenzanthracene (five fused, aromatic rings), methylcholanthrene (five rings - four fused, aromatic), and 3,4-benzpyrene (five fused, aromatic rings) (Morrison and Boyd 1966; Szpunar 1993).

Although the health effects of the individual organic compounds comprising POM are not exactly alike, some characteristics are considered representative of the class. These compounds may enter the body quickly and easily by inhalation, ingestion, and skin absorption. They tend to migrate to the fatty tissues of the body, and tend to be stored

primarily in the kidneys, liver, and fat, with smaller amounts in the spleen, adrenal glands, and ovaries. Most exit through the excretory system within a few days. Human exposure by breathing or skin contact for long periods may result in cancer. Animal studies indicate harmful reproductive and immune system effects, birth defects, and decreased body weight. The following specific organic compounds are examples (DHHS 1990a; Szpunar 1993). 


\section{E.2.3.1 Benzidine}

Benzidine is toxic by ingestion, inhalation, and skin absorption and is carcinogenic. Acute (short-term) exposure to large amounts can cause skin rashes, irritation, and damage to certain body tissues and organs, such as the bladder. Long-term exposure can result in bladder damage (lesions), which may progress to invasive cancer if not found and treated in the early stages. The time required for the development of cancer decreases as the level of exposure increases (DHHS 1989b; Szpunar 1993).

\section{E.2.3.2 Benzo(a)pyrene}

Benzo(a)pyrene is toxic by inhalation and is an active carcinogen (Hawley 1977). Preliminary estimates of the potential health impacts from the emissions of POM and PAHs from coal combustion and coal conversion processes were made using benzo(a)pyrene or benzene-soluble organic materials. In fact, the health impacts from PAHs from coal, coal combustion, and coal conversion have been estimated by comparing the actual benzo(a)pyrene exposures and associated health risks with those of coke oven workers (DOE 1980).

\section{E.2.3.3 Dibenzofuran}

Dibenzofuran is probably toxic; however, no toxicological profile by the U.S. Department of Health and Human Services was available for review of dibenzofuran at this time (Szpunar 1993).

\section{E.2.3.4 Naphthalene}

Naphthalene is toxic primarily by inhalation but also by ingestion and skin . absorption. Hemolytic anemia (a condition involving the breakdown of the red blood cells) is the primary health concern for humans exposed for either short or long periods. Other common effects include nausea, vomiting, diarrhea, kidney damage, jaundice, and liver damage. Cataracts may also be caused by inhalation exposure. Neither cancer nor birth defects have been demonstrated (DHHS 1990b; Szpunar 1993).

\section{E.2.3.5 Dioxin}

Dioxin (2,3,7,8-tetrachlorodibenzo-p-dioxin) is toxic by ingestion, inhalation, and skin absorption. In humans, it causes chloracne, a severe skin lesion that usually occurs on the head and upper body. Chloracne is more disfiguring than common acne and often lasts for years after the initial exposure. Chloracne may cause liver damage, loss of appetite, weight loss, and digestive disorders in humans. Animal studies have indicated toxicity to the immune system, spontaneous abortions, malformations in offspring, weight loss resulting in death, and carcinogenicity (DHHS 1987; Szpunar 1993). 


\section{E.2.4 Compounds of the Trace Elements}

\section{E.2.4.1 Arsenic}

Arsenic compounds are toxic by ingestion (primarily), inhalation, and skin absorption (to a much lesser extent); they may also be carcinogenic. Arsenic has been recognized as a human poison since ancient times, and large doses can produce death. Lower levels of exposure may produce injury in a number of different body tissues or systems (Szpunar 1992).

A common effect in humans by ingestion is irritation of the digestive tract, leading to pain, nausea, vomiting, and diarrhea. Other effects include decreased production of red and white blood cells, abnormal heart function, blood vessel damage, liver and/or kidney injury, impaired nerve function causing a "pins and needles" feeling in the hands and feet, and skin abnormalities. Arsenic ingestion has been reported to increase the risk of cancer in the liver, bladder, kidneys, and lungs. Inhalation exposure may produce the same types of systemic health effects produced by ingestion, but in a much milder form; of greater concern is lung cancer. Dermal contact may result in mild to severe irritation of the skin, eyes, or throat. On the other hand, despite all the adverse health effects associated with arsenic exposure, there is some evidence that low levels of exposure may be beneficial to good health. Although no cases of arsenic deficiency in humans have been found, animal deficiencies have been documented (DHHS 1989e; Szpunar 1992).

\section{E.2.4.2 Beryllium}

Beryllium can be toxic, depending on the amount and duration of exposure. Not all of the effects that beryllium and its compounds have on human health are well understood, and not all forms are equally toxic. Short-term human exposure to soluble beryllium compounds can cause the development of inflammation and swelling of the lungs; removal from exposure results in a reversal of symptoms. Long-term exposure has been reported to cause chronic beryllium disease in sensitive individuals, characterized by shortness of breath, scarring of the lungs, and berylliosis (noncancerous growths in the lungs). Both acute and chronic beryllium disease can be fatal, depending on the severity of the exposure. Dermal contact may develop into a skin allergy for sensitized individuals; noncancerous growths may form on the skin if beryllium enters cuts. Inhalation of beryllium and its compounds is presumed by the U.S. Environmental Protection Agency to have some cancer-causing potential in the human lung (DHHS 1988a; Szpunar 1992).

\section{E.2.4.3 Cadmium}

Cadmium is not known to have any beneficial effects, and it can cause a number of adverse health effects. Cadmium is toxic to virtually every system in animals, whether ingested, injected, or inhaled. Ingestion of high doses causes severe irritation to the stomach, 
leading to vomiting and diarrhea; inhalation of high doses leads to severe irritation of the lungs. Of greater concern is long-term, low-level exposure, which causes kidney and lung damage and lung cancer. Exposure injures the liver, the testes, the immune system, the nervous system, and the blood. A low but prolonged intake of cadmium is suspected to lead to hypertension and reduced longevity in laboratory animals (DHHS 1989f; Szpunar 1993).

Cadmium is highly toxic, especially by inhalation of dust or fume. It may be fatal. Cadmium plating of food and beverage containers has resulted in a number of outbreaks of gastroenteritis (food poisoning). With respect to dust and soluble compounds, the cadmium tolerance is $0.2 \mathrm{mg} / \mathrm{m}^{3}$ of air; for oxide fume its tolerance is $0.1 \mathrm{mg} / \mathrm{m}^{3}$ of air. Soluble compounds of cadmium are highly toxic; however, ingestion usually induces a strong emetic action (vomiting), which minimizes the risk of fatal or severe poisoning (Hawley 1977; Szpunar 1992).

Schroeder (1967) showed a positive correlation between the cadmium levels in air in U.S.A. cities and the incidence of cardiovascular diseases in those cities. The disease of itai-itai in Japan has now been well-documented as being caused by the ingestion of cadmium, zinc, and lead from mining operations (Szpunar et al. 1980; Szpunar 1992).

\section{E.2.4.4 Chromium}

Although considered an essential nutrient in the trivalent state required for normal metabolism of carbohydrate, glucose, cholesterol, and fat in humans, chromium compounds in the hexavalent state are highly toxic by inhalation, ingestion, and skin absorption and probably carcinogenic by inhalation (Szpunar 1992).

Although exposure to metallic chromium is not well-characterized, elemental chromium and its trivalent compounds are relatively nontoxic. $\mathrm{Cr}^{+3}$ occurs naturally in soil, volcanic dust, and gases; it has not been found to be toxic, even when associated with wastewaters and industrial discharges. Nevertheless, although short-term exposure to $\mathrm{Cr}^{+3}$ does not generally appear to result in adverse health effects, very large doses of $\mathrm{Cr}^{+3}$ may prove harmful (DHHS 1989c; Szpunar 1992).

Signs of $\mathrm{Cr}^{+3}$ deficiency in humans include weight loss and impairment of the body's ability to remove glucose from the blood. The minimum human daily requirement of $\mathrm{Cr}^{+3}$ for optimal health is not known, but a daily ingestion of 50-200 $\mu \mathrm{g}$ per day has been estimated to be safe and adequate. Brewer's yeast and fresh foods are good sources of $\mathrm{Cr}^{+3}$ (DHHS 1989c; Szpunar 1992).

Short-term exposure to $\mathrm{Cr}^{+6}$, on the other hand, can result in adverse effects at the site of contact. The hexavalent compounds have an irritative and corrosive effect on tissue, resulting in ulcers and dermatitis on prolonged contact (e.g., irritation of the nasal mucosa, perforation of the nasal septum, and irritation of the gastrointestinal tract). It may also cause adverse effects in the kidney and liver (Hawley 1977; DHHS 1989c; Szpunar 1992). 
Long-term exposure of workers to airborne levels of $\mathrm{Cr}^{+6}$ has been associated with lung cancer, occurring long after exposure to $\mathrm{Cr}^{+6}$ has ended. Compounds of $\mathrm{Cr}^{+6}$ are regarded as probable cancer-causing substances in humans exposed by inhalation. Inhalation exposure to $\mathrm{Cr}^{+6}$ may also result in adverse effects on the respiratory system and may affect the immune system. Tolerance for chromium dust and fume is $1 \mathrm{mg} / \mathrm{m}^{3}$ of air (Hawley 1977; DHHS 1989c; Szpunar 1992).

\section{E.2.4.5 Lead}

Probably no other element besides mercury has been subjected to greater research efforts than lead. The long-standing problem of lead toxicity in humans has been well documented. Toxic primarily by inhalation and ingestion, especially with respect to its organic compounds (lead alkyls), lead compounds may also be carcinogenic. Regardless of how lead enters the body, most of it accumulates there and remains stored in the teeth and bone (Szpunar 1992).

People with more than $0.5 \mathrm{ppm}$ lead in their blood show visible signs of lead poisoning - constipation, headaches, anemia, paralysis, blindness, insanity, and, finally, at higher levels, death. Also, lead can cause sterility, miscarriage, still births, and infant mortality and mental retardation (Szpunar 1992).

There is no well-established role for lead as an essential trace element in nutrition. However, lead is a well-known cumulative poison in humans. Generally, lead enters the body by inhalation or ingestion, but much less lead enters through the skin than through the lungs or gastrointestinal tract. The effects of lead are the same no matter how it enters the body. Because some lead is stored in the body each time a person is exposed, the levels of lead in bone and teeth increase as one gets older. Unstored lead is removed through the excretory system (DHHS 1990c; Szpunar 1992).

Exposure is especially dangerous for the unborn because their bodies can be harmed while they are being formed, resulting in premature birth, low birth weight, or spontaneous abortion. Young children are at risk because they may ingest significant amounts of lead when they put toys or other objects soiled with lead-containing dirt in their mouths. For infants or young children, exposure has been shown to decrease intelligence scores, slow growth, and cause hearing problems. These effects appear to last as children get older and can interfere with successful performance in school. Moreover, these health effects can occur at exposure levels once thought to be safe (Szpunar et al. 1980; Szpunar 1992).

Exposure to high levels of lead can cause brain and kidney damage in adults and children, may increase blood pressure in middle-aged men, and may affect the male reproductive system, especially sperm. Although lead has not been shown definitely to cause cancer in humans, laboratory animals have developed tumors, indicating the same possibility in humans (DHHS 1990c). Organic compounds, especially lead alkyls, are even more poisonous than the inorganic compounds of lead. Therefore, because of the wide array of 
organic compounds potentially emitted from coal-fired combustion, lead potentially poses a significant threat to man (Szpunar 1992).

\section{E.2.4.6 Nickel}

Exposure to nickel and its compounds results from breathing air, ingesting drinking water and food that contain nickel and its compounds, and skin contact with a wide range of consumer products. Very small amounts of nickel have been shown to be essential for normal growth and reproduction in some species of animals; thus, small amounts of nickel are also thought to be essential to nutrition in humans. Nickel is a cofactor of the enzyme urease and can substitute for calcium in some processes (DHHS 1988b; Szpunar et al. 1980; Szpunar 1992).

The most common adverse effects of nickel exposure noted in the general population are skin allergies. Surveys indicate that $2.5-5.0 \%$ of the population may be sensitive to nickel. Individuals may be sensitized by frequent or prolonged contact with nickel-containing or nickel-plated consumer products such as jewelry. However, in persons not sensitive to nickel, normal long-term oral, inhalation, and skin exposures to low levels of nickel have not been associated with adverse health effects. Accidental or suicidal ingestion of very high amounts of some nickel compounds (but not nickel metal) may result in death (Szpunar 1992).

Inhalation in the work place has produced asthma in nickel platers exposed to nickel sulfate $\left(\mathrm{NiSO}_{4}\right)$ and in welders exposed to nickel oxide $\left(\mathrm{NiO}_{\mathrm{x}}\right)$. From the inhalation of nickel refinery dust, which contains nickel subsulfide, increased deaths from lung and nasal cavity cancers and possible voice-box cancer have been reported. However, there are no nickel refineries in the U.S.A. and, hence, no nickel refinery dust and no nickel subsulfide (DHHS 1988b; Szpunar 1992).

The carcinogenesis of nickel is inversely related to the solubility of its compounds, and the least soluble in aqueous media appear to be the most carcinogenic. Nickel carbonyl has been implicated as a possible carcinogen in metal workers and tobacco smokers (Szpunar et al. 1980; Szpunar 1992).

\section{E.2.4.7 Selenium}

About 50-150 $\mu \mathrm{g}$ per day of selenium is required in the human diet. Selenium and most of its compounds are not considered to be carcinogenic; in fact, several studies suggest that normal amounts of dietary selenium may protect against cancer. However, selenium sulfide has been shown to be carcinogenic in animals via ingestion. Selenium compounds have not been shown to cause reproductive effects in humans or other mammals (Agency for Toxic Substances and Disease Registry 1989).

High dietary concentrations of selenium can cause brittleness and loss of nails and hair, dermatitis, swelling, numbness or tingling in the extremities, and pain in the limbs. In 
severe cases of selenium poisoning, paralysis may develop. Estimates of selenium absorption from the digestive tract range from 44 to $100 \%$, and insoluble elemental selenium is probably poorly absorbed. The no observed adverse effect level for selenium was estimated from a correlation between blood selenium levels that were shown to reflect clinical signs of intoxication and the estimated intake levels (Agency for Toxic Substances and Disease Registry 1989).

Respiratory tract irritation can result from short-term inhalation of high levels of selenium dusts or selenium compounds in industrial settings; nausea, elevated pulse rate, and irritation of the skin and eyes have also been reported. Absorption is dependent on the chemical form of selenium, but limited data indicate that both elemental selenium and selenious acid are absorbed via inhalation. A standard reference concentration is not currently available to assess inhalation exposures. Dermal contact with selenium dust and selenium dioxide can cause dermatitis, but data are not available to quantify dermal absorption.

\section{E.3 REFERENCES FOR APPENDIX E}

Agency for Toxic Substances and Disease Registry, 1989, Toxicological Profile for Selenium, ATSDR/TP-89/21, prepared by Clement Associates, Dec.

Conference on Radiation Control Program Directors, Inc., 1978, Natural Radioactivity Contamination Problems, EPA-520/4-77-015, prepared for U.S. Environmental Protection Agency, Washington, D.C.

DHHS - see U.S. Department of Health and Human Services.

DOE - see U.S. Department of Energy.

Eisenbud, M., 1987, Environmental Radioactivity from Natural Industrial, and Military Sources, 3rd Ed., Academic Press, Harcourt Brace Jovanovich, New York.

Hassett-Sipple, B.M., 1991, Revised Criteria for Selecting High-Risk Pollutants for the Purpose of the Clean Air Act, Section 112(i)(5)(E), memorandum, U.S. Environmental Protection Agency, Washington, D.C., May.

Hawley, G.G., 1977, The Condensed Chemical Dictionary, 9th ed., Van Nostrand Reinhold Co., New York, N.Y.

Health and Safety Executive, 1992, The Tolerability of Risks from Nuclear Power Stations, London, England.

ICRP - see International Commission on Radiological Protection. 
International Commission on Radiological Protection, 1990, Radiation Protection, ICRP Publication 60, 1990 Recommendations of the International Commission on Radiological Protection, Pergamon Press, New York.

Morrison, R.T., and R.N. Boyd, 1966, Organic Chemistry, Second Edition, Allyn and Bacon, Inc., Boston, Mass.

National Council on Radiation Protection and Measurements, 1987a, Radiation Exposure of the U.S. Population from Consumer Products and Miscellaneous Sources, NCRP Report No. 95, Bethesda, Md.

National Council on Radiation Protection and Measurements, 1987b, Ionizing Radiation Exposure of the Population of the United States, NCRP Report No. 93, Bethesda, Md.

National Council on Radiation Protection and Measurements, 1989, Exposure of the U.S. Population from Occupational Radiation, NCRP Report No. 101, Bethesda, Md.

National Research Council, 1977, Drinking Water and Health, National Academy of Sciences, Washington, D.C.

NCRP - see National Council on Radiation Protection and Measurements.

Schroeder, H.A., 1967, Circulation 35:570.

Szpunar, C.B., 1992, Air Toxic Emissions from the Combustion of Coal: Identifying and Quantifying Hazardous Air Pollutants from US. Coals, ANL/EAIS/TM-83, Argonne National Laboratory, Argonne, Ill., Sept.

Szpunar, C.B., 1993, unpublished information, Argonne National Laboratory, Argonne, Illinois.

Szpunar, C.B., et al., 1980, The Fate of Trace Elements in Coal Combustion, Report COR.24KW.80, Exxon Research and Engineering, Baytown, Texas, Dec.

United Nations Scientific Committee on the Effects of Atomic Radiation, 1982, Ionizing Radiation: Sources and Biological Effects, United Nations, New York.

UNSCEAR - see United Nations Scientific Committee on the Effects of Atomic Radiation.

U.S. Department of Energy, 1980, Comparative Assessment of Health and Safety Impacts of Coal Use, DOE/EV-0069, Washington, D.C., March.

U.S. Department of Health and Human Services, 1987, Toxicological Profile Report for 2,3, 7,8-Tetrachlorodibenzo-p-dioxin, prepared by Syracuse Research Corporation, Arlington, Va., for Public Health Service, Agency for Toxic Substances and Disease Registry, Washington, D.C., Nov. 
U.S. Department of Health and Human Services, 1988a, Toxicological Profile for Beryllium, ATSDR/TP-88/07, prepared by Syracuse Research Corporation, Arlington, Va., in collaboration with the U.S. Environmental Protection Agency, Washington, D.C., for Public Health Service, Agency for Toxic Substances and Disease Registry, Washington, D.C., Dec.

U.S. Department of Health and Human Services, 1988b, Toxicological Profile for Nickel, ATSDR/TP-88/19, prepared by Syracuse Research Corporation, Arlington, Va., in collaboration with the U.S. Environmental Protection Agency, Washington, D.C., for Public Health Service, Agency for Toxic Substances and Disease Registry, Washington, D.C., Dec.

U.S. Department of Health and Human Services, 1989a, Toxicological Profile for Toluene, prepared by Life Systems, Inc., Dallas, Texas, under subcontract to Clement Associates, Inc., Los Altos, Calif., in collaboration with the U.S. Environmental Protection Agency, Washington, D.C., for Public Health Service, Agency for Toxic Substances and Disease Registry, Washington, D.C., Dec.

U.S. Department of Health and Human Services, 1989b, Toxicological Profile for Benzidine, prepared by Life Systems, Inc., Dallas, Texas, under subcontract to Clement Associates, Inc., Los Altos, Calif., in collaboration with the U.S. Environmental Protection Agency, Washington, D.C., for Public Health Service, Agency for Toxic Substances and Disease Registry, Washington, D.C., Dec.

U.S. Department of Health and Human Services, 1989c, Toxicological Profile for Chromium, ATSDR/TP-88/10, prepared by Syracuse Research Corporation, Arlington, Va:, in collaboration with the U.S. Environmental Protection Agency, Washington, D.C., for Public Health Service, Agency for Toxic Substances and Disease Registry, Washington, D.C., July.

U.S. Department of Health and Human Services, 1989d, Toxicological Profile for Benzene, ATSDR/TP-88/03, prepared by Oak Ridge National Laboratory, Oak Ridge, Tenn., in collaboration with the U.S. Environmental Protection Agency, Washington, D.C., for Public Health Service, Agency for Toxic Substances and Disease Registry. Washington, D.C., May.

U.S. Department of Health and Human Services, 1989e, Toxicological Profile for Arsenic, ATSDR/TP-88/02, prepared by Life Systems, Inc., Dallas, Texas, in collaboration with the U.S. Environmental Protection Agency, Washington, D.C., for Public Health Service, Agency for Toxic Substances and Disease Registry, Washington, D.C., March.

U.S. Department of Health and Human Services, 1989f, Toxicological Profile for Cadmium, ATSDR/TP-88/08, prepared by Life Systems, Inc., Dallas, Texas, in collaboration with the U.S. Environmental Protection Agency, Washington, D.C., for Public Health Service, Agency for Toxic Substances and Disease Registry, Washington, D.C., March.

U.S. Department of Health and Human Services, 1990a, Toxicological Profile for Polycyclic Aromatic Hydrocarbons, TP-90-20, prepared by Clement Associates, Inc., Los Altos, Calif., for Public Health Service, Agency for Toxic Substances and Disease Registry, Washington, D.C., Dec. 
U.S. Department of Health and Human Services, 1990b, Toxicological Profile for Naphthalene and 2-Methylnaphthalene, TP-90-18, prepared by Life Systems, Inc., Dallas, Texas, under subcontract to Clement Associates, Inc., Los Altos, Calif, for Public Health Service, Agency for Toxic Substances and Disease Registry, Washington, D.C., Dec.

U.S. Department of Health and Human Services, 1990c, Toxicological Profile for Lead, ATSDR/TP-88/17, prepared by Syracuse Research Corp., Arlington, Va., in collaboration with the U.S. Environmental Protection Agency, Washington, D.C., for Public Health Service, Agency for Toxic Substances and Disease Registry, Washington, D.C., June.

U.S. Environmental Protection Agency, 1993, Motor Vehicle-Related Air Toxics Study, Office of Air and Radiation, Washington, D.C., March.

USEPA - see U.S. Environmental Protection Agency.

U.S. Government Printing Office, 1991, Budget of the United States Government, Fiscal Year 1992, Part Two, Washington, D.C.

Wehner, F., 1978, "Legal and Practical Aspects of Radioactivity in Consumer Products in the Federal Republic of Germany," in Radioactivity in Consumer Products, NUREG/CP-0001, AA Moghissi et al. (eds.), U.S. Nuclear Regulatory Commission, Washington, D.C.

Wilson, R., and E.A.C. Crouch, 1987, "Risk Assessment and Comparisons: An Introduction," Science 236:267-270. 
F-1

\section{APPENDIX F:}

QUESTIONNAIRE ON RECYCLING AND LIST OF RESPONDENTS 


$$
\text { F-2 }
$$

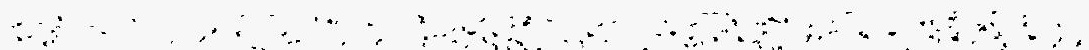




\section{APPENDIX F: \\ QUESTIONNAIRE ON RECYCLING AND LIST OF RESPONDENTS}

\section{F.1 QUESTIONNAIRE ON RECYCLING}

Argonne National Laboratory is conducting an evaluation of recycling currently contaminated radioactive scrap metal. Part of this study assesses the opinions and position of the industry, environmental groups, and other concerned parties. To assist us in this effort, please provide answers to the following questions, with supporting documentation as requested:

1. Name/Affiliation/Address/Phone Number:

2. Has your organization taken a position in the past on BRC, (Below Regulatory Concern) regulations proposed by NRC? What was that position, and could you provide your written rationale, e.g. testimony, position paper etc.? 
3. Does your organization have a position on the recycling of radioactive scrap metal? If yes, could you provide any rationale that has been developed?

4. What are your major concerns regarding the recycling of radioactive scrap metal?

5. If recycling was proposed for only radioactive scrap metal with trace amounts of contamination would your group be more likely, or less likely to (support) or (oppose) such an approach? Why? 
6. Considering that the alternative to recycling some radioactive scrap metal is disposal, and that disposal creates additional problems of its own, how do you evaluate the trade-offs of recycling $\mathrm{v}$. disposal?

7. Have you or your group completed, or have available, any evaluations, analyses, or other background materials on your position? Please provide if possible.

8. Are there any other groups or individuals you would suggest we interview for this study? Please provide names and phone numbers: 
9. Do you have any other comments or suggestions regarding the recycling of radioactive scrap metal?

Thank you for your time and interest. Please use additional sheets as necessary. Call me with any questions at 202/488-2448.

Please return this form by January 8,1993 , to:

Christopher Burke, Argonne National Laboratory, 370 L'Enfant Promenade, S.W., Washington, D.C. 20024-2578. FAX: 202/488-2413 


\section{F.2 SURVEY RESPONDENTS}

\section{Environmental Groups}

William Magovern

Critical Mass Energy Project

215 Pennsylvania Ave., S.E.

Washington, DC 20003

James D. Werner

Natural Resources Defense Council 1350 New York Ave., N.W.

Washington, DC 20005

Diane D'Arrigo

Nuclear Information and Resource Service

1424 16th St., N.W., \#601

Washington, DC 20036

Don Gray

Environmental \& Energy Study Group 122 C Street, N.W., Suite 700

Washington, DC 20001

Susan L. Hiatt ,

Director

Ohio Citizens for Responsible Energy

8275 Munson Road

Mentor, OH 44060

\section{Trade Associations}

Peter Hernandez

American Iron \& Steel Institute

1101 17th Street, N.W., Suite 1300

Washington, DC 20036

Michael Mattia

Risk-Management Director

Institute of Scrap Recycling Industries 1325. G. Street, N.W.

Washington, DC 20005
Roger Ney

National Council for Radiation

Protection and Measurements

7910 Woodmont Ave., \#800

Bethesda, MD 20814

Mark Rubin

American Petroleum Institute

1201 Main Street, Suite 2535

Dallas, TX 75202

\section{Trade Unions}

Lynn MacDonald

Sheet Metal Workers International

Association

1750 New York Ave., N.W.

Washington, DC 20006

\section{Industry}

D.C. Pierce

Reclamation Division

Reynolds Metals Company

Richmond, VA 23261

\section{International-Environmental}

Ralph Mallo

Stichting Natuur en Milieu

Donkerstraat 17

$3511 \mathrm{~KB}$ Utrecht

The Netherlands 
F-8 